\title{
The SAFRR (Science Application for Risk Reduction) Tsunami Scenario
}
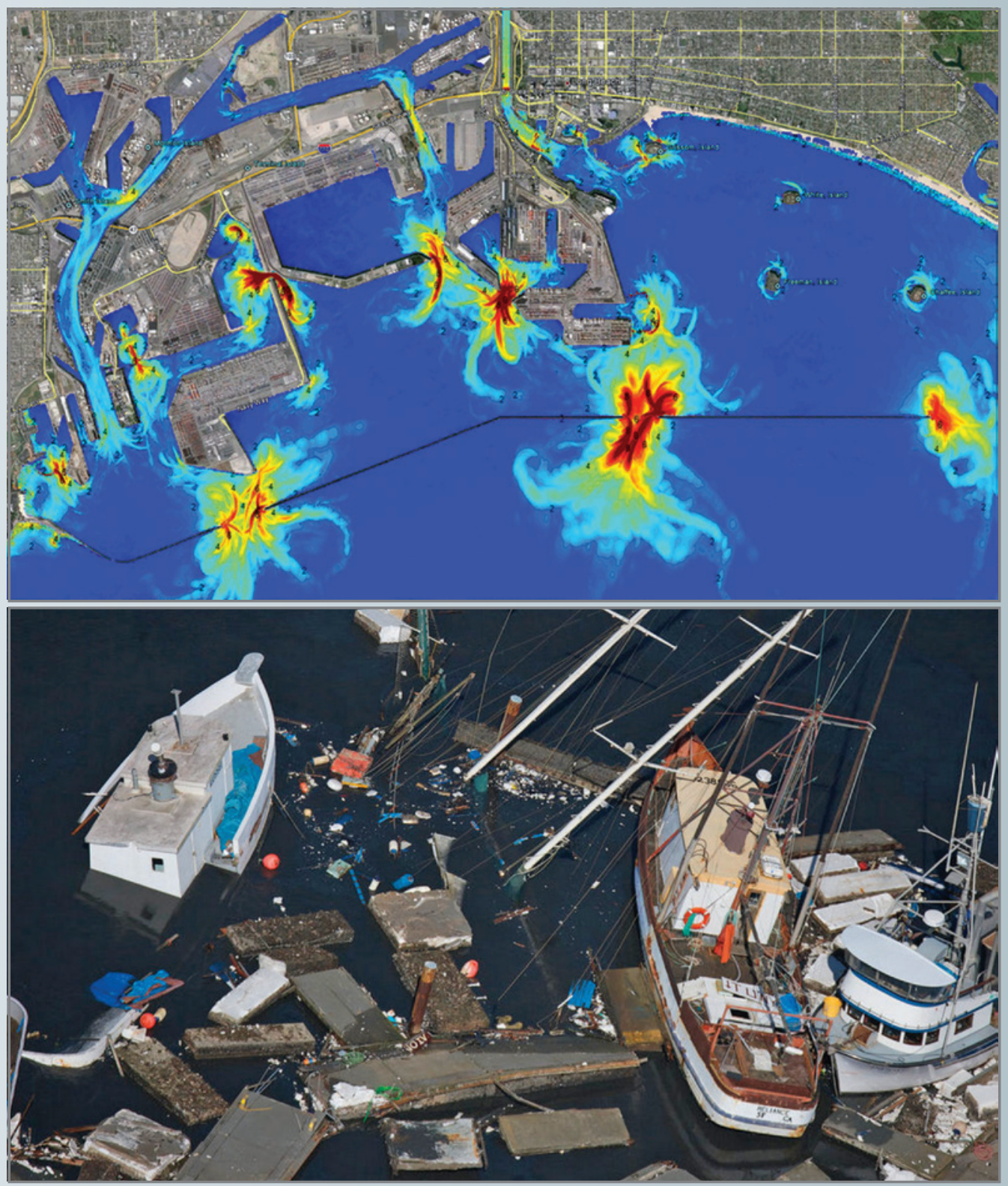

Open-File Report 2013-1170

California Geological Survey Special Report 229 
This page intentionally left blank 


\section{The SAFRR (Science Application for Risk Reduction)} Tsunami Scenario-Executive Summary and Introduction
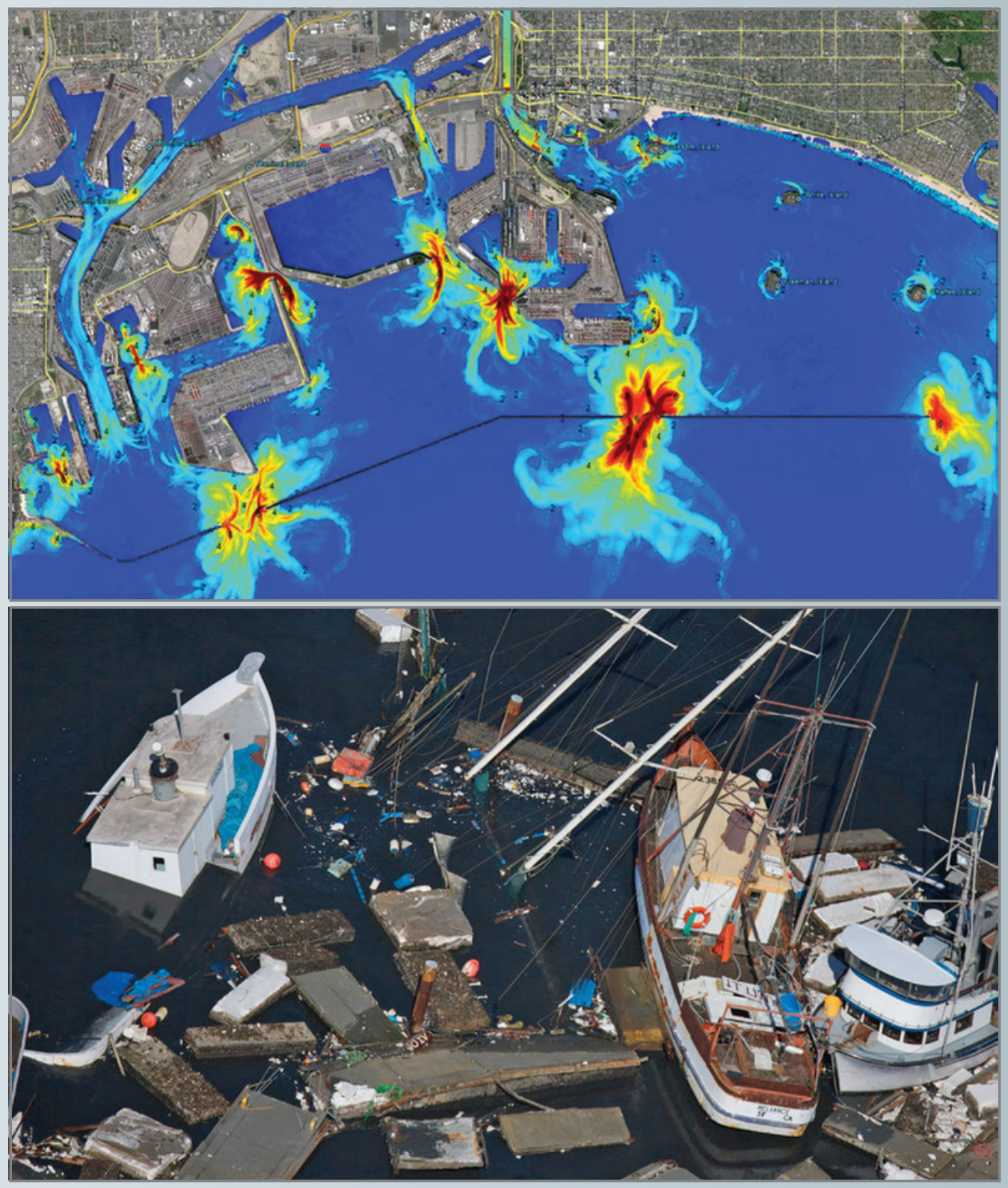

Open-File Report 2013-1170-A

California Geological Survey Special Report 229 
COVER - Top: maximum current speeds for the Ports of Los Angeles and Long Beach generated during the SAFRR tsunami scenario (in knots). Bottom: damage to boats and docks at Crescent City Harbor, California, due to the tsunami generated by the M9.1 Tohoku earthquake in 2011. (C) 2011 The Oregonian. All rights reserved. Reprinted with permission. 


\section{The SAFRR (Science Application for Risk Reduction) Tsunami Scenario-Executive Summary and Introduction}

By Stephanie L. Ross, Lucile M. Jones, Kevin Miller, Keith A. Porter, Anne Wein, Rick I. Wilson, Bohyun Bahng, Aggeliki Barberopoulou, Jose C. Borrero, Deborah M. Brosnan, John T. Bwarie, Eric L. Geist, Laurie A. Johnson, Stephen H. Kirby, William R. Knight, Kate Long, Patrick Lynett, Carl E. Mortensen, Dmitry J. Nicolsky, Suzanne C. Perry, Geoffrey S. Plumlee, Charles R. Real, Kenneth Ryan, Elena Suleimani, Hong Kie Thio, Vasily V. Titov, Paul M. Whitmore, and Nathan J. Wood

Open-File Report 2013-1170-A

California Geological Survey Special Report 229

U.S. Department of the Interior

U.S. Geological Survey 


\section{U.S. Department of the Interior \\ SALLY JEWELL, Secretary}

\section{U.S. Geological Survey \\ Suzette M. Kimball, Acting Director}

U.S. Geological Survey, Reston, Virginia 2013

For product and ordering information:

World Wide Web: http://www.usgs.gov/pubprod

Telephone: 1-888-ASK-USGS

For more information on the USGS-the Federal source for science about the Earth, its natural and living resources, natural hazards, and the environment:

World Wide Web: http://www.usgs.gov

Telephone: 1-888-ASK-USGS

Suggested citation:

Ross, S.L., Jones, L.M., Miller, Kevin, P., K.A., Wein, A., Wilson, Ri.I., Bahng, B., Barberopoulou, A., Borrero, J.C., Brosnan, D.M., Bwarie, J.T., Geist, E.L., Johnson, L.A., Kirby, S.H., Knight, W.R., Long, K., Lynett, P., Mortensen, C.E., Nicolsky, D.J., Perry, S.C., Plumlee, G.S., Real, C.R., Ryan, K., Suleimani, E., Thio, H., Titov, V.V., Whitmore, P.M. and Wood, N.J., 2013, SAFRR (Science Application for Risk Reduction) Tsunami Scenario-Executive Summary and Introduction: U.S. Geological Survey Open-File Report 2013-1170-A, in Ross, S.L., and Jones, L.M., eds., The SAFRR (Science Application for Risk Reduction) Tsunami Scenario: U.S. Geological Survey Open-File Report 2013-1170, 17 p., http://pubs.usgs.gov/of/2013/1170/a/.

Any use of trade, product, or firm names is for descriptive purposes only and does not imply endorsement by the U.S. Government.

Although this information product, for the most part, is in the public domain, it also may contain copyrighted materials as noted in the text. Permission to reproduce copyrighted items must be secured from the copyright owner. 


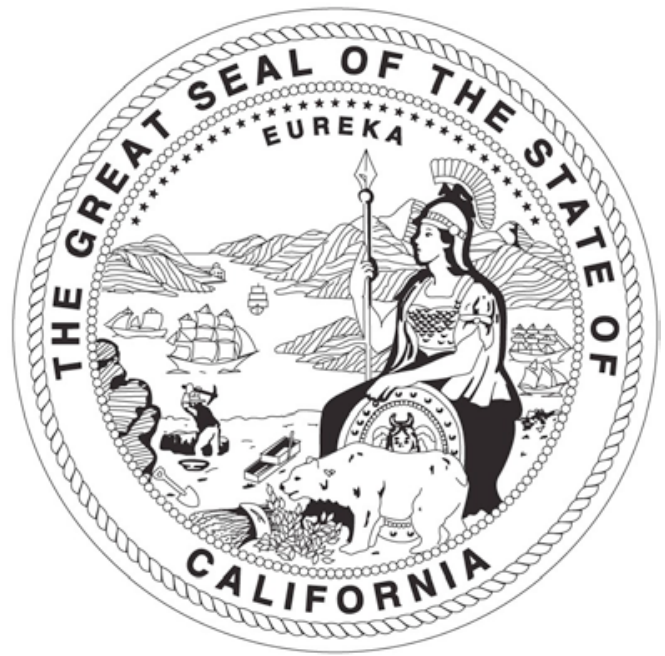

STATE OF CALIFORNIA EDMUND G. BROWN JR. GOVERNOR

\section{THE NATURAL RESOURCES AGENCY JOHN LAIRD \\ SECRETARY FOR RESOURCES \\ DEPARTMENT OF CONSERVATION MARK NECHODOM DIRECTOR}

\section{CALIFORNIA GEOLOGICAL SURVEY JOHN G. PARRISH, Ph.D. STATE GEOLOGIST}




\section{Contents}

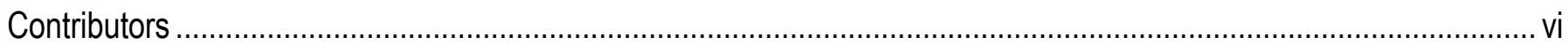

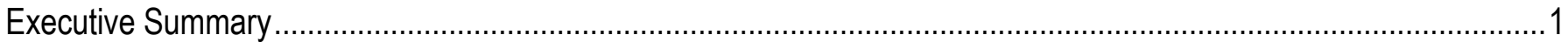

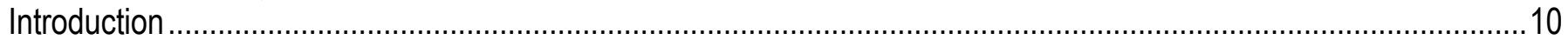

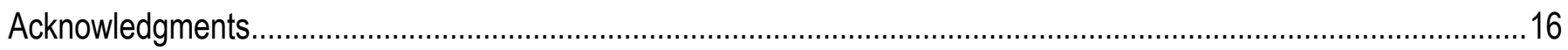

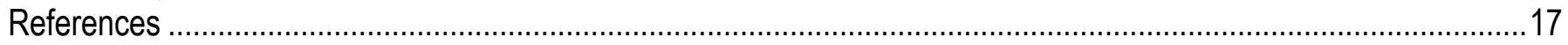




\section{Contributors}

The SAFRR Tsunami Scenario was developed by a large team of experts from many different disciplines. The coordinating committee is the group who participated in the biweekly coordinating committee conference calls and assured that the different working groups communicated effectively.

\section{SAFRR Tsunami Scenario Coordinating Committee}

Stephanie L. Ross, U.S. Geological Survey (USGS), SAFRR Tsunami Scenario Project Manager Lucile M. Jones, USGS, SAFRR Project Chief

Bohyun Bahng, National Oceanic and Atmospheric Administration, National Weather Service,

West Coast and Alaska Tsunami Warning Center (NOAA/NWS/WCATWC)

Aggeliki Barberopoulou, Geological and Nuclear Sciences, New Zealand

Jose C. Borrero, University of Southern California and eCoast Ltd.

Deborah M. Brosnan, University of California, Davis

Erin Burkett, USGS

John T. Bwarie, USGS

Eric L. Geist, USGS

Laurie A. Johnson, Laurie Johnson Consulting

Stephen H. Kirby, USGS

William R. Knight, NOAA/NWS/WCATWC

Kate Long, California Governor's Office of Emergency Services (Cal OES)

Patrick Lynett, University of Southern California

Kevin Miller, Cal OES

Carl E. Mortensen, USGS

Dmitry J. Nicolsky, Alaska Earthquake Information Center (AEIC), Geophysical Institute, University of Alaska

Suzanne C. Perry, USGS

Geoffrey S. Plumlee, USGS

Keith A. Porter, University of Colorado, Boulder

Charles R. Real, California Geological Survey (CGS)

Kenneth Ryan, University of California at Riverside

Elena Suleimani, AEIC, Geophysical Institute, University of Alaska

Hong Kie Thio, URS Corporation

Vasily V. Titov, NOAA, Pacific Marine Environmental Laboratory

Anne Wein, USGS

Paul M. Whitmore, NOAA/NWS/WCATWC

Rick I. Wilson, CGS

Nathan J. Wood, USGS 


\section{Other Authors}

The people listed below are authors of other chapters of this report but were not part of the coordinating committee.

William Byers, Private Consultant

Dylan Caldwell, Humboldt State University

Catherine Chagué-Goff, University of New South Wales and Australian Nuclear Science and Technology Organisation

David Dykstra, Moffatt and Nichol Engineers

James Goff, University of New South Wales

Nick Graehl, Lettis Consultants International, formerly at Humboldt State University

Eileen Hemphill-Haley, Humboldt State University

Don Hoirup, CA Dept. of Water Resources

Bruce Jaffe, USGS

Harvey Kelsey, Humboldt State University

Robert Leeper, USGS

Amy Lim, Moffatt and Nichol Engineers

Casey Loofbourrow, Humboldt State University

Mary McGann, USGS

Suzette A. Morman, USGS

David D. Oglesby, University of California at Riverside

Jeff Peters, USGS

Robert Peters, USGS

Jamie Ratliff, USGS

Bruce Richmond, USGS

Adam Rose, University of Southern California

Carma San Juan, USGS

Charles Scawthorn, SPA Risk LLC.

David Scholl, USGS

Kimberley Shoaf, Center for Public Health and Disasters, Fielding School of Public Health, University of California, Los Angeles

Sangyoung Son, University of Southern California

Costas Synolakis, University of Southern California and Hellenic Centre for Marine Research

Roland von Huene, USGS

Steve Watt, USGS

Dan Wei, University of Southern California

Ray Wells, USGS

Ian Sue Wing, Boston University

\section{Other Contributors}

We gratefully acknowledge the following people for providing their expertise; however, they bear no responsibility for the contents of the report.

Robel Afewerki, Port of Los Angeles (POLA) Engineering Angus Alexander, Los Angeles County Fire Department (LACoFD)

Mariana Amatullo, Art Center College of Design (ACCD) 
Susan Asturias, San Diego County Office of Emergency Services (OES)

Rich Baratta, Port of Long Beach

Richard Berman, Port of San Francisco (POSF)

Bob Bertelli, Fisherman, POLA

Roy Bibbens, California Department of Transportation (Caltrans)

Rick Blakely, USGS

Mike Blood, Coronado Fire Department

Eric Boldt, National Weather Service (NWS)

Donna Boston, Orange County Emergency Management Division

Sonia Brown, Cal OES

Chris Brown, POLA

Damon Burgett, POSF

Bob Butchart, Cal OES Ports \& Harbors

Ed Byrne, POSF

Helen Cahng, ACCD

Nnenia Campbell, University of Colorado

Eric Caris, POLA Business Development

Dale Carnathan, Ventura County OES

Tom Carter, POSF

Mo Chang, US Army Corps of Engineers

Christopher Chase, POLA

Mike Christensen, POLA

Douglas Christenson, Geophysical Institute of the University of Alaska at Fairbanks

Bent Christiansen, POLA

Ken Chu, POLA

Tim Clark, POLA

Larry Collins, LACoFD

Larry Cottrill, POLB

Brandon Cowan, POSF

Dale Cox, USGS

Greg Crow, HB Marine Safety

Carrie Cruz, San Bernardino County OES

George Cummings, Los Angeles Port Police

John Davey, POSF

Patti David, Los Angeles Department of Water and Power (LA DWP)

Amy Draut, USGS

Sherban Duncan, POSF

Brooke Duthoy, Orange County OES

Ron Eguchi, ImageCat, Inc.

Lauren Eisele, POSF

David Eisenman, UCLA Center for Public Health and Disasters

Eric Endersby, Morro Bay Harbor Director

Peggy Erdner, Orange County OES

Joann Eres, California Department of Fish and Wildlife

Terry Erwin, Smithsonian Institution

Brett Fahning, Fisherman, Crescent City 
Andrienne Fedrick, Port of Los Angeles

Johanna Fenton, Cal OES, EQ \& Tsunami Program

David Flamm, Santa Barbara County Office of Emergency Management

Desiree Fox, Caltrans

Mike Frazier, LACoFD Lifeguards

Jeff Freymueller, Geophysical Institute of the University of Alaska at Fairbanks

Stuart Fricke, POLA

Michael Galvin, POLA

Rene Garcia, Caltrans

Al Garcia, LA DWP

Keith Garcia, Los Angeles Port Police

Guy Gelfenbaum, USGS

Tony Gioiello, POLA

Kenneth Goettel, Goettel and Associates Inc.

Aaron Golbus, POSF

Jim Goltz, Cal OES retired

Mike Graychik, Los Angeles Port Police

Ed Green, Port of Long Beach

Scott Grindy, San Mateo Harbor District

Pastor Guerara, Cal OES

Zach Hammil, Sonoma County OES

Roger Hansen, Geophysical Institute of the University of Alaska at Fairbanks

Anne Hardinger, City of Berkeley

Stephen Harrison, NOAA/NWS

Akira Hasegawa, Tohoku University

Anita Hayden, Los Angeles Port Police

Lisa Hayes, LA DWP

Gavin Hayes, USGS

Darryl Hebert, Oceanside Fire Department

Jack Hedge, POLA Real Estate

Cindy Henderson, Del Norte County OES

Ryota Hino, Tohoku University

Susan Hocevar, Naval Post-Graduate School, Monterey

Suzie Howser, Port of Humboldt Bay and Woodley Island Marina

Doug Huls, Cal OES

Charlie Huyck, ImageCat Inc.

T. Iinuma, Tohoku University

Y. Ito, Tohoku University

Chen Ji, University of California Santa Barbara

Radiah Jones, US Coast Guard (USCG)

Dan Kane, POLB

Kevin Keady, Caltrans

Michael Keenan, POLA Planning

Emily Knight, Ocean Science Trust

Captain Lynn Korwatch, Marine Exchange of the San Francisco Bay Region

Thorne Lay, University of California Santa Cruz 
Willie Lee, USGS

Thomas Lefko, USCG Sector San Francisco, Contingency Planning and Force Readiness

Noli Legaspi, LA DWP

Jill Lemon, USCG

Stephen Mahaley, San Mateo OES

Joe Maldonado, POLA CBM Division

Caryn Margita, USCG

Toru Matsuzawa, Tohoku University

Jay McAmis, Santa Barbara County OES

Linda McIntyre, Moss Landing Harbor District

Captain Dick McKenna, Marine Exchange

Dwayne Meadows, NOAA

La Mer Walker, ACCD

Kathy Merkovsky, POLA

Brevyn Mettler, Huntington Beach Fire Dept.

Jenny Miller Garmendia, AWARE

Nancy Miller, LACoFD

John Miller, USGS

Sarah Minson, USGS, formerly at California Institute of Technology

Walter Mooney, USGS

Alan Nelson, USGS

Steve Ng, Caltrans

Leon Nixon III, Los Angeles Port Police

Mike O'Brien, Port of Oakland, Port Facilities Security Officer

Debra O'Malia, Oxnard Fire Dept.

Emile Okal Northwestern University

Diane Oshima, POSF

Tom Ostrom, Caltrans

Karl Pan, POLA

Pietro Parravano, Fisherman, Half Moon Bay

Aaron Pfannenstiel, Huntington Beach (RBF Consultant)

Scott Phemister, POLB

Eleyne Phillips, USGS

George Plafker, USGS

Abbas Pourheidari, Caltrans

Uday Prasad, POSF

Cindy Pridmore, CGS

Stephen Rea, San Diego

Sidney Reade, Monterey County OES

Steven Reel, POSF

Jeffrey Robinson, Area G Disaster Management

Joe Roger, POSF

Emily Roland, USGS

Peter Rudd, LA DWP

Elisa Ruffino, ACCD

Monica Ruzich, Orange County ARC 
Holly Ryan, USGS

Sidonie Sansom, POSF, Director of Homeland Security

Petty Santos, Los Angeles Port Police

John Schelling, State of Washington

Hope Seligson, MMI Consulting

Shaun Shahrestani, POLA

Jeri Siegel, Cal OES

Mark Simons, California Institute of Technology,

Benjamin Sleeter, USGS

Tim Smith, LACoFD

Jessamyn Specht, Oceanside Fire Department

Keith Stahnke, San Francisco Bay Area Water Emergency Transportation Authority

Ming Tai, ACCD

Ian Taneguchi, California Department of Fish and Wildlife

Alex Tardy, NWS San Diego

Daryoush Tavatli, Caltrans

Karen Taylor, POSF

Jeff Terry, Los Angeles OES

Doug Thiessen, Port of Long Beach

Katherine Thompson, Center for Research on Environmental Decisions

Curtis Thompson, Los Angeles Port Police

Jen Tucker, San Clemente

Martin Villa, USCG

Ronnie Villanueva, Harbor Homeland Security

Wendy Walsh, Naval Post-Graduate School, Monterey

David Walsh, POLA

Tim Werle, City of Los Angeles Fire Dept. (LAFD)

Malcolm Williams, Rand Corporation

Jennifer Williams, USCG

Guillaume Wolf, ACCD

Roger $\mathrm{Wu}$, POLB

Richard Young, Harbormaster, Crescent City

Dapeng Zhao, Tohoku University

\section{Evaluation of the Tsunami Scenario}

The USGS engaged a team from the University of Colorado, Boulder, to document the scenario process and provide an external evaluation of its effectiveness in increasing awareness and knowledge of the users in the coastal community. Their report will be completed after the release of the scenario. Apart from the description of the logic model process in the Introduction, they bear no responsibility for the contents of our report. The team included:

Liesel A. Ritchie

Kathleen Tierney

Nnenia Campbell

Courtney Farnham

Brandi Gilbert

Jamie Vickery 


\section{Executive Summary}

The Science Application for Risk Reduction (SAFRR) tsunami scenario depicts a hypothetical but plausible tsunami created by an earthquake offshore from the Alaska Peninsula and its impacts on the California coast. The tsunami scenario is a collaboration between the U.S. Geological Survey (USGS), the California Geological Survey, the California Governor's Office of Emergency Services (Cal OES), the National Oceanic and Atmospheric Administration (NOAA), other Federal, State, County, and local agencies, private companies, and academic and other institutions. This document presents evidence for past tsunamis, the scientific basis for the source, likely inundation areas, current velocities in key ports and harbors, physical damage and repair costs, economic consequences, environmental and ecological impacts, social vulnerability, emergency management and evacuation challenges, and policy implications for California associated with this hypothetical tsunami. We also discuss ongoing mitigation efforts by the State of California and new communication products. The intended users are those who need to make mitigation decisions before future tsunamis, and those who will need to make rapid decisions during tsunami events. The results of the tsunami scenario will help managers understand the context and consequences of their decisions and how they may improve preparedness and response. An evaluation component will assess the effectiveness of the scenario process for target stakeholders in a separate report to improve similar efforts in the future.

\section{Scenario Design}

Several historical distant-source tsunamis, including those generated by the 1946 magnitude (M) 8.1 Aleutian, 1960 M9.5 Chile, and 1964 M9.2 Alaska earthquakes, caused known inundation along portions of the northern and central California coast. Twenty wetland sites were evaluated for paleotsunami evidence as part of the most comprehensive tsunamideposit field program ever undertaken in California. Paleotsunami sands, which indicate past tsunami inundation, were found in Half Moon Bay and Crescent City stemming from the 1946 and 1964 Alaskan events, respectively, and showed that evidence for distant-source tsunamis can be found in California's coastal marshes (see fig. 1 for locations). Tsunami sand from the 1700 Cascadia event was also found in Crescent City. Similar sand units at those sites (older than 1946 at Half Moon Bay, and between 1700 and 1964 in Crescent City) are pending further analyses to determine if they were also deposited by tsunami. In southern California, the potential for discovering tsunami deposits is low relative to other parts of the state due to the lower modeled wave heights for many tsunami sources and because most coastal wetlands in southern California have been disturbed by human activity.

The source earthquake for the scenario, defined by the USGS Tsunami Source Working Group, is set in the Semidi subduction sector, between Kodiak Island and the Shumagin Islands off the Pacific coast of the Alaska Peninsula (fig. 1 of the Introduction). The strike of the fault in that area tends to focus the waves towards the California coast and especially towards southern California and the economically critical Ports of Los Angeles and Long Beach (fig. 1). The Semidi sector's geology and tectonic setting are similar to the setting of the 2011 Tohoku event, so the assumed slip distribution is approximately that of the Tohoku earthquake adapted to the 
fault structure in the Semidi sector. The scenario earthquake has a moment magnitude of 9.1 and a fault length of $360 \mathrm{~km}$.

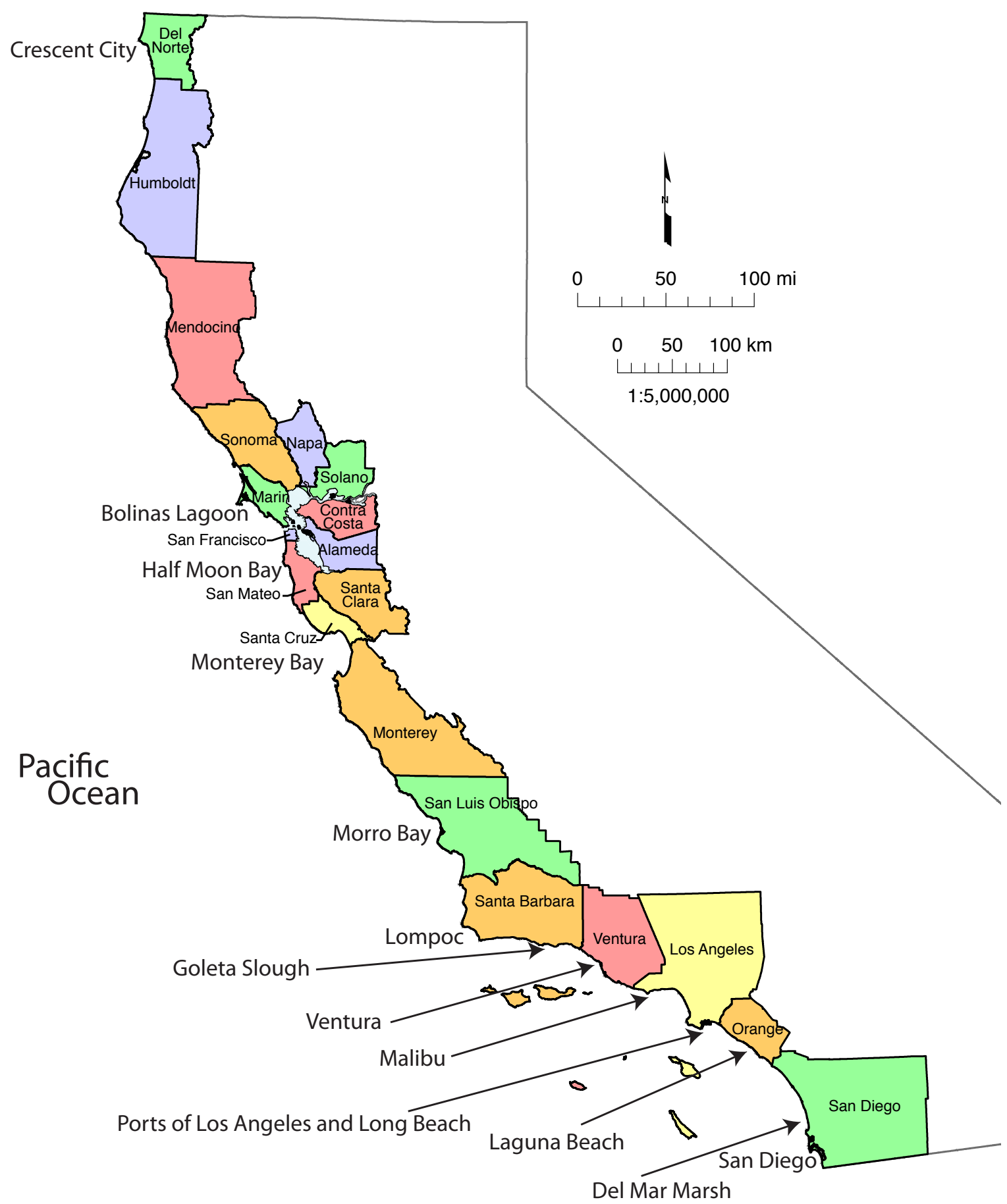

Figure 1. Map showing the 20 coastal counties in California and locations of features mentioned in the text. Digital geographic data from the State of California Spatial Information Library. 
For purposes of making the scenario more tangible, we have simulated an earthquake that occurs at 11:57 a.m. PDT on Thursday March 27, 2014, which is the 50 ${ }^{\text {th }}$ anniversary of the 1964 Alaska earthquake and tsunami. Travel times to California from the occurrence of the earthquake to the arrival of the first tsunami waves range from 4 hours in Crescent City to almost 6 hours in San Diego (fig. 1). Thus, tsunami warnings and wave arrivals would occur during a workday afternoon.

\section{Tsunami Modeling}

Six independent teams of scientists were engaged to create computer models of the tsunami source and tsunami wave propagation field. A coarse model of wave height was run for the whole Pacific basin, higher resolution models were run for coastal areas primarily in California, and water-current velocity models were analyzed for a few ports and harbors in southern California. Overlap between the models shows that the results are consistent, stable, and credible. Only one model was chosen to create the inundation maps, but all of the main features highlighted here are shared among the models; they all show similar wave amplitudes, current velocities, and runup.

The modeled tsunami waveforms are quite different in character at different locations along the California coast. The initial waves at each location are among the largest. However, the first wave is the largest one in only a few locations such as Monterey Bay and Morro Bay (fig. 1). In most cases the largest waves arrive several hours - sometimes more than 7 hours-after the initial one. Especially in southern California, the tsunami waves attenuate slowly in time.

The shape of the California coast, bending east near Lompoc (fig. 1), causes the wave height of the tsunami (which approaches from the north) to be significantly reduced in southern California compared to the wave height in central and northern California. The tsunami hazard from this scenario is generally less in southern California than elsewhere along the California coast. However, some areas of southern California may be more vulnerable because of low-lying topography, larger coastal population, and concentration of maritime assets.

\section{Inundation and Evacuation}

The time of high tide is significant in determining the amount of inundation. By planning for the scenario earthquake at a time when high tide coincides with larger wave heights, the area inundated increases. Some of the largest Pacific Ocean tsunamis in the twentieth century (for example, waves propagating from the 1960 M9.6 Chile, 1964 M9.2 Alaska, and 2011 M9.1 Tohoku earthquakes) coincided with low tide in southern California, so this scenario is plausibly worse than the historic events. For many sections of the California coast, the inundation area for the scenario simulated in this report is up to several times the areas for those previous events.

The area of inundation is limited where the coastline is steep. More than half of California's coastline is cliff, which prevents inundation beyond the beach in those areas. In other locations, inundation varies from the first few street blocks to completely submerged peninsulas and man-made islands. The State of California has developed a map of estimated maximum inundation considering a wide range of the largest credible tsunami sources. The inundation area in the SAFRR Tsunami Scenario extends farther inland than the State's maximum inundation area in only a few places, due to more detailed modeling and higherresolution topographic input used for the SAFRR Scenario, not because of a larger source event. The higher resolution modeling of the SAFRR Tsunami Scenario also showed tsunami surges and bores traveling several miles inland up coastal rivers. In addition to the State maps, local 
jurisdictions have created evacuation maps which take into account not only modeled inundation, but streets and landmarks to guide people to safe, high ground when outside. These evacuation lines are the most conservative, drawn further inland than any modeled inundation lines that exist for California, as they were produced for both life safety and emergency operations.

Over the entire California coastline, less than 40 percent of the State's maximum tsunami inundation zone is flooded in the SAFRR Tsunami Scenario. Fourteen cities have more than 1,000 residents in the scenario inundation area, with the largest affected areas in Long Beach and San Diego (fig. 1). Other highly impacted areas are low-lying portions of southern Los Angeles and northern Orange Counties, along with coastal communities in Northern California including Del Norte, Marin, San Francisco, Alameda, and Santa Cruz Counties. Nearly 92,000 people live inside the SAFRR Tsunami Scenario inundation zone. An additional 175,000 residents would be evacuated if such an order were to be given using the State's maximum tsunami inundation zone. An estimated 81,000 employees would be in the scenario inundation zone with an additional 88,000 within the State's maximum tsunami inundation zone. Additionally, more than 260,000 visitors would be expected on California's beaches and in parks on the day of the scenario event. The visitor numbers would increase to over one million if the same tsunami were to occur during summer months, when beach and coastal use is highest. An estimated 8,500 residents in the SAFRR tsunami scenario inundation zone would likely need shelter because of damage to their homes. Some island and peninsula communities, and low-lying landfill islands within the ports, could provide serious evacuation challenges because of limited exit options and short warning time prior to expected inundation. Evacuations would also be a challenge for dependent-care populations such as patients in hospitals and nursing homes and children in daycare facilities. Education and planning tailored to each of these communities would be required to make tsunami evacuations successful.

\section{Currents in Ports and Maritime Issues}

In addition to inundation, the scenario tsunami would generate strong, unpredictable currents in the ocean close to shore, causing significant damage in harbors and bays. An extrapolation of the damage in California from the 2011 Tohoku tsunami predicts that the SAFRR scenario tsunami, which produces larger waves and currents in California than did the 2011 event, will damage or sink one-third of the boats and damage or destroy over one-half of the docks in California coastal marinas. Small craft damages would include commercial fishing boats. In northern California, the scenario timing in March is considered the off-season and many fishermen would be away from their boats, which aggravates the exposure of the fleets to the tsunami. Loose boats would become floating debris or sink, posing navigational hazards to other vessels. Areas in California that survived the 2011 Tohoku tsunami unscathed could easily be damaged in this scenario and other future large tsunamis.

Boats at sea have lower risks during tsunamis, but the hazards increase in shallow, coastal waters. In southern California, March is an active fishing time and fishermen target coastal pelagic fish, which live near the surface of coastal waters, and dive for nearshore benthic invertebrates, which live near the bottom. The currents from the scenario tsunami would make coastal fishing difficult, and dive fishing would be extremely hazardous because of tsunami surge. Persistent strong currents and debris would make it difficult for boats to return to port. It might be many months before vessels could return to work because of damage to harbor infrastructure and fish processing plants. Alerts to take their boats to sea, alerts to remain at sea, 
and contingency planning for the possibility that they cannot return to port could improve outcomes for the fishing fleets.

Larger vessels that remain in ports might also be vulnerable. For example, given the short time between the tsunami warning being issued and the first wave arrival (3.5 hours at the Ports of Los Angeles and Long Beach), it may be difficult or impossible to fully execute the Merchant Vessel Dispersal Plan for Los Angeles and Long Beach Harbors, and damage to vessels in the ports is possible. Other ports in San Francisco Bay and San Diego Bay are also likely to be damaged in such a scenario.

Fires would likely start at many sites where fuel and petrochemicals are stored in ports and marinas. Many fires during past tsunamis have been caused when flammable liquids were released, spread by water, and ignited by mechanisms such as electrical leakage, short circuits, and sparks created by pieces of debris colliding. It is difficult to quantify the extent of the potential losses because they depend heavily on whether the fires spread.

\section{Impacts to the Environment and Ecosystems}

The scenario tsunami has the potential to cause environmental contamination in both inundated areas onshore and the coastal marine and estuarine environments. Potential sources for contamination are many and varied, and include, for example, debris from damaged piers, ships, commercial and industrial facilities, and large numbers of residences; petroleum products released from damaged ships and inundated or damaged marine petroleum terminals, petroleum storage facilities, marinas, power plants, and airports; raw sewage from inundated wastewater treatment plants; household and commercial building contents (lubricants, fuels, paints, pesticides, fertilizers, electronics); smoke, ash, and debris from fires; runoff from inundated agricultural fields containing pesticides, herbicides, and fertilizers; and redistribution of existing contaminated sediments in ports, the near-shore marine environment, and in estuaries, sloughs, and bays.

Based on recent past disasters, the cleanup of debris, damaged buildings, contaminated sediments, and other potentially hazardous materials in ports, harbors and inundation areas could be a long and costly process and add to business interruption. Characterization of debris, tsunami sediment deposits, and sands used to replenish beaches for the presence of asbestos, lead paint, pesticides, and other potentially hazardous materials would be needed to determine appropriate disposal measures (for example, placement in specialized landfills), and the ability to reuse or recycle these materials. Such assessments could add significant time and costs to the postdisaster cleanup and recovery. Environmental damage and restoration costs have not been thoroughly studied for disasters, so it is difficult to provide reasonable estimates for the total environmental costs of the scenario tsunami. This is a topic where future research is needed. Cleanup and recovery of inundated and damaged areas could take days, months, or years depending on the severity of impacts and the available resources for recovery. Improving preparedness, mitigation, and continuity planning for tsunamis can reduce damage and economic impacts and enhance recovery efforts.

Ecosystems have evolved with tsunamis but their resilience to tsunamis depends on their health and abundance. Where heavily impacted by humans, California's natural resources are no longer robust in the face of extreme events. Malibu, Laguna, and other beaches are already suffering chronic erosion problems and it is uncertain whether sand eroded by the surge would return fully or naturally; communities may be faced with expensive and controversial beach nourishment challenges. 
The strong currents would pick up material so that sediment scour, sediment deposition, and environmental contamination would be serious issues and would increase downtime and recovery costs in harbors. Coastal pelagic species are unlikely to be significantly impacted but benthic invertebrate species and their habitats would be vulnerable. As with many aspects of this scenario, we cannot fully quantify all the impacts, but preliminary attempts to model the sediment transport in California due to the 2011 Tohoku tsunami show that sediment transport and environmental contamination can become major issues.

As coastal marshes are inundated, they absorb wave energy and slow the speed of tsunami surges, preventing damage to human communities. However, marshes adjacent to urban or industrial areas, including Goleta Slough and Del Mar Marsh (fig. 1) would likely be inundated with urban and or industrial debris and possibly contaminants, both of which have proven difficult to clean up. Restoration sites including coastal wetlands, beaches, shellfish beds, and low-lying islands would be inundated, and several sites would be at risk from surge, sediments, debris and contaminants. Restoration areas at Del Mar and Bolinas Lagoon (fig. 1) would be extensively inundated. This is significant because of the high financial, scientific and community investment made or being made in restoration.

\section{Economic Implications}

A significant economic impact of the scenario in California may be disruptions of the Ports of Los Angeles and Long Beach. A tsunami warning would advise evacuation of port personnel. Strong and dangerous currents would last for two days. Therefore, the ports would be shut down for at least that long. There would also be inundation of dry land in the ports resulting in approximately $\$ 100$ million in damages to container and vehicle cargo and related systems, and additional downtime at some terminals. The direct exposure of port trade value from damages and downtime totals more than $\$ 1.2$ billion, while associated business interruption losses would be more than triple that value. However, resilience in the forms of using excess cargo handling capacity, using existing inventories of materials, and working extra shifts could reduce these business interruption losses by an order of magnitude.

Coastal fisheries, particularly invertebrate species such as sea cucumber, sea urchin, inshore crab, and spiny lobster are vulnerable to risk from surge, debris or other habitat damage and fishery disruptions. Collectively these fisheries are valued at about $\$ 78$ million per year. Shellfish farms and restored shellfish beds along the central and northern California coast and San Francisco Bay area are also at risk. Business interruption to commercial fishing at the ports would involve lost fishing days, perished catch, and damages to vessels, but in our estimates an allowance was made for the industry to make up for lost fishing days.

Although there is only a small exposure for the agricultural sector, there would be damage and impacts to soils, crops, and infrastructure that have not been experienced in recent distant-source tsunamis. Repair to agricultural fields and infrastructure could cost $\$ 4$ million. This estimate does not include soil remediation, which could add substantially to costs.

These and other damages estimated from the scenario are summarized in table 1. Repair and replacement of boats and docks in California marinas are estimated to be much greater than related business interruption. Property damages include about 69,000 single-family-equivalent homes. The business interruption from property damages would be increased by evacuation of an area larger than the inundation zone. Highway repairs include potential damage to the OaklandSan Francisco Bay Bridge Toll Plaza, and railroad repairs include tracks, infrastructure, and rolling stock. Agricultural damages pertain to crop income losses. We have estimated repair and 
replacement costs of approximately $\$ 3.4$ billion to California marinas, coastal properties, and the Ports of Los Angeles and Long Beach. Collectively, these damages expose approximately $\$ 6$ billion of business interruption losses, assuming no resilience in sectors of the California economy. These potential losses could be reduced by 80-90 percent with the implementation of resilience strategies. Impacts will vary across sectors; those industries dependent on trade through the ports (and therefore relatively more affected by business interruption) potentially include leather, metals, and motor vehicle manufacturing. Service industries related to marinas may gain from price increases outstripping quantity reductions. The fishing sector may suffer from business interruption, but fishermen who escape damage to their boats and find places to moor and land their catch may benefit from higher revenue and lower competition while others may suffer significant economic hardship. Similarly, business interruption will vary across communities with local impacts such as those experienced in Crescent City after the 2011 Tohoku tsunami, for example (Wein and others, 2013). However, reconstruction that would be partially funded by disaster funds and insurance (financial forms of resilience) would eventually provide a stimulus to the local and State economies.

Potential economic losses due to physical damage and business interruption in the SAFRR tsunami scenario.

[Figures are in 2010 USD. For 2013 values, add 6 percent]

\begin{tabular}{|c|c|c|c|}
\hline \multirow[b]{2}{*}{ Assets } & \multirow{2}{*}{$\begin{array}{c}\text { Repair } \\
\text { cost } \\
\text { (in millions) }\end{array}$} & \multicolumn{2}{|c|}{ Business interruption cost (in millions) } \\
\hline & & $\begin{array}{c}\text { Without resilience } \\
\text { strategies }\end{array}$ & $\begin{array}{l}\text { With resilience } \\
\text { strategies * }\end{array}$ \\
\hline Ports of Los Angeles and Long Beach & $\$ 100$ & $\$ 4,300$ & $\$ 200-900$ \\
\hline Fishing in Port of Los Angeles & & $\$ 2$ & $\$ 0.3$ \\
\hline Marinas, docks, and small craft & $\$ 700$ & $\$ 30$ & \\
\hline Property & $\$ 2,600$ & $\$ 1,700$ & $\$ 300$ \\
\hline Roads and bridges & $\$ 80$ & & \\
\hline Railroads & $\$ 2$ & & \\
\hline Agriculture & $\$ 4$ & & \\
\hline Total (rounded) & $\$ 3,500$ & $\$ 6,000$ & $\$ 500-1200$ \\
\hline
\end{tabular}

* The estimates are maximum resilience potential, but may not be implemented at that level because of administrative and managerial issues

\section{Public Policy Issues}

Translating the lessons of the SAFRR Tsunami Scenario into action may depend on changes in public policy. The USGS does not make recommendations for specific policy decisions but below we list a number of issues that could be considered by policy makers.

With few modern large tsunami experiences to draw upon, the vast majority of disasterrelated policy reflects learning from other perils and it is not as well developed for tsunamis as it is for other hazards and disaster-management policy areas in both California and elsewhere in the United States. The lack of experience, risk awareness, planning, and implementation practices for tsunami mitigation, preparedness, response, and recovery in some communities could amplify impacts and losses, even beyond what has been estimated for this scenario. There is an overarching challenge to reach the general public as well as special-interest sectors such as the maritime community, and to adequately train and prepare the multiple levels and types of 
governments to mitigate tsunami hazards and manage the impacts and consequences of this scenario and other potential tsunamis that threaten California. Possible courses of action to strengthen tsunami-related policy and to enhance California tsunami resiliency include:

- Continue the National Tsunami Hazard Mitigation Program, TsunamiReady and affiliated state and local programs, and recruit and assist all California coastal communities, ports, and harbors to become TsunamiReady.

- Develop a coordinated and sufficiently robust policy framework for tsunami hazard assessment and mitigation planning for California coastal communities, ports, and harbors. The framework could includes adoption of official state tsunami hazard zones under the State Seismic Hazard Mapping Act, better integration of tsunami hazard zones in state and local planning and development requirements and tsunami-resilient buildingdesign-code provisions, and consistent guidelines statewide for maritime tsunami response and recovery.

- Advance multihazard mitigation planning along California's coast and bays to more holistically address issues of future tsunami risk, sea level rise, coastal flooding and erosion, and earthquake-induced liquefaction.

- Conduct baseline ecological surveys to take account of potential tsunamis and emergency plans that include ecosystems and natural resources; they would help to alleviate damage to valuable resources and communities.

- Encourage responders and government managers at all levels to conduct selfassessments, devise exercises, and utilize tsunami evacuation playbooks and maritime mapping and guidelines under development by the State of California. These activities could test assumptions embedded in warning and evacuation protocols, emergency response and planning, and organizational structures and systems. These approaches would also test the abilities of the emergency management systems to scale up and meet the demands of large tsunami disasters.

- To help facilitate recovery following a major tsunami, promote broader participation in the National Flood Insurance Program, improved regulatory and permitting processes for port dredging and disposal and removal of debris and contaminated soil, and the development of other resources and tools to assist coastal communities, ports and harbors, and the fishing and agriculture sectors.

- Enhance tsunami risk awareness by amending California's natural hazards disclosure law to notify real estate purchasers when a property is located in a tsunami hazard zone.

- Expand California's annual ShakeOut earthquake exercise and outreach effort to include tsunami education and preparedness.

- Strengthen tsunami education and training for key professionals working in engineering as well as land use, hazard mitigation, and response planning along California's coast.

- Develop State and local policies that foster both rapid assessment of potential tsunamirelated contamination and rapid decision making for disposal options should hazardous debris or sediment be identified.

Recognizing many of these issues after the 2010 Chile and 2011 Tohoku tsunamis, the State of California has begun to improve planning in the evacuation/response, maritime, landuse, and recovery communities. The SAFRR tsunami scenario provides valuable information that helps stimulate further improvements at the state and local level.

This scenario is intended to support local decisionmakers in understanding potential risks for a possible future tsunami that may require evacuation and cause damage, and to improve 
coordination, communication, and mitigation before that event. Positive outcomes have already resulted from the SAFRR tsunami scenario. For instance, emergency managers in areas where the scenario inundation exceeds the State's maximum inundation zone have been notified and evacuation plans have been updated appropriately. The State has also worked with NOAA's West Coast and Alaska Tsunami Warning Center to modify future message protocols by moving the location of a preset breakpoint between alert zones that would have impeded effective evacuations in this scenario. The SAFRR tsunami scenario provides the basis for further improvements to the resilience of coastal communities to future large tsunamis. Although our specific results pertain to California, the approach and the lessons learned from our scenario can be applied to other regions.

For more detail on these results, please see the other chapters of this report. They are available at http://pubs.usgs.gov/of/2013/1170 


\section{Introduction}

\section{By Stephanie L. Ross, Lucile M. Jones, Keith A. Porter, Liesel A. Ritchie, and Hong Kie Thio}

The U.S. Geological Survey Science Application for Risk Reduction (SAFRR) project, in collaboration with the California Geological Survey (CGS), the California Governor's Office of Emergency Services (Cal OES), the National Oceanic and Atmospheric Administration (NOAA), other Federal, State, County, and local agencies, private companies, and academic and other institutions, have developed the SAFRR tsunami scenario to describe in detail the impacts of a tsunami generated by a hypothetical but realistic moment magnitude (M) 9.1 earthquake offshore of the Alaska Peninsula (fig. 1). Our target audience includes people who need to plan for a potential tsunami such as emergency managers, business continuity planners, maritime managers, land use planners, corporate real estate managers, and elected officials. This scenario attempts to provide these people more information about what they are planning for.

The overarching objective of SAFRR and its predecessor, the Multi-Hazards Demonstration Project (MHDP), is to foster the use of science in decision making in order to help communities reduce losses from natural disasters. As requested by emergency managers and other community partners, our primary approach has been to provide comprehensive, scientifically credible scenarios that start with a model of a meteorological or geologic event and extend it through estimates of damage, casualties, and major social and economic consequences at the societal level. The scenarios are based on plausible events that are likely enough to be worth planning for and may require multijurisdictional or regional planning. No scientist can guarantee that a particular disaster will happen, but a plausible event is one that is consistent with our scientific knowledge. An event worth planning for is one that is plausible and would produce such significant effects that preparation for this event will improve outcomes for a variety of possible occurrences.

The first MHDP product was the ShakeOut scenario (Jones and others, 2008), addressing a hypothetical earthquake on the southern San Andreas Fault. The ShakeOut scenario spawned the successful Great California ShakeOut, now an annual event and the nation's largest emergency preparedness exercise. It has also been adopted in other states and abroad with the same name, making the ShakeOut an international contribution. The ShakeOut scenario was followed by the ARkStorm scenario (Porter and others, 2010), which addresses California winter storms that surpass hurricanes in their destructive potential.

Some of the tsunami scenario's goals included developing advanced models of currents and inundation for the event; spurring research related to Alaskan earthquake sources; engaging port, harbor and Coast Guard decision makers; estimating the physical damages and downtimes, and examining the economic impacts to the California economy with and without resilience; understanding the ecological, environmental, and societal impacts of coastal inundation; creating enhanced communication products for decision-making before, during, and after a tsunami; and evaluating the scenario-development process. The State of California, through CGS and Cal OES, is using the SAFRR tsunami scenario as an opportunity to evaluate policies regarding tsunami impact. The scenario will serve as a long-lasting resource to enhance preparedness and inform decision makers. 


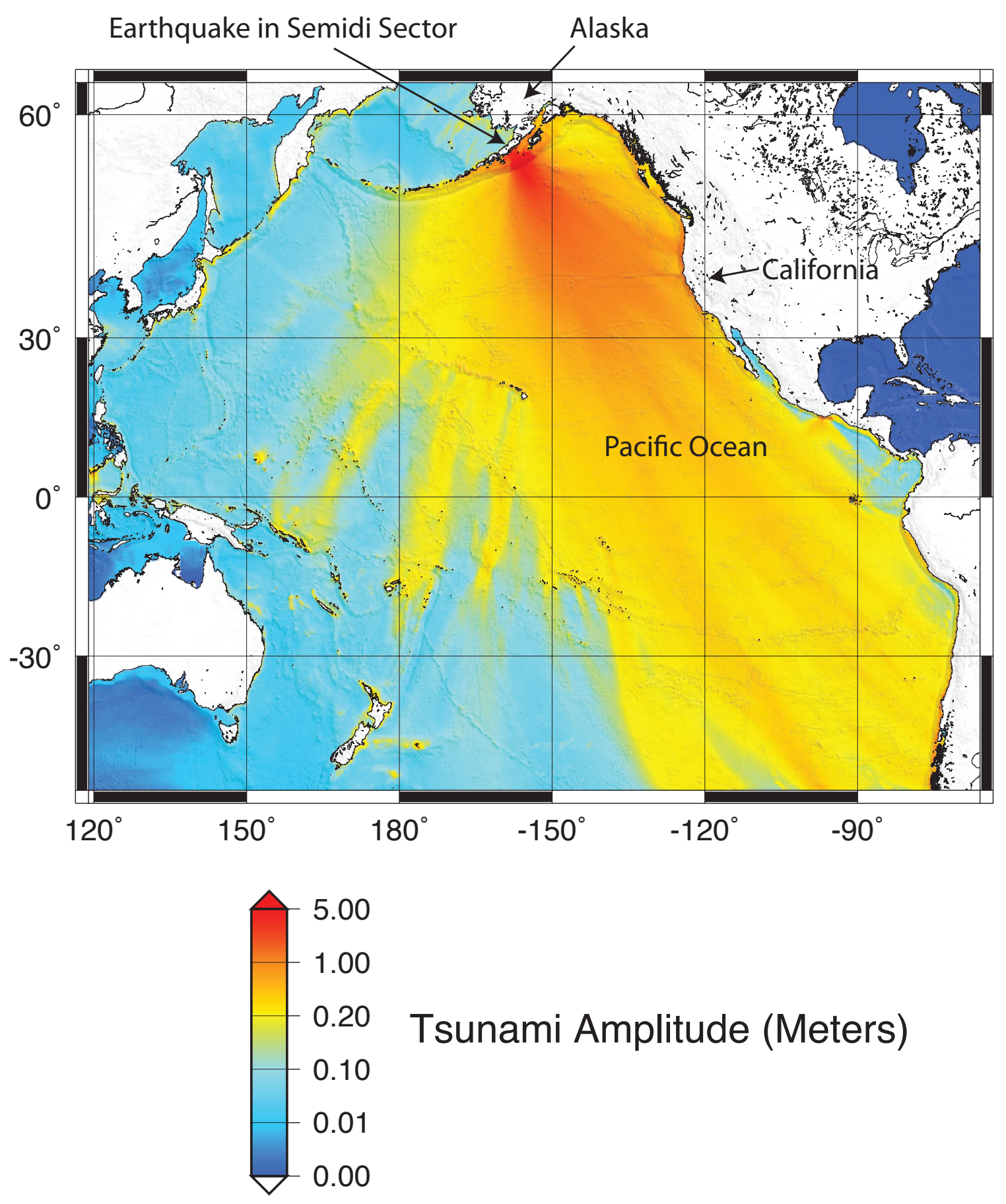

Figure 1. Maximum wave heights of the tsunami simulated in the SAFRR (Science Application for Risk Reduction) tsunami scenario across the Pacific basin. 
To accomplish such a broad set of goals, we needed to engage a wide range of disciplines. The SAFRR tsunami scenario was organized by a coordinating committee and several working groups, including Earthquake Source, Paleotsunami/Geology Field Work, Tsunami Modeling and Mapping, Engineering and Physical Impacts, Ecological Impacts, Environmental Impacts, Emergency Management and Education, Social Vulnerability, Economic and Business Impacts, Policy, and Evaluators. The coordinating committee included the working group leads. To ensure that specialists from a wide range of disciplines stayed on the same evolving page, the coordinating committee held biweekly teleconferences. Members of individual working groups were invited to join the calls. The tsunami modelers remained engaged, participating in the teleconferences to make sure their results were understood and appropriately applied.

The tsunami scenario process is being evaluated by researchers from the Natural Hazards Center at the University of Colorado Boulder. This is the first time that a scenario of this scale has been formally and systematically evaluated by an external party. As an early step in the evaluation process, a logic model (fig. 2) was developed in consultation with key stakeholders to illustrate how the scenario is intended to achieve the goal of fostering the use of science in decision making. The logic model demonstrates that resource investment and activities in working groups produce project outputs that are designed to improve community resilience to tsunamis. It helps ensure a common understanding of the way the project is intended to work, how activities are monitored, and how outputs and outcomes are evaluated.

The model presented here is somewhat different from more traditional logic models that present detailed inputs such as staff/personnel time, volunteers, partners, money, materials, equipment, technology, and so forth. On the far left side of the tsunami scenario logic model are the highest level inputs associated with the development of the tsunami scenario- the working groups. There are a total of 10 working groups, with an additional committee facilitating the coordination and integration of all of these groups. In each box is the name of the working group and its fundamental responsibilities. Moving to the center of the model are the outputs expected as a result of the combined efforts of the workings groups. This is the "what" component of the project - what is being done? Included in those boxes are the various activities associated with the tsunami scenario, all of which are conducted in the context of the desired outcomes of the project - the next column to the right. The content of these boxes represents the "so what?" of the project, or the impacts of the efforts of the working groups and the overall scenario. It is the desired project outcomes that frame the working group efforts and the project outputs; they also guide evaluation efforts. On the far right of the model is the ultimate goal of the tsunami scenario - to foster the use of science in decision-making. Finally, the "ongoing evaluation activities" label at the bottom of the graphic represents the notion that reflection and evaluation are continuous throughout the life of the project, from its developmental and formative phases through the rollout of the scenario. 


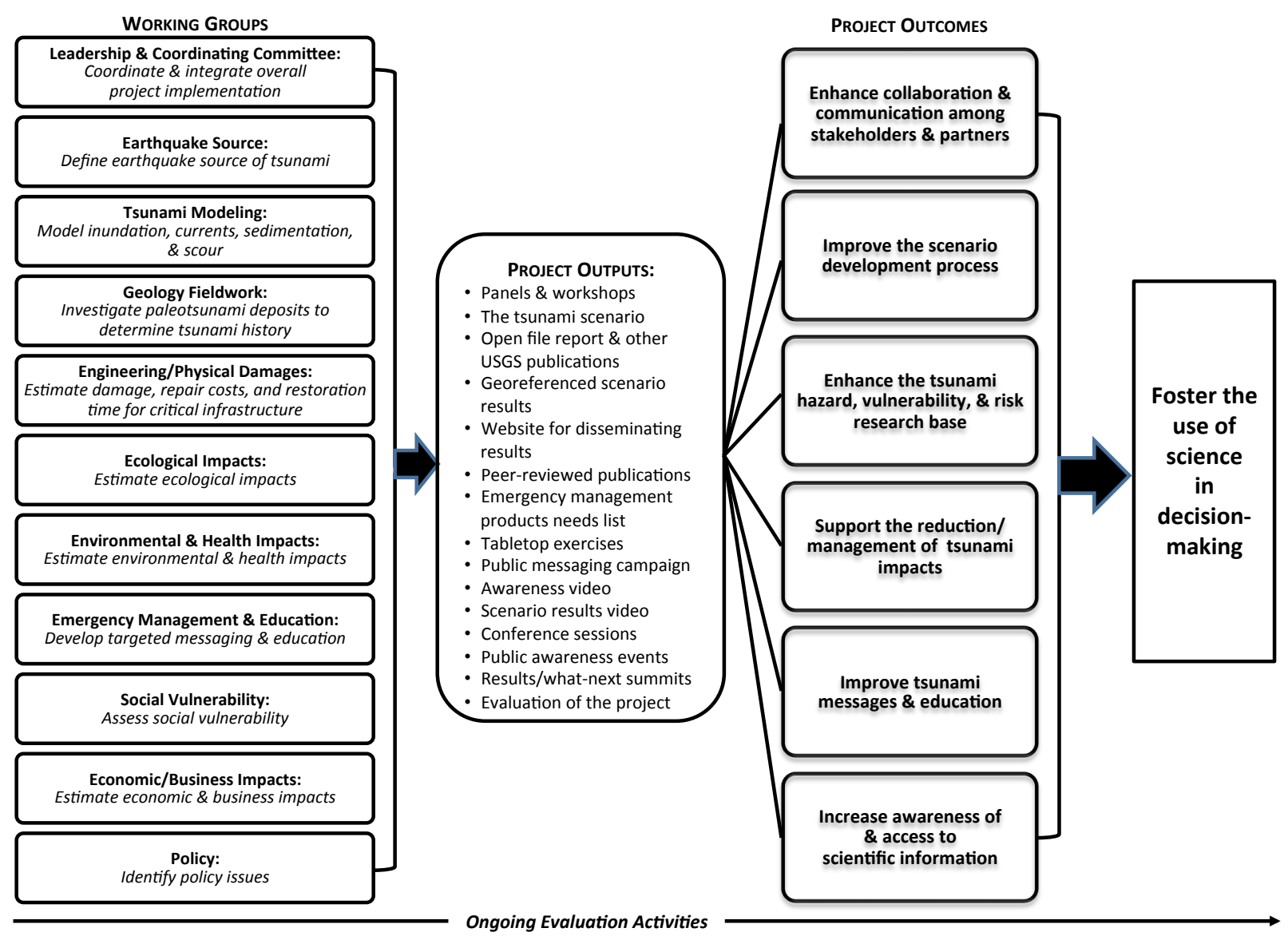

Figure 2. Tsunami scenario project logic model.

Because of the national economic importance of the Ports of Los Angeles and Long Beach, the source earthquake was designed to impact southern California. The scenario earthquake, defined by the USGS Tsunami Source Working Group, is an earthquake similar to the 2011 M9.1 Tohoku event, but set in the Semidi subduction sector (fig. 1) between Kodiak Island and the Shumagin Islands off the Pacific coast of the Alaska Peninsula (Kirby and others, 2013). Comparisons of the geology and tectonic settings between Tohoku and the Semidi sector suggest that this location is appropriate and the earthquake plausible.

Several tsunami-modeling studies were conducted covering a range of methods, geographic locations, and model resolutions (SAFRR Tsunami Modeling Working Group, 2013). Two studies examined how including different models of the physics of earthquake rupture and different characterization of the tsunami generating process affects the tsunami as it strikes southern California. Another two studies used the generation of the tsunami as inputs and then modeled the propagation of the waves across the ocean, into the near shore environment, and onto land.

Tsunami models are computed by representing the ocean at points on a grid. Coarse grids were used to model the tsunami in the open ocean and progressively finer grids were used to model the tsunami near shore and in important locations. Tsunamis increase in height as they 
approach the shore. In southern California, the tsunami amplitudes would range from 1 to 3 meters near shore. In central California, from Lompoc through Marin County, they would range from 2 to 7 meters in amplitude. And in northern California, the range would be from 3 to 7 meters. Project modelers assumed high tide conditions, increasing the total tsunami height by about a meter.

Where there was geographic overlap, the results from several modelers are remarkably similar even though the modeling methods differ. The similarity between different models suggests a degree of scientific consensus that should provide confidence in the scenario results.

These models were used to draw inundation lines that delimit the area of dry land that is flooded during the tsunami. Those inundation lines were adjusted by examining fine-scale structures such as steep beaches and levees that may not be well represented in the gridded bathymetric and topographic data used in the numerical calculations. These examinations used high-resolution topographic data, aerial photography, and site visits by field teams.

Two other studies modeled the hydrodynamics, including current velocities, in the Ports of Los Angeles and Long Beach, San Diego, and in Ventura Harbor. High current velocities would occur where the scenario tsunami would be forced through channels and these highly localized features could produce jets and whirlpools. Maximum modeled currents in Ventura Harbor would exceed 14 knots and have widespread speeds of 8 knots, which is fast enough to cause significant damage. In contrast, the Ports of Los Angeles, Long Beach, and San Diego would experience widespread currents that are less extreme, reaching 6 to 8 knots in just a few locations. But, in those locations, the modeled currents are fast enough to damage mooring dolphins, potentially break mooring lines, and impede navigation.

We determined how often tsunami waves similar to those in the SAFRR tsunami scenario would impact different spots along the California coast. Using an aggregate of sources from around the Pacific Ocean, waves with the same or larger offshore amplitude as those in the scenario would occur, on average, on the order of hundreds of years (fig. 3).

Earthquakes like the scenario posited here have happened elsewhere under very similar geological conditions. When they have happened, tsunamis resulted. Several historical transoceanic tsunamis, including those produced by the 1946 M8.1 Aleutian, 1960 M9.5 Chile, and 1964 M9.2 Alaska earthquakes, caused known inundation along portions of the northern and central California coast. Earthquakes like these will occur in the future and will generate tsunamis. The physics of wave motion are well understood, and there is very little uncertainty about tsunami travel times. When they impinge on the built environment, even in well constructed areas, tsunamis cause damage; they can injure and kill people, and they can disrupt the economy. California's experience with tsunamis over the last century is probably far from the worst that can happen. A tsunami generated by the scenario source discussed here would be bigger and cause much more damage in California than the 2011 Tohoku tsunami, the Chilean tsunamis of 2010,1960, and 1922, and the Alaskan-Aleutians tsunamis of 1964 and 1946. Thus, there is strong reason to believe that California faces a tsunami threat that could realistically cause billions of dollars in losses and, although we have not discussed it here, substantial loss of life.

There are uncertainties. The degree of inundation in any particular place, and the resulting losses, are uncertain for many reasons, having to do with imperfect knowledge about the tsunami source, bathymetry and topography, roughness of the sea floor, precise quantities and vulnerability of assets, the resourcefulness of emergency responders and the people and businesses whose property is affected, and financial responses. The uncertainties operate in both 


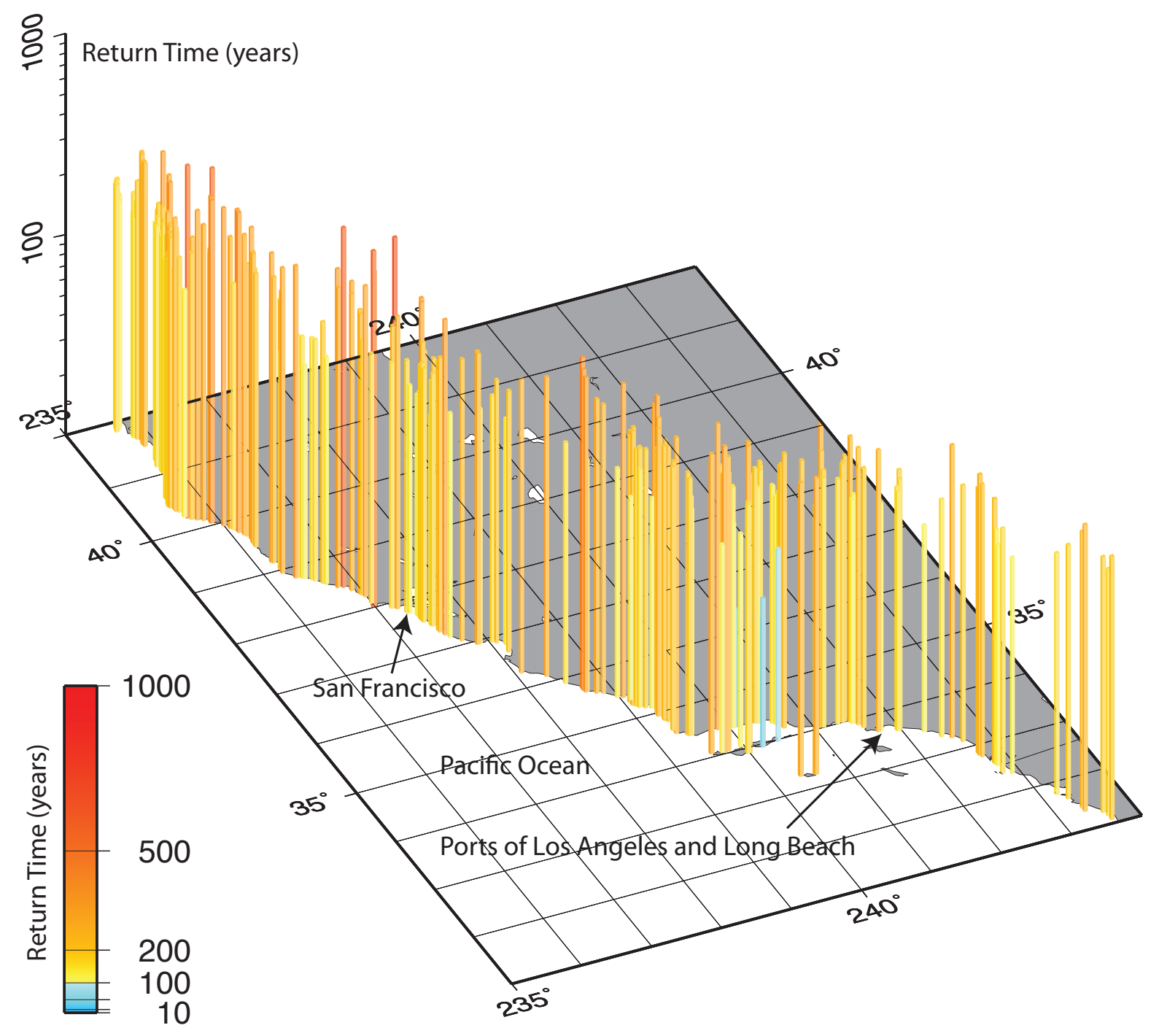

Figure 3. Map of the California coast, where bars at individual locations show equivalent return times of the offshore amplitudes of the tsunami simulated by the SAFRR (Science Application for Risk Reduction) scenario when compared to the Probabilistic Tsunami Hazard Analysis of Thio and others (2010). The probabilistic map is based on a comprehensive analysis of tsunamis from sources around the Pacific, their recurrence rates and probabilities, and is an aggregate of thousands of individual scenario calculations. The return time gives the average time between tsunami waves, at each site, that are as larger or larger than the SAFRR scenario tsunami at that site and is shown by both the height and color of each bar.

directions: the particular earthquake-generated tsunami simulated in this project could produce more severe losses than are depicted here, as well as less severe losses. Earth scientists, engineers and social scientists will continue to study the processes discussed here in an attempt to better understand them and more accurately estimate the outcomes of future tsunamis. When tsunamis occur that affect California, there will probably be surprises, effects, or sequences of events we did not expect - a bigger earthquake than we imagined possible could occur, or our 
engineered facilities and defense structures may not perform as well as we had planned, or people could make unexpected mistakes in the response that aggravates the damage and loss of life.

There are also caveats. The scenario describes actions taken by ports where all communication and emergency response activities are performed quickly and correctly, largely without serious mistakes. But human error, including unanticipated delays in communication or decision-making, could lead to greater damage, greater economic losses, or more severe environmental outcomes than are posited here. There are also likely unforeseen short- and longterm issues that we may not have considered. And although the scenario was relatively detailed in and around the Ports of Los Angeles and Long Beach, other areas of the California coastline outside the ports were evaluated with less detail. Some of these areas, especially in central and northern California, will experience higher waves than southern California. The evaluation of those regions has not been done to the same level of detail as for the Ports of Los Angeles and Long Beach. Consequently, we might not fully understand the short- and long-term impacts to these other ports and harbors.

The timing of the tsunami can have a considerable impact on potential exposure to damage and risk to life. The scenario is set during March 2014, coinciding with the $50^{\text {th }}$ anniversary of the 1964 Alaska earthquake and tsunami. Although the outcomes of the scenario at that time are significant, greater challenges and impacts might result if the scenario were to occur during a summer weekend when beachgoers and recreational boaters are more numerous along the California coast.

The time of high tide is significant in determining inundation. By planning this earthquake at a time when high tide coincides with larger wave heights, the area inundated increases. Though the highest tides only cover about 4 hours per day, preparing for this possibility ensures that we are well prepared, especially when hazardous tsunami conditions can last for up to one or two days. In the other direction, long-term sea level rise due to climate change will increase the inundation area if an event like the SAFRR tsunami scenario occurs later in this century; we have not included that effect in our analysis.

While our uncertainties and caveats affect the quantities we have estimated, they do not change our finding about the qualitative threat to California that is posed by tsunamis from distant earthquakes. Because our uncertainties operate in both directions, and because an underestimate of loss can be graver than an overestimate, they provide more reason to prepare for a severe California tsunami, rather than to wait for scientists to eliminate all uncertainties.

In a speech to the National Defense Executive Reserve Conference (1957), President Eisenhower said, "Plans are worthless, but planning is everything. There is a very great distinction because when you are planning for an emergency you must start with this one thing: the very definition of "emergency" is that it is unexpected, therefore it is not going to happen the way you are planning." The SAFRR Tsunami Scenario depicts an event that will not happen exactly as presented. However, it provides a useful opportunity for planning.

\section{Acknowledgments}

The authors thank reviewers Ruth Harris, Susan Russell-Robinson and Ross Stein and editor Claire Landowski for improving the SAFRR Tsunami Scenario Executive Summary and Introduction. The overall SAFRR Tsunami Scenario report owes a large debt of gratitude to 
Carolyn Donlin, head of the of the Menlo Park Publishing Service Center, Linda Rogers, head of the Tacoma Publishing Service Center and the editors who worked on the various chapters and aspects of the report, for their support and dedication; they include Peter Stauffer, John Buursma, Mike Diggles, Jeanne DiLeo, Jim Hendley, Cory Hurd, Claire Landowski, Jeffery Suwak, and Tracey Suzuki. We also thank Sandra Dedeaux for her excellent logistical support of the project.

\section{References}

Eisenhower, D.D., 1957, From a speech to the National Defense Executive Reserve Conference in Washington, D.C. (November 14, 1957) in Public Papers of the Presidents of the United States, Dwight D. Eisenhower, 1957: National Archives and Records Service, Government Printing Office, 818 p., ISBN $0160588510,9780160588518$.

Kirby, S., Scholl, D., von Heune, R., Wells, R., and members of the USGS Tsunami Source Working Group, 2013, Alaska earthquake source for the SAFRR Tsunami Scenario, chap. B in Ross, S.L., and Jones, L.M., eds., The SAFRR (Science Application for Risk Reduction) Tsunami Scenario: U.S. Geological Survey Open-File Report 2013-1170, 43 p., http://pubs.usgs.gov/of/2013/1170/b/.

Jones, L.M., Bernknopf, R., Cox, D., Goltz, J., Hudnut, K., Mileti, D., Perry, S., Ponti, D., Porter, K., Reichle, M., Seligson, H., Shoaf, K., Treiman, J., and Wein, A., 2008, The ShakeOut Scenario: U.S. Geological Survey Open-File Report 2008-1150 and California Geological Survey Preliminary Report 25, 312 p. and 10 appendixes, http://pubs.usgs.gov/of/2008/1150/.

Porter, K., Wein, A., Alpers, C., Baez, A., Barnard, P., Carter, J., Corsi, A., Costner, J., Cox, D., Das, T., Dettinger, M., Done, J., Eadie, C., Eymann, M., Ferris, J., Gunturi, P., Hughes, M., Jarrett, R., Johnson, L., Le-Griffin, H.D., Mitchell, D., Morman, S., Neiman, P., Olsen, A., Perry, S., Plumlee, G., Ralph, M., Reynolds, D., Rose, A., Schaefer, K., Serakos, J., Siembieda, W., Stock, J., Strong, D., Wing, I.S., Tang, A., Thomas, P., and Topping, K., 2010, Overview of the ARkStorm Scenario: U.S. Geological Survey Open-File Report 2010-1312, 183 p. and appendixes, http://pubs.usgs.gov/of/2010/1312/.

The SAFRR Tsunami Scenario Modeling Working Group, 2013, Modeling for The SAFRR Tsunami Scenario - Generation, Inundation, and Currents in Ports and Harbors, chap. D in Ross, S.L., and Jones, L.M., eds., The SAFRR (Science Application for Risk Reduction) Tsunami Scenario: U.S. Geological Survey Open-File Report 2013-1170, 127 p., http://pubs.usgs.gov/of/2013/1170/d/.

Thio, H.K., Somerville, P., and Polet, J., 2010, Probabilistic Tsunami Hazard in California: Berkeley, Calif., Pacific Earthquake Engineering Research Center Report 2010/108, 331 p., http://peer.berkeley.edu/publications/peer_reports/reports_2010/web_PEER2010_108_THIOet al.pdf/.

Wein, A., Rose, A., Sue Wing, I., Wei, D., 2013, Economic impacts of the SAFRR tsunami scenario in California, chap. H in Ross, S.L., and Jones, L.M., eds., The SAFRR (Science Application for Risk Reduction) Tsunami Scenario: U.S. Geological Survey Open-File Report 2013-1170, 56 p., http://pubs.usgs.gov/of/2013/1170/h/. 
This page intentionally left blank 
science for a changing world

\section{Alaska Earthquake Source for the SAFRR Tsunami Scenario}

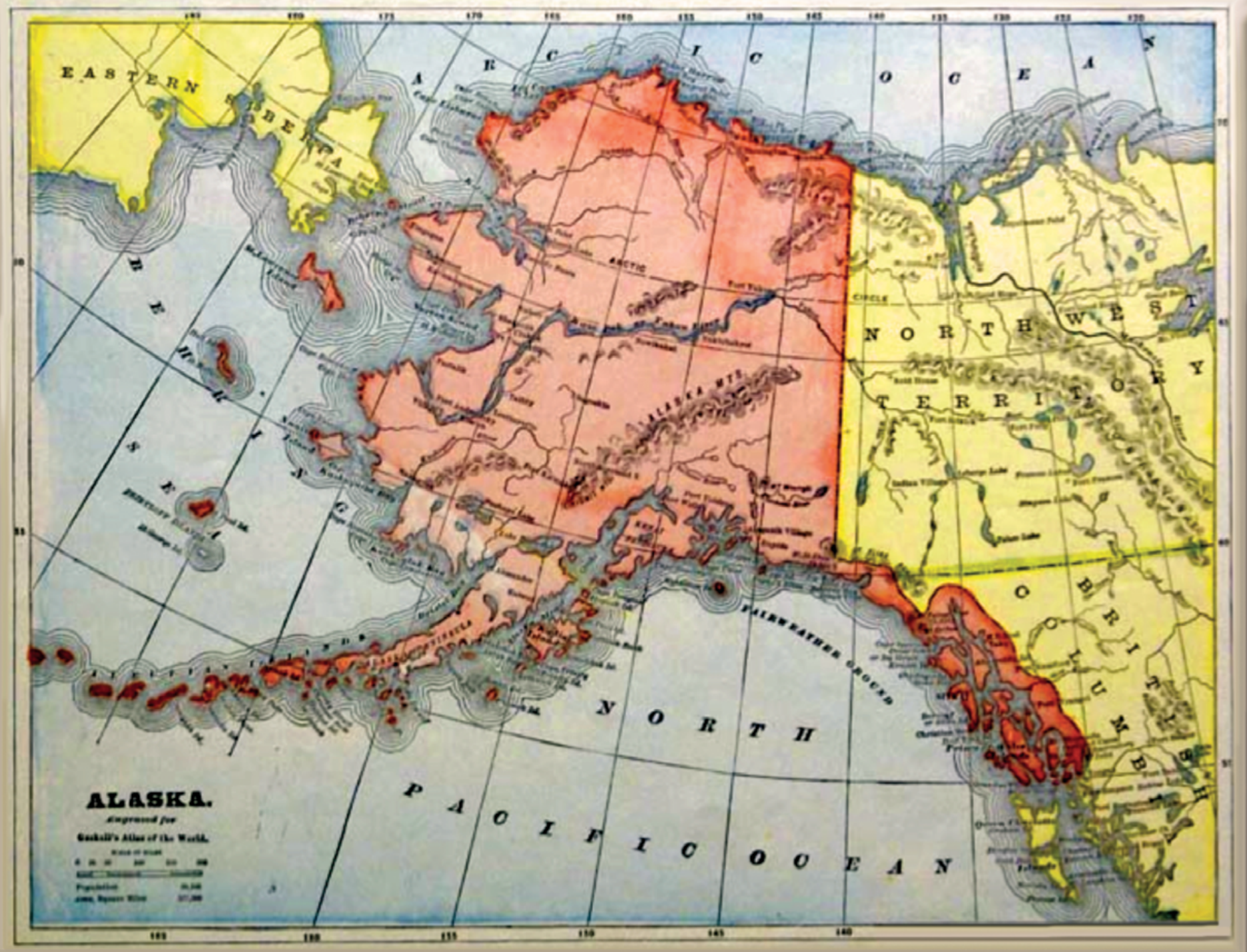

Open-File Report 2013-1170-B

California Geological Survey Special Report 229

U.S. Department of the Interior

U.S. Geological Survey 
COVER: Early map of Alaska Territory (in Gaskell's New and Complete Family Atlas of the World), 1896 


\section{The SAFRR (Science Application for Risk Reduction) Tsunami Scenario}

Stephanie Ross and Lucile Jones, Editors

\section{Alaska Earthquake Source for the SAFRR Tsunami Scenario}

By Stephen Kirby, David Scholl, Roland von Huene, and Ray Wells

Open-File Report 2013-1170-B

California Geological Survey Special Report 229

U.S. Department of the Interior

U.S. Geological Survey 


\section{U.S. Department of the Interior \\ SALLY JEWELL, Secretary}

\section{U.S. Geological Survey \\ Suzette M. Kimball, Acting Director}

U.S. Geological Survey, Reston, Virginia 2013

For product and ordering information:

World Wide Web: http://www.usgs.gov/pubprod

Telephone: 1-888-ASK-USGS

For more information on the USGS—-the Federal source for science about the Earth, its natural and living resources, natural hazards, and the environment:

World Wide Web: http://www.usgs.gov

Telephone: 1-888-ASK-USGS

Suggested citation:

Kirby, S., Scholl, D., von Huene, R., and Wells, R., 2013, Alaska earthquake source for the SAFRR tsunami scenario, chap. B, in Ross, S.L., and Jones, L.M., eds., The SAFRR (Science Application for Risk Reduction) Tsunami Scenario: U.S. Geological Survey Open-File Report 2013-1170, 40 p., http://pubs.usgs.gov/of/2013/1170/b/.

Any use of trade, product, or firm names is for descriptive purposes only and does not imply endorsement by the U.S. Government.

Although this information product, for the most part, is in the public domain, it also may contain copyrighted materials as noted in the text. Permission to reproduce copyrighted items must be secured from the copyright owner. 


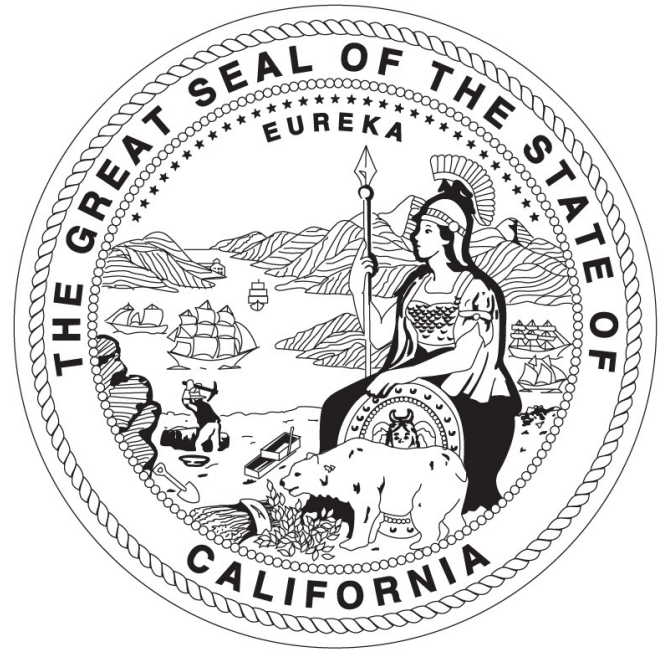

STATE OF CALIFORNIA

EDMUND G. BROWN JR. GOVERNOR

THE NATURAL RESOURCES AGENCY JOHN LAIRD

SECRETARY FOR RESOURCES

\author{
DEPARTMENT OF CONSERVATION \\ MARK NECHODOM \\ DIRECTOR
}

\title{
CALIFORNIA GEOLOGICAL SURVEY JOHN G. PARRISH, Ph.D. \\ STATE GEOLOGIST
}




\section{Acknowledgments}

We are grateful for the help, guidance, and advice provided by the generosity of the following colleagues: Contributing U.S. Geological Survey (USGS) Tsunami Source Working Group members (TSWG): Holly Ryan, Rick Blakely, Stephanie Ross, George Plafker, Eric Geist, Willie Lee, Emily Roland, Amy Draut, Guy Gelfenbaum, and Walter Mooney; other USGS: Gavin Hayes (Golden, Colo.), Alan Nelson (Golden), and John Miller (Denver, Colo.); California Geological Survey: Rick Wilson. We appreciate the support of the following in tsunami modeling: Hong Kie Thio (URS Corp.); Roger Hansen, Elena Suleimani, and Dmitri Nicolsky (all Geophysical Institute of the University of Alaska at Fairbanks; Aggeliki Barberopoulou (University of Southern California); the 2011 Tohoku earthquake slip modelers, especially Thorne Lay (University of California Santa Cruz), Chen Ji (University of California Santa Barbara), Mark Simons (California Institute of Technology), Sarah Minson (Formerly at

California Institute of Technology and now at the U.S. Geological Survey in Seattle), Y. Ito and T. Inuma (both at Tohoku University). We are grateful also for advice and discussions in Japan with Ryota Hino, Dapeng Zhao, Toru Matsuzawa, and Akira Hasegawa (all at Tohoku University); Douglas Christenson, Jeff Freymueller, and Roger Hansen (all at the Geophysical Institute of the University of Alaska at Fairbanks); Emile Okal (Department of Earth and Planetary Sciences, Northwestern University). We thank Eleyne Phillips (USGS) for geographic information system construction and images and Peter Stauffer (USGS, Menlo Park) for his helpful edit. 


\section{Contents}

Abstract

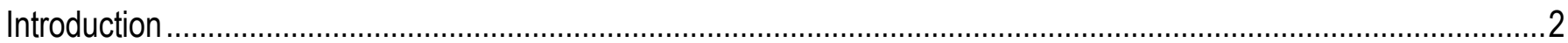

Tectonic Setting and the Instrumental, Historical, and Prehistoric Seismic and Tsunamic Record of the

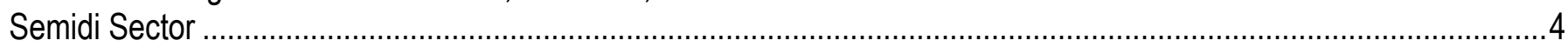

Comparisons Between the Semidi and Tohoku Subduction Sectors ....................................................................

Characterizing the Scalar Seismic Moment of the 11 March 2011 Tohoku Earthquake, Slip Models, and

Development of a Synoptic Slip Distribution Model and Target Range of Model Parameters.......................................

Creating a Subfault Grid and Applying a Tohoku-Type Slip Distribution to the Semidi Sector .....................................10

Scaling of Average Slip During Seismogenic Rupture for Giant Earthquakes with Moment Magnitude: How

Useful a Guide is it?

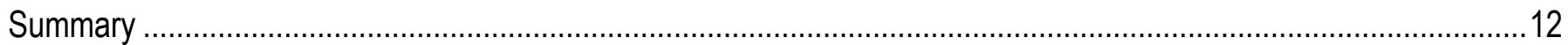

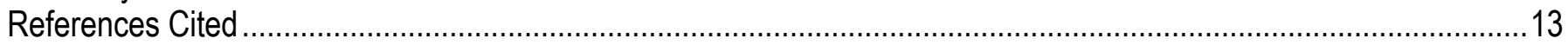

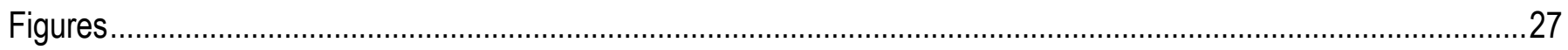

Appendix. Supplementary Information......................................................................................................... 40 


\title{
Alaska Earthquake Source for the SAFRR Tsunami Scenario
}

\author{
By Stephen Kirby, David Scholl, Roland von Huene, and Ray Wells \\ "What did happen can happen again [elsewhere]" \\ - Paraphrased aphorism \\ "Extreme events can and do happen..." \\ - Thorne Lay and Hiroo Kanamori, Physics Today, 2011 \\ "Hope for the best, but prepare for the worst." \\ - An oft-quoted adage.
}

\section{Abstract}

Tsunami modeling has shown that tsunami sources located along the Alaska Peninsula segment of the Aleutian-Alaska subduction zone have the greatest impacts on southern California shorelines by raising the highest tsunami waves for a given source seismic moment. The most probable sector for a $M_{\mathrm{w}} \sim 9$ source within this subduction segment is between Kodiak Island and the Shumagin Islands in what we call the Semidi subduction sector; these bounds represent the southwestern limit of the $1964 M_{\mathrm{w}} 9.2$ Alaska earthquake rupture and the northeastern edge of the Shumagin sector that recent Global Positioning System (GPS) observations indicate is currently creeping. Geological and geophysical features in the Semidi sector that are thought to be relevant to the potential for large magnitude, long-rupture-runout interplate thrust earthquakes are remarkably similar to those in northeastern Japan, where the destructive $M_{\mathrm{w}} 9.1$ tsunamigenic earthquake of 11 March 2011 occurred.

In this report we propose and justify the selection of a tsunami source seaward of the Alaska Peninsula for use in the Tsunami Scenario that is part of the U.S. Geological Survey (USGS) Science Application for Risk Reduction (SAFRR) Project. This tsunami source should have the potential to raise damaging tsunami waves on the California coast, especially at the ports of Los Angeles and Long Beach. Accordingly, we have summarized and abstracted slip distribution from the source literature on the 2011 event, the best characterized for any subduction earthquake, and applied this synoptic slip distribution to the similar megathrust geometry of the Semidi sector. The resulting slip model has an average slip of $18.6 \mathrm{~m}$ and a moment magnitude of $M_{\mathrm{w}}=9.1$. The 2011 Tohoku earthquake was not anticipated, despite Japan having the best seismic and geodetic networks in the world and the best historical record in the world over the past 1,500 years. What was lacking was adequate paleogeologic data on prehistoric earthquakes and tsunamis, a data gap that also presently applies to the Alaska Peninsula 
and the Aleutian Islands. Quantitative appraisal of potential tsunami sources in Alaska requires such investigations.

\section{Introduction}

\section{Background}

Tsunami modeling has shown that the most effective subduction earthquakes for raising tsunami waves along southern California shorelines are those that occur offshore of the Alaska Peninsula (Thio and others, 2010; fig. 1). We review the instrumental and preinstrumental record of seismicity in that region and conclude that the previous cumulative seismic slip in the instrumental history in the Semidi sector, which we define as between Kodiak Island and the Shumagin Islands, is small. Although nearby subduction sectors have generated great and giant tsunamigenic earthquakes in 1946 and 1964, those earthquakes did not cause damaging tsunami waves along southern California shorelines, largely because of their different trench azimuths and positions and differences in tsunami wave-field directivity and in sea-floor bathymetry between source and receiving shoreline. For a giant earthquake $\left(M_{\mathrm{w}} \geq 8.5\right)$, the Semidi subduction sector may therefore be the optimum subduction sector for producing tsunami waves along southern and central California shorelines.

The M9.1 Tohoku subduction earthquake of 11 March 2011 changed the way that many earthquake scientists think about subduction earthquakes and their tsunami effects. First, the 2011 event was not anticipated because of the lack of historical information about previous earthquakes of this size. Although an earthquake that occurred in the year 869 produced large runups along Sendai Bay (Minoura and others, 2001), paleotsunamic evidence is lacking farther north along the Sanriku coast (Sugawara and others, 2011, unpublished field guide on the Jogan and 2011 Tohoku tsunami deposits). Based on this limited known length of tsunami effects in AD 869, tsunami modeling showed that a source magnitude of 8.1 to 8.3 adequately explained the runups and inundations suggested by the paleotsunamic record (Satake and others, 2007). Therefore the historical record in Japan, even though it is among the longest for any region on Earth, was inadequate to have anticipated an earthquake of the magnitude of the 2011 event. More prehistoric information on subduction earthquakes and tsunamis was clearly needed, such as has been found in Cascadia and the eastern Gulf of Alaska subduction sectors. Secondly, on-land Global Positioning System (GPS) data did not have sufficient resolution to determine that the locking on the Japan Trench subduction margin extended to the Japan Trench. Thirdly, Tohoku University and the Japan Agency for Marine-Earth Science (JAMSTEC), and other Japanese partners installed sea-floor GPS instruments, pressure gages, tsunami wave meters, and cabled sea-floor instruments in the source region before the 11 March 2001 earthquake. Analysis of those data indicated that extraordinarily high maximum slip occurred during the earthquake rupture near the trench, as large as $80 \mathrm{~m}$. Without this sea-floor instrumentation, the true nature of this tsunami source would not have been revealed.

The above considerations indicate that for earthquakes of this moment magnitude, events with compact rupture areas and large associated average and peak slip probably occur on time scales of thousands of years (Satake, 2011). Historical and instrumental information are consequently inadequate to establish the likelihood of the occurrence of 
such events. Scientists tasked with considering tsunami hazards and risks must therefore ask the question - could such a tsunamigenic earthquake occur in "my" subduction zone (McCaffrey, 2007, 2008)?

\section{Our Charge}

The purpose of this report is to summarize briefly and justify the selection of a tsunami source seaward of the Alaska Peninsula for use in the Tsunami Scenario that is part of the U.S. Geological Survey (USGS) Science Application for Risk Reduction (SAFRR) Project. Our charge was to propose a tsunami source offshore of the Alaska Peninsula that had the potential to raise damaging tsunami waves along California coastlines, especially at the ports of Los Angeles and Long Beach. This source needed to be credible and plausible in light of the state of knowledge in early 2012, when this tsunami source scenario was formulated, and to represent an event that could occur sometime in the future. Being the most likely next large tsunami source for southern California shorelines was not a requirement. The specific source presented in this report was described and discussed on 27 February 2012 at the USGS facilities in Menlo Park, California, by participating members of the USGS Tsunami Source Working GroupStephanie Ross, Scenario Manager for SAFRR, David Scholl, Ray Wells, Rick Blakely, Roland von Huene, Willie Lee, Walter Mooney, Amy Draut, and Tracy Vallier (all USGS); Rick Wilson (California Geological Survey); and Roger Hansen (Geophysical Institute at the University of Alaska at Fairbanks, GI/UAF). Other participants on conference call for this meeting were Hong Kie Thio (URS Corporation), George Choy (USGS, Golden, Colo.), Elena Suleimani and Dmitry Nicolsky (GI/UAF), Lucy Jones (USGS, Pasadena), Kenny Ryan (University of California Riverside), David Lockner and Tom Brocher (both USGS Earthquake Science Center) and Dale Cox (USGS, Pasadena). After discussion of the proposed source, the participants offered no alternatives and, when specifically asked, there were no objections to the scenario being put forward as the official USGS SAFRR Tsunami Scenario model. The model was also discussed in presentations by Kirby at Tohoku University in May 2012 and at the University of Alaska Geophysical Institute in February 2012, where opportunities for questions and comments were both offered and exercised.

In this source selection, we chose to apply a Tohoku-type tsunami source because of strong similarities in the geologic and geophysical frameworks of the Semidi and Tohoku subduction sectors, similarities that we summarize in this report. We do not claim that this source has the highest probability among possible future great and giant tsunamigenic earthquakes. Such probability cannot be assessed without comprehensive paleoseismic and paleotsunamic surveys in the Semidi sector. Lacking such information, our goal is to posit a $M_{\mathrm{w}} \sim 9$ tsunami source that could plausibly occur at some time in the future based on the similarities in framework geology and geophysics between the Semidi and Tohoku subduction segments. Put another way, is such a source plausible given our present state of knowledge or lack of knowledge? We not only lack sufficient prehistoric data on the Semidi sector on average recurrence times, but we also do not know how late we are in the average giant earthquake return time and how much stored slip has accumulated. It cannot be claimed with any confidence that the probability of a compact, 
high-average-slip tsunamigenic earthquake is impossibly low in the Semidi segment. The same could have been said, but was not, about the likelihood of a giant subduction earthquake in the southern Tohoku subduction margin on 10 March 2011, just prior to the catastrophe that occurred one day later.

\section{Plan of This Report}

Our plan for this report is to first review the tectonic setting and the history of seismicity and tsunami generation on the subduction zone in the Pacific offshore the Alaska Peninsula. Secondly, we compare the geological and geophysical frameworks of the Tohoku and Semidi subduction segments and evaluate whether their similarities outweigh their differences. Thirdly, we abstract from the numerous slip models for the 2011 Tohoku earthquake a simplified synoptic slip model that we apply to a threedimensional (3-D) model for the geometry of the Semidi-segment of the megathrust boundary, which was found very similar to that of the Tohoku segment. We explain briefly how the geometrical subfault model was constructed and how we populated that array with coseismic slip. Fourthly, we discuss the subject of scaling of rupture sizes and average slip with scalar seismic moment and moment magnitude for subduction earthquakes in light of the inadequacy of the existing seismic record for giant subduction earthquakes $\left(M_{\mathrm{w}}>8.5\right)$, and we discuss challenges in using a scaling law as a guide to earthquake sources in this seismic moment range. Finally, the 3-D slip distribution for the tsunami scenario source will be provided in a spreadsheet that may be found in an appendix as supplemental information. In the interest of making this report as brief as possible, we summarize relevant information as much as is practical in tables. The information sources that we used in producing the Semidi sector slip model were largely limited to those available as of 25 January 2012, but they include final publication citations that were previously available only in abstract.

\section{Tectonic Setting and the Instrumental, Historical, and Prehistoric Seismic and Tsunamic Record of the Semidi Sector}

The following account includes events in the Semidi sector and nearby segments of the Aleutian-Alaska subduction zone (table 1). It also reviews the maximum tsunami wave heights produced by earthquakes in this segment at key Pacific coastal locations, especially in California (National Geophysical Data Center, 2012; Novosibirsk Tsunami Laboratory, 2012).

\section{The $M_{\mathrm{w}} 8.2$ to 8.3 Subduction Earthquake of 10 November 1938}

The instrumental history of the Semidi sector for events with $M>7$ and of great earthquakes in nearby segments is summarized in table 2 and illustrated in figures $2 \mathrm{a}, 3 \mathrm{~b}$, and 4a. The 1938 main-shock epicenter places it near the Slab 1.0 interface at depths between 20 and $40 \mathrm{~km}$ (table 1). (Slab 1.0 is a global 3-D slab geometry model based on the hypocenters of interplate thrust earthquakes and subduction plate boundary information from seismic reflection profiles - see Hayes and others, 2012). The relocated 1-month aftershocks of the 1938 event (Emile Okal, written commun., 2010) cover most 
of the Semidi sector, nearly out to the trench. Although the 10 November 1938 earthquake was an $M_{\mathrm{w}} 8.2-8.3$ event, recorded wave heights are all less than $0.3 \mathrm{~m}$ and tsunami modeling of its small regional and far-field tsunami waves indicate that its three slip patches had an average slip of about 1.1 to $2.1 \mathrm{~m}$ and a maximum slip of $3.3 \mathrm{~m}$ in the easternmost subfault (Johnson and Satake, 1994, 1995). An independent seismic waveform analysis also indicates that average slip was about $2 \mathrm{~m}$ (Estabrook and others, 1994). These are very small slips in light of cumulative relative plate motion in the Semidi sector since 1938 (about $4.5 \mathrm{~m}$ ) and the potential for large stored slip prior to the instrumental era.

All told, the small number of other large instrumentally documented earthquakes (figs. 2a, 3b, and 4) indicates that a very small release of accumulated slip has occurred in the century plus of plate motion since the beginning of global seismology in about 1899 . During this period more than $6.8 \mathrm{~m}$ of plate motion occurred. None of the great earthquakes in adjoining sectors or the 1938 event have produced recorded tsunami waves in southern California greater than $1.1 \mathrm{~m}$ (table 1).

\section{Gulf of Alaska Sector}

The $M 9.2$ to 9.3 earthquake of 28 March 1964 was the largest instrumentally recorded earthquake in Alaska and the second largest in the global instrumental record (International Seismological Center, 2013). The four published inversions of geodetic and seismic data for slip-accumulation distribution, although differing in data selection, methodology, and details of the resultant slip inversion, all recognize two patches of large slip, one under the Prince William Sound area and one trenchward of Kodiak Island and the pass southwest of the Kenai Peninsula and northeast of Kodiak Island (Holdahl and Sauber, 1993; Christensen and Beck, 1994; Johnson and others, 1996; Ichinose and others, 2007; Suito and Freymueller, 2009). This pattern is also consistent with the aftershock distribution. Ichinose and others (2007) also subdivided the Prince William Sound patch into two subfaults and verified the trenchward Kodiak slip region. These findings and other considerations suggest that as a conservative approach, the northeast limit of the SAFRR tsunami scenario source should not extend under the Kodiak subduction sector, because it represents rupture for a relatively recent earthquake.

\section{The $M_{\mathrm{w}}$ 8.6 Unimak Island/Sanak Island Earthquake of 1 April 1946}

This shock (see fig. 2a) was unusual in several related respects: it was generally deficient in high-frequency energy, its epicenter was very near the Aleutian Trench, and it had unusually high potency as a tsunami source both in the near and far fields (Kanamori, 1972; Johnson and Satake, 1997, Okal and others, 2002, 2003; Lopéz and Okal, 2006). Its tsunami magnitude was 9.3 (Abe, 1979). It was one of the first earthquakes identified as being of the "tsunami" earthquake category that produces outsized tsunami waves compared to their conventional moment magnitudes (Kanamori, 1972). The average slip was about $8 \mathrm{~m}$ or more as estimated by López and Okal (2006). The directivity of tsunami waves from this source toward Hawaii made it particularly destructive. There are similarities in the geologic frameworks of the southwest Alaska Peninsula continental slope where the 1946 earthquake occurred and the Semidi sector 
(Bruns and others, 1987) that suggest that a component of slow-rupture, high-near-trench slip could also occur in the Semidi sector (von Huene and others, 2012).

\section{Regional Stored Slip Accumulations Based on GPS Observations.}

Freymueller and Beavan (1999); Fletcher and others (2001); Fournier and Freymueller (2007), Freymueller and others (2008), and Cross and Freymueller (2008) have described the results of Global Positioning System (GPS) observations in Alaska. Their analyses indicate that the region northeast of the Shumagin Islands is presently "locked" and has been accumulating stored slip, In contrast, the southwest offshore sector of the Alaska Peninsula, which includes the Shumagin Islands, is probably creeping, although resolution is thought to be poor for the subduction boundary near the trench far from the nearest GPS instruments. However, we do not know whether this creeping condition represents the long-term way that subduction motion is accommodated in the Shumagin sector. These same locked versus creeping conclusions about these two sectors adjacent to the Semidi sector were adopted as inputs in the most current USGS probabilistic seismic hazard map for the State of Alaska (Wesson and others, 2007) and we adhere to their assessment.

\section{Historical Record for Tsunamigenic Earthquakes in the Semidi Sector: the 1788 Event and the Purported Tsunamigenic 1847-1848 Earthquake}

Russian information on earthquake occurrence and seismic intensities and tsunami inundations in Alaska prior to the Territory's purchase by the United States in 1867 is typically fragmentary, mostly recorded long after the event by those who were not eyewitnesses and citing observations at sparse locations. Even event dates are unclear from this incomplete record.

July/August 1788. - A short few years after Russian long-term settlement began on the Alaska Peninsula and its offshore islands, two events occurred in that region. The sources of information (see Davies and others, 1981; Sykes and others, 1981) on these events are the following. (1) W. Merkul'ev (b.?; d.1828), a warehouse manager on Kodiak Island at the time of the 22 August 1788 earthquake and tsunami: He wrote a letter shortly after the events, describing them to his boss, Grigory Ivanovich Shelekhov (1747-1786), cofounder of the Shelekhov-Golikov Company. (2) G.I. Davydov, who was in Alaska in the first decade of the 19th century: His accounts were published in English in 1813. (3) Russian Orthodox priest Ioann (Father John) Veniaminov (1797-1879), who was in Alaska from 1824 to about 1840: His diary was published in 1840. (4) Geologist Pëtr Pavlovich Doroshin (1823-1875), who arrived in Russian Alaska in 1848 and wrote of his experience in a report that was published in 1870. Only Merkul'ev was an eyewitness. The others collected information decades after the events, and those impressions and descriptions were published decades after collection. Not surprisingly, there is confusion as to the exact dates of these events and which events preceded others. The experiences of Merkul'ev on 22 July (in the present-day Gregorian calendar) describing the strong earthquake ground motions and tsunami inundations at Three Saints Harbor, located in a fjord on the south coast of Kodiak Island, carry the most weight because they are first-hand and written shortly after the events. In reviewing all of these records, S.L. Soloviev (1968; English translation published 1990) implies in his figure 1 
that there was one giant earthquake that ruptured about $650 \mathrm{~km}$ of the Alaska Peninsula margin from south of Kodiak to Sanak Island. This source model seems very unlikely because of the insistence by Veniaminov, a keen interviewer and native-language interpreter, that big tsunami waves occurred on Unga and Sanak Islands on 7 August (again according to the present-day Gregorian calendar), 16 days after the 22 July earthquake and tsunami waves reported by Merkul'ev.

Another possibility was raised by Emile Okal (written commun., 2011) that a large earthquake occurred on 22 July somewhere along the subduction margin between the Gulf of Alaska and Sanak Island and that 16 days later, on 7 August' a large submarine landslide occurred near the southwest end of the Alaska Peninsula that was triggered as a delayed response by the ground motions of the earlier 22 July earthquake. According to this model, it was this localized submarine landslide tsunami source that flooded the settlement on Unga and destroyed livestock on Sanak Island, both to levels up to a few tens of meters above sea level. Okal's interpretation is strengthened by recent geophysical investigations of the continental slope southwest of the Shumagin Islands that reveal morphological evidence for large submarine slumps near the southern edge of the continental shelf (Roland von Huene, unpublished swath-map image, 2013).

Okal's hypothesis seems to satisfy most of the historical records that might be judged reliable, including the lack of evidence for strong earthquake ground motions on 7 August. We are left with a large earthquake occurring somewhere off the Alaska Peninsula on 22 July 1788 that was large enough to raise waves 3-10 $\mathrm{m}$ high at the old harbor in Three Saints Bay, Kodiak (a narrow fjord) and produced at least localized strong ground motions and sustained aftershocks at that locality. As to its seismic moment, area of rupture, and average slip, we lack adequate information to go further. Any assumption that the 1788 event(s) resulted in complete release of stored interplate slip is unsupported by the sparse evidence summarized above. Without such an assumption, the present-day state of stored interplate slip cannot be estimated. A continuing search for 1788 tsunami deposits on ocean-facing embayments along the Pacific side of the Alaska Peninsula and its islands may resolve some of the questions about this earthquake and the tsunami waves that it produced.

1847/1848 - This "event," cited in Davies and others (1981), is extremely doubtful (Lander and Lockridge, 1989). It is based on an historical account of a strong "orphan" tsunami in Tahiti, the source of which is now unclear because Tahiti is not a plate-boundary tsunami source. The same authors suggest that tsunami waves of similar potency occurred in Hawaii in the mid-to-late 1840's. Although earthquakes were felt in early morning of 15 April 1848 off the Alaska Peninsula at Chirikof and Unga Islands, no report of tsunami waves are known by the authors of the present report for that part of Alaska on any date in the years 1847 or 1848 . Moreover, none of the other qualified compilers of tsunami events and large earthquakes in the modern era recognize this "event" as valid for Alaska (Lander, 1996; Novosibirsk Tsunami Laboratory, 2012; Pararas-Carayannis and Calebaugh, 1977; Brockman and others, 1988; Lander and Lockridge, 1996).

We conclude from this historical record of tsunamigenic earthquakes that an unknown amount of seismogenic slip occurred in July and possibly August 1788. The lack of historical and instrumental evidence for a large area of tsunamigenic slip ( $>4 \mathrm{~m}$ ) since then suggests that cumulative historical seismogenic slip release has been small. 
Clearly information on prehistoric tsunamigenic earthquakes in the Semidi sector is needed for future guidance on the likelihood of a giant tsunamigenic earthquake.

\section{The Paleogeologic Record.}

Just a few short years ago, Gary Carver and George Plafker wrote that paleogeologic investigations of subduction earthquakes were largely restricted to the Gulf of Alaska subduction sector (Carver and Plafker, 2008). This situation has changed greatly in the past 5 years through partnerships between USGS scientists-largely supported by the USGS Multihazards Demonstration Project (MHDP), by SAFRR (the successor of MHDP), and by the Alaska Earthquake Hazards Project, and university scientists supported largely by the National Science Foundation (NSF) and the USGS, and a geologist with the State of Alaska Division of Geological and Geophysical Surveys. Over the last several summer seasons, field surveys have visited Chirikof Island, Sitkinak Island near Kodiak, and Simeonof Island in the southeast Shumagin Islands.

Results from these surveys so far are preliminary and unpublished, and correlations between islands are not yet confidently identified. Alan Nelson (USGS, Golden) and others have compiled what is known so far (unpublished report, 2012). However, the initial findings are encouraging at two of these sites, one on Chirikof and one on Sitkinak. These investigators have dated possible and probable tsunami deposits and evidence for elevation changes possibly caused by large subduction earthquakes. Intervals between dated events vary greatly - from as little as one hundred to a few hundred years up to many hundreds to 1,300 years. At the long end of these interevent intervals, slip accumulations of many tens of meters are possible.

Preliminary findings from geologic field work on Simeonof Island in the Shumagin Islands imply little strain accumulation and release on the Aleutian-Alaska megathrust beneath the Shumagin Islands in the past 3,400 years (Witter and others, 2012). These initial paleogeologic results provide support for the interpretation of GPS observations summarized earlier in this report that the Shumagin sector is largely slipping aseismically and that the western limit of rupture for scenario models should not include the Shumagin sector.

As embayments, salt marshes, and tidal flats are investigated on more and more islands, such as Sanak Island southwest of the Shumagins and Unga Island in the Shumagins, and onshore along the Pacific coast of the Alaska Peninsula, we should have a fuller picture of the chronology of prehistoric megathrust earthquake occurrence in the offshore of the Alaska Peninsula. In the meantime, we see nothing in these preliminary results that vitiates the tsunami source that we posit in the next section.

\section{A Plausible Tsunamigenic Source Location-the Semidi Subduction Sector: Rupture Dimensions and Geographic Placement}

Our reasons for restricting the source area for the scenario tsunami to between the Shumagin Islands and Kodiak Island were given above. Thus, rupture length is limited to about $400 \mathrm{~km}$ or less. The regional depth limit for interplate thrust earthquakes on the

Alaska Peninsula is about $45 \mathrm{~km}$ and the down-dip dimension of the Slab 1.0 plate 
boundary model from the Alaska Trench to that depth is about 200 to $220 \mathrm{~km}$ (Hayes and others, 2012). These are the spatial limits within which our scenario source must be placed. This requires a relatively compact source with a large average slip for a $M_{\mathrm{w}} \sim 9$ subduction earthquake. We show below that the source dimensions and moment magnitude of the 11 March 2011 Tohoku earthquake match these requirements and that there are many similarities in the geology and geophysics of these two subduction margins that make this application plausible.

\section{Comparisons Between the Semidi and Tohoku Subduction Sectors}

In table 2, we summarize the geologic and geophysical features in these two subduction-zone segments: relative plate motions, average age and sea-floor roughness of the incoming oceanic plate, average trench depths, forearc bathymetric morphologies, fault structures, average dip of the megathrust boundaries, the trench-to-shoreline distance, activities of the volcanic arcs, and other features. There is typically wide variability in these features among subduction zones of the world (Scholl and others, 2013). As discussed more fully by Ryan and others (2012a, 2012b), there are remarkable similarities in the seismic images of structures in the Tohoku and Semidi margins (fig. 4). The major differences, such as the ages of the incoming plates and trench sediment thicknesses, are not directly relevant to the question of tsunami potential, because the instrumental and historical record shows that great and giant subduction earthquakes occur over wide ranges of incoming plate ages and trench sediment fill (Scholl and others, 2013). Moreover, the basic structural similarities between these two subduction margins are obvious. One important feature of the Tohoku margin in the vicinity of the region of highest slip in 2011 is the presence of a large landward-dipping normal fault that was evidently reactivated during the 2011 earthquake (fig. 5). Japanese scientists have called this a branch fault because it branches off the megathrust boundary (Kodaira, 2012; Kodaira and others, 2012). This structure is thought to represent the dynamic adjustment of the offshore forearc to a steep gradient in coseismic slip on the subduction boundary. Such "branch" normal faults are seen in most seismic sections crossing the trench slope of the Alaska Peninsula (Bruns and others, 1987), but better resolution is needed to resolve such structures that cross the Semidi sector (fig. 4; Ryan and others, 2012b).

\section{Characterizing the Scalar Seismic Moment of the 11 March 2011 Tohoku Earthquake, Slip Models, and Development of a Synoptic Slip Distribution Model and Target Range of Model Parameters}

Because of the density of GPS, seismic, and tide-gage networks in Japan, seafloor instruments offshore, and intense interest in using global tide-gage and seismic instruments, the 2011 Tohoku earthquake is the best-characterized subduction earthquake in history. The reported scalar seismic moments range from 3.8 to $5.7 \times 10^{22} \mathrm{~N} \cdot \mathrm{m}$, equivalent to an $M_{\mathrm{w}}$ of 9.0 to 9.1 (table 3), now among the five largest magnitudes in the 
instrumental record. We chose a scalar moment of $4.9 \times 10^{22} \mathrm{~N} \cdot \mathrm{m}\left(M_{\mathrm{w}} 9.1\right)$ as our target moment within this range of reported values. The Tohoku event has been extensively studied in the past 3 years. The resulting coseismic slip models vary greatly in the data that they use in their inversions, their methodologies, assumed subfault geometries, and other assumptions that went into these models. Naturally, there is a fairly wide diversity in the resulting models (table 4), including rupture lengths (160 to $440 \mathrm{~km}$ ), down-dip dimensions (120 to $220 \mathrm{~km}$ ), average slip (12 to $25 \mathrm{~m}$ ), and peak coseismic slips (27 to $85 \mathrm{~m}$ ). In general, those models constrained by local and regional Japanese data have the best spatial resolution from stations on land but have limited geographic coverage and resolution for slips on the subduction boundary near the Japan Trench far from land. On the other hand, those models that only use far-field tide-gage and seismic data have better geographic coverage but more limited spatial resolution. It was the measurements from sea-floor GPS, pressure gages, and tethered tsunami gages that supplied the most convincing evidence that unprecedented slip, as much as $85 \mathrm{~m}$, occurred near the Japan Trench. Because most of these sea-floor instruments were located along a narrow trenchnormal corridor, trench-parallel resolution was limited. In our opinion the most convincing models are the hybrid ones that incorporate far-field seismic and tide-gage data, onshore Japanese seismic, and onshore tide-gage data, as well as data from sea-floor instruments. Our expectation is that giant large-slip earthquakes like the 2011 Tohoku earthquake have occurred elsewhere in the past, but the lack of sea-floor data has prevented them from being identified. We posit that such an event could occur in the Semidi sector.

We abstract from such models the following simplified synoptic view of the 11 March 2011 source:

- A compact source with the following dimensions: 300 to $440 \mathrm{~km}$ long parallel to trench, and 150 to $200 \mathrm{~km}$ downdip

- Maximum coseismic slip near the trench: $65 \mathrm{~m}$

- Average slip: $\sim 18 \mathrm{~m}$

- Bilateral rupture from the main-shock epicenter

- A rough along-strike symmetry, with peak slip along the trench segment midline and slip falloff toward the trench-parallel limits of rupture.

\section{Creating a Subfault Grid and Applying a Tohoku-Type Slip Distribution to the Semidi Sector}

\section{A 3-D Megathrust Boundary Geometry and the Construction of Subfault Segments}

We constructed an approximation of a curviplanar subfault geometry by the following procedure: Using geographic information system (GIS) tools, a first row of $25 \times 50 \mathrm{~km}$ rectangular surface tiles was constructed with the southeast boundaries approximately coincident with a smoothed trench line and shared corners along this line. We then propagated this first row of tiles approximately perpendicular to the trench, producing an $8 \times 8$ array of surface tiles (fig. 6). Naturally, this array of tiles increasingly overlapped laterally with adjacent tiles interior to the array as new rows of tiles were 
created toward the volcanic arc. Those overlaps were graphically eliminated by creating shared lateral boundaries and corners (fig. 7). The trench-parallel subfault boundaries are approximately parallel to the lines representing depth contours in Slab 1.0 (fig. 2a). Finally, these polygonal surface tiles were projected vertically onto the Slab 1.0 surface and the resultant subfault areas adjusted as $A^{\prime}=A / \cos \theta$ where $A$ is the area of the surface tile, $A^{\prime}$ is the projected area of the plate-boundary subfault on the dipping plate boundary, and $\theta$ is the dip angle in the Slab 1.0 model at the centroid of the polygonal tile. Such a procedure produces subfaults of variable area, dip, and azimuths of line segments defining their boundaries and conforms to what we presently know about the 3D geometry of this subduction sector.

\section{Applying this Simplified Synoptic Slip Model for the 2011 Tohoku earthquake to the Semidi Sector Array}

In adapting the foregoing abstraction from slip models of the Tohoku-Oki earthquake to the Semidi subduction sector, we imposed smoothly varying slip from subfault to subfault (figs. 8, 9, and 10). Abrupt changes in average slip distribution in subfaults are not considered justified and in any case should not affect the longwavelength approximation of tsunami models in the far field. Seismic reflection surveys crossing the Japan Trench after the 2011 Tohoku earthquake show that trench-fill sediments and the outermost inner trench slope underwent distributed deformation by thrust faulting during the event (Kodaira and others, 2012). Accordingly, we expect that such distributed slip would represent an equivalent reduced maximum slip under the deformed soft sediments in the part of the Semidi frontal prism and trench-fill nearest the Aleutian Trench. The whole frontal prism in the Semidi sector is about 20 to $25 \mathrm{~km}$ wide, about the same width as in the Tohoku sector (von Huene and Cullota, 1989; von Huene and others 1994; Ryan and others, 2012b; von Huene and others, 2012).

\section{The Final Version of the Semidi Sector Source}

The lateral and down-dip dimensions of the final array are $358 \mathrm{~km}$ and $205 \mathrm{~km}$, respectively, close to the targeted Tohoku-source dimensions (compare summary in the section above on developing model parameters for Tohoku and tables 4 and 5). The average dip of our Semidi array is about $12^{\circ}$, compared to the slightly larger average dip of the seismogenic megathrust boundary of about $13^{\circ}$ for Tohoku (table 2). Using a depth-varying shear modulus of 30,40 , and 50 gigapascals (GPa), consistent with rockphysics models, the slip distribution that we adopted produces a summed seismic moment of $4.9 \times 10^{22} \mathrm{~N} \cdot \mathrm{m}$, which is close to the average value for the Tohoku-Oki source investigations summarized in table 3 . The latitudes, longitudes, and depths at each corner of the subfault grid and at the subfault geometrical centroids are documented in the appendix (table A, Supplementary Information).

\section{Scaling of Average Slip During Seismogenic Rupture for Giant Earthquakes with Moment Magnitude: How Useful a Guide is it?}


Estimating source dimensions and moment magnitudes is difficult even in the digital era of seismology. Source dimensions estimated in the pre-digital era from aftershock distributions are suspect, in view of the fact that for recent giant subduction earthquakes, aftershocks extend far beyond the areas of significant modeled seismogenic slip. For example, the aftershock zone for the 2011 Tohoku earthquake is roughly twice as large as the coseismic area of significant slip (Hayes, 2011). Also, recent earthquakes of comparable moment magnitude - 2004 Sumatra $M_{\mathrm{w}} 9.15$ (Chlieh and others, 2007) and 2011 Tohoku $M_{\mathrm{w}} 9.1$ (this synopsis) - have estimated average slips that differ by more than a factor of three to four ( $5 \mathrm{~m}$ versus 15 to $20 \mathrm{~m}$, respectively). There is a similar scale of variability in average slip for smaller subduction earthquakes, although modeling of events smaller than $M_{\mathrm{w}} 8.0$ becomes increasingly uncertain with decreasing moment magnitude. With such intrinsic variability, one can question the utility of using the scaling of average slip versus scalar seismic moment as a tool for forecasting possible earthquake ground motions and the tsunami wave field.

Satake and Tanioka (1996) and Satake and others (2008), in reviewing what was then known about large tsunamigenic subduction earthquakes worldwide, speculated about the role of poorly consolidated sediments in the outer forearc prism closest to the trench in seismogenesis and tsunamigenesis. For most big interplate thrust earthquakes, significant coseismic slip probably does not occur under the prism but does occur deeper in the megathrust boundary. For certain less frequent giant earthquakes, large slip can and does occur under the prism, often in conjunction with slip deeper along the subduction boundary. The Tohoku earthquake in 2011 was such a compound-rupture earthquake. Satake (2011), following the 2011 Tohoku event, proposed that such compound-rupture events may be a part of a "supercycle" of subduction earthquakes in some subduction zones that occur on millennial time scales and hence are distinct from more typical centuries-scale great subduction earthquake cycles that have smaller average slip. In a way, such segmentation is the downdip counterpart of the along-strike segmentation of ruptures that allows for infrequent multi-segment ruptures leading to great and giant supercycle tsunamigenic earthquakes, such as the $M$ 8.4-8.6 Hoei earthquake of 28 October 1707 in the Nankai subduction zone (Ando, 1975). If such a view is correct, then the occurrence of supercycle earthquakes involving both up-dip/down-dip segmentation would lead to a different type of scaling than rupture just involving large but not exceptional slip down-dip of a forearc frontal prism. Our challenge is to search for geological and geophysical features of subduction zones that may give us insights into whether a particular subduction zone is prone to such supercycle subduction earthquakes.

\section{Summary}

Tsunami modeling has demonstrated that giant subduction earthquakes along the Pacific side of the Alaska Peninsula would produce more potent tsunami waves along California shorelines than would such earthquakes at any other distant location. GPS measurements indicate that the Semidi subduction sector between Kodiak Island and the Shumagin Islands is currently "locked" and has probably not experienced large seismogenic slip (>10 m) in centuries. In the search of a plausible coseismic slip source for a giant subduction earthquake in the critical Semidi sector of the Alaska subduction system, the USGS Tsunami Source Working Group for the SAFRR tsunami scenario 
used the source characteristics of the $M_{\mathrm{w}} \sim 9$ Tohoku earthquake as a proxy for a number of reasons:

- Close examination of the megathrust geometry, geology, and geophysics of the Semidi subduction sector off the Alaska Peninsula and the Tohoku margin off Japan indicates that, although not identical twins, these subduction systems share many features that are probably relevant factors in governing the occurrence of damaging far-field tsunami waves.

- The 2011 Tohoku earthquake is the best -characterized giant earthquake and tsunami source in history, and its occurrence has prompted a reevaluation of subduction systems elsewhere for the potential of similarly potent tsunami sources.

- The compact nature of the Tohoku source also makes it an ideal "fit" to the spatial dimensions of the Semidi subduction sector as we define it between Kodiak Island and the Shumagin Islands.

- When allowances are made for differences in methodologies, data used to constrain the models, and resolution limits, the parameters of our source model are consistent with the Tohoku model literature. We fitted a simple polygonal subfault array to the curviplanar shape of the plate boundary of the Semidi sector based on the USGS Slab 1.0 geometrical model for the sector. We then put forward a simplified synoptic slip distribution in this array to emulate the Tohoku earthquake based on our interpretations of the model literature for this event.

- The immense seismic moment of the Tohoku earthquake of 2011 was not anticipated, in spite of a long historical record of earthquakes in Japan. This fact underscores the importance of paleogeologic investigations along the Alaska subduction margin to establish a long-term prehistoric record of the occurrence of great and giant subduction earthquakes and the tsunami waves that they spawn.

\section{References Cited}

Abe, K., 1979, Size of great earthquakes of 1837-1974 inferred from tsunami data: Journal of Geophysical Research, v. 84, no. B4, p. 1561-1568, doi:10.1029/JB084iB04p01561.

Ando, M., 1975, Source mechanisms and tectonic significance of historical earthquakes along the Nankai trough: Tectonophysics, v. 27, no. 2., p. 119-140.

Bird, P., 2003, An updated digital model of plate boundaries: Geochemistry Geophysics Geosystems, v. 4, no. 3, p. 1027, doi:10.1029/2001GC000252.

Boyd, T. and Lerner-Lam, A.L.,1988, Spatial distribution of turn-of-the-century seismicity along the Alaska-Aleutian arc, Bull. Seismological Soc. Am. V. 78, p. 635650.

Boyd, T.M., Taber, J.J., Lerner-Lam, A. L., and Beavan, J., 1988, Seismic rupture and arc segmentation within the Shumagin Islands Seismic Gap, Alaska: Geophysical Research Letters, v. 15, no. 3, p. 201-204. 
Brockman, S.R., Espinosa, A.F., and Michael, J.A. 1988, Catalog of intensities and magnitudes for earthquakes in Alaska and the Aleutian lslands-I786-1981: U.S. Geological Survey Bulletin 1840, 199 p.

Bruns, T.R., von Huene, R., Culotta, R.C., Lewis, S.D., and Ladd, J.W., 1987. Geology and petroleum potential of the Shumagin margin, Alaska, chap. 8 of Scholl, D.W., Grantz, A. and Vedder, J.G., eds., Geology and resource potential of the continental margin of western North America and adjacent ocean basins-Beaufort Sea to Baja California: Houston, Tex., Circumpacific Council for Energy and Mineral Resources, Earth Science Series, v. 6, p. 157-189.

Carver, G.A., and Plafker, G., 2008, Paleoseismicity and neotectonics of the Aleutian subduction zone - an overview, in Freymueller, J.T., Haeussler, P.J., Wesson, R.L., and Ekström, G., eds., Active tectonics and seismic potential of Alaska: Washington D.C., American Geophysical Union, Geophysical Monograph Series, v. 179, p. 43-63.

Chlieh, M., and 10 others, 2007, Coseismic slip and afterslip of the great $M_{w} 9.15$ Sumatra-Andaman earthquake of 2004: Bulletin of the Seismological Society of America, v. 97, S152-S173, doi:10.1785/0120050631.

Christensen, D.H., and Beck, S.L., 1994, The rupture process and tectonic implications of the great 1964 Prince Williams Sound earthquake: Pageoph, v. 142, no. 1, p. 29-53.

Columbia University, 2013, Global Centroid Moment Tensor (CMT) Project: Last accessed February 2013. URL: http:/www.globalcmt.org/

Cross, R.S., and Freymueller, J.T., 2008, Evidence for and implications of a Bering plate based on geodetic measurements from the Aleutians and western Alaska: Journal of Geophysical Research, v. 113, B07405, doi:10.1029/2007JB005136, 2008.

Davies, J., Sykes, L., House, L., and Jacob, K., 1981, Shumagin seismic gap, Alaska Peninsula; history of great earthquakes, tectonic setting, and evidence for high seismic potential: Journal of Geophysical Research, v. 86, p. 3821-3855.

Doser, D.I., 2006, Relocations of earthquakes (1899-1917) in south-central Alaska: Pure and Applied Geophysics, v. 163, p. 1461-1476.

Engdahl, E.R., and A. Villaseñor, 2002, Global Seismicity: 1900-1999, in W.H.K. Lee, H. Kanamori, P.C. Jennings, and C. Kisslinger, eds., International Handbook of Earthquake and Engineering Seismology, Part A, Chapter 41, pp. 665-690, Academic Press.

Estabrook, C.H., and Boyd, T.M., 1992, The Shumagin Islands, Alaska earthquake of 31 May 1917: Bulletin of the Seismological Society of America, v. 82, p. 755-773.

Estabrook, C.H., Jacob, K.H., and Sykes, L.R., 1994, Body wave and surface wave analysis of large and great earthquakes along the eastern Aleutian arc, 1923-1993: Implications for future events: Journal of Geophysical Research, v. 99, no. B6, p. 11643-11662.

Fletcher, H.J., Beavan, J., Freymueller, J., and Gilbert, L., 2001, High interseismic coupling of the Alaska subduction zone SW of Kodiak Island inferred from GPS data: Geophysical Research Letters, v. 28, no. 3, p. 443-446.

Fournier, T.J., and Freymueller, J.T., 2007, Transition from locked to creeping subduction in the Shumagin region, Alaska: Geophysical Research Letters, v. 34, L06303, doi:10.1029/2006GLO29073. 
Freymueller, J.T., and Beavan, J., 1999, Absence of strain accumulation in the western Shumagin Segment of the Alaska subduction zone: Geophysical Research Letters, v. 26, no. 21, p. 3233-3336.

Freymueller, J.T., Woodard, H., Cohen, S.C., Cross, R., Elliott, J., Larsen, C.F., Hreinsdóttir, S., and Zweck, C., 2008, Active deformation in Alaska based on 15 years of GPS measurements, in Freymueller, J.T., Haeussler, P.J., Wesson, R.L., and Ekström, G., eds., Active tectonics and seismic potential of Alaska: Washington D.C., American Geophysical Union, Geophysical Monograph Series, v. 179, p. 1-42.

Fujii, Y., Satake, K., Sakai, S., Shinohara, M., and Kanazawa, T., 2011, Tsunami source of the 2011 off the Pacific coast of Tohoku earthquake: Earth Planets Space, v. 63, p. $815-820$.

Haeussler, P.J., and Plafker, G., 1995, Earthquakes in Alaska: U.S. Geological Survey Open-File Report, 95-624, 1 sheet poster in pdf form.

Hayes, G., 2011, Rapid source characterization of the $2011 \mathrm{M}_{\mathrm{w}} 9.0$ off the Pacific coast of Tohoku earthquake: Earth Planets Space, v. 63, p. 529-534.

Hayes, G.P., Wald, D.J., and Johnson, R.L., 2012, Slab 1.0: A three-dimensional model of global subduction zone geometries: Journal of Geophysical Research 117, B01302, doi:10.1029/2011JB008524.

Holdahl, S. and J. Sauber, 1993, Coseismic slip in the 1964 Prince William Sound earthquake: a new geodetic inversion, Pageoph. , 14(4), 55-82.

Ichinose, G., Somerville, P., Thio, H.K., Graves, R., and O’Connell, D., 2007, Rupture process of the 1964 Prince William Sound, Alaska, earthquake from the combined inversion of seismic, tsunami, and geodetic data: Journal of Geophysical Research, v. 112, B07306, doi:10.1029/2006JB004728.

Ide, S., Baltay, A., and Beroza, G.C., 2011, Shallow dynamic overshoot and energetic deep rupture in the $2011 \mathrm{Mw} 9.0$ Tohoku-Oki earthquake: Science, v. 332, p. 14261429, doi:10.1126/science.1207020.

Iinuma, T., and 11 others, 2011, Coseismic slip distribution of the 2011 off the Pacific Coast of Tohoku earthquake deduced from land and seafloor geodesy: Abstract G51A0853, presented at 2011 Fall Meeting, American Geophysical Union, San Francisco, California, 5-9 December.

Iinuma, T., and 10 others, 2012, Coseismic slip distribution of the 2011 off the Pacific Coast of Tohoku Earthquake (M9.0) refined by means of seafloor geodetic data: Journal of Geophysical Research 117, B07409, 18 p., doi:10.1029/2012JB009186.

International Seismological Center, 2013, ISC-GEM Global Instrumental Earthquake Catalogue (1900-2009): Accessed [February 2013] at http://www.isc.ac.uk/iscgem/. Ito, Y., Tsuji, T., Osada, Y., Kido, M., Inazu, D., Hayashi, Y., Tsushima, H., Hino, R., and Fujimoto, H., 2011, Frontal wedge deformation near the source region of the 2011 Tohoku-Oki earthquake: Geophysical Research Letters, v. 38, no. 7, L00G05, doi:10.1029/2011GL048355.

Johnson, J.M., and Satake, K, 1994, Rupture extent of the 1938 Alaskan earthquake as inferred from tsunami waveforms: Geophysical Research Letters. v. 21, p. 733, doi:10.1029/94GL00333.

Johnson, J. M., and K. Satake, 1995, Source parameters of the 1957 Aleutian and 1938 Alaskan earthquakes from tsunami waveforms, in: "Tsunami: progress in prediction, disaster prevention and warning”, eds. Y. Tsuchiya and N. Shuto, p. 71-84, Kluwer. 
Johnson, J.M. and Satake, K., 1997, Estimation of seismic moment and slip distribution of the April 1, 1946, Aleutian tsunami earthquake: Journal of Geophysical Research, v. 102, p. 11765-11774.

Johnson, J.M., Satake, K., Holdahl, S.R., and Sauber, J., 1996, The 1964 Prince William Sound earthquake; joint inversions of tsunami and geodetic data: Journal Of

Geophysical Research, v. 101, p. 523-532.

Kanamori, H., 1972, Mechanism of tsunami earthquakes: Physics of Earth and Planetary Interiors, v. 6, p. 346-359.

Kodaira, S., 2012, Marine geophysical survey of Tohoku quake rupture zone (abs.): Network for Earthquake Engineering Simulation, last accessed in February 2013. URL at http://nees.org/resources/4176.

Kodaira, S., No, T., Nakamura, Y., Fuiwara, T., Kaiho, Y., Miura, S., Takahashi, N., Kaneda, Y., and Taira, A., 2012, Coseismic fault rupture at the trench axis during the 2011 Tohoku-oki earthquake: Nature Geoscience, v. 5, p. 646-650, doi:10.1038/ngeo1547.

Koketsu, K., Yokota, Y., Nishimura, N., Yagi, Y., Miyazaki, S., Satake, K., Fujii, Y., Miyake, H., Sakai, S., Yamanaka, Y., and Okada, T., 2011, A unified source model for the 2011 Tohoku earthquake: Earth and Planetary Science Letters, v. 310, p. 480-487.

Lander, J.F., 1996, Tsunamis affecting Alaska 1737-1996: Boulder, Colorado, National Oceanic and Atmospheric Administration, National Geophysical Data Center, 155 p. Available online at http://www.ngdc.noaa.gov/hazard/data/publications/Kgrd-31.pdf.

Lander, J.F., and Lockridge, P.A., 1989, United States tsunamis (including United States possessions) 1690-1988: Boulder, Colorado, National Oceanic and Atmospheric Administration, National Geophysical Data Center, Publication 41-2., http://www.ngdc.noaa.gov/seg/hazard/data/tsupub/pub41-2.pdf.

Lay, T., Ammon, C.J., Kanamori, H., Xue, L., and Kim, M.J., 2011, Possible large neartrench slip during the $2011 \mathrm{Mw} 9.0$ off the Pacific coast of Tohoku earthquake: Earth Planets Space, v. 63, no. 7, p. 687-692.

Lopéz, A., and Okal, E.A., 2006, A seismological reassessment of the source of the 1946 Aleutian 'tsunami' earthquake: Geophysical Journal International, v. 165, p. 835-849.

McCaffrey, R., 2007, The Next Great Earthquake, Science, v. 315, p. 1675-1676.

McCaffrey, R., 2008, Global frequency of magnitude 9 earthquakes, Geology, 36, 263266.

Minson, S.E., Simons, M., Beck, J.L., Jiang, J., Ortega Culaciati, F.H., Inbal, A., Owen, S.E., and Sladen, A., 2011, A Bayesian exploration of kinematic rupture parameters for the great 2011 Tohoku-Oki earthquake: American Geophysical Union, Fall Meeting 2011, abstract U41D-06.

Minoura and 5 others, 2001, The 869 Jogan tsunami deposit and recurrence interval for large-scale tsunami on the Pacific coast of northeast Japan, Journal of Natural Disaster Science, v. 23, p. 83-88.

Nettles, M., Ekström, G., and Koss, H., 2011, Centroid-moment-tensor analysis of the 2011 off the Pacific coast of Tohoku earthquake and its larger foreshocks and aftershocks: Earth Planets Space, v. 63, p. 519-523.

National Geophysical Data Center, 2012, Global tsunami events and runups: National Oceanic and Atmospheric Administration, National Geophysical Data Center, last accessed January 2012, at http://www.ngdc.noaa.gov/hazard/tsu_db.shtml. 
Novosibirsk Tsunami Laboratory, 2012, Historical tsunami database for the world ocean: Accessed February, 2012 at http://tsun.sscc.ru/nh/tsunami.php.

Okal, E.A., Synolakis, C.E., Fryer, G.J., Heinrich, P., Borrero, J.C., Ruscher, C., Arcas, D., Guille, G., and Rousseau, D., 2002, A field survey of the 1946 Aleutian tsunami in the far field: Seismological Research Letters, v. 73, p. 490-503.

Okal, E.A., Plafker, G., Synolakis, C.E., and Borrero, J.C., 2003, Near-field survey of the 1946 Aleutian tsunami on Unimak and Sanak Islands: Bull. Seismological Society of America, v. 93, p. 1226-1234.

Ozawa, S., Nishimura, T., Suito, H., Kobayashi, T., Tobita, M., and Imakiira, T., 2011, Coseismic and postseismic slip of the 2011 magnitude-9 Tohoku-Oki earthquake: Nature, v. 475, p. 373-376.

Pacheco, J., and Sykes, L.R., 1992, Seismic moment catalogue of large shallow earthquakes, 1900 to 1989: Bulletin of the Seismological Society of America, v. 82, p. 1306-1349.

Pararas-Carayannis, G., and Calebaugh, P.J., 1977, Catalog of tsunamis in Hawaii, revised and updated: National Oceanic and Atmospheric Administration, World Data Center A for Solid Earth Geophysics, 78 p.

Pollitz, F., Bürgmann, R., and Banerjee, P., 2011, Geodetic slip model of the 2011 M9.0 Tohoku earthquake: Geophysical Research Letters, v. 38, L00G08, doi:10.1029/2011GL048632

Ryan, H.F., von Huene, R., Scholl, D., and Kirby, S., 2012a, Tsunami hazards to U.S. coasts from giant earthquakes in Alaska: Eos (American Geophysical Union Transactions), v. 93, p. 185-186.

Ryan, H.F., von Huene, R., Wells, R. E., Scholl, D. W., Kirby, S., and Draut, A. E., 2012b, History of earthquakes and tsunamis along the eastern Aleutian-Alaska Megathrust, with implications for tsunami hazards in the California Continental Borderland: U.S. Geological Survey Professional Paper 1795-A, 31 p.

Santini, S., Dragoni, M., and Spada, G., 2003, Asperity distribution of the 1964 Great Alaska earthquake and its relation to subsequent seismicity in the region:

Tectonophysics, v. 367, p. 219-233.

Satake, K., 2011, The great off Tohoku earthquake of 11 March 2011: Presentation at International Union of Geodesy and Geophysics Meeting, Melbourne, Australia, 28 June - 7 July 2011.

Satake, K. and Tanioka, T., 1996, Source of tsunami and tsunamigenic earthquakes in subduction zones, Pure and Appl. Geophysics, v. 94, p. 467-483

Satake, K., and Tanioka, Y., 1999, Sources of tsunami and tsunamigenic earthquakes in subduction zones: Pure and Applied Geophysics, v. 154, p. 467-483.

Satake, K., Sawai, Y., Shishikura, M., Okamura, Y., Namegaya, Y., and Yamaki, S., 2007, Tsunami source of the unusual AD 869 earthquake off Miyagi, Japan, inferred from tsunami deposits and numerical simulation of inundation: American Geophysical Union, Fall Meeting 2007, Abstract \#T31G-03.

Satake, K., Namegaya, Y., and Yamaki, S., 2008, Numerical simulation of the AD 869 Jogan tsunami in Ishinomaki and Sendai plains: Geological Survey of Japan, Active Fault and Earthquake Center, Report no. 8, p. 71-89. Available online at http://unit.aist.go.jp/actfault-eq/seika/h19seika/pdf/03.satake.pdf. 
Scholl, D.W., Kirby, S.H, von Huene, R., Ryan, H., and Wells, R.W., 2013, Great megathrust earthquakes and the subduction of thick sections of sediment, tectonically eroded debris, and low-relief sea floor, in Fildani, A., Piper, D.J.W., and Scholl, D., eds., Exploring the deep sea and beyond-contributions to marine geology in honor of William R. Normark: Geological Society of America, Geosphere, in press.

Shao, G., and Ji, C., 2011, Rupture characterizations of the $2011 \mathrm{Mw} 9.1$ off the Pacific coast of Tohoku earthquake and its March $9^{\text {th }} \mathrm{Mw} 7.4$ foreshock constrained by an unprecedented dataset for subduction earthquakes: American Geophysical Union, Fall Meeting 2011, abstract U34A-03.

Shao, G., Li, X., Ji, C., and Maeda, T., 2011, Focal mechanism and slip history of the $2011 \mathrm{M}_{\mathrm{w}} 9.1$ off the Pacific coast of Tohoku earthquake, constrained with teleseismic body and surface waves: Earth Planets Space, v. 63, p. 559-564.

Shillington, D.J., Bécal, A., Nedimovich, M.R., Kuhn, H., and Webb, S.C., 2012, Alongstrike variations in the structure of the downgoing plate in the subduction zone off the Alaska Peninsula: American Geophysical Union, Fall Meeting 2012, abstract T13H-02 Siebert, L., Simkin, T., and Kimberly, P., 2011, Volcanoes of the world (3d ed.): Smithsonian Institution and University of California Press, $551 \mathrm{p}$.

Simons, M., and 14 others, 2011, The 2011 magnitude 9.0 Tohoku-Oki earthquake; mosaicking the megathrust from seconds to centuries: Science, v. 322, p. 1421-1425, doi:10.1126/science.1206731, 2011.

Smithsonian National Museum of Natural History, 2013, Global volcanism program; volcanoes of the world: Last accessed in February 2013 at http://www.volcano.si.edu/index.cfm.

Soloviev, S.L., 1968, The Sanak Kodiak Island tsunami of 1788 [in Russian]: Moscow, Nauka, The Tsunami Problem, Moscow, Nauka, p. 232-237. [English translation in Science of Tsunami Hazards, v. 8, no. 1, p. 34-38, 1990.]

Soloviev, S.L., and Go, Ch.N., 1975, Catalogue of tsunamis on the eastern shore of the Pacific Ocean [in Russian]: Moscow, Nauka, 203 p. [Translated into English by the Canadian Institute for Scientific and Technical Information, National Research Council, Ottawa, Canada.]

Sugawara, D., 2011, Deposits of the 869 Jogan and 2011 Tohoku-oki tsunamis: Unpublished Field Guide and Supplement (26 October field trip to near-coastal sites along Sendai Bay south of Sendai).

Sugawara, D., Imamura, F., Goto, K., Matsumoto, H., and Minoura, K., 2011, The 869 Jogan and the 2011 Tohoku-oki earthquake tsunamis: American Geophysical Union, Fall Meeting 2011, Abstract NH13G-08.

Suito, H., and Freymueller, J.T., 2009, A viscoeleastic and afterslip postseismic deformation model for the 1964 Alaska earthquake: Journal of Geophysical Research, v. 114, no. B11, doi:10.1029/2008JB005954.

Sykes, L.R., 1971, Aftershock zones of great earthquakes, seismicity gaps, and earthquake prediction for Alaska and the Aleutians: Journal of Geophysical Research, v. 76, p. 8021-8041.

Sykes, L.R., Kissinger, J.B., House, L., Davies, J.N., and Jakob, K.H., 1981, Rupture zones of great earthquakes in the Alaska-Aleutian Arc, 1784 to 1980: Journal of Geophysical Research, v. 86, p. 3821-3855. 
Thio, H.K., Somerville, P., and Polet, J., 2010, Probabilistic tsunami hazard in California: Pacific Earthquake Engineering Research Center, PEER_Report 2010-108, 61 p. Available online at http://peer.berkeley.edu/publications/peer_reports.html.

von Huene, R., and Culotta, R., 1989, Tectonic erosion at the front of the Japan Trench convergent margin: Tectonophysics, v. 160, p. 75-90.

von Huene, R., Klaeschena, D., Cropp, B., and Miller, J., 1994, Tectonic structure across the accretionary and erosional parts of the Japan Trench margin: Journal of Geophysical Research, v. 99, p. 22349-22361.

von Huene, R., Miller, J., and Weinrebe, W., 2012, Subducting plate geology in three great earthquake ruptures on the western Alaska margin, Kodiak to Unimak: Geosphere, v. 8, no. 3, p. 628-644, doi:10.1130/GES00715.

Wells, R.E., Blakely, R.J., Scholl, D.W., and Dinterman, P.A., 2003, Basin-centered asperities in great subduction zone earthquakes - a link between slip, subsidence, and subduction erosion?: Journal of Geophysical Research, v. 108, p. 2507, doi:10.1029/2002JB002072.

Wells, R.E., Blakely, R.J., Scholl, D.W., and Ryan, H.F., 2011, Seismicity, topography, and free-air gravity of the Aleutian-Alaska subduction zone: American Geophysical Union, Fall Meeting 2011, abstract T21B-2322.

Wesson, R.L., Boyd, O.S., Mueller, C.S., Bufe, C.G., Frankel, A.D., and Petersen, M.D., 2007, Revision of time-independent probabilistic seismic hazard maps for Alaska: U.S. Geological Survey Open-File Report 2007-1043, 33 p.

Witter, R.C., Engelhart, S.E., Briggs, R.W., Koeler, R.D., and Gelfenbaum, G., 2012, Little strain accumulation and release on the Alaska-Aleutian megathrust beneath the Shumagin Islands in the last 3400 Years?: Geological Society of America Abstracts with Programs, v. 44, no. 7, p. 413, https://gsa.confex.com/gsa/2012AM/webprogram/Paper206745.html.

Yagi, Y., and Fukuhata, Y., 2011, Rupture process of the 2011 Tohoku-oki earthquake and absolute elastic strain release: Geophysical Research Letters, v. 38, no. L19307, doi:10.1029/2011GL048701. 
Table 1. Large instrumentally documented earthquakes and tsunami runups in the Semidi Sector and adjacent sectors of the Aleutian-Alaska subduction zone.

[Dates given as year (YYYY), month (MM), day (DD), hour (hh), minute (mm), and second (ss.s); epicenters for events before 1920 generally have large uncertainties; NR, no tsunami runups or damage reports at this site for this event in online tsunami databases of the National Geophysical Data Center (NGDC) and the Novosibirsk Tsunami Laboratory; X, no records or no instruments known to be in operation; s, shallow ( $<60 \mathrm{~km})$, presumed or established; - , no data]

\begin{tabular}{|c|c|c|c|c|c|c|c|c|c|c|c|c|c|c|c|c|c|c|c|c|}
\hline \multirow[t]{2}{*}{ YYYY } & \multirow[t]{2}{*}{ MM } & \multirow[t]{2}{*}{ DD } & \multirow[t]{2}{*}{$\mathrm{HH}$} & \multirow[t]{2}{*}{ MM } & \multirow[t]{2}{*}{$\begin{array}{l}\text { SS. } \\
\text { S }\end{array}$} & \multirow[t]{2}{*}{$\begin{array}{l}\text { Tsunami } \\
\text { reports? }\end{array}$} & \multirow[t]{2}{*}{$\begin{array}{l}\text { Latitude } \\
{ }^{\circ} \mathrm{N}\end{array}$} & \multirow[t]{2}{*}{ Longitude ${ }^{\circ} \mathrm{E}$} & \multirow[t]{2}{*}{$\begin{array}{l}\text { Depth, } \\
\text { km }\end{array}$} & \multirow[t]{2}{*}{$M_{\mathrm{w}} / M_{\mathrm{s}}$} & \multicolumn{10}{|c|}{$\begin{array}{c}\text { Max. } \\
\text { tsunami } \\
\text { runup, m }\end{array}$} \\
\hline & & & & & & & & & & & $\begin{array}{c}\text { San } \\
\text { Diego, } \\
\text { CA }\end{array}$ & $\begin{array}{c}\text { Long } \\
\text { Beach, } \\
\text { CA }\end{array}$ & $\begin{array}{c}\text { Los } \\
\text { Angeles, } \\
\text { CA }\end{array}$ & $\begin{array}{c}\text { Santa } \\
\text { Monica, } \\
\text { CA }\end{array}$ & $\begin{array}{c}\text { Half } \\
\text { Moon } \\
\text { Bay, } \\
\text { CA }\end{array}$ & $\begin{array}{l}\text { Cres } \\
\text {-cent } \\
\text { City, } \\
\text { CA }\end{array}$ & $\begin{array}{c}\text { Seward. } \\
\text { AK }\end{array}$ & $\begin{array}{c}\text { Hilo } \\
\text { Harbor, } \\
\text { HI }\end{array}$ & $\begin{array}{c}\text { Largest } \\
\text { far-field } \\
\text { wave } \\
\text { height }\end{array}$ & $\begin{array}{c}\text { Largest } \\
\text { near-field } \\
\text { wave } \\
\text { height }\end{array}$ \\
\hline $1938^{1}$ & 11 & 10 & 20 & 18 & 41.2 & Yes & 55.18 & -158.181 & 25 & $8.2-8.3$ & 0.1 & $\mathrm{X}$ & NR & 0.05 & NR & 0.18 & 0.08 & 0.3 & 0.3 & 0.1 \\
\hline $1948^{2}$ & 5 & 14 & 22 & 31 & 43.4 & No & 54.71 & -160.880 & $\mathrm{~s}$ & 7.2 & $\mathrm{X}$ & $\mathrm{X}$ & $\mathrm{X}$ & $\mathrm{X}$ & $\mathrm{X}$ & $\mathrm{X}$ & $\mathrm{X}$ & $\mathrm{X}$ & - & - \\
\hline $1989^{3}$ & 9 & 4 & 13 & 15 & 0.2 & No & 55.63 & -156.912 & $\mathrm{~s}$ & 7.0 & NR & NR & NR & NR & NR & NR & NR & NR & - & - \\
\hline $1906^{4}$ & 12 & 23 & 17 & 22 & 0.0 & No & 56.85 & -153.900 & $\mathrm{~s}$ & 7.2 & $\mathrm{X}$ & $\mathrm{X}$ & $\mathrm{X}$ & $\mathrm{X}$ & $\mathrm{X}$ & $\mathrm{X}$ & $\mathrm{X}$ & $\mathrm{X}$ & - & - \\
\hline $1917^{5}$ & 5 & 31 & 8 & 47 & 20.0 & No & 54.93 & -159.433 & 29 & 7.4 & $\mathrm{X}$ & $\mathrm{X}$ & $\mathrm{X}$ & $\mathrm{X}$ & $\mathrm{X}$ & $\mathrm{X}$ & $\mathrm{X}$ & $\mathrm{X}$ & - & - \\
\hline $1917^{6}$ & 12 & 21 & 17 & 54 & & No & 55.29 & -152.350 & $\mathrm{~s}$ & 7.3 & $\mathrm{X}$ & $\mathrm{X}$ & $\mathrm{X}$ & $\mathrm{X}$ & $\mathrm{X}$ & $\mathrm{X}$ & $\mathrm{X}$ & $\mathrm{X}$ & - & - \\
\hline $1917^{7}$ & 12 & 28 & 21 & 14 & & No & 55.59 & -152.750 & $\mathrm{~s}$ & $>7$ & $\mathrm{X}$ & $\mathrm{X}$ & $\mathrm{X}$ & $\mathrm{X}$ & $\mathrm{X}$ & $\mathrm{X}$ & $\mathrm{X}$ & $\mathrm{X}$ & - & - \\
\hline $1946^{8}$ & 4 & 1 & 12 & 29 & 1.6 & Yes & 53.31 & -162.880 & $\mathrm{~s}$ & 8.6 & 0.2 & 0.2 & 0.34 & $\mathrm{X}$ & 3.5 & 0.9 & 0.1 & 8.8 & 20 & 42.0 \\
\hline $1964^{9}$ & 3 & 28 & 3 & 36 & & yes & 61.04 & -147.730 & $\mathrm{~s}$ & $\begin{array}{l}9.2 \text { to } \\
9.3\end{array}$ & 0.5 & NR & 0.49 & 1.08 & 3.8 & 4.79 & NR & 3.0 & 4.8 & 34.4 \\
\hline
\end{tabular}

1. No reported runups in AK exceeding $0.1 \mathrm{~m}$. Tsunami modeling suggests three small slip patches averaging $\sim 1.1 \mathrm{~m}[\mathrm{Johnson}$ and Satake, 1994, 1995]. Average slip $\sim 2 \mathrm{~m}$ based on seismic waveform modeling (Estabrook and others.,1994). This weak tsunami source only had 9 sites reporting, probably all tide gauge stations; 2. Location: Sykes (1971). $M_{\mathrm{w}}$ : Estabrook and others (1994). No known tsunami observations (Not in NGDC tsunami source database); 3. $M_{\mathrm{w}}$

(Harvard and Global CMT. Location; 4. Epicenter: Doser (2006); Ms: Pacheco and Sykes (1992); No known tsunami observations (Not in NGDC tsunami source database); 5. Epicenter: Boyd \& Lerner-Lam 1988). $M_{\mathrm{w}}=M_{\mathrm{s}}$ from Estabrook and Boyd, (1992). No known tsunami observations (Not in NGDC tsunami source database); 6. Doser (2006)*. Possible off trench location. No known tsunami observations (Not in NGDC tsunami source database); 7. Diane Doser (2006)*. Possible off-trench location. No known tsunami observations (Not in NGDC tsunami source database); 8. Epicenter and $M_{\mathrm{w}}$ : Lopez and Okal (2006); Epicenter near trench. Slow rupture. Far-field runup survey (Okal et al., 2003)/ Near-field survey (Okal et al., 2002). NGDC lists 508 tsunami record sites. Okal and others (2003) adds another 54.; 9. Two patches of slip, one under Prince William Sound, another trenchward of Kodiak Island. NGDC lists 391 tsunami record sites. 
Table 2. Geological and geophysical comparisons between the Semidi Sector of the Aleutian-Alaska subduction zone and the Tohoku Sector of the Japan-Trench subduction zone.

$[\mathrm{mm} / \mathrm{y}$, millimeters per year; Ma, millions of years ago; $\mathrm{m}$, meters; $\mathrm{km}$, kilometers; $M$, magnitude $]$

\begin{tabular}{|c|c|c|c|}
\hline Feature & Semidi Sector, Alaska & Tohoku Sector, Japan & Sources and Notes \\
\hline Convergence rate, $\mathrm{mm} / \mathrm{y}$ & $\begin{array}{l}60 \text { (nearly trench-normal motion). Pacific: } \\
\text { Alaska peninsula relative motion. }\end{array}$ & $\begin{array}{l}83 \text { (nearly trench-normal motion). Pacific } \\
\text { Plate: Okotsk Plate relative plate motion. }\end{array}$ & $\begin{array}{l}\text { Bird, 2003; Freymueller and others, } \\
\text { 2008, Cross and Freymueller (2008). } \\
\text { Both moderately fast rates. }\end{array}$ \\
\hline
\end{tabular}

$M 8.5$ to 9.5 strongly tsunamigenic events (instrumental and historical) show no apparent trend with incoming plate age, ranging from 10 (Cascadia)

to 140 (Tohoku) Ma for such subduction sectors.

Sea-floor roughness of trench fill bathymetery on incoming plate

Thickness of trench fill, m
Relatively smooth (Fig. 2A) with some local trench sea-floor roughness partly muted by sediment fill.

$1.25 \mathrm{~km}$ [Shillington and others (2012)]
Smooth except near Japan Trench cusps and $\sim 500 \mathrm{~m}$ normal fault scarps offsetting sediment (Fig. 2B)

$0.5 \mathrm{~km}$ (von Huene and others, 1994)
Smooth incoming sea-floor is often associated with $M_{\mathrm{w}}>8.7$ earthquakes with long rupture runouts, presumably caused by fewer geometrical barriers to rupture (Scholl and others, 2013).

Ryan, H. and Draut, A., 2012, unpublished map showing sediment fill in the Aleutian trench. 


\begin{tabular}{|c|c|c|c|}
\hline Feature & Semidi Sector, Alaska & Tohoku Sector, Japan & Sources and Notes \\
\hline $\begin{array}{l}\text { Thickness of subduction channel } \\
\text { sediments landward of frontal } \\
\text { prism, km }\end{array}$ & $\sim 1.0 \pm 0.5$ & $\sim 1.0 \pm 0.5$ & Ryan and others, 2012 \\
\hline Average trench depth, $\mathrm{km}$ & 5 & 7 & Depends on trench sedimentary fill. \\
\hline $\begin{array}{l}\text { Maximum throws of off- trench } \\
\text { normal faults, } m\end{array}$ & $\begin{array}{l}>250 \mathrm{~m} \text { (Shillington and others, 2012). } \\
\text { Scarps only cut abyssal sediments. }\end{array}$ & $\begin{array}{l}\sim 500 \mathrm{~m} \text { (Japan Coast Guard website). } \\
\text { Scarps only cut abyssal sediments. }\end{array}$ & $\begin{array}{l}\text { Scarps probably not strong barriers to } \\
\text { interplate thrust faulting since only } \\
\text { sediments need be deformed. }\end{array}$ \\
\hline $\begin{array}{l}\text { Off-trench seismicity and outer- } \\
\text { rise expression: seismicity rate } \\
\text { and maximum magnitude }\end{array}$ & $\begin{array}{l}\text { Rate: Low except south and southwest of } \\
\text { Kodiak; Maximum magnitude: } \sim 7\end{array}$ & Rate: High; Maximum magnitude: 8.6 & $\begin{array}{l}\text { Differences in off-trench seismicity } \\
\text { rates reflect differences in plate age and } \\
\text { thickness. Doser (2006) relocated } \\
\text { several large off-trench and near-trench } \\
\text { events that occurred in } 1917 \text { south of } \\
\text { Kodiak Island, possibly in the Pacific } \\
\text { Plate (See Table I). }\end{array}$ \\
\hline $\begin{array}{l}\text { Approximate regional depth limit } \\
\text { of interplate thrust earthquakes } \\
\text { offshore of Alaska Peninsula SW } \\
\text { of Kodiak Island. }\end{array}$ & $\sim 55$ & $\sim 50$ & $\begin{array}{l}\text { Slab } 1.0 \text { model (Hayes and others, } \\
\text { 2012) }\end{array}$ \\
\hline Average trench fill, $\mathrm{km}$ & $1.5 \pm 0.5$ & $0.75 \pm 0.5$ & $\begin{array}{l}\text { Von Huene and others, 1994), Holly } \\
\text { Ryan (personal communication, 2012) }\end{array}$ \\
\hline \multirow[t]{3}{*}{ Forearc bathymetric features } & Trench-parallel ridges in frontal prism & Trench-parallel ridges in frontal prism & \\
\hline & $\begin{array}{l}\text { Prominent ridge near transition between } \\
\text { frontal prism and slope basins }\end{array}$ & Muted ridge & \\
\hline & Forearc sedimentary basins & Forearc sedimentary basins & \\
\hline
\end{tabular}




\begin{tabular}{|c|c|c|c|}
\hline Feature & Semidi Sector, Alaska & Tohoku Sector, Japan & Sources and Notes \\
\hline \multirow[t]{4}{*}{$\begin{array}{l}\text { Offshore forearc structure and } \\
\text { tectonics }\end{array}$} & $\begin{array}{l}\text { Frontal Prism and Transition: Thrust faults } \\
\& \text { folds extending into trench sediment fill. } \\
\text { Downdip prism width: } \sim 25 \mathrm{~km} \text {. }\end{array}$ & $\begin{array}{l}\text { Outer Prism and Transition: Thrust faults } \\
\& \text { folds extending into trench sediment } \\
\text { fill. Down-dip prism width } \sim 20 \mathrm{~km} \text {. }\end{array}$ & $\begin{array}{l}\text { Ryan and others (2012); Roland von } \\
\text { Huene, unpublished data } 2012 .\end{array}$ \\
\hline & $\begin{array}{l}\text { Transition zone: Possible branch normal } \\
\text { faults and thrust faults }\end{array}$ & $\begin{array}{l}\text { Transition zone: Branch normal faults and } \\
\text { thrust faults }\end{array}$ & Ryan and others (2012) \\
\hline & $\begin{array}{l}\text { Shelf: Shumagin Basin revealed by } \\
\text { bathymetry, seismic reflection and gravity } \\
\text { lows and basin-bounding gravity gradients. }\end{array}$ & $\begin{array}{l}\text { Shelf: Discontinuous basins revealed by } \\
\text { seismic reflection and gravity lows and } \\
\text { basin-bounding gravity gradients. }\end{array}$ & $\begin{array}{l}\text { Bruns and others (1987); Wells and } \\
\text { others (2003), Wells and others (2011), } \\
\text { Ryan and others (2012) }\end{array}$ \\
\hline & $\begin{array}{l}\text { High-wave-speed "basement" rocks extend to } \\
\text { within about } 20-30 \mathrm{~km} \text { of the Alaska trench. }\end{array}$ & $\begin{array}{l}\text { High-wave-speed "basement" rocks extend } \\
\text { to within about } 20-30 \mathrm{~km} \text { of the Japan } \\
\text { trench. }\end{array}$ & Ryan and others (2012) \\
\hline $\begin{array}{l}\text { Average seaward forearc plate } \\
\text { boundary dip and (dip range in } 10 \\
\text { km depth segments to } \sim 50 \mathrm{~km} \\
\text { depth). }\end{array}$ & $12^{\circ}\left(5\right.$ to $\left.20^{\circ}\right)$ & $13^{\circ}\left(5\right.$ to $\left.23^{\circ}\right)$ & $\begin{array}{l}\text { Determined from Slab } 1.0 \text { model } \\
\text { (Hayes and others, 2012) }\end{array}$ \\
\hline $\begin{array}{l}\text { Average trench-to-shoreline } \\
\text { distance, } \mathrm{km}\end{array}$ & $\sim 240$ & $\sim 220$ & $\begin{array}{l}\text { Measured using Google Earth. Only } \\
\text { appoximate given complex coastlines. }\end{array}$ \\
\hline $\begin{array}{l}\text { Average trench to volcanic arc } \\
\text { distance, } \mathrm{km}\end{array}$ & $\sim 290$ & $\sim 290$ & Measured using Google Earth \\
\hline Volcanic arc activity & $\begin{array}{l}\text { Vigorous arc including Holocene caldera- } \\
\text { forming eruptions }\end{array}$ & $\begin{array}{l}\text { Vigorous arc including Holocene caldera- } \\
\text { forming eruptions }\end{array}$ & $\begin{array}{l}\text { Siebert, Simkin, and Kimberly (2011), } \\
\text { Volcanoes of the World. }\end{array}$ \\
\hline
\end{tabular}


Table 3. Estimates of the seismic moment and moment magnitude of the 11 March 2011 Tohoku earthquake. [CMT, Centroid Moment Tensor Project ; USGS, U.S. Geological Survey]

\begin{tabular}{|c|c|c|c|}
\hline Reference & Method & Moment, $\mathrm{N}-\mathrm{m}^{*} 10^{22}$ & $M_{\mathrm{w}}$ \\
\hline Global CMT & CMT & 5.30 & 9.1 \\
\hline USGS & CMT & 4.5 & 9.0 \\
\hline Hayes (2011) & Teleseismic waveform inversion & 4.04 & 9.0 \\
\hline USGS website & W phase inversion & 3.9 & 9.0 \\
\hline $\begin{array}{l}\text { UCSB (Shao and Ji (2011), } \\
\text { fall } 2011 \text { AGU Abstract } \\
\text { and presentation }\end{array}$ & Seismic: teleseismic waveform inversion, strong motion, GPS (land and sea-floor) & 5.36 & 9.1 \\
\hline $\begin{array}{l}\text { Lay and others (EPS 2011) } \\
\text { P-MOD2 model and fall }\end{array}$ & & & \\
\hline 2011 AGU presentation & Teleseismic P-wave waveform modeling & 3.84 & 9.0 \\
\hline Yagi and Fukuhata (2011) & Teleseismic waveform inversion & 5.7 & 9.1 \\
\hline
\end{tabular}


Table 4. Models of slip distribution for the $M_{w} 9.1$ Tohoku earthquake.

[L, lengh of rupture; $\mathrm{W}$, width of rupture; km, kilometers; Av., average; $\mathrm{m}$, meters; PG, pressure gage; GPS, Global Positioning System; TG, tide gage; Wfs, waveforms; SM, strong motion; BB, broadband; *, circumscribed by resolution limits]

\begin{tabular}{|c|c|c|c|c|c|c|}
\hline Reference & Data types & $\begin{array}{l}\mathrm{L}, \\
\mathrm{km}\end{array}$ & $\begin{array}{l}\mathrm{W}, \\
\mathrm{km}\end{array}$ & $\begin{array}{l}\text { Av. slip, } \\
\text { m }\end{array}$ & Min. Slip, m & Max. slip, m \\
\hline $\begin{array}{l}\text { Ito and others } \\
\text { (2011) }\end{array}$ & Sea-floor PG GPS & & & & & 80 \\
\hline $\begin{array}{l}\text { Iinuma and others } \\
\text { (2012) }\end{array}$ & $\begin{array}{l}\text { Sea-floor PG, } \\
\text { GPS,tide and } \\
\text { tsunami gages }\end{array}$ & $160^{*}$ & $120^{*}$ & $\sim 20$ & 0 & 85 \\
\hline $\begin{array}{l}\text { Fujii and others } \\
\text { (2011) }\end{array}$ & Tsunami model & 350 & 200 & $\sim 20$ & 2 & 40 \\
\hline $\begin{array}{l}\text { Ozawa and others } \\
\text { (2011) }\end{array}$ & Japan GPS & 400 & $\sim 200$ & $\sim 12$ & 4 & 27 \\
\hline $\begin{array}{l}\text { Pollitz and others } \\
\text { (2011) }\end{array}$ & $\begin{array}{l}\text { Japan and regional } \\
\text { GPS, sea-floor GPS }\end{array}$ & 440 & 180 & $12-16$ & $\sim 5$ & $\sim 35$ \\
\hline $\begin{array}{l}\text { Shao and Ji } \\
\text { (2011); Shao and } \\
\text { others (2011) }\end{array}$ & $\begin{array}{l}\text { Broadband wave- } \\
\text { forms, GPS, TG }\end{array}$ & 330 & 180 & 25 & 4 & 70 \\
\hline $\begin{array}{l}\text { Minson and others } \\
\text { (2011); Simons } \\
\text { and others (2011) }\end{array}$ & $\begin{array}{l}\text { Regional GPS } \\
\text { teleseismic/tsunamic } \\
\text { Wfs, GPS }\end{array}$ & $160^{*}$ & $120^{*}$ & $20-25$ & $\sim 10$ & 65 \\
\hline $\begin{array}{l}\text { Koketsu and } \\
\text { others (2011) }\end{array}$ & $\begin{array}{l}\text { Teleseismic Wfs, } \\
\text { SM, GPS, tsunami } \\
\text { observations }\end{array}$ & 310 & 180 & $\sim 18$ & $\sim 5$ & $\sim 40$ \\
\hline $\begin{array}{l}\text { Lay and others } \\
\text { (2011) }\end{array}$ & BB P-waveforms & 320 & 220 & 15.9 & 4 & 62 \\
\hline $\begin{array}{l}\text { Ide and others } \\
\text { (2011) }\end{array}$ & Teleseismic Wfs & 330 & 220 & $\sim 15$ & 0 & 30 \\
\hline Hayes (2011) & Teleseismic Wfs & $\sim 300$ & 150 & $\sim 15$ & $\sim 4$ & 32 \\
\hline $\begin{array}{l}\text { Yagi and } \\
\text { Fukuhata (2011) }\end{array}$ & Teleseismic Wfs & $\sim 350$ & 175 & $\sim 20$ & $\sim 5$ & 50 \\
\hline
\end{tabular}


Table 5. Summary table of properties for the Semidi Sector coseismic slip model.

\begin{tabular}{|c|c|c|c|}
\hline Property Name & Value & Minimum & Maximum \\
\hline Number of subfaults & 64 & & \\
\hline Total source length, $\mathrm{L}$ at trench, $\mathrm{km}$ & 358 & & \\
\hline Range of summed subfault lengths along row, km & & 322 & 358 \\
\hline Total source downdip width, $\mathrm{W}, \mathrm{km}$ & 205 & & \\
\hline Total area of subfaults, $\mathrm{km}^{2}$ & 73,396 & & \\
\hline Average subfault area, $\mathrm{km}^{2}$ & 1147 & & \\
\hline Range of subfault areas, low/high, $\mathrm{km}^{2}$ & & 1,056 & 1,242 \\
\hline Average slip, m & 18.6 & & \\
\hline Slip range, low/high, $\mathrm{m}$ & 0 & 65 & \\
\hline Total seismic moment, Mo, $\mathrm{N} \cdot \mathrm{m}$ & $4.91 \times 10^{22}$ & & \\
\hline Moment magnitude, $M_{\mathrm{w}}$ & 9.13 & & \\
\hline Epicenter: latitude $\left({ }^{\circ} \mathrm{N}\right)(\mathrm{d} 4 \text { Centroid })^{1}$ & 55.8 & & \\
\hline Epicenter: longitude $\left({ }^{\circ} \mathrm{E}\right)(\mathrm{d} 4 \text { Centroid })^{1}$ & -156.7 & & \\
\hline
\end{tabular}

\footnotetext{
${ }^{1}$ The centroid of an epicenter is the location of the weighted average of the earthquake slip.
} 


\section{Figures}

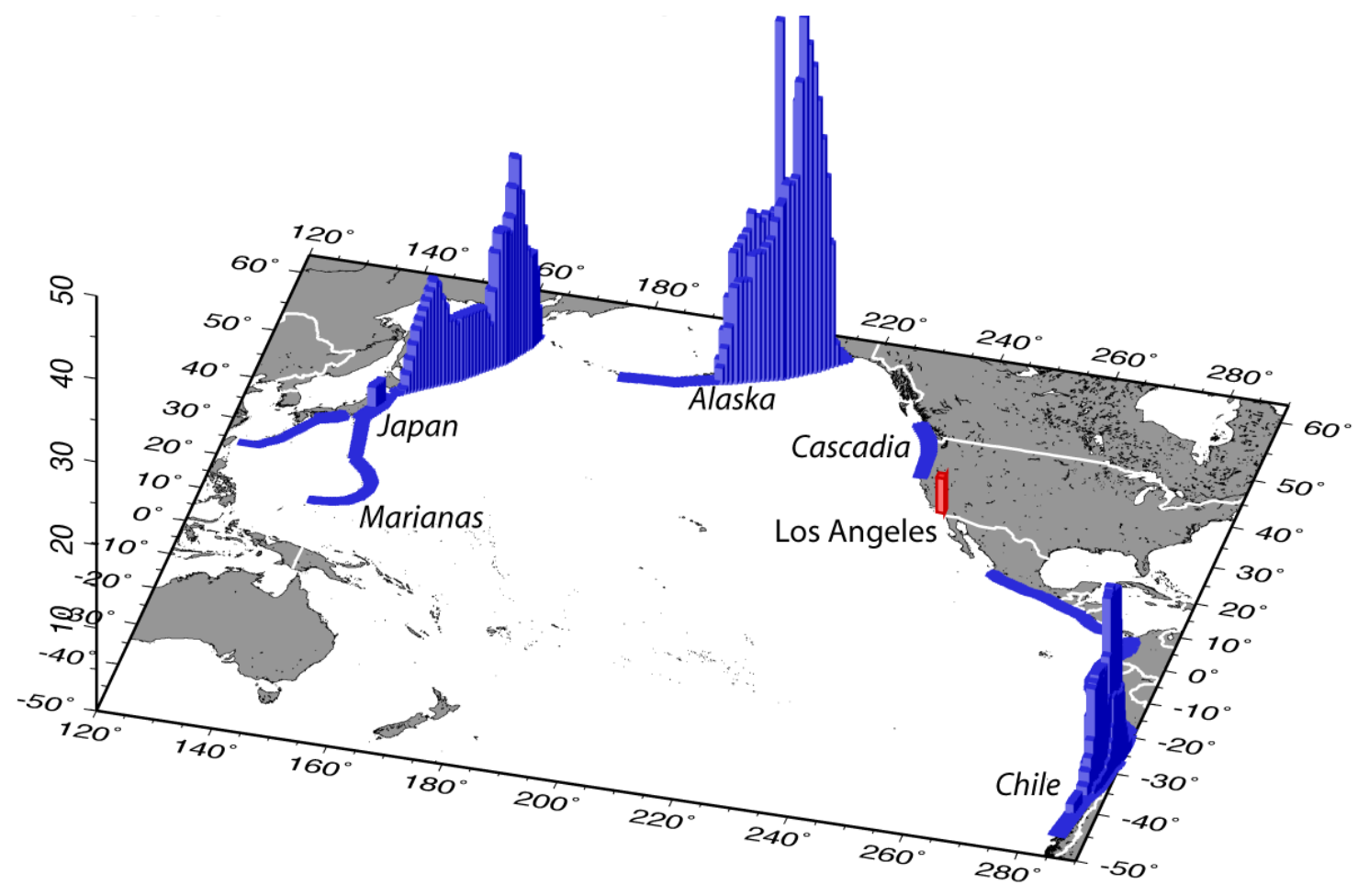

Figure 1. Map of the Pacific region showing source disaggregation for Los Angeles for tsunami peak wave height at 475-year return period (courtesy of Hong Kie Thio, URS Corporation). Vertical bar heights show that subduction earthquakes along the Alaska Peninsula have the greatest impacts on Los Angeles shorelines for a give seismic moment of the source subduction earthquake. 


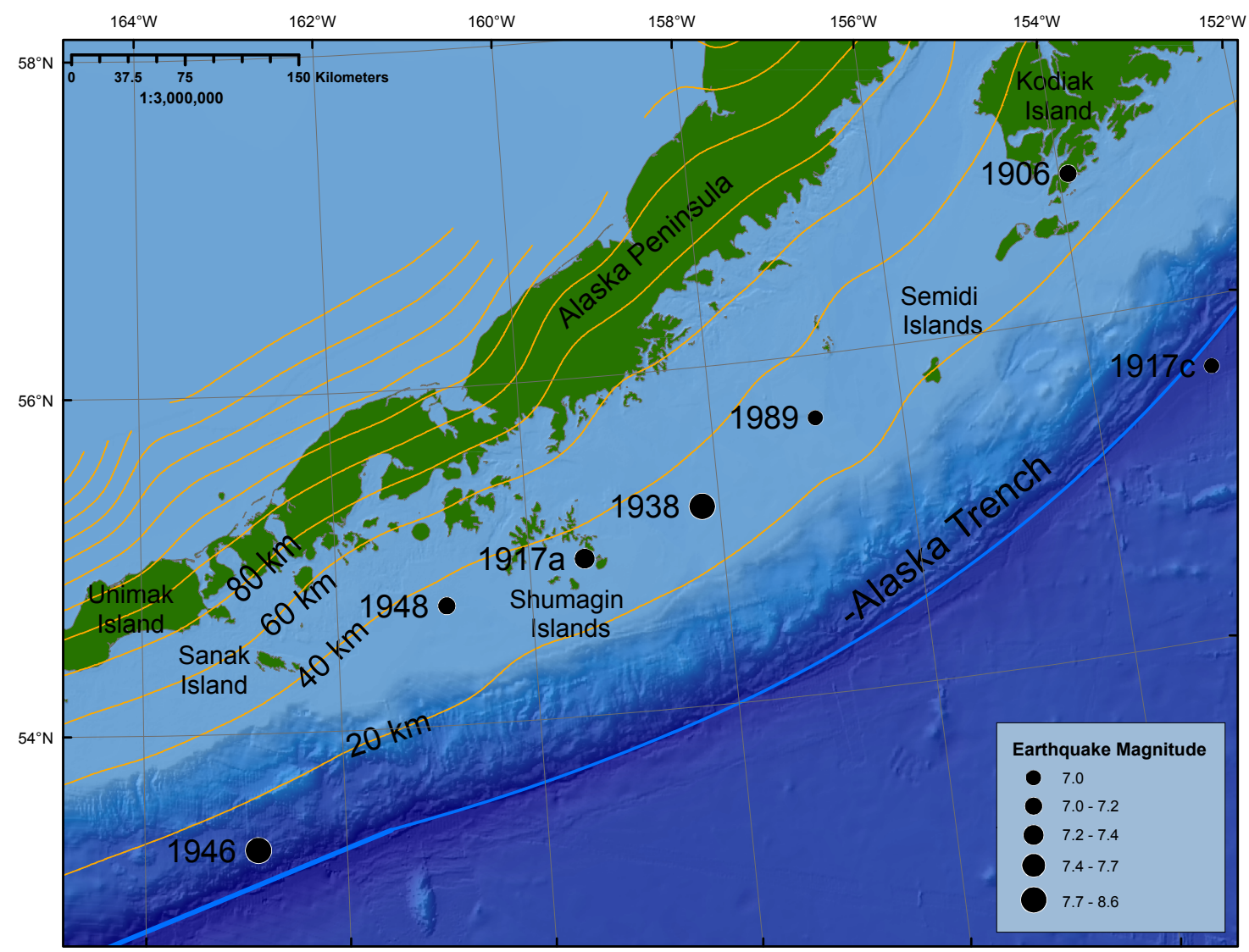

Figure 2A 


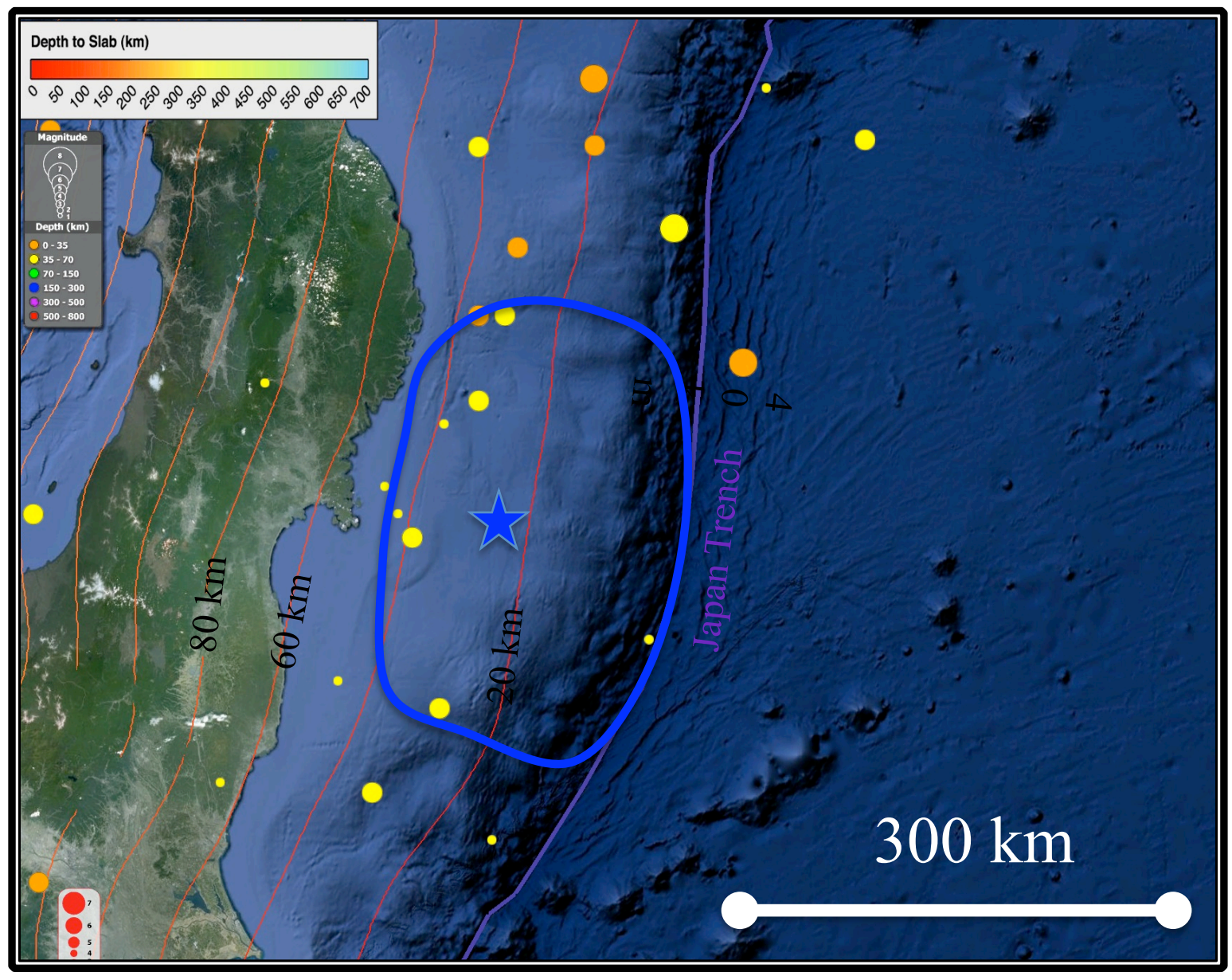

Figure 2. Maps showing locations of large earthquakes along the Aleutian-Alaska and the Tohoku, Japan, subduction margins. $A$, Summary map of the locations of large $(\mathrm{Mw} \geq 7.0)$ shallow $(<60 \mathrm{~km})$ earthquakes along the southwest end of the Alaska Peninsula subduction sector since 1900 (filled black symbols are the epicenters of presumed interplate thrust earthquakes that have occurred since 1900). The yellow contours represent 20-km depth intervals from the Slab 1.0 model (Hayes and others, 2012), and the blue line is the axis of the Alaska-Aleutian trench at an average water depth of about $5 \mathrm{~km}$. Earthquake data sources: Sykes (1971), Boyd and others (1988), Estabrook and others (1994), Engdahl and Villaseñor (2002), Doser (2006), ISC-GEM catalogue of earthquake magnitudes (2012). B, Summary map of the locations of large $(\mathrm{Mw} \geq 7.0)$ shallow $(<60 \mathrm{~km})$ earthquakes along the Japan Trench subduction sector that occurred since 1900 and before 2011 (filled orange and yellow symbols are the epicenters of presumed interplate thrust earthquakes). The epicenter and approximate area of significant rupture for the M9.1 Tohoku earthquake of 11 March 2011 are shown as a blue star and a blue closed line segment, respectively. The rupture area overlaps the epicentral areas of numerous $M \geq 7.0$ earthquakes. Note that the majority of the epicenters of large events occurred at depths between 20 and $40 \mathrm{~km}$, as is the case for the Semidi sector of the Alaska Peninsula (shown in a). 

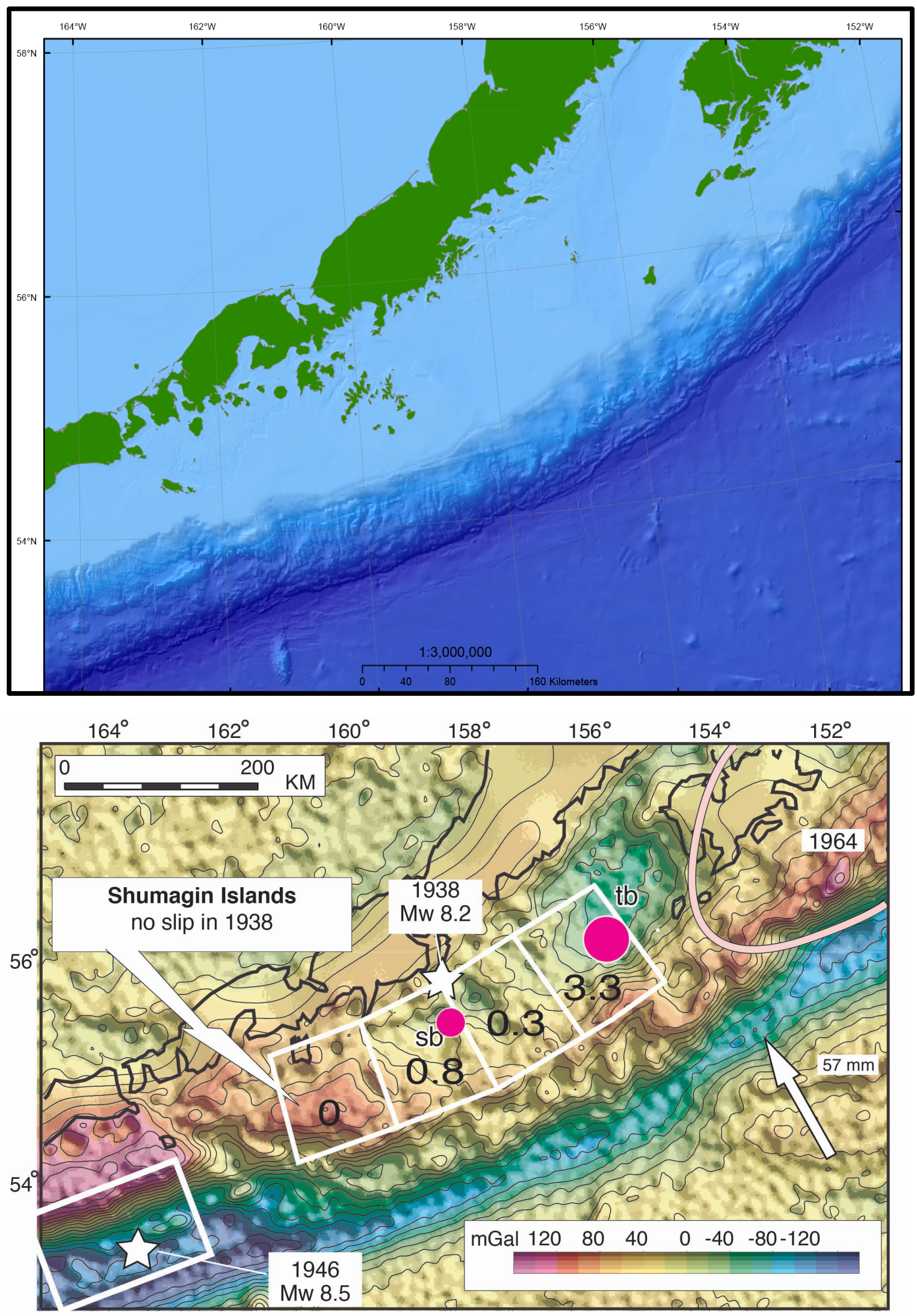
Figure 3. Maps showing bathymetry and free-air gravity of a part of the Alaska Peninsula subduction margin. $A$, Color shaded relief map of the bathymetry of the southwest half of the Alaska Peninsula (data source, National Geophysical Data Center; map construction by Holly Ryan). Parallel ridges northwest of the otherwise flat-bottomed trench are largely a consequence of active thrust faulting, folding, and slumps in the outer prism. $B$, Free-air gravity reveals structural highs and lows (basins) along Semidi Islands segment and likely show the extent of framework basement rock southeastward to the strong gradient along the trench (Wells and others, 2003). The locations where significant slip occurred in 1938 (white rectangles), average 1938 slip in meters (black labels), and high moment release in 1938 (red circles) are from Johnson and Satake (1994) and Estabrook and others (1994). These features suggest that not only was the slip release small in the 1938 event $(\sim 2 \mathrm{~m}$, see text), but also the updip sector of the subduction boundary may not have ruptured significantly in 1938. 

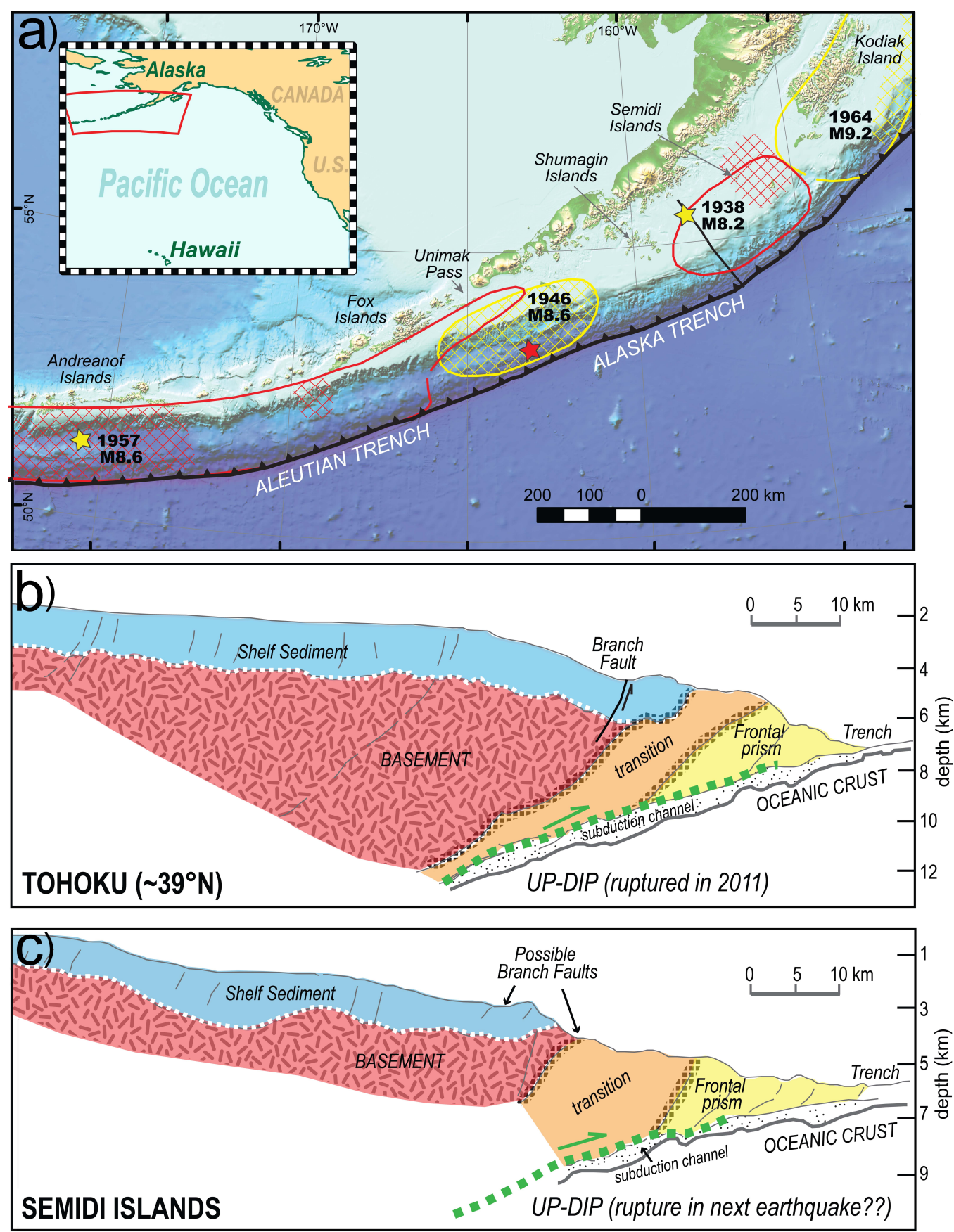

Figure 4. Map of the Alaska margin and cross sections of both the Alaska and Tohoku, Japan, subduction margins. (Figure and caption modified from Ryan and others, 2012a.) a, The Alaskan margin showing epicenters (stars), rupture zones (red and yellow outlines), and areas of largest slip (greater than $3 \mathrm{~m}$, red and yellow cross-hatching) of instrumentally recorded large earthquakes. Black line with barbs shows the location of the Alaskan- Aleutian subduction zone's main trench on the sea floor. b, Structure section across the similar Tohoku margin crossing the north end of the Tohoku earthquake rupture (after von Huene and others, 1994). c, Structure section across the 1938 epicenter near Semidi Islands, located in figure 4a 
(from von Huene and others, 2012). In both profiles framework crust extends nearly to the trench. A transition zone between basement and frontal prism material is poorly imagedbetter characterization of these zones will help assess hazards. The dashed green lines show the border between the downward dipping subducting slab and the continental crust thrusting over it 


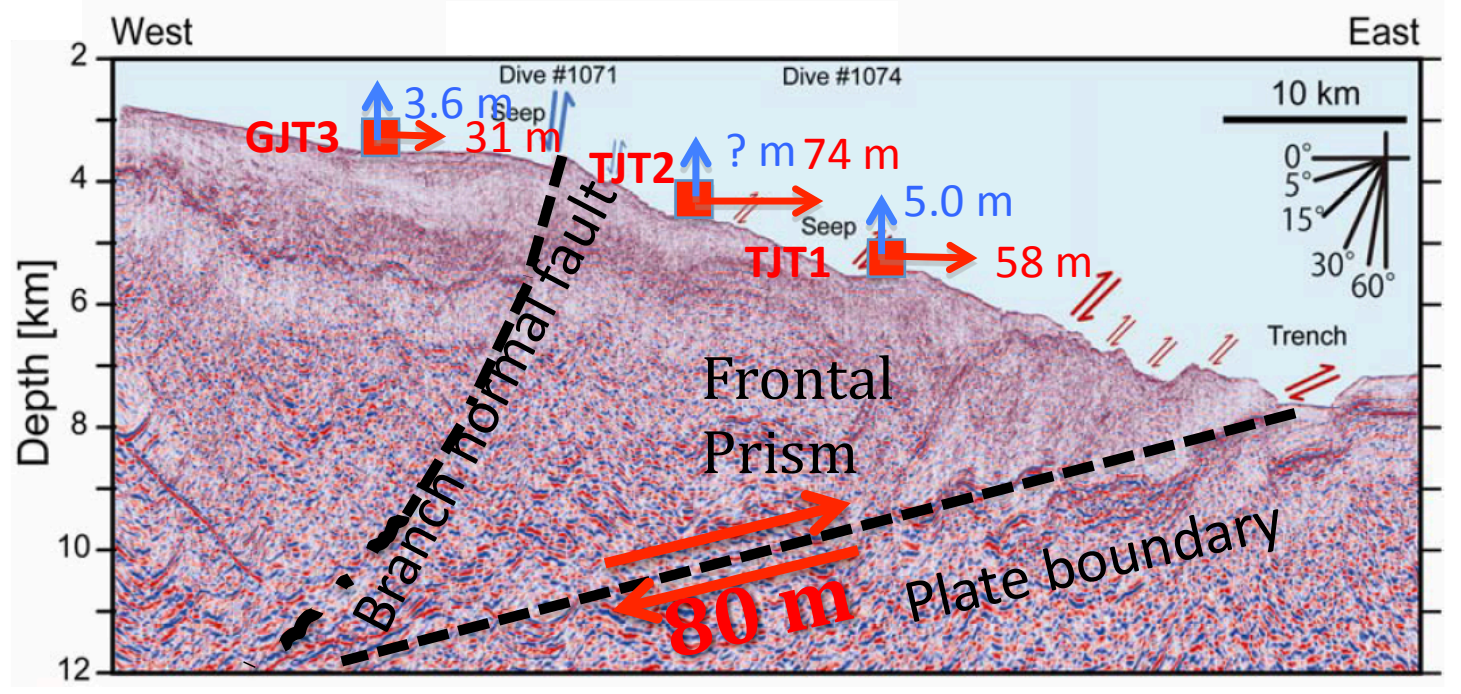

Figure 5. Seismic-reflection survey cross-section image perpendicular to the Japan Trench near $38^{\circ} \mathrm{N}$ acquired before the 11 March 2011 Tohoku-oki earthquake, with arrows showing the horizontal (red arrows) and vertical (blue arrows) motions of sea-floor instruments during the earthquake. Modified from Ito and others (2011). The motions of the sea-floor instruments are consistent with an average of $80 \mathrm{~m}$ of coseismic slip under the frontal prism. Note the normal fault branching off the plate-boundary fault that is thought to represent the kinematic accommodation of such a steep downdip gradient in slip on the subduction boundary. Angular scale in upper right shows the true dip angles. 


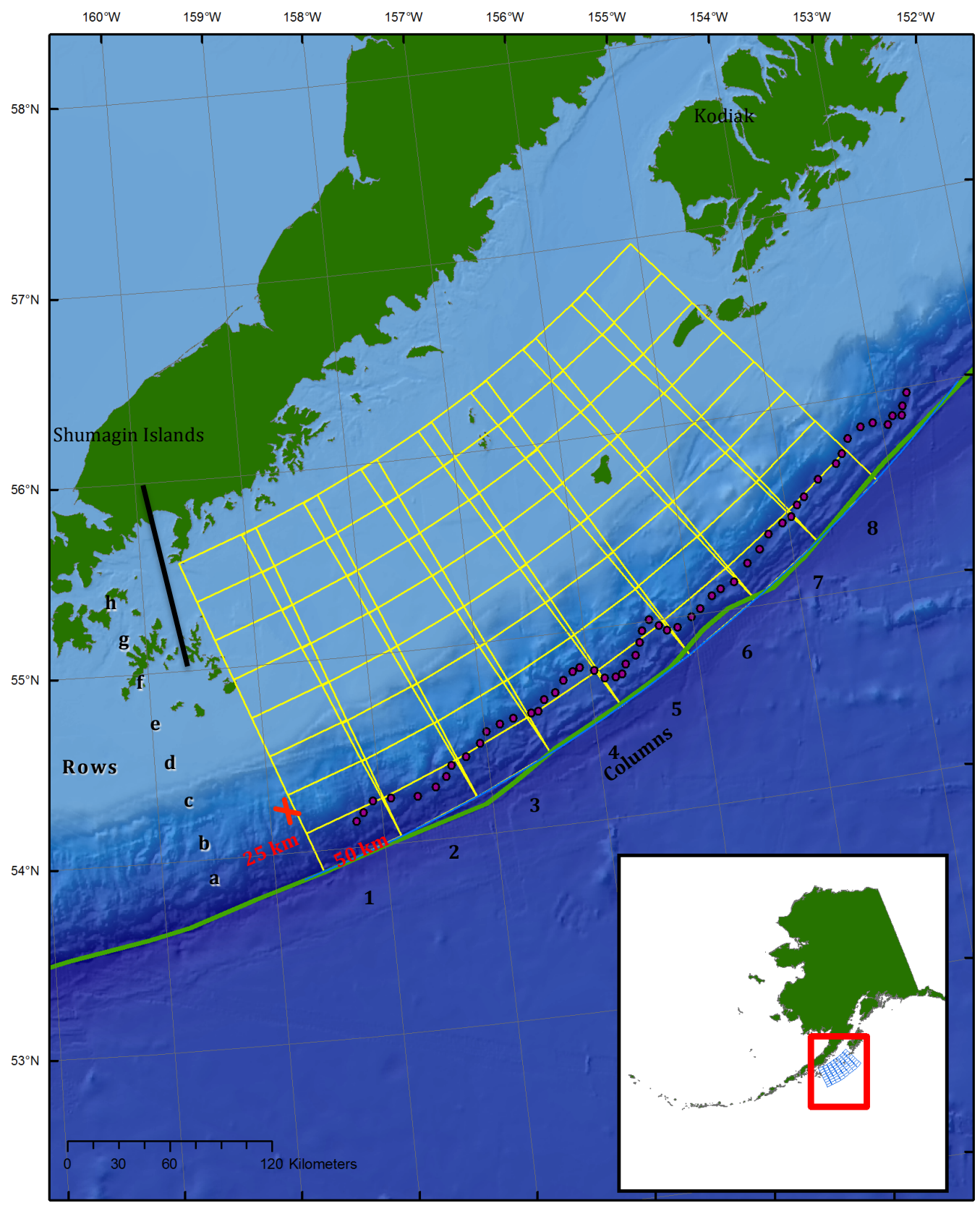

Figure 6. Map of the initial surface subfault grid of $25 \times 50 \mathrm{~km}$ cells adapted to the Semidi subduction sector bathymetry off the Alaska Peninsula. Each subfault area is identified and labeled by the row and column in the subfault grid where it is located. Unwanted overlaps between adjacent subfaults are eliminated graphically in figure 7 . Red dots indicate the boundary of the frontal prism as picked by Roland von Huene. Color shaded relief from National Geophysical Data Center. 


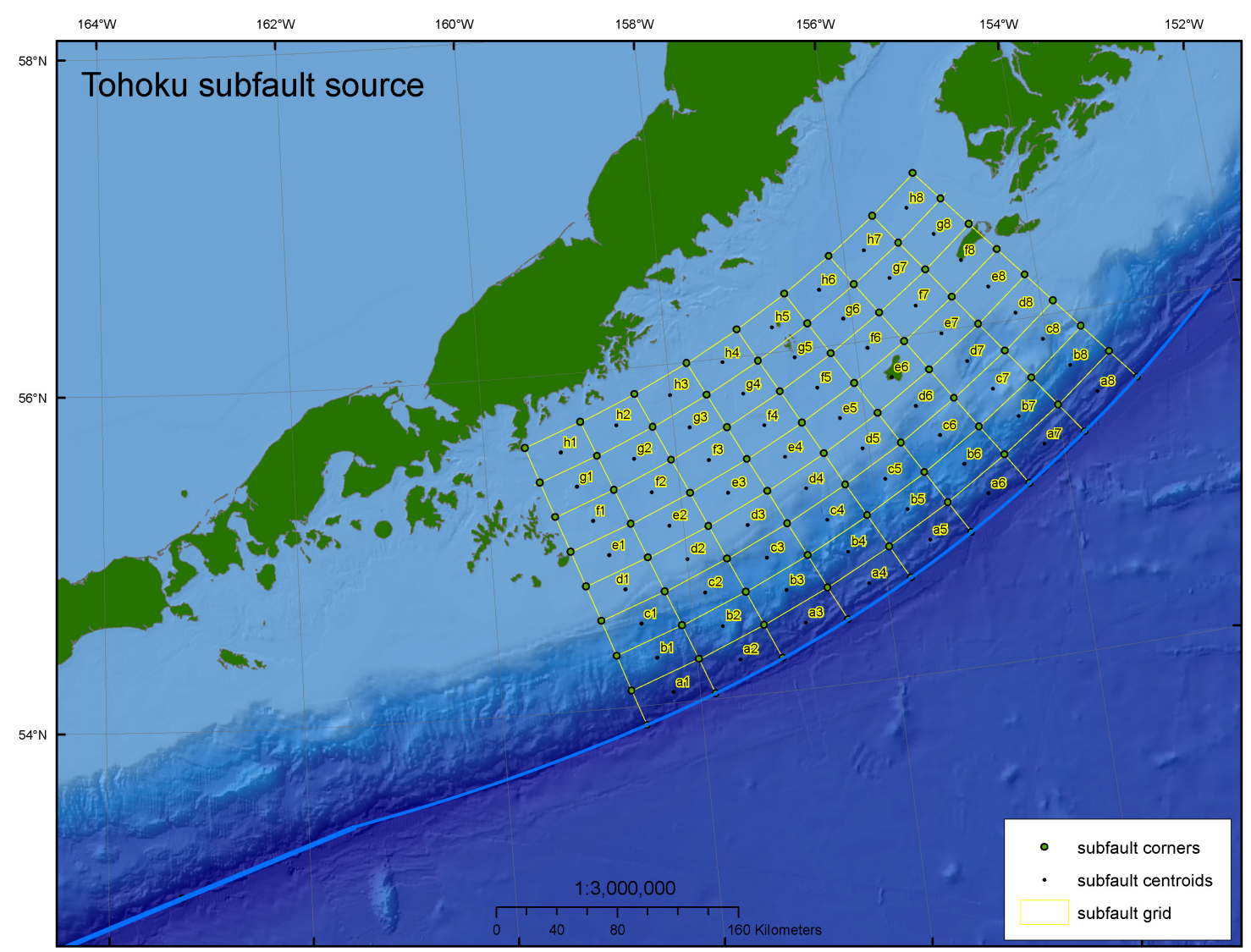

Figure 7. Map showing final surface projection of subfault grid in the Semidi sector, with subfault boundary overlaps removed and matrix subfaults labeled. 


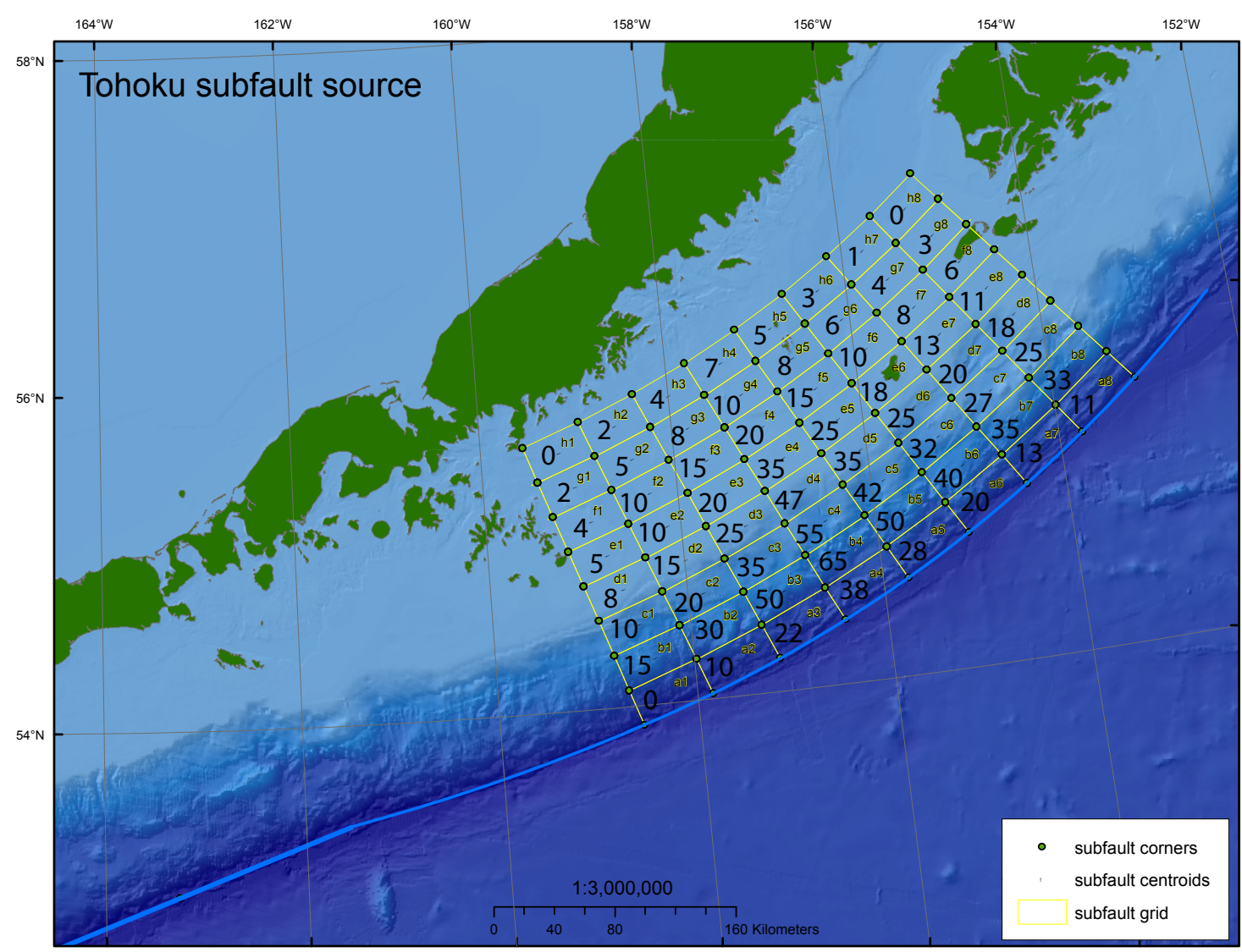

Figure 8. Map of the final 3-D subfault grid of the Semidi sector, with posited seismic-slip distribution in meters (red labels) based on a synoptic summary of the Mw 9.1 Tohoku earthquake slip models. Depth contours on subduction boundary (based on Slab 1.0) are shown in yellow. 


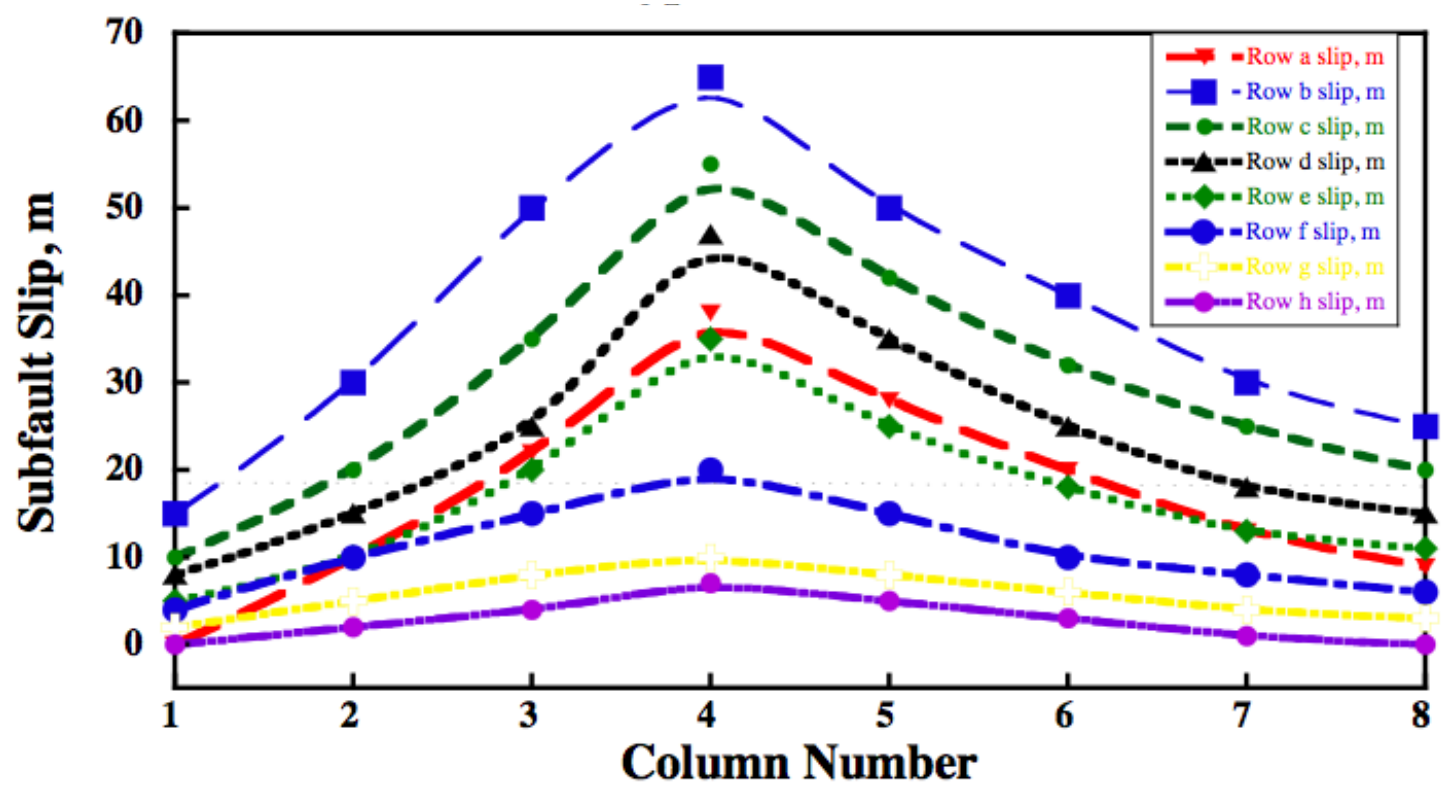

Figure 9. Plotted trench-parallel profiles of seismic slip in subfault rows of the Semidi sector grid at increasing distances from the Alaska Trench (row "a" is closest to the trench). 


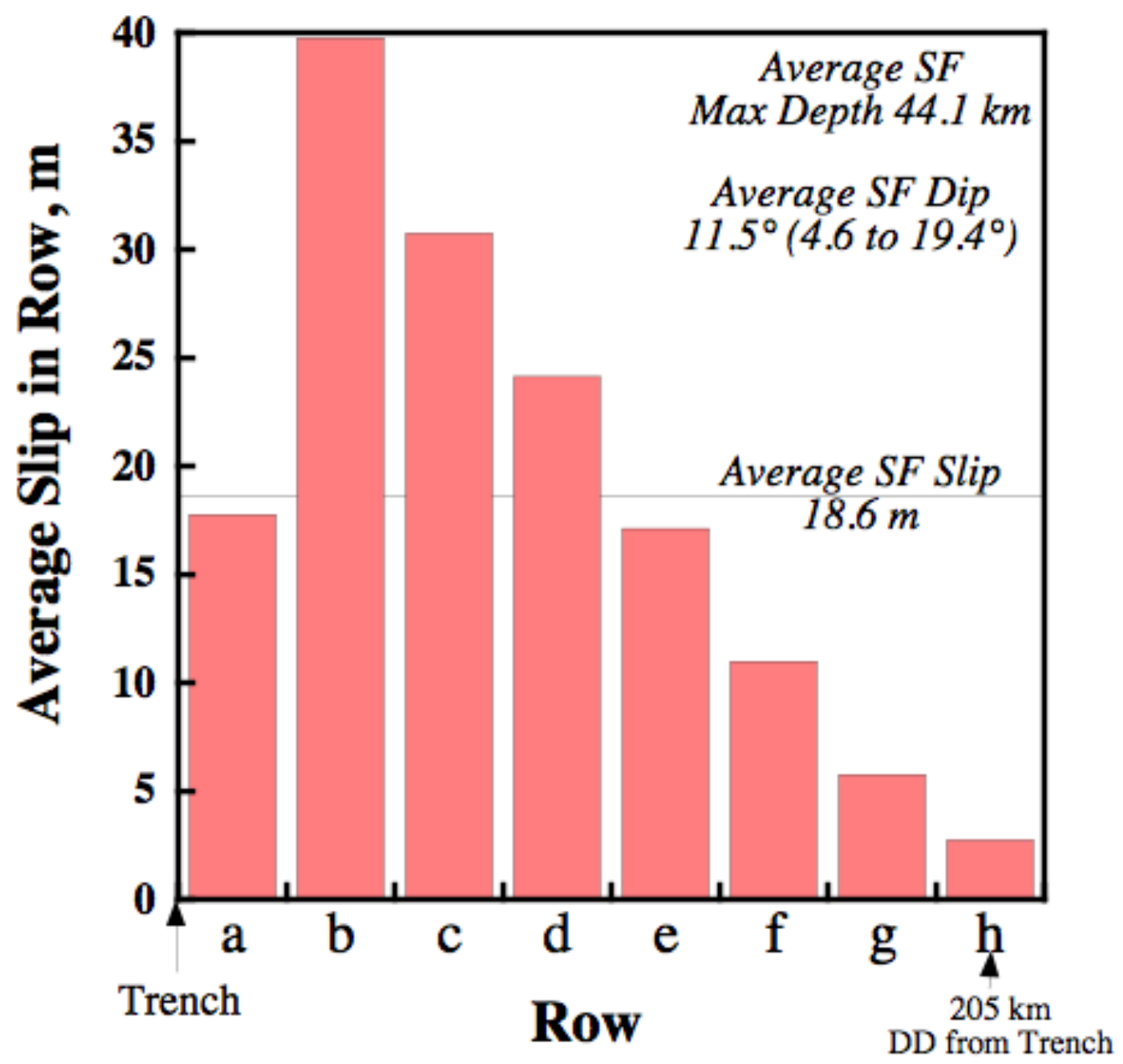

Figure 10. Histogram showing average slip in subfault rows of the Semidi sector grid parallel to the Alaska Trench. SF is subfault. DD is downdip. 


\section{Appendix. Supplementary Information}

Table A. Spreadsheet summarizing the subfault geometry and slip distribution for the SAFRR Southern California Tsunami Scenario [See the accompanying file]. 
This page intentionally left blank 


\section{Modeling for the SAFRR Tsunami Scenario-Generation, Propagation, Inundation, and Currents in Ports and Harbors}

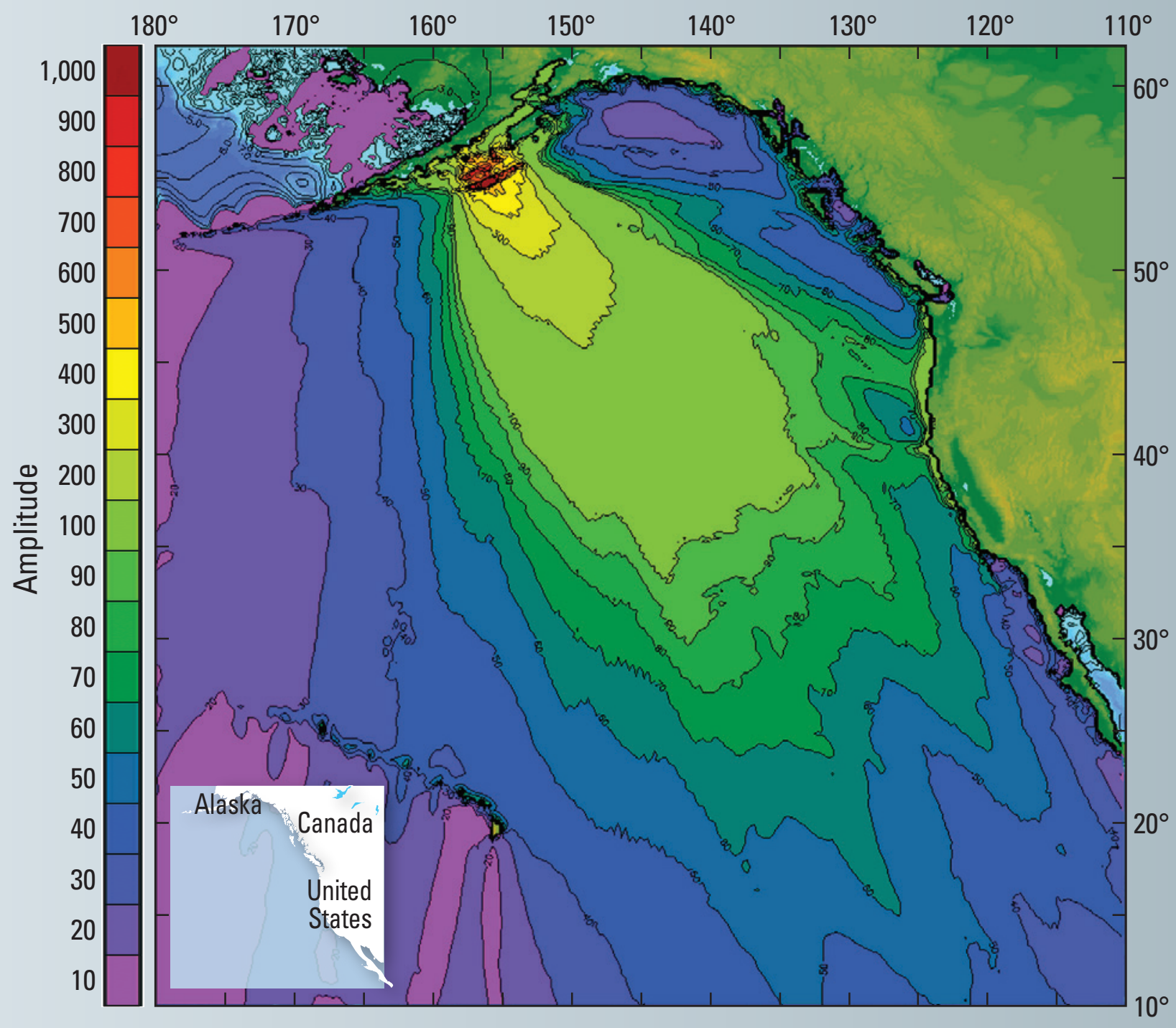

Open-File Report 2013-1170-D

California Geological Survey Special Report 229 
COVER-Maximum tsunami amplitude of scenario tsunami throughout the northeast Pacific Ocean using the Method of Splitting Tsunami (MOST) model. Image courtesy Vasily Titov, National Oceanic and Atmospheric Administration/Pacific Marine Environmental Laboratory. 
The SAFRR (Science Application for Risk Reduction) Tsunami Scenario

Stephanie Ross and Lucile Jones, Editors

\section{Modeling for the SAFRR Tsunami Scenario-Generation, Propagation, Inundation, and Currents in Ports and Harbors}

By the SAFRR Tsunami Modeling Working Group

Open-File Report 2013-1170-D

California Geological Survey Special Report 229

U.S. Department of the Interior

U.S. Geological Survey 


\section{U.S. Department of the Interior \\ SALLY JEWELL, Secretary}

\section{U.S. Geological Survey \\ Suzette M. Kimball, Acting Director}

U.S. Geological Survey, Reston, Virginia 2013

For product and ordering information:

World Wide Web: http://www.usgs.gov/pubprod

Telephone: 1-888-ASK-USGS

For more information on the USGS-the Federal source for science about the Earth, its natural and living resources, natural hazards, and the environment:

World Wide Web: http://www.usgs.gov

Telephone: 1-888-ASK-USGS

Suggested citation:

The SAFRR Tsunami Modeling Working Group, 2013, Modeling for the SAFRR Tsunami Scenario-Generation, propagation, inundation, and currents in ports and harbors, chap. D, in Ross, S.L., and Jones, L.M., eds., The SAFRR (Science Application for Risk Reduction) Tsunami Scenario: U.S. Geological Survey Open-File Report 2013-1170, 136 p., http://pubs.usgs.gov/of/2013/1170/d/.

Any use of trade, product, or firm names is for descriptive purposes only and does not imply endorsement by the U.S. Government.

Although this information product, for the most part, is in the public domain, it also may contain copyrighted materials as noted in the text. Permission to reproduce copyrighted items must be secured from the copyright owner. 


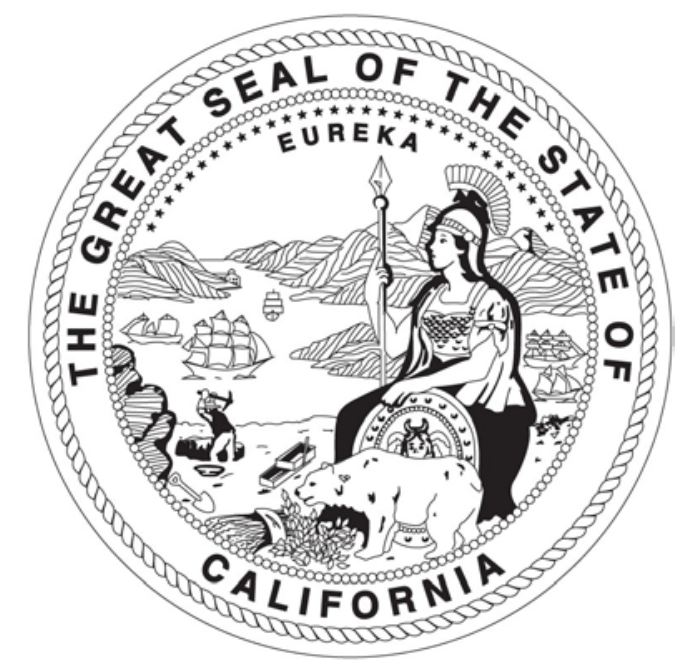

STATE OF CALIFORNIA EDMUND G. BROWNJR. GOVERNOR

THE NATURAL RESOURCES AGENCY JOHN LAIRD

SECRETARY FOR RESOURCES

DEPARTMENT OF CONSERVATION MARK NECHODOM DIRECTOR

CALIFORNIA GEOLOGICAL SURVEY JOHN G. PARRISH, Ph.D.

STATE GEOLOGIST 


\section{Contents}

Modeling for the SAFRR Tsunami Scenario-Generation, Propagation, Inundation, and Currents in Ports and

Harbors

Preface

1. Effects of Subfault Discretization and Horizontal Displacement on Tsunami Generation ........................................2

Vertical Deformation Summation Effect Induced by Abruptly Changing Fault Dip................................................2

Influence of Initial Sea Level Profile by Horizontal Slip over Sloping Seafloor ..........................................................

2. Modeling Sea-Floor Deformation and Tsunami Generation using Dynamic Finite Element Analysis ........................6

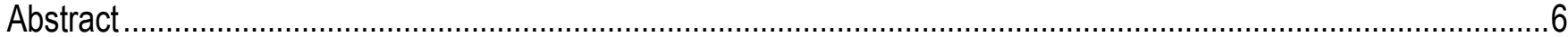

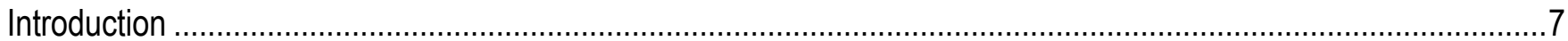

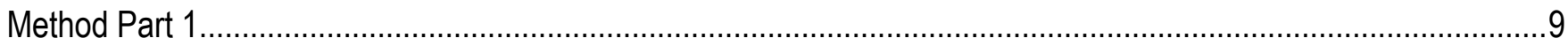

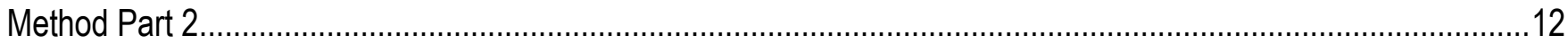

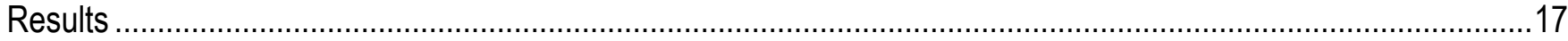

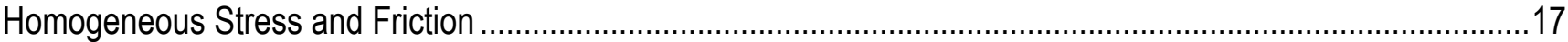

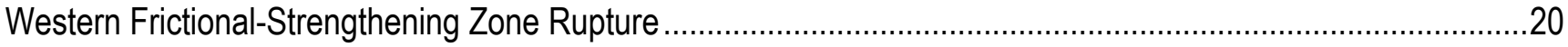

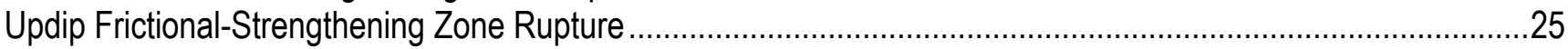

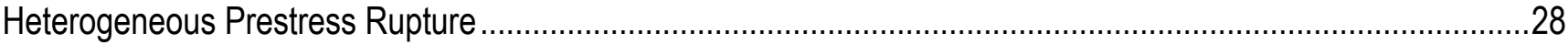

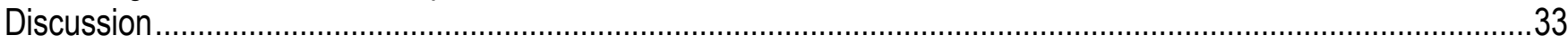

3. Modeling of Tsunami Wave Excitation, Propagation, and Inundation ...............................................................35

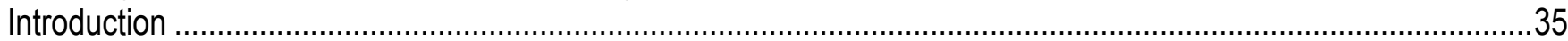

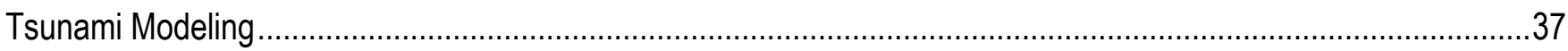

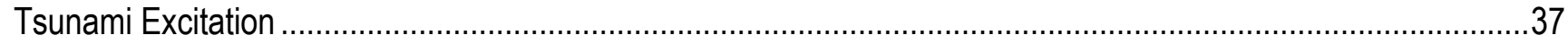

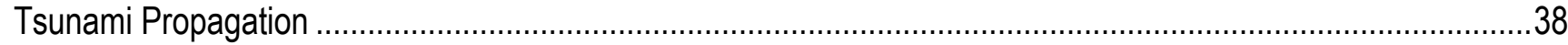

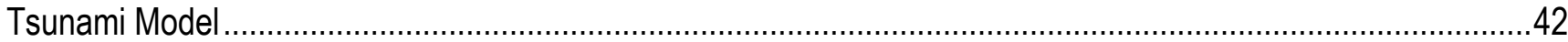

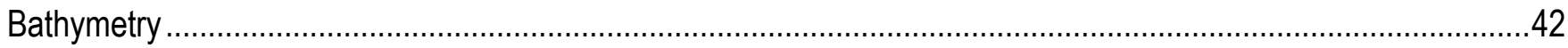

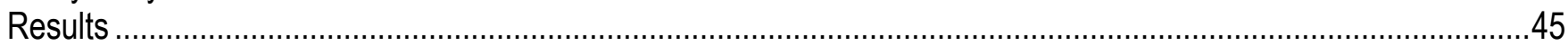

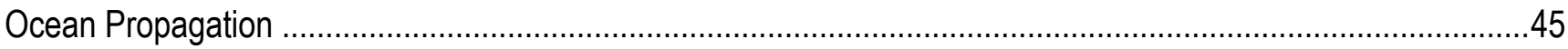

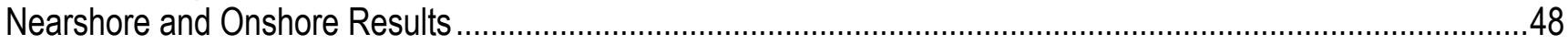

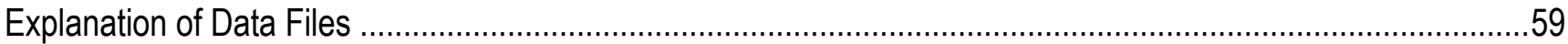

4. Numerical Modeling of Tsunami Effects in Southern California from a Hypothetical M9.1 Earthquake near the

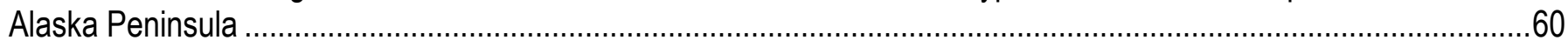

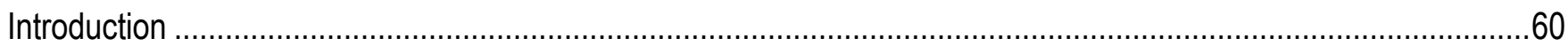

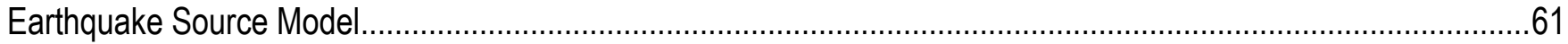

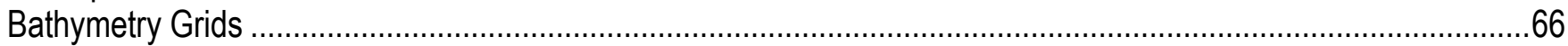

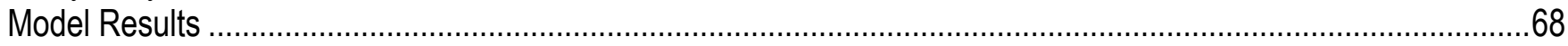

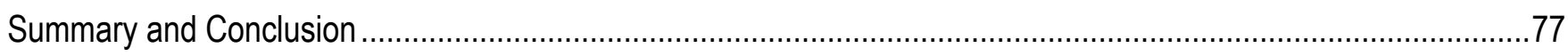

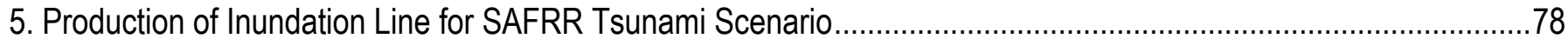

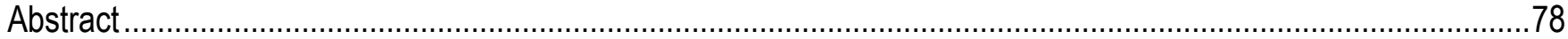

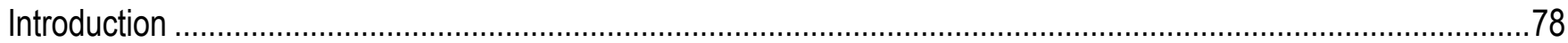

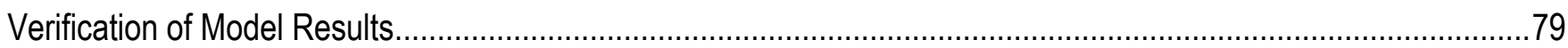

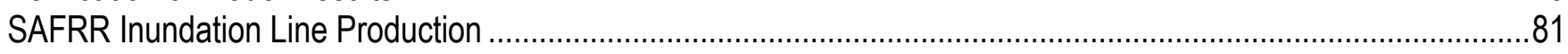

Comparison of SAFRR Inundation Line to State Inundation Line ..................................................................

6. Modeling Tsunami Dynamics in the Port of Los Angeles, California ................................................................84

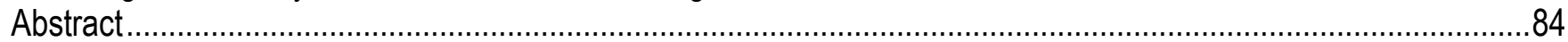

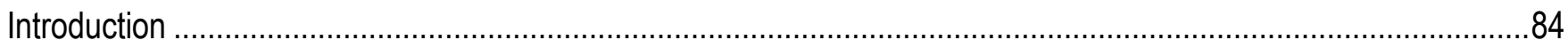

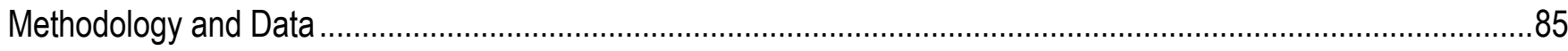




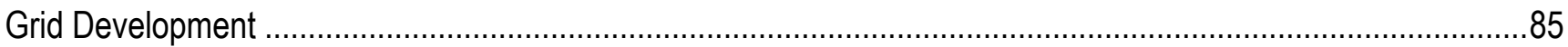

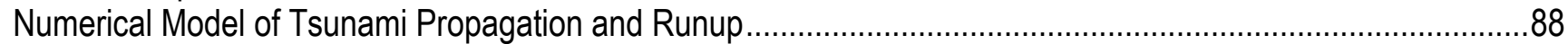

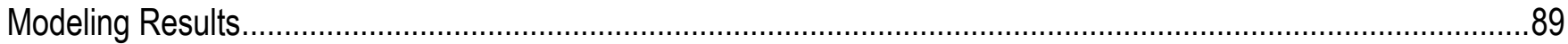

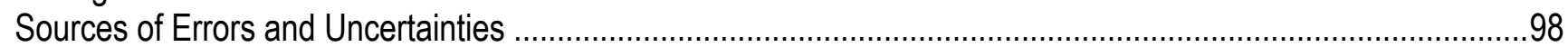

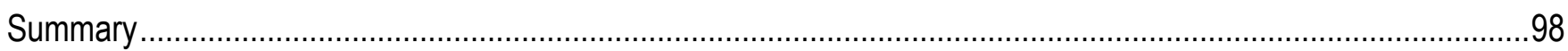

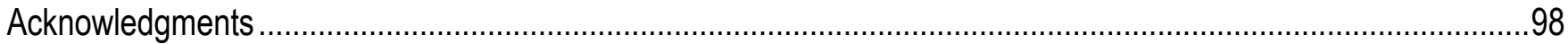

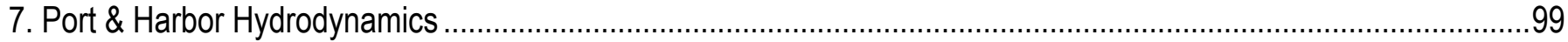

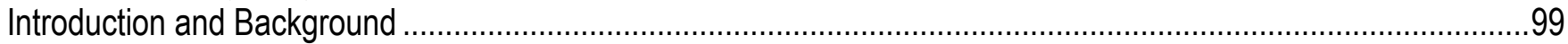

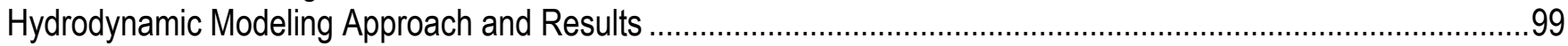

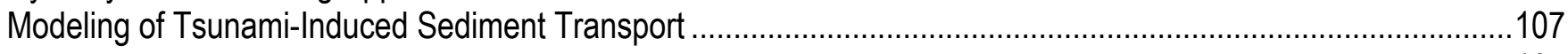

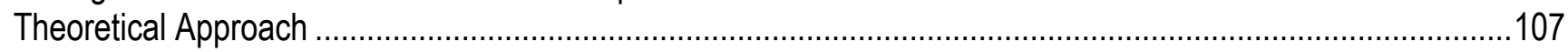

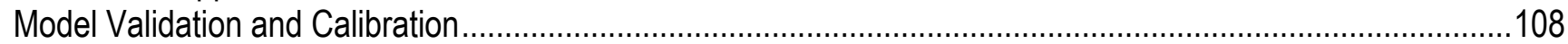

Model Application to Santa Cruz Harbor, California .............................................................................113

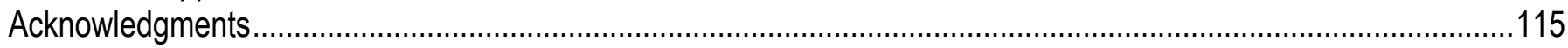

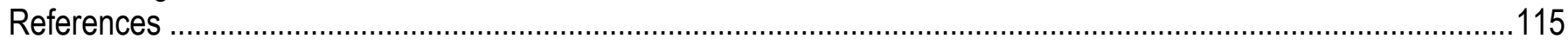

Appendix A-SAFRR Tsunami Inundation Maps for Select Areas of California's Coast ..........................................122

\section{Figures}

1. Map-view diagram showing vertical displacement ( $Z$, in meters) in the 2014 tsunami scenario computed at the West Coast and Alaska Tsunami Warning Center (WCATWC) .

2. Map-view diagram showing vertical displacement (Z, in meters) in the 2014 tsunami scenario computed .. at WCATWC based on smoothed subfault dips and a splitting of each subfault into fifths $(5 \mathrm{~km} \times 50 \mathrm{~km} \ldots$.

subfaults) .....................................................................................................................

3. Map-view diagram showing difference in vertical displacement ( $Z$, in meters) between the original $64 \ldots . . .$. subfault source and the 320 subfault source with smoothly varying dip. ..............................................

4. Map-view diagram showing total sea-floor vertical movement ( $Z$, in meters) for the 2014 tsunami exercise computed using a smoothly varying dip on 320 source blocks and including vertical uplift induced by horizontal motion over sloping seafloor. .........................................................................

5. Map-view diagram showing vertical sea-floor motion ( $Z$, in meters) induced by horizontal slip over sloping seafloor.

6. Rupture tunneling through a strengthening zone. Top: Map view of a frictional-strengthening zone modeled in the middle of a homogeneous, planar, 2-D fault in a whole space using slip-weakening $(\mathrm{SW})$, rate-state ageing law (RS-AL), and rate-state slip law (RS-SL) friction parameterizations in finite element code FaultMod.

7. Model approximation to a section of the Alaska-Aleutian megathrust. Top: Cartoon block diagram of fault geometry of the hanging wall using 3-D finite element code EQDyna

8. Cross-sectional diagrams illustrating two models with frictional-strengthening zones in (top) the westernmost portion and (bottom) the most updip portion of the fault.

9. Graphs of shear stress versus slip for a point in the weakening zone (red, left) and a point in the strengthening zone (blue, right), using time-weakening friction to model a 3-D megathrust earthquake ...... within the Alaskan-Aleutian subduction zone.

10. Diagrammatic views of the fault surface showing snapshots of rupture propagation at 27,512 , and $70 \ldots$ $s$ for a homogeneous model (spatially constant prestress, dip angle, and frictional coefficients). ..........18

11. Diagrams showing fault slip (top) and total vertical free surface deformation (bottom) for the homogeneous model. 
12. Map showing peak tsunami amplitudes (color scale in $\mathrm{m}$ ) resulting from the homogeneous earthquake rupture model in the geographic region of interest.

13. Diagrammatic views of the fault surface showing snapshots of rupture propagation at 27,52 , and $70 \mathrm{~s} \ldots$ for a model with a frictional-strengthening zone from 100 to $179 \mathrm{~km}$ along-strike and over the entire ........ downdip extent of the model (see fig. 8, top), motivated by GPS data showing an unlocked section of ..... the fault that borders our study area to the west ............................................................................22

14. Diagrams showing fault slip (top) and total vertical free surface deformation (bottom) for the western ...... frictional-strengthening zone model. .......................................................................................23

15. Map showing peak tsunami amplitudes (color scale in $\mathrm{m}$ ) resulting from the western frictional-strengthening zone model.

16. Diagrammatic views of the fault surface showing snapshots of rupture propagation at 27,52 , and $70 \mathrm{~s} . .$. for a model with a frictional-strengthening zone from 0 to $-50 \mathrm{~km}$ downdip and across the entire along-strike extent of the model

17. Diagrams showing fault slip (top) and total vertical free surface deformation (bottom) for the updip frictional-strengthening zone model.

18. Map showing peak tsunami amplitude (color scale in $\mathrm{m}$ ) resulting from the updip frictional-. strengthening zone model.

19. Diagrammatic views of the fault surface showing snapshots of rupture propagation at 27,52 , and $70 \mathrm{~s} \ldots$ for a heterogeneous prestress model.

20. Diagrammatic views of the fault plane showing initial shear stress (top) and normal stress (bottom) for the heterogeneous prestress model.

21. Diagrams showing the slip distribution used in the SAFRR Tsunami Scenario (top), as well as the fault slip (middle) and total vertical free surface deformation (bottom) for the dynamic heterogeneous prestress model.

22. Map showing peak tsunami amplitudes (color scale in $\mathrm{m}$ ) resulting from the heterogeneous prestress .....

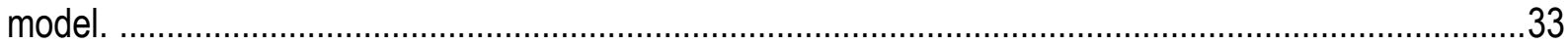

23. Map of the northeastern Pacific Basin. …………………………………………………........

24. Map showing vertical deformation field of the earthquake source region, which is used as initial

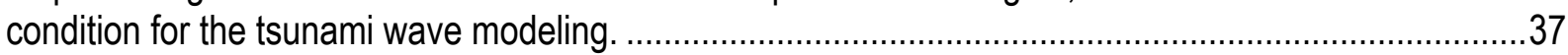

25. Diagrammatic sketch showing the coordinate system for tsunami model............................................38

26. Map showing locations of the high-resolution grids $(0.96 \mathrm{arc} \mathrm{sec}, \sim 30 \mathrm{~m})$ along the California coast. ..43

27. Map of maximum tsunami amplitudes. ...............................................................................4

28. Tsunami wave-height time series (marigrams) from the scenario tsunami for various locations along

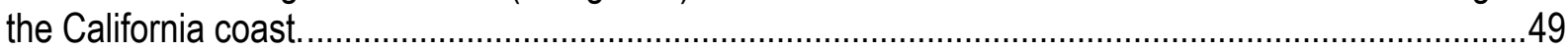

29. Maps showing maximum amplitude (top) and maximum flow depth (bottom) in and around the Ports of Los Angeles and Long Beach. ............................................................................................50

30. Time series of velocity (east, top; north, center) and wave height (bottom) for the scenario tsunami ......... waves in the Port of Los Angeles. ..............................................................................................

31. Maps showing maximum amplitude and flow depth of the scenario tsunami around Crescent City, California.

32. Maps showing maximum amplitude and flow depth of the scenario tsunami around the San Francisco shoreline just inside the Golden Gate.

33. Maps showing maximum amplitude and flow depth of the scenario tsunami in Half Moon Bay, California.

34. Maps showing maximum amplitude and flow depth of the scenario tsunami along the eastern shore of Monterey Bay, California.

35. Maps showing maximum amplitude and flow depth of the scenario tsunami around Morro Bay, 
36. Maps showing maximum amplitude and flow depth of the scenario tsunami around Avila Beach, California. Maps showing maximum amplitude and flow depth of the scenario tsunami at San Diego, California....58 Map showing the source regions and potentially affected coasts in the ComMIT propagation model database for tsunamis in the world's oceans.

41. Map showing surface displacement computed by the MOST version of Okada's (1985) elastic dislocation model.

42. Maps showing the ComMIT subfault segments (left) that most closely match the source region defined for this study (right).

43. Maps showing surface deformation cause by a 16-segment fault model derived from 4-segment averages of the 64-segment fault model.

44. Map showing computed surface deformation created by an alternate version of the 16-segment fault model for the tsunami source region.

49.

50.

51.

52. Time series outputs showing tsunami wave heights in each of the nearshore regions.

Maps showing maximum computed tsunami wave heights in the A-level (coarsest) grids along the southern California coast.

Maps showing maximum computed tsunami wave heights (left) and current speeds (right) at Marina del Rey, California.

Maps showing modeled maximum tsunami wave heights and current speeds in San Pedro Bay and sites within the bay at different grid levels.

58. Map showing the SAFRR tsunami inundation line (blue) in the Port of Los Angeles (left part of image) .... and the adjacent Port of Long Beach. ..................................................................................... 82

59. Maps showing the vertical deformation of the ocean floor resulting from the hypothetical earthquake in

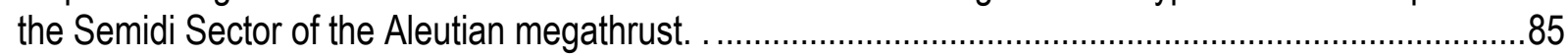

60. Map showing the coarsest grid (PA02) which covers the central and northern Pacific Ocean, and the 24-arc-second grid (SC24), which is centered at the Port of Los Angeles. .......................................86

61. Map showing telescoping embedded bathymetry/topography grids (SC24, SC08, LA55, and LA12) for numerical modeling of tsunami propagation and runup along the southern California coast. .................87

62. Maps showing modeled wave heights and water flow depths in the Ports of Los Angeles and Long Beach.

63. Map showing locations of time-series points (numbered red triangles) on the California coast near the Port of Los Angeles. 
64. Time-series plots of modeled water level and velocity at the selected locations on the California coast .... near Los Angeles.

65. Maps showing modeled flow depths from the scenario tsunami in Los Angeles Harbor with different values of the Manning coefficient.

66. Maps showing inundation and flow depths in Los Angeles Harbor under two different scenarios. .........97

67. Map showing maximum predicted water surface elevation from the scenario tsunami, relative to mean high water datum, for Ventura harbor.

68. Map showing maximum predicted tsunami-induced currents (knots; 1 knot $=0.51 \mathrm{~m} / \mathrm{s}$ ) for Ventura Harbor.

69. Map showing maximum predicted tsunami-induced currents ( $\mathrm{knots} ; 1 \mathrm{knot}=0.51 \mathrm{~m} / \mathrm{s}$ ) for San Diego Harbor.

70. Map showing maximum predicted tsunami-induced currents (knots) for the Port of Los Angeles.........105

71. Map showing maximum predicted tsunami-induced currents (knots) for the Port of Long Beach..........106

72. Graphs comparing measured and simulated dam-break flows over a movable bed at different elapse time after dam break. $x=0$ : position of dam. Elevation $=0$ : initial bed surface elevation.

73. Diagrammatic cross section showing experimental setup for breaking solitary waves on a sloping sand

beach.

74. Graphs comparing measured and calculated beach profiles for Kobyashi test. .................................110

75. Graphs comparing experimental (Exp.) and numerical (Num.) simulated temporal free surface elevations at different locations (gauges $\mathrm{G} 1$ to $\mathrm{G} 8$ ) during the fifth wave in the simulated erosion of a beach profile.

76. Diagrams showing side view (a) and plan view (b) of the experimental setup of a dam-break flow through a partial breach over a moveable bed.

77. Graphs comparing measured (Exp) and calculated (Num) bottom profiles in the case of the partially breached dam-break test (Xiao and others, 2010).

78. Graphs comparing measured (Exp) and calculated (Num) (with backscatter model) bottom profiles in

the case of the partially breached dam-break test . ......................................................................113

79. Changes in bottom bathymetry from tsunami-induced currents in Santa Cruz Harbor, California. .......114

\section{Tables}

1. Model and material properties for all simulations in this study.

2. Initial shear stress $\tau_{0}$, initial normal stress $\sigma_{0}$, the static friction coefficient $\mu_{s}$, the dynamic friction coefficient $\mu_{d}$, and the strengthening friction coefficient $\mu_{d}$ (strength) (if applicable) for all four models in .... this study...

3. Maximum vertical free-surface displacements $Z_{\max }$ and average fault slip $\langle S\rangle$ for all four models in this study.

4. Longitude and latitude of the boundaries of coarse and 1st nested grid .............................................44

5. Longitude and latitude of the boundaries of the 2nd order grid (4.8 arcsec) .........................................44

6. Longitude and latitude of the boundaries of the highest resolution grids (.96 arcsec) ...............................44

7. Slip amount (in meters) on each subfault segment of the original source model. ....................................63

8. A 16-segment subfault comprising 4-segment average slip amounts from the 64-segment model............64

9. An ad-hoc, trial and error, modified version of the 16-segment fault model used for the simulations. ........65

10. Fault parameters for the 16-segment source based on the NOAA-ComMIT propagation database. ........66

11. Nested grids used to compute propagation of tsunamis generated along the Alaska Peninsula to the Port of Los Angeles.

12. Locations where the simulated water level and velocity in the scenario tsunami are recorded. 
13. Differences in assumptions under the three considered tsunami scenarios:....... 


\title{
Modeling for the SAFRR Tsunami Scenario-Generation, Propagation, Inundation, and Currents in Ports and Harbors
}

\author{
By the SAFRR Tsunami Modeling Working Group ${ }^{1}$
}

\section{Preface}

\author{
By Eric L. Geist
}

This U.S. Geological Survey (USGS) Open-File report presents a compilation of tsunami modeling studies for the Science Application for Risk Reduction (SAFRR) tsunami scenario. These modeling studies are based on an earthquake source specified by the SAFRR tsunami source working group (Kirby and others, 2013). The modeling studies in this report are organized into three groups. The first group relates to tsunami generation. The effects that source discretization and horizontal displacement have on tsunami initial conditions are examined in section 1 (Whitmore and others). In section 2 (Ryan and others), dynamic earthquake rupture models are explored in modeling tsunami generation. These models calculate slip distribution and vertical displacement of the seafloor as a result of realistic fault friction, physical properties of rocks surrounding the fault, and dynamic stresses resolved on the fault.

The second group of papers relates to tsunami propagation and inundation modeling. Section 3 (Thio) presents a modeling study for the entire California coast that includes runup and inundation modeling where there is significant exposure and estimates of maximum velocity and momentum flux at the shoreline. In section 4 (Borrero and others), modeling of tsunami propagation and high-resolution inundation of critical locations in southern California is performed using the National Oceanic and Atmospheric Administration's (NOAA) Method of Splitting Tsunami (MOST) model and NOAA's Community Model Interface for Tsunamis (ComMIT) modeling tool. Adjustments to the inundation line owing to fine-scale structures such as levees are described in section 5 (Wilson).

The third group of papers relates to modeling of hydrodynamics in ports and harbors. Section 6 (Nicolsky and Suleimani) presents results of the model used at the Alaska Earthquake Information Center for the Ports of Los Angeles and Long Beach, as well as synthetic time series of the modeled tsunami for other selected locales in southern California. Importantly, section 6 provides a comparison of the effect of including horizontal displacements at the source described in section 1 and differences in

\footnotetext{
${ }^{1}$ Members of the working group (in alphabetical order): Bohyun Bahng (National Oceanic and Atmospheric Administration, West Coast and Alaska Tsunami Warning Center), José Borrero (University of Southern California and eCoast Ltd.), Eric L. Geist (U.S. Geological Survey; SAFRR Tsunami Modeling Coordinator), William Knight (National Oceanic and Atmospheric Administration, West Coast and Alaska Tsunami Warning Center), Patrick Lynett (University of Southern California), Dmitry J. Nicolsky (Alaska Earthquake Information Center, Geophysical Institute, University of Alaska), David D. Oglesby (University of California Riverside), Kenny Ryan (University of California Riverside), Sangyoung Son (University of Southern California), Elena N. Suleimani (Alaska Earthquake Information Center, Geophysical Institute, University of Alaska), Costas Synolakis (University of Southern California and Hellenic Centre for Marine Research), Hong Kie Thio (URS Corporation), Vasily Titov (National Oceanic and Atmospheric Administration, Pacific Marine Environmental Laboratory), Paul Whitmore (National Oceanic and Atmospheric Administration, West Coast and Alaska Tsunami Warning Center), and Rick Wilson (California Geological Survey).
} 
bottom friction on wave heights and inundation in the Ports of Los Angeles and Long Beach. Modeling described in section 7 (Lynett and Son) uses a higher order physical model to determine variations of currents during the tsunami and complex flow structures such as jets and eddies. Section 7 also uses sediment transport models to estimate scour and deposition of sediment in ports and harbors-a significant effect that was observed in southern California following the 2011 Tohoku tsunami. Together, all of the sections in this report form the basis for damage, impact, and emergency preparedness aspects of the SAFRR tsunami scenario.

Three sections of this report independently calculate wave height and inundation results using the source specified by Kirby and others (2013). Refer to figure 29 in section 3, figure 52 in section 4, and figure 62 in section 6 . All of these results are relative to a mean high water (MHW) vertical datum. Slight differences in the results are observed in East Basin of the Port of Los Angeles, Alamitos Bay, and the Seal Beach National Wildlife Refuge. However, given that these three modeling efforts involved different implementations of the source, different numerical wave propagation and runup models, and slight differences in the digital elevation models (DEMs), the similarity among the results is remarkable.

\title{
1. Effects of Subfault Discretization and Horizontal Displacement on Tsunami Generation
}

\author{
By Paul Whitmore, Bohyun Bahng, and William Knight
}

\section{Vertical Deformation Summation Effect Induced by Abruptly Changing Fault Dip}

A common practice in tsunami modeling is to break a fault source up into multiple subfaults and then use the Okada static dislocation formulae to compute the vertical displacement from each subfault and sum these together to determine the total uplift. A potential problem with this approach is noted when the dip angle changes abruptly between subfaults located updip or downdip from each other. The effect is for the trough produced by the updip subfault to decrease the uplift produced by the downdip subfault. An abrupt change in dip likely does not represent the actual situation; a smoothly varying dip would reproduce the event uplift more realistically.

The 2014 Alaska Peninsula tsunami scenario (Kirby and others, 2013) was examined to see whether the abrupt change in dips influenced the resultant uplift. The 64 subfaults as defined by Kirby and others were first used to compute static vertical displacement in the traditional manner. Figure 1 shows this uplift.

The 64 subfaults used in the 2014 scenario are approximately $50 \mathrm{~km}$ long by $25 \mathrm{~km}$ wide (downdip). They are arranged in 8 rows with 8 subfaults in each row, producing approximately a 400$\mathrm{km}$-long by $200-\mathrm{km}$-wide source zone. To test the influence of abrupt dip changes in the downdip direction, each subfault is divided into 5 units approximately $50 \mathrm{~km}$ long by $5 \mathrm{~km}$ wide (320 subfaults total). A spline fit is used to compute the subfault dips respecting the original dips. That is, each subfault $(50 \mathrm{~km} \times 5 \mathrm{~km})$ is assigned a dip that smoothly interfaces with the next downdip subfault. The vertical displacement is computed for each of the 320 subfaults and summed. Figure 2 shows the summation based on the 320 subfaults with smoothly varying dips from farthest updip to farthest downdip subfault.

Figure 3 shows the difference between the traditional approach of summing up 64 subfaults (fig. 1) and the smoothly dipping approach (fig. 2). Note that the uplift in figure 2 has a longer spatial period and that figure 3 shows significant differences between the two approaches. 


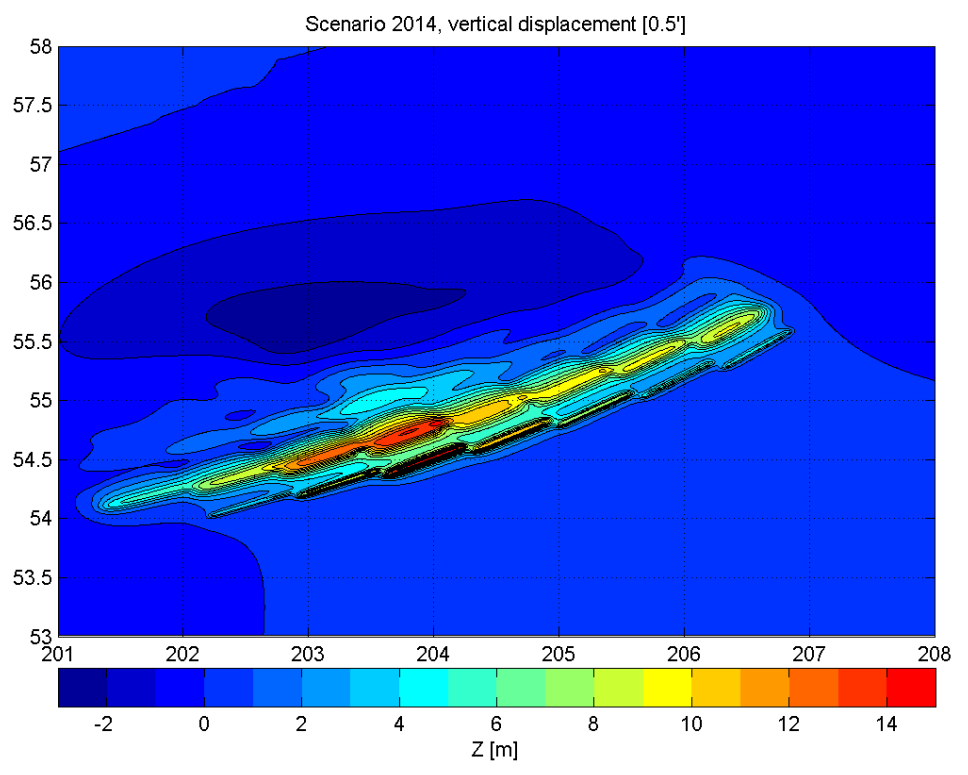

Figure 1. Map-view diagram showing vertical displacement ( $Z$, in meters) in the 2014 tsunami scenario computed at the West Coast and Alaska Tsunami Warning Center (WCATWC) based on 64-subfault summation. Degrees of longitude and latitude indicated for horizontal and vertical axes, respectively.

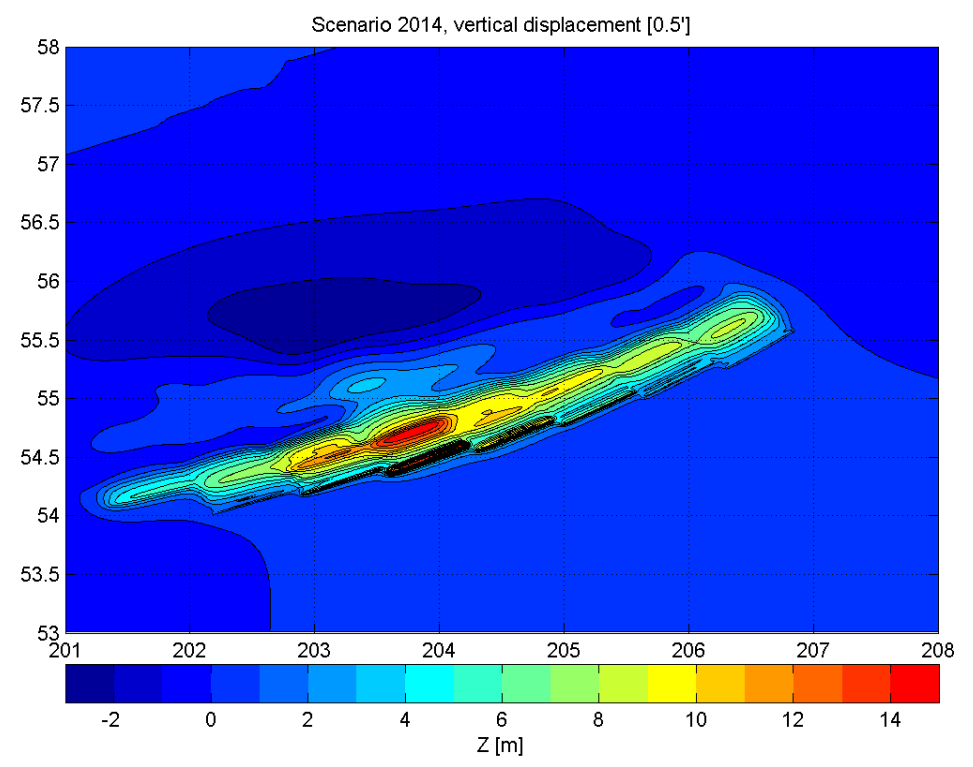

Figure 2. Map-view diagram showing vertical displacement (Z, in meters) in the 2014 tsunami scenario computed at WCATWC based on smoothed subfault dips and a splitting of each subfault into fifths $(5 \mathrm{~km} \times 50 \mathrm{~km}$ subfaults). Degrees of longitude and latitude indicated for horizontal and vertical axes, respectively. 


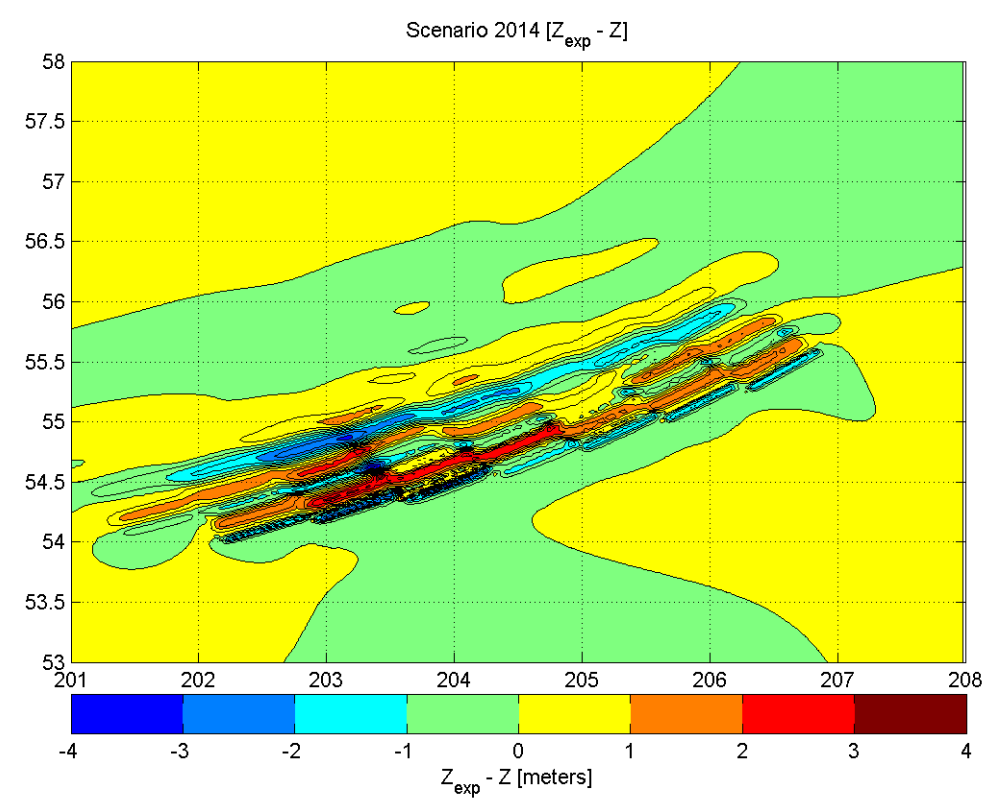

Figure 3. Map-view diagram showing difference in vertical displacement ( $Z$, in meters) between the original 64 subfault source and the 320 subfault source with smoothly varying dip. Degrees of longitude and latitude indicated for horizontal and vertical axes, respectively.

\section{Influence of Initial Sea Level Profile by Horizontal Slip over Sloping Seafloor}

Another factor not normally considered in determining sea-floor uplift given earthquake fault parameters is the contribution of the horizontal component of slip over an inclined seafloor. Several studies have shown that this contribution can be significant where the seafloor is inclined. We examine the 2014 tsunami exercise source to determine if the horizontal component of slip is important when determining sea-floor uplift.

Figure 4 shows the sea-floor uplift using the 320 source zones of figure 2 and adding the vertical uplift induced by horizontal slip over inclined sea-floor surfaces. Note that the impact of including this type of motion is significant over the continental slope (which in this case happens to be where most of the horizontal motion occurs). The pixilation of this figure relates to the bathymetric data increment (5 feet, $1.52 \mathrm{~m}$ ) on which the horizontal slip influence was computed. While this is fairly coarse, the overall level of uplift is significantly greater when including this component. Note the difference in scale between figure 4 and figure 2. Figure 5 shows the difference between figures 2 and 4 ; that is, the vertical motion induced by horizontal slip. In this case, the induced vertical motion exceeds $8 \mathrm{~m}$ in some areas and will likely be an important factor to take into account when numerically generating the tsunami. 


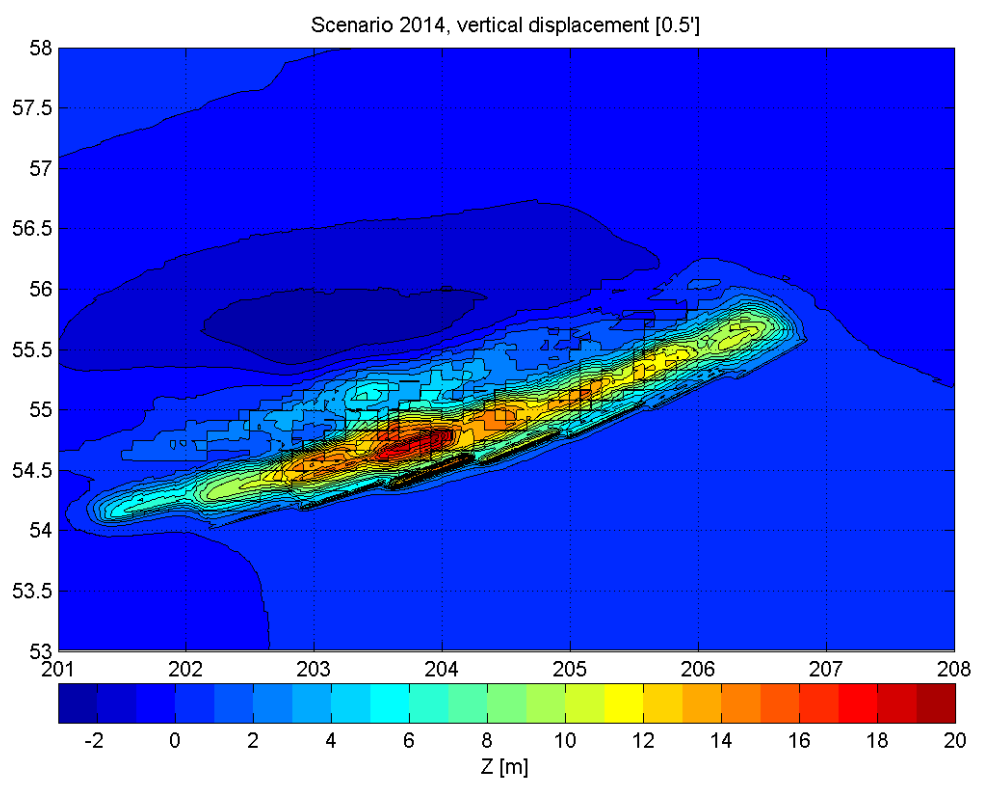

Figure 4. Map-view diagram showing total sea-floor vertical movement ( $Z$, in meters) for the 2014 tsunami exercise computed using a smoothly varying dip on 320 source blocks and including vertical uplift induced by horizontal motion over sloping seafloor. Pixilation caused by grid increment used in the bathymetry data. Degrees of longitude and latitude indicated for horizontal and vertical axes, respectively.

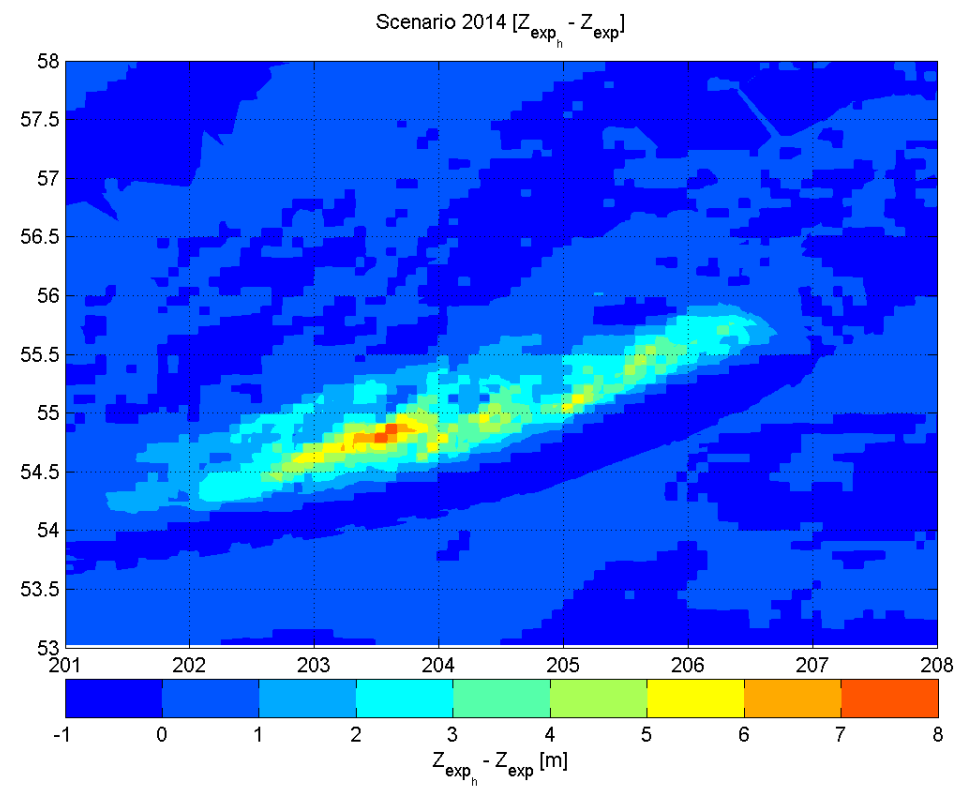

Figure 5. Map-view diagram showing vertical sea-floor motion (Z, in meters) induced by horizontal slip over sloping seafloor. Pixilation caused by grid increment used in the bathymetry data. Degrees of longitude and latitude indicated for horizontal and vertical axes, respectively. 


\title{
2. Modeling Sea-Floor Deformation and Tsunami Generation using Dynamic Finite Element Analysis
}

\author{
By Kenny Ryan, David D. Oglesby, and Eric L. Geist
}

\begin{abstract}
Motivated by the 2011 M9 Tohoku earthquake and potential earthquakes on the AlaskanAleutian megathrust, we use computational simulations to investigate the effects of fault-rupture dynamics on slip, free surface deformation, and resulting tsunami formation from scenario $M 9.1$ megathrust earthquakes. Unlike static dislocation models, dynamic models account for the force that the entire fault system exerts on each individual element of the model for each time step, so that earthquake rupture takes a path that is consistent with the physics of the model. To isolate the effects of different physical variables, we model four different dynamic rupture scenarios: a spatially homogenous prestress and frictional parameter scenario, two scenarios with rate-strengthening-like friction (for example, Dieterich, 1992), and one scenario with spatially heterogeneous prestress. Given geometric, material, and plate-coupling data along the Alaska-Aleutian megathrust assembled from the Science Application for Risk Reduction team (SAFRR) (Bruns and others, 1987; Johnson and Satake, 1994; Santini and others, 2003; Wells and others, 2003; Wells and others, 2011; Hayes and others, 2012), we are able to dynamically model rupture of an $M 9.1$ earthquake. The homogeneous model shows an average fault slip of $18.6 \mathrm{~m}$, with the same seismic moment as the source model used by the SAFRR team to investigate large-scale effects on western U.S. coastlines from a tsunami generated along the Alaskan-Aleutian subduction zone, and a maximum vertical free surface displacement of $5.77 \mathrm{~m}$. However, adding a frictional strengthening zone to an along-strike region of the fault reduces average fault slip to $14.6 \mathrm{~m}$ and the maximum vertical free surface displacement to $5.74 \mathrm{~m}$, while significantly reducing the maximum free surface displacement in the area updip from the strengthening zone. Adding a frictional strengthening zone to an updip region of the fault reduces average fault slip to $10.4 \mathrm{~m}$ and the maximum vertical free surface displacement to $2.86 \mathrm{~m}$, while significantly reducing the maximum free surface displacement over the entire megathrust. A model with heterogeneous prestress results in a more heterogeneous slip distribution, relative to the homogeneous model; this slip distribution qualitatively matches the slip distribution of the source model used by the SAFRR team. The heterogeneous prestress model has the same average fault slip as the homogeneous model and a maximum vertical free surface displacement of $7.04 \mathrm{~m}$. Corresponding tsunami models, which use a finite difference method to solve linear long-wave equations (Shuto, 1991; Satake, 2002), match temporally evolving seafloor deformation to the free surface deformation from the rupture simulations. Tsunami models show reduced peak amplitudes in the area above the frictional-strengthening zones, relative to the homogeneous case. A tsunami resulting from a heterogeneous fault prestress model results in peak amplitudes immediately above the hanging wall that are spatially more varied than in the homogeneous model, but the overall beaming pattern and maximum amplitudes along the local coasts are similar. All tsunami models also show the resultant gravity wave from the breakout of the earthquake rupture to the seafloor (Oglesby and others, 2000). Tsunamis generated along the AlaskaAleutian megathrust offshore of the Alaska Peninsula could have large adverse effects on Pacific coasts (Ryan and others, 2012).
\end{abstract}




\section{Introduction}

Megathrust earthquakes in subduction zones are known generators of large, transoceanic tsunamis (for example, Kanamori, 1972). Ryan and others (2012) demonstrated that a tsunami resulting from a large megathrust earthquake on the Alaskan-Aleutian subduction zone (their figure 1) would propagate across the Pacific Ocean and strike the U.S west coast, potentially causing significant damage to ports and other populated areas. Because of its earthquake and tsunami hazards, the Alaskan-Aleutian subduction zone has been well studied seismically and geodetically (for example, Freymueller and others, 2008). Using Global Positioning System (GPS) measurements, Freymueller and Beavan (1999) show that the western Shumagin segment of the Alaskan-Aleutian subduction zone is creeping (figure 1 of Ryan and others, 2012). They further suggest that the entire downdip extent of this section of the megathrust may be unlocked and thus slipping at the local plate-convergence rate. Surface deformation along the Alaskan-Aleutian megathrust is a complex process that results from different mechanisms, including postseismic deformation, spatial variations in plate coupling, and movement of large crustal blocks (Freymueller and others, 2008). Additionally, Freymueller and others (2008) find that both the width of the seismogenic zone and the distribution of locked and creeping zones vary substantially along strike throughout the Alaskan-Aleutian subduction zone.

The distribution of locked and creeping sections along subduction zones is important for tsunami generation and coastline inundation. Kanamori (1972) notes that sediments in the trench could help produce a mechanism for some tsunami earthquakes - earthquakes that cause relatively small ground shaking but larger than expected tsunamis. Specifically, sediments could alter the frictional properties of the fault, making it a locally creeping (stable sliding) section, as well as producing slower rupture propagation during earthquakes. Hyndman and others (1997) point out that stable sliding regions can be caused by unconsolidated sediments in the updip section and by either high temperature or hydrated serpentinite at depth - and that global seismogenic zones typically lie at depths between $10 \mathrm{~km}$ and 40 km., For 525 earthquakes around the circum-Pacific, including earthquakes along the Alaskan-Aleutian subduction zone, Bilek and Lay (2002) show longer rupture durations for shallow $(<15 \mathrm{~km})$ thrust events than for deeper $(>15 \mathrm{~km})$ thrust events. Furthermore, they suggest that conditionally stable and fully stable sliding zones located on the most updip section of a thrust fault can slow rupture velocity and increase duration.

Dynamic rupture models of dip-slip faults are extremely helpful in understanding the free surface deformation that leads to tsunami generation. Specifically, using sea-floor deformation from rupture dynamics as time-dependent boundary conditions for tsunami generation may provide insight into tsunami formation and local propagation. Standard dislocation models use a static slip distribution to model the resulting tsunami (Okada, 1985), whereas for dynamic models the slip distribution is not known beforehand but is rather a calculated result of the model. Dynamic models can validate existing dislocation models by using realistic friction parameterizations and fault geometry to match the slip distribution of the dislocation model and to analyze the resulting tsunami in time. Although dynamic modeling cannot replace the utility of standard dislocation modeling, it can be a useful complement.

Numerical and experimental models show that dip-slip faults exhibit normal stress fluctuations from seismic-wave reflections off the free surface (Brune, 1996; Nielsen, 1998; Oglesby and others, 1998; Oglesby and Archuleta, 2000; Oglesby and others, 2000). For nonvertical dip-slip faults, the free surface allows seismic waves to reflect back and hit the fault again, altering the stress field on the fault near the free surface. Oglesby and others (1998) show that as rupture approaches the free surface along a thrust/reverse fault, there is an increase in normal stress ahead of the crack tip and a decrease in normal stress behind the crack tip; this effect leads to amplified fault motion near the surface (relative to a normal or strike-slip fault rupture). Furthermore, when rupture travels updip along a dip-slip fault and 
reaches the free surface, it produces a breakout phase (a slip pulse traveling back downdip) and a strong Rayleigh wave traveling along the surface (Burridge and Halliday, 1971; Oglesby and others, 1998), with reverse/thrust faults having stronger breakout phases than normal or strike-slip faults. The particle displacement is also greatly enhanced on the hanging wall relative to the footwall. In agreement with numerical models, Brune's (1996) laboratory foam-block thrust models also produce these effects. Enhanced slip near the trench is capable of generating larger amplitude tsunamis than equivalent slip at depth (Geist, 1999; Geist and Bilek, 2001; Geist, 2002).

In the first part of this work, we use the dynamic finite element code FaultMod (Barall, 2008) to show that simple slip-weakening friction (see, for example, Ida, 1972) can serve as a very accurate proxy for rate-strengthening friction as derived from the rate-state framework (Dieterich, 1978, 1979; Ruina, 1980, 1983; Linker and Dieterich, 1992). With this approach to friction thus validated, we then use the dynamic finite element code EQDyna (Duan and Oglesby, 2006) to model 3-D ruptures, using time-weakening friction (Andrews, 2004), along a megathrust approximating a portion of the AlaskanAleutian subduction zone. In order to model megathrust faults more realistically, it is important to simulate unstable and stable sliding zones (for example, outer boundaries of seismogenic zones); such models typically use a rate- and state-dependent (RS) friction parameterization (see, for example, Hyndman and others, 1997; Scholz, 1998) to capture the physics of slip under varying degrees of frictional stability. In particular, an increase in the steady-state friction coefficient with slip rate can characterize the stable sliding zones that border the seismogenic zones.

The general form of RS friction is (Dieterich, 1978, 1979; Ruina, 1980, 1983):

$$
\tau=\left\lfloor\mu_{o}+a \ln \left(\frac{V}{V_{o}}\right)+b \ln \left(\frac{\theta}{\theta_{o}}\right)\right\rfloor \sigma^{e f f}
$$

where $\mu_{0}$ represents a constant reference value for the coefficient of friction; $\mathrm{a}$ and $\mathrm{b}$ are constitutive parameters estimated from laboratory experiments; $V_{\mathrm{o}}$ and $\theta_{\mathrm{o}}$ are reference values for slip rate and the state of the sliding surface, respectively, such that when $V=V_{\mathrm{o}}$ and $\theta=\theta_{\mathrm{o}}$ the friction coefficient is $\mu_{\mathrm{o}} ; \theta$ abstractly represents the average age of contacts at some sliding velocity; and $\sigma^{\text {eff }}$ is the effective normal stress. Within the RS formulation, a positive rate-strengthening parameter $(a-b)$, where a and $\mathrm{b}$ are experimentally determined (Dieterich, 1978, 1979) through observed stress drop, indicates velocity strengthening or stable slip, and a negative parameter indicates velocity weakening or the potential for unstable slip. For reverse/thrust faults it has been suggested that such rate-strengthening zones can simulate weak zones in the inner margin of the trenches, possibly characterized by large amounts of sediment. Sliding experiments on ultrafine-grained quartz (Chester and Higgs, 1992) suggest that rateweakening behavior occurs between 100 and $300{ }^{\circ} \mathrm{C}$ under wet conditions, while higher temperatures lead to a rate-strengthening parameter $(a-b)$ of 0.03 . Experiments on granite (Blanpied and others, 1998) found rate-weakening at lower slip speeds (for example, $1 \mu \mathrm{m} / \mathrm{s}$ ) with a rate-strengthening parameter of approximately 0.004 and rate-strengthening at higher slip speeds (for example, 1,000 $\mu \mathrm{m} / \mathrm{s}$ ) with a rate-strengthening parameter of approximately 0.01 .

Real faults likely have heterogeneous stress regimes in addition to distributed frictionally stable and unstable sliding zones; these features can lead to complex stress interactions during rupture. In order to reproduce accurate slip distributions from real earthquakes, dynamic modeling studies incorporate heterogeneous prestress distributions (for example, Olsen and others, 1997; Peyrat and others, 2001; Guatteri and others, 2003; Olsen and others, 2009). However, the resulting total slip distributions typically are much smoother than prestress distributions, as a result of stress interactions from large portions of the fault slipping simultaneously. Beroza and Mikumo (1996) suggest that slip duration for a point on a fault can decrease in cases of high prestress heterogeneity through a self-healing mechanism. 
Thus, modeling earthquakes with heterogeneous prestress should result in both heterogeneous rupture propagation (that is, highly variable rupture speed) and heterogeneous slip distributions.

Tsunami generation and propagation are influenced by the slip distribution, geometry, and material properties along the tsunami-generating fault (Geist, 1999; Geist and Dmowska, 1999; Geist and Bilek, 2001; Geist, 2002). These studies indicate that slip distribution near the trench most significantly affects tsunami generation, amplitude, and local runup, versus slip distribution further downdip. Geist and Dmowska (1999) show that dip-directed slip variations affect the maximum amplitude and steepness of the local tsunami, whereas along-strike slip variations result in strike-parallel amplitude changes in the tsunami that are conserved during local propagation, altering the beaming pattern of the tsunami. Geist and Bilek (2001) point out that estimates of initial tsunami size depend on estimates of shear modulus variation with depth. They analyzed 360 circum-Pacific subduction zone earthquakes and found that in order to match observed source time functions, both a relative reduction in shear modulus and an increase in slip near the trench are needed.

Additionally, megathrust earthquakes can incorporate complex slip distributions on multiple fault segments. Thrust events involving rupture of a splay fault can greatly affect the distribution of seafloor deformation and the resultant tsunami (Cummins and Kaneda, 2000). DeDontney and Rice (2012) suggest that the 2004 Indian Ocean tsunami may have resulted from two major areas of uplift, the main thrust and a splay fault, and further note that splay faults with steeper dip angles require less slip to produce the same vertical sea-floor deformation as the main thrust fault. Whether or not a rupture can propagate onto a splay fault can depend on the dynamics of the earthquake (Wendt and others, 2009). Wendt and others (2009) dynamically modeled the time-dependent earthquake and tsunami generation process on a large thrust fault with a connected, steeper splay fault. They show that if a barrier is introduced on the main thrust fault, rupture can propagate onto the smaller splay fault and produce larger vertical sea-floor deformation and correspondingly larger (local) maximum tsunami wave heights.

\section{Method Part 1}

In this study we simulate zones of weak fault coupling for an updip portion and for an alongstrike portion of the Alaska-Aleutian megathrust (fig. 7). Although the primary finite element method (FEM) code EQDyna (Duan and Oglesby, 2006) used in this study can model 3-D, shallow dipping, megathrust ruptures, it does not incorporate rate-state friction. Thus, in order to approximate ratestrengthening frictional properties from rate-state friction using a simple slip-weakening-type friction formulation (for example, time-weakening friction, Andrews, 2004), we test three different friction laws using a secondary 2-D FEM code FaultMod (Barall, 2008) that does incorporate rate-state friction in the form of linear slip-weakening (SW) friction and two forms of rate- and state-dependent friction: ageing law (RS-AL), and slip law (RS-SL). We use results from the secondary code FaultMod to model mode II (slip parallel to rupture propagation) dynamic rupture, with a frictional interface, along a planar fault in a whole space (fig. 6, top). Generally, finite element codes divide a given continuum of mass (for example, the Earth's crust) into a number of elements that can then be used to run computations on applied forces, assuming elasticity and a frictional parameterization. FaultMod has been validated in Southern California Earthquake Center/U.S. Geological Survey (SCEC/USGS) rupture benchmark problems (Barall, 2009; Harris and others, 2009, 2011). The code incorporates artificial viscous damping (Dalguer and Day, 2007), as well as algorithmic damping to help damp spurious oscillations and energy-absorbing boundary conditions along the mesh edges to avoid artificial reflections from the model boundaries. 

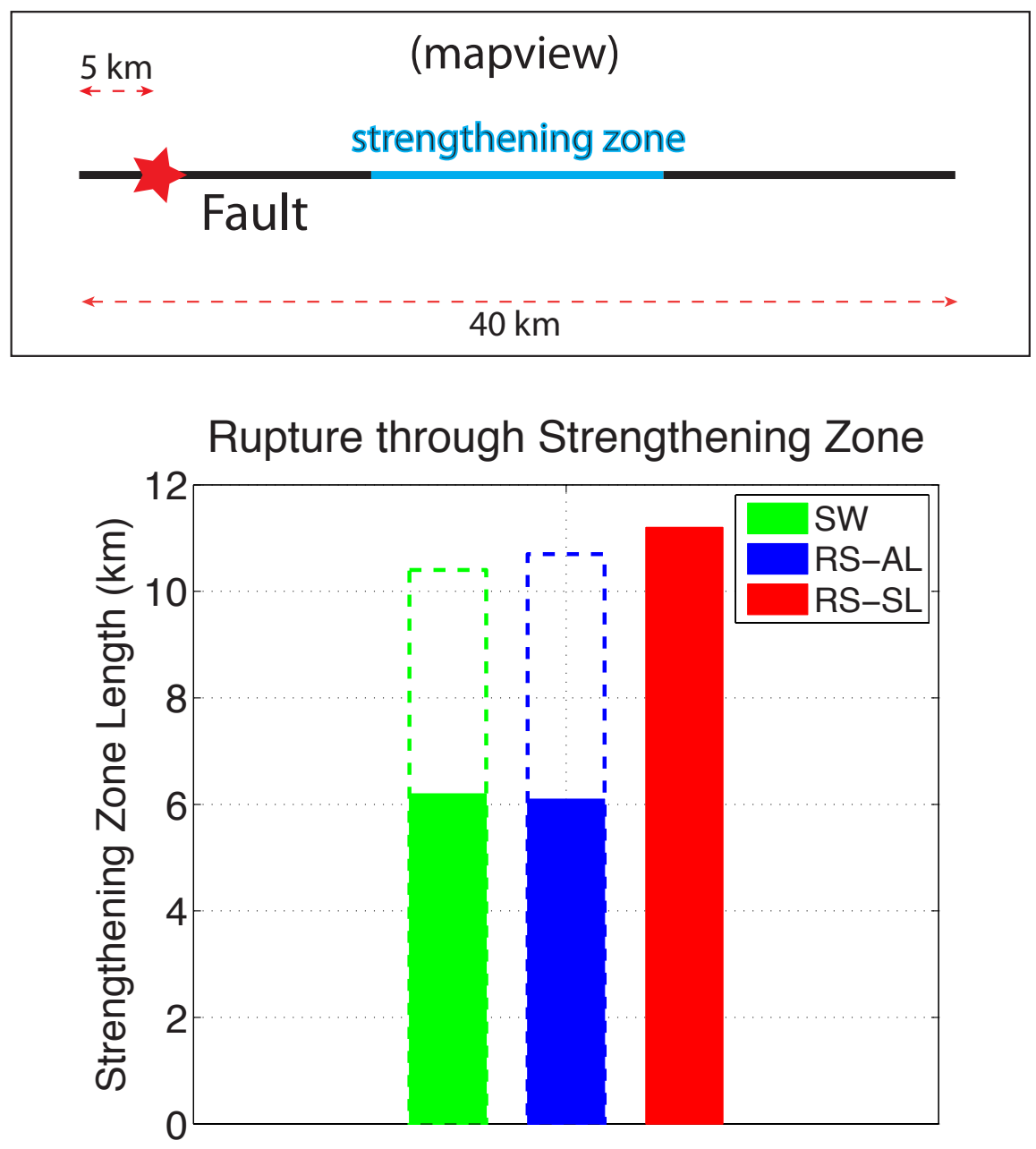

Figure 6. Rupture tunneling through a strengthening zone. Top: Map view of a frictional-strengthening zone modeled in the middle of a homogeneous, planar, 2-D fault in a whole space using slip-weakening (SW), ratestate ageing law (RS-AL), and rate-state slip law (RS-SL) friction parameterizations in finite element code FaultMod. The red star denotes the nucleation zone ( $1.5 \mathrm{~km}$ radius). We increase the size of the strengthening zone, for each friction formulation, until rupture cannot tunnel through the entire strengthening zone. Bottom: Bar graph showing that SW (green) and RS-AL (blue) models tunnel through similar maximum-sized strengthening zones with equivalent slip-weakening distances (solid bars), while SW (green), RS-AL (blue), and RS-SL (red) models tunnel through similar maximum-sized strengthening zones with equivalent fracture energy (dashed bars). For our models, the condition for strengthening using slip-weakening friction is equation 8.

The criterion for linear slip-weakening friction is as follows (Ida, 1972):

$$
\mu= \begin{cases}\frac{\mu_{d}-\mu_{s}}{d_{o}} d \delta+\mu_{s}, & d \delta<d_{o} \\ \mu_{d}, & d \delta \geq d_{o}\end{cases}
$$

where the friction coefficient $\mu$ drops from a static value to a dynamic value over a slip-weakening distance $d_{0}$. 
Following Barall (2009), we use a modified form of the bracketed term in equation 1 that does not become singular for very small slip velocities:

$$
\mu=\arcsin h\left\lfloor\frac{V}{2 V_{o}} \exp \left(\frac{\mu_{o}+\psi}{a}\right)\right\rfloor \approx \mu_{o}+a \ln \left(\frac{V}{V_{o}}\right)+\psi
$$

This form of the RS law closely approximates equation 1 for slip velocities of seismological interest. Note that the right hand side of equation 3 has the form of the effective friction coefficient in equation 1 with $\psi=b \ln \left(\theta / \theta_{0}\right)$, or conversely, $\theta=\theta_{0} \exp (\psi / b)$. Conceptually, $\psi$ represents the strength of contacts. For the RS-AL, the state variable evolves according to the equation:

$$
\frac{d \theta}{d t}=\frac{-1}{\theta_{s s}}\left(\theta-\theta_{s s}\right)
$$

In the RS-SL, the state variable evolves according to the equation:

$$
\frac{d \psi}{d t}=\frac{-V}{L}\left(\psi-\psi_{s s}\right)
$$

Both the RS-AL (equation 4) and the RS-SL (equation 5) reduce to the standard formula for steady-state sliding:

$$
\psi_{s s}=-b \ln \left(\frac{V}{V_{o}}\right)
$$

Rupture is constrained to take place on a $40-\mathrm{km}$ fault (fig. 6, top). We add a frictional-strengthening zone to the center of the fault. For the rate-state simulations this is a rate-strengthening zone governed by the steady state equation:

$$
\frac{d \mu_{s s}}{d \ln V}=a-b
$$

such that when constitutive parameter $b$ is larger than constitutive parameter $a$, the steady state friction value decreases as velocity increases, and thus this represents a velocity-weakening zone. However, when constitutive parameter $b$ is smaller than constitutive parameter $a$, the steady state friction value increases with increasing velocity, and this represents a velocity-strengthening zone. Dieterich (1978, 1979) experimentally determined a and $b$ values to be on the order of 0.01 ; we use values of 0.008 and 0.012 for parameters $a$ and $b$, respectively, to simulate rate-weakening. We use values of 0.016 and 0.012 for parameters $a$ and $b$, respectively, to represent a region of rate-strengthening. The length of strengthening zone is variable and allows us to determine the maximum length of strengthening zone that rupture can tunnel through for each of the three friction laws. We find that the friction coefficients in linear slip-weakening (SW) friction can be tuned to match the rate-state models, so that each friction law tunnels through a similar-sized strengthening zone. Specifically, by analyzing stress-versus-slip weakening curves for the rate-state models within the rate-strengthening zones and within the rateweakening zones (black segments in figure 6), we tune $\mu$ s and $\mu \mathrm{d}$ so that the three friction laws have similar weakening curves. For equivalent slip-weakening distances, both SW friction and RS-AL models can tunnel through similar-sized strengthening zone lengths (fig. 6, bottom) and result in similar slip distributions. We note that the relatively nonlinear RS-SL tunnels though larger strengthening zones but that, with equivalent fracture energy (Andrews, 1976; Guatteri and Spudich, 2000), all three models 
tunnel through similar-sized zones and result in similar slip distributions. The general equation required by $\mathrm{SW}$ friction to match RS formulations in the strengthening zone is:

$$
\tau_{o}<\mu_{d} \sigma_{o}
$$

where $\tau_{\mathrm{o}}$ is the initial shear stress, $\mu_{d}$ is the dynamic friction coefficient, and $\sigma_{\mathrm{o}}$ is the initial normal stress. Thus, we have found a useful approximation for rate-strengthening friction using a simpler slipweakening formulation. Note that this not the same as slip-hardening, which requires the dynamic friction coefficient to be larger than the static friction coefficient. In this study, we simulate ratestrengthening behavior by altering $\mu_{\mathrm{d}}$ within the strengthening zones. Under our configuration, shear stress will ultimately increase with slip, assuming no normal stress change. However, dip-slip faults involve dynamic normal stress fluctuations, including reductions that could result in a shear stress drop even in the presence of rate-strengthening.

\section{Method Part 2}

In this study we use the 3-D finite element method (FEM) code EQDyna (Duan and Oglesby, 2006) to model mode II dynamic rupture, with a frictional interface along a megathrust intersecting the free surface (fig. 7, top), and the corresponding free surface deformation. Rupture is constrained to take place only on the fault. The megathrust is $358 \mathrm{~km}$ along strike, $205.1 \mathrm{~km}$ downdip, and $35.6 \mathrm{~km}$ in depth, with a constant dip angle of $10^{\circ}$ (as determined by the Earthquake Source working group in the SAFRR scenario). EQDyna also has been validated in SCEC/USGS rupture benchmark problems (Harris and others, 2009, 2011). The code incorporates artificial damping (Duan and Day, 2008) to help reduce spurious oscillations. Additionally, we implement a large enough buffer around the fault so that a P-wave cannot travel to the edge of the model and back to the fault within the model duration, 200 seconds. We consider fault ruptures with model and material properties given in tables 1 and 2 .

We note that the nucleation zone (shown as a red star in figure 8) used in all models in this study has a radius of $16 \mathrm{~km}$ (as indicated by table 1). The nucleation zone is small relative to the size of the modeled megathrust and does not significantly affect the overall slip distribution in our models; for example, there are no obvious asymmetric slip patterns (for example, large amount of slip) near or around the nucleation zone in figure 11. Additionally, we implement a finite element size of approximately $2 \mathrm{~km}$ along the modeled fault. Decreasing the element size for our full model is not possible because of computational limitations. However, we have tested smaller fault models $(34 \mathrm{~km}$ along strike and $20 \mathrm{~km}$ downdip) — with the same homogeneous input parameters used in this study - to determine whether our results are grid dependent. We found similar slip distributions, slip rates, and rupture velocities for these smaller earthquake models using $0.5-\mathrm{km}, 1-\mathrm{km}, 1.5-\mathrm{km}$, and $2-\mathrm{km}$ element sizes. We therefore believe that a $2-\mathrm{km}$ element size is reasonable and appropriate in this study of a much larger modeled fault, although we cannot directly test this. 


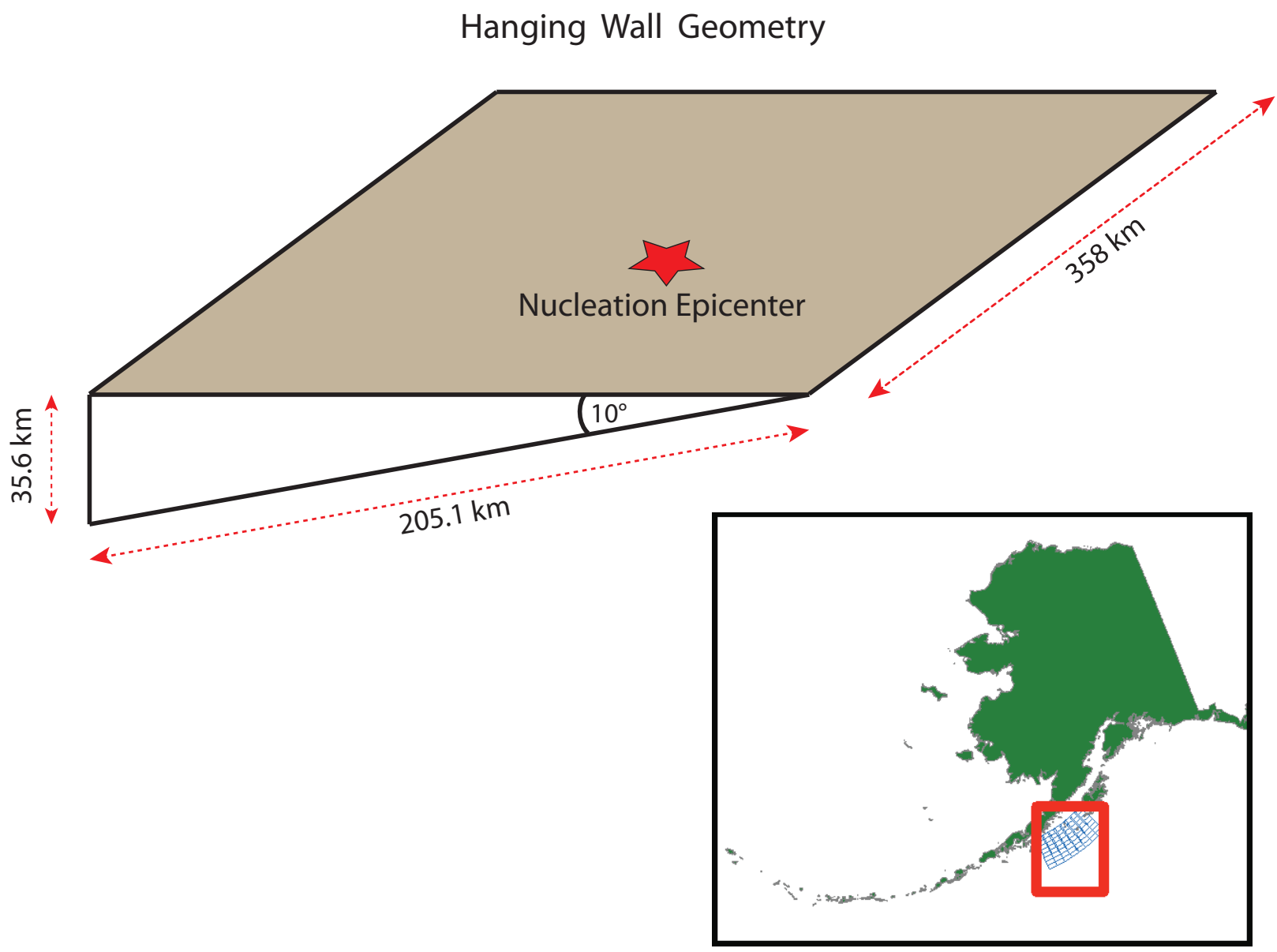

Figure 7. Model approximation to a section of the Alaska-Aleutian megathrust. Top: Cartoon block diagram of fault geometry of the hanging wall using 3-D finite element code EQDyna (Duan and Oglesby, 2006). We use a planar fault geometry with a constant dip of 10o, an along-strike distance of $358 \mathrm{~km}$, a depth of $35.6 \mathrm{~km}$, and a downdip distance of $205.1 \mathrm{~km}$. The fault intersects the free surface. Each element along the fault surface is approximately $2 \mathrm{~km}$ along strike and $2 \mathrm{~km}$ downdip. Additionally, we implement a buffer zone around the fault to ensure waves do not reflect off the model boundary and return to the fault. Bottom: Map showing geographic region of interest with the section of the Alaska-Aleutian megathrust we are approximating (image from Earthquake Source working group in the SAFRR scenario) 
Table 1. Model and material properties for all simulations in this study. [km, kilometer; m, meter; GPa, gigapascal; s, second]

\begin{tabular}{l|l}
\hline Density & $2670 \mathrm{~kg} / \mathrm{m}^{3}$ \\
Shear Modulus & $40.00 \mathrm{GPa}$ \\
Bulk Modulus & $66.67 \mathrm{GPa}$ \\
S-wave speed & $3.871 \mathrm{~km} / \mathrm{s}$ \\
P-wave speed & $6.704 \mathrm{~km} / \mathrm{s}$ \\
Fault Area & $73,426 \mathrm{~km}$ \\
Nucleation Depth & $15.50 \mathrm{~km}$ \\
Nucleation Radius & $16.00 \mathrm{~km}$ \\
Nucleation Speed & $2.000 \mathrm{~km} / \mathrm{s}$ \\
Nucleation Location (along strike) & $22.38 \mathrm{~km}$ \\
Nucleation Location (downdip) & $-89.26 \mathrm{~km}$ \\
Element Size (along fault) & $\approx 2 \mathrm{~km}$ \\
Time Step & $0.01 \mathrm{~s}$ \\
Distance Along-Strike & $358.0 \mathrm{~km}$ \\
Distance Downdip & $205.1 \mathrm{~km}$ \\
Dip Angle & $10^{\circ}$ \\
$t_{\mathrm{o}}$ & $2.600 \mathrm{~s}$ \\
Hydrodynamic Grid Size & $2 \mathrm{~km}$ \\
Hydrodynamic Time Step & $0.1 \mathrm{~s}$ \\
\hline
\end{tabular}

Table 2. Initial shear stress $\tau_{0}$, initial normal stress $\sigma_{0}$, the static friction coefficient $\mu_{s}$, the dynamic friction coefficient $\mu_{d}$, and the strengthening friction coefficient $\mu_{d}$ (strength) (if applicable) for all four models in this study.

[MPA, megapascals]

\begin{tabular}{cccccc} 
& $\tau_{\circ}[\mathrm{MPa}]$ & $\sigma_{\circ}[\mathrm{MPa}]$ & $\boldsymbol{\mu}_{\boldsymbol{s}}$ & $\boldsymbol{\mu}_{\boldsymbol{d}}$ & $\boldsymbol{\mu}_{\boldsymbol{d}}(\mathbf{s t r e n g t h})$ \\
\hline Homogeneous Prestress/Friction & 3.172 & 11.06 & 0.5630 & 0.1333 & \\
West Frictional-strengthening & 3.172 & 11.06 & 0.5630 & 0.1333 & 0.3218 \\
Updip Frictional-strengthening & 3.172 & 11.06 & 0.5630 & 0.1333 & 0.3218 \\
Heterogeneous Prestress & $0-24.26$ & $1.090-84.60$ & 0.5630 & 0.1333 &
\end{tabular}

For simplicity we use a homogeneous material structure with average midcrustal material properties (see, for example, Harris and others, 2009), although future models may incorporate 3-D material structure heterogeneity. We use a time-weakening friction law (Andrews, 2004; Duan and Day, 2008), in which the stress at a point drops from its static to sliding frictional level over a characteristic time. This friction law produces behavior similar to that of slip-weakening friction, with an effective slip-weakening distance $d_{\mathrm{o}}$ that is proportional to the square root of rupture velocity multiplied by the distance rupture has propagated:

$$
d_{o} \propto \frac{\Delta \tau}{G} \sqrt{\frac{V_{r u p t} t_{o} L}{k}}
$$

where $\Delta \tau$ is the stress drop, $G$ is the shear modulus, $V_{\text {rupt }}$ is the rupture velocity, $t_{\mathrm{o}}$ is the time over which the friction coefficient drops from its static value to its dynamic value, $L$ is the distance rupture has 
propagated, and the value of $k$ depends on the shape of the stress-slip weakening curve. As recommended by Andrews (2004), we use a time-weakening value $t_{\mathrm{o}}$ that is the amount of time it would take for an S-wave to traverse more than three elements (we use five elements) along the fault interface. This parameterization allows us to achieve accuracy and smoothness of the breakdown zone as the rupture front increases in speed and amplitude away from the nucleation zone. As noted above, the computer code EQDyna does not incorporate rate- and state-dependent friction, so we use timeweakening friction with equation 8 as a proxy for rate-strengthening-like zones.

In this study we use four different rupture models: a spatially constant prestress and frictional coefficient model (hereinafter referred to as the homogeneous model), two models with frictionalstrengthening zones, and a spatially heterogeneous prestress model. For frictional-strengthening zone models, we use equation 8 with time-weakening friction to simulate rate-strengthening-like zones on updip and along-strike portions of the megathrust (fig. 8; see table 2 for friction coefficients). Specifically, we implement frictional-strengthening zones in either the westernmost portion of the fault (100 km to $179 \mathrm{~km}$ along strike) or the most updip portion of the fault ( $0 \mathrm{~km}$ to $-50 \mathrm{~km}$ downdip). As an example of how time-weakening in these models corresponds to either rate-weakening or ratestrengthening, figure 9 shows stress-slip weakening curves for a point in a frictional-weakening zone and a point in a frictional-strengthening zone for the western frictional-strengthening zone model (locations marked in figure 13). There is a clear stress drop from the initial stress in the weakening zone and a stress increase in the strengthening zone. However, we note that a stress increase is not required for all points in our frictional-strengthening zone, because large dynamic reductions in normal stress can still result in a shear stress drop during sliding. For the heterogeneous prestress model, we divide the fault into 64 subfault sections, each section with a different prestress. The objective of this model is to qualitatively match the slip distribution used by the Earthquake Source working group within the SAFRR Tsunami Scenario team (Kirby and others, 2013). Previous studies show that scaling the prestress distribution in dynamic earthquake models is one way to match observed slip distributions (for example, Olsen and others, 1997; Olsen and others, 2009). 

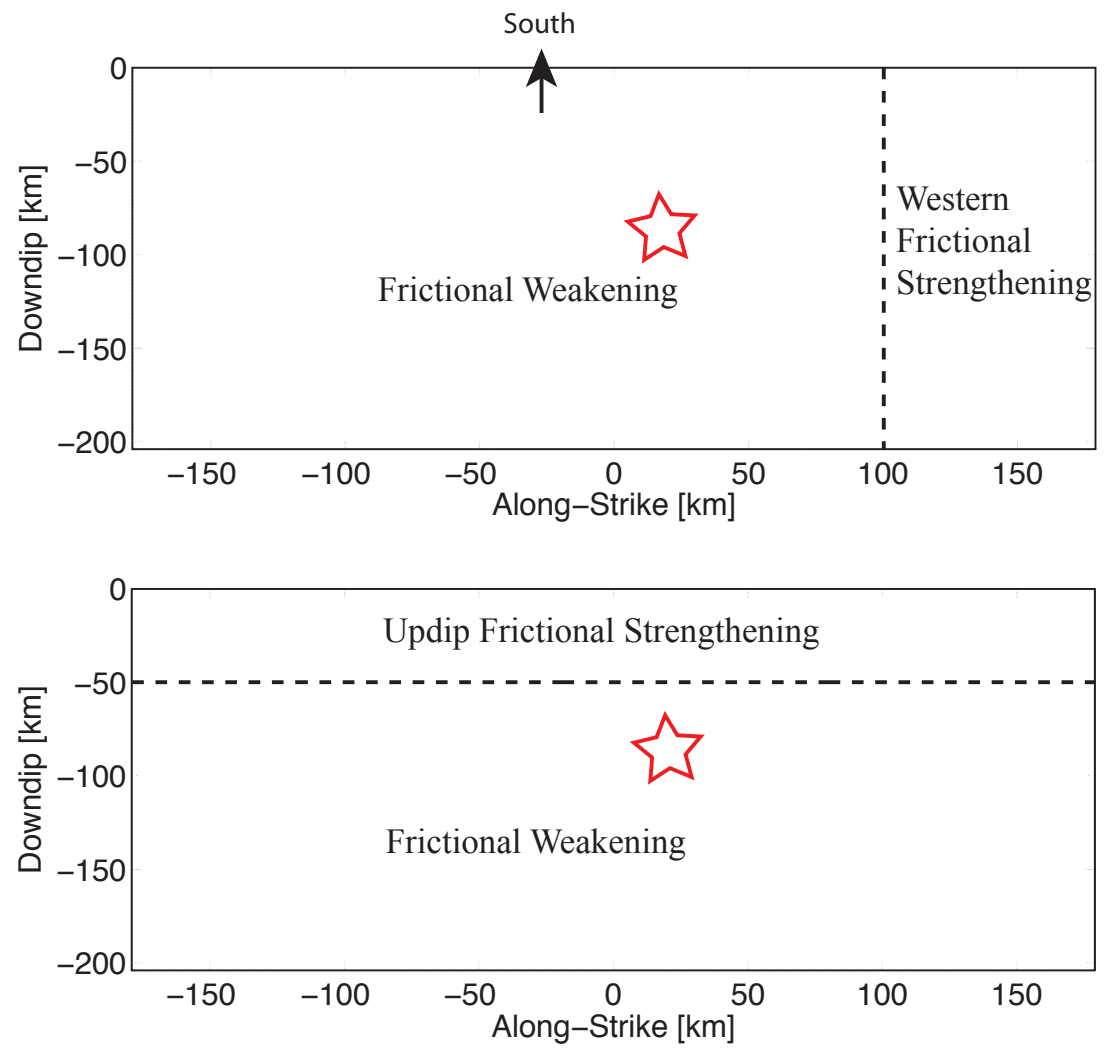

Figure 8. Cross-sectional diagrams illustrating two models with frictional-strengthening zones in (top) the westernmost portion and (bottom) the most up-dip portion of the fault. Note that the point of view is from above the hanging wall, perpendicular to the fault surface. Stars indicate the nucleation zone, which is at the same location for all models. The strengthening areas are 16,203 km2 and 17,900 km2 for the top and bottom models, respectively. See table 2 for frictional coefficients.
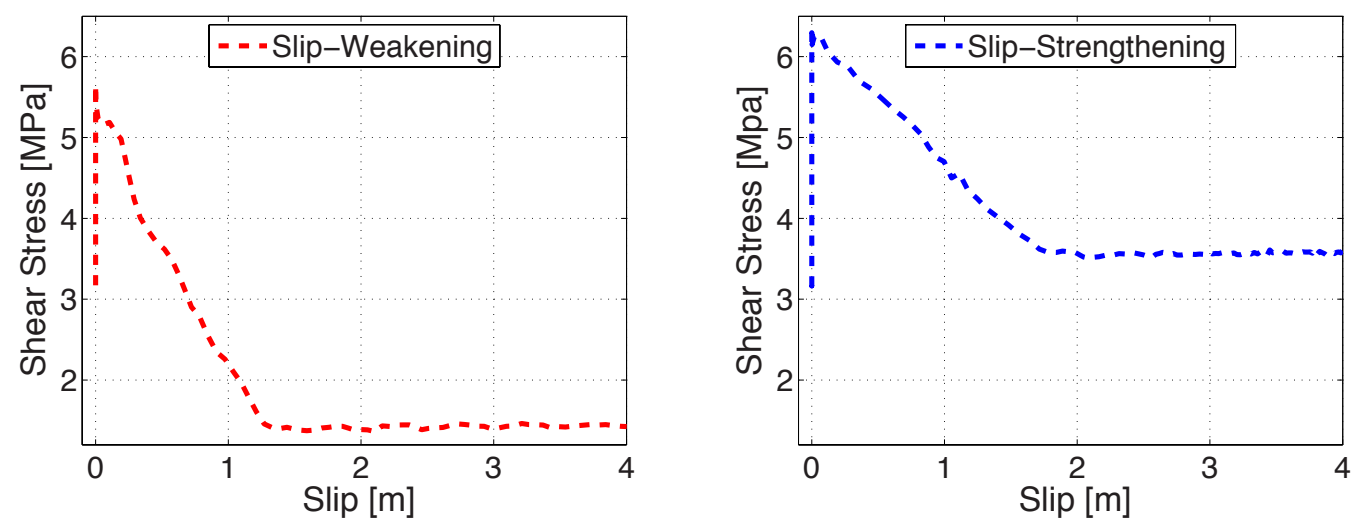

Figure 9. Graphs of shear stress versus slip for a point in the weakening zone (red, left) and a point in the strengthening zone (blue, right), using time-weakening friction to model a 3-D megathrust earthquake within the Alaskan-Aleutian subduction zone. Point locations are marked by red and blue stars in figure 13 (3rd panel down). Results show a decrease in shear stress within the frictional-weakening zone, and an increase in shear stress in the frictional-strengthening zone. Note that shear stress depends on both friction coefficient and normal stress during sliding. 
A dynamic finite element code does not just produce a rupture pattern on a fault; it also produces the full wave field and surface deformation. After dynamically modeling earthquake rupture, we feed the resulting time-dependent free surface (that is, seafloor) displacements into a hydrodynamic code using a 2-D finite difference method to solve linear long wave equations (Shuto, 1991; Satake, 2002). In this way, we can model the generation of a tsunami from our dynamic earthquake models. Specifically, time dependent 3-D sea-floor deformation from our earthquake models are used as a time-dependent boundary condition for our hydrodynamic models, assuming that the water surface is displaced by the combined effects from vertical and horizontal sea-floor displacement (Tanioka and Satake, 1996). The leap-frog, finite-difference method of computing of tsunami propagation, described by Satake (2007), is used with the ETOPO1 digital elevation model (http://www.ngdc.noaa.gov/mgg/global/global.html). Incorporation of both dynamic codes allows us to simulate tsunami formation and local propagation in time. Hydrodynamic model parameters are given in table 1.

\section{Results}

In this study we focus on rupture dynamics, fault slip distribution, free surface deformation, and the resulting tsunami for four different models: a homogeneous set of prestress and frictional conditions, a western frictional-strengthening zone, an updip frictional-strengthening zone, and a heterogeneous prestress condition (figs. 8 through 22). Both the homogeneous and heterogeneous prestress models match the seismic moment of the dislocation model determined by the Earthquake Source working group within the SAFRR Tsunami Scenario team. For each model, differences in the rupture dynamics ultimately result in different tsunami formations, local maximum water wave amplitudes, and tsunami beaming patterns. We note two key parameters for each model: the maximum vertical free surface displacement $Z_{\max }$ and the average fault slip $<S>$ (table 3), which affect maximum tsunami height and the initial tsunami height distribution.

Table 3. Maximum vertical free-surface displacements $Z_{\max }$ and average fault slip $\langle S\rangle$ for all four models in this study.

\begin{tabular}{ccc}
\hline Model & $\boldsymbol{Z}_{\max }[\mathbf{m}]$ & $<\boldsymbol{S}[\mathbf{m}]$ \\
\hline Homogeneous Prestress/Friction & 5.77 & 18.6 \\
West Frictional-strengthening & 5.74 & 14.6 \\
Updip Frictional-strengthening & 2.86 & 10.4 \\
Heterogeneous Prestress & 7.04 & 18.6 \\
\hline
\end{tabular}

\section{Homogeneous Stress and Friction}

Figure 10 shows slip-rate snapshots of the homogeneous earthquake rupture at $27 \mathrm{~s}, 52 \mathrm{~s}$, and 70 $\mathrm{s}$ into the simulation. The fault experiences large slip rate pulses near the free surface due to dynamic unclamping of the fault and geometric asymmetry of the hanging wall/footwall (Brune, 1996; Nielsen, 1998; Oglesby and others, 1998; Oglesby and Archuleta, 2000; Oglesby and others, 2000), resulting in a strong breakout phase and the generation of an oceanic Rayleigh wave. Rupture proceeds over the entire fault zone. Fault slip and total vertical free surface deformation for the homogeneous model are shown in figure 11. The largest amount of slip is near the surface, corresponding to large vertical displacement 
on the surface near the fault trace. Average fault slip is $18.6 \mathrm{~m}$, and maximum vertical surface displacement is $5.77 \mathrm{~m}$. Figure 12 displays local peak tsunami amplitude, resulting from the homogeneous earthquake rupture model, in the geographic region of interest. Water height corresponds well with free surface deformation, and the largest tsunami amplitudes are located closest to the trench. In the model, the Shumagin Islands, Alaska Peninsula, and Kodiak Island are hit with particularly large wave heights from the local tsunami. The tsunami amplitude has a strong southward beaming effect, indicating potential damage to coastlines in Hawaii and the western United States as well as other coastlines around the Pacific rim in the simulation.

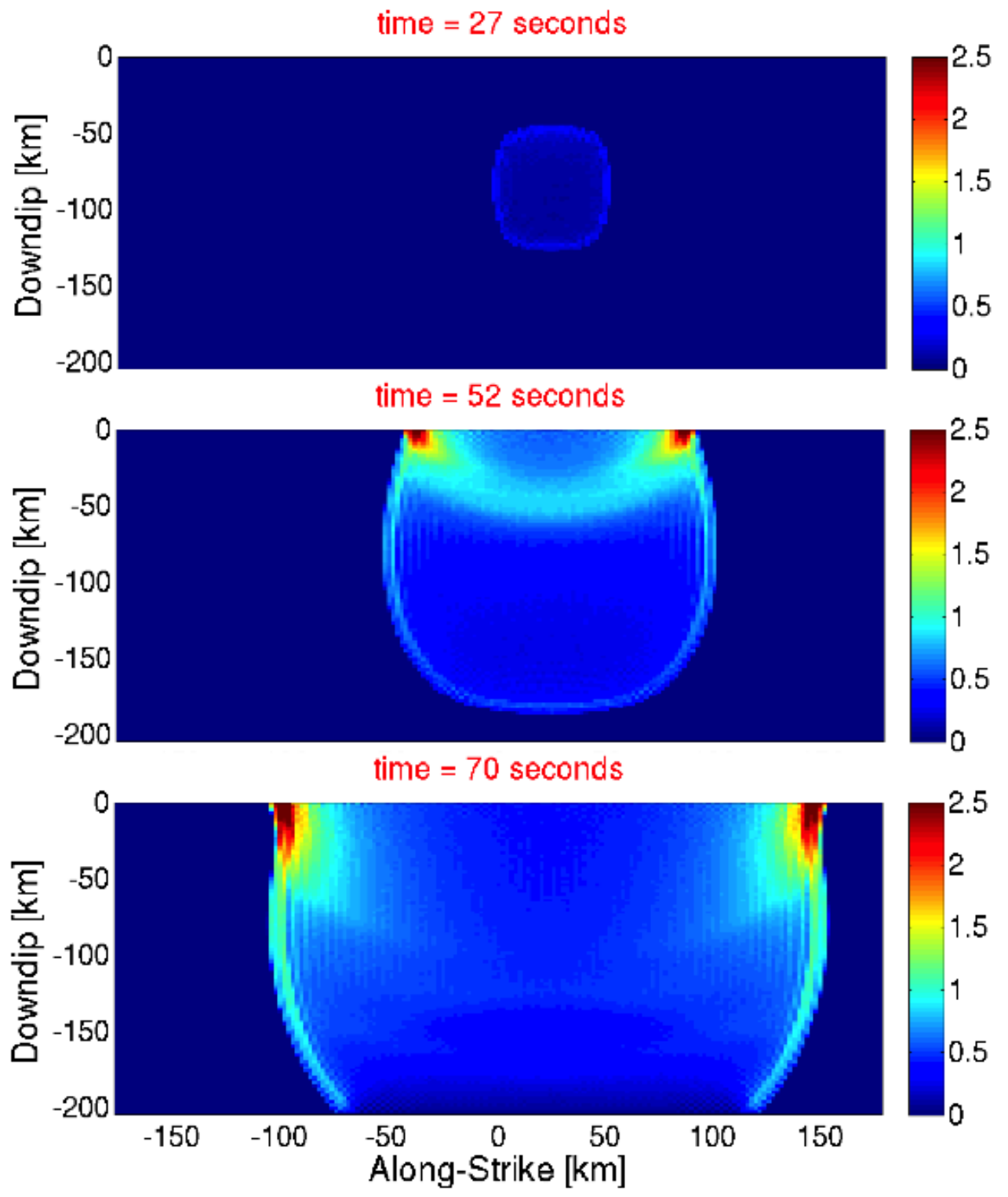

Figure 10. Diagrammatic views of the fault surface showing snapshots of rupture propagation at 27, 512, and $70 \mathrm{~s}$ for a homogeneous model (spatially constant prestress, dip angle, and frictional coefficients). Colors represent slip rate in $\mathrm{m} / \mathrm{s}$. Rupture shows large slip rate pulses nearest the free surface. Rupture proceeds over the entire fault zone (entire region shown), beginning at the nucleation zone (indicated in figure 8). 

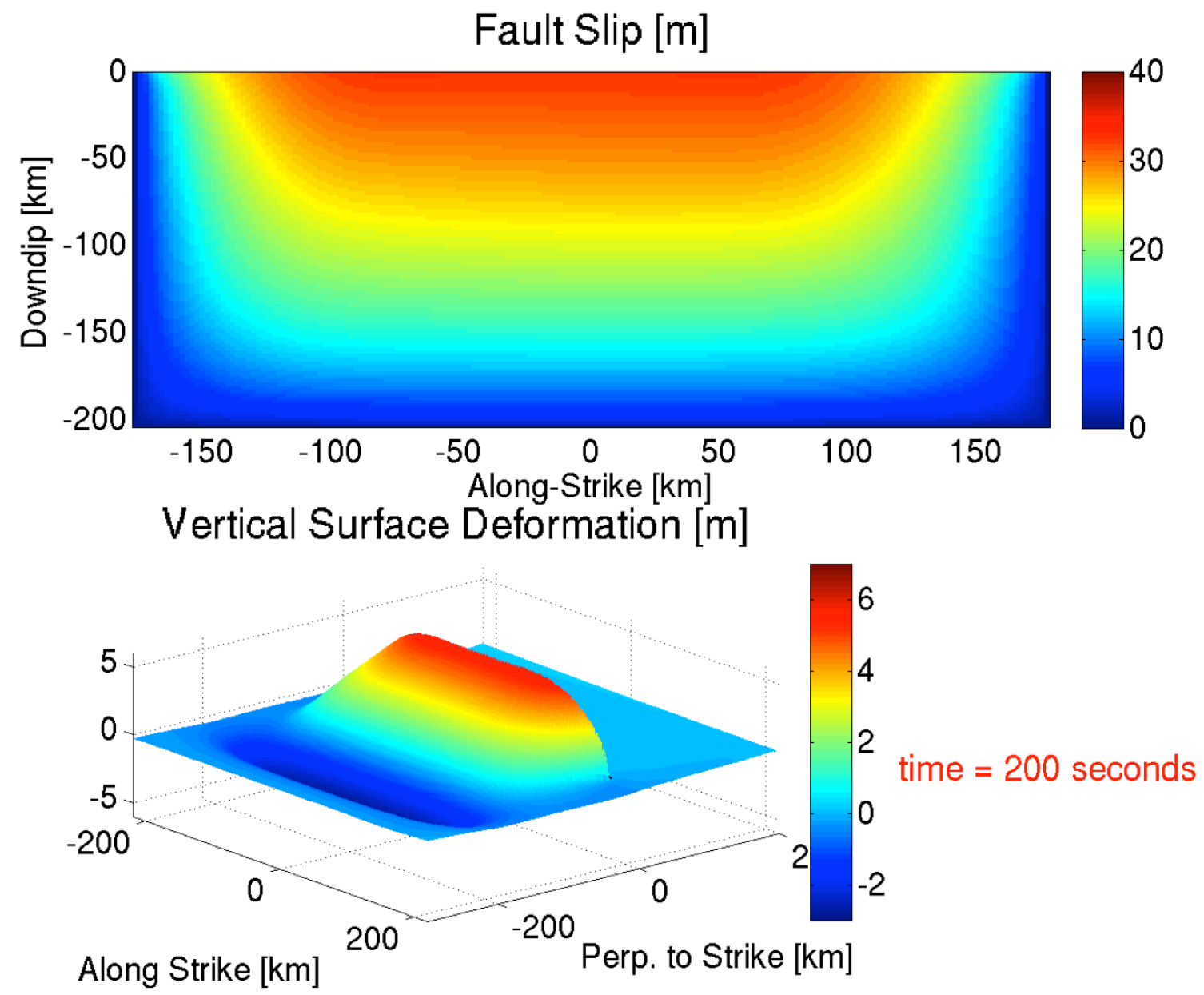

Figure 11. Diagrams showing fault slip (top) and total vertical free surface deformation (bottom) for the homogeneous model. The largest amount of slip is near the surface, corresponding to large vertical displacement on the surface near the fault trace. Average fault slip is $18.6 \mathrm{~m}$, and maximum vertical surface displacement is $5.77 \mathrm{~m}$. 

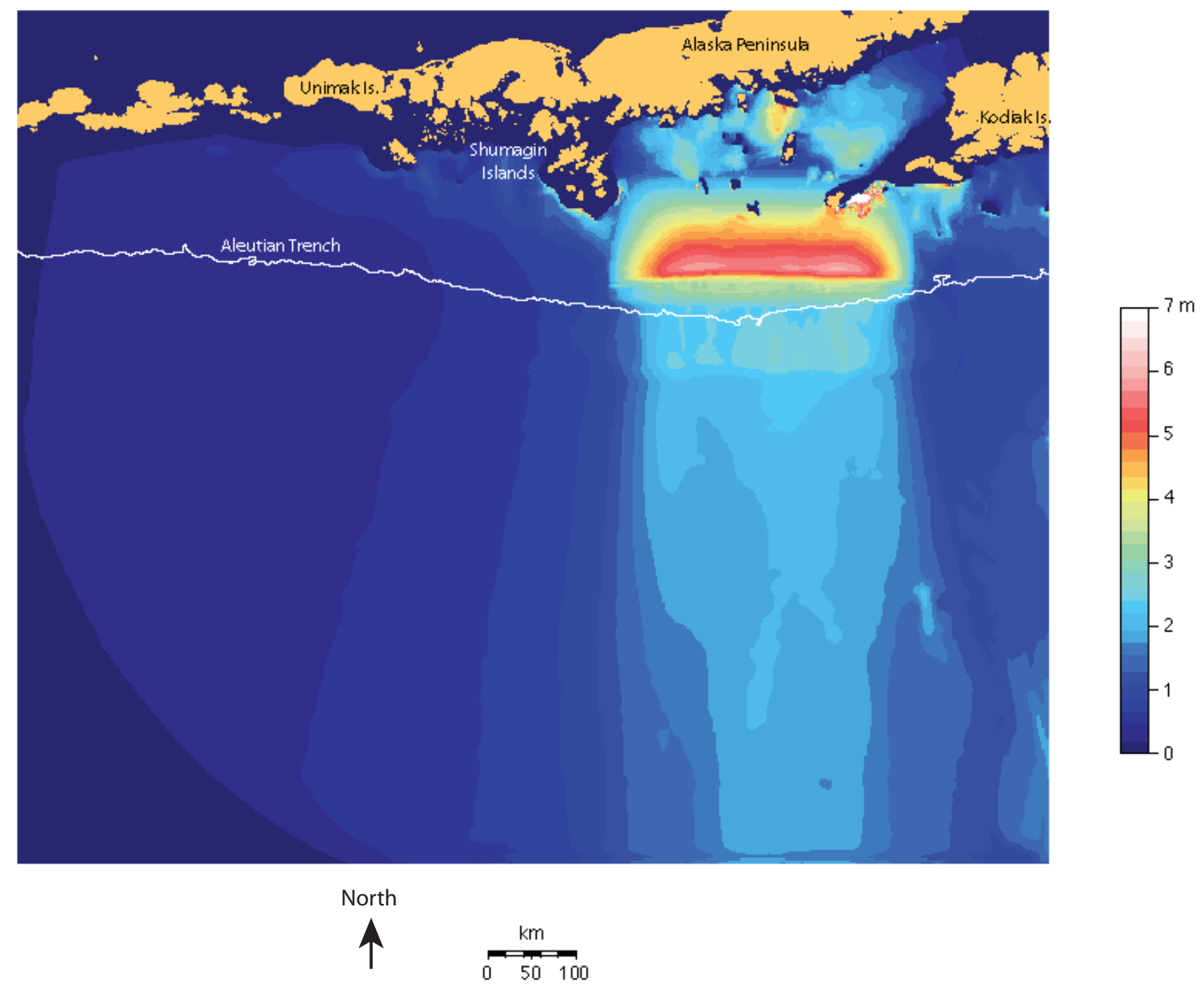

Figure 12. Map showing peak tsunami amplitudes (color scale in $\mathrm{m}$ ) resulting from the homogeneous earthquake rupture model in the geographic region of interest. The white line represents the Aleutian Trench. Water height corresponds well with free surface deformation (fig. 11, bottom). The Shumagin Islands, Alaska Peninsula, and Kodiak Island are struck with particularly large water height from the local tsunami. Additionally, the tsunami amplitude has a strong southward beaming effect.

\section{Western Frictional-Strengthening Zone Rupture}

The homogeneous model discussed above assumes homogeneous frictional conditions along the entire extent of the fault. Realistically, however, faults are likely heterogeneous in frictional properties as well as in their initial stress conditions. GPS data show an unlocked section of the fault bordering our study area to the west (Freymueller and Beavan, 1999; Freymueller and others, 2008). In an effort to incorporate a more realistic frictional regime, we implement a frictional-strengthening zone in the westernmost $79 \mathrm{~km}$ of the megathrust (fig. 8, top). Figure 13 shows slip-rate snapshots of rupture propagation for a model with such a western frictional-strengthening zone. This model shows large slip rate pulses nearest the free surface as in the homogeneous model; however, the strengthening zone diminishes the slip rate pulse significantly relative to the homogeneous model. Note the difference in 
slip rates in the two models at 70 seconds. Rupture proceeds over the entire fault, including through the strengthening zone. The largest slip in the strengthening zone occurs near the free surface, most likely because of dynamic unclamping and the geometric asymmetry near the free surface. We note that the extent that rupture can penetrate a frictional-strengthening zone depends on fault geometry, friction coefficients, initial stress regimes, and location of the nucleation zone. While a strengthening zone in principle releases no seismic energy, slip can still occur, and is driven by seismic energy released on other (weakening) parts of the fault. Figure 14 illustrates fault slip and total vertical free surface deformation for the western frictional-strengthening zone model. Average fault slip is decreased by $4 \mathrm{~m}$ (18.6 to $14.6 \mathrm{~m}$ ), relative to the homogeneous model. Surface deformation is substantially decreased in the region above the strengthening zone, relative to the homogeneous model; however, the maximum vertical surface displacement is decreased only marginally (from 5.77 to $5.74 \mathrm{~m}$ ). The local peak modeled tsunami amplitudes resulting from the western frictional-strengthening zone model are shown in figure 15. Water height corresponds well with vertical free surface deformation, with the largest tsunami amplitude distributed above the frictional-weakening zone. Converting a western portion of the fault to a frictional-strengthening zone greatly reduces tsunami amplitude locally north of the strengthening zone in the Shumagin Islands region of the heterogeneous model, and it redirects the beaming pattern of the basin-propagating (far-field) tsunami slightly in a counterclockwise direction, but with similar maximum amplitude, relative to the homogeneous model. 


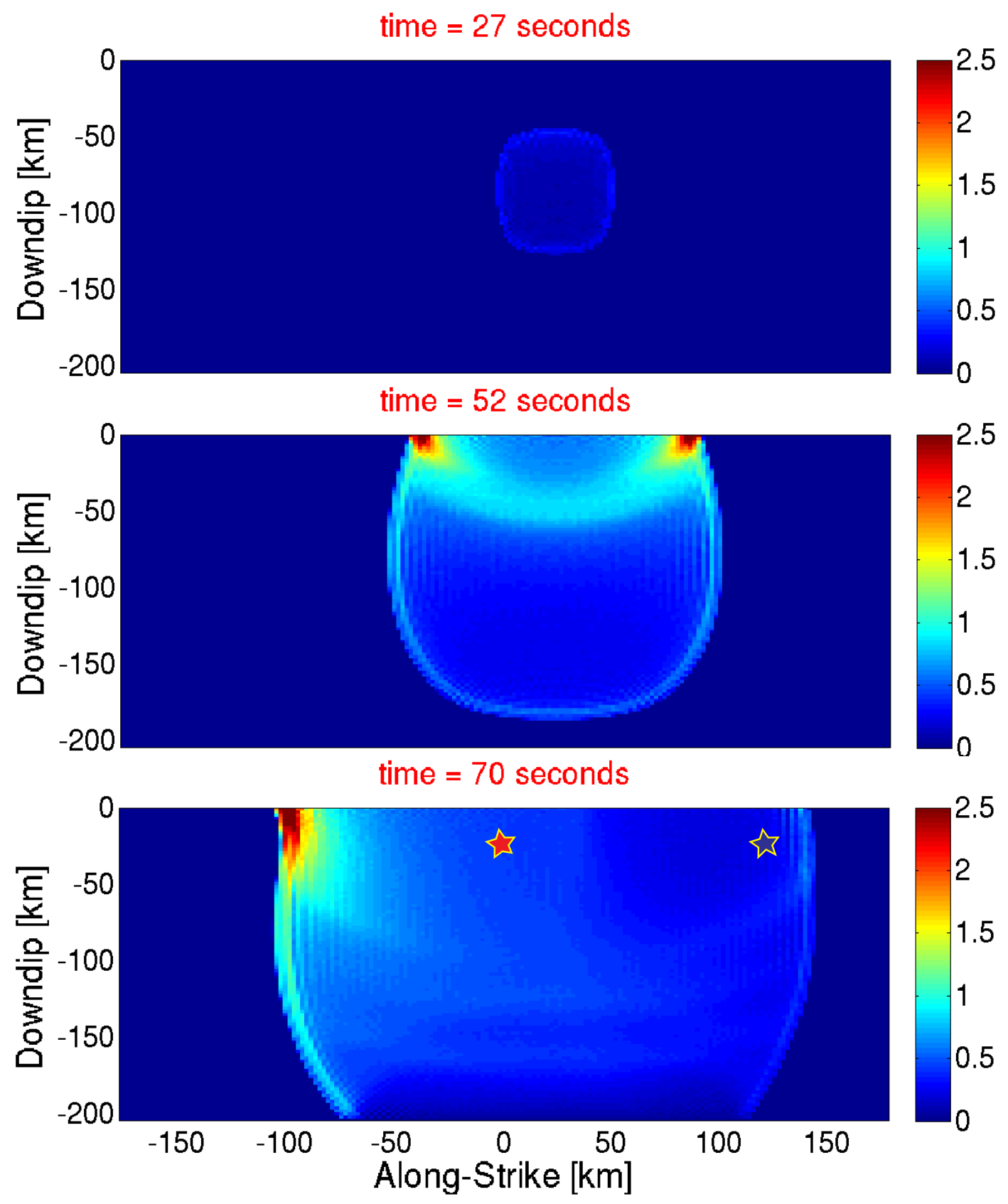

Figure 13. Diagrammatic views of the fault surface showing snapshots of rupture propagation at 27, 52 , and $70 \mathrm{~s}$ for a model with a frictional-strengthening zone from 100 to $179 \mathrm{~km}$ along-strike and over the entire downdip extent of the model (see fig. 8, top), motivated by GPS data showing an unlocked section of the fault that borders our study area to the west (Freymueller and Beavan, 1999). Colors represent slip rate in $\mathrm{m} / \mathrm{s}$. Rupture shows large slip rate pulses nearest the free surface; however, the strengthening zone diminishes the slip rate pulse substantially, relative to the homogeneous model. Note the difference in slip rate between this model and the homogeneous model at 70 seconds. Rupture proceeds over the entire strengthening zone. The red and blue stars correspond to the sampling points for the stress weakening plots in figure 9 . 

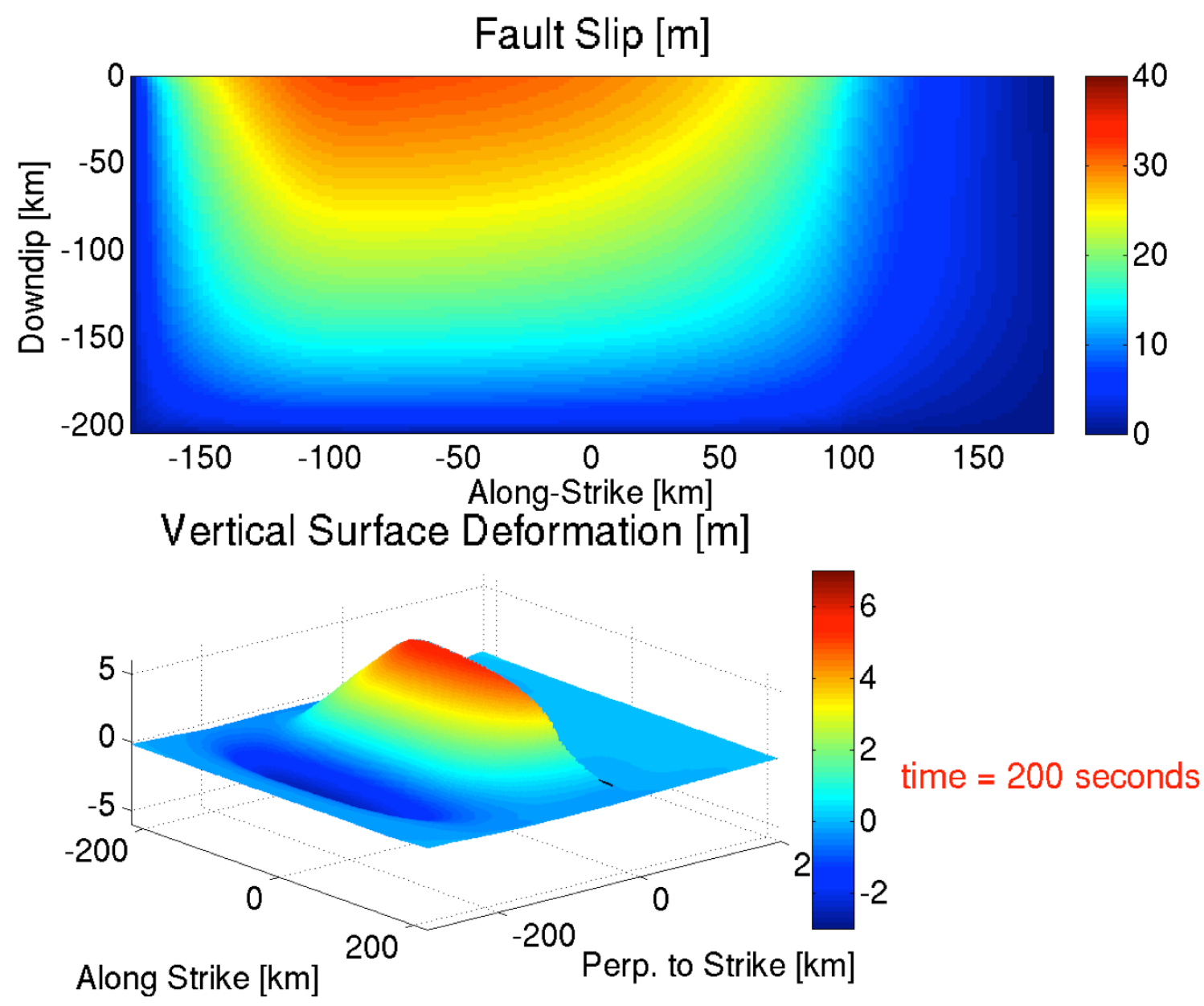

Figure 14. Diagrams showing fault slip (top) and total vertical free surface deformation (bottom) for the western frictional-strengthening zone model. Average fault slip is decreased by $4 \mathrm{~m}(18.6$ to $14.6 \mathrm{~m})$ in the strengthening model, relative to the homogeneous model. Surface deformation is substantially decreased in the region above the strengthening zone, relative to the homogeneous model; however, the maximum vertical surface displacement is decreased marginally (5.77 to $5.74 \mathrm{~m})$. 

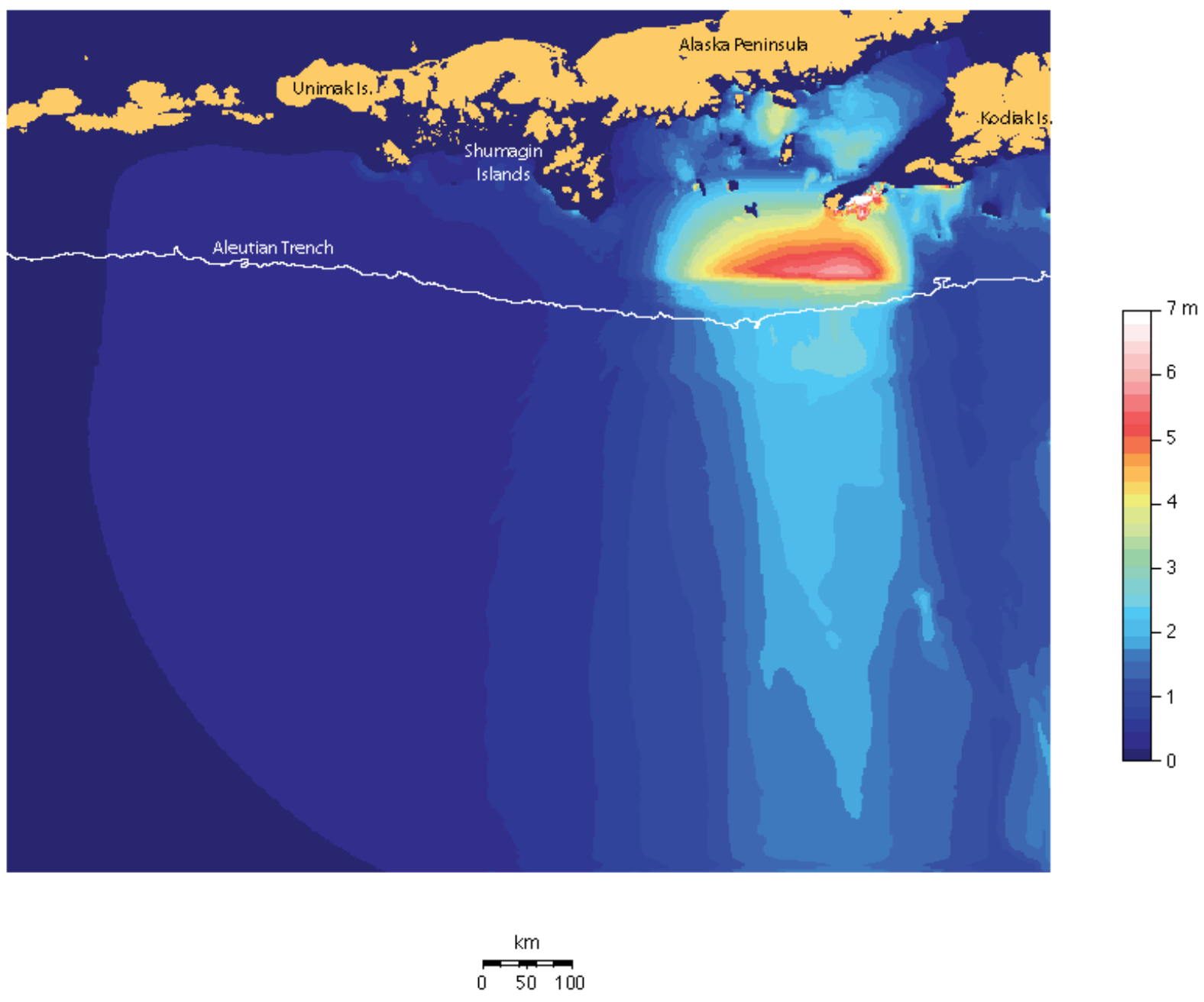

Figure 15. Map showing peak tsunami amplitudes (color scale in $\mathrm{m}$ ) resulting from the western frictionalstrengthening zone model. Water height corresponds well with free surface deformation (fig. 14, bottom). Converting a western portion of the fault to a frictional strengthening zone greatly reduces tsunami amplitudes locally above the strengthening zone in the Shumagin Islands region and alters the beaming pattern of the basin-propagating (far-field) tsunami to a more counterclockwise direction, relative to the homogeneous model. Also, peak amplitudes are reduced near the coasts of the Shumagin Islands. 


\section{Updip Frictional-Strengthening Zone Rupture}

It has been suggested that subduction zones can have frictional-strengthening regimes close to the trench due to material and frictional properties (for example, Kanamori, 1972; Hyndman and others, 1997). As a first-order effort to model such a frictional regime, we implement a frictional-strengthening zone in the most updip $50 \mathrm{~km}$ of the megathrust (fig. 8, bottom). Figure 16 shows slip-rate snapshots for this model. In contrast to the models discussed above, the fault experiences its largest slip rate pulses $\sim 100 \mathrm{~km}$ downdip from the free surface, and the slip rate pulse is dramatically reduced over the entire fault relative to the homogeneous model. Note the difference in slip rate between the homogeneous and updip frictional-strengthening models at 52 and 70 seconds. Rupture proceeds over the entire fault, including through the strengthening zone. Within the strengthening zone, the largest slip rates occur along the free surface. Figure 17 displays fault slip and total vertical free surface deformation for the updip frictional-strengthening zone model. Average fault slip is decreased by $8.2 \mathrm{~m}$ (18.6 to $10.4 \mathrm{~m})$ in the updip strengthening model, relative to the homogeneous model. Surface deformation is decreased broadly along the free surface, relative to the homogeneous model, and the maximum vertical surface displacement is decreased $(5.77$ to $2.86 \mathrm{~m})$. Adding an updip frictional-strengthening zone reduces slip across the entire fault more than a western strengthening zone with similar area and the same frictional coefficients. Local peak tsunami amplitudes resulting from the updip frictional-strengthening zone model are shown in figure 18. Water height corresponds well with vertical free surface deformation, showing a broad decrease in the local maximum tsunami height compared to the homogeneous model. Adding a strengthening zone to the updip portion of the fault greatly reduces tsunami amplitudes locally above the strengthening zone near the trench, and it reduces the maximum amplitude of the southward beam but does not change the beam direction of the far-field tsunami, relative to the homogeneous rupture. 


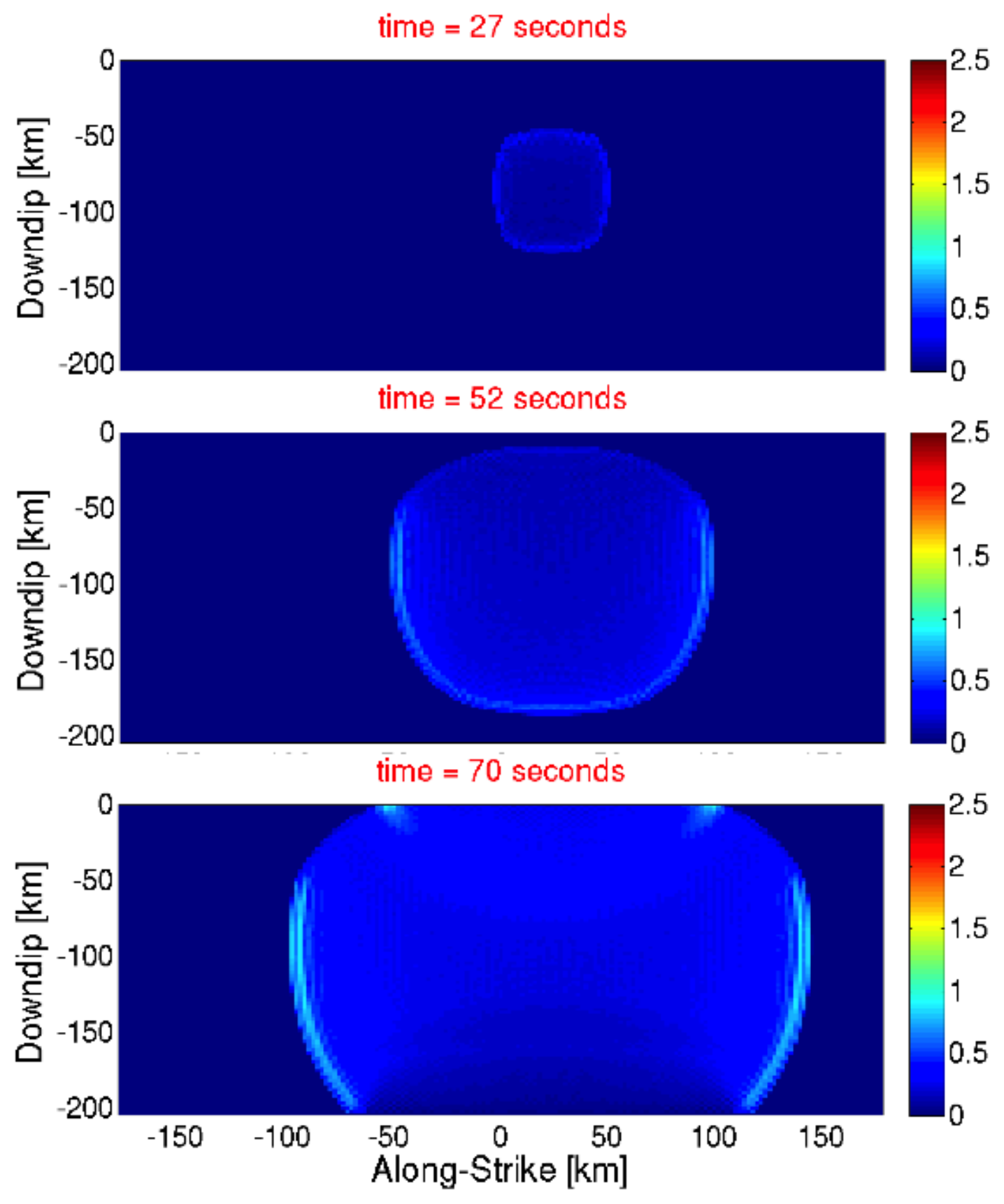

Figure 16. Diagrammatic views of the fault surface showing snapshots of rupture propagation at 27, 52 , and $70 \mathrm{~s}$ for a model with a frictional-strengthening zone from 0 to $-50 \mathrm{~km}$ downdip and across the entire along-strike extent of the model (see fig. 8, bottom). Colors represent slip rate in $\mathrm{m} / \mathrm{s}$. Rupture shows largest slip rate pulses $\sim 100 \mathrm{~km}$ downdip from the surface, and the slip rate pulse is dramatically reduced over the entire fault, relative to the homogeneous model. Note the difference in slip rate between this and the homogeneous models at 52 and 70 seconds. Rupture proceeds through the entire strengthening zone. 

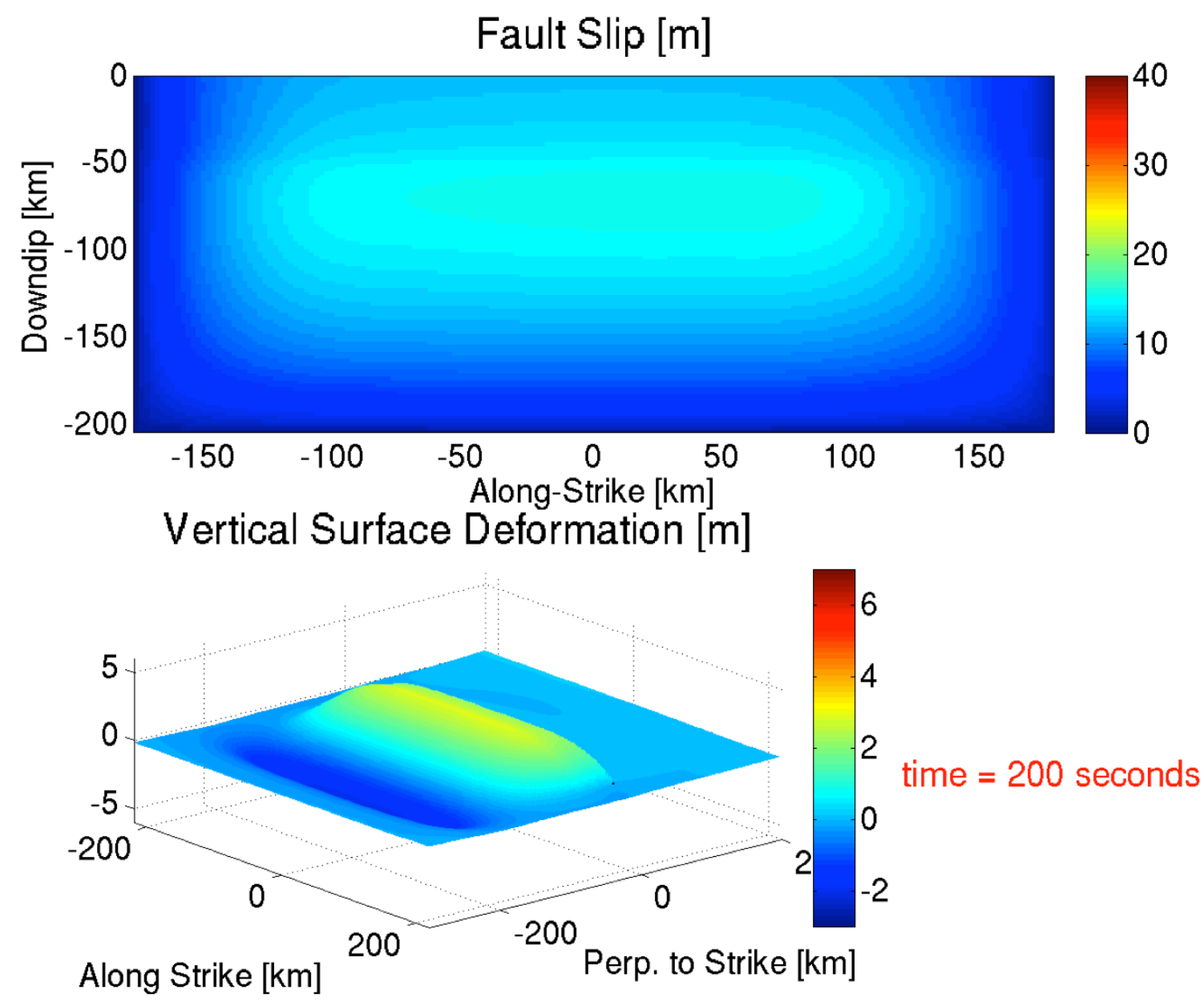

Figure 17. Diagrams showing fault slip (top) and total vertical free surface deformation (bottom) for the updip frictional-strengthening zone model. Average fault slip is decreased by $8.2 \mathrm{~m}$ (18.6 to $10.4 \mathrm{~m}$ ) in the strengthening model, relative to the homogeneous model. Surface deformation is decreased broadly along the free surface, relative to the homogeneous model, and the maximum vertical surface displacement is significantly decreased (5.77 to $2.86 \mathrm{~m}$ ). Note that adding an updip strengthening zone reduces slip across the entire fault-much more so than a western strengthening zone with similar area. 

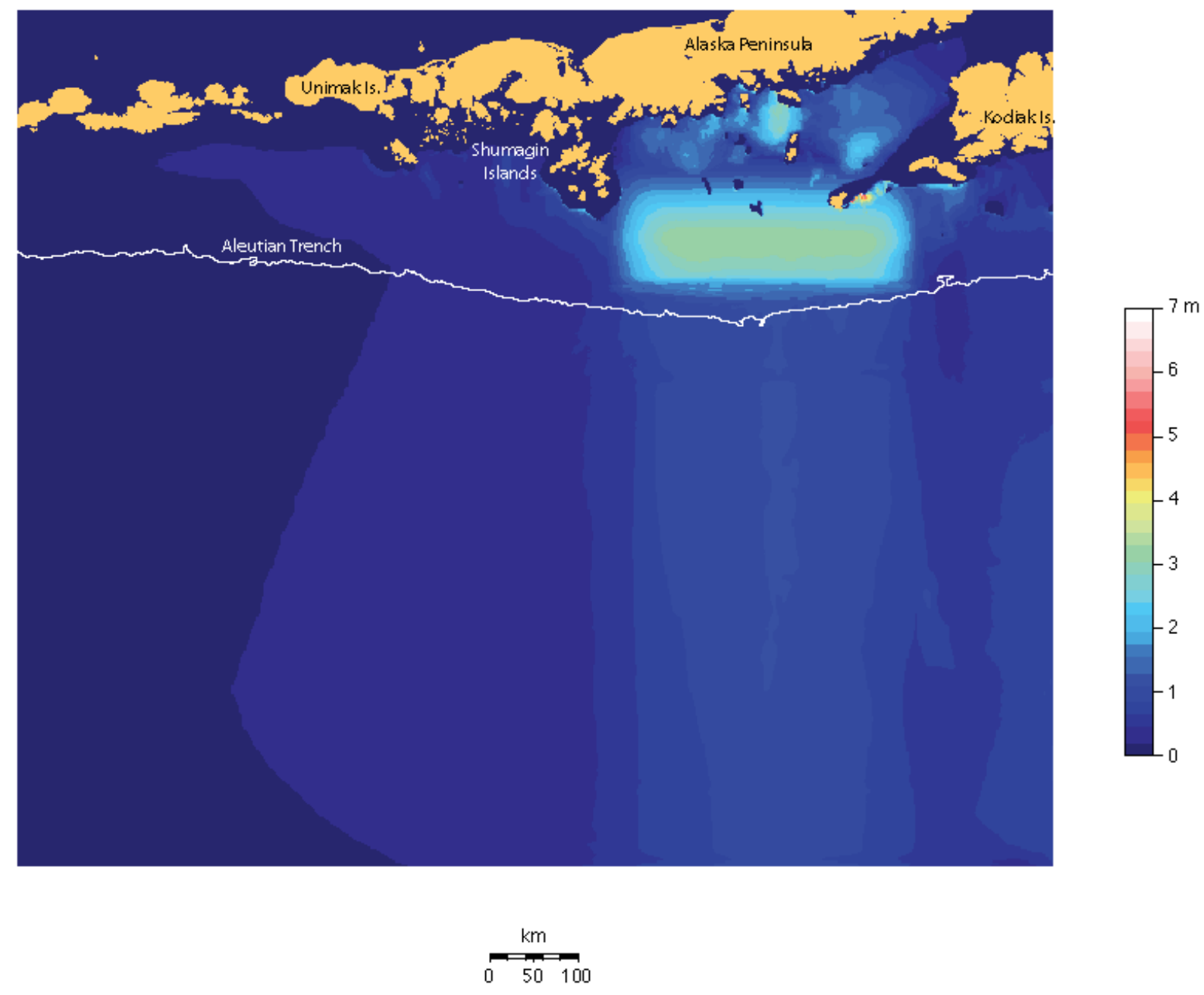

Figure 18. Map showing peak tsunami amplitude (color scale in $\mathrm{m}$ ) resulting from the updip frictional-strengthening zone model. Water height corresponds well with free surface deformation (fig. 17, bottom). Adding a strengthening zone to the updip portion of the fault greatly reduces tsunami amplitude locally above the strengthening zone as well as broadly above the free surface, relative to the homogeneous model, and it reduces the amplitude of the far-field beaming pattern. In addition, peak amplitudes are substantially reduced near the coasts of the Shumagin Islands, the Alaska Peninsula, and Kodiak Island.

\section{Heterogeneous Prestress Rupture}

The three models discussed above assume homogeneous prestress conditions along the entire extent of the fault. However, observational data imply that earthquakes typically have strongly heterogeneous slip distributions that further imply heterogeneous prestress (for example, Olsen and others, 1997). Indeed, the SAFRR tsunami models use a heterogeneous slip model stimulated by the 2011 Tohoku-Oki event and supported by seismic, geodetic, and geologic data along the AlaskanAleutian subduction zone (Kirby and others, 2013). Figure 19 shows slip-rate snapshots of rupture propagation for a heterogeneous prestress model designed to qualitatively match the SAFRR dislocation model. As in the case of the homogeneous stress distribution, the fault experiences large slip-rate pulses 
nearest the free surface. However, because of some high-stress areas downdip, it also experiences high slip rates in other locations. Additionally, the main slip pulse is spatially heterogeneous; it does not have rough elliptical symmetry, reflecting a rupture speed that varies across the fault. Note the difference in slip rate between the homogeneous model and heterogeneous prestress model for each snapshot. Rupture proceeds over the entire fault zone for the heterogeneous prestress model. Figure 20 shows shear prestress and normal prestress distributions. The limiting values are shown in table 2 . Figure 21 displays the slip distribution used in the SAFRR Tsunami Scenario (Kirby and others, 2013), as well as fault slip and total vertical free surface deformation for the dynamic heterogeneous prestress model. Average fault slip is the same as in the homogeneous model $(18.6 \mathrm{~m})$, and the maximum vertical surface displacement is increased (5.77 to $7.04 \mathrm{~m}$ ), relative to the homogeneous model. The heterogeneous prestress leads to a more heterogeneous slip distribution and vertical free surface deformation, compared with the homogeneous model. The slip distribution model from the Earthquake Source working group within the SAFRR Tsunami Scenario (Kirby and others, 2013) and the slip distribution from the dynamic model are qualitatively similar, indicating that the slip distribution used by Kirby and others (2013) is self-consistent from a physical standpoint: it is possible to obtain such a slip distribution using relatively rigorous physics from a heterogeneous prestress pattern. The total slip distribution is spatially much smoother (fig. 21, middle) than our initial stress configurations. We note that tuning initial prestress to get a certain slip distribution is an iterative process, and that further tuning would likely result in a slip distribution more closely matched to the top panel in figure 21, but with gradually diminishing returns. Figure 22 shows local peak tsunami amplitudes resulting from the heterogeneous prestress model. Water height corresponds well with vertical free surface deformation, showing peak tsunami amplitudes above regions of the fault nearest the trench with maximum slip. Although the peak amplitudes immediately above the hanging wall are spatially more varied than in the homogeneous model, the overall beaming patterns and maximum amplitudes along the local coasts are similar. 

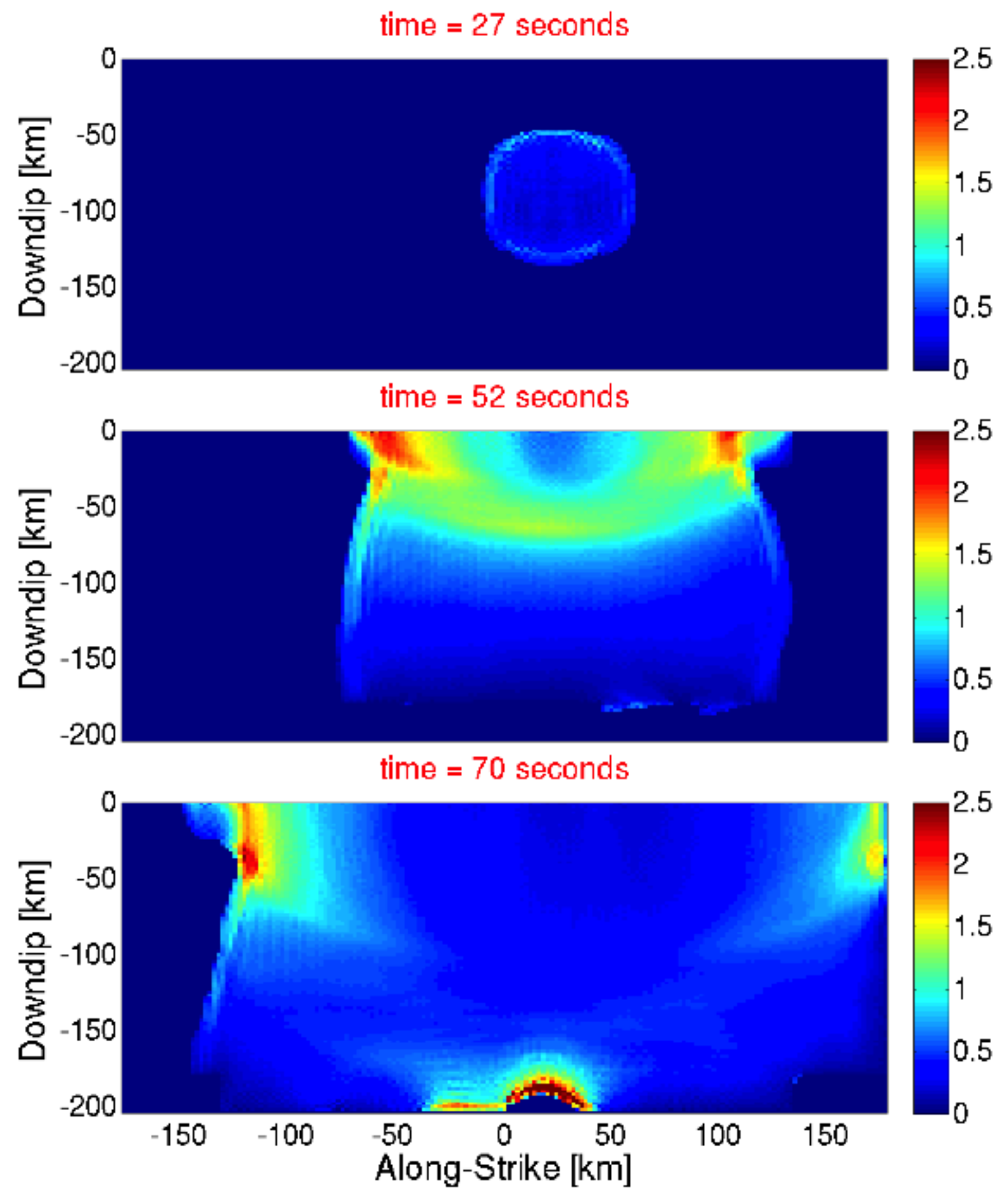

Figure 19. Diagrammatic views of the fault surface showing snapshots of rupture propagation at 27,52 , and $70 \mathrm{~s}$ for a heterogeneous prestress model. Colors represent slip rate in $\mathrm{m} / \mathrm{s}$. The fault experiences large slip rate pulses nearest the free surface and for some areas downdip (in contrast to the homogeneous model). Note the difference in slip rate between the homogeneous model and heterogeneous prestress model for each snapshot. Rupture proceeds over the entire fault zone. 

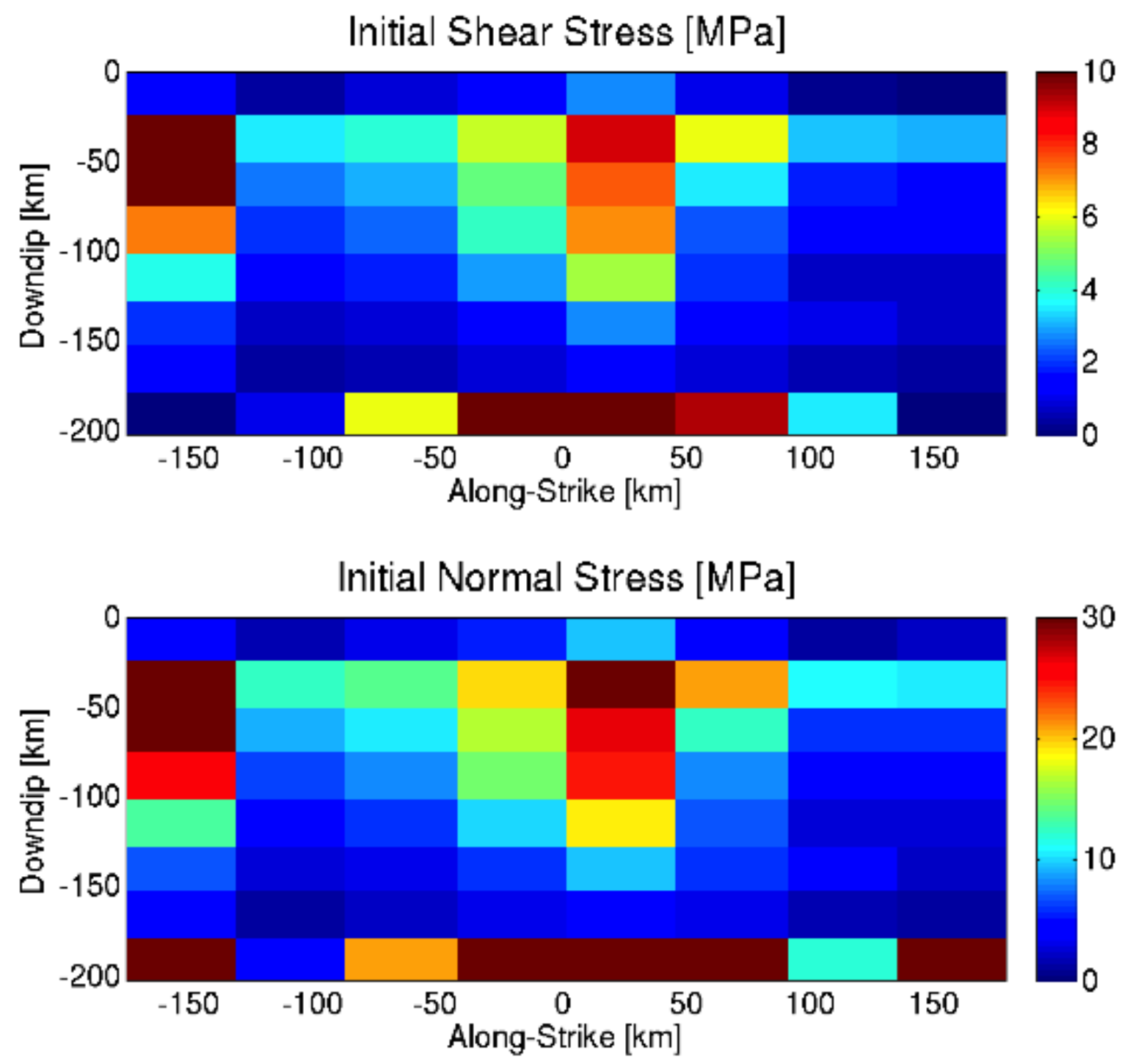

Figure 20. Diagrammatic views of the fault plane showing initial shear stress (top) and normal stress (bottom) for the heterogeneous prestress model. The limiting values of stress are shown in table 2. The total slip distribution is spatially much smoother (fig. 21 , middle) than our initial stress configuration. 

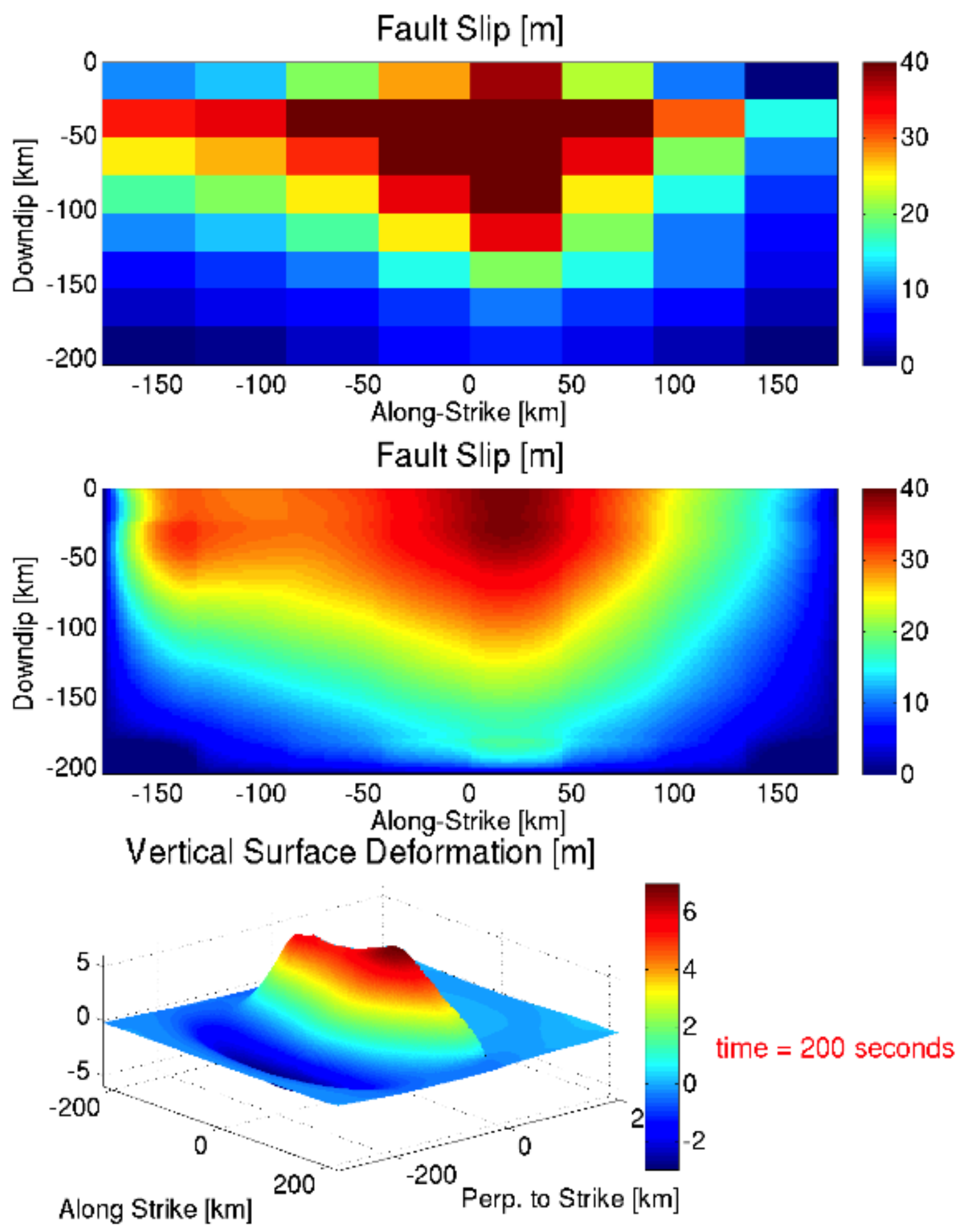

Figure 21. Diagrams showing the slip distribution used in the SAFRR Tsunami Scenario (top), as well as the fault slip (middle) and total vertical free surface deformation (bottom) for the dynamic heterogeneous prestress model. Average fault slip is the same as in the homogeneous model $(18.6 \mathrm{~m})$, and the maximum vertical surface displacement is increased $(5.77$ to $7.04 \mathrm{~m}$ ) relative to the homogeneous model. The heterogeneous prestress leads to a more heterogeneous slip distribution and vertical free surface deformation, compared with the homogeneous model. The dynamic slip distribution (middle panel) qualitatively resembles the top panel. 

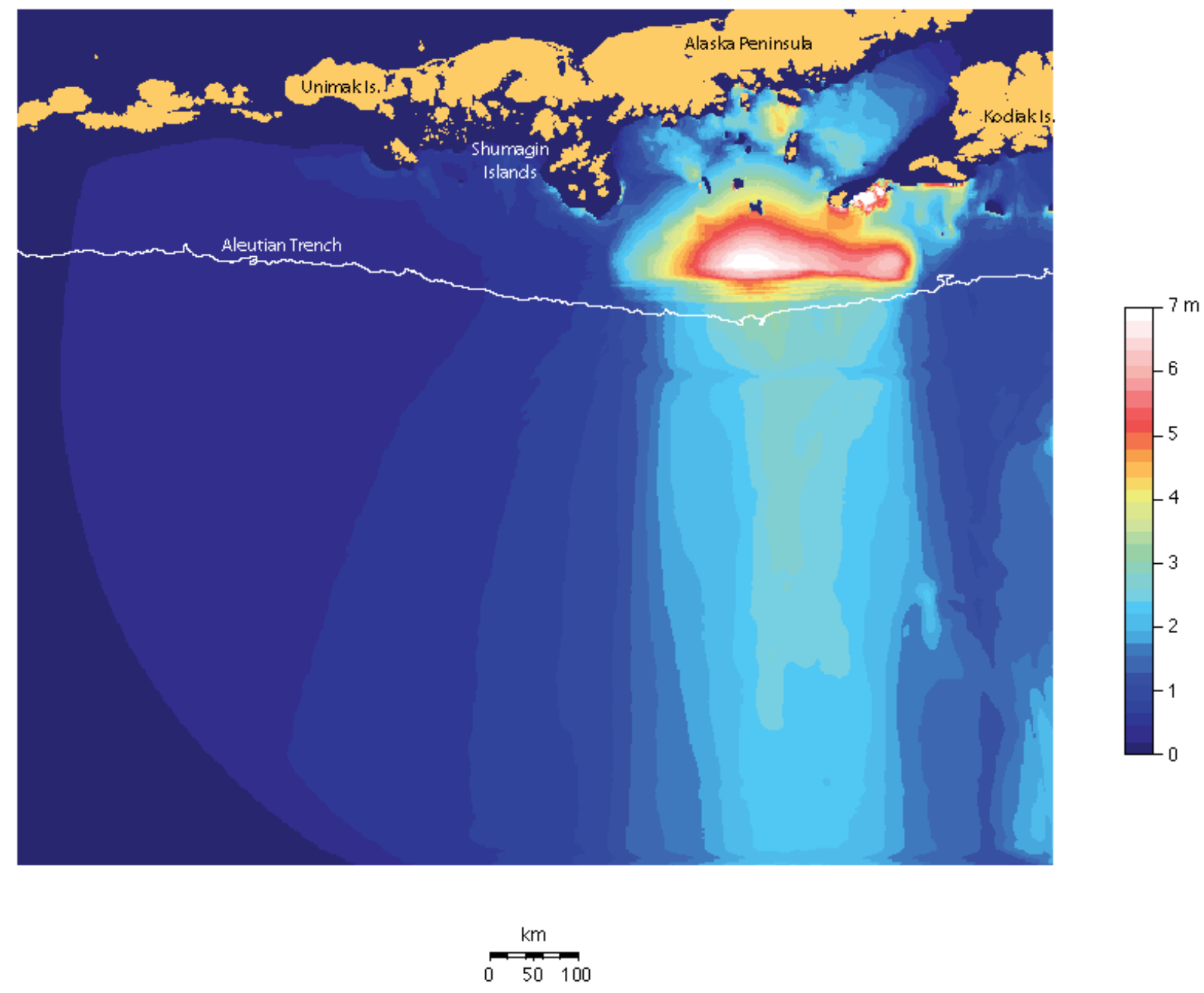

Figure 22. Map showing peak tsunami amplitudes (color scale in $\mathrm{m}$ ) resulting from the heterogeneous prestress model. Although the peak amplitudes immediately above the hanging wall are spatially more variable than in the homogeneous model, the overall beaming patterns and amplitudes along the local coasts are similar.

\section{Discussion}

The four earthquake rupture models in this study generate four different tsunami models along a portion of the Alaskan-Aleutian subduction zone. How a tsunami is locally generated in this region affects inundation and runup on local coasts (that is, Alaska Peninsula) and could affect propagation across the Pacific Ocean onto coastlines along the Pacific rim. For the homogeneous model, there are large slip pulses near the free surface (fig. 10) that result from the dynamic unclamping of the fault and the geometric asymmetry of the hanging wall/footwall. In turn, this effect results in large slip near the free surface and therefore large vertical free surface deformation near the trench (fig. 11). The consequent modeled tsunami most significantly propagates northward and southward into and from the Alaska Peninsula (fig. 12). A completely homogeneous prestress and frictional parameter earthquake rupture model that produces the largest slip near the trench has important implications for the resulting 
tsunami, because sea-floor displacement is most sensitive to fault slip near the trench (Okada, 1985). Large-amplitude tsunamis can be generated by slip distributions localized near the trench.

Including a frictional-strengthening segment (emulating rate-strengthening behavior) along the Shumagin sector in the model significantly affects the slip distribution and initial tsunami wavefield. The rupture propagates through the entire strengthening zone, but with greatly reduced slip rate, and this effect reduces the overall average slip on the fault commensurately (figs. 13 and 14). The surface deformation is consequently scaled downward in this zone of lower slip. Importantly, the beaming pattern of the far-field tsunami is shifted for the western strengthening rupture, relative to the homogeneous rupture (fig. 15). Therefore, far-field tsunami propagation can shift, potentially changing inundation and runup on coastlines along the Pacific rim. It is interesting to note that the computationally simulated rupture can penetrate a strengthening zone that is as large as $80 \mathrm{~km}$ wide along strike. The dynamic reduction of normal stress due to the dip-slip geometry may facilitate this rupture propagation near the free surface. In other words, in our models time-dependent normal stress induced by the free surface allows thrust rupture to more easily penetrate a rate-strengthening region near the surface. This result raises the prospect that rupture might be able to propagate through such a zone into another frictional weakening zone in future earthquakes, generating a larger earthquake and tsunami.

Including a frictional-strengthening segment updip near the trench also significantly affects the slip distribution and initial tsunami wavefield (figs. 16 through 18). Adding a strengthening zone updip affects average fault slip to a greater degree than does adding a strengthening zone along strike. Without a frictional-strengthening zone updip (for example, the homogeneous model), rupture propagates energetically updip, sending radiation to the entire fault, promoting slip. Because it prevents the strong seismic radiation from the most updip section of a thrust fault during rupture, a frictional-strengthening zone updip broadly effects the slip and slip rate for the rest of the fault. As a result, we see a broad decrease in maximum tsunami amplitude, but with a similar beaming pattern when compared to the homogeneous rupture. Slip distributions near the trench are known to be important for tsunami generation (Geist, 1999; Geist and Dmowska, 1999; Geist and Bilek, 2001; Geist, 2002). Our results show slowed rupture propagation in frictional-strengthening zones with a lower peak slip rate, but these zones still have significant slip in those regions. This result hints at a possible mechanism for tsunami earthquakes (Kanamori, 1972).

We note that adding a frictional-strengthening zone along strike or updip does not preclude the ruptures from having static stress drops, particularly in the case of thrust earthquakes (Oglesby and others, 1998). Static stress drop depends on the dynamics of the rupture. It is possible to obtain a stress drop in a frictional-strengthening zone because of a large free-surface-induced reduction in normal stress (Kozdon and Dunham, in press), since the sliding frictional resistance is equal to the friction coefficient multiplied by the normal stress.

A heterogeneous prestress model significantly affects the slip distribution and initial tsunami wavefield, with the largest peak tsunami amplitudes above portions of the fault with the largest slip (fig. 21). Although average slip is the same in the homogeneous rupture and the heterogeneous prestress rupture, the latter has a larger maximum vertical free surface displacement because slip is more localized. Nonetheless, the beaming pattern of the far-field tsunami is similar for both models (figs. 12 and 22). We match the seismic moment in the heterogeneous prestress model to the source model used by Kirby and others (2013) through a trial and error process. We also qualitatively match the slip distribution of the dynamic model to the source model (fig. 21). The total slip distribution is spatially much smoother than the initial stress configurations (figs. 20 and 21), in agreement with previous studies (Olsen and others, 1997; Olsen and others, 2009). Considering all four rupture models in this 
study, as well as previously studied and observed megathrust events in other parts of the world (for example, Ammon and others, 2011), the SAFRR Tsunami Scenario dislocation model appears to be self-consistent as a tsunami source, even when modeled as a complex rupture that involves frictionalstrengthening updip and (or) along strike as well as a heterogeneous prestress. Adding more precise source parameters in 3-D (for example, complex fault geometry, material properties, and stochastic stress fields) would further this study and help produce more realistic modeled sea-floor deformation.

We use a simple planar fault geometry in this study; however, previous work by Oglesby and Archuleta (2003) suggests that fault slip and low-frequency ground motion are relatively unchanged for a nonplanar thrust fault with an abrupt change in dip when compared to a planar fault with an equivalent dip near the free surface. This result suggests that the shallow dipping rupture process is most important in producing ground motion. Combining this with the strong dependence of tsunami generation on slip near the trench (an area that generally has the shallowest dip for a subduction zone), we feel comfortable (at least to first order) using a planar fault with a small dip in this study to study effects on local tsunami generation. However, to better model the dynamics of the rupture process as well as the resultant tsunami, more accurate fault geometry should be used in future modeling efforts.

Using dynamic earthquake rupture models coupled, in time, with hydrodynamic models can be a very useful tool. We show that rupture dynamics on a megathrust can play an important role in tsunami generation and local propagation. It is true that tsunami formation is relatively insensitive to the temporal evolution of rupture. In other words, taking the final sea-floor deformation as an initial condition for tsunami generation would produce a tsunami not tremendously different from one produced by the time-dependent sea-floor deformation. However, this does not mean that the tsunami generation is insensitive to the spatiotemporal details of the rupture process. Indeed, the rupture path and overall slip distribution (which are first-order determinants of the tsunami) crucially depend on dynamic stress interactions (see, for example, Harris and Day, 1993), and thus on these spatiotemporal effects. For thrust faults in particular, it is very instructive to analyze results from dynamic models, because time-dependent normal stress fluctuations that arise from the free surface affect slip rates and slip distribution. Additionally, rupture propagation through stable-sliding zones can be accurately modeled dynamically, and may be used to simulate tsunami earthquakes. Thus, dynamic modeling may be an important complement to standard dislocation models for tsunami hazard analysis in the future.

\section{Modeling of Tsunami Wave Excitation, Propagation, and Inundation}

\section{By Hong Kie Thio}

\section{Introduction}

This section presents the results of a numerical modeling analysis of tsunami propagation and inundation along the coast of California from the SAFRR Alaska scenario source model (Kirby and others, 2013) (fig. 23) as well as the dynamic rupture models (Ryan and others, section 2, above). Detailed runup and inundation modeling for areas along the California coast is performed where there is significant exposure. For all areas, I not only provide the maximum wave heights and inundation throughout the region but also the maximum velocity and momentum flux at the shoreline, which may be more appropriate parameters to estimate the impact of tsunami on engineered structures. An overview of my modeling effort and some examples of some of the high-resolution modeling is 
presented. For more detailed information, refer to the actual data files that have been produced and made available for this project.

Detailed runup and inundation modeling was performed for areas along the California coast where there is significant exposure. For all areas, the results not only provide the maximum wave heights and inundation throughout the region but also the maximum velocity and momentum flux at the shoreline, which may be more appropriate parameters to estimate the impact of tsunami on engineered structures. The section presents an overview of our modeling effort and some examples of some of the high-resolution modeling. For more detailed information, please refer to the actual data files that have been produced and made available for this project.

\section{NE Pacific Basin}

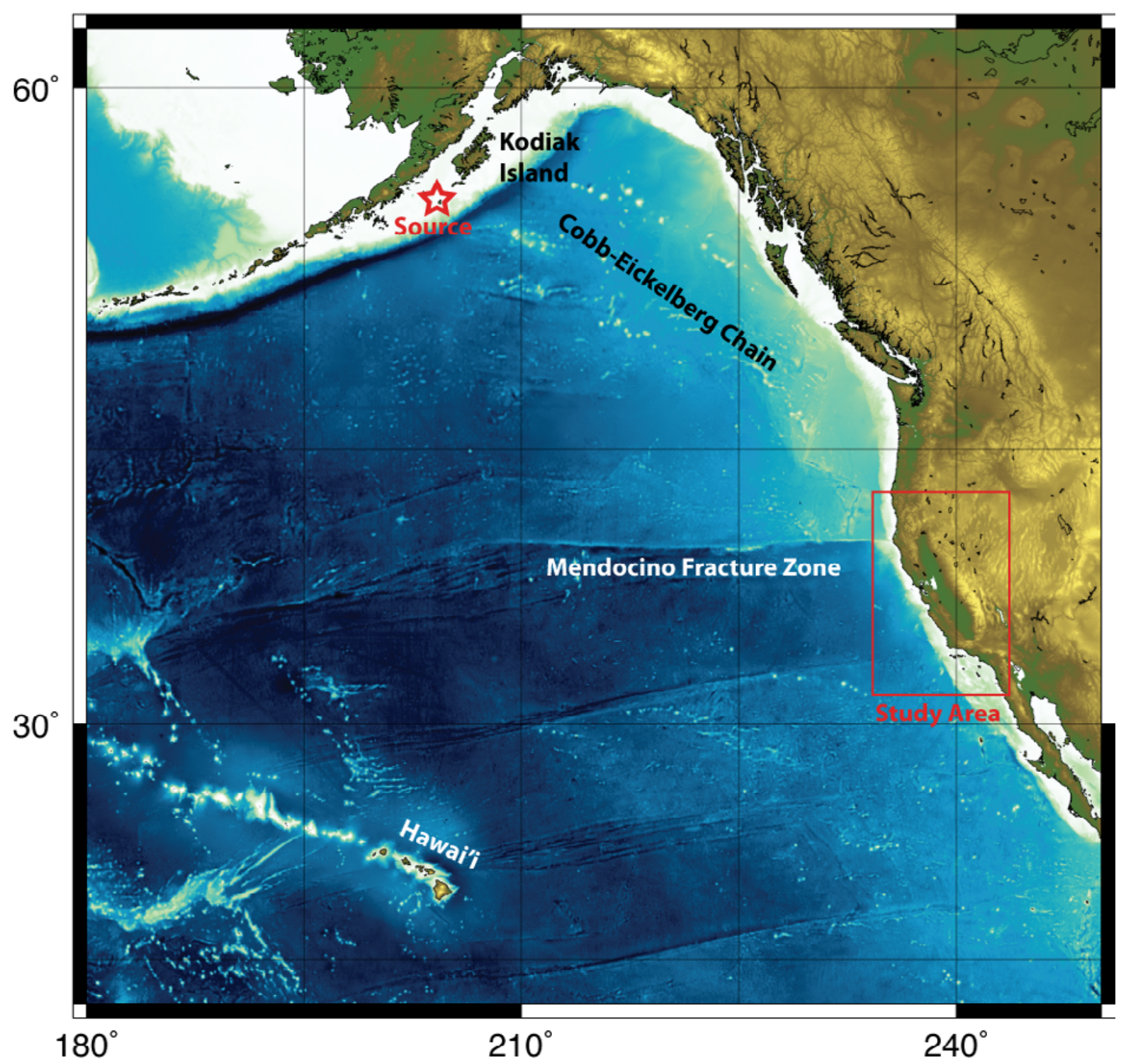

Figure 23. Map of the northeastern Pacific Basin. The scenario source location is indicated with a star; the area of high-resolution modeling (California) is indicated with the red box. 


\section{Tsunami Modeling}

The simulation of tsunami waves consists of two steps. First, the sea-floor deformation resulting from slip on a fault plane is computed using elastic theory. Then, this static deformation field is used as the starting condition for the actual tsunami propagation and inundation calculations. Our particular implementation of the tsunami propagation and inundation model was developed by Satake (1995) and has been widely used since by many researchers (for example, Baba and others, 2004; Fujii and Satake, 2006; Ichinose and others, 2007; Thio and others, 2007; Burbridge and others, 2008; Baba and others, 2009).

\section{Tsunami Excitation}

The tsunami excitation by earthquake sources is modeled by translating the vertical deformation field of the earthquake source (surface faulting) into a vertical displacement of the ocean surface. This method is commonly used in tsunami studies (for example, Satake, 1995; Titov and Synolakis, 1996) and has been shown to be valid for long-wavelength deformation (rupture extent $>>$ water depth). The static displacement fields were computed from the slip distribution provided by Kirby and others (2013) using a frequency-wave-number integration technique (FK) with a simple layered crustal model (Wang and others, 2003, 2006). This method allows for an efficient computation of the static displacement field of a buried rupture using elastic theory. The ground deformation field is shown in figure 24 . The pattern shown is typical for a shallow subduction thrust, with a very pronounced region of uplift (with a maximum of $14 \mathrm{~m}$ ) near the trench and a broader area of subsidence in the back-arc region.

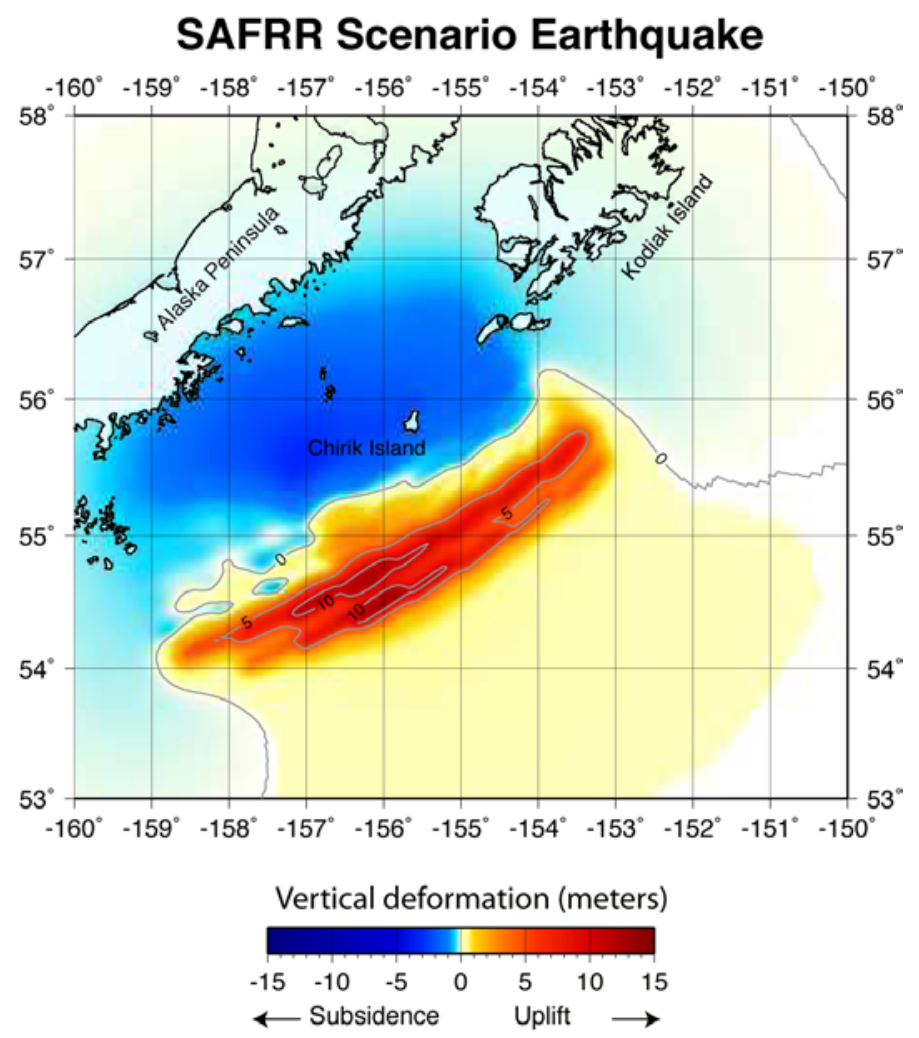

Figure 24. Map showing vertical deformation field of the earthquake source region, which is used as initial condition for the tsunami wave modeling. 


\section{Tsunami Propagation}

An Eulerian approach is used to describe the particle motion of the fluid. This describes only the velocity changes of the fluid at some point and at some instant of time rather than describing its absolute displacement. Consider a wave that is a propagating disturbance from an equilibrium state. Gravity waves occur when the only restoring force is gravity. When the horizontal scale of motion is much larger than the water depth, then the vertical acceleration of water is much smaller than the gravity acceleration and thus negligible. This means that the whole water mass from the bottom to the surface is assumed to move uniformly in a horizontal direction. This kind of gravity wave is also known as a "long wave." Long-wave approximations are appropriate when the water depth of lakes and oceans $(<5 \mathrm{~km})$ is much smaller than the length of the disturbance (fault lengths $\sim 10-1,000 \mathrm{~km}$ ). This approximation gives an accurate description of tsunami wave propagation in the open ocean. In order to also model the propagation of tsunami waves in coastal areas, an approximation to the wave equation is used in which the low-amplitude linear long-wave requirements are relaxed, as shown below.

General Linear Gravity Wave

The following is a derivation of the general case of gravity waves for two dimensions, where $x$ is the horizontal direction and $z$ is vertical direction (fig. 25).

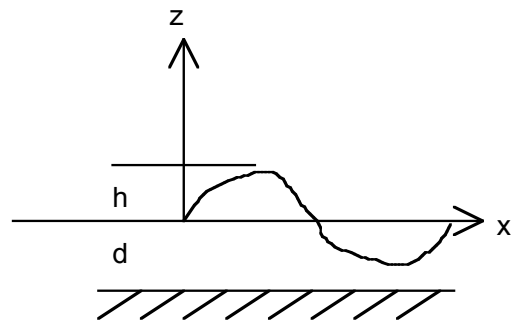

Figure 25. Diagrammatic sketch showing the coordinate system for tsunami model.

We start from the Euler's equation of motion that considers the conservation of momentum on a volume of water. The Newton equations can be simplified as

$$
\frac{d}{d t} V=g-\frac{1}{\rho} \nabla p
$$

where $d / d t$ is the total derivative ( $\partial / \partial t$ is the partial derivative) with respect to time, $g$ is the gravitational acceleration, $V=(u, w)$ are the depth averaged velocities in the $x$ and $z$ directions, $\rho$ is the density, and $p$ is the fluid pressure. Figure 25 shows that $h$ is the tsunami wave height and $d$ is the water depth. Next consider the conservation of mass to derive the equation of continuity,

$$
\frac{\partial \rho}{\partial t}+\nabla \cdot(\rho V)=0
$$

which for incompressible fluid becomes

$$
\nabla \cdot V=0
$$

From the Euler equation of motion the horizontal and vertical acceleration components are 


$$
\begin{aligned}
& \frac{d u}{d t}=-\frac{1}{\rho} \frac{\partial p}{\partial x} \\
& \frac{d w}{d t}=-g-\frac{1}{\rho} \frac{\partial p}{\partial z}
\end{aligned}
$$

The relation between $h$ and $p$ is seen through the hydrostatic pressure equation,

$$
p=-\rho g(h-z)+p_{0}
$$

where $h$ is the wave height, $z$ is the water depth, and $p_{0}$ is the pressure of one atmosphere at $z=0$ and $h$ $=0$. The horizontal and vertical pressure gradients given from the slope of the water surface,

$$
\begin{aligned}
& \frac{\partial}{\partial x} p=p g \frac{\partial h}{\partial x} \\
& \frac{d}{d z} p=-\rho g
\end{aligned}
$$

are combined with the Euler equation to give the horizontal and vertical components,

$$
\begin{aligned}
& \frac{d u}{d t}=-g \frac{\partial h}{\partial x} \\
& \frac{d w}{d t}=0
\end{aligned}
$$

For ocean tsunamis, the nonlinear advective term is small and can be ignored; therefore the equation of motion is,

$$
\begin{aligned}
& \frac{d u}{d t}=\frac{\partial u}{\partial t}+u \frac{\partial u}{\partial x} \approx \frac{\partial u}{\partial t} \\
& \frac{\partial u}{\partial t}=-g \frac{\partial h}{\partial x}
\end{aligned}
$$

Next consider the conservation of mass for a region with a small length $d x$. Because the volume change per unit time must be equal to the flow rate of water going out of this region, we can therefore write

$$
\begin{aligned}
& \frac{\partial}{\partial t}\{(h+d) d x\}=-\frac{\partial}{\partial x}\{u(h+d)\} d x \\
& \frac{\partial h}{\partial t}=-\frac{\partial}{\partial x}\{u(h+d)\} \\
& \frac{\partial h}{\partial t}=-\frac{\partial}{\partial x}(d u)
\end{aligned}
$$

which is the simplified equation of continuity when the amplitude of the wave is small compared to the water depth. The so-called small-amplitude, linear, long-wave assumption is valid for most of tsunami propagation paths except near coasts. 
Nonlinear Gravity Waves and Shallow Water Waves

Linear theory is often sufficient to model the propagation of tsunami in open oceans. However, in the nearshore environment, and in particular for inundation, nonlinear effects become very important and need to be included as well.

Without a viscous force to dissipate wave energy, the equations would have water motion continue forever. In order to include the viscous effect, we can add a term for viscous stress to the equation of motion. We only consider a shear stress at the water bottom, and the normal stress is already included and equal to the pressure. The shear stress in two dimensions is experimentally estimated as

$$
\tau_{x}^{b} \approx C_{f} v_{x} \sqrt{v_{x}^{2}+v_{y}^{2}}
$$

and the frictional force is

$$
F_{x}{ }^{b}=C_{f} \frac{v_{x} \sqrt{v_{x}^{2}+v_{y}^{2}}}{d+h},
$$

where $v_{\mathrm{x}}$ and $v_{\mathrm{y}}$ are now the horizontal components of velocity.

Satake (1995) adopted two types of frictional coefficients from engineering hydrodynamics for including bottom friction for tsunamis. These are the De Chezy $(C)$ and Mannings's roughness $(n)$ coefficients. These have different dimensions; therefore a nondimensional frictional coefficient $C_{f}$ is related to these two coefficients by

$$
C_{f}^{2}=\frac{g}{C_{c}^{2}}
$$

and

$$
C_{f}=\frac{g n^{2}}{(d+h)^{1 / 3}} .
$$

Manning's roughness coefficient $n$ is used for a uniform turbulent flow on a rough surface. It indicates that the bottom friction varies with water depth. We use an $n$ of $0.03 \mathrm{~m}^{-1 / 3} \mathrm{~s}$, typical for coastal waters. If $n$ is translated to $C_{f}$, then $n$ becomes $2.3 \times 10^{-3}$ for a total depth of $50 \mathrm{~m}$ and $1 \times 10^{-2}$ for a total depth of $0.6 \mathrm{~m}$, which agree well with observational values of tidal flow and runup of solitary waves (see Satake, 1995).

Because the Earth is rotating, there is a force apparently acting on a body of water. In an inertial reference frame (fixed on the rotating Earth), this force is called the Coriolis force. The derivation of this term is beyond the scope of this report and we refer the reader to textbooks on analytical mechanics. The vertical component of the Coriolis force is much smaller than gravity $\left(3 \mathrm{~cm} / \mathrm{s}^{2}\right.$ compared to 980 $\mathrm{cm} / \mathrm{s}^{2}$ at 4,000-m depth). In a local Cartesian coordinate system, the horizontal components are given by

$$
\begin{aligned}
& F_{x}{ }^{c o r}=-f v_{y} \\
& F_{y}{ }^{c o r}=f v_{x}
\end{aligned}
$$

where $f$ is the Coriolis parameter, and this force always acts to the right hand side of the motion in the northern hemisphere. 
The equations for general gravity waves are derived without making the small-amplitude, linear long-wave approximation appropriate when the wave height is much smaller than the water depth $(h<<d)$. If we expand the hyperbolic tangent function using the Taylor series expansion and include the first and second order terms, then the corresponding equation of motion becomes

$$
\frac{\partial u}{\partial t}=-g \frac{\partial h}{\partial x}+\frac{1}{3} d^{2} \frac{\partial^{3} u}{\partial x^{2} \partial t}
$$

which is also known as the Boussinesq equation. After relaxing the small amplitude assumption, the equation of motion and continuity are given as

$$
\begin{aligned}
& \frac{d u}{d t}+u \frac{\partial u}{\partial x}=-g \frac{\partial h}{\partial x} \\
& \frac{\partial h}{\partial t}=-\frac{\partial}{\partial x}\{u(h+d)\}
\end{aligned}
$$

These equations are for the finite-amplitude shallow water waves. For the linear case, the phase velocity is given by the following Taylor series expansion of the hyperbolic tangent function,

$$
c=\sqrt{g d}\left\{1-\frac{2 \pi^{2}}{3}\left(\frac{d}{\lambda}\right)^{2}\right\},
$$

where $l$ is the wavelength. In the nonlinear case the $d$-term in the phase velocity is replaced by the total height of the water column $(d+h)$ which gives us a phase velocity of the form

$$
c \sim \sqrt{g(d+h)} .
$$

Note that in the nonlinear case there appears a phenomenon of amplitude dispersion - the larger the amplitude, the faster the wave speed. As a consequence, peaks of a wave catch up with troughs in front of them, and the forward-facing portion of the wave continues to get steeper. This wave will eventually break.

Including the bottom friction and Coriolis force, the equation of motion for shallow water waves can be written for a two-dimensional case as follows:

$$
\begin{aligned}
& \frac{\partial U}{\partial t}+U \frac{\partial U}{\partial x}+V \frac{\partial U}{\partial y}=-f V-g \frac{\partial h}{\partial x}-C_{f} \frac{U \sqrt{U^{2}+V^{2}}}{d+h} \\
& \frac{\partial V}{\partial t}+U \frac{\partial V}{\partial x}+V \frac{\partial V}{\partial y}=-f U-g \frac{\partial h}{\partial y}-C_{f} \frac{V \sqrt{U^{2}+V^{2}}}{d+h}
\end{aligned}
$$

and the equation of continuity is

$$
\frac{\partial h}{\partial t}+\frac{\partial}{\partial x}\{U(h+d)\}+\frac{\partial}{\partial y}\{V(h+d)\}=0
$$

where the coordinate system is $x=$ east $y=$ south, $f$ is the Coriolis parameter, $C_{f}$ is a nondimensional frictional coefficient, and $U$ and $V$ are the depth-averaged velocities in the $x$ and $y$ directions, respectively. In the equation of motion, the first term on the left side is the local acceleration term, the second and third terms on the left are the advection terms, the first term on the right side is the Coriolis 
force, the second term on the right is the restoring force from gravitation acceleration, and the third term on the right is the bottom friction force.

\section{Tsunami Model}

The tsunami propagation has been modeled using a staggered grid finite-difference algorithm in the so-called shallow water approximation, where the wavelength of the tsunami is assumed to be much larger than the water depth. In these circumstances the only restoring force, when the water level is out of equilibrium, is gravity so that the whole water mass from the bottom to the surface is assumed to move uniformly in a horizontal direction. Shallow water (or "long wave") approximations are appropriate when the water depth of lakes and oceans $(0-10 \mathrm{~km})$ is much smaller than the length of the disturbance (fault lengths $\sim 50-1,000 \mathrm{~km}$ ).

The equations of motion and equation of continuity described above are solved in a spherical coordinate system by finite-difference method using the staggered leapfrog method (see, for example, Satake, 1995). For the advection terms, an upwind difference scheme is used (for example, Press and others, 2007). The land-sea boundary condition in the linear computation is total reflection, and in the nonlinear case there is a moving boundary condition and runup is considered. The time step of computation is determined to satisfy the stability condition (Courant condition) in the linear case and by trial and error for the nonlinear finite-difference computations.

The nested grid setup consists of a master grid with a coarse grid spacing and a number of nested finer grids with decreasing grid sizes around areas of interest. The relations between the coarser and finer grids are referred to as parent (coarse) and child (fine), and every child grid can be a parent grid of an even higher resolution grid. Our finite difference scheme allows for more than one child for every parent, with the only condition that same-level child-grids do not overlap (or are separated by only a few grid points in the parent grid, and that the reduction in grid spacing from parent to child is an odd factor. In practice, the reduction is either 3 or 5 , because larger reduction factors would introduce large numerical errors.

In the current model, the deep ocean part is sampled at 120 arc seconds $(\sim 3.6 \mathrm{~km})$. Because of the very long wavelength of the tsunami waves in the deep ocean, such a sampling is sufficient for accurate results and reduces the computation time and memory requirements considerably. Closer to shore, several nested grids step down to $0.96 \operatorname{arc} \sec (\sim 30 \mathrm{~m})$ at the sites of interest. The timestep for these runs is $0.2 \mathrm{~s}$. Currently, the code uses a fixed timestep, which generally is controlled by the finest grid size.

\section{Bathymetry}

The bathymetry used for the open ocean propagation was derived from the SRTM30+ model by Becker and others (2009). This model (fig. 23) is based on a variety of data, but along the coast of North America, a significant source is the National Geophysical Data Center (NGDC) coastal relief model. The higher resolution grids used for the inundation modeling were all provided through the NGDC Tsunami Inundation Gridding program. Most of these data are available in a resolution of 1/3 arc sec, or approximately $10 \mathrm{~m}$. These data were resampled to a resolution of $1 \operatorname{arc} \sec (\sim 30 \mathrm{~m})$ for the final inundation grids, as well as even lower resolutions for the intermediate nested grids (fig. 26). 


\section{SAFFR Tsunami Model: high resolution grids}

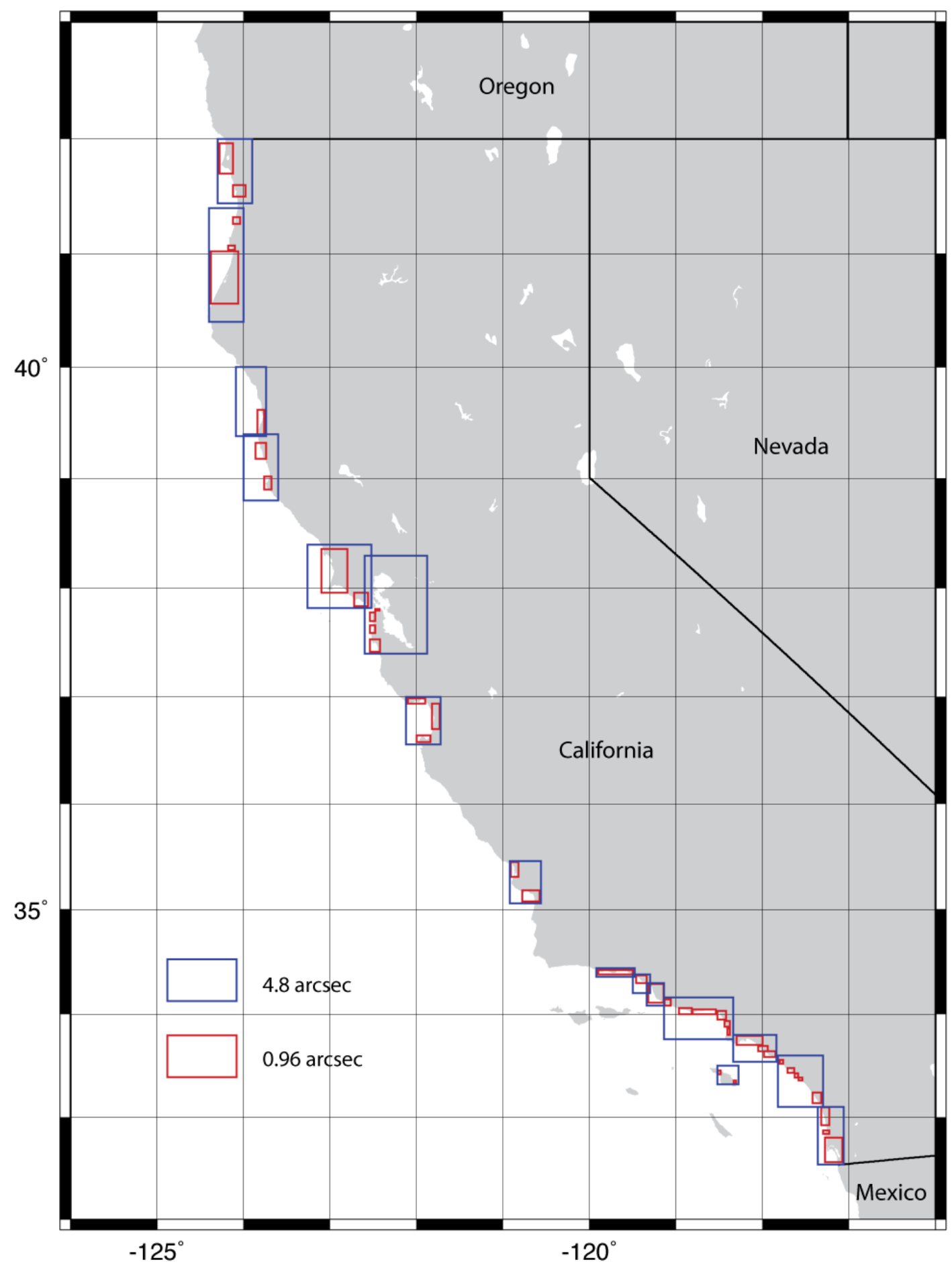

Figure 26. Map showing locations of the high-resolution grids ( $0.96 \mathrm{arc} \mathrm{sec}, \sim 30 \mathrm{~m})$ along the California coast. Also shown are the parent grids with a resolution of $4.8 \operatorname{arc~sec}(\sim 150 \mathrm{~m})$. 
Coordinates for the grids used are given in Tables 4 through 6 .

Table 4. Longitude and latitude of the boundaries of coarse and 1st nested grid

\begin{tabular}{ccccc}
\hline Area & West & East & South & North \\
\hline Pacific $(120$ arc sec) & 120 & $250(-110)$ & 12 & 62 \\
California $(24 \operatorname{arc~sec})$ & -125 & -116 & 31 & 43 \\
\hline
\end{tabular}

Table 5. Longitude and latitude of the boundaries of the 2 nd order grid (4.8 arcsec)

\begin{tabular}{ccccc}
\hline Area & West & East & South & North \\
\hline Crescent City & -124.300 & -123.900 & 41.440 & 42.000 \\
Humboldt Bay & -124.400 & -124.000 & 40.400 & 41.400 \\
Fort Bragg & -124.920 & -123.740 & 39.380 & 40.000 \\
Arena Cove & -124.000 & -123.600 & 38.800 & 39.400 \\
Marin County & -123.260 & -122.520 & 37.820 & 38.400 \\
San Francisco & -122.600 & -121.880 & 37.400 & 38.300 \\
Monterey Bay & -122.120 & -121.720 & 36.560 & 37.000 \\
Port San Luis & -120.920 & -120.560 & 35.060 & 35.460 \\
Santa Barbara & -119.920 & -119.480 & 34.360 & 34.440 \\
Ventura & -119.340 & -119.140 & 34.080 & 34.300 \\
Rincon & -119.500 & -119.300 & 34.200 & 34.380 \\
Santa Monica Bay & -119.140 & -118.340 & 33.760 & 34.160 \\
South Bay & -118.340 & -117.840 & 33.540 & 33.800 \\
Catalina & -118.520 & -118.280 & 33.320 & 33.500 \\
Oceanside & -117.820 & -117.300 & 33.100 & 33.600 \\
San Diego & -117.360 & -117.060 & 32.540 & 33.100 \\
\hline
\end{tabular}

Table 6. Longitude and latitude of the boundaries of the highest resolution grids (.96 arcsec)

\begin{tabular}{ccccc}
\hline Area & West & East & South & North \\
\hline Crescent City & -124.280 & -124.120 & 41.700 & 41.960 \\
Klamath & -124.120 & -123.980 & 41.500 & 41.600 \\
Orick & -124.120 & -124.040 & 41.260 & 41.320 \\
Trinidad & -124.180 & -124.100 & 41.032 & 41.072 \\
Humboldt Bay & -124.380 & -124.060 & 40.560 & 31.020 \\
Fort Bragg & -123.840 & -123.760 & 39.400 & 39.320 \\
Mendocino & -123.860 & -123.740 & 39.180 & 39.020 \\
Arena Cove & -123.760 & -123.680 & 38.900 & 37.960 \\
Stinson Beach & -122.720 & -122.560 & 37.840 & 38.360 \\
Point Reyes & -123.100 & -122.800 & 37.960 & 38.200 \\
Marin County & -122.650 & -122.500 & 37.700 & 38.200 \\
San Francisco & -122.540 & -121.920 & 37.360 & 37.812 \\
Golden Gate & -122.480 & -122.428 & 37.800 & 37.660 \\
West Frisco & -122.540 & -122.480 & 37.700 & 37.532 \\
Pacifica & -122.540 & -122.480 & 37.592 & 36.988 \\
Half Moon Bay & -122.540 & -122.420 & 37.420 & 36.940 \\
Santa Cruz & -122.100 & -121.900 & 36.940 & 36.644 \\
Monterey Bay & -121.824 & -121.732 & 36.700 & 35.452 \\
Monterey & -122.000 & -121.840 & 36.580 & 35.184 \\
Morro Bay & -120.912 & -120.820 & 35.312 & 34.424 \\
Avila Beach & -120.780 & -120.580 & 35.080 & 34.288 \\
Santa Barbara & -119.900 & -119.500 & 34.380 & 34.372 \\
Ventura & -119.324 & -119.144 & 34.108 & 34.140 \\
Rincon & -119.460 & -119.340 & 34.300 & 34.060 \\
Point Mugu & -119.136 & -119.060 & 34.084 & 34.044 \\
Malibu & -118.968 & -118.816 & 34.000 & \\
Malibu & -118.812 & -118.540 & 34.000 &
\end{tabular}




$\begin{array}{ccccc}\text { Santa Monica } & -118.520 & -118.420 & 33.948 & 34.032 \\ \text { Manhattan Beach } & -118.440 & -118.380 & 33.880 & 33.932 \\ \text { Redondo Beach } & -118.408 & -118.380 & 33.800 & 33.860 \\ \text { POLA/POLB } & -118.300 & -118.000 & 33.700 & 33.788 \\ \text { Huntington Beach } & -118.048 & -117.940 & 33.640 & 33.692 \\ \text { Newport Beach } & -117.984 & -117.852 & 33.584 & 33.640 \\ \text { Avalon } & -118.336 & -118.304 & 33.332 & 33.360 \\ \text { Isthmus } & -118.516 & -118.484 & 33.420 & 33.456 \\ \text { Laguna Beach } & -117.800 & -117.760 & 33.520 & 33.560 \\ \text { Dana Point } & -117.712 & -117.632 & 33.432 & 33.480 \\ \text { San Clemente } & -117.628 & -117.588 & 33.384 & 33.428 \\ \text { San Onofre } & -117.584 & -117.540 & 33.356 & 33.384 \\ \text { Oceanside } & -117.420 & -117.320 & 33.140 & 33.240 \\ \text { Encinitas } & -117.320 & -117.228 & 32.924 & 33.096 \\ \text { San Diego } & -117.280 & -117.080 & 32.560 & 32.800 \\ \text { La Jolla } & -117.300 & -117.228 & 32.840 & 32.872\end{array}$

The original high-resolution grids were defined relative to mean high water (MHW). The expected highest tide on the day of the scenario is $20 \mathrm{~cm}$ above $\mathrm{MHW}$, and we lowered the elevation models by this amount to simulate the tsunami waves arriving during high tide.

Even though we used high quality elevation models that were specifically developed for tsunami inundation studies, there are still limitations to these data that can result in inaccurate inundation models. Different elevation datasets have been used to provide dense coverage for these areas, and these may have different uncertainties associated with them. Also, at a resampling to 30-m horizontal resolution it is possible that certain narrow features such as levees disappear or develop holes that can allow inundation to take place where in reality the levees would be sufficient to keep the water out.

\section{Results}

The simulations were run on a computing cluster at the URS Corporation office in Los Angeles. We ran simultaneous runs for the different subregions, each of which consisted of several levels of child grids. The entire set of simulations typically would take a day and a half to complete.

The results that are presented here come in different forms, such as maps of maximum amplitude, velocity, and momentum, as well as time series of wave height and velocity. The maxima are taken over the entire duration of the simulations (15 hours). The maps of maximum wave amplitudes show the maximum amplitude and extent of the inundation over the timespan of the computations. We also computed flow depth, which is the height of the water column at any place. The maps of nearshore and onshore maximum amplitudes are all taken from the 0.96 arc sec $(\sim 30 \mathrm{~m})$ grids. In some cases, permeable structures such as jetties and breakwaters are represented as solid walls in the original models. The holes created by the resampling in these cases may (inadvertently) result in a more realistic modeling environment in those cases.

\section{Ocean Propagation}

In figure 27, we show the maximum wave amplitudes across the northeastern Pacific, from the source in Alaska to the target areas along the California coast. Several characteristics of tsunami wave propagation are discernible on this map (with the annotations corresponding to the list below):

- Source directivity - the amplitude patterns show a clear directional dependence, with the maxima in direction perpendicular to the strike of the fault plane (A). This is because the wavefront in that direction is linear in shape, which reduces the attenuation due to geometrical spreading. 
- Focusing due to ocean bathymetry - an example is the effect of the Cobb-Eickelberg seamount chain (B), which has a shallower bathymetry and thus lower propagation velocity, than the surrounding ocean and therefore acts as a waveguide, which can lead to areas of elevated tsunami amplitudes along the coast.

- The Mendocino Fracture Zone - this feature (C) often acts as a waveguide, especially for tsunami arriving from sources farther to the west, such as the Kurile subduction zone and Japan. In the scenario case, we still see some effect as well, because it defines a significant contrast in bathymetry.

- Shoaling - as the bathymetry becomes shallower, the amplitude of the tsunami waves increases, an effect called shoaling, and this is clearly visible along most of the coastline (D). This effect is even more pronounced when we look at the higher resolution inundation maps.

- Coastline geometry - the shape of the California coast, bending east near Lompoc, causes the impact of tsunami from the north to be significantly reduced there compared to central California. The Continental Borderlands are in a kind of shadow zone (E) and in general the tsunami hazard there is smaller than elsewhere along the California coast. 


\section{SAFRR Scenario Maximum Amplitudes}
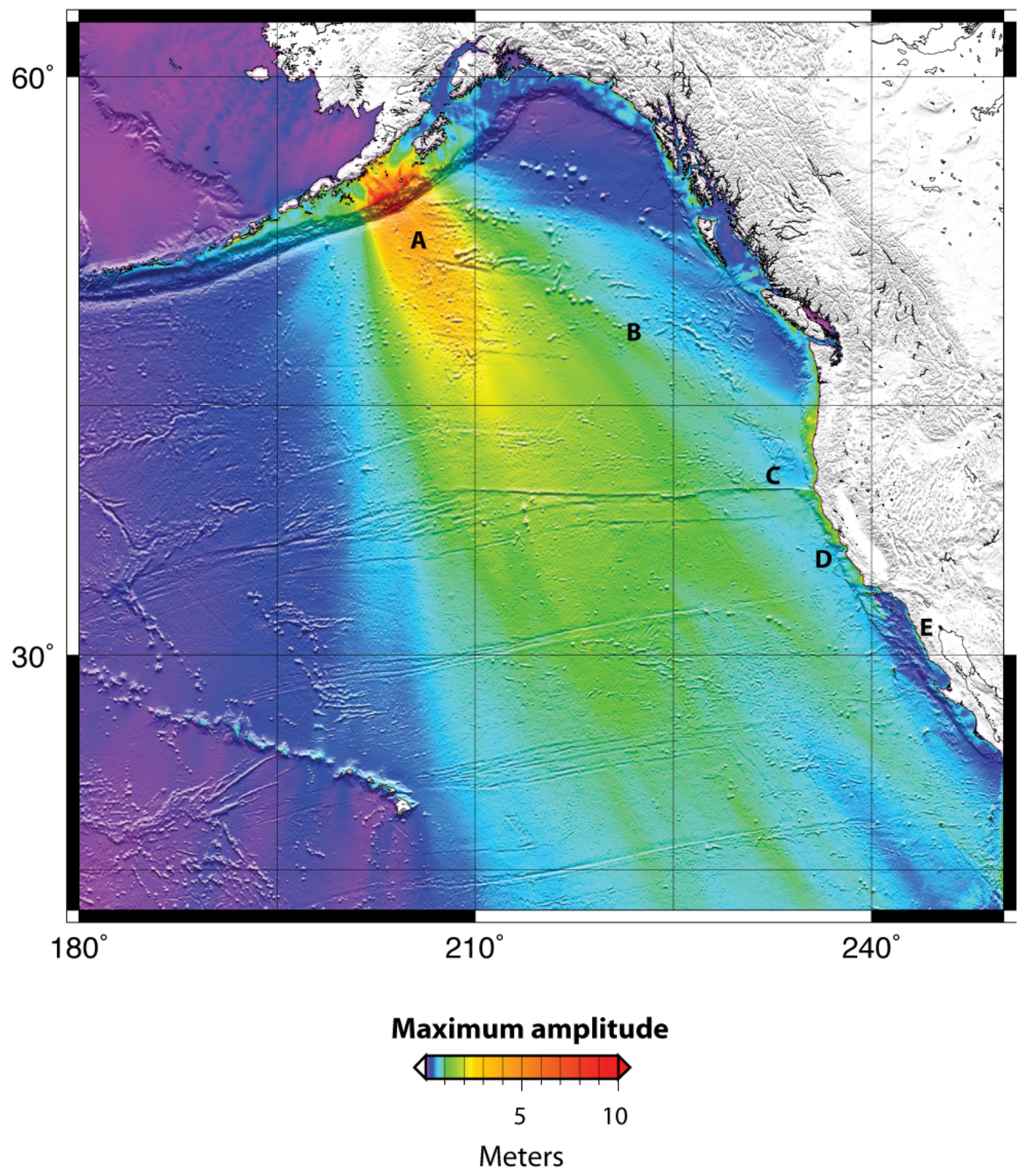

Figure 27. Map of maximum tsunami amplitudes. The letters mark locations referred to in the text. 
Figure 28 shows the water-level time series (marigrams) for selected points ordered from south at the top to north at the bottom. The move-out due to longer distances from north to south is very clear. Travel times to California range from 4 hours to Crescent City to almost 6 hours to San Diego. The waveforms are quite different in character. Although all the initial waves are up, only rarely is the first arrival the largest arrival (for example, Monterey Bay, Morro Bay). In most cases the largest waves arrive several hours, and sometimes more than 7 hours, after the initial arrival. Especially in southern California, the tsunami waves attenuate only slowly in time, which may be partly a result of trapped energy in the Continental Borderlands.

\section{Nearshore and Onshore Results}

As mentioned before, as waves move closer to shore their amplitudes increase because of the shoaling effect. This is clearly visible in the high-resolution maps, such as the one for the Ports of Los Angeles and Long Beach, shown in figure 29. Whereas the amplitudes in deep water are on the order of $1 \mathrm{~m}$, they increase to more than 2 and even up to $4 \mathrm{~m}$ at the shoreline and inland. Our model predicts some significant inundation along the waterfront in Long Beach and Seal Beach, as well as in some of the inner harbor areas. The inundation flow depths, which are also shown in figure 29 (only for areas with elevation higher than $\mathrm{MHW}$ ) reach up to $2 \mathrm{~m}$ in a few locations. As mentioned before, we should be careful to interpret these results directly without evaluating the detailed local topography, but it is clear that this scenario produces significant tsunami amplitudes in this area. The complete 3-component time series (east and north velocity and wave height) at a location within the harbor area (fig. 30) shows significant wave activity for more than 8 hours after the first onset of the tsunami. Here, depth-averaged peak velocities are on the order of $0.5 \mathrm{~m} / \mathrm{s}$, with the maximum amplitude at around $1 \mathrm{~m}$. 


\section{Tsunami timeseries}

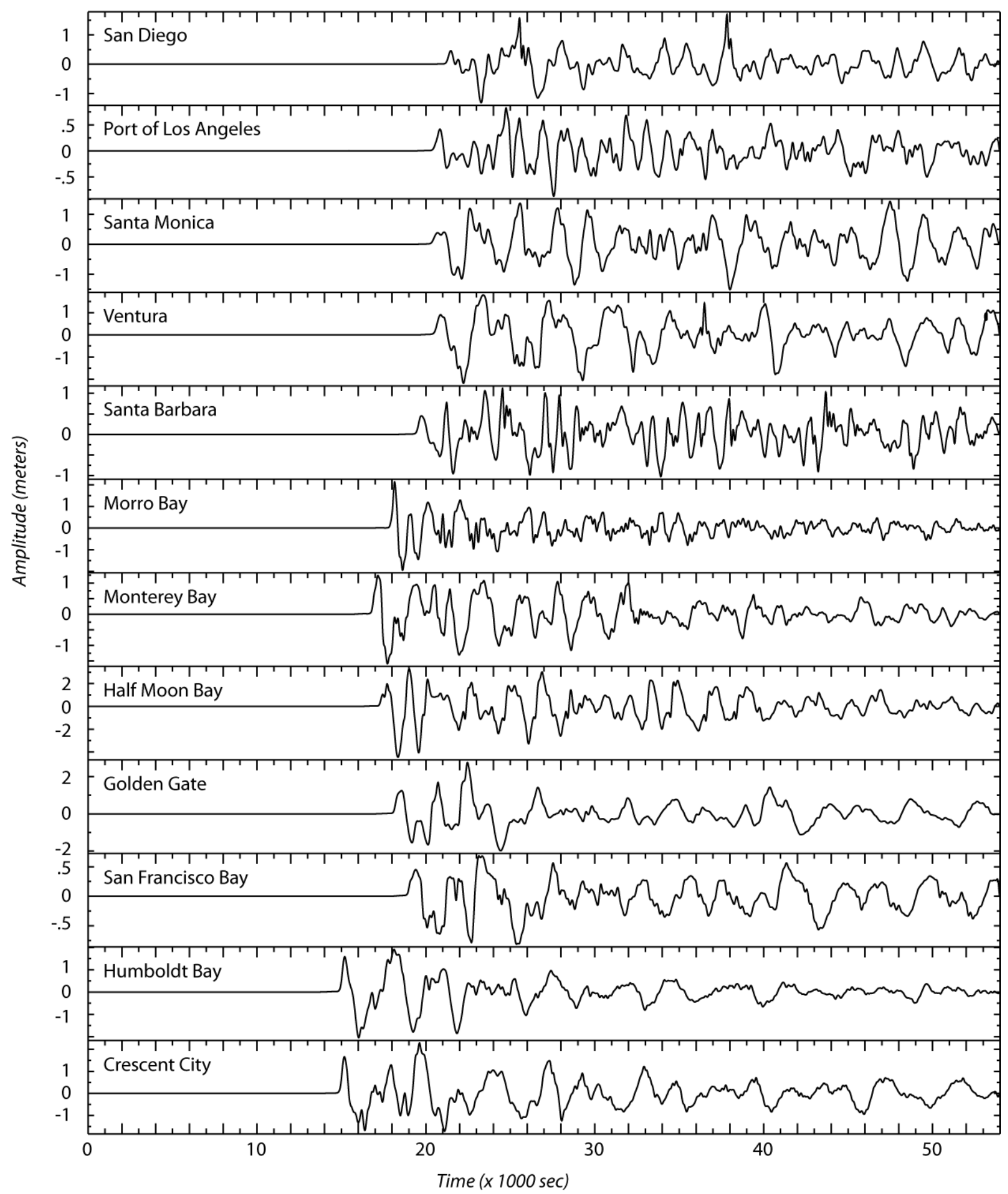

Figure 28. Tsunami wave-height time series (marigrams) from the scenario tsunami for various locations along the California coast. 


\section{Ports of Los Angeles/Long Beach}
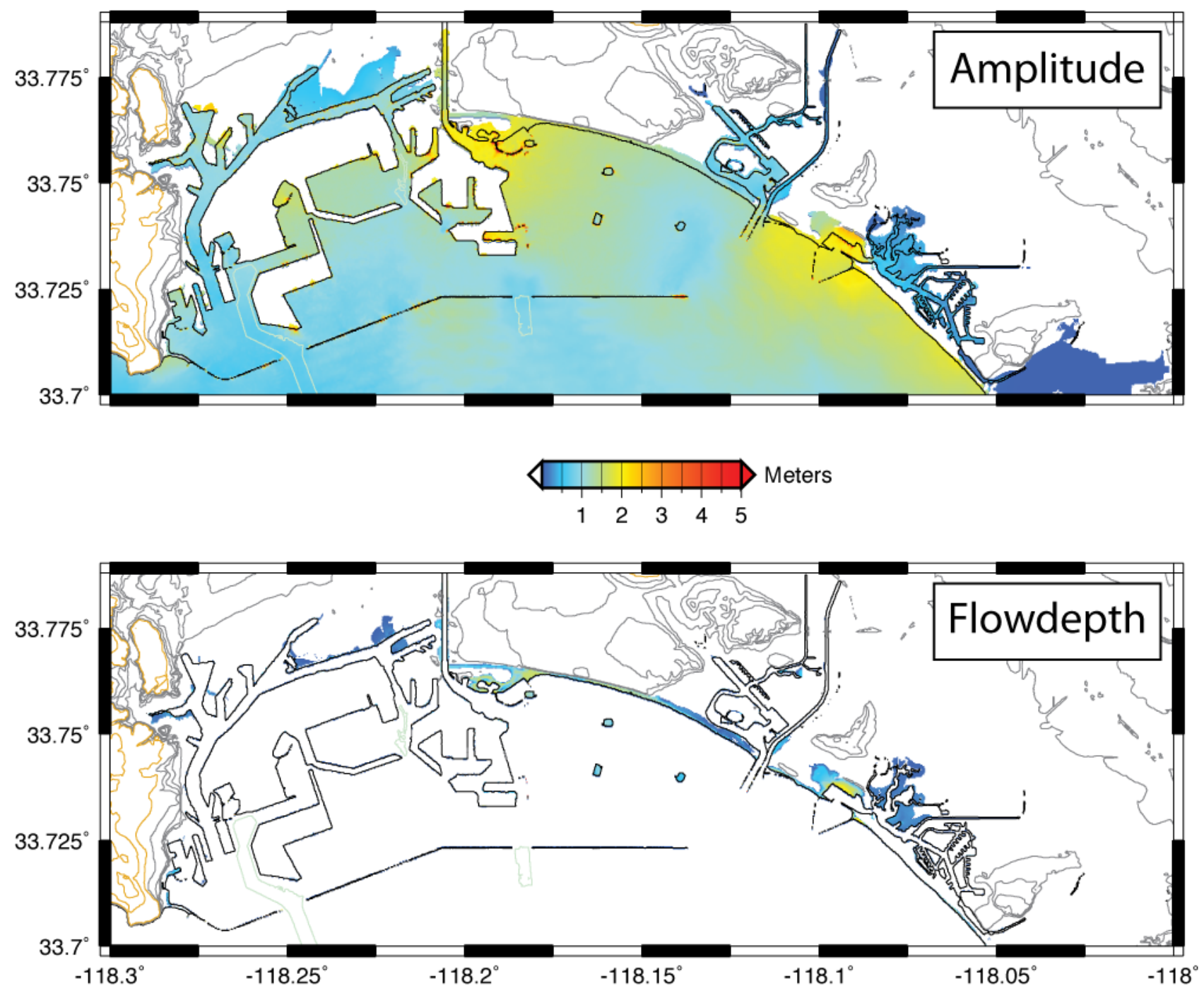

Figure 29. Maps showing maximum amplitude (top) and maximum flow depth (bottom) in and around the Ports of Los Angeles and Long Beach. The flow depths are only shown for areas where the elevations are above mean high water. Color bar refers to both amplitude and flow depth. 


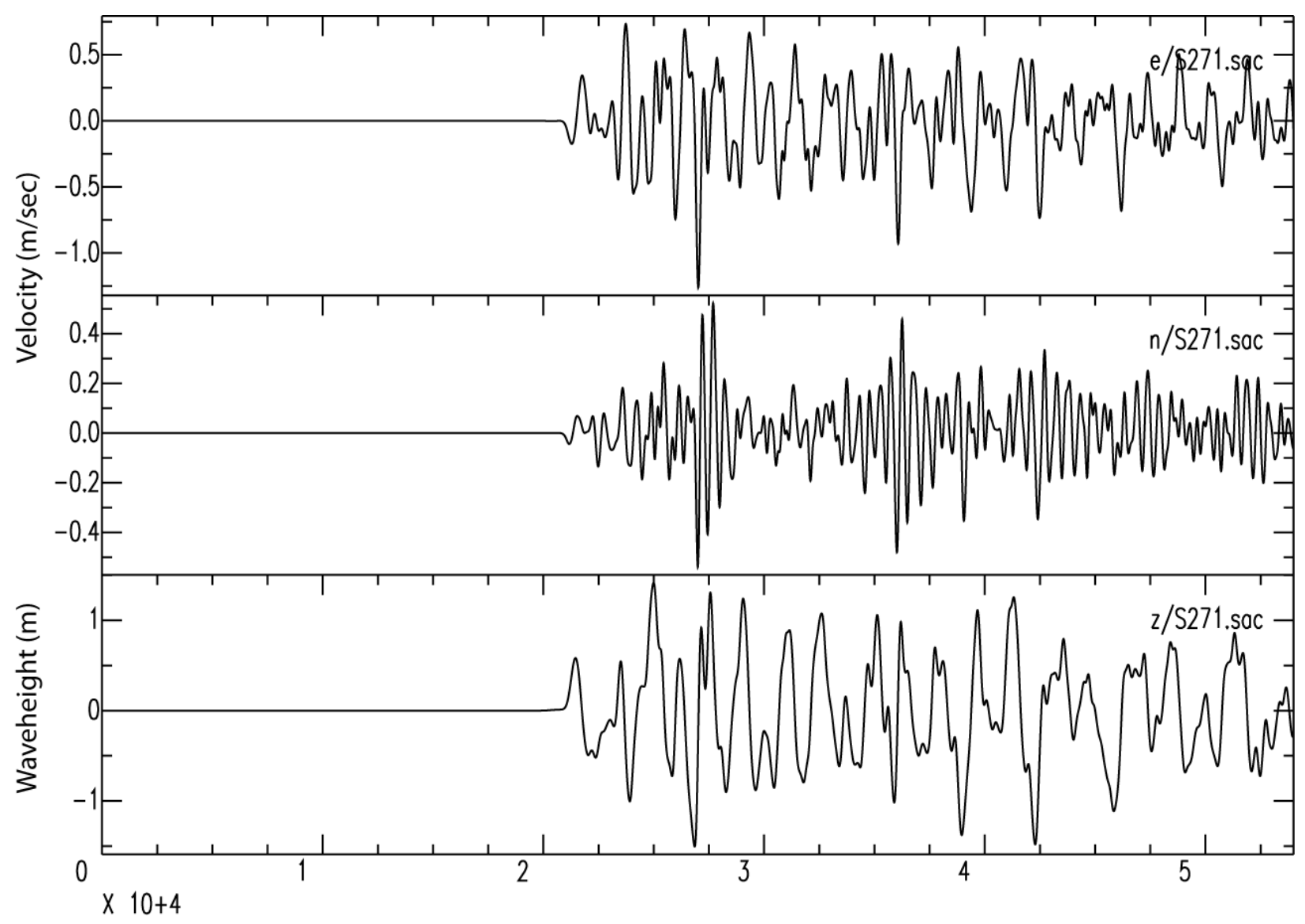

Time in seconds $(x$ 10000)

Figure 30. Time series of velocity (east, top; north, center) and wave height (bottom) for the scenario tsunami waves in the Port of Los Angeles.

In figures 31 through 38, we present similar maps for a few selected high-resolution areas along the coast. Crescent City (fig. 31) shows significant flooding of the harbor and downtown area, which is not unexpected given the severe damage that the city experienced after the 1964 Alaska earthquake. Judging from the large-scale tsunami pattern in figure 27, it appears that in addition to local resonance effects (Horrillo and others, 2008; Kowalik and others, 2008; Dengler and Uslu, 2011), the focusing due to the Cobb-Eickelberg seamount chain may contribute to the severity of the tsunami in this region.

Tsunamis increase in height as they approach the shore. In southern California, the tsunami amplitudes would range from 1 to 3 meters near shore. In central California, from Lompoc through Marin County, they would range from 2 to 7 meters in amplitude. And in northern California, the range would be from 3 to 7 meters. Project modelers assumed high tide conditions, increasing the total tsunami height by about a meter. Note that the color scale in the figures saturates at $5 \mathrm{~m}$, so the figures do not fully show the highest tsunami amplitudes. 


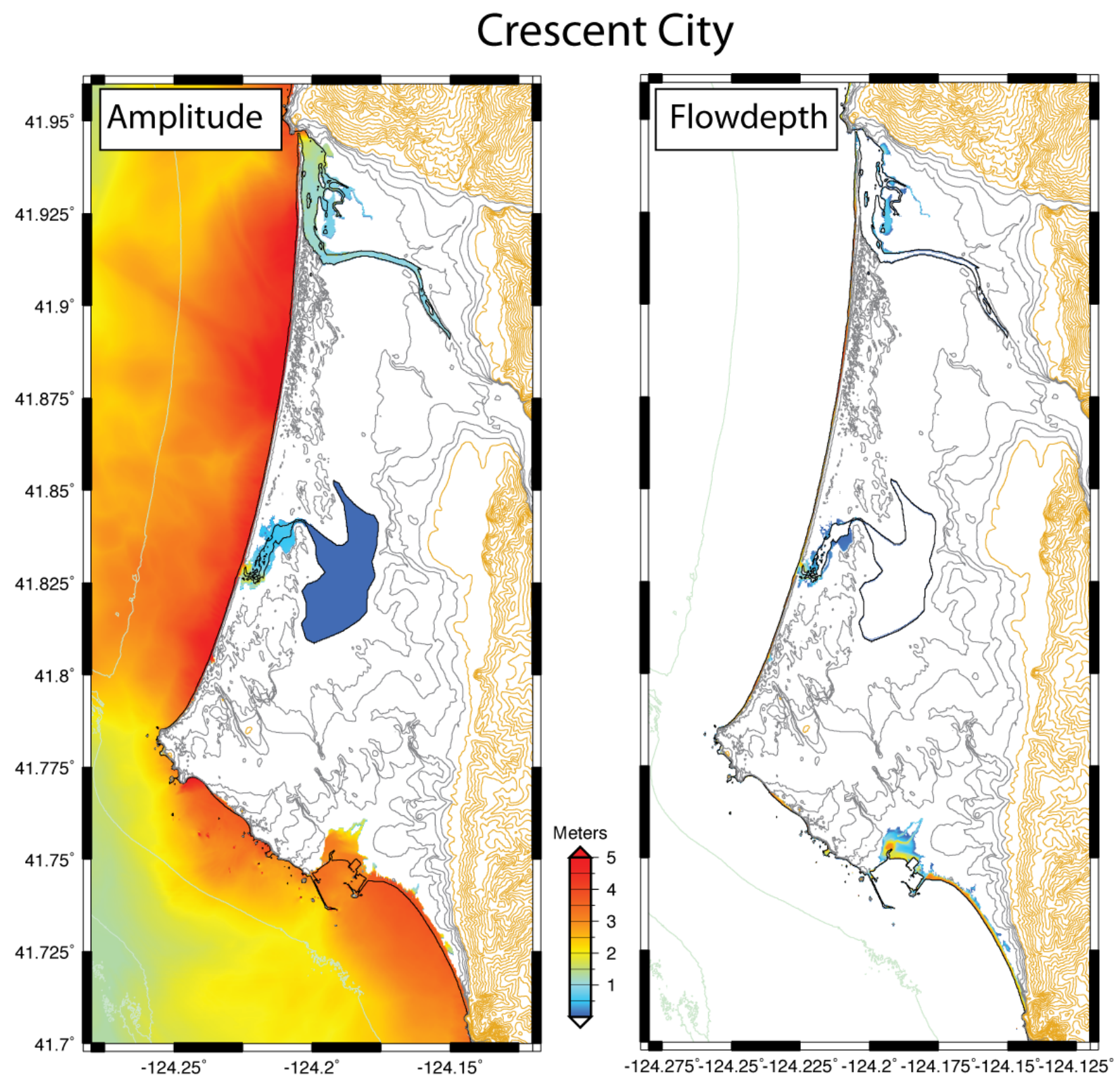

Figure 31. Maps showing maximum amplitude and flow depth of the scenario tsunami around Crescent City, California.

Farther south, we find significant tsunami wave heights and some inundation all along the central California coast, such as at the Golden Gate entrance to San Francisco Bay (fig. 32), Half Moon Bay (fig. 33), Monterey Bay (fig. 34), Morro Bay (fig. 35), and Port San Luis (fig. 36). Entering the Continental Borderlands area in Southern California, the tsunami amplitudes decrease, as was already visible in figure 4 and can also be seen, for instance, on the maps of Ventura (fig. 37), the Los Angeles/Long Beach Ports (fig. 29), and the San Diego area (fig. 38). 


\section{Golden Gate}
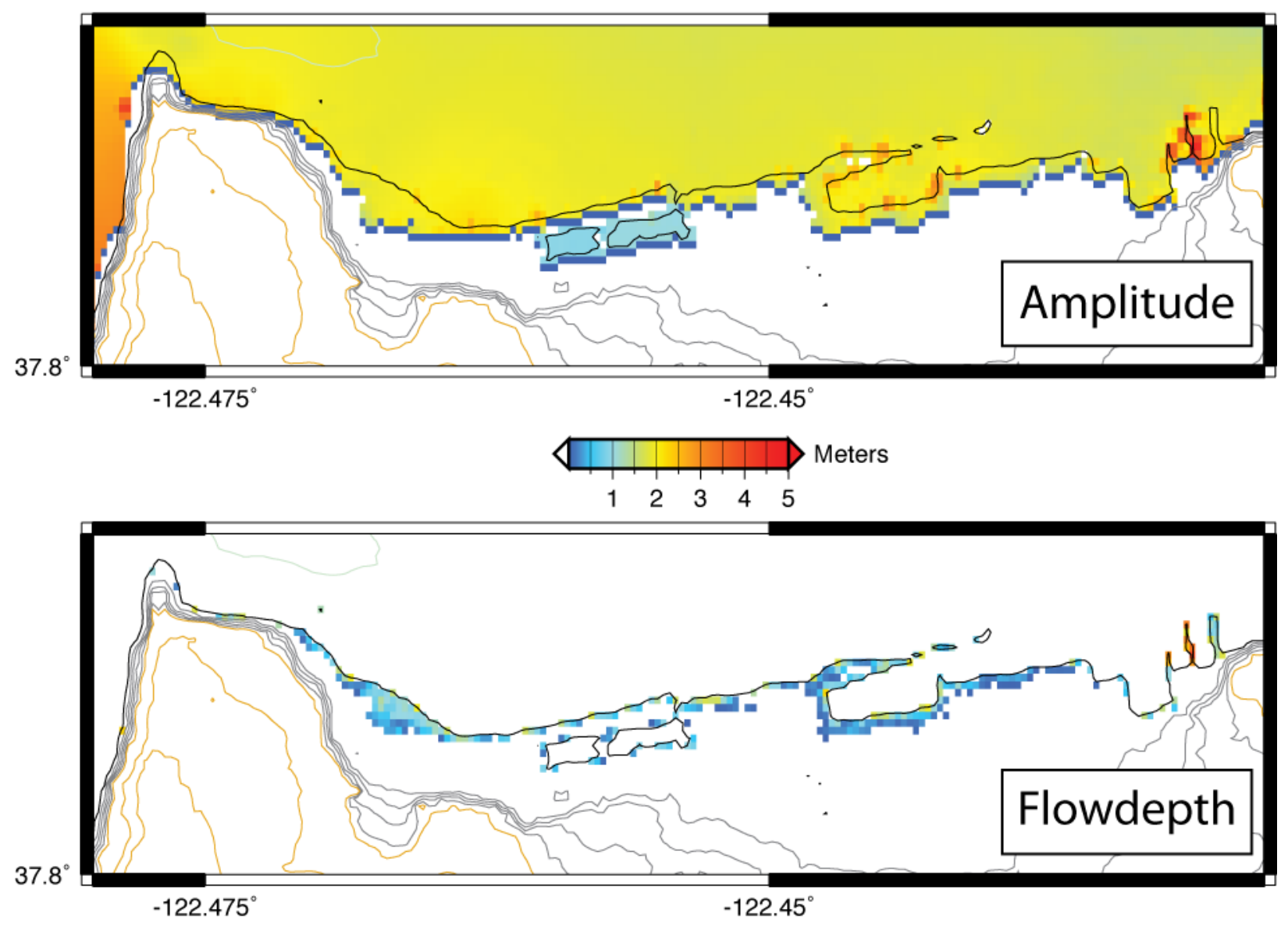

Figure 32. Maps showing maximum amplitude and flow depth of the scenario tsunami around the San Francisco shoreline just inside the Golden Gate. 


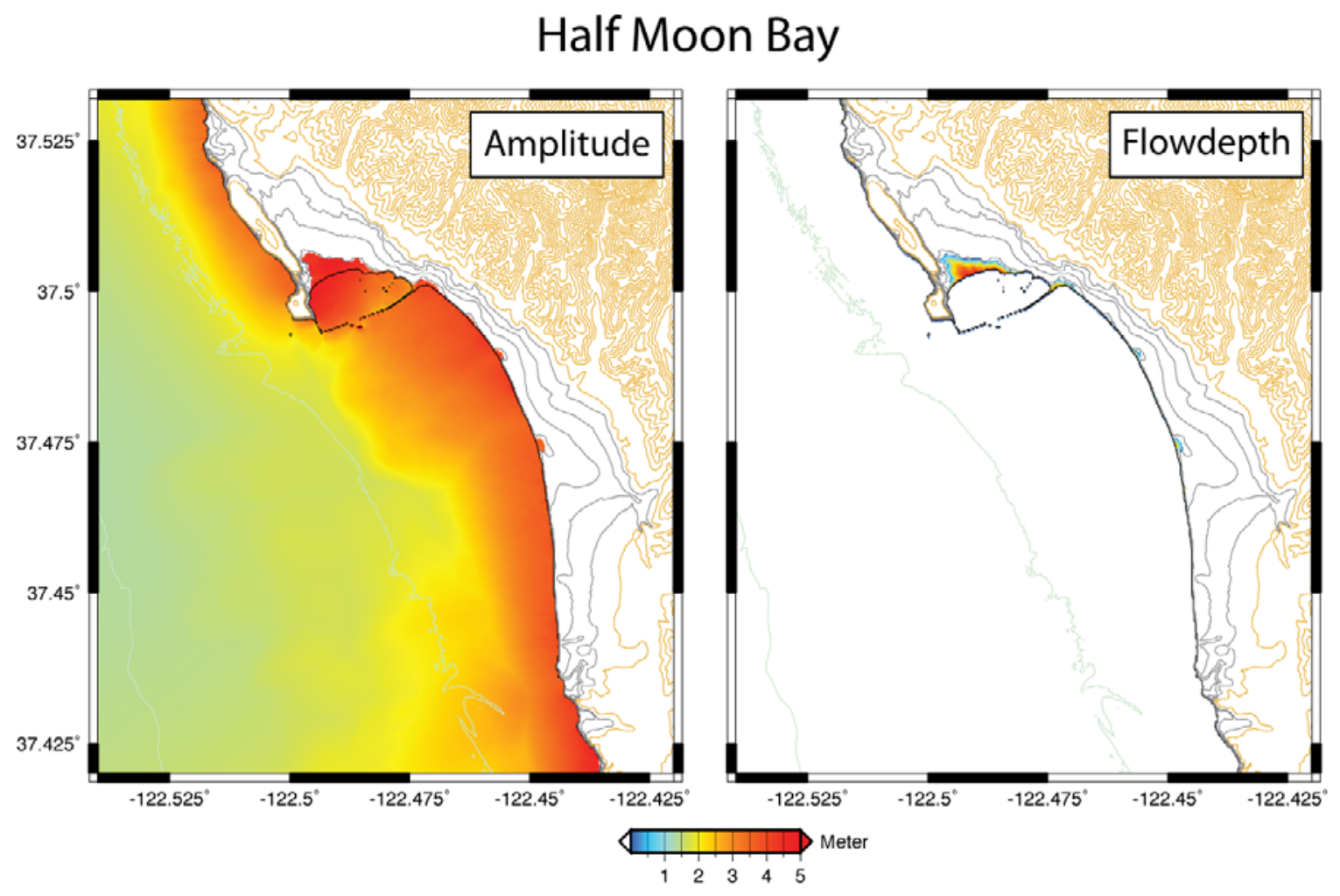

Figure 33. Maps showing maximum amplitude and flow depth of the scenario tsunami in Half Moon Bay, California. 


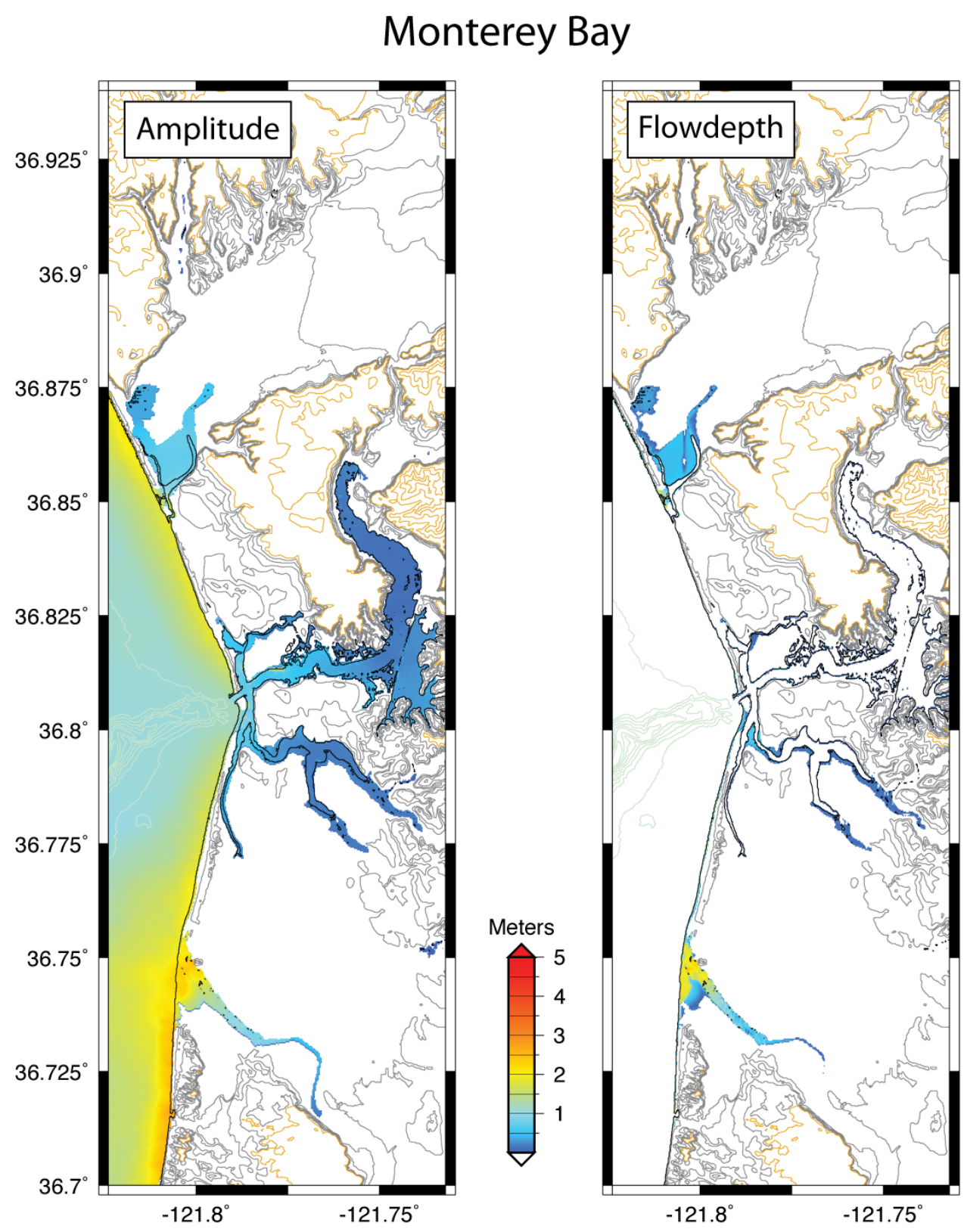

Figure 34. Maps showing maximum amplitude and flow depth of the scenario tsunami along the eastern shore of Monterey Bay, California. 


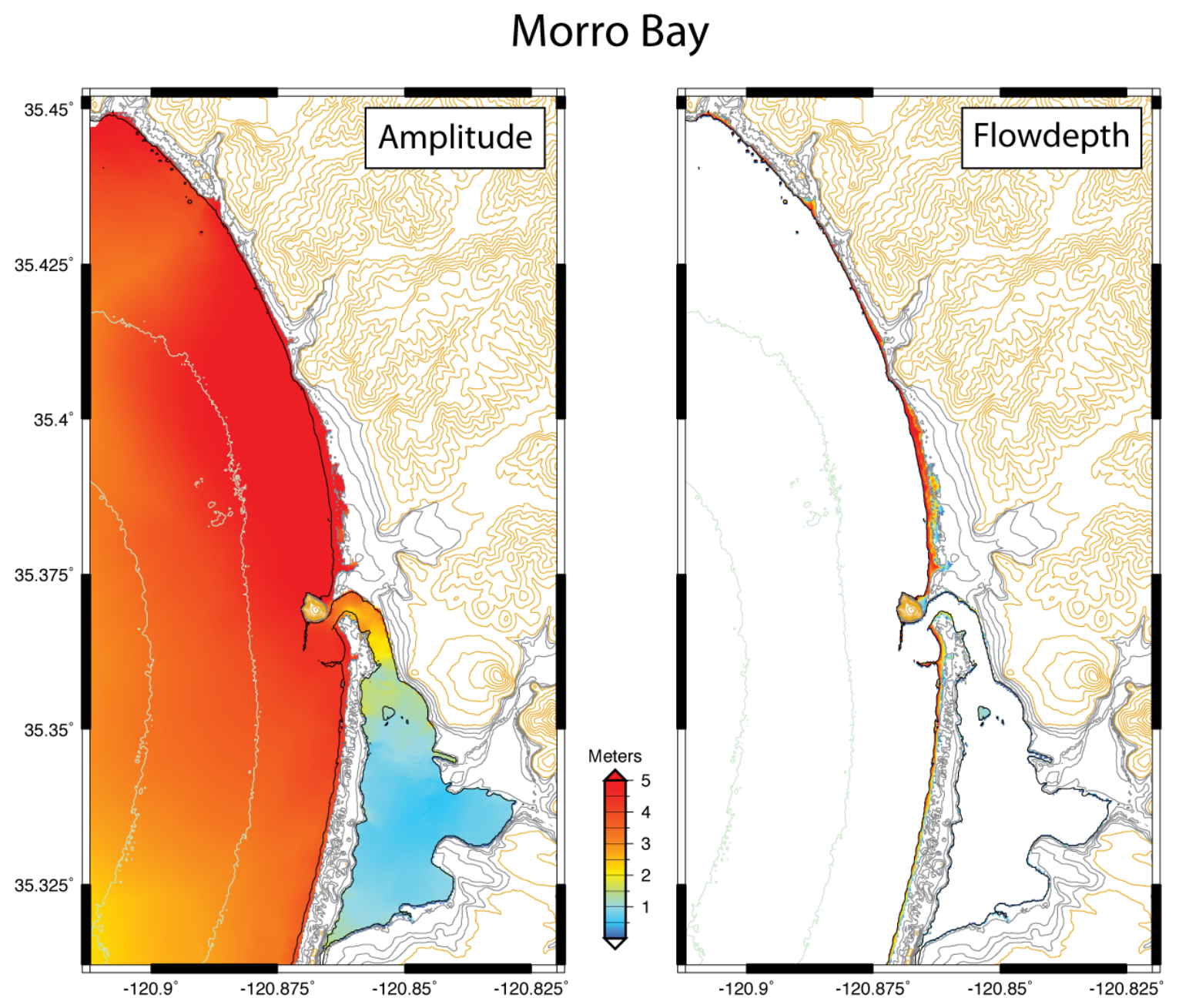

Figure 35. Maps showing maximum amplitude and flow depth of the scenario tsunami around Morro Bay, California. 


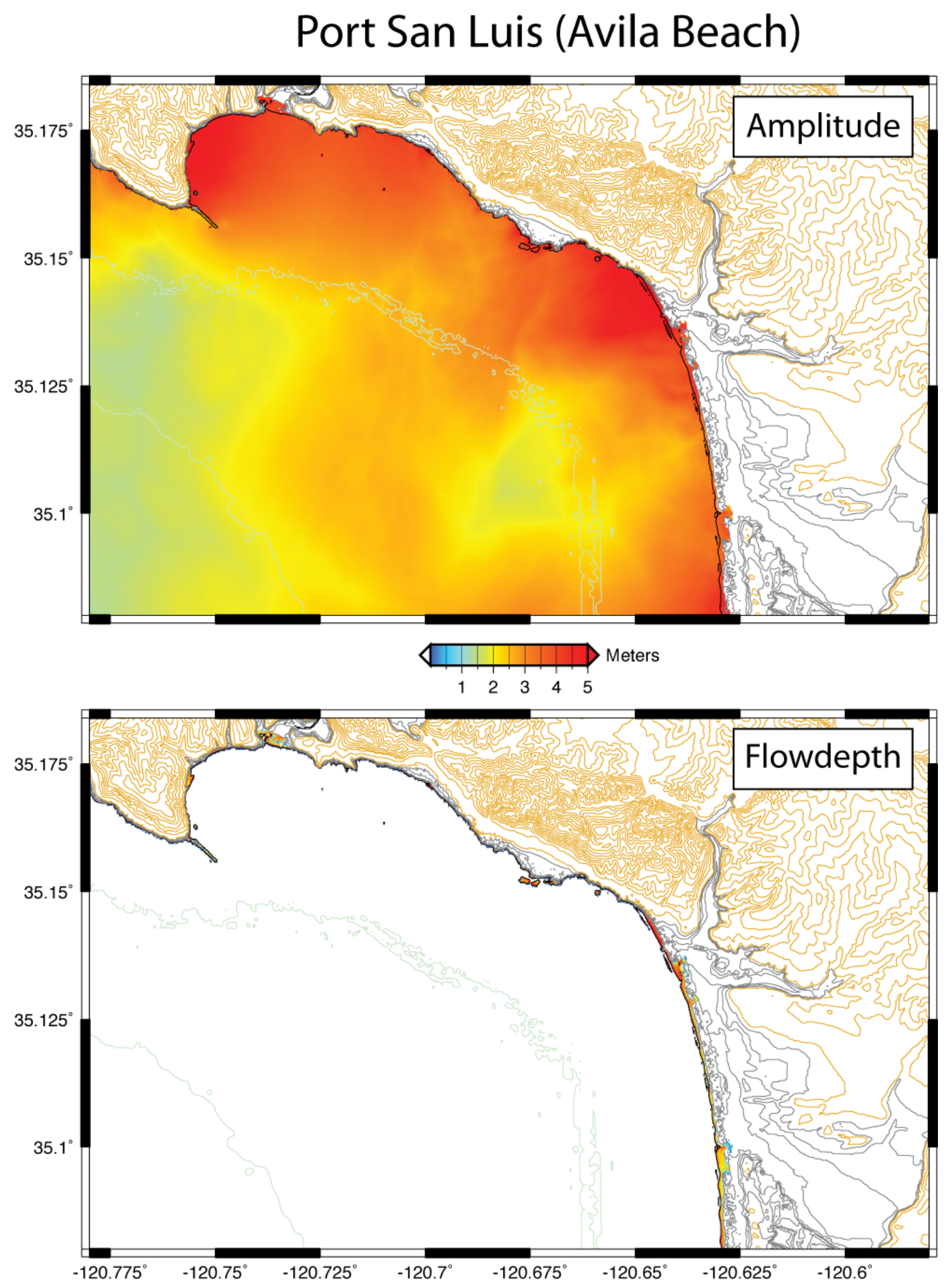

Figure 36. Maps showing maximum amplitude and flow depth of the scenario tsunami around Avila Beach, California. 
Ventura
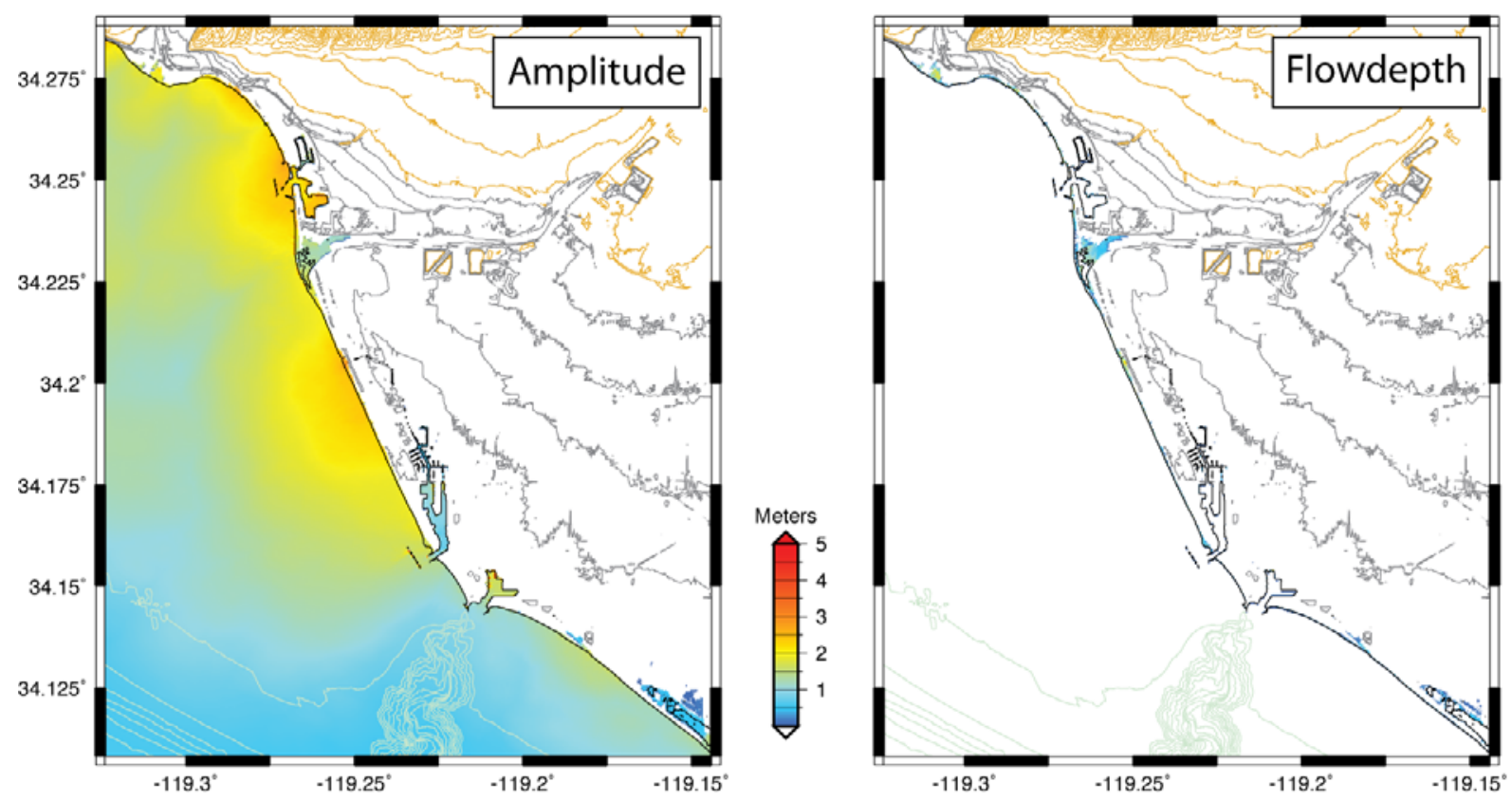

Figure 37. Maps showing maximum amplitude and flow depth of the scenario tsunami at Ventura, California.

\section{San Diego}
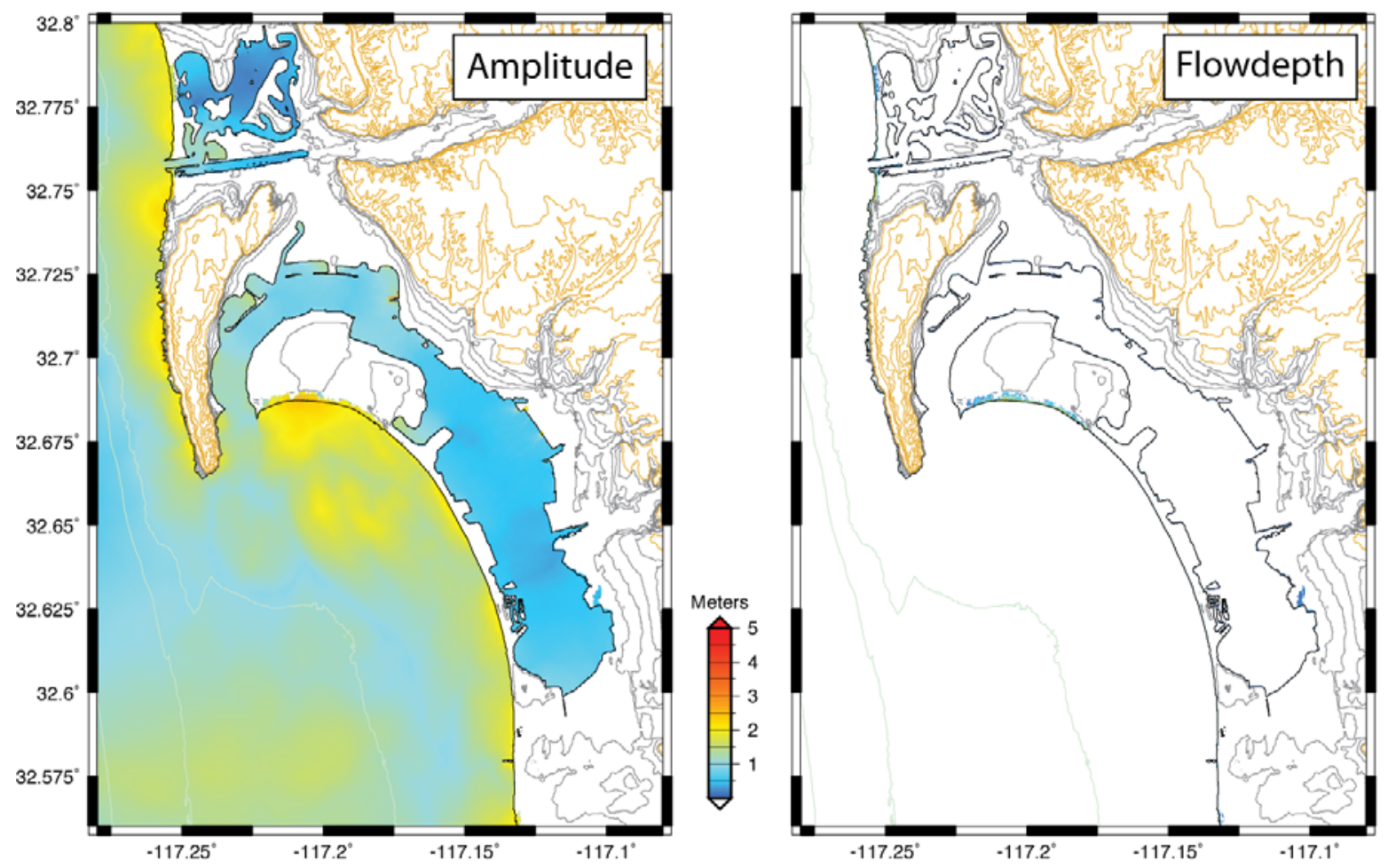

Figure 38. Maps showing maximum amplitude and flow depth of the scenario tsunami at San Diego, California. 
The locations of all these detailed maps are shown in figure 26, but they can also be found tabulated and referenced in tables 4 through 6 . All the high-resolution maps have been made available in ASCII format as well as in the form of kmz files for viewing in Google Earth. The contents of the data files (both primary wave height/drawdown and velocity data, as well as derived products such as momentum flux, are explained below.

\section{Explanation of Data Files}

The maps and other products derived using software of the URS Corporation show the results of the modeling of the scenario tsunami along different parts of the California coast. All maps are at a resolution of approximately $30 \mathrm{~m}$ and were derived from the database provided by the National Geophysical Data Center's Tsunami Gridding Project (http://www.ngdc.noaa.gov/mgg/inundation/). The $\mathrm{kmz}$ files contain the following types of data (using the Oceanside grid as example):

- Inundation-Oceanside.kmz - map of maximum tsunami amplitude. Units are meters, relative to reference level, which is high tide $+0.2 \mathrm{~m}$ (maximum tide level for that particular day).

- Flowdepth-Oceanside.kmz - map of maximum height of the water level above the ground surface at any location. Derived from maximum tsunami amplitude minus the topography.

- Velocity-Oceanside.kmz - map of maximum flow speed $(\mathrm{m} / \mathrm{s})$ in any direction. Note that the velocity is recorded for any flow depth, and large velocities beyond the shorelines may reflect movement of very thin layers of water during inundation.

- Drawdown-Oceanside.kmz - lowest tsunami amplitude relative to the reference level (high tide + $0.2 \mathrm{~m})$.

- Mindepth-Oceanside.kmz - map of minimum height of the water level relative to the solid ground (including seafloor). These maps are primarily useful to study the possibility of vessels running aground during drawdown. 


\title{
4. Numerical Modeling of Tsunami Effects in Southern California from a Hypothetical M9.1 Earthquake near the Alaska Peninsula
}

\author{
By José Borrero, Costas Synolakis, and Vasily Titov
}

\section{Introduction}

The work presented here describes the hydrodynamic numerical modeling of tsunami-induced effects at several sites along the southern California coast. This modeling study is conducted in support of the U.S. Geological Survey's (USGS) SAFRR: Science Application for Risk Reduction project. The objective of this study is to describe in detail, using the best available science, the effects on the coast and infrastructure of southern California of a hypothetical, but possible, large tsunami generated by a magnitude 9.1 earthquake offshore of the Alaska Peninsula. The results will enable researchers to better understand and prepare for natural disasters and can also be disseminated as educational material for the public.

The model earthquake is defined to occur at 11:50 a.m. PDT (10:50 a.m. Alaska time) on Thursday March 27th, 2014, the 50th anniversary of the great 1964 Alaska earthquake, which generated California's most destructive tsunami in recorded history. The simulations presented here should enable emergency responders, as well as port officials and engineers, to better understand the potential impact of this type of event.

The numerical modeling presented here was carried out using the Community Model Interface for Tsunamis (ComMIT) numerical modeling tool. The ComMIT model interface was developed by the National Oceanic and Atmospheric Administration's (NOAA) Center for Tsunami Research (NCTR) following the disastrous December 26, 2004, Indian Ocean tsunami as a way to efficiently distribute assessment capabilities amongst tsunami prone countries.

The backbone of the ComMIT system is a database of precomputed deep water propagation results for tsunamis generated by unit (for example, $1 \mathrm{~m})$ displacements on fault plane segments $(100 \mathrm{x}$ $50 \mathrm{~km}$ ) positioned along the world's subduction zones. Currently, there are 1,691 precomputed unitsource propagation model runs covering the world's oceans included in the propagation database (fig. 39). Using linear superposition, the deep ocean tsunami propagation results from more complex faulting scenarios can be created by scaling and (or) combining the precomputed propagation results from a number of unit sources (Titov and others, 2011). The resulting transoceanic tsunami propagation results are then used as boundary inputs for a series of nested nearshore grids covering a coastline of interest. The nested model propagates the tsunami to shore, computing wave height, velocity, and overland inundation. The hydrodynamic calculations contained within ComMIT are based on the MOST (Method Of Splitting Tsunami) algorithm developed by Titov and Synolakis $(1995,1998)$.

During a real tsunami event, the ComMIT system can also be used in conjunction with real-time recordings of tsunami waveforms on one or more of the deep ocean tsunameter (DART) stations deployed throughout the oceans to fine-tune details of an earthquake source mechanism in real time. An iterative algorithm that selects and scales the unit source segments is used until an acceptable fit to the observed DART data is met. Because there are currently several DART stations in operation along the Aleutian trench, a tsunami emanating from this region would be recorded by the system and updated source models would be made available, allowing for an assessment of the potential tsunami impact 
before its arrival on the affected shores. This approach was used successfully to assess the impacts of the Tohoku tsunami in New Zealand (Borrero and others, 2012).

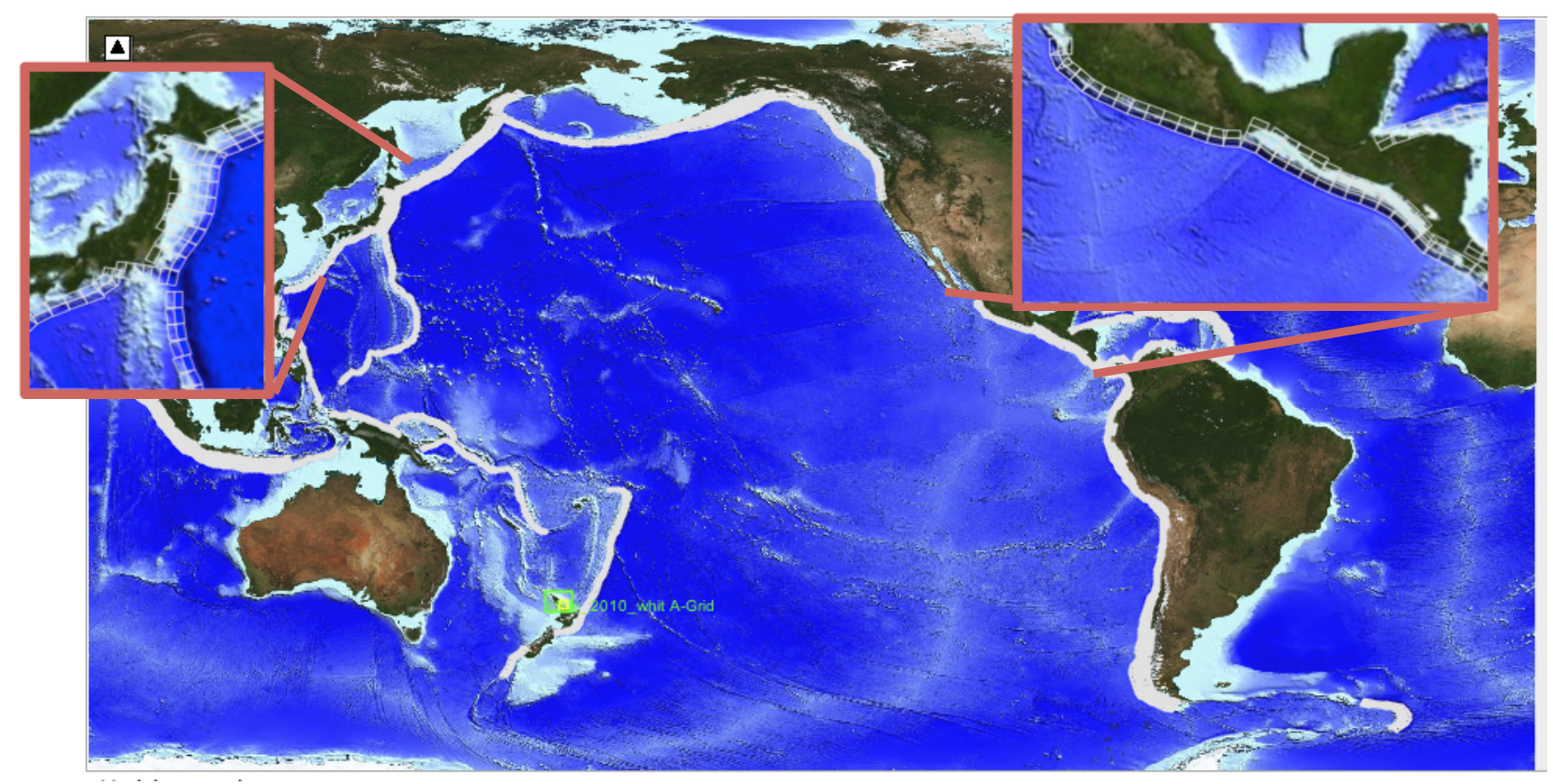

Figure 39. Map showing the source regions and potentially affected coasts in the ComMIT propagation model database for tsunamis in the world's oceans. Inset maps show the details of the source zone discretization into rectangular subfaults.

\section{Earthquake Source Model}

The earthquake source model for this scenario was defined by the U.S. Geological Survey (USGS) (fig. 40). The source was defined by 64 subfaults, each approximately $25 \times 50 \mathrm{~km}$, for a total fault plane area of $400 \times 200 \mathrm{~km}$. The sources featured variable slip amounts and dip angles. Rake was assumed to be pure dip-slip, while strike angle varied across the segments to maintain alignment with the trench bathymetry. The rock rigidity values also varied with harder material at depth (50 GPa) and softer material near the surface (30 GPa). 


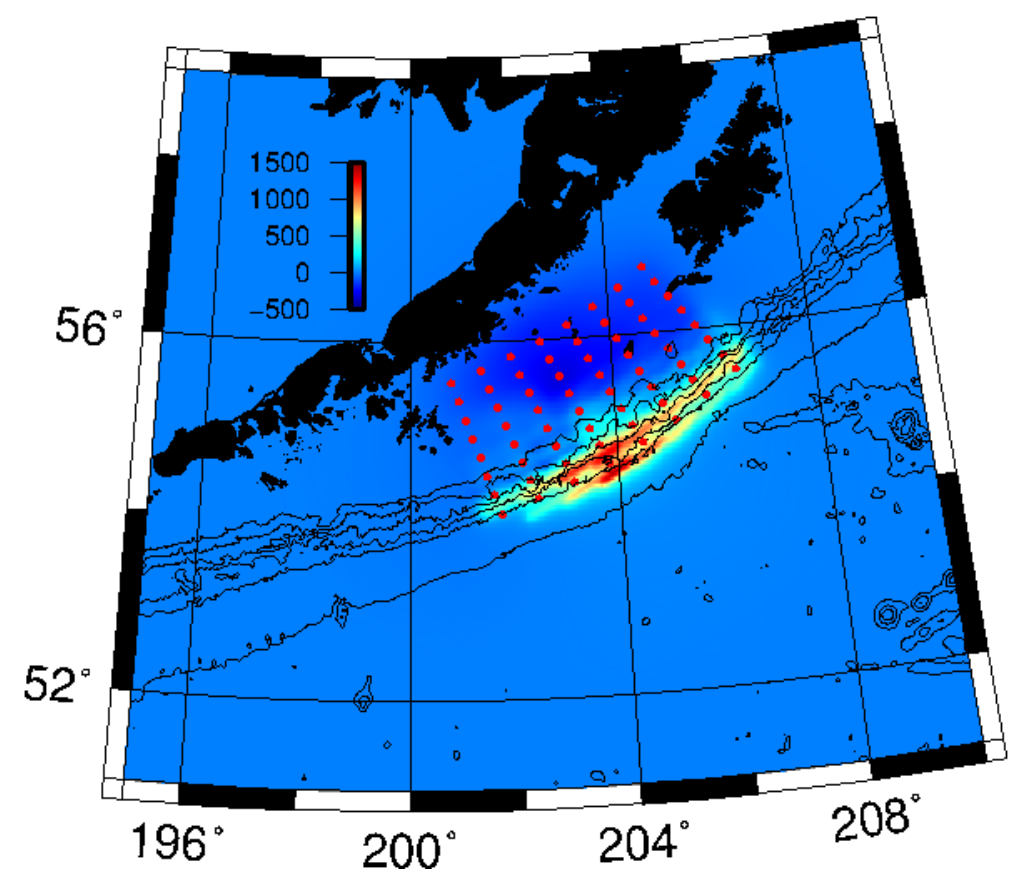

Figure 40. Map showing deformation data for the scenario tsunami provided by the USGS. Subfault epicenters are indicated by the red dots.

To calibrate the initial condition for implementation into the ComMIT model, we used the subfault information provided by USGS to initialize a version of the Okada (1985) elastic dislocation model. Figure 41 shows the output from that exercise and suggests that this particular version of the elastic deformation model gives similar result to the defined source scenario.

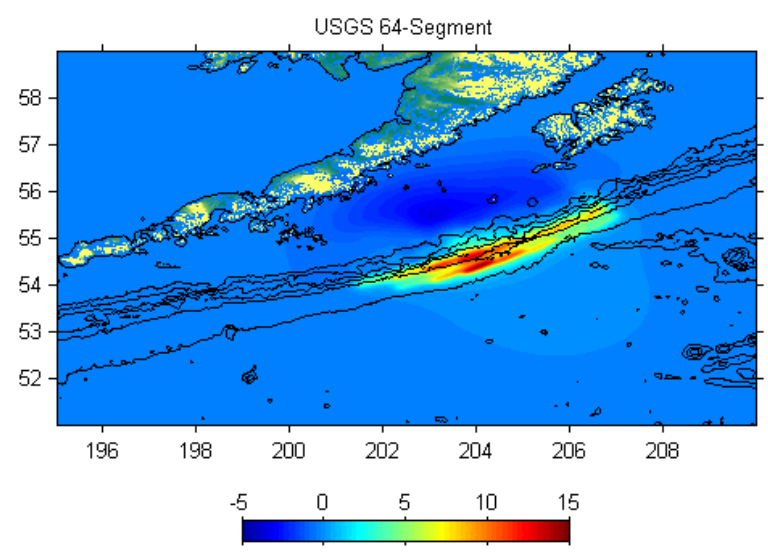

Figure 41. Map showing surface displacement computed by the MOST version of Okada's (1985) elastic dislocation model. Color scale in meters. 
Because the subfault size used in the ComMIT framework is larger than the subfaults used in the USGS source model, we adapted the 64-segment model into a 16-segment model compatible with the subfault geometry available via the ComMIT model interface as shown in figure 42 .
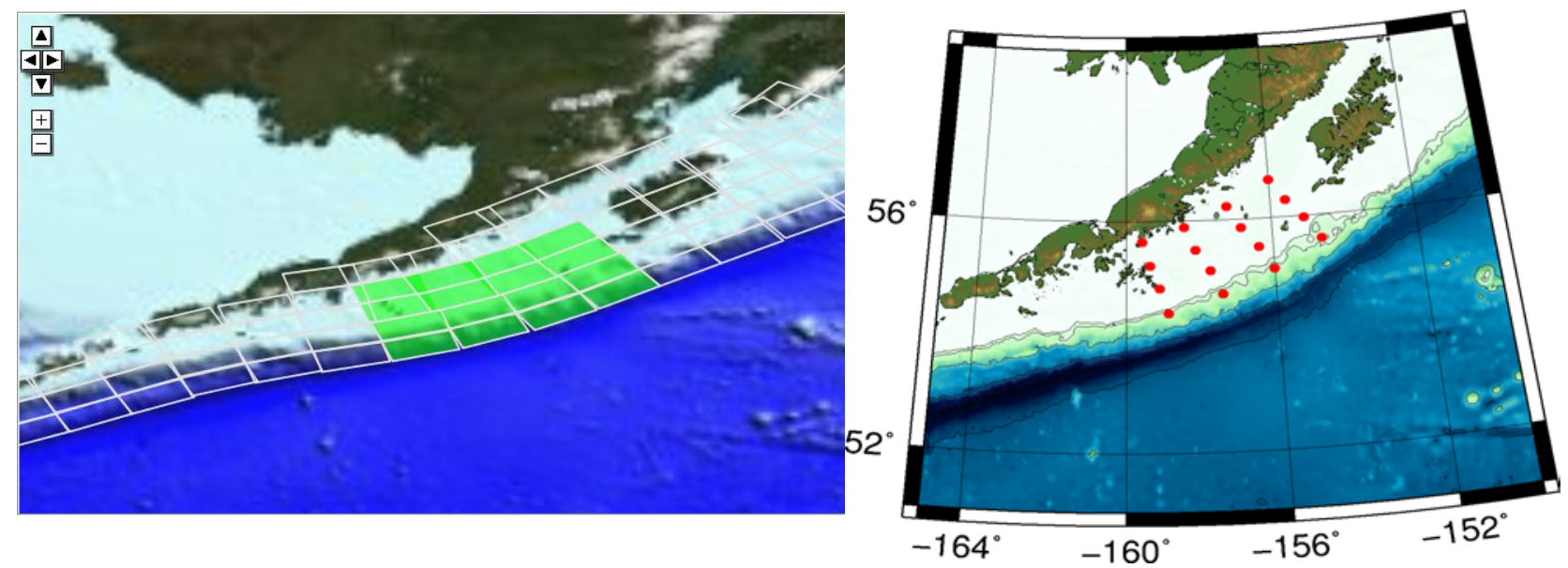

Figure 42. Maps showing the ComMIT subfault segments (left) that most closely match the source region defined for this study (right).

To implement the source model into the ComMIT model, the 64-segment source model (average slip $=18.63 \mathrm{~m}$ ) was compiled into four-segment clusters as indicated in table 7 . The average of each four-segment cluster was then used as the slip over each of the $100 \mathrm{~km} \times 50 \mathrm{~km}$ subfaults available to the ComMIT model. Slip amounts are indicated in table 8. The elastic deformation model was then used to compute the corresponding sea-floor deformation (fig. 43).

Table 7. Slip amount (in meters) on each subfault segment of the original source model. Average slip is $18.6 \mathrm{~m}$. The average slip over the four segments highlighted in red is $53 \mathrm{~m}$.

\begin{tabular}{|c|c|c|c|c|c|c|c|c|}
\hline \multirow{2}{*}{ North } & \multicolumn{5}{|c|}{ West } & \multicolumn{3}{|c|}{ East } \\
\hline & 0 & 2 & 4 & 7 & 5 & 3 & $\overline{1}$ & 0 \\
\hline & 2 & 5 & 8 & 10 & 8 & 6 & 4 & 3 \\
\hline & 4 & 10 & 15 & 20 & 15 & 10 & 8 & 6 \\
\hline & 5 & 10 & 20 & 35 & 25 & 18 & 13 & 11 \\
\hline & 8 & 15 & 25 & 47 & 35 & 25 & 20 & 18 \\
\hline & 10 & 20 & 35 & 55 & 42 & 32 & 27 & 25 \\
\hline & 15 & 30 & 50 & 65 & 50 & 40 & 35 & 33 \\
\hline South & 0 & 10 & 22 & 38 & 28 & 20 & 13 & 11 \\
\hline
\end{tabular}


Table 8. A 16-segment subfault comprising 4-segment average slip amounts from the 64-segment model. Average slip $=18.5 \mathrm{~m}$.
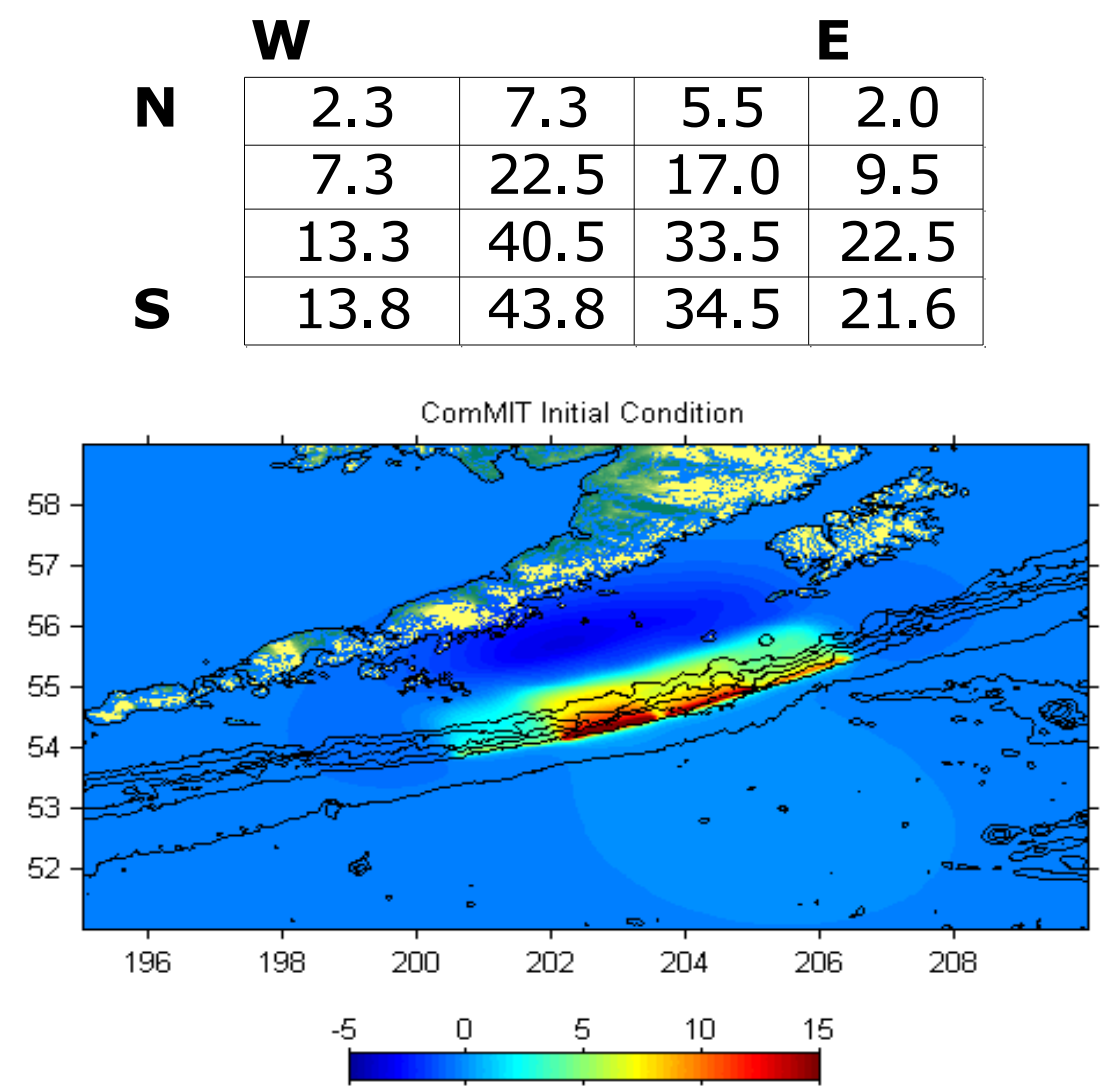

Figure 43. Maps showing surface deformation caused by a 16 -segment fault model derived from 4-segment averages of the 64-segment fault model. Color scale in meters.

It is apparent that the deformation predicted by this representation of the slip distribution is somewhat different from that in the 64-segment model. However, the magnitude and areal extent of uplift and subsidence are comparable. In an effort to fine-tune the source to fit the deformation pattern produced by the 64-segment model, we used an ad hoc, trial and error approach to distribute slip across the segments with the goal of maintaining the overall average slip. In this process we noted that choosing the four segments highlighted with the red outline in table 7 yields an average slip of $53 \mathrm{~m}$, which is larger than the average of any other grouping of four segments. We used this number simply as guidance as to what the highest allowable slip amount would be on one segment of the 16-fault model.

While there are virtually an infinite number of possible slip distributions, we eventually chose one that somewhat approximates the deformation pattern indicated in the original 64-segment approach. The primary difference between the 16-segment and 64-segment fault models is the location of the maximum displacement relative to the trench axis. The more detailed 64-segment approach is able to push the deformation towards the southeast and into deeper water than is possible with the constraints imposed by the unit-source geometry used in the ComMIT modeling approach. For this study, we present model results based on the revised deformation model (tables 9 and 10, fig. 44). 
Table 9. An ad-hoc, trial and error, modified version of the 16-segment fault model used for the simulations. Average slip $=18.6 \mathrm{~m}$.

\begin{tabular}{c|c|c|c|c|}
\multicolumn{2}{l}{$\mathbf{W}$} \\
\cline { 2 - 5 } $\mathbf{N}$ & 5 & 7 & 7 & 3 \\
\cline { 2 - 5 } & 10 & 23 & 25 & 12 \\
\cline { 2 - 5 } $\mathbf{S}$ & 15 & 30 & 48 & 15 \\
\cline { 2 - 5 } & 10 & 32 & 40 & 15 \\
\cline { 2 - 5 } & & &
\end{tabular}

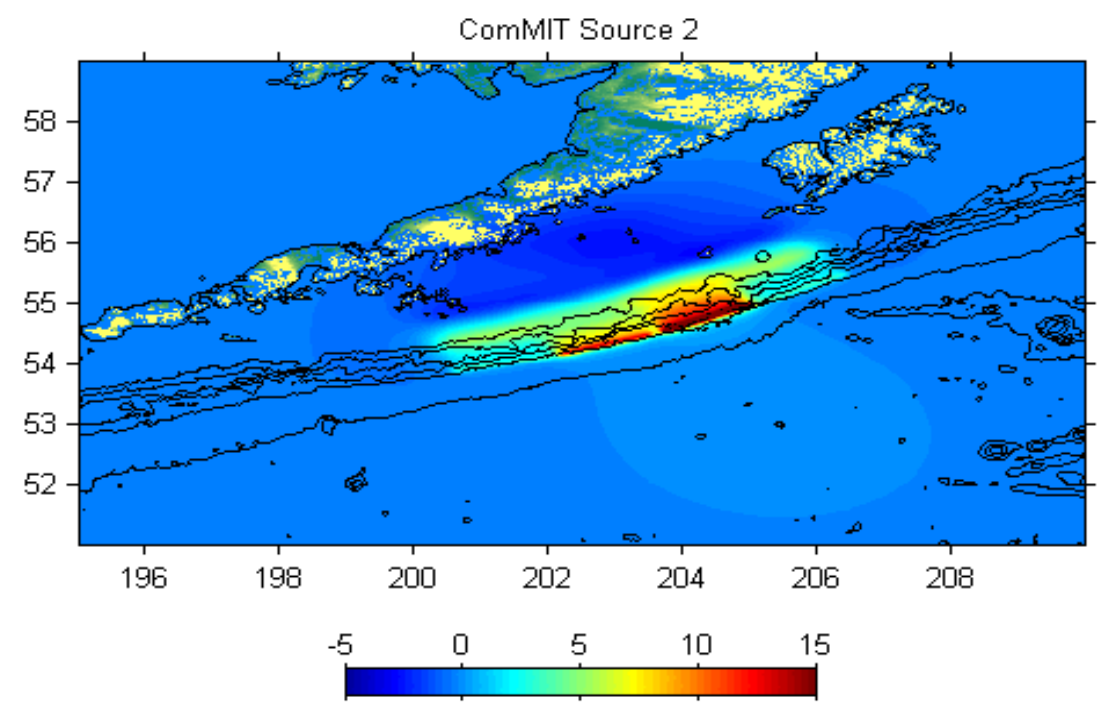

Figure 44. Map showing computed surface deformation created by an alternate version of the 16-segment fault model for the tsunami source region. Color scale in meters. 
Table 10. Fault parameters for the 16-segment source based on the NOAA-ComMIT propagation database.

\begin{tabular}{llllllll}
\hline Segment Name & Longitude (deg W) & Latitude (deg E) & Strike (deg) & Dip (deg) & Depth $(\mathbf{k m})$ & $\begin{array}{c}\text { Slip 1 } \\
(\mathbf{m})\end{array}$ & $\begin{array}{c}\text { Slip 2 } \\
(\mathbf{m})\end{array}$ \\
\hline acsz-28a & 200.882 & 54.830 & 253.0 & 15 & 17.94 & 13.3 & 15.0 \\
acsz-28b & 201.108 & 54.400 & 253.0 & 15 & 5.00 & 13.8 & 10.0 \\
acsz-28y & 200.417 & 55.641 & 252.7 & 15 & 43.82 & 2.3 & 5.0 \\
acsz-28z & 200.636 & 55.225 & 252.9 & 15 & 30.88 & 7.3 & 10.0 \\
acsz-29a & 202.261 & 55.133 & 247.0 & 15 & 17.94 & 40.5 & 30.0 \\
acsz-29b & 202.565 & 54.720 & 247.0 & 15 & 5.00 & 43.8 & 32.0 \\
acsz-29y & 201.573 & 55.889 & 246.0 & 15 & 43.82 & 7.3 & 7.0 \\
acsz-29z & 201.880 & 55.491 & 246.2 & 15 & 30.88 & 22.5 & 23.0 \\
acsz-30a & 203.604 & 55.509 & 240.0 & 15 & 17.94 & 33.5 & 48.0 \\
acsz-30b & 203.997 & 55.120 & 240.0 & 15 & 5.00 & 34.5 & 40.0 \\
acsz-30y & 202.772 & 56.232 & 240.2 & 15 & 43.82 & 5.5 & 7.0 \\
acsz-30z & 203.152 & 55.853 & 240.5 & 15 & 30.88 & 17.0 & 25.0 \\
acsz-31a & 204.895 & 55.970 & 236.0 & 15 & 17.94 & 22.5 & 15.0 \\
acsz-31b & 205.340 & 55.598 & 236.0 & 15 & 5.00 & 23.0 & 15.0 \\
acsz-31y & 203.990 & 56.661 & 235.3 & 15 & 43.82 & 2.0 & 3.0 \\
acsz-31z & 204.432 & 56.302 & 235.7 & 15 & 30.88 & 9.5 & 12.0 \\
& & & & & Average & $\mathbf{1 8 . 6}$ & $\mathbf{1 8 . 6}$ \\
\hline
\end{tabular}

\section{Bathymetry Grids}

The ComMIT model uses a system of three nested numerical grids for the nearshore inundation part of the modeling process. Model grid bathymetry was obtained from the National Geophysical Data Center's (NGDC) Tsunami Inundation Digital Elevation Models (DEM's) (NGDC:

http://www.ngdc.noaa.gov/mgg/inundation/). The data are freely available for download, and for this project we worked from the Santa Monica and San Diego datasets. Each of these datasets is provided at a resolution of $1 / 3$ arc sec, or approximately $10 \mathrm{~m}$. Coarser model bathymetry grids of $9 \operatorname{arc~sec}$ and 2 arc sec covering regional areas were constructed by downsampling the higher resolution source bathymetry. An example of the grid extents for sites in San Pedro Bay is shown in figure 45. Grid systems for a total of eight sites were produced for this study; these included Marina Del Rey in Santa Monica Bay, Long Beach, Seal Beach, Anaheim Bay, Newport Bay, Del Mar, La Jolla, and Mission Bay (Figure 46). The model datum is set to mean high water (MHW). 
(a)
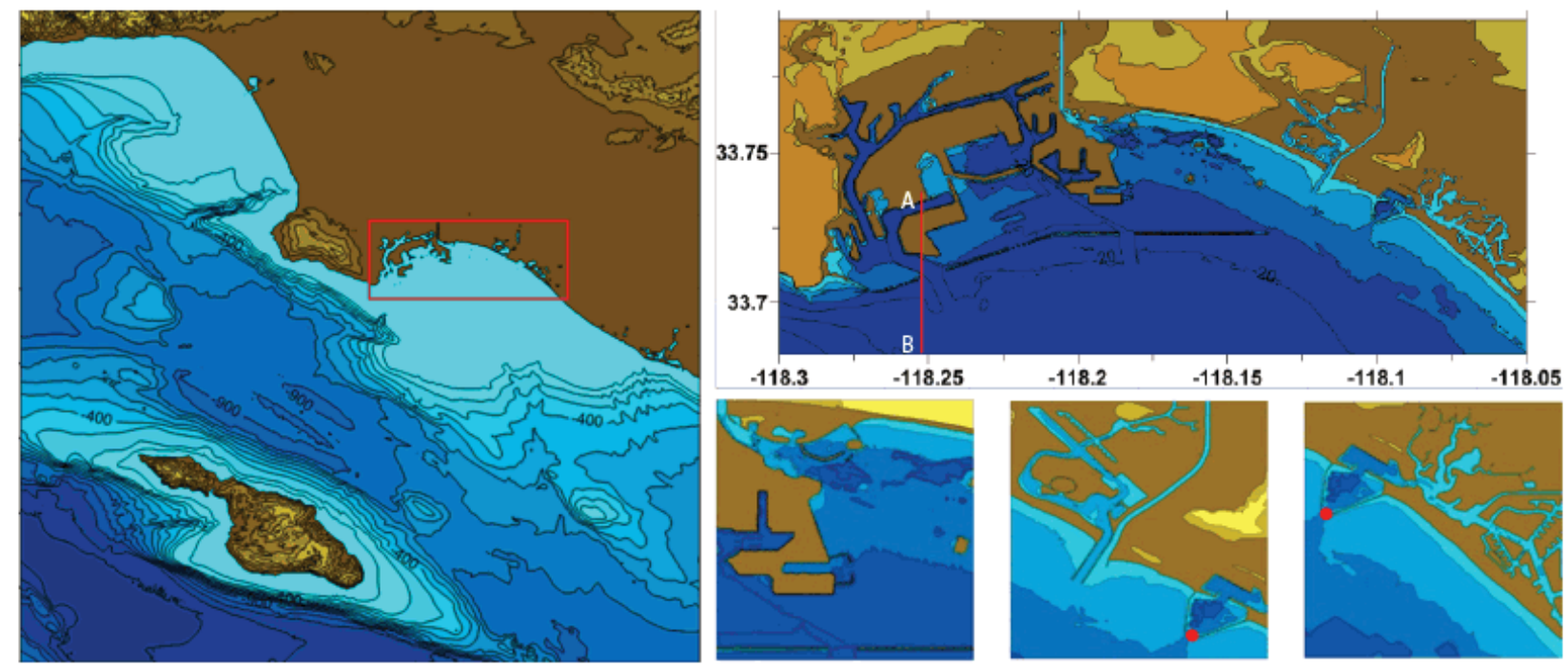

(b)

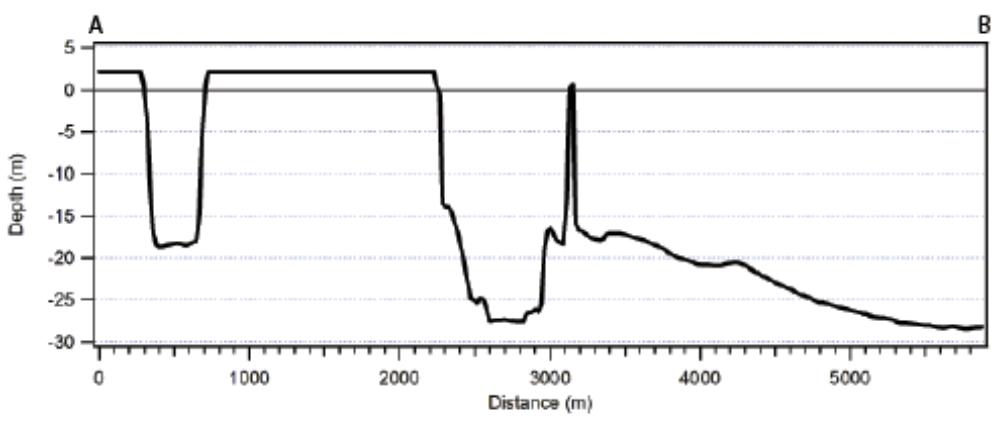

Figure 45. Maps and graph showing model results for San Pedro Bay, California. (a) Examples of the grid coverage for sites in San Pedro Bay. Grid resolutions are 9 arc sec (upper left), 2 arc sec (upper right), and 1/3 arc sec (three small maps). The location of the bathymetry transect (A-B) plotted in panel (b) is indicated with the red line. Red dots indicate location of time-series plots shown in Figures 47 and 48 . (b) Bathymetry transect (A-B) across Terminal Island, the entrance channel, and the western breakwater segment. 


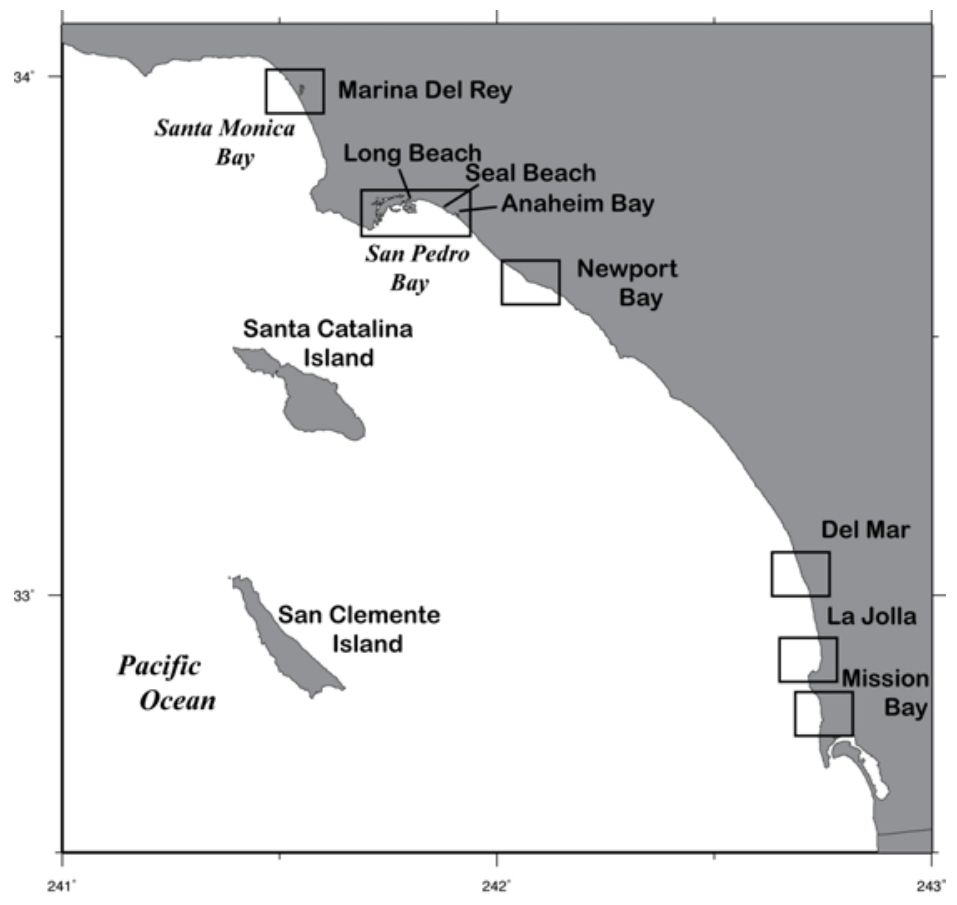

Figure 46. Map showing the sites of modeled tsunami effects in southern California covered by this study.

\section{Model Results}

A sensitivity test was first performed to compare the model results between the two earthquake source models described above. This test was conducted only on the Marina del Rey bathymetry. The results presented in figure 47 show that the model output is relatively insensitive to differences in the slip distribution at the source. We also investigated the consistency of the model results over different model grid configurations. For this test, the same tsunami source was used and model output was compared from a point corresponding to the same location in two model grids with overlapping areas. This test compared the model output at the entrance to Anaheim bay, a location covered by both the Seal Beach and Anaheim Bay grids (see the location of the red dot in figure 45. The results shown in figure 48 show that the model results are consistent for each of those two grids, providing a first-order reality check on the model results. 


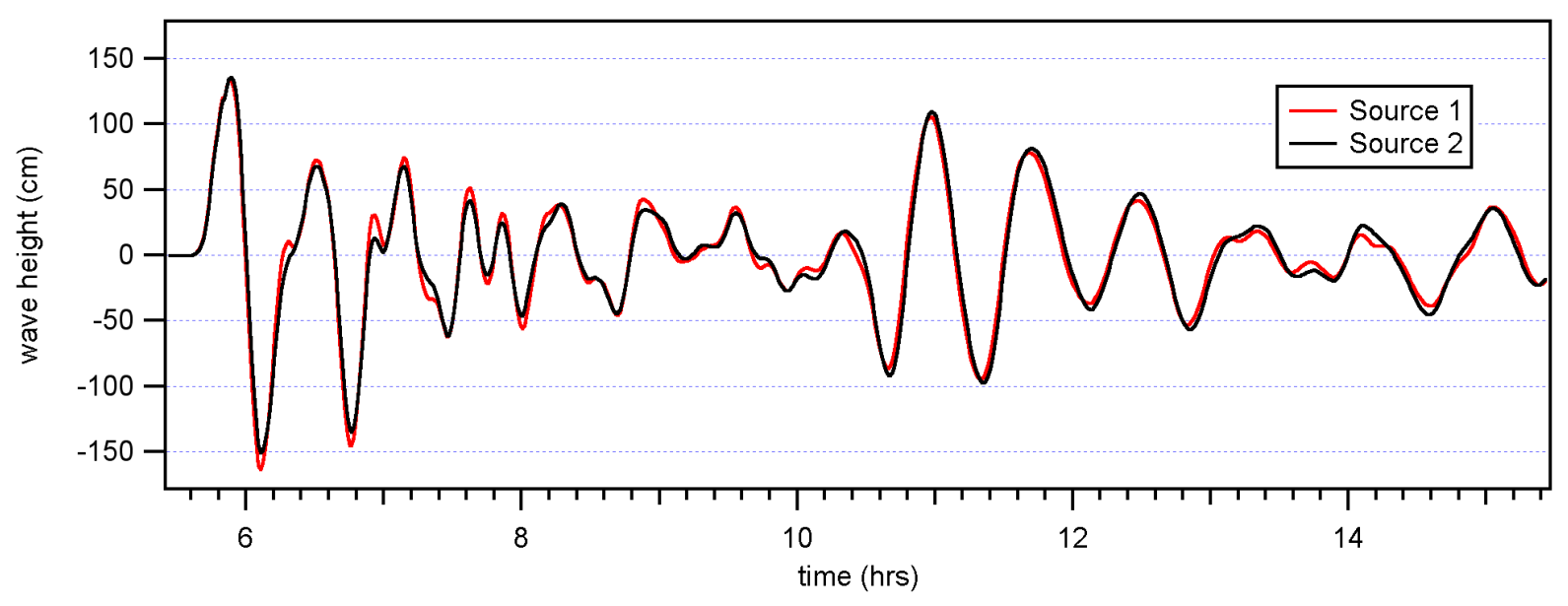

Figure 47. Plot of modeled wave height at Marina del Rey, comparing the effects from tsunami source 1 and tsunami source 2 .

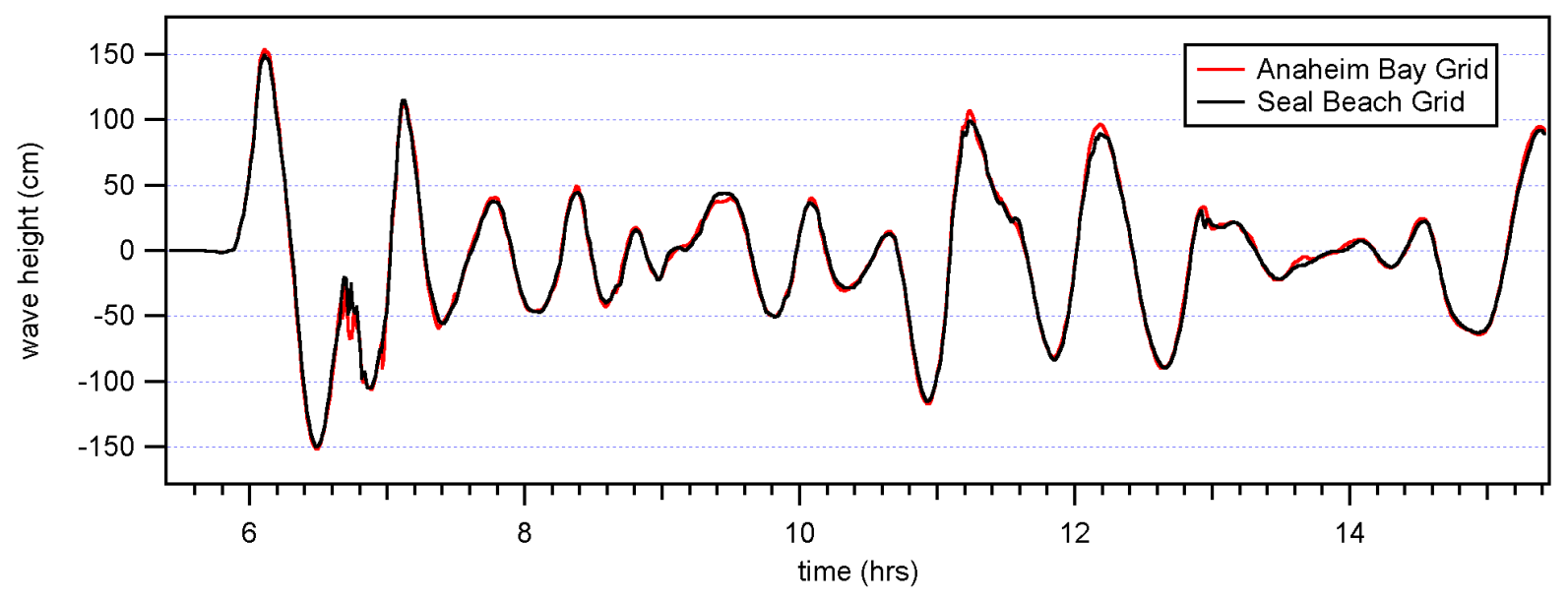

Figure 48. Plot of modeled wave height at the entrance to Anaheim Bay from separate model runs with overlapping model grids. Note that the model returns from the two grids are virtually identical.

The model was then run for the remainder of the nearshore grid regions using tsunami source 2 . Model outputs in the form of maximum computed wave height and maximum current speed are presented in figures 49-54. Time-series outputs of wave height from a nearshore point (approximately 5 -m depth) in each of the model grids are presented in figure 49. These plots show that the tsunami arrival times along the southern California coast would be just under 6 hours after the earthquake, with the wave reaching the northern sites (such as Marina del Rey) before the southern sites (such as Mission Bay). There is some discrepancy in this general rule, as indicated by the timing of the peak wave heights at the San Pedro Bay sites (Long Beach, Seal Beach, and Anaheim Bay). The shallow waters around these areas slow the tsunami arrival such that peak wave heights occur several minutes after peak wave heights at sites further south (that is, Newport through Mission Bay). Note also that the sites located in Santa Monica and San Pedro Bays have a very noticeable resurgence in tsunami wave heights occurring 10.5 to 13 hours after the earthquake ( 4.5 to 7 hours after arrival). While this feature is evident at the other sites, it is not as large or long lasting as at Santa Monica or San Pedro Bay. This feature is an 
indication of the susceptibility of these areas to long-wave resonance, enhanced tsunami wave heights, and extended tsunami duration.

Figure 50 presents the maximum computed water level over the coarsest (A-level) nearshore grids. These two plots show the maximum tsunami wave heights on a regional scale. The effect of seiching in Santa Monica Bay is evident, as well as the elevated wave heights in San Pedro Bay. Figure 51 presents the maximum computed wave height and current velocity in the region around Marina del Rey. Although the wave heights predicted by the model are not extremely large, the currents induced by the tsunami are significant, particularly on the entrance channel to the marina basin and at the ends of each of the marina slipways.

Figure 52 plots the model results for the scenario tsunami at the marine facilities located in San Pedro Bay, south of Los Angeles. This area is home to the ports of Los Angeles and Long Beach, the recreational and residential marinas of Alamitos Bay and Huntington Harbor, and the military installation of Anaheim Bay and the Naval Weapons Station. This area is also one of the most strongly affected by a far field tsunami originating from Alaska. The model results predict maximum water levels of up to $2.5 \mathrm{~m}$, with some significant overland flooding and coastal inundation. Inundation is predicted around the area of downtown Long Beach, as well as over the barrier beach at Belmont Shores and into the grounds around the Naval Weapons Station. Tsunami current speeds are also significant, particularly where the flows are constrained by coastal structures such as harbor training walls or jetties.

The effects at Newport Bay (fig. 53) are not as significant. The predicted wave heights are small and the current speeds are slower. This is probably due to the generally southward-facing orientation of the shoreline here, which does not receive the full, head-on brunt of tsunami coming from the west and northwest. There is however evidence of some small-scale inundation on properties inside the Harbor.

Farther south, the open coast sites of Del Mar (fig. 54) and La Jolla (fig. 55) do not show a strong tsunami signal. The maximum tsunami wave height is on the order of $1.25 \mathrm{~m}$ and does not induce any substantial inundation. A small amount of coastal inundation is evident at the entrance to the Del Mar lagoon (see fig. 54); however, it is not significant.

Finally, at Mission Bay, more substantial tsunami effects are seen (fig. 56). Even though the tsunami wave heights are similar to the heights modeled at Del Mar and La Jolla, the lower topography along Mission Beach leads to some on-land inundation. There are also strong currents modeled to occur in the entrance channel to Mission Bay. 


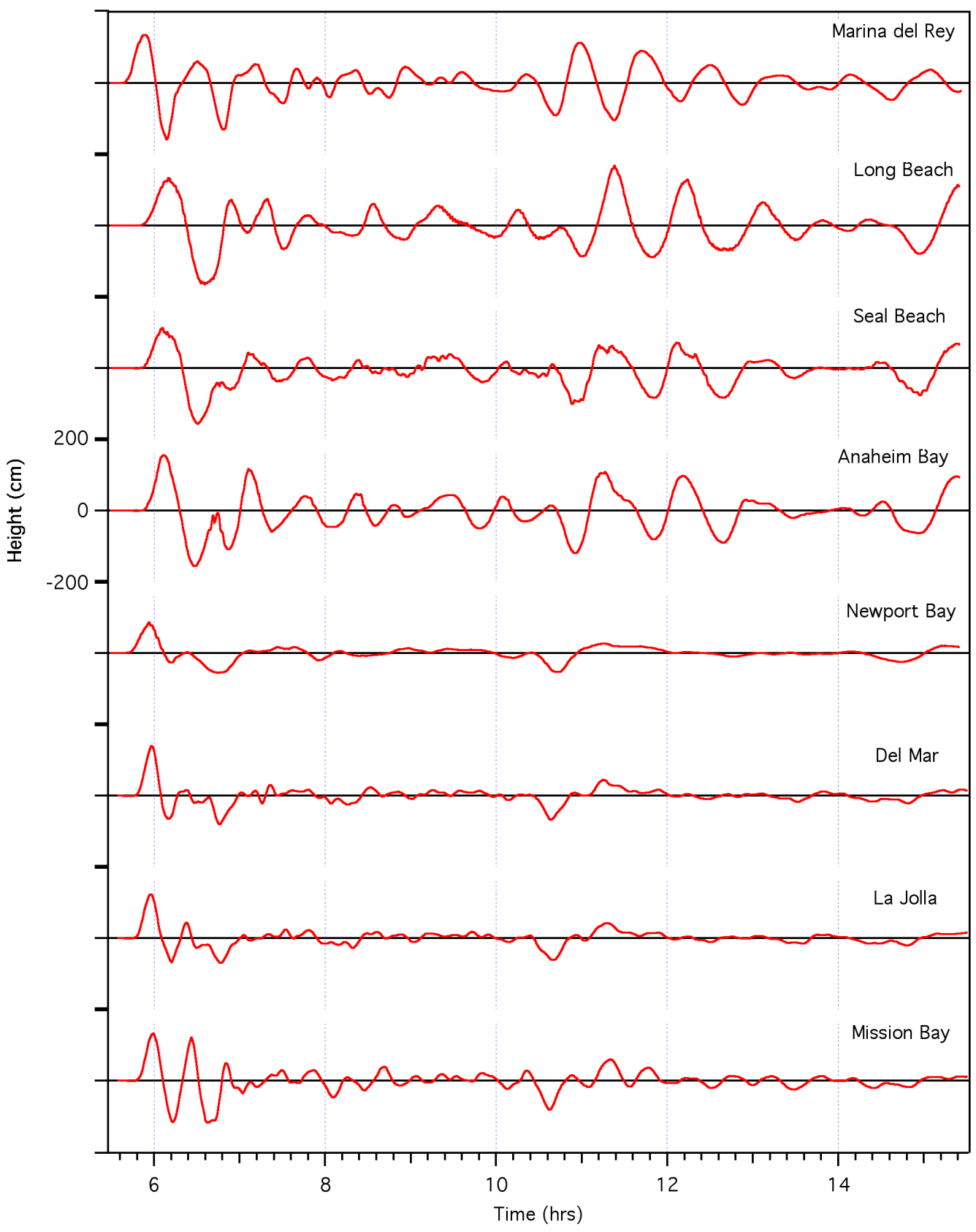

Figure 49. Time series outputs showing tsunami wave heights in each of the nearshore regions. 

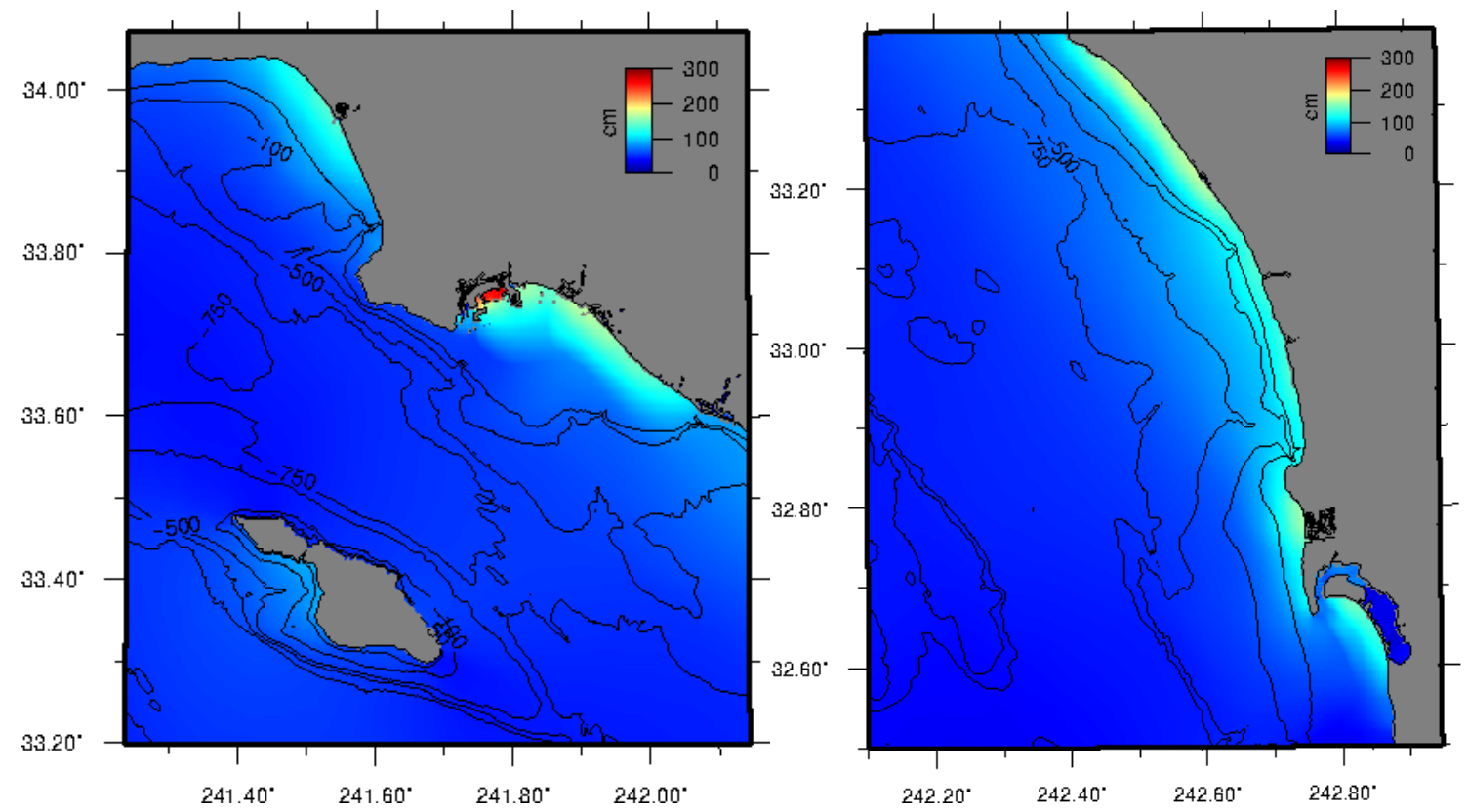

Figure 50. Maps showing maximum computed tsunami wave heights in the A-level (coarsest) grids along the southern California coast. Grid resolution is 9 arc sec.
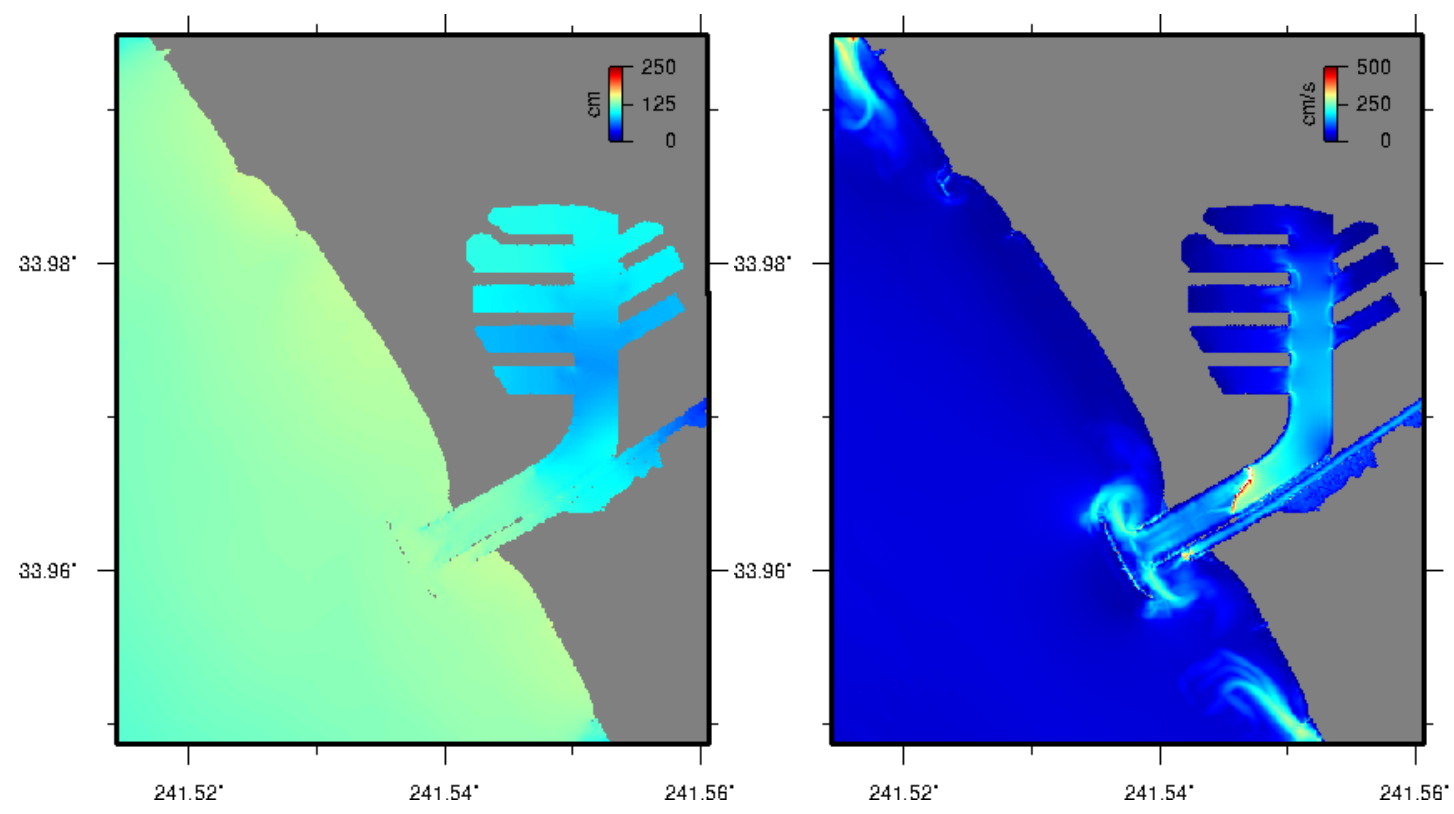

Figure 51. Maps showing maximum computed tsunami wave heights (left) and current speeds (right) at Marina del Rey, California. 
(a)

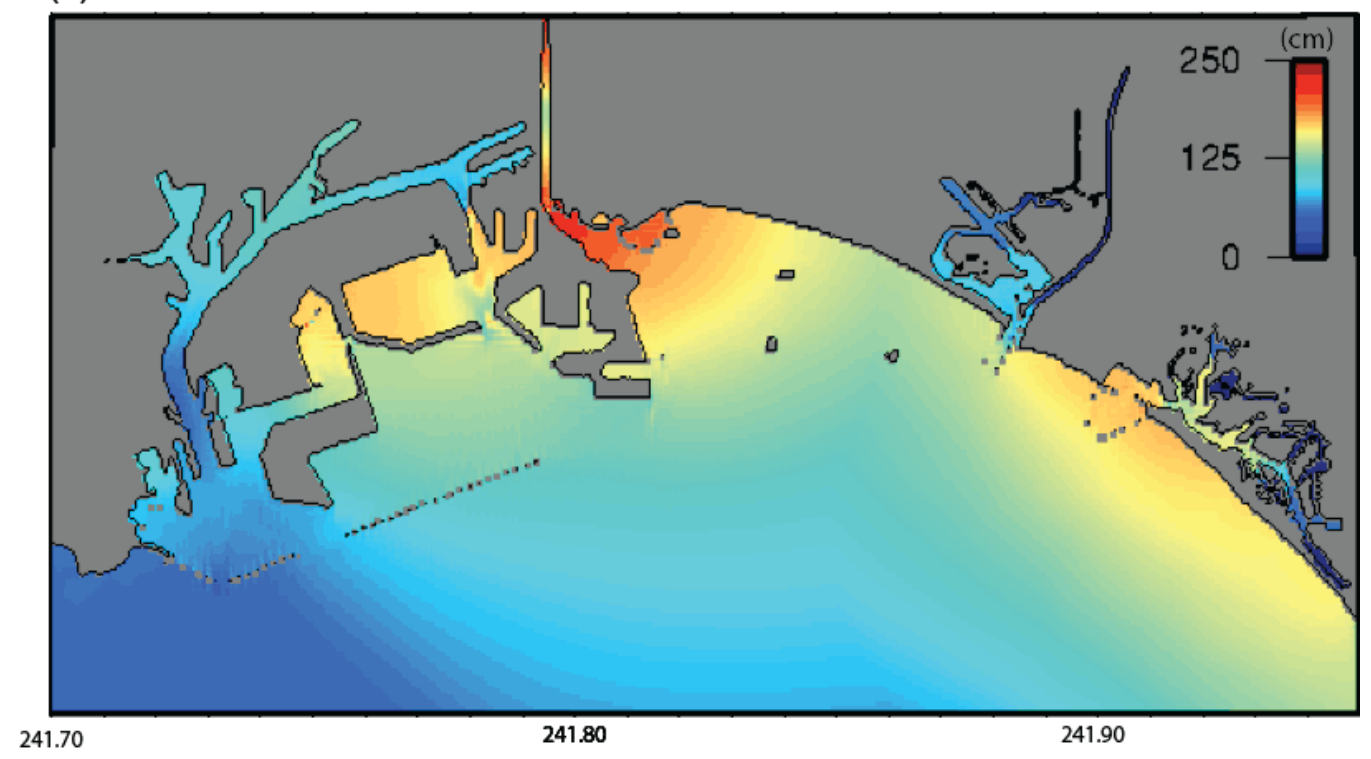

(b)
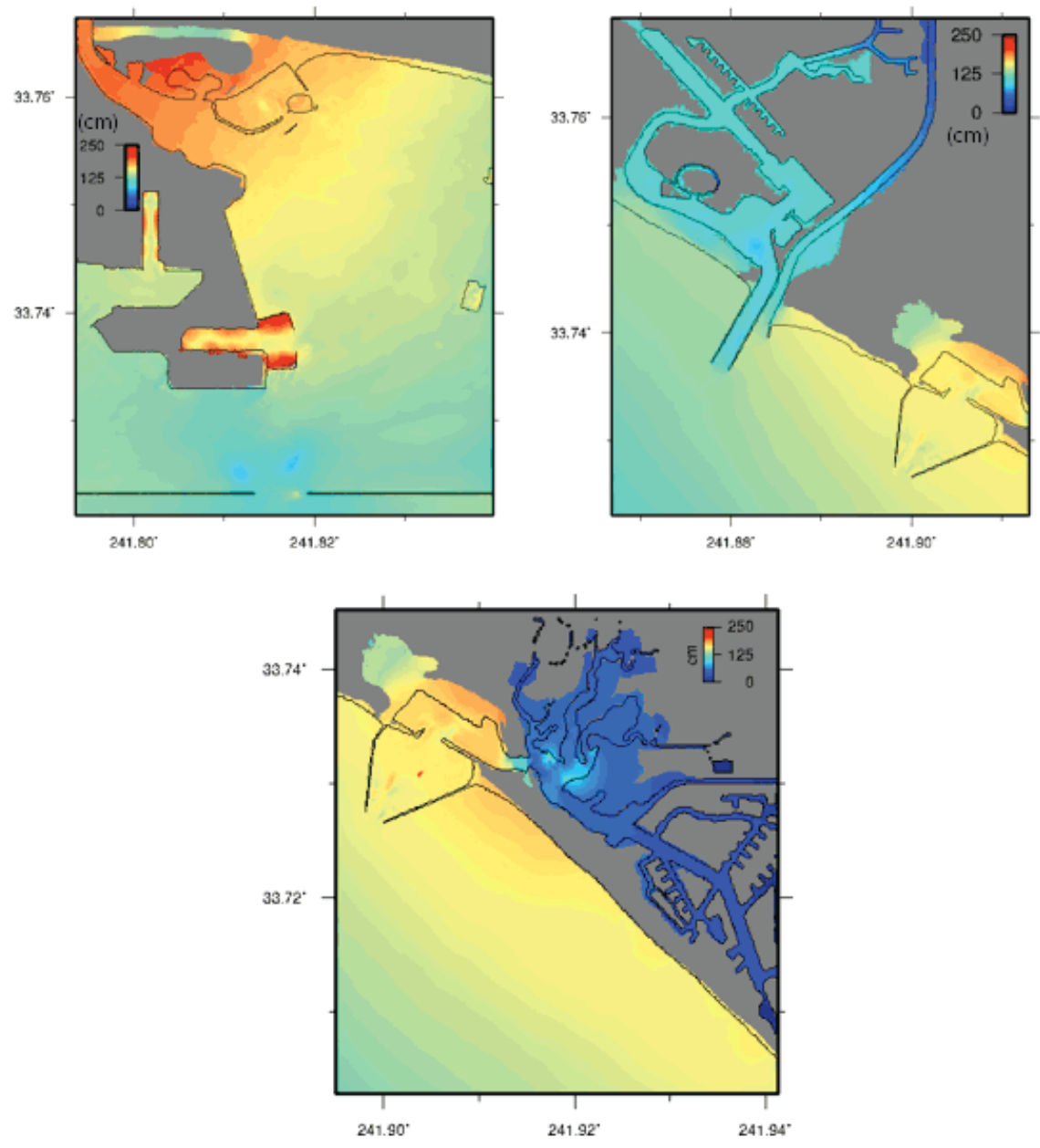
(c)
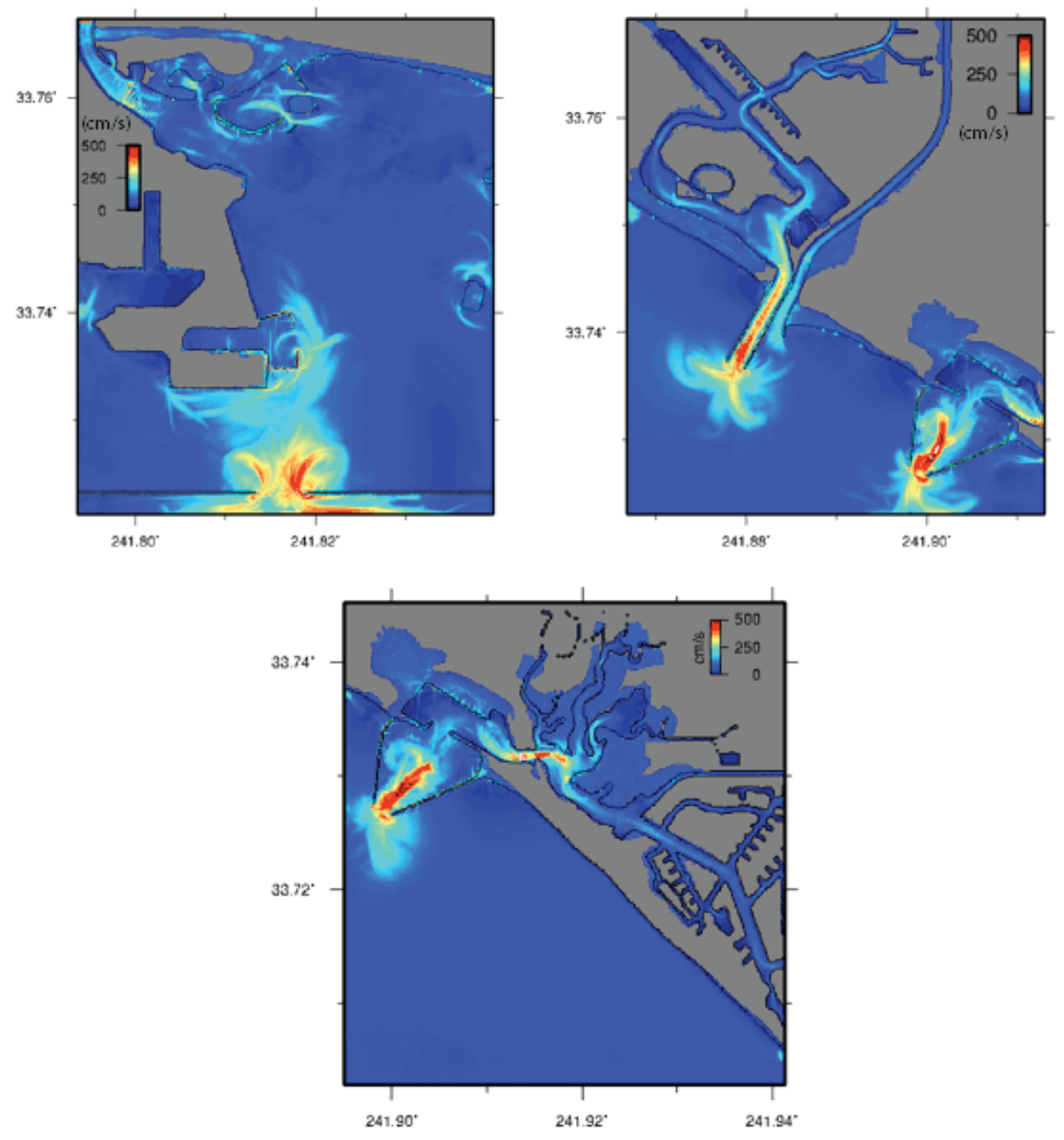

Figure 52. Maps showing modeled maximum tsunami wave heights and current speeds in San Pedro Bay and sites within the bay at different grid levels. Wave heights are in centimeters and current speeds are in $\mathrm{cm} / \mathrm{sec}$. (a) Modeled maximum tsunami wave heights in the B-level (2 arc sec) grid covering the marine facilities in San Pedro Bay. (b) Modeled maximum tsunami wave heights in the C-level (1/3 arcsec) grids covering three important maritime installations-Port of Long Beach (left), Seal Beach and Alamitos Bay (middle), and Anaheim Bay, Naval Weapon Station (right). (c) Modeled maximum tsunami current speeds in the C-Level (1/3 arcsec) grids covering the same regions as above. 

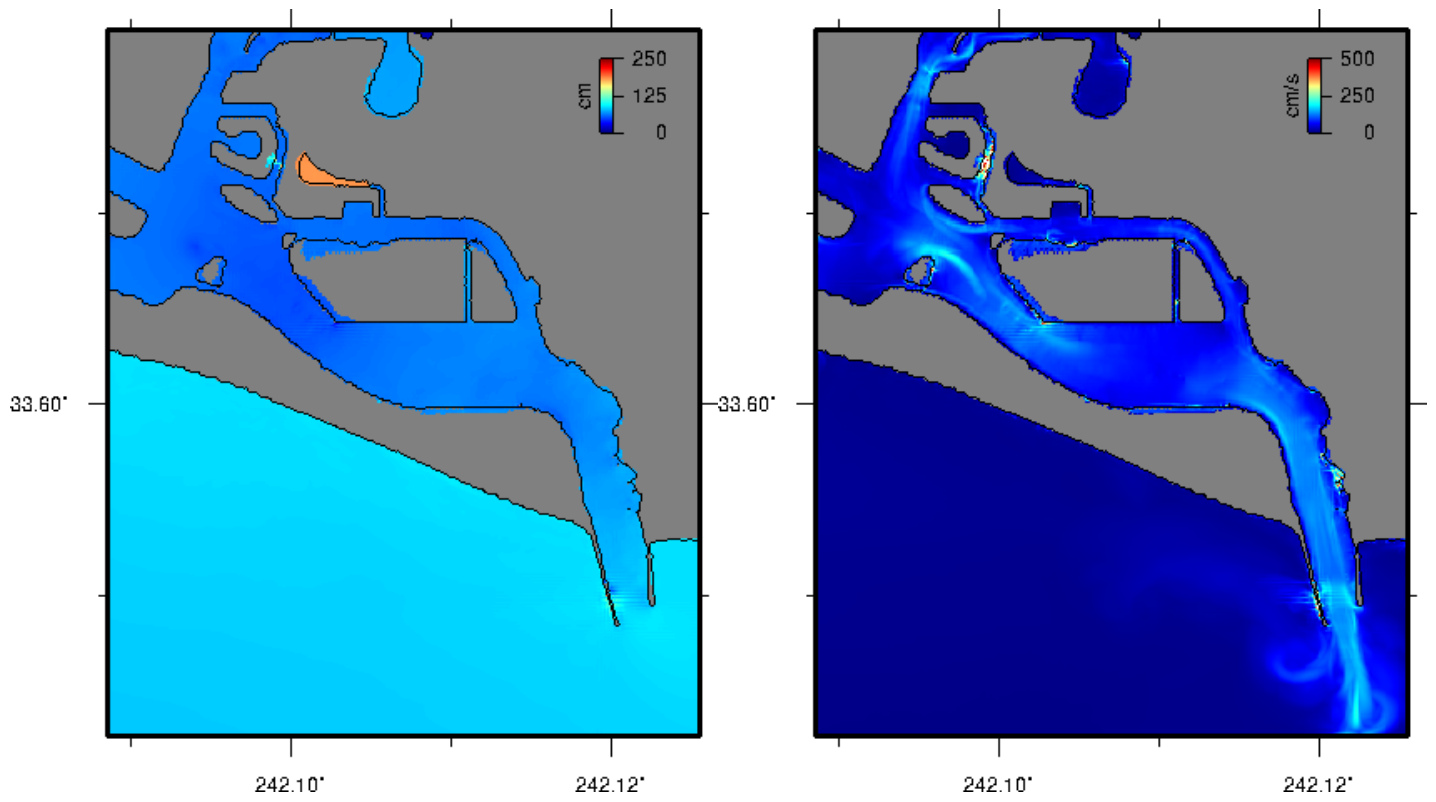

Figure 53. Maps showing modeled maximum tsunami height (left) and current speed (right) in Newport Bay.
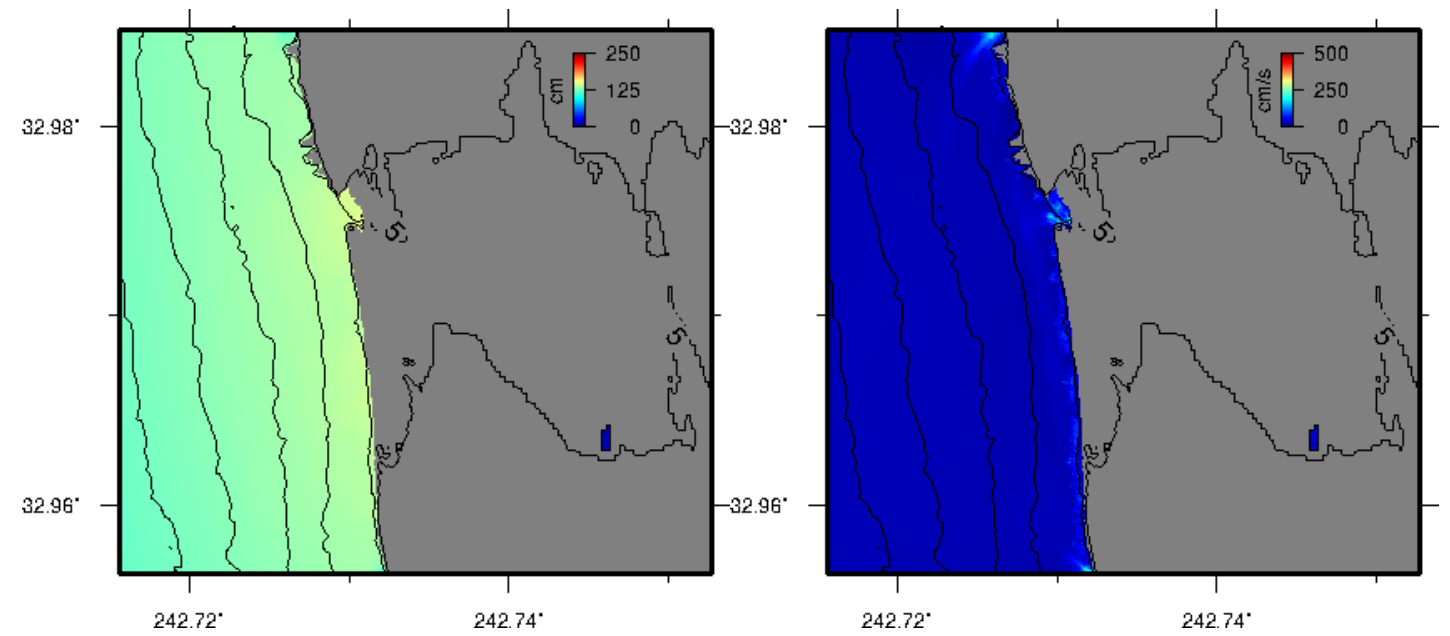

Figure 54. Maps showing modeled maximum tsunami height (left) and current speed (right) at Del Mar. The black line on land is the 5-meter topographic contour. 

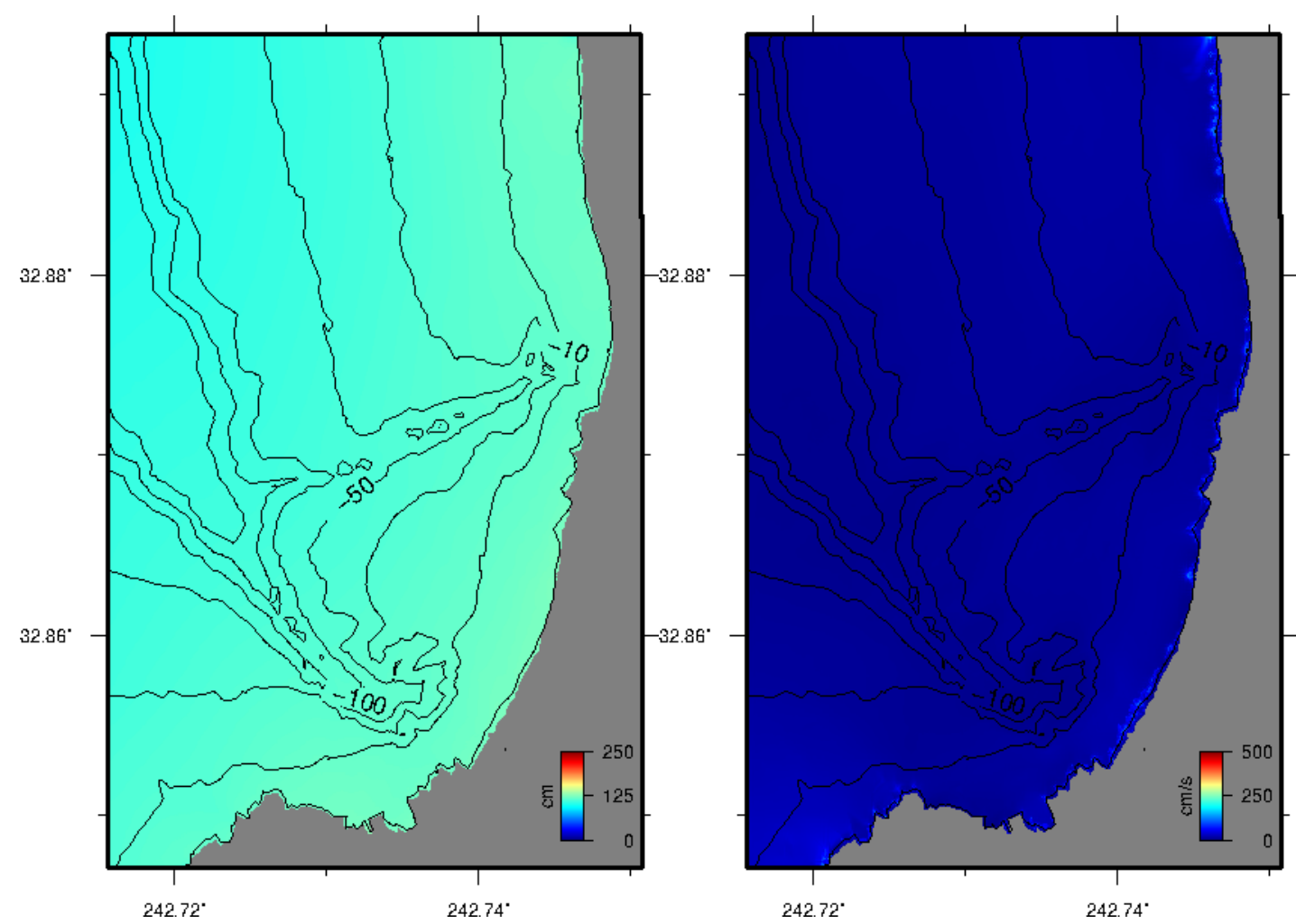

Figure 55. Maps showing modeled maximum tsunami height (left) and current speed (right) at La Jolla.
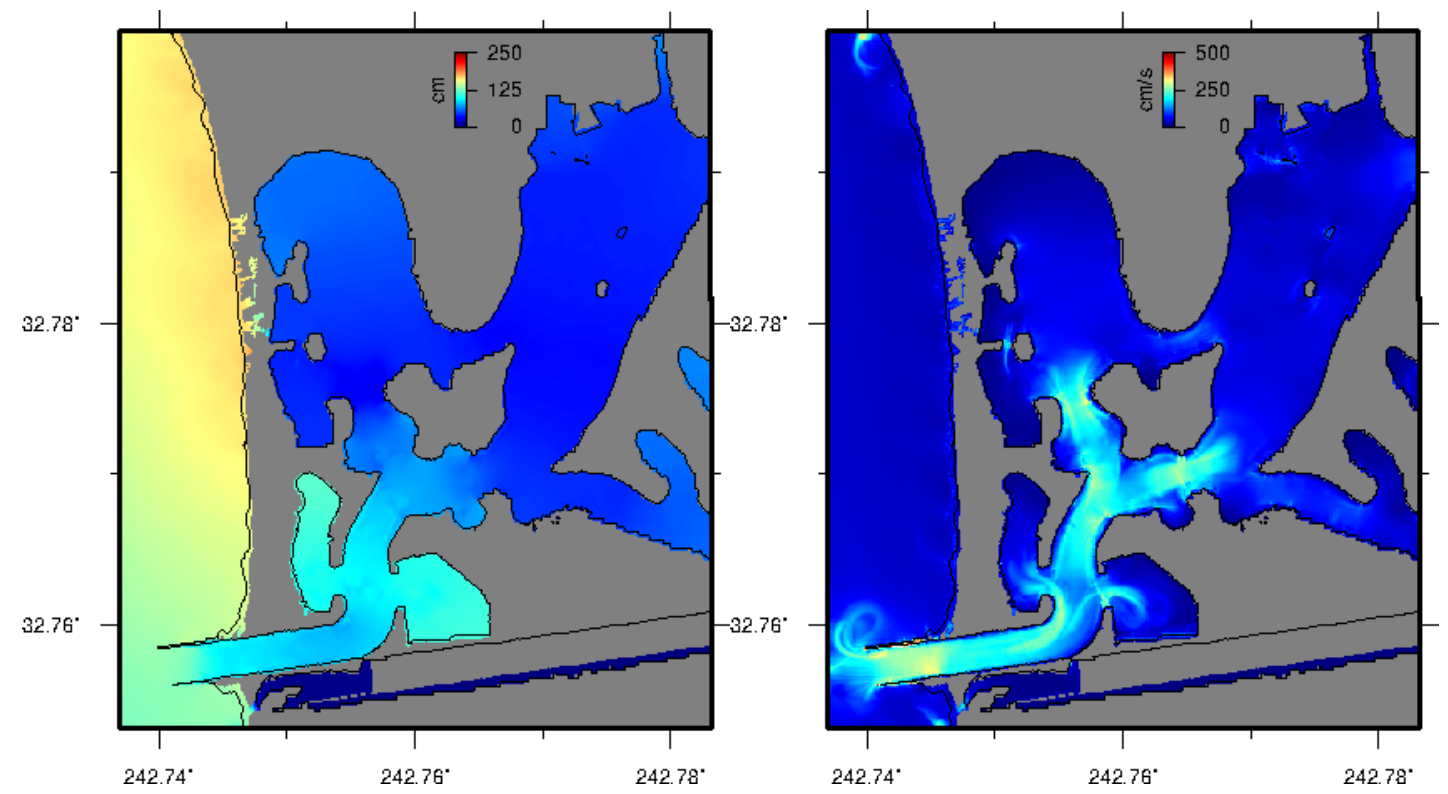

Figure 56. Maps showing modeled maximum tsunami height (left) and current speed (right) in Mission Bay. 


\section{Summary and Conclusion}

This modeling study has explored the effects on the coast of Southern California of a tsunami from a distant source. It investigated the effect of a very large (M9.1) event offshore of the Alaska Peninsula on several sites in Southern California. Study sites include Marina del Rey, the ports area of San Pedro Bay (Long Beach, Seal Beach, Alamitos Bay, and Anaheim Bay), Newport Bay, Del Mar, La Jolla, and Mission Bay.

Tsunami waves from the Aleutian source region begin to affect the Southern California coast in approximately 6 hours, with the largest wave occurring within the first hour of the tsunami event. At sites in Santa Monica and San Pedro Bays, there is a resurgence in the tsunami energy that occurs approximately 4.5 to 7 hours after the tsunami first arrival. This resurgence is evident at the other sites; however, it is not as big nor as long lasting as in Santa Monica and San Pedro Bays.

Overall, the strongest tsunami effects occur in the San Pedro Bay area, an area that coincides with some of the most significant infrastructure developments. Thus the strongest tsunami effects affect an area most vital to commerce and economy in southern California. The effects in this area include strong currents in the vicinity of coastal structures, as well as overland inundation and flooding. Open coast sites such as Newport, Del Mar, and La Jolla do not experience this and only see maximum tsunami wave heights of approximately $1.25 \mathrm{~m}$, a wave height that is less than a typical tidal range for the area. Although only small-scale inundation is predicted for the Del Mar and La Jolla areas, Mission Beach and Mission Bay are shown to be susceptible to possibly more inundation on the heavily populated beach front, as well as being affected by strong currents in the bay entrance and some inundation on the land inside the bay. 


\title{
5. Production of Inundation Line for SAFRR Tsunami Scenario
}

\author{
By Rick Wilson
}

\begin{abstract}
To help evaluate the impacts from the SAFRR scenario tsunami event, a line of potential tsunami inundation was produced that represents the flood limits to numerical modeling results. Numerical modeling was completed using digital elevation models (DEMs) with grid resolutions of 10 $\mathrm{m}$ in select locations in southern California (see Borrero and others, section 4) and $30 \mathrm{~m}$ for most other parts of the California coast selected for modeling (see Thio, section 3). The DEMs were produced by the National Geophysical Data Center, which combined bathymetric and topographic data in a seamless dataset for tsunami modeling. Although models using these data are good for identifying general tsunami amplitudes, the DEMs and model results, because of resolution limitations, do not always accurately depict flooding where sudden topographic changes and manmade flood control structures exist. These types of problematic conditions include steep wave-cut beaches, port docks, and river levees. For this reason, recently collected (2009-2011), 1-m resolution lidar (light detection and ranging) DEMs were used to digitize an inundation line to identify where modeled flood limits would likely extend or be contained. In some locations, inundation maps were verified in the field or by use of orthoimagery and stereophotography, with an understanding of the limitations of the DEMs and imagery used. Because of the importance of the Ports of Los Angeles and Long Beach to the SAFRR project, a detailed review of landfill plans was performed to check the inundation line in that area. A similar process of inundation-line production was used by the California Geological Survey (CGS) and the California Governor's Office of Emergency Services (Cal OES) during the completion of the State inundation line for emergency response planning.
\end{abstract}

\section{Introduction}

Numerical tsunami modeling is a computationally complex method to demonstrate how tsunamis that are generated and propagated across the ocean inundate coastal regions of dry land. Most numerical model platforms have gone through validation exercises to demonstrate that the mathematical computations are verified (National Tsunami Hazard Mitigation Program, 2012). For this reason, the accuracy of the numerical models is less likely to be questioned. In most cases, the accuracy of the modeled inundation is more dependent on the accuracy and resolution of the digital elevations models (DEMs) used.

In 2009, a set of tsunami inundation maps were produced for emergency response statewide (Wilson and others, 2008; Barberopoulou and others, 2009). Numerical modeling was performed for a suite of large local- and distant-source tsunami scenarios, the results of which were combined into a single data layer that represented all potential areas that could potentially be flooded. This conservative approach was needed to make sure that during any large tsunami event, local evacuation plans would consider all areas of potential tsunami flooding.

During the production of the inundation maps, errors in the numerical model results were discovered that could have impacted the accuracy of the resulting map. A thorough investigation of the results determined that the errors were a product of either errors in the 30-m and 90-m DEMs used or limitations of these DEMs to resolve higher resolution features, such as (1) steep wave-cut beaches, (2) rock-covered slopes along waterfront areas, (3) port docks and seawalls, and (4) river and flood control 
levees. Where these issues existed, a geographic information system (GIS) platform was used to incorporate 3-m and 5-m radar-interferometric DEMs and 10-m U.S. Geological Survey (USGS) National Elevation Dataset (NED) DEMs to more accurately project where flooding could travel onshore. All DEMs were adjusted to mean high water tidal datums to accommodate potential worst-case inundation conditions. A preliminary line of potential inundation was generated, verified in the field with county emergency managers and other local map experts, and then finalized and released to the public. This method conformed to the National Tsunami Hazard Mitigation Program's guidelines and best practices for tsunami inundation modeling for evacuation planning (National Tsunami Hazard Mitigation Program, 2009).

Participants in the modeling and mapping aspect of the USGS SAFRR scenario project were cognizant of potential similar limitations to the modeling. Field investigations of the initial 10-m and 30-m modeling results were performed to verify the accuracy of the modeling. Although the resolution and accuracy of this modeling were considerably higher than in the previous statewide inundation mapping project, errors were discovered. The following discussion addresses these errors and the methods that were used to create a more accurate tsunami inundation product.

\section{Verification of Model Results}

Once the initial tsunami modeling results were produced, field teams consisting of USGS, CGS, and Cal OES personnel were formed to review the tsunami model products. In southern California, field team members visited a dozen coastal locations between Redondo Beach (Los Angeles County) and Newport Beach (Orange County). Although modeling results accurately portrayed the waterfront tsunami amplitudes in some areas, the modeled inundation areas were not always reflective of the topography and man-made structures inland. For example, figure 57 demonstrates how the 1-m tsunami runup flood level appears to overtop a river levee near the mouth of the Santa Ana River that was measured to be at least $3 \mathrm{~m}$ high. Because the levee is only $5 \mathrm{~m}$ wide, this manmade feature was not captured on the 10-m or 30-m DEMs used for tsunami modeling and, therefore, areas behind the levees showed erroneous flooding. Other areas where tsunami flooding was not accurately portrayed included steep, wave-cut beach fronts in Huntington Beach and underground parking garages in downtown Long Beach. 


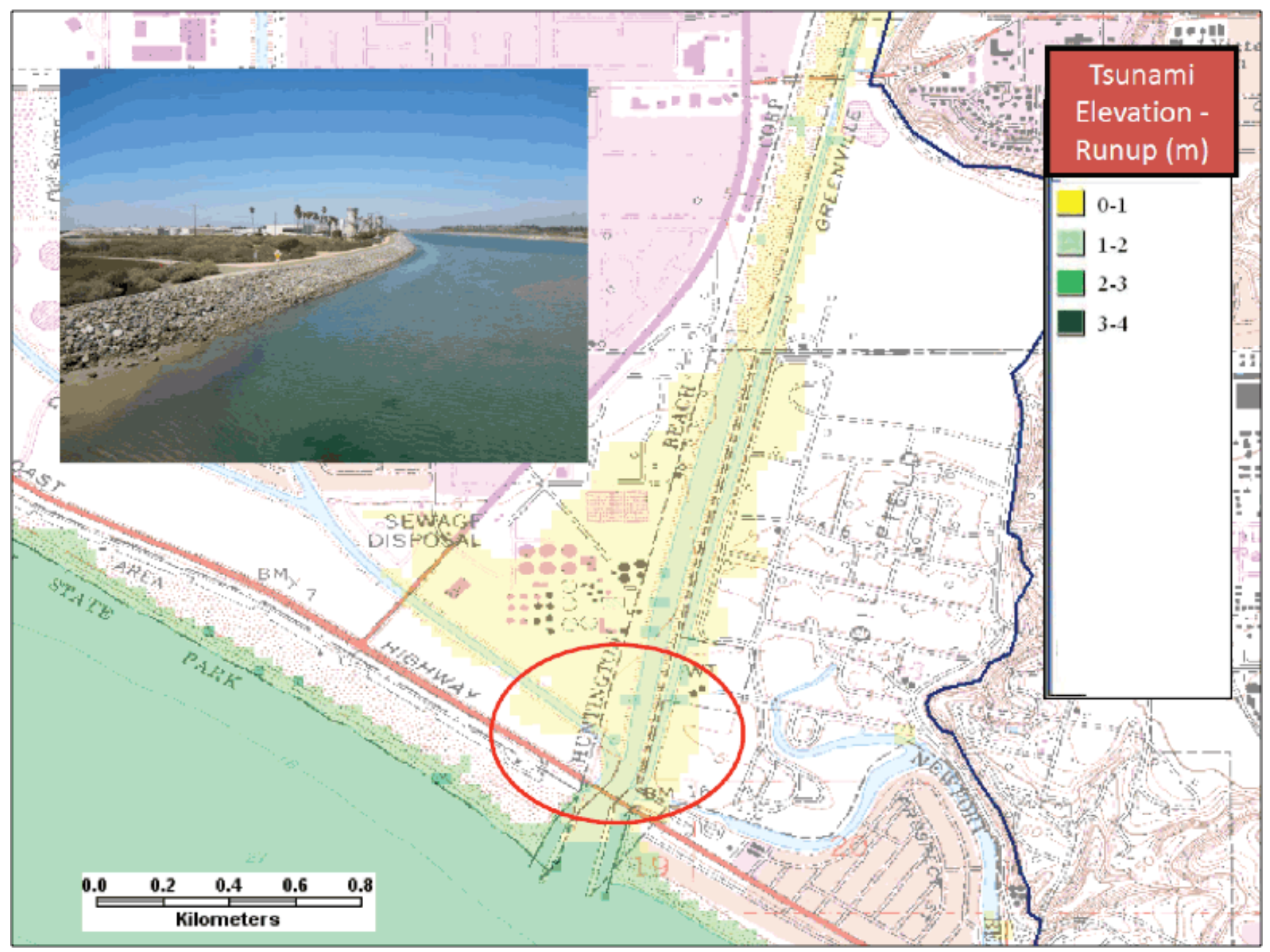

Figure 57. Map showing SAFRR modeled tsunami amplitude results near the outflow for the Santa Ana River in Orange County. The red oval identifies the area of the photo showing the $+3-m$ high levees. These levees (shown in the inset photo) should not be overtopped by the 1-m high tsunami flow. The blue line is the location of the 2009 state tsunami inundation line. Topographic map used as a base map for this figure.

In the Ports of Los Angeles and Long Beach, similar issues were found with the accuracy of model results. Several areas of recent artificially filled land were not included in the DEM used in modeling. In other cases, where tsunami modeling amplitudes overtopped waterfront piers by 1 to $2 \mathrm{~m}$, modeled flooding appeared to stop at the piers despite areas behind the piers being at a lower elevation. Additional information helping to address some of these issues was requested from Moffett and Nichol, the engineering consultants for the Ports.

Fieldwork was also initiated in northern California, specifically in the southwestern part of San Francisco Bay. Preliminary modeling results indicated that large sections of residential areas in Redwood City and Foster City could be inundated by a 1-m-amplitude tsunami. After looking closely at the levees bordering the edges of San Francisco Bay, the field team determined that tsunami inundation would not be anticipated to travel beyond these levees. Therefore, the residential areas in these cities should not be included in the inundation area for the project. 


\section{SAFRR Inundation Line Production}

Based on the recommendations from the field teams, it was determined that an inundation line should be produced to correctly define where tsunami flooding could inundate. CGS employed a method similar to the work performed on the 2009 State inundation maps. A GIS platform was used to digitize the inundation line, employing 1-m resolution DEMs to determine the extent of potential flooding (DEMs from California Coastal Conservancy: http://www.opc.ca.gov/2012/03/coastalmapping-lidar-data-available/). These DEMs, which are based on lidar data collected between 2009 and 2011 using an airborne system, represent the most comprehensive and accurate coastal topographic data available.

The initial fieldwork helped guide where problem areas needed to be addressed. For several locations in southern California, the inundation line extended inland where it was clear that beach and waterfront areas would not contain the modeled wave heights of the scenario tsunami. In northern California, inundation was confined by levees along the edge of San Francisco Bay. River levees throughout the State were also analyzed to determine if they would confine the flow of the tsunami.

In the Ports of Los Angeles and Long Beach, careful evaluation of the model results led to the production of a more consistent and accurate tsunami inundation line. Low-lying regions were incorporated into the inundation area beyond where tsunami flooding was projected to overtop the piers (fig. 58). Design plans for artificial land fill within the Ports were cross referenced with recent USGS orthophotographic imagery (circa 2011) to determine where tsunami inundation would occur. CGS coordinated closely with Moffatt and Nichol, the engineering consultant for the Ports, to adjust the limits for inundation where appropriate. Although significant work went into the production of the inundation line in the Ports, further detailed evaluation in the field would be needed to determine if more subtle manmade structures, such as small berms and retaining walls, would change the areas of inundation from the tsunami. Appendix A includes examples of inundation for selected areas of the California coast. 


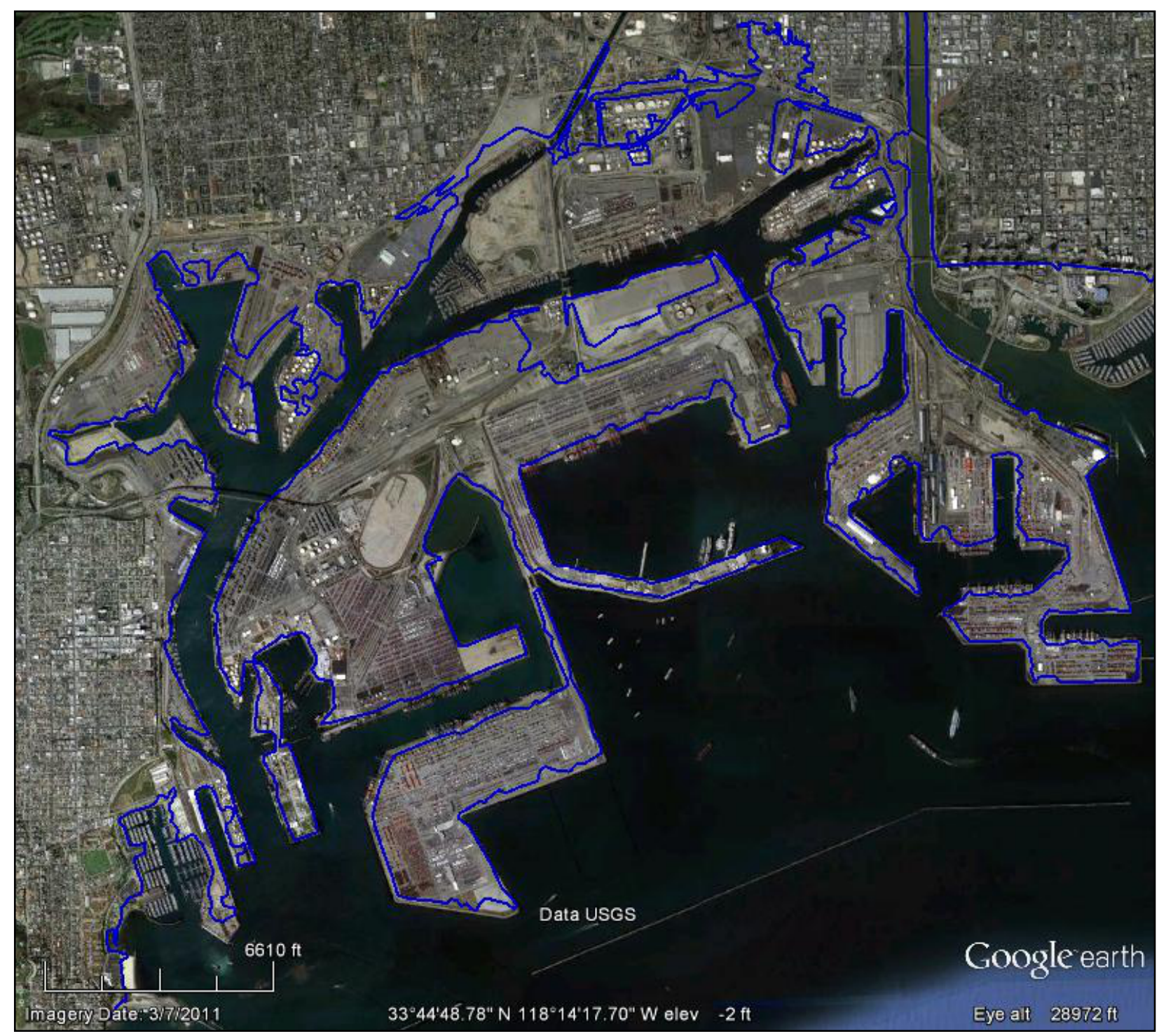

Figure 58. Map showing the SAFRR tsunami inundation line (blue) in the Port of Los Angeles (left part of image) and the adjacent Port of Long Beach. A number of the waterfront areas around the ports show overtopping by the modeled tsunami surge. 


\section{Comparison of SAFRR Inundation Line to State Inundation Line}

To determine if evacuation plans for coastal communities should be updated, CGS compared the inundation line from the SAFRR scenario to that from the 2009 statewide product. The SAFRR scenario tsunami is considered a very large distant-source event for the California's coast, comparable to some of the "worst-case" sources used during production of the 2009 statewide inundation maps. The modeling results produced for the SAFRR scenario are of higher resolution than those produced for the state inundation maps. The topographic lidar DEM used for the SAFRR line production is a higher resolution, more accurate DEM than what was available when the state inundation line was produced. This evaluation found that the state inundation line was equal to or more conservative (further inland) in almost all areas and under most conditions, with two exceptions:

1. The higher resolution modeling results for SAFRR demonstrated that tsunamis could travel farther up large rivers feeding into the ocean. In some cases, modeled tsunami surges and bores traveled as far as 4 to 5 miles upriver.

2. Higher resolution SAFRR models indicated that amplification of tsunami surges occurred in small inlets and harbors within San Diego and San Francisco Bays, producing tsunami wave heights approximately $0.5 \mathrm{~m}$ to $1 \mathrm{~m}$ higher than modeling for the 2009 state inundation maps.

For these areas, CGS and Cal OES contacted the relevant emergency management agencies in the coastal jurisdictions to inform them of the situation, and evacuation plans were updated where it was appropriate. 


\title{
6. Modeling Tsunami Dynamics in the Port of Los Angeles, California
}

\author{
By Dmitry J. Nicolsky and Elena N. Suleimani
}

\begin{abstract}
We have numerically modeled the extent of inundation in the Port of Los Angeles from a tsunami generated by a hypothetical $M_{\mathrm{w}} 9.1$ earthquake in a segment of the Aleutian megathrust near the Alaska Peninsula. The result of this tsunami scenario is intended to provide assistance in tsunami hazard assessment, evacuation planning, and public education for reducing future casualties and damage from tsunamis.
\end{abstract}

\section{Introduction}

Subduction of the Pacific Plate under the North American Plate along the Alaska-Aleutian subduction zone has resulted in numerous great earthquakes and still has a large potential to generate tsunamis threatening Alaska and other States and territories of the United States. The Aleutian megathrust, where the Pacific Plate is being subducted, is the most seismically active tsunamigenic fault zone in the United States. Several historical tsunamis generated by earthquakes along the AlaskaAleutian subduction zone traveled across the Pacific Ocean and struck exposed locations around the ocean, resulting in widespread damage and loss of life.

Given the many similarities in tectonic and geologic settings between the Semidi Sector of the Alaska-Aleutian subduction zone and the Tohoku segment of the Kamchatka-Kuril-Japan subduction zone, the U.S. Geological Survey (USGS) Tsunami Source Working Group proposed modeling a hypothetical earthquake similar in its slip distribution to the 2011 Tohoku event. The rupture zone of the hypothetical earthquake lies in the Semidi Sector, between Kodiak Island and the Shumagin Islands off the Pacific coast of the Alaska Peninsula (fig. 22; see fig. 12 for locations). Contours of the sea-floor deformation due to this hypothetical earthquake are displayed in figure 59. The proposed slip distribution was parameterized by multiple subfaults (Kirby and others, 2013), and the vertical and horizontal displacements at the seafloor are computed by the Okada (1985) formulae. The left plot in figure 59 shows the sea-floor deformation due only to the vertical displacements, while the right plot displays the vertical deformation that takes into the account both the vertical and horizontal displacements. At some parts of the ocean bottom with steep bathymetric gradients, the contribution to the sea-floor deformation by the horizontal displacements can be as much as $6 \mathrm{~m}$. 

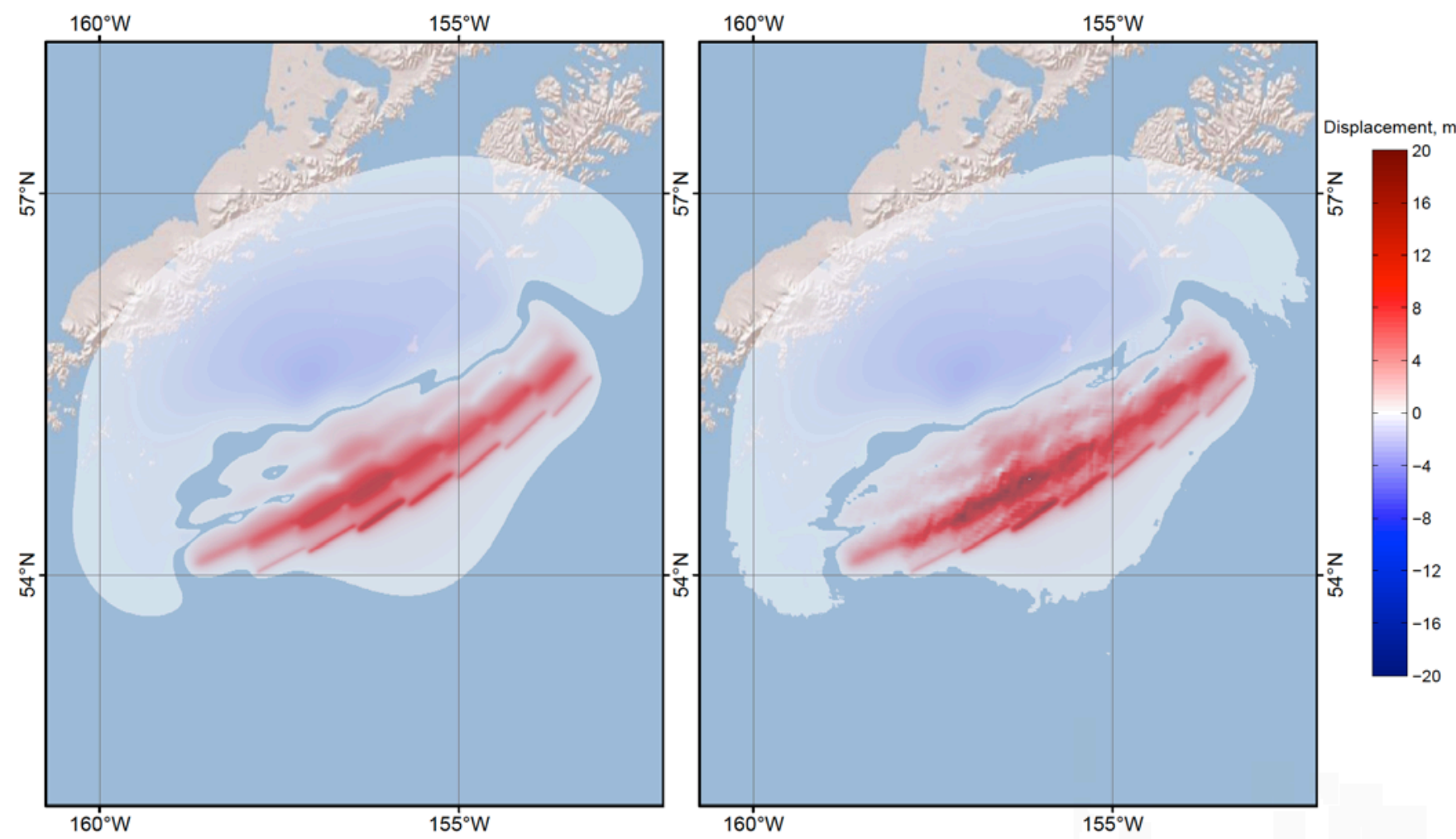

Figure 59. Maps showing the vertical deformation of the ocean floor resulting from the hypothetical earthquake in the Semidi Sector of the Aleutian megathrust. Left: the deformation is assumed to be equal to the vertical displacements. Right: the deformation is computed according to both the vertical and horizontal displacements.

\section{Methodology and Data}

\section{Grid Development}

To simulate inundation in the Port of Los Angeles by a potential tsunami that can be triggered by the $M_{\mathrm{w}} 9.1$ earthquake near the Alaska Peninsula, we employ a series of nested computational grids. A nested grid allows for higher resolution in areas where it is needed, without expending computer resources in areas where it is not. The extent of each grid used for modeling tsunami waves in the Port of Los Angeles is shown in figures 60 and 61 and listed in table 11. The coarsest grid, whose resolution is 2 arc minutes, spans the central and northern Pacific Ocean, while the highest resolution grid covers the Port of Los Angeles, including Anaheim Bay and a part of Bolsa Bay. The spatial resolution of the high-resolution grid satisfies National Oceanic and Atmospheric Administration (NOAA) minimum recommended requirements for computation of tsunami inundation (National Tsunami Hazard Mitigation Program, 2010). We briefly summarize some of these requirements as follows. Modeling of inundation should be performed using numerical grids with cell sizes less than 3 arc seconds $(\sim 90 \mathrm{~m})$, because cell sizes coarser than this tend to degrade inundation modeling results. The source elevation data in the grids should be thoroughly documented (see figs. 60 and 61). To resolve significant features that affect inundation, the computational grid should be fine enough that the feature covers more than three cells. We note that passages in the Port, between jetties and narrow channels in the wildlife refuge, are resolved with more than three grid cells. 


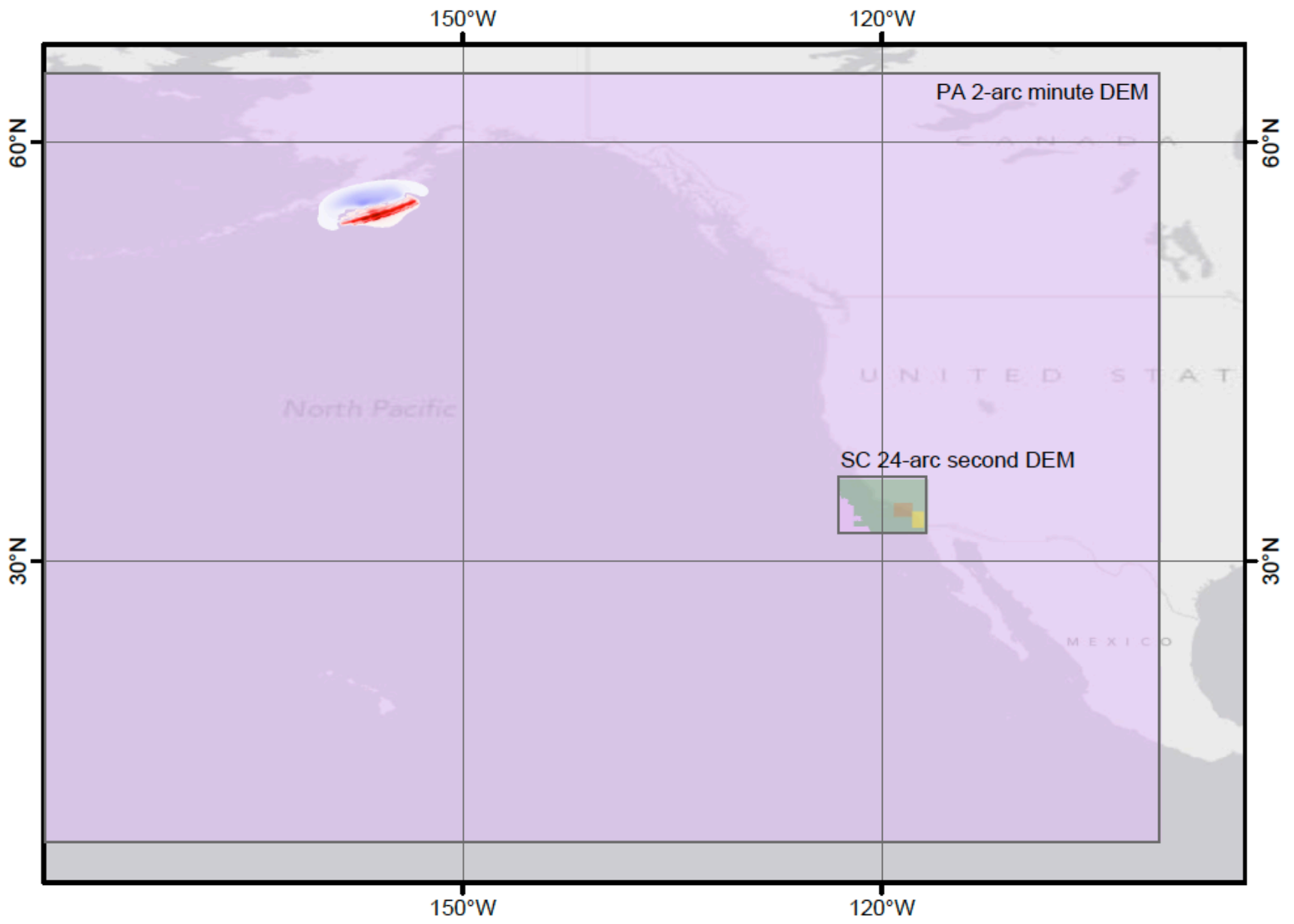

E-Topo 2 Global Relief Model, 2 arc-minute DEM

Southern California Coastal Relief Model, 3 arc-second DEM

San Diego, CA 1/3 arc-second MHW DEM

Santa Monica, CA 1/3 arc-second MHW DEM

Figure 60. Map showing the coarsest grid (PA02) which covers the central and northern Pacific Ocean, and the 24-arc-second grid (SC24), which is centered at the Port of Los Angeles. The data used to construct the embedded grids near the Port of Los Angeles are provided by the National Geophysical Data Center (NGDC), and their data extents are marked by different colors. 


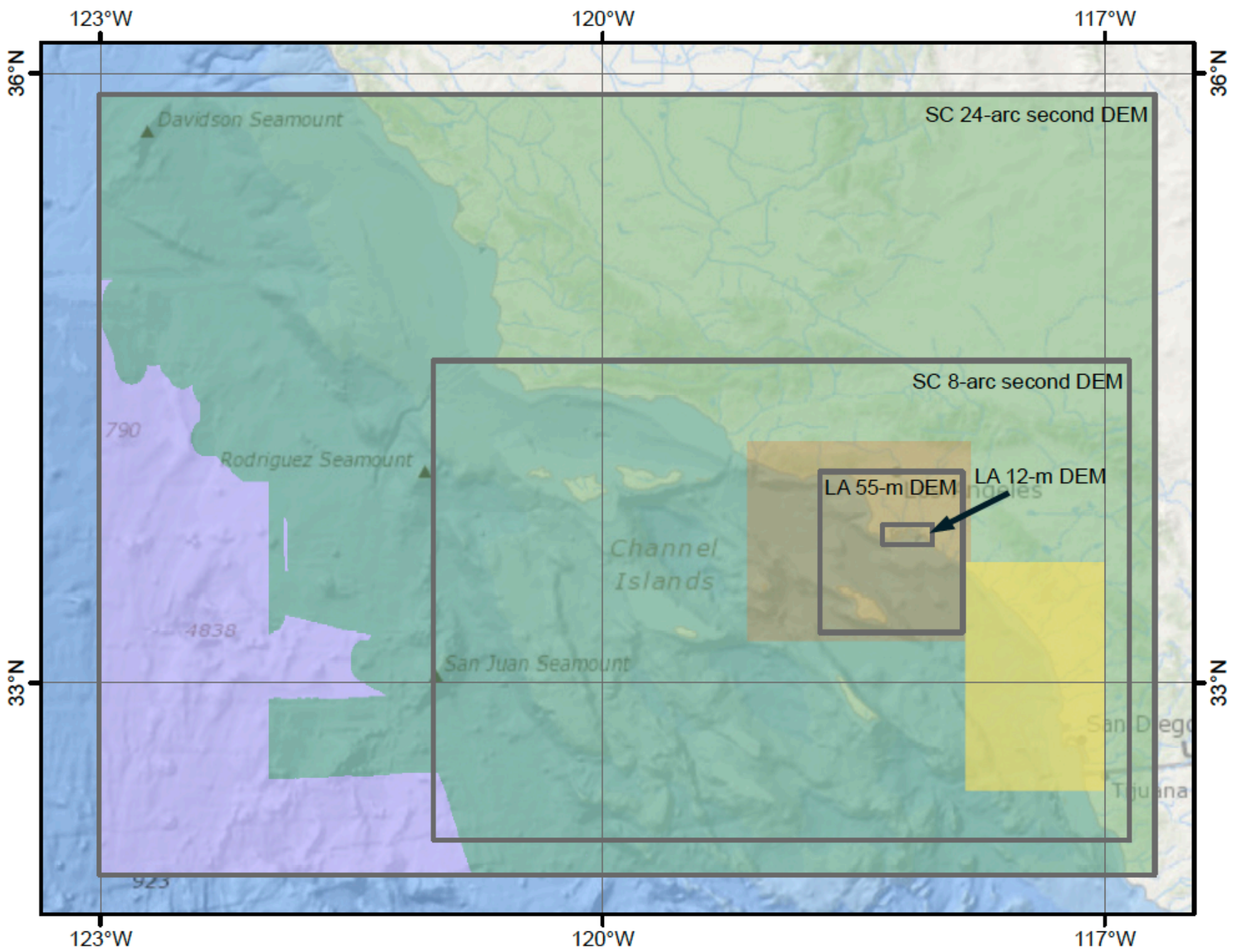

E-Topo 2 Global Relief Model, 2 arc-minute DEM

Southern California Coastal Relief Model, 3 arc-second DEM

San Diego, CA 1/3 arc-second MHW DEM

Santa Monica, CA 1/3 arc-second MHW DEM

Figure 61. Map showing telescoping embedded bathymetry/topography grids (SC24, SC08, LA55, and LA12) for numerical modeling of tsunami propagation and runup along the southern California coast. Extent of each embedded grid is marked by a gray rectangle. The data used to construct the embedded grids are provided by the National Geophysical Data Center (NGDC), and their data extents are marked by different colors. One-third arc second is approximately $10.3 \mathrm{~m}$. 
Table 11. Nested grids used to compute propagation of tsunamis generated along the Alaska Peninsula to the Port of Los Angeles.

[The high-resolution grid is used to compute the inundation. Note that the grid resolution in meters is not uniform and is used to illustrate grid fineness. The first dimension is the longitudinal grid resolution, while the second is the latitudinal grid resolution.]

\begin{tabular}{lcccc}
\hline \multicolumn{1}{c}{ Grid name } & \multicolumn{2}{c}{ Resolution } & $\begin{array}{c}\text { East-West } \\
\text { boundaries }\end{array}$ & $\begin{array}{c}\text { South-North } \\
\text { boundaries }\end{array}$ \\
\hline PA02 & $120 \times 120$ & $3,100 \times 3,700$ & $120.00 \mathrm{E}-100.00 \mathrm{~W}$ & $10.00 \mathrm{~N}-65.00 \mathrm{~N}$ \\
SC24 & $24 " \times 24^{\prime \prime}$ & $614 \times 740$ & $116.70 \mathrm{~W}-123.00 \mathrm{~W}$ & $32.00 \mathrm{~N}-35.90 \mathrm{~N}$ \\
SC08 & $8^{\prime \prime} \times 8^{\prime \prime}$ & $206 \times 247$ & $116.85 \mathrm{~W}-121.00 \mathrm{~W}$ & $32.20 \mathrm{~N}-34.60 \mathrm{~N}$ \\
LA55 & $8 / 3^{\prime \prime} \times 8 / 5^{\prime \prime}$ & $68.4 \times 49.3$ & $117.85 \mathrm{~W}-118.70 \mathrm{~W}$ & $33.25 \mathrm{~N}-34.05 \mathrm{~N}$ \\
LA12 (high-resolution) & $8 / 15^{\prime \prime} \times 2 / 5^{\prime \prime}$ & $13.7 \times 12.3$ & $118.03 \mathrm{~W}-118.33 \mathrm{~W}$ & $33.69 \mathrm{~N}-33.79 \mathrm{~N}$ \\
\hline
\end{tabular}

The bathymetry data for the 2-arc-minute resolution grid, whose partial extent is shown in figure 60 , is extracted from the ETOPO2 data set (NOAA, National Geophysical Data Center). Telescoping embedded bathymetry/topography grids (SC24, SC08, LA55, and LA12) are used for numerical modeling of tsunami propagation and runup. The extent of each embedded grid is marked by a gray rectangle (figs. 60 and 61). The data used to construct the embedded grids are provided by NGDC, and their data extents are marked by different colors.

\section{Numerical Model of Tsunami Propagation and Runup}

NOAA recently published a technical memorandum that outlines major requirements for numerical models used in inundation mapping and tsunami forecasting and describes a procedure for model evaluation (Synolakis and others, 2007). There are two major components to this process. The first is model validation, which ensures that the model correctly solves appropriate equations of motion by comparing model results with known solutions. This is achieved through analytical and laboratory benchmarking. The second component is model verification, or testing the model, using observations of real events through field data benchmarking.

The numerical model that is currently used by the Alaska Earthquake Information Center (AEIC) to model the hypothetical tsunami in the Port of Los Angeles has been validated through a set of analytical benchmarks and tested against laboratory and field data (Nicolsky and others, 2011; Nicolsky, 2012). The model solves nonlinear shallow-water equations using a finite-difference method on a staggered grid. For any coarse-fine pair of computational grids, we apply a time explicit numerical scheme as follows. First, we compute the water flux within a coarse-resolution grid. These calculated flux values are used to define the water flux on a boundary of the fine-resolution grid. Next, the water level and then the water flux are calculated over the fine-resolution grid. Finally, the water level computed in the fine-resolution grid is used to define the water level within the area of the coarseresolution grid that coincides with the fine grid. Despite the fact that nested grids decrease the total number of grid cells needed to preserve computational accuracy within certain regions of interest, actual simulations are still time demanding if parallel computing is not implemented. Here, we use the Portable Extensible Toolkit for Scientific computation (PETSc), which provides sets of tools for the parallel numerical solution of shallow-water equations (Balay and others, 2004). In particular, each computational grid listed in table 11 can be subdivided among an arbitrary number of processors. The above-mentioned passing of information between the water flux and level is implemented efficiently using PETSc subroutines.

To simulate tsunami dynamics caused by a sea-floor deformation due to an earthquake, we assume some simplifications. First, an initial displacement of the ocean surface is equal to the vertical displacement of the ocean floor induced by the earthquake rupture process. Second, the finite speed of 
the rupture propagation along the fault is not taken into account-we consider the ocean bottom displacement to be instantaneous. Third, the initial topography is modified to account for coseismic deformation of land due to the earthquake.

At the end of a tsunami simulation, each of the grid points has either a value of 0 if no inundation occurs or 1 if seawater reaches the grid point at any time. The inundation line approximately follows the 0.5 contour between these 0 - and 1-point values. Although the developed algorithm has passed through the rigorous benchmarking procedures (Nicolsky and others, 2011; Nicolsky, 2012), there is still an uncertainty in the placement of the inundation line. However, this uncertainty is to a great degree unknown because the inundation line is the result of a complex modeling process. Affecting the accuracy of the inundation line are many factors on which the model depends, including suitability of the earthquake source model, accuracy of the bathymetric and topographic data, and adequacy of the numerical model in representing the generation, propagation, and runup of tsunamis. In this study, we do not attempt to adjust the modeled inundation limits to account for these uncertain factors.

We note that there are several limitations of the model. One of the important shortcomings is that it does not take into account the periodic change of sea level due to tides. We conducted all model runs using bathymetric data that correspond to the MHW tide level in the Port of Los Angeles.

\section{Modeling Results}

We model propagation of the tsunami generated by the hypothetical earthquake in the area of Alaska Peninsula using the Alaska Tsunami Online Modeling (ATOM) interface (http://atom.giseis.alaska.edu). The tsunami dynamics were modeled for 12 hours, with the time step in the coarsest grid equal to 1 second. To preserve stability of the computations, the time step in the highresolution grid was set equal to 0.012 seconds. The initial water displacement is assumed to be equal to the vertical displacements by the Okada's formulae (the left plot in fig. 59), and the Manning roughness in all nested grids is set to be $\mu=0.01$. The modeling results show that the first wave arrives at the Port of Los Angeles about 5 hours after the earthquake, and that the significant wave action starts approximately 6 hours after the earthquake. The maximum calculated wave height with respect to the MHW level is plotted in the top plot in figure 62. The bottom plot in the same figure illustrates the hypothetical flow depth above the dry land.

In addition to the simulated maximum water level and flow depth, we display the computed water level and velocity at selected points along the coast of Los Angeles and inside the Los Angeles harbor. Locations of these points are marked by numbers and red triangles in figures 62 and 63 . We plot the computed sea level and water velocity at all selected locations in figure 64. The geographic coordinates of the selected locations are listed in table 12. 

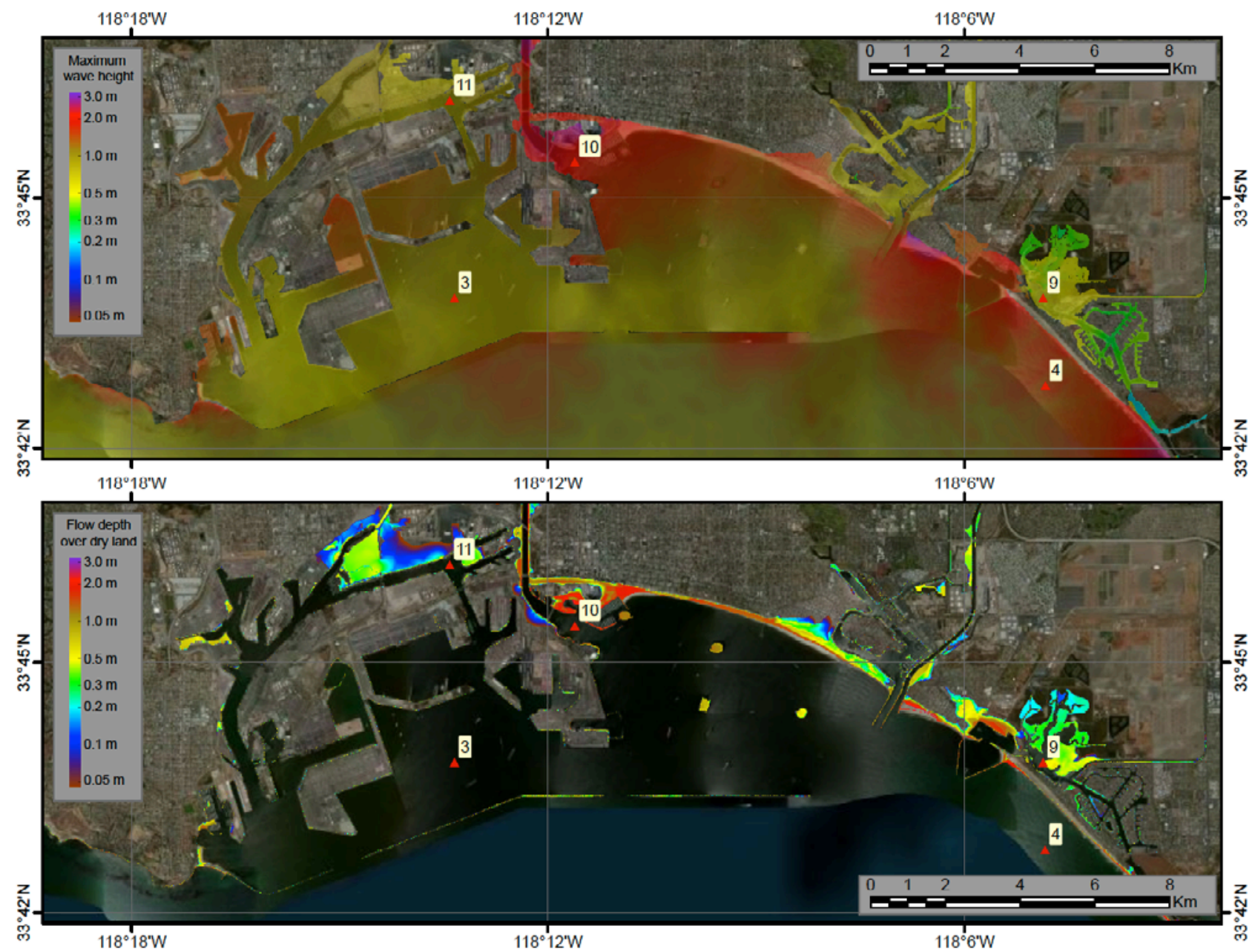

Figure 62. Maps showing modeled wave heights and water flow depths in the Ports of Los Angeles and Long Beach. Numbers mark locations for which data are given in figure 64 and table 12. Top: the maximum potential wave height above the mean high water (MHW) level. Bottom: the simulated water flow depth above the dry land. The DEM corresponds to the present-day MHW datum. 


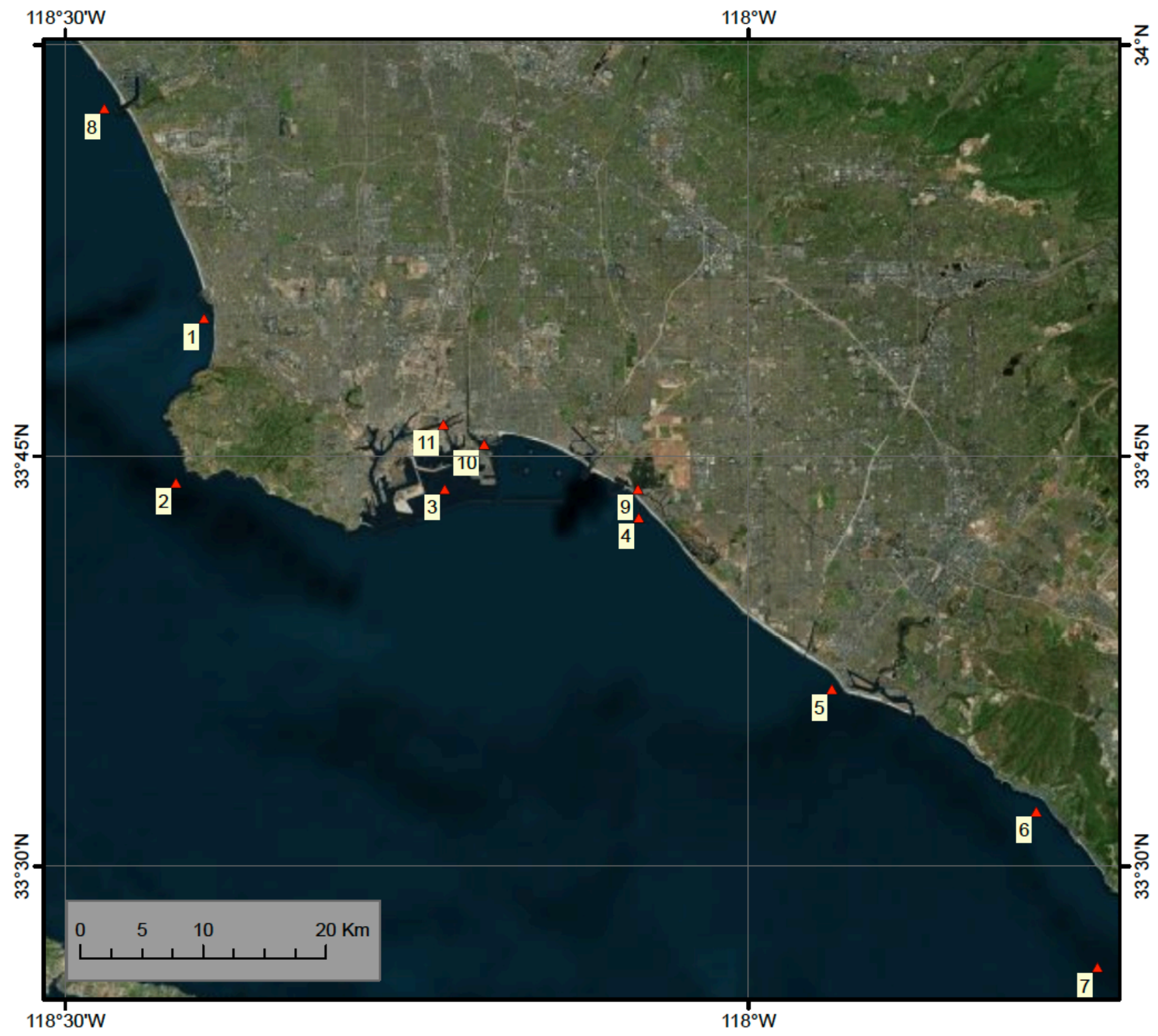

Figure 63. Map showing locations of time-series points (numbered red triangles) on the California coast near the Port of Los Angeles. Locations of the points are given in table 12, and data obtained there appear in figure 64. 

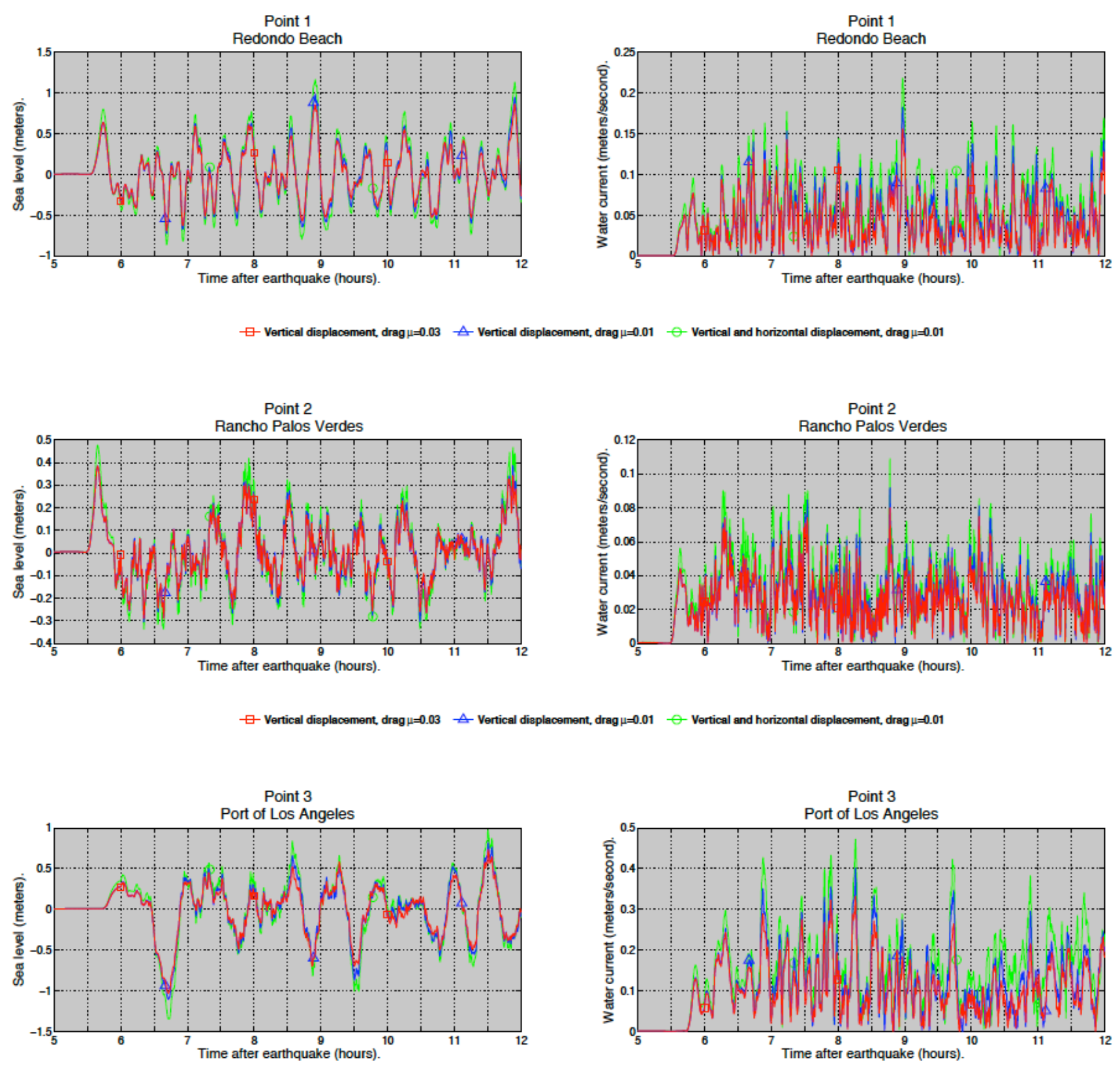

$\square$ Vertical diaplacement, drag $\mu=0.03 \triangle$ Vertical displacement, drag $\mu=0.01 \quad \ominus$ - Vertical and horizontal displacement, drag $\mu=0.01$

Point 4

Sunset Beach

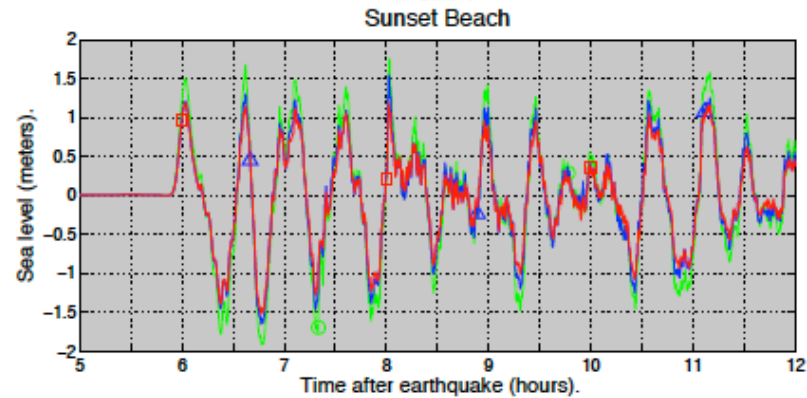

Point 4

Sunset Beach

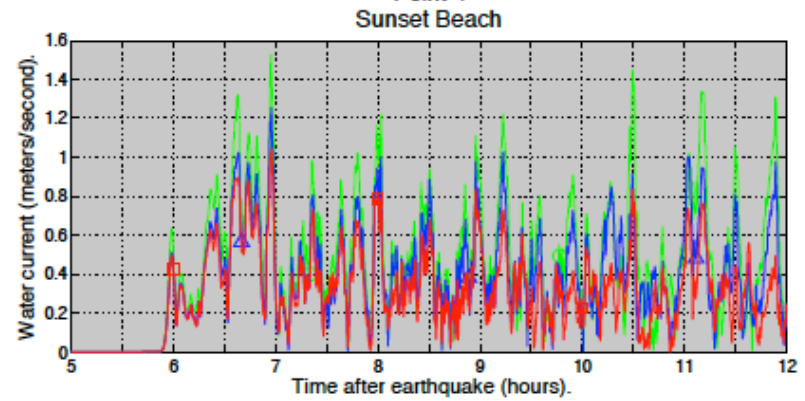

$\square$ Vertical diaplacement, drag $\mu=0.03 \triangle$ Vertical dieplacement, drag $\mu=0.01 \quad-$ Vertical and horizontal diaplacement, drag $\mu=0.01$ 

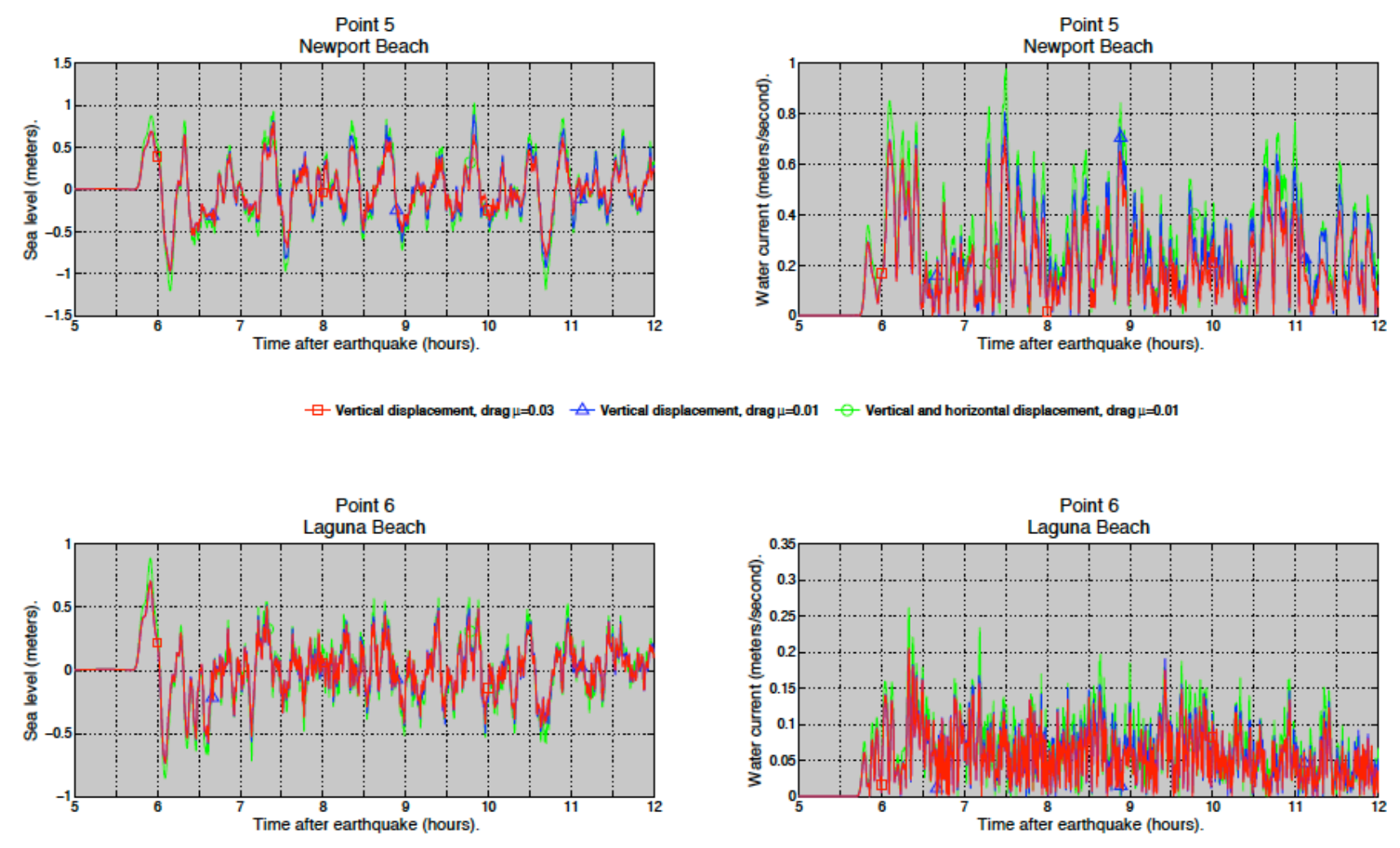

$\square$ Vertical dieplacement, drag $\mu=0.03 \triangle$ Vertical dieplacement, drag $\mu=0.01 \quad-$ Vertical and horizontal dieplacement, drag $\mu=0.01$
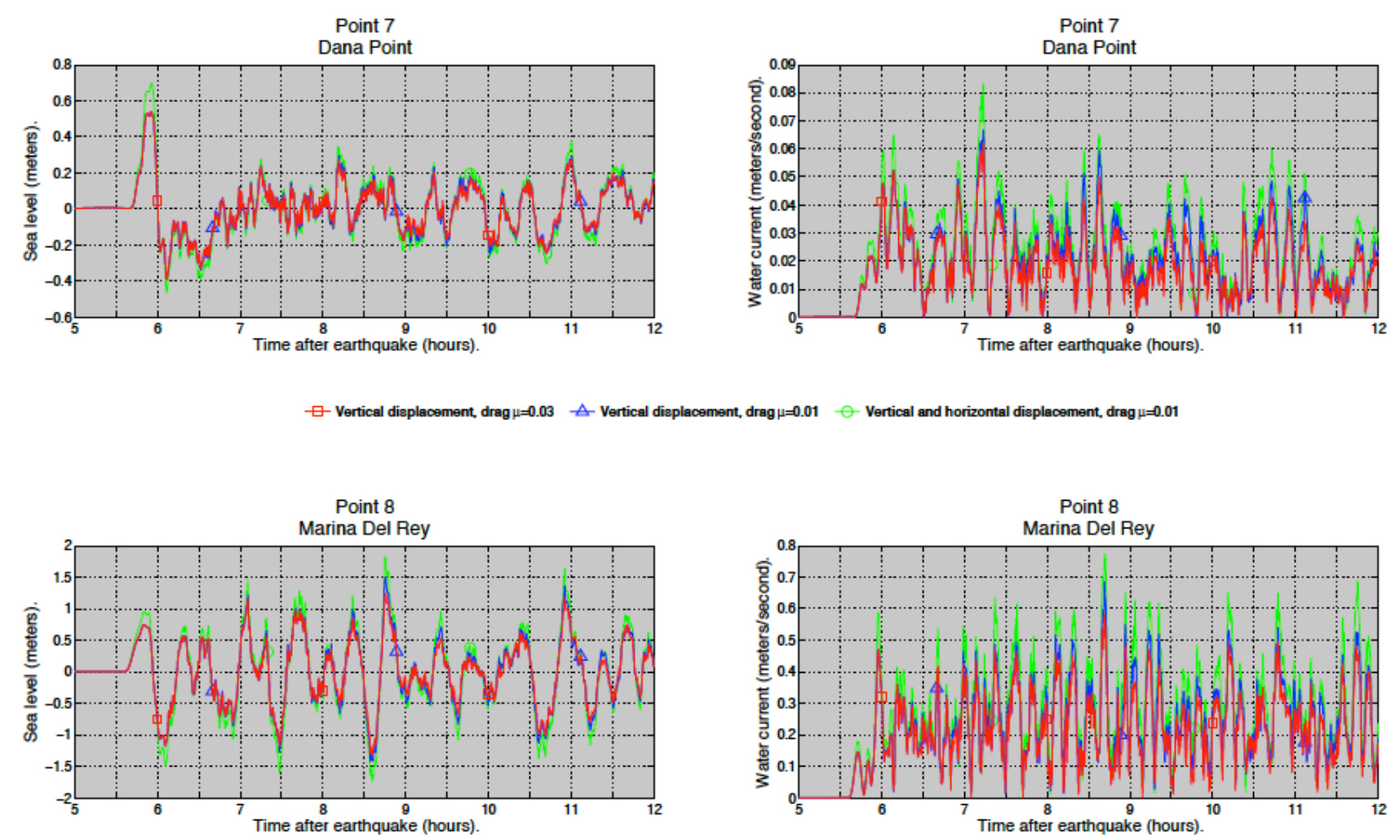

$\square$ Vertical diaplacement, drag $\mu=0.03 \triangle$ Vertical dieplacement, drag $\mu=0.01$

- Vertical and horizontal diaplacement, drag $\mu=0.01$ 

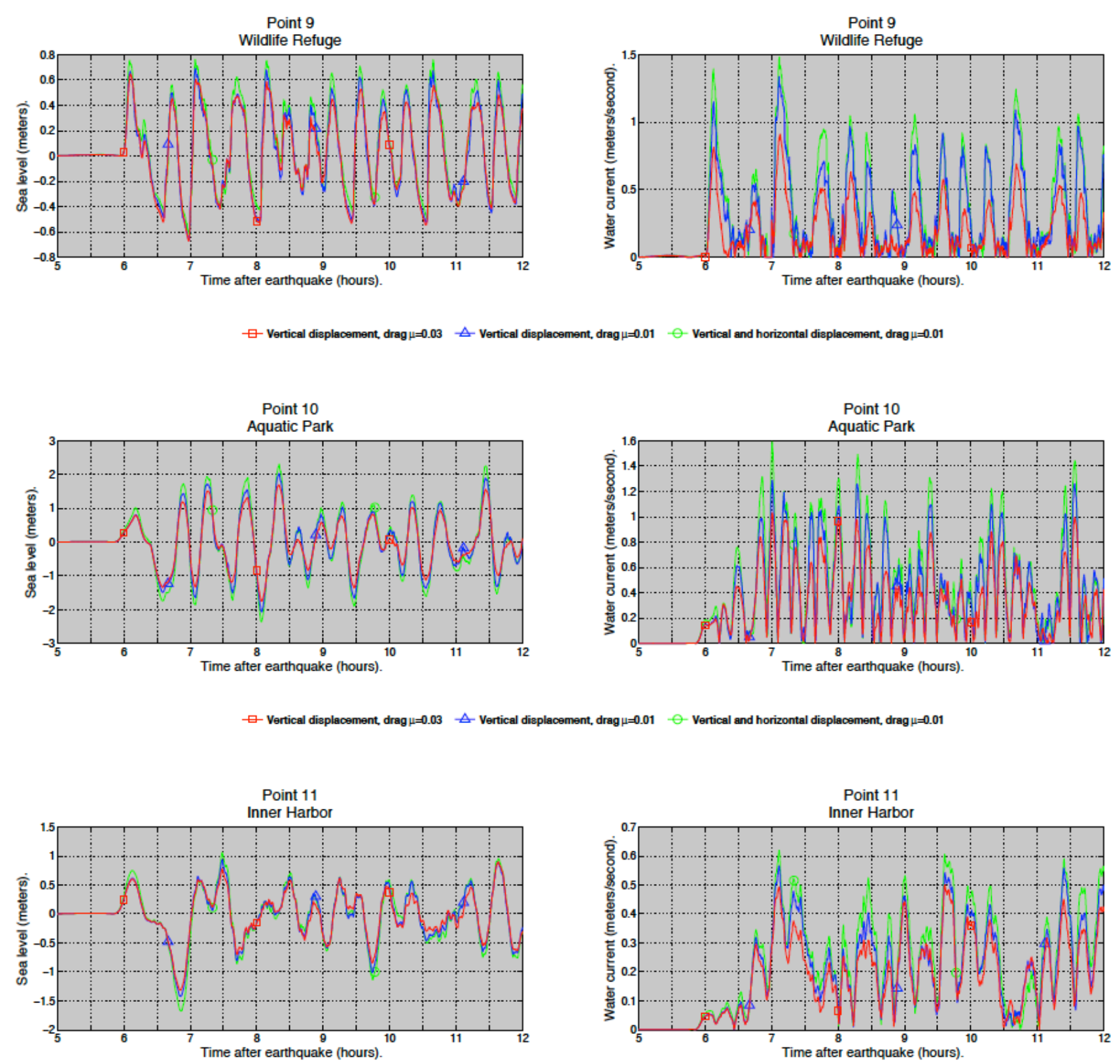

Figure 64. Time-series plots of modeled water level and velocity at the selected locations on the California coast near Los Angeles. The modeled water height is given with respect to the mean high water (MHW) tide level. Red line: vertical displacement only at the source and $\mu=0.03$. Blue line: vertical displacement only at the source and $\mu=0.01$. Green line: vertical and horizontal displacement at the source and $\mu=0.01$. 
Table 12. Locations where the simulated water level and velocity in the scenario tsunami are recorded. [Locations shown on figures 62 and 63; data from the locations presented in figure 64]

\begin{tabular}{cccc}
\hline ID & Lon & Lat & Label \\
\hline 1 & -118.39889 & 33.83389 & Redondo Beach \\
2 & -118.41944 & 33.73389 & Rancho Palos Verdes \\
3 & -118.22250 & 33.73000 & Port of LA \\
4 & -118.08056 & 33.71250 & Sunset Beach \\
5 & -117.93889 & 33.60806 & Newport Beach \\
6 & -117.78917 & 33.53333 & Laguna Beach \\
7 & -117.74444 & 33.43806 & Dana Point \\
8 & -118.47167 & 33.96139 & Marina Del Rey \\
9 & -118.08111 & 33.73000 & Wildlife Refuge \\
10 & -118.19361 & 33.75722 & Aquatic Park \\
11 & -118.22361 & 33.76944 & Inner Harbor \\
\hline
\end{tabular}

To assess sensitivity of the hypothetical inundation with respect to the bottom friction, we consider an additional scenario. As in the previous scenario, we assume that the initial deformation is equal to the vertical displacement computed by Okada's formulae, but now set the Manning roughness $\mu=0.03$. The maps of computed flow depth for the two scenarios are compared in figure 65 . Note that significant differences between the computed inundation zones occur inside the Los Angeles harbor (point 11) and near the Aquatic Center (point 10). The largest difference in the inundation extents is observed in flat areas, where the water flow can easily spread laterally and the bottom friction is important. In most of the flooded areas the difference in the simulated flow water depths is less than 0.2 $\mathrm{m}$. The difference in inundation can also be partially explained by the slightly larger wave heights that are modeled in the case of $\mu=0.01$ - compare the water level plots for points 10 and 11 in figure 64 . We emphasize that the degree of inundation along the northern edge of the displayed extent, near the Los Angeles River (fig. 65), can be a numerical artifact due to the solid-wall boundary condition imposed along the northern edge of the high-resolution grid. 


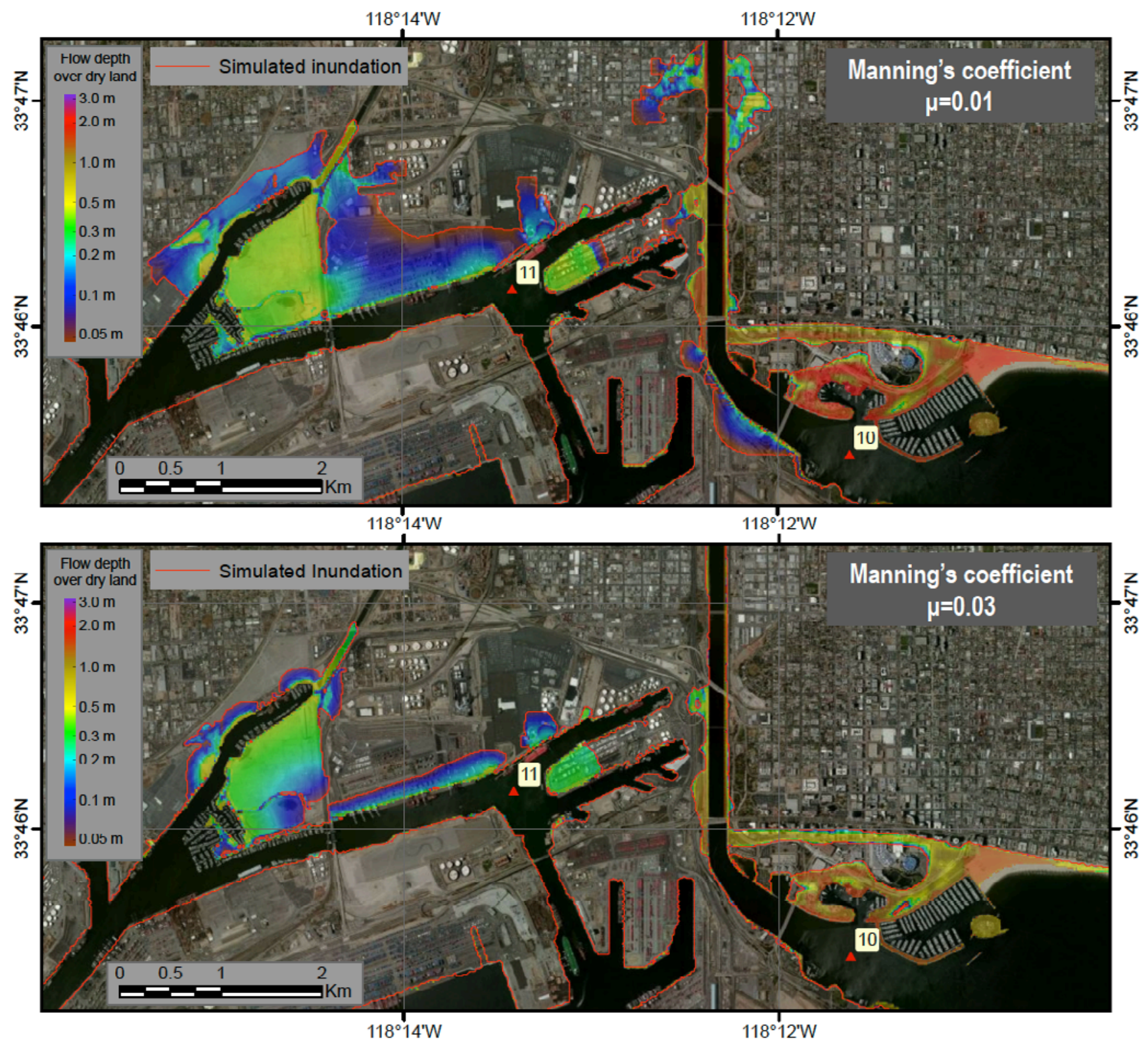

Figure 65. Maps showing modeled flow depths from the scenario tsunami in Los Angeles Harbor with different values of the Manning coefficient. Top: the flow depth above the dry land in the case of Manning's coefficient $\mu=0.01$. Bottom: the potential flow depth in the case of $\mu=0.03$. The coseismic deformation is assumed to be equal to the vertical sea-floor displacement. The most significant differences in the simulated inundation occur in the completely flat areas.

To analyze sensitivity of the hypothetical inundation to inclusion of the horizontal displacements into the sea-floor deformation, we consider another scenario. Here, the initial sea-floor displacement is computed with a contribution of the horizontal coseismic displacements, and the Manning roughness $\mu$ is set to 0.01 . The differences in these parameters among all three considered scenarios are listed in table 13. The computed hypothetical inundation zones for the first and last considered scenarios are shown in figure 66. The difference in the maximum water level near the Aquatic Park and in the Inner Harbor can be as much as 0.25 and 0.15 meters, respectively, which is high enough to cause inundation 
in some flats regions. The time series of the water level dynamics at points 10 and 11 are shown in figure 64 .

Table 13. Differences in assumptions under the three considered tsunami scenarios:

\begin{tabular}{ccc} 
& Sea-floor deformation & Manning's coefficient \\
\hline Scenario 1 & Vertical displacement only & $\mu=0.01$ \\
Scenario 2 & Vertical displacement only & $\mu=0.03$ \\
Scenario 3 & Vertical and horizontal displacements & $\mu=0.01$ \\
\hline
\end{tabular}

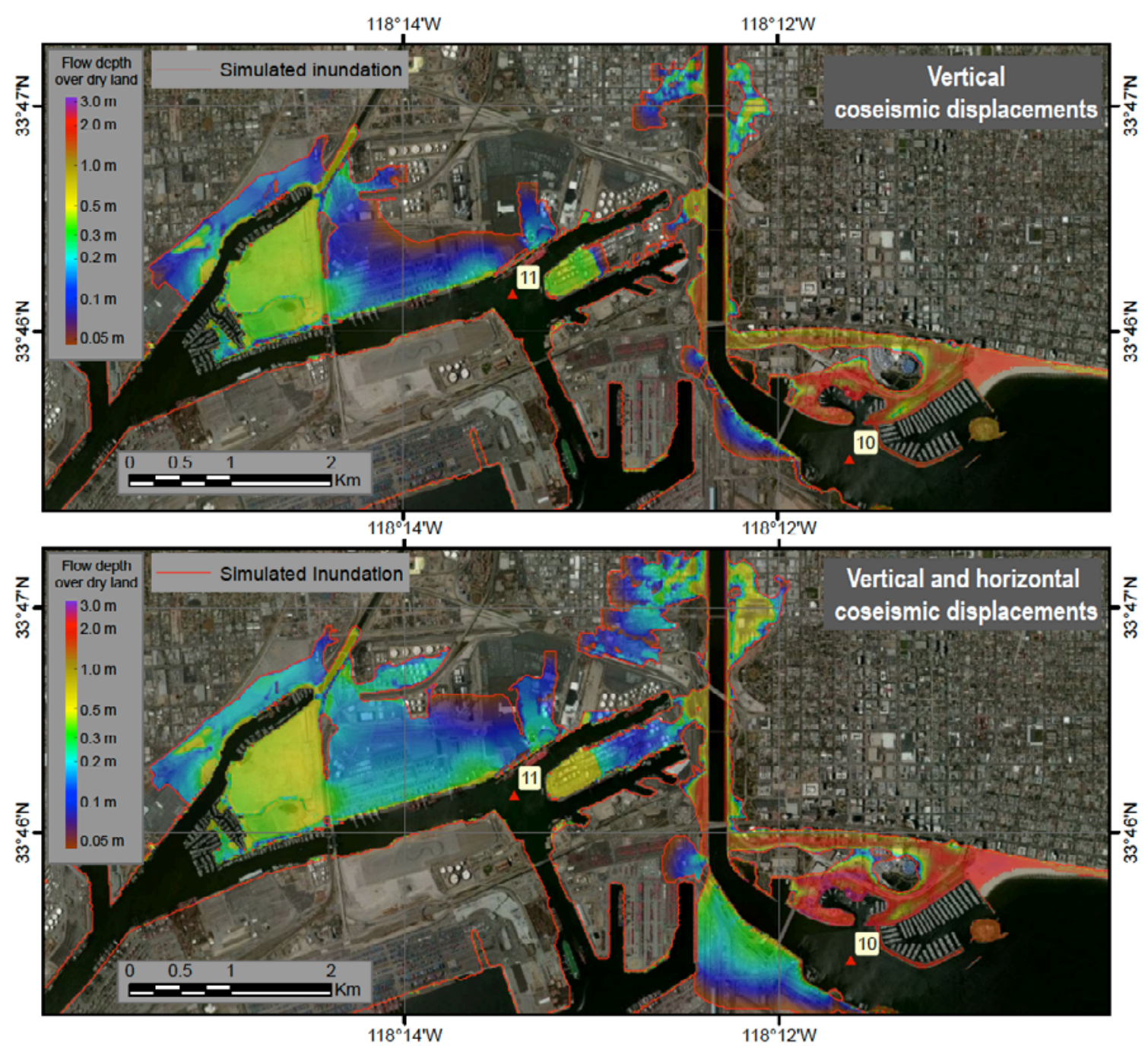

Figure 66. Maps showing inundation and flow depths in Los Angeles Harbor under two different scenarios. Top: the flow depth modeled under the assumption that the vertical coseismic deformation is equal to the vertical displacement of the seafloor during the earthquake. Bottom: the flow depth modeled under the assumption that the vertical coseismic deformation is a product of both the vertical and horizontal displacements of the seafloor during the earthquake. The Manning coefficient $\mu$ is assumed to be equal to 0.01 in both cases. 


\section{Sources of Errors and Uncertainties}

The hydrodynamic model used to calculate tsunami propagation and runup is a nonlinear fluxformulated shallow water model (Nicolsky and others, 2011). It passed the validation and verification tests required for models used to simulate the tsunami dynamics (Synolakis and others, 2007; National Tsunami Hazard Mitigation Program, 2012). This model is currently employed to simulate the hypothetical tsunamis along the coast of Alaska and was successfully applied to model the 1964 tsunami propagation and runup. The model is being verified to simulate historic tsunamis along the California coast. The source mechanism remains the biggest unknown in the problem of tsunami modeling. Because the initial condition for the modeling is determined by the displacement of the ocean bottom, the largest source of errors is the earthquake model.

The horizontal resolution of the grid used for inundation modeling is about $12-13 \mathrm{~m}$. This resolution is high enough to describe major relief features, but small topographic features, buildings, and other facilities cannot be accurately resolved. The San Pedro, Middle, and Long Beach breakwaters are resolved with one or two grid cells in the high-resolution DEM, while some smaller jetties might have some partial breaks in the DEM.

\section{Summary}

In this study we present the results of numerical modeling of earthquake-generated tsunamis for the Port of Los Angeles, California. The results of our modeling (figs. 62, 64-66) have been based on the best information available and are believed to be accurate; however, their preparation required many assumptions. Actual conditions during a tsunami event may vary from those considered, so the accuracy cannot be guaranteed. The limits of inundation shown should be used only as a guideline and require an expert interpretation. Actual areas inundated will depend on specifics of the earth deformations, on land construction, and on tide level, and they may differ from areas shown on the figures. The numerical results are not intended for land-use regulation or building-code development.

\section{Acknowledgments}

This project was supported in part by the Cooperative Institute for Alaska Research (CIFAR) with funds from the National Oceanic and Atmospheric Administration (NOAA) under cooperative agreement NA08OAR4320751 with the University of Alaska, and in part by the California Geological Survey under agreement 1011-023. Numerical calculations for this work were supported by a grant of High Performance Computing (HPC) resources from the Arctic Region Supercomputing Center (ARSC) at the University of Alaska Fairbanks as part of the U.S. Department of Defense High Performance Computing Modernization Program. 


\title{
7. Port \& Harbor Hydrodynamics
}

\author{
By Patrick Lynett and Sangyoung Son
}

\section{Introduction and Background}

In coastal locations where flooding and inundation are not a significant tsunami hazard for a particular event, the strong and erratic currents induced by the tsunami can still lead to major damage. Areas that are particularly exposed to tsunami current hazards are ports, harbors, and marinas. The 2011 Japan tsunami caused widespread damage to harbors along the California coastline; these effects were almost exclusively due to strong currents (Lynett and others, 2012). Also during the 2011 event, there was a remarkable occurrence at the Naval Harbor in Guam. Two nuclear submarines, tied side-by-side in series to the wharf, were pulled from their lines and floated briefly without control in the Harbor. The recorded tsunami amplitude (crest elevation) in this location was only 1 foot $(0.3 \mathrm{~m})$, and the hindcast modeled currents were 4 knots $(2 \mathrm{~m} / \mathrm{s})$.

During the 2004 Indian Ocean tsunami, damage to harbors was noted in a series of papers by Okal and others (2006a,b,c). The most remarkable of these events occurred in the Port of Salalah, Oman. About 90 minutes after tsunami first arrival, strong currents near the farthest offshore unloading berth broke all of the mooring lines on a 285-m ship, the Maersk Mandraki, and pulled it away from the terminal and out of the Port. The vessel then drifted on the currents for hours, spinning numerous times, before beaching on a nearby sandbar. Once the vessel was pulled from its berth, tugs were quickly dispatched to the ship. However, because of the complex and rapidly varying nature of the flowessentially a mess of large eddies and jets of current - the tugs were unable to control the motion of the Mandraki. At nearly the same time as the Mandraki parted its lines, the 292-m Maersk Virginia was approaching the Port entrance, and strong currents caused it to strike a breakwater. The Virginia experienced only minor damage due to this collision, and the Captain waited offshore of the entrance for 7 additional hours until he deemed the currents safe enough to enter the Port.

There were no direct measurements of the currents in the Port of Salalah, and we rely on numerical hindcasting of the event to provide flow speeds. Near the initial location of the Mandraki, numerically predicted currents are approximately 6 knots $(3 \mathrm{~m} / \mathrm{s})$. For both the Salalah and Guam examples, the flow speeds would conventionally be thought of as not strong enough to pull a vessel from its lines; however, the highly sheared and rotational nature of the currents in these areas likely produced very irregular drag loading on the hull, including significant yaw, causing the vessel to act as a huge moment arm and leading to uneven loading of mooring lines. The goal of this modeling exercise is to perform highly detailed and resolved tsunami current simulations, such that the remarkable effects observed recently in harbors might be understood and evaluated for the SAFRR scenario.

\section{Hydrodynamic Modeling Approach and Results}

With incident tsunami information provided by basin-scale propagation models, high-resolution simulations with a high-order physics model have been done for select locations. Specifically, the dispersive, rotational, and turbulent flow model of Kim and Lynett (2011) is applied at San Diego Bay, Ports of Los Angeles (POLA) and Long Beach (POLB), and Ventura Harbor. For these three coastal locations, a uniform spatial resolution of $5 \mathrm{~m}$ is used, and the tsunami signal is super-imposed over the tidal signal, such that the complete hydrodynamic forcing is included. The tsunami signal is taken from a 2-arc-min resolution, open-ocean propagation simulation of the entire Pacific Ocean basin using the 
COMCOT model (Liu and others, 1995), forced with the initial condition described in previous sections. The simulations presented in this section take the output from the propagation simulation at the 25-m offshore depth; at this depth, the tsunami height (maximum crest-to-trough distance) is $1.1 \mathrm{~m}$ at POLA/POLB, $2.2 \mathrm{~m}$ at Ventura, and $2.1 \mathrm{~m}$ at San Diego, with wave periods of the leading waves in the range of 20-30 minutes.

A weakly dispersive and rotational Boussinesq-type modeling approach is used for the simulations in this section. Recently, a number of nontraditional Boussinesq approaches have been developed, with the goal of including horizontal vorticity explicitly in the flow field. An attempt to include these dynamics under a breaking wave is found in Veeramony and Svendsen (2000), with further advances given in Musemeci and others (2005). A similar attempt, resulting in the model employed here, was made by Kim and others (2009), who included the viscous effects of a bottom shear, and the associated rotationality, directly in a Boussinesq-type derivation. Although this leads to a far more complex equation model, it includes the physics necessary to simulate boundary shear and the complete coupling of these effects with a nonlinear, dispersive wave field. This model can predict the friction-induced changes to the vertical profile of velocity under weakly unsteady flow, and it thereby can provide good estimates of internal kinematics. It is also able to translate the bottom-created horizontal vorticity into a vertical vorticity field. Most important to the harbor simulations provided here, results include highly localized current features, such as jets and whirlpools, which tend to exhibit the greatest flow speeds. Additionally, all of the numerical efforts here implement established aspects of Boussinesq-type modeling, developed by the lead author and other researchers. These aspects include wind wave breaking (Kennedy and others, 2000; Lynett, 2006) and accurate moving boundary schemes for shoreline motion (Lynett and others, 2002). Because Boussinesq-type models tend to be complicated sets of lengthy equations, usually requiring high-order numerical solution schemes, the computational cost of a solution is not insignificant. To lessen this burden, a parallel implementation based on message passing interface (MPI) has been used here (Sitanggang and Lynett, 2005), permitting the large-scale simulation (tens of square kilometers and tens of millions of grid points) in a reasonable duration of processing time.

Figures 67 and 68 show the predicted maximum sea-surface elevations and current speed, respectively, for Ventura Harbor. Flood elevations are between 2 and $3 \mathrm{~m}$ in the area, with water overtopping the dune in a couple of locations. Maximum currents through the Ventura Harbor channel exceed 14 knots $(7.2 \mathrm{~m} / \mathrm{s})$, with widespread maximum speeds greater than 8 knots $(4 \mathrm{~m} / \mathrm{s})$. Under these conditions it would be reasonable to expect widespread damage to floating infrastructure throughout the harbor. 


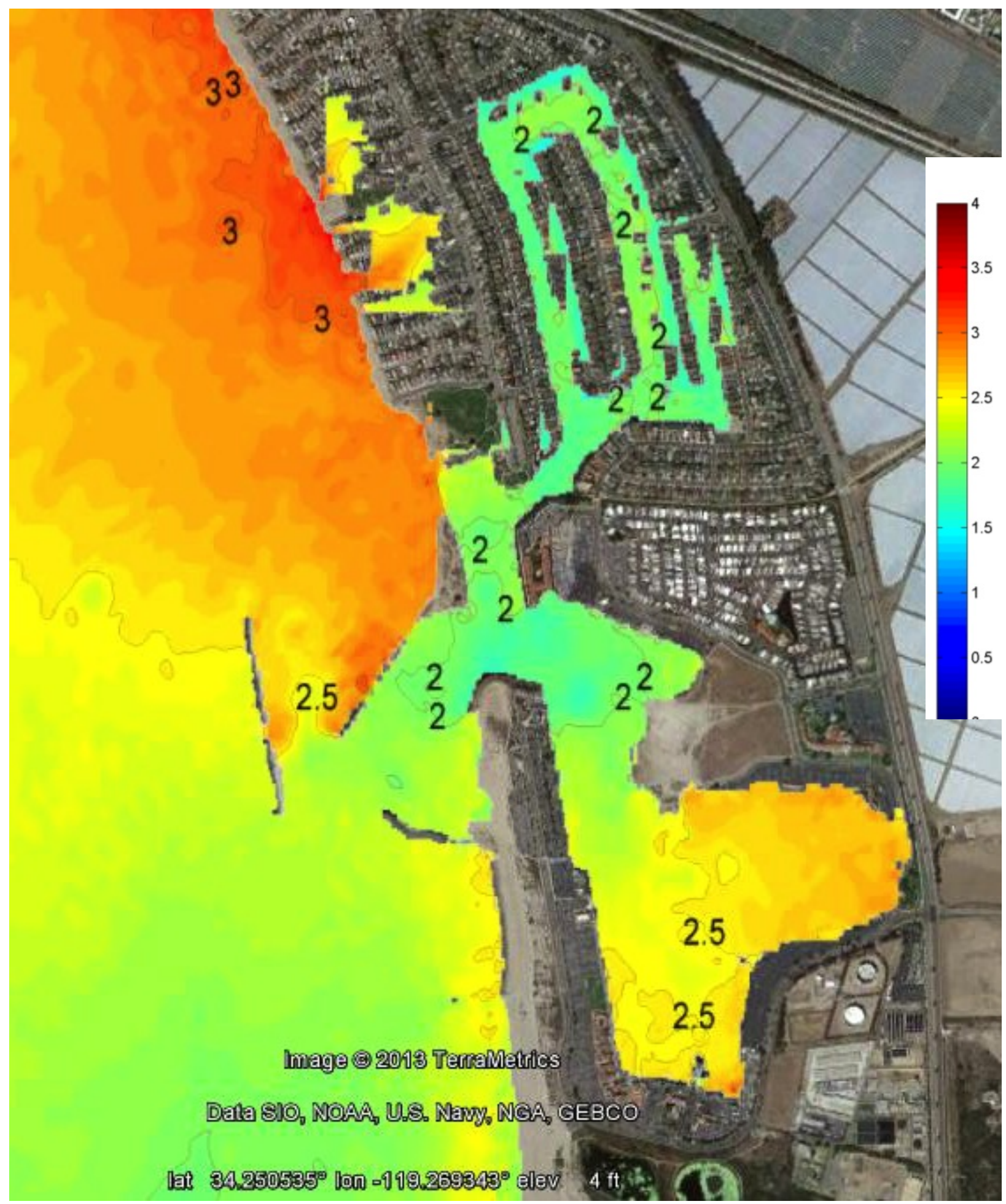

Figure 67. Map showing maximum predicted water surface elevation from the scenario tsunami, relative to mean high water datum, for Ventura harbor. Color scale in meters. 


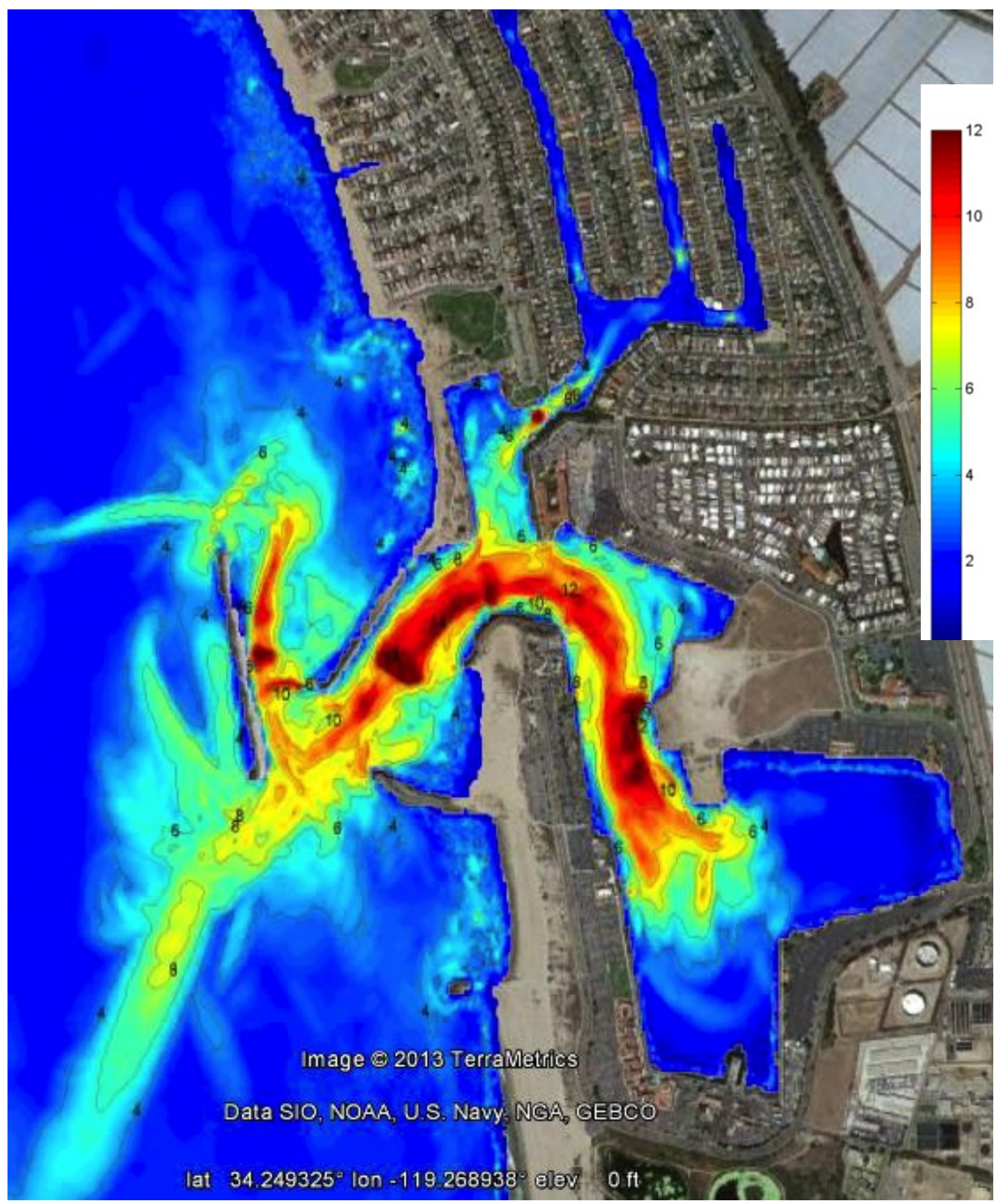

Figure 68. Map showing maximum predicted tsunami-induced currents (knots; $1 \mathrm{knot}=0.51 \mathrm{~m} / \mathrm{s}$ ) for Ventura Harbor. Color scale in knots. 
The maximum predicted currents in San Diego Bay are given in figure 69. In general, the modeled current speeds are not great. The Shelter Island area appears to be the most at-risk location in the Bay, but strong currents might also affect Point Loma. Farther inside the Bay, near the primary naval piers, currents are weak, and vessel complications here have a low probability. Debris from Shelter Island could plausibly cause obstructions in the main channel and hinder traffic in and out of the Bay.

Figures 70 and 71 give maximum current speeds for the Port of Los Angeles (POLA) and the Port of Long Beach (POLB), respectively. Note that the numerical domain used here was continuous; the POLA and POLB were in fact simulated together because they are adjacent and contiguous. In the POLA, currents are strongest at Angels Gate, the Cabrillo Marina, the Boat Yard, and the old Navy Yard. Once the tsunami event is underway, navigation through the Gate would be very dangerous. In the Cabrillo Marina and Boat Yard, currents are likely strong enough to break apart floating docks, damage piles, and pull small vessels from their mooring lines. The strongest currents are found in the old Navy Yard; however there are no exposed floating assets in this immediate area. At the POLB, again strong currents are found at Queens Gate. Also in the POLB, strong and jet-like currents are predicted at the entrance to the main cargo container area (Pier J). Currents here may be strong enough to damage, and possible break, mooring lines. 


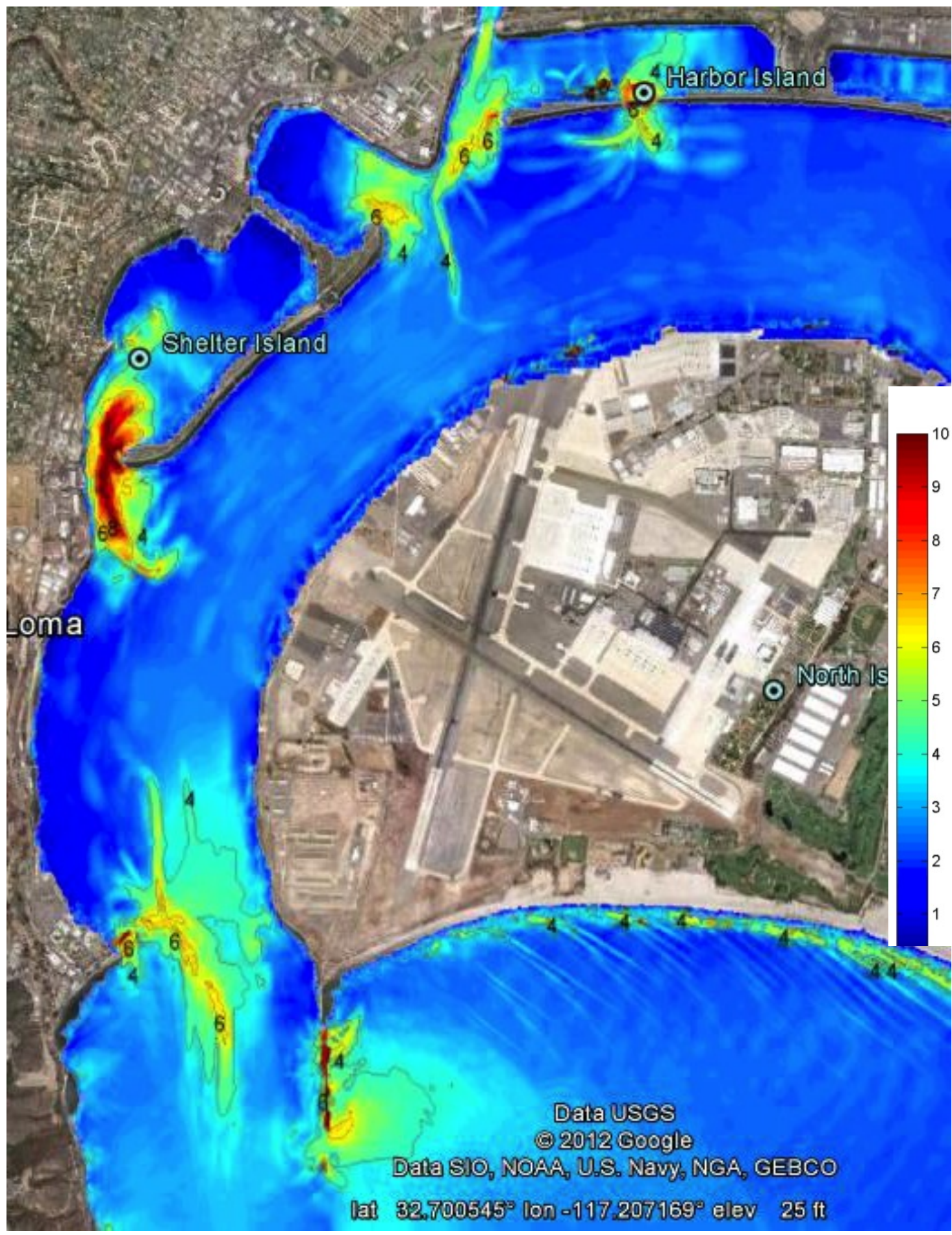

Figure 69. Map showing maximum predicted tsunami-induced currents (knots; $1 \mathrm{knot}=0.51 \mathrm{~m} / \mathrm{s}$ ) for San Diego Harbor. Color scale in knots. 


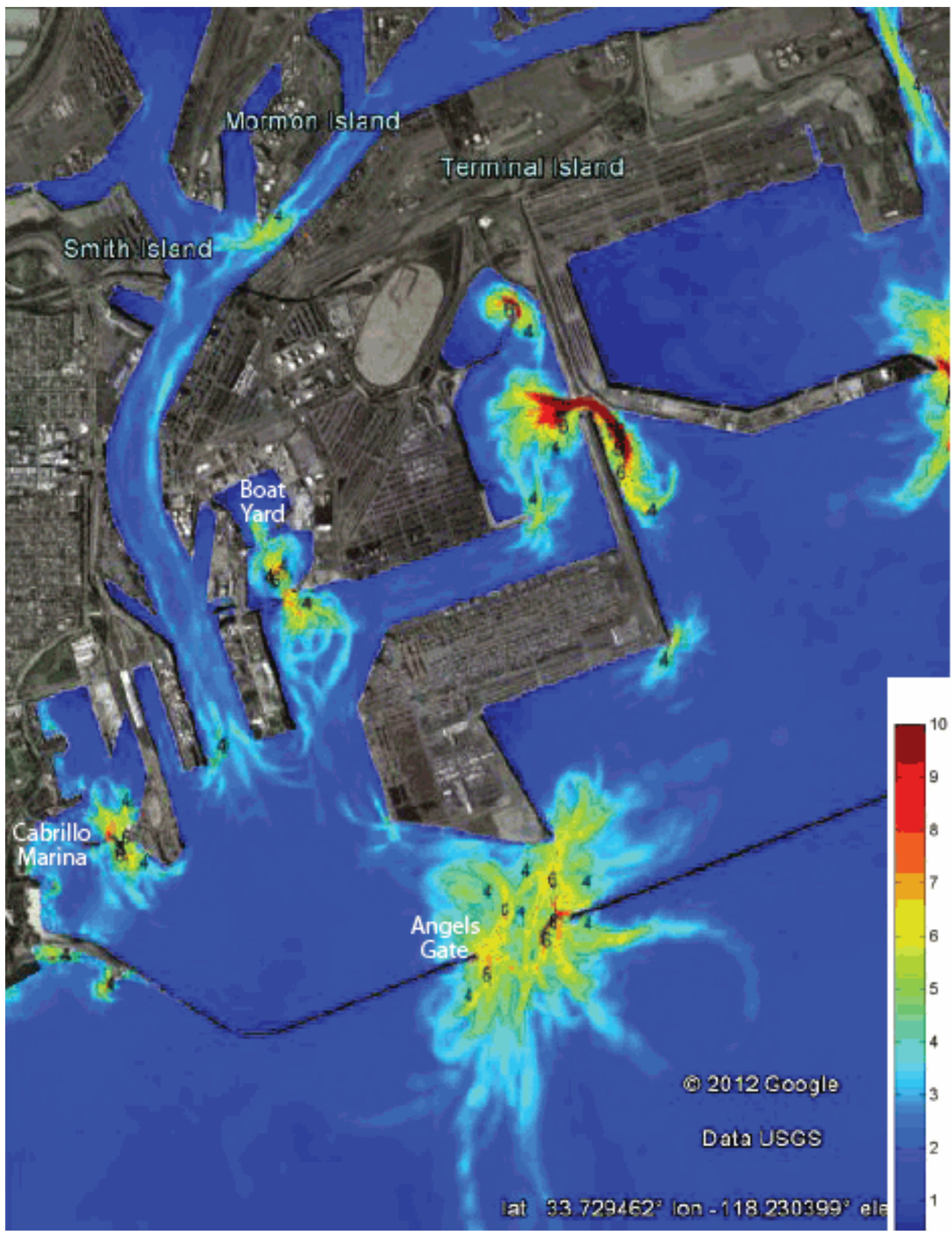

Figure 70. Map showing maximum predicted tsunami-induced currents (knots) for the Port of Los Angeles. 


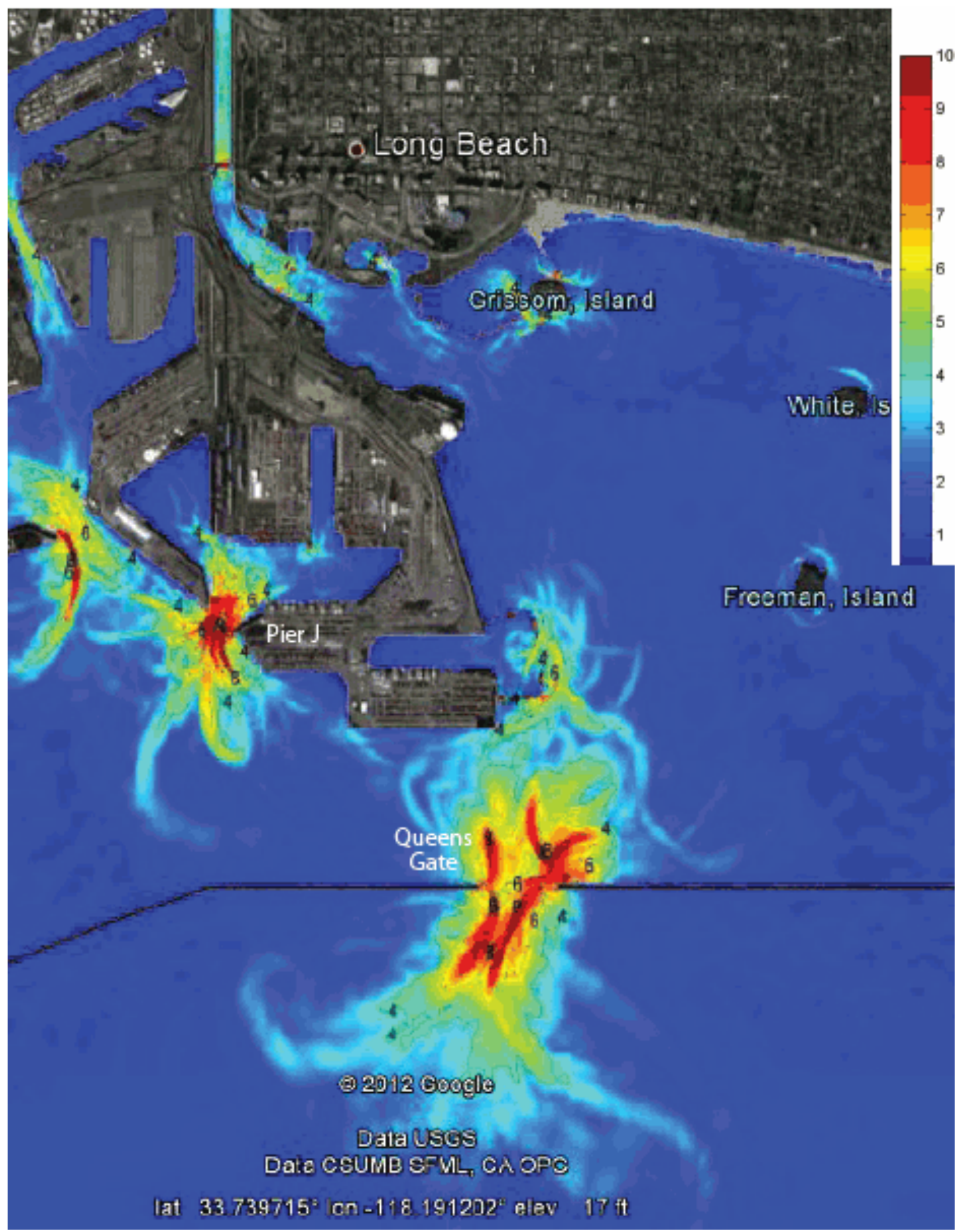

Figure 71. Map showing maximum predicted tsunami-induced currents (knots) for the Port of Long Beach. 


\section{Modeling of Tsunami-Induced Sediment Transport}

\section{Theoretical Approach}

In this modeling we attempt to use a weakly dispersive Boussinesq model to study transport and morphological changes in the nearshore area (see, for example, Xiao and others, 2010). In the present study, three separate models, as given below, are coupled appropriately to create a complete sediment transport model system in the coastal area. The hydrodynamic foundation is the same as that used in the above section, and is given in condensed form as:

$\frac{\partial H}{\partial t}+\frac{\partial H U}{\partial x}+\frac{\partial H V}{\partial y}+B_{c}=\frac{E-D}{1-p}$

$\frac{\partial H U}{\partial t}+\frac{\partial H U^{2}}{\partial x}+\frac{\partial H U V}{\partial y}+g H \frac{\partial \zeta}{\partial x}+H B_{x}+U B_{c}=-\frac{(E-D) U}{1-p}$

$\frac{\partial H V}{\partial t}+\frac{\partial H U V}{\partial x}+\frac{\partial H V^{2}}{\partial y}+g H \frac{\partial \zeta}{\partial y}+H B_{y}+V B_{c}=-\frac{(E-D) V}{1-p}$

where $H=\zeta+h$ is total water depth, $\zeta$ is surface elevation, $h$ is water depth, and $U$ and $V$ are the $x$ and $y$ components of velocity at $-0.531 \mathrm{~h} . B_{c}, B_{x}, B_{y}$ represent higher order terms adding dispersive and bedfrictional turbulent effects, which distinguish this Boussinesq system from a potential shallow-water set. Full descriptions for those terms can be found in Kim and others (2009) and Son and others (2011).

Note also that some source terms are added here to the "fixed-bed" Boussinesq model on the right hand side, among which $E$ and $D$ are sediment erosion and deposition fluxes, respectively, and $p$ is bed porosity (Cao and others, 2004; Xiao and others, 2010). Sediment transport is modeled as:

$\frac{\partial H C}{\partial t}+\frac{\partial H C U}{\partial x}+\frac{\partial H C V}{\partial y}=\frac{\partial}{\partial x}\left(K_{x} H \frac{\partial C}{\partial x}\right)+\frac{\partial}{\partial y}\left(K_{y} H \frac{\partial C}{\partial y}\right)+E-D$

where $C$ is the depth-averaged sediment concentration and $K_{x}, K_{y}$ are the sediment diffusivities, assumed to be the same as the turbulent eddy viscosity (Rakha and others, 1997). Sediments entrained by the flow field are governed by the transport model above. This model is a typical form for scalar transport, but has additional source and sink terms on the right hand side, to account for the addition and removal of sediment to and from the water column through erosion and deposition, respectively. In this study erosion and deposition fluxes are calculated by empirical formulas.

The erosion flux can be obtained by (Cao and others, 2004):

$E=\left\{\begin{array}{cl}\varphi\left(\theta-\theta_{c}\right)\left(U^{2}+V^{2}\right)^{0.5} H^{-1}\left(d_{50}\right)^{-0.2} & \text { if } \theta>\theta_{c} \\ 0 & \text { else }\end{array}\right.$

whereas deposition flux can be calculated by

$D=C_{a} w_{0}$

In the above equations,

$$
\begin{aligned}
& \theta=\frac{U_{*}^{2}}{\left(\rho_{s} / \rho_{w^{-}}-g d_{50}\right.} ; \text { Shields parameter } \\
& \theta_{c}=\text { critical Shields parameter }(=0.045 \text { in this study }) \\
& U_{*}=\sqrt{f} U ; \text { friction velocity } \\
& f=\frac{g n^{2}}{H^{1 / 3}} ; \text { friction factor using Manning's formula }
\end{aligned}
$$


$n=$ Manning's coefficient

$\rho_{s}=$ density of sediment

$\rho_{w}=$ density of water $\left(1,000 \mathrm{~kg} / \mathrm{m}^{3}\right.$ is used in this study $)$

$d_{50}=$ median grain diameter

$\varphi=$ empirical coefficient

$C_{a}=C$ near-bed concentration

$=\min [2.0,(1-p) / C]$

$\mathrm{w}_{0}=\frac{4 \times g \times d_{50}}{3 \times(0.2)\left(\rho_{s} / \rho_{w^{-1}}\right)} ;$ fall velocity (see Ponce, 1989$)$

The morphological evolution of the seafloor is given by the simple conservation equation

$\frac{\partial h}{\partial t}=\frac{(E-D)}{1-p}$

which is, of course, controlled only by the erosion and deposition rates. The updated bathymetry predicted by this equation is then used in the hydrodynamic model; all of these equations are coupled and solved simultaneously.

In the hydrodynamic model, turbulent closure models for bed stress, bottom-induced turbulence, wave-breaking, and stochastic backscatter are included in the higher-order terms $\left(B_{c}, B_{x}, B_{y}\right)$ of the equations. Although complete details of the individual components can be found directly in relevant references, some are briefly introduced here. For the calculation of bottom-induced turbulence, Smagorinsky's turbulent eddy viscosity model for horizontal eddy viscosity and Elder's (1959) model for vertical eddy viscosity are adopted (Kim and others, 2009). It is well recognized that turbulent energy transfer from subgrid scales to resolved scales can be significant in regions where high shear stresses are present. To yield a better representation of this $3 \mathrm{D}$ turbulent process in the $2 \mathrm{HD}$ model, the stochastic backscatter model proposed by Hinterberger and others (2007) is included in $\left(B_{x}, B_{y}\right)$. Through the inclusion of the above-mentioned physics in the model, which have increasingly important effects in shallow regions, a more realistic and physically rigorous recreation of the sediment transport can be achieved.

\section{Model Validation and Calibration}

To validate the developed model, four typical tests have been attempted. First, one-dimensional dam-break flow over a movable bed is simulated by the model and compared with the laboratory data by Fraccarollo and Capart (2002). The experiment was performed in a channel with 2.5-m length, 0.1-m width and $0.25-\mathrm{m}$ depth, which had $0.1 \mathrm{~m}$ initial water depth upstream while a dry condition was initially retained downstream. PVC particles of $3.5-\mathrm{mm}$ diameter with $1,540-\mathrm{kg} / \mathrm{m}^{3}$ density were used for the movable bed materials.

In the numerical simulation, the grid size $(d x)$ is $0.005 \mathrm{~m}$ and time step $(d t)$ is dynamically determined by a Courant number of 0.1 . The sediment porosity $(p)$ and settling velocity $\left(w_{0}\right)$ are set to 0.3 and $0.18 \mathrm{~m} / \mathrm{s}$, respectively, based on Wu and Wang (2008). Manning's coefficient $(n)$ is 0.025 , and the empirical coefficient in the erosion flux equation $(\varphi)$ is 0.003 . Simulated results compared with measured data are shown in figure 72 . Generally good agreement between calculation and measurement is found, while some discrepancies exist in surface elevations near the leading front and hydraulic jump locations. 

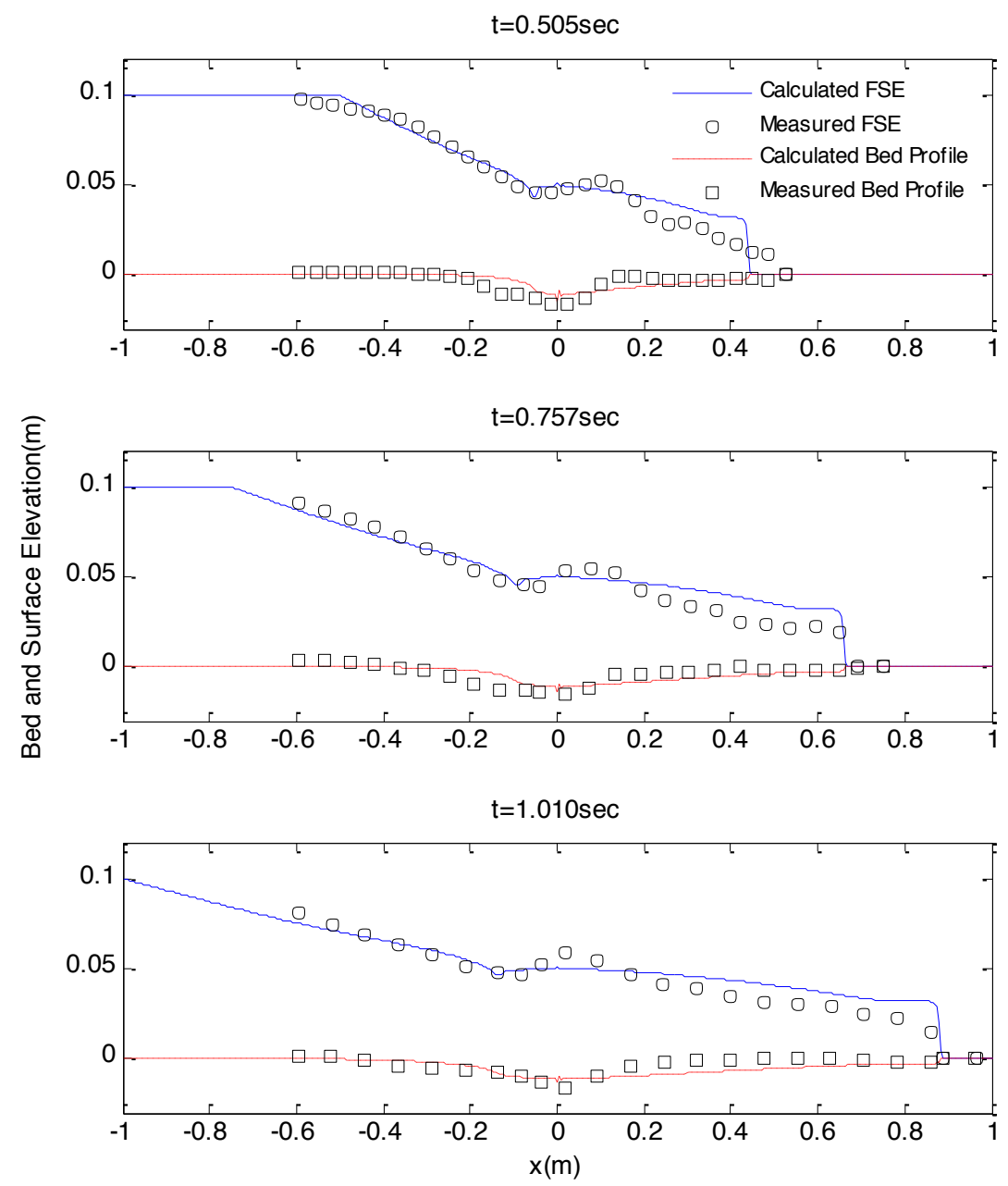

Figure 72. Graphs comparing measured and simulated dam-break flows over a movable bed at different elapse time after dam break. $x=0$ : position of dam. Elevation $=0$ : initial bed surface elevation.

Recently, Kobayashi and Lawrence (2004) carried out laboratory experiments in a wave flume (length $30 \mathrm{~m}$, width $2.4 \mathrm{~m}$, and height $1.5 \mathrm{~m}$ ) to study beach profile changes under breaking solitary waves, as shown in figure 73 . A solitary wave of $0.216-\mathrm{m}$ height was generated by wave paddle and propagated to the sloping beach composed of sand grains. The water depth beyond the base of the beach was $0.8 \mathrm{~m}$. The beach has initial slope of 1:12 that is expected to be changed by the breaking solitary waves. The solitary wave was repeated eight times to consider the effects by multiple wave attacks. Bottom profiles after four and eight waves, as well as surface elevations at eight locations (G1 to G8) across the beach after four waves, were measured. The median grain diameter $\left(d_{50}\right)$, fall velocity $\left(w_{0}\right)$, specific gravity, and porosity $(p)$ are $0.18 \mathrm{~mm}, 2.0 \mathrm{~cm} / \mathrm{s}, 2.6$, and 0.4 , respectively. 


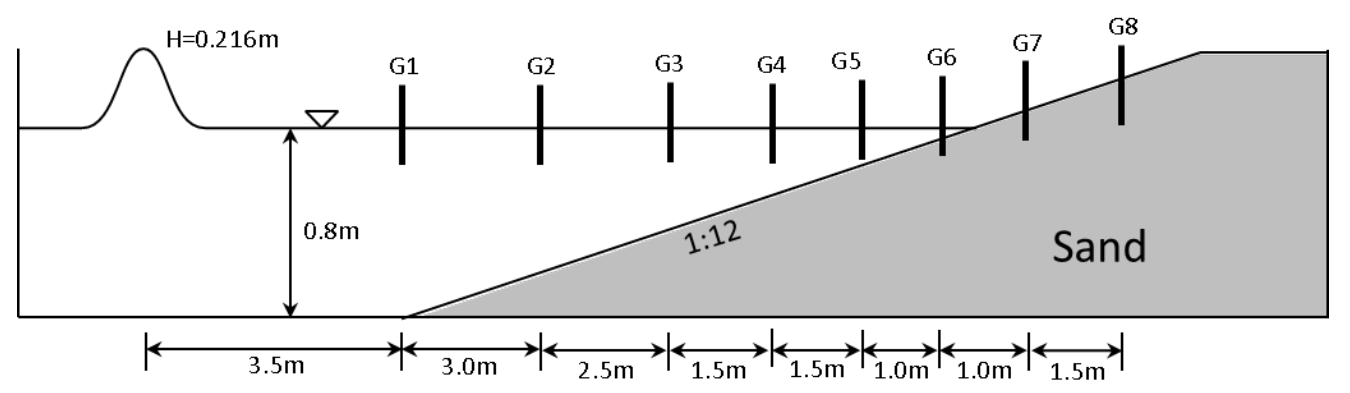

Figure 73. Diagrammatic cross section showing experimental setup for breaking solitary waves on a sloping sand beach.

To evaluate the accuracy and performance of the model, their experiment was recreated through numerical modeling using the same conditions as in the experimental setup. The simulation was performed using a uniform grid size of $0.1 \mathrm{~m}$ and varying time step with a Courant number of 0.4 . For Manning's coefficient $(n)$ and empirical parameter $(\varphi), 0.025$ and $7.5 \times 10^{-6}$ are used, respectively. Additionally, to account for turbulent mixing and dissipation by wave breaking, the eddy-viscosity model proposed by Kennedy and others (2000) is adopted in the test.

Calculated beach profiles compared with the measured data are shown in figure 74. Fairly good agreement is found in both results after four and eight waves. Significant erosion at the foreshore is observed in both measured and computed results, which may be explained by the strong backwash current caused when the solitary wave rushes back down. The entrained sediments are deposited on the seaward side. In figure 75, calculated surface elevations agree well with measurements, although some errors are seen in gauges G6-G8 for wave runup and rundown. This discrepancy is largely due to the errors in the simulated shoreline (fig. 74), which affects the water depth.
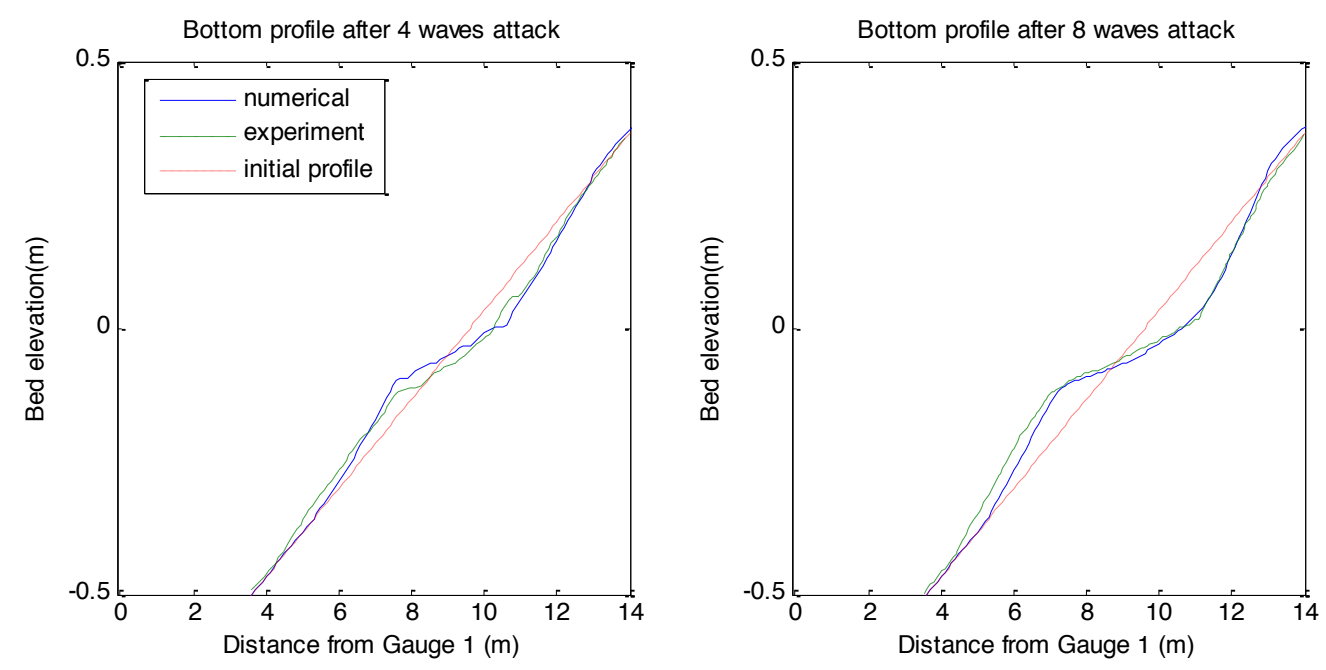

Figure 74. Graphs comparing measured and calculated beach profiles for Kobyashi test. 

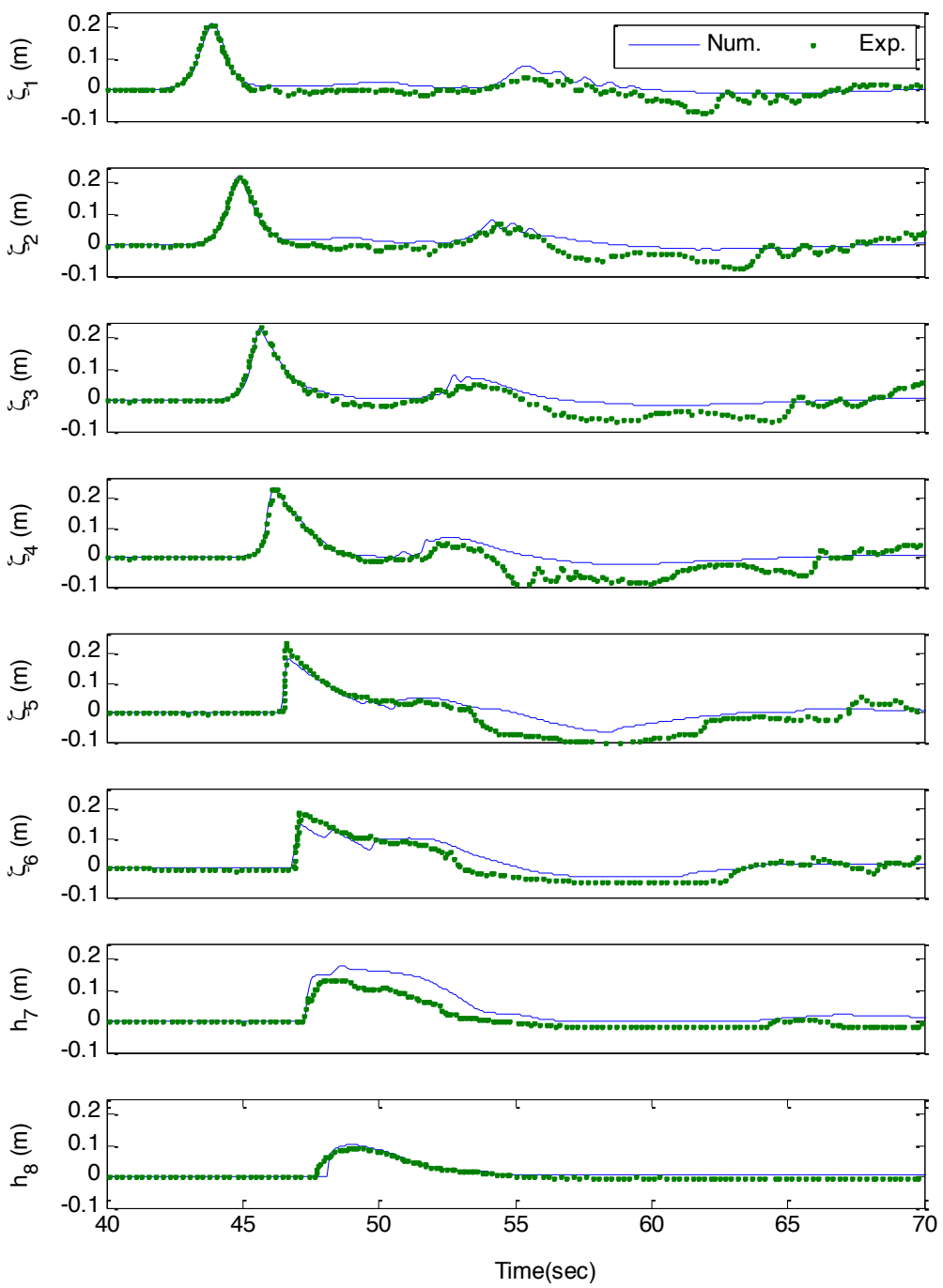

Figure 75. Graphs comparing experimental (Exp.) and numerical (Num.) simulated temporal free surface elevations at different locations (gauges $\mathrm{G} 1$ to $\mathrm{G} 8$ ) during the fifth wave in the simulated erosion of a beach profile.

Finally, the case of flow in a partially breached dam-break was used to test the present model. This test was conducted experimentally in Xiao and others (2010). Figure 76 depicts the experimental setup of the test, in which the middle of the channel has a moveable bed section composed of coal ash. The median diameter $\left(d_{50}\right)$ of the coal ash was $0.135 \mathrm{~mm}$ and the density was $2,248 \mathrm{~kg} / \mathrm{m}^{3}$. Initial water depths were $0.4 \mathrm{~m}$ and $0.12 \mathrm{~m}$ for upstream and downstream, respectively. Strong jet-like flow through the 0.2 -m-wide gap caused significant erosion, and cross-sectional profiles of the bottom were measured at $\operatorname{cs} 1(x=2.5 \mathrm{~m})$ and $\operatorname{cs} 2(x=3.5 \mathrm{~m})$ after 20 seconds. 
(a) Side view
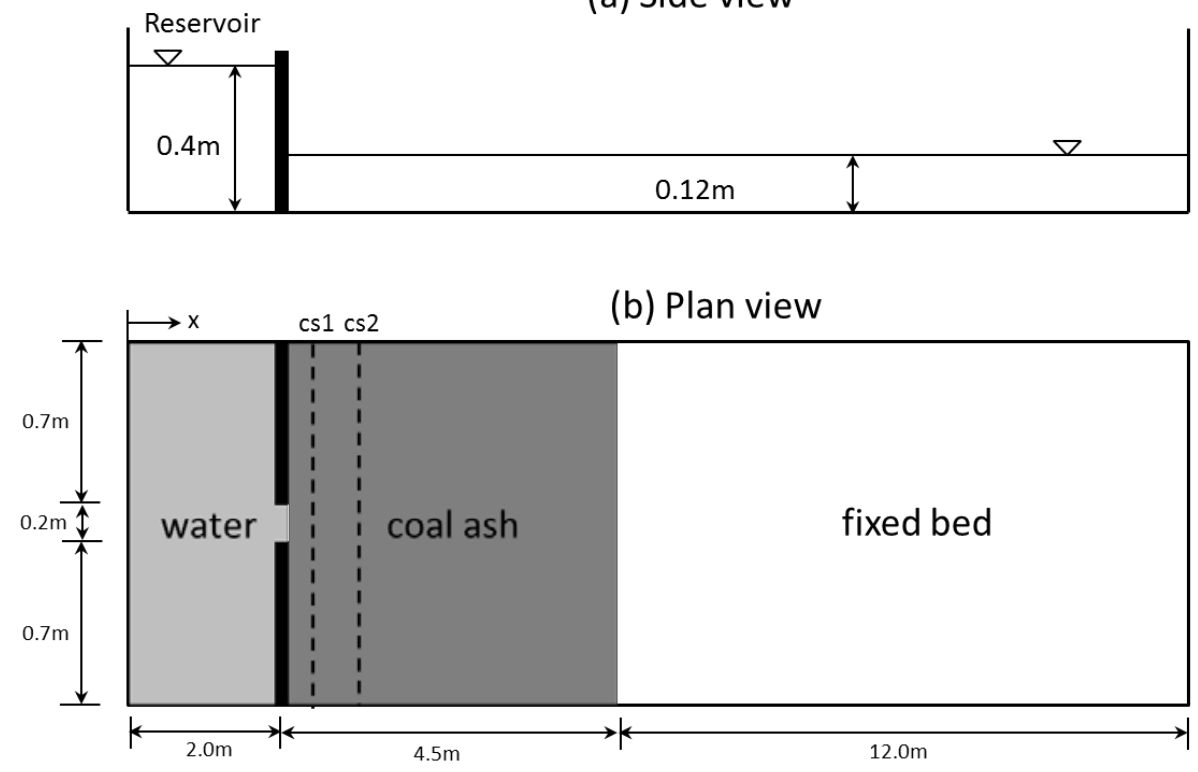

Figure 76. Diagrams showing side view (a) and plan view (b) of the experimental setup of a dam-break flow through a partial breach over a moveable bed. Cross-sectional profiles of the bottom were measured at locations cs1 and cs2.

The identical situation to this experimental test has been reproduced numerically with a grid resolution of $0.025 \mathrm{~m}$. As in previous tests, our time step varies and is based on a Courant number of 0.3. Following Xiao and others (2010), Manning's coefficient $(n)$ is set to 0.015 while the empirical parameter $(\varphi)$ is tuned to $5.0 \times 10^{-5}$ based on Kim and Lee (2011). Fall velocity can be approximated by an empirical formula (Ponce, 1989) because it is not given explicitly in the experimental description.

Figure 77 compares the bottom profiles in the simulated and measured data. Reasonable agreement is seen at both profiles cs1 and cs2, but the simulation overestimates the peak erosion depth at cs1. As pointed out by Hinterberger and others (2007), in depth-averaged 2D modeling, turbulence backscattering needs to be considered when strong horizontal shear exists (as near the breached gap in this test). Through it, turbulence energy transfer from unresolved subdepth scale to the resolved 2D flows can be explained. Figure 78 shows the same results as in figure 77 but with the backscatter model used. Prediction of maximum erosion depth at cs1 is much improved by including backscatter model. 

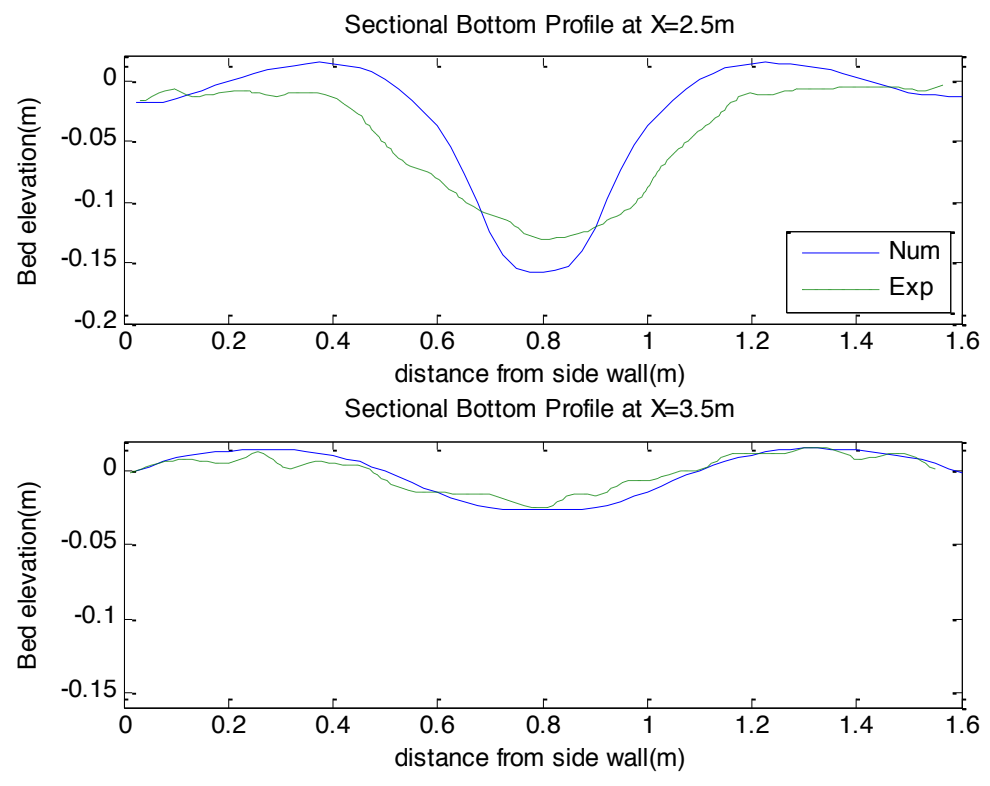

Figure 77. Graphs comparing measured (Exp) and calculated (Num) bottom profiles in the case of the partially breached dam-break test (Xiao and others, 2010).
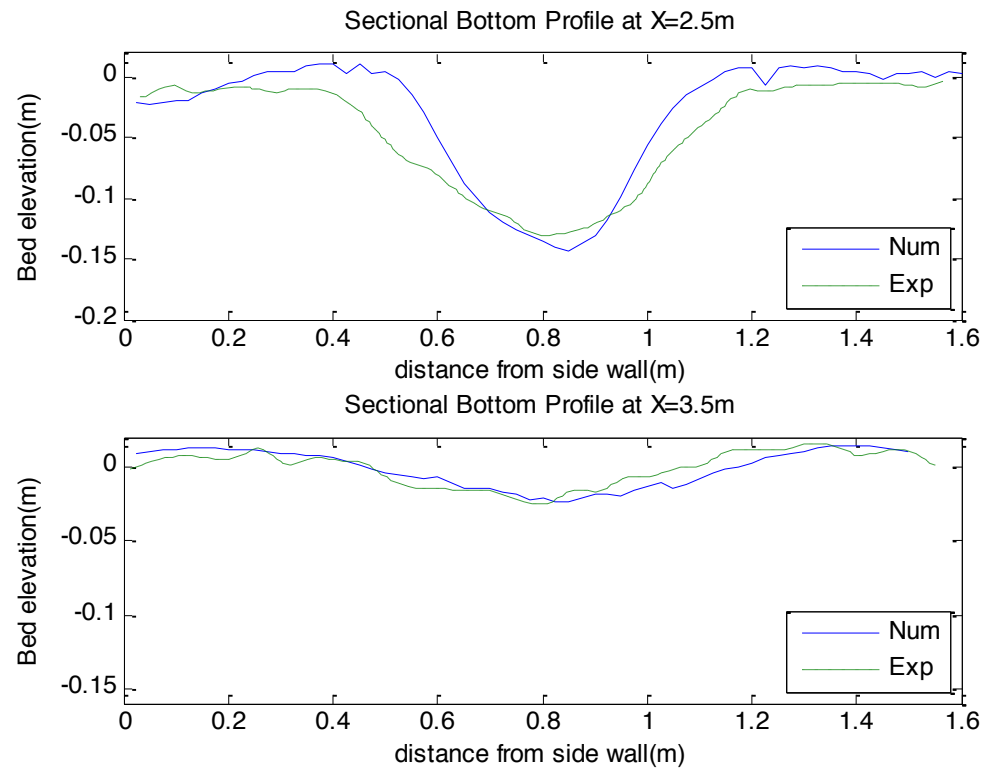

Figure 78. Graphs comparing measured (Exp) and calculated (Num) (with backscatter model) bottom profiles in the case of the partially breached dam-break test (Xiao and others, 2010).

\section{Model Application to Santa Cruz Harbor, California}

Some recent observations have shown that far-field tsunami events can lead to severe changes in bottom morphology, especially in the nearshore area (Lacy and others, 2012; Wilson and others, 2012). Because relatively small-amplitude tsunami waves $(<1-2 \mathrm{~m})$ can create strong current fields near harbor basins (see, for example, Son and others, 2011; Lynett and others, 2012), tsunamis have great 
potential to mobilize bed sediments. Needless to say, therefore, it is important to estimate tsunami currents accurately in the nearshore area in evaluating morphological changes near the shoreline. Traditional approaches to estimate sediment transport by tsunami waves are based on the shallow-water equation model (for example, Li and others, 2012).

As a practical application of the present model to the coastal region, the 2011 Japan tsunami event is considered For precise estimations of current fields from far-field tsunami waves in the nearshore area, a multigrid and multiphysics model developed by Son and others (2011) was applied to 2011 Japan event. A total of five nested layers were employed, with different levels of resolution. The final layer has the smallest domain focusing only on the Santa Cruz Harbor area, with relatively fine grid size $(10 \mathrm{~m})$, and is solved by Boussinesq equations to account for higher order effects by dispersive and turbulent processes. On the other hand, the rest of the layers, which generally cover a larger domain with deeper ocean rather than the shallow coastal region, are solved by shallow-water equations. The parametric values used in the sediment model are the median sediment diameter $d_{50}=0.15 \mathrm{~mm}$, Manning's coefficient $(n)=0.025$, and the empirical parameter $(\varphi)=5.0 \times 10^{-5}$, which is an acceptable value for coastal sedimentation (see, for example, Kim and Lee, 2011). The Courant number of the Boussinesq model is set to 0.4 .

The simulation was performed for 14 hours of tsunami waves at the harbor to allow enough duration for the erosion and sedimentation processes. Resultant bathymetric change at the harbor entrance is shown in figure 79, compared with observed data. The overall pattern of sedimentation and erosion is quite well recreated by the numerical model.

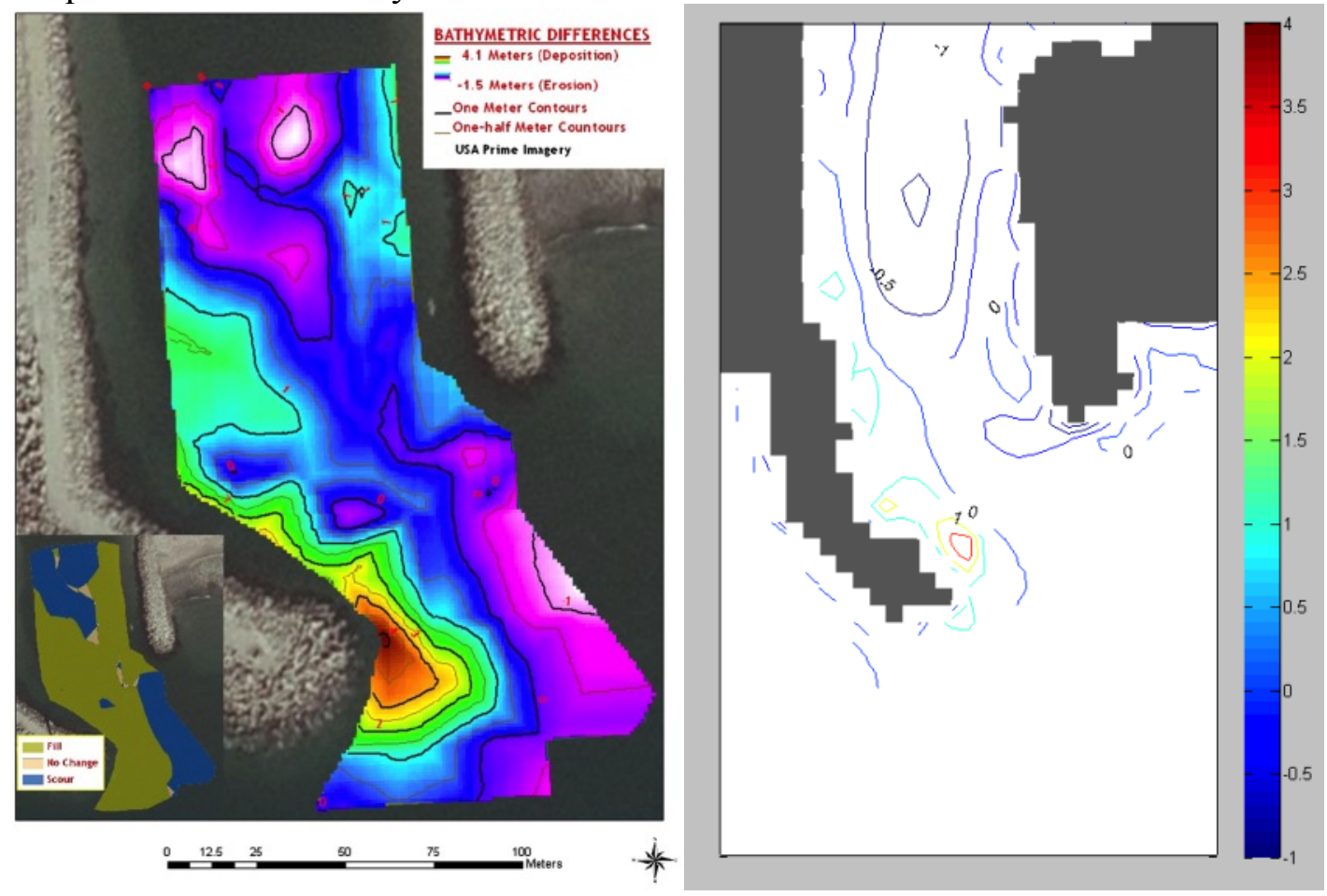

Figure 79. Changes in bottom bathymetry from tsunami-induced currents in Santa Cruz Harbor, California. Left: observed changes in the 2011 Japan tsunami event, excerpted from Wilson and others (2012). Right: computed bathymetric changes from the simulation. Color scale in meters (positive = deposition; negative $=$ erosion). 


\section{Acknowledgments}

The Science Application for Risk Reduction (SAFRR) Tsunami Modeling Working Group gratefully acknowledges the constructive and helpful comments of the following reviewers: Yong Wei (National Oceanic and Atmospheric Administration/Pacific Marine Environmental Laboratory), David Dykstra (Moffatt \& Nichol), Ruth Harris (U.S. Geological Survey, USGS), and Jessica Lacy (USGS). The SAFRR tsunami project and the modeling effort described in this report would not have been possible without the expert coordination and management efforts of Stephanie Ross (USGS).

\section{References}

Ammon, C.J., Lay, T., Kanamori, H., and Cleveland, M., 2011, A rupture model of the 2011 off the Pacific coast of Tohoku earthquake: Earth Planets Space, v. 63, p. 693-696.

Andrews, D.J., 1976, Rupture velocity of plane strain shear cracks: Journal of Geophysical Research, v. 81, p. 5679-5687.

Andrews, D.J., 2004, Rupture models with dynamically determined breakdown displacement: Bulletin of the Seismological Society of America, v. 94, p. 769-775.

Baba, T., Hirata, K., and Kaneda, Y., 2004, Tsunami magnitudes determined from ocean-bottom pressure gauge data around Japan: Geophysical Research Letters, v. 31, doi:10.1029/2003GL019397.

Baba, T., Cummins, P.R., Thio, H.K., and Tsushima, H., 2009, Validation and joint inversion of teleseismic waveforms for earthquake source models using deep ocean bottom pressure records-a case study of the 2006 Kuril megathrust earthquake: Pure and Applied Geophysics, v. 166, p. 55-76.

Balay, S., Buschelman, K., Eijkhout, V., Gropp, W.D., Kaushik, D., Knepley, M.G., McInnes, L.C., Smith, B.F., and Zhang, H., 2004, PETSc Users Manual, Revision 2.1.5: Argonne National Laboratory Tech. Rep. ANL-95/11.

Barall, M., 2008, FaultMod Finite Element Code, available at http://scecdata.usc.edu/cvws/download/codedesc/Barall_FaultMod_Desc.pdf, 6 p.

Barall, M., 2009, A grid-doubling finite-element technique for calculating dynamic three-dimensional spontaneous rupture on an earthquake fault: Geophysical Journal International, v. 178, p. 845-859.

Barberopoulou, A., Borrero, J.C., Uslu, B., Kalligeris, N., Goltz, J.D., Wilson, R.I., and Synolakis, C.E., 2009, New maps of California to improve tsunami preparedness: Eos (American Geophysical Union Transactions), v. 90(16), p. 137-138.

Becker, J.J., Sandwell, D.T., Smith, W.H.F., Braud, J., Binder, B., Depner, J., Fabre, D., Factor, J., Ingalls, S., Kim, S.-H., Ladner, R., Marks, K., Nelson, S., Pharaoh, A., Trimmer, R., Von Rosenberg, J., Wallace, G., and Weatherall, P., 2009, Global bathymetry and elevation data at 30 arc seconds resolution; SRTM30_PLUS: Marine Geodesy, v. 32, p. 355-371.

Beroza, G.C., and Mikumo, T., 1996, Short slip duration in dynamic rupture in the presence of heterogeneous fault properties: Journal of Geophysical Research, v. 103, p. 489-511.

Bilek, S.L., and Lay, T., 2002, Tsunami earthquakes possibly widespread manifestations of frictional conditional stability: Geophysical Research Letters, v. 29, doi:10.1029/2002GL015215.

Blanpied, M.L., Tullis, T.E., and Weeks, J.D., 1998, Effects of slip, slip rate, and shear heating on the friction of granite: Journal of Geophysical Research, v. 103, p. 489-511.

Borrero, J.C., Bell, R., Csato, C., DeLange, W., Goring, D., Greer, D., Pickett, V., and Power, W.L., 2012, Observations, effects and real time assessment of the March 11, 2011 Tohoku-oki tsunami in New Zealand: Pure and Applied Geophysics, doi: 10.1007/s00024-00012-00492-00026.

Brune, J.N., 1996, Particle motions in a physical model of shallow angle thrust faulting: Proceedings of the Indian Academy of Sceinces (Earth Planetary Sciences), v. 105, p. L196-L206. 
Bruns, T.R., von Huene, R., Culotta, R.C., Lewis, S.D., and Ladd, J.W., 1987, Geology and petroleum potential of the Shumagin margin, Alaska, in Scholl, D.W., Grantz, A., and Vedder, J.G., eds., Geology and Resource Potential of the Continental Margin of Western North America and Adjacent Ocean Basins: Circum-Pacific Council for Energy and Mineral Resources, Earth Science Series, v. 6, p. 157-189.

Burbridge, D., Cummins, P.R., Mleczko, R., and Thio, H.K., 2008, A probabilistic tsunami hazard assessment for western Australia: Pure and Applied Geophysics, v. 165, p. 2059-2088.

Burridge, R., and Halliday, G.S., 1971, Dynamic shear cracks with friction as models for shallow focus earthquakes: Geophysical Journal of the Royal Astronomical Society, v. 25, p. 261-283.

Cao, Z., Pender, G., Wallis, S., and Carling, P., 2004, Computational dam-break hydraulics over erodible sediment bed: Journal of Hydraulic Engineering, v. 130, p. 689-703.

Chester, F.M., and Higgs, N.G., 1992, Multimechanism friction constitutive model for ultrafine quartz gouge and hypocentral conditions: Journal of Geophysical Research, v. 97, p. 1859-1870.

Cummins, P.R., and Kaneda, Y., 2000, Possible splay fault slip during the 1946 Nankai earthquake: Geophysical Research Letters, v. 27, no. 17, p. 2725-2728.

Dalguer, L.A., and Day, S.M., 2007, Staggered-grid split-node method for spontaneous rupture simulation: Journal of Geophysical Research, v. 112, doi:10.1029/2006JB004467.

DeDontney, N., and Rice, J.R., 2012, Tsunami wave analysis and possibility of splay fault rupture during the 2004 Indian Ocean earthquake: Pure and Applied Geophysics, v. 169, p. 1707-1735.

Dengler, L., and Uslu, B., 2011, Effects of harbor modification on Crescent City, California's tsunami vulnerability: Pure and Applied Geophysics, v. 168, p. 1175-1185.

Dieterich, J.H., 1978, Time-dependent friction and the mechanics of stick-slip: Pure and Applied Geophysics, v. 116, p. 790-806.

Dieterich, J.H., 1979, Modeling of rock friction. Part 1. Experimental results and constitutive equations: Journal of Geophysical Research, v. 84, p. 2161_2168.

Dieterich, J.H., 1992, Earthquake nucleation on faults with rate- and state-dependent strength:

Tectonophysics, v. 211, p. 115-134.

Duan, B., and Day, S., 2008, Inelastic strain distribution and seismic radiation from rupture of a fault kink: Journal of Geophysical Research, v. 113, doi:10.1029/2008JB005847.

Duan, B., and Oglesby, D.D., 2006, Heterogeneous fault stresses from previous earthquakes and the effect on dynamics of parallel strike-slip faults: Journal of Geophysical Research, doi:10.1029/2008JB005847.

Elder, J.W., 1959, The dispersion of marked fluid in turbulent shear flow: Journal of Fluid Mechanics, v. 5, p. 544-560.

Fraccarollo, L., and Capart, H., 2002, Riemann wave description of erosional dam-break flows: Journal of Fluid Mechanics, v. 461, p. 183-228.

Freymueller, J.T., and Beavan, J., 1999, Absence of strain accumulation in the western Shumagin segment of the Alaska subduction zone: Geophysical Research Letters, v. 26, p. 3233-3236.

Freymueller, J.T., Woodard, H., Cohen, S.C., Cross, R., Elliot, J., Larsen, C.F., Hreinsodóttir, S., and Zweck, C., 2008, Active deformation processes in Alaska, based on 15 years of GPS measurements, in Freymueller, J.T., Haeussler, P.J., Wesson, R.L., and Ekström, G., eds., Active tectonics and seismic potential of Alaska: Washington, D. C., American Geophysical Union, p. 1-42.

Fujii, Y., and Satake, K., 2006, Source of the July 2006 West Java tsunami estimated from tide gauge records: Geophysical Research Letters, v. 33, doi:10.1029/2006GL028049.

Geist, E.L., 1999, Local tsunamis and earthquake source parameters: Advances in Geophysics, v. 39, p. 117-209. 
Geist, E.L., 2002, Complex earthquake rupture and local tsunamis: Journal of Geophysical Research, v. 107, doi:10.1029/2000JB000139.

Geist, E.L., and Bilek, S.L., 2001, Effect of depth-dependent shear modulus on tsunami generation along subduction zones: Geophysical Research Letters, v. 28, no. 7, p. 1315-1318.

Geist, E.L., and Dmowska, R., 1999, Local tsunamis and distributed slip at the source: Pure and Applied Geophysics, v. 154, p. 485-512.

Guatteri, M., Mai, P.M., Beroza, G.C., and Boatwright, J., 2003, Strong ground-motion prediction from stochastic-dynamic source models: Bulletin of the Seismological Society of America, v. 93, p. 301313.

Guatteri, M., and Spudich, P., 2000, What can strong-motion data tell us about slip-weakening faultfriction laws?: Bulletin of the Seismological Society of America, v. 90, p. 98-116.

Harris, R.A., and Day, S., 1993, Dynamics of fault interaction; parallel strike-slip faults: Journal of Geophysical Research, v. 98, p. 4461-4472.

Harris, R.A., and 21 others, 2009, The SCEC/USGS dynamic earthquake rupture code verification exercise: Seismological Research Letters, v. 80, p. 119-126.

Harris, R.A., and 13 others, 2011, Verifying a computational method for predicting extreme ground motion: Seismological Research Letters, v. 82, p. 638-644.

Hayes, G.P., Wald, D.J., and Johnson, R.L., 2012, Slab 1.0; a three-dimensional model of global subduction zone geometries: Journal of Geophysical Research, v. 117, doi:10.1029/2011JB008524.

Hinterberger, C., Fröhlich, J., and Rodi, W., 2007, Three-dimensional and depth-averaged large eddy simulations of some shallow water flows: Journal of Hydraulic Engineering, v. 133, p. 857-872.

Horrillo, J., Knight, W., and Kowalik, Z., 2008, Kuril Islands tsunami of November 2006, 2. Impact at Crescent City by local enhancement: Journal of Geophysical Research, v. 113, doi:10.1029/2007JC004404.

Hyndman, R.D., Yamano, M., and Oleskevich, D.A., 1997, The seismogenic zone of subduction thrust faults: The Island Arc, v. 6, p. 244-260.

Ichinose, G., Somerville, P., Thio, H.K., Graves, R., and O'Connell, D., 2007, Rupture process of the 1964 Prince William Sound, Alaska, earthquake from the combined inversion of seismic, tsunami, and geodetic data: Journal of Geophysical Research, v. 112, doi:10.1029/2006JB004728.

Ida, Y., 1972, Cohesive force across the tip of a longitudinal-shear crack and Griffith's specific surface energy: Journal of Geophysical Research, v. 77, p. 3796-3805.

Johnson, J.M., and Satake, K., 1994, Rupture extent of the 1938 Alaskan earthquake as inferred from tsunami waveforms: Geophysical Research Letters, v. 21, p. 733-736.

Kanamori, H., 1972, Mechanism of tsunami earthquakes: Physics of the Earth and Planetary Interiors, v. 6, p. 346-359.

Kennedy, A.B., Chen, Q., Kirby, J.T., and Dalrymple, R.A., 2000, Boussinesq modeling of wave transformation, breaking and runup, I. one dimension: Journal of Waterway, Port, Coastal, and Ocean Engineering, v. 126, p. 39-47.

Kim, D.-H., and Lynett, P.J., 2011, Turbulent mixing and passive scalar transport in shallow flows: Physics of Fluids, v. 23, doi:10.1063/1061.3531716.

Kim, D.-H., and Lynett, P.J., 2011, Turbulent mixing and passive scalar transport in shallow flows: Physics of Fluids, v. 23, doi:10.1063/1061.3531716.

Kim, D.-H., Lynett, P., and Socolofsky, S., 2009, A depth-integrated model for weakly dispersive, turbulent, and rotational fluid flows: Ocean Modeling, v. 27, p. 198-214.

Kirby, S., Scholl, D., von Huene, R., and Wells, R., 2013, Alaska earthquake source for the SAFRR tsunami scenario, chap. B, in Ross, S.L., and Jones, L.M., eds., The SAFRR (Science Application for 
Risk Reduction) Tsunami Scenario: U.S. Geological Survey Open-File Report 2013-1170, 46 p., http://pubs.usgs.gov/of/2013/1170/b/.

Kobayashi, M., and Lawrence, A., 2004, Cross-shore sediment transport under breaking solitary waves: Journal of Geophysical Research, v. 109, doi:10.1029/2003JC002084.

Kowalik, Z., Horrillo, J., Knight, W., and Logan, T., 2008, Kuril Islands tsunami of November 2006, 1. Impact at Crescent City by distant scattering: Journal of Geophysical Research, v. 113, doi: 10.1029/2007JC004402.

Kozdon, J.E., and Dunham, E.M., in press [? see comments at top of references], Rupture to the trench; dynamic rupture simulations of the 11 March 2011 Tohoku earthquake: Bulletin of the Seismological Society of America.

Lacy, J., Rubin, D., and Buscombe, D., 2012, Currents, drag, and sediment transport induced by a tsunami: Journal of Geophysical Research, v. 117, doi:10.1029/2012JC007954.

Li, L., Qiu, Q., and Huang, Z., 2012, Numerical modeling of the morphological change in Lhok Nga, west Banda Aceh, during the 2004 Indian Ocena tsunami; understanding tsunami deposits using a forward modeling method: Natural Hazards, v. 64, p. 1549-1574.

Linker, M.F., and Dieterich, J.H., 1992, Effects of variable normal stress on rock friction; observations and constitutive equations: Journal of Geophysical Research, v. 97, p. 4923-4940.

Liu, P.L.-F., Cho, Y.S., Yoon, S.B., and Seo, S.N., 1995, Numerical simulations of the 1960 Chilean tsunami propagation and inundation at Hilo, Hawaii, in Tsuchiya, Y., and Shuto, N., eds., Tsunamiprogress in prediction, disaster prevention and warning: Kluwer Academic Publishers, p. 99-115.

Lynett, P., 2006, Wave breaking velocity effects in depth-integrated models: Coastal Engineering, v. 53, p. 325-333.

Lynett, P.J., Wu, T.-R., and Liu, P.L.-F., 2002, Modeling wave runup with depth-integrated equations: Coastal Engineering, v. 46, p. 89-107.

Lynett, P.J., Borrero, J.C., Weiss, R., Son, S., Greer, D., and Renteria, W., 2012, Observations and modeling of tsunami-induced currents in ports and harbors: Earth and Planetary Science Letters, $\mathrm{V}$. 327-328, p. 68-74.

Musumeci, R.E., Svendsen, I.A., and Veeramony, J., 2005, The flow in the surf zone; a fully nonlinear Boussinesq-type of approach: Coastal Engineering, v. 52, p. 565-598.

National Tsunami Hazard Mitigation Program (NTHMP), 2009, Guidelines and best practices for tsunami inundation modeling for evacuation planning: U.S. Department of Commerce, National Oceanic and Atmospheric Administration, $7 \mathrm{p}$.

National Tsunami Hazard Mitigation Program (NTHMP), 2010, Guidelines and best practices for tsunami inundation modeling for evacuation planning: National Oceanic and Atmospheric

Administration, NTHMP Mapping \& Modeling Subcommittee, 8 p.

National Tsunami Hazard Mitigation Program (NTHMP), 2012, Proceedings and results of the 2011 NTHMP Model Benchmarking Workshop: U.S. Department of Commerce, National Oceanic and Atmospheric Administration, $436 \mathrm{p}$.

Nicolsky, D.J., 2012, Alaska tsunami model, in Proceedings and results of the 2011 NTHMP Model Benchmarking Workshop: Boulder, Colorado, U.S. Department of Commerce/National Oceanic and Atmospheric Administration Special Report, p. 55-87.

Nicolsky, D.J., Suleimani, E.N., and Hansen, R.A., 2011, Validation and verification of a numerical model for tsunami propagation and runup: Pure and Applied Geophysics, v. 168, p. 1199-1222.

Nielsen, S.B., 1998, Free surface effects on the propagation of dynamic rupture: Geophysical Research Letters, v. 25, p. 125-128. 
Oglesby, D.D., and Archuleta, R.J., 2000, Dynamics of dip-slip faulting; explorations in two dimensions: Journal of Geophysical Research, v. 105, p. 13643-13653.

Oglesby, D.D., and Archuleta, R.J., 2003, The three-dimensional dynamics of a nonplanar thrust fault: Bulletin of the Seismological Society of America, v. 93, p. 2222-2235.

Oglesby, D.D., Archuleta, R.J., and Nielsen, S.B., 1998, Earthquakes on dipping faults; the effects of broken symmetry: Science, v. 280, p. 1055-1059.

Oglesby, D.D., Archuleta, R.J., and Nielsen, S.B., 2000, The three-dimensional dynamics of dipping faults: Bulletin of the Seismological Society of America, v. 90, p. 616-628.

Okada, Y., 1985, Surface deformation due to shear and tensile faults in a half-space: Bulletin of the Seismological Society of America, v. 75, p. 1135-1154.

Okal, E.A., Fritz, H.M., Raad, P.E., Synolakis, C.E., Al-Shijbi, Y., and Al-Saifi, M., 2006a, Oman field survey after the December 2004 Indian Ocean tsunami: Earthquake Spectra, v. 22, p. S203-S218.

Okal, E.A., Fritz, H.M., Raveloson, R., Joelson, G., Pancoskova, P., and Rambolamanana, G., 2006b, Madagascar field survey after the December 2004 Indian Ocean tsunami: Earthquake Spectra, v. 22, p. S263-S283.

Okal, E.A., Sladen, A., and Fritz, H.M., 2006c, Mauritius and Réunion Islands, field survey after the December 2004 Indian Ocean tsunami: Earthquake Spectra, v. 22, p. S241-S261.

Olsen, K.B., Madariaga, R., and Archuleta, R.J., 1997, Three-dimensional dynamic simulation of the 1992 Landers earthquake: Science, v. 278, p. 834-838.

Olsen, K.B., Day, S.M., Dalguer, L.A., Mayhew, J., Cui, Y., Zhu, J., Cruz-Atienza, V.M., Roten, D., Maechling, P., Jordan, T.H., Okaya, D., and Chourasia, A., 2009, ShakeOut-D; Ground motion estimates using an ensemble of large earthquakes on the southern San Andreas fault with spontaneous rupture propagation: Geophysical Research Letters, v. 36, doi:10.1029/2008GL036832.

Peyrat, S., Olsen, K., and Madariaga, R., 2001, Dynamic modeling of the 1992 Landers earthquake: Journal of Geophysical Research, v. 106, p. 26467-26482.

Ponce, V.M., 1989, Engineering hydrology, principles and practices: Prentice Hall, 640 p.

Press, W.H., Teukolsky, S.A., Vetterling, W.T., and Flannery, B.P., 2007, Numerical recipes-the art of scientific computing ( $3 \mathrm{~d}$ ed.): Cambridge, Cambridge University Press, 1,235 p.

Rakha, K., Deigaard, R., and Broker, I., 1997, A phase-resolving cross shore sediment transport model for beach profile evolution: Coastal Engineering, v. 31, p. 231-261.

Ruina, A.L., 1980, Friction laws and instabilities; a quasistatic analysis of some dry friction behavior: Providence, R.I., Brown University, Ph.D. dissertation, 99 p.

Ruina, A.L., 1983, Slip instability and state variable friction laws: Journal of Geophysical Research, v. 88, p. 10359-10370.

Ryan, H.F., von Huene, R., Scholl, D.W., and Kirby, S.H., 2012, Tsunami hazards to U.S. coasts from giant earthquakes in Alaska: Eos (American Geophysical Union Transactions), v. 93, p. 185-186.

Santini, S., Dragoni, M., and Spada, G., 2003, Asperity distribution of the 1964 Great Alaska earthquake and its relation to subsequent seismicity in the region: Tectonophysics, v. 367, p. 219-233.

Satake, K., 1995, Linear and nonlinear computations of the 1992 Nicaragua earthquake tsunami: Pure and Applied Geophysics, v. 144, p. 455-470.

Satake, K., 2002, Tsunamis, in Lee, W.H.K., Kanamori, H., Jennings, P.C., and Kisslinger, C., eds., International handbook of earthquake and engineering seismology, Part A: San Diego, Academic Press, p. 437-451.

Satake, K., 2007, Tsunamis, in Kanamori, H., and Schubert, G., eds., Treatise on geophysics, Volume 4-Earthquake seismology: Elsevier, p. 483-511.

Scholz, C.H., 1998, Earthquakes and friction laws: Nature, v. 391, p. 37-42. 
Shuto, N., 1991, Numerical simulation of tsunamis — its present and near future: Natural Hazards, v. 4, p. 171-191.

Sitanggang, K.I., and Lynett, P., 2005, Parallel computation of highly nonlinear Boussinesq equation model through domain decomposition: International Journal for Numerical Methods in Fluids, v. 49, no. 57-74.

Son, S., Lynett, P., and Kim, D.-H., 2011, Nested and multi-physics modeling of tsunami evolution from generation to inundation: Ocean Modeling, v. 38, p. 96-113.

Synolakis, C.E., Bernard, E.N., Titov, V.V., Kanoglu, U., and González, F.I., 2007, Standards, criteria, and procedures for NOAA evaluation of tsunami numerical models: National Oceanic and Atmospheric Administration, Pacific Marine Environmental Laboratory Technical Memorandum OAR PMEL-135, 55 p.

Tanioka, Y., and Satake, K., 1996, Tsunami generation by horizontal displacement of ocean bottom: Geophysical Research Letters, v. 23, p. 861-865.

Thio, H.K., Somerville, P., and Ichinose, G., 2007, Probabilistic analysis of strong ground motion and tsunami hazards in southeast Asia: Journal of Earthquake and Tsunami, v. 1, doi:10.1142/S1793431107000080.

Titov, V.V., and Synolakis, C.E., 1995, Modeling of breaking and nonbreaking long wave evolution and runup using VTSC-2: Journal of Waterway, Port, Coastal, and Ocean Engineering, v. 121, p. 308316.

Titov, V.V., and Synolakis, C.E., 1996, Numerical modeling of 3-D long wave runup using VTCS-3, in Yeh, H., Liu, P.L.F., and Synolakis, C.E., eds., Long wave runup models: Singapore, World Scientific Publishing Co., p. 242-248.

Titov, V.V., and Synolakis, C.E., 1998, Numerical modeling of tidal wave runup: Journal of Waterway, Port, Coastal, and Ocean Engineering, v. 124, p. 157-171.

Titov, V.V., Moore, C.W., Greenslade, D.J.M., Pattiaratchi, C., Badal, R., Synolakis, C.E., and Kanoglu, U., 2011, A new tool for inundation modeling; community modeling interface for tsunamis (ComMIT): Pure and Applied Geophysics, v. 168, p. 2121-2131.

Veeramony, J., and Svendsen, I.A., 2000, The flow in surf-zone waves: Coastal Engineering, v. 39, p. 93-122.

Wang, R., Lorenzo-Martin, F., and Roth, F., 2003, Computation of deformation induced by earthquakes in a multi-layered elastic crust--FORTRAN programs EDGRN/EDCMP: Computers \& Geosciences, v. 29, p. 195-207.

Wang, R., Lorenzo-Martin, F., and Roth, F., 2006, Erratum to "Computation of deformation induced by earthquakes in a multi-layered elastic crust--FORTRAN programs EDGRN/EDCMP": Computers \& Geosciences, v. 32, p. 1817.

Wells, R.E., Blakely, R.J., Sugiyama, Y., Scholl, D.W., and Dinterman, P.A., 2003, Basin-centered asperities in great subduction zone earthquakes - a link between slip, subsidence, and subduction erosion?: Journal of Geophysical Research, v. 108, no. B10, 2507, doi:10.1029/2002JB002072.

Wells, R.E., Blakely, R.J., Scholl, D.W., and Ryan, H.F., 2011, Seismicity, topography, and free-air gravity of the Aleutian-Alaska subduction zone: American Geophysical Union, Fall Meeting, Abstract T21B-2322.

Wendt, J., Oglesby, D.D., and Geist, E.L., 2009, Tsunamis and splay fault dynamics: Geophysical Research Letters, v. 36, doi:10.1029/2009GL038295.

Wilson, R.I., Barberopoulou, A., Miller, K.M., Goltz, J.D., and Synolakis, C.E., 2008, New maximum tsunami inundation maps for use by local emergency planners in the State of California, USA [abs.]: 
Eos (American Geophysical Union Transactions), v. 89(53), Fall Meeting Supplement, p. OS43D1343.

Wilson, R., Davenport, C., and Jaffe, B., 2012, Sediment scour and deposition within harbors in California (USA), caused by the March 11, 2011 Tohoku-oki tsunami: Sedimentary Geology, v. 282, doi:10.1016/j.sedgeo.2012.1006.1001.

Wu, W., and Wang, S., 2008, One-dimensional explicit finite-volume model for sediment transport with transient flows over movable beds: Journal of Hydraulic Research, v. 46, p. 87-98.

Xiao, J., Lin, B., Falconer, R., and Wang, G., 2010, Modeling dam-break flows over mobile beds using a 2D coupled approach: Advances in Water Resources, v. 33, p. 171-183. 


\section{Appendix A-SAFRR Tsunami Inundation Maps for Select Areas of California's Coast}

The Science Application for Risk Reduction (SAFRR) tsunami scenario would cause inundation of dry land along California's coast. The following maps provide examples of inundation for select areas of the coastline. These maps identify residential, business, and maritime areas and assets that could become flooded during a large tsunami event generated in the Pacific offshore the Alaska Peninsula. A GoogleEarth KML file provided on the U.S. Geological Survey and California Geological Survey SAFRR Web sites shows all areas mapped in California where inundation could occur from this scenario. The CGS SAFRR tsunami scenario web site provides access to the inundation maps and other information related to the scenario. This web site is found at

http://www.conservation.ca.gov/cgs/geologic_hazards/Tsunami/Pages/SAFRR.aspx

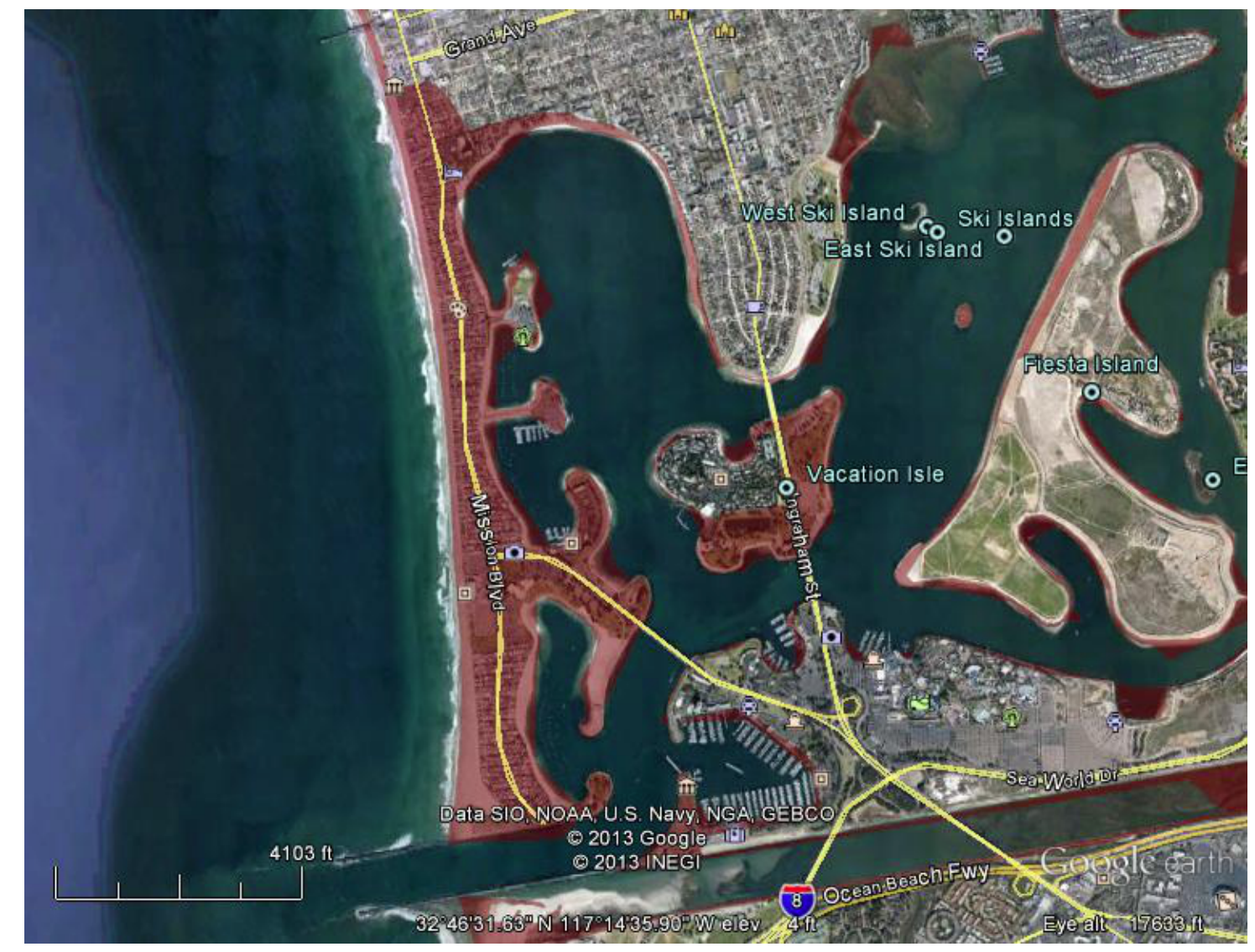

Figure A1 San Diego County - Ocean Beach: Peninsula is overtopped. 


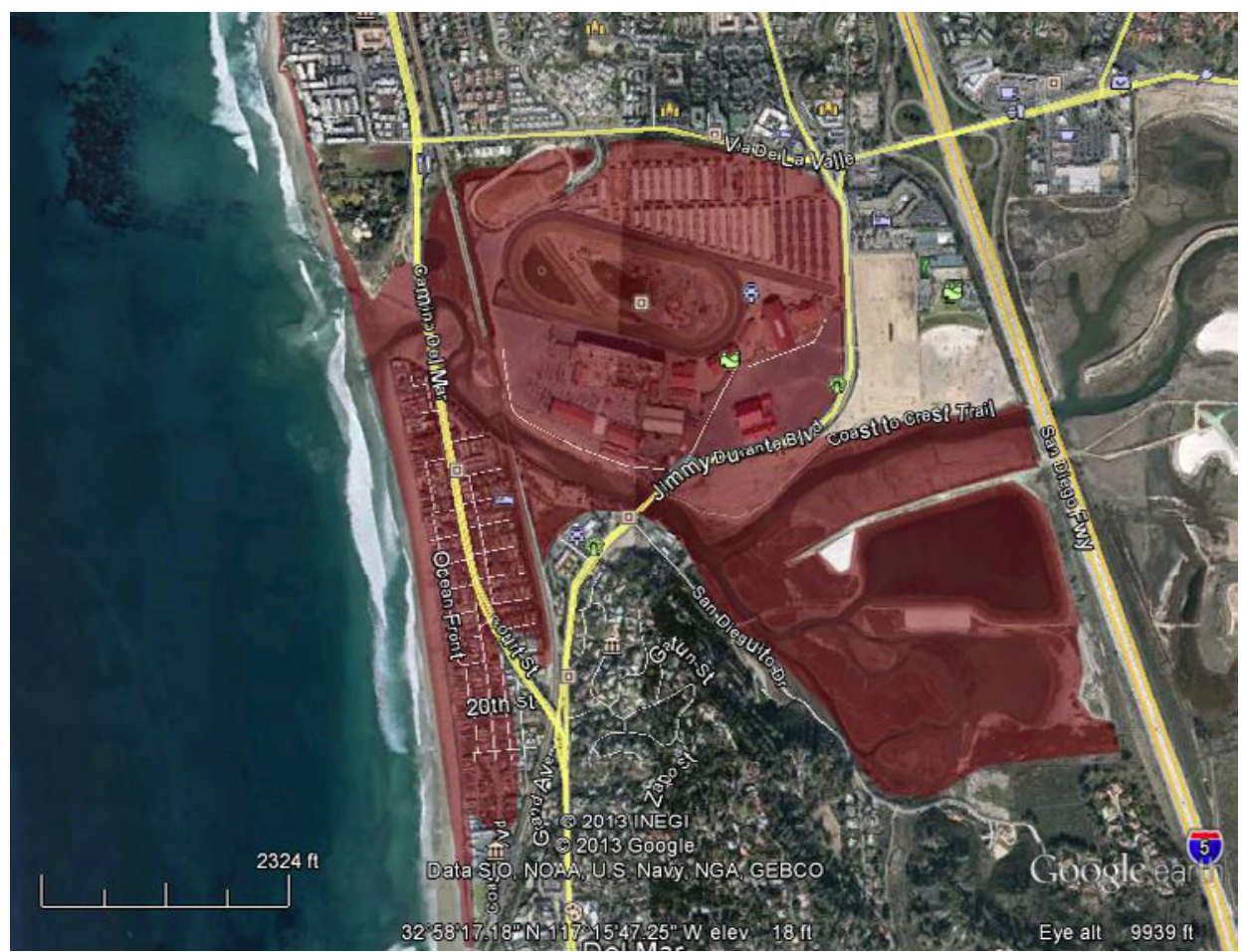

Figure A2 San Diego County - Del Mar: Several blocks and fairgrounds flooded.

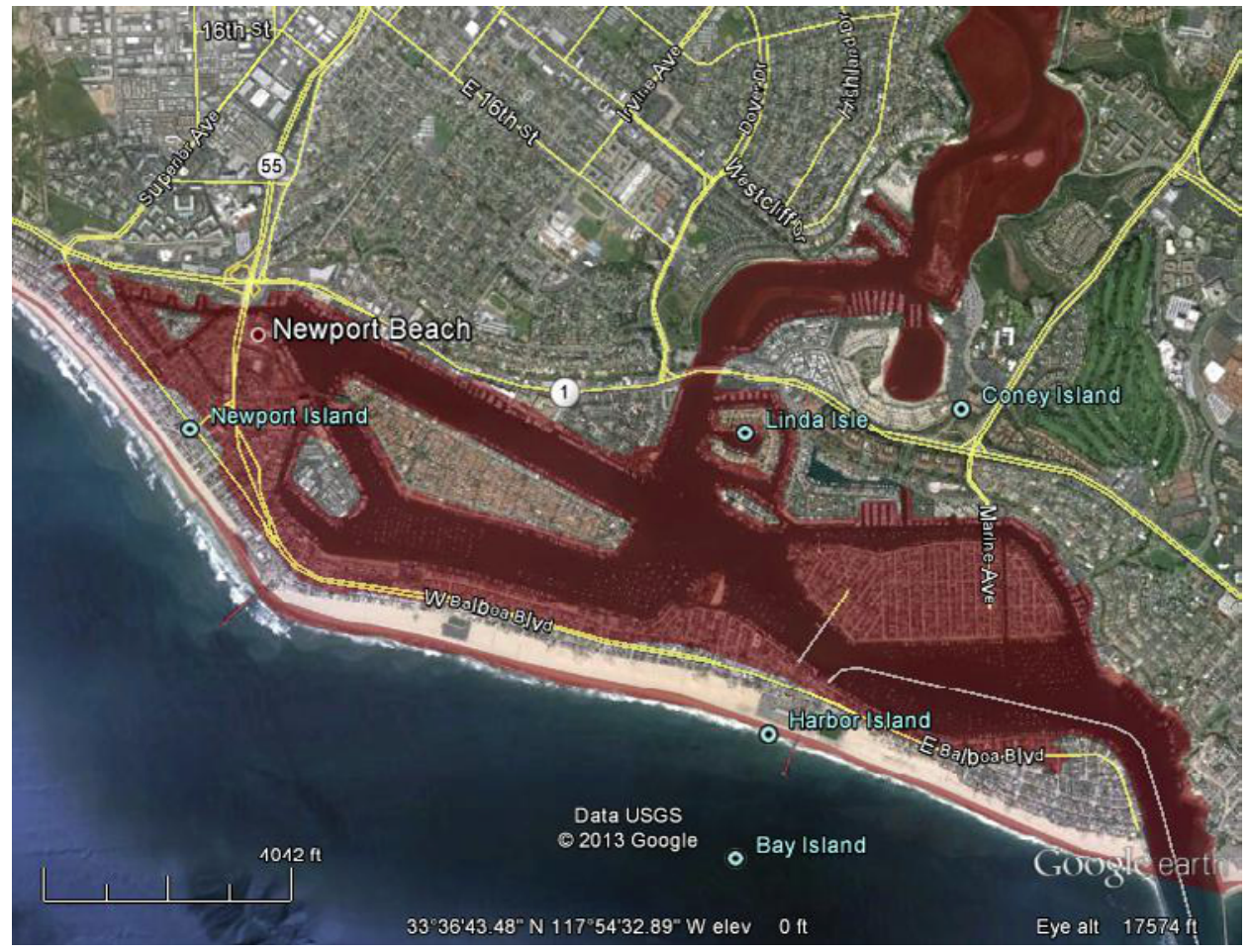

Figure A3 Orange County - Newport Beach: Complete and partial flooding of islands and near overtopping of Balboa Peninsula 


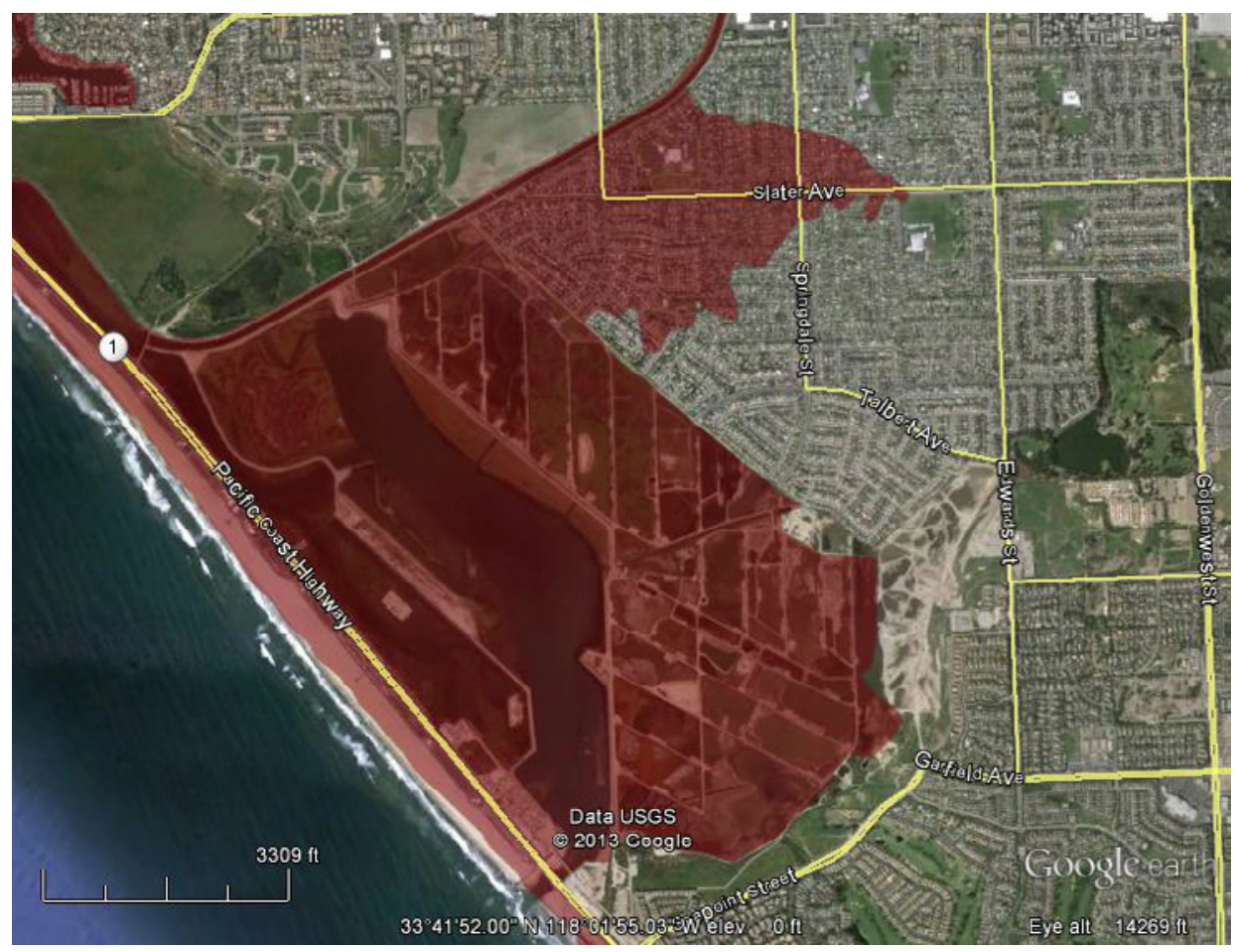

Figure A4 Orange County - Huntington Beach: Flooding overtops some levees and floods areas inland.

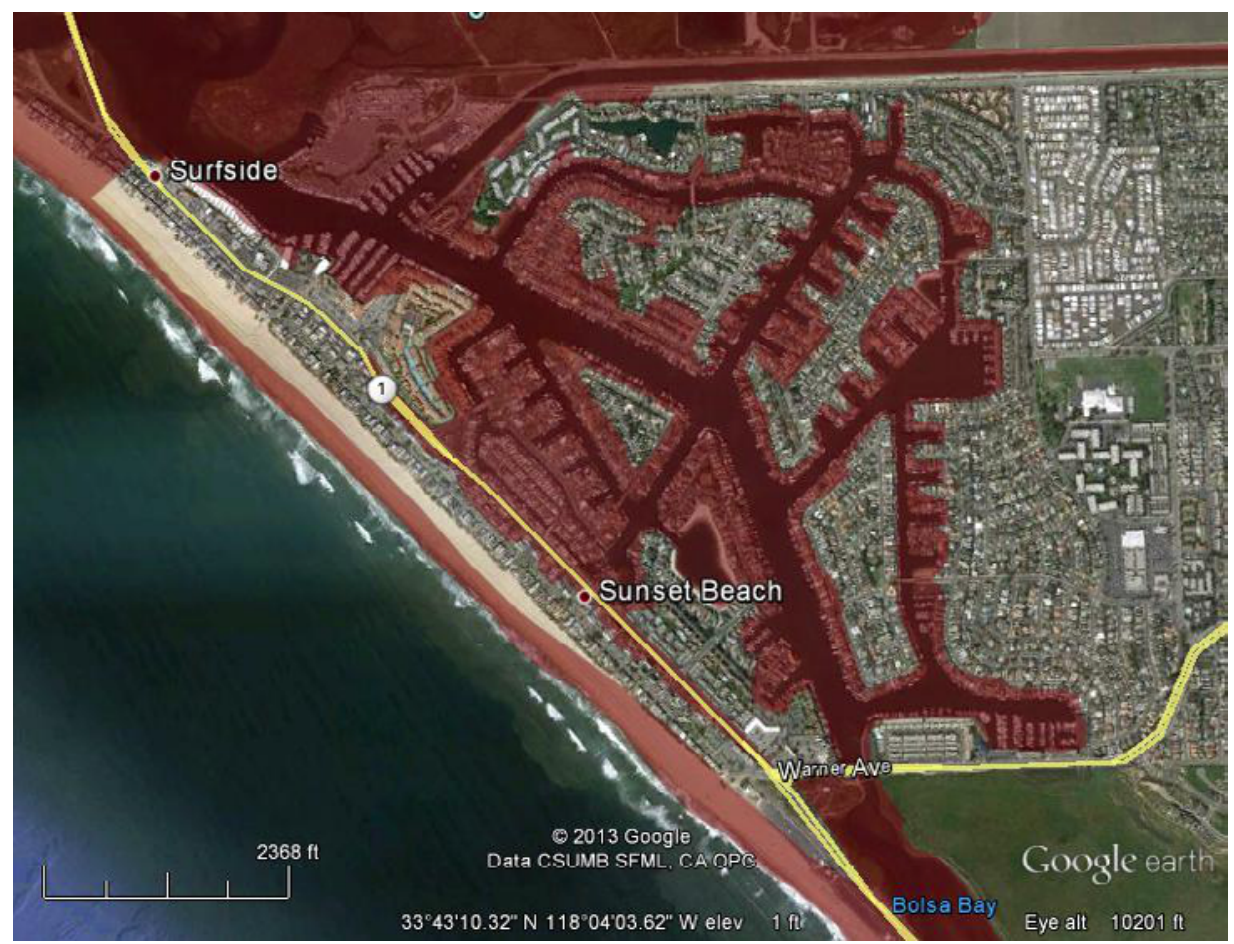

Figure A5 Orange County - Huntington Beach (Sunset Beach): Flooding isolates and nearly overtops all parts of the community. 


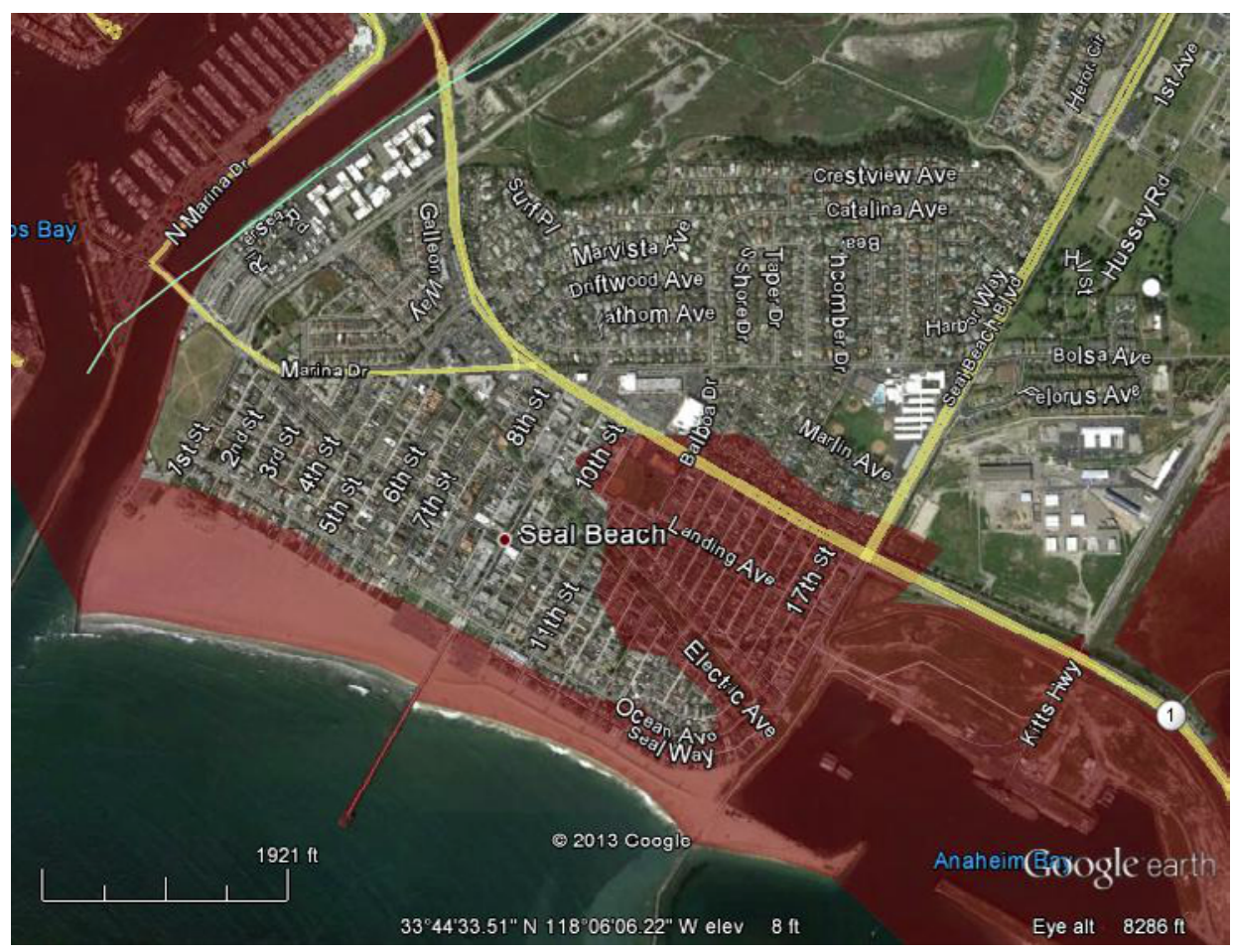

Figure A6 Orange County - Seal Beach: Flooding occurs behind beach-front areas.

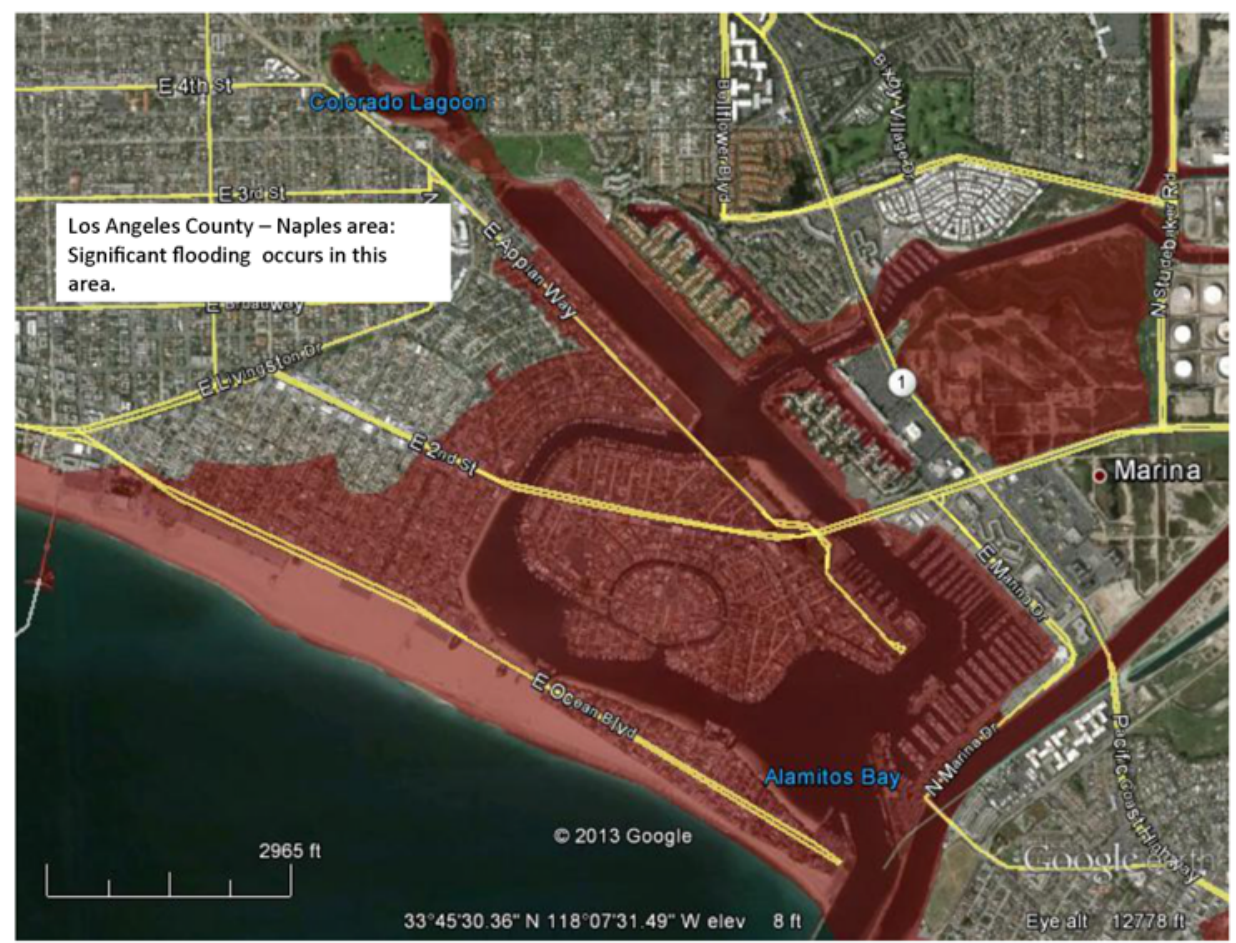

Figure A7 Los Angeles County - Naples area: Significant flooding occurs in this area. 


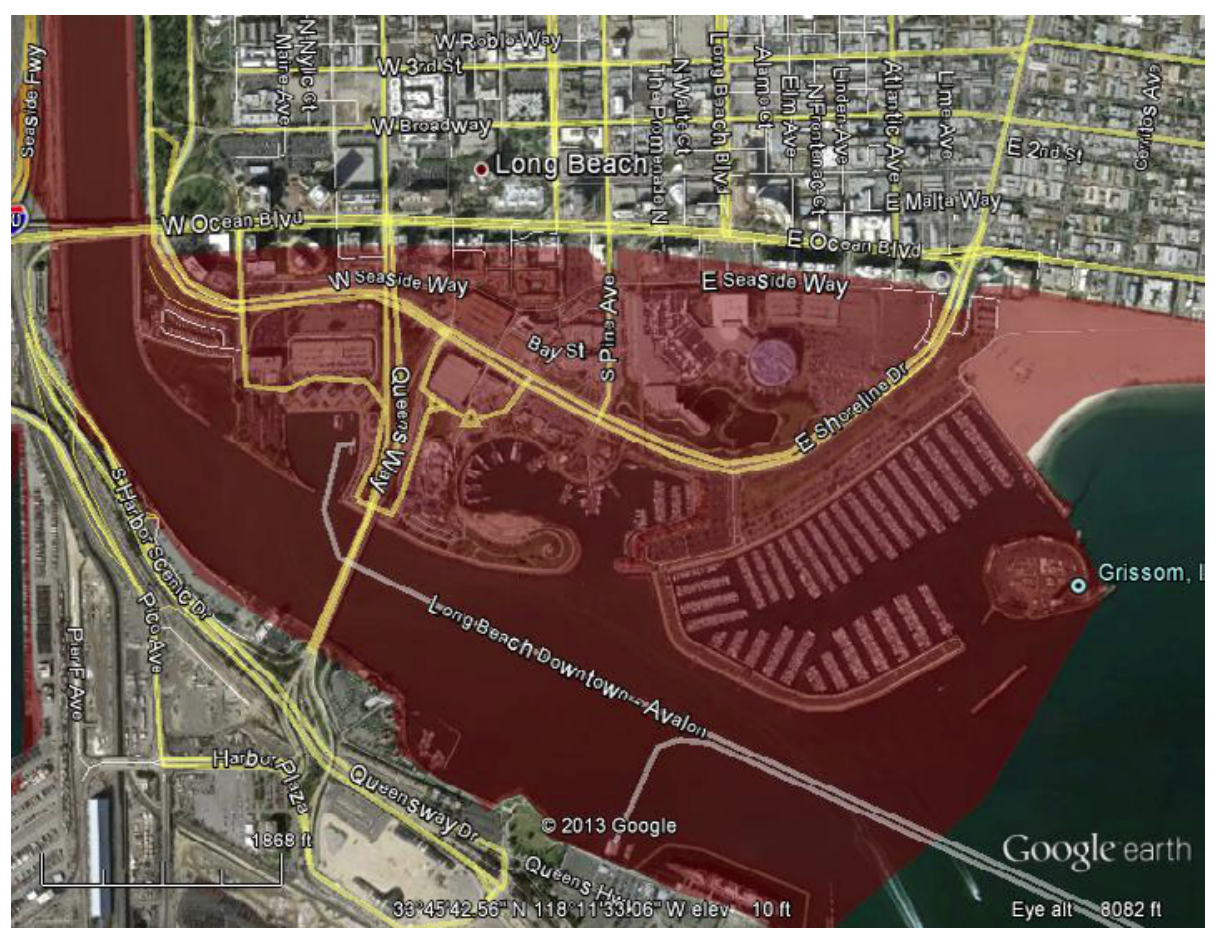

Figure A8 Los Angeles County - Long Beach: Flooding of downtown area occurs where many

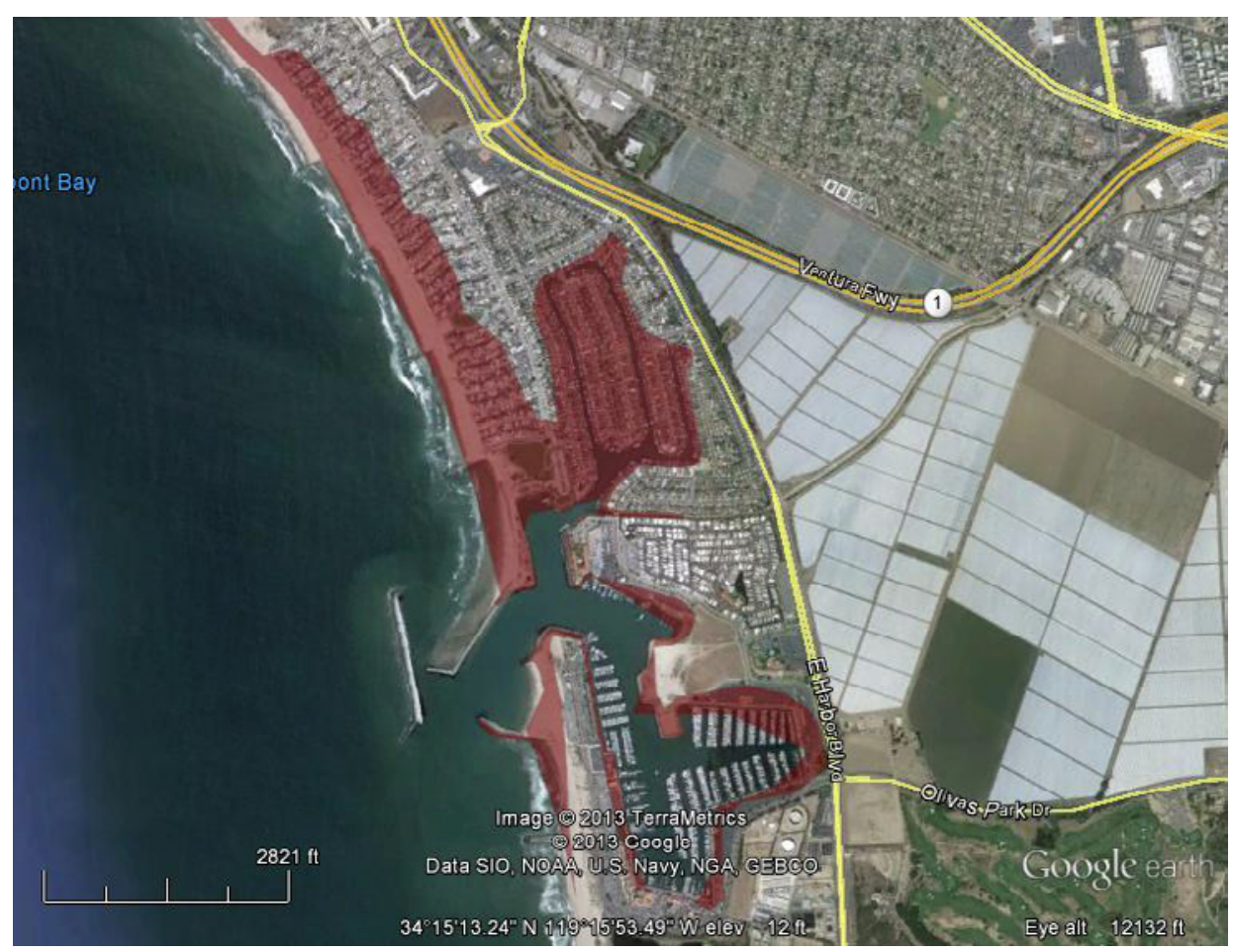

Figure A9 Ventura County: Ventura and harbor: Several blocks and islands are inundated. 


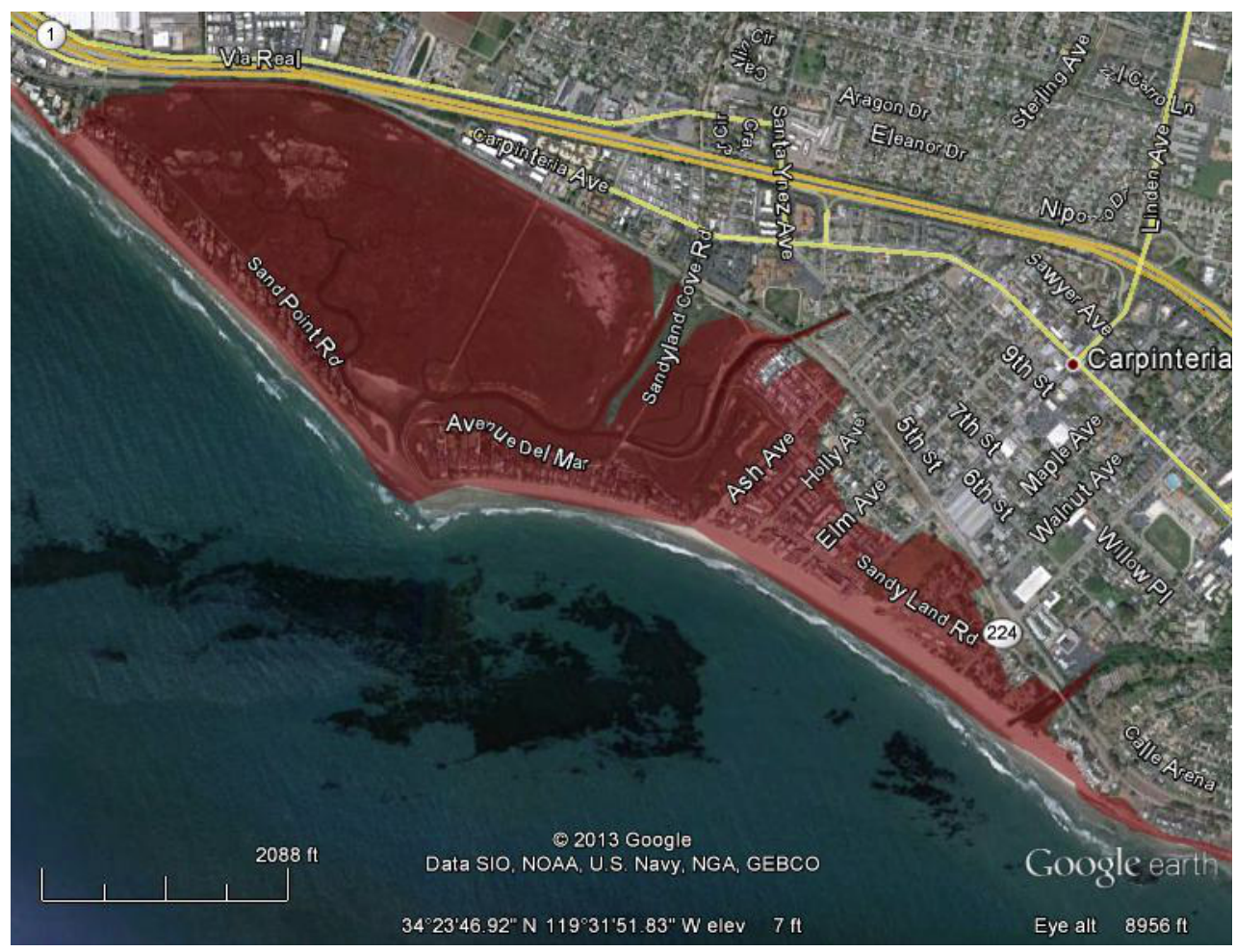

Figure A10 Santa Barbara County - Carpinteria: Several blocks are inundated.

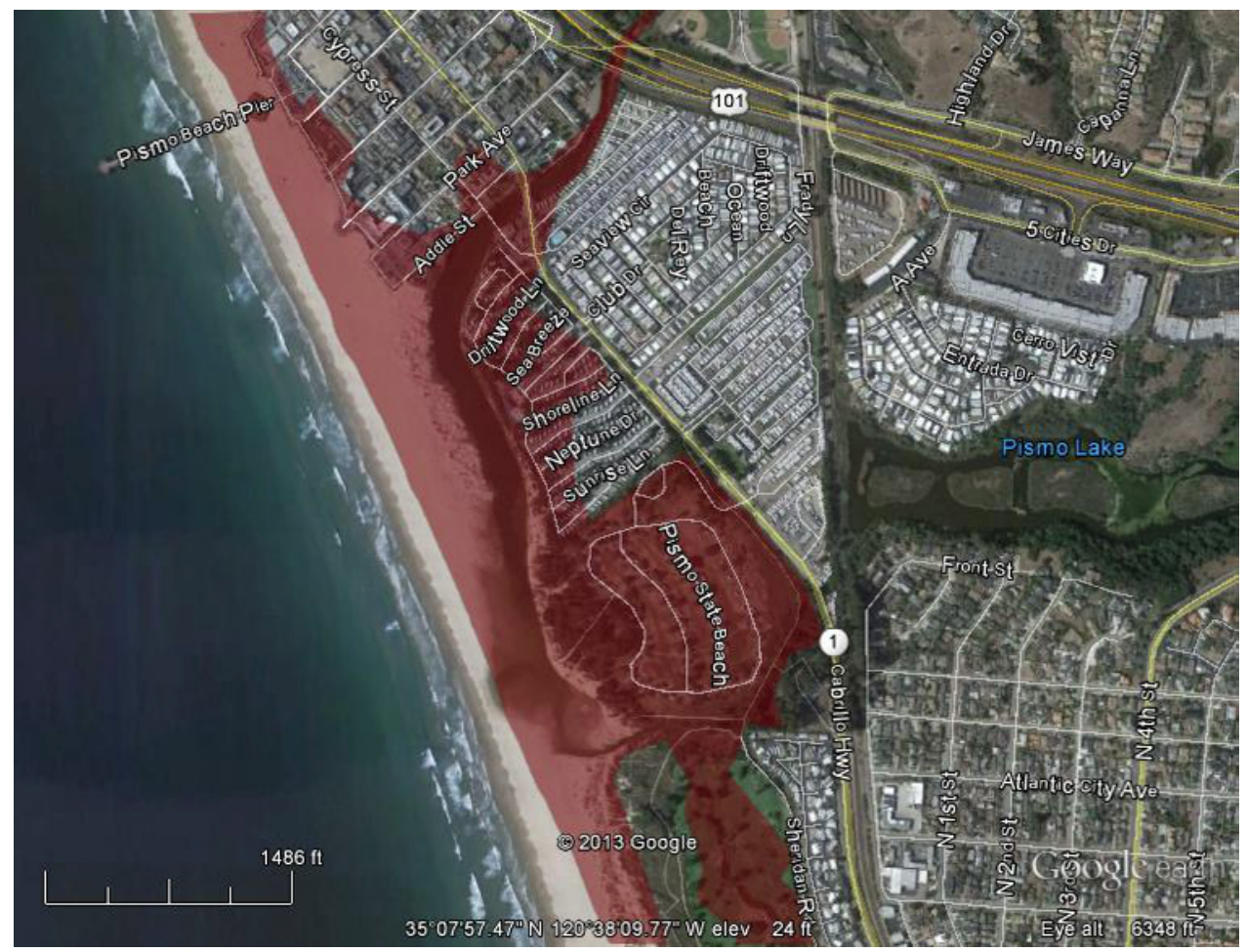

Figure A11 San Luis Obispo County - Pismo Beach dunes and portions of the city are inundated. 


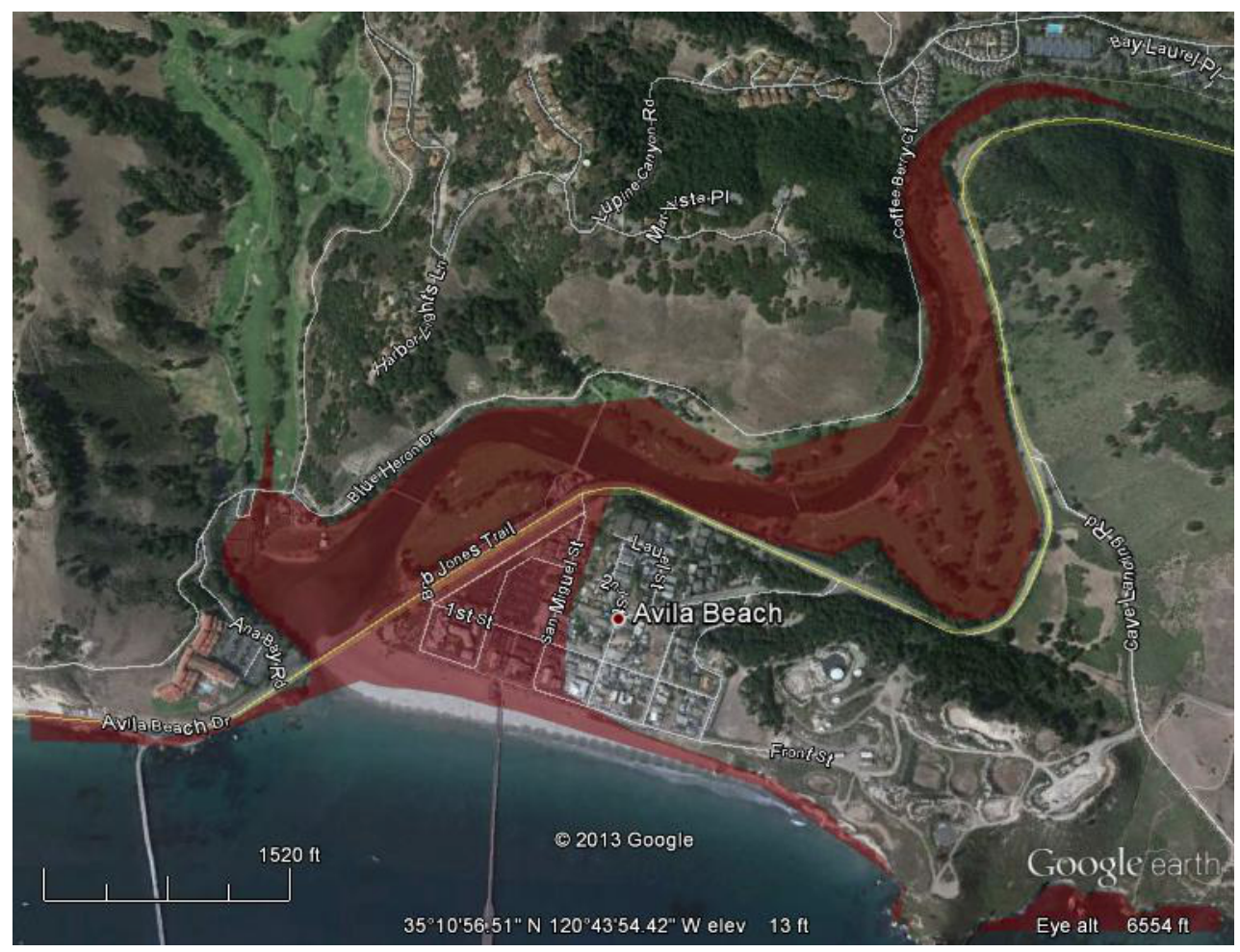

Figure A12 San Luis Obispo County - Portions of Avila Beach are flooded by a tsunami over 5m in height.

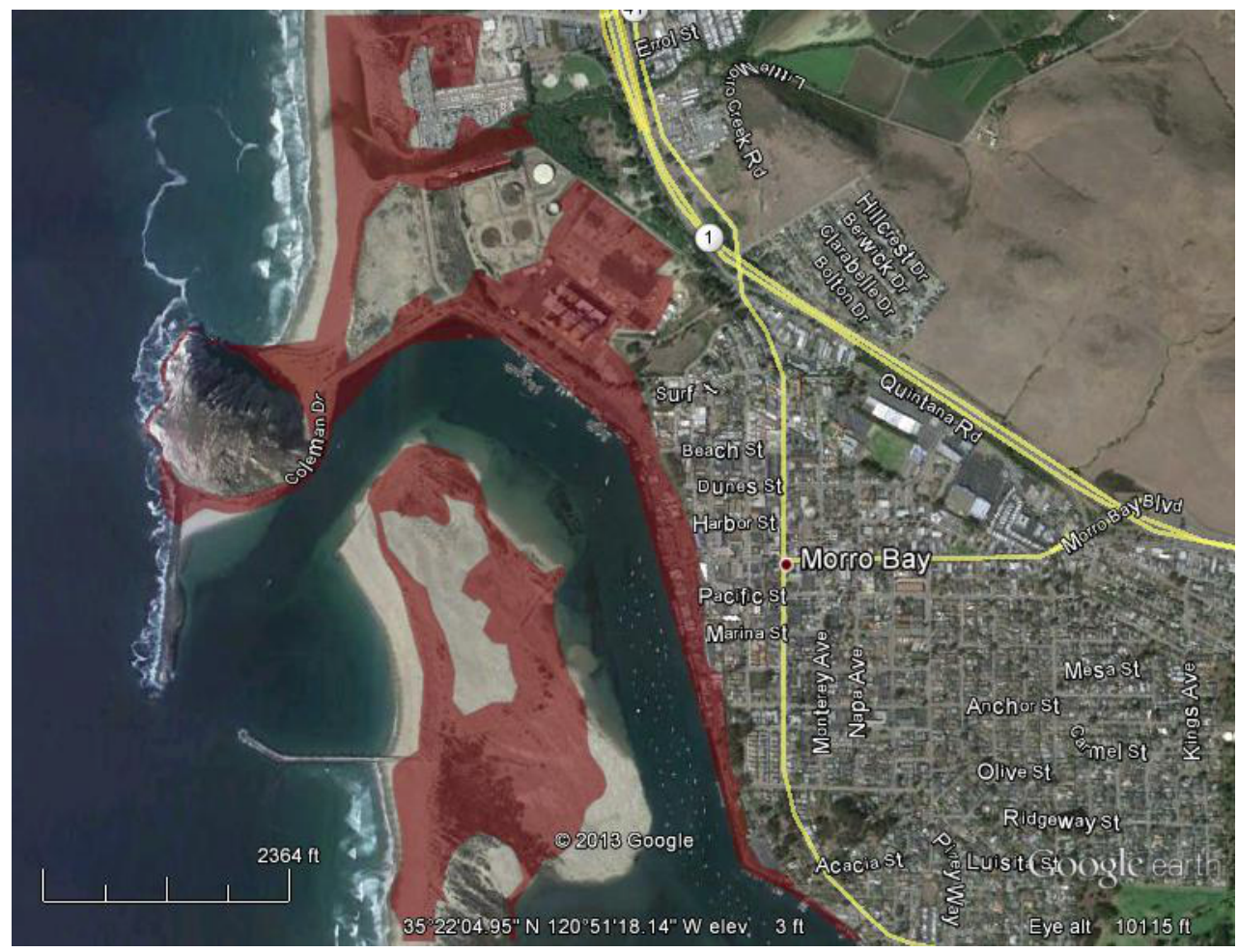

Figure A13 San Luis Obispo County - Morro Bay: The Embarcadero is inundated. 


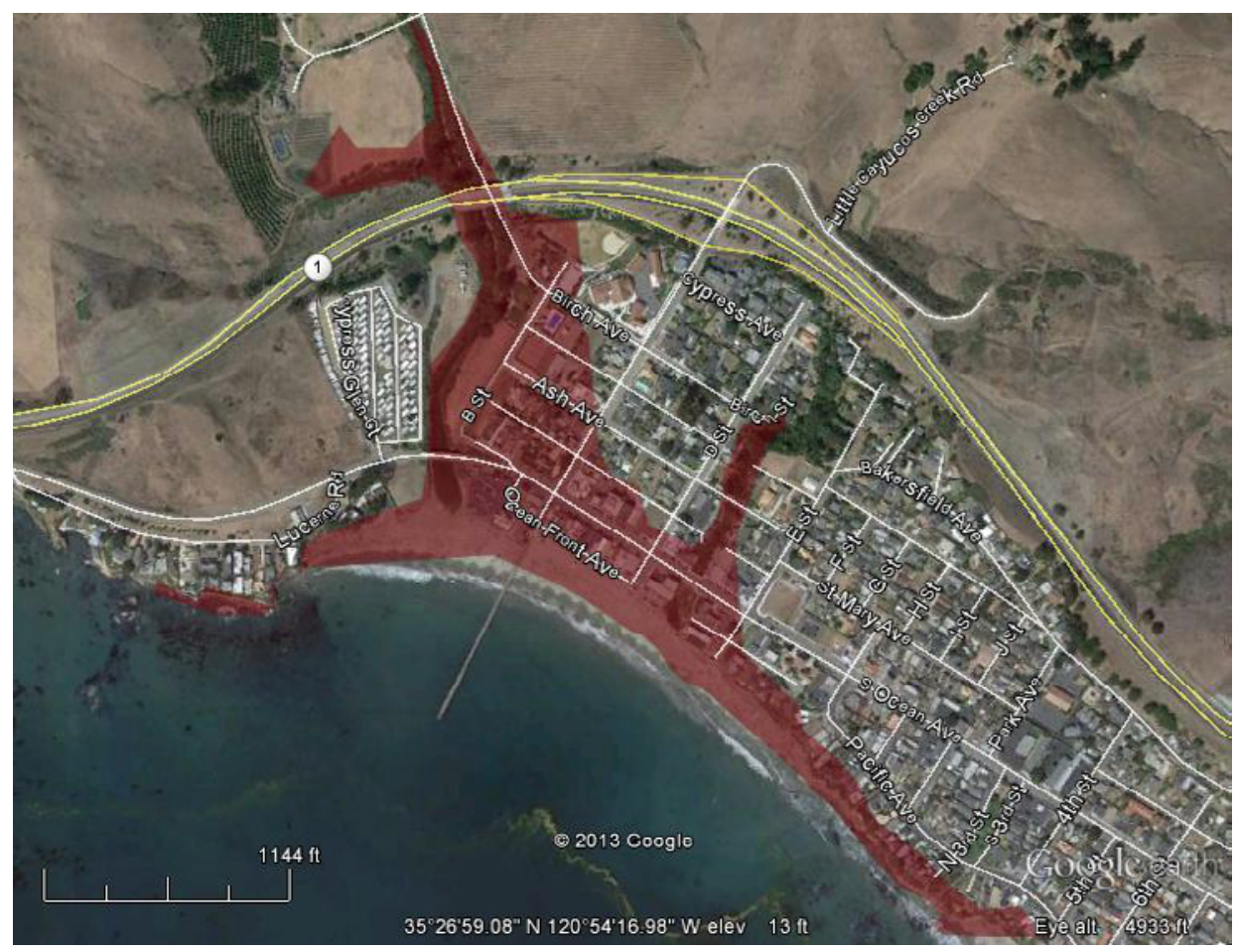

Figure A14 San Luis Obispo County - Cayucos: Several blocks of the town are inundated.

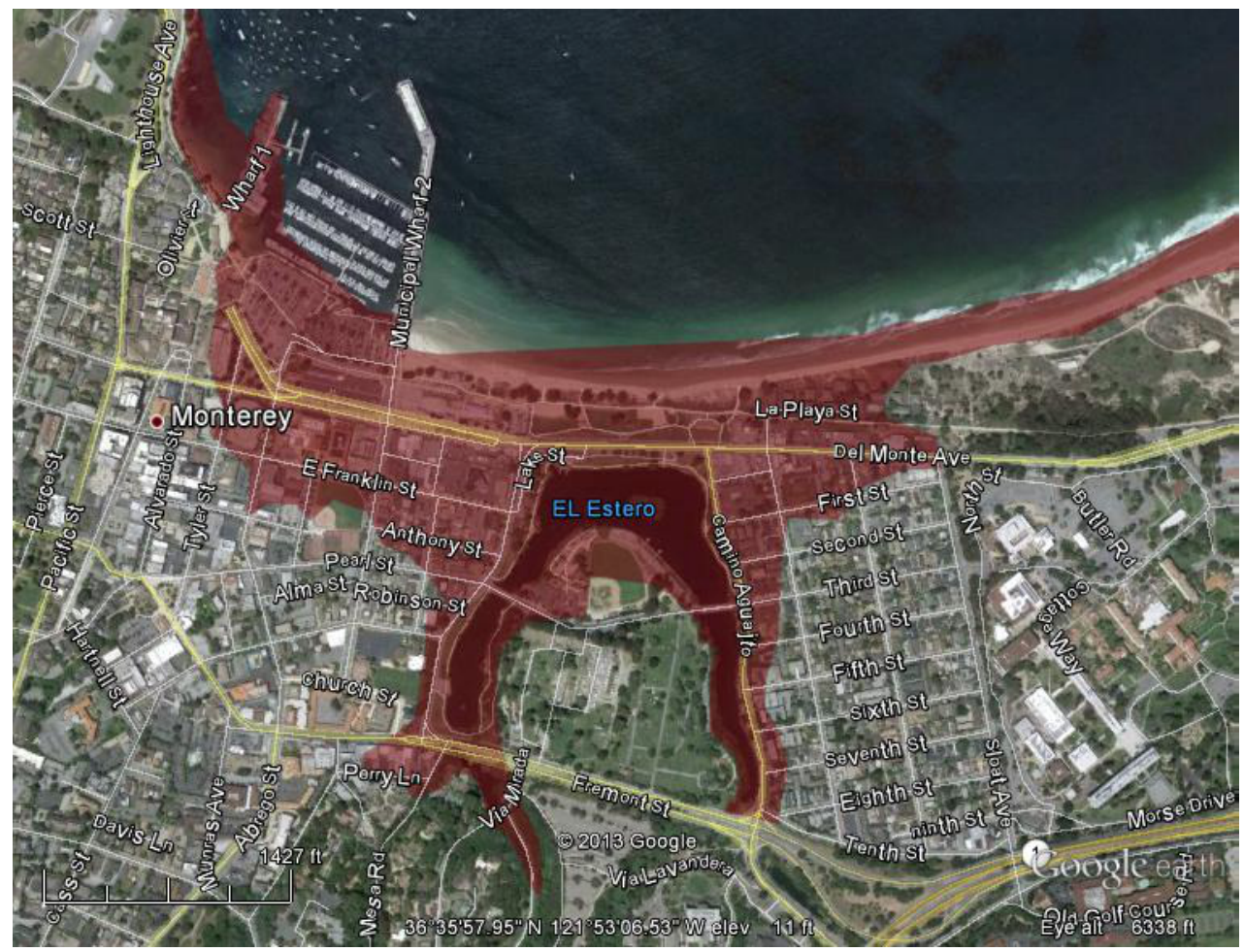

Figure A15 Monterey County - Monterey: Flooding in the downtown and waterfront areas occurs. 


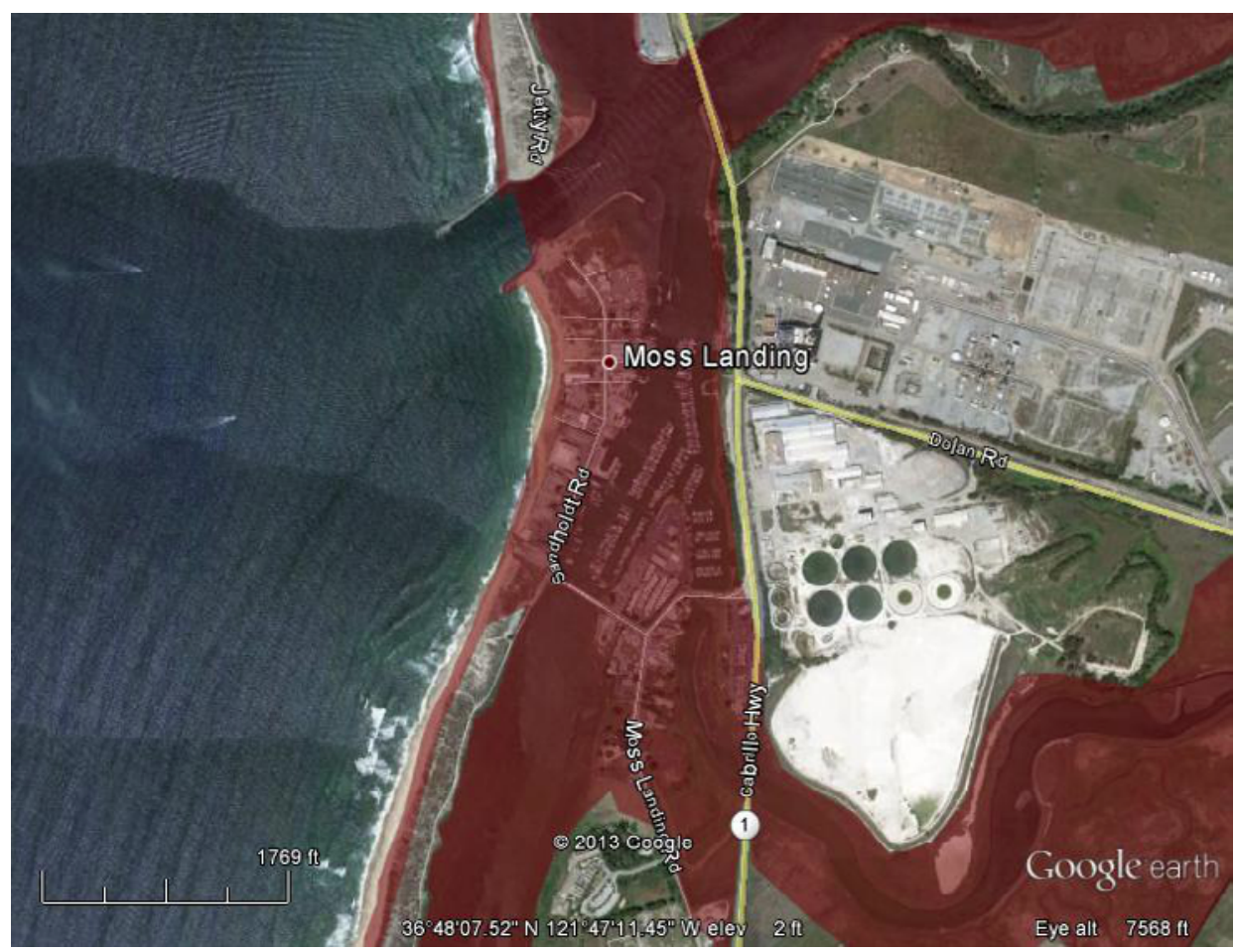

Figure A16 Monterey County - Moss Landing peninsula gets overtopped and inundated.

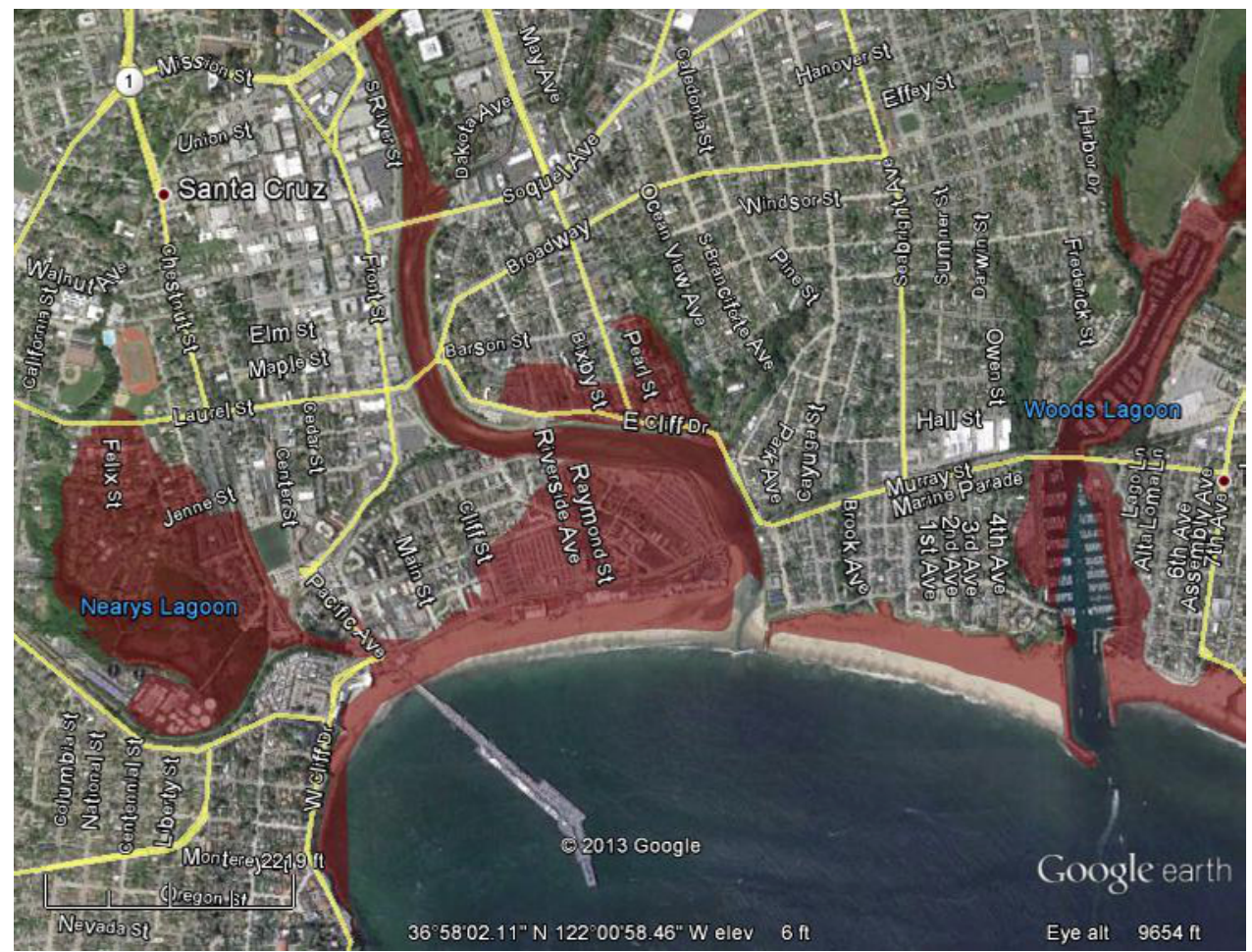

Figure A17 Santa Cruz County - Santa Cruz: Flooding of area around Beach and Boardwalk and other inland areas. 


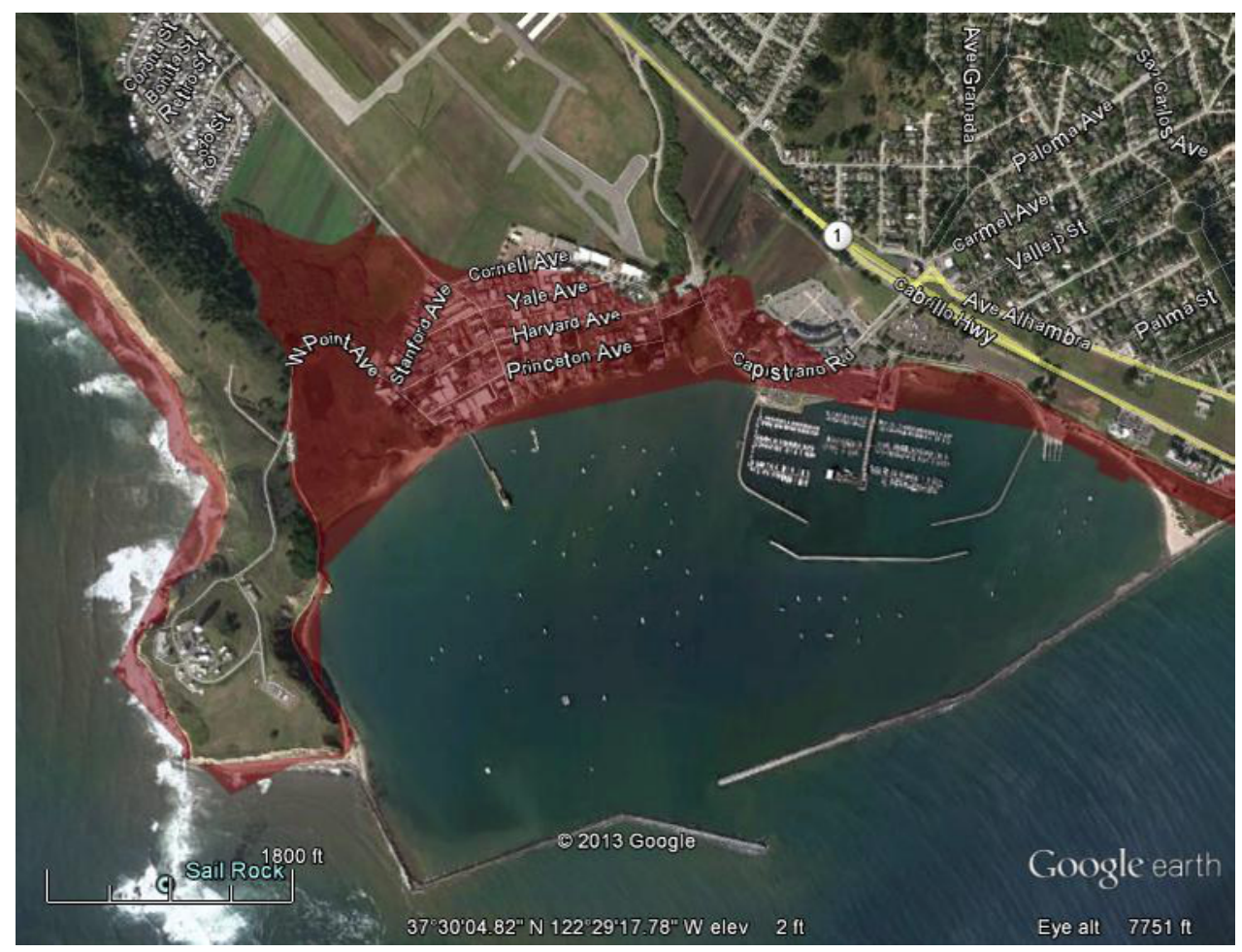

Figure A18 San Mateo County - Princeton/Half Moon Bay: Flooding of all of Princeton and Half Moon Bay waterfront occurs.

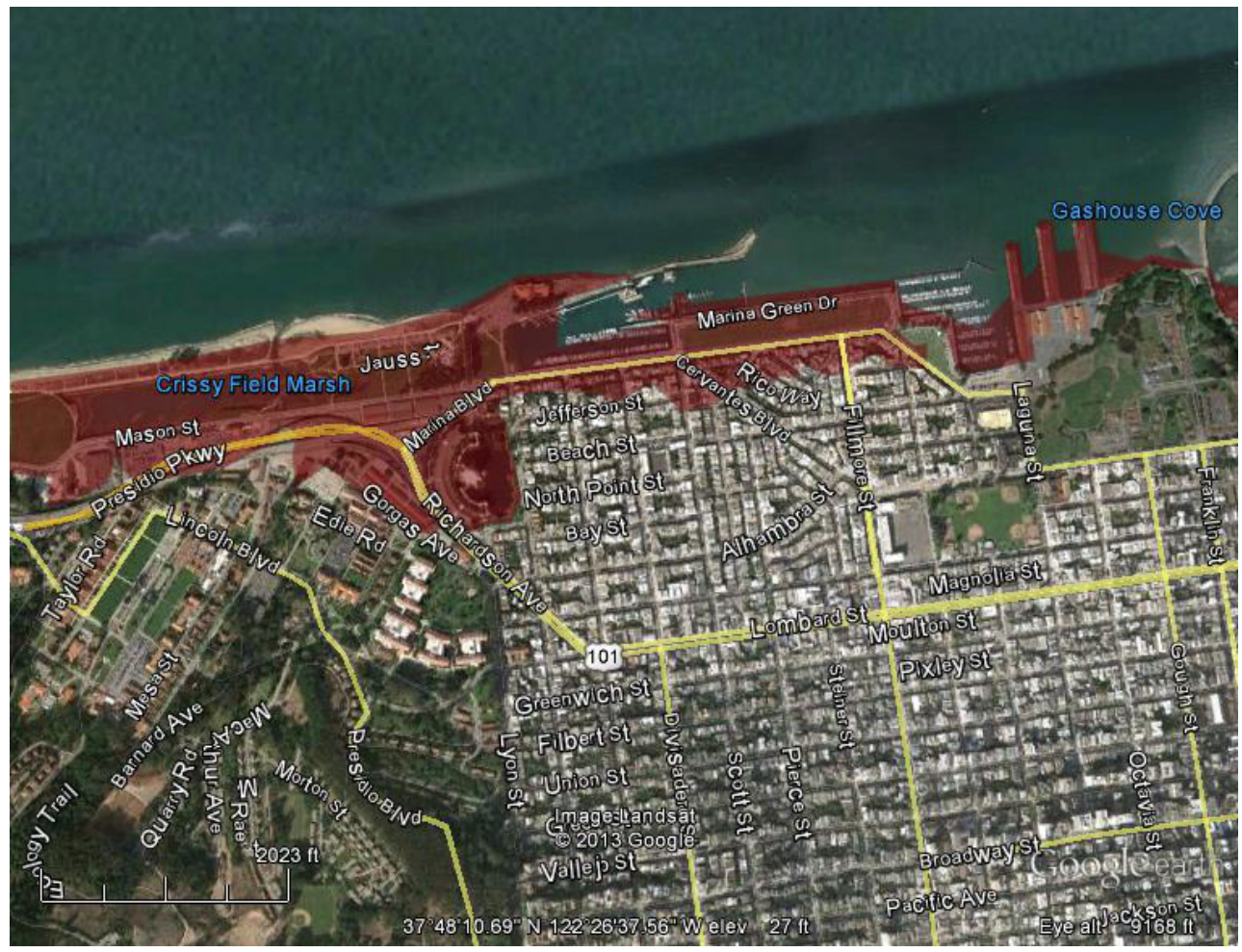

Figure A19 San Francisco: Flooding in parts of Marina District. 


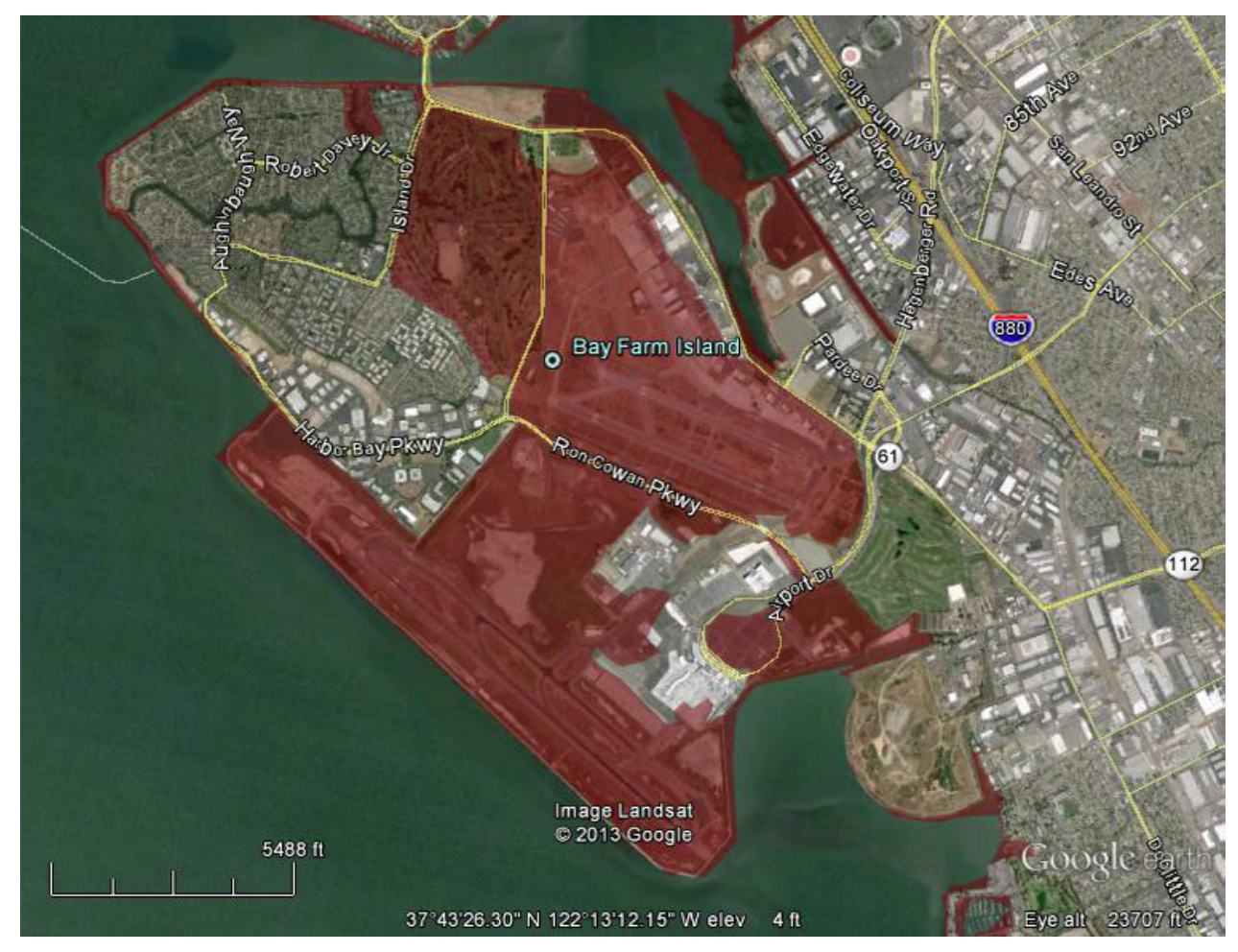

Figure A20 Alameda County - Oakland: Large portions of Bay Farm Island and Oakland Airport are flooded.

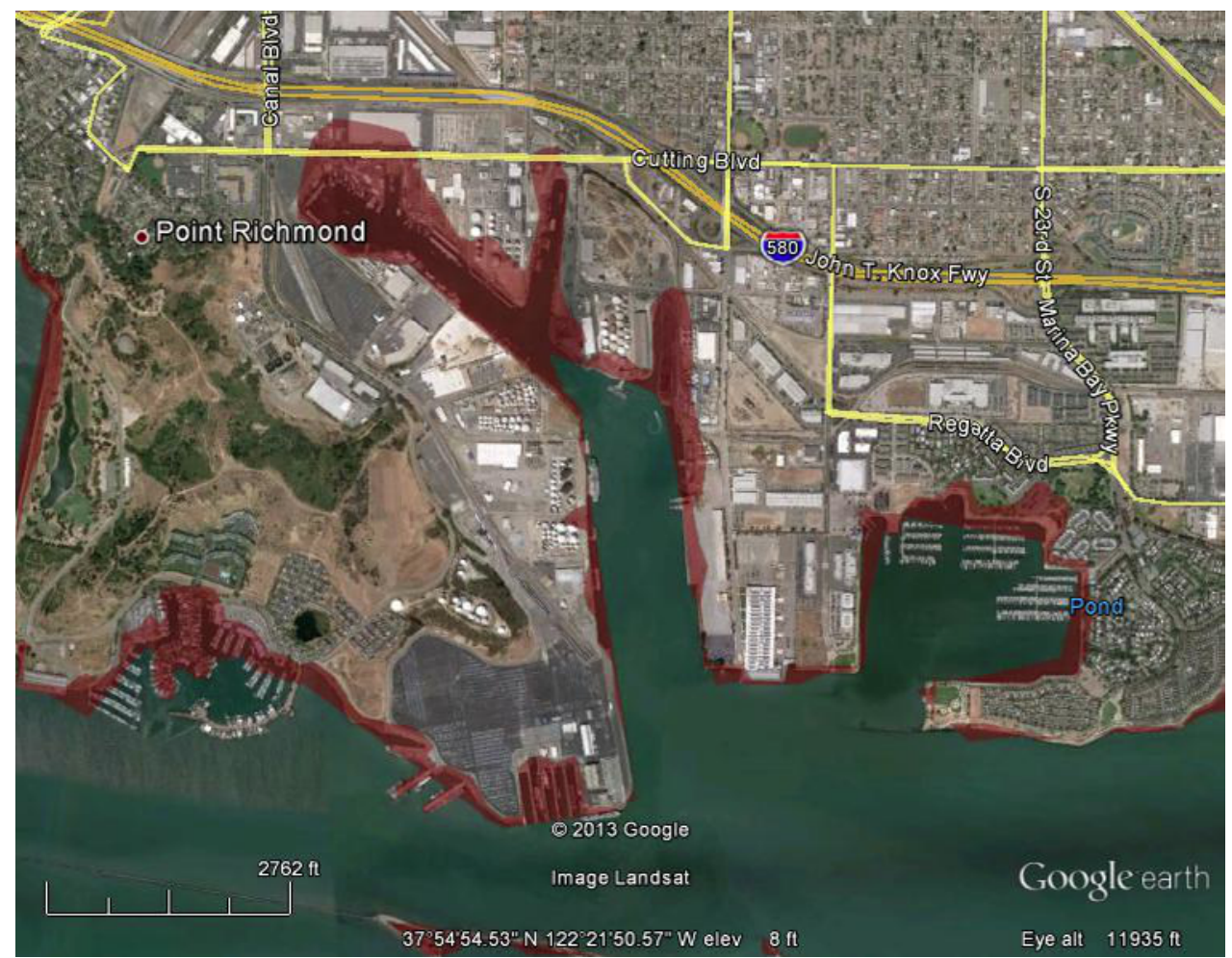

Figure A21 Contra Costa County - Areas around Port of Richmond are inundated. 


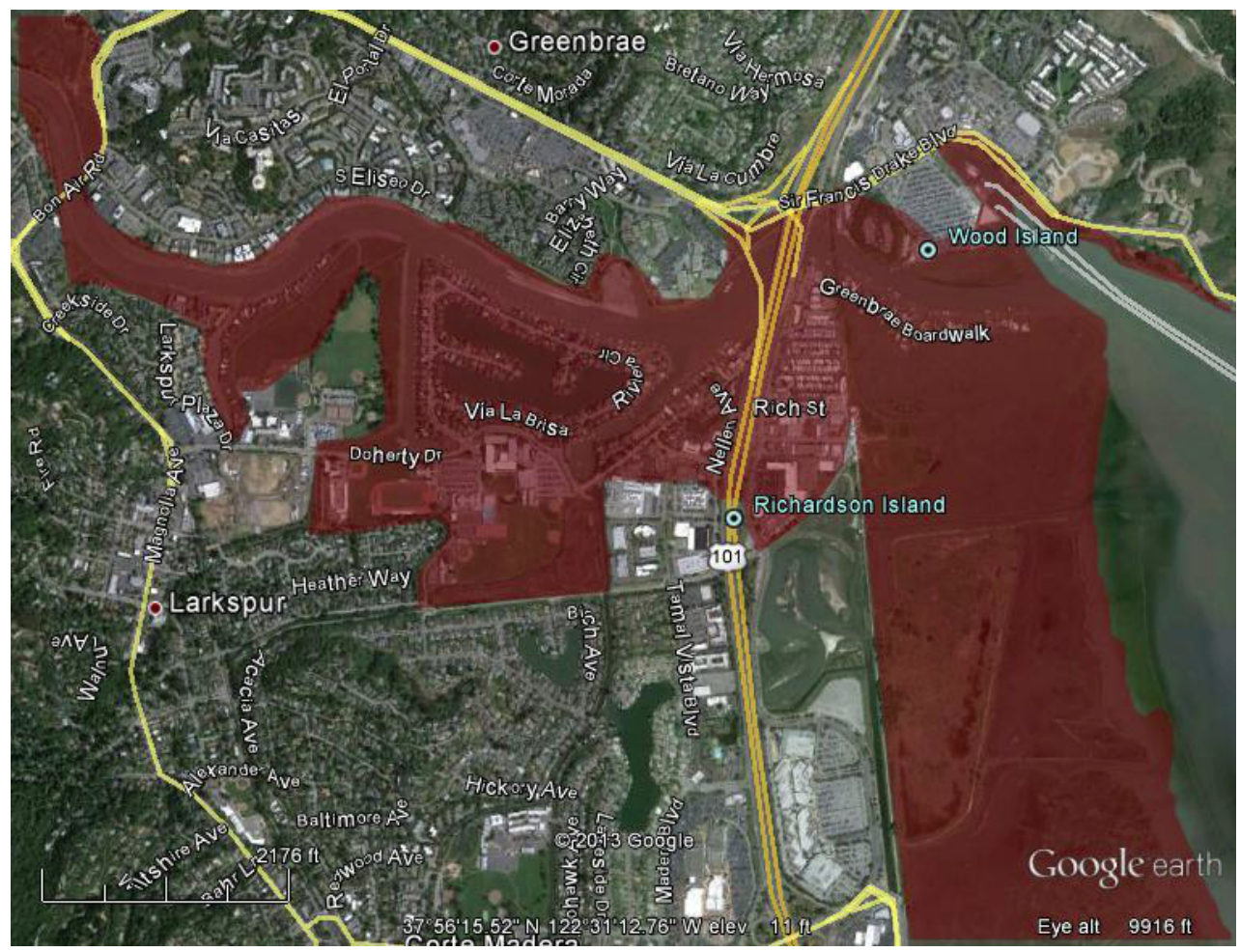

Figure A22 Marin County - Areas around Richardson Bay are inundated.

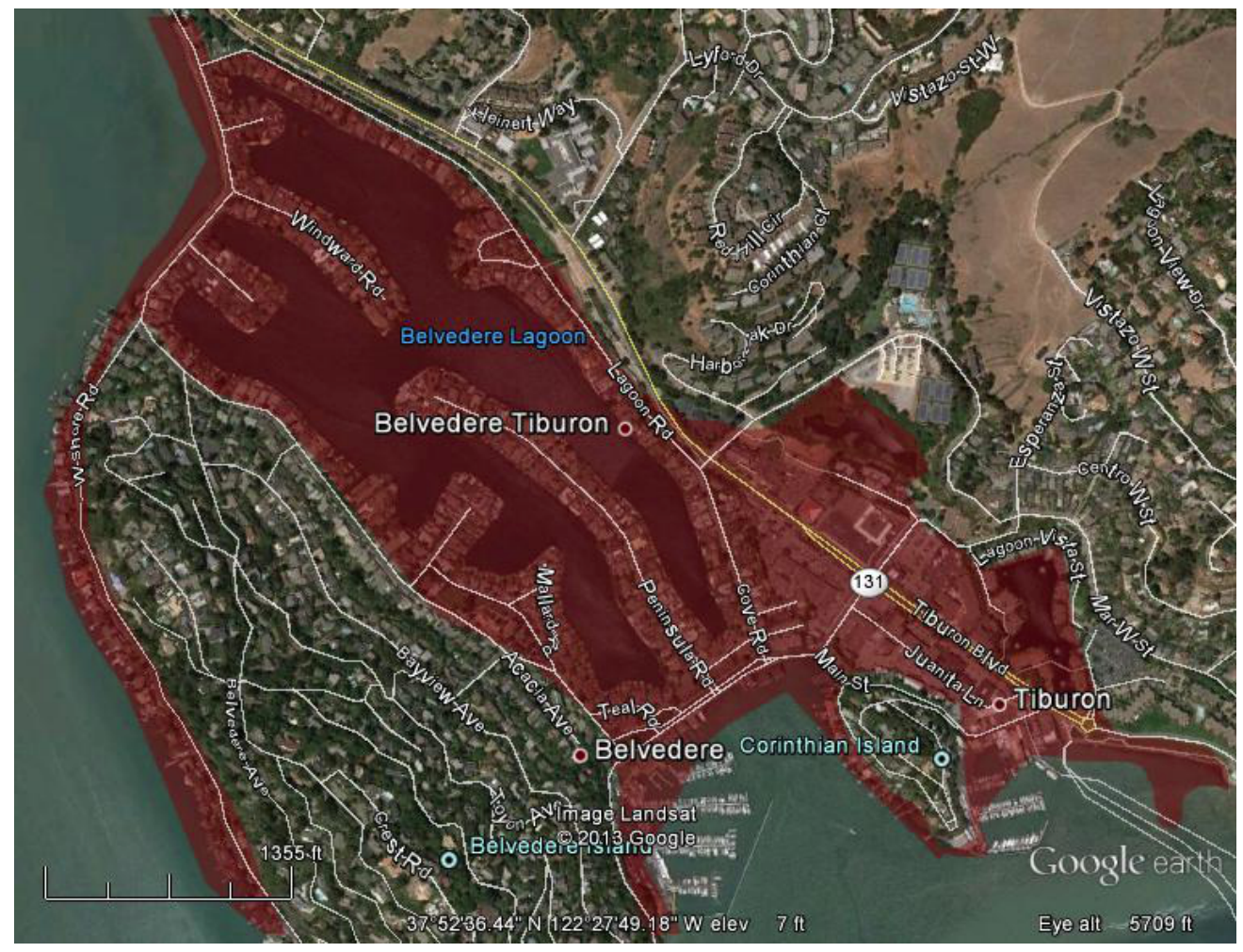

Figure A23 Marin County - Belvedere and Tiburon: A large number of low-lying homes are flooded. 


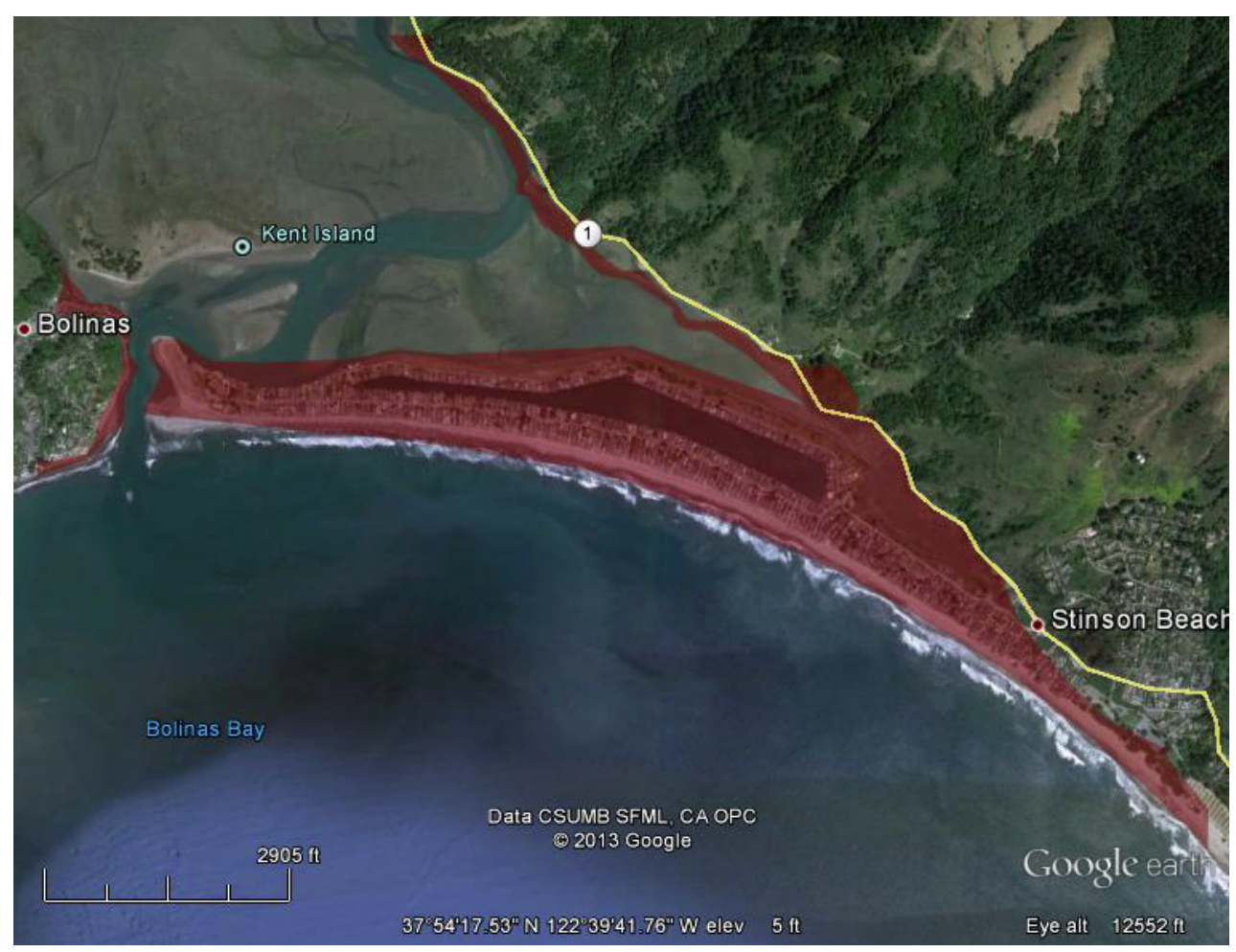

Figure A24 Marin County - Stinson Beach: A large number of homes on the peninsula are flooded.

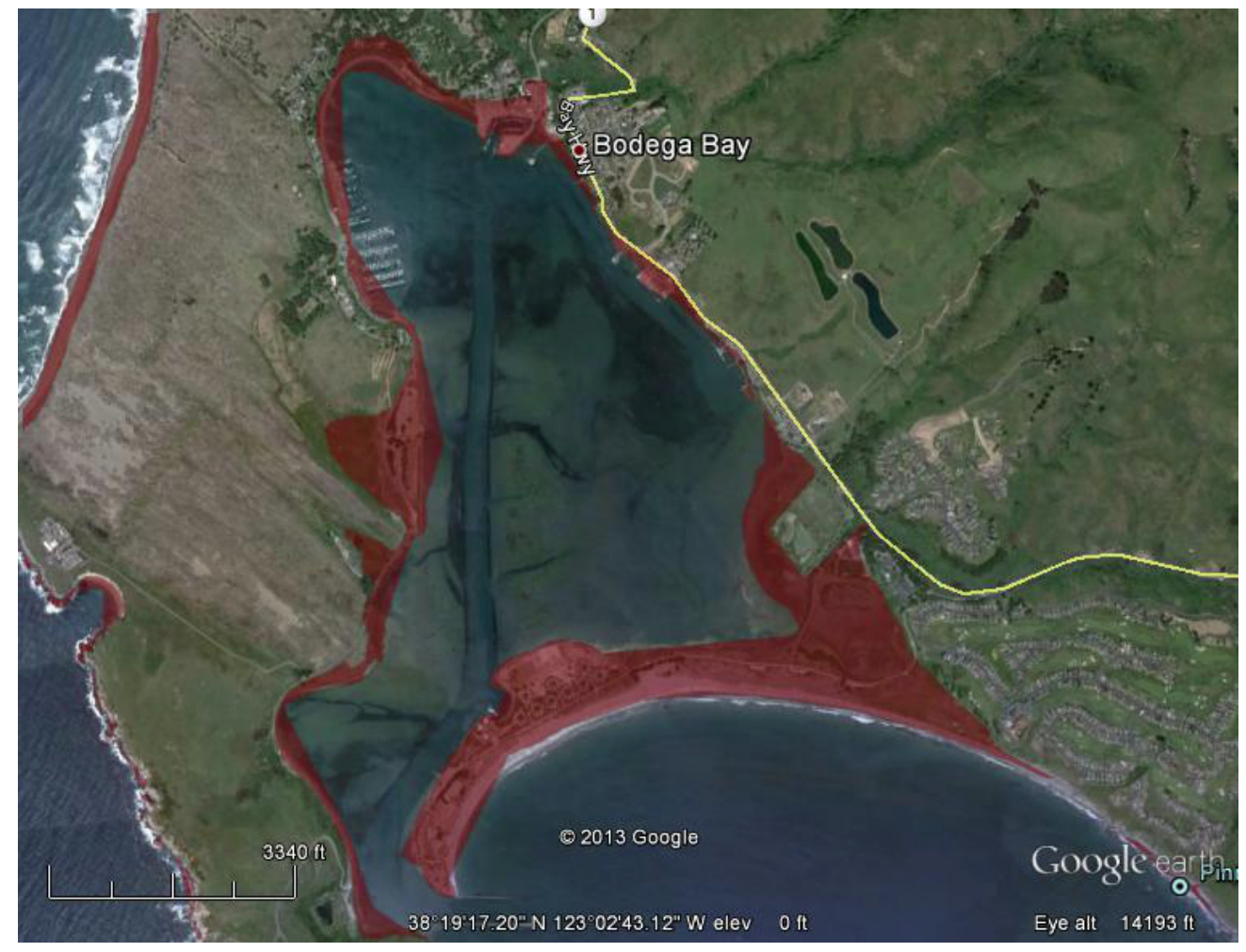

Figure A25 Sonoma County - The Bodega Bay peninsula campground gets overtopped. 


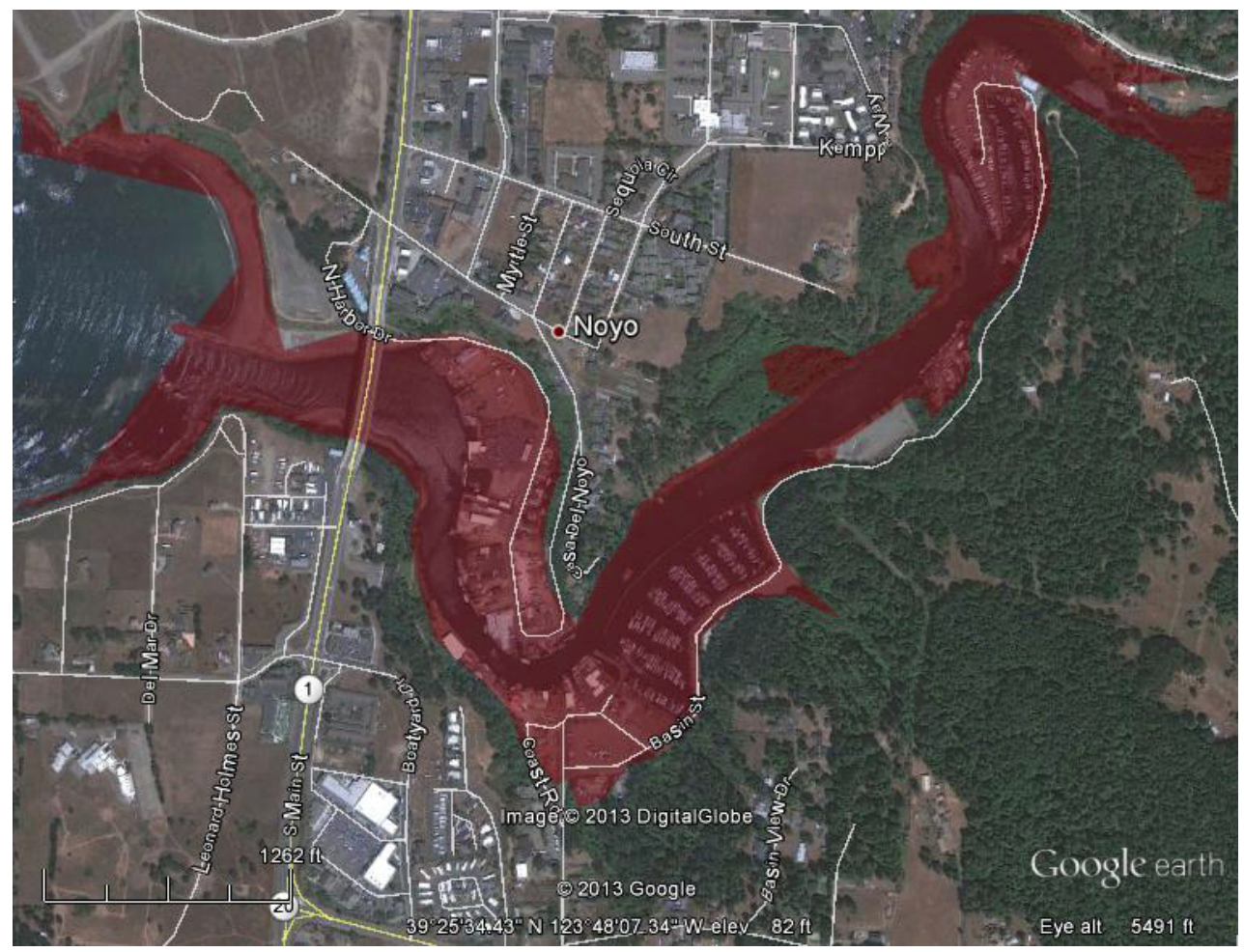

Figure A26 Mendocino County - Low-lying areas within Noyo River harbor gets inundated.

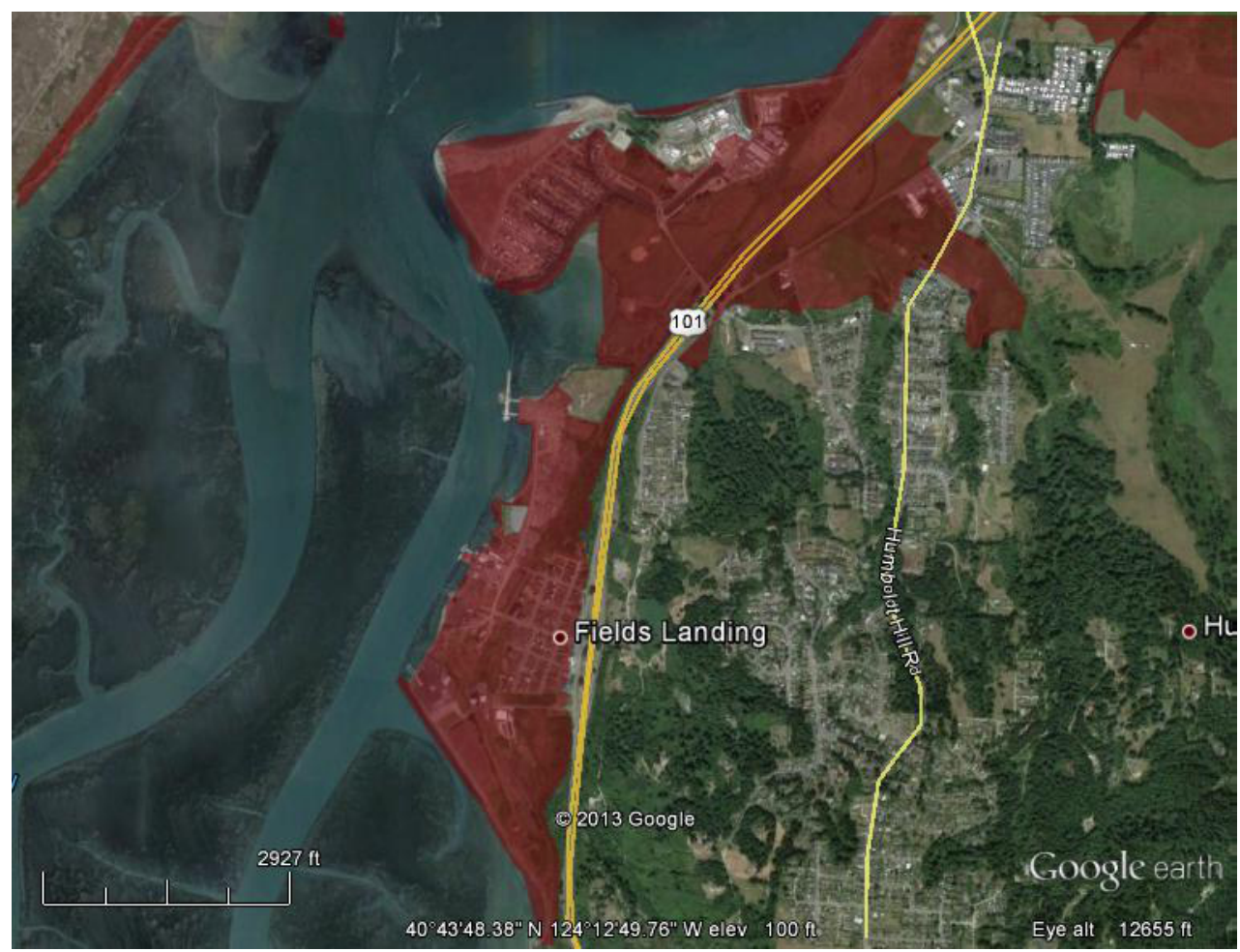

Figure A27 Humboldt County - Significant portions of Fields Landing and King Salmon get inundated. 


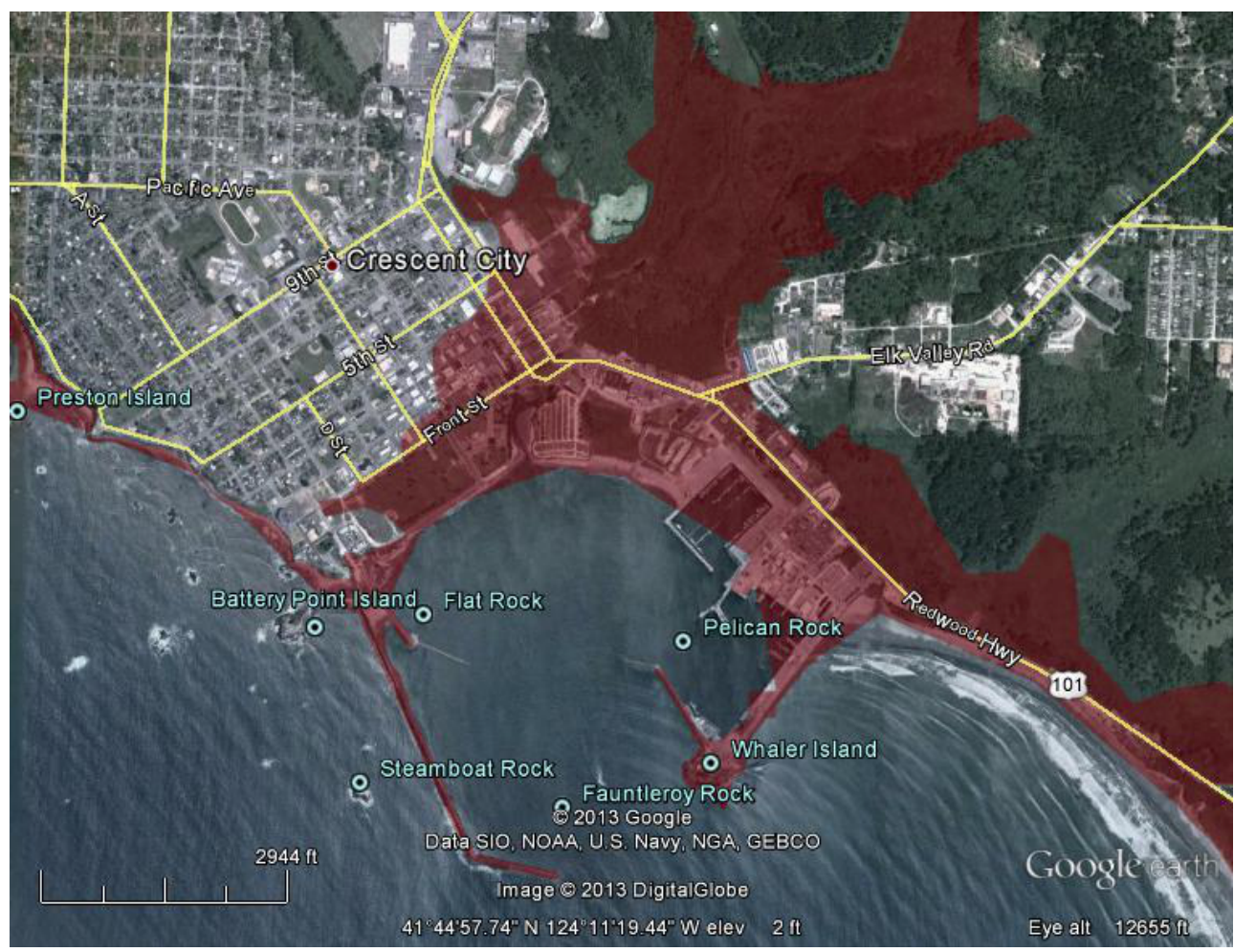

Figure A28 Del Norte County - All of the waterfront area in Crescent City gets inundated. 
This page intentionally left blank 


\section{The SAFRR Tsunami Scenario-Physical Damage in California}

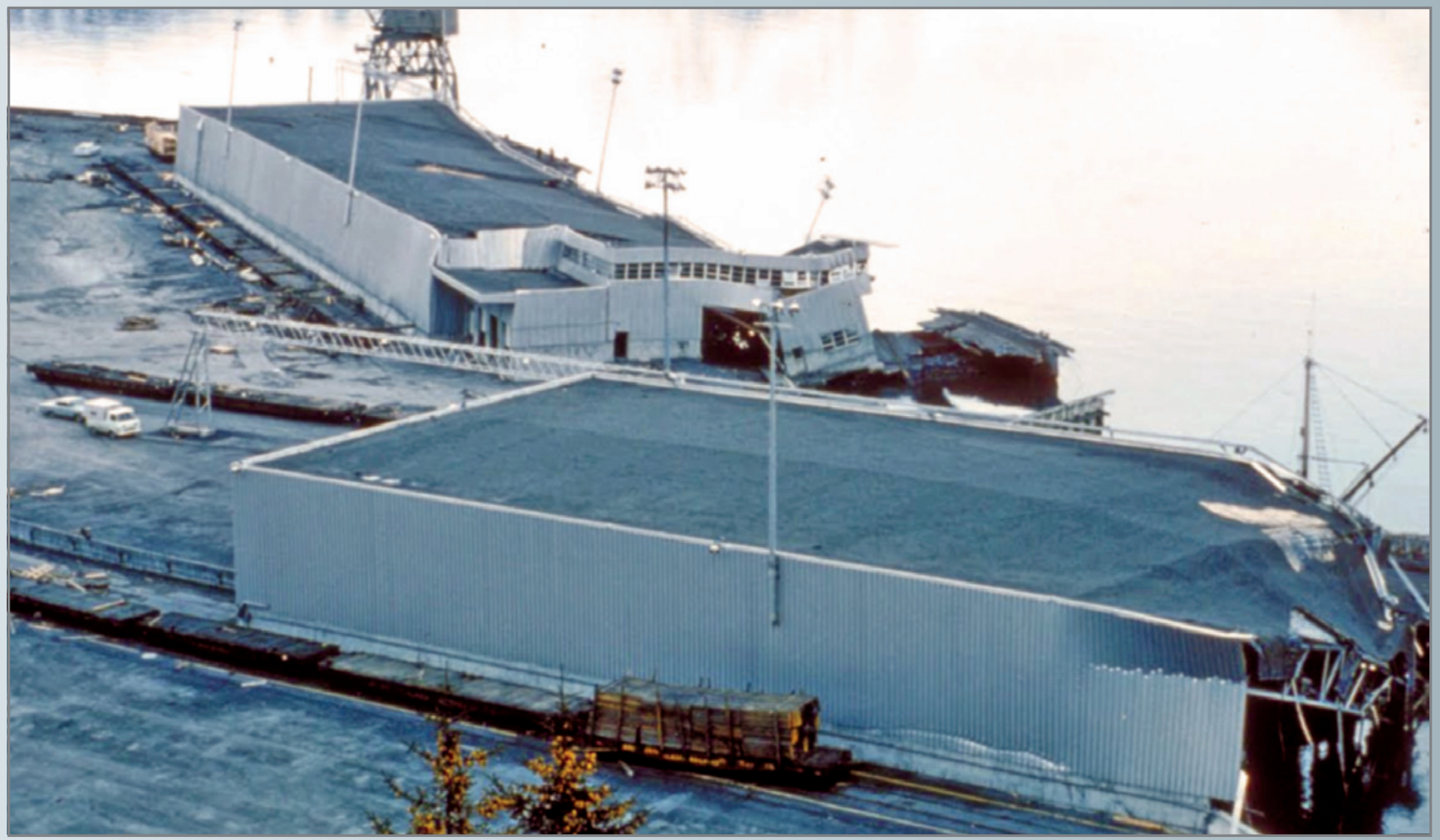

Open-File Report 2013-1170-E

California Geological Survey Special Report 229 
COVER: Tsunami damage to port buildings in Seward Alaska, March 1964. This tsunami caused severe damage in communities around the Pacific Rim, including Alaska, Hawaii, Washington, Oregon, and California. (Photograph: Karl V. Steinbrugge Collection, National Information Service for Earthquake Engineering, University of California, Berkeley. Photo credit: Mildred E. Kirkpatrick, courtesy of the National Information Service for Earthquake Engineering, EERC, University of California, Berkeley. 


\section{The SAFRR (Science Application for Risk Reduction) Tsunami}

Scenario

Stephanie Ross and Lucile Jones, Editors

\section{The SAFRR Tsunami Scenario-Physical Damage in California}

By Keith Porter, William Byers, David Dykstra, Amy Lim, Patrick Lynett, Jamie Ratliff, Charles Scawthorn, Anne Wein, and Rick Wilson

Open-File Report 2013-1170-E

California Geological Survey Special Report 229

U.S. Department of the Interior

U.S. Geological Survey 


\section{U.S. Department of the Interior \\ SALLY JEWELL, Secretary}

\section{U.S. Geological Survey \\ Suzette M. Kimball, Acting Director}

U.S. Geological Survey, Reston, Virginia: 2013

For product and ordering information:

World Wide Web: http://www.usgs.gov/pubprod

Telephone: 1-888-ASK-USGS

For more information on the USGS—-the Federal source for science about the Earth, its natural and living resources, natural hazards, and the environment:

World Wide Web: http://www.usgs.gov

Telephone: 1-888-ASK-USGS

Suggested citation:

Porter, K., Byers, W., Dykstra, D., Lim, A., Lynett, P., Ratliff, J., Scawthorn, C., Wein, A., and Wilson, R., 2013, The SAFRR tsunami scenario-Physical damage in California, chap. E in Ross, S.L., and Jones, L.M., eds., The SAFRR (Science Application for Risk Reduction) Tsunami Scenario: U.S. Geological Survey Open-File Report 2013-1170, 168 p., http://pubs.usgs.gov/of/2013/1170/e/.

Any use of trade, firm, or product names is for descriptive purposes only and does not imply endorsement by the U.S. Government.

Although this information product, for the most part, is in the public domain, it also may contain copyrighted materials as noted in the text. Permission to reproduce copyrighted items must be secured from the copyright owner. 


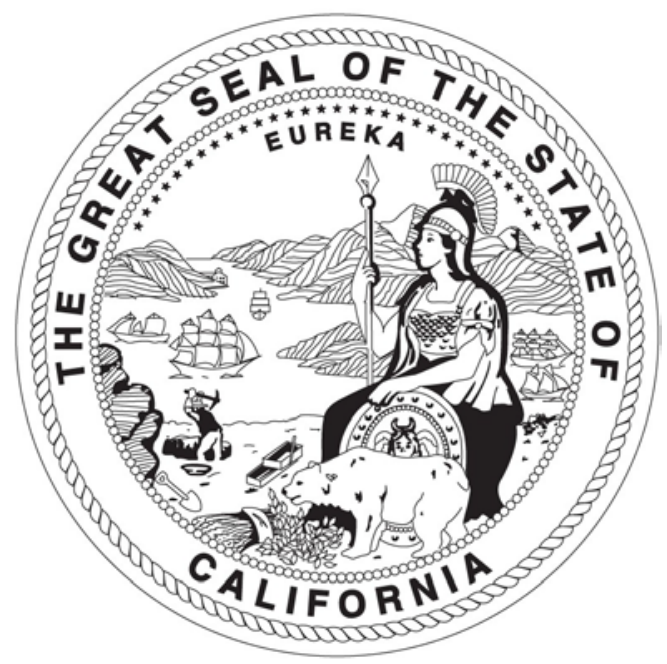

STATE OF CALIFORNIA EDMUND G. BROWN JR. GOVERNOR

THE NATURAL RESOURCES AGENCY JOHN LAIRD

SECRETARY FOR RESOURCES

\author{
DEPARTMENT OF CONSERVATION \\ MARK NECHODOM \\ DIRECTOR
}

\title{
CALIFORNIA GEOLOGICAL SURVEY \\ JOHN G. PARRISH, Ph.D. \\ STATE GEOLOGIST
}




\section{Contents}

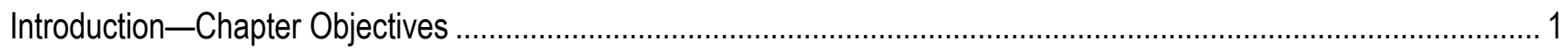

Damage and Restoration of the Ports of Los Angeles and Long Beach ............................................................ 2

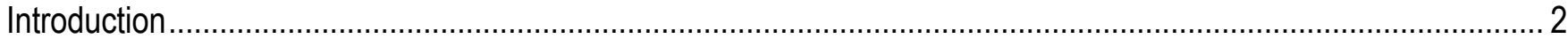

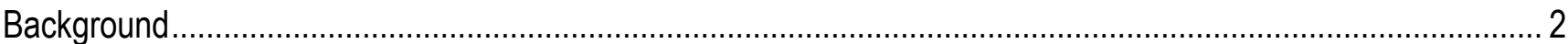

Historical Tsunami Events at the Ports of Los Angeles and Long Beach ..................................................... 2

Damage and Restoration of Similar Ports During Tsunamis .......................................................................... 4

Damage To and Caused by Vessels .............................................................................................

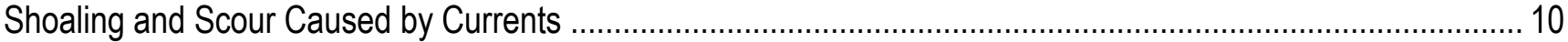

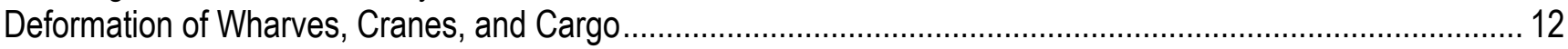

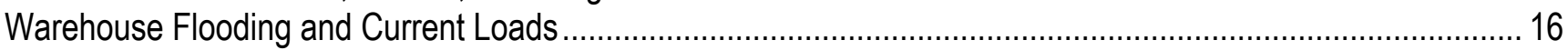

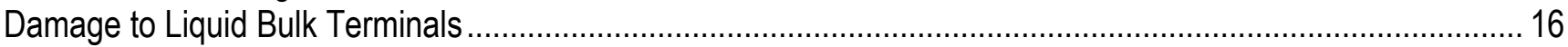

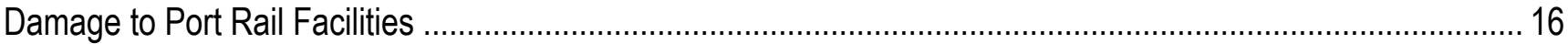

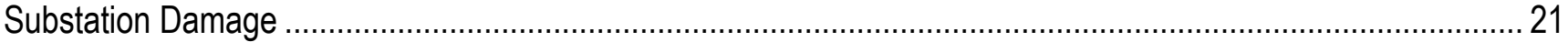

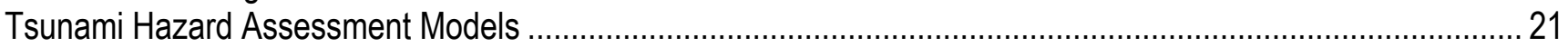

Tsunami Messages Related to the Ports of Los Angeles and Long Beach ..................................................... 21

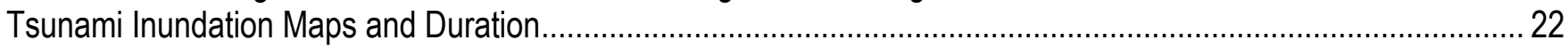

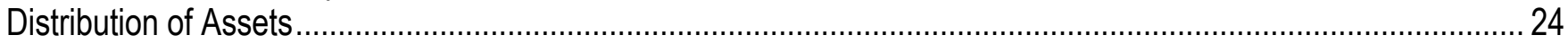

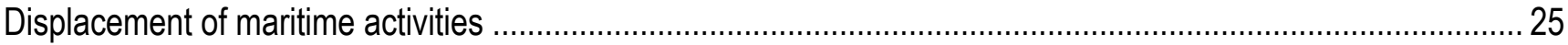

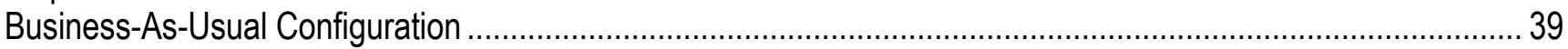

Physical Damage, Losses, and Logistics in the SAFRR Tsunami Scenario ......................................................... 43

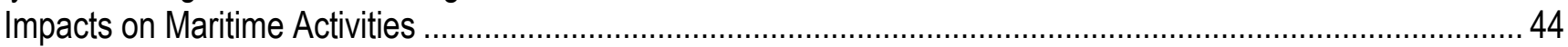

Port of Long Beach …………………………………

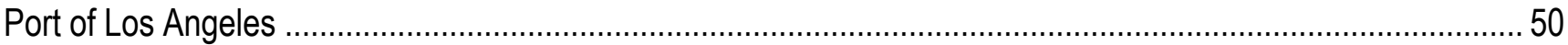

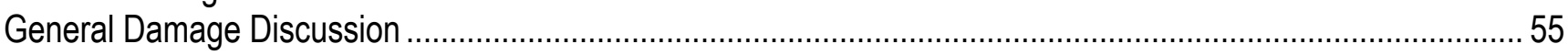

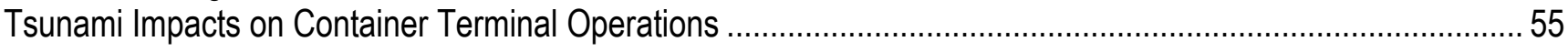

Tsunami Impacts on Truck and Rail Movement.................................................................................5

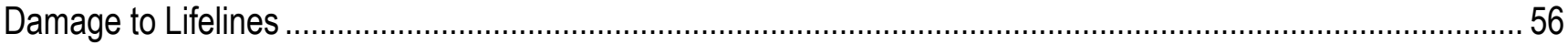

Damage to Other West Coast Ports .....................................................................................................5

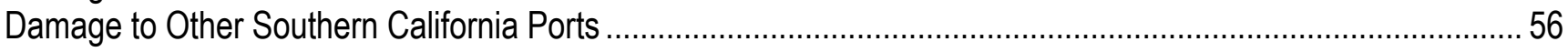

Damage to the Port of San Francisco ............................................................................................... 57

Damage to Port of San Francisco Headquarters Building …………..................................................... 58

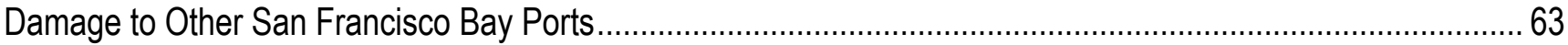

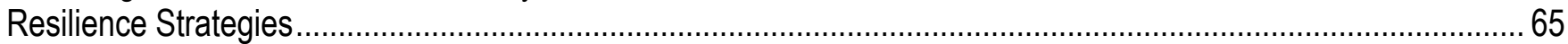

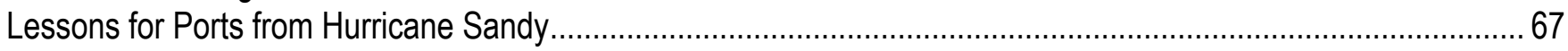

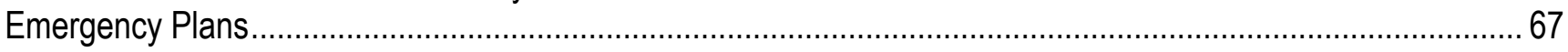

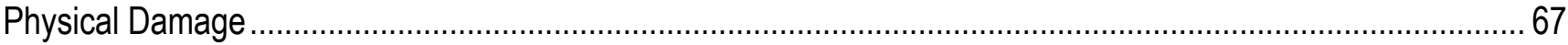

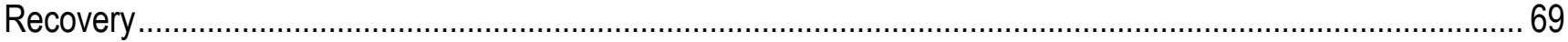

Threats to Life Safety ................................................................................................................... 70

Damage to Large Vessels in the Ports of Los Angeles and Long Beach............................................................. 70

Previous Instances of Vessels Breaking Their Moorings ........................................................................... 70

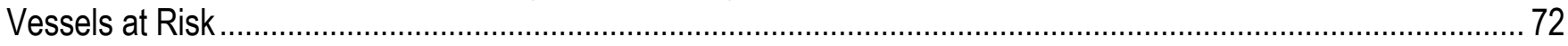

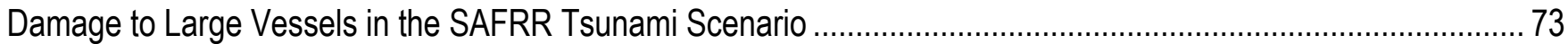

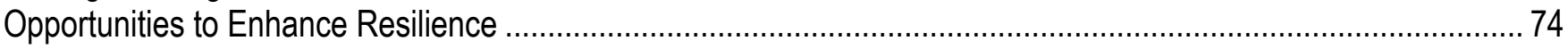

Damage and Restoration of Marinas and Small Craft..................................................................................... 75 


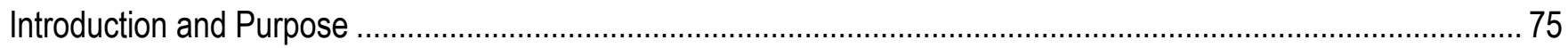

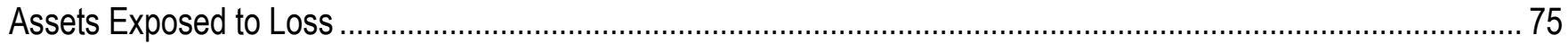

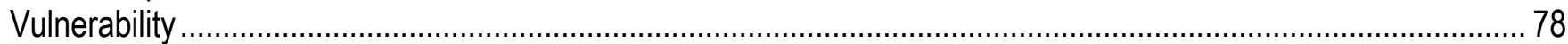

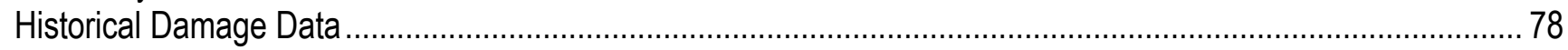

Fragility Functions for Velocity-Induced Damage ..................................................................................... 81

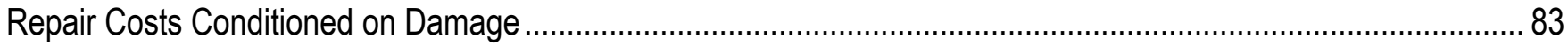

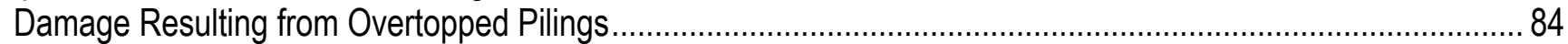

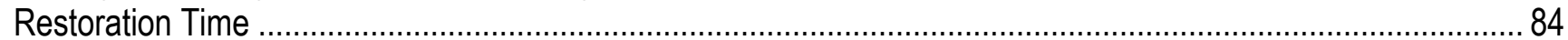

Damage to Marinas and Small Craft in the SAFRR Tsunami Scenario ............................................................ 85

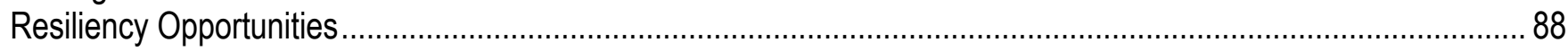

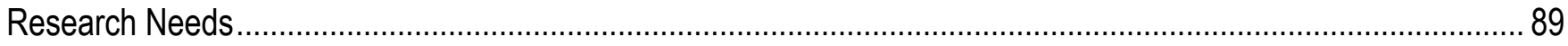

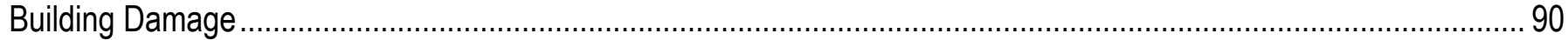

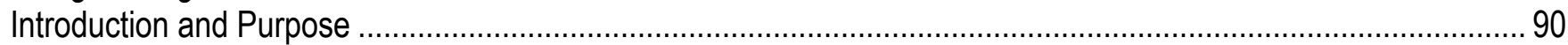

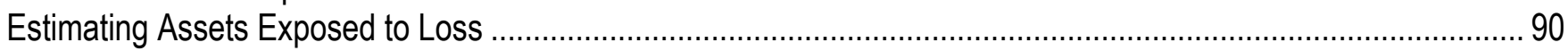

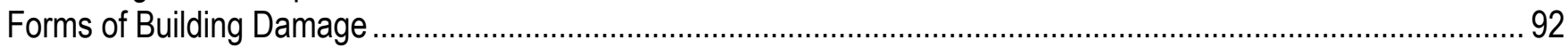

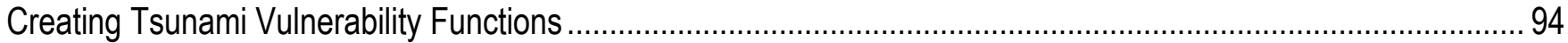

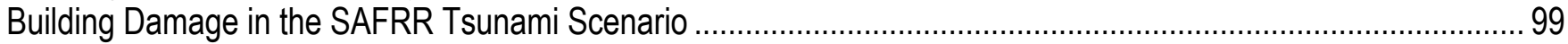

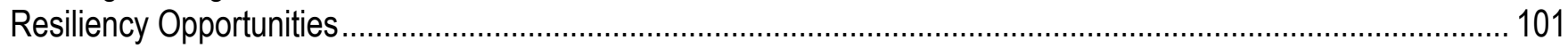

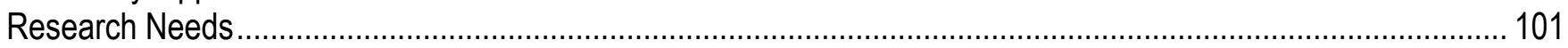

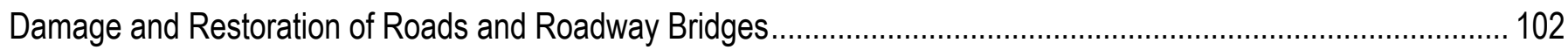

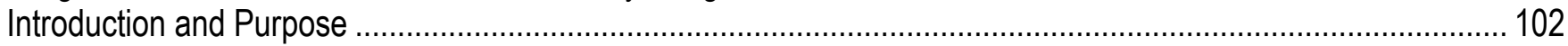

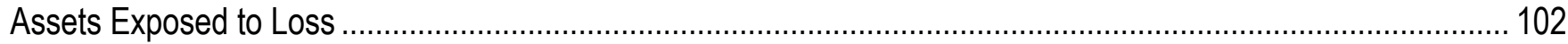

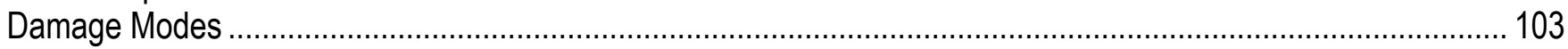

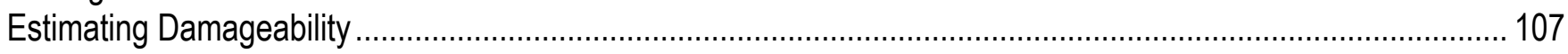

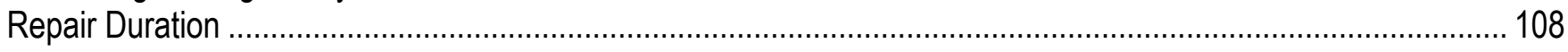

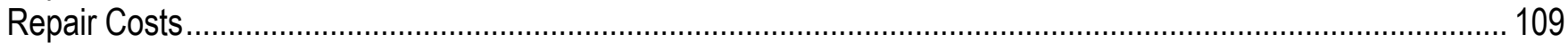

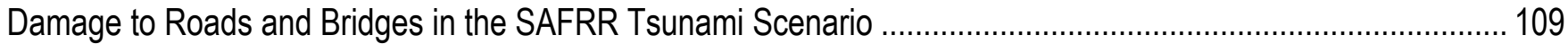

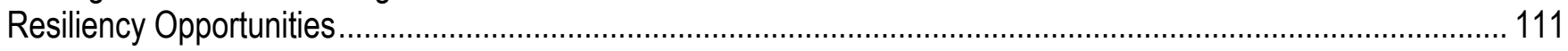

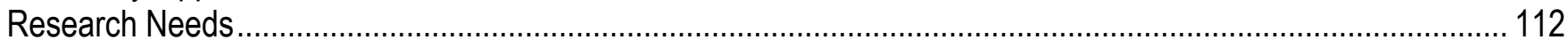

Damage and Restoration of Railroads in the SAFRR Tsunami Scenario ............................................................ 112

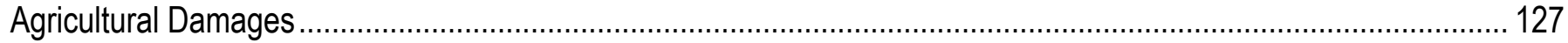

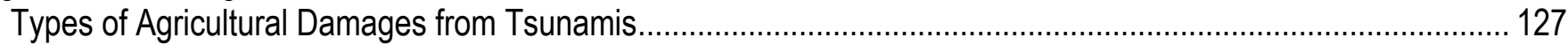

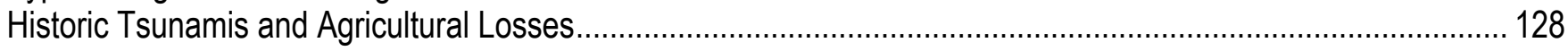

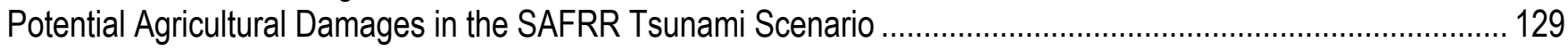

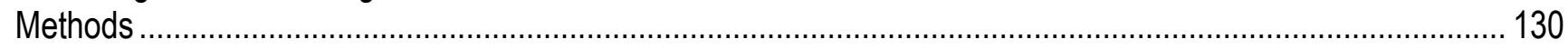

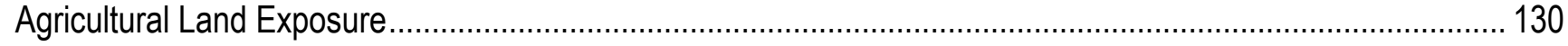

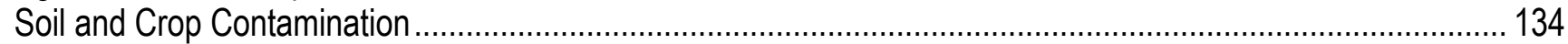

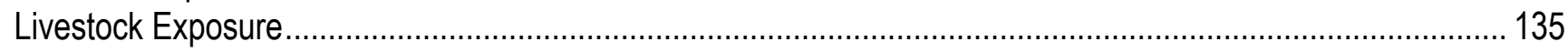

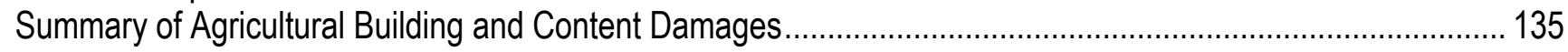

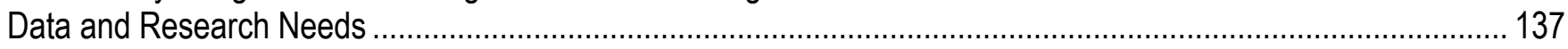

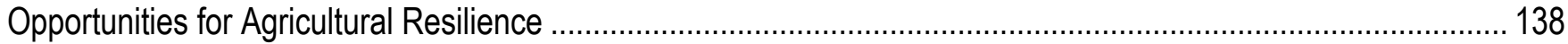

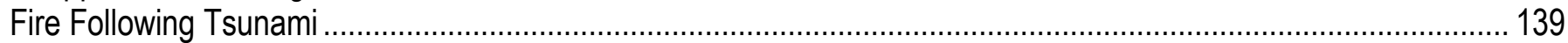

Review of Fires Following Historic Tsunamis and the Related Literature ........................................................ 139

1755 Lisbon Earthquake and Tsunami ............................................................................................... 140

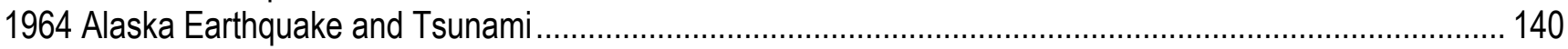

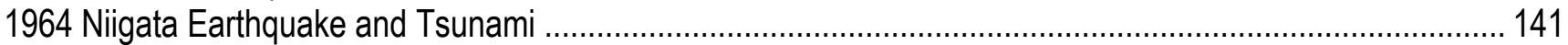

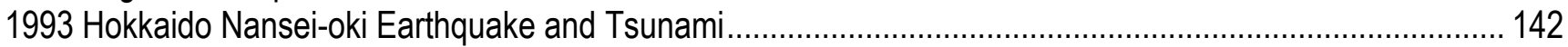




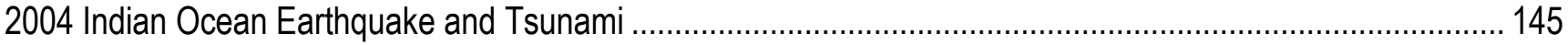

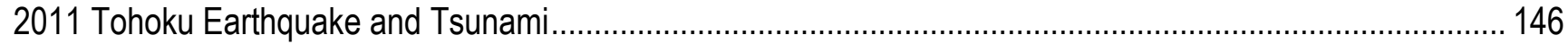

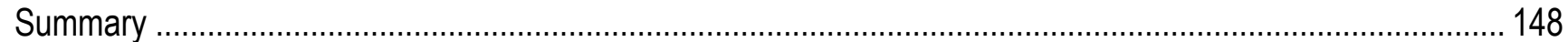

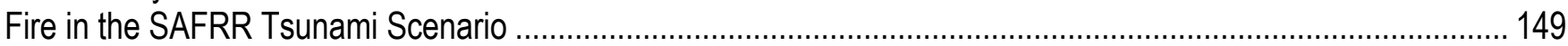

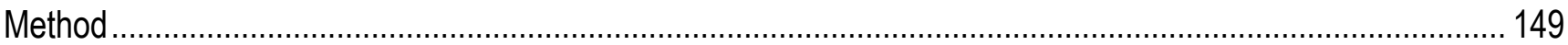

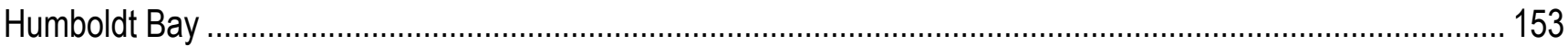

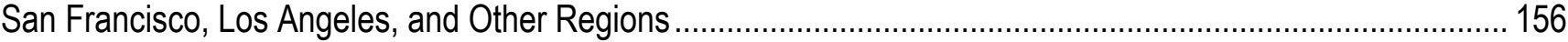

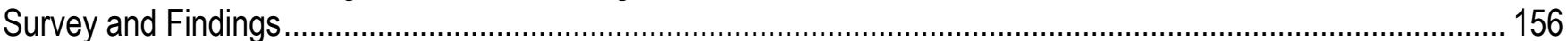

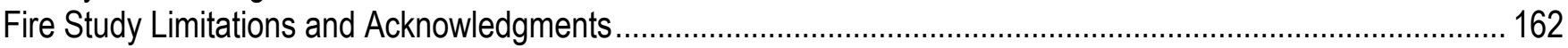

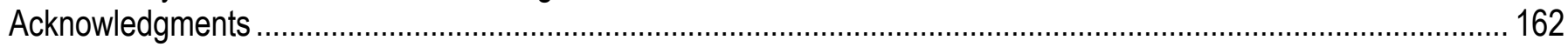

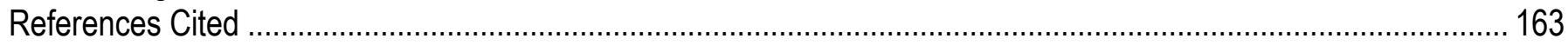

\section{Figures}

1. Tide gage records at Port of Los Angeles Berth 60 for the 1960 Chilean Tsunami and the 1964 Alaskan Tsunami

2. Photograph of Sri Lanka Port of Galle dredge grounded on wharf by a 5.3-meter tsunami wave during the 2004 Sumatra tsunami

3. Photograph of MV Glovis Mercury displaced on top of wharf and damaged crane at Sendai Port, Japan, during 2011 Tohoku tsunami .......................................................................................

4. Photograph of Port of Colombo, Sri Lanka-A ship lost control in this entrance during the

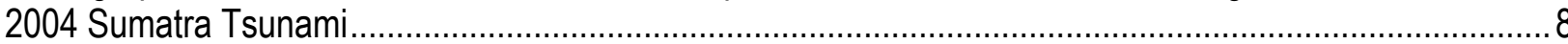

5. Photograph of broken back of coal carrier in navigation channel at Port of Shinchi, Japan, during the 2011 Tohoku tsunami

6. Photograph of Port of Chennai, India-Vessel hitting shore crane during the 2004 Sumatra

Tsunami.....

7. Photograph of Port of Chennai, India—-two mooring dolphins missing after the 2004 Sumatra

Tsunami

8. Photograph of hoppers destroyed by out of control vessel in Port of Chennai, India, during the

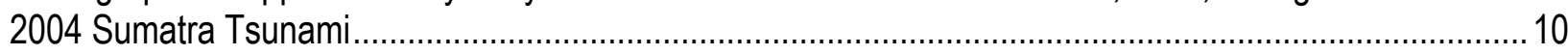

9. Photograph of breakwater damaged in Chile 2010 Tsunami ................................................................11

10. Photograph of seawall and road damaged in Chile Tsunami of 2010 ..................................................11

11. Photographs of damage from 2004 Sumatra Tsunami in Port Blair, India .............................................. 13

12. Photograph of utility and crane rail trench filled with debris and utilities damaged by the 2004 Sumatra Tsunami in Port Blair, India ............................................................................................. 13

13. Photograph of flooding of container wharf at Port of Chennai, India, in the 2004 Sumatra Tsunami .....

14. Photograph of damaged container crane motor in Port of Sendai, Japan, following the 2011 Tohoku tsunami

15. Photograph of container cranes collapsed due to tsunami current forces at Port of Shinchi, Japan, following the 2011 Tohoku tsunami...

16. Photograph of undamaged steel at Port of Sendai, Japan, following the 2011 Tohoku tsunami..................15

17. Photograph of Sri Lankan Port of Galle warehouse damage during 2004 Sumatra Tsunami ......................17

18. Photograph of pier deck removed in Chile Tsunami of 2010 ............................................................ 17

19. Photographs of damage by the 2011 Tohoku, Japan, tsunami ............................................................ 18 
20. Photograph of a fire at the Cosmo Oil Refinery in Ichihara after the 2011 Tohoku, Japan, tsunami

21. Photograph of pipes whose supports seem to have been undermined by tsunami scour in Ishinomaki, Japan, after the 2011 Tohoku tsunami .... 19

22. Photograph of tsunami-damaged tanks in Ishinomaki, Japan, after the Tohoku 2011 tsunami...................19

23. Photograph of tank floated off its foundation during the 2011 Tohoku, Japan, tsunami ...............................2 20

24. Photograph of railroad-bridge deck removed during the 2011 Tohoku, Japan, tsunami ..............................20

25. San Pedro Harbor, California, Middle Harbor marigram for the SAFRR tsunami scenario............................23

26. San Pedro Harbor, California, Turning Basin marigram for the SAFRR tsunami scenario ...........................23

27. Inundation map during the SAFRR tsunami for the Ports of Long Beach and Los Angeles .........................25

28. Map of maximum velocity for the Ports of Long Beach and Los Angeles during the SAFRR tsunami 26

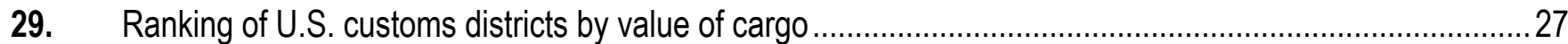

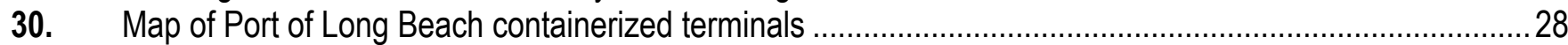

31. Map of Port of Long Beach cargo types - dry bulk ...................................................................... 30

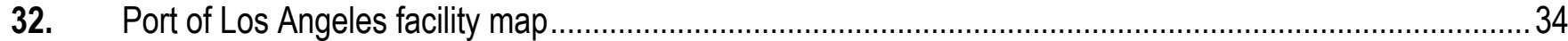

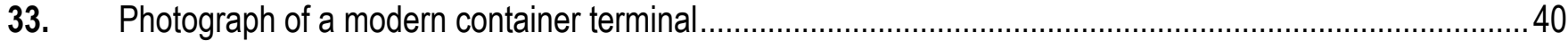

34. Diagram of San Pedro Bay loaded import container movement scenarios.............................................. 42

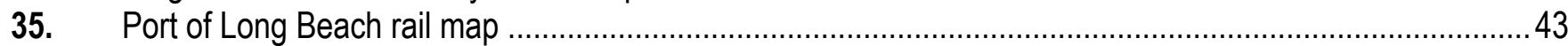

36. Marigrams in San Francisco Bay area for the SAFRR tsunami scenario. ................................................57

37. Wave amplitudes in the San Francisco Bay area for the SAFRR tsunami scenario....................................59

38. Flooding along the San Francisco Embarcadero reaches 1 to 2 meters and wave velocities reach 5 to 10 meters per second (10-20 knots) in the SAFRR tsunami scenario. 59

39. Inundation along the San Francisco Embarcadero in the SAFRR tsunami scenario...................................60

40. Velocities (left) and flow depth (right) at Port of San Francisco cargo piers in the SAFRR tsunami scenario.

41. Velocities $(A)$ and flow depth $(B)$ at Port of San Francisco Pier 45 in the SAFRR tsunami scenario 62

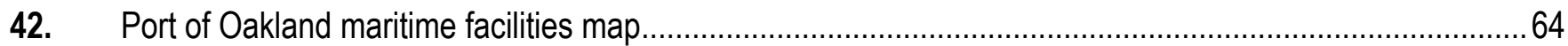

43. Flow depths and inundation line at Port of Oakland in the SAFRR tsunami scenario. ...............................64

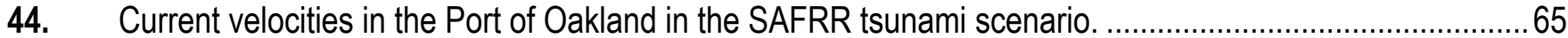

45. Photographs of damage from Hurricane Sandy at New York and New Jersey ports ................................69

46. Photograph of Drilling Vessel Chikyu, which was damaged in the 2011 Tohoku earthquake and tsunami

47. A, Photograph of MV Rena aground on Astrolabe Reef, New Zealand, on October 13, 2011;

$B$, Photograph of the Norfolk Express.

48. Image showing one location in the Port of Long Beach near a berth where tsunami currents exceed 6 knots ( 3 meters per second) in the SAFRR tsunami scenario...

49. Diagram showing motion of a particle representing a vessel in the Port of Long Beach moored at Pier $\mathrm{J}$ that parts its mooring lines and collides with nearby piers in the SAFRR tsunami scenario 74

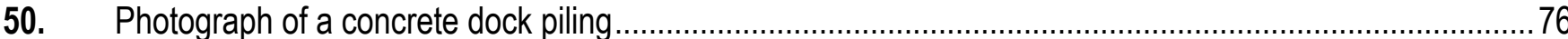

51. Photograph of boats sunk by the tsunami generated by the 2011 Tohoku, Japan, earthquake within Crescent City, California's, small boat basin.

52. Graph showing fragility model for boats and docks in the SAFRR tsunami scenario. 83

53. Graph showing restoration of damaged and destroyed docks after the SAFRR tsunami scenario 
54. Diagrams of paths of hypothetical floating debris from Port of Los Angeles marinas 3.5 to 6.5 hours after the first arrival of the SAFRR tsunami.

55. Most of the losses to marinas in the SAFRR tsunami scenario are to the 10 marinas shown on this map, attributable to high current velocities or high wave heights. .88

56. Photographs of apparent effects of hydrodynamic pressure on buildings in Japan affected by the 2011 Tohoku tsunami

57. Photographs of wetting, soiling, and deposition of debris in buildings in Japan affected by the 2011 Tohoku tsunami

58. Graphs of sample tsunami vulnerability functions for a large wood-frame building (W2) being used as a multifamily dwelling (RES3) of moderate-code construction .....................................................99

59. Map of coastal bridges and low-elevation roads in the SAFRR tsunami scenario study area ....................103

60. Photographs of embankment scour at Route 45 bridge (Takada Bypass) over Route 141 (Hamaiso Highway) due to the 2011 Tohoku tsunami. 104

61. Photographs of tsunami damage from the 2011 Tohoku, Japan, tsunami.............................................105

62. Photographs showing a contrast in tsunami scour potential resulting from roadway elevation.................. 105

63. Photographs of bridges whose superstructures were pushed or floated off their piers in the 2011 Tohoku, Japan, tsunami.

64. Photograph of example from the 2011 Tohoku, Japan, tsunami of how small craft represent a debris hazard for bridges 106

65. Photograph of damage from a barge impact on the Jokawa Bridge over the Higashimatsushima River in the 2011 Tohoku, Japan, tsunami that destroyed the middle span and damaged the other spans ....

66. Map of SAFRRR tsunami scenario bridge and roadway damage locations

67. Photograph of overturned passenger cars in Komagamine, Japan after 2011 Tohoku, Japan, tsunami

68. Photograph of overturned passenger train locomotive in Komagamine, Japan, after the 2011 Tohoku tsunami.

69. Photograph of displaced steel girder span near Rikuzen Takata after 2011 Tohoku, Japan, tsunami

70. Photograph of damaged piers of the JR Rail Viaduct crossing the Tsuya River, Japan, after the 2011 Tohoku tsunami.

71. Photograph of Coquimbo rail yard after 1922 Atacama, Chile, tsunami

72. Photograph of overturned locomotive at Seward after 1964 Alaska tsunami ..........................................118

73. Photograph of Seward yard after 1964 Alaska tsunami........................................................................ 119

74. Photograph of open deck trestle damage from 1983 Hurricane Alicia in the United States ......................119

75. Photograph of track damage from 2008 Hurricane lke in the United States.......................................... 120

76. Map of conditions, when SAFRR tsunami warning is received, at locations in ports of Los Angeles and Long Beach where inundation will be deep enough to damage cars left standing on track.

77. Satellite image annotated with details of location "A" (see fig. 76) at time of the SAFRR tsunami warning.

78. Satellite image showing Eel River Delta, Humboldt County, land inundated in the SAFRR tsunami scenario.

9. Satellite image showing land inundated in the SAFRR tsunami scenario around Moss Landing in Monterey County.....

80. Photograph of fire ignitions in the town of Aonae on the southern tip of Okushiri Island, Japan, following the 1993 Hokkaido Nansei-oki earthquake and tsunami. 
81. Photograph of tsunami and fire damage on southeast Okushiri Island in the community of Aonae, Japan, following the 1993 Hokkaido Nansei-oki earthquake and tsunami ..

82. Diagram of tsunami effects in the town of Aonae on the southern tip of Okushiri Island, Japan, following the 1993 Hokkaido Nansei-oki earthquake and tsunami.

83. Photograph of Krueng Raya, Aceh, Indonesia, deep water port after the 2004 Indian Ocean tsunami

84. Photograph of MV Shiramizu aground in Shinchi following the 2011 Tohoku, Japan, earthquake and tsunami.

85. Map showing 111 California coastal petroleum facilities.

86. Map showing 46 California petroleum facilities sited in proximity to possible tsunami effects

87. Images of example of small marina fueling dock not considered in this study of fire in the

SAFRR tsunami scenario

88. Satellite image of Humboldt Bay, California, showing the three oil facilities in the area

89. Satellite image of Humboldt Bay, California, showing the three oil facilities in the area and annotated with tsunami flood depths for the SAFRR tsunami scenario

90. Satellite image of a Humboldt Bay, California, oil facility

91. Photographs of Port of Los Angeles Berth 163 wood wharf and manifold and piping to storage tanks ......

92. Photographs of Port of Los Angeles Berth 163

93. Photographs of Port of Los Angeles Berth 167-9 manifolding, piping, and secondary

containment

94. Cross-section diagram of a typical marine oil terminal (image from Charles Scawthorn)........................... 160

95. Photograph of Los Angeles Fire department fireboat 2, the Warner L. Lawrence...

96. Map image showing a random "snapshot" of Ports of Los Angeles and Long Beach ship traffic-six tankers and 26 cargo vessels are inside the breakwater

\section{Tables}

2. Port of Long Beach container terminal throughput values.

3. Port of Long Beach dry bulk summary.

8. Port of Los Angeles liquid bulk summary. ..................................................................................... 37

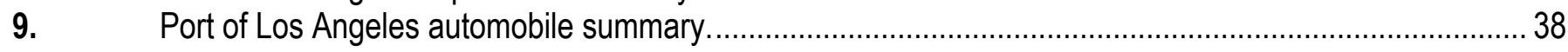

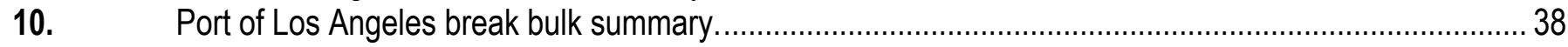

11. Port of Los Angeles marinas and small craft slips........................................................................ 39

12. Assigning damage value to the Port of Long Beach and Port of Los Angeles...................................... 44

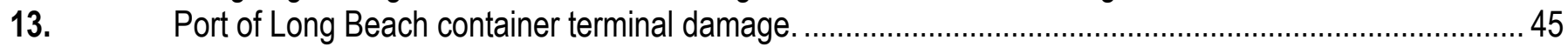

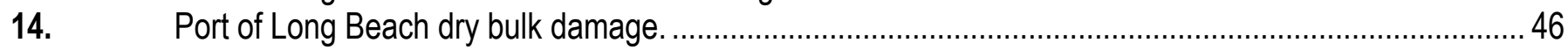

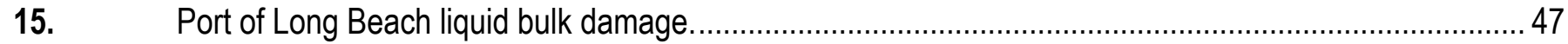

16. Port of Long Beach break bulk damage. ..................................................................................... 48

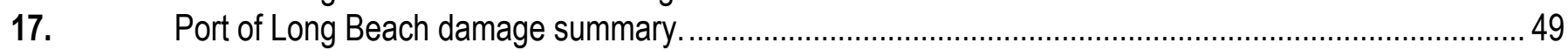

18. Port of Los Angeles container terminal damage. ....................................................................... 50 


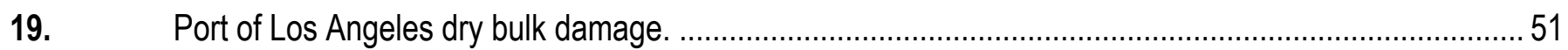

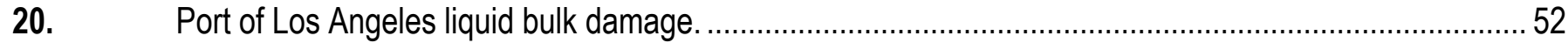

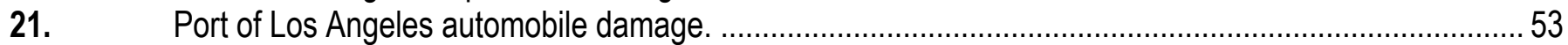

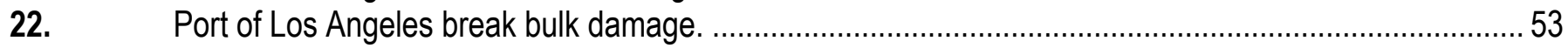

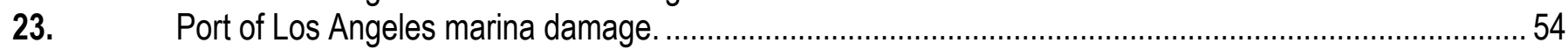

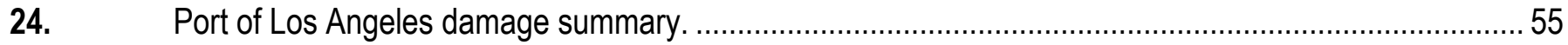

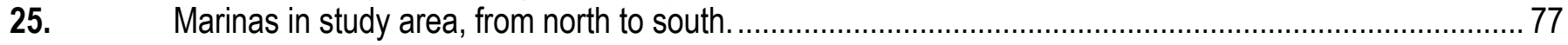

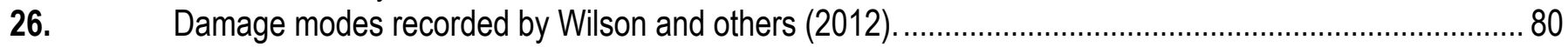

27. Building damage in the SAFRR tsunami scenario. ..................................................................... 100

28. Building and content value in California Governor's Office of Emergency Services' (Cal OES)

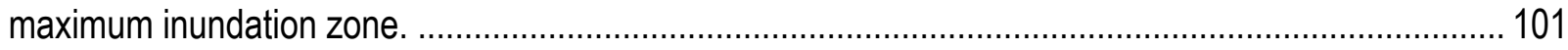

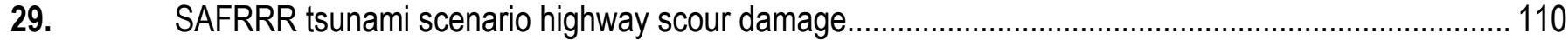

30. SAFRRR tsunami scenario bridge embankment scour damage................................................... 111

31. Tide gages near several coastal stretches of railway................................................................ 122

32. County-level distribution of agricultural land in the SAFRR tsunami scenario inundation zone............. 132

33. Selected agricultural (HAZUS-MH AGR1) building loss statistics in the SAFRR tsunami

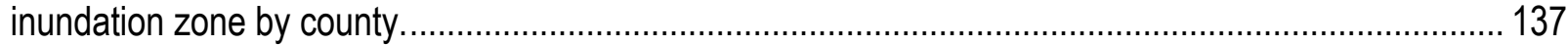

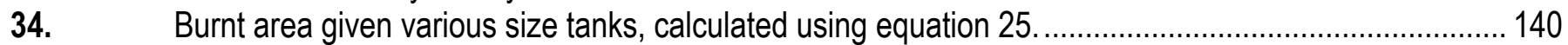

35. Summary findings for California petroleum facilities for fire following tsunami in the SAFRR tsunami scenario. 


\title{
The SAFRR Tsunami Scenario-Physical Damage in California
}

By Keith Porter, ${ }^{1}$ William Byers, ${ }^{2}$ David Dykstra, ${ }^{3}$ Amy Lim,${ }^{3}$ Patrick Lynett, ${ }^{4}$ Jamie Ratliff, ${ }^{5}$ Charles Scawthorn, ${ }^{6}$ Anne Wein, ${ }^{5}$ and Rick Wilson ${ }^{7}$

\section{Introduction-Chapter Objectives}

\author{
By Keith Porter
}

This chapter attempts to depict a single realistic outcome of the SAFRR (Science Application for Risk Reduction) tsunami scenario in terms of physical damage to and recovery of various aspects of the built environment in California. As described elsewhere in this report, the tsunami is generated by a hypothetical magnitude 9.1 earthquake seaward of the Alaska Peninsula on the Semidi Sector of the Alaska-Aleutian Subduction Zone, 495 miles southwest of Anchorage, at 11:50 a.m. Pacific Daylight Time (PDT) on Thursday March 27, 2014, and arriving at the California coast between 4:00 and 5:40 p.m. (depending on location) the same day. Although other tsunamis could have locally greater impact, this source represents a substantial threat to the state as a whole.

One purpose of this chapter is to help operators and users of coastal assets throughout California to develop emergency plans to respond to a real tsunami. Another is to identify ways that operators or owners of these assets can think through options for reducing damage before a future tsunami. A third is to inform the economic analyses for the SAFRR tsunami scenario. And a fourth is to identify research needs to better understand the possible consequences of a tsunami on these assets. The asset classes considered here include the following:

- Piers, cargo, buildings, and other assets at the Ports of Los Angeles and Long Beach

- Large vessels in the Ports of Los Angeles and Long Beach

- Marinas and small craft

- Coastal buildings

- Roads and roadway bridges

- Rail, railway bridges, and rolling stock

- Agriculture

\footnotetext{
${ }^{1}$ University of Colorado at Boulder and SPA Risk LLC.

${ }^{2}$ Private consultant.

${ }^{3}$ Moffatt and Nichol Engineers.

${ }^{4}$ University of Southern California.

${ }^{5}$ U.S. Geological Survey.

${ }^{6}$ SPA Risk LLC.

${ }^{7}$ California Geological Survey.
} 
- Fire following tsunami

Each asset class is examined in a subsection of this chapter. In each subsection, we generally attempt to offer a historical review of damage. We characterize and quantify the assets exposed to loss and describe the modes of damage that have been observed in past tsunamis or are otherwise deemed likely to occur in the SAFRR tsunami scenario. Where practical, we offer a mathematical model of the damageability of assets exposed to loss. Then, applying the damageability model and the velocity, wave amplitude, and inundation models discussed in other SAFRR chapters we offer a single realistic depiction of damage. Other outcomes are of course possible for this hypothetical event. Where practical we estimate repair costs and estimate the duration required to restore the assets to their pre-tsunami condition. We identify opportunities to enhance the resiliency of the assets, either through making them less vulnerable to damage or able to recover more quickly in spite of the damage.

Finally, we identify uncertainties in the modeling where research would improve our understanding of the underlying mechanisms of damage and loss or otherwise improve our ability to estimate the future impacts of tsunamis and inform risk-management decisions for tsunamis. However, it is certain that the kinds of damages discussed here have occurred in past tsunamis, even in developed nations, and in a sufficiently large event, will occur in California. Our uncertainties can operate in either direction, either leading to an overestimate of damage or an underestimate. Therefore, losses in an actual future tsunami could be greater than depicted here. Furthermore this evaluation is not intended to be an exhaustive depiction of what could happen in this or similar tsunamis. Other impacts could occur that are not presented here.

\title{
Damage and Restoration of the Ports of Los Angeles and Long Beach
}

\author{
By David Dkystra, Amy Lim, and Keith Porter
}

\section{Introduction}

\section{Background}

The purpose of this section is to provide a detailed estimate of tsunami impacts in the Ports of Los Angeles and Long Beach (POLA/POLB) and a more general assessment of potential damage to other ports and harbors along the California coast. The detailed assessment of impacts to POLA/POLB is an engineering evaluation of the impacts to vessels and port structures, along with the resulting supply-chain impacts.

For the purposes of estimating the impacts to POLA/POLB, it is assumed that vessel traffic and cargo inventories are as indicated in the Google Earth image dated March 7, 2011. The engineering evaluation presented in this section includes an estimate of physical impacts to the ports, damage costs, repair activities, other restoration activities, and resilience strategies. The impacts to shipping and infrastructure are based on conditions illustrated in the March 7, 2011, Google Earth image.

\section{Historical Tsunami Events at the Ports of Los Angeles and Long Beach}

Prior to evaluating potential tsunami damage to POLA/POLB from the SAFRR scenario, it is useful to review the impacts associated with historical tsunamis. Although these historical 
events are not necessarily equivalent to the SAFRR scenario, they do help inform the process of evaluating the potential damage from the proposed scenario based on engineers' experiences during the events. Over the years, there have been measurements of significant water level fluctuations in the ports related to distant tsunamis from sources located in Alaska and Chile. Although tsunamis were generated from other sources, such as the 2004 Sumatra earthquake and 2011 Tohoku earthquake, these events did not generate significant water level fluctuations in POLA/POLB. The significant historical events include the following:

- 1922 Chilean tsunami

- 1946 Aleutian tsunami

- 1960 Chilean tsunami

- 1964 Alaskan tsunami

- 2010 Chilean tsunami

These events and their associated seismic moments are summarized in table 1.The basic data for these tsunamis in Southern California are available from Wilson (1971), Raichlen (1972), Berkman and Symons (1964), and Spaeth and Berkman (1967). Note that because of the magnitude, proximity, and directionality of the tsunami scenario, effects in the Ports of Los Angeles and Long Beach from this tsunami would be greater than in these past events.

An example of the tide gage records (marigrams) during the 1960 and 1964 events is presented in figure 1. The initial wave heights, as measured from peak to trough, reached as high as approximately 4.5 feet (ft) for the 1960 and 1964 tsunamis, as shown. It should be noted that the configuration of the harbor has changed over the years compared with what exists today in both ports, but the tsunami response has remained consistent over time and over varying locations within the Ports (Moffatt and Nichol, 2007).

It is significant to note that tsunamis generated by distant seismic sources other than those listed above for Alaska and Chile do not produce inland inundation in southern California during the 20th Century. The most recent major 2011 Tohoku earthquake and tsunami in Japan produced measured water level fluctuations on the order of 1 to $2 \mathrm{ft}$. The 2004 Sumatra earthquake and tsunami produced wave heights on the order of inches in POLA/POLB. There was no reported damage to any port facilities in either of these events.

On the basis of discussions with engineers from POLA/POLB and review of available literature, the only historical tsunamis to generate significant damage were the 1960 Chilean and 1964 Alaskan tsunamis. A Los Angeles Times articles at of 1960 suggests approximately \$1 million worth of damage and two deaths. The damage was limited to a small craft harbor area along the Cerritos Channel where strong currents damaged boats, floating docks, and guide piles. There was no impact to port facilities or infrastructure during the 1960 Chilean tsunami or any of the other tsunamis. During the 1964 Alaska tsunami, 100 boats were unmoored and six were sunk (Lander and others, 1993). During the most recent tsunami from the 2010 Chilean tsunami, port operations and vessel navigation were halted as a result of the advanced tsunami warning. Strong currents were observed by the port pilots in some of the constricted channels. The currents persisted for several days, making navigation somewhat more difficult.

It should be noted that the port facilities at Los Angeles and Long Beach are extensively engineered and continually upgraded to conform to the latest codes, including increased seismic considerations. The facilities are also being continuously modified to provide efficient handling of cargo, increasing vessel traffic, and increasing vessel sizes. The improvements include the breakwaters, jetties, shoreline revetments, channel protections, and wharves. These continued improvements contribute toward minimizing risk of damage during tsunami events. 
Table 1. Historical seismic events with tsunamis in the Ports of Los Angeles and Long Beach.

$\left[M_{w}\right.$, moment magnitude]

\begin{tabular}{llll}
\multicolumn{1}{c}{ Source } & \multicolumn{1}{c}{ Date } & Magnitude $M_{W}$ \\
\hline Chile & November 10, 1922 & 8.5 & \\
Aleutian Trench & April 1, 1946 & 8.1 \\
Chile & May 23, 1960 & 9.5 \\
Alaska & March 28, 1964 & 9.2 \\
Chile & February 27, 2010 & 8.8 \\
\hline
\end{tabular}

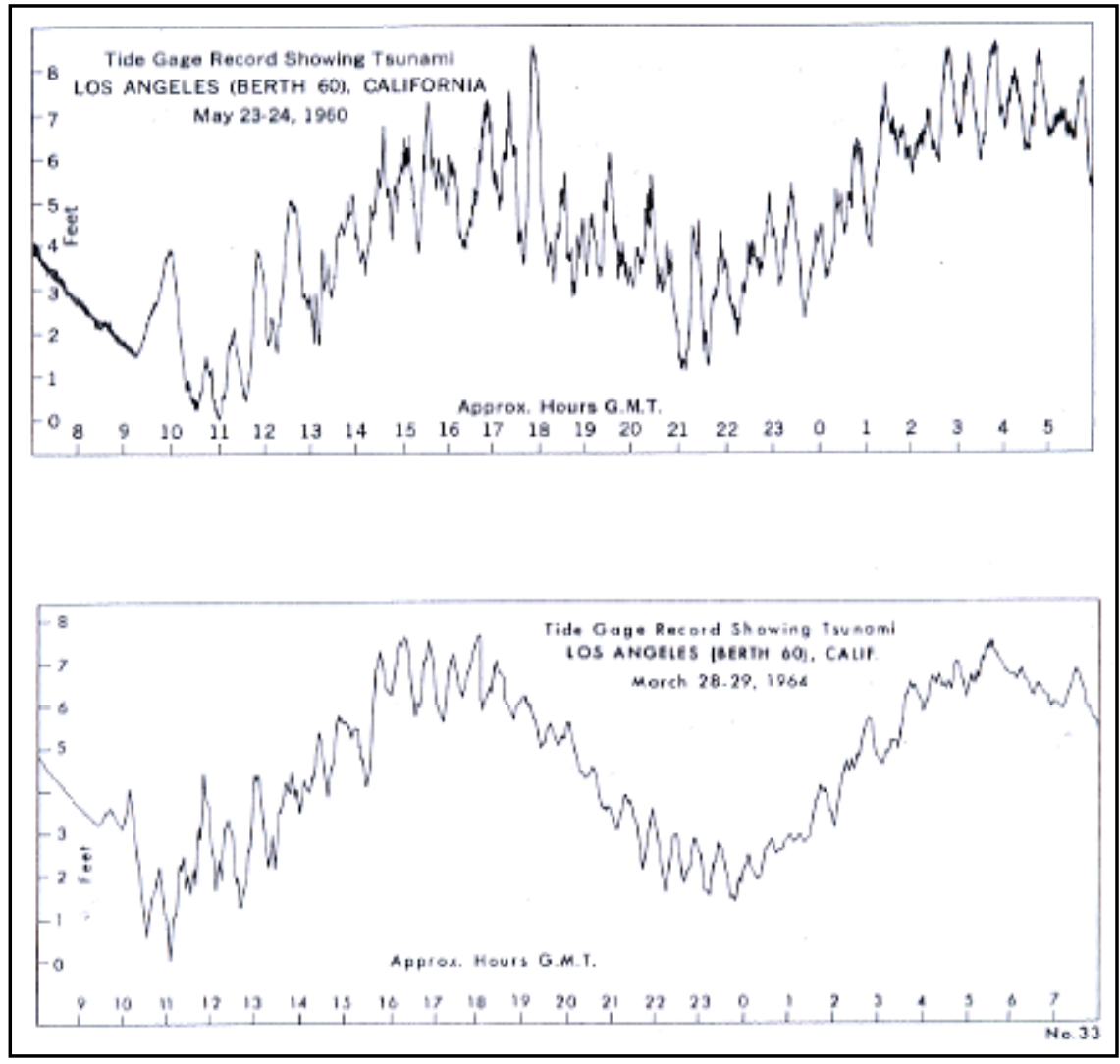

Figure 1. Tide gage records at Port of Los Angeles Berth 60 for the 1960 Chilean Tsunami and the 1964 Alaskan Tsunami (image from U.S. Coast and Geodetic Survey).

\section{Damage and Restoration of Similar Ports During Tsunamis}

Over the past decade, there have been three devastating tsunamis around the world: the 2004 Sumatra tsunami, the 2010 Chilean tsunami, and the 2011 Tohoku, Japan tsunami.

Following each of these tsunamis, many reconnaissance teams representing the engineering community were sent to review the damage at impacted sites and to learn about port design implications (American Society of Civil Engineers (ASCE), Coasts, Oceans, Ports, and Rivers Institute, (COPRI), 2005, 2010, and ASCE, Technical Council on Lifeline Earthquake Engineering (TCLEE), 2011). In addition, there is a PIANC (World Association for Waterborne Transport Infrastructure) Working Group 53 preparing a report on tsunami disasters in ports (PIANC, 2009). The reports from these reconnaissance teams and PIANC participants have provided a wealth of information on possible port damage mechanisms. In addition, several Moffatt and Nichol (M\&N) personnel have participated in these reconnaissance teams and have 
provided personal observations. The discussion in this section summarizes some of the damage mechanisms that have occurred in port facilities around the world during these most recent tsunami events. Not all these damage mechanisms are necessarily applicable to the ports.

The three most recent tsunami events created the most damage near the coastline immediately adjacent to the seismic source. There was very little advance warning other than ground shaking during the earthquakes. The lack of warning time increased the vulnerability of nearby ports since there was little time to prepare or evacuate. Although southern California is a seismically active zone, the faults are predominantly strike slip faults, which are much less likely to generate major tsunamis compared to the subduction zone faults of the most recent extreme tsunamis. Earthquakes on these faults could still generate submarine landslides that could cause a large local tsunami with minimal warning time, but these events have a low occurrence probability. Thus, locally generated major tsunamis in southern California with the associated minimal warning time are unlikely.

It was also noted by the reconnaissance teams that port facilities that were well engineered generally fared better than older, or less well-maintained, ports. This was particularly evident in Chile and Japan where tsunami events are relatively common and building codes are geared toward minimizing both the seismic damage and resultant tsunami damage. For the case of both the Chile 2010 and the Tohoku, Japan tsunamis, it was noted that the bulk of the damage was related to the extreme tsunamis rather than failures from the seismic event. This suggests that most of the observed damage to the port facilities following these events was the result of the tsunamis.

\section{Damage To and Caused by Vessels}

The first class of port damage is related to vessels within the port, both navigating and moored vessels. The most commonly observed, and a dramatic phenomenon, is the displacement of vessels onto land by the rising water level and flooding. This requires substantial inundation exceeding the vessel draft. Examples of this type of damage are illustrated in figures 2 and 3. The Sumatra tsunami of 2004 deposited a dredge on a Sri Lankan wharf, damaging port buildings and other infrastructure (fig. 2). The vessel MV Glovis Mercury was deposited on a wharf in Sendai, shown in figure 3, damaging a crane and a port building. Removal of these vessels and repair to the facilities is typically on the order of a few months. Because of the shallow inundation depth and limited flooded area throughout POLA/POLB for the identified scenario, this damage mechanism is unlikely in the ports with the possible exception of small craft and floating debris. 


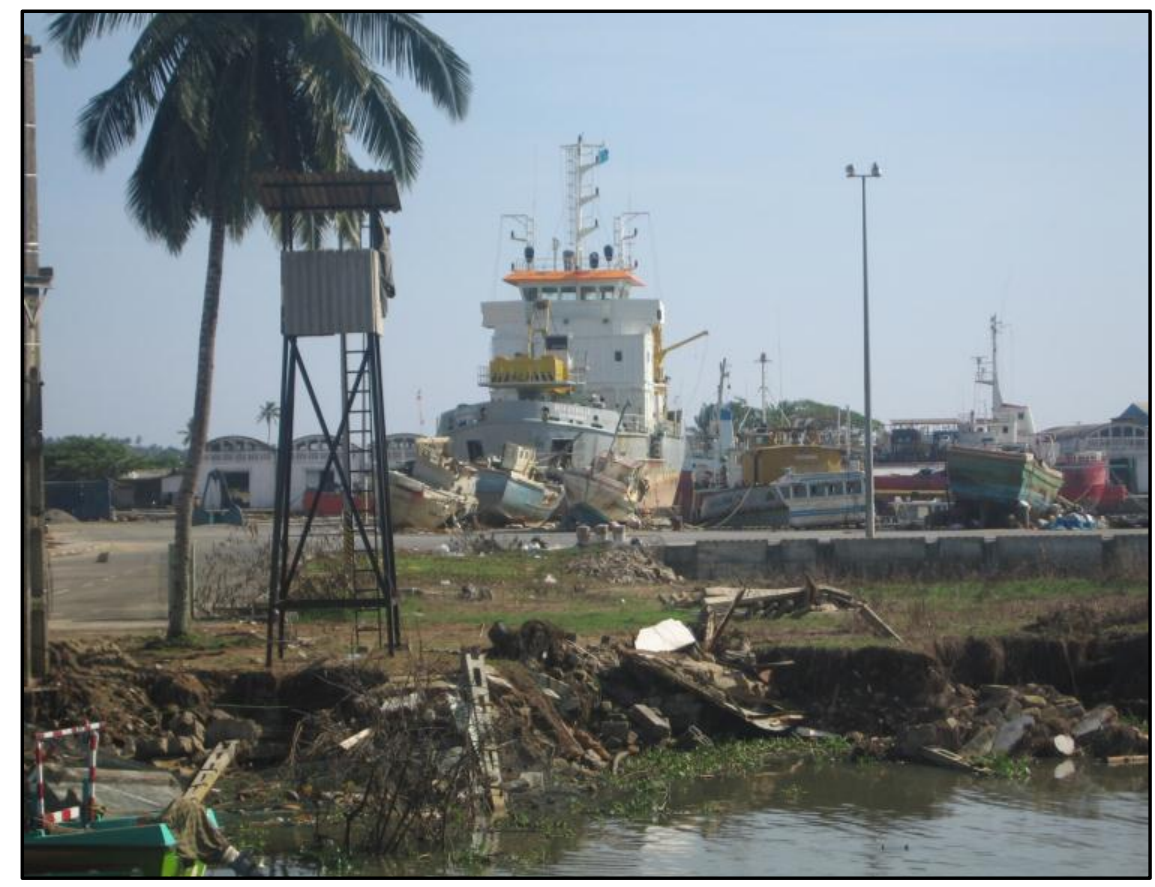

Figure 2. Photograph of Sri Lanka Port of Galle dredge grounded on wharf by a 5.3-meter tsunami wave during the 2004 Sumatra tsunami (photograph from American Society of Civil Engineers, Coasts, Oceans, Ports, and Rivers Institute, 2005).

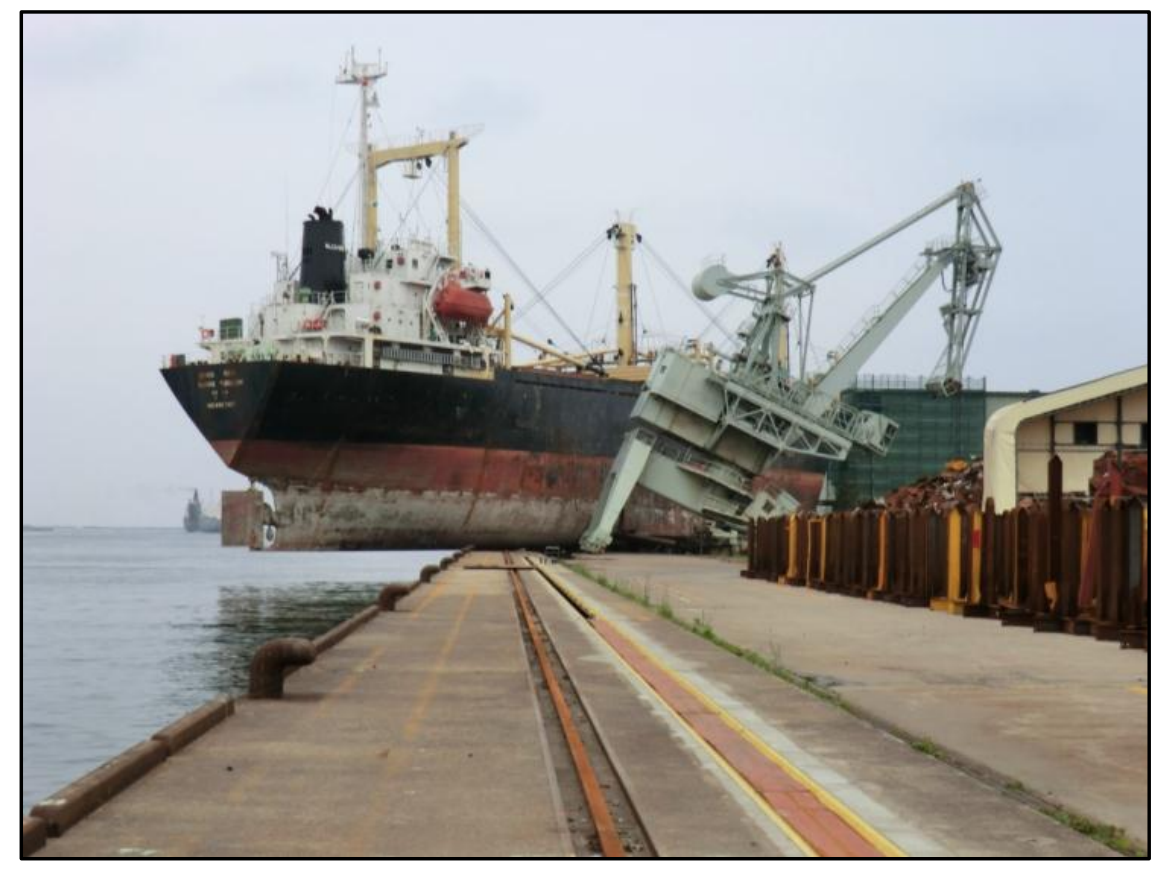

Figure 3. Photograph of MV Glovis Mercury displaced on top of wharf and damaged crane at Sendai Port, Japan, during 2011 Tohoku tsunami (photograph by Keith Porter). 
The strong currents associated with tsunami propagation through port areas makes navigation extremely difficult and can result in vessels striking breakwaters and other port structures. If the vessels are damaged and sink within main shipping channels or harbor entrances, all vessel traffic will be halted until the channel is cleared. This type of vulnerability is illustrated in figures 4 and 5. Clearing the channel would normally be on the order of weeks, depending on the availability of equipment to remove the vessels. Repair of wharves or similar structures will take longer. If the damage is to a breakwater or jetty, the damage may not be immediately necessary for maintaining operations. Headland and others (2006) conducted vessel-maneuvering simulations for POLA/POLB during a hypothetical tsunami event. Their conclusions suggested difficult, but manageable maneuvering through Angel's Gate during the peak currents of the hypothetical event.

Strong currents can also have the potential to damage the mooring components for the vessels within the harbor due to excessive current drag on the vessels. This results in broken mooring lines, wharf bollards, or, in more extreme cases, broken mooring dolphins. Once the vessel is essentially freely floating within the harbor, there is a danger of striking port facilities. This type of damage is illustrated in figures 6 through 8 . These examples are for the Port of Chennai, India as a result of the 2004 Sumatra tsunami. Despite the evident damage, the port was operating at significant capacity within days of the tsunami, because it is a fairly modern port. Vessels were rerouted to other undamaged berths and cleanup operations were optimized to restore minimally damaged facilities and reduce down time. Older, less well-engineered port facilities were reported to take significantly longer to return to capacity following the Chile 2010 tsunami.

In addition to current loads on moored vessels, there is evidence that vessels moving vertically due to the tsunami water level fluctuations can cause lines to part if the lines are not properly tended during the tsunami (Headland and others 2006). As the vessels rise with the water level, the lines become taut and potentially part.

Water level fluctuations within ports can persist for days following the initial arrival of the tsunami with consequent unpredictable high currents. The persistence of these erratic currents is of concern because there may be the possibility of harbor resonance with the tsunami wave and possible impacts to port operations sensitive to currents, such as container wharves where excessive vessel motion may produce hazardous conditions during crane placement of containers (PIANC, 2009). 


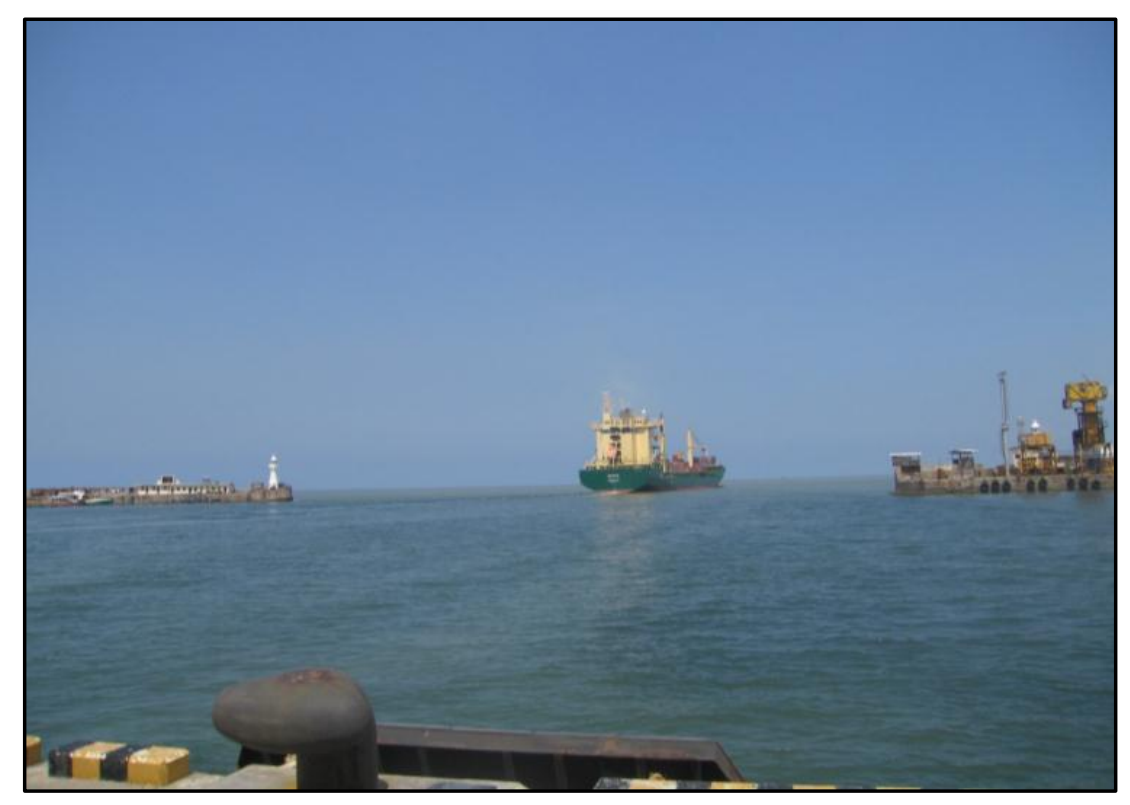

Figure 4. Photograph of Port of Colombo, Sri Lanka-A ship lost control in this entrance during the 2004 Sumatra Tsunami (photograph from American Society of Civil Engineers, Coasts, Oceans, Ports, and Rivers Institute, 2005).

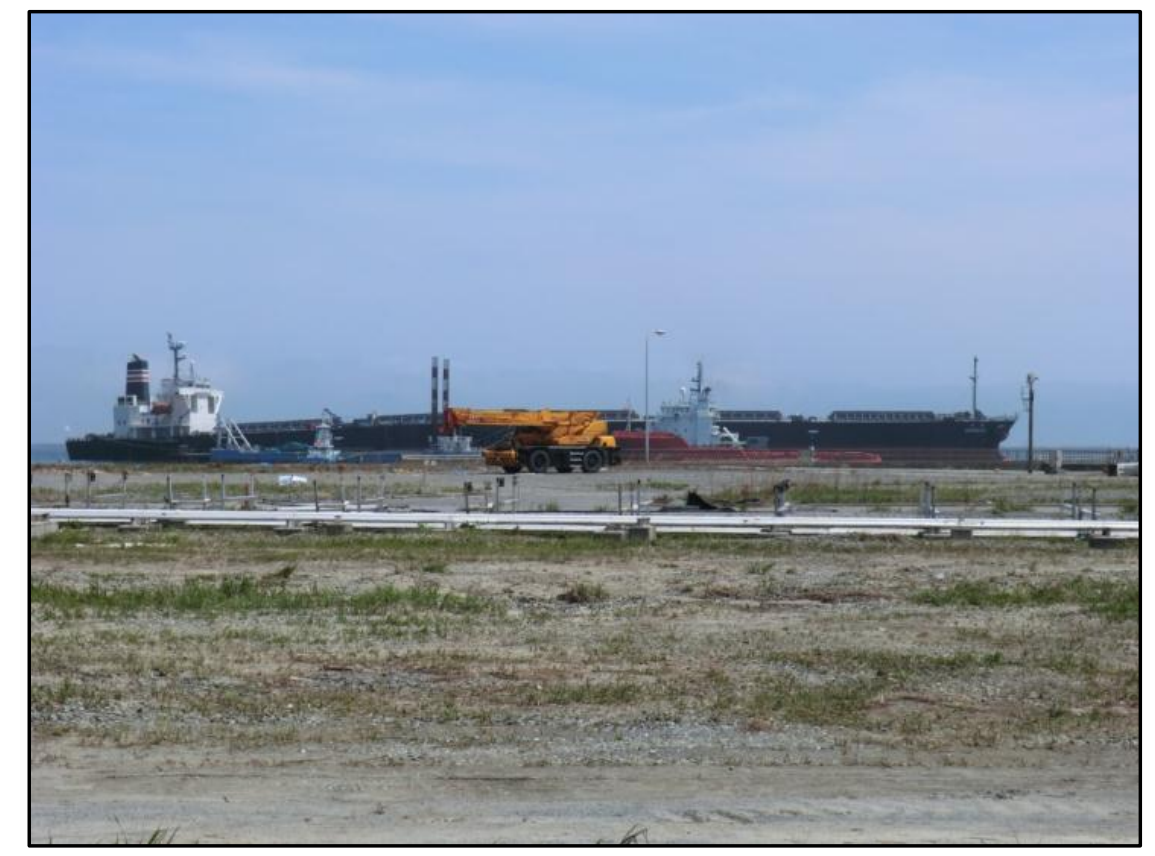

Figure 5. Photograph of broken back of coal carrier in navigation channel at Port of Shinchi, Japan, during the 2011 Tohoku tsunami (photograph by Keith Porter). 


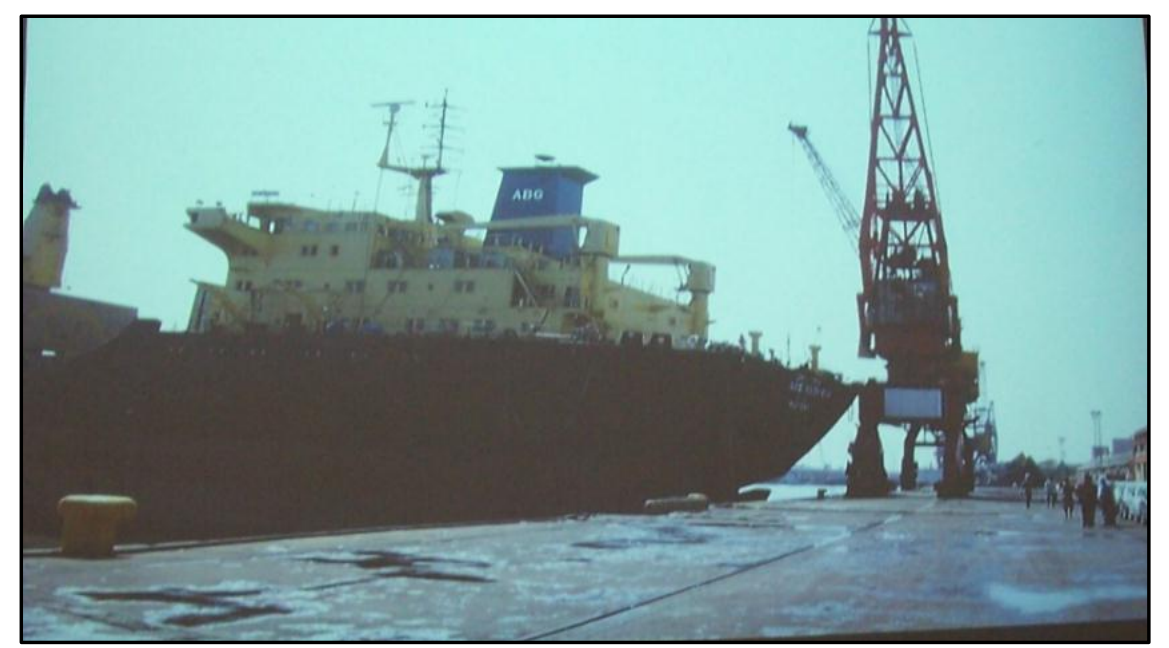

Figure 6. Photograph of Port of Chennai, India-Vessel hitting shore crane during the 2004 Sumatra Tsunami (photograph by Martin Eskijian).

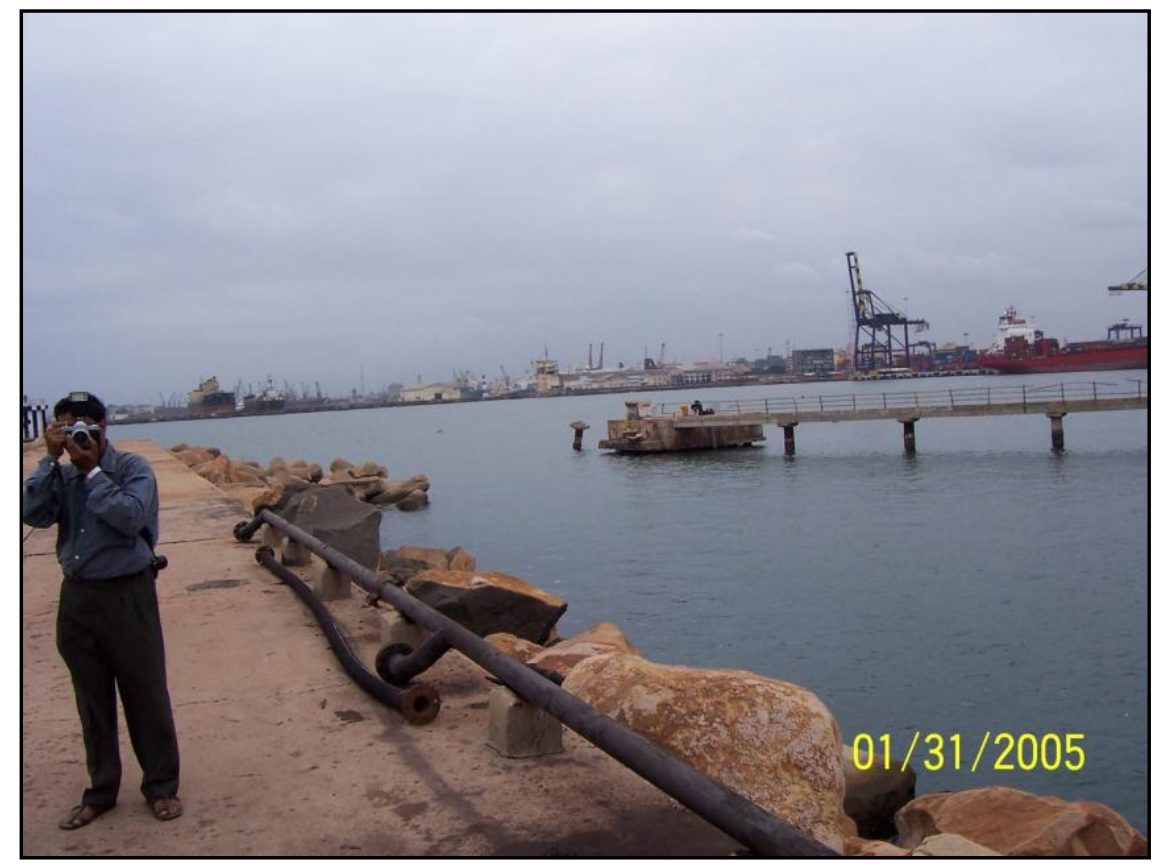

Figure 7. Photograph of Port of Chennai, India-two mooring dolphins missing after the 2004 Sumatra Tsunami (photograph by Martin Eskijian). 


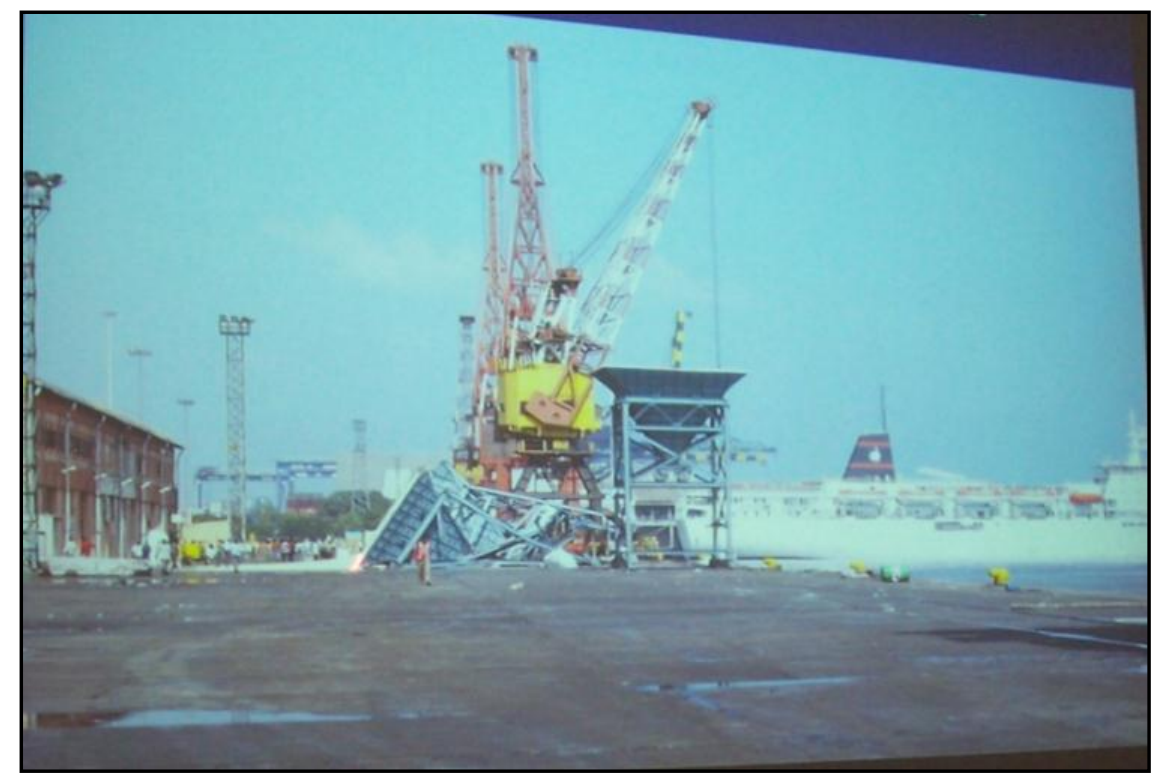

Figure 8. Photograph of hoppers destroyed by out of control vessel in Port of Chennai, India, during the 2004 Sumatra Tsunami (photograph by Martin Eskijian).

\section{Shoaling and Scour Caused by Currents}

The second class of damage is direct damage to port facilities and infrastructure from tsunami flooding. There is the potential for scour or shoaling due to substantial sediment movement during the tsunami. Sediment transport during the tsunami scenario, possibly resulting in scour or shoaling, was not simulated, but impacts can be significant. During the 2004 Sumatra tsunami, the Port of Galle in Sri Lanka experienced 2 meters (m) of shoaling within the harbor, which impacted vessel navigation within the port. A bathymetric survey would be required following the tsunami to identify this damage, which may not be immediately apparent. Either other viable channels would have to be identified or the port would be limited in operations. This could possibly be accommodated by restricting the draft of vessels accessing the port. The shoal material would have to be dredged prior to restoring normal port operations, which could take on the order of a few months depending on the availability of dredges.

The scour resulting from the high current speeds could also result in scour around the base of rock armored slopes or breakwater and impact the stability of these types of structures. Damage to the actual slope armor is illustrated in figure 9 during the Chile tsunami of 2010. This damage actually occurred on the lee side of the breakwater where the tsunami overtopped the breakwater. The armor units were displaced down slope toward the toe of the breakwater. These displaced armor units could impact navigation if they are within the navigation channel. Another example of a damaged armor revetment is illustrated in figure 10, where a seawall and adjacent road were damaged from the overtopping during the Chile tsunami of 2010. Typically, damaged breakwaters or armored revetments would not impact port operations following the tsunami because they would remain fairly functional. 


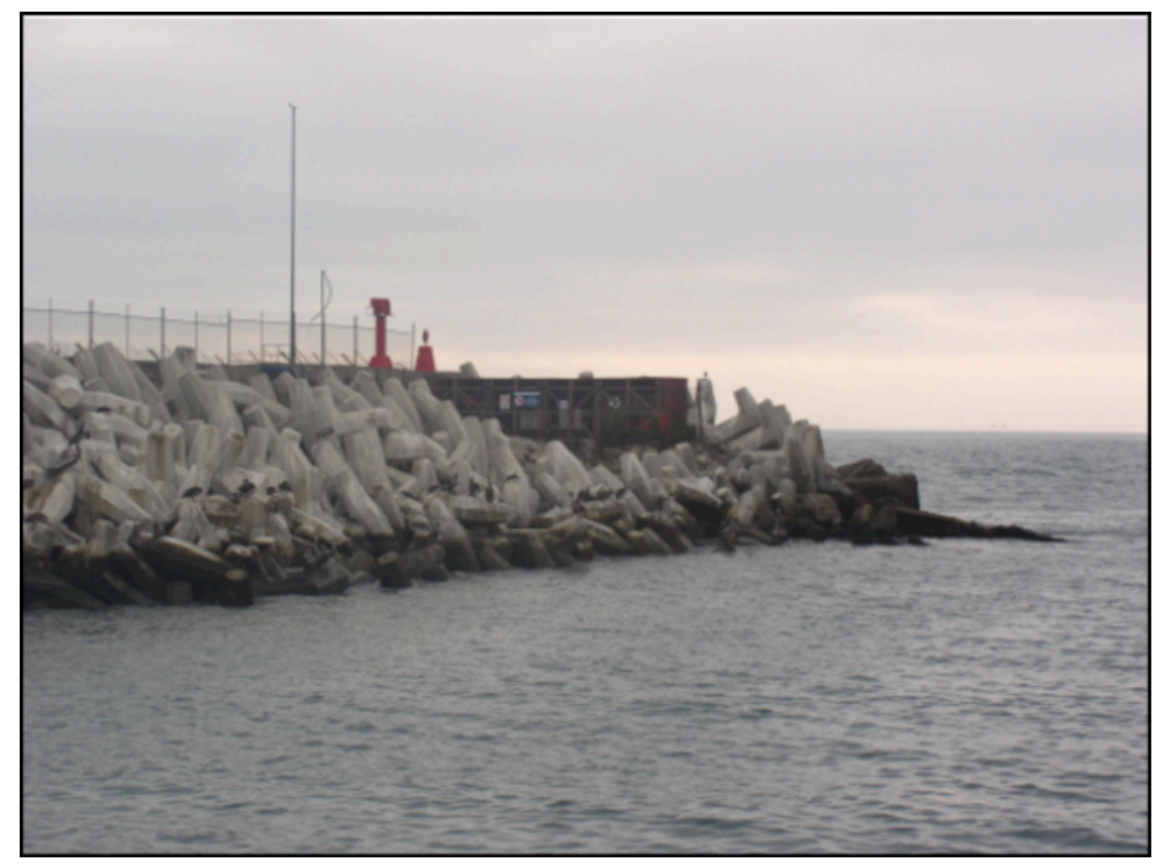

Figure 9. Photograph of breakwater damaged in Chile 2010 Tsunami (photograph from American Society of Civil Engineers, Coasts, Oceans, Ports, and Rivers Institute, 2005).

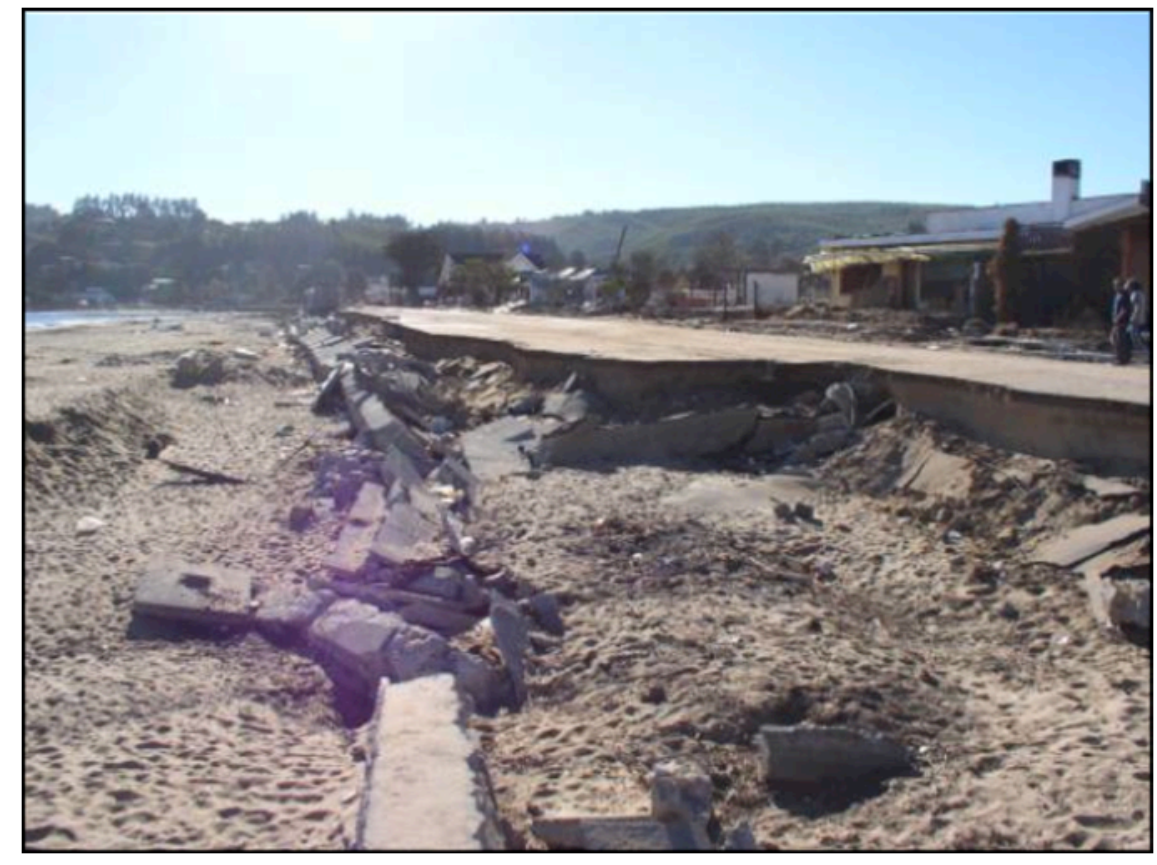

Figure 10. Photograph of seawall and road damaged in Chile Tsunami of 2010 (photograph from American Society of Civil Engineers, Coasts, Oceans, Ports, and Rivers Institute, 2005). 


\section{Deformation of Wharves, Cranes, and Cargo}

Tsunami damage to container wharves has also been observed at several ports. Displacement of the pile-supported wharf area relative to the backfilled land area is illustrated in figure $11 \mathrm{~A}$. The actual mechanism for this displacement is unclear, but it could be related to scour around the supporting piles, damage to the piles themselves, or excessive hydrostatic vertical load during the tsunami. It is possible that the displacement in this particular case at Port Blair was caused by seismic failure because the earthquake ground motions here were substantial. Container crane rails have also been misaligned, as illustrated in figure $11 B$, due to flow over the decks or pile damage from scour. The utility trenches and crane power supply trenches have been damaged by filling in with mud and debris, as illustrated in figure 12 .

There is a potential for empty containers to float off the container wharf if the inundation depth is great enough. These floating containers could cause damage to adjacent structures if currents are sufficiently high. In the case illustrated in figure 13 for the Port of Chennai, India, the flow depth was inadequate to displace the containers, as they were stacked sufficiently high. If full, it may be assumed that the contents of the bottom containers will be damaged beyond recovery. All impacts to containership facilities would likely take on the order of weeks to repair and restore operations. It should be noted that the cranes themselves were not damaged in Port Blair or the Port of Chennai, and were operational within days after the tsunami.

Container crane damage can occur if the motors are submerged during the tsunami. This damage potential is illustrated in figure 14. Container cranes can also be damaged by strong currents at the base, as illustrated in figure 15. These types of damage to the container cranes will take several months to repair and restore the container berths to operation. Break bulk cargo, such as steel, is less vulnerable to tsunami damage, as shown figure 16. 

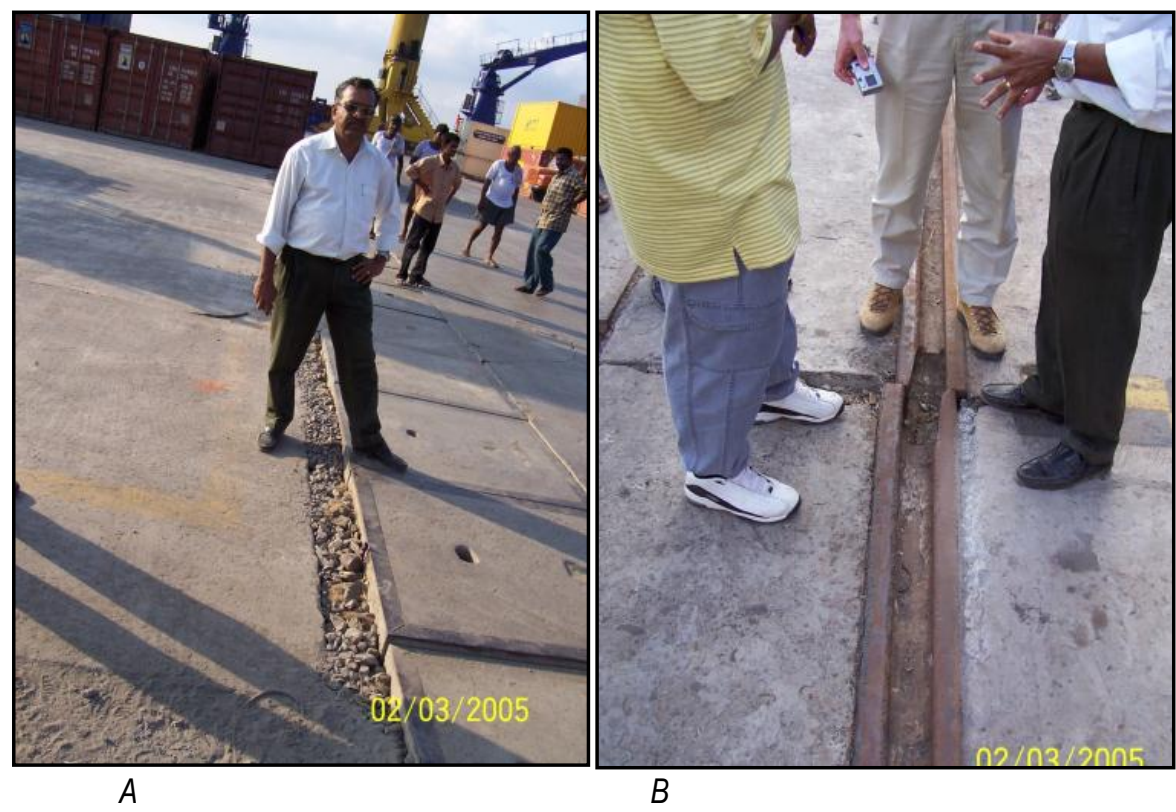

Figure 11. Photographs of damage from 2004 Sumatra Tsunami in Port Blair, India. A, Differential settlement between pile supported wharf and backfill area in Port Blair, India. $B$, Container crane rail misalignment. (Photographs by Martin Eskijian).

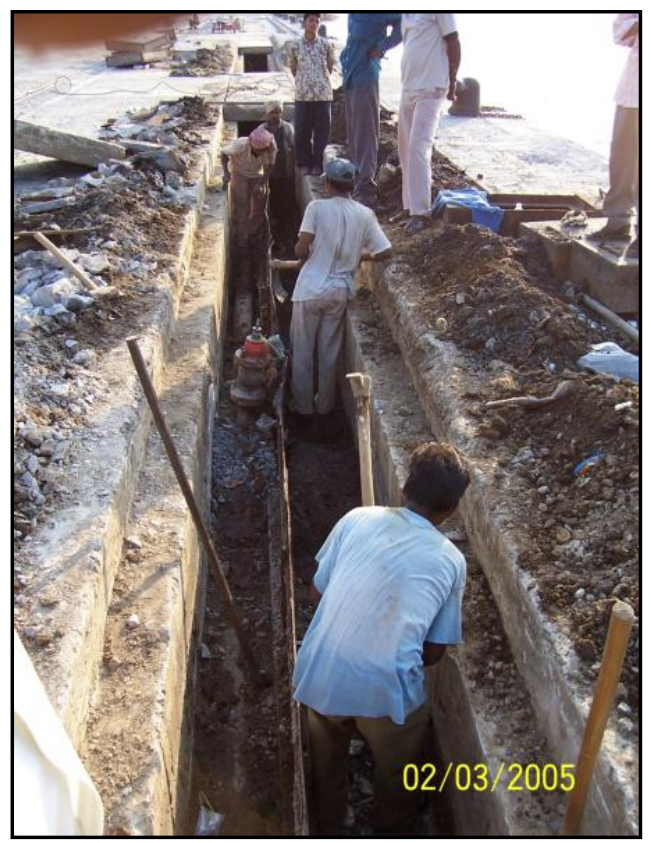

Figure 12. Photograph of utility and crane rail trench filled with debris and utilities damaged by the 2004 Sumatra Tsunami in Port Blair, India (photograph by Martin Eskijian). 


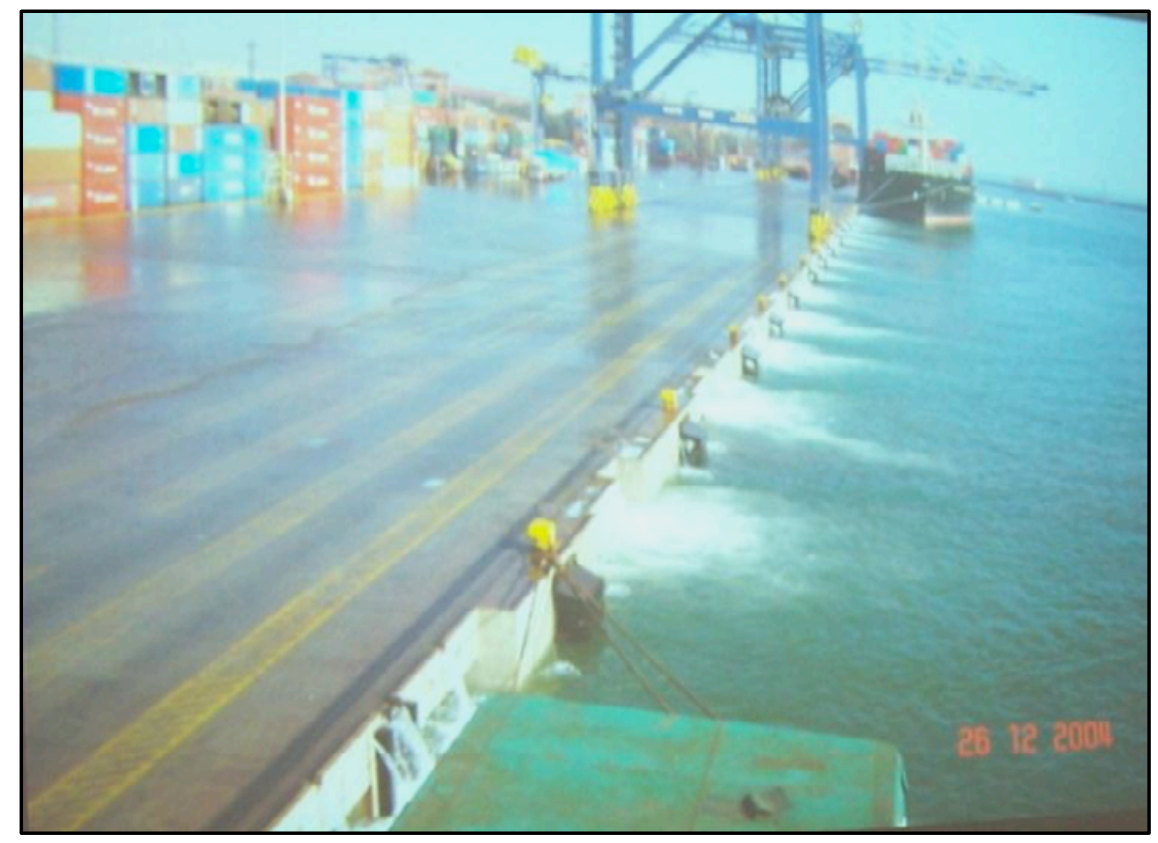

Figure 13. Photograph of flooding of container wharf at Port of Chennai, India, in the 2004 Sumatra Tsunami (4.1-meter tsunami wave) (photograph by Martin Eskijian).

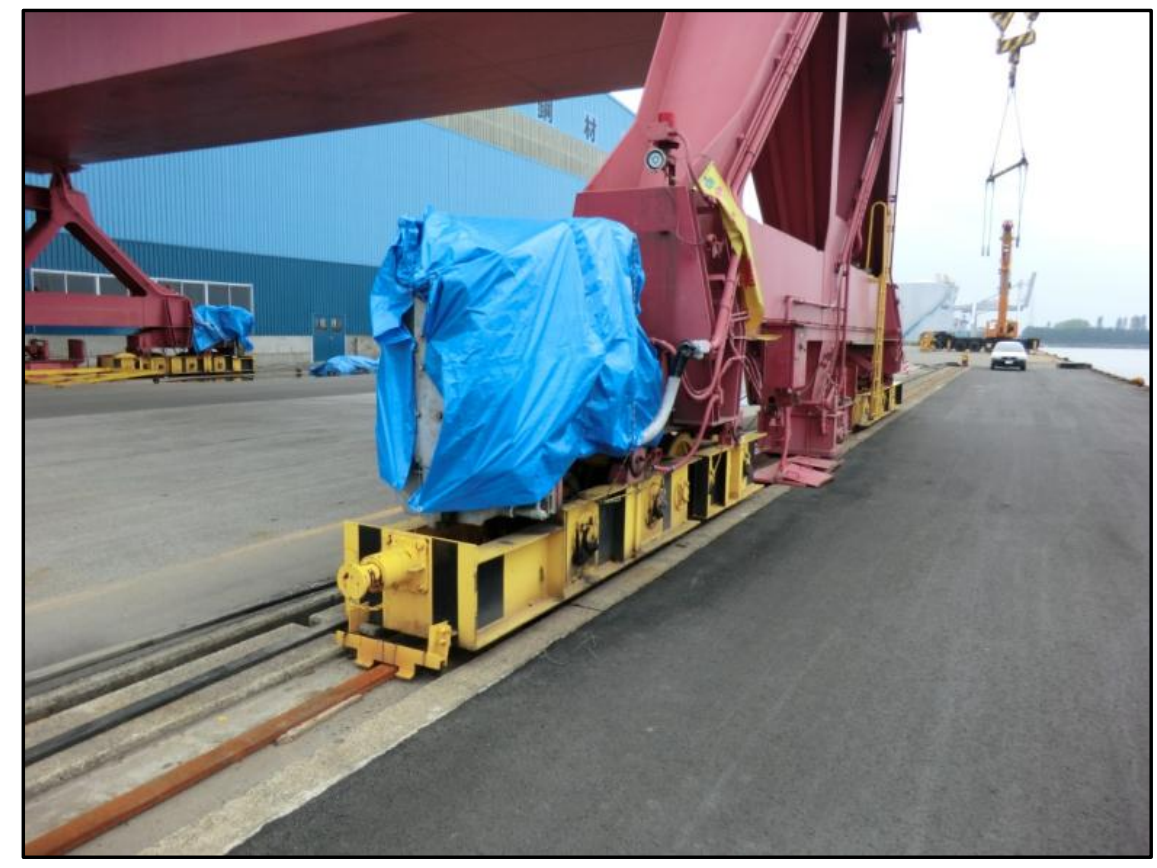

Figure 14. Photograph of damaged container crane motor in Port of Sendai, Japan, following the 2011 Tohoku tsunami (photograph by Keith Porter). 


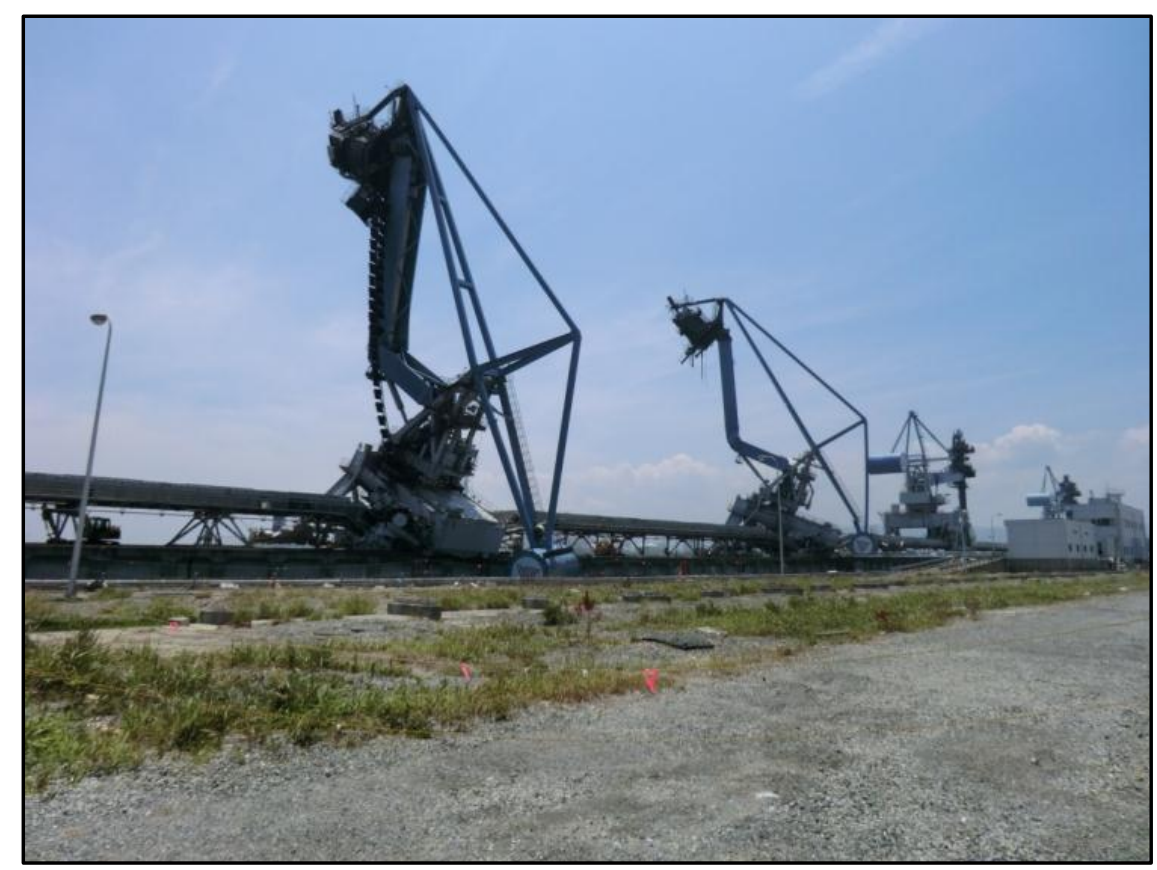

Figure 15. Photograph of container cranes collapsed due to tsunami current forces at Port of Shinchi, Japan, following the 2011 Tohoku tsunami (photograph by Keith Porter).

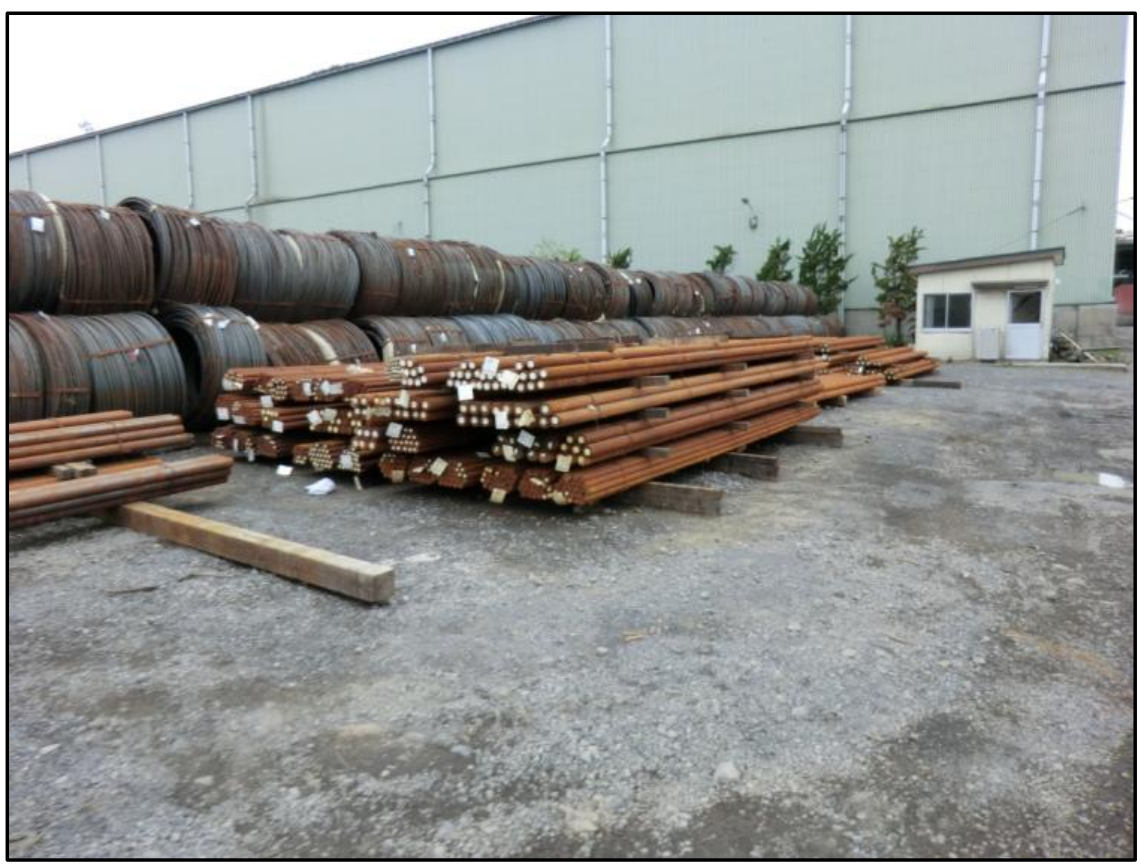

Figure 16. Photograph of undamaged steel at Port of Sendai, Japan, following the 2011 Tohoku tsunami (photograph by Keith Porter). 


\section{Warehouse Flooding and Current Loads}

Port warehouses adjacent to the waterfront may be damaged due to the flooding and current loads on the structures, as illustrated in figure 17. Floating debris, other than ships, such as vehicles, containers, and other equipment and structures can cause damage to otherwise undamaged facilities. Where there is warehouse damage, there is the possibility of igniting electrical fires. Where sheet pile walls exist within the ports, there is the possibility of damage to the walls from hydrostatic pressure from flooding, seafloor scour at the toe, and wave forces. Pier decks can be removed from the tops of the supporting piles, as shown in figure 18. This is likely due to wave uplift in conjunction with the high current speeds striking the side of the decks. Deck uplift with removal or damage can be significant if the tsunami wave period is short enough. For the case of the Chile tsunami of 2010, illustrated in figure 18, both mechanisms may have contributed because the tsunami event was a near field event, which typically contains shorter period waves than distant tsunami sources. Repair of these types of damage could take several months to a year. Tsunamis can flood cargo storage areas, wetting or floating vehicles and containerized cargo, as illustrated in figure 19.

\section{Damage to Liquid Bulk Terminals}

Liquid bulk terminals may be susceptible to damage by rupturing pipelines. For example, as illustrated in figure 20, the Tohoku tsunami "caused multiple breaks of pipelines and many small hydrocarbon leakages from pipe connections which ignited. In two places, releases of heavy oil $\left(4,400\right.$ and $3,900 \mathrm{~m}^{3}$, respectively) were triggered due to connected pipe breaking by the tsunami." (Kraussman and Cruz, 2013). Figure 21 shows how tsunami scour can undermine pipe supports. Tanks can be damaged by tsunami flows or debris, as shown in figure 22, and empty tanks can be floated away from their foundations, as illustrated in figure 23. These types of impacts could present significant environmental damage as the product is released into the flood waters and subsequently transported over a wide region.

California oil terminals are currently designed and maintained to the latest standards provided in Marine Oil Terminal Engineering and Maintenance Standards (MOTEMS) (California State Lands Commission, 2010) incorporated in the California Building Code. The MOTEMS requirements incorporate mechanisms for rapidly shutting down oil pipelines to minimize the risk of an oil spill during a seismic event. A similar approach would be used during a tsunami event.

Current practice within most ports of the world and specifically California is to construct a containment dike or wall around tank farms and pipelines. These containment dikes are designed to retain any leakage within the designated area, but could also easily be designed to be of sufficient height to reduce or eliminate tsunami overtopping. The tank farms within the ports are all contained within dikes or walls, which would reduce or eliminate the potential for floating tanks and damaging pipelines.

\section{Damage to Port Rail Facilities}

Many modern ports include trains for transporting goods from the port facilities. There is the potential for train rails to be damaged similarly to container crane rails. Where rail bridges are included, there is the potential for the rail decks to be removed similarly to open piers, as illustrated in figure 24 . Where rail links are crucial to port operations, this type of damage could 
result in significant downtime to the port following the tsunami because damage repair would likely be on the order of a few months. Rail is addressed more broadly elsewhere in this chapter.

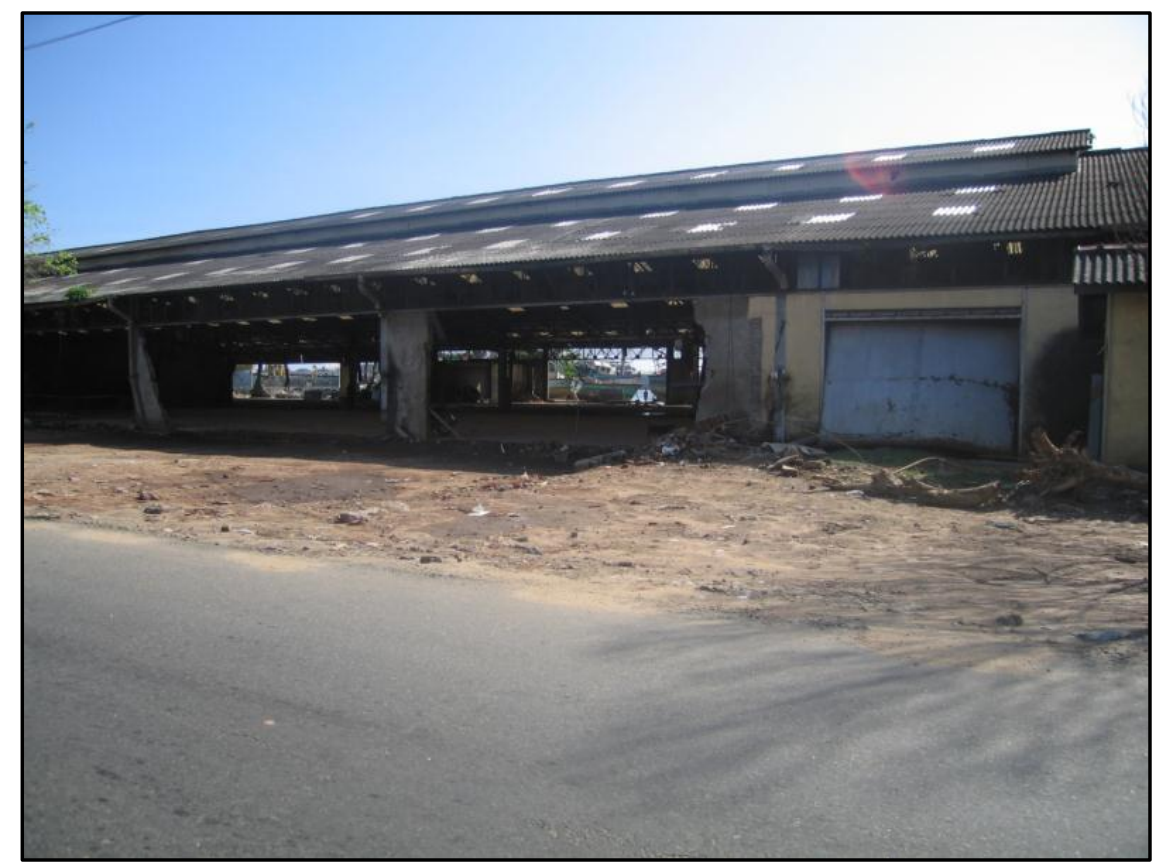

Figure 17. Photograph of Sri Lankan Port of Galle warehouse damage during 2004 Sumatra Tsunami (photograph from American Society of Civil Engineers, Coasts, Oceans, Ports, and Rivers Institute, 2005).

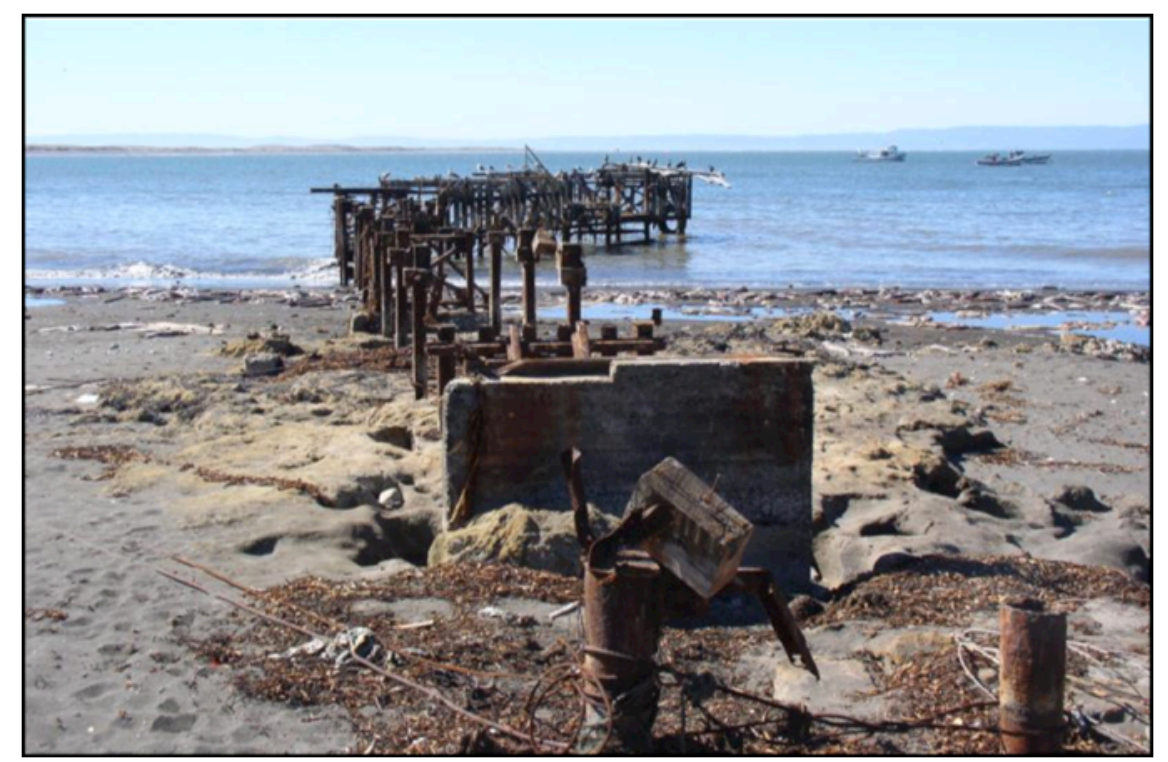

Figure 18. Photograph of pier deck removed in Chile Tsunami of 2010 (photograph from American Society of Civil Engineers, Coasts, Oceans, Ports, and Rivers Institute, 2010). 

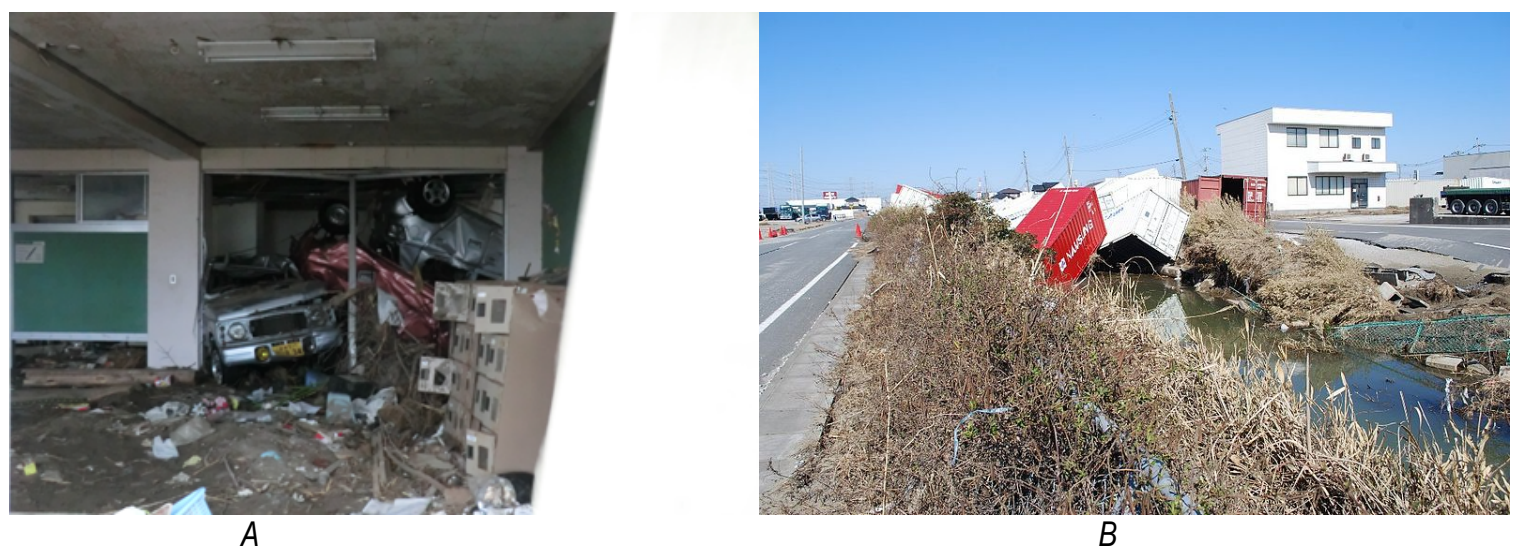

Figure 19. Photographs of damage by the 2011 Tohoku, Japan, tsunami. $A$, Cars floated into a building by the 2011 Tohoku tsunami (photograph by Keith Porter). B, Cargo containers in Kashima after the 2011 Tohoku tsunami (photograph from Wikimedia Commons).

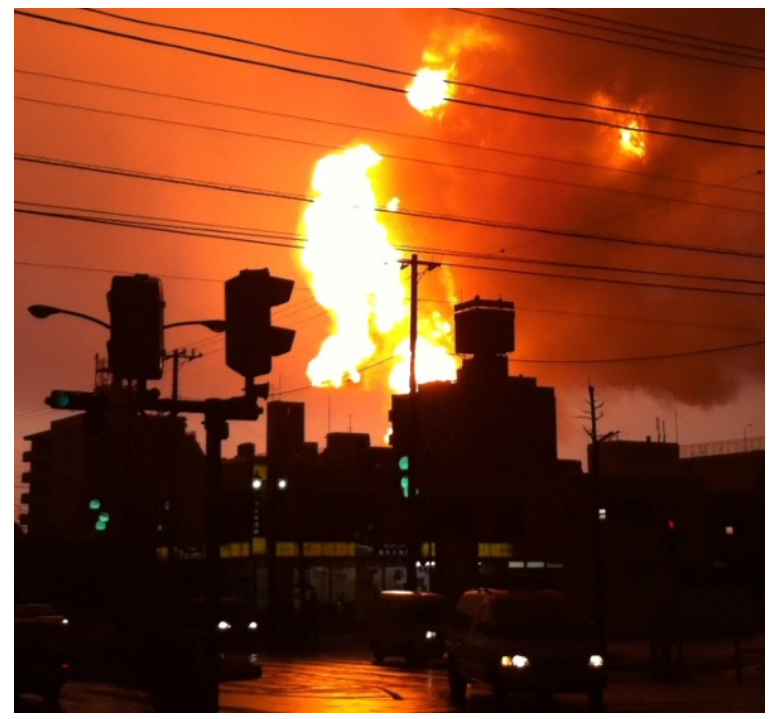

Figure 20. Photograph of a fire at the Cosmo Oil Refinery in Ichihara after the 2011 Tohoku, Japan, tsunami (photograph from Wikimedia Commons). 


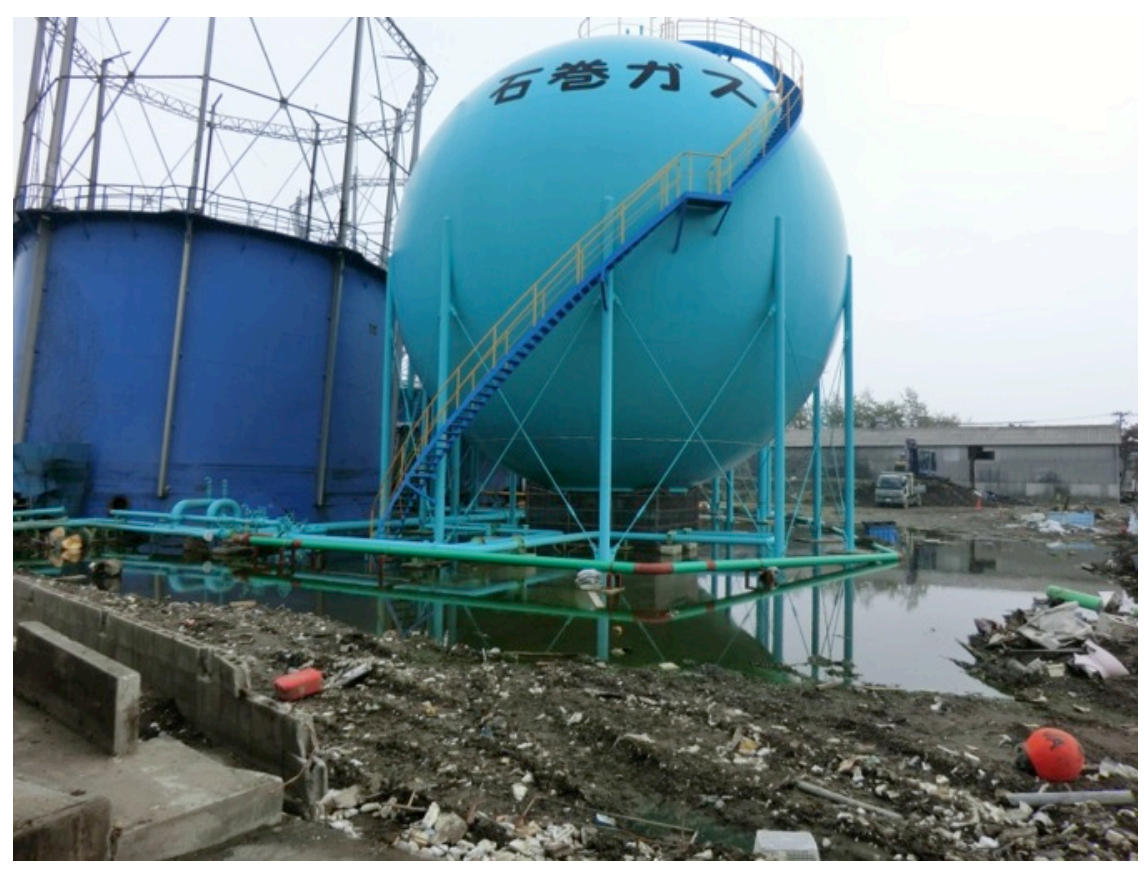

Figure 21. Photograph of pipes whose supports seem to have been undermined by tsunami scour in Ishinomaki, Japan, after the 2011 Tohoku tsunami (photograph by Keith Porter).

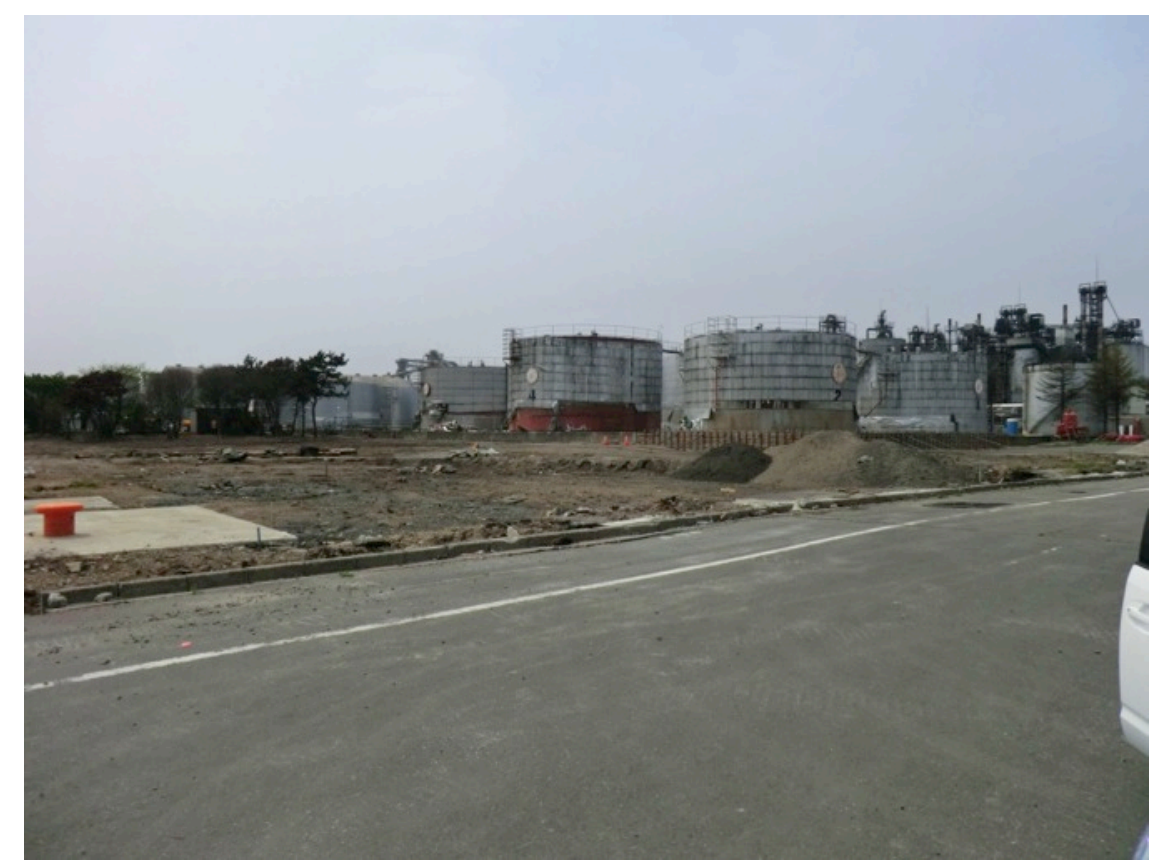

Figure 22. Photograph of tsunami-damaged tanks in Ishinomaki, Japan, after the Tohoku 2011 tsunami (photograph by Keith Porter). 


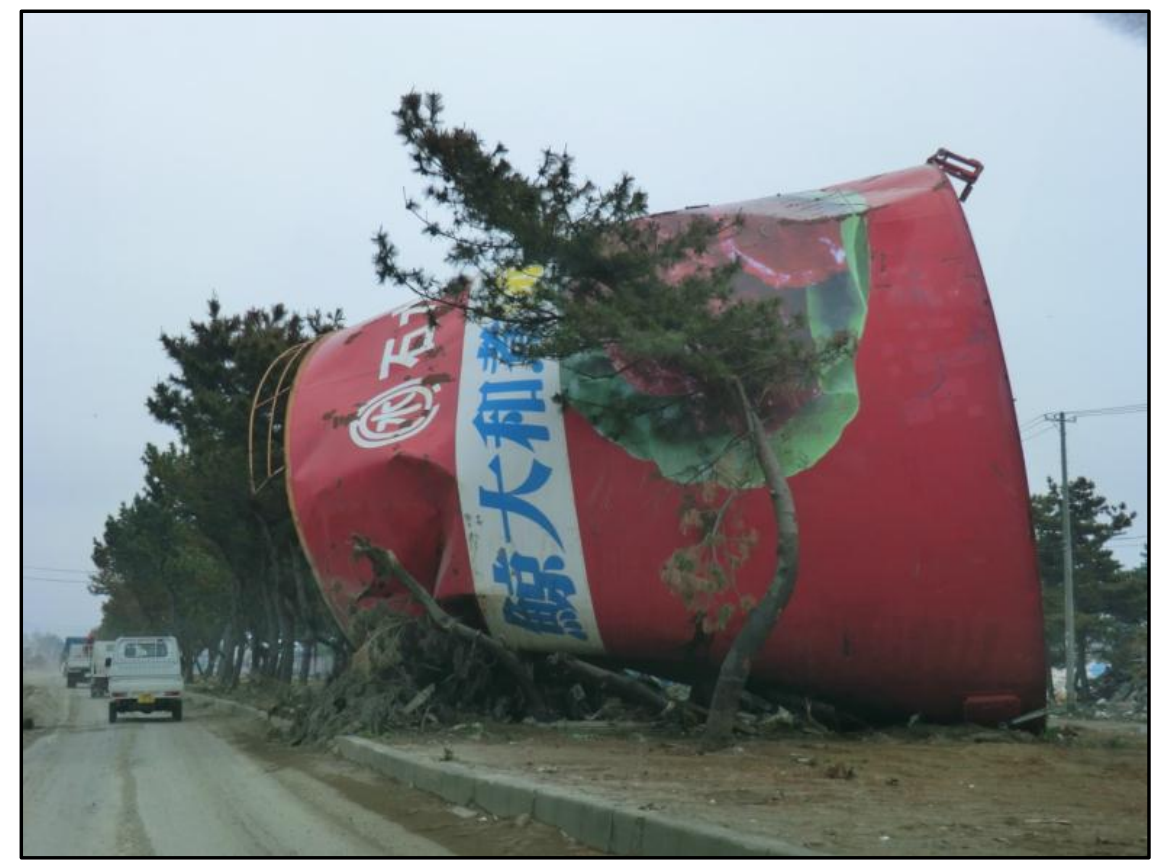

Figure 23. Photograph of tank floated off its foundation during the 2011 Tohoku, Japan, tsunami (photograph by Keith Porter).

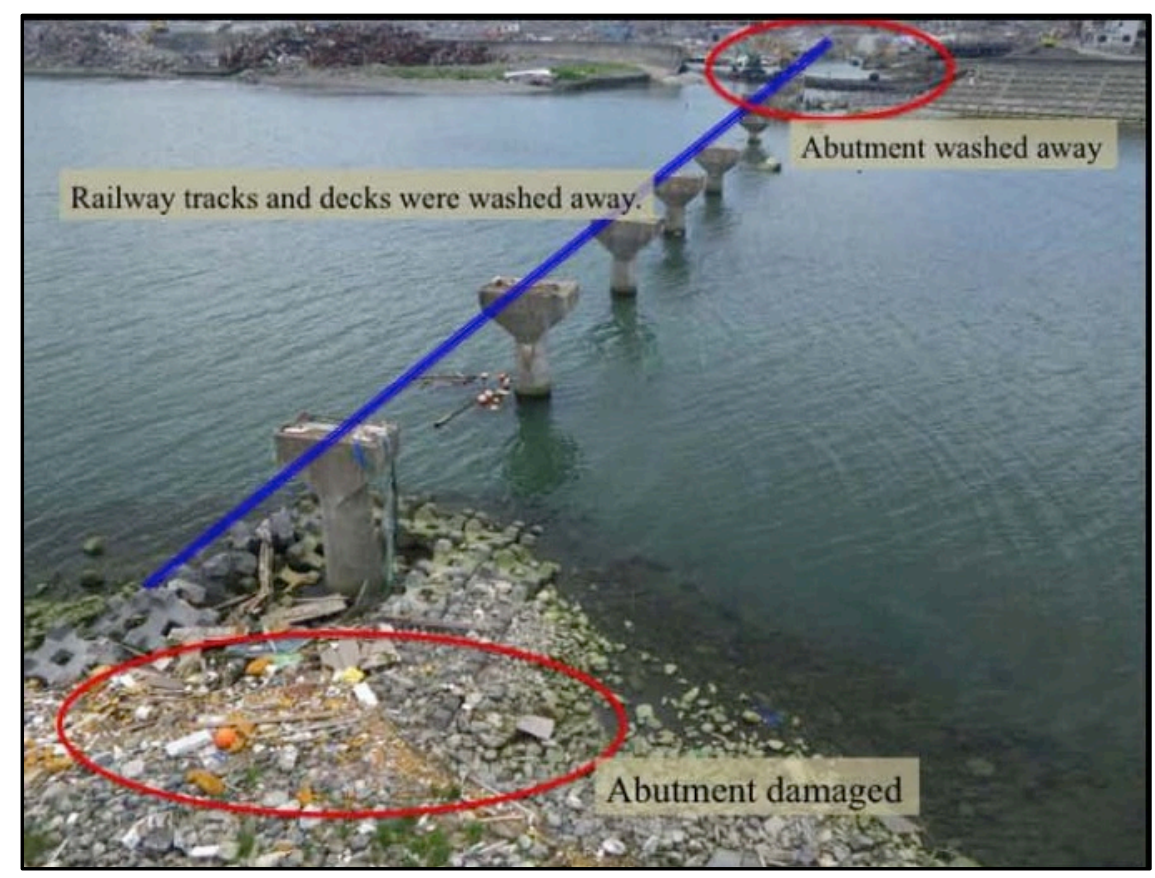

Figure 24. Photograph of railroad-bridge deck removed during the 2011 Tohoku, Japan, tsunami (photograph from American Society of Civil Engineers, Technical Council on Lifeline Earthquake Engineering, 2011). 


\section{Substation Damage}

Other potential damage to the ports is flooding of power substations, thus shutting down all port facilities. This damage is extremely significant in that custom-built transformers can take more than six months to replace. The likelihood of substation damage or impacts to port operations can be reduced by placement of the substations inland away from areas of expected inundation or construction of containment dikes or walls to reduce the risk of flooding.

Substation damage also makes evacuation more difficult and hazardous. There was a case in the Chile tsunami of 2010 where the power was lost while a container crane was placing a container in the hull of the vessel. The container ship attempted to leave port to protect the vessel and destroyed the crane in the process (COPRI, 2010). The scenario suggests that the seismic event was responsible for the power loss because it was still possible for the vessel to successfully navigate. A more robust design of the power system for seismic sources may have eliminated this problem.

\section{Tsunami Hazard Assessment Models}

Generalized tsunami hazard assessment models are currently very limited for use in the United States. The Federal Emergency Management Agency (FEMA), in conjunction with the National Institute of Building Sciences has developed a model for estimating losses from natural disasters. The primary purpose of the model, Hazards U.S.-Multihazard (HAZUS-MH), is to provide a methodology and software application to develop earthquake, flood, and hurricane losses at a regional scale. These loss estimates would be used primarily by local, State, and regional officials to plan and stimulate efforts to reduce risks from disasters and to prepare for emergency response and recovery.

Although the HAZUS model proves to be a valuable source for loss estimation, the hazards estimation database is rather generic and not necessarily up to date. M\&N has applied the model for a tsunami hazards assessment for POLA/POLB in a previous effort, but the damage assessment provided in this current SAFRR scenario is more accurate due to the use of a 'snapshot' assessment on specific terminals and vessels on a particular day.

\section{Tsunami Messages Related to the Ports of Los Angeles and Long Beach}

In this scenario, a tsunami watch is issued for Coastal California shortly after the earthquake (11:54 a.m. on March 27, 2014), with a forecast start of the tsunami at San Pedro (and thus the Ports of Los Angeles and Long Beach) at 5:37 p.m. the same day. The watch is issued by the National Oceanic and Atmospheric Administration's (NOAA) National Weather Service (NWS) West Coast/Alaska Tsunami Warning Center in Palmer, Alaska. A tsunami watch means the warning center does not yet know the expected impact in the area addressed, and advises the reader to stay alert for further instructions.

The watch is replaced at 2:05 p.m. on March 27, 2014, by a tsunami warning for the coastal areas of California from Alamitos Bay, 20 miles southeast of Los Angeles OregonCalifornia border (which includes the Ports of Los Angeles and Long Beach). For areas under tsunami warning, NOAA informs the reader that "Widespread dangerous coastal flooding accompanied by powerful currents is possible and may continue for many hours after tsunami arrival" and that "the first wave may not be the largest." The reader in a warning area is advised to "move inland to higher ground," not to "go to the coast to observe the tsunami" nor to "return to the coast until local emergency officials indicate it is safe to do so." In the 2:05 p.m. tsunami 
message, NOAA advises the reader that the forecast start of the tsunami at San Pedro is 5:35 p.m. with amplitudes of $1.6 \mathrm{ft} \pm 0.5 \mathrm{ft}(0.5 \mathrm{~m} \pm 0.15 \mathrm{~m})$ at San Pedro. In particular, this amplitude would be at NOAA National Data Buoy Center station 46222, at coordinates $33.618^{\circ} \mathrm{N}$. $118.317^{\circ} \mathrm{W}$., about 6.4 nautical miles (11.8 kilometers, $\mathrm{km}$ ) southeast of San Pedro harbor where the water is $457 \mathrm{~m}$ deep. Amplitudes would be greater in the harbor. Because NOAA's tsunami messages provide amplitudes in U.S. units, we quote these and provide SI unit in parentheses.

Thus it is 3.5 hours before the tsunami's arrival that NOAA first warns the Ports of Los Angeles and Long Beach that a tsunami with powerful currents and widespread dangerous coastal flooding is coming in 3.5 hours. Note that as further tsunami messages arrive, the forecast tsunami arrival time does not change significantly, but forecast amplitude at San Pedro does increase, as follows.

- 3:01 p.m.: estimated amplitude increased to $1.7 \mathrm{ft} \pm 0.5 \mathrm{ft}(0.52 \mathrm{~m} \pm 0.15 \mathrm{~m})$

- 4:01 p.m.: estimated amplitude increased to $1.8 \mathrm{ft} \pm 0.5 \mathrm{ft}(0.55 \mathrm{~m} \pm 0.15 \mathrm{~m})$

- 5:02 p.m.: estimated amplitude increased to $2.0 \mathrm{ft} \pm 0.6 \mathrm{ft}(0.61 \mathrm{~m} \pm 0.18 \mathrm{~m})$

- 6:02 p.m.: estimated amplitude increased to $2.2 \mathrm{ft} \pm 0.6 \mathrm{ft}(0.67 \mathrm{~m} \pm 0.18 \mathrm{~m})$, with an amplitude of $1.2 \mathrm{ft}(0.37 \mathrm{~m})$ already observed at the San Pedro buoy.

- 7:01 p.m.: estimated amplitude increased to $2.3 \mathrm{ft} \pm 0.7 \mathrm{ft}(0.70 \mathrm{~m} \pm 0.21 \mathrm{~m}, 1.2 \mathrm{ft}$ or 0.37 m observed)

- $\quad$ 8:01 p.m.: estimated amplitude increased to $2.4 \mathrm{ft} \pm 0.7 \mathrm{ft}(0.73 \mathrm{~m} \pm 0.21 \mathrm{~m}, 2.8 \mathrm{ft}$ or $0.85 \mathrm{~m}$ already observed)

- 9:01 p.m. the forecast amplitude has not changed but $3.1 \mathrm{ft}(0.94 \mathrm{~m})$ has been observed.

- At 5:04 p.m. on Friday March 28, 2014, 29 hours after the earthquake, the warning for San Pedro is changed to an advisory

- At 9:01 a.m. on Saturday March 29, 2014 (45 hours after the earthquake), the advisory is cancelled for the stretch of the California coast from a point 15 miles southeast of Santa Barbara to the California-Mexico border, which includes the Ports of Los Angeles and Long Beach.

\section{Tsunami Inundation Maps and Duration}

The tsunami propagation modeling indicates that the first wave produces the maximum wave amplitude and associated maximum currents. The maximum drawdown and significant waves will have passed by 6:00 p.m. PDT, a little over an hour after initial arrival, but as shown in figures 25 and 26, significant wave activity continues for several hours after the arrival of the first wave. As the tsunami reflects around the Pacific Ocean, higher than normal current speeds and less severe water level fluctuations in POLA/POLB are predicted to occur over the following several days. The base water depth at time of the tsunami's arrival is taken as 20 centimeters (cm) above mean high water (denoted here by $\mathrm{MHW}+20$ ). 


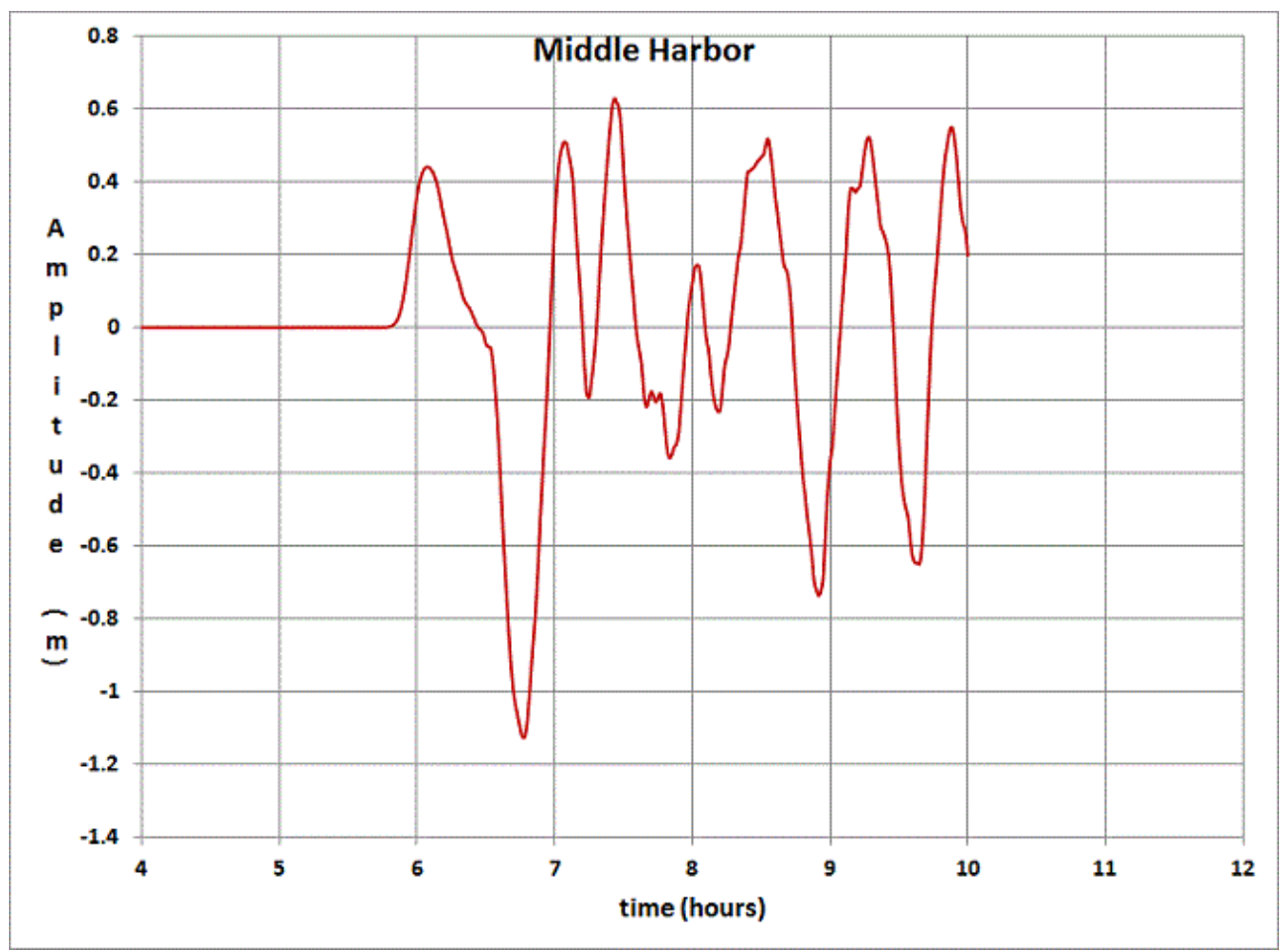

Figure 25. San Pedro Harbor, California, Middle Harbor marigram for the SAFRR tsunami scenario.

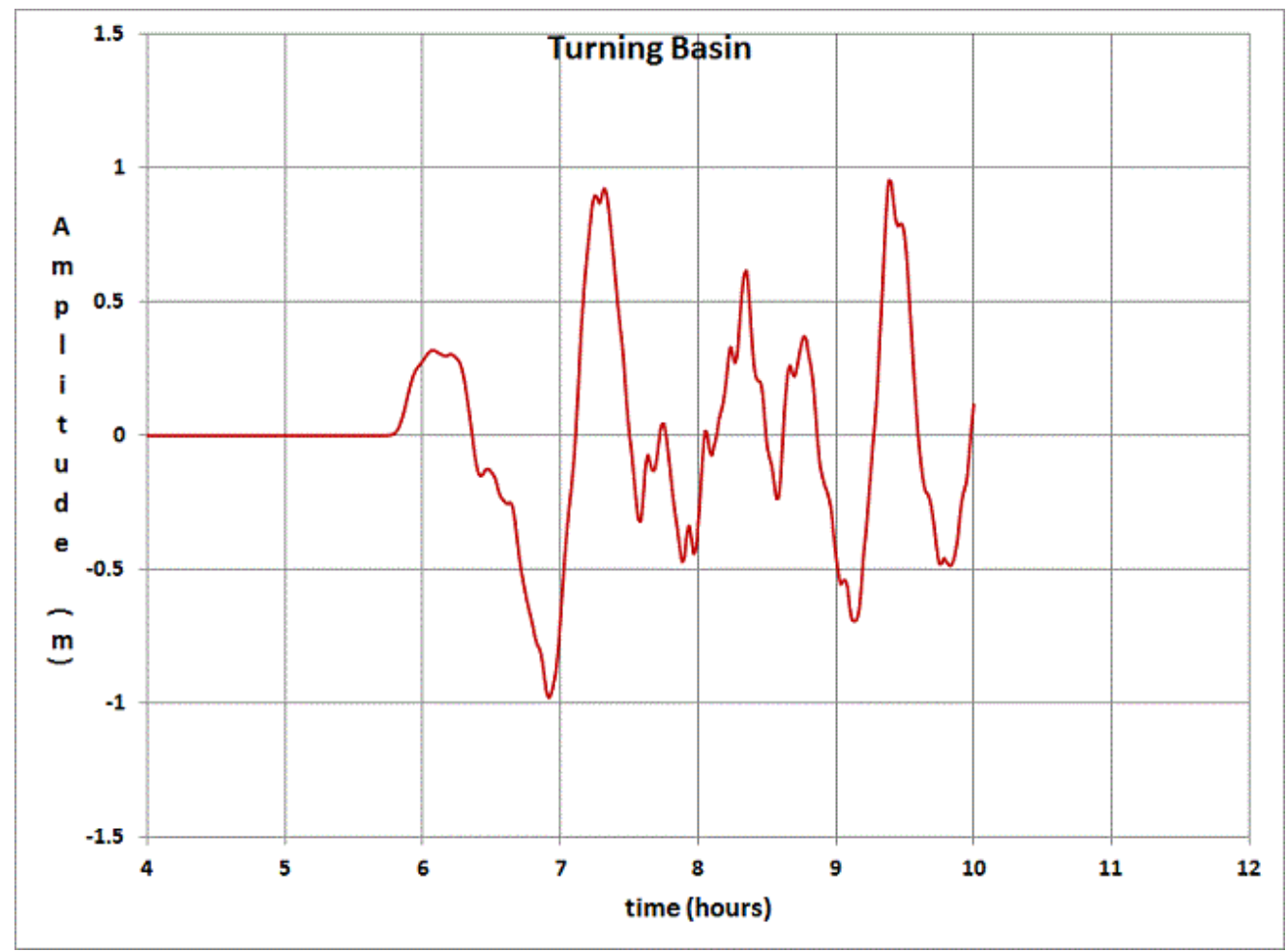

Figure 26. San Pedro Harbor, California, Turning Basin marigram for the SAFRR tsunami scenario. 
Basin-wide hydrodynamic modeling was conducted for the selected SAFRR tsunami source seaward of the Alaska Peninsula on the Semidi Sector of the Alaska-Aleutian subduction zone. Higher resolution and high-order modeling was conducted for selected ports and harbors including the Ports of Los Angeles and Long Beach. The hydrodynamic modeling resolution for inundation in the ports was $10 \mathrm{~m}$. The limit of inundation (referred to here as the inundation line) was based on 2009-2011 topography from LIDAR DEM with 1-m resolution.

The DEM used for the basis of the hydrodynamic modeling and creation of the inundation limits did not include some of the additional landfills and other modifications to the ports since the development of the DEM. Therefore, recent aerial photography (circa 2011) was used to check and update the inundation maps to reflect the newer landfills. These landfill areas included the Cabrillo Marina shoreline reconfiguration, Port of Long Beach Pier G, Middle Harbor, and Pier T dry dock landfills, and the Port of Los Angeles landfill in the dry dock area adjacent to the U.S. Coast Guard station. Two areas in the Port of Long Beach near Pier G and Piers E/F, where landfill work is currently ongoing, were not altered. The resolution of the DEM was insufficient to resolve containment dikes and containment walls surrounding tank farms. If these structures are adequately designed to withstand tsunami loads and depths, no inundation would occur there. In addition, maximum current speeds through the channel constrictions leading to basins where landfills are being constructed would be expected to be reduced, because the tsunami prism within the basins is reduced. Figure 25 depicts the resultant inundation limits for San Pedro Harbor.

Figure 26 represents the maximum tsunami-generated current velocities. Maximum current speeds reach as high as 8 knots through Angel's Gate and Queens Gate and some of the channel constrictions leading to specific basin areas such as Southeast Basin and West Basin in the Port of Long Beach. Maximum current speeds along the sides of the channels where vessels are moored are generally 2 to 3 knots.

\section{Distribution of Assets}

The Ports of Los Angeles and Long Beach make up two of the busiest ports on the west coast. Together, they are the number-one container port in the United States. In 2011, the ports accounted for approximately 10 percent of the U.S. total volume of foreign waterborne cargo and 22 percent of the U.S. total foreign value of cargo, as shown in figure 27 . In the event of a tsunami, neighboring ports along the west coast that may serve as alternative vessel loading/ unloading locations include the Port of Seattle, the Port of Tacoma, the Vancouver-Prince Rupert ports in Canada, and possibly some ports in Mexico. Other closer alternate ports along the Pacific coast are expected to experience some damage and operational downtime during the tsunami scenario. These include Port Hueneme, the Port of San Diego, the Port of Oakland, and the Port of San Francisco. 


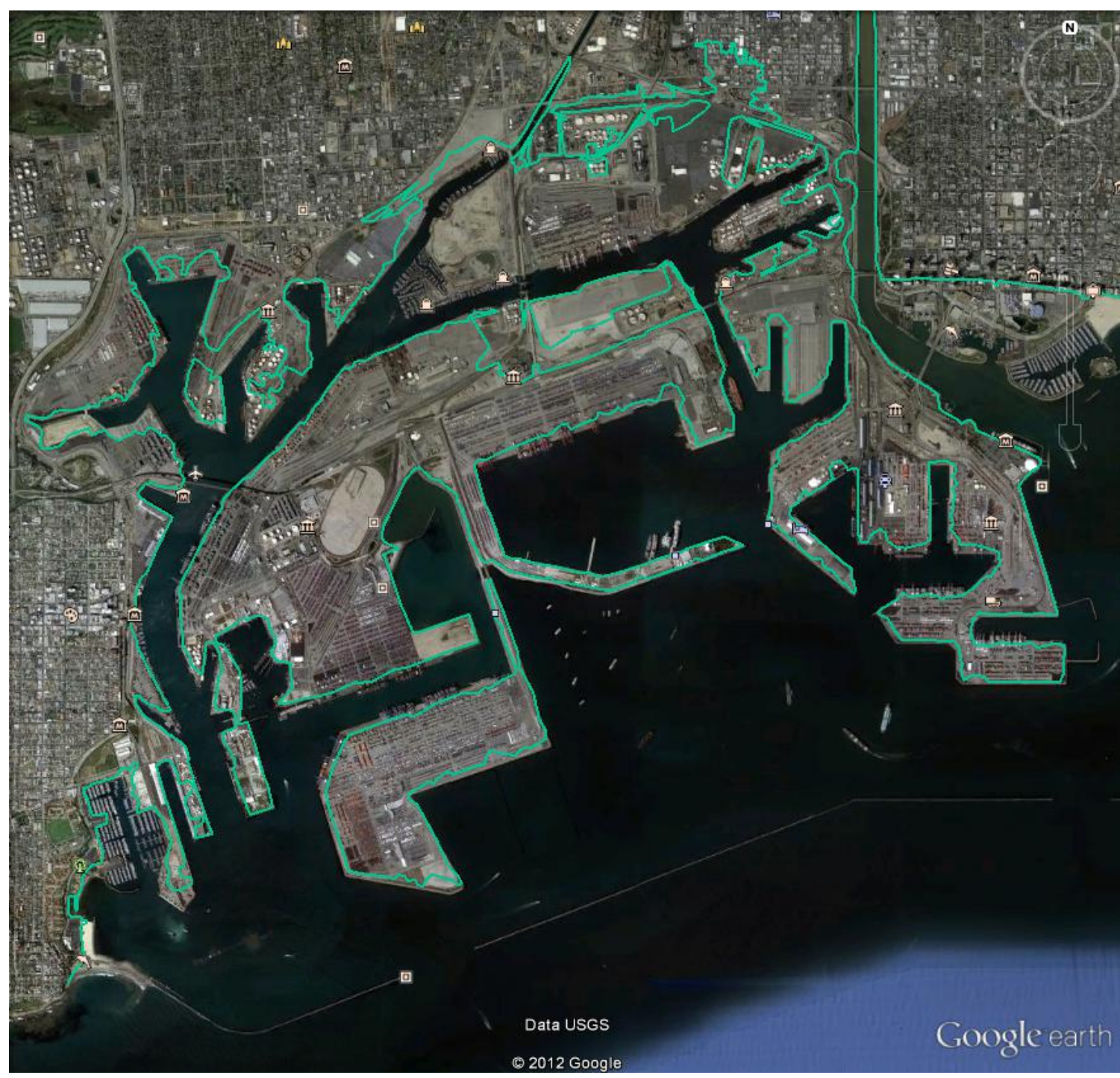

Figure 27. Inundation map during the SAFRR tsunami for the Ports of Long Beach and Los Angeles. Green line, maximum run-up. (Base map from Google Earth.)

\section{Displacement of maritime activities}

The following section summarizes the major cargo present at POLA/POLB during the tsunami scenario. The location and travel direction of vessels in the harbor during the tsunami were taken from the satellite imagery and Maritime Exchange information on March 7, 2011 (figure 25). These particular vessels are listed under 'Vessel Name' in table 2. Quantities of cargo exposed to the tsunami were estimated from the 2011 annual throughput values.

Throughput values for March 27, 2014, are assumed to take on the same throughput values of a typical day in 2014. 


\section{Port of Long Beach}

\section{Containerized}

Containerized cargo includes any type of cargo moving within standard shipping containers. Such containers primarily contain finished goods such as clothing, toys, and furniture. Liquids and other unique cargoes may be shipped in specialized containers. Figure 28 highlights the main container terminals at the Port of Long Beach and distribution of cargo types can be seen in figure 29. Projected annual and average daily throughput values for each terminal are presented in table 2. Column indicating "Projected throughout on March 27, 2014," is assumed to be the same value at the location at 11:50 a.m. March 27, 2014. Vessel names are given at each location to provide some tangible detail on the day of the tsunami. At locations where no vessel name is listed, assume no particular vessel is present.

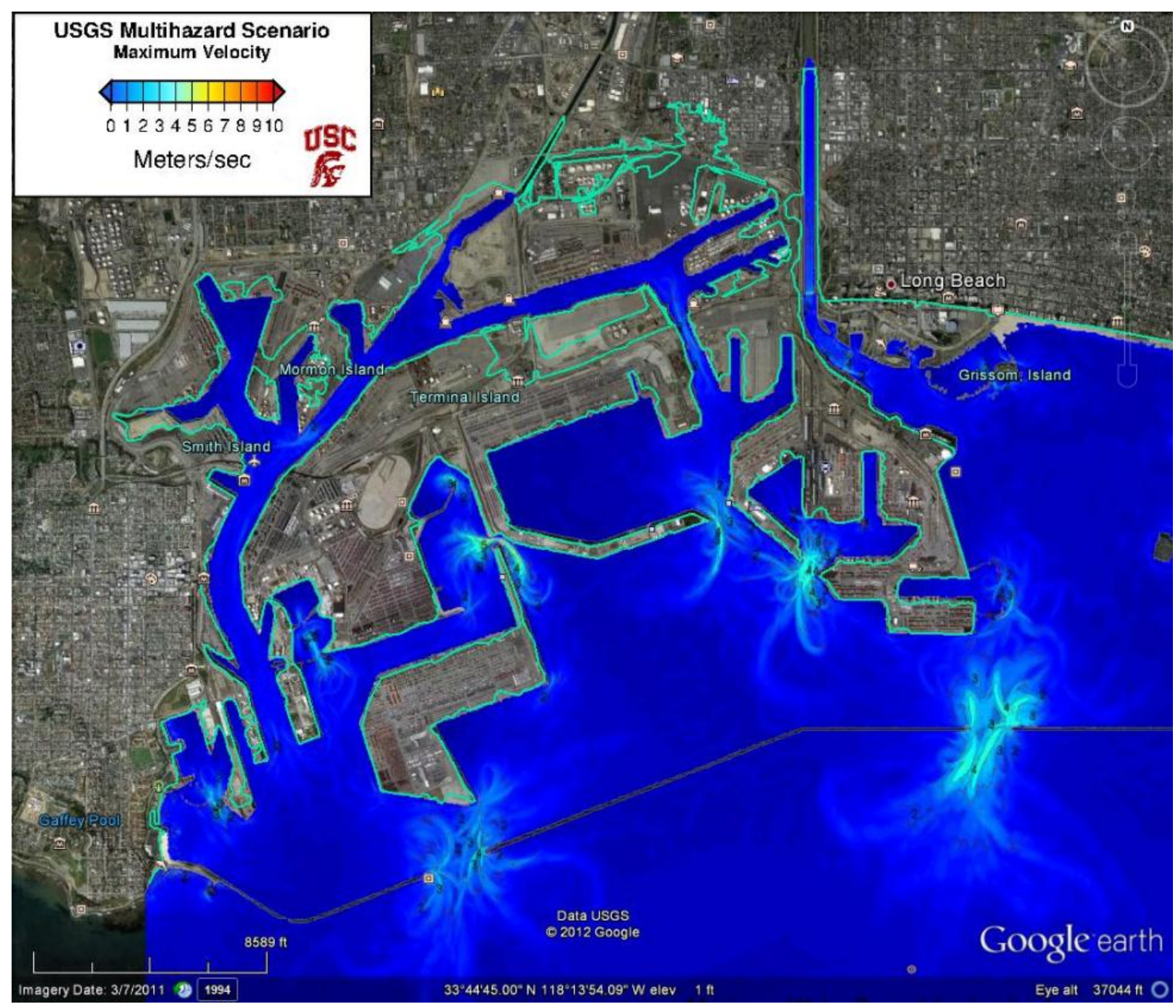

Figure 28. Map of maximum velocity for the Ports of Long Beach and Los Angeles during the SAFRR tsunami. Green line, maximum run-up. (Base map from Google Earth.) 


\begin{tabular}{|c|c|c|c|c|c|c|c|c|}
\hline \multicolumn{9}{|c|}{$\begin{array}{l}\text { U.S. WATERBORNE FOREIGN TRADE } 2011 \\
\text { RANKING OF U.S. CUSTOMS DISTRICTS BY VALUE OF CARGO } \\
\text { Millions of U.S. Dollars }\end{array}$} \\
\hline \multicolumn{3}{|c|}{ EXPORTS } & \multicolumn{3}{|c|}{ IMPORTS } & \multicolumn{3}{|c|}{ TOTAL TRADE } \\
\hline Rank & Customs District & Dollars & Rank & Customs District & Dollars & Rank & Customs District & Dollars \\
\hline 1 & Houston-Galveston, TX & $\$ 108,943$ & 1 & Los Angeles, CA & $\$ 302,134$ & 1 & Los Angeles, CA & $\$ 381,712$ \\
\hline 2 & Los Angeles, CA & $\$ 79,578$ & 2 & New York City, NY & $\$ 150,244$ & 2 & Houston-Gal veston, TX & $\$ 242,508$ \\
\hline 3 & New York City, NY & $\$ 57,799$ & 3 & Houston-Galveston, TX & $\$ 133,564$ & 3 & New York City, NY & $\$ 208,043$ \\
\hline 4 & New Orleans, LA & $\$ 57,015$ & 4 & New Orleans, LA & $\$ 96,346$ & 4 & New Orleans, LA & $\$ 153,361$ \\
\hline 5 & Savannah, GA & $\$ 34,378$ & 5 & Seattle, WA & $\$ 62,772$ & 5 & Seattle, WA & $\$ 87,794$ \\
\hline 6 & Miami, FL & $\$ 26,577$ & 6 & Savannah, GA & $\$ 51,346$ & 6 & Savannah, GA & $\$ 85,723$ \\
\hline 7 & Seattle, WA & $\$ 25,023$ & 7 & San Francisco, CA & $\$ 46,598$ & 7 & San Francisco, CA & $\$ 69,209$ \\
\hline 8 & Norfolk, VA & $\$ 24,132$ & 8 & Philadelphia, PA & $\$ 46,218$ & 8 & Charleston, SC & $\$ 58,893$ \\
\hline 9 & San Francisco, CA & $\$ 22,611$ & 9 & Charleston, SC & $\$ 36,660$ & 9 & Norfolk, VA & $\$ 54,990$ \\
\hline 10 & Charleston, SC & $\$ 22,234$ & 10 & Port Arthur, TX & $\$ 33,604$ & 10 & Philadelphia, PA & $\$ 54,321$ \\
\hline 11 & Baltimore, MD & $\$ 20,634$ & 11 & Norfolk, VA & $\$ 30,858$ & 11 & Baltimore, MD & $\$ 51,391$ \\
\hline 12 & Tampa, FL & $\$ 16,191$ & 12 & Baltimore, MD & $\$ 30,757$ & 12 & Miami, FL & $\$ 50,066$ \\
\hline 13 & Columbia-Snake, OR & $\$ 12,990$ & 13 & Miami, FL & $\$ 23,489$ & 13 & Port Arthur, TX & $\$ 44,370$ \\
\hline 14 & Port Arthur, TX & $\$ 10,766$ & 14 & Mobile, AL & $\$ 22,372$ & 14 & Tampa, FL & $\$ 32,590$ \\
\hline 15 & Mobile, AL & $\$ 9,075$ & 15 & Tampa, FL & $\$ 16,399$ & 15 & Mobille, AL & $\$ 31,446$ \\
\hline 16 & Philadelphia, PA & $\$ 8,102$ & 16 & U.S. Virgin Islands & $\$ 12,150$ & 16 & Columbia-Snake & $\$ 22,334$ \\
\hline 17 & Wilmington, NC & $\$ 4,126$ & 17 & Boston, MA & $\$ 10,957$ & 17 & U.S. Virgin Islands & $\$ 14,432$ \\
\hline 18 & Anchorage, AK & $\$ 4,080$ & 18 & Columbia-Snake & $\$ 9,343$ & 18 & Boston, MA & $\$ 13,113$ \\
\hline 19 & San Juan, PR & $\$ 3,396$ & 19 & San Juan, PR & $\$ 9,201$ & 19 & San Juan, PR & $\$ 12,597$ \\
\hline 20 & Detroit, MI & $\$ 3,339$ & 20 & Providence, RI & $\$ 6,620$ & 20 & Wilmington, NC & $\$ 10,426$ \\
\hline 21 & U.S. Virgin Islands & $\$ 2,281$ & 21 & Wilmington, NC & $\$ 6,300$ & 21 & Providence, RI & $\$ 6,984$ \\
\hline 22 & Boston, MA & $\$ 2,156$ & 22 & Honolulu, $\mathrm{HI}$ & $\$ 5,239$ & 22 & Honolulu, $\mathrm{HI}$ & $\$ 5,525$ \\
\hline 23 & Ogdensburg, NY & $\$ 1,098$ & 23 & San Diego, CA & $\$ 5,146$ & 23 & San Diego, CA & $\$ 5,252$ \\
\hline 24 & Cleveland, $\mathrm{OH}$ & $\$ 781$ & 24 & Portland, ME & $\$ 3,791$ & 24 & Anchorage, AK & $\$ 4,902$ \\
\hline 25 & Buffalo, NY & $\$ 717$ & 25 & Chicago, IL & $\$ 1,440$ & 25 & Detroit, MI & $\$ 4,640$ \\
\hline 26 & Portland, ME & $\$ 686$ & 26 & Detroit, MI & $\$ 1,300$ & 26 & Portland, ME & $\$ 4,476$ \\
\hline 27 & Mineapolis, MN & 440.58 & 27 & Cleveland, $\mathrm{OH}$ & $\$ 1,231$ & 27 & Cleveland, $\mathrm{OH}$ & $\$ 2,012$ \\
\hline 28 & Providence, RI & $\$ 365$ & 28 & Laredo, $\mathrm{TX}$ & $\$ 945$ & 28 & Chicago, IL & $\$ 1,666$ \\
\hline 29 & Laredo, TX & 343 & 29 & Anchorage, AK & $\$ 823$ & 29 & Laredo, TX & $\$ 1,288$ \\
\hline 30 & Honolulu, $\mathrm{HI}$ & $\$ 286$ & 30 & Duluth, MN & $\$ 650$ & 30 & Ogdensburg. NY & $\$ 1,106$ \\
\hline 31 & Chicago, IL & $\$ 226$ & 31 & Mineapolis, MN & $\$ 225$ & 31 & Buffalo, NY & $\$ 904$ \\
\hline 32 & Milwaukee, WI & $\$ 207$ & 32 & Buffalo, NY & $\$ 187$ & 32 & Duluth, MN & $\$ 832$ \\
\hline 33 & Duluth, MN & $\$ 181$ & 33 & Milwaukee, WI & $\$ 172$ & 33 & Mineapolis, MN & $\$ 666$ \\
\hline 34 & San Diego, CA & $\$ 107$ & 34 & Ogdensburg, NY & $\$ 9$ & 34 & Milwaukee, WI & $\$ 379$ \\
\hline \multirow[t]{2}{*}{35} & Washington, DC & $\$ 3$ & 35 & Washington, DC & $\$ 6$ & 35 & Washington, DC & $\$ 9$ \\
\hline & Total & $\$ 570,286$ & & Total & $\$ 1,159,096$ & & Total & $\$ 1,729,382$ \\
\hline
\end{tabular}

Figure 29. Ranking of U.S. customs districts by value of cargo (data from U.S. Census Bureau, 2013). 


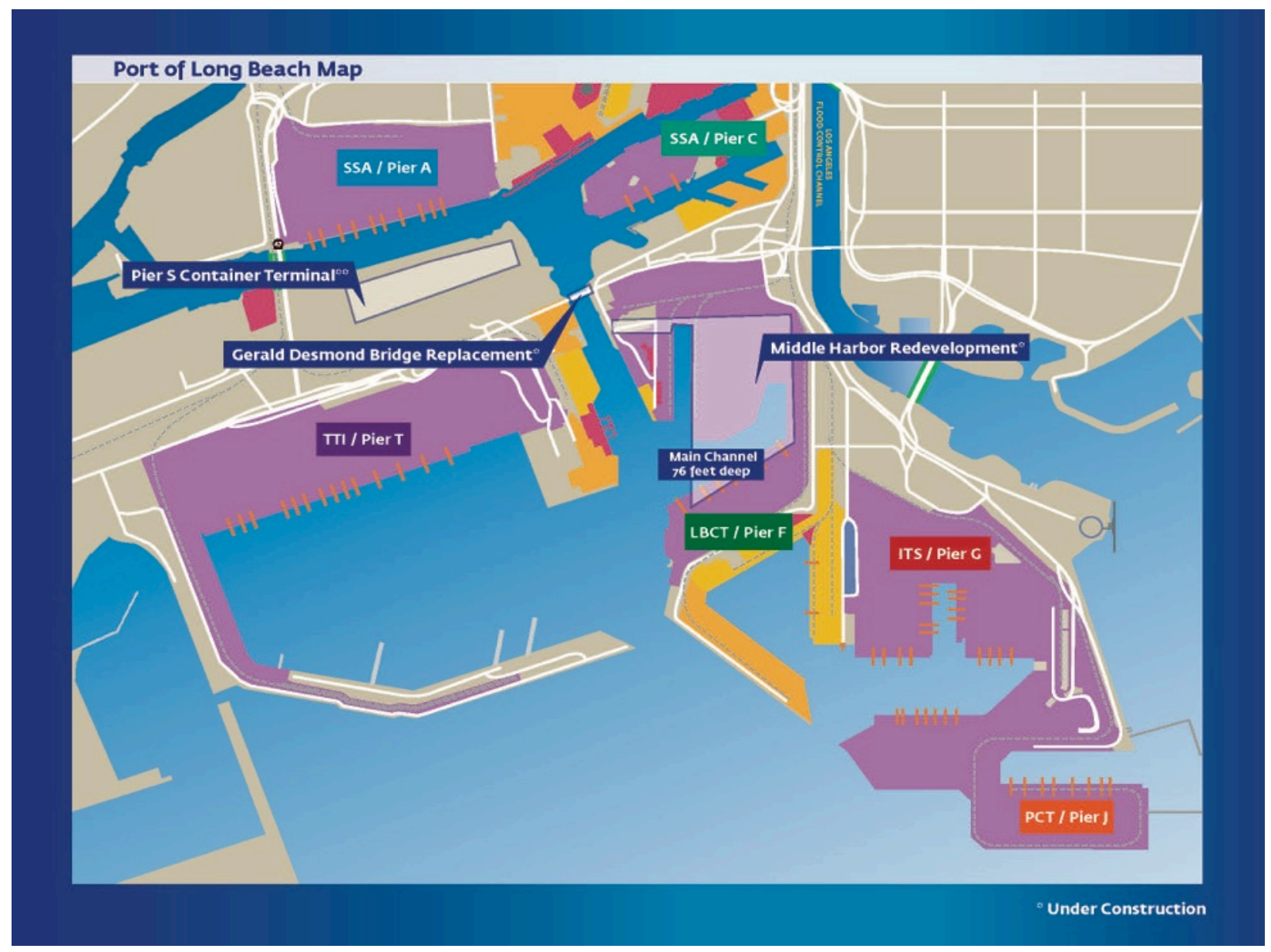

Figure 30. Map of Port of Long Beach containerized terminals (image courtesy Port of Long Beach). 
Table 2. Port of Long Beach container terminal throughput values.

[TEUs, twenty-foot equivalent units]

\begin{tabular}{|c|c|c|c|c|c|c|}
\hline Location & $\begin{array}{c}2011 \\
\text { Throughput } \\
\text { (TEUs) }\end{array}$ & $\begin{array}{l}2014 \\
\text { Projected } \\
\text { Throughput } \\
\text { (TEUs)* }^{*}\end{array}$ & $\begin{array}{l}\text { Projected } \\
\text { throughput on } \\
\text { March } 27,2014 \\
\text { (TEUs) }\end{array}$ & $\begin{array}{l}\text { Gantry } \\
\text { Cranes }\end{array}$ & Acreage & Vessel Name \\
\hline $\begin{array}{l}\text { Pier T Berth } \\
\text { T132-T140 }\end{array}$ & $1,358,000$ & $1,561,700$ & 4,290 & 14 & 385 & Hanjin \\
\hline $\begin{array}{l}\text { Pier G: } \\
\text { Berths } \\
\text { G226-G236 }\end{array}$ & 743,000 & 854,450 & 2,347 & 17 & 246 & CSAV LUMACO \\
\hline $\begin{array}{l}\text { Pier F: } \\
\text { Berths F6- } \\
\text { F10 } \\
\text { Pier J. }\end{array}$ & 671,000 & 771,650 & 2,120 & 7 & 102 & $\begin{array}{l}\text { OOCL TOKYO- } \\
\text { Arrival 3:15 p.m. }\end{array}$ \\
\hline $\begin{array}{l}\text { Pier J: } \\
\text { Berths J243- } \\
\text { J247, J266, } \\
\text { J270 }\end{array}$ & $1,613,000$ & $1,854,950$ & 5,096 & 7 & 256 & $\begin{array}{l}\text { POS HONGKONG, } \\
\text { departing }\end{array}$ \\
\hline $\begin{array}{l}\text { Pier A: } \\
\text { Berths A88- } \\
\text { A96 }\end{array}$ & $1,340,000$ & $1,541,000$ & 4,234 & 10 & 200 & $\begin{array}{l}\text { SEA-LAND } \\
\text { INREPID, arrived } \\
\text { 4:15 a.m. }\end{array}$ \\
\hline $\begin{array}{l}\text { Pier C: } \\
\text { Berths C60- } \\
\text { C62 }\end{array}$ & 337,000 & 387,550 & 1,065 & 3 & 70 & $\begin{array}{l}\text { MAUNAMWILI, } \\
\text { arrived 6:45 p.m. }\end{array}$ \\
\hline Total & $6,062,000$ & $6,971,300$ & 19,152 & 58 & 1,259 & \\
\hline
\end{tabular}

*Projected 5-percent annual container growth rate. 


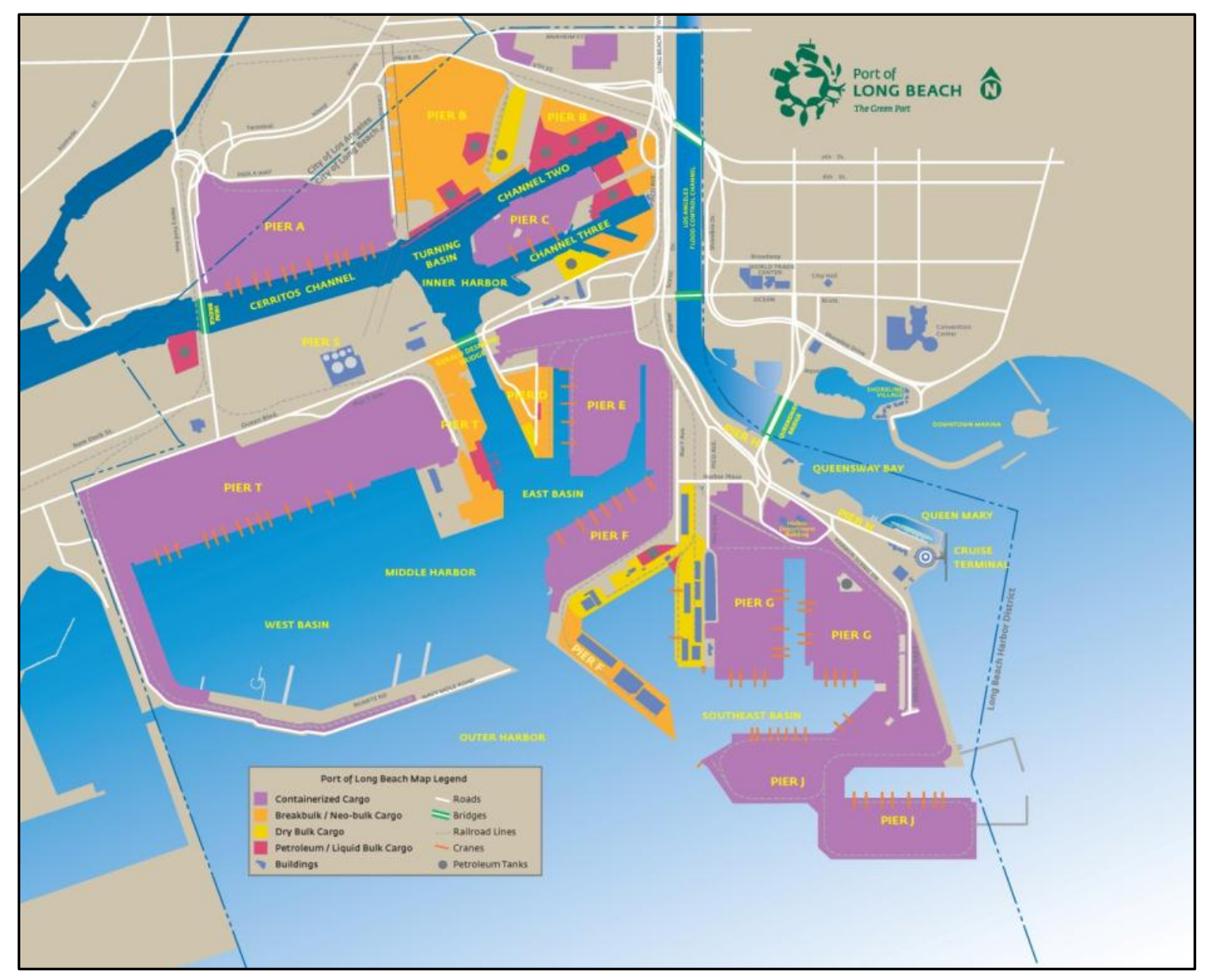

Figure 31. Map of Port of Long Beach cargo types-dry bulk (image courtesy Port of Long Beach). 
Dry bulk includes dry cargoes that are shipped in bulk and measured by weight or volume. Based on past dry bulk growth statistics, it is assumed 2014 throughput values are constant with 2011 throughput values, as presented in table 3 .

Table 3. Port of Long Beach dry bulk summary.

[MTPH, metric tons per hour; --, no data]

\begin{tabular}{|c|c|c|c|c|c|c|}
\hline Location & Material & $\begin{array}{l}\text { Equipment/ } \\
\text { Facilities }\end{array}$ & $\begin{array}{l}2011 \\
\text { Through- } \\
\text { put value } \\
\text { (metric } \\
\text { tons) }\end{array}$ & $\begin{array}{l}\text { Projected } \\
\text { throughput on } \\
\text { March 27, 2014 } \\
\text { (metric tons) }\end{array}$ & Acreage & Vessel Name \\
\hline $\begin{array}{l}\text { Pier D- } \\
\text { Berth D46 }\end{array}$ & Gypsum & $\begin{array}{l}\text { Elevated receiving } \\
\text { hopper served by an } \\
\text { elevated electric belt } \\
\text { conveyor system. }\end{array}$ & 111,000 & 305 & 9 & -- \\
\hline $\begin{array}{l}\text { Pier D- } \\
\text { Berth D32 }\end{array}$ & Cement & $\begin{array}{l}\text { Silo capacity }-50,000 \\
\text { tons. Unloads conveyer } \\
\text { system direct to silos. }\end{array}$ & & & 2 & -- \\
\hline $\begin{array}{l}\text { Pier F- } \\
\text { Berth F211 }\end{array}$ & $\begin{array}{l}\text { Petroleum Coke, } \\
\text { prilled sulfur }\end{array}$ & $\begin{array}{l}\text { Receipt, storage, } \\
\text { blending, and vessel } \\
\text { loading of petroleum } \\
\text { coke. Import/Export of } \\
\text { prilled sulfur. }\end{array}$ & 711,000 & 1954 & 7 & -- \\
\hline $\begin{array}{l}\text { Pier F- } \\
\text { Berth F208 }\end{array}$ & Cement & $\begin{array}{l}2 \text { pneumatic ship } \\
\text { unloaders with } 800 \\
\text { MTPH and } 180 \mathrm{MTPH} \\
\text { capacity. }\end{array}$ & & & 4 & -- \\
\hline $\begin{array}{l}\text { Pier F- } \\
\text { Berth F210 }\end{array}$ & Salt & $\begin{array}{l}\text { Movable incline } \\
\text { elevated electric belt } \\
\text { conveyor system with } \\
\text { receiving hopper } \\
\text { extending from wharf } \\
\text { to stockpile area. } \\
\text { Packing g plant } \\
\text { adjacent. }\end{array}$ & & & 5 & -- \\
\hline $\begin{array}{l}\text { Pier G- } \\
\text { Berths } \\
\text { G212-G214 }\end{array}$ & $\begin{array}{l}\text { Petroleum coke, } \\
\text { coal, potash, borax, } \\
\text { sodium sulfate, } \\
\text { soda ash, } \\
\text { concentrates, and } \\
\text { prilled sulfur. }\end{array}$ & $\begin{array}{l}2 \text { electric traveling } \\
\text { bulk ship loaders. }\end{array}$ & $6,950,000$ & 19,094 & 23 & $\begin{array}{l}\text { LEO } \\
\text { ADVANCE, } \\
\text { departing } \\
3 / 8 / 11\end{array}$ \\
\hline $\begin{array}{l}\text { Pier B- } \\
\text { Berth B82 }\end{array}$ & Gypsum & $\begin{array}{l}\text { Adjustable, elevated } \\
\text { receiving hopper } \\
\text { served by an elevated } \\
\text { electric belt conveyor } \\
\text { system extending to } \\
40,000 \text { ton capacity } \\
\text { storage building. }\end{array}$ & 137,000 & 377 & 19 & -- \\
\hline Total & & & $7,909,000$ & 21,730 & 69 & \\
\hline
\end{tabular}


Liquid forms of bulk cargo are measured by weight or volume. Commodities like crude oil, gasoline, and miscellaneous chemicals are common liquid bulk cargoes. Based on past liquid bulk growth statistics, it is assumed 2014 throughput values are constant with 2011 throughput values, as presented in table 4 .

Table 4. Port of Long Beach liquid bulk summary.

[--. no data]

\begin{tabular}{|c|c|c|c|c|c|c|}
\hline Location & $\begin{array}{l}\text { Cargoes } \\
\text { Served }\end{array}$ & $\begin{array}{l}\text { Equipment/ } \\
\text { Facilities }\end{array}$ & $\begin{array}{c}2011 \\
\text { Throughput } \\
\text { values } \\
\text { (metric tons) }\end{array}$ & $\begin{array}{c}\text { Projected } \\
\text { throughput } \\
\text { on March 27, } \\
2014 \text { (metric } \\
\text { tons) }\end{array}$ & Acreage & $\begin{array}{l}\text { Vessel } \\
\text { Name }\end{array}$ \\
\hline $\begin{array}{l}\text { Pier T- } \\
\text { Berth } \\
\text { T121 }\end{array}$ & $\begin{array}{l}\text { Crude oil and } \\
\text { petroleum } \\
\text { products }\end{array}$ & $\begin{array}{l}\text { Four 16-in. diameter } \\
\text { articulated crude } \\
\text { unloading arms and one } \\
8 \text { " dia. Particular } \\
\text { bunker/diesel loading } \\
\text { arm }\end{array}$ & $17,916,000$ & 49,220 & 6 & -- \\
\hline $\begin{array}{l}\text { Pier B- } \\
\text { Berths } \\
\text { B76-80 }\end{array}$ & $\begin{array}{l}\text { Petroleum } \\
\text { products }\end{array}$ & $\begin{array}{l}\text { Four 16-in. diameter } \\
\text { articulated crude } \\
\text { unloading arms and one } \\
8 \text { " dia. Particular } \\
\text { bunker/diesel loading } \\
\text { arm }\end{array}$ & & & 6 & -- \\
\hline $\begin{array}{l}\text { Pier B } \\
\text { Berth } \\
\text { B82,83 }\end{array}$ & $\begin{array}{l}\text { Gasoline, } \\
\text { ethanol, } \\
\text { gasoline blend } \\
\text { stocks, diesel, } \\
\text { biodiesel }\end{array}$ & $\begin{array}{l}\text { Two 8-inch dock hoses } \\
\text { connecting into two } 10 \text { - } \\
\text { inch dock lines capable } \\
\text { of receiving up to } \\
\text { 12,000 BBLS per hour } \\
\text { Discharge capacity: }\end{array}$ & $10,649,000$ & 29,300 & 6 & -- \\
\hline $\begin{array}{l}\text { Pier B- } \\
\text { Berth } \\
\text { B84-B87 }\end{array}$ & $\begin{array}{l}\text { Crude oil, } \\
\text { petroleum } \\
\text { products, } \\
\text { bunker fuel. }\end{array}$ & $\begin{array}{l}32,000 \text { BBLS, } 24 \text { in } \\
\text { pipeline to storage and } \\
\text { tank farm. Storage } \\
\text { capacity-245,000 } \\
\text { BBLS } \\
\text { Storage capacity- }\end{array}$ & & & 11 & -- \\
\hline $\begin{array}{l}\text { Pier F- } \\
\text { Berths } \\
\text { F209-211 }\end{array}$ & $\begin{array}{l}\text { Petroleum } \\
\text { products and } \\
\text { bunker fuel }\end{array}$ & $\begin{array}{l}425,000 \text { BBLS. } \\
\text { Pipeline system to } \\
\text { handle ships, barges, } \\
\text { trucks, railcars. } \\
\text { Dedicated pump/piping }\end{array}$ & $2,311,000$ & 6,350 & 5 & $\begin{array}{l}\text { PENN 91, } \\
\text { departing } \\
3 / 9 / 11\end{array}$ \\
\hline $\begin{array}{l}\text { Pier S } \\
\text { Berth } \\
\text { S101 }\end{array}$ & $\begin{array}{l}\text { Miscellaneous } \\
\text { bulk liquid } \\
\text { chemicals }\end{array}$ & $\begin{array}{l}\text { system to transfer } \\
\text { products to and from } \\
\text { ships, barges, railcars } \\
\text { and tank trucks. Storage } \\
\text { cap. } 15 \text { million gallons. }\end{array}$ & $2,030,000$ & 5,580 & 10 & -- \\
\hline Total: & & & $31,826,000$ & 90,450 & 44 & \\
\hline
\end{tabular}


Large or heavy items such as steel, lumber, machinery, and food products moved on pallets are Break Bulk cargoes. Roll On-Roll Off cargoes are items that are driven on and off a vessel. Based on past break bulk growth statistics, it is assumed 2014 throughput values are constant with 2011 throughput values, as presented in table 5. Automobile terminal will assume a capacity of 80 percent.

Table 5. Port of Long Beach break bulk/roll on-off summary.

[n/a, not applicable; --. no data]

\begin{tabular}{|c|c|c|c|c|c|}
\hline Location & $\begin{array}{l}\text { Equipment/ } \\
\text { Facilities }\end{array}$ & $\begin{array}{l}2011 \\
\text { Throughput } \\
\text { Values }\end{array}$ & $\begin{array}{c}\text { Projected } \\
\text { throughput } \\
\text { on March 27, } \\
2014 \\
\end{array}$ & Acreage & Vessel Name \\
\hline $\begin{array}{l}\text { Pier F } \\
\text { Berths } \\
\text { F204-F205 }\end{array}$ & $\begin{array}{l}\text { Steel products, plywood, } \\
\text { and lumber. }\end{array}$ & & & 21 & -- \\
\hline $\begin{array}{l}\text { Pier F- } \\
\text { Berth F206, } \\
\text { F207 }\end{array}$ & $\begin{array}{l}\text { Steel products, plywood, } \\
\text { lumber, project cargoes, } \\
\text { and large machinery. }\end{array}$ & $\begin{array}{l}440,000 \\
\text { metric tons }\end{array}$ & $\begin{array}{l}1,209 \text { metric } \\
\text { tons }\end{array}$ & 22 & -- \\
\hline $\begin{array}{l}\text { Pier F } \\
\text { Berth F201 }\end{array}$ & Standby berth & & & 600 & -- \\
\hline $\begin{array}{l}\text { Pier D, } \\
\text { Berth D50- } \\
\text { D54 }\end{array}$ & $\begin{array}{l}\text { Crescent Warehouse } \\
\text { Company }\end{array}$ & $\mathrm{n} / \mathrm{a}$ & $\mathrm{n} / \mathrm{a}$ & 13.3 & -- \\
\hline $\begin{array}{l}\text { Pier T, } \\
\text { Berth T122 }\end{array}$ & $\begin{array}{l}\text { Lumber and Lumber } \\
\text { products }\end{array}$ & & & 17 & \\
\hline $\begin{array}{l}\text { Pier T } \\
\text { Berth T118 }\end{array}$ & $\begin{array}{l}\text { Recyclable metal and } \\
\text { steel products. }\end{array}$ & $\begin{array}{l}904,000 \\
\text { metric tons }\end{array}$ & $\begin{array}{l}2,484 \text { metric } \\
\text { tons }\end{array}$ & 16 & $\begin{array}{l}\text { PANAMAX } \\
\text { SUCCESS, departing } \\
3 / 8 / 11\end{array}$ \\
\hline $\begin{array}{l}\text { Pier T- } \\
\text { Berth T122 }\end{array}$ & $\begin{array}{l}\text { Lumber and lumber } \\
\text { products. }\end{array}$ & & & 18 & -- \\
\hline $\begin{array}{l}\text { Pier B } \\
\text { Berth B82, } \\
\text { B83 }\end{array}$ & $\begin{array}{l}\text { Automobiles, Office } \\
\text { building, processing } \\
\text { buildings, body shop and } \\
\text { car wash }\end{array}$ & $\begin{array}{l}121,000 \\
\text { vehicles }\end{array}$ & $\begin{array}{l}2,000 \\
\text { vehicles }\end{array}$ & 168 & -- \\
\hline Total & & & & 875.3 & \\
\hline
\end{tabular}




\section{Port of Los Angeles}

\section{Containerized}

Figure 30 highlights the main container terminals at the Port of Los Angeles. Projected annual and average daily throughput values for each terminal can be seen in table 6 . Column indicating "Projected throughout on March 27, 2014," is assumed to be the same value at the location at 11:50 a.m. 27 March 2014. Vessel names are given at each location to provide some tangible detail on the day of the tsunami. At locations where no vessel name is listed, assume no particular vessel is present.

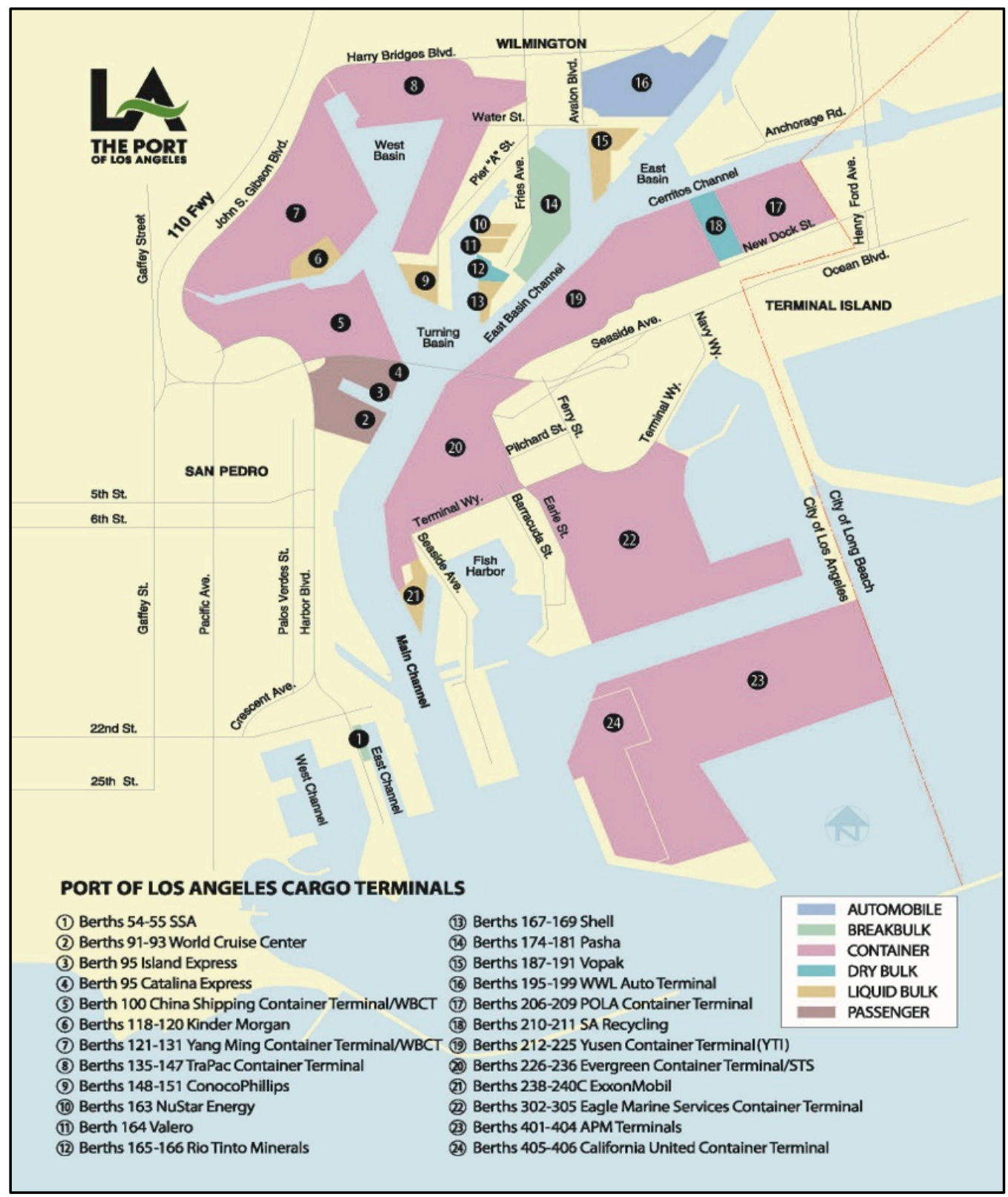

Figure 32. Port of Los Angeles facility map (image courtesy Port of Los Angeles). 
Table 6. Port of Los Angeles container terminal throughput values.

[TEUs, twenty-foot equivalent units; --. no data]

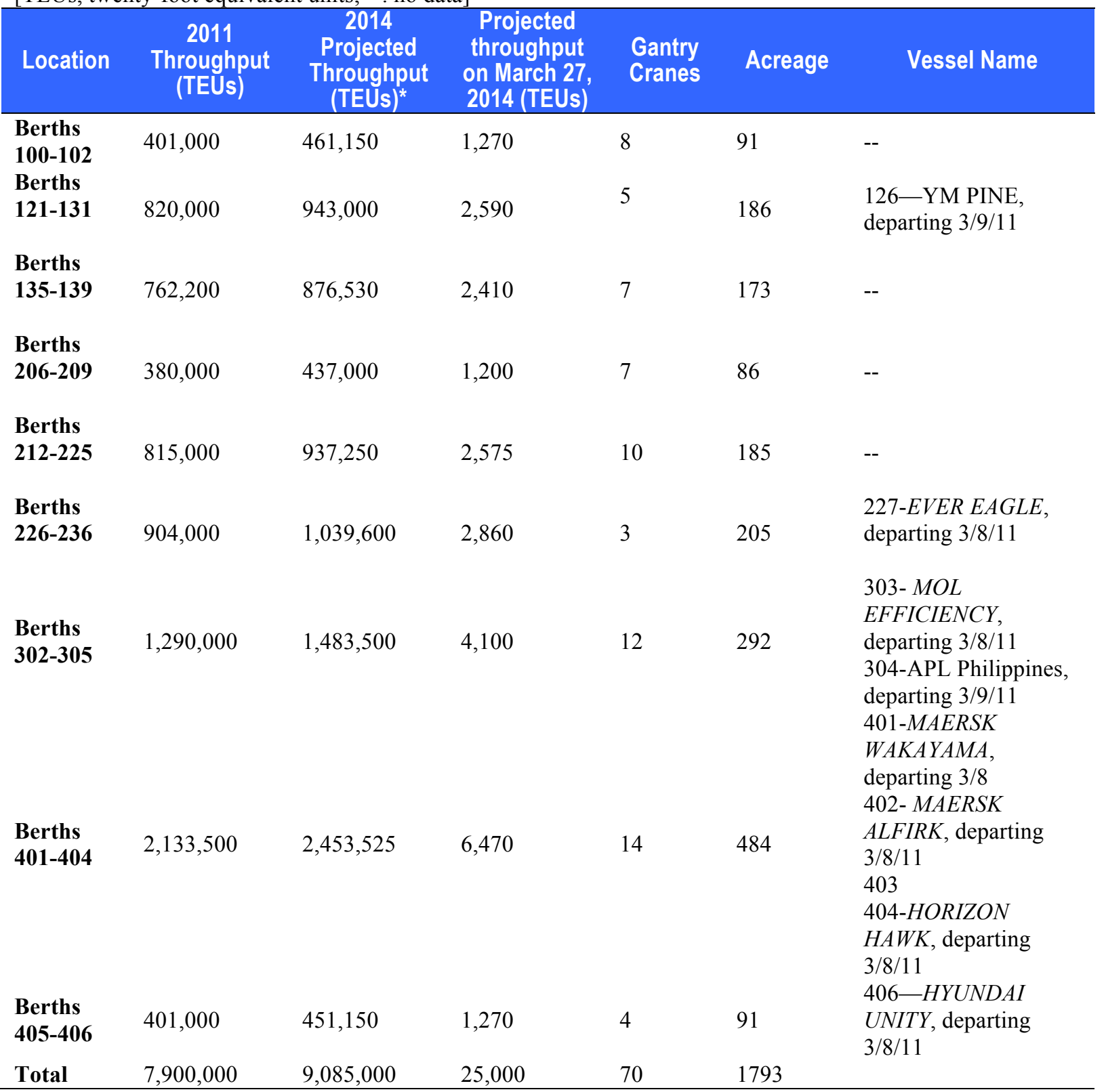

*Projected 5 percent annual container growth rate. 
Based on past dry bulk growth statistics, it is assumed 2014 throughput values are constant with 2011 throughput values, as presented in table 7.

Table 7. Port of Los Angeles dry bulk summary.

[--. no data]

\begin{tabular}{|c|c|c|c|c|c|c|}
\hline Location & $\begin{array}{l}\text { Terminal } \\
\text { features }\end{array}$ & $\begin{array}{c}2011 \\
\text { Throughput } \\
\text { (metric tons) }\end{array}$ & $\begin{array}{l}2014 \text { Projected } \\
\text { Throughput } \\
\text { (metric tons) }\end{array}$ & $\begin{array}{c}\text { Projected } \\
\text { throughput on } \\
\text { March 27, 2014 } \\
\text { (metric tons) }\end{array}$ & Acreage & Vessel Name \\
\hline $\begin{array}{l}\text { Berths } \\
165-166\end{array}$ & $\begin{array}{l}\text { Industrial } \\
\text { borates }\end{array}$ & 306,570 & 306,570 & 843 & 7 & -- \\
\hline $\begin{array}{l}\text { Berths } \\
210-211\end{array}$ & $\begin{array}{l}\text { grades of } \\
\text { ferrous and } \\
\text { non-ferrous } \\
\text { scrap metals }\end{array}$ & $1,169,340$ & $1,169,340$ & 3,212 & 26.7 & -- \\
\hline Total & & $1,200,000$ & $1,475,910$ & 4,055 & 27.4 & \\
\hline
\end{tabular}


Based on past liquid bulk growth statistics, it is assumed 2014 throughput values are constant with 2011 throughput values, as presented in table 8 .

Table 8. Port of Los Angeles liquid bulk summary.

\begin{tabular}{|c|c|c|c|c|c|c|}
\hline Location & Use: & $\begin{array}{l}2011 \text { Throughput } \\
\text { (metric tons) }\end{array}$ & $\begin{array}{c}2014 \\
\text { Projected } \\
\text { Throughput } \\
\text { (metric tons) }\end{array}$ & $\begin{array}{c}\text { Projected } \\
\text { throughput } \\
\text { on March 27, } \\
2014 \text { (metric } \\
\text { tons) }\end{array}$ & Acreage & Vessel Name \\
\hline $\begin{array}{l}\text { Berths } \\
\text { 118-120 }\end{array}$ & $\begin{array}{l}\text { Receiving } \\
\text { exporting } \\
\text { petroleum } \\
\text { products }\end{array}$ & 980,866 & 980,866 & 2,695 & 12.4 & -- \\
\hline $\begin{array}{l}\text { Berths } \\
148-151\end{array}$ & $\begin{array}{l}\text { Vessel } \\
\text { unloading of } \\
\text { partly or } \\
\text { fully refined } \\
\text { petroleum } \\
\text { products }\end{array}$ & 495,540 & 495,540 & 1,361 & 13.5 & -- \\
\hline Berth 163 & Marine oil & 295,440 & 295,440 & 812 & 5.8 & -- \\
\hline Berth 164 & $\begin{array}{l}\text { Fuels and } \\
\text { lubricants }\end{array}$ & $1,466,680$ & $1,466,680$ & 4,030 & 10.5 & -- \\
\hline $\begin{array}{l}\text { Berths } \\
167-169\end{array}$ & $\begin{array}{l}\text { Fuels and } \\
\text { lubricants }\end{array}$ & $1,906,238$ & $1,906,238$ & 5,237 & 9.1 & -- \\
\hline $\begin{array}{l}\text { Berths } \\
187-191\end{array}$ & $\begin{array}{l}\text { Liquid bulk } \\
\text { chemical } \\
\text { products }\end{array}$ & $4,284,192$ & $4,284,192$ & 11,778 & 34.7 & $\begin{array}{l}\text { 189- SUNSET } \\
\text { BAY, depart } \\
\text { 3/7/11 p.m. }\end{array}$ \\
\hline $\begin{array}{l}\text { Berths } \\
\text { 238-240C }\end{array}$ & $\begin{array}{l}\text { Fuels and } \\
\text { lubricants }\end{array}$ & 836,141 & 836,141 & 229 & 31.4 & -- \\
\hline Total & & $10,265,097$ & $10,265,097$ & & 117.4 & \\
\hline
\end{tabular}




\section{Automobile}

From the satellite imagery, the automobile berth is estimated to be 80 percent full. Assuming 2011 vehicle storage is constant in 2014 (table 9), the number of vehicles present at the time of the tsunami can be projected.

Table 9. Port of Los Angeles automobile summary.

\begin{tabular}{llllll} 
Location & Terminal features & $\begin{array}{c}\text { Projected } \\
\text { automobiles on } \\
\text { March 27, 2014 }\end{array}$ & Berth length & Acreage \\
\hline $\begin{array}{l}\text { Berths } \\
\mathbf{1 9 5 - 1 9 9}\end{array}$ & $\begin{array}{l}\text { Storage capacity up } \\
\text { to 8,000 vehicles }\end{array}$ & 6,400 & 2,250 feet & 85 & \\
\hline
\end{tabular}

Break Bulk

Large or heavy items such as steel, lumber, machinery and food products moved on pallets are break-bulk cargoes. Based on past break bulk growth statistics, it is assumed 2014 throughput values are constant with 2011 throughput values, as presented in table 10.

Table 10. Port of Los Angeles break bulk summary.

[n/a, not applicable; --. no data]

\begin{tabular}{|c|c|c|c|c|c|c|}
\hline Location & $\begin{array}{l}\text { Terminal } \\
\text { features }\end{array}$ & $\begin{array}{l}2011 \\
\text { Throughput } \\
\text { (metric tons) }\end{array}$ & $\begin{array}{l}2014 \text { Projected } \\
\text { Throughput } \\
\text { (metric tons) }\end{array}$ & $\begin{array}{c}\text { Projected } \\
\text { throughput } \\
\text { on March } 27, \\
2014 \text { (metric } \\
\text { tons) }\end{array}$ & Acreage & Vessel Name \\
\hline $\begin{array}{l}\text { Berths } \\
49-53\end{array}$ & $\begin{array}{l}\text { Use: Break bulk } \\
\text { steel }\end{array}$ & $\mathrm{n} / \mathrm{a}$ & $\mathrm{n} / \mathrm{a}$ & $\mathrm{n} / \mathrm{a}$ & 24 & -- \\
\hline $\begin{array}{l}\text { Berths } \\
54-55\end{array}$ & $\begin{array}{l}\text { Imported meats, } \\
\text { Chilean fruit, } \\
\text { kiwis, apples }\end{array}$ & 119,000 & 119,000 & 327 & 12 & -- \\
\hline $\begin{array}{l}\text { Berths } \\
174-181\end{array}$ & Steel & $1,950,000$ & $1,950,000$ & 5,357 & 40 & $\begin{array}{l}\text { 176-Pacific } \\
\text { Flores, } \\
\text { departing } \\
3 / 8 / 11\end{array}$ \\
\hline Total & & $2,069,000$ & $2,069,000$ & 5,684 & 76 & \\
\hline
\end{tabular}




\section{Small Craft Basins}

Within the Port of Los Angeles, there are a total of 16 marinas containing 3,795 recreational boat slips. There are 10 marinas located in Wilmington, five in San Pedro and one on Terminal Island, as summarized in table 11.

Table 11. Port of Los Angeles marinas and small craft slips.

\begin{tabular}{lll}
\hline \multicolumn{1}{c}{ Marina Name } & \multicolumn{1}{c}{ Location } & \multicolumn{1}{c}{ Slips } \\
Al Larson's Marina & Berth 258 & 128 \\
Cabrillo Beach Yacht Club & Berth 35 & 184 \\
Cabrillo Way Marina & Berths 42-43 & 697 \\
California Yacht Marina-Cabrillo Marina & Berth 29-33 & 885 \\
California Yacht Marina & Berth 202 & 266 \\
Cerritos Yacht Anchorage & Berth 205 & 90 \\
Holiday Harbor-Fleitz Bros. & Berth 34 & 300 \\
Holiday Harbor & Berth 201 & 169 \\
Island Yacht Anchorage \#1 & Berth 205 & 22 \\
Island Yacht Anchorage \#2 & Berth 200X & 116 \\
Leeward Bay Marina & Berth 201 & 190 \\
Lighthouse Yacht Landing & Berth 205 & 70 \\
Pacific Yacht Landing & Berth 203 & 178 \\
San Pedro Marina & Berth 80 & 85 \\
Yacht Centre-Newmarks & Berth 204 \\
Yacht Haven Marina & Berth 202 & 250 \\
\hline
\end{tabular}

\section{Business-As-Usual Configuration}

Modern container terminals are complex facilities designed to unload and load vessels and transfer containers to and from landside modes of transportation, that is, trucks and trains. Understanding how these facilities operate is important to understanding the potential changes or damages that may occur during and after a tsunami event.

Typical Container Terminal Operations

Terminal Components

In general, a modern container terminal (see figure 33) integrates a variety of physical components and operational processes. The physical components consist of:

- Dock structures or wharves with large, electric-powered gantry cranes;

- Container storage areas, known as the container yard;

- Entrance and exit gate complexes that include paperwork management facilities, physical screening facilities (for example, truck and chassis inspection areas, radiation monitors, and custom facilities), and truck queuing areas;

- Maintenance buildings for terminal equipment and chassis;

- Operations control buildings for marine and gate operations;

- An administration building;

- For terminals with intermodal capability, a rail yard and a rail operations control building; and

- Cargo handling equipment, including yard tractors, chassis for containers, light trucks and utility vehicles, and several types of mobile cranes and container handling equipment. 
The operational processes include loading and unloading ships at the wharves, storing and handling containers in the container yard, managing in-terminal rail yard operations, dispatching containers to off-dock rail yards, and managing container delivery and pickup by trucks for local destinations.

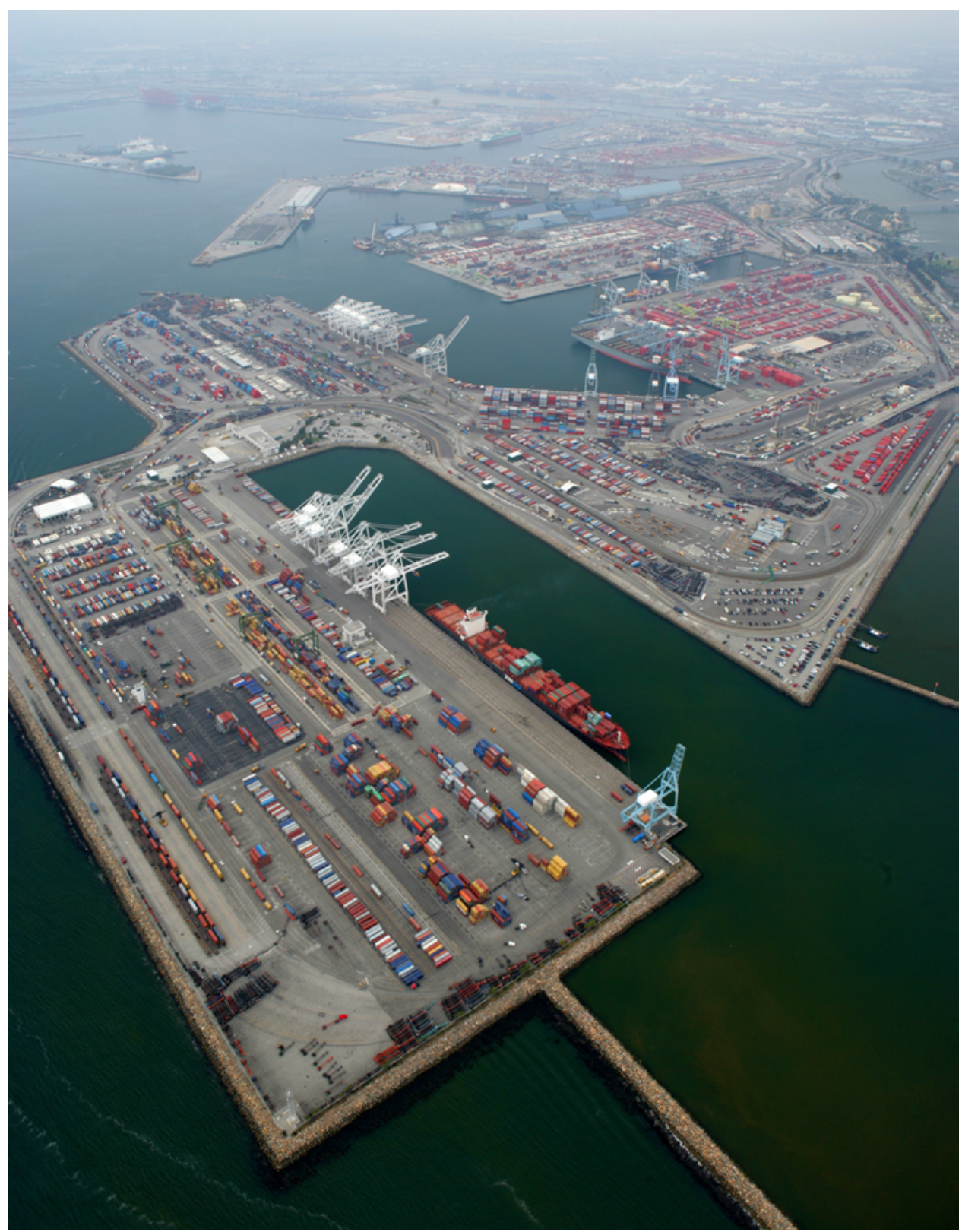

Figure 33. Photograph of a modern container terminal (photograph from Wikimedia Commons). 
Import containers arrive at and export containers depart from the terminals via container ships. Most container ships range from 700 to more than 1,100 feet in length and have cargo capacities from a few thousand to over 9,000 twenty-foot equivalent units (TEUs).

Once the vessel is tied at the wharf, the containers are loaded and unloaded by gantry cranes onto wheeled chassis. The cranes have steel wheels and are mounted on steel rails so they can move along the dock to serve multiple hatches and vessels. Each crane has a boom that is lowered over the vessel. The boom supports a container-lifting "spreader" with twist-locking corner devices that attach to the top corner castings of the containers to lift them. A crane operator rides in a cab above the spreader and controls the attachment and release functions. These cranes, which include specialized, highly computerized equipment that allows productive operations, can transfer 25 to 40 containers per hour. Typical modern gantry cranes stand approximately 150 feet high when the boom is outstretched and approximately 200 feet high when the boom is lifted, and mount on rails set 100 feet apart.

The number of cranes simultaneously servicing one ship can vary from one to five, or even more, depending on the size of the ship, the number of other vessels berthed at the terminal crane site, the availability of cranes, and the ship's scheduled port time. The amount of time a vessel spends at the berth varies with the amount of cargo to be unloaded and loaded and the number of cranes assigned to work the ship. Typical call durations range from 36 hours for small ships to five days for the largest vessels. Loading and unloading operations usually proceed around the clock.

\section{Container Handling}

After import containers are unloaded, they undergo security inspection. Each container is sealed with a metal ribbon attached to the doors, allowing a customs officer to ensure the contents of the container were not tampered with during voyage. Most containers are screened with an X-ray device, but every day some containers are inspected manually.

Once containers are off the vessel, they are taken to the container yard for temporary storage pending pickup by truck or train. Most of the export containers to be loaded are already stacked in the part of the container yard nearest the vessel berth and are transported to the crane via hostlers.

\section{Gate Operations}

Containers arrive at and depart from the terminal through the gate complex. The gate interchange is the legal exchange of possession of the container from the terminal to the trucking company, or vice versa.

Locally bound import containers are turned over to street-legal tractors (that is, semitrailer trucks) that arrive to pick up the cargo. The trucks arrive at the terminal either hauling export cargo or "bobtail" (that is, a tractor without a trailer) and, after presenting the appropriate paperwork, are directed to the container's location. For stacked cargo, the truck may need to pick up a chassis and then wait for a crane to load the container onto the chassis. For wheeled cargo, the truck can hitch up to the loaded chassis and proceed to the exit gate. Trucks hauling import cargo are processed out of the terminal at the exit gate, which involves passing through a radiation portal monitor, being inspected for road readiness, and clearing customs and brokerage paperwork. 
Loaded export containers arriving from California, Arizona, Nevada, and some points farther east typically arrive at the gate on chassis pulled by trucks and are stacked or parked in the container yard to await their ship. Export cargo arriving from more distant locations typically arrive at the terminal via rail, either directly at the terminal's on-dock rail yard or at another local rail yard from which it is trucked to the terminal gate for receiving. Cargo containers are transferred from the rail cars to chassis or bomb carts using mobile cranes or RTGs and hauled by yard tractors to preplanned locations in the yard, where the containers are either lifted to grounded spots by another crane or parked on their chassis.

\section{Truck Movement}

Trucks fill the gap between the railcar and the shipper's loading dock, hauling containers between the warehouses, factories, or docks and the intermodal rail yards. Trucks are the vital first and last link in the goods movement chain. Short-haul trucking of marine cargo containers is known as drayage. Containers may be drayed between a marine terminal and an intermodal rail yard or between a marine terminal and a local distribution center, store, or transloading warehouse (see fig. 34).

Most of the population of the U.S. lives within 50 miles of the coast or of a major intermodal rail yard, and trucks excel at serving these markets because they can pick up a container and dray it to its destination the same day, with time remaining to return with a loaded or empty container (a movement not shown in fig. 34).

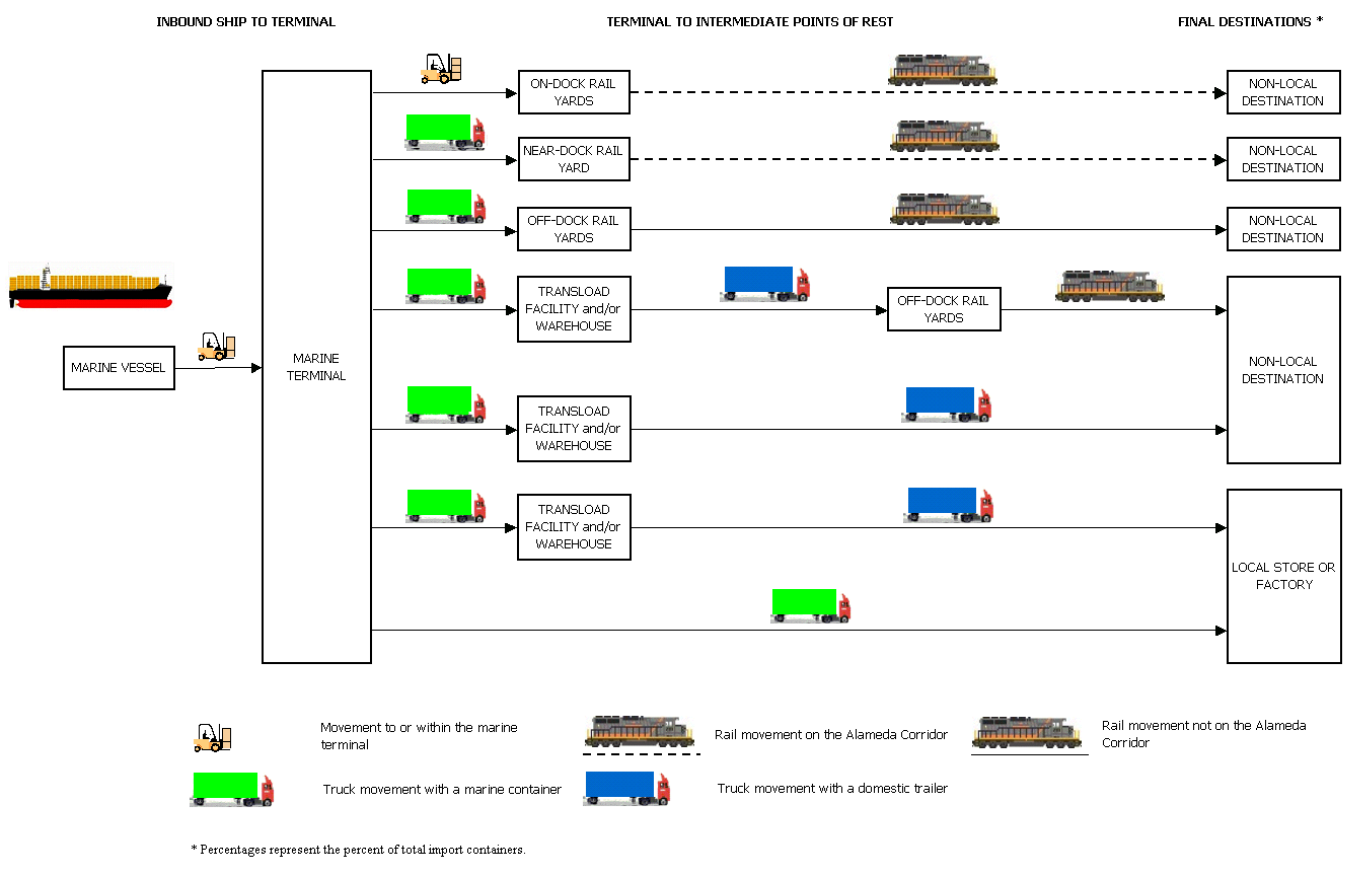

Figure 34. Diagram of San Pedro Bay loaded import container movement scenarios (image courtesy of Port of Long Beach). 


\section{Rail Movement}

Five of the six container terminals at the Port of Long Beach are equipped with on-dock rail. On-dock rail allows containers to be loaded onto a train right at the terminal, minimizing travel time and costs. From a Port of Long Beach on-dock rail facility, a container can reach Chicago in about 72 hours. On average, about 60 trains depart from the on-dock rail facilities every week. The Port of Long Beach is served by two major trunk-line railroads: Union Pacific Railroad (UP) and BNSF Railway (BNSF), and a regional switching railroad, the Pacific Harbor Line (PHL).

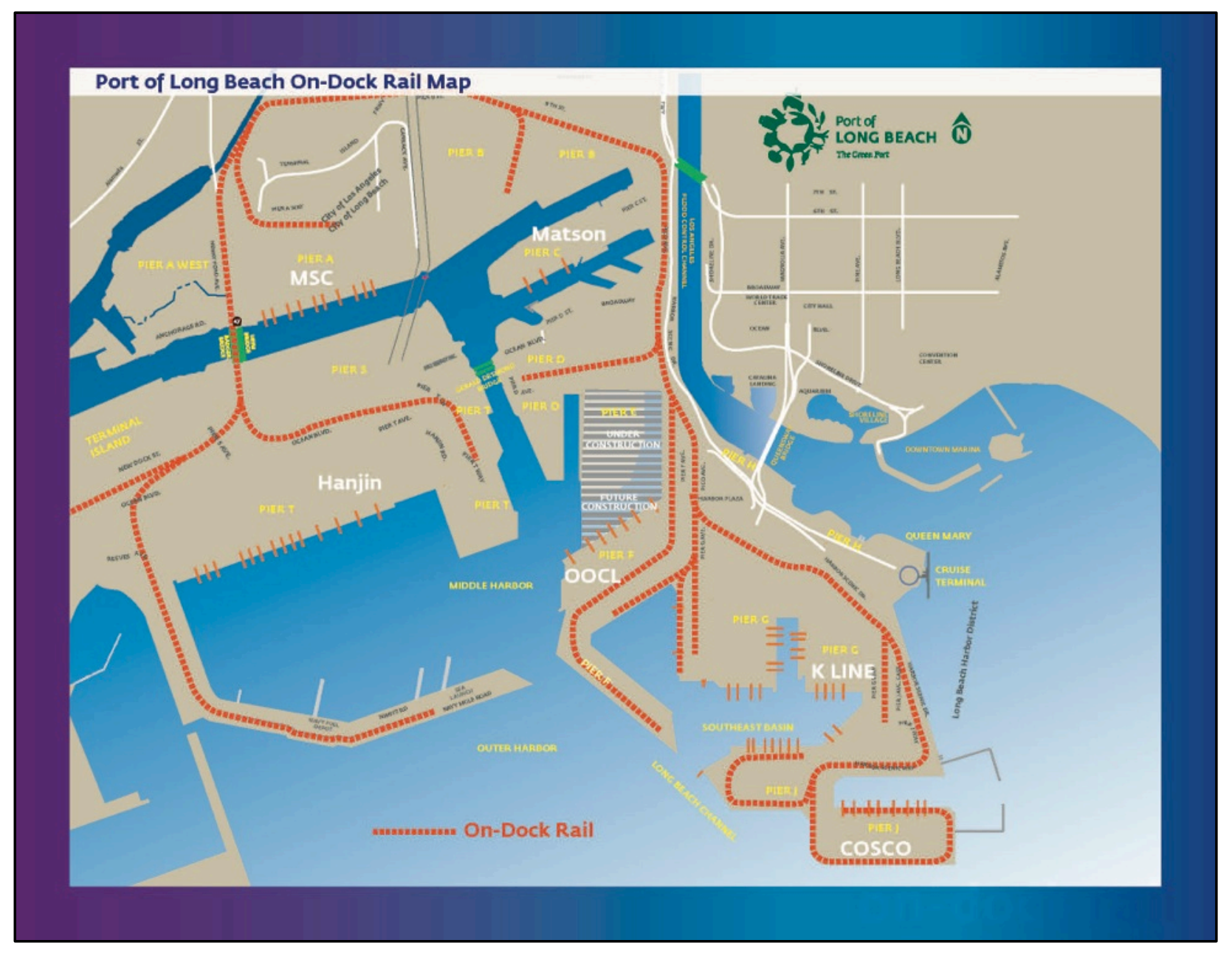

Figure 35. Port of Long Beach rail map (image courtesy Port of Long Beach).

\section{Physical Damage, Losses, and Logistics in the SAFRR Tsunami Scenario}

Damage assessment has been quantified through careful analysis of each individual terminal at the time of the tsunami. A number of assumptions have been made in relation to damage assessment based on past tsunami experience and professional engineering judgment. With approximately four hours of warning time before the first wave arrives in the San Pedro Harbor, it has been estimated there will be at least 2 days in which port operations will come to a halt. The first day will consist of safely shutting down operations, beefing up moorings, 
deploying tug boats, removing vessels where possible, and generally preparing for the tsunami arrival and evacuation of personnel. The second day is allocated for inspection of facilities prior to restoring operations. Not all terminals will be restored to full capacity based on observed damage. All loading and unloading equipment will be disengaged to prevent damage. The following sections summarize these damages.

\section{Impacts on Maritime Activities}

The majority of the impact on maritime activities can be attributed to the container terminals and dry bulk facilities. An important assumption to note is that the gantry crane motors are above water level during inundation, leaving minimal to no damage to cranes during the tsunami. It is possible crane power supply trenches will be flooded as well as some substations. However, discussions with design electrical engineers suggest that long-term damage to these facilities is not likely if they are properly shutdown prior to tsunami arrival. These facilities should be able to power up as soon as they are dried out from flooding.

The inundation levels for the tsunami scenario are insufficient to float any large vessels onto land so there will not be any damage related to this potential mechanism.

When assigning a dollar value to damages, refer to 2011 average value of damages in table 12. Values were retrieved from USA Trade Online (U.S. Census Bureau, 2012b). To obtain damage values in tables 13 through 22, "Value of Damage (\$/TEU)" or "Value of Damage (\$/Metric Ton)" from table 12 were multiplied by numbers in "Projected Throughput impacted on March 27, 2014." Import and exports are noted where available. For container traffic, this information is not readily available. It is suggested that the damage value to containers be distributed based on overall ratio of container imports to container exports.

Table 12. Assigning damage value to the Port of Long Beach and Port of Los Angeles.

[US\$, U.S. dollars; kg, kilograms; TEUs, twenty-foot equivalent units]

\begin{tabular}{llll}
\hline \multicolumn{1}{c}{ Values } & \multicolumn{1}{c}{2009} & \multicolumn{1}{c}{2010} & 2011 \\
\hline Sum of Containerized Vessel Value (US\$) & $\$ 228,372,241,028$ & $\$ 277,098,700,554$ & $\$ 309,743,852,223$ \\
Sum of Containerized Vessel SWT (kg) & $56,871,671,800$ & $65,776,161,955$ & $68,793,600,118$ \\
Sum of TEUs (from kg) & $7,393,931$ & $8,660,123$ & $8,959,111$ \\
Value of Damage (\$/per TEU) & $30,886.44$ & $31,997.09$ & $34,573.06$ \\
Value of Damage (\$/per Metric Ton) & $4,015.57$ & $4,212.75$ & $4,502.51$ \\
\hline
\end{tabular}




\section{Port of Long Beach}

Damage assessment for the Port of Long Beach is presented in table 13 through 16.

Containerized

Table 13. Port of Long Beach container terminal damage.

[TEUs, twenty-foot equivalent units; --, no data; \%, percent]

\begin{tabular}{|c|c|c|c|c|}
\hline Location & $\begin{array}{l}\text { March 27, } \\
2014 \\
\text { Throughput } \\
\text { (TEUs) }\end{array}$ & $\begin{array}{l}\text { Projected } \\
\text { Throughput } \\
\text { impacted on } \\
\text { March } 272014 \\
\text { (TEUs) }\end{array}$ & $\begin{array}{l}\text { Value of } \\
\text { Damage } \\
\text { (U.S. Dollar) }\end{array}$ & Damage Assessment \\
\hline $\begin{array}{l}\text { Pier T Berth } \\
\text { T132-T140 }\end{array}$ & 4,290 & 0 & -- & No damage \\
\hline $\begin{array}{l}\text { Pier G: } \\
\text { Berths G226- } \\
\text { G236 }\end{array}$ & 2,347 & 0 & -- & No damage \\
\hline $\begin{array}{l}\text { Pier F: Berths } \\
\text { F6-F10 }\end{array}$ & 2,120 & 0 & -- & No damage \\
\hline $\begin{array}{l}\text { Pier J: Berths } \\
\text { J243-J247, } \\
\text { J266, J270 }\end{array}$ & 5,096 & 0 & -- & No damage \\
\hline $\begin{array}{l}\text { Pier A : } \\
\text { Berths A88- } \\
\text { A96 }\end{array}$ & 4,234 & 635 & $\$ 21,000,000$ & $15 \%$ loss to daily throughput value \\
\hline $\begin{array}{l}\text { Pier C: Berths } \\
\text { C60-C62 }\end{array}$ & 1,065 & 160 & $\$ 6,000,000$ & $\begin{array}{l}15 \% \text { loss to daily throughput value. } \\
\text { Significant number of containers on } \\
\text { wheels (chassis) }\end{array}$ \\
\hline Total & 19,152 & 795 & $\$ 27,000,000$ & \\
\hline
\end{tabular}


Dry Bulk

Table 14. Port of Long Beach dry bulk damage.

[--, no data; $\%$, percent]

\begin{tabular}{|c|c|c|c|c|c|}
\hline Location & Material & $\begin{array}{l}\text { March } 27 \\
2014^{*} \\
\text { Throughput } \\
\text { (metric tons) }\end{array}$ & $\begin{array}{l}\text { Projected } \\
\text { Throughput } \\
\text { impacted on } \\
\text { March } 272014 \\
\text { (metric tons) }\end{array}$ & $\begin{array}{l}\text { Value of Damage } \\
\text { (U.S. Dollar) }\end{array}$ & Damage Assessment \\
\hline $\begin{array}{l}\text { Pier D- } \\
\text { Berth D46 }\end{array}$ & Gypsum & 205 & 31 & $\$ 140,000$ & $\begin{array}{l}15 \% \text { loss to daily } \\
\text { throughput value; imported } \\
\text { material }\end{array}$ \\
\hline $\begin{array}{l}\text { Pier D- } \\
\text { Berth D32 }\end{array}$ & Cement & 100 & -- & -- & No damage \\
\hline $\begin{array}{l}\text { Pier F- } \\
\text { Berth } \\
\text { F211 }\end{array}$ & $\begin{array}{l}\text { Petroleum } \\
\text { Coke, } \\
\text { prilled } \\
\text { sulfur }\end{array}$ & & 33 & $\$ 148,000$ & $\begin{array}{l}5 \% \text { loss to daily throughput } \\
\text { value; imported material }\end{array}$ \\
\hline $\begin{array}{l}\text { Pier F- } \\
\text { Berth } \\
\text { F208 }\end{array}$ & Cement & 1,954 & -- & & No damage \\
\hline $\begin{array}{l}\text { Pier F- } \\
\text { Berth } \\
\text { F210 }\end{array}$ & Salt & & 65 & $\$ 292,000$ & $\begin{array}{l}10 \% \text { loss to daily } \\
\text { throughput value; imported } \\
\text { material }\end{array}$ \\
\hline $\begin{array}{l}\text { Pier G- } \\
\text { Berths } \\
\text { G212- } \\
\text { G214 }\end{array}$ & $\begin{array}{l}\text { Petroleum } \\
\text { coke, coal, } \\
\text { potash, } \\
\text { borax, } \\
\text { sodium } \\
\text { sulfate, } \\
\text { soda ash, } \\
\text { concentrate } \\
\text { s, and } \\
\text { prilled } \\
\text { sulfur. }\end{array}$ & 19,094 & -- & -- & No damage \\
\hline $\begin{array}{l}\text { Pier B- } \\
\text { Berth B82 }\end{array}$ & Gypsum & $\begin{array}{l}377 \text { metric } \\
\text { tons }\end{array}$ & -- & -- & No damage \\
\hline Total & & $\begin{array}{l}21,730 \text { metric } \\
\text { tons }\end{array}$ & 129 & $\$ 580,500$ & \\
\hline
\end{tabular}


Liquid Bulk

Table 15. Port of Long Beach liquid bulk damage.

[--, no data]

\begin{tabular}{|c|c|c|c|c|c|}
\hline Location & $\begin{array}{l}\text { Cargoes } \\
\text { Served }\end{array}$ & $\begin{array}{c}\text { March } 27 \\
2014 \\
\text { Throughput } \\
\text { (metric tons) }\end{array}$ & $\begin{array}{c}\text { Projected } \\
\text { Throughput } \\
\text { impacted on } \\
\text { March } 27 \\
2014 \\
\text { (metric tons) }\end{array}$ & $\begin{array}{c}\text { Value of Damage } \\
\text { (U.S. Dollar) }\end{array}$ & Damage Assessment \\
\hline $\begin{array}{l}\text { Pier T- } \\
\text { Berth } \\
\text { T121 }\end{array}$ & $\begin{array}{l}\text { Crude oil and } \\
\text { petroleum } \\
\text { products }\end{array}$ & 49,220 & -- & $\begin{array}{l}\$ 50,000 \text { mooring } \\
\text { damage }\end{array}$ & $\begin{array}{l}\text { Damage to mooring } \\
\text { hardware; crippled for } 6 \\
\text { weeks; imported crude oil }\end{array}$ \\
\hline $\begin{array}{l}\text { Pier B- } \\
\text { Berths } \\
\text { B76-80 }\end{array}$ & $\begin{array}{l}\text { Petroleum } \\
\text { products }\end{array}$ & & & & No damage \\
\hline $\begin{array}{l}\text { Pier B } \\
\text { Berth } \\
\text { B82,83 }\end{array}$ & $\begin{array}{l}\text { Gasoline, } \\
\text { ethanol, } \\
\text { gasoline blend } \\
\text { stocks, diesel, } \\
\text { biodiesel }\end{array}$ & 29,300 & -- & -- & No damage \\
\hline $\begin{array}{l}\text { Pier B- } \\
\text { Berth } \\
\text { B84-B87 }\end{array}$ & $\begin{array}{l}\text { Crude oil, } \\
\text { petroleum } \\
\text { products, } \\
\text { bunker fuel. }\end{array}$ & & & & No damage \\
\hline $\begin{array}{l}\text { Pier F- } \\
\text { Berths } \\
\text { F209-211 }\end{array}$ & $\begin{array}{l}\text { Petroleum } \\
\text { products and } \\
\text { bunker fuel }\end{array}$ & 6,350 & -- & -- & No damage \\
\hline $\begin{array}{l}\text { Pier S } \\
\text { Berth } \\
\text { S101 }\end{array}$ & $\begin{array}{l}\text { Miscellaneous } \\
\text { bulk liquid } \\
\text { chemicals }\end{array}$ & 5,580 & -- & $\$ 1,050,000$ & $\begin{array}{l}\text { No damage to products, } \\
\text { facility out of commission } \\
\text { for a month, } \$ 1 \text { million in } \\
\text { building repair. Currently } \\
\text { not in use. Most recently } \\
\text { used as low-sulfur diesel } \\
\text { import. }\end{array}$ \\
\hline
\end{tabular}


Table 16. Port of Long Beach break bulk damage.

[n/a, not applicable; --. no data]

\begin{tabular}{|c|c|c|c|c|c|}
\hline Location & $\begin{array}{l}\text { Equipment/ } \\
\text { Facilities }\end{array}$ & $\begin{array}{l}\text { March } 272014 \\
\text { Throughput }\end{array}$ & $\begin{array}{l}\text { Projected } \\
\text { Throughput } \\
\text { impacted on } \\
\text { March } 27 \\
2014 \\
\text { (metric tons) }\end{array}$ & $\begin{array}{l}\text { Value of Damage } \\
\text { (U.S. Dollar) }\end{array}$ & $\begin{array}{c}\text { Damage } \\
\text { Assessment }\end{array}$ \\
\hline $\begin{array}{l}\text { Pier F } \\
\text { Berths } \\
\text { F204-F205 }\end{array}$ & $\begin{array}{l}\text { Steel products, } \\
\text { plywood, and } \\
\text { lumber. }\end{array}$ & & -- & -- & No damage \\
\hline $\begin{array}{l}\text { Pier F- } \\
\text { Berth F206, } \\
\text { F207 }\end{array}$ & $\begin{array}{l}\text { Steel products, } \\
\text { plywood, lumber, } \\
\text { project cargoes, } \\
\text { and large } \\
\text { machinery. }\end{array}$ & 1,209 metric tons & -- & -- & No damage \\
\hline $\begin{array}{l}\text { Pier F } \\
\text { Berth F201 }\end{array}$ & Standby berth & & -- & -- & No damage \\
\hline $\begin{array}{l}\text { Pier D, } \\
\text { Berth D50- } \\
\text { D54 }\end{array}$ & $\begin{array}{l}\text { Crescent } \\
\text { Warehouse } \\
\text { Company }\end{array}$ & $\mathrm{n} / \mathrm{a}$ & -- & $\mathrm{n} / \mathrm{a}$ & $\begin{array}{l}15 \% \text { loss to daily } \\
\text { throughput value. } \\
\text { recently vacated. }\end{array}$ \\
\hline $\begin{array}{l}\text { Pier T, } \\
\text { Berth T122 }\end{array}$ & $\begin{array}{l}\text { Lumber and } \\
\text { Lumber products }\end{array}$ & & -- & $\$ 50,000$ & $\begin{array}{l}\text { Mooring damage, } 1 \\
\text { month down time. } \\
\text { Import material. }\end{array}$ \\
\hline $\begin{array}{l}\text { Pier T } \\
\text { Berth T118 }\end{array}$ & $\begin{array}{l}\text { Recyclable metal } \\
\text { and steel } \\
\text { products. }\end{array}$ & 2,474 metric tons & -- & $\$ 50,000$ & $\begin{array}{l}\text { Mooring damage, } 1 \\
\text { month down time. } \\
\text { Export material. }\end{array}$ \\
\hline $\begin{array}{l}\text { Pier T- } \\
\text { Berth T122 }\end{array}$ & $\begin{array}{l}\text { Lumber and } \\
\text { lumber products. } \\
\text { Automobiles, }\end{array}$ & & -- & -- & No damage \\
\hline $\begin{array}{l}\text { Pier B } \\
\text { Berth B82, } \\
\text { B83 }\end{array}$ & $\begin{array}{l}\text { Office building, } \\
\text { processing } \\
\text { buildings, body } \\
\text { shop and car wash }\end{array}$ & 2,000 vehicles & 2,000 vehicles & $\begin{array}{l}(\$ 24,000 / \text { vehicle }) \\
\$ 48,000,000\end{array}$ & $\begin{array}{l}100 \% \text { vehicle } \\
\text { damaged. Imported } \\
\text { vehicles. }\end{array}$ \\
\hline Total & & & 2,000 vehicles & $\$ 48,100,000$ & \\
\hline
\end{tabular}

Notes: The average value lost for an automobile is taken to be $\$ 24,000 /$ vehicle. The figure extrapolates from 2010 retail values of import vehicles according to the U.S. Census Bureau (2012a), reduced by 13 percent for retail markup per Kelley Blue Book (2013) and TrueCar (2013). 
Port of Long Beach Damage Summary

Table 17. Port of Long Beach damage summary.

[TEUs, twenty-foot equivalent units; --, no data]

\begin{tabular}{lll} 
Cargo Type & $\begin{array}{c}\text { Projected } \\
\text { Throughput } \\
\text { impacted on March } \\
\mathbf{2 7} \mathbf{2 0 1 4}\end{array}$ & \multicolumn{1}{c}{$\begin{array}{c}\text { Value of Damage } \\
\text { (U.S. Dollar) }\end{array}$} \\
\hline $\begin{array}{l}\text { Containerized } \\
\text { Dry Bulk }\end{array}$ & $\begin{array}{l}\text { 795 TEUs } \\
\text { 129 metric tons }\end{array}$ & $\$ 27,000,000$ \\
Liquid Bulk & -- & $\$ 580,500$ \\
Break Bulk & 2,000 vehicles & $\$ 1,050,000$ \\
Total & & $\$ 48,100,000$ \\
\hline
\end{tabular}




\section{Port of Los Angeles}

Damage assessment for the Port of Los Angeles is presented in tables 18 through 23 .

Refer to table 12 for average damage values per cargo type.

Containerized

Table 18. Port of Los Angeles container terminal damage.

[TEUs, twenty-foot equivalent units; --, no data; \%, percent]

\begin{tabular}{|l|l|l|l|l|}
\hline Location & $\begin{array}{c}\text { Projected } \\
\text { throughput on } \\
\text { March 27, } \\
2014 \text { (TEUs) }\end{array}$ & $\begin{array}{c}\text { Projected } \\
\text { Throughput } \\
\text { impacted on } \\
\text { March 27, 2014 } \\
\text { (TEUs) }\end{array}$ & $\begin{array}{c}\text { Value of } \\
\text { Damage (U.S. } \\
\text { Dollar) }\end{array}$ & \multicolumn{1}{|c|}{ Damage Assessment } \\
\hline $\begin{array}{l}\text { Berths } \\
\mathbf{1 0 0 - 1 0 2}\end{array}$ & 1,270 & -- & -- & No Damage \\
\hline $\begin{array}{l}\text { Berths } \\
\mathbf{1 2 1 - 1 3 1}\end{array}$ & 2,590 & -- & -- & No Damage \\
\hline $\begin{array}{l}\text { Berths } \\
\mathbf{1 3 5 - 1 3 9}\end{array}$ & 2,410 & 241 & $\$ 8,314,500$ & $10 \%$ loss to daily throughput value \\
\hline $\begin{array}{l}\text { Berths } \\
\mathbf{2 0 6 - 2 0 9}\end{array}$ & 1,200 & -- & -- & No Damage, No longer used as terminal \\
\hline $\begin{array}{l}\text { Berths } \\
\mathbf{2 1 2 - 2 2 5}\end{array}$ & 2,575 & -- & -- & No Damage \\
\hline $\begin{array}{l}\text { Berths } \\
\mathbf{2 2 6 - 2 3 6}\end{array}$ & 2,860 & -- & -- & No Damage \\
\hline $\begin{array}{l}\text { Berths } \\
\mathbf{3 0 2 - 3 0 5}\end{array}$ & 4,100 & -- & -- & No Damage \\
\hline $\begin{array}{l}\text { Berths } \\
\mathbf{4 0 1 - 4 0 4}\end{array}$ & 6,470 & -- & -- & No Damage \\
\hline $\begin{array}{l}\text { Berths } \\
\mathbf{4 0 5 - 4 0 6}\end{array}$ & 1,270 & -- & $\$ 8,314,500$ & No Damage \\
\hline Total & 25,000 & 241 & & - \\
\hline
\end{tabular}


Dry Bulk

Table 19. Port of Los Angeles dry bulk damage.

\begin{tabular}{|c|c|c|c|c|c|}
\hline Location & $\begin{array}{l}\text { Terminal } \\
\text { features }\end{array}$ & $\begin{array}{l}\text { Projected } \\
\text { throughput on } \\
\text { March 27, } 2014 \\
\text { (metric tons) }\end{array}$ & $\begin{array}{c}\text { Projected } \\
\text { Throughput } \\
\text { impacted on } \\
\text { March } 272014 \\
\text { (metric tons) }\end{array}$ & $\begin{array}{l}\text { Value of } \\
\text { Damage }\end{array}$ & Damage Assessment \\
\hline $\begin{array}{l}\text { Berths } \\
165-166\end{array}$ & $\begin{array}{l}\text { Industrial } \\
\text { borates }\end{array}$ & 843 & 85 & $\$ 382,000$ & $\begin{array}{l}10 \% \text { loss to daily } \\
\text { throughput, Out of } \\
\text { commission for } 2 \text { weeks. } \\
\text { Off-line for } 2 \text { weeks for } \\
\text { cleanup. Exported } \\
\text { material. }\end{array}$ \\
\hline $\begin{array}{l}\text { Berths } \\
210-211\end{array}$ & $\begin{array}{l}\text { Handles all } \\
\text { grades of } \\
\text { ferrous and } \\
\text { non-ferrous } \\
\text { scrap metals } \\
\end{array}$ & 3,212 & -- & -- & No Damage \\
\hline Total & & 4,055 & 27.4 & $\$ 382,000$ & \\
\hline
\end{tabular}


Liquid Bulk

Table 20. Port of Los Angeles liquid bulk damage.

\begin{tabular}{|c|c|c|c|c|c|}
\hline Location & Use: & $\begin{array}{l}\text { Projected } \\
\text { throughput on } \\
\text { March 27, } \\
2014 \text { (metric } \\
\text { tons) }\end{array}$ & $\begin{array}{l}\text { Projected } \\
\text { Throughput } \\
\text { impacted on } \\
\text { March 27, } \\
2014\end{array}$ & $\begin{array}{c}\text { Value of } \\
\text { Damage (U.S. } \\
\text { Dollar) }\end{array}$ & Damage Assessment \\
\hline $\begin{array}{l}\text { Berths } \\
118-120\end{array}$ & $\begin{array}{l}\text { Receiving } \\
\text { exporting } \\
\text { petroleum } \\
\text { products }\end{array}$ & 2,695 & -- & -- & No Damage \\
\hline $\begin{array}{l}\text { Berths } \\
\text { 148-151 }\end{array}$ & $\begin{array}{l}\text { Vessel } \\
\text { unloading of } \\
\text { partly or } \\
\text { fully refined } \\
\text { petroleum } \\
\text { products }\end{array}$ & 1,361 & -- & -- & $\begin{array}{l}\text { No damage. Containment walls } \\
\text { or berms protect tanks }\end{array}$ \\
\hline Berth 163 & Marine oil & 812 & -- & -- & $\begin{array}{l}\text { No damage to product. Facility } \\
50 \% \text { capacity for } 1 \text { month. } \\
\text { Imported material }\end{array}$ \\
\hline Berth 164 & $\begin{array}{l}\text { Fuels and } \\
\text { lubricants }\end{array}$ & 4,030 & -- & -- & $\begin{array}{l}\text { No damage to product. Facility } \\
50 \% \text { capacity for } 1 \text { month. } \\
\text { Imported and exported material }\end{array}$ \\
\hline $\begin{array}{l}\text { Berths } \\
167-169\end{array}$ & $\begin{array}{l}\text { Fuels and } \\
\text { lubricants }\end{array}$ & 5,237 & -- & -- & $\begin{array}{l}\text { No damage to product. Facility } \\
50 \% \text { capacity for } 1 \text { month. } \\
\text { Imported and exported material }\end{array}$ \\
\hline $\begin{array}{l}\text { Berths } \\
187-191\end{array}$ & $\begin{array}{l}\text { Liquid bulk } \\
\text { chemical } \\
\text { products }\end{array}$ & 11,778 & -- & -- & $\begin{array}{l}\text { No damage to product. facility } \\
\text { down } 50 \% \text { capacity for } 1 \\
\text { month. Imported and exported } \\
\text { material }\end{array}$ \\
\hline $\begin{array}{l}\text { Berths } \\
\text { 238-240C }\end{array}$ & $\begin{array}{l}\text { Fuels and } \\
\text { lubricants }\end{array}$ & 229 & -- & $\$ 50,000$ & $\begin{array}{l}\text { Damage to mooring equipment, } \\
\text { no product damage. Imported } \\
\text { crude. Alternate berth available }\end{array}$ \\
\hline Total & & 21,428 & -- & $\$ 50,000$ & \\
\hline
\end{tabular}




\section{Automobile}

The average wholesale value for automobile damage is taken to be $\$ 24,000 /$ vehicle. The figure extrapolates from 2010 retail values of import vehicles according to the U.S. Census Bureau (2012a), reduced by 13 percent for retail markup per Kelley Blue Book (2013) and TrueCar (2013).

Table 21. Port of Los Angeles automobile damage. $[\%$, percent $]$

\begin{tabular}{|l|l|l|l|l|l|}
\hline Location & Terminal features & $\begin{array}{c}\text { Projected } \\
\text { automobiles on } \\
\text { March 27, 2014 }\end{array}$ & $\begin{array}{c}\text { Automobiles } \\
\text { impacted on } \\
\text { March 27, 2014 }\end{array}$ & $\begin{array}{c}\text { Value of } \\
\text { Damage (U.S. } \\
\text { Dollar) }\end{array}$ & Damage Assessment \\
\hline $\begin{array}{l}\text { Berths } \\
\mathbf{1 9 5 - 1 9 9}\end{array}$ & $\begin{array}{l}\text { Storage capacity } \\
\text { up to 8000 } \\
\text { vehicles }\end{array}$ & 6,400 & 650 & $\$ 15,600,000$ & $\begin{array}{l}10 \% \text { vehicles damaged. } \\
\text { Imported vehicles. }\end{array}$ \\
\hline
\end{tabular}

Break Bulk

Table 22. Port of Los Angeles break bulk damage.

[n/a, not applicable; --, no data; \%, percent]

\begin{tabular}{|l|l|l|l|l|l|}
\hline \multicolumn{1}{|c|}{ Location } & $\begin{array}{c}\text { Terminal } \\
\text { features }\end{array}$ & $\begin{array}{c}\text { Projected } \\
\text { throughput on } \\
\text { March 27, } \\
2014 \text { (metric } \\
\text { tons) }\end{array}$ & $\begin{array}{c}\text { Projected } \\
\text { Throughput } \\
\text { impacted on } \\
\text { March 27 2014 } \\
\text { (metric tons) }\end{array}$ & $\begin{array}{c}\text { Value of } \\
\text { Damage } \\
\text { (U.S. Dollar) }\end{array}$ & Damage Assessment \\
\hline Berths 49-53 & $\begin{array}{l}\text { Use: break } \\
\text { bulk steel }\end{array}$ & $\mathrm{n} / \mathrm{a}$ & -- & -- & No damage \\
\hline Berths 54-55 & $\begin{array}{l}\text { Imported } \\
\text { meats, } \\
\text { Chilean fruit, } \\
\text { kiwis, apples }\end{array}$ & 327 & -- & -- & No damage \\
\hline Total & Steel & 5,357 & 535 & $\$ 2,408,850$ & $\begin{array}{l}\text { 10\% product damage, } \\
\text { Building out of } \\
\text { commission for 2 } \\
\text { weeks. Imported } \\
\text { material. }\end{array}$ \\
\hline
\end{tabular}

Small Craft Basins

All marinas located where the East Basin and Cerritos Channel meet will experience significant damage. The majority of the marinas will experience some damage, as they will be directly exposed to the current velocities. Damage to small craft basins marinas is addressed elsewhere in this chapter. 
Table 23. Port of Los Angeles marina damage.

\begin{tabular}{|l|l|l|l|}
\hline \multicolumn{1}{|c|}{ Marina Name } & \multicolumn{1}{c|}{ Slips } & \multicolumn{1}{c|}{ Slips Affected } & Value of Damage \\
\hline Al Larson's Marina & Berth 258 & 128 & 50 \\
\hline Cabrillo Beach Yacht Club & Berth 35 & 184 & 50 \\
\hline Cabrillo Way Marina & Berths 42-43 & 697 & 100 \\
\hline $\begin{array}{l}\text { California Yacht Marina- } \\
\text { Cabrillo Marina }\end{array}$ & Berth 29-33 & 885 & 100 \\
\hline California Yacht Marina & Berth 202 & 266 & 266 \\
\hline Cerritos Yacht Anchorage & Berth 205 & 90 & 90 \\
\hline Holiday Harbor-Fleitz Bros. & Berth 34 & 300 & 300 \\
\hline Holiday Harbor & Berth 201 & 169 & 169 \\
\hline Island Yacht Anchorage \#1 & Berth 205 & 22 & 22 \\
\hline Island Yacht Anchorage \#2 & Berth 200X & 116 & 116 \\
\hline Leeward Bay Marina & Berth 201 & 190 & 190 \\
\hline Lighthouse Yacht Landing & chapter in this \\
\hline Pacific Yacht Landing & Berth 205 & 70 & 70 \\
\hline San Pedro Marina & Berth 203 & 178 & 178 \\
\hline Yacht Centre-Newmarks & Berth 80 & 85 & 20 \\
\hline Yacht Haven Marina & Berth 202 & 250 & 250 \\
\hline
\end{tabular}




\section{Port of Los Angeles Damage Summary}

Table 24. Port of Los Angeles damage summary.

[TEUs, twenty-foot equivalent units; --, no data]

\begin{tabular}{|l|l|l|}
\multicolumn{1}{|c|}{ Cargo Type } & $\begin{array}{c}\text { Projected Throughput impacted } \\
\text { on March 27, 2014 }\end{array}$ & \multicolumn{1}{c|}{$\begin{array}{c}\text { Value of Damage } \\
\text { (U.S. Dollar) }\end{array}$} \\
\hline Containerized & 241 TEUs & $\$ 8,314,500$ \\
\hline Dry Bulk & 27.4 metric tons & $\$ 382,000$ \\
\hline Liquid Bulk & -- & $\$ 50,000$ \\
\hline Automobiles & 650 metric tons & $\$ 15,600,000$ \\
\hline Break Bulk & 535 metric tons & $\$ 2,408,850$ \\
\hline Small Craft Marina & 2,000 slips & (elsewhere in this chapter) \\
\hline Total & & $\$ 26,755,350$ \\
\hline
\end{tabular}

\section{General Damage Discussion}

Mooring design of the terminals in POLA/POLB typically includes a mooring analysis for the proposed vessels that incorporates winds, waves, and current forcing to the moored vessels to compute loads on the mooring components, including mooring lines, bollards, and fenders. When mooring loads resulting from high currents representative of a tsunami are compared with the loads generated by design wind speeds, generally the loads resulting from the winds are the controlling factor for design purposes. This is particularly true for container vessels with high wind profiles due to the stacked containers. The currents can be more of a contributing factor for liquid bulk carriers, as their wind profile is less and the draft more significant. However, the bulk of the currents adjacent to the liquid bulk terminals in both ports do not generally appear to be sufficient to overload the mooring components to the extent that the vessels would become free floating. Some damage to the mooring components is expected and has been included in the assessment. Alternate moorings would be available to prevent loss of terminal function at Port of Long Beach Berths T118, 121, and 122.

Where automobiles are indicated as being damaged, it is assumed that the damage will be limited to the vehicles and they will not become free-floating debris items in the navigation channel. This assumption is based on the limited water depth over the automobile storage facilities, relatively small currents, and the fact that the storage facilities are located some distance inland from the pier headline. Removal of the vehicles following the tsunami will entail shipping them inland in the normal manner to scrap yards.

There is some commercial fishing activity in the Port of Los Angeles located within Fish Harbor and adjacent to Ports O Call. Damage to fishing vessels and other small craft is addressed elsewhere in this chapter. The inundation limits along the boundary of Fish Harbor are along the fringe of the basin and suggest some flooding of the waterfront area and possibly damaging some of the associated fish processing and shipping facilities.

\section{Tsunami Impacts on Container Terminal Operations}

With approximately 4 hours of warning before the first wave arrives in the San Pedro Harbor, it is realistic that there will be at least 2 days in which port operations will come to a halt. The first day during the tsunami propagation will consist of strategically and safely shutting down operations. The second day will consist of inspections of the facilities to identify any 
damage. Some terminals may be up and running after the tsunami warning is cancelled on Saturday 29 March. Gate operations will cease and all personnel will follow evacuation procedures. All loading and unloading equipment will be disengaged to prevent damage.

\section{Tsunami Impacts on Truck and Rail Movement}

With a warning time of 3.5 hours, teamsters will have time to remove trucks to an offsite location away from the inundation areas. (Rail is addressed elsewhere in this chapter) Continued truck movement may involve movement of vehicles away from inundation areas to prevent damage or relocation of other equipment that may potentially be harmed. Once the port is evacuated, all truck movement will come to a halt until the tsunami warning is cancelled. After the third day, it is believed that there will be minimal impact on truck and rail movement due to a tsunami of this magnitude. The simulated tsunami inundation at the rail and road bridge to Pier 400 will come close to the soffit of the superstructure, but is not expected to impact the superstructure or damage the bridges. The high currents may dislocate some of the armor stone protecting the bridge abutments and channel area, but should not undercut the foundations. The armor stone was designed to accommodate expected high current speeds when constructed.

\section{Damage to Lifelines}

All electrical wiring and equipment inside vaults and pull boxes are continuously submersible. At the first warning of a tsunami, substations will be powered down to prevent any possible damage to equipment and protective devices. Drying out of equipment should only take a few days to a week. There does not appear to be significant damage to major SCE power vaults from water levels and inundation limits. Water runoff should only take a few days to clear and should have minimal impact to POLA/POLB operations.

\section{Damage to Other West Coast Ports}

The tsunami scenario impacts are modeled for other major ports along the Pacific coast including San Diego, Port Hueneme, San Francisco, Oakland, Richmond, and Redwood City. These are potential alternate ports where vessels could call when the Ports of Los Angeles and Long Beach are not available. However, these ports are not likely to be available during the tsunami event or possibly for days afterward. No detailed assessment of the tsunami damage to these other ports was conducted as part of this project. Some general observations are discussed in this section.

\section{Damage to Other Southern California Ports}

The Port of San Diego operates two marine terminals, neither of which would be inundated by the tsunami. They would be expected to have minimal damage. However, there are a large number of navy piers that may be flooded and vessels may be present. Navy procedures typically call for vessels to leave port if possible. Remaining vessels may have some damage to the mooring components due to the water level fluctuation and/or high currents. Supplies on piers may be floated off causing debris issues. The major issue within the Port of San Diego area is the numerous small craft basins that will likely sustain significant damage due to the high currents and lesser design criteria compared to commercial and naval facilities. For example, strong currents damaged docks and boats around Shelter Island during the 2011 Tohoku and 2010 Chile tsunamis (Wilson and others, 2012). Free-floating small craft are likely to create a 
significant debris problem following the tsunami. Note that marina damage in San Diego is addressed later in this chapter.

Port Hueneme specializes in shipping break bulk cargo, palletized produce, and automobile imports and exports. The extent of the inundation is expected to cause damage to several warehouses and operations buildings. The automobile import/export terminal would not be flooded, and automobiles are not expected to be damaged. The detailed tsunami modeling indicates currents as high as 12 nautical miles per hour (kt) in the entrance channel, which is sufficient for possible scour of the channel and possible damage to the toe armor of the jetties. The scour will possibly deposit sediment in the interior of the harbor that will require maintenance dredging following the tsunami.

\section{Damage to the Port of San Francisco}

Farther north along the California coast, the ports in the San Francisco Bay (San Francisco, Oakland, and Richmond, and Redwood City) would also be affected by the tsunami. They would have 30 minutes less warning time than the southern California ports. In this hypothetical event, NOAA posts a tsunami watch for the San Francisco Bay within a few minutes after the earthquake (here, 11:54 a.m. PDT on Thursday March 27, 2014), and upgrades it to a tsunami warning at 2:05 p.m., 3 hours before the first wave's estimated arrival time at 5:02 p.m. At 2:05 p.m., NOAA estimates wave heights in San Francisco of $2.1 \mathrm{ft} \pm 0.6 \mathrm{ft}(0.64 \mathrm{~m} \pm$ $0.18 \mathrm{~m}$; NOAA's simulated tsunami messages use U.S. units, so these are repeated here first) and a duration of $9 \mathrm{hr}$. The estimated wave height at San Francisco increases with later tsunami messages, reaching $2.7 \mathrm{ft} \pm 0.8 \mathrm{ft}(0.82 \mathrm{~m} \pm 0.24 \mathrm{~m})$ at 5:02 p.m., $2.9 \mathrm{ft} \pm 0.9 \mathrm{ft}(0.88 \mathrm{~m} \pm 0.27$ $\mathrm{m})$ at 6:02 p.m., by which time a buoy at station 46026, 20 miles (17.4 nautical miles) west of the Golden Gate, has observed a maximum wave height of $3.4 \mathrm{ft}(1.0 \mathrm{~m})$, which ultimately reaches $3.7 \mathrm{ft}(1.1 \mathrm{~m})$. The warning is downgraded to an advisory at 8:02 p.m. on Friday 28 March, 32 hours after the earthquake. It is cancelled at 12 p.m. PDT on Saturday 29 March, 48 hours after the earthquake.

The tsunami model used in this study estimates wave heights in excess of $2 \mathrm{~m}(6 \mathrm{ft})$ at the Golden Gate in approximately the 3rd wave about 90 minutes after the $1^{\text {st }}$, around 6:30 p.m., as illustrated in figure 36 .

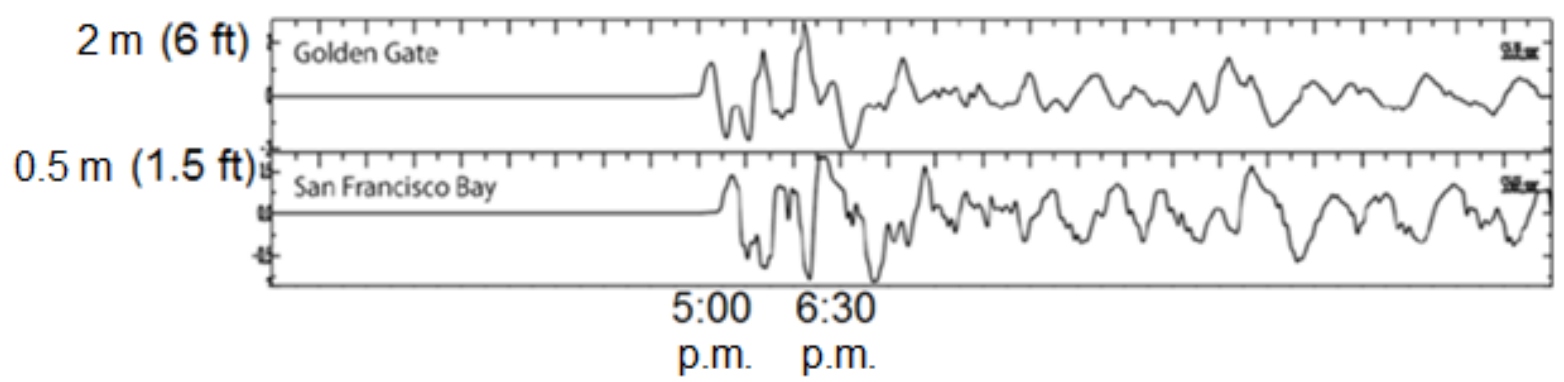

Figure 36. Marigrams in San Francisco Bay area for the SAFRR tsunami scenario ( $\mathrm{m}$, meters; $\mathrm{ft}$, feet).

Maximum wave amplitudes above MHW+20 vary throughout the San Francisco Bay area, reaching $5 \mathrm{~m}(15 \mathrm{ft})$ in along the Pacific Coast and parts of the bay's shore, as shown in figure 37. The tsunami is expected to cause flooding along the San Francisco Embarcadero, with flow depths of 1-2 m (3-6 ft). Currents along the Embarcadero reach 5-10 m/sec (10-20 kt); see figure 38 . 


\section{Damage to Port of San Francisco Headquarters Building}

The Port of San Francisco has its offices at Pier 1, which is estimated as being flooded to a depth of 1-2 m (3-6 ft). The 1st floor of the office would be heavily damaged by that level of inundation. Crucial computer equipment is on the upper level of the port headquarters and so would probably escape damage, but the two 300 kilowatt $(\mathrm{kW})$ generators are on the 1st floor and would be damaged. Commercial space in lowrise reinforced concrete shearwall buildings can take 3 months to repair after experiencing $130 \mathrm{~m}^{3} / \mathrm{sec}^{2}$ momentum flux (maximum depth does not occur at the same time as maximum velocity), so the headquarters would be inoperative for months during repair. The port does not have a backup operations facility, and would most likely operate at least temporarily out of the San Francisco Emergency Operations Center.

Commercial Real Estate at the Port of San Francisco

The port derives much of its revenue from the rental of commercial real estate $(\$ 59$ million of $\$ 73$ million total revenue in fiscal year 2011-2012), especially at Pier 39 and the Ferry Building, both of which are modeled as flooding to a depth of 1-2 m (3-6 ft, see figure 39) and maximum velocities of 5-10 m/sec (10-20 kt), and so would likely be inoperative for several months. Leases assign responsibility for cleanup, and may vary between tenants. It was unclear from conversations with port personnel whether the real estate division maintains emergency plans for such a contingency, although they do have radios for emergency communication and expect to warn tenants using their Cooper Industries notification system. Within the port's commercial real estate, the largest impacts would be to Pier 39 and Fisherman's Wharf, which are visited by 14 million tourists per year. The cruise terminal at Pier 27 is modeled as being vacant (no cruise ship there) at the time of the tsunami. Damage to the cruise terminal would likely displace cruise activities for up to a season. 

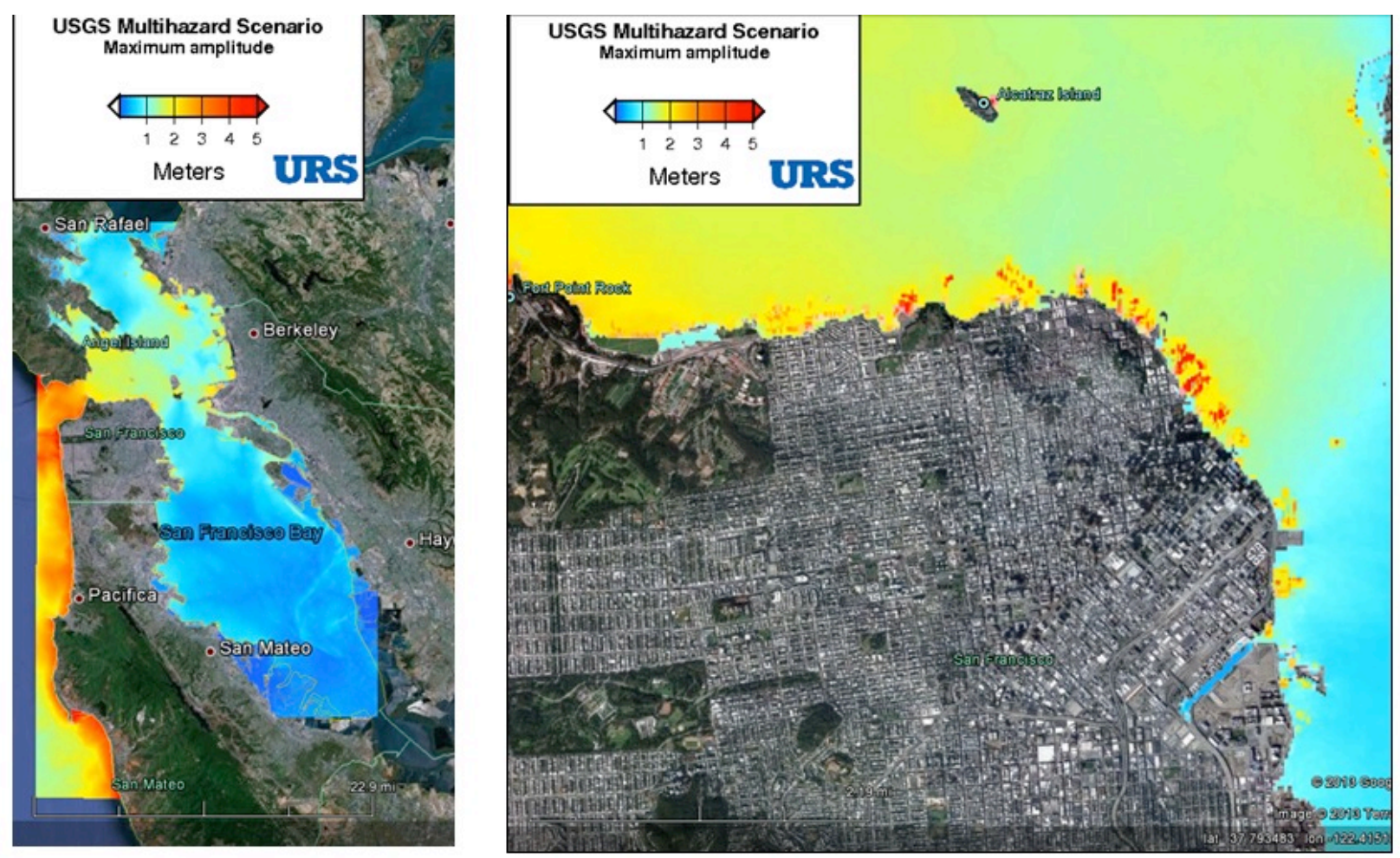

Figure 37. Wave amplitudes in the San Francisco Bay area for the SAFRR tsunami scenario.
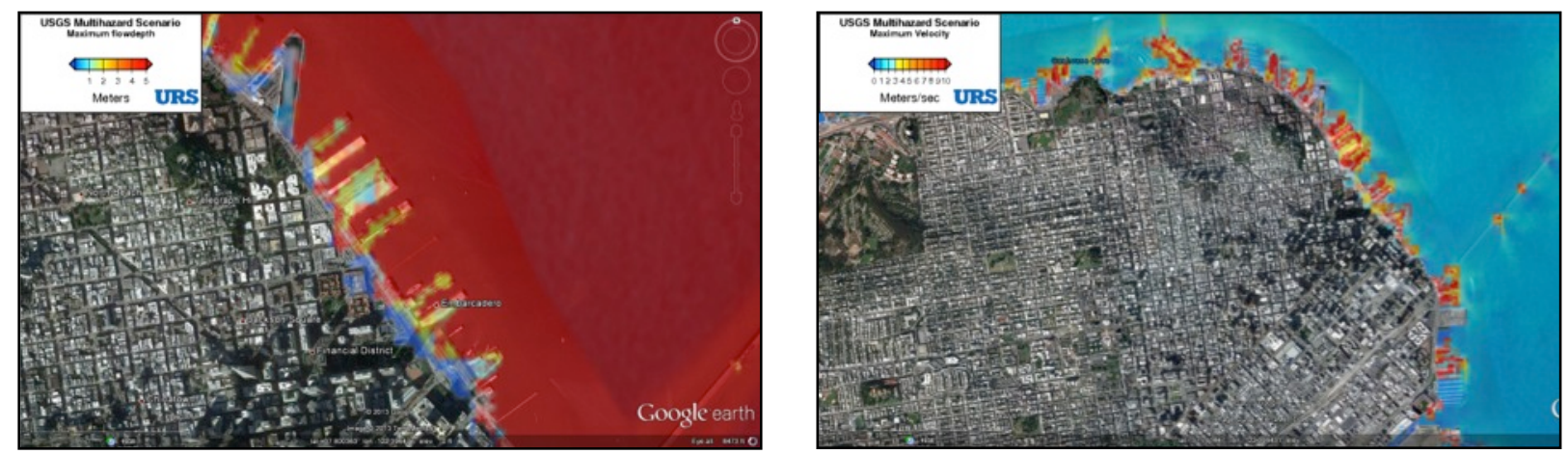

Figure 38. Flooding along the San Francisco Embarcadero reaches 1 to 2 meters and wave velocities reach 5 to 10 meters per second (10-20 knots) in the SAFRR tsunami scenario. 


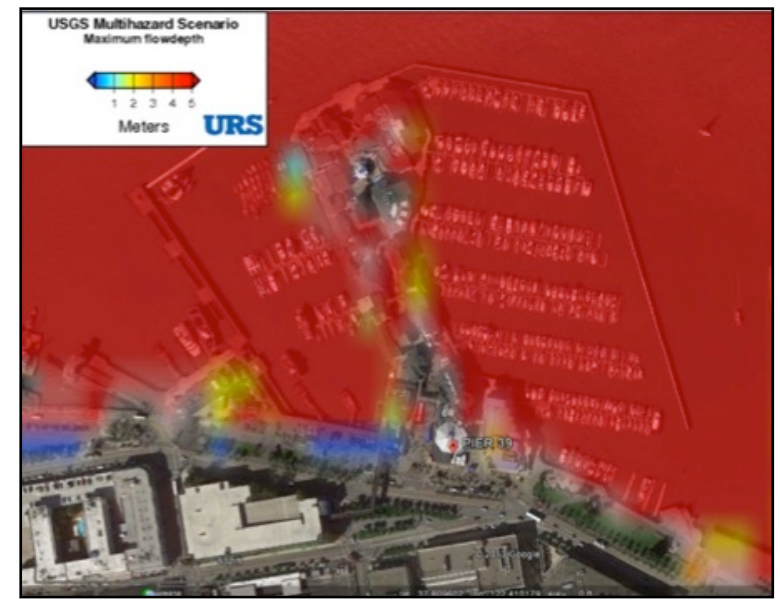

A

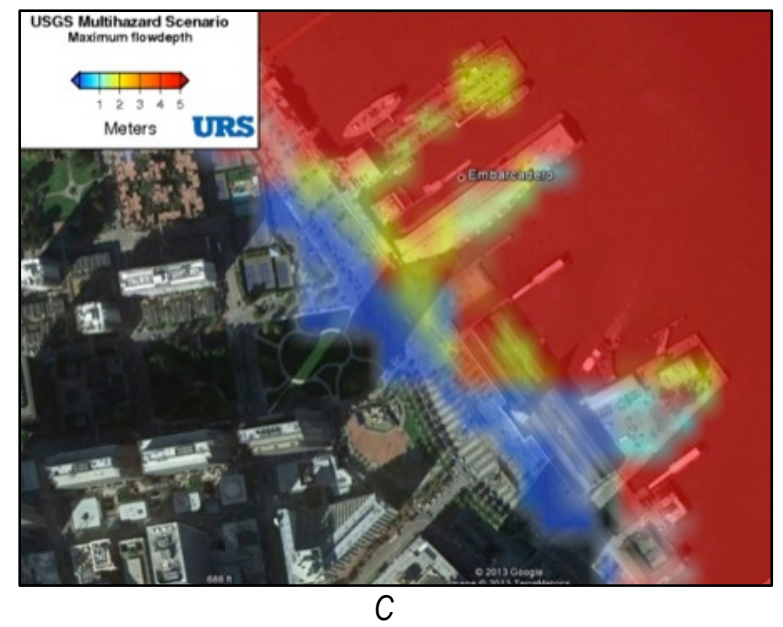

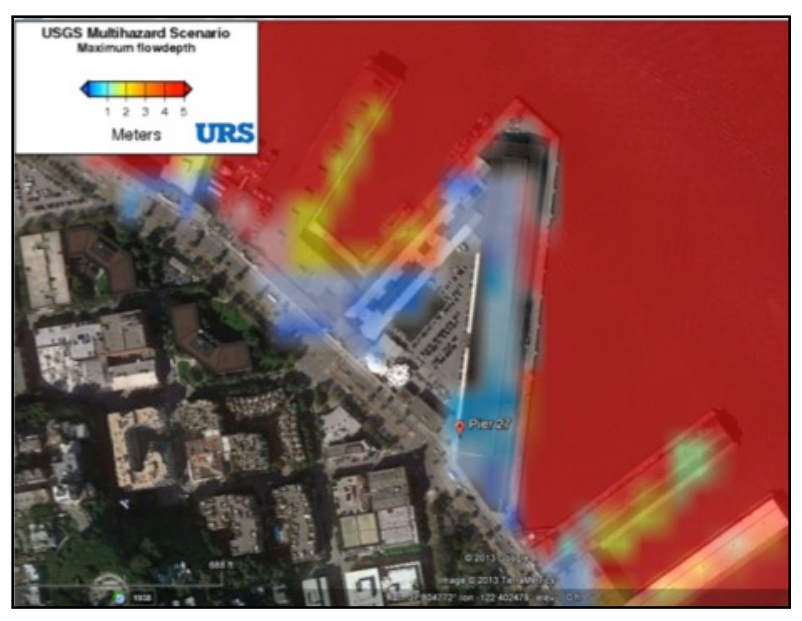

B

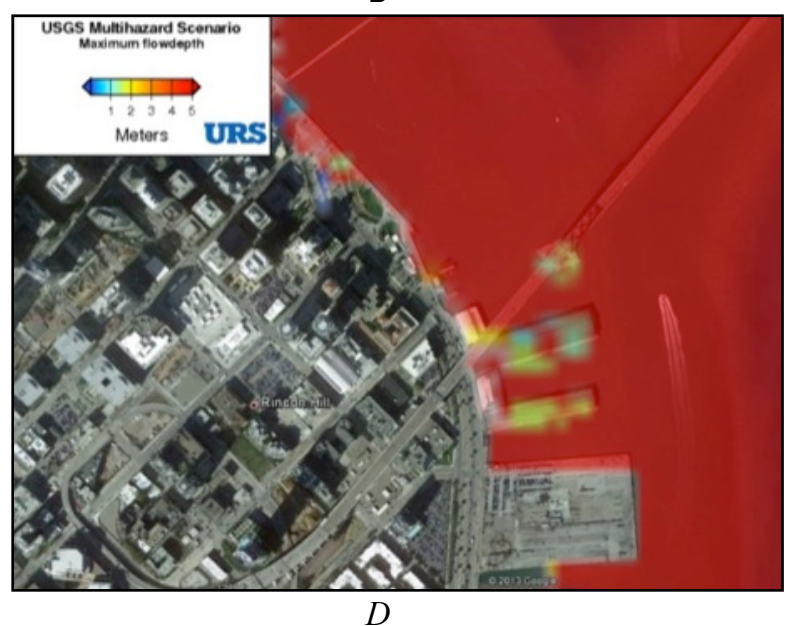

Figure 39. Inundation along the San Francisco Embarcadero in the SAFRR tsunami scenario: A, Pier 39; $B$, Pier 27; C, Pier 1 and Ferry Building; and D, Pier 26.

\section{Ferry Operations}

It is unclear whether the tsunami could damage the access gangways for ferries. As long as the collars do not get damaged, port personnel believe that ferry operations would not be impacted by damage, although debris on the piers at ferry berths would have to be cleaned up before ferry operations could resume.

\section{Cargo Operations at the Port of San Francisco}

The Port of San Francisco handles approximately 1 million tons of cargo annually (1.24 million in calendar year 2012) from approximately 40 cargo vessel calls annually at Piers 80,94 , and 96 . Because these piers are occasionally flooded simply by high tides, they would certainly be flooded in the tsunami scenario. Most of the cargo is imported breakbulk (1.21 million tonslargely steel and aggregate) that port personnel believe would be undamaged by flooding. However, the cargo office would be damaged just as would be the headquarters building, along with equipment such as forklifts. There might be one or two cargo vessels berthed at the time of the tsunami. Port personnel believe that in the event of a tsunami warning, harbor staff would alert vessel masters to move their vessel to the southern part of the San Francisco Bay. As 
previously noted, there would be approximately 3 hours between the time NOAA issued a tsunami warning for the San Francisco Bay and the arrival of the 1st wave. With currents near the waterfront of 5-10 m/sec (10-20 kt; see fig. 40), vessels that were unmoored but still near the waterfront when the tsunami first arrived would be nearly impossible to control, so the timely movement of vessels would be crucial to avoiding damage to the vessels and piers.
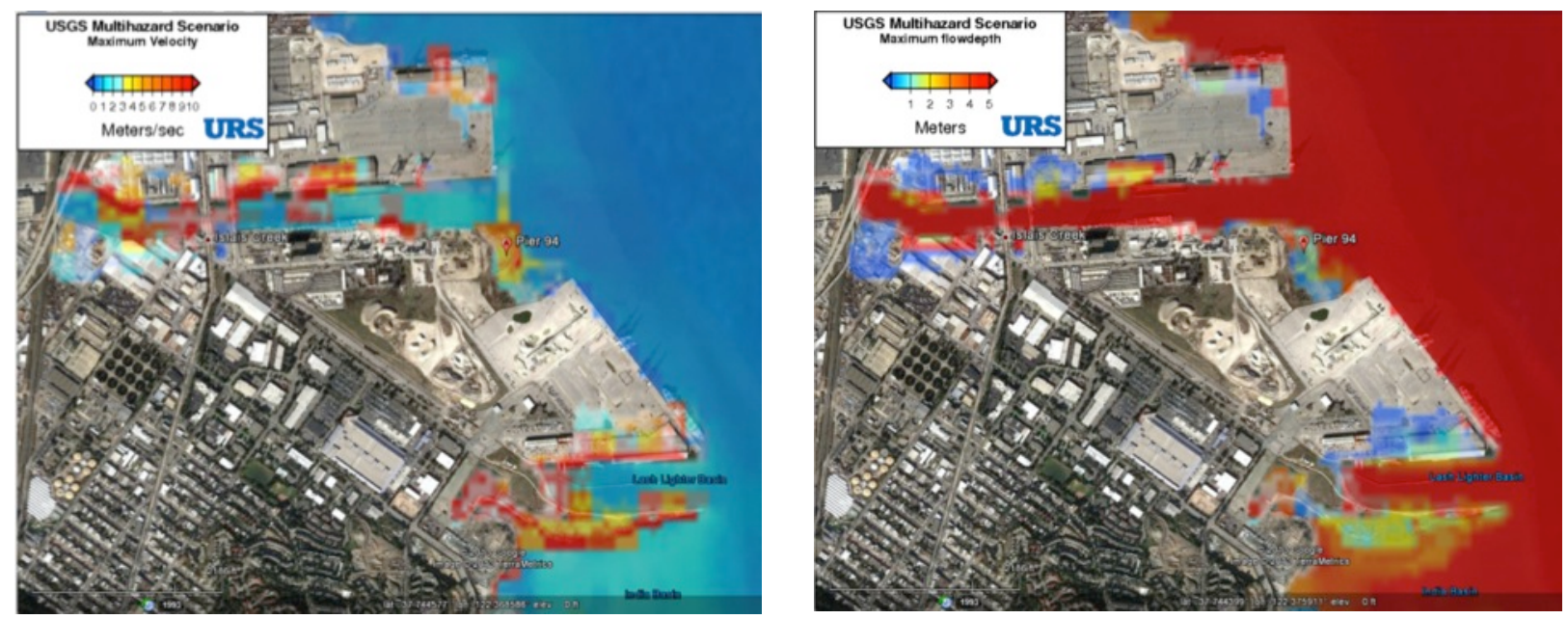

Figure 40. Velocities (left) and flow depth (right) at Port of San Francisco cargo piers in the SAFRR tsunami scenario.

\section{Commercial Fishing Fleet}

There are approximately 180 boats in the commercial fishing fleet at Pier 45 . Port personnel believe that active boats would be moved to the southern bay, but since March is largely an idle time for the commercial fishing fleet, that would amount to only approximately 40 of the 180 boats. The inner lagoon, where 120 of the boats are berthed, is estimated to experience 2 to $8 \mathrm{~m} / \mathrm{sec}(4-16 \mathrm{kt})$ currents, enough to damage or sink commercial boats remaining there. (Port personnel expect that no more than 20 percent of the owners of boats in the recreational marinas would be close enough to move their boats during the available warning time. Recreational marinas are addressed later in this chapter.) Pier 45 also has a fish processing and

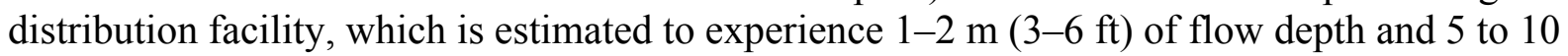
$\mathrm{m} / \mathrm{sec}(10-20 \mathrm{kt})$ velocity. This would be sufficient to cause heavy damage to the processing and distribution facility and render it inoperative for at least several months. Port personnel believe that dock repairs could render the fishing pier inoperative for a year, and that dock repairs might not be completed for as much as 2 years. 

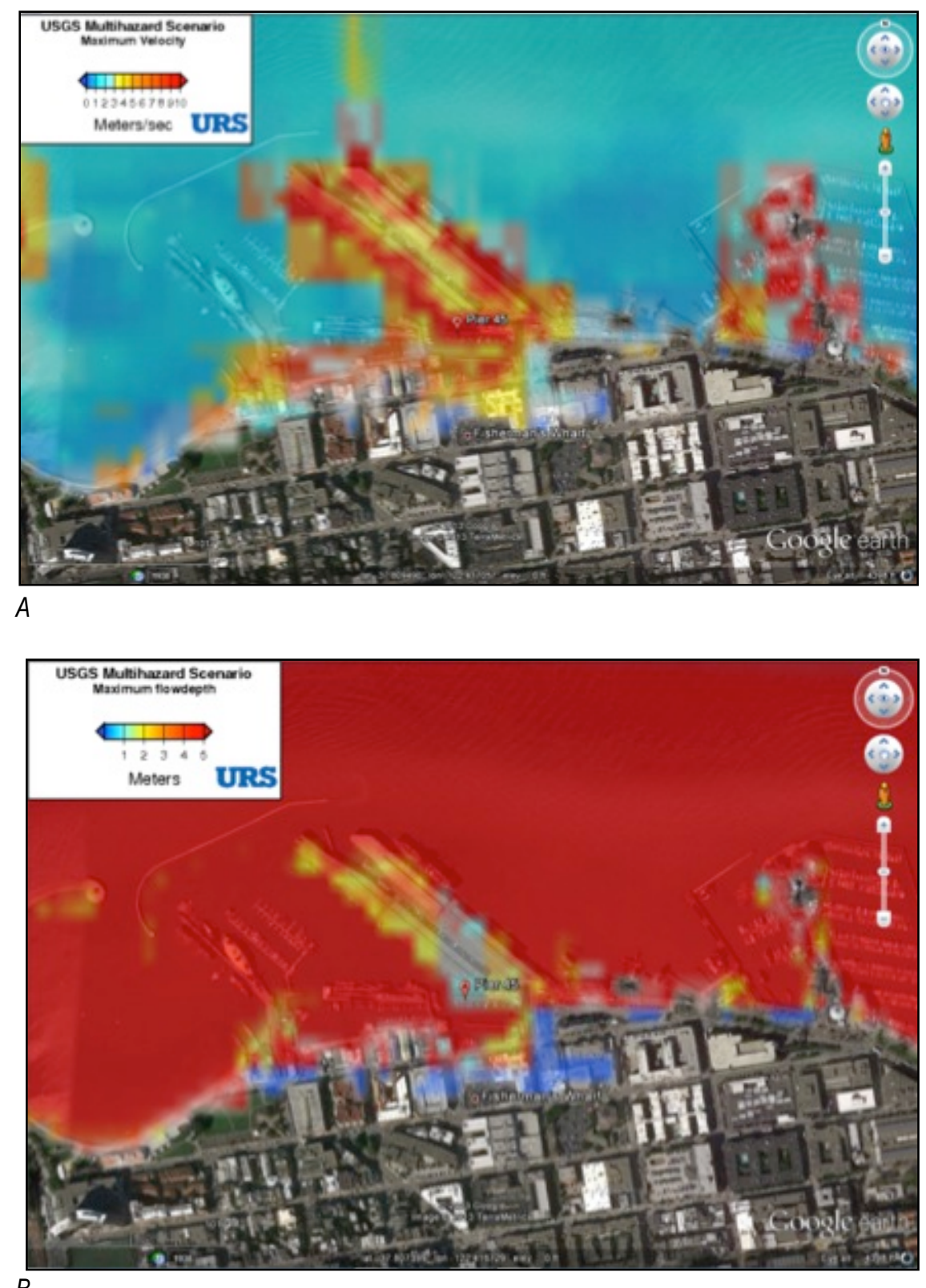

Figure 41. Velocities $(A)$ and flow depth $(B)$ at Port of San Francisco Pier 45 in the SAFRR tsunami scenario. 
The Port of San Francisco has a unique feature - an old seawall along much of its waterfront that is in various stages of structural integrity. We did not evaluate the potential for a tsunami to damage the seawall, but that may be worth investigating, especially at high-value locations or where crucial lifelines such as the Auxiliary Water Supply System, BART (Bay Area Rapid Transit), Muni (San Francisco Municipal Transportation Agency), or telecommunications are located near the seawall and could be damaged by its collapse.

\section{Damage to Other San Francisco Bay Ports}

The Ports of Oakland, Richmond, and Redwood City are also located within San Francisco Bay, which protects the ports from open coast swell conditions compared to the Ports of Los Angeles and Long Beach. Wave loads on structures and vessels are generally limited to shorter period, locally generated wind waves. Although these wind waves can be significant during storm activity, they have a significantly shorter wave period that generally decreases the loads. In general, design criteria are frequently controlled by currents and wind rather than waves. As such, the San Francisco Bay ports are likely better prepared for the current loads on vessels and structures during a tsunami. These commercial ports are also designed to the latest State engineering standards.

Figure 42 shows the extent of the maritime facilities in the Port of Oakland. As shown in figures 43 and 44, flow depths at piers and other port facilities are generally less than $0.5 \mathrm{~m}$, and maximum currents are generally $1-2 \mathrm{~m} / \mathrm{sec}(2-4 \mathrm{kt})$. Flooding is limited to the edges of wharves with the exception of the Ben E Nutter and TraPac terminals, where significant numbers of cargo containers and truck trailers are stored or parked.

Based on the inundation limits, it would be expected that a similar damage rate would occur as in the parts of the Ports of Los Angeles and Long Beach that are inundated. The total damage to these ports will generally be in proportion to their shipping volume compared to San Pedro Harbor, possibly somewhat higher in the Ben E Nutter and TraPac terminals where container yards and bulk areas are hypothesized to be flooded. There are also several small craft harbors throughout the area that are likely to experience more damage than the commercial facilities. These small craft will likely pose a significant debris and cleanup problem. 


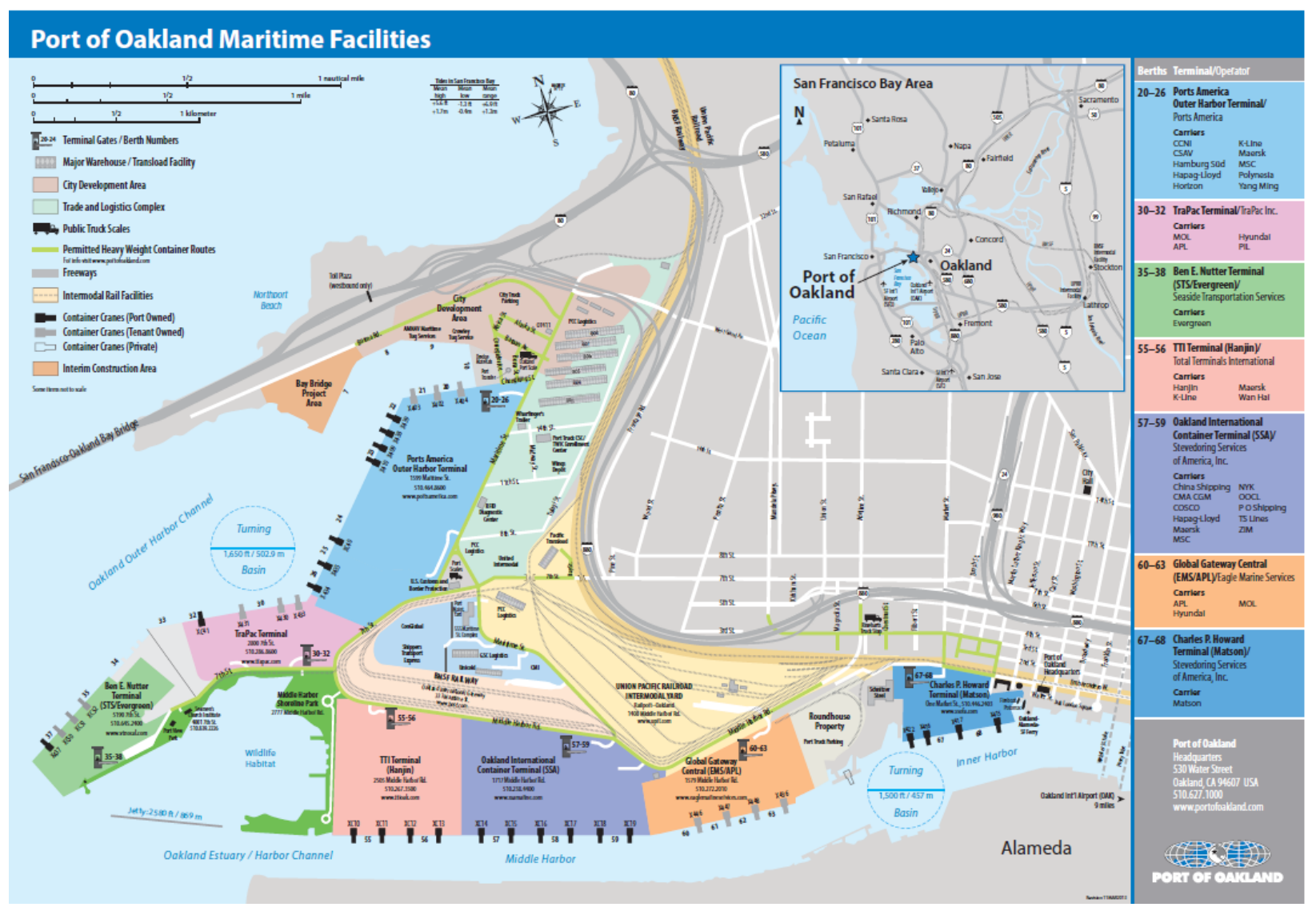

Figure 42. Port of Oakland maritime facilities map (Port of Oakland, 2013).

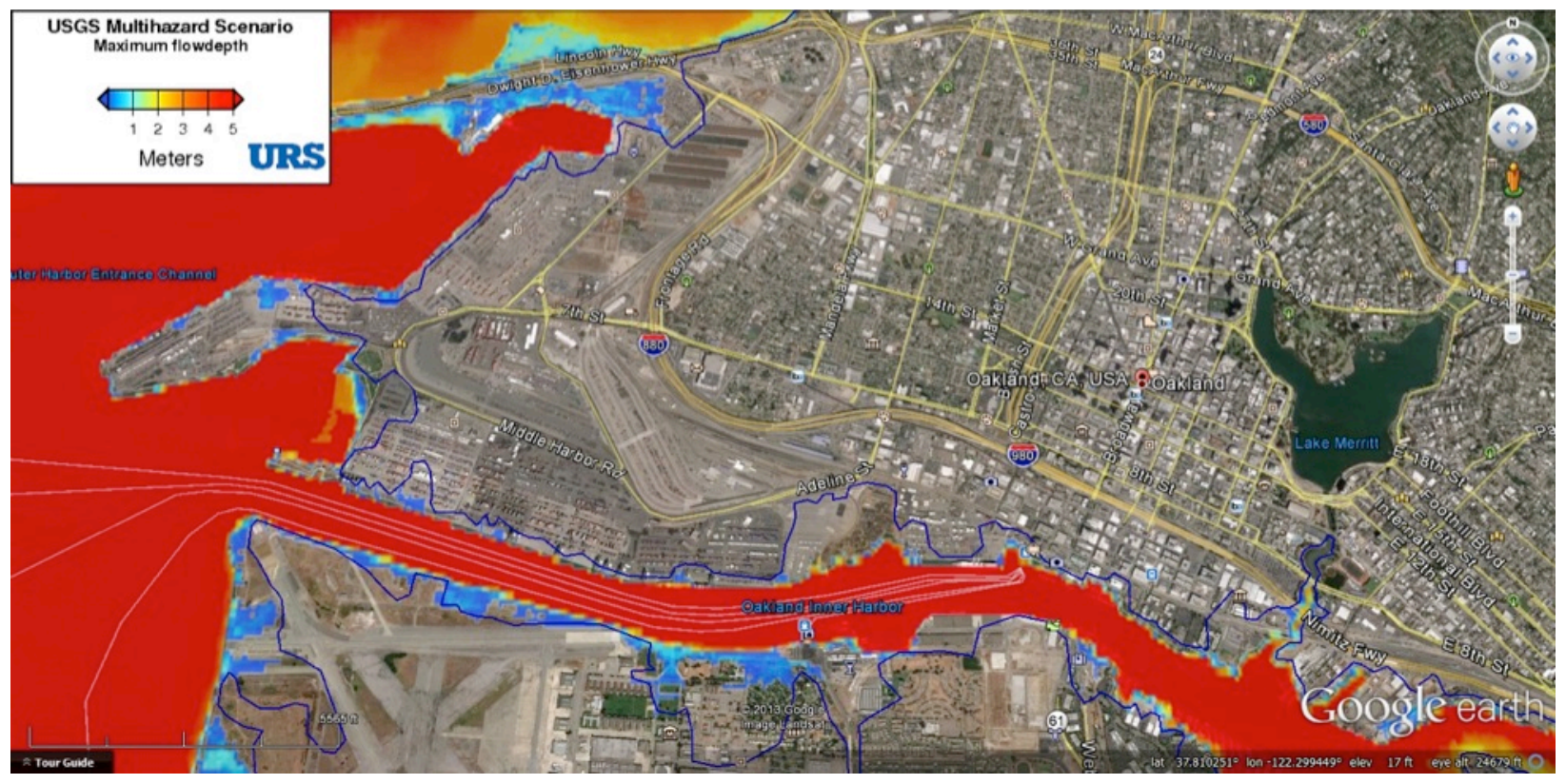

Figure 43. Flow depths and inundation line at Port of Oakland in the SAFRR tsunami scenario. 


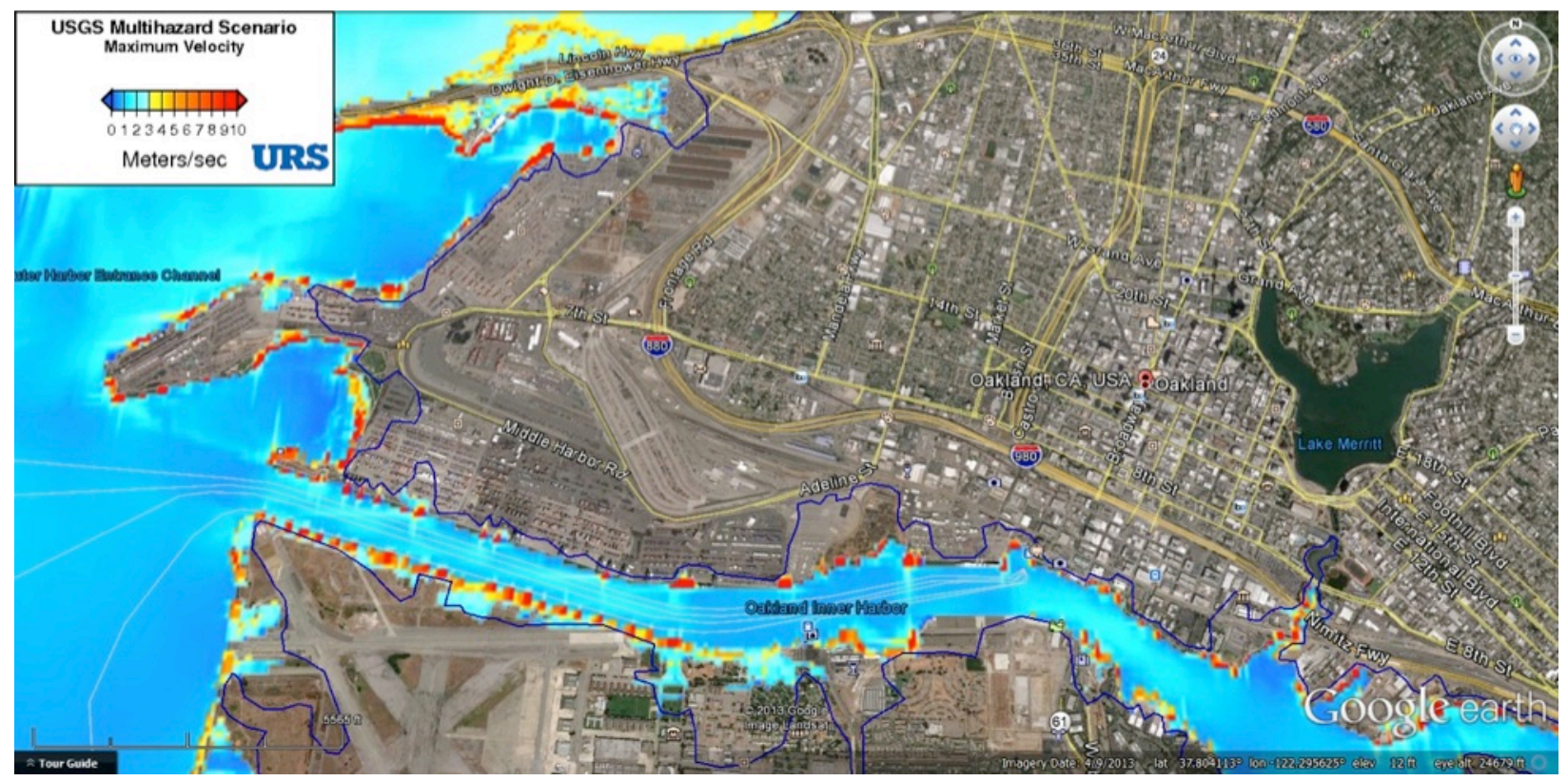

Figure 44. Current velocities in the Port of Oakland in the SAFRR tsunami scenario.

\section{Resilience Strategies}

On the basis of the somewhat limited overall damage to infrastructure in the Ports of Los Angeles and Long Beach, there are limited opportunities for improved engineering strategies. The most significant area of the Ports of Los Angeles and Long Beach to be flooded is in the area of Pier A at the Port of Long Beach. There will be damage to imported vehicles and damage to containers. The Port of Long Beach is well aware of the low area and has made an economic decision to not raise the land area. Operations buildings in this area have raised foundations to limit the risk of flooding and associated damage to infrastructure. Personnel evacuation procedures need to be developed for the safety of people working in the area. Given the leadtime for the proposed scenario, there should adequate time to shut down operations in this area and safely evacuate all personnel.

One design feature that could possibly be reviewed and improved on is the containment dikes around pipelines and tank farms. The crest of these containment dikes could be designed such that inundation will not occur within the contained areas. This will limit the damage to the facilities and reduce the likelihood of environmental damage from oil spills. Most of the tank farms are protected by containment dikes, but elevations should be confirmed against the proposed tsunami elevations. This may also entail more detailed modeling of hydrodynamics in the vicinity of the containment dikes and walls.

The bulk of the resilience strategies consist of developing and exercising a response plan in the event of a tsunami warning. There are several procedures that could be implemented to mitigate damage from the provided scenario. The most crucial issue to be addressed is the safety of the vessels because any freely floating vessel or even any vessel underway during the extremely high currents presents a risk to the vessel and port facilities. The current operations plan developed by the U.S. Coast Guard and the port pilots is to keep any approaching vessels from entering the port following receipt of a tsunami warning. Any vessels that can be safely removed from the harbor should be removed. During the Chile tsunami of 2010, some vessels in 
Chilean ports were able to successfully leave port despite the tsunami arrival time of less than 30 minutes after the seismic event. This should be incorporated in the plan. However, there needs to be a reasonably accurate estimate of the arrival time to minimize the risk of vessels being caught navigating during tsunami arrival. Priority for removing vessels should be given to bulk liquid vessels to minimize environmental risk of spills during the tsunami.

In addition to removing vulnerable vessels during the tsunami-warning period, further investigations of vessel maneuvering during high currents should be conducted. Some work was conducted along these lines in Headland and others (2006) suggesting reasonable success in maneuvering vessels during a tsunami.

Possibly the most important procedure to be developed is to shut down all operations as quickly as possible once the tsunami warning is received. This would include shutting down pumps to liquid bulk tankers and disconnecting hoses. Container cranes should be shut down and safely stored with arms up to minimize the possibility of vessels striking them. Power should be shutdown to reduce or eliminate damage to the power trenches or the cranes. Terminal substations should also be shutdown wherever possible to reduce or eliminate damage to these substations. For dry bulk terminals, the conveyors should be shut down to reduce damage to the motors, which can be flooded in some cases. Nonessential personnel should begin evacuation immediately.

For those vessels remaining in POLA/POLB through the tsunami, tugboats should be deployed to assist in maintaining control of the vessels at their respective berths. Vessels should deploy additional mooring lines where possible. These mooring lines will have to be tended by ship personnel during the tsunami to allow the vessels to rise and fall with the water level so that mooring components such as bollards, mooring lines, and fenders are not overloaded or damaged. This can be accomplished by either manually controlling the shipboard winches or setting the shipboard winches to constant tension where possible instead of breaking the winches. For the tsunami scenario defined in this project, engineering judgment and experience with previous tsunami events within POLA/POLB suggests no damage to any of the vessels within the harbor other than small craft (with one exception discussed later). This conclusion was reached after extensive discussion of the scenario with senior engineers at the ports and senior engineers from design consulting firms.

One additional opportunity to enhance resiliency: a plan to evacuate all nonessential personnel would need to be exercised. As discussed earlier, the ports would have 3.5 hours from the time NOAA first transmits it tsunami warning for San Pedro (at 2:05 p.m. PDT on Thursday Mar 27, 2014) until the forecast arrival of the tsunami at 5:35 p.m. In that time port operators, emergency response personnel and tenants would have to receive the message, understand its contents, and successfully take self-protective action such as shutting off power, removing or elevating crucial documents and other assets, and evacuating the port. Given experience in Hurricane Sandy (discussed next), that is not much time. The resiliency opportunity is to review, exercise, and enhance an evacuation plan as appropriate. The exercise could examine the potential for traffic congestion leaving the port, to check that all port personnel can safely evacuate in that period of time, and to think through potential delays or misunderstandings in decision-making and communication? We discuss policy issues more deeply elsewhere in this report. All of these preparedness, response and recovery plans would need to be regularly exercised to be reliable and effective. 


\section{Lessons for Ports from Hurricane Sandy}

In March 2013 representatives of the Port Authority of New York and New Jersey (PANYNJ) discussed with SAFRR personnel the port's experience in Hurricane Sandy. They summarized emergency plans, physical damage and recovery activities, and major threats to life safety, focusing on PANYNJ port facilities in Port Newark, Port Elizabeth, Jersey City, Bayonne, Staten Island, and Brooklyn.

\section{Emergency Plans}

PANYNJ maintains a contingency plan in accordance with both Federal standards and industry best practices. It has 25 to 30 annexes covering various perils. The plan for hurricane focuses on wind impacts. Preparations deal with lowering stacks of containers to 3 high, battening loose items, not accepting berth applications, tying cranes together, and maintaining tugs on standby. The hurricane plan did not address storm surge, although the port does possess maps showing expected extent of flooding color coded by Saffir-Simpson Intensity (SSI). The logic appears to be that each SSI increment corresponds to an expected degree of storm surge and therefore flooding. (Since 2010, SSI has been revised as the Saffir-Simpson Hurricane Wind Scale to exclude flood ranges, storm surge estimations, rainfall, and location.) Hurricane Sandy produced greater storm surge than the model used to create the map predicted. In fact, until the day before landfall, the National Weather Service (NWS) estimated 6 to $7 \mathrm{ft}$ of storm surge at the ports. At 11 a.m. Sunday October 28, 2012, the day before landfall, the NWS revised the estimate to 13 to $14 \mathrm{ft}$ as a result of a change in the storm's direction. The terminal operators had just reconfigured containers to be stacked lower so as to minimize wind forces, thus putting more containers at ground level and more containers in the flood zone. Because containers are moved by union labor, which requires significant advanced notice to mobilize, it was too late to reconfigure the container stacks. Note that the port personnel with whom we spoke did not have topographic maps or other maps that would show inundation as a function of storm surge. They relied on maps that relied on a model that underestimated flooding in storm surge.

One relevant lesson for the Tsunami Scenario is that this scenario uses models that estimate earthquake magnitude, rupture area, hypocenter, rupture velocity, and various other parameters. Although it is useful for planning, it should not be considered to represent an upper bound of the environmental excitation, that is, the flow depths, currents, extent of inundation, and so on. Another lesson for emergency planning: port personnel indicated that Hurricane Sandy has reinforced the need to stay out of the habit of only reacting to the last event. They also advised that generally the only people who take flooding seriously are those who had personally experienced it in the past. Both of these observations seem relevant to operators of California facilities who do not have personal experience with tsunamis and flooding.

\section{Physical Damage}

Flooding destroyed 16,000 vehicles and thousands of containers (see fig. 45). The truck fleet was heavily damaged: port personnel estimate that up to 20 percent of drayage truck fleet was lost, approximately 2,000 of 10,000 trucks in the New York and New Jersey region that serve the port, and the fleet has not yet fully recovered. In addition, approximately 15 percent of the chassis fleet was destroyed. Mechanical and electrical equipment associated with sewer lift stations were damaged, as were traffic signals and railroad crossing equipment, so much so that rail traffic is still using flares and flagmen in March 2013; PANYNJ described the power grid 
and electrical equipment as a "giant Achilles' heel." Some fuel tanks inside of earthen berms at the facilities along the Arthur Kill were emptied in advance of the storm to protect the stored product, but as a result when storm surge inundated them, the tanks floated off their foundations and were damaged. Tanks behind containment walls fared better. A buried propane tank floated to the surface but did not ignite. Container handling equipment was damaged, including straddle carriers, reach stackers, fork lifts, and electrical equipment on most gantries. Electrical equipment was repaired on enough gantry cranes and container handling equipment within 6 days that the port was able to return to business, although some are still being repaired in March 2013. These damages were the greatest hindrances to recovery. Note the resemblance between hurricane damage in figure 45 and tsunami damage shown in figure 19. 

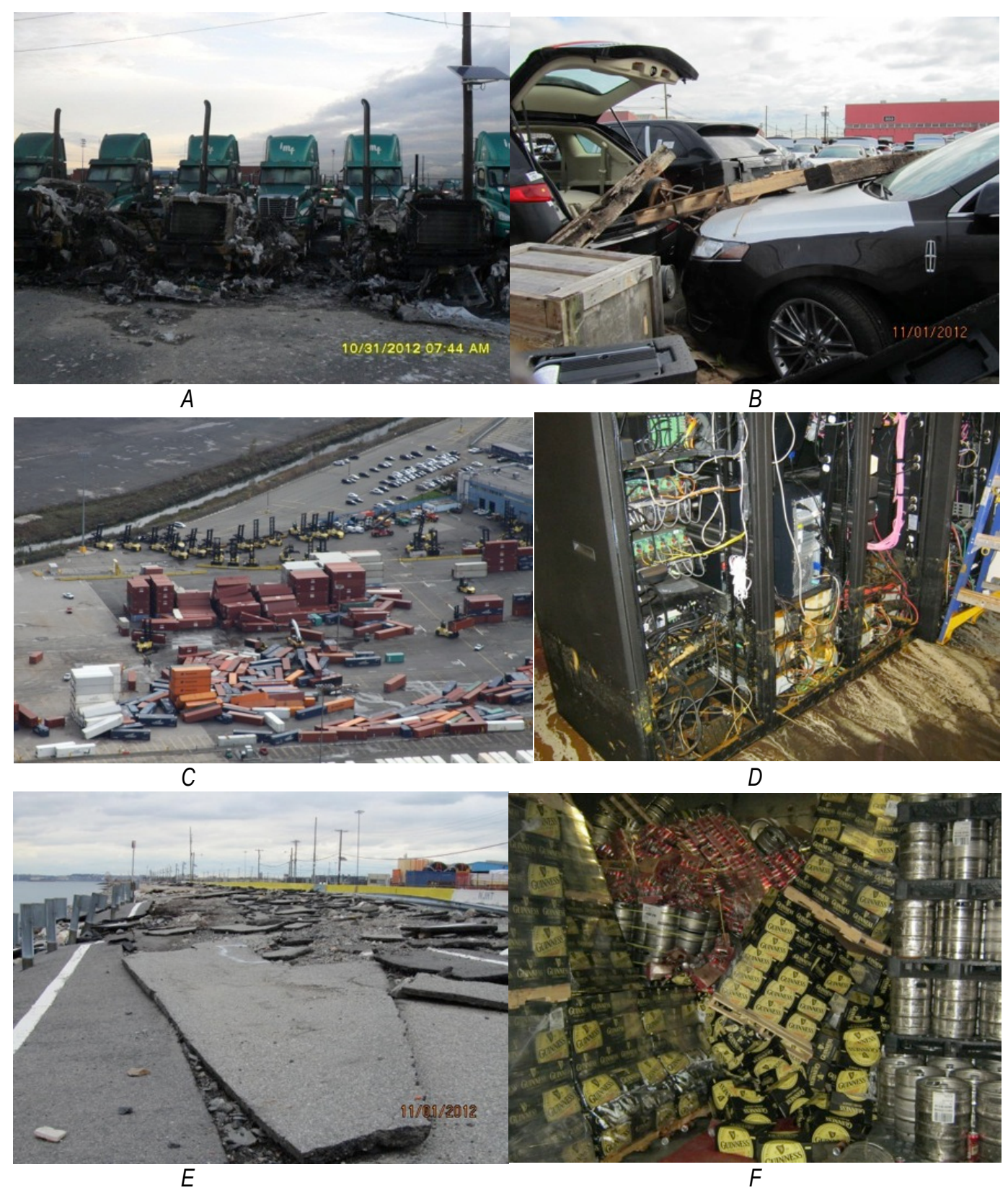

Figure 45. Photographs of damage from Hurricane Sandy at New York and New Jersey ports: $A$, flooding damaged 20 percent of the truck fleet, often by igniting fires and, $B$, destroyed 16,000 import vehicles. $C$, Flooding and wind damaged thousands of containers and much of the ports' cargo handling equipment; $D$, electrical and computer equipment were flooded and damaged; $E$, scour damaged pavements; and F, Flooding destroyed product in port warehouses. (Images from Port Authority of New York and New Jersey).

\section{Recovery}

Commercial power was available from the public utility an average of 5 days after landfall, though some tenants were not ready to receive power. However, power lines kept falling after the hurricane passed. As of March 2013, underground lines in certain locations 
were still being replaced. PANYNJ is still seeing impacts of damage to electric power. PANYNJ speculated that latent damage could be observed for years. Sewer and firefighting were restored after 6 days. Telecom was still being restored in March 2013; a Verizon phone facility still was being restored. Lack of fuel caught many people off guard, but the PANYNJ had its own gas resources, which port personnel found invaluable. Channels and berths were surveyed within 3 days after landfall, and debris did not prevent ships from returning. Ships began to arrive 6 days after landfall, gates opened 7 days after landfall, and daylight-only restrictions were lifted 8 days after landfall. In that time, some ships diverted to Philadelphia, Norfolk, and Savannah. All facilities except the Brooklyn cruise terminal were in operation 8 days after landfall.

The Brooklyn cruise terminal shed was damaged with rollup doors staved in, its security equipment destroyed, and fixed gangways damaged. The Brooklyn cruise terminal returned to operation in December 2012. No pier damage has been observed yet. Port personnel indicated that it would be valuable in the future to have alternative operating space on high ground to conduct business, along with a stockpile of emergency generators, mobile guard booths, and other equipment needed for emergency operations. The relevance of these observations here is that many of the same damages are posited to occur in the present scenario, especially flooding and loss of vehicles and damage to electrical equipment. PANYNJ's advice regarding alternative operating space, mobile guard booths, fuel, and other emergency supplies may be relevant to California facilities.

\section{Threats to Life Safety}

There were no injuries or deaths on port facilities, though port personnel indicated that some emergency service personnel raced floodwaters as they evacuated. Had power not been shut down, people could have been injured or killed by electrocution. The PANYNJ offered the following advice to other port operators faced with the potential for inundation: shut down power, know when you have done all you can, and focus on evacuation, not waiting until the last minute to remove personnel.

\section{Damage to Large Vessels in the Ports of Los Angeles and Long Beach}

\section{By Keith Porter}

\section{Previous Instances of Vessels Breaking Their Moorings}

High wave amplitudes have lifted large vessels onto piers and breakwaters in past tsunamis, as discussed elsewhere in this report. Such amplitudes are not present in the SAFRR tsunami scenario in California ports. Another hazard exists: large vessels have broken their moorings in past tsunamis. For example, two U.S. Navy submarines moored in Guam parted their mooring lines when the tsunami from the 2011 Tohoku, Japan, earthquake caused currents there estimated to be less than $4 \mathrm{kt}$. In the 2004 Sumatra tsunami, the cargo vessel Maersk Mandraki broke its moorings and drifted for hours in the Port of Salalah, Oman. At approximately the same time as the Mandraki was pulled from its berth, the Maersk Virginia was hit by strong and erratic currents at the Port of Salalah entrance, pushing the vessel into a breakwater and causing minor damage. The captain of the Virginia waited for an additional 7 hours for currents to subside before attempting to reenter the port. A number of similar examples 
of vessels parting their lines were recorded during the 2004 event in the Indian Ocean, with ships ranging from 50 to $290 \mathrm{~m}$ in length. Currents affecting the Mandraki are difficult to estimate but were likely in the range of 6-8 kt (Okal and others, 2006a,b,c).

Once a vessel becomes unmoored in strong currents, it may be difficult to regain control. In the 2004 Sumatran tsunami, a vessel attempted to leave Port Blair, South Andaman Islands during a strong current and could not exit the port (Eskijian, written commun., March 2, 2013). In the 2011 Tohoku earthquake and tsunami in the port of Hachinohe, Aomori, the 56,752-ton deep-sea scientific drilling vessel Chikyu was damaged when her crew lost control of the vessel (CDEX Web Magazine 2012; fig. 46). Her captain was informed that the tsunami wave amplitude would be $1 \mathrm{~m}$, and he decided to keep the Chikyu moored to its pier. He was then warned that the wave amplitude would be $9 \mathrm{~m}$, not $1 \mathrm{~m}$, and he decided to depart. He had the crew cut the mooring lines. The vessel had just cut loose when the tsunami struck. Currents were too high and too erratic for the crew to control the vessel. The ship collided with piers and damaged one of its propulsion pods. For such an event to occur in the Ports of Los Angeles and Long Beach would require that vessels were still in the harbor or moored when the tsunami struck, and the currents there were substantial and adversely aligned with respect to vessels.

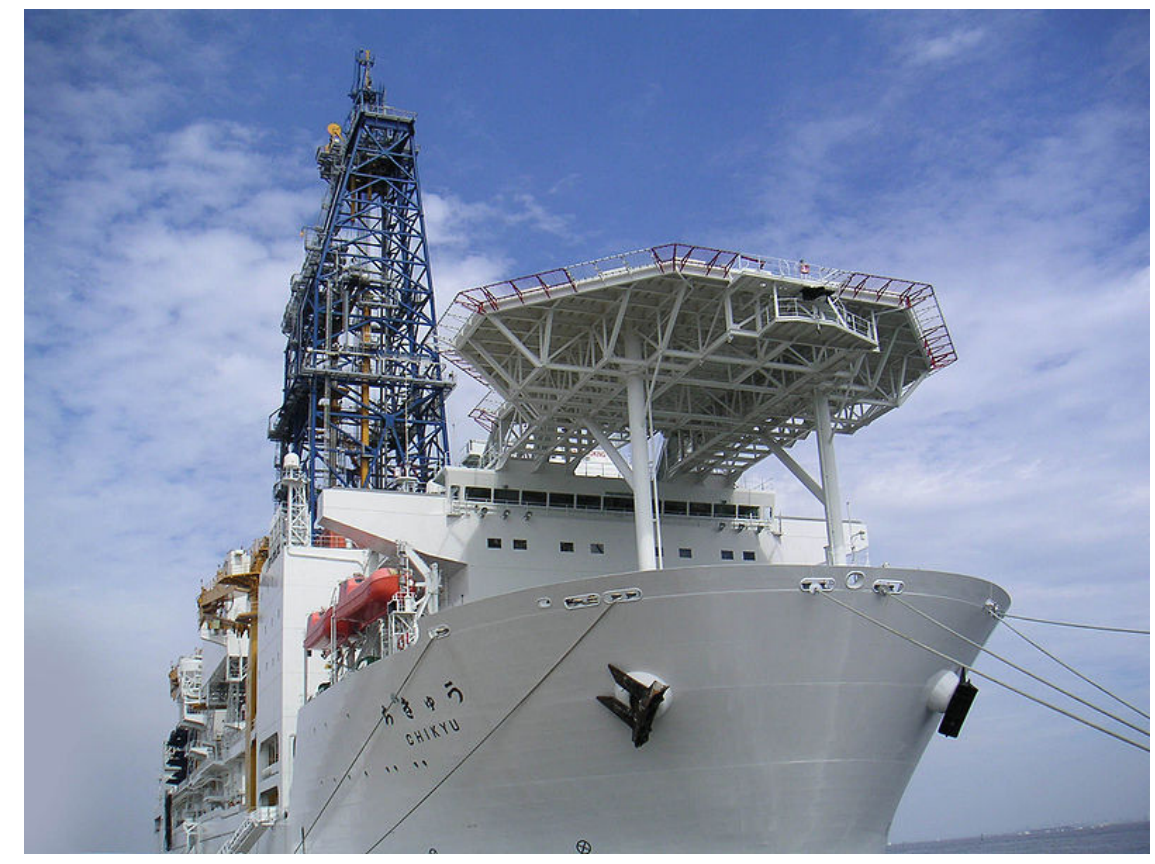

Figure 46. Photograph of Drilling Vessel Chikyu, which was damaged in the 2011 Tohoku earthquake and tsunami (from Wikimedia Commons).

Once its crew loses control of a ship, it can collide with other vessels or piers, it can become grounded, and possibly sink. There are 39 instances recorded at http://shipwrecklog.com (accessed June 2013) during the period June 2011 through May 2013 of container vessels becoming grounded or colliding with piers, wharves, or docks. Among these instances, three were accompanied by leakage of oil or other pollution (Bareli March 16, 2012; Celina March 9, 2012; and MV Rena October 5, 2011), and two of these sank (Bareli and MV Rena). So sinking of a container ship (as in the case of the MV Rena; fig. 47A) is rare, even when the ship runs 
aground or collides with other vessels or piers. Far more common is that the vessel is undamaged and or is quickly refloated, as in the case of the Norfolk Express (fig. 47B).

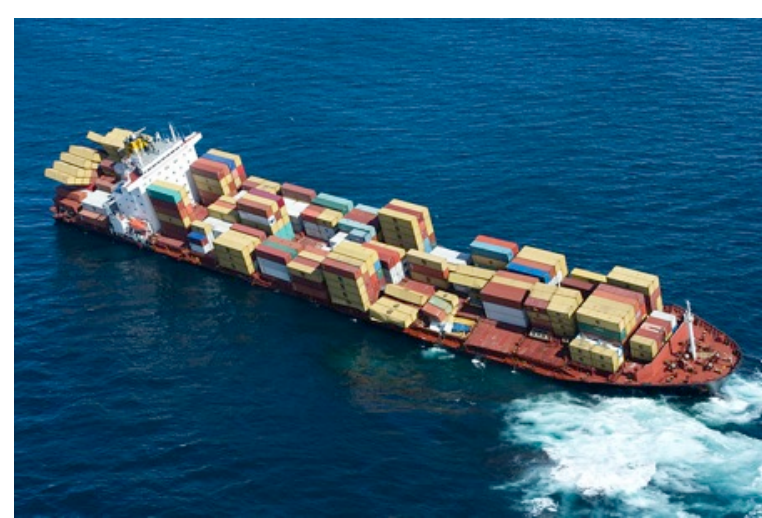

$A$

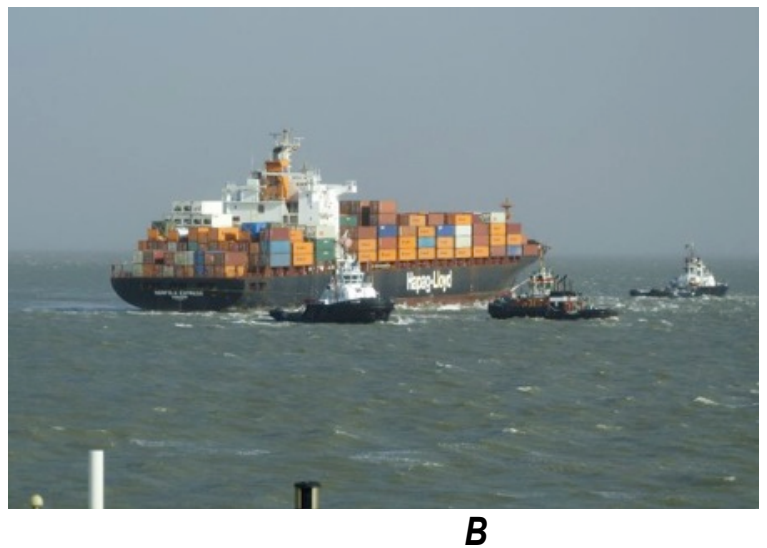

B

Figure 47. A, Photograph of MV Rena aground on Astrolabe Reef, New Zealand, on October 13, 2011 (from Wikimedia Commons); $B$, Photograph of the Norfolk Express (from http://www.havariekommando.de).

Would ships still be moored 4 hours after the tsunami warning is issued? The U.S. Coast Guard Vessel Dispersal Plan (Laferrierre, 2011) specifies procedures for the dispersal of vessels from the Ports of Los Angeles and Long Beach in emergency situations, including earthquakes and other natural disasters. It does not specify particular triggers or guidance in terms of tsunami warning time, wave amplitudes, or other factors. It calls on vessel masters to use pilots and tugboats to get underway whenever possible, but it also allows vessel masters to leave port without a tug or pilot if they deem it necessary.

\section{Vessels at Risk}

The Ports of Los Angeles and Long Beach can routinely contain 30 to 40 large vessels at any time. With current pilot staffing and available tugs, port pilots estimate that they can remove 5 to 8 ships per hour from the harbor, suggesting that it could take 4 to 8 hours to evacuate the port once decision is made, if all ordinary protocols are followed, and if vessel masters do not decide to leave port without tug or pilot. (Tugs are the limiting factor, rather than pilots.) Recall that the Ports of Los Angeles and Long Beach would have 3.5 hours of warning. It therefore seems plausible that vessels would still be moored when the tsunami struck. If such a vessel were then subjected to strong currents, it could part its moorings.

It seems plausible that currents in excess of $6 \mathrm{kt}$ would be sufficient to cause a ship to break its mooring lines. There is at least one berth at Pier J where tsunami currents exceed $6 \mathrm{kt}$ (fig. 48), in a direction perpendicular to a moored vessel that ordinarily intrudes slightly into the channel near a constriction that would cause high currents. The situation is similar to the berth where the Maersk Madraki broke loose in 2004 (Okal and others, 2006a,b, and c). The scenario therefore hypothesizes that such an event occurs. We imagine either the U.S. Coast Guard decides not to disperse the port or it takes some time to decide to issue the order to disperse, and ship's masters decide not to evacuate on their own accord. These conditions might exist because of limited guidance in the dispersal plan or the sense that the tsunami warning does not provide enough information to warrant dispersal. 


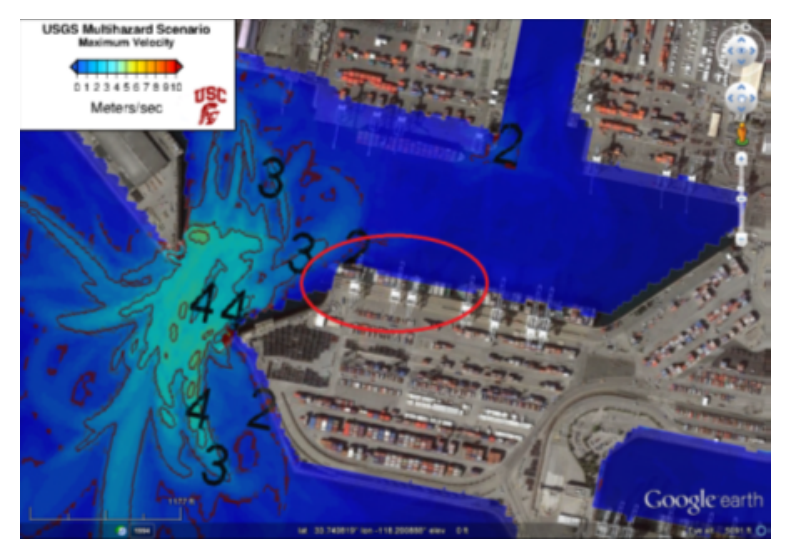

Figure 48. Image showing one location in the Port of Long Beach near a berth where tsunami currents exceed 6 knots ( 3 meters per second) in the SAFRR tsunami scenario (base image from Google Earth).

\section{Damage to Large Vessels in the SAFRR Tsunami Scenario}

We hypothesize that a vessel in the Port of Long Beach moored at Pier J parts its mooring lines and its crew cannot regain control before it collides with nearby piers. We have performed a simulation of the trajectory of an object originating at that berth. The simulation shows the current exceeding $6 \mathrm{kt}$ at that berth at 7:10 p.m. on Mar 27, 2014. The object, representing the imagined unmoored vessel, comes close to Pier J and Pier G several times during the next 20-30 minutes, apparently close enough to damage the vessel and pier if the crew cannot regain sufficient control (fig. 49). The simulation is somewhat simplified: the vessel's inertia and dimensions are neglected, as are the effects of any remaining mooring lines. However, the simulation illustrates the potential for the vessel to impact Pier J or G or both, perhaps several times, and possibly impact other vessels still moored at Pier G. 


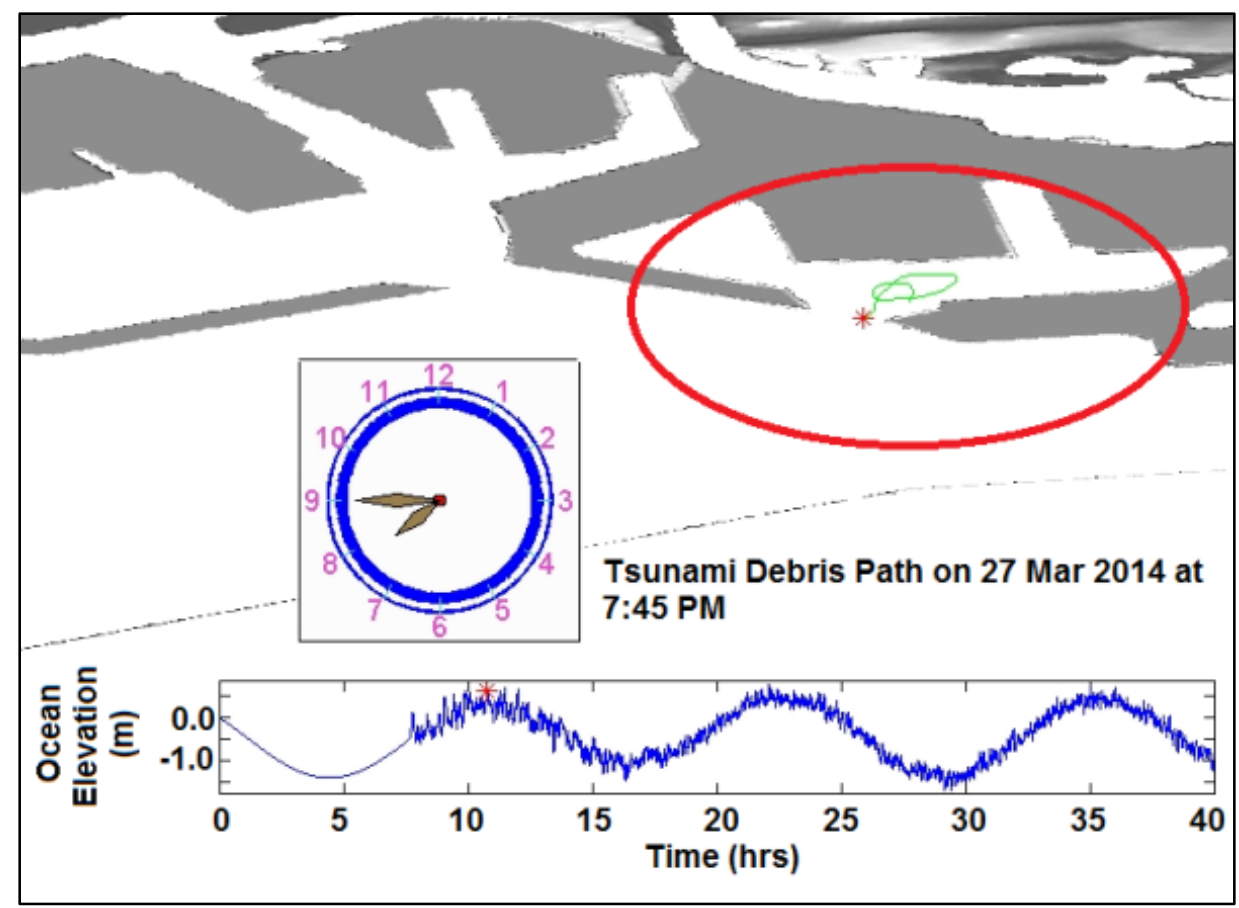

Figure 49. Diagram showing motion of a particle representing a vessel in the Port of Long Beach moored at Pier $\mathrm{J}$ that parts its mooring lines and collides with nearby piers in the SAFRR tsunami scenario. The particle released from the selected berth when the current exceeds 6 knots. The trajectory shown covers the time on March 27, 2014, from 7:10 p.m. (when first released) to 7:45 p.m. (by which time the vessel has either been brought under control or has already collided with one or more piers). (hrs, hours; $m$, meters.)

It seems realistic therefore that the impact would damage the vessel, Pier J (a container berth), and a crane at Pier J. (The vessel, experiencing some combination of surge, sway, heave, and yaw, damages the crane, which is located within $1 \mathrm{~m}$ of the edge of the pier and cannot be moved away from the edge of the pier). In this scenario, the vessel does not sink, and is removed once the tsunami warning is lifted. As a result, the vessel does not create any navigation issues that cannot be worked around beyond the 2 days during which the port is shut down. Nor does it experience a fuel spill or cause other pollution. That the vessel does not sink or cause a spill is consistent with 92 percent of groundings recorded by shipwrecklog.com during June 2011 through May 2013, although clearly the possibility exists. After the tsunami, it could take two weeks for a structural engineer to certify the pier as safe (or several months to repair it if otherwise) and several months to repair or replace the damaged crane. The two adjacent berths are used with the remaining 6 cranes, producing a modest reduction in shipping capacity, and there are no other lingering effects of the vessel damage.

\section{Opportunities to Enhance Resilience}

The foregoing scenario suggests an opportunity to enhance port resiliency by reviewing the U.S. Coast Guard Dispersal Plan, perhaps adding guidance for decision-making in the event of tsunami that varies with warning time and estimated wave amplitudes, and considering the berths that are likely to experience the highest velocities in an adverse direction. It might be 
valuable to test a procedure for dispersing major vessels from the ports within 3.5 or fewer hours. The test could include a tabletop exercise in which pilots, the U.S. Coast Guard, and a representative of other actors in the port dispersal plan imagine a warning has just been issued, and test their ability to carry out the plan. It could be with small craft standing in for major vessels, and could be incorporated into a regular exercise for tsunami preparedness. Such an activity might be particularly valuable if the scenario depicted here - a single vessel that does not sink and only damages one pier-might realistically be exceeded in a real tsunami.

\title{
Damage and Restoration of Marinas and Small Craft
}

\author{
By Keith Porter, Patrick Lynett, and Rick Wilson
}

\section{Introduction and Purpose}

This section presents an estimate of tsunami effects on small craft in the scenario. It is based on an inundation line and current velocities modeled by SAFRR scientists, knowledge of the locations of marinas drawn from remote sensing (Google Earth), and observations of historic tsunami damage to similar vessels. The objectives of this section are as follows:

- Summarize the locations and sizes of marinas exposed to loss.

- Identify the most common damage modes observed in past tsunamis.

- Estimate the damageability of vessels and floating docks, that is, quantify the conditions under which damage is assumed to occur.

- Describe repair activities and estimate the repair duration and repair costs for each mode of damage.

- Combine the foregoing to identify particular locations where it is realistic for damage to occur in the scenario. Estimate repair costs, repair durations, and traffic delays.

- Identify options for enhancing resiliency.

- Identify research needs.

\section{Assets Exposed to Loss}

There are approximately 58 coastal marinas and small craft harbors within the areas studied. We examined satellite imagery dated March 2011 to estimate the number of boats. In some cases we adjusted the estimates where harbor websites provided number of slips, in which case we factored number of slips by the apparent ratio of boats to slips in the satellite imagery. We provided the estimates to harbormasters by email and adjusted the numbers when corrected by the harbormasters. The Google Earth imagery does not show boundaries between adjacent marinas in the same harbor that are managed by distinct organizations, and we could find no other statewide map that distinguished between adjacent marinas, so the figure of 46 marinas refers to geographically distinct, as opposed to legally distinct, marinas.

An estimate of the number of boats in harbor on March 27, 2014, is shown in table 25, along with an approximate range of maximum tsunami wave velocity in each marina (denoted "Max V" in the table), and maximum wave height above mean higher high water ("Max D"). The table shows that the marinas in the study area contain on the order of 43,000 boats, mostly tied to floating docks. Velocities are in $\mathrm{m} / \mathrm{sec}$ (to convert to knots, multiply by 2 ). Heights are in meters above mean higher high water. Records noted "USC estimate" are those where a finer- 
resolution model was used to estimate velocities. "Pilings overtop" means that the tsunami wave is estimated to overtop the pilings. If the dock floats up over the top of the piling, it is no longer restrained from lateral movement. Pilings are designed to be tall enough to restrain the dock under tidal fluctuations, but a tsunami can raise the dock higher and allow it to float free. See for example figure 50. In the present case, we have indicated that pilings are overtopped where any of the following is true: (A) wave amplitude exceeds $2.0 \mathrm{~m}$ above mean higher high water, (B) the harbormaster has indicated that the pilings will be overtopped, or (C) an examination of Google Earth Street View imagery suggests that the pilings are too short for the tsunami amplitude.

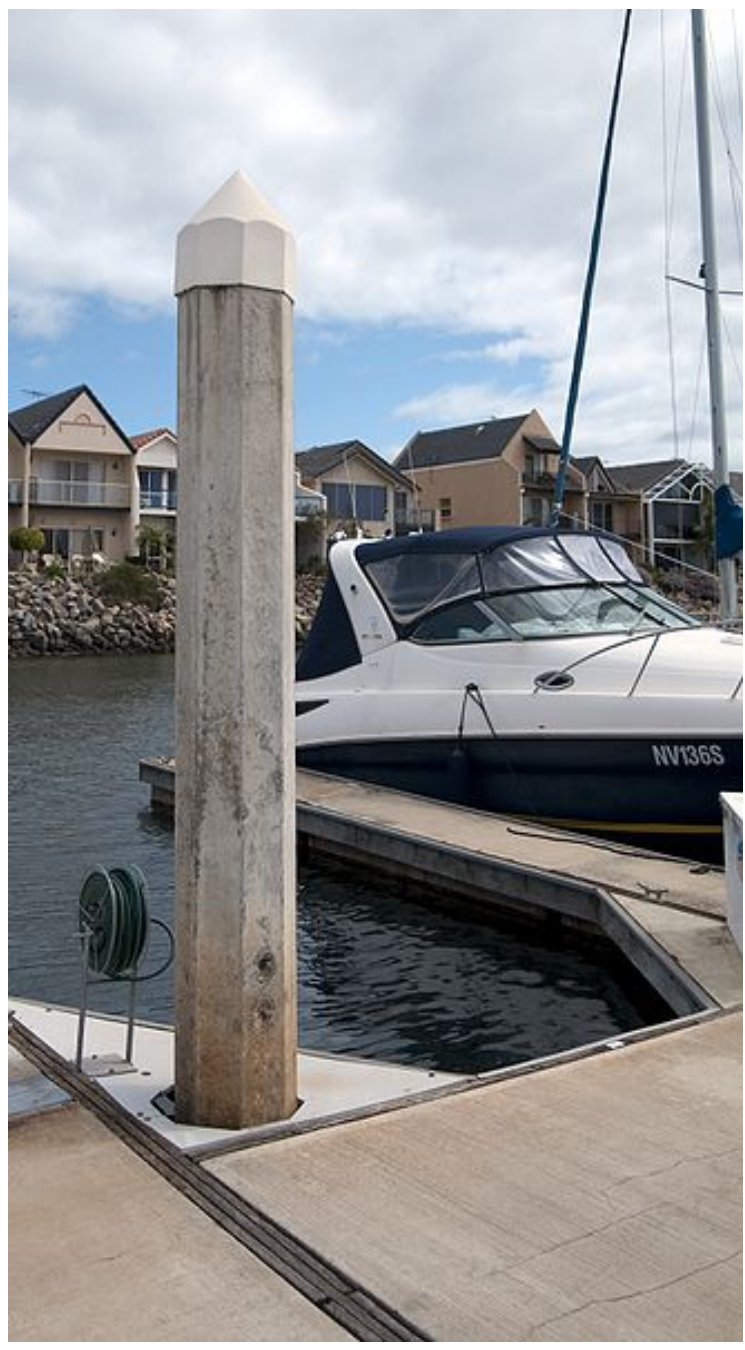

Figure 50. Photograph of a concrete dock piling (from Wikimedia Commons). 
Table 25. Marinas in study area, from north to south.

\begin{tabular}{|c|c|c|c|c|c|c|c|}
\hline Name & $\begin{array}{l}\text { Latitude } \\
{ }^{\circ} \mathrm{N}\end{array}$ & $\begin{array}{l}\text { Longitude } \\
{ }^{\circ} \mathrm{E}\end{array}$ & Boats & Docks & $\begin{array}{c}\operatorname{Max} V \\
(\mathrm{~m} / \mathrm{sec})^{\mathrm{a}}\end{array}$ & $\begin{array}{c}\text { Max D, } \\
\text { m }^{\mathrm{b}}\end{array}$ & $\begin{array}{l}\text { Pilings } \\
\text { overtop }\end{array}$ \\
\hline Crescent City Harbor & 41.745 & -124.187 & 100 & 2 & $5-10$ & 3.0 & Yes \\
\hline Trinidad Harbor & 41.054 & -124.144 & 50 & 0 & $5-10$ & 4.0 & Yes \\
\hline Humboldt Bay Harbor & 40.808 & -124.163 & 450 & 12 & $4-8$ & 1.0 & No \\
\hline Dolphin Isle Marina & 39.4297 & -123.798 & 70 & 1 & $0-2$ & 2.5 & Yes \\
\hline Noyo Harbor & 39.4239 & -123.8058 & 230 & 5 & $4-5$ & 2.5 & Yes \\
\hline Porto Bodega Marina & 38.3331 & -123.0522 & 36 & 1 & $2-4$ & 2.5 & Yes \\
\hline Spud Point Marina & 38.3304 & -123.0564 & 250 & 5 & $3-5$ & 2.5 & Yes \\
\hline Inverness Yacht Club & 38.1027 & -122.8566 & 76 & 2 & $0-2$ & 1.5 & Yes \\
\hline Marina Bay & 37.916 & -122.353 & 300 & 6 & $2-4$ & 2.0 & No \\
\hline Point Richmond & 37.908 & -122.382 & 400 & 8 & $2-4$ & 2.0 & No \\
\hline Clipper Yacht Harbor & 37.870 & -122.496 & 350 & 7 & $3-6$ & 1.5 & No \\
\hline Berkeley Marina & 37.866 & -122.318 & 1,100 & 22 & $3-6$ & 1.0 & No \\
\hline Sausalito Yacht Harbor & 37.860 & -122.482 & 900 & 18 & $2-4$ & 1.0 & No \\
\hline Emeryville Marina & 37.839 & -122.313 & 700 & 14 & $3-6$ & 2.0 & No \\
\hline Treasure Isle Marina & 37.816 & -122.371 & 100 & 2 & $4-8$ & 2.0 & No \\
\hline $\begin{array}{l}\text { Fisherman's Wharf, San } \\
\text { Francisco }\end{array}$ & 37.810 & -122.417 & 300 & 6 & $4-8$ & 2.0 & No \\
\hline Pier 39 San Francisco & 37.810 & -122.411 & 300 & 6 & $4-8$ & 2.0 & No \\
\hline Ft Mason, San Francisco & 37.807 & -122.433 & 350 & 7 & $4-8$ & 2.0 & No \\
\hline $\begin{array}{l}\text { San Francisco Marina Yacht } \\
\text { Harbor }\end{array}$ & 37.805 & -122.445 & 150 & 3 & $4-8$ & 2.0 & No \\
\hline Alameda Grand Marina & 37.782 & -122.251 & 1,900 & 38 & $2-4$ & 1.0 & No \\
\hline $\begin{array}{l}\text { South Beach Harbor, San } \\
\text { Francisco }\end{array}$ & 37.781 & -122.385 & 700 & 14 & $2-4$ & 1.0 & No \\
\hline Mission Bay, San Francisco & 37.772 & -122.386 & 20 & 1 & $2-4$ & 1.0 & No \\
\hline San Leandro Marina & 37.703 & -122.193 & 455 & 8 & $2-4$ & 1.0 & No \\
\hline Sierra Point Marina, Brisbane & 37.673 & -122.384 & 500 & 10 & $2-4$ & 1.0 & No \\
\hline Oyster Point Marina, Brisbane & 37.667 & -122.383 & 500 & 10 & $2-4$ & 1.0 & No \\
\hline $\begin{array}{l}\text { Coyote Point Yacht Harbor, } \\
\text { Burlingame }\end{array}$ & 37.589 & -122.320 & 250 & 5 & $2-4$ & 1.0 & No \\
\hline $\begin{array}{l}\text { Pacific Shores Marina, } \\
\text { Redwood City }\end{array}$ & 37.513 & -122.196 & 100 & 2 & $1-2$ & 0.5 & No \\
\hline Port of Redwood City & 37.508 & -122.208 & 100 & 2 & $1-2$ & 0.5 & No \\
\hline Bair Island Marina & 37.502 & -122.220 & 300 & 6 & $1-2$ & 0.5 & No \\
\hline Pilar Point Harbor & 37.496 & -122.480 & 300 & 6 & $4-8$ & 4.0 & Yes \\
\hline Santa Cruz & 36.964 & -122.002 & 1,000 & 20 & $3-6$ & 3.5 & Yes \\
\hline Moss Landing & 36.807 & -121.785 & 610 & 12 & 1 & 1.0 & No \\
\hline Monterey Harbor & 36.605 & -122.892 & 200 & 4 & $4-8$ & 3.0 & Yes \\
\hline $\begin{array}{l}\text { Morro Bay Harbor-floating } \\
\text { docks }\end{array}$ & 35.366 & -120.856 & 300 & 6 & $3-6$ & 2.0 & Yes \\
\hline $\begin{array}{l}\text { Morro Bay Harbor-moorings } \\
\text { and piers }\end{array}$ & 35.366 & -120.856 & 200 & 0 & $3-6$ & 2.0 & No \\
\hline Port San Luis & 35.167 & -120.742 & 40 & 1 & $3-6$ & 4.5 & Yes \\
\hline Santa Barbara Harbor & 34.404 & -119.688 & 1,200 & 24 & $4-8$ & 2.0 & Yes \\
\hline Ventura Harbor & 34.246 & -119.260 & 1,200 & 24 & $4-8^{\mathrm{c}}$ & $2.5^{\text {(c) }}$ & Yes \\
\hline Channel Islands Harbor & 34.171 & -119.209 & 4,000 & 80 & $3-6$ & 1.5 & Yes \\
\hline Marina Del Ray & 33.972 & -118.452 & 4,000 & 80 & $2-4$ & 1.0 & No \\
\hline Redondo Beach Marina & 33.8469 & -118.3983 & 1,480 & 30 & $1-2$ & 1.5 & Yes \\
\hline POLA Berths 200-205 & 33.766 & -118.248 & 1,516 & 30 & $1-2^{\mathrm{c}}$ & 1.0 & No \\
\hline Downtown Marina & 33.761 & -118.193 & 85 & 10 & $1-2^{\mathrm{c}}$ & 2.0 & No \\
\hline Long Beach Shoreline Marina & 33.758 & -118.184 & 1,764 & 32 & $1-2^{c}$ & 2.0 & No \\
\hline Alamitos Bay & 33.747 & -118.116 & 1,200 & 24 & $4-8$ & 1.0 & No \\
\hline
\end{tabular}


Table 25. Marinas in study area, from north to south.-Continued

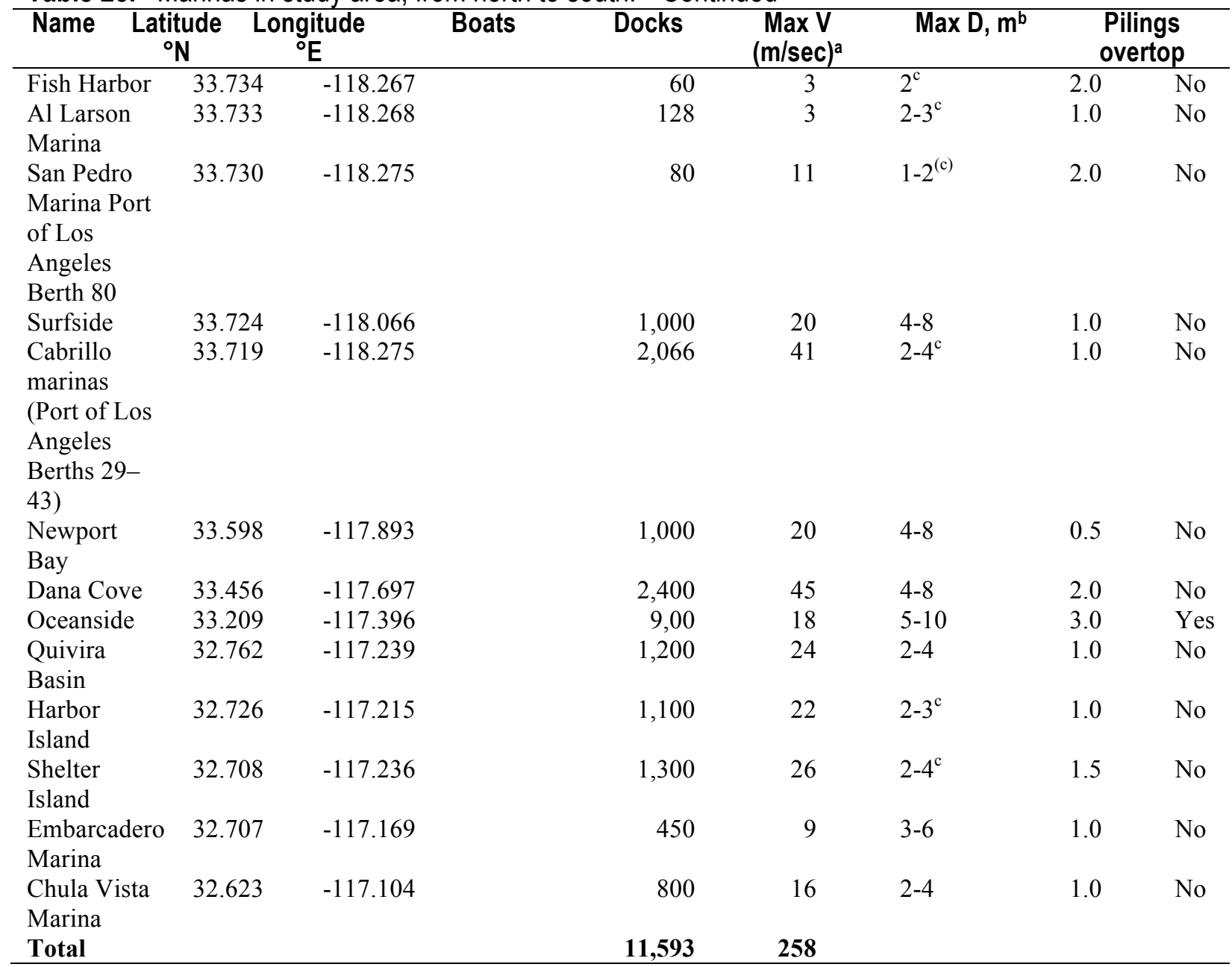

${ }^{\mathrm{a}} \mathrm{Max} \mathrm{V}=$ maximum velocity, meters per second (m/sec). For knots, multiply by 2 .

${ }^{\mathrm{b}} \mathrm{Max} \mathrm{D}=$ maximum wave amplitude, meters $(\mathrm{m})$ above mean higher high water. Note $1 \mathrm{~m} \approx 3$ feet.

${ }^{\mathrm{c}} \mathrm{USC}$ (University of California) estimate from finer-resolution model.

\section{Vulnerability}

\section{Historical Damage Data}

Wilson and others (2012) record the following damage modes were observed in California after the 2010 Chile earthquake and the 2011 Tohoku earthquake, generally boats were damaged or sunk and docks damaged or destroyed. Associated with each observation is some measure of the currents or wave amplitudes accompanying the damage. Although the relationship between strong currents and damage can vary greatly within and between harbors, the results in the table indicate that boat damage could occur when velocities reach 4 or $5 \mathrm{~m} / \mathrm{sec}$ ( 8 to $10 \mathrm{kt}$ ). For some harbors, like Crescent City and Santa Cruz, 1 in 5 damaged boats sank when velocities were in the range of $4-8 \mathrm{~m} / \mathrm{sec}(8-16 \mathrm{kt}$; see fig. 51$)$. 


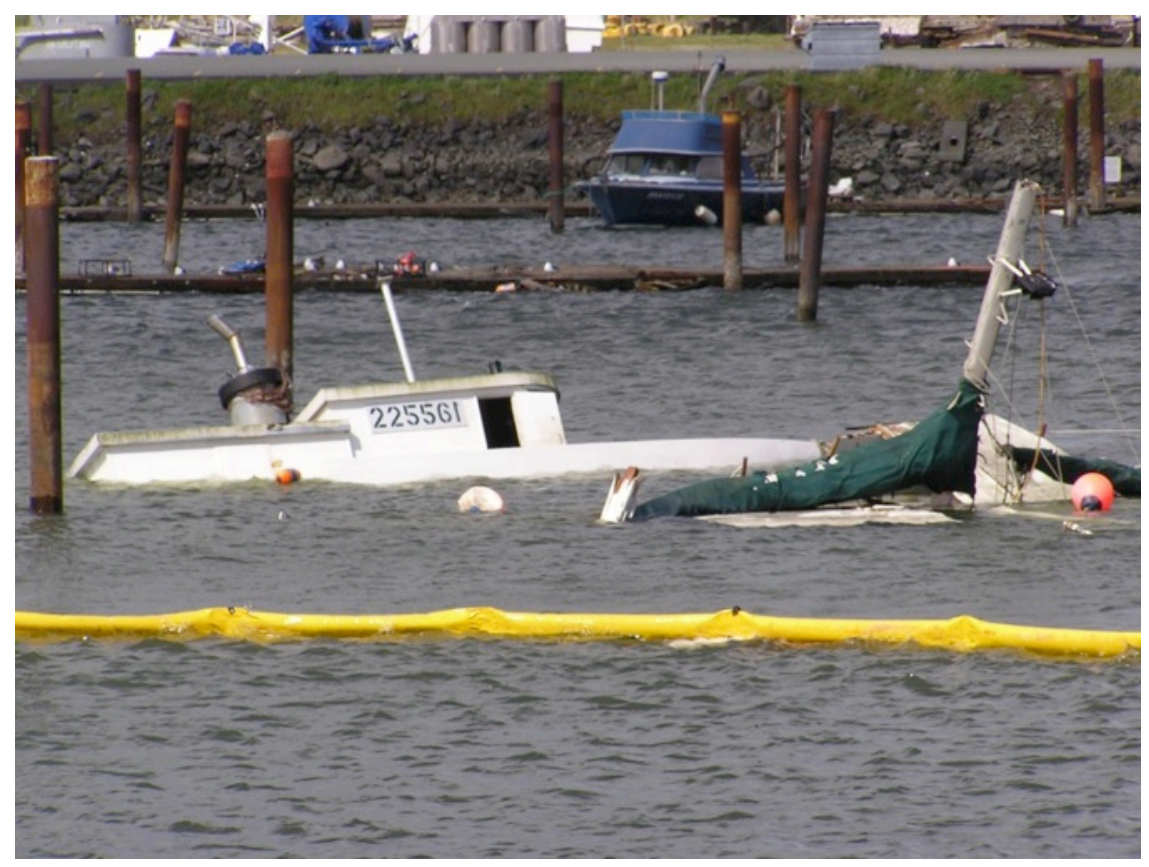

Figure 51. Photograph of boats sunk by the tsunami generated by the 2011 Tohoku, Japan, earthquake within Crescent City, California's, small boat basin (photograph by Rick Wilson).

Dock damage may also occur at about the same velocities depending on the location of the dock in the harbor, because currents vary throughout the harbor. Age matters because dock materials can degrade over time. Orientation of the docks matters, because the currents that flow parallel to a dock, impose lower bending moments (a sort of prying action) on its connections than do currents that flow perpendicular to it. Piling height matters because the tsunami can overtop short pilings, as previously mentioned. A detailed structural analysis of the docks and moored craft under the scenario currents could provide a better estimate of dock damage and an indication of which are most susceptible to tsunami damage. 
Table 26. Damage modes recorded by Wilson and others (2012).

[m, meters; $\mathrm{m} / \mathrm{sec}$, meters per second]

\begin{tabular}{|c|c|c|}
\hline \multirow{2}{*}{$\begin{array}{c}\text { Damage mode } \\
\text { Vessel collision when vessels break free of moorings }\end{array}$} & Example & Tsunami effects \\
\hline & $\begin{array}{l}\text { Santa Cruz } \\
2010\end{array}$ & $\begin{array}{l}5 \mathrm{~m} / \mathrm{sec}, 2.2 \mathrm{~m} \text { tidal } \\
\text { fluctuation }\end{array}$ \\
\hline Vessels almost run aground while returning to harbor & $\begin{array}{l}\text { Santa } \\
\text { Barbara } 2010\end{array}$ & $\begin{array}{l}4.5 \mathrm{~m} / \mathrm{sec}, 0.9 \mathrm{~m} \text { tsunami } \\
\text { wave amplitude }\end{array}$ \\
\hline 20 damaged docks, $\$ 300,000-500,000$ repair cost & Ventura 2010 & $6-7 \mathrm{~m} / \mathrm{sec}$ \\
\hline $\begin{array}{l}8 \mathrm{~m} \text { sailboat swamped, damaged beyond repair; rescue of passengers } \\
\text { required }\end{array}$ & $\begin{array}{l}\text { Mission Bay } \\
2010\end{array}$ & $\begin{array}{l}3 \mathrm{~m} \text { standing wave at Bay } \\
\text { entrance }\end{array}$ \\
\hline $\begin{array}{l}\text { Part of a dock destroyed. } 25 \mathrm{~m}, 100 \text {-ton fishing vessel tore its dock } \\
\text { from its moorings }\end{array}$ & $\begin{array}{l}\text { Shelter } \\
\text { Island, San } \\
\text { Diego Bay } \\
2010\end{array}$ & $\begin{array}{l}1 \mathrm{~m} \text { tsunami amplitude; } 5 \\
\mathrm{~m} / \mathrm{sec} \text { current }\end{array}$ \\
\hline $\begin{array}{l}\text { All docks heavily damaged or destroyed ( } \$ 20 \text { million in damage), } 16 \\
\text { boats sunk, } 47 \text { damaged. Sediment removal took } 10 \text { months. Repair } \\
\text { work ongoing after } 15 \text { months. Interestingly, post-Tohoku repairs } \\
\text { upgraded the marina for an assumed surge of } 2.5 \mathrm{~m} \text { (Trenkwalder, } \\
2013 \text {, oral commun.). The present scenario estimates } 3 \mathrm{~m} \text { of surge } \\
\text { above mean higher high water }\end{array}$ & $\begin{array}{l}\text { Crescent City } \\
2011\end{array}$ & $\begin{array}{l}2.5 \mathrm{~m} \text { tsunami wave } \\
\text { amplitude, } 4.5 \mathrm{~m} / \mathrm{sec}\end{array}$ \\
\hline Dock and infrastructure damage at openings to 2 harbors & $\begin{array}{l}\text { Noyo River } \\
2011\end{array}$ & No info \\
\hline Minor damage to docks and boats & $\begin{array}{l}\text { San } \\
\text { Francisco } \\
\text { Bay } 2011\end{array}$ & $\begin{array}{l}0.3-1.5 \mathrm{~m} \text { wave } \\
\text { amplitude }\end{array}$ \\
\hline $\begin{array}{l}23 \text { of } 29 \text { docks significantly damaged or destroyed. } 14 \text { boats sunk, } \\
\text { dozens damaged. Repair work ongoing after } 15 \text { months. }\end{array}$ & $\begin{array}{l}\text { Santa Cruz } \\
2011\end{array}$ & $\begin{array}{l}1.6-1.9 \mathrm{~m} \text { wave amplitude, } \\
7 \mathrm{~m} / \mathrm{sec} \text { currents }\end{array}$ \\
\hline $\begin{array}{l}\text { Docks sheared their wooden piles at metal ring connectors; } \$ 1.75 \\
\text { million repair costs. }\end{array}$ & $\begin{array}{l}\text { Moss } \\
\text { Landing } \\
2011\end{array}$ & $\begin{array}{l}2 \mathrm{~m} \text { tsunami tidal } \\
\text { fluctuation }\end{array}$ \\
\hline Damaged to several boats, docks, and maritime infrastructure & $\begin{array}{l}\text { Morro Bay } \\
2011\end{array}$ & $\begin{array}{l}1.6 \mathrm{~m} \text { peak tsunami } \\
\text { amplitude, } 2.5 \mathrm{~m} \text { peak-to- } \\
\text { trough tidal fluctuation. } 7 \\
\mathrm{~m} / \mathrm{sec} \text { in confined parts of } \\
\text { the harbor }\end{array}$ \\
\hline $\begin{array}{l}\text { Harbor personnel injured helping boaters to dock; } \$ 150,000 \text { dock } \\
\text { damage }\end{array}$ & Ventura 2011 & $1.3 \mathrm{~m}$ tsunami amplitude \\
\hline $\begin{array}{l}\text { Boat, dock, and harbor infrastructure damage } \$ 130,000 \text {. Four people } \\
\text { knocked off shoreline rocks }\end{array}$ & $\begin{array}{l}\text { Mission Bay } \\
2011\end{array}$ & $<1 \mathrm{~m}$ tsunami amplitude \\
\hline Police pontoon boat dragged under a dock and sunk $-\$ 40,000$. Minor & Shelter & \\
\hline hull damage to 2 other police boats whose moorings broke. & Island, San & \\
\hline & $\begin{array}{l}\text { Diego Bay } \\
2011\end{array}$ & \\
\hline
\end{tabular}


Because wave heights in the SAFRR scenario event are 3 to 4 times larger than the 2010 and 2011 events, especially north of Point Conception, marinas and harbors would likely face more significant tsunami hazards. Extreme fluctuations in water level caused by the tsunami could cause damage to boat keels and dock and boat connections. With significant flow depths and inundation of dry land around harbors expected, dock connections could float above the tops of piles causing docks (and attached boats) to float freely within the harbors. Free-floating boats and docks would become tsunami debris capable of additional damage to surrounding structures. Harbor infrastructure (for example, electrical lines, sewage, and petroleum pipelines) could also become significantly damaged by loose docks and boats. Offshore moorings could also conceivably be damaged, either by dragging the anchor (commonly a concrete block attached to a mooring line and buoy) or by parting (breaking) the mooring line.

Testing and cleanup of hazardous materials could delay restoration of harbors. For example, after the 2011 tsunami, reconstruction efforts in Crescent City Harbor were delayed by over 10 months due to complications in permitting and sampling of the 150,000 cubic-meters of sediment deposited in the basin by the tsunami (Wilson and others, 2012). A larger tsunami scenario, like that of the SAFRR project, would cause similar damage and sediment movement to dozens of harbors in the State, would likely cause even longer delays because regulatory and recovery resources would be stretched very thin. Environmental problems are addressed in greater detail elsewhere in the scenario study.

\section{Fragility Functions for Velocity-Induced Damage}

There is some standard practice in earthquake engineering on how to create a mathematical model of the damageability of an object subjected to seismic excitation. See for example Porter and others (2007). In that procedure, the objective is to create an idealized mathematical model of damageability. Typically (though not always) the model is a lognormal cumulative distribution function of the capacity of the object to resist a specified damage state, in terms of a scalar measure of environmental excitation, termed an intensity measure (IM). The damage state is commonly defined in terms of the observable evidence of damage and the repair required to restore the object to its pre-event condition. The evidence is commonly tabulated in terms observations either of the actual level of excitation causing each instance of damage to occur (type-A data, where A refers to actual excitation), or the number and fraction of instances where the damage state was exceeded, and the maximum excitation associated with each observation (type-B data, where B refers to bounding excitation). There are other kinds of damageability evidence described in Porter and others (2007) that are not relevant here. These include type-C (capacity) data, where specimens were subjected to varying levels of excitation but none were damaged; type-D (derived) fragility, which applies engineering first principles to estimate the excitation at which a modeled specimen fails; and type-E (expert opinion) data, which represents a last resort absent types A-D data.

We assume vessel and dock damage can be modeled as a function of tsunami velocity using the convention of a capacity parameter idealized as a lognormal random variable with some reasonable logarithmic standard deviation; it is common to use 0.4 , absent better data. The evidence offered by Wilson and others (2012) are insufficient to create a strongly defensible fragility function, but at least they suggest some reasonable parameter values. Only two set of observation are sufficient to plot damage (fraction of vessels damaged or sunk) versus intensity: Crescent City (2011) and Santa Cruz (2011). We estimated number of boats exposed to the tsunami from satellite imagery prior to the tsunami, and divided the reports of damaged or suck 
boats by the estimated number of boats exposed. For Santa Cruz, we interpreted "dozens" to mean 120; results are sensitive to this assumption. We fit fragility functions through points averaged from these data, as shown in figure 52. (A maximum-likelihood method could also be used to determine parameter values, but that approach seems excessively refined for such crude data.) The fragility functions for "boat at least damaged" and "boat sinks" are thus respectively:

$$
\begin{gathered}
P\left[D_{\text {boat }} \geq 1 \mid V=v\right]=\Phi\left(\frac{\ln (v / 6.5)}{0.4}\right) \\
P\left[D_{\text {boat }}=2 \mid V=v\right]=\Phi\left(\frac{\ln (v / 9.9)}{0.4}\right)
\end{gathered}
$$

where $P[D \geq d \mid V=v]$ denotes the probability that any given boat reaches or exceeds damage state $d$ (that is, $d=1$ means damaged, $d=2$ means sunk), $V$ is the maximum tsunami wave velocity in the marina measured in $\mathrm{m} / \mathrm{sec}$, and $\Phi$ is the normal cumulative distribution function. Figure 52 illustrates these curves and a fragility function for dock damage, whose form is similar:

$$
P\left[D_{\text {dock }}=1 \mid V=v\right]=\Phi\left(\frac{\ln (v / 3.5)}{0.4}\right)
$$

Equations (1) and (2) are used to estimate the probability that a boat is damaged but not sunk, as follows:

$$
P\left[D_{\text {boat }}=1 \mid V=v\right]=P\left[D_{\text {boat }} \geq 1 \mid V=v\right]-P\left[D_{\text {boat }}=2 \mid V=v\right]
$$




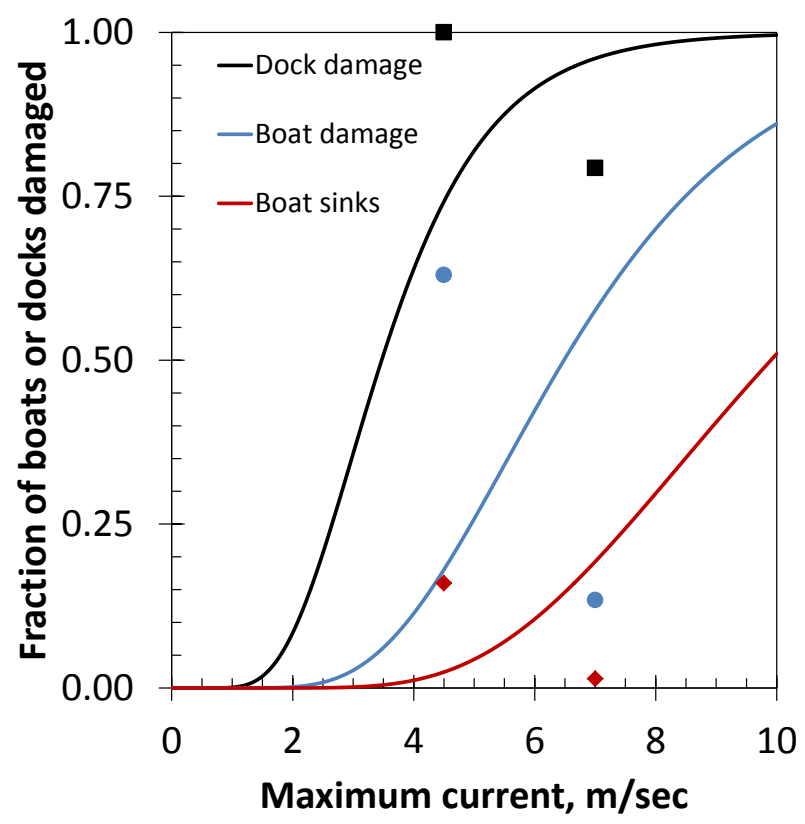

Figure 52. Graph showing fragility model for boats and docks in the SAFRR tsunami scenario. This model considers only current velocities. Elsewhere we recognize that boats secured to docks whose pilings are overtopped experience much greater damage. Dots represent data; curves are roughly fit to them. Though the data are sparse, the curves are plausible. ( $\mathrm{m} / \mathrm{sec}$, meters per second.)

\section{Repair Costs Conditioned on Damage}

Ideally each damage state is defined unambiguously, in quantitative terms of observed symptoms of damage and a clear set of repair measures required to restore the object to its preevent condition. Except in the case of "boat sinks," the foregoing fragility functions lack that clarity. Qualifiers such as "slight," "minor," or "significant" still beg the question of what repairs are required and how much they cost, questions that are not answered by the available evidence. The following costs conditioned on damage state are therefore order-of-magnitude estimates. The replacement cost for a boat can be taken as approximately uniformly distributed between $\$ 25,000$ and $\$ 75,000$, although higher and lower prices exist, based on a sample of 2010-2013

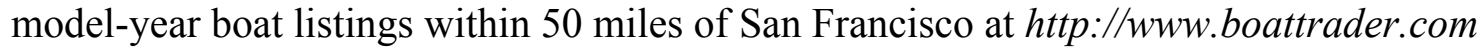
(accessed May 15, 2013). We use Boat Trader's average price of $\$ 50,000$ for the same sample. Damage is assumed to cost 20 percent of the replacement cost. The average cost to repair a damaged dock is taken as $\$ 6,000$, based on a reported $\$ 114,000$ to repair 20 damaged docks in the Berkeley marina after the 2011 Tohoku tsunami (Hardinger, written commun., 2012). If the dock is damaged, one repair is required per 50 slips, again based on Berkeley's experience in 2011. Replacing concrete modular floats is estimated to cost $\$ 100$ per square foot $\left(\mathrm{ft}^{2}\right)$ (Trenkwalder, 2013, oral commun.). Each slip requires approximately $300 \mathrm{ft}^{2}$ of dock, based on sample California marinas. Thus, destroyed docks are assumed to cost $\$ 30,000$ per slip to demolish and replace. Replacement of a pile could also approach $\$ 10,000$ to $\$ 15,000$ (Trenkwalder, 2013, oral commun.). 


\section{Damage Resulting from Overtopped Pilings}

With high tides and tsunami wave heights together sometimes exceeding $4 \mathrm{~m}$, a strong potential exists for docks to float off their pilings. Piling heights vary between marinas, and some are relatively short, so we queried harbormasters about piling heights, asking them whether the wave heights estimated by URS would cause docks to float off their pilings. Where harbormasters replied that docks would float off their pilings, or where harbormasters did not reply but wave heights were at least $2.5 \mathrm{~m}$ above the reference water level, that is, above mean high water plus $20 \mathrm{~cm}(\mathrm{MHW}+20)$, we assumed that pilings are overtopped. In such a case, all boats are assumed to be damaged, half of them sink, an assumption that several harbormasters agreed with and none disagreed with. We have also assumed that among docks that float off, 25 percent can be salvaged, and the other 75 percent require replacement, as suggested by an engineer involved in post-Tohoku marina repairs (Trenkwalder, 2013, oral commun.), who says that floats would be damaged from impact from loose boats or other floats, cleats breaking wales (as a result of cross-grain bending), and utilities (potable water and power) would be damaged from loss of structural support. Repairs would typically consist of replacing timber wales, reusing salvaged floats, reattaching salvaged cleats, and reconnecting utilities. We estimate the cost to replace or repair freed docks at $\$ 80 / \mathrm{ft}^{2} \cdot 300 \mathrm{ft}^{2} /$ slip, where we use $\$ 80$ rather than $\$ 100$ because 25 percent of floats at freed docks could be salvaged with some cost, say $\$ 20 / \mathrm{ft}^{2}$, for the salvage effort.

\section{Restoration Time}

To assess restoration time, we inquired of 26 California harbormasters about restoration of damage under the scenario tsunami and about their experience in the 2011 Tohoku tsunami. Replies were limited, so the following restoration model is speculative, although consistent with four harbormasters' experience in 2011. Harbormasters of marinas where the majority of docks were damaged but not destroyed reported repairs taking 1 to 2 months. They speculated that if all of their docks were destroyed, repairs could take 1 to 3 years, especially municipal marinas where repair funding would be an issue. Conceivably repair durations might be briefer in a future tsunami through streamlining of the regulatory process and by applying lessons learned from Tohoku, but we have assumed that the speed of recovery is similar to 2011.

We therefore offer the following simple restoration model, illustrated in figure 53. In Equation (5), $R(t)$ refers to the fraction of the marina operating normally $t$ days after the tsunami alert or warning is lifted, $f_{1}$ is the fraction of docks that are damaged but not destroyed by the tsunami, and $f_{2}$ is the fraction of docks destroyed by the tsunami, meaning that they have to be demolished and replaced. Equation (6) says that damaged docks are restored linearly with time, and completely restored within 30 days. Equation (7) says that it takes 3 months to demolish and arrange financing to replace destroyed docks, and then the remainder of 2 years to complete the replacement.

$$
\begin{gathered}
R(t)=\left(1-f_{1}-f_{2}\right)+f_{1} \cdot g_{1}(t)+f_{2} \cdot g_{2}(t) \\
g_{1}(t)=\frac{t}{30} \quad t \leq 30 \text { days } \\
=1 \quad t>30 \text { days }
\end{gathered}
$$




$$
\begin{array}{rlrl}
g_{2}(t) & =0 & t \leq 90 \text { days } \\
& =\frac{t-90}{640} & 90 \text { days }<t \leq 730 \text { days } \\
& =1 & 730 \text { days }<t
\end{array}
$$

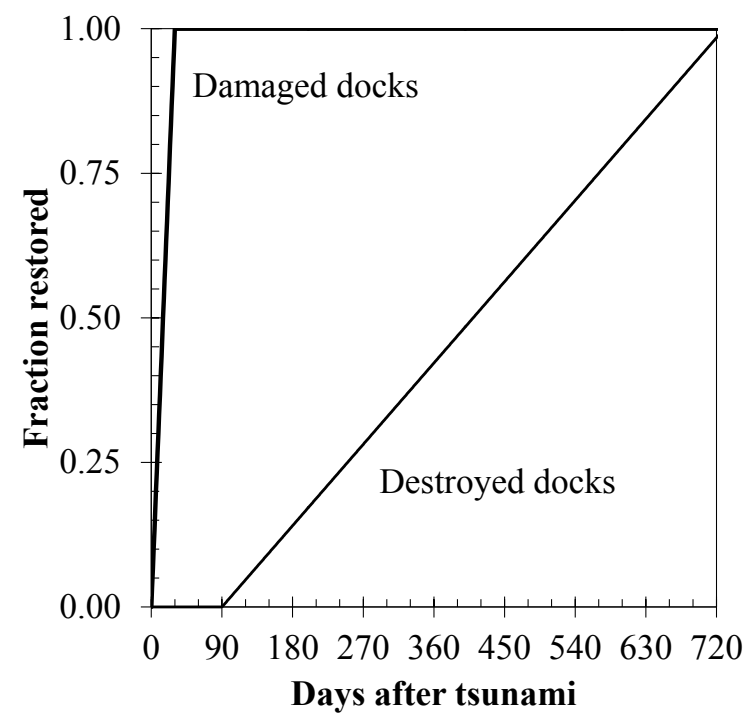

Figure 53. Graph showing restoration of damaged and destroyed docks after the SAFRR tsunami scenario.

\section{Damage to Marinas and Small Craft in the SAFRR Tsunami Scenario}

Taking the exposed quantities and velocities shown in table 25 and the vulnerability relationship just proposed, one can estimate the following consequences:

- 8,900 boats are damaged and are repairable. This amounts to 1 in 5 boats in the study area.

- 6,600 boats sink (about 1 in 7).

- 360 docks are damaged and are repairable (about 1 in 2; docks sizes vary, but a typical dock might comprise 50 slips).

- 170 docks are destroyed and must be replaced (1 in 5).

- The total expected value of loss is approximately $\$ 700$ million, of which approximately $\$ 420$ million is boat repair and replacement, \$280 million in dock repair and replacement. This total represents approximately 20 percent of the estimated replacement cost of all small craft and floating docks in the study area. (Of this total, \$20 million was already mentioned in the section on the Port of Los Angeles, so the total excluding this figure is $\$ 680$ million.)

- Note that we have not estimated the cost associated with sediment transport such as dredging and environmental remediation. These costs could be substantial, conceivably in the hundreds of millions of dollars. Nor does the tsunami modeling address all harbors throughout the State.

Considering that perhaps 40 percent of boats in Crescent City and 80 percent of Santa Cruz's docks were damaged in the 2011 Tohoku tsunami, these figures ( 1 in 3 boats damaged or 
sunk) in a tsunami pointed more directly at California does not seem unrealistically high, and it may be low. These figures omit potential damage to offshore moorings.

Using the foregoing model, it is estimated that two thirds of the loss comes from five large harbors with high enough waves that pilings are overtopped: Channel Islands Harbor (short pilings confirmed by harbormaster), Redondo Beach Marina (not confirmed, but pilings look shorter than the $1.5 \mathrm{~m}$ wave height above MHW+20 modeled here), Santa Barbara Harbor (short pilings confirmed by harbormaster), Ventura Harbor (not confirmed, but $2.5 \mathrm{~m}$ waves above MHW+20 strongly suggests overtopping) and Santa Cruz Harbor (not confirmed, but $3.5 \mathrm{~m}$ waves above MHW+20 strongly suggests overtopping). Channel Islands accounts for 1 in 4 of all of the damaged or sunk boats; and together with the next five (Redondo Beach, Santa Barbara, Ventura Harbor, Dana Cove, and Santa Cruz), these six harbors account for 2/3rd of all damaged or sunk boats. As shown in figure 55, this is not just a Northern California event: marinas from one end of the State to the other can be heavily damaged by a single tsunami. The figure shows the 10 marinas that contribute the most to the total economic loss postulated by the scenario because they are large and have high wave heights or velocities.

Boat damage can pose a navigation hazard. The Cabrillo marinas (POLA Berths 29-43) and the marinas at POLA Berths 200-205 would have approximately 90 damaged boats and 5 sunk. If any of the damaged or sunk boats broke loose from their slips, they could represent a navigation hazard to large ships in the Port of Los Angeles, as illustrated in figure 54. Shelter Island and Harbor Island similarly represent a potential threat to the Port of San Diego, contributing 30 damaged boats and 2 sunk. The Alameda Grand Marina near the Port of Oakland might have 45 damaged boats and 3 sunk. Marina Bay near the Port of Richmond is hypothesized to have 7 damaged boats, 1 sunk. 


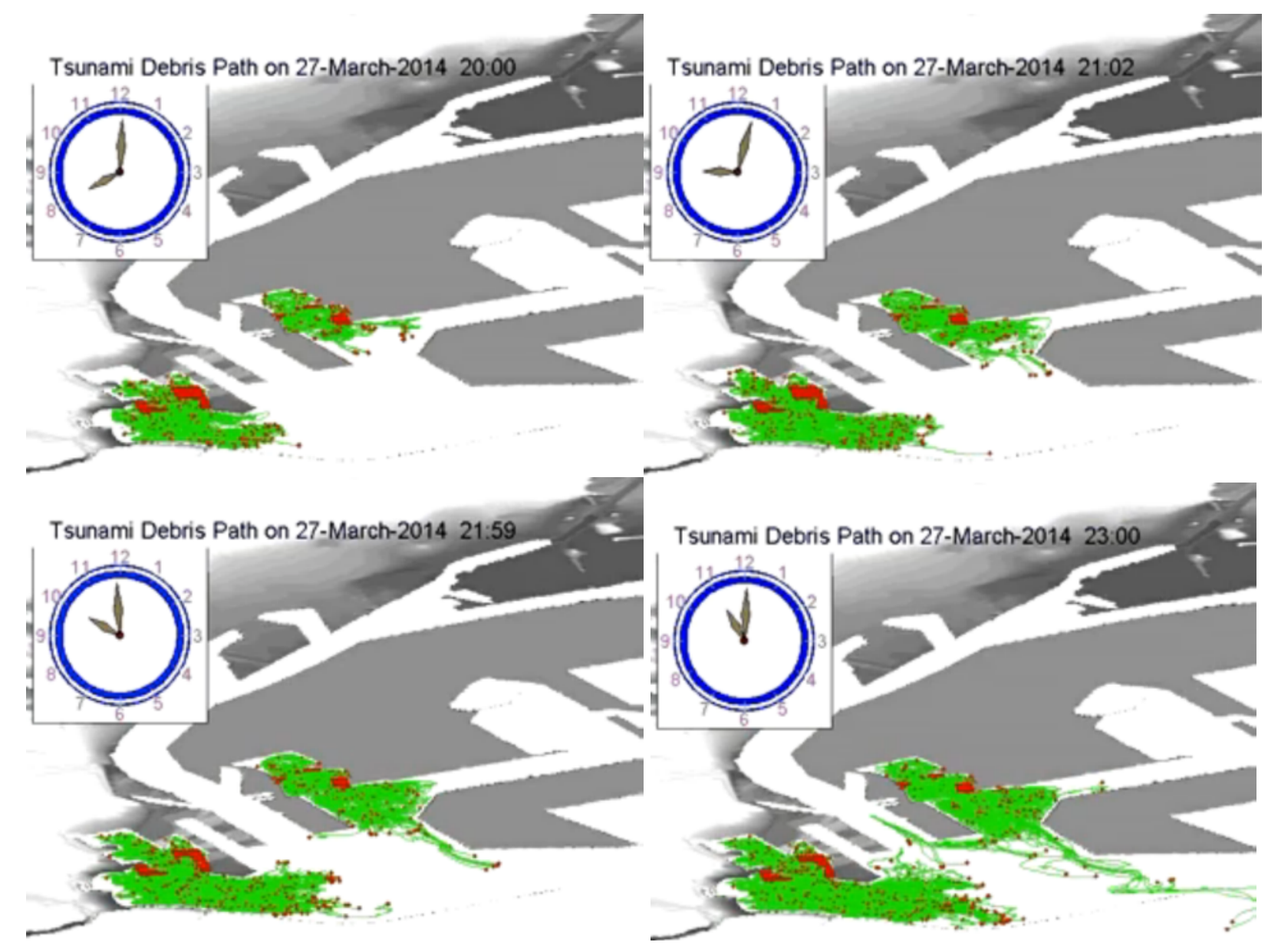

Figure 54. Diagrams of paths of hypothetical floating debris from Port of Los Angeles marinas 3.5 to 6.5 hours after the first arrival of the SAFRR tsunami.

The most significant repair delays would be attributable to removing potentially contaminated debris and sediment, especially if testing and permitting were required, but we have not estimated sediment transport so no particular locations are identified here where this would be an issue. 


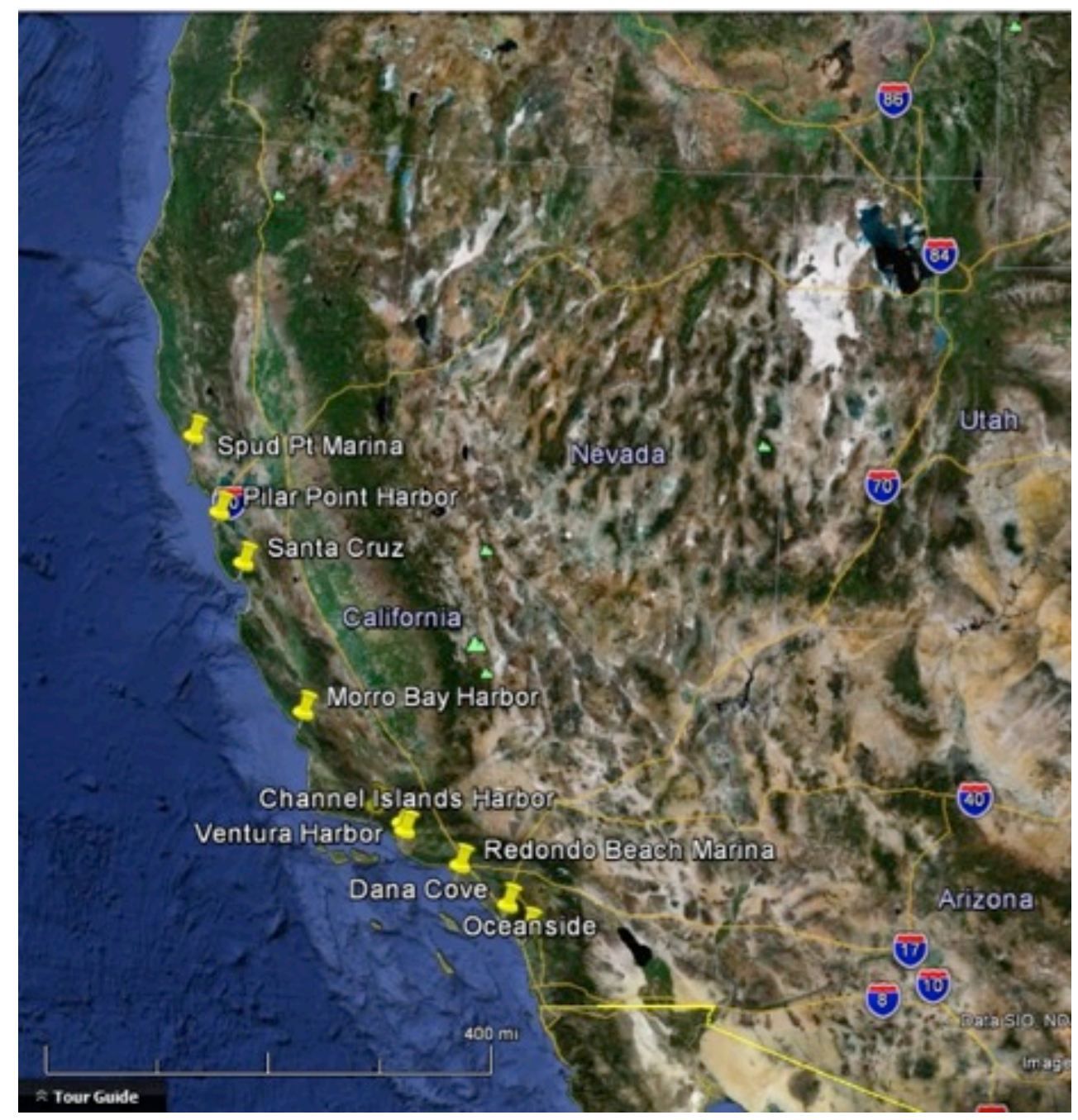

Figure 55. Most of the losses to marinas in the SAFRR tsunami scenario are to the 10 marinas shown on this map, attributable to high current velocities or high wave heights (base image from Google Earth).

Repair of breakwaters, rock slope protection, and dredging will add substantially to losses in the tsunami. In the 2011 Tohoku earthquake, the Crescent City Marina experienced $2.5 \mathrm{~m}$ surge and 12-kt velocities. This undermined rock slope protection and deposited close to 80,000 cubic yards of sand and debris in the marina basin. The required dredging and rock slope protection repair costs totaled approximately $\$ 6$ million, according to Trenkwalder (2013, oral commun.). We have not estimated sediment transport nor identified particular locations of likely damage to breakwaters and slope protection, but these are likely and could add $\$ 100$ million in losses.

\section{Resiliency Opportunities}

Boat and dock damage could be greatly reduced by increasing the heights of pilings; more than half the damage is attributed to docks floating off their pilings (though boats could be damaged by current velocities as well). It is practical to add height to most kinds of pilings, although doing so raises strength concerns. Boat damage could also be reduced by moving boats 
offshore or to safe anchorage during the warning period, or by removing them from the water onto trailers, but this seems impractical for more than a small number of boats in most recreational boating communities. Most boat owners would not likely be on or near their boats when the warning was issued. U.S. Coast Guard personnel voiced the opinion that moving large numbers of boats out of their harbors simultaneously would tend to cause more life-safety threats than warranted by the potential property savings. The boats would have to stay out of the harbor for at least 12 hours, which means until the morning of March 28, and which would be problematic for many boat owners with families to care for and require solid advance planning in terms of understanding the need for taking enough fuel, food, water, and having the navigational skill to remain at sea for extended periods. The Coast Guard would be hard pressed to support so many boats all hastily put to sea, all likely in a bunch, all night. In addition, damage within harbors could prevent boats from returning.

\section{Research Needs}

Future tsunamis can be more severe than California's recent experience in the Tohoku and Chile tsunamis, so absent significant changes to the vulnerability of boats and docks, California's marinas will experience greater damage in more-severe tsunamis. The research needs discussed here are about refining models of that damage. That is, these research needs address improvements in our ability to estimate asset fragility, to better understand damage mechanisms, and to better inform risk mitigation decisions.

There is a good deal of simplification in the marina damage model presented here. Fragility functions are based on only two observations. Standard procedures call for several more. We intend these fragility functions to represent plausible relationships for purposes of developing a scenario; they are not offered for other purposes. However, the paucity of data used to derive the fragility functions reflects limited literature, not limited experience: California marinas have recently enough experienced tsunamis that have caused such extensive damage to boats and docks that it should be practical to find sufficient data to produce high-quality fragility functions that could be used in loss estimation. It would also be worthwhile to quantify the damageability of offshore moorings for small craft.

Repair costs for damaged docks are based on limited repair-cost data from Berkeley and from catalog prices of docks. An additional effort to collect more cost data on docks and boat repair would be desirable. Results are largely proportional to these guesses, by which we mean that if the estimate of the average repair cost for a damaged boat is high or low by a factor of two, so is the estimate of total loss. Velocity observations are aggregated, with single midrange values for entire marinas, despite that the velocity may vary significantly within a marina. Boat and dock orientation and interaction could relate to damageability in ways that are not reflected in these two observations.

Piling heights are in many cases based on Google Earth Street View from nearby streets. It was necessary in these cases to judge the tidal stage from the photos and to estimate how much piling height would remain above the water at mean higher high water. Results are sensitive to these judgments. If we overestimated piling heights, and in fact they were uniformly half as tall above $\mathrm{MHW}+20$ than we judged, then the property damage could be $\$ 400$ million more ( $\$ 1.1$ billion total property damage): 12,000 boats would be damaged and 11,000 sunk, meaning that half of California pleasure boats in the study area would be damaged or sunk. But lacking a highresolution velocity model and more-detailed harbor infrastructure and damage data, the foregoing is as much as is practical. 
More could be done. There has been a good deal of research on the tsunami fragility of buildings, but the authors could find none on the fragility of boats (in the sense of a mathematical relationship between tsunami wave velocity or amplitude and damage to small craft). Such a relationship would be valuable given the number of craft exposed and the hazard they may pose to navigation if damaged. Standard procedures exist for the derivation of earthquake-related fragility functions for building components; these have been easily adapted to boat damage due to tsunami. The data collection procedures for earthquake damage to building components could similarly be applied to boats damaged by the next tsunami. We have sought and received from California harbormasters anecdotal data on marina restoration times in past tsunamis, but it has been said that the plural of anecdote is not data. A more exhaustive survey with high response rates would be required to draw deeply defensible conclusions about the factors that affect repair time and to create a good mathematical model.

Additional research and assistance regarding piling heights and boat movement or evacuation are also clear needs. The California State Tsunami Program is focusing on this type of work for maritime communities by studying safe depth and distance required for offshore evacuation and strong tsunami currents within harbors in order to provide consistent guidance from findings to harbor authorities, emergency planners, and the public.

\section{Building Damage}

\section{By Keith Porter}

\section{Introduction and Purpose}

This section presents an estimate of tsunami effects on buildings from the SAFRR tsunami scenario. It is based on a map of flow depths and momentum flux by URS Corp., modified by an inundation line produced by the California Geological Survey (CGS). Where the inundation line extends farther inland from the URS map, flow depth is estimated to be $1.5 \mathrm{ft}$. Where the inundation line is closer to the shore than the URS map, the URS map is clipped to exclude the portions that CGS believes are not inundated. It also draws on a preliminary tsunami vulnerability model developed for the National Institute of Building Sciences (NIBS) as part of NIBS' efforts to create a HAZUS-MH tsunami loss model.

The objectives of this portion of the study are as follows:

- Summarize the value and location of buildings exposed to loss

- Summarize and illustrate common forms of building damage in tsunamis

- Summarize the development of tsunami vulnerability functions from the HAZUS-MH draft damage model

- Estimate the repair cost and repair duration of these assets

- Identify options for enhancing resiliency

- Identify research needs

\section{Estimating Assets Exposed to Loss}

HAZUS-MH offers a nationwide default building-stock inventory, but it can be difficult to use outside of HAZUS-MH (as is sometimes desirable): it is encoded in 15 tables in 2 Microsoft Access databases for each of 50 States. A Microsoft Access database is developed 
here that links to the HAZUS-MH tables, and includes 54 scripted query language (SQL) queries, a macro to perform them all, and a number of supporting tables, for the purpose of extracting the HAZUS-MH inventory to a single de-normalized table, which is more practical for use in the present study. The table shows by Census block, tract, county or State: square footage of construction, building value, content value, and number of indoor occupants at 2 p.m., 2 a.m., and 5 p.m. The quantities are distributed by HAZUS-MH occupancy classification, structure type, and design level.

Let us denote the quantities of square footage, building value, and content value by $A, V b$, and $V c$, respectively. We begin by distributing square footage, building value, add content value by census block, occupancy class, and material, as follows:

$$
\begin{gathered}
A_{\text {block,occ, matl }}=A_{\text {block,occ }} \cdot P c t_{\text {matl locc }} \\
V b_{b l o c k, o c c, \text { matl }}=V b_{b l o c k, o c c} \cdot P c t_{\text {matl locc }} \\
V c_{\text {block,occ,matl }}=V c_{\text {block,occ }} \cdot \frac{P c t_{\text {matl locc }}}{100}
\end{gathered}
$$

In these equations, $P c t_{\text {matl loc }}$ is used to distribute square footage and value equally. There does not appear to be any documentation to indicate whether the Pct values in the HAZUS-MH tables refer to square footage, building value, content value, or other factors, but HAZUS-MH does not appear to have any data to distinguish the percentage of one quantity, such as square footage, from that of another, such as building value. The same percentages are used regardless of which quantity is being distributed. This may be a somewhat crude assumption: fraction of area may be very different from fraction of value in highly disparate occupancies. However, it seems sufficient considering other sources of error in risk analyses. Once the area and values have been distributed to the level of block, occupancy class, and material, they are then further distributed to the level of structure type and design level as follows:

$$
\begin{gathered}
A_{b l o c k, o c c, t y p e, d e s i g n}=A_{b l o c k, o c c, \text { matl }} \cdot P c t_{t y p e, d e s i g n \mid m a t l} \\
V b_{b l o c k, o c c, t y p e, d e s i g n}=V b_{b l o c k, o c c, \text { matl }} \cdot P c t_{t y p e, d e s i g n \mid m a t l} \\
V c_{b l o c k, o c c, t y p e, d e s i g n}=V c_{b l o c k, o c c, \text { matl }} \cdot P c t_{t y p e, d e s i g n \mid m a t l},
\end{gathered}
$$

where $P c t_{\text {type,design|matl }}$ denotes the fraction of square footage in the given material represented by the given particular structure type and design level.

In a parallel effort, URS Corp staff estimated flow depth and momentum flux on a $30 \mathrm{~m}$ gridded basis; these raster data were imported to a GIS for further analysis. U.S. Geological Survey (USGS) staff intersected the URS maps with census block boundaries and masked out water features, meaning that the portions of census block in water were removed from the portions on land. The USGS staff then calculated the remaining fraction of each census block with positive flow depth ("inundated fraction"), and estimated the average flow depth and momentum flux in the inundated fraction of each census block. The inundated fraction of each census block area was assumed to be the same fraction of building value with some inundation. This fraction was applied to building area, building value, content value and occupancy, to estimate the quantities of buildings and occupants with positive flow depth. 
By this process, it appears that the tsunami has positive flow depths in 1800 city blocks, affecting 100 million square feet of buildings valued at \$13 billion (replacement cost new, only including the subset of buildings in the inundated portion of coastal census blocks) and $\$ 8$ billion of contents (replacement cost new, same subset). See table 27 for inventory totals by county. These totals include only the scenario inundation zones in the study area, not areas that would be inundated in such a scenario but that fell outside the study areas.

Buildings that are wetted by the tsunami in this scenario (and that are in the study area) represent approximately 37 percent of the inventory inside the maximum inundation zone developed by the California Governor's Office of Emergency Services (Cal OES). As noted elsewhere in this report, Cal OES's maximum inundation zone represents an envelope of inundation from many large distant and local-source tsunamis that could affect California, not just a single tsunami. That fact accounts for part of the difference between this tsunami and the Cal OES maximum inundation zone. Much of the rest is because the Cal OES inundation zone is delineated for the entire California coast, whereas our model only examines a portion of the coast. See table 28 for our estimate of the inventory inside Cal OES's maximum inundation zone. As shown in the table, this tsunami is a statewide event, not just a northern or southern California disaster: counties along the entire coast have significant inundation compared with the Cal OES inundation zone.

\section{Forms of Building Damage}

Buildings affected by tsunamis tend to be damaged by the following mechanisms, illustrated in figures 56 and 57:

1. Hydrodynamic pressure of the moving water damages building finishes and structural members, potentially causing local pressure-related damage to building components or displacement of the entire building. This damage can be due to either the inflow or outflow of water. Figure 56 shows instances of damage from Japan in 2011 where buildings were completely swept away.

2. Wetting of building and contents components that are subject to water damage, such as carpets, electrical wiring, wall finishes, computers and other contents.

3. Soiling of building and contents by soil deposited by tsunami flows.

4. Impact or deposition of water-borne debris.

5. Fire or release of hazardous materials. These issues are addressed elsewhere.

6. Buoyancy can lift and transport a building from its foundation.

7. Scour can erode soil around the building, especially at corners. 

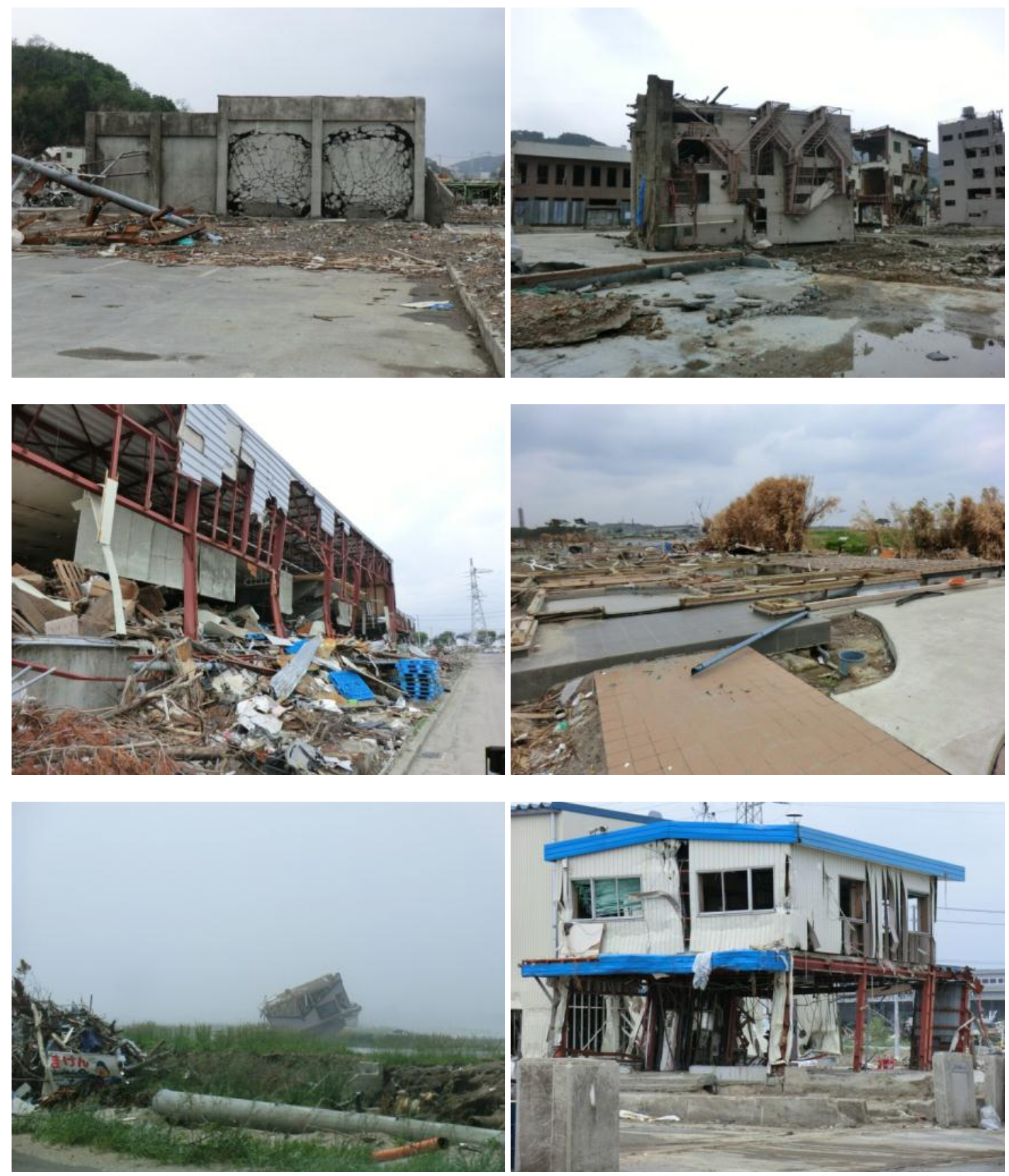

Figure 56. Photographs of apparent effects of hydrodynamic pressure on buildings in Japan affected by the 2011 Tohoku tsunami (photographs by Keith Porter). 

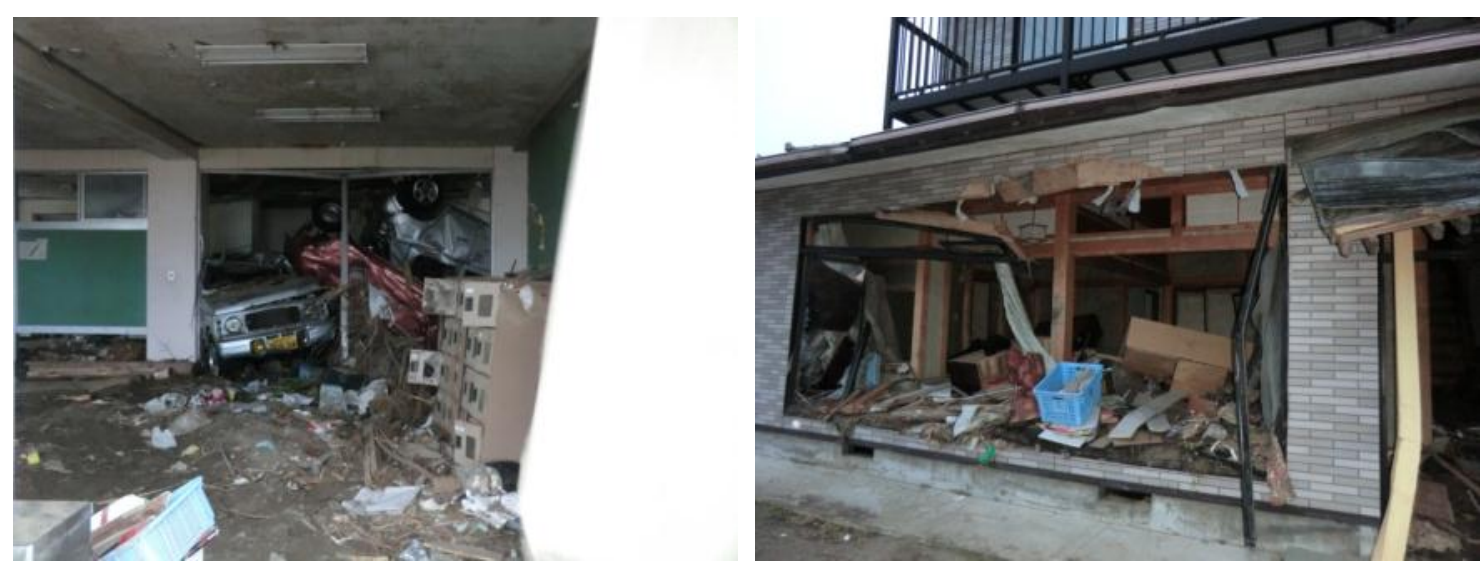

Figure 57. Photographs of wetting, soiling, and deposition of debris in buildings in Japan affected by the 2011 Tohoku tsunami (photographs by Keith Porter).

\section{Creating Tsunami Vulnerability Functions}

Physical damage and repair costs for buildings and contents can be estimated as functions of tsunami loading, commonly measured in terms of momentum flux $(m)$ and flow depth $(f)$. The result is referred to here as a vulnerability function. We considered two sources for these: a draft analytical model in development for the HAZUS-MH tsunami model (Kircher, written commun., 2012) and recently published empirical relationships derived from experience in the 2011

Tohoku tsunami (Suppasri and others, 2013).

The model offered by Suppasri and others (2013) is based on a survey by the Ministry of Land, Infrastructure and Transportation of Japan, with more than 250,000 structures surveyed. The set of data has details on damage level, structural material, number of stories per building and location (town). It provides a set of fragility functions that depict the probability of reaching or exceeding each of six qualitatively defined damage states as a function of inundation depth. It offers the advantage of drawing on a very large survey of building damaged by tsunami flows.

The HAZUS-MH draft model relates damage state, repair cost, and duration of loss of functionality to both depth (for nonstructural components and contents) and momentum flux (for structural components) for U.S. construction. It borrows from riverine and coastal flood damage models developed by the U.S. Army Corps of Engineers and others over several decades and supplements these with analytical models that use engineering first principles to estimate structural forces, resistance, damage, and loss. It offers the advantages of transparency, application of a great deal of U.S. domestic damage experience in floods, ability to estimate quantitative measures of performance (repair cost and loss of functionality), and consistency with developing U.S. codes. For these reasons, we employ the HAZUS-MH model here. Note that we do not use the HAZUS-MH vulnerability functions in HAZUS-MH; the software has not been distributed yet. Rather we use the vulnerability functions in a database outside of HAZUS$\mathrm{MH}$. Note also that the HAZUS-MH Tsunami module is still under development, and that significant changes could occur prior to release of production software.

In HAZUS-MH, a vulnerability function applies to a single combination of model building type (16 types related to construction material and lateral force resisting system), height (low rise, mid-rise, or high rise), code era (precode, low code, moderate code, high code), and occupancy type (33 varieties of residential, commercial, industrial, agricultural, religion, government, and education). The vulnerability functions reflect an uncertain discrete damage 
state D for each building component (structural, nonstructural, and contents) and an expected value of repair cost conditioned on damage state. The probability mass function of the uncertain damage state is evaluated using fragility functions in the form of a lognormal cumulative distribution function that reflects the assumption that components have an uncertain capacity to resist each damage state, and that the capacity is lognormally distributed. The duration of loss of function ("downtime") is assumed to be a function of structural damage state. The vulnerability functions for building, contents, and downtime are denoted here by $M D F_{B}, M D F_{C}$, and $M D F_{T}$, respectively, and are evaluated as follows.

$$
\begin{aligned}
M_{B}(m, f) & =\sum_{d=2}^{4} P\left[D_{S}=d \mid M=m\right] \cdot E\left[L_{S} \mid D_{S}=d\right] \\
& +\sum_{d=2}^{4} P\left[D_{N}=d \mid F=f\right] \cdot E\left[L_{N} \mid D_{N}=d\right] \\
M D F_{C}(f)= & \sum_{d=2}^{4} P\left[D_{C}=d \mid F=f\right] \cdot E\left[L_{C} \mid D_{C}=d\right] \\
M_{T}(m, f)= & \sum_{d=2}^{4} P\left[D_{S}=d \mid M=m\right] \cdot E\left[L_{T} \mid D_{S}=d\right]
\end{aligned}
$$

where

$$
\begin{aligned}
& P\left[D_{S}=d \mid M=m\right]=\Phi\left(\frac{\ln \left(m / \theta_{S, d}\right)}{\beta_{S, d}}\right)-\Phi\left(\frac{\ln \left(m / \theta_{S, d+1}\right)}{\beta_{S, d+1}}\right) \quad d \in\{2,3\} \\
& =\Phi\left(\frac{\ln \left(m / \theta_{S, d}\right)}{\beta_{S, d}}\right) \quad d=4 \\
& P\left[D_{N}=d \mid F=f\right]=\Phi\left(\frac{\ln \left(f / \theta_{N, d}\right)}{\beta_{N, d}}\right)-\Phi\left(\frac{\ln \left(f / \theta_{N, d+1}\right)}{\beta_{N, d+1}}\right) \quad d \in\{2,3\} \\
& =\Phi\left(\frac{\ln \left(f / \theta_{N, d}\right)}{\beta_{N, d}}\right) \quad d=4 \\
& P\left[D_{C}=d \mid F=f\right]=\Phi\left(\frac{\ln \left(f / \theta_{C, d}\right)}{\beta_{C, d}}\right)-\Phi\left(\frac{\ln \left(f / \theta_{C, d+1}\right)}{\beta_{C, d+1}}\right) \quad d \in\{2,3\} \\
& =\Phi\left(\frac{\ln \left(f / \theta_{C, d}\right)}{\beta_{C, d}}\right) \quad d=4
\end{aligned}
$$


$f=$ a particular values of $\mathrm{F}$

$D_{S}=$ damage state of structural components, $D_{S} \in\{0,1,2,3,4\}$. Only damage states 2,3 , and 4 are assumed to contribute to tsunami loss.

$D_{N}=$ damage state of nonstructural components, $\mathrm{D}_{N} \in\{0,1,2,3,4\}$. Only damage states 2,3 , and 4 are assumed to contribute to tsunami loss.

$D_{C}=$ damage state of contents, $D_{C} \in\{0,1,2,3,4\}$. Only damage states 2,3 , and 4 are assumed to contribute to tsunami loss.

$d=$ particular value of $D$

$P[\mathrm{~A} \mid \mathrm{B}]=$ probability that $\mathrm{A}$ is true given that $\mathrm{B}$ is true

$E[\mathrm{~A} \mid \mathrm{B}]=$ expected value of $\mathrm{A}$ is true given that $\mathrm{B}$ is true

$E\left[L_{S} \mid D_{S}=d\right]=$ mean damage factor of structural component in damage state $d$ (damage factor $=$ structural repair cost as a fraction of building replacement cost new, where the building comprises the structural and nonstructural components), and $d \in\{2,3,4\}$. Estimates of $E\left[L_{S} \mid D_{S}=d\right]$ are tabulated in NIBS and FEMA (2009). They vary by occupancy class.

$E\left[L_{N} \mid D_{N}=d\right]=$ mean damage factor of nonstructural components in damage state $d$ (damage factor $=$ nonstructural repair cost as a fraction of building replacement cost new), $d \in\{2,3,4\}$. Values are tabulated in NIBS and FEMA (2009) and vary by occupancy class. For tsunami, they are the sum of the nonstructural drift-sensitive and nonstructural acceleration-sensitive values from the earthquake methodology.

$E\left[L_{C} \mid D_{C}=d\right]=$ mean damage factor of contents in damage state $d$ (damage factor = content repair cost as a fraction of content replacement cost new), $d \in\{2,3,4\}$. Values are tabulated in NIBS and FEMA (2009) and vary by occupancy class. Half the value of contents is assumed to be recoverable after earthquake shaking but not after tsunami, so these values are taken as double the earthquake-related quantities tabulated in NIBS and FEMA (2009).

$E\left[L_{T} \mid D_{S}=d\right]=$ mean duration of loss of function of a building whose structural component is in damage state $d, d \in\{2,3,4\}$. It is calculated as the product of repair time, denoted here by $B C T_{d}$ and a factor $M O D_{d}$ between 0.0 and 1.0 that reflects the fraction the repair time after which the building is functional again, even if repairs are ongoing. Median values of $B C T_{d}$ and $M O D_{d}$ are tabulated in NIBS and FEMA (2009) and vary by occupancy class. NIBS and FEMA (2009) does not suggest the form of the probability distribution of $B C T$ conditioned on $d$. There is an information-theory justification for assuming that, given a damage state $d, B C T_{d}$ is uniformly distributed between two bounds. Under this condition, the median value of $B C T_{d}$ is also its mean value, which we denote here by $E\left[B C T \mid D_{S}=d\right]$. The HAZUS-MH developers offer $M O D_{d}$ as point estimates and do not suggest any distribution (or discuss uncertainty for that matter), so we treat it as a point estimate as well. Thus,

$$
E\left[L_{T} \mid D_{S}=d\right]=E\left[B C T \mid D_{S}=d\right] \cdot M O D_{d}
$$

$S, d=$ median capacity of structural component to resist damage state $d, d \in\{2,3,4\}$; values are estimated in Kircher (written commun., 2012) and vary by model building type, height, and code era

$S, d=$ logarithmic standard deviation of capacity of structural component to resist damage state $d, d \in$ $\{2,3,4\}$; tabulated in Kircher (written commun., 2012) and vary by model building type, height, and code era

$N_{N, d}=$ median capacity of nonstructural component to resist damage state $d, d \in\{2,3,4\}$; tabulated in Kircher (written commun., 2012) and varying by model building type and height, but not code era.

${ }_{N, d}=$ logarithmic standard deviation of capacity of nonstructural component to resist damage state $d$, $d \in\{2,3,4\}$; tabulated in Kircher (written commun., 2012) and varying by model building type and height, but not code era. 
$C, d=$ median capacity of contents to resist damage state $d, d \in\{2,3,4\}$; tabulated in Kircher (2012) and varying by model building type and height, but not code era.

$C, d=$ logarithmic standard deviation of capacity of contents to resist damage state $d, d \in\{2,3,4\}$; tabulated in Kircher (written commun., 2012) and varying by model building type and height, but not code era.

The vulnerability functions were evaluated at 51 levels of momentum flux $m \in\left\{10^{0}\right.$, $\left.10^{0.1}, 10^{0.2}, \ldots 10^{5}\right)$ cubic feet per second squared $\left(\mathrm{ft}^{3} / \mathrm{sec}^{2}\right)$ and 51 levels of flow depth $\mathrm{f} \in\left\{10^{0}\right.$, $\left.10^{0.1}, 10^{0.2}, \ldots 10^{5}\right) \mathrm{ft}$ for each combination of model building type, height, code era, and occupancy class, for a total of approximately 10,000 vulnerability functions (4008 each for structural and downtime, and 1002 each for nonstructural and contents, which do not vary by code era.). A sample set of vulnerability functions is shown in figure 58 , for a large woodframe multifamily dwelling of moderate-code construction, such as a 1950s-era apartment building along the San Francisco Pacific shoreline. Here are some sample calculations for losses to a large woodframe building (W2) moderate code, multifamily dwelling (RES3) at $m=1,000 \mathrm{ft}^{3} / \mathrm{sec}^{2}$ (for structural vulnerability) and $h=10 \mathrm{ft}$ depth (for nonstructural and contents vulnerability).

From Kircher (written commun., 2012),

$$
\begin{aligned}
& S, 2=\quad S, 3=\quad S, 4=571 \mathrm{ft}^{3} / \\
& S, 2=\quad S_{, 3}=\quad S_{, 4}=0.83 \\
& N, 2=\quad{ }_{N, 3}=12 \mathrm{ft} \\
& N, 4=24 \mathrm{ft} \\
& N, 2=\quad{ }_{N, 3}=0.78 \\
& N, 4=0.65 \\
& C, 2=\quad C, 3=3 \mathrm{ft} \\
& C, 4=15 \mathrm{ft} \\
& C, 2=\quad C, 3=0.78 \\
& C, 4=0.65 \\
& m=1000 \mathrm{ft}^{3} / \mathrm{sec}^{2} \\
& h=10 \mathrm{ft}
\end{aligned}
$$

From NIBS and FEMA (2009),

$$
\begin{aligned}
& E\left[L_{S} \mid D_{S}=2\right]=0.023 \\
& E\left[L_{S} \mid D_{S}=3\right]=0.117 \\
& E\left[L_{S} \mid D_{S}=4\right]=0.234 \\
& E\left[L_{N} \mid D_{N}=2\right]=0.05+0.027=0.077 \\
& E\left[L_{N} \mid D_{N}=3\right]=0.25+0.08=0.33 \\
& E\left[L_{N} \mid D_{N}=4\right]=0.5+0.266=0.766 \\
& E\left[L_{C} \mid D_{C}=2\right]=2 \cdot 0.05=0.10 \text { (that is, } 2 x \text { the earthquake loss) }
\end{aligned}
$$




$$
\begin{aligned}
& E\left[L_{C} \mid D_{C}=3\right]=2 \cdot 0.25=0.50 \\
& E\left[L_{C} \mid D_{C}=4\right]=2 \cdot 0.5=1.0
\end{aligned}
$$

Evaluating Equation (17),

$$
\begin{aligned}
& P\left[D_{S}=2 \mid M=1000\right]=P\left[D_{S}=3 \mid M=1000\right]=0 \\
& P\left[D_{S}=4 \mid M=1000\right]=0.75
\end{aligned}
$$

Evaluating Equation (18),

$$
\begin{aligned}
& P\left[D_{N}=2 \mid F=10\right]=0 \\
& P\left[D_{N}=3 \mid F=10\right]=0.32 \\
& P\left[D_{N}=4 \mid F=10\right]=0.09
\end{aligned}
$$

Evaluating Equation (19),

$$
\begin{gathered}
P\left[D_{C}=2 \mid F=10\right]=0 \\
P\left[D_{C}=3 \mid F=10\right]=0.67 \\
P\left[D_{C}=4 \mid F=10\right]=0.27 \\
P\left[D_{N}=d \mid F=f\right]=\Phi\left(\frac{\ln \left(f / \theta_{N, d}\right)}{\beta_{N, d}}\right)-\Phi\left(\frac{\ln \left(f / \theta_{N, d+1}\right)}{\beta_{N, d+1}}\right) \\
=\Phi\left(\frac{\ln \left(f / \theta_{N, d}\right)}{\beta_{N, d}}\right) \\
d \in\{2,3\}
\end{gathered}
$$

Figure 58 shows for example that once depth reaches the top of the 2nd story of the building, the depth-sensitive contents are a complete loss, whereas nonstructural damage is about 50 percent of the building value. Note that although content vulnerability applies to content value, both nonstructural vulnerability and structural vulnerability are expressed as a fraction of total building replacement cost new structural plus nonstructural, so they add. However, because they do not have the same intensity measure type - nonstructural is sensitive to flow depth, structural to momentum flux - the curves cannot be summed on a two-dimensional (2-D) chart. Once momentum flux exceeds approximately $1,000 \mathrm{ft}^{3} / \mathrm{sec}^{2}$ - such as say $10 \mathrm{ft}$ depth and 10 $\mathrm{ft} / \mathrm{sec}$ velocity, or $3 \mathrm{~m}$ depth and $3 \mathrm{~m} / \mathrm{sec}$ or $6 \mathrm{kt}$ velocity - the repairs take 18 months. 

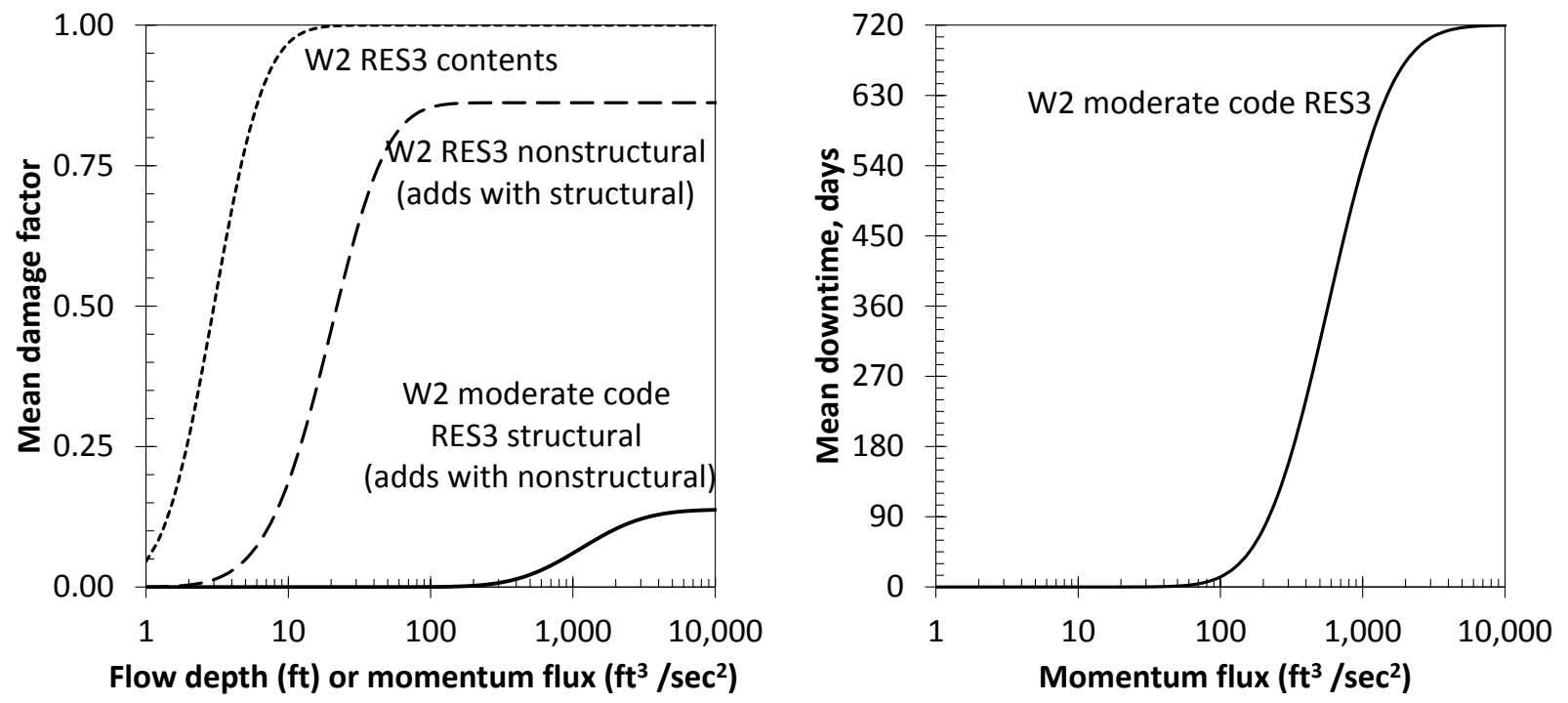

Figure 58. Graphs of sample tsunami vulnerability functions for a large wood-frame building (W2) being used as a multifamily dwelling (RES3) of moderate-code construction. (ft3/sec ${ }^{2}$, cubic feet per second squared).

\section{Building Damage in the SAFRR Tsunami Scenario}

Vulnerability functions were applied to the estimates of value exposed using the mapped average flow depths and momentum flux by census block (masked to exclude water and portions of the census blocks not inundated). The tsunami affects approximately 1840 census blocks statewide, including 100 million square feet of buildings valued at $\$ 13$ billion and $\$ 8.4$ billion of contents. These estimates assume that building value is uniformly distributed over the normally dry portion of each census block. The scenario produces approximately $\$ 1.8$ billion in building and content damage, mostly contents. These figures represent 2.2 percent of building value and 18 percent of content value lost in wetted buildings. See table 27 .

The reader should bear in mind that the HAZUS-based analysis gives the expected value from a probabilistic estimate of loss, considering a variety of uncertainties. To illustrate, imagine that there were some buildings valued at $\$ 10$ million and inundated such that they had a 1percent chance of $\$ 1,000,000$ loss and 99 -percent chance of $\$ 0$ loss. The expected value of loss is $\$ 10,000$. It is hard to imagine a particular outcome in which $\$ 10$ million of building value is damaged by tsunamis and then is repaired for $\$ 10,000$, but that is not what the $\$ 10,000$ represents. 
Table 27. Building damage in the SAFRR tsunami scenario.

$\left[\mathrm{M}\right.$, million; $\mathrm{ft}^{2}$, square feet; \%, percent]

\begin{tabular}{|c|c|c|c|c|c|}
\hline County & $\begin{array}{l}\text { Wetted building } \\
\text { area, million } \mathrm{ft}^{2}\end{array}$ & $\begin{array}{l}\text { Wetted building } \\
\text { value, \$M }\end{array}$ & $\begin{array}{l}\text { Content value in } \\
\text { wetted } \\
\text { buildings, \$M }\end{array}$ & $\begin{array}{l}\text { Building } \\
\text { loss, \$M }\end{array}$ & $\begin{array}{l}\text { Content } \\
\text { loss, \$M }\end{array}$ \\
\hline Alameda & 11.1 & $\$ 1,453$ & $\$ 1,066$ & $\$ 20.0$ & $\$ 164.4$ \\
\hline Contra Costa & 1.3 & $\$ 153$ & $\$ 128$ & $\$ 1.7$ & $\$ 19.0$ \\
\hline Del Norte & 1.2 & $\$ 107$ & $\$ 66$ & $\$ 4.4$ & $\$ 17.2$ \\
\hline Humboldt & 4.9 & $\$ 499$ & $\$ 331$ & $\$ 12.9$ & $\$ 62.1$ \\
\hline Los Angeles & 10.2 & $\$ 1,294$ & $\$ 743$ & $\$ 23.4$ & $\$ 139.8$ \\
\hline Marin & 9.7 & $\$ 1,526$ & $\$ 927$ & $\$ 33.6$ & $\$ 170.1$ \\
\hline Mendocino & 0.9 & $\$ 97$ & $\$ 61$ & $\$ 0.9$ & $\$ 8.9$ \\
\hline Monterey & 2.9 & $\$ 359$ & $\$ 228$ & $\$ 12.0$ & $\$ 51.9$ \\
\hline Orange & 17.4 & $\$ 2,286$ & $\$ 1,293$ & $\$ 26.4$ & $\$ 206.6$ \\
\hline San Diego & 18.9 & $\$ 2,205$ & $\$ 1,259$ & $\$ 60.9$ & $\$ 240.0$ \\
\hline San Francisco & 11.1 & $\$ 1,651$ & $\$ 1,252$ & $\$ 55.1$ & $\$ 257.2$ \\
\hline San Luis Obispo & 0.8 & $\$ 86$ & $\$ 49$ & $\$ 1.6$ & $\$ 8.4$ \\
\hline San Mateo & 5.3 & $\$ 767$ & $\$ 505$ & $\$ 28.4$ & $\$ 91.2$ \\
\hline Santa Cruz & 4.8 & $\$ 621$ & $\$ 355$ & $\$ 14.9$ & $\$ 69.2$ \\
\hline Ventura & 2.2 & $\$ 241$ & $\$ 138$ & $\$ 2.3$ & $\$ 20.9$ \\
\hline Total & 103 & $\$ 13,345$ & $\$ 8,401$ & $\$ 298.4$ & $\$ 1,526.9$ \\
\hline$\%$ of wetted value & & & & $2.2 \%$ & $18.2 \%$ \\
\hline
\end{tabular}


Table 28. Building and content value in California Governor's Office of Emergency Services' (Cal OES) maximum inundation zone.

[M, million; \%, percent]

\begin{tabular}{lrrrc}
\hline \multicolumn{1}{c}{ County } & $\begin{array}{c}\text { Wetted building } \\
\text { area million } \mathrm{ft}^{2}\end{array}$ & $\begin{array}{c}\text { Wetted building } \\
\text { value } \mathbf{\text { M }}\end{array}$ & $\begin{array}{c}\text { Content value } \\
\text { in wetted } \\
\text { buildings } \mathbf{~ M ~}\end{array}$ & $\begin{array}{c}\text { Scenario building + } \\
\text { contents value as \% of } \\
\text { value in Cal OES max. } \\
\text { inundation zone }\end{array}$ \\
\hline Alameda & 52 & $\$ 6,996$ & $\$ 5,053$ & $21 \%$ \\
Contra Costa & 3 & 410 & 315 & $39 \%$ \\
Del Norte & 3 & 295 & 198 & $35 \%$ \\
Humboldt & 13 & 1,436 & 996 & $34 \%$ \\
Los Angeles & 21 & 2,738 & 1,633 & $47 \%$ \\
Marin & 24 & 3,729 & 2,274 & $41 \%$ \\
Mendocino & 1 & 139 & 94 & $68 \%$ \\
Monterey & 6 & 822 & 495 & $28 \%$ \\
Orange & 61 & 7,850 & 4,764 & $64 \%$ \\
San Diego & 28 & 3,365 & 2,063 & $39 \%$ \\
San Francisco & 16 & 2,547 & 1,954 & $37 \%$ \\
San Luis Obispo & 2 & 215 & 128 & \\
San Mateo & 14 & 2,034 & 1,398 & $34 \%$ \\
Santa Barbara & 0 & 42 & 24 & \\
Santa Clara & 3 & 350 & 411 & $63 \%$ \\
Santa Cruz & 13 & 1,775 & 1,101 & $\mathbf{3 7 \%}$ \\
Solano & 1 & 80 & 52 & \\
Sonoma & 1 & 117 & 60 & \\
Ventura & 3 & 390 & 210 & \\
Total & $\mathbf{2 6 5}$ & $\mathbf{3 5 , 3 3 0}$ & $\mathbf{2 3 , 2 2 3}$ & \\
\hline
\end{tabular}

\section{Resiliency Opportunities}

The figures in table 27 are fairly modest in the aggregate as California natural disasters go - less than $\$ 2$ billion - but would undoubtedly be painful to those affected, especially those who are uninsured or underinsured and lack the resources to repair damage. One opportunity to enhance resiliency is to ensure that people living in or doing business in potentially inundated areas are aware of the National Flood Insurance Program or commercial flood insurance. Another opportunity is to provide coastal communities with the California Geological Survey's maps of the potential extent of tsunami inundation, to inform those communities' decisions about their zoning plans. The State is working on probabilistic inundation maps for land-use planning that might help to identify areas that are more susceptible to tsunami inundation.

\section{Research Needs}

As with marinas, future tsunamis can be more severe than California's recent experience in the Tohoku and Chile tsunamis, so absent significant changes to the protection and vulnerability of coastal buildings, they will experience greater damage in more-severe tsunamis. Just as with marinas, the research needs discussed here are about refining models of that damage: improving our ability to estimate building fragility, improving our modeling of damage and loss, and making better-informed risk-management decisions.

It would be valuable to compare the HAZUS estimate of exposed building value with the finer-resolution database of businesses and dwellings prepared by others on this project. It would also be valuable to compare the developing HAZUS vulnerability model with an empirical one that was published after this study was complete. The HAZUS database reflects the census of 
population and housing, which publishes its data by census block, not by street address. Coastal development might not be uniformly distributed over the census block, as was assumed here. Buildings along waterfronts and in marinas might cluster near the shore, whereas coastal buildings that do not have a function related to the water might be located farther from the shore.

\title{
Damage and Restoration of Roads and Roadway Bridges
}

\author{
By Keith Porter
}

\section{Introduction and Purpose}

This section presents an estimate of tsunami effects on Caltrans (California Department of Transportation) highways and bridges from the SAFRR tsunami scenario. It is based on an inundation line and current velocities modeled by SAFRR scientists, knowledge of the locations and elevations of highways and coastal bridge embankments drawn from remote sensing (Google Earth), observations of historic tsunami damage to similar assets, and an approximate analysis that considers Federal Highway Administration (FHWA) and Caltrans design guidelines. It draws on a half-day discussion between SAFRR staff and eight Caltrans engineers in Sacramento on Oct 3, 2012, and a review of this memo by Caltrans engineers (Mark Yashinsky and Steve $\mathrm{Ng}$ ) and USGS staff (Ann Wein). The objectives of this memo are as follows:

Summarize the State and local road and bridge assets exposed to loss.

Identify the most common damage modes observed in past tsunamis.

Estimate the damageability of these assets, that is, quantify the conditions under which damage is assumed to occur.

Describe repair activities and estimate the repair duration and repair costs for each mode of damage.

Combine the foregoing actions to identify particular locations where it is realistic for damage to occur in the scenario. Estimate repair costs, repair durations, and traffic delays.

Identify options for enhancing resiliency.

Identify research needs

An important issue that is not addressed here is road closure of evacuation routes. This topic represents a gap that will be addressed in another part of the scenario study.

\section{Assets Exposed to Loss}

There are approximately 54 coastal highway bridges and 12 stretches of low-elevation highway and local roadway (less than 5 meters or so) within the study area. These are clustered around Eureka, the San Francisco Bay, and along the south coast from Ventura to San Diego, as shown in figure 59. In the figure, bridges are colored yellow and roads are red. 


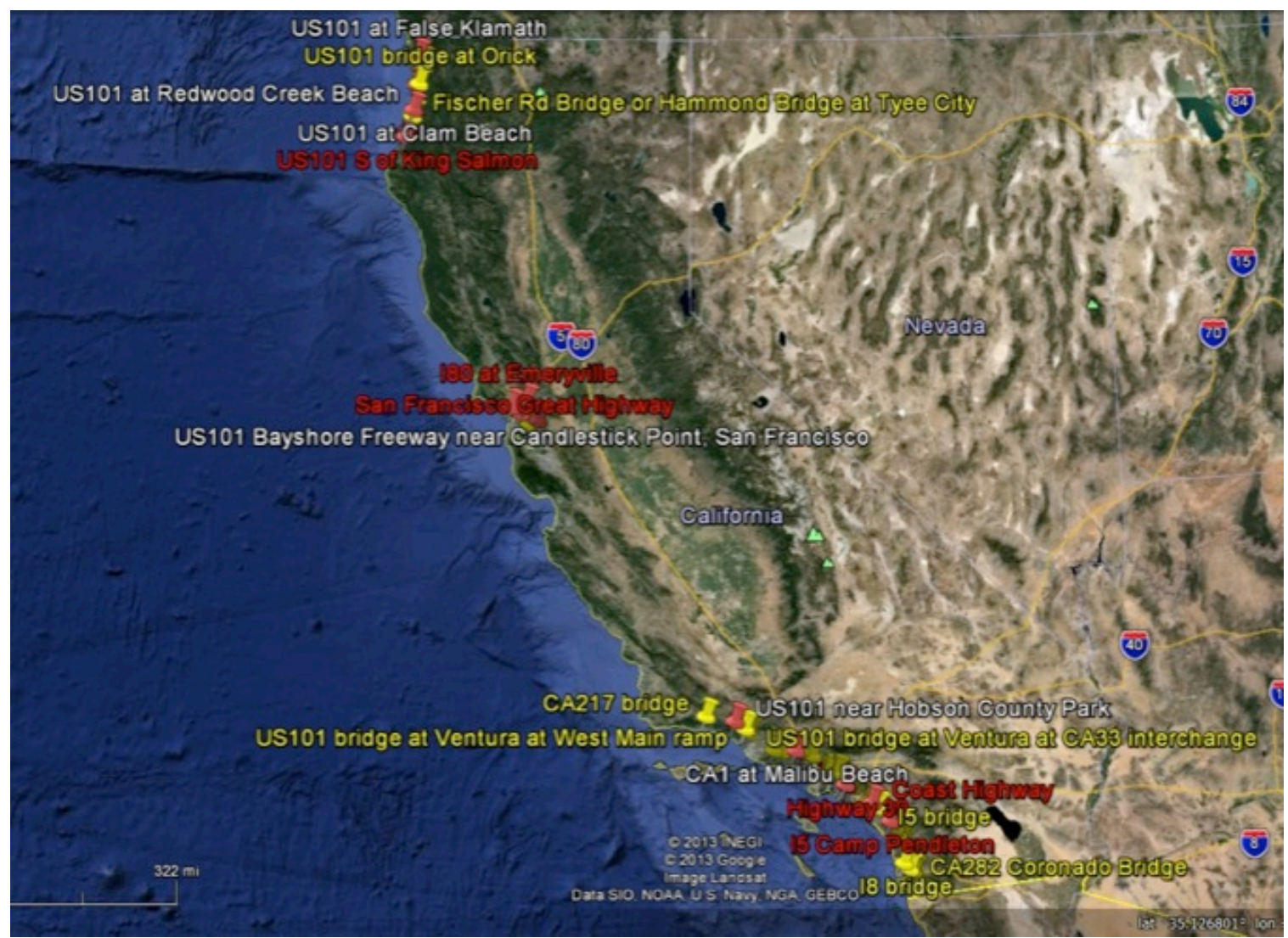

Figure 59. Map of coastal bridges and low-elevation roads in the SAFRR tsunami scenario study area.

Only a subset are damaged in the scenario (base image from Google Earth).

\section{Damage Modes}

The relevant damage modes that have been observed in past tsunamis or identified in Caltrans Memo to Designers 20-13 (2010) includes:

Scour damage to embankments and erosion of fill. This is expected to occur where the embankment is located at or near channel banks, and the embankment obstructs the flow. According to FHWA (2011), vortices form near embankments and piers. See figure 60 for examples.

Scour damage to roads. This is expected to occur where the roadway is on a levee or embankment and tsunami flows can form vertical vortices on the downstream side or horizontal vortices on the upstream side, especially near culverts. Even in locations with high flow depth and velocity, where the road is level with or below the adjacent ground and offers no soil embankment to scour, it seems to resist tsunami damage. See figure 61 for an illustration of a coastal road near Shinchi, Japan, scoured away by the Tohoku tsunami. See figure 62 for a road near the Port of Sendai that was not damaged by the tsunami. Similar to FHWA (2011) comments about vortices near piers and embankments, we hypothesize that the difference between these two sites was the presence or absence of a crown that would cause the road to intrude into the flow and thereby create scour-producing vortices. 
Hydrodynamic pressure on or buoyant uplift of bridge superstructures, as in figure 63 . This damage mode is not expected to occur in the present scenario because no Caltrans or local bridge appears to be affected by waves reaching the bridge superstructure.

Scour damage to bridge pier foundations. Caltrans engineers, especially Ng, expect that this damage mode is unlikely to occur in the present scenario. The expected tsunami waves are less than the design considerations for normal riverine discharge design. The events of Tohoku would appear to confirm this.

Impact from debris. Floating debris (for example, boats, buildings, and trees) could strike bridge piers and might need to be cleared away. Vessels impacted bridges in the Tohoku tsunami, as shown in figures 64 and 65. Navy Way at the Port of Los Angeles is the location where there are large enough vessels nearby to cause damage significant enough to carry away a bridge superstructure. The ports, however, have stated that it is unlikely and perhaps unrealistic that large ships would become unmoored or lose control while underway, though they do not completely discount the possibility. Such an impact is considered here to be a possibility, but is not explicitly included as part of the scenario.
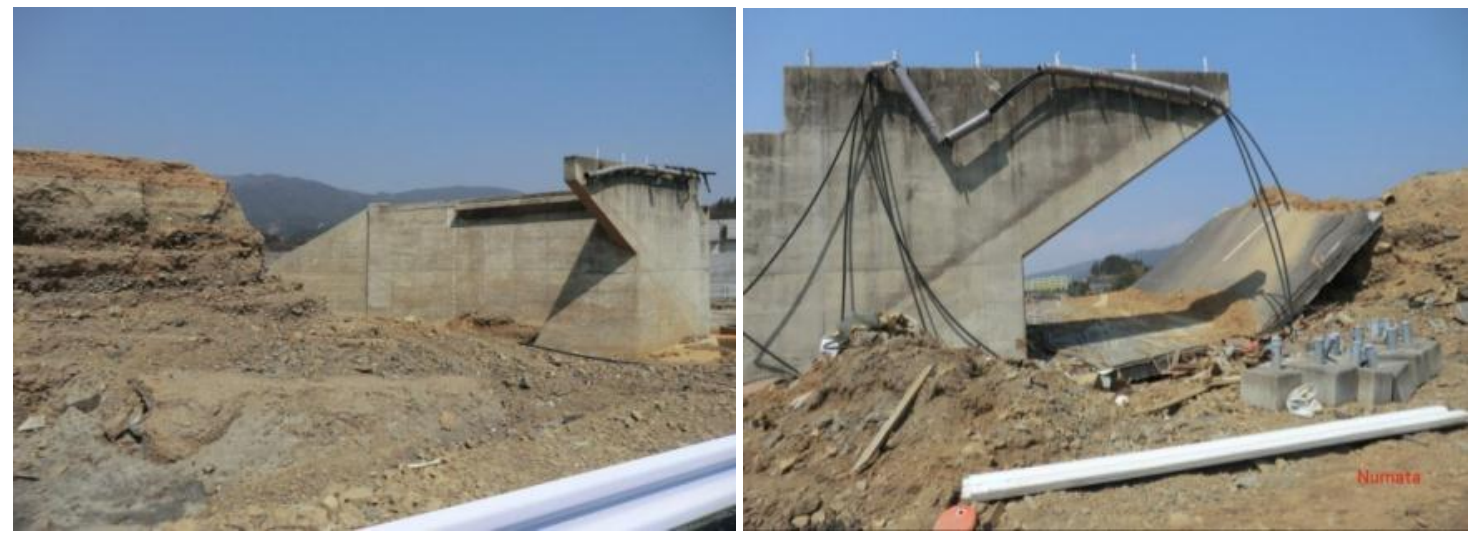

Figure 60. Photographs of embankment scour at Route 45 bridge (Takada Bypass) over Route 141 (Hamaiso Highway) due to the 2011 Tohoku tsunami (photographs by Charles Scawthorn). 

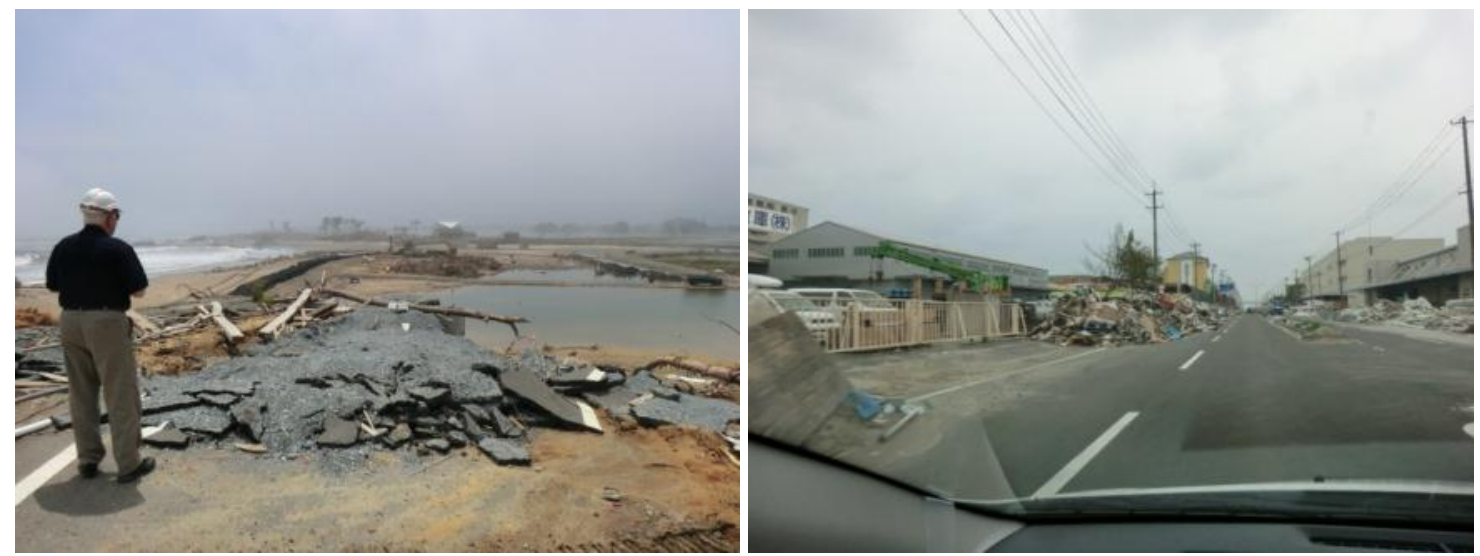

Figure 61. Photographs of tsunami damage from the 2011 Tohoku, Japan, tsunami: Left, About 1 mile of Route 38 north of Shinchi was washed away by the 2011 Tohoku tsunami. Right, Roads throughout the Port of Sendai were largely undamaged despite high currents and depths; they had no embankments that could generate scouring vortices. (Photographs by Keith Porter.)
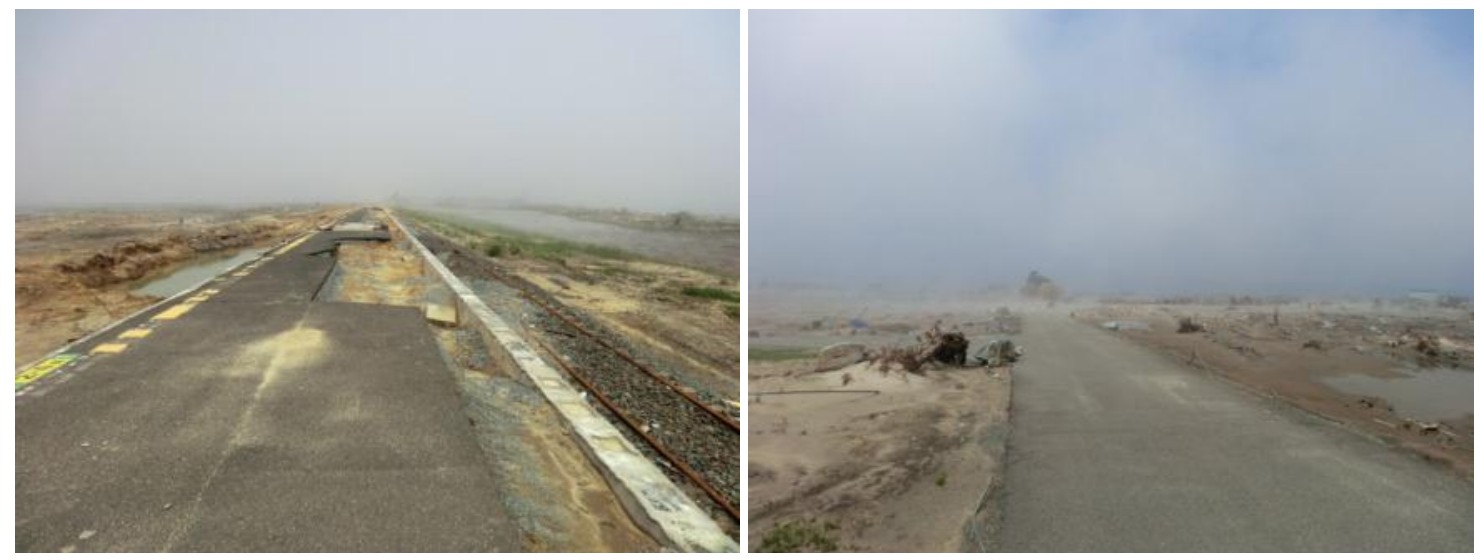

Figure 62. Photographs showing a contrast in tsunami scour potential resulting from roadway elevation. The left image is a view looking north from a commuter railway platform on the Sendai, Japan, plain. Before the 2011 Tohoku tsunami, it had had rail on both sides of the platform; now only a short stretch on the east (ocean) side and large scour pits on the west (landward) side. There is no sign of the railbed or rail. On the right is a nearby road, largely undamaged, on the seaward side of the rail line. The road is largely undamaged. (Photographs by Keith Porter.) 


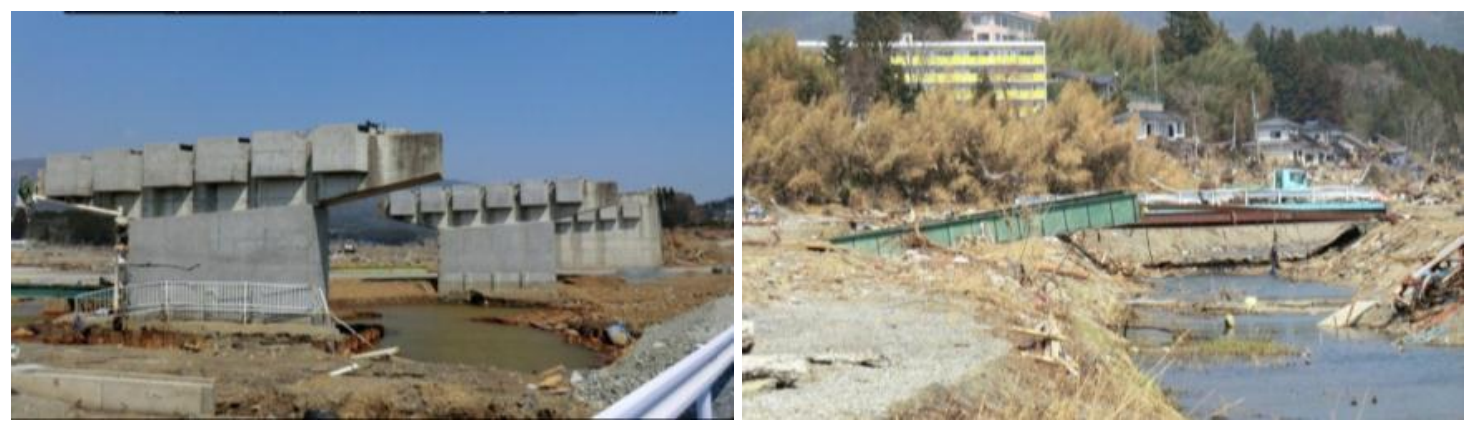

Figure 63. Photographs of bridges whose superstructures were pushed or floated off their piers in the 2011 Tohoku, Japan, tsunami (photographs by Charles Scawthorn).

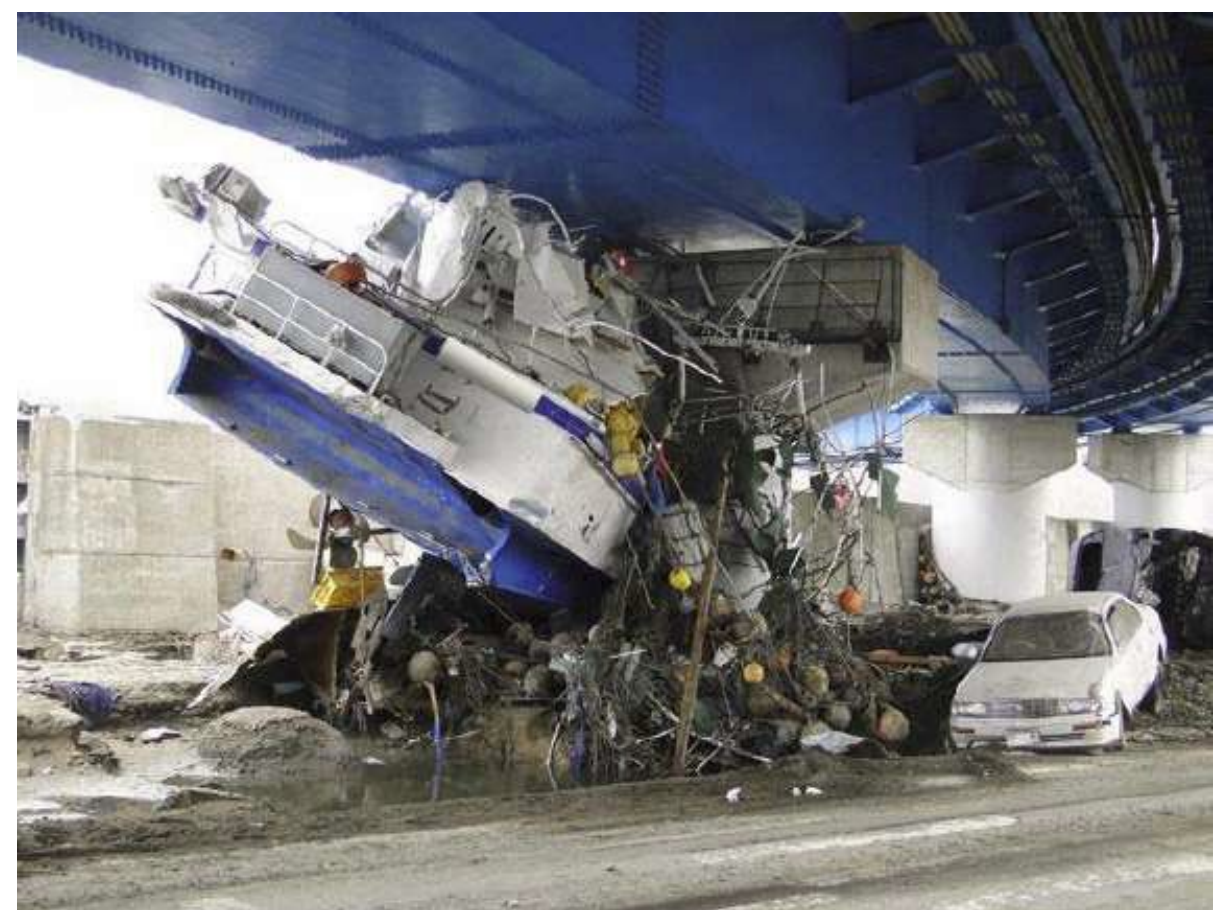

Figure 64. Photograph of example from the 2011 Tohoku, Japan, tsunami of how small craft represent a debris hazard for bridges; the Miyako Bridge across the Hei River in the City of Miyako (photograph by Junichi Hoshikuma). 


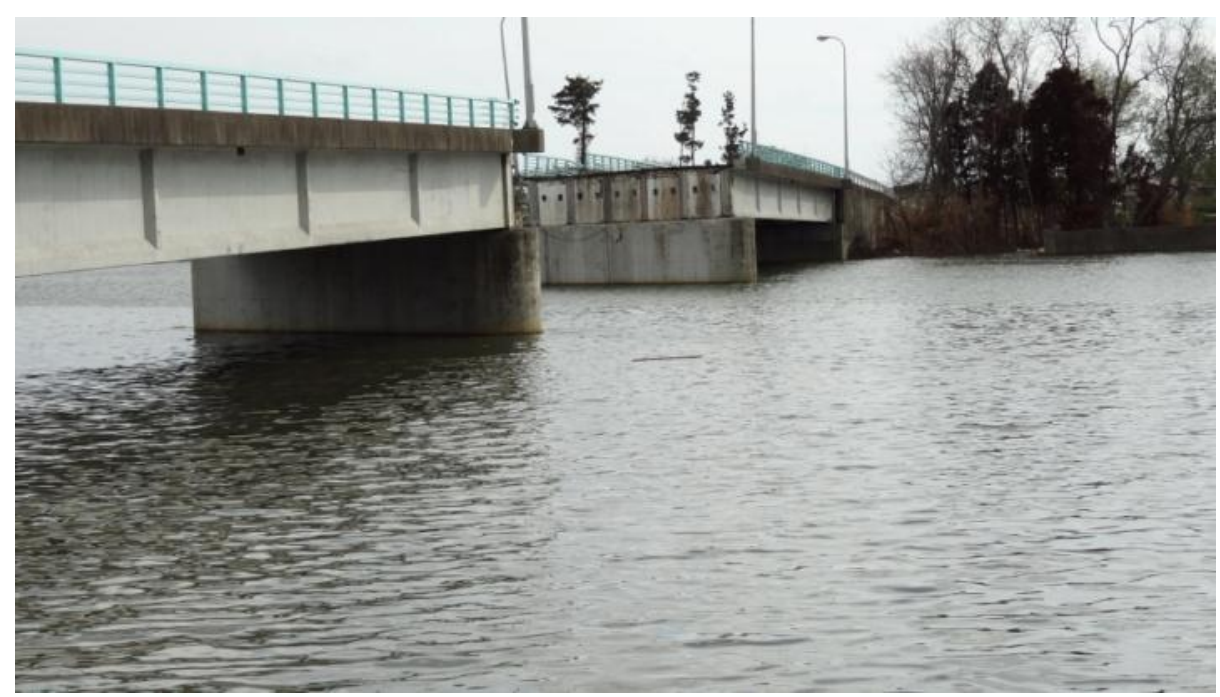

Figure 65. Photograph of damage from a barge impact on the Jokawa Bridge over the Higashimatsushima River in the 2011 Tohoku, Japan, tsunami that destroyed the middle span and damaged the other spans (photograph by Junichi Hoshikuma).

\section{Estimating Damageability}

The focus here is on damage modes 1 and 2. Let us begin with damage mode 1, scour damage to bridge abutments. Commercial and public scour models exist for the risk analysis or design of bridges, dams, and reservoirs, but they appear to be inappropriate for the present use. Some do not take event-specific input data (for example, HYRISK). Others require bridge and abutment geometry and materials data that are unavailable or prohibitively time consuming to analyze on a wide scale (for example, Flow-3D). The present project takes a more approximate approach to estimating damage. This level of detail seems appropriate to the task of estimating a realistic level of damage, which can then be used to determine whether and where detailed analysis is required.

FHWA (2011) offers advice regarding design against this failure mode, stating that "Available technology has not developed sufficiently to provide reliable abutment scour estimates for all hydraulic flow conditions that might be reasonably expected to occur at an abutment. Therefore, engineering judgment is required in designing foundations for abutments." This is an important modeling gap, but despite the gap it is still necessary to select a threshold current depth and velocity at which scour damage would reasonably occur. At a minimum, it can be seen as a first cut at a plausible level of damage. (If that damage potential seems to be substantial, the result can at least motivate the development of analytical models supported by field observation and laboratory testing.)

For Froude number $(V / g y)<0.80$, where $V$ denotes velocity at the contracted section, $g$ denotes acceleration due to gravity, and $y$ denotes depth of flow, Federal Highway Administration (2011) recommends $D_{50}$ (median stone diameter) of

$$
\frac{D_{50}}{y}>\frac{K}{S_{S}-1}\left(\frac{V^{2}}{g y}\right) \text {, }
$$


where $K$ depends on abutment geometry but is approximately 1.0 and $S_{S}$ is the specific gravity of riprap, which we take as 2.4. We are not interested in design of riprap but in the analysis of the potential for scour damage knowing $D_{50}, y, V$, and other factors. In equation 22, depths cancel. Let us assume as a first estimate a median stone diameter of $0.3 \mathrm{~m}$. We substitute 0.3 for $D_{50}$ and solve for $V$, which results in the following expression:

$$
V<\sqrt{\frac{\left(S_{S}-1\right) \cdot g \cdot D_{50}}{K}}
$$

It evaluates as

$$
\begin{aligned}
& V<\sqrt{\frac{(2.4-1) \cdot 9.81 \frac{m}{\mathrm{sec}^{2}} \cdot 0.3 m}{1.0}} \\
& V<2 m / \mathrm{sec}
\end{aligned}
$$

Which suggests that if $D_{50}=0.3 \mathrm{~m}$, the design is sufficient to resist scour damage as long as $V_{\max }$ $<2 \mathrm{~m} / \mathrm{sec}$. Checking the Froude number at say $V=2 \mathrm{~m} / \mathrm{sec},(2 / 9.81)<0.8 y$ limits the applicability of equation 24 to $y>0.25 \mathrm{~m}$. For $V=5 \mathrm{~m} / \mathrm{sec}, y>0.6 \mathrm{~m} / \mathrm{sec}$, so the expression seems general enough for present purposes. That is, we do not need to consider the case of the Froude number exceeding 0.80 .

We assume that the design guideline is conservative, perhaps with a safety factor of 3, so the median capacity of an embankment with $D_{50}=0.3 \mathrm{~m}$ to resist scour might be $V=6 \mathrm{~m} / \mathrm{sec}$, meaning 50-percent chance of scour at $6 \mathrm{~m} / \mathrm{sec}$. The capacity scales with $D_{50}{ }^{0.5}$, meaning that with $\mathrm{D}_{50} 1 / 4$ th the assume diameter, that is, 3-inch diameter stone, the median capacity is halved to $3 \mathrm{~m} / \mathrm{sec}$. This seems to be a reasonable threshold for such an approximate analysis, where we do not actually know whether there is any riprap at all on any given embankment. It also satisfies intuition; a 3-m/sec flow feels like it could scour an embankment with a cover of 3-inch diameter stones.

Turning to damage mode 2 , because roads are not necessarily armored in any way, let us assume soil conditions, say $D_{50}=0.01 \mathrm{~m}$ and $S_{S}=1.2$. This yields $\mathrm{V}<0.14 \mathrm{~m} / \mathrm{sec}$. Even with some added conservatism, it suggests that any flow over an elevated roadway where vortices can form on the downstream side is likely to cause scour damage.

To recap, for purposes of estimating realistic damage to bridge embankments and roadways in the SAFRR tsunami scenario, we assume that embankment scour occurs to bridges where the embankment obstructs the flow and $V>3 \mathrm{~m} / \mathrm{sec}$. Any flow over an elevated roadway (elevated in the sense that vortices can form on the downstream side) is assumed to cause scour damage.

\section{Repair Duration}

The degree of damage and duration of repair is more problematic, especially here where we are limited to a very approximate analysis for a number of roads and bridges and little scope to consider site-specific information. Degree of damage would seem to depend on some integral involving velocity over duration of flow. For convenience, we assume that all cases are the same. Bridge embankment scour requires say 4 days to backfill and repave. Roadway scour requires 
say 1 day per 1,000 feet to repair in a rural area, say 1 day per 2,500 feet in an urban area with high traffic demand. In the case of a rural road with an alternate route and the existing alignment is at high risk to repeated tsunami damage, let us add 3 months for decision-making to select the new alignment

Traffic disruption is likely to be briefer than repair duration, especially where alternate routes are available. Let us assume that, where an alternate route is available, traffic is merely slowed and not cut off, and that we need not quantify the delay. Otherwise, traffic is stopped for the duration of the repairs: 3 days for a bridge embankment and 2 days per 1,000 ft of roadway.

\section{Repair Costs}

The General Accounting Office estimates the cost of highway construction at $\$ 1$ to $\$ 9$ million per lane-mile, with costs varying widely (GAO, 2003). Let us assume that roadway repair costs on the order of $\$ 5$ million per lane-mile. This figure was judged reasonable by Caltrans staff in a October 3, 2012, panel discussion, and further supported by construction cost statistics for new highway construction in Florida, adjusted for location. We assume the repair of a bridge abutment damaged by scour costs $\$ 150,000$. (This assumes a crew of 12 working 32 hours at a cost to the State of $\$ 150$ per hour, the figure doubled to include material and equipment, and a 25-percent premium for urgency.)

\section{Damage to Roads and Bridges in the SAFRR Tsunami Scenario}

We compared the criteria described above to the locations of highways and highway bridges and the modeled inundation line and current velocities estimated elsewhere in this study. Figure 66 shows damage locations; they are clustered near Eureka, in the San Francisco Bay, and along the south coast from Malibu to just north of San Diego. In the figure, damaged roads are shown in red and damaged bridge embankments are in yellow. This is a subset of the assets shown in figure 59. Table 29 details roadway damage at six locations where the scour conditions described above are met. Table 30 details the scenario's hypothetical scour damage to bridge embankments.

The total length of damaged roadway is approximately 5 miles. The width of the damaged road varies from place to place. The total damage is approximately 20 lane-miles. The repair cost is approximately $\$ 100$ million. Traffic delays are none to 2 days, but two stretches of U.S. 101 might take 3-4 months to repair to allow for decisions about rerouting. Public assistance grants would probably provide $\$ 80$ million from the Federal government to perform repairs, with the remaining $\$ 20$ million borne by the State.

As shown in table 30, bridge embankment scour damage is hypothesized to occur at 12 locations, 7 of them on to CA1 between Malibu and Costa Mesa. The table shows velocities at each bridge location, which are generally in the range of 3-10 m/sec. It also shows wave heights for information purposes (generally 1-2 m), though these are not used to identify damage locations. Bridge embankments not listed in the table either do not intrude into the channel, or have velocities below $3 \mathrm{~m} / \mathrm{sec}$. The table also shows estimated repair costs. Total repair cost is $\$ 3$ million. All but one have alternate routes available.

There are several stretches of highway and local roadway that are wetted, but not with the required scour conditions - elevated roadway with soil on upstream or downstream side that can be eroded by vortices. These include stretches of the Pacific Coast Highway, CA39, CA75, CA92, US101 and the San Francisco Great Highway. These stretches do not appear in table 29. 
There are a few bridges slightly inland of the coast where embankments intrude into the current (according to the inundation line), but the velocity model does not reach.

Tables 29 and 30 note which hypothetical damage locations are part of the Strategic Highway Network (STRAHNET). STRAHNET is a network of highways deemed to be important to the United States' strategic defense policy and which provide defense access, continuity and emergency capabilities for defense purposes. They could be important to the supply chain for emergency supplies. As with other damage locations, where STRAHNET routes are damaged the traffic would be detoured to local roads. There is no program that distinguishes STRAHNET routes from any other route, so the fact that a route is STRAHNET would have no bearing on decisions to improve the tsunami resistance of the route before a disaster (called "betterment" by Caltrans).

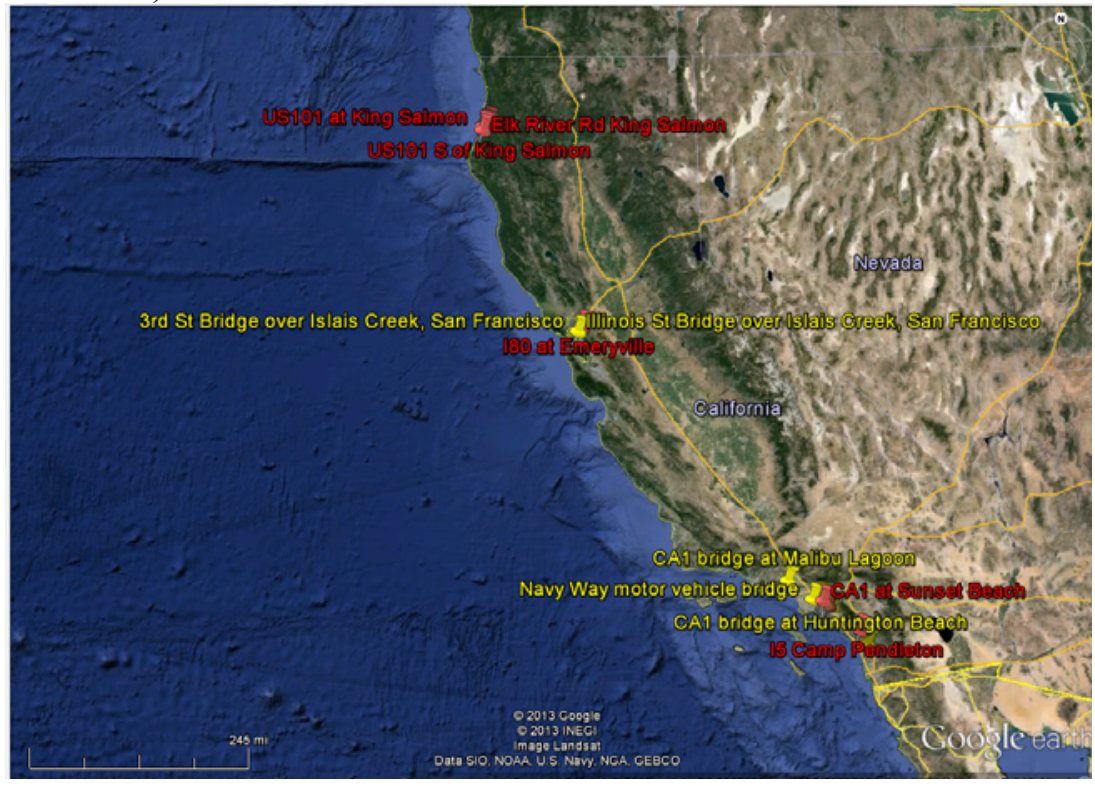

Figure 66. Map of SAFRRR tsunami scenario bridge and roadway damage locations. Road damage is shown in red, bridges in yellow. This is a subset of the assets shown in figure 59. (Base image from Google Earth.)

Table 29. SAFRRR tsunami scenario highway scour damage.

[sn, Strategic Highway Network, STRAHNET; mi, miles; ft, feet; \$M, millions of dollars]

\begin{tabular}{|c|c|c|c|c|c|c|c|}
\hline Location & Length & $\begin{array}{l}\text { Lane- } \\
\text { miles }\end{array}$ & $\begin{array}{l}\text { Alt } \\
\text { route }\end{array}$ & Realign & Delay & $\begin{array}{c}\text { Repair } \\
\text { days }\end{array}$ & $\begin{array}{l}\text { Cost, } \\
\text { \$M }\end{array}$ \\
\hline US101 Eureka (sn) & $1 \mathrm{mi}, 4$ lanes & 4.0 & Yes & Maybe & No & 95 days & $\$ 20$ \\
\hline $\begin{array}{l}\text { US101 King Salmon } \\
\text { (sn) }\end{array}$ & $1,000 \mathrm{ft}, 4$ lanes & 0.8 & No & No & 1 day & 1 day & $\$ 4$ \\
\hline $\begin{array}{l}\text { US101 S of King } \\
\text { Salmon (sn) }\end{array}$ & $1 \mathrm{mi} 4$ lanes & 4.0 & Yes & Maybe & No & 95 days & $\$ 20$ \\
\hline I80 Emeryville (sn) & $\begin{array}{l}1 \mathrm{mi}, 2 \text { of } 10 \\
\text { lanes }\end{array}$ & 2.0 & Yes & No & No & 2 days & $\$ 10$ \\
\hline I5 Camp Pendleton (sn) & $\begin{array}{l}2,000 \mathrm{ft}, 4 \text { of } 8 \\
\text { lanes }\end{array}$ & 1.6 & Yes & No & No & 2 days & $\$ 8$ \\
\hline CA1 Costa Mesa & $3,000 \mathrm{ft}, 6$ lanes & 3.6 & Yes & No & No & 3 days & $\$ 18$ \\
\hline CA1 Sunset Beach & $1 \mathrm{mi}, 4$ lanes & 4.0 & Yes & No & No & 3 days & $\$ 20$ \\
\hline Total & $4.6 \mathrm{mi}$ & 20 & & & & & $\$ 100$ \\
\hline
\end{tabular}


Table 30. SAFRRR tsunami scenario bridge embankment scour damage.

[sn, Strategic Highway Network, STRAHNET; mi, miles; ft, feet; \$M, millions of dollars; m, meter; m/sec, meters per second. Wave heights are above mean high water plus 20 centimeters $(\mathrm{MHW}+20)]$

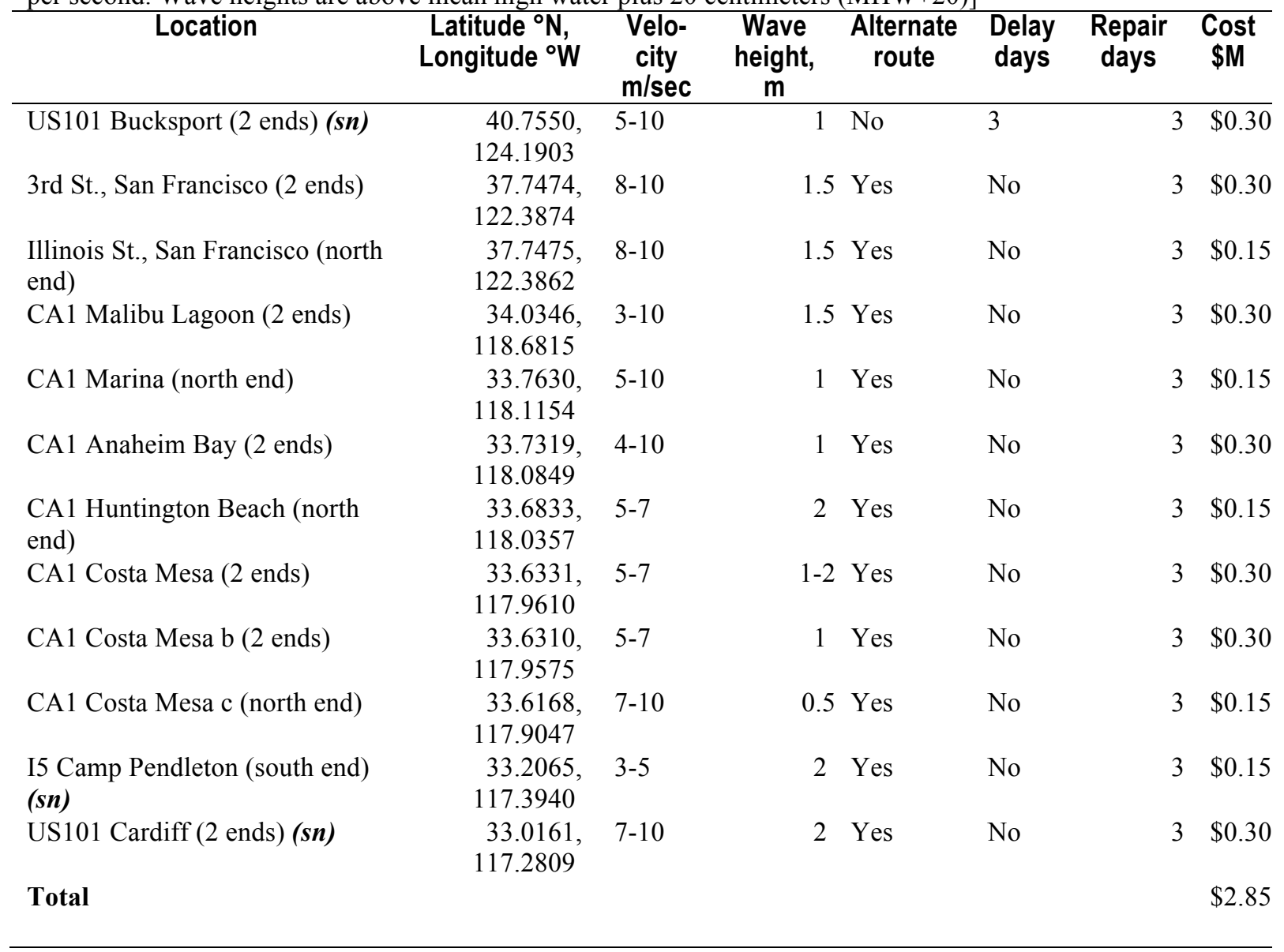

\section{Resiliency Opportunities}

Caltrans has strategies for quickly restoring roads and bridges. As with previous disasters such as fires, earthquakes, and floods, Caltrans has contractors bid the days and cost for a repair or replacement. An economist determines the cost for each day the road is closed and the bidder with the lowest total bid is awarded the contract. Only a few contractors are asked to bid for each job to keep the process efficient. The governor declares a state of emergency so the contracting process is abbreviated and does not require an Environmental Impact Statement (EIS).

One other opportunity to enhance resiliency might be to review plans with local officials about changing the alignment or increasing the elevation of roads that are particular exposed to tsunami damage. Two such stretches were identified here. Discussions and planning before a disaster might reduce decision-making delays in the event of an actual tsunami. Another opportunity might be to examine bridge embankments like those identified here for future improvements. As noted earlier, this study does not address evacuation routes and road closures during the warning period. 


\section{Research Needs}

The scenario depicted here relies on simplifications about damageability, especially about threshold levels of velocity causing embankment scour. It suggests that a large Alaskan teletsunami could cause on the order of $\$ 80$ million in damage affecting 16 lane-miles of highway and 13 bridges. These figures are offered to understand the order of magnitude of damage for such a tsunami and for design emergency response plans. They can inform community decisions about emergency planning, but they do not represent the results of a detailed engineering analysis.

Caltrans and the Pacific Earthquake Engineering Research (PEER) Center are pursuing such analyses. They are supporting tsunami hazard work being done by URS Corp. The CGS is preparing to make detailed maps of wave elevation and velocity for different return periods provided by URS. Caltrans will write bridge design procedures for tsunami loading, in part using computer modeling of fluid-structure interaction with the finite-element software LS-DYNA by researchers at Oregon State University's (OSU) NEES facility. (NEES refers to Network for Earthquake Engineering Simulation, a program of the National Science Foundation). Caltrans will determine whether a Cascadia subduction event produces larger tsunami loads on bridges as part of its research program.

PEER is considering a project or example to frame a new performance-based tsunami engineering (PBTE) methodology. The SAFRR tsunami scenario might be an ideal case study. Among the data needs for such a methodology would be detailed maps (perhaps by lidar) of existing bridges and coastal roads, necessary to apply scour models to roads and bridge abutments. Such an effort might also require a database of fragility and repair-cost data, along the lines of PEER's prior work developing 2nd generation performance-based earthquake engineering (PBEE-2) methodology.

Finally, note that the Federal Emergency Management Agency and California counties are developing an Earthquake and Tsunami Response Plan for the West Coast, focusing on the consequences of a Cascadia subduction earthquake and tsunami. This study may address highway and bridge damage in northern California counties as well as Oregon and Washington. The FEMA effort and the present one share common concerns but address different scenarios. The interested reader is referred to the project Facebook page at https://www.facebook.com/RCTWG?filter=3 (accessed November 1, 2012).

\section{Damage and Restoration of Railroads in the SAFRR Tsunami Scenario}

\section{By William Byers}

Significant to extreme damage to railroads has been documented in 94 earthquakes and slight or minor damage in 20 others. The earliest of these was the 1859 magnitude 7.6 Copiapo, Chile, earthquake. There are doubtless other earthquakes that caused railroad damage for which documentation was not found or does not exist. In 11 of the 94 earthquakes, significant to extreme damage was caused by earthquake-generated tsunamis. These earthquakes were all in subduction zones and had magnitudes ranging from 7.3 to 9.5. Nine were inter-plate. One involved a normal rupture in the subducting slab. It is possible that the tsunami associated with 
this last-mentioned earthquake was caused by an under-ocean landslide. The tsunami in one other subduction zone earthquake of undetermined type caused some railroad damage.

Most railroad damage from tsunamis was in the same area as other earthquake damage but the tsunami generated by the December 26, 2004, Sumatra earthquake caused severe railroad damage, including washing a train off the track at a location over 1,000 miles away in Sri Lanka.

Four of the 94 earthquakes causing major railroad damage generated tsunamis which either did not affect railroads or caused only slight damage as there were no railroads in locations significantly impacted by the tsunamis. Of the 79 earthquakes that did not generate tsunamis, nine were inter-plate thrust earthquakes in subduction zones, 26 were in subduction zones but not identified as inter-plate. Seven of these were in the subducting slab and eight in the overriding plate. The locations, relative to the plate interface, of the other 11 fractures were not determined.

On the basis of this sample, there is an appreciable risk of railroad damage from earthquake-generated tsunamis, including tsunamis generated by remote earthquakes. For comparable wave heights, damage from tsunamis can be expected to be similar to that from hurricane storm surges. Information on railroad damage is available for Hurricanes Alicia in 1983, and Ike in 2008 (Byers, 2011) and Katrina in 2005. Storm surges at selected locations of railroad damage were estimated to be in the order of 9 feet (as much as 4 feet above the track over a distance of about 5 miles) for Alicia; 20 to 28 feet (up to 20 feet above the track over a distance of about 100 miles) for Katrina; and 14 feet (as much as 10 feet above the track over a distance of about 15 miles) for Ike.

The tsunami associated with the March 11, 2011, Tohoku, Japan, earthquake provides extreme examples of the types of railroad damage normally associated with tsunamis. These are illustrated by figures 67 through 70. Similar, but in many cases less extreme, damage was caused by other tsunamis. Bridge spans were also washed off piers in the 1908 Messina earthquake (Davison, 1936). There was also, less severe, bridge damage in the 1946 Nankai earthquake (Okamoto, 1984). Rolling stock was overturned or derailed in the 1922 Atacama, Chile (Willis, 1929), the 1964 Alaska (Sturman, 1973), the 2004 Sumatra and the 2010 Maule, Chile (Chile Railways, 2010) earthquakes. Tracks and embankments were submerged and/or washed out: in the 1908 Messina (12 miles) (Morris, 1909), the 1922 Atacama (Willis, 1929), the 1933 Sanriku (Okamoto, 1984), the 1946 Nankai (Okamoto, 1984), the 1964 Alaska (Sturman, 1973), the 1964 Niigata (Kawasumi and others, 1968) and the 2010 Maule, Chile (Chile Railways, 2010), earthquakes. Debris was deposited on tracks in varying quantities and signal systems damaged in most, if not all, tsunamis. Railroad car ferry loading facilities were damaged in the 1964 Alaska (Sturman, 1973), and the 1968 Tokachi-oki (Okamoto, 1984) earthquakes. Damage from earlier tsunamis is shown in figures 71 through 73 . Hurricane storm surge damage depended on both the height of the surge and the types of construction exposed. It included debris on tracks, washed out ballast, track washed out-of -line, track washed off bridges and moderate to extreme bridge damage. Examples of relatively limited damage are shown in figures 74 and 75. 


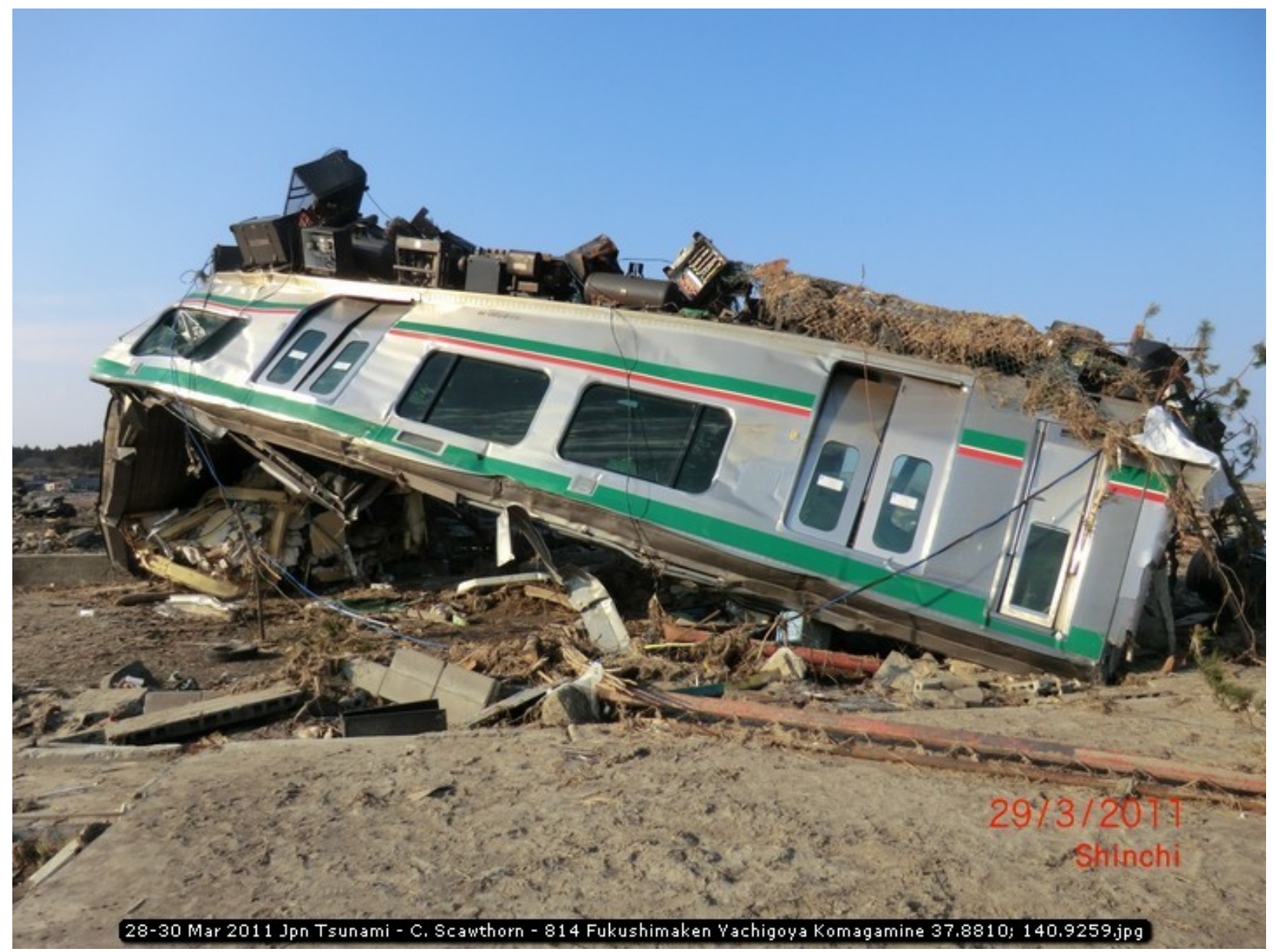

Figure 67. Photograph of overturned passenger cars in Komagamine, Japan after 2011 Tohoku, Japan, tsunami. Wave height at location unknown. (Photograph by Charles Scawthorn.) 


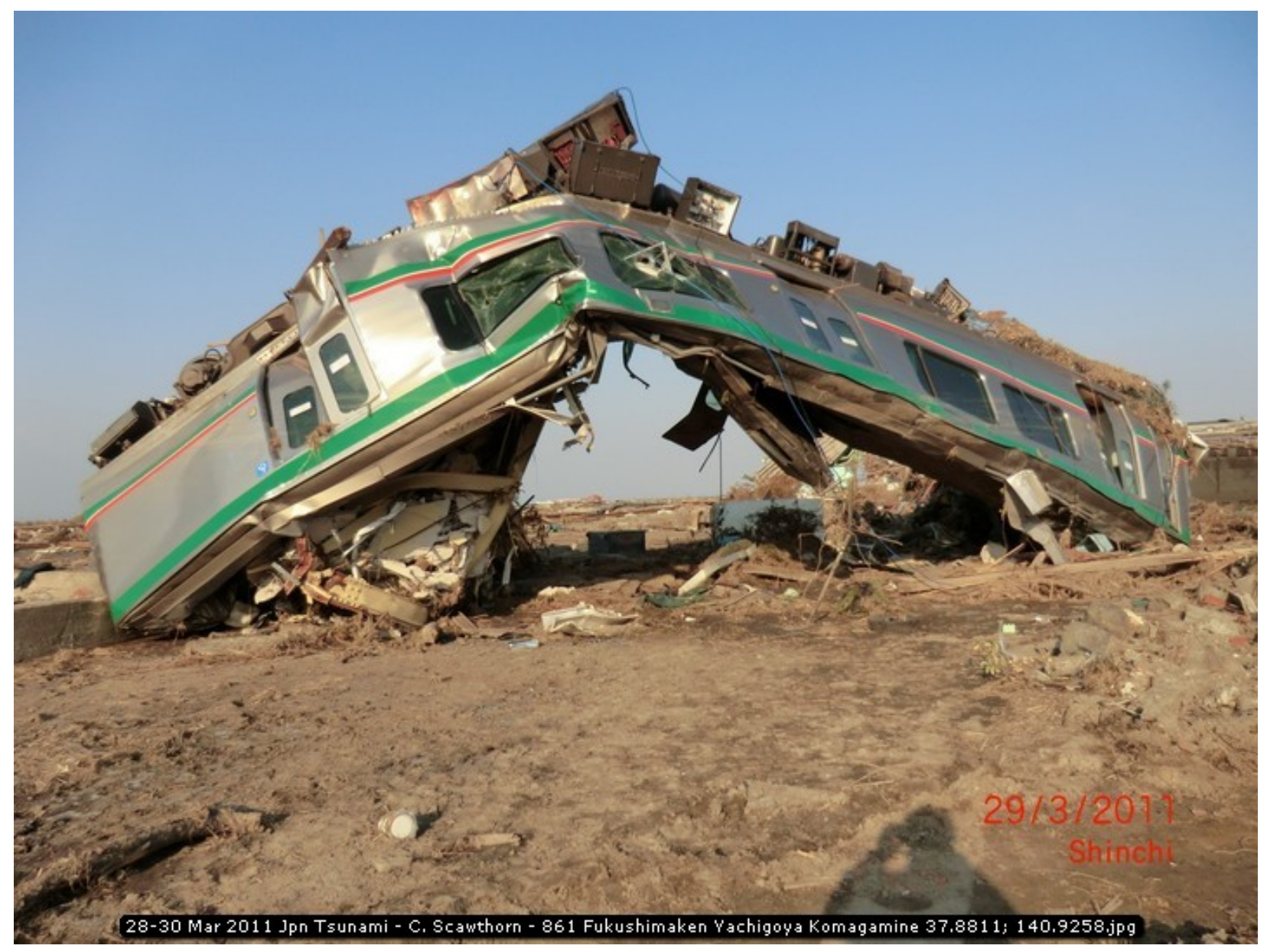

Figure 68. Photograph of overturned passenger train locomotive in Komagamine, Japan, after the 2011 Tohoku tsunami (photograph by Charles Scawthorn). 


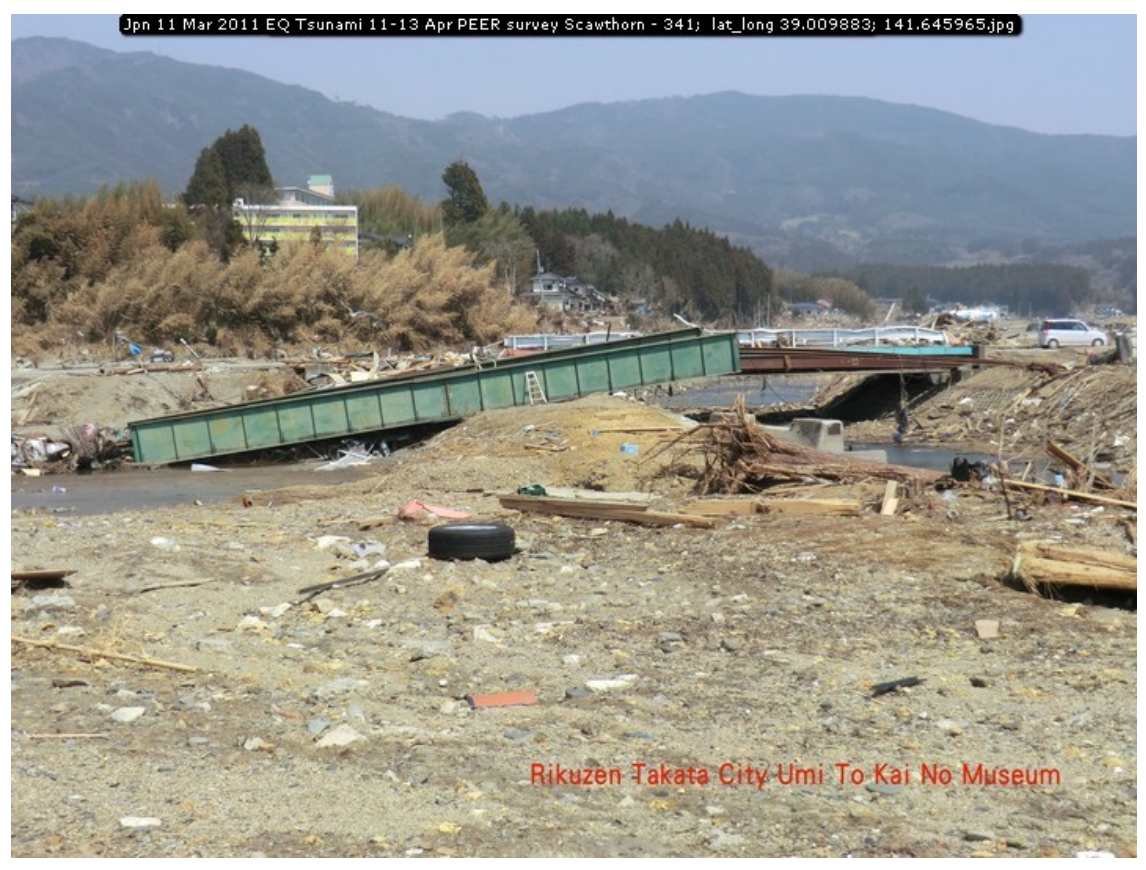

Figure 69. Photograph of displaced steel girder span near Rikuzen Takata after 2011 Tohoku, Japan, tsunami (photograph by Charles Scawthorn). 


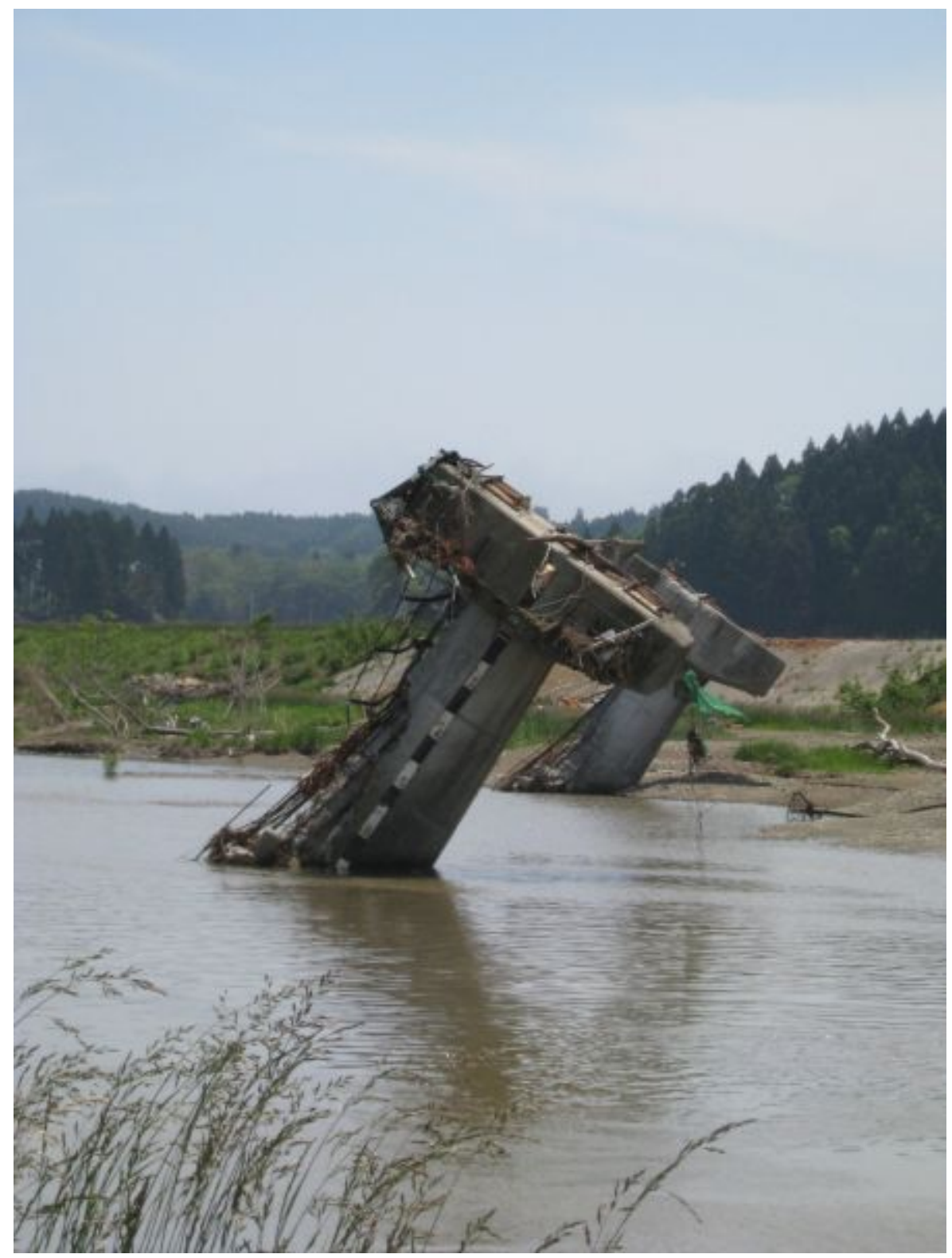

Figure 70. Photograph of damaged piers of the JR Rail Viaduct crossing the Tsuya River, Japan, after the 2011 Tohoku tsunami (photograph by Shideh Dashti). 


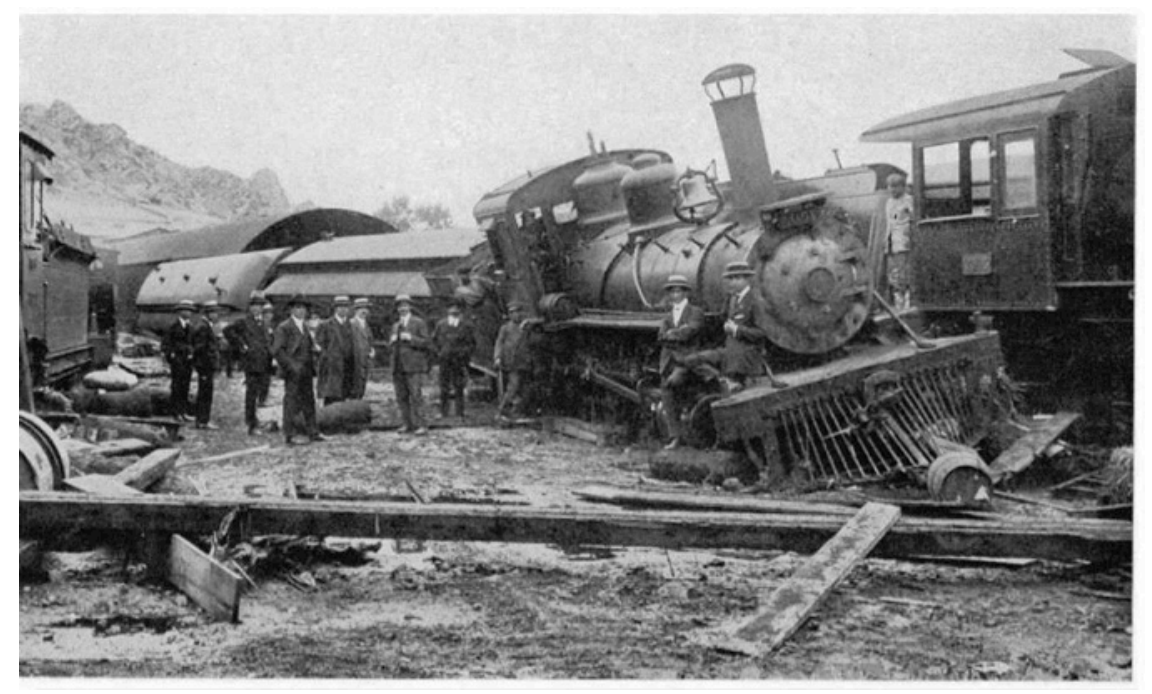

Figure 71. Photograph of Coquimbo rail yard after 1922 Atacama, Chile, tsunami. Run-up height is given as 26 feet but elevation of yard is not known. Estimated wave height in the yard is between 5 and 15 feet. (Photograph from Willis, 1929.)

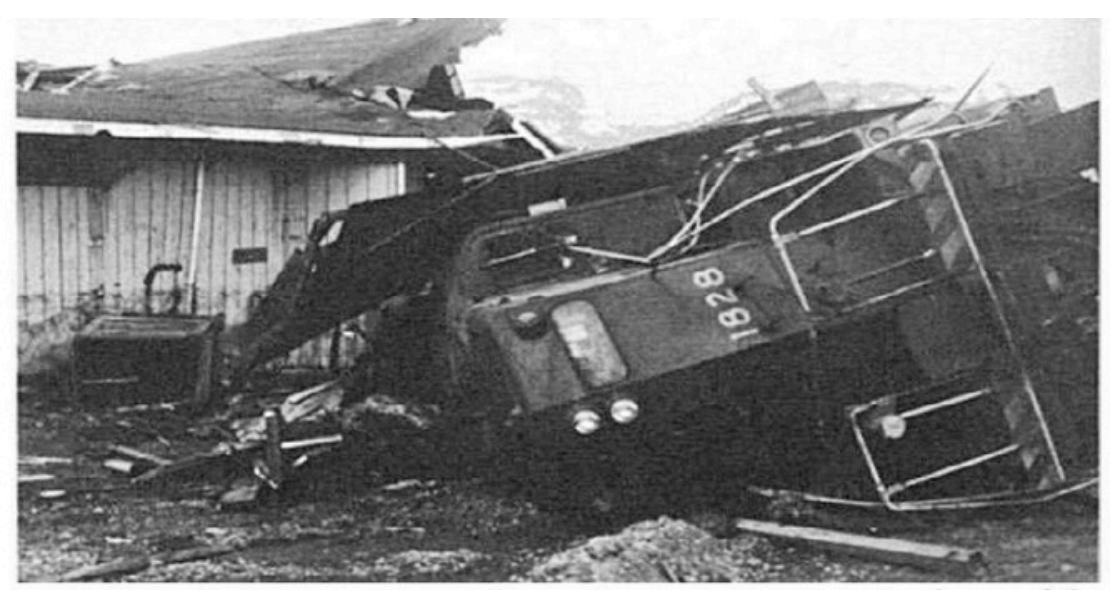

Figure 72. Photograph of overturned locomotive at Seward after 1964 Alaska tsunami. Run-up height at Seward after the 1964 Alaska tsunami was about 40 feet. (Photograph from Sturman, 1973.) 


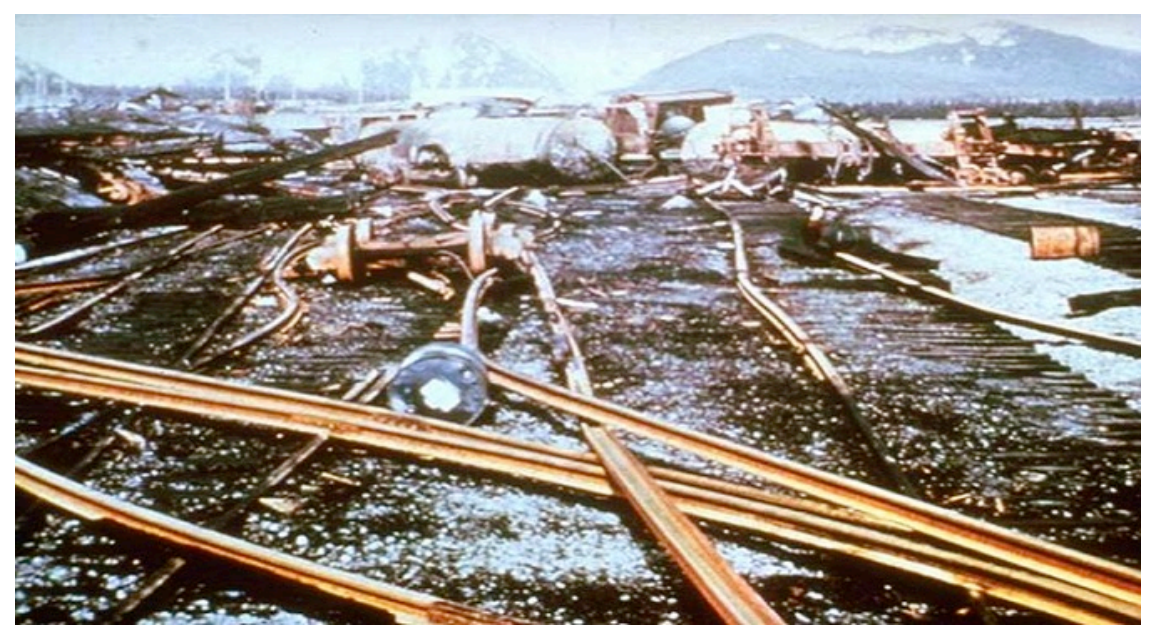

Figure 73. Photograph of Seward yard after 1964 Alaska tsunami. Estimated wave height in the Seward yard is between 25 and 35 feet (photograph courtesy of National Oceanic and Atmospheric Administration, National Geophysical Data Center).

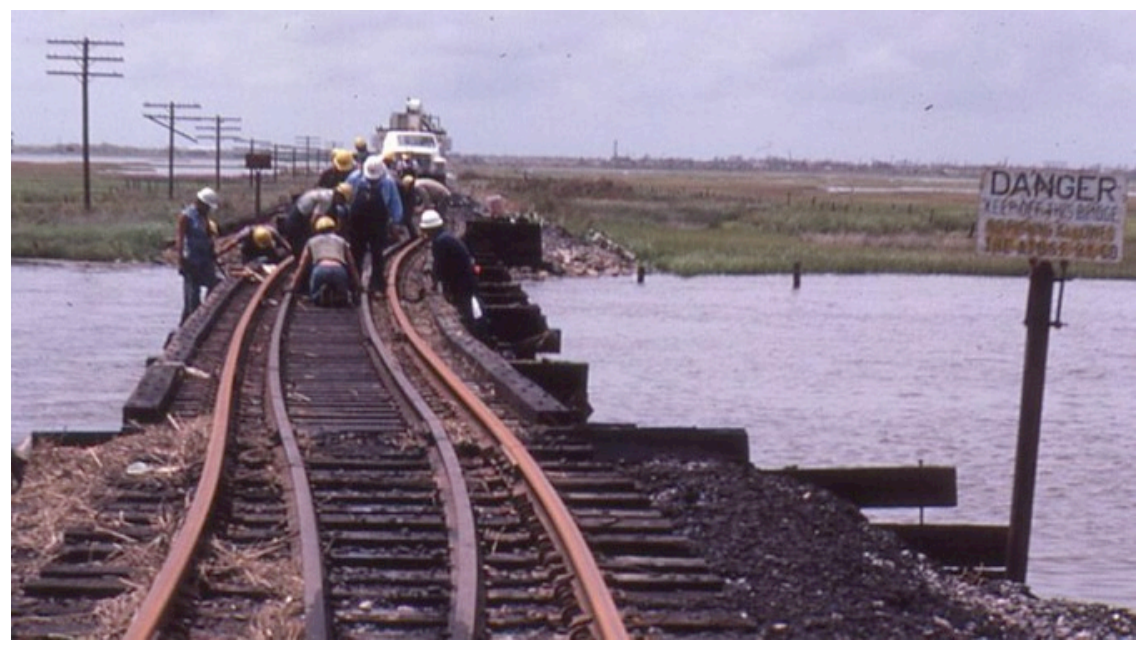

Figure 74. Photograph of open deck trestle damage from 1983 Hurricane Alicia in the United States. Deck shifted by return flow. Surge depth was about 3 feet above track, about 5 feet above bottom of deck. (Photograph by William Byers.) 


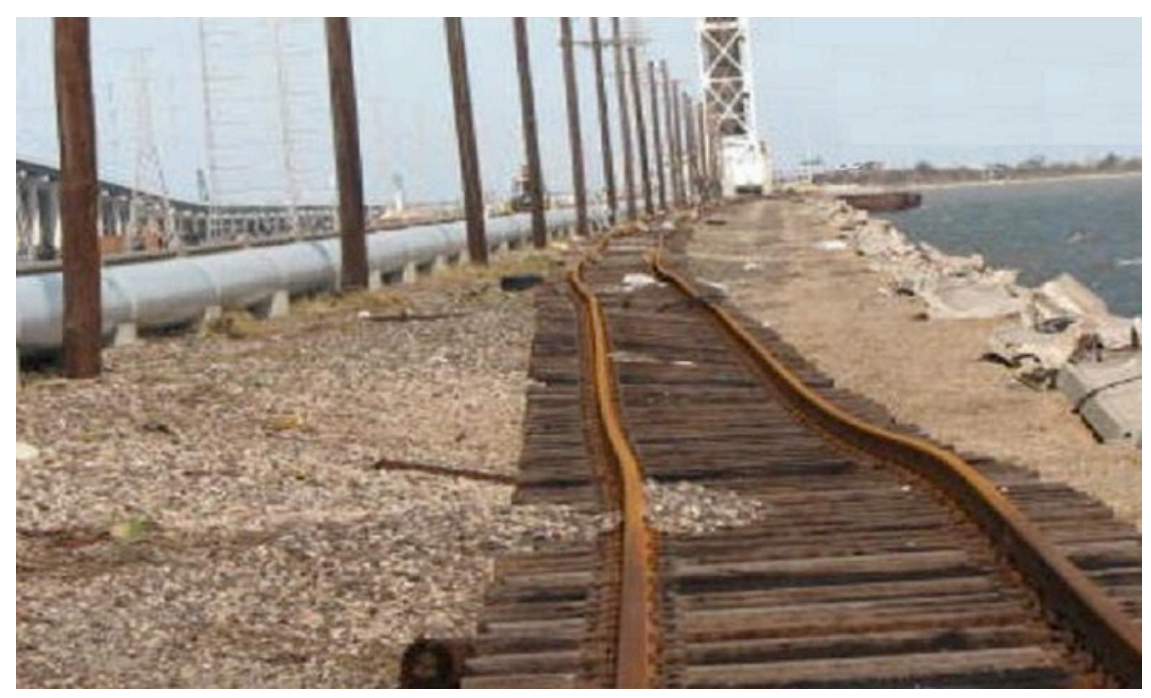

Figure 75. Photograph of track damage from 2008 Hurricane lke in the United States. Surge depth was about 3 feet above track (photograph by Ross Ruckel). 
Tsunami damage is the result of one or more of three mechanisms that are shared to a greater or less extent by other types of flooding. Submergence to various depths occurs to the limit of inundation. Erosion of soil and other granular material requires a minimum depth but depends primarily on the velocity and duration of flow. Direct wave effects result from buoyancy, lateral pressure of the wave, upward pressure when the surface of the wave rises against exposed horizontal surfaces and impact from floating debris.

It is impossible to know where trains will be at the time of the hypothetical tsunami, but for the sake of depicting a particular outcome it is useful to assume some particular location for trains. To that end, it is assumed here that, at the time the tsunami warning is issued, trains and other movable railroad equipment will be located as shown in a Google Earth image from March 2012. However, with the amount of warning anticipated, there should be no trains in locations subject to damage. Article 1.2.2.4-Tsunamis in chapter 9 Seismic Design for Railway Structures of the American Railway Engineering and Maintenance-of-Way Association Manual for Railway Engineering (AREMA, 2012) contains the following recommended practice:

After a tsunami warning is issued to the railroad, train dispatchers shall notify all trains and engines within the areas vulnerable to the tsunami to move out of those areas before the estimated arrival of the tsunami. To the extent possible all other equipment should also be moved. The movement should be to the closest location at an elevation deemed to be safe. This movement may be in reverse of the train's normal movement.

For any remotely generated tsunami, train dispatchers would have plenty of time to get all trains moved to safe areas. However, damage to track and other fixed facilities and to any equipment remaining on inundated yard tracks or side tracks can be expected. The extent of damage depends on the depth of inundation, the velocity and, for erosion of ballast or embankment, the duration of the velocity.

Removal of wave deposited debris will probably be required on a major portion of any tracks inundated to a depth of one foot or more. Ballasted track would probably not be significantly damaged if inundated to a depth of less than one foot. Ballast has been protected from erosion by hurricane storm surges with a depth in the order of 5 feet by asphalt injection but the cost would probably not be justified for tsunamis due to their low frequency of occurrence at vulnerable locations. Track alignment has been maintained well enough to allow limited operation under storm surges as great as 10 to 15 feet by anchoring to piles located on both sides of the track at about 300 foot spacing (Byers, 2011) but, again, the cost would not be justified. At the ports of Los Angeles and Long Beach, and at some other locations, tracks are encased in concrete paving with its surface at the same level as the top of rail. Track in concrete paving would probably withstand inundation to a depth of several feet unless the pavement is undermined. At these locations, debris would be removed as part of clearing the paved area. However, it might be necessary to remove debris from the flangeways (the openings parallel to the rail that are made through platforms, pavements, track structures to permit passage of wheel flanges). This would probably be done by high-pressure flushing.

Electrical/electronic components of signal systems are typically about 2 feet above the track. If the water depth significantly exceeds this value, it would damage or destroy the instrument cases in which these components are housed. Electric motors of switch machines would be submerged by near the top of rail. Unless struck by debris, signal masts would probably survive wave heights in the order of 5 to 10 feet.

Damage to bridges will require a wave of appreciable amplitude. Very few railroad bridges have shallow foundations on erodible material. Typically they have deep foundations 
consisting of driven piles or reinforced concrete drilled piers or are founded on rock. Old timber bridges built in the early 1900s typically have pile depths of approximately 25-30 feet and may be subject to scour when currents exceed 6 to $8 \mathrm{kt}$. New bridges typically consist of concrete or steel superstructures supported by driven steel piles or reinforced concrete drilled piers, typically with sufficient depth to avoid scour. We examined bridges rail bridges along the entire coast in the study area and found one case where velocities were significant enough to cause scour: the Santa Margarita River (Trestle) bridge near Camp Pendleton. At this bridge, $10 \mathrm{kt}$ currents could potentially cause scour around the 30 -feet piles, though it seem unlikely to be sufficient to cause the failure of the bridge. Therefore, scour is an unlikely mode of failure along the Coastal Rail Corridor. We found no cases where the wave was high enough to impact the bridge soffit, and therefore superstructure displacement also seems unlikely.

An open deck timber trestles trestle had its deck washed out of line by a relatively low hurricane storm surge with a maximum height of about 5 feet above the track. Attachment of the deck to the bents was probably broken during inward flow and final misalignment occurred during outward flow of the surge. Unanchored track was washed out under a surge estimated as being in the order of 3 feet over the track. Track anchored to piles at intervals of about 300 feet remained essentially in alignment after a surge of about 14 feet over the track (Byers, 2011).

If water reaches a depth significantly greater than 3 inches above the top of rail, traction motors of locomotives are subject to damage. Locomotives, cars with loads of particularly high value or hazardous materials and other particularly important equipment would be moved to high ground. This is based on railroads' policies for removing equipment from Galveston Island in advance of hurricanes during the period when Galveston was a major port and rail terminal. However, a number of both loaded and empty cars may still remain vulnerable in ports or low elevation yards and side tracks adjacent to the coast. If water reaches a depth significantly greater than 8 inches above the top of rail, bearings and brakes of cars are subject to damage. If the crest of the wave is over about 2 feet above the top of rail, lading in double stack container cars and hopper cars is subject to water damage. If the crest of the wave is over about 4 feet above the top of rail, lading in most cars is subject to water damage and there is a risk of derailing standing cars, particularly empty cars. At the crucial depths where a type of damage begins, a small change in water depth can cause a disproportionate change in total damage.

In addition to the areas vulnerable to the scenario tsunami, there are near-by areas that would be vulnerable to greater wave amplitudes or to similar tsunamis arriving at a higher tidal stage. Tidal ranges for many of the vulnerable areas are appreciable. Data for several tide gages along portions of the California coast with adjacent railroads are shown in table 31 .

Table 31. Tide gages near several coastal stretches of railway.

[max., maximum; min., minimum; ft, feet]

\begin{tabular}{|c|c|c|}
\hline \multirow[t]{2}{*}{ Location of Tide Gage } & \multicolumn{2}{|c|}{$\begin{array}{l}\text { Difference between max. } \\
\text { high and min. low tides }\end{array}$} \\
\hline & Typical Day & Typical Year \\
\hline Port Chicago (on Sacramento/San Joaquin River Delta) & $5 \mathrm{ft}$ & $6.9 \mathrm{ft}$ \\
\hline Richmond & $5 \mathrm{ft}$ & $9.6 \mathrm{ft}$ \\
\hline San Francisco & $5 \mathrm{ft}$ & $9.5 \mathrm{ft}$ \\
\hline Monterey & $4 \mathrm{ft}$ & $9.2 \mathrm{ft}$ \\
\hline Santa Barbara & $4 \mathrm{ft}$ & $9.0 \mathrm{ft}$ \\
\hline Los Angeles & $4 \mathrm{ft}$ & $9.2 \mathrm{ft}$ \\
\hline San Diego & $4 \mathrm{ft}$ & $9.5 \mathrm{ft}$ \\
\hline
\end{tabular}


Inundation limits and modeled flow depths given in the scenario are used to estimate damage. Even if there is no damage or inundation of railroad facilities, there will be interference with normal operation and associated costs during the period that the tsunami warning is in effect and while post-tsunami inspections of tracks are being performed. Damage will be discussed from north to south.

There are no longer operated rail lines at vulnerable locations in California north of the San Francisco Bay area. (There is a vulnerable line in Washington along Puget Sound.)

At Richmond, slightly more than one half mile of a rarely-used track to the former Atchison, Topeka and Santa Fe Railway (AT\&SF) car ferry slip would be inundated to a maximum depth of about two to three feet. Before reaching the BNSF Railway Richmond yard, the wave would have to pass through a short tunnel. Entrance and exit head losses, friction in the tunnel along with limited duration of the wave and a large area for dissipation upon leaving the tunnel would prevent inundation of any significant depth in the yard. (A 5-foot higher wave would inundate about $3 \frac{1}{2}$ miles of additional track at 4 locations in Richmond and Oakland.)

The Union Pacific (UP) operates a line from the San Francisco Bay area to Los Angeles that runs parallel to the coast at a number of locations from near Watsonville to Ventura. There is also a branch to Santa Cruz. At some locations, the line is very close to the coast and low enough to be vulnerable to tsunamis. The line carries both freight and passenger trains. Both the UP and BNSF have lines between the San Francisco Bay area and Los Angeles that run through the Central Valley, would not be affected by a tsunami, and would serve as detour routes.

At Santa Cruz, about 0.1 mile of track in a concrete paved street would be inundated to a depth of less than one foot. (A 5-foot higher tsunami would increase the maximum depth by 5 feet and the length involved by one half mile.)

Near Carpinteria, there is a 0.9 mile stretch of main track with 3 ballasted deck bridges that would be inundated to a maximum depth of about 3 feet. Considerable washed out ballast, some track severely misaligned or washed off embankment, and insignificant bridge damage can be expected at this location. There would also be immersion damage to some signal system equipment. (A 5-foot higher wave would increase this segment by 0.8 mile and add 2.3 miles of main track in segments near Summerland and Ventura, including a 700 foot bridge that would not be damaged and a 152 foot open deck trestle which would have minor damage, as well as 1.8 miles of tracks and the bearings on three cars at the U.S. Navy's construction battalion facility at Port Hueneme.)

In addition to freight trains, thirteen passenger trains, including 11 commuter trains, operate over the track near Carpinteria. Four of these are scheduled to pass the affected area between the time of the earthquake and the arrival of the tsunami. The first of these is scheduled to clear the area by 12:48 p.m. and would probably be allowed to proceed normally if running on time. Later trains would probably be held at safe locations until after the tsunami's arrival. Freight trains, which do not have defined schedules, would be dispatched in a similar manner.

Considering the time required for mobilization and performing the work, the line could be expected to be out-of-service for up to three days, depending on the availability of ballast and track surfacing equipment. Although through movements would be prevented during this period, intermediate points could be served from one end or the other. If equipment and train crews are available, separate sections of passenger trains could be run north and south of the damaged area and through passengers transferred between sections by bus. Freight could be moved through the connection on the appropriate side of the track closure. 
The area of greatest rail vulnerability involves tracks and equipment at the Ports of Los Angeles and Long Beach. Track damage would be limited as tracks in the areas of greater inundation depth and velocity are primarily in concrete slabs and not subject to damage from washed out ballast. Damage to containers and their contents should be considered as part of the damage to the ports unless the containers are loaded on cars. Damage to containers and contents on cars is a part of railroad damage. No estimate will be made of the value of lading in containers but it should, on average, be similar to that in other loaded containers in the ports.

All movement of cars into the port would be stopped when the tsunami warning is received. There will be sufficient time to move all cars in the port area that are coupled to locomotives to safe locations as the locomotives are removed. Although they may not meet the requirements of the definition, these movements will be referred to as "trains". Remaining cars are vulnerable to damage related to the depth of inundation. Significant inundation of tracks occurs at locations "A", "B" and "C" in figure 76. 


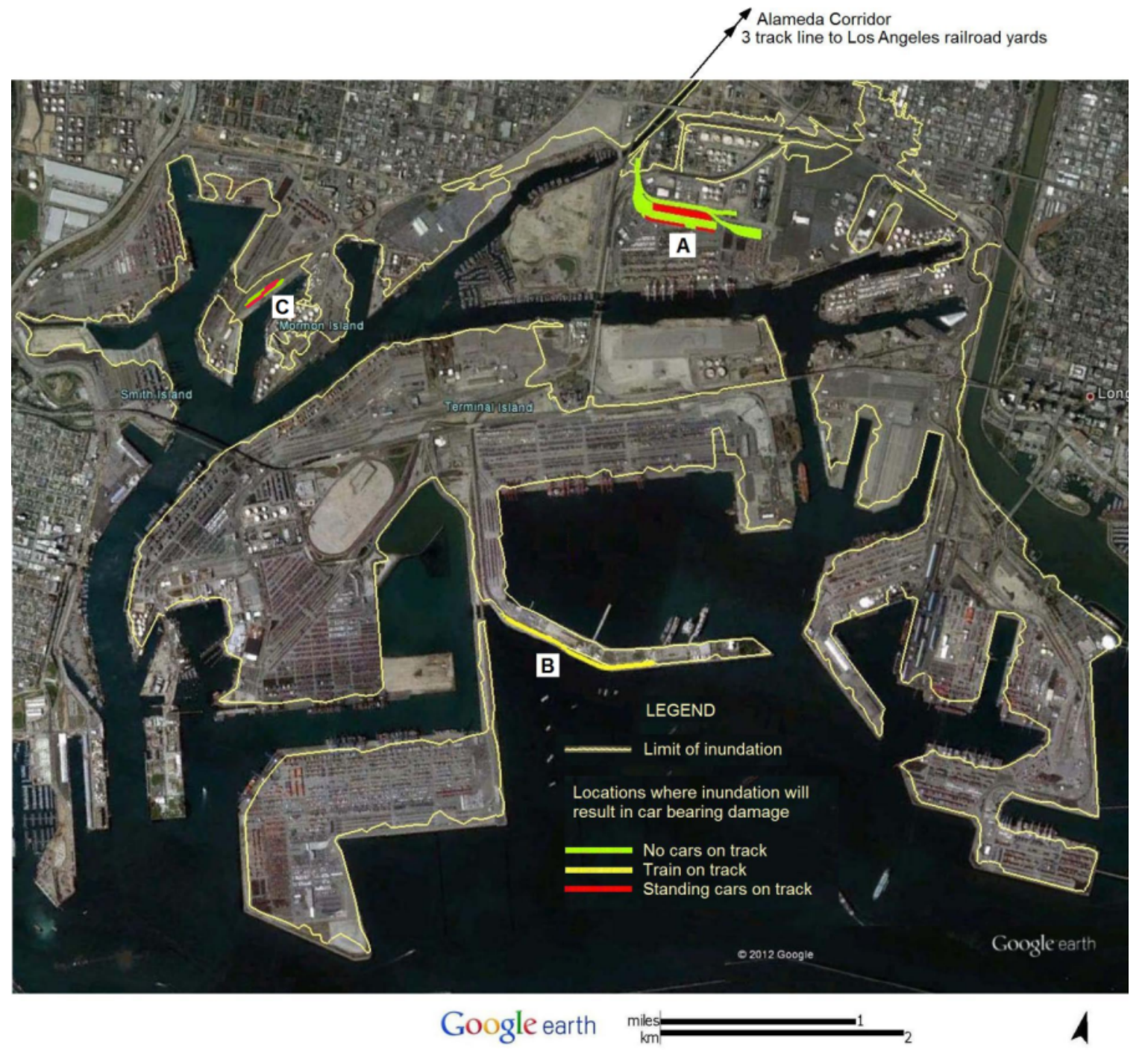

Figure 76. Map of conditions, when SAFRR tsunami warning is received, at locations in ports of Los Angeles and Long Beach where inundation will be deep enough to damage cars left standing on track (base image from Google Earth).

Details of the region at Location "A" with water depth great enough to cause wheelbearing damage are shown in figure 77. This depth is less than the depth that would cause track damage. Segments of track with inundation depth great enough to cause damage are coloredgreen if unoccupied, red if occupied by either loaded or empty cars. This amounts to nearly five miles of track with about $1 / 4$ mile on ballast and the rest in concrete slabs. Track repairs would be relatively light, involving cleaning flangeways after trash is removed from the slabs as part of general port cleanup and any necessary restoration of ballast, lining and surfacing of the track on ballast. 


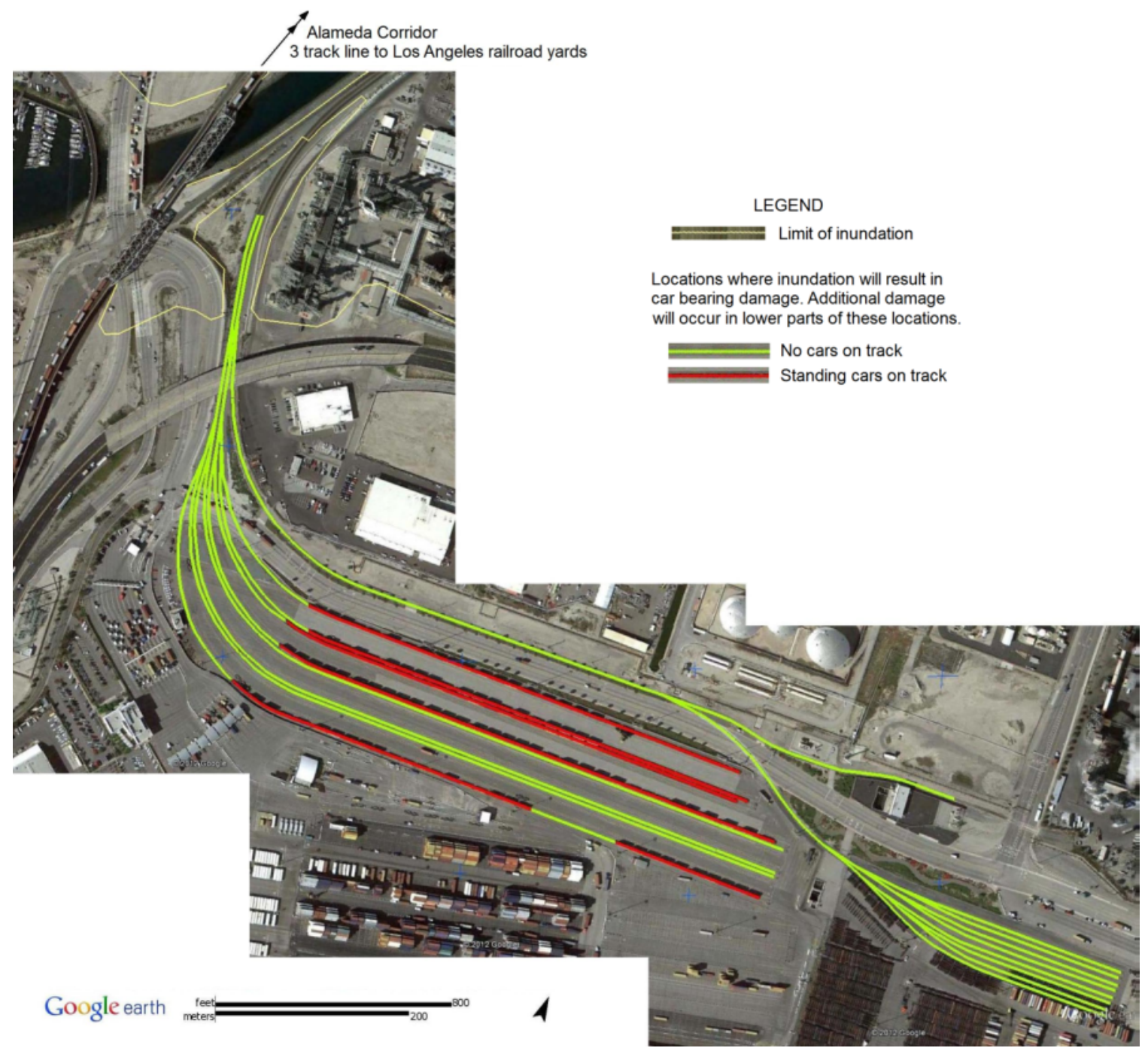

Figure 77. Satellite image annotated with details of location "A" (see fig. 76) at time of the SAFRR tsunami warning (base image from Google Earth).

Any car wheel bearings that are submerged must be reconditioned (or replaced) according to interchange rules. As a practical matter, this normally involves replacing the entire wheelset and shipping the damaged wheelset to a shop for reconditioning. Thirty two cars for transporting containers, including 4-axle cars, 8-axle articulated cars and 12-axle articulated cars, will require replacement of 316 wheelsets. Water depths will be great enough to damage vulnerable lading in 149 containers on loaded cars. The extent of damage depends on the nature of the lading that cannot be determined by viewing the exterior of the typical container. It can vary from a bulk commodity or other situation in which wetting of the bottom part of the contents destroys the value of all of the contents to material in water-tight drums that would be unaffected by partial immersion. It is reasonable to assume that no more than 10 to 20 percent of these containers would either be empty of have lading that would not be subject to water damage. Value of damaged lading will not be estimated but, on average, should be similar to the average value of lading in other containers at the ports. 
The "train" at Location "B" would be moved to a safe location but cars would remain at Location " $C$ ". Seventeen cars at Location " $C$ " would have water damage to the bearings of 68 wheelsets.

AMTRAK, Metrolink, and North County Transit District operate a line between Los Angeles and San Diego that follows the coast between San Clemente and San Diego owned in part by Metrolink in Orange County, by North County Transit District in Northern San Diego County, and by Metropolitan Transit System in Southern San Diego County. The line carries Amtrak and commuter trains during the day and BNSF freight trains at night. Except for short stretches of BNSF track in San Diego, which are a few feet above the tsunami run-up elevation, the tracks are NOT well above any tsunami inundation. No railroad damage is expected in this area.

The estimated cost of repairs to fixed property — track, bridges and signals — is slightly over one million dollars. Repairs to cars will have a similar cost. The cost of train delays and less efficient operation during the repair period could equal the cost of repairs to railroad property. This is in addition to the damage to lading in 120 to 135 loaded containers. (Damage to containers is addressed in the section dealing with the ports.)

\section{Agricultural Damages}

By Jamie Ratliff and Anne Wein

With more than 25 million acres of active farmland National Agricultural Statistics Service (NASS) (2009), California is one of the largest agricultural producers in the United States. Tsunamis like the proposed scenario can potentially adversely impact agriculture. Agriculture in California, though mostly confined to the Central Valley and other interior areas of the State, is also practiced along the coast and therefore susceptible to tsunami inundation. Smaller coastal farms and enterprises could be disproportionately affected by a tsunami. The losses could be direct and immediate (destroyed crops, drowned/displaced livestock, obliterated farming equipment, and damaged/destroyed buildings). Longer-term losses could pertain to restoring the land from the effects of debris, salinization, and topsoil removal. Indirect impacts from contamination of the soils and food supply could result from tsunami damages to infrastructure housing hazardous waste (for example, chemical spills, manure, and pesticides stored on farms) or reworked marine sediments (Plumlee and others, 2013). Historically, events like the 2004 Indian Ocean and 2011 Tohoku, Japan, tsunamis caused enormous amounts of agricultural losses (for example, stock, revenue, and life) in many regions located closest to the tsunami's origin.

\section{Types of Agricultural Damages from Tsunamis}

Inundation causes various types of damages to agricultural enterprises. Low-lying terrain like deltas can be particularly susceptible to tsunami inundation due to wide expanses of flat land barely above sea level. Though tsunami waves are relatively slow-moving when they inundate the land compared to their speed in open water-wave speeds in open water can be as high as 500 miles per hour (mph), whereas wave speeds near the coast reduce to less than $40 \mathrm{mph}$ 
(International Tsunami Information Center, 2013) — the speed is still fast enough to tear up crops and pastures, displace or drown livestock, and damage infrastructure.

The rapid movement of tsunami inundation waters across croplands can remove topsoil from the land along with any crops. Topsoil tends to be the more organic (and therefore nutrient rich) component of arable land, so scouring reduces the overall viability of the soil for crops. Replacing the topsoil is time-consuming and expensive, though it can sometimes be accomplished using biomass-rich crops. In addition, scoured topsoil can be deposited in other areas, modifying local topography and changing soil properties (Subagyono and others, 2005). Furthermore, debris carried by tsunami waves can also damage or destroy crops by cluttering up cropland or depositing silts and clays that form a more impermeable barrier and make water infiltration into soil more difficult (Subagyono and others, 2005).

Salinization of crop soils is another destructive agricultural hazard caused by tsunamis. Tsunami inundation infiltrates crops and saturates soil, potentially rendering cropland useless. When too much salt is present in the soil, osmosis leads to water being leached out of instead of taken in by crops through their roots. In addition, sediment deposits can sometimes inhibit leaching - the removal of salt from soil by flushing it with freshwater. Generally unless heavy, consistent rainfall or persistent irrigation occurs to wash salt out of the soil, only deep-rooted or salt-tolerant crops can be grown on inundated land until the salt content is reduced sufficiently to permit more salt-sensitive crops to be grown again United Nations Food and Agriculture Organization (FAO)(2005a).

Contamination of soil, food, and water supplies is a concern both economically and ecologically. For example, following the 2011 Tohoku earthquake, Japanese agricultural products (such as rice and fish) from Fukushima Prefecture had their distribution restricted for fear that radiation from the damaged Fukushima Daiichi nuclear power plant had contaminated the products (Kajitani and others, 2013); radiation from damage to nuclear power plants is not a concern in our tsunami scenario because coastal power plants are outside the modeled inundation zone. Livestock can also be adversely impacted by contamination-poor water supplies or radiation poisoning can kill livestock and cause defects in livestock products (for example, eggs, milk, and meat).

All types of tsunami damages impact various aspects of agriculture. Crops can be damaged or destroyed. Infrastructure (for example, barns) can be flooded, damaged by debris, or simply broken by tsunami inundation. Other equipment like tractors can be washed away or damaged by water and debris. Lifeline and crucial services damages (such as transportation and electricity) can cause agricultural losses to farms (dairy farms, in particular) both in and outside the tsunami inundation zone. Farmers and their staff may suffer injuries, be displaced, or even lose their lives as a result of tsunami inundation; livestock may experience these same problems. Damages to crops may be affected by the amount of time the land remains inundated (Porter and others, 2010). Finally, the time of year the event occurs affects the severity of damages to crops and livestock. For example, seedlings and calves are more vulnerable than more established crops and livestock.

\section{Historic Tsunamis and Agricultural Losses}

A number of tsunamis have resulted in varying levels of damage to agriculture (for example, crops, infrastructure, and livestock). In the past 10 years, the 2004 Indian Ocean tsunami and the 2011 Tohoku tsunami have recorded information about crop and livestock 
damages in various countries. Other tsunamis, such as the 2010 Chile, 2010 Sumatra, and 2009 Samoa tsunamis, also had some impact on agriculture in their countries of origin.

The 2004 Indian Ocean tsunami, one of the most destructive tsunamis in recorded history, damaged or destroyed agricultural land in many Southeast Asia countries. India and Indonesia were some of the hardest-hit countries, with nearly 40,000 hectares (ha; 99,000 acres) of Indonesia's field area destroyed and over 50,000 ha damaged and nearly 12,000 ha (30,000 acres) of India's crop lands damaged (International Fund for Agricultural Development, 2005). In Thailand, where damages were less severe, approximately 100 ha (250 acres) of cropland and 1,600ha (4,000 acres) of plantation land were affected, resulting in an estimated 376 million Baht (\$12.3 million U.S.) in damages and losses. Uprooted oil palms and coconut trees required replacement. More than 10,000 animals drowned, leading to an estimated 17.6 million Baht (\$570,000 U.S.) of livestock losses across six provinces (Asian Disaster Preparedness Center, 2005). Nearly 40 percent of the arable land on the island of Sumatra in Indonesia was estimated to be unusable for at least a few years (FAO, 2005b). The Maldives and Sri Lanka also had relatively significant agricultural damages: around 50 percent of agricultural land in the Maldives was completely destroyed, and approximately $1 / 3$ of Sri Lanka's production in the peak cropping season was lost in the main paddy growing areas (International Fund for Agricultural Development, 2005).

In Japan after the 2011 Tohoku earthquake, agricultural damage was estimated at about 950 billion Yen (¥) (\$9.32 billion U.S.). About 23,500 ha (58,000 acres) of land including about 20,000 ha $[49,000$ acres] of rice paddies and 3,500 ha [8,600 acres] of upland fields were washed away or flooded by tsunami inundation. After one year, less than half of fields damaged by salinization had been restored; over half of the damaged farms in the disaster zone were still inoperable (Japan Ministry of Agriculture, Forestry and Fisheries, 2012). After 2 years, 80 percent of the rice fields in Sendai have been desalinated and some farmers are cultivating rice for the first time in three years (Hirama, 2013).

The failure at the Fukushima Daiichi nuclear power plant following the tsunami introduced major concerns about radiation contaminating remaining crops in multiple prefectures surrounding the plant. Restrictions on export and consumption of leafy (lettuce, cabbage) and flowerhead (broccoli, cauliflower) vegetables from these prefectures was restricted for a short time pending more comprehensive testing. Dairy products like milk and eggs, as well as meat products, like pork, were also restricted pending further testing in Fukushima prefecture (Johnson, 2011).

Although tsunamis can cause serious damage to agricultural land, reports on agricultural damages in California following tsunamis of record are non-existent. The 2010 Chile and 2011 Tohoku tsunamis damaged marinas along much of the coast of Northern California without inundating land (CGS, 2012). Although no evidence of agricultural damages from the 1964 Alaska tsunami could be found, similar to the SAFRR tsunami scenario, land and communities in California were inundated.

\section{Potential Agricultural Damages in the SAFRR Tsunami Scenario}

Agricultural damages in the SAFRR tsunami scenario are summarized in terms of land exposure and crop income losses, soil and crop contamination sources; exposed livestock value, and damages to agricultural buildings and contents. We were not able to address field remediation costs and restoration times. 


\section{Methods}

To establish how much agricultural land is potentially exposed in the SAFRR tsunami scenario inundation zone, agricultural land cover data were intersected with the scenario inundation zone and wave velocity/flow depth data and summarized by county using geographic information systems software. "Cropland" and "agricultural land" are defined as follows: cropland refers to land that was cropped (for example, for wheat or strawberries) and agricultural land includes both cropland and land that was not (but could have been) used for crops or was used for livestock (such as fallow/idle cropland or pasture).

Two different land use datasets were considered for the agricultural land exposure analysis. Vector land survey data from the California Department of Water Resources (DWR) and raster remotely sensed cropland data from NASS were both processed to provide a range of agricultural exposure values. DWR data collected through a series of land surveys and extensively ground-truthed are potentially more accurate. However, the surveys were completed between 1993 and 2006 and do not cover every coastal county (DWR, 2013). NASS Cropland Data Layer (CDL) data have complete coverage at 30-m resolution and are more current - CDL data are updated yearly - but are far more reliant on automated processes to complete the classification (NASS, 2013).

An examination of the 2007 Census of Agriculture for California revealed that every county in the State has at least a nominal amount of farmland in use (NASS, 2009). Therefore, the decision was made to use the CDL for this analysis to capture exposed agriculture in counties not surveyed by DWR. The currency of the CDL data was also preferable because crops can change from year to year-the entire study area was included in the 2012 CDL, unlike the DWR data where different counties were surveyed in different years. The 2012 crop distribution is not intended to predict what the crop distribution will be in 2014; this analysis uses these data as a proxy to provide a general idea of what agricultural impacts could be possible for the SAFRR tsunami scenario.

Other sources were used to address the other types of agricultural damages. DWR data was consulted for indications of livestock (poultry, feedlots, and dairy) in the inundation zone and confirmed using satellite imagery. Crude estimates of crop income loss and exposed livestock value relied on agricultural damage analyses conducted for the ARkStorm scenario (Porter and others, 2010). Sources of soil and crop contamination were extracted from the environmental and environmental-health implications in the SAFRR tsunami scenario (Plumlee and others, 2013). Finally, more detailed information about how building and content losses were calculated is provided in the Building Damage section of this report.

\section{Agricultural Land Exposure}

Approximately 90,600 acres of land lie in the scenario inundation zone; around 9,600 acres (11 percent) is agricultural land (based on the 2012 CDL). Alfalfa is the most common crop in the inundation zone, making up 42 percent of inundated agricultural land. Trucktransported crops (such as carrots and strawberries) and field crops are a distant second and third, only representing 0.5 and 0.4 percent of inundated agricultural land. Non-crop uses such as pastureland and fallow/idle land waiting to be rotated in the next growing season make up the majority of inundated agriculture at 57 percent of the total.

At the county level, Humboldt County is by far the most exposed agriculturally to the SAFRR tsunami scenario: 23 percent of the 22,064 inundated acres in the county is agricultural. San Luis Obispo, Mendocino, and Sonoma Counties also have a relatively high percentage of 
inundated agricultural land relative to total inundated land (22, 18, and 15 percent, respectively), however the overall amount of inundated land in these counties is relatively small (1,972 acres, 2,397 acres, and 758 acres respectively). The vast majority of potentially affected cropland lies in Humboldt County (94 percent of total inundated cropland), and 99 percent of the affected cropland in the county contains alfalfa-type crops (such as alfalfa and hay). Monterey County ranks a distant third for exposed cropland at only 59 acres (1 percent of total inundated cropland), but the county has the most non-alfalfa cropland in the inundation zone. Trucktransported crops and field crops are prominent in Monterey County. Table 32 presents the distribution of agricultural land in the inundation zone by county, figure 78 illustrates the dominance of grass- and pasturelands in the inundation zone in Humboldt County, and figure 79 shows the wider variety of croplands in the inundation zone in Monterey County.

Borrowing from the ARkStorm agricultural analysis (Porter and others, 2010) and assuming that production on inundated agricultural lands is lost for one year for annual crops and alfalfa and multiple years for vineyards, rough estimates of crop income losses amount to approximately $\$ 3.5$ million in 2010 dollars. This calculation includes no revenue losses from non-crop lands. More than 90 percent of the income losses accrue from inundation of alfalfa croplands. Vineyards are potentially the next greatest source of losses if the crop has to be reestablished, a costly process that occurs over multiple years. Truck-transported crops register as the third highest category of crop income losses.

Wave velocities and flow depths were modeled along with inundation for the SAFRR tsunami scenario. The maximum wave velocity on alfalfa croplands is $12 \mathrm{~m} / \mathrm{sec}(27 \mathrm{mph})$ in Humboldt County and the maximum flow depth (the maximum height of the tsunami wave relative to the topography) is $5 \mathrm{~m}$ in Mendocino County. The overall maximum wave velocity on cropland is about $24 \mathrm{~m} / \mathrm{sec}(54 \mathrm{mph})$ on grain cropland in Los Angeles County, whereas the greatest flow depth on cropland of around $6 \mathrm{~m}$ occurs on vineyards in Marin County. For the most part, however, wave velocities average around $2 \mathrm{~m} / \mathrm{sec}(4 \mathrm{mph})$ and flow depths average around $1 \mathrm{~m}$ on cropland. 
Table 32. County-level distribution of agricultural land in the SAFRR tsunami scenario inundation zone.

\begin{tabular}{|c|c|c|c|c|c|c|c|c|c|c|c|}
\hline \multirow[b]{2}{*}{ County Name } & \multicolumn{3}{|c|}{ Total (acres) } & \multicolumn{8}{|c|}{ Agricultural Breakdown by Crop Class (acres) } \\
\hline & Inundated & $\begin{array}{c}\text { Agricultur } \\
\text { al }\end{array}$ & $\begin{array}{l}\text { County } \\
\text { Total }\end{array}$ & $\underset{1}{\text { Alfalfa }}$ & $\underset{2}{\text { Grains }}$ & $\begin{array}{l}\text { Field } \\
\text { Crops }^{3}\end{array}$ & Rice & Truck $^{5}$ & Tomatoes & Vineyards & $\begin{array}{l}\text { Non- } \\
\text { Crop }^{6}\end{array}$ \\
\hline Del Norte County & 7,943 & 711 & 787,271 & 0 & 0 & 0 & 0 & 0 & 0 & 0 & 711 \\
\hline Humboldt County & 22,064 & 5,151 & $2,552,467$ & 3,861 & 0 & 14 & 1 & 1 & 0 & 0 & 1,274 \\
\hline Mendocino County & 2,397 & 441 & $2,447,320$ & 118 & 2 & 0 & 0 & 0 & 0 & 1 & 320 \\
\hline Sonoma County & 758 & 116 & $1,016,190$ & 0 & 0 & 0 & 0 & 0 & 0 & 0 & 116 \\
\hline Marin County & 7,264 & 627 & 513,906 & 0 & 1 & 0 & 0 & 0 & 0 & 4 & 622 \\
\hline Contra Costa County & 1,692 & 3 & 325,809 & 0 & 0 & 0 & 0 & 0 & 0 & 0 & 3 \\
\hline Alameda County & 9,737 & 48 & 210,717 & 8 & 2 & 0 & 0 & 2 & 0 & 0 & 36 \\
\hline San Francisco County & 1,617 & 59 & 148,323 & 0 & 0 & 0 & 0 & 0 & 0 & 0 & 59 \\
\hline San Mateo County & 7,452 & 338 & 438,460 & 0 & 0 & 0 & 0 & 13 & 0 & 0 & 325 \\
\hline Santa Cruz County & 795 & 67 & 313,973 & 0 & 0 & 5 & 0 & 0 & 0 & 0 & 63 \\
\hline Monterey County & 4,741 & 442 & $2,366,171$ & 12 & 0 & 14 & 0 & 24 & 8 & 1 & 383 \\
\hline $\begin{array}{l}\text { San Luis Obispo } \\
\text { County }\end{array}$ & 1,972 & 428 & $2,239,106$ & 32 & 0 & 2 & 0 & 4 & 0 & 1 & 389 \\
\hline Santa Barbara County & 1,081 & 36 & $2,368,170$ & 0 & 0 & 0 & 0 & 0 & 0 & 0 & 36 \\
\hline Ventura County & 1,587 & 68 & $1,304,811$ & 0 & 0 & 0 & 0 & 0 & 0 & 0 & 68 \\
\hline Los Angeles County & 6,274 & 331 & $2,336,717$ & 0 & 3 & 0 & 0 & 0 & 0 & 0 & 328 \\
\hline Orange County & 6,420 & 368 & 336,942 & 0 & 0 & 0 & 0 & 0 & 0 & 0 & 368 \\
\hline San Diego County & 6,828 & 334 & $2,553,199$ & 0 & 5 & 0 & 0 & 0 & 0 & 0 & 329 \\
\hline Study Area Total & 90,621 & 9,570 & $22,259,552$ & 4,031 & 13 & 34 & 1 & 45 & 8 & 8 & 5,429 \\
\hline
\end{tabular}

${ }^{1}$ Alfalfa crops include alfalfa, hay, and other pasture grasses.

${ }^{2}$ Grains includes wheat, rye, oats, and triticale.

${ }^{3}$ Field crops include corn, cotton, barley, safflower, beans, peas, and other non-staple grains/legumes.

${ }^{4}$ Orchard crops include fruit and nut trees (such as apple, orange, almond, and walnut).

${ }^{5}$ Truck crops include strawberries, carrots, cantaloupe, pumpkins, and other bush/bulb/vine (except grape)/tuber crops.

${ }^{6}$ Non-crop land includes fallow/idle cropland, shrubland, barren land identified as agricultural land by the National Agricultural Statistics Service (NASS), and 


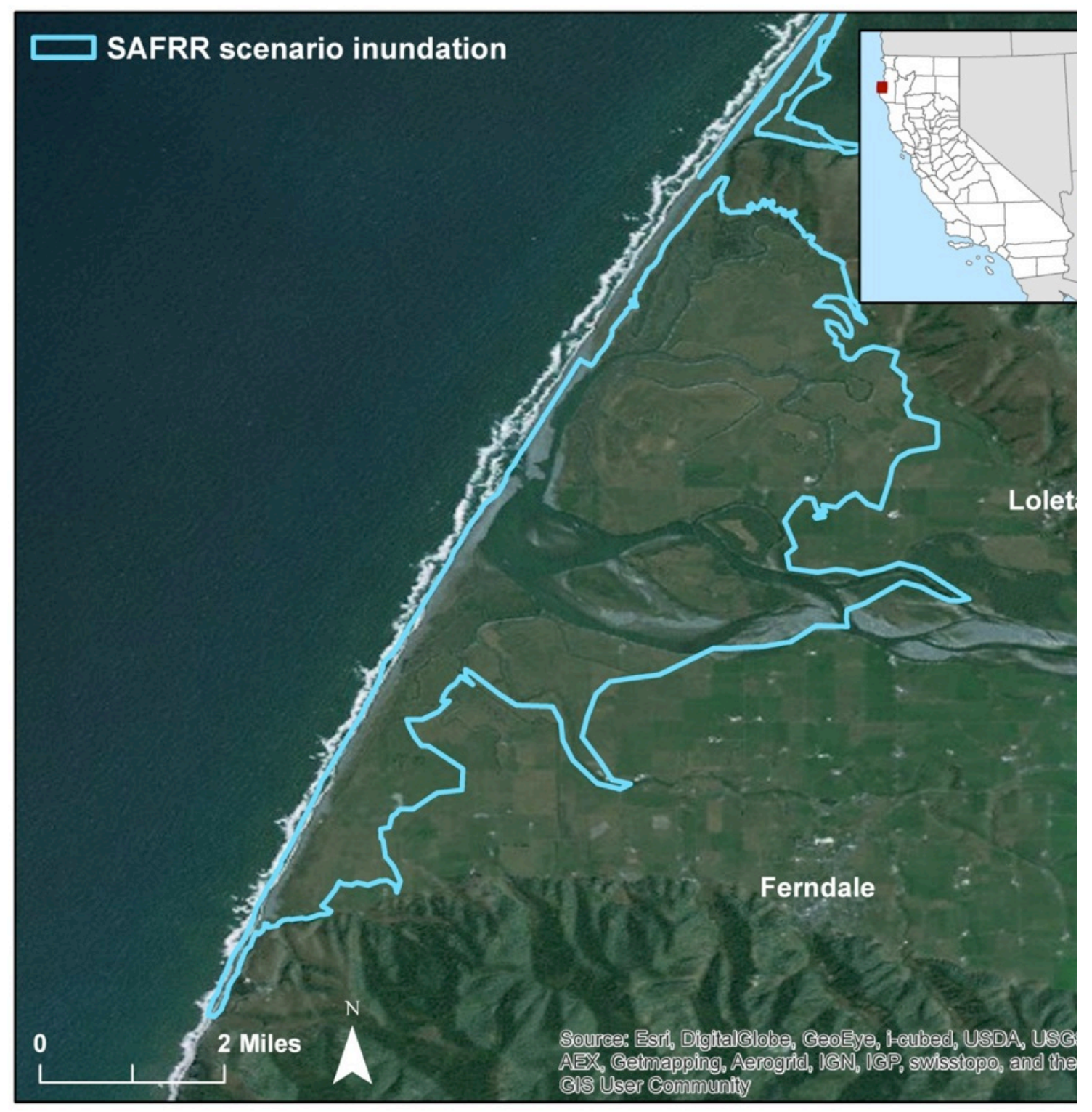

Figure 78. Satellite image showing Eel River Delta, Humboldt County, land inundated in the SAFRR tsunami scenario (blue outline). Much of the inundated area in Humboldt County is pastureland (I used for livestock) and land used for alfalfa-type crops. 


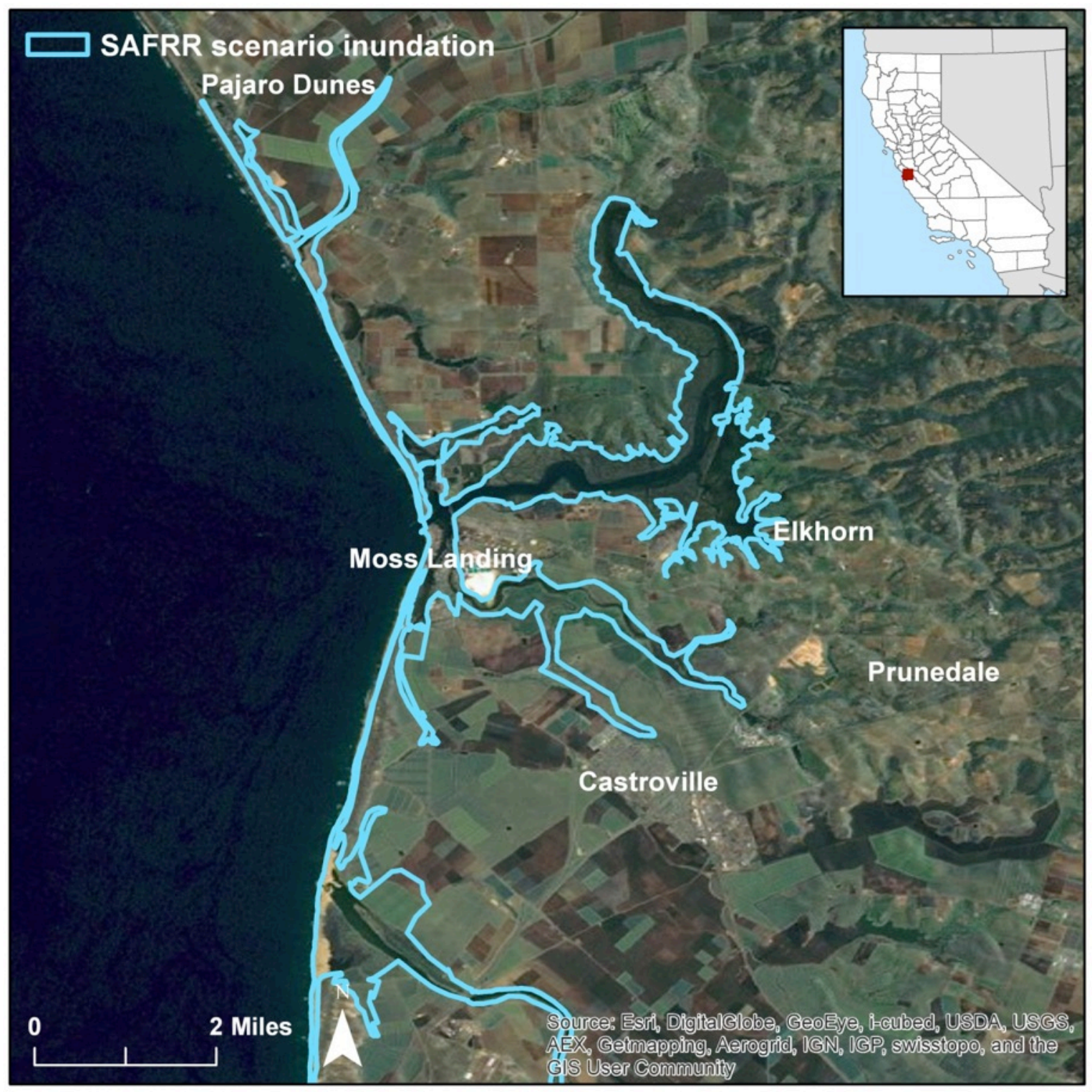

Figure 79. Satellite image showing land inundated in the SAFRR tsunami scenario (blue outline) around Moss Landing in Monterey County. Although far less of Monterey County's inundated land is agricultural relative to other affected counties, more of it is field crops and truck-transported crops.

\section{Soil and Crop Contamination}

Although no hazardous waste facilities are located in the tsunami scenario inundation zone (for example, Diablo Canyon Nuclear Power Plant in San Luis Obispo County is on the coast but not found to be in danger of inundation in this scenario), several urban and industrial contamination sources are close enough to the coast to pose a threat to agriculture. The Eel River Delta in Humboldt County, the largest agricultural extent in the inundation zone, is also at risk of contamination due to reworked marine sediments from cities upriver. The agricultural land 
around Humboldt Bay north of the Eel River Delta is situated near a potential source of industrial contamination as well as reworked sediment contamination. In northern Monterey County, Moss Landing State Wildlife Area and Elkhorn Slough National Estuarine Sanctuary are at risk of being exposed to potential industrial contamination from the north (Plumlee and others, 2013). Some industrial facilities and processing plants (such as warehouses and chemical plants) can be found beyond but still close to the inundation zone (an example of this is the wastewater treatment facility just south of the airport in Oceano in San Luis Obispo County) - these facilities could pose contamination threats if the tsunami damage impacts operations or if inundation actually extends farther than modeled. For further detail and discussion regarding potential contamination and environmental hazards in general, refer to Plumlee and others (2013).

\section{Livestock Exposure}

Agricultural land includes land used to support livestock. Data from the California Department of Food and Agriculture (CDFA) (John Rowden, April 23, 2013, written commun.) suggested that some dairies were potentially located along the coast. DWR data indicated dairy land use in the inundation zone; the presence of two dairies in the inundation zone was confirmed by visually inspecting satellite imagery. The CDFA data also provided dairy herd numbers and sizes by county. Using the average herd size in Humboldt County and a value of $\$ 1,300 /$ head (Porter and others, 2010) the exposed livestock value is approximately $\$ 250,000$.

\section{Summary of Agricultural Building and Content Damages}

Agricultural land is not the only asset that would be damaged by the scenario tsunami. Agricultural buildings (defined by NIBS and FEMA [2009] as agricultural facilities and offices, which may include, for example, barns and silos) are also of concern for tsunami damages. Selected census-block-level data falling in the scenario inundation zone were used to calculate building and content losses by HAZUS-MH building occupancy type. Given tsunami inundation and velocity and depth, HAZUS building loss estimates are derived from damage state probabilities for building types, repair and replacement costs per square footage, and building square footage. For a more detailed explanation of how building losses were estimated and what criteria were used to select areas for analysis, please refer to the Building Damage section of this report. Slightly more than $\$ 190,000$ in building losses and $\$ 1.04$ million in content losses are estimated to be incurred in the almost $200,000 \mathrm{ft}^{2}$ of building area classified in HAZUS-MH as agricultural (code AGR1) in the tsunami inundation zone statewide. A maximum of 117 days is estimated to complete repairs to agricultural infrastructure statewide.

At the county level, San Diego County has the highest estimated agricultural building and content losses in the analyzed census blocks even though the county has little agricultural land in the inundation zone. Around 39,000 $\mathrm{ft}^{2}$ of San Diego County building area classified as agricultural in the HAZUS-MH building inventory are in analyzed census blocks in the inundation zone (20 percent of the agricultural building stock that is inundated statewide). Building losses in San Diego County are estimated at around $\$ 76,000$ (40 percent of the total State AGR1 building losses), whereas content losses are estimated to be approximately $\$ 210,000$ (20 percent of the State total). The estimated building repair time in San Diego County of 117 days is the State maximum. In contrast, Humboldt County, which has the most agricultural land in the tsunami inundation zone, is a distant second for building and content losses $(\$ 31,000$ [16 percent] and \$180,000 [17 percent], respectively), while requiring an estimated maximum of 107 days to complete building repairs. San Mateo County has truck-transported crops in the scenario 
inundation zone and agricultural building and content damages comparable to Humboldt County. A complete list of building damages by county is presented in table 33. Overall, crop income losses likely dominate agricultural building and content losses. Furthermore, if field remediation costs for a flood event (Porter and others, 2010) are an indication of tsunami inundation field remediation costs, these could be on a par with the crop income losses. 
Table 33. Selected agricultural (HAZUS-MH AGR1) building loss statistics in the SAFRR tsunami inundation zone by county.

$\left[\mathrm{ft}^{2}\right.$, square feet; \$, 2010 U.S. dollars]

\begin{tabular}{|c|c|c|c|c|c|}
\hline County Name & $\begin{array}{l}\text { Building } \\
\text { Area }\left(\mathrm{ft}^{2}\right)\end{array}$ & $\begin{array}{l}\text { Building } \\
\text { Value (\$) }\end{array}$ & $\begin{array}{l}\text { Building } \\
\text { Loss (\$) }\end{array}$ & $\begin{array}{l}\text { Content } \\
\text { Loss (\$) }\end{array}$ & $\begin{array}{l}\text { Maximum } \\
\text { Repair Time } \\
\text { (Days) }\end{array}$ \\
\hline Del Norte County & 591 & 46,728 & 260 & 3,110 & 0 \\
\hline Humboldt County & 38,918 & $3,121,972$ & 31,659 & 181,452 & 104 \\
\hline Mendocino County & 8,715 & 714,759 & 3,796 & 43,850 & 0 \\
\hline Sonoma County & 0 & 0 & 0 & 0 & 0 \\
\hline Marin County & 22,342 & $1,969,329$ & 13,525 & 135,200 & 11 \\
\hline Contra Costa County & 277 & 23,733 & 132 & 1,580 & 0 \\
\hline Alameda County & 27,881 & $2,408,096$ & 9,982 & 129,177 & 5 \\
\hline San Francisco County & 1,318 & 122,373 & 681 & 8,145 & 0 \\
\hline San Mateo County & 20,213 & $1,816,089$ & 41,028 & 157,314 & 26 \\
\hline Santa Cruz County & 5,635 & 503,887 & 3,525 & 34,532 & 0 \\
\hline Monterey County & 944 & 77,568 & 567 & 6,071 & 0 \\
\hline $\begin{array}{l}\text { San Luis Obispo } \\
\text { County }\end{array}$ & 20,499 & $1,655,665$ & 7,333 & 88,021 & 5 \\
\hline Santa Barbara County & 0 & 0 & 0 & 0 & 0 \\
\hline Ventura County & 4,208 & 338,718 & 1,539 & 19,581 & 0 \\
\hline Los Angeles County & 2,574 & 205,313 & 1,784 & 16,895 & 0 \\
\hline Orange County & 2,790 & 221,864 & 1,234 & 14,766 & 0 \\
\hline San Diego County & 39,213 & $3,101,084$ & 75,877 & 209,591 & 117 \\
\hline Study Area Total & 196,119 & $16,327,178$ & 192,923 & $1,049,284$ & 117 \\
\hline
\end{tabular}

Note: Values are based on percentages of building stocks by census block identified as inundated by the tsunami scenario. Only areas where inundation was modeled were considered for the analysis, and only census blocks in the inundation zone meeting the criteria specified in Building Damage section of this chapter were used.

\section{Data and Research Needs}

Although this preliminary analysis covers the entire California coast, it is reliant on data that are processed remotely and only field-verified in some locations. The CDL data are intended to provide detailed information about cropland in the United States, but the data are less accurate than survey data like the DWR data. When classification or validation processes change for remotely-sensed data like CDL, the results can vary significantly from one year to the next: for example, the total cropland acreage in the inundation zone in 2010 is approximately 2,600 acres whereas around 4,100 acres are identified from the 2012 data. This may be a result of variations in training data for data classification because the major land cover class that changed between the two years according to the analysis was grassland. USGS National Land Cover Dataset (NLCD) land cover data are used to classify anything not identified as agricultural, so one possibility is that portions of grass-based classes in 2010 were reclassified as NLCD grassland in 2012. Classifying cropland and pasture is extremely difficult because it tends to get confused with grassland when using automated classification methods (for an example, showing how grassland was the most inconsistently classified class between NLCD and the USGS Gap Analysis Program land-cover dataset, please refer to Wardlow and Egbert, 2003). The training data used from agricultural surveys and ground-truthing changed in 2011, which would have also 
had an impact on how data were classified and might partially explain the difference in cropland between 2010 and 2012 CDL data (NASS, 2013). The DWR data, on the surface, seem like a better data source because those data were extensively verified in the field, but the lack of complete coverage and the number of years spent to complete such surveys make the available DWR data less reliable.

The available data for analyzing livestock impacts in the inundation zone was very limited. The resolution of agricultural census data is too coarse for strips of land along the coast. The CDL data only provides one class that is livestock-related and that is pasture grasses which neglects to identify herd sizes and feedlots. We were able to identify two dairies in the inundation zone using multiple sources from CDFA, DWR, and satellite imagery. Spatial livestock data is needed to better assess potential livestock exposure in the SAFRR tsunami scenario.

Finally, although research has been conducted on economic losses in agriculture due to flooding (for example, Porter and others, 2010) this particular analysis did not have the requisite information to establish field rehabilitation costs and times (and related crop income losses) for tsunami inundated agricultural land. Costs for leaching salt out of soil, cleaning up debris, and reestablishing damaged crops after a tsunami are largely unavailable. Some additional proxy data for calculating tsunamigenic agricultural losses could be obtainable from rising climate change research concerned with salinity management on agricultural lands. Although it might be possible to coarsely approximate losses based on observations of the 2011 Tohoku, Japan, earthquake, uncertainty about the type and extent of damage to agriculture in each county remains a barrier.

\section{Opportunities for Agricultural Resilience}

This analysis summarizes the types of agricultural damages possible in California from the SAFRR tsunami scenario. The 9,600 acres of inundated agricultural land may make up a very small portion of the approximately 25 million acres of agricultural land in the State. Consequently, the estimated crop, livestock, and building/content losses are not factored into the analysis of economic impacts in California. However, locally those acres support the livelihood of a number of farmers and employees. Salinization, debris deposition, soil scour, and contamination all present long-term issues that would need to be carefully and quickly dealt with in order to minimize productivity losses for affected farms. Given that most of these exposed agricultural acres are found in the poorer northern counties (California Department of Finance, 2009) the distribution of agricultural damages raises concern about financing the recovery of the affected enterprises. Impediments to recovery may further impact farmers in these counties.

The analysis assumes farmers do not mitigate any losses; warning of a far-field tsunami allows time for evacuation or protection of equipment, and livestock. Information specifically geared to dealing with livestock (for example, transportation and shelter) in California is posted (Division of Agriculture and Natural Resources, 1999). Although tsunami preparedness information directed specifically at farmers does not appear to be available, flood preparedness information can provide some basic guidelines. Taking precautions such as having disaster kits with food, water, and medical supplies readily available and tagging and recording livestock information will reduce losses. Web sites like http://www.prep4agthreats.org and http://awic.nal.usda.gov provide farmers with information regarding various aspects of disaster preparedness. However, less can be done to prevent field damages, putting the onus back on recovery to prevent further losses. 


\title{
Fire Following Tsunami
}

\author{
By Charles Scawthorn
}

This section assesses the potential for fires following the scenario tsunami. We begin with a brief review of fires following historic tsunamis and the related literature to gain insight into ignition and fire spread mechanisms under post-tsunami conditions. The review reveals that tsunamigenic fires are typically fueled by spreading waterborne liquid fuels released from petrochemical facilities damaged by the tsunami. On the basis of this finding, we then examine the scenario affected area for petrochemical facilities, identifying 47 major tank farms and other facilities that might be impacted by the tsunami. This examination reveals two areas, the port of Richmond (in San Francisco Bay) and the port complex of Los Angeles/Long Beach, that contain petrochemical facilities that may be impacted by the tsunami, leading to spreading oil fires borne on the tsunami waters. Given the concentration of oil tank farms in the Ports of Richmond, and especially in the Port of Los Angeles/Port of Long Beach (POLA/POLB) complex, we feel it is possible but not very likely that a spreading fire will result from tsunami damage in at least one of these facilities. If such a fire were to occur, in the context of a tsunami and its attendant other damage, it is likely it would spread over water to other facilities, resulting in a common cause fire and possibly destruction of several of these facilities. Lastly, there are typically several tankers at berths in POLA/POLB — given the perhaps two to four hour warning for the scenario tsunami, it is quite possible that one or more oil tankers may be caught in the harbor and contribute to the size and severity of any spreading fire.

\section{Review of Fires Following Historic Tsunamis and the Related Literature}

Tsunamis are sometimes followed by fires. The literature on tsunamigenic fires is sparse- Shuto (1987) was perhaps the first to systematically examine the phenomenon, concluding after a review of historical events and an examination of the physics of oil spread on water that the final burned area due to spreading oil on water correlates with the boundary between the gravity-viscous and surface tension-viscous regimes of empirical formulas. Shuto compares numerical methods such as Goto (1985), which include the effects of inertia, gravity and viscosity empirical formulas that only give the size of the spread of oil, finding the former more informative. Subsequently, (Shuto, 2006) provides an equation for estimation of the final size of a burning oil spill on water:

$$
A_{B}=324 \cdot V
$$

where $A_{B}=$ Area burnt (square meters, $\mathrm{m}^{2}$ ) and $V=$ volume of spilled oil (kiloliters, $\mathrm{kL}$ ). Shuto's equation is tabulated in table 34 for sizes of typical petroleum product tank sizes (small to very large) - for example, if the contents of a filled very large $(50,000 \mathrm{~kL})$ tank are completely released, the burn area is about 16 square kilometers $\left(\mathrm{km}^{2}\right)$, or equivalent a square about $4 \mathrm{~km}$ on a side. 
Table 34. Burnt area given various size tanks, calculated using equation 25.

\begin{tabular}{lllrl}
\multicolumn{6}{l}{$\left[\mathrm{H} / \mathrm{D}\right.$, height divided by diameter; $\mathrm{m}$, meters; $A_{B}$, area burnt; $\mathrm{m}^{2}$, square meters $]$} \\
$\begin{array}{l}\text { Volume (kilo } \\
\text { liters) }\end{array}$ & $\begin{array}{c}\text { Equivalent tank } \\
\text { diameter }(\mathrm{m}) \\
{[\mathrm{H} / \mathrm{D}=0.5]}\end{array}$ & $\begin{array}{c}\text { Typical tank } \\
\text { size }\end{array}$ & $A_{B}\left(\mathrm{~m}^{2}\right)$ & $\begin{array}{c}\text { Dimension of equivalent } \\
\text { square }(\mathrm{m})\end{array}$ \\
\hline $\mathbf{1 , 0 0 0}$ & 14 & small & 320,000 & 566 \\
$\mathbf{3 , 0 0 0}$ & 20 & medium & 960,000 & 980 \\
$\mathbf{1 0 , 0 0 0}$ & 29 & large & $3,200,000$ & 1,789 \\
$\mathbf{5 0 , 0 0 0}$ & 50 & very large & $16,000,000$ & 4,000 \\
\hline
\end{tabular}

To gain insight into ignition and fire spread mechanisms under post-tsunami conditions, we next review selected tsunamis, and the fires they caused.

\section{Lisbon Earthquake and Tsunami}

The earthquake occurred on November 1, 1755, and was centered in the Atlantic Ocean, about $200 \mathrm{~km}$ west-southwest of Cape St. Vincent. Lisbon was heavily damaged. A very strong tsunami caused heavy destruction along the coasts of Portugal, southwestern Spain, and western Morocco. About 30 min after the quake, a large wave swamped the area near Bugie Tower on the mouth of the Tagus. The area between Junqueria and Alcantara in the western part of the city was the most heavily damaged by a total of three waves with maximum height estimated at $6 \mathrm{~m}$, each dragging people and debris out to sea and leaving exposed large stretches of the river bottom. A devastating fire following the earthquake raged for five days and destroyed a large part of Lisbon. No information is available on the causes of the fires, but in central Lisbon they destroyed areas that had been damaged by the tsunami, so that some of the fires were likely caused by the tsunami.

\section{Alaska Earthquake and Tsunami}

The most complete treatment of fires associated with the March 27, 1964, magnitude 9.2 Alaska earthquake and tsunami is the report by the National Board of Fire Underwriters (National Board of Fire Underwriters and Pacific Fire Rating Bureau, 1964). A number of communities were affected, in which almost all fires occurred in the waterfront areas and were associated with tsunami inundation. Specifically:

- Anchorage was by far the largest affected community but was not affected by tsunami, and "fires were few and of a minor nature."

- $\quad$ Seward: tsunami waves "swept up into the town for a distance of 1 to 2 blocks in most areas and as far as 5 blocks in an area of small homes and trailer courts...An oil tanker had been loading gasoline and was in the process of loading diesel oil when the earthquake struck. Hose connections broke, oil and some residual gasoline from hose and pipe lines ignited, possibly from electrical sources or by friction, and a sea wave which quickly followed swept burning liquids along the waterfront and inland for several hundred feet. The fire involved 2 flammable liquid bulk plants and warehouses some 8 blocks apart, 2 dwellings, and the city's standby electric power plant."

- Valdez: "Fires erupted at 2 waterfront tank farms from gasoline and oil leaking from tanks damaged by the earthquake and waves. The source of ignition at one plant was apparently power wires that dropped on a metal pump house roof. Burning liquids were carried along the waterfront, and the resulting fires involved parts of the 2 tank farms and 
destroyed 4 business buildings. Fires were left to burn themselves out as fire-fighters either could not reach the fires due to high water and debris or, when flooding subsided, could get no water from fire hydrants. Fortunately there was no strong wind to spread fires further."

- Whittier: "The earthquake, followed by seismic sea waves, destroyed pier facilities and an oil tank, spread flammable liquids along the waterfront, and a fire that followed destroyed several tanks and waterfront structures in 2 different locations."

- Crescent City, California: "There were 2 fires, both in areas outside the city, during the emergency. One, believed to have occurred when a tank truck was thrown by a wave into an automobile sales and service garage, was in an area without mains or hydrants .... The second fire was about 300 feet away in a bulk oil plant. It reportedly occurred by arcing from fallen electrical wires igniting leaking gasoline and oil after undiked tanks were knocked over by a large stump or log. Fifty-five-gallon drums stored nearby exploded and burned, contributing to the spread of the fire. Fire-fighters and apparatus were described as being virtually surrounded by burning liquids floating on the water and these factors together with another threatened sea wave, made fire-fighting extremely difficult. Although this plant was destroyed, a seriously exposed bulk oil plant nearby was saved with only slight damage, water being obtained from a hydrant nearby." In summary, significant fires only occurred in tsunami inundated areas, even at great distance in Crescent City, and were generally associated with liquid fuel facilities which, once ruptured, resulted in spreading fires on water that caused sympathetic fires at other liquid fuel facilities. Of particular interest is the oil tanker-related fire at Seward, which might have been mitigated with some warning.

\section{Niigata Earthquake and Tsunami}

The June 16, 1964, magnitude 7.5 Niigata (Japan) earthquake is well known for two effects - the widespread occurrence of liquefaction and a large fire at the Showa oil refinery that burned for several days. As summarized by a recent report (Cruz and others, 2009):

"The oil refinery fires triggered by the 1964 Niigata earthquake and tsunami in Japan serve as an example of the potentially catastrophic effects of a tsunami when it affects a highly industrialized and urbanized area. During this event, a $4 \mathrm{~m}$ tsunami was triggered by the 7.5 magnitude earthquake which initially caused fires in five storage tanks and oil spills in hundreds more at two oil refineries in Niigata (Iwabuchi et al., 2006). The tsunami hit the already earthquake stricken facility resulting in:

- Additional damage to storage tanks and plant processing equipment by collision with tsunami-driven objects and by the hydrodynamic forces of the tsunami (Iwabuchi and others, 2006).

- The spread of leaked oil by the tsunami current into the harbor and on inundated land (Iwabuchi and others, 2006).

- The spread of burning crude oil carried by the flood waters causing the fires to extend to other parts of the plant including the heating furnace, the heat recovery boiler, the reactor of the catalytic conversion process, the hydrolysis treatment equipment, and the bottom of the hydrolysis reactor for the desulphurization process (Akatsuka and Kobayashi, 2008) 
- The spread of ignited crude oil carried by the flood waters into residential areas and the destruction of 286 houses by the fire, 2006)."

\section{Hokkaido Nansei-oki Earthquake and Tsunami}

The July 12, 1993, Hokkaido Nansei-oki, Japan, magnitude 7.7 earthquake and tsunami caused major damage on Okushiri Island, to the west of Hokkaido (figures 80, 81). As summarized in (Yanev and others, 1993):

"The only known fire ignitions during the earthquake occurred in Aonae on the southern tip of Okushiri Island. Most of the town is oriented north-south and sited on or almost on the beach, only a few meters above sea level. The rest of the town is located on a central bluff about $20 \mathrm{~m}$ high where a lighthouse, the town offices, and the fire station are sited, as shown in (figure 80). The lower part of Aonae is densely built-up with narrow streets and typical building spacing of about $3 \mathrm{~m}$. The buildings are generally one and two story, typically with Japanese wood post and beam construction, although some steel and concrete structures were also present. Exterior coverings are often noncombustible stucco or cement board over wood, with corrugated metal roofing. Large amounts of exposed wood trim, however, compromise the fire protection. Occupancies are generally commercial closer to the wharf area and residential behind (at the base of the bluff), although many buildings are mixed occupancies.

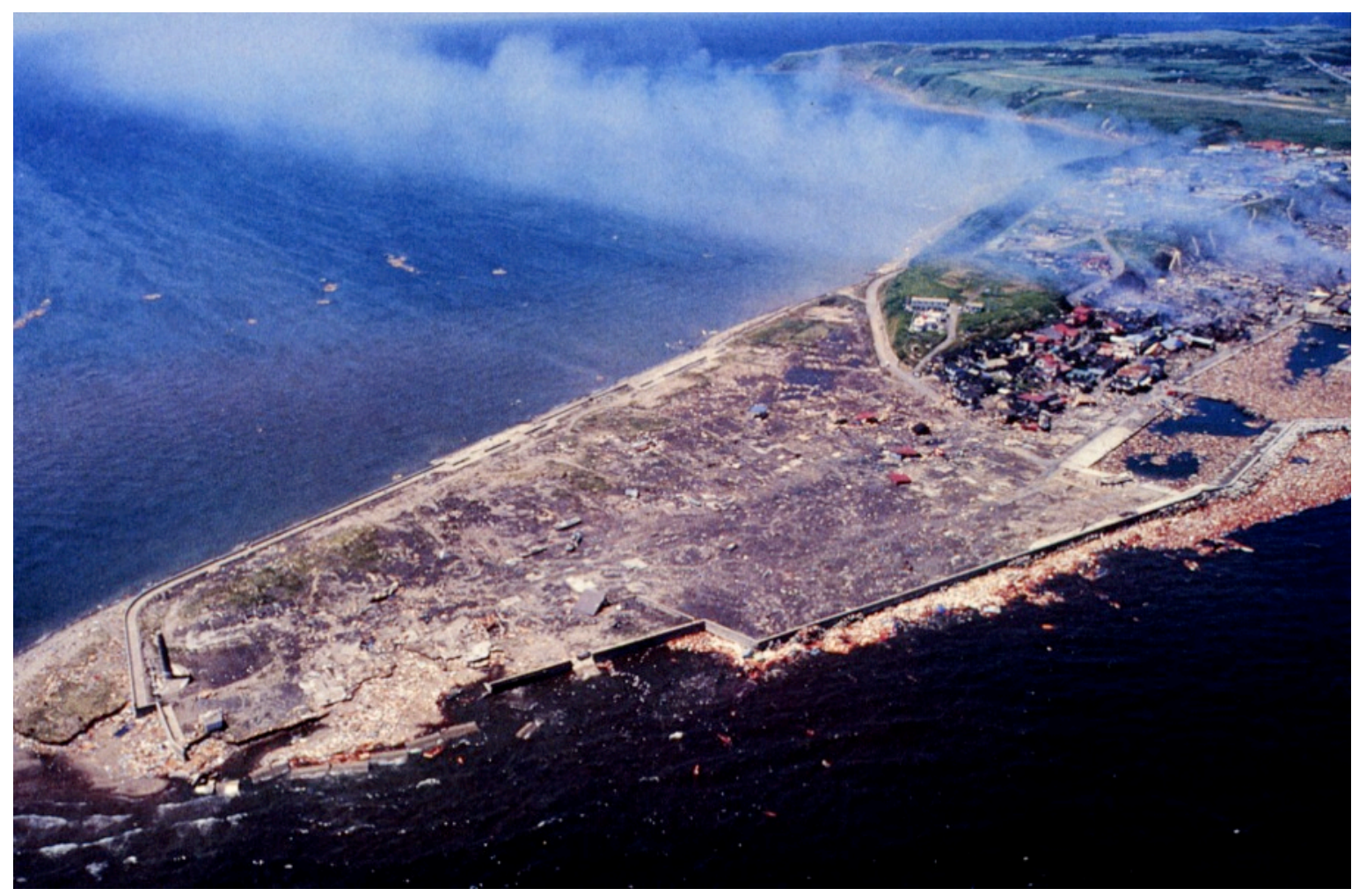

Figure 80. Photograph of fire ignitions in the town of Aonae on the southern tip of Okushiri Island, Japan, following the 1993 Hokkaido Nansei-oki earthquake and tsunami (photograph from Yanev and others, 1993). 
The town is protected against fire by a 38-member trained volunteer fire department headed by a full-time professional. The apparatus consists of two engines of typical Japanese size and configuration-each pumper has a 2,000-liter booster tank and carries 10 lengths of 20-mlong 65 -mm-diameter hose. The capacity of the pumps is approximately 2,600 liters per minute. Each engine also carries two 4-m lengths of hard suction hose equipped with bamboo strainer baskets. Relative to U.S. equipment, these fire engines are smaller in dimensions and capacity. This smaller size expedites passage through narrower Japanese streets, such as those in Aonae. A third fire engine was present in Aonae at the time of the earthquake; this engine was in poor condition, however, and was parked at the south end of town where it was destroyed by the tsunami.

Fire hydrants are located around the town but are not used because the water mains are insufficiently sized and pressured to provide adequate water for fire control. Small fires are fought from engine booster tanks, while the main fire emergency water is stored in underground cisterns sited throughout the town. Individual cistern capacity is 40,000 liters, which is accessed through a concrete manhole cover. Shortly after the earthquake, the fire department made a circuit of the town looking for fires. Seeing none and concerned about a possible tsunami, they returned to the fire station. Within a few minutes following the earthquake, the tsunami swept through the lower area wrecking many buildings and scattering debris over a wide area. The tsunami also destroyed the main water line at its attachment point near a bridge. At approximately 10:40 P.M. the fire department received a citizen alarm of a fire in the lower area. A brigade of 10 men immediately responded and attempted to reach the fire by driving down the main street but found the street blocked by debris. They then returned to the top of the bluff and took a second route down the southern part of the bluff. 


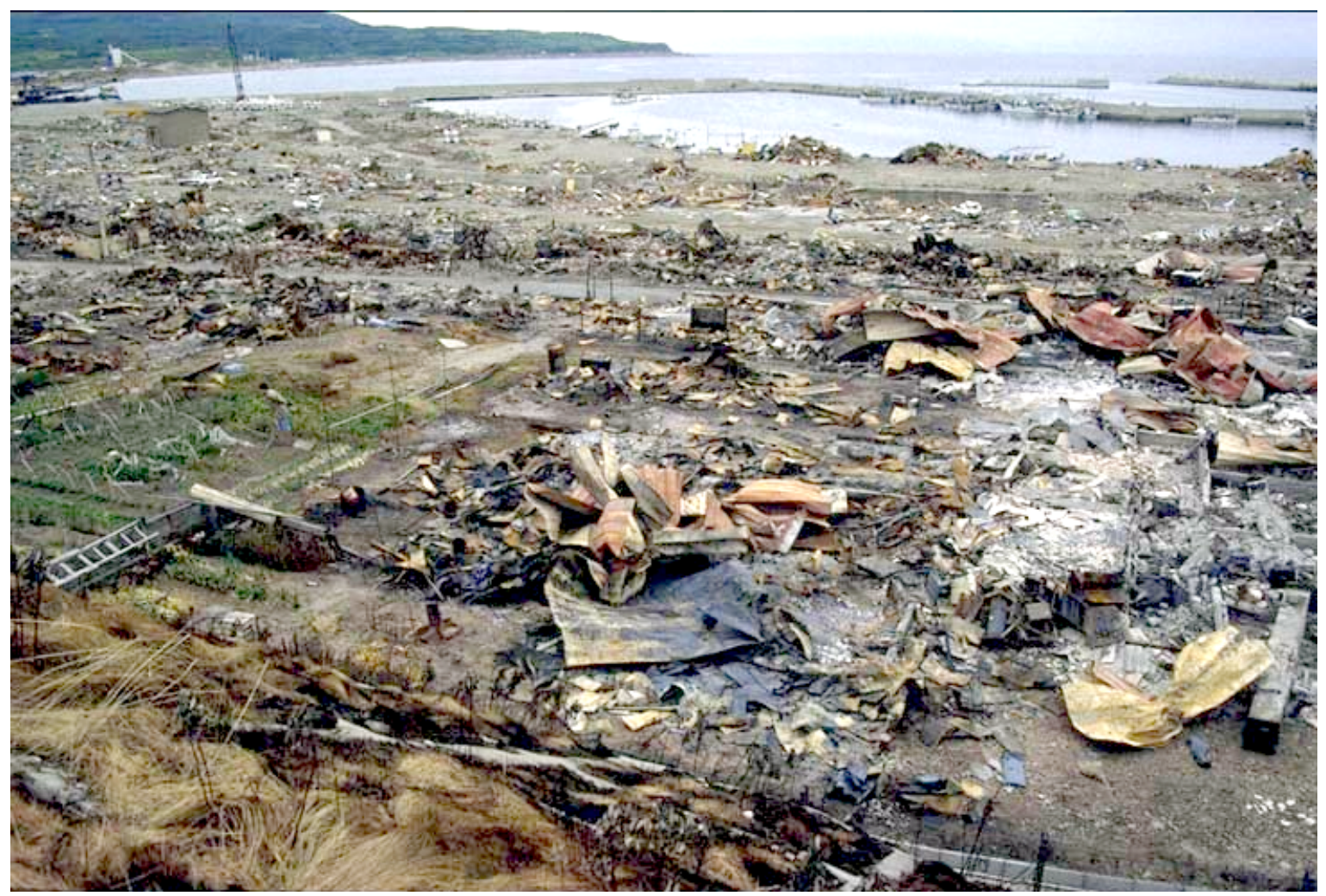

Figure 81. Photograph of tsunami and fire damage on southeast Okushiri Island in the community of Aonae, Japan, following the 1993 Hokkaido Nansei-oki earthquake and tsunami. Orientation is looking northeast. Numerous fires broke out following the tsunami, adding to the property loss and misery. More than 120 people were killed in Japan (Okushiri and Hokkaido Islands) by the tsunami. (Photograph by Dennis Sigrist.)

The probable causes and the effects of the fire are illustrated in (figure 82). The fire began in a structure above the area directly affected by the tsunami, so it likely began as a result of the earthquake. The precise site of initial ignition is unknown, although the approximate location is shown in (figure 82). The initial source of the ignition is also unknown (at this time); however, villagers told of earthquake shaking turning over all of their furniture, so numerous ignition sources were available (e.g., cooking and heating appliances, and fuel storage tanks). At the time of ignition, wind was from the east at about 1.5 meters per second with gusts up to about 5 meters per second. 


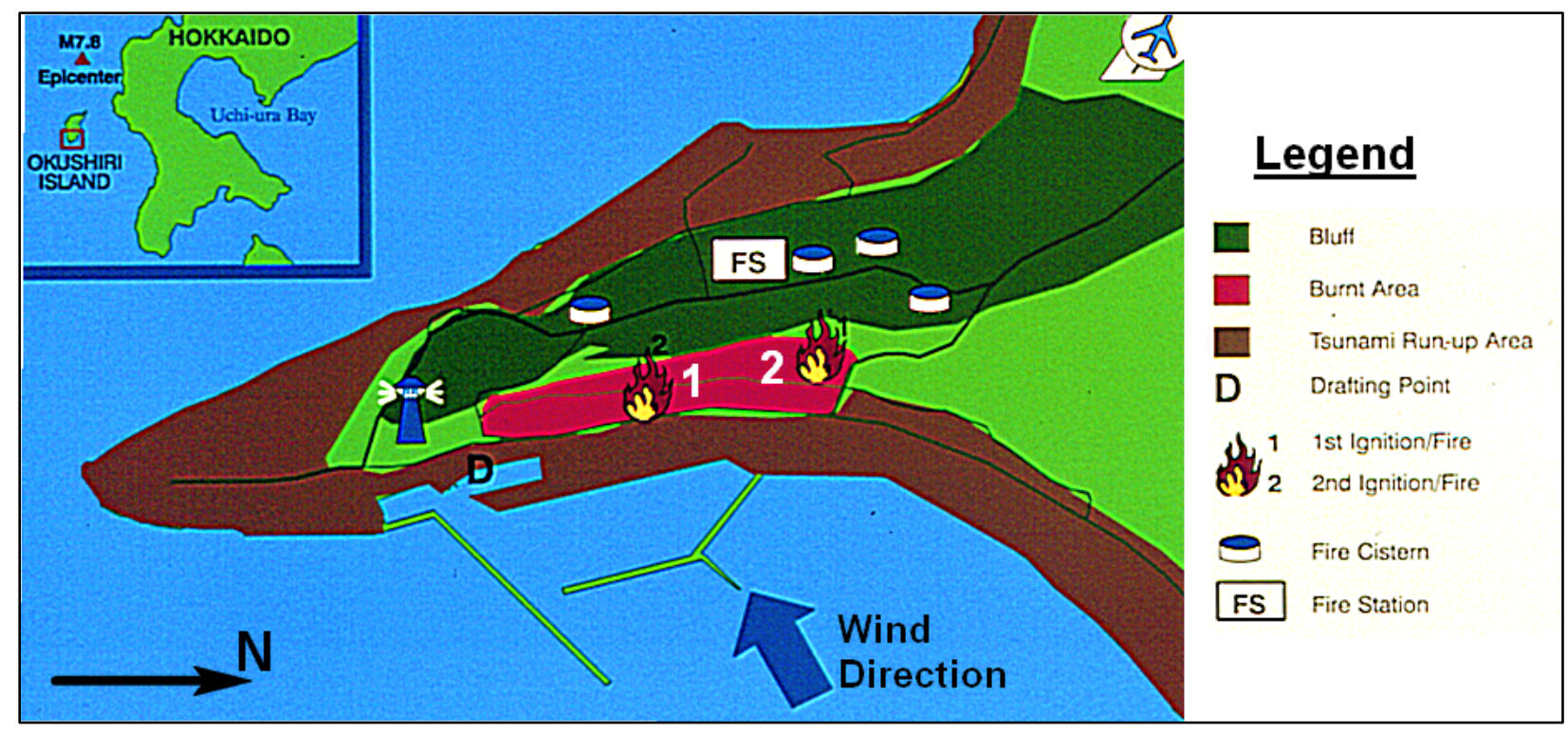

Figure 82. Diagram of tsunami effects in the town of Aonae on the southern tip of Okushiri Island, Japan, following the 1993 Hokkaido Nansei-oki earthquake and tsunami (from Yanev and others, 1993).

Firefighting was from hand lines supplied from the pumpers on top of the bluff, drafting from the cisterns. Fire progress was southward (cross-wind) and relatively slow; suppression efforts significantly impeded fire progress, but the firefighters were unable to stop the fire. Fire progress was aided by flammables normally stored in each home, as well as the fact that almost all houses had outdoor 490-liter elevated kerosene tanks for heating [e.g., propane tanks $(20 \mathrm{~kg})$ for cooking]. The kerosene tanks were quite likely a principal factor in the fire spread. All such tanks were found empty after the fire, most having vented safely through the top vent pipe. The venting was most likely caused by radiant heat causing the kerosene to boil. Eight exploded propane tanks and two ruptured kerosene tanks were documented. Reportedly, every time the fire department seemed to be gaining headway, the fire would flare up again, probably due to successive involvement of these tanks. Additional materials fueling the spread of the fire were considerable scrap wood in and among the buildings, and numerous vehicles, which added gasoline, tires, and flammable interiors to the conflagration.

Fire spread was southward at about 35 meters per hour, with firefighting on the downwind edge. Two hours into the fire, a second fire ignited behind the fire line. At about 4 A.M. (6 hours after the earthquake), available water from the cisterns was exhausted. Citizen volunteers assisted in moving the hose over debris from the bluff top to the port, where the two pumpers drafted from the harbor. At this point, the advancing fire front was about $90 \mathrm{~m}$ wide. The fire department used equipment to move debris and two buildings, creating a firebreak. Leading four hand lines from the drafting pumpers, the fire was successfully stopped at about 9 A.M., saving several dozen houses that were in the path of the advancing fire."

\section{Indian Ocean Earthquake and Tsunami}

The December 26, 2004, Indian Ocean magnitude 9.1 earthquake and tsunami caused major damage and loss of life in Sumatra, Indonesia and in Thailand, Sri Lanka and India. Only 
one minor fire is known to have been caused by the earthquake and tsunami (Scawthorn and others, 2006). Of more interest is the damage to the deep-water port at Kreung Raya, Aceh, Indonesia, (oil and dry cargo), which was inundated by the tsunami and lost half its piping and 3 of 9 oil tanks (fig. 83). A ship was offloading at the port at the time of the earthquake - it immediately slipped its moorings, headed out to sea, and was undamaged by the tsunami. No fire was reported at the oil terminal.

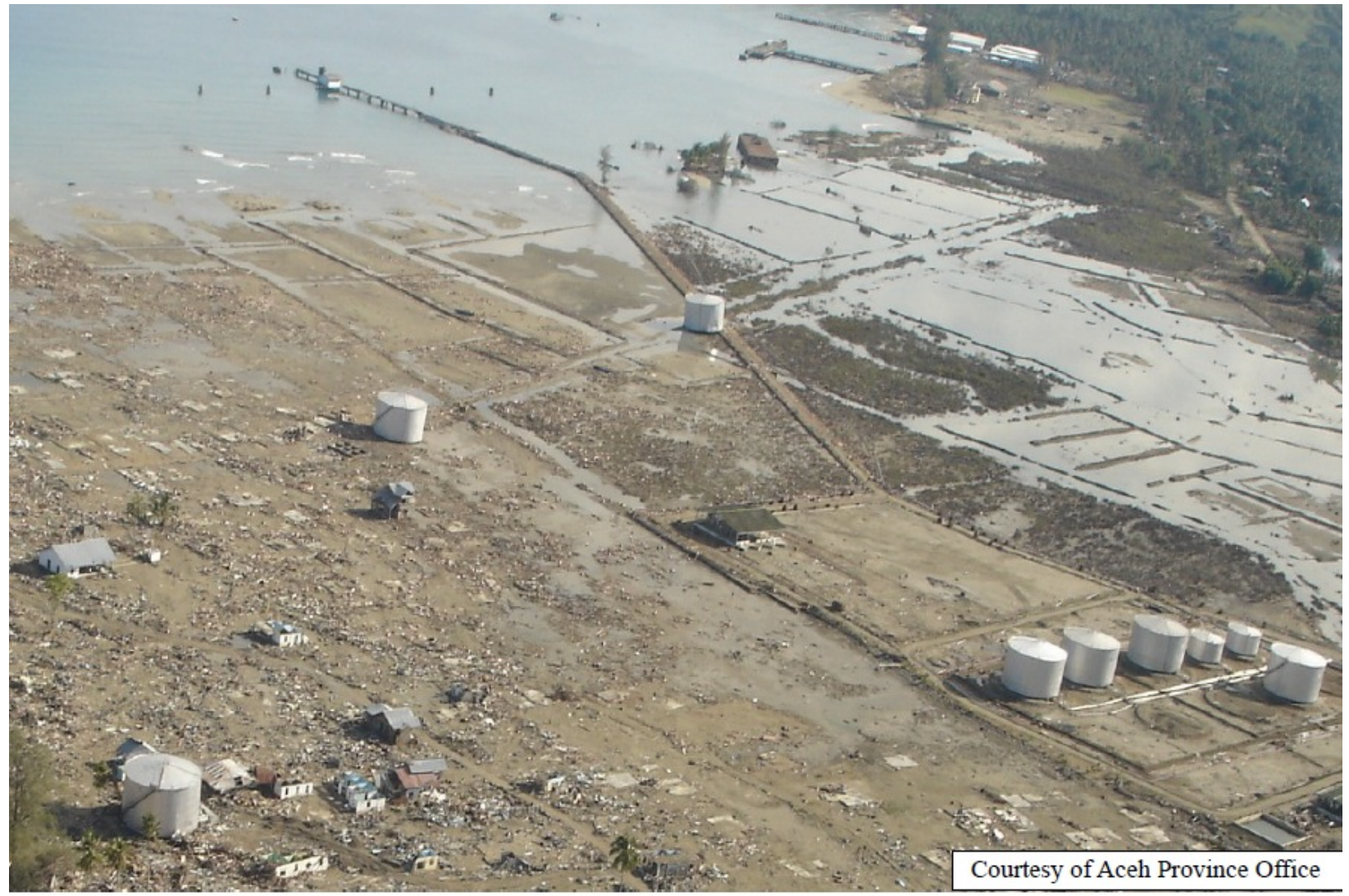

Figure 83. Photograph of Krueng Raya, Aceh, Indonesia, deep water port after the 2004 Indian Ocean tsunami. Three tanks (reported to have been empty or near empty) of nine tanks floated about 500 meters. (Photograph from Aceh Province Office.)

\section{Tohoku Earthquake and Tsunami}

The March 11, 2011, magnitude 9.0 Tohoku, Japan, earthquake and tsunami caused extensive loss of life and damage in eastern Japan, and spawned 284 fires (Japan Fire and Disaster Management Agency, 2012) including two at major oil refineries. The tsunami was higher than expected and, despite warnings, was responsible for most of the life loss and damage, and about half of all the fires in the event. Analysis of all the significant tsunami-related fires is still underway and a full review is beyond the scope of this report so that only summary findings are provided:

"Nearly half of the ... fires that occurred ... resulted from the tsunami. Typical fires that occurred in the Sanriku coastal region arose from a lot of combustible materials, such as houses and vehicles, which were destroyed and swept away by the tsunami waves toward a 
mountain, caught fire from a source of fire (domestic and other various fuels) drifted there, and spread into town areas and forests. On the other hand, in plain areas where the population and industries were concentrated, a small number of fuels, such as household gas cylinders and vehicles scattered about the town, joined together into a mass of combustible materials, which are estimated to have made a great contribution to potential outbreak or spread of fires. In any region, it is estimated that tsunami fires were caused by a combination of various potential factors such as an electric leakage, a short circuit, and sparks from a crash, but most of them are accidental factors and it would remain difficult to investigate the true causes . . . Finally, one of the similar characteristics in the regions where tsunami fires expanded is that the fires expanded as the local fire-fighting force was severely diminished due to the tsunami. The fires were left uncontrolled for about two days until emergency fire response teams arrived at the sites and started fire extinguishing activities . . .." (Yamada and others, 2012)

Regarding causes of tsunamigenic fires, (Sekizawa and Sasaki, 2012) concluded:

1. Spillage, ignition, and flow of oil or LPG from upturned or collapsed storage tanks in industrial areas, and subsequent ignition of urban areas and buildings.

2. Spillage from upturned kerosene tanks and LPG cylinders in residential buildings, or spillage from broken distribution pipes.

3. Ignition of buildings by burning buildings or debris carried by the tsunami.

4. Ignition of buildings by burning ships or cars carried by the tsunami.

5. Acceleration of the oxidation of iron by salt contained in seawater, resulting in spontaneous ignition from heat trapped in mounds of debris containing iron.

Two basic mechanisms for tsunamigenic fire spread were identified based on this eventin the first phase, the fires are typically burning liquid fuels borne on the water surface, until the tsunami reaches its maximum runup. At that location, large amounts of building and other flammable debris are deposited by the tsunami, are ignited by the water borne fires, and burn for extended periods (Hokugo and others, 2012).

Another aspect of note is the damage in this event to ocean-going vessels. The tsunami did not arrive until 20 to 30 minutes following the shaking, so that vessels in port had some warning and might have been expected to leave shallow waters and ride out the tsunami. However, a number of large vessels totaling about 500,000 dead-weight ton (DWT) were damage in ports, such as the 91,000 DWT MV Shiramizu, which was grounded in the port of Shinchi (fig. 84). 


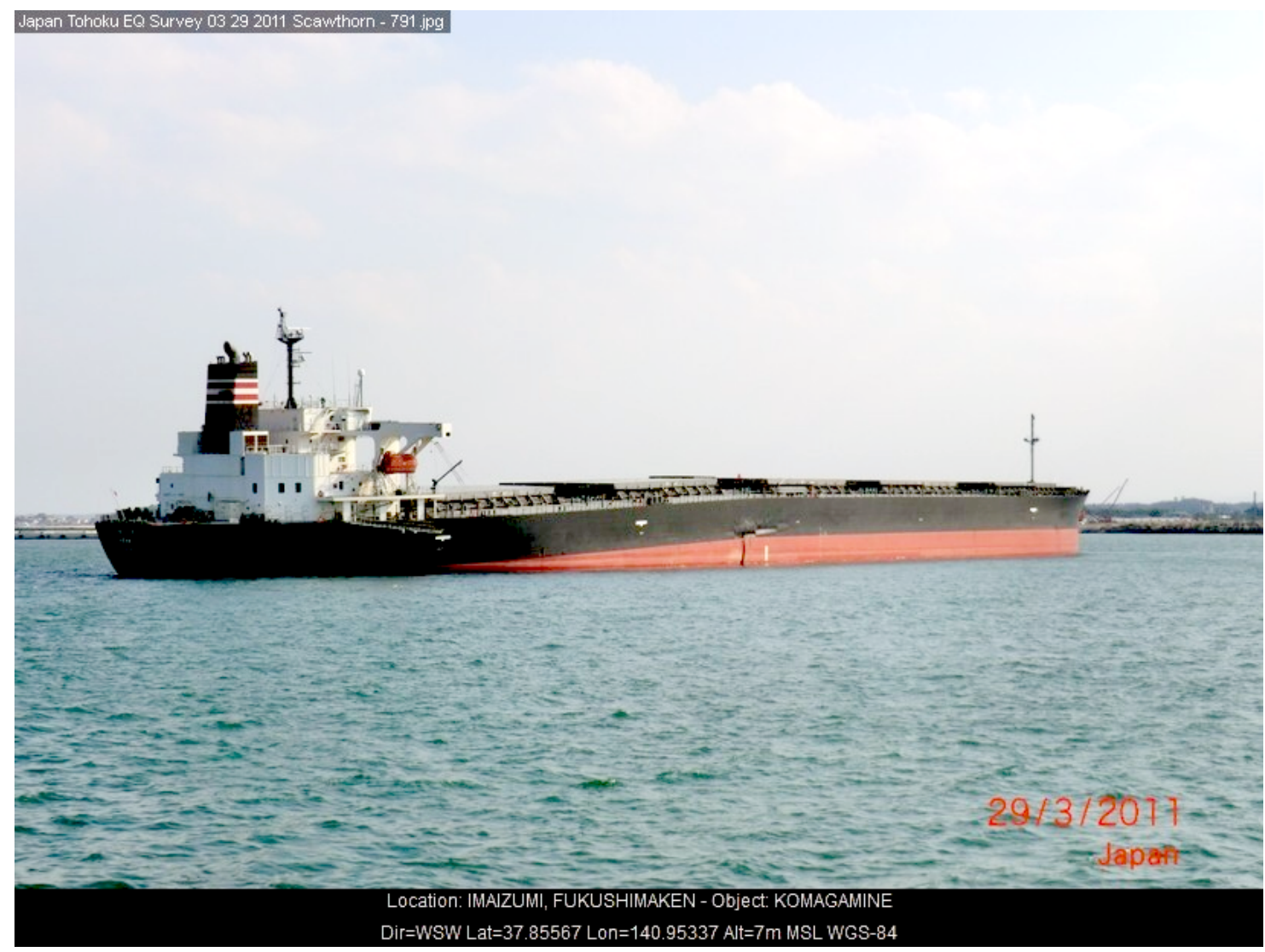

Figure 84. Photograph of MV Shiramizu aground in Shinchi following the 2011 Tohoku, Japan, earthquake and tsunami (photograph by Charles Scawthorn).

\section{Summary}

On the basis of the foregoing, it may be observed:

1. Fires often, but not always, occur within the inundation zone of a tsunami. Notable tsunamis that are not recorded as causing numerous or large fires include the 1960 and 2010 Chilean events. As a rule of thumb, it is conservative to assume that tsunamis will cause fires.

2. Tsunamigenic fires are typically fueled by spreading water borne liquid fuels released from port or petrochemical facility piping or tanks damaged or floated by the tsunami. Sources of ignition are numerous and varied-investigating them in detail is probably less fruitful than conceding that, in the presence of such water borne fuels, that ignitions are very likely given the large extent of liquid fuels mingling with debris jostling and likely to generate sparks.

3. Large ships such as oil tankers, even with tsunami warning, may not be able to evacuate a port. Strong currents and congestion of vessels all attempting to evacuate simultaneously are challenges that should be investigated. 


\section{Fire in the SAFRR Tsunami Scenario}

This section assesses the study area based on the findings from the previous section, focusing on coastal petrochemical facilities storing significant amounts of flammable product.

\section{Method}

To identify these facilities, an Environmental Protection Agency (EPA) database (ftp://ftp.epa.gov/EmisInventory/emiss_shp2003/us/, accessed March 1,2013) was employed that identified 111 such facilities in California (fig. 85). The database dates from 2003 and therefore may be expected to have some errors. Facilities significantly inland were eliminated from this initial list, resulting in 46 facilities requiring review (fig. 86 and table 35). Each of these facilities, almost all of which are tank farms, are reviewed next.

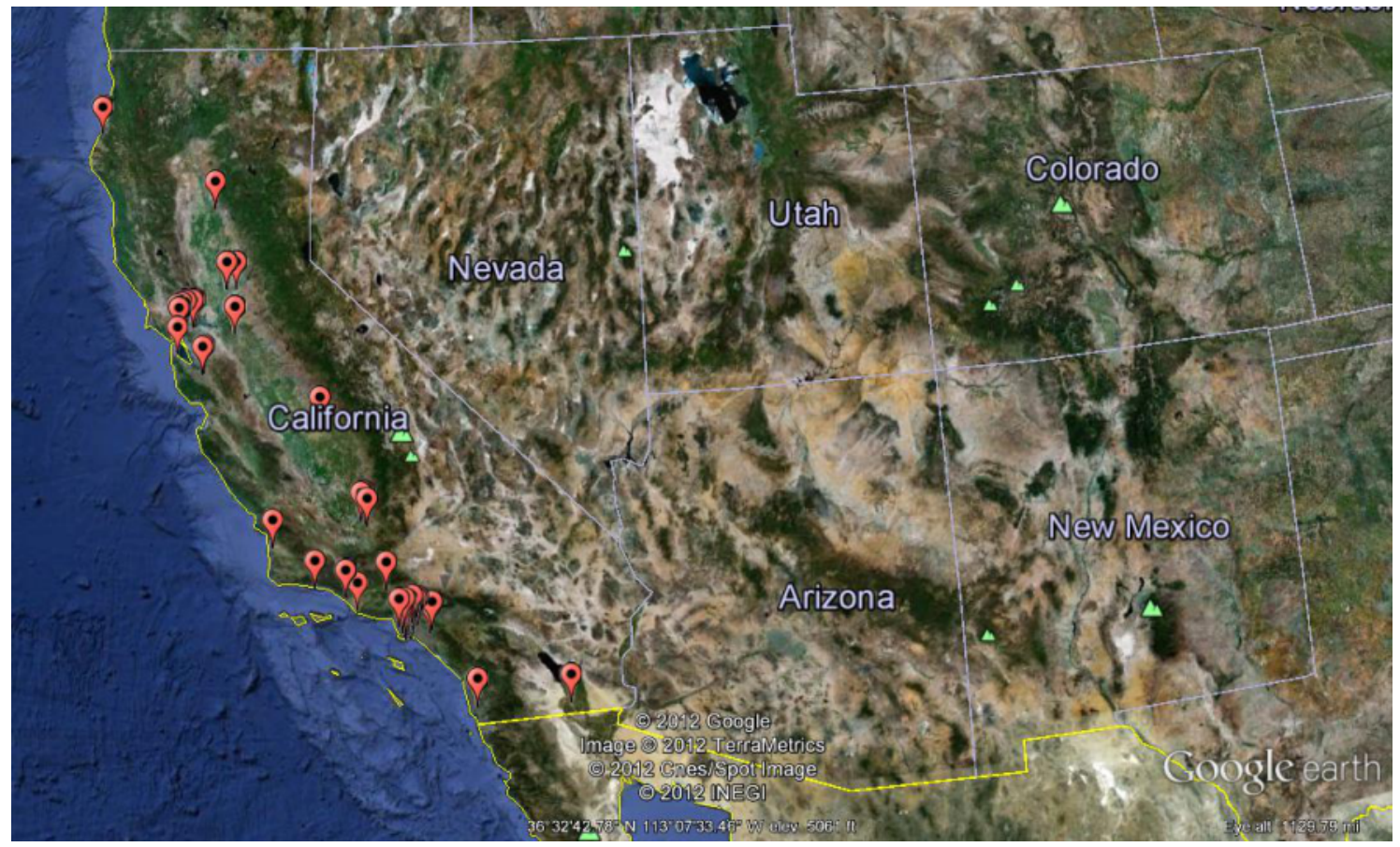

Figure 85. Map showing 111 California coastal petroleum facilities (data from Environmental Protection Agency database: ftp://ftp.epa.gov/Emis/nventory/emiss_shp2003/us/accessed March 1, 2013) (base image from Google Earth). 


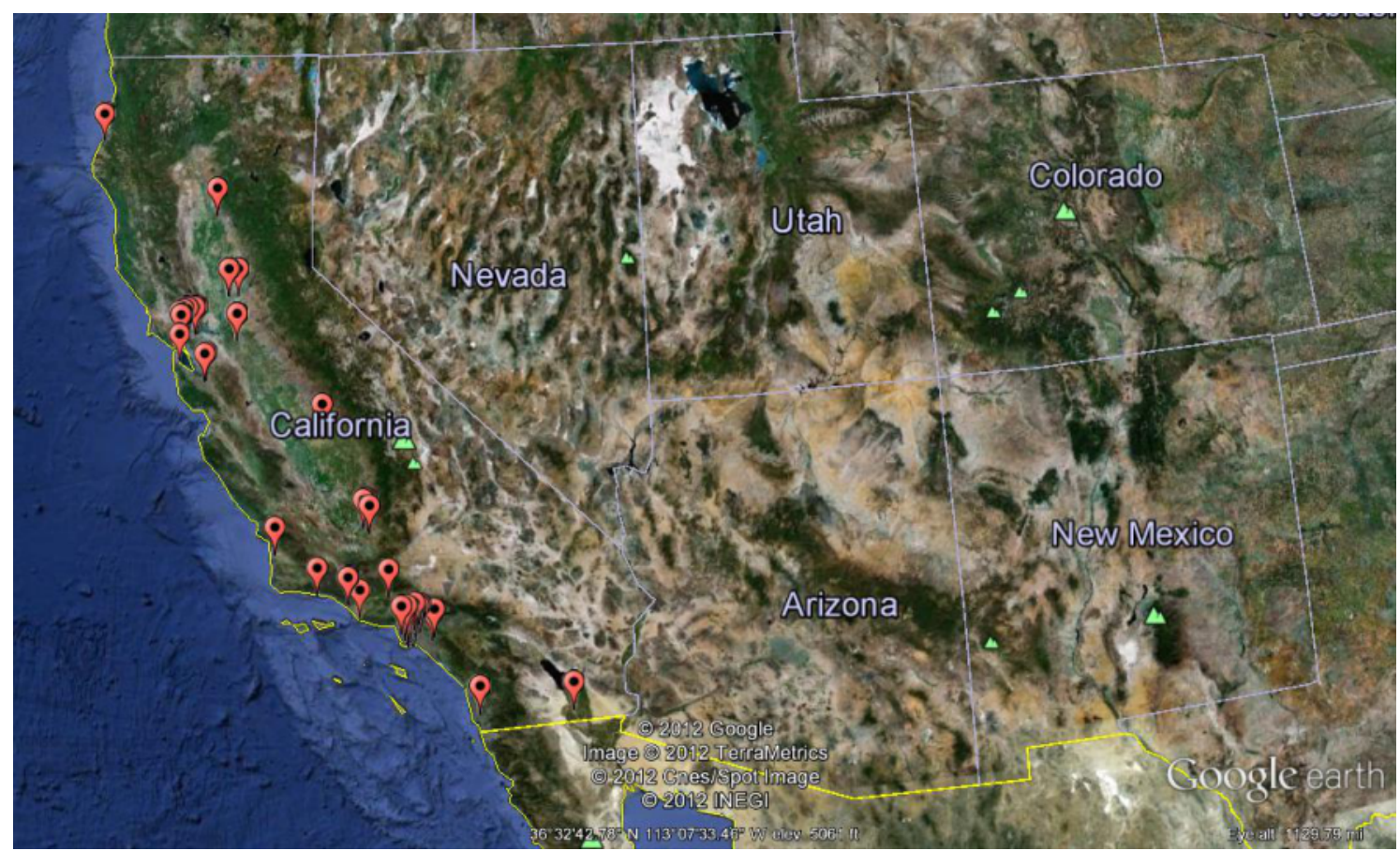

Figure 86. Map showing 46 California petroleum facilities sited in proximity to possible tsunami effects (data from Environmental Protection Agency database:

ftp://ftp.epa.gov/Emis/nventory/emiss_shp2003/us/, accessed March 1, 2013) (base image from Google Earth).

The methodology employed is a close visual examination of aerial imagery (that is, Google Earth imagery) of the facilities vis-à-vis the anticipated tsunami inundation depth, to determine whether the tanks are likely to be subjected to flooding. If flooded, floating and possible rupture of connections is considered possible, leading to release of flammable product. Almost all tanks examined are protected by a secondary containment berm or wall, as required by regulations, and the presence and approximate height of this protection (as could be judged from the Google Earth imagery) was considered. Regarding the aforementioned regulations, 40CFR 112 requires " . . . secondary means of containment for the entire capacity of the largest single container and sufficient freeboard to contain precipitation ...." [emphasis added]. Data on the largest tank in each facility is also listed in table 35, and this is used to calculate a burnt area based on Shuto's equation (that is, equation 25). 
Table 35. Summary findings for California petroleum facilities for fire following tsunami in the SAFRR tsunami scenario.

[Function (Fct): $\mathrm{T}=$ Tank Farm, $\mathrm{R}=$ Refinery. $A_{B}$, area burnt; $\mathrm{m}$, meters; $\mathrm{km}^{2}$, square kilometers]

\begin{tabular}{|c|c|c|c|c|c|c|c|c|c|c|c|c|c|}
\hline No. & Name & City & Fct. & $\begin{array}{c}\text { Latitud } \\
\text { e }\end{array}$ & Longitude & $\begin{array}{c}\text { No. } \\
\text { tanks }\end{array}$ & $\begin{array}{c}\text { Larges } \\
\text { t tank } \\
\text { diamet } \\
\text { er }(m)\end{array}$ & $\begin{array}{c}\text { Larg } \\
\text { est } \\
\text { tank } \\
\text { heig } \\
\text { ht } \\
\text { (m) }\end{array}$ & $\begin{array}{c}\text { Tsuna } \\
\text { mi } \\
\text { height } \\
\text { (m) }\end{array}$ & $\begin{array}{l}\text { Protect } \\
\text { ed? }\end{array}$ & $\begin{array}{l}\text { With } \\
\text { in } \\
\text { floo } \\
\text { d } \\
\text { zone }\end{array}$ & Flooded? & $\begin{array}{c}A_{B} \\
\left(\mathrm{~km}^{2}\right. \\
)\end{array}$ \\
\hline 1 & Unocal & Eureka & $\mathrm{T}$ & 40.796 & -124.183 & \multicolumn{8}{|c|}{ no tanks found } \\
\hline 2 & Chevron & Eureka & $\mathrm{T}$ & 40.778 & -124.193 & 10 & 30 & 10 & 1.5 & somewhat & yes & possible & 2.3 \\
\hline 3 & Oil Term Co. & Eureka & $\mathrm{T}$ & 40.770 & -124.194 & \multicolumn{8}{|c|}{ no tanks found } \\
\hline 4 & Paktank & Richmond & $\mathrm{T}$ & 37.958 & -122.421 & \multicolumn{8}{|c|}{ no tanks found } \\
\hline 5 & Richmond & Richmond & $\mathrm{R}$ & 37.923 & -122.368 & \multicolumn{5}{|c|}{ outside tsunami zone } & no & marine terminal & \\
\hline 6 & Texaco & Richmond & $\mathrm{T}$ & 37.923 & -122.368 & many & 40 & 20 & 2 & yes & partial & possible & 8.0 \\
\hline 7 & Unitank & Richmond & $\mathrm{T}$ & 37.920 & -122.369 & many & 13 & 13 & $3+$ & somewhat & partial & possible & 0.6 \\
\hline 8 & Time Oil & Richmond & $\mathrm{T}$ & 37.920 & -122.363 & many & 20 & 20 & $3+$ & somewhat & partial & possible & 2.0 \\
\hline 9 & Unocal & Richmond & $\mathrm{T}$ & 37.918 & -122.365 & many & 26 & 20 & $3+$ & somewhat & partial & possible & 3.4 \\
\hline 10 & Petromark & Richmond & $\mathrm{T}$ & 37.912 & -122.386 & \multicolumn{8}{|c|}{ no tanks found } \\
\hline 11 & Arco & Richmond & $\mathrm{T}$ & 37.913 & -122.366 & many & 25 & 20 & $3+$ & somewhat & partial & possible & 3.1 \\
\hline 12 & Shell & $\begin{array}{l}\text { South San } \\
\text { Francisco }\end{array}$ & $\mathrm{T}$ & 37.640 & -122.398 & 3 & 30 & 20 & 1 & yes & no & unlikely & \\
\hline 13 & Shell & San Jose & $\mathrm{T}$ & 37.395 & -121.876 & \multicolumn{8}{|c|}{ no tanks found } \\
\hline 14 & Southern Pacific P/L & Milpitas & $\mathrm{T}$ & 37.374 & -121.910 & \multicolumn{8}{|c|}{ no tanks found } \\
\hline 15 & Arco & Goleta & $\mathrm{T}$ & 34.423 & -119.832 & \multicolumn{8}{|c|}{ no tanks found (Goleta Sanitary District, but next to airport) } \\
\hline 16 & Shell & Ventura & $\mathrm{T}$ & 34.308 & -119.286 & \multicolumn{8}{|c|}{ no tanks found } \\
\hline 17 & USA-Oil & Ventura & $\mathrm{T}$ & 34.298 & -119.301 & \multicolumn{8}{|c|}{ no tanks found } \\
\hline 18 & Oxnard & Oxnard & $\mathrm{R}$ & 34.125 & -119.100 & \multicolumn{8}{|c|}{ no tanks found } \\
\hline 19 & El Segundo & El Segundo & $\mathrm{R}$ & 33.903 & -118.395 & many & & & & yes & no & no & \\
\hline 20 & Wilmington & Wilmington & $\mathrm{R}$ & 33.785 & -118.263 & \multicolumn{8}{|c|}{ outside tsunami zone } \\
\hline 21 & Texaco & Wilmington & $\mathrm{T}$ & 33.788 & -118.239 & \multicolumn{8}{|c|}{ outside tsunami zone } \\
\hline 22 & Wilmington & Wilmington & $\mathrm{T}$ & 33.789 & -118.227 & \multicolumn{8}{|c|}{ outside tsunami zone } \\
\hline
\end{tabular}




\begin{tabular}{|c|c|c|c|c|c|c|c|c|c|c|c|c|c|}
\hline No. & Name & City & Fct. & $\begin{array}{l}\text { Latitud } \\
\mathrm{e}\end{array}$ & Longitude & $\begin{array}{l}\text { No. } \\
\text { tanks }\end{array}$ & $\begin{array}{c}\text { Larges } \\
\text { t tank } \\
\text { diamet } \\
\text { er }(m)\end{array}$ & $\begin{array}{c}\text { Larg } \\
\text { est } \\
\text { tank } \\
\text { heig } \\
\text { ht } \\
\text { (m) }\end{array}$ & $\begin{array}{c}\text { Tsuna } \\
\text { mi } \\
\text { height } \\
\text { (m) }\end{array}$ & $\begin{array}{l}\text { Protect } \\
\text { ed? }\end{array}$ & $\begin{array}{l}\text { With } \\
\text { in } \\
\text { floo } \\
\text { d } \\
\text { zone }\end{array}$ & Flooded? & $\begin{array}{c}\left.\begin{array}{c}A_{B} \\
\left(\mathrm{~km}^{2}\right.\end{array}\right) \\
)\end{array}$ \\
\hline 24 & Wilmington & Wilmington & $\mathrm{R}$ & 33.772 & -118.288 & \multicolumn{8}{|c|}{ outside tsunami zone } \\
\hline 25 & Bray Oil Co. & Torrance & $\mathrm{T}$ & 33.765 & -118.294 & \multicolumn{8}{|c|}{ outside tsunami zone } \\
\hline 26 & Texaco & Long Beach & $\mathrm{T}$ & 33.776 & -118.221 & 9 & 45 & 10 & 1 & yes & yes & possible & 5.1 \\
\hline 27 & Petro-Diamond & Long Beach & $\mathrm{T}$ & 33.776 & -118.219 & \multicolumn{8}{|c|}{ no tanks found } \\
\hline 28 & Arco & Long Beach & $\mathrm{T}$ & 33.777 & -118.213 & many & 45 & 10 & $1 \sim 3 \mathrm{~m}$ & yes & partial & possible & 5.1 \\
\hline 29 & Time Oil & San Pedro & $\mathrm{T}$ & 33.761 & -118.292 & \multicolumn{8}{|c|}{ outside tsunami zone } \\
\hline 30 & Wilmington & Wilmington & $\mathrm{T}$ & 33.765 & -118.258 & many & 31 & 10 & 3 & yes & partial & possible & 2.4 \\
\hline 31 & Golden Eagle & Wilmington & $\mathrm{T}$ & 33.761 & -118.265 & \multicolumn{3}{|c|}{ similar to no. 37 Shell } & & & & possible & 5.1 \\
\hline 32 & Chevron Chem. & Wilmington & $\mathrm{T}$ & 33.759 & -118.266 & \multicolumn{3}{|c|}{ similar to no. 37 Shell } & & & & possible & 5.1 \\
\hline 33 & Union Pacific & Wilmington & $\mathrm{T}$ & 33.759 & -118.266 & \multicolumn{3}{|c|}{ similar to no. 37 Shell } & & & & possible & 5.1 \\
\hline 34 & Unocal & Wilmington & $\mathrm{T}$ & 33.756 & -118.271 & many & 45 & 17 & 2 & yes & partial & unlikely & \\
\hline 35 & Golden West & San Pedro & $\mathrm{T}$ & 33.758 & -118.258 & \multicolumn{8}{|c|}{ no tanks found } \\
\hline 36 & Gatx & Wilmington & $\mathrm{T}$ & 33.756 & -118.265 & \multicolumn{8}{|c|}{ no tanks found } \\
\hline 37 & Shell & Wilmington & $\mathrm{T}$ & 33.755 & -118.266 & many & 45 & 10 & $2+$ & yes & yes & possible & 5.1 \\
\hline 38 & Chevron & Wilmington & $\mathrm{T}$ & 33.752 & -118.275 & \multicolumn{8}{|c|}{ no tanks found } \\
\hline 39 & Indies Terminals & Terminal Island & $\mathrm{T}$ & 33.754 & -118.260 & \multicolumn{8}{|c|}{ no tanks found } \\
\hline 40 & Refiners Marketing Co. & Terminal Island & $\mathrm{T}$ & 33.747 & -118.265 & \multicolumn{8}{|c|}{ no tanks found } \\
\hline 41 & Mobil & San Pedro & $\mathrm{T}$ & 33.745 & -118.264 & 7 & & & & yes & no & no & \\
\hline 42 & C. Brewer & Long Beach & $\mathrm{T}$ & 33.753 & -118.205 & \multicolumn{8}{|c|}{ no tanks found } \\
\hline 43 & Exxon & Long Beach & $\mathrm{T}$ & 33.751 & -118.207 & 6 & 45 & 12 & 3 & yes & yes & possible & 6.1 \\
\hline 44 & Mobil & Terminal Island & $\mathrm{T}$ & 33.736 & -118.272 & 19 & 40 & 13 & 2 & yes & no & unlikely & \\
\hline 45 & C. Brewer & Long Beach & $\mathrm{T}$ & 33.746 & -118.189 & 1 & & & & yes & no & no & \\
\hline 46 & Unocal & San Pedro & $\mathrm{T}$ & 33.726 & -118.282 & many & 24 & 17 & 2 & yes & partial & possible & 2.5 \\
\hline 47 & Oakland Airport & Oakland & & & & 3 & 24 & 24 & 1 & yes & yes & unlikely & \\
\hline 48 & Kinder Morgan & Port of Los Angeles & $\mathrm{T}$ & & & 18 & 45 & 16 & 3 & yes & yes & possible & 8.1 \\
\hline 49 & UNK Port of Long Beach & Port of Long Beach & $\mathrm{T}$ & & & 6 & 16 & 13 & 1 & yes & yes & possible & 0.8 \\
\hline 50 & $\begin{array}{l}\text { Freeman, Chaffee, White } \\
\text { Grissom Islands }\end{array}$ & Port of Long Beach & $\mathrm{T}$ & 33.741 & -118.154 & many & 13 & 8 & 1 & no & yes & possible & 0.3 \\
\hline
\end{tabular}


Not examined are facilities not in the database, except a few identified during this investigation (for example, a few tanks at Oakland airport). Power plants, military installations and small fueling docks at local marinas are not examined. Small fueling docks exist at almost all marinas (for example, fig. 87), and undoubtedly some of these will rupture and release modest amounts of flammable liquids, leading to localized fires.

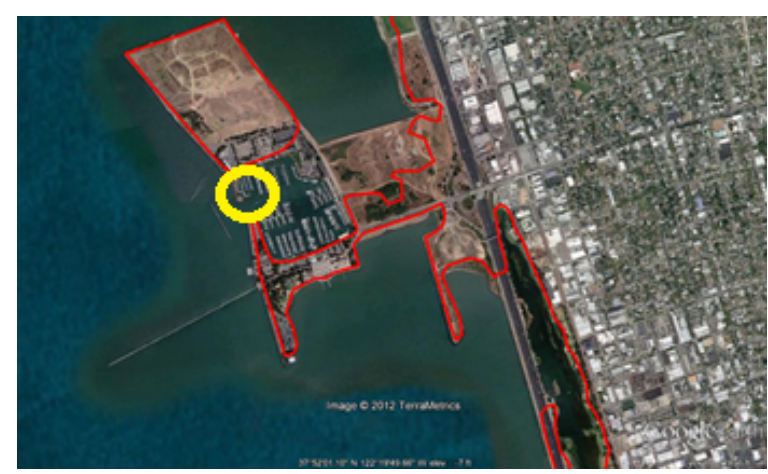

A

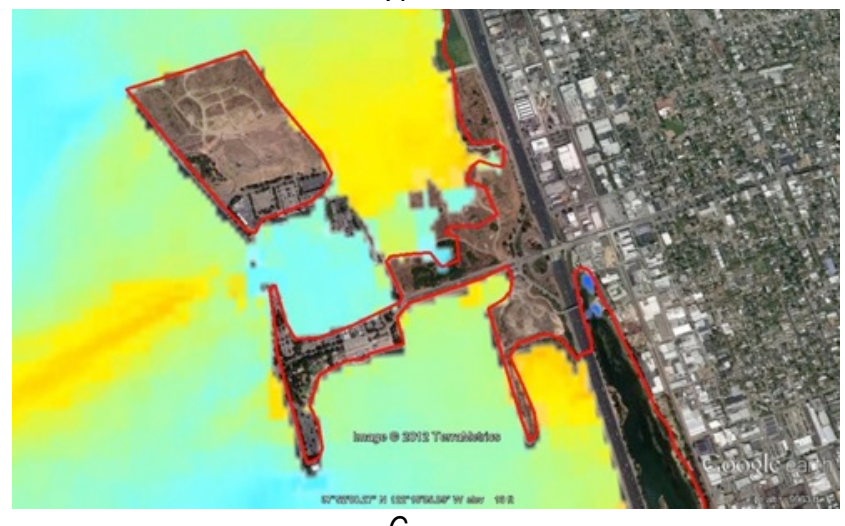

C

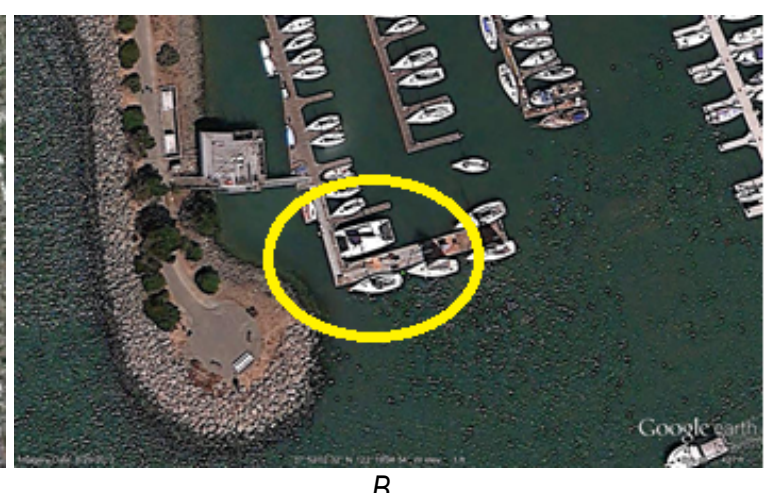

$B$

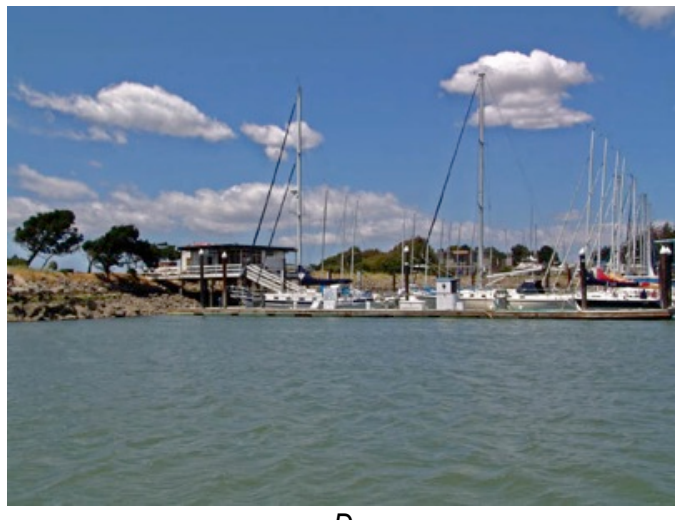

$D$

Figure 87. Images of example of small marina fueling dock not considered in this study of fire in the SAFRR tsunami scenario. Example is Berkeley Marina, California: $A$, marina and inundation boundaries; $B$, closeup of fueling dock; $C$, flood depths; and $D$, view of fueling dock from water level. ( $A-C$ base images from Google Earth; photograph by Charles Scawthorn.)

This methodology is necessarily limited in accuracy, and it is possible that large facilities have been overlooked, tanks misidentified, and other errors introduced. Nevertheless, the method are overall reasonable and the findings probably overall robust.

\section{Humboldt Bay}

Three facilities are listed in the EPA database for Humboldt Bay, as shown figures 88 and 89 (the latter showing flood depths, determined by others in this report). Examination of aerial imagery indicated in fact only one facility in existence at the time of the Google Earth imagery (fig. 90), the tanks of which are protected by a wall that would appear to be overtopped given the 2 to $3 \mathrm{~m}$ inundation expected at this site. The facility is therefore considered "possible" for flooding. Given the size of the largest tank, the resulting burnt area would be over $2 \mathrm{~km}^{2}$. 


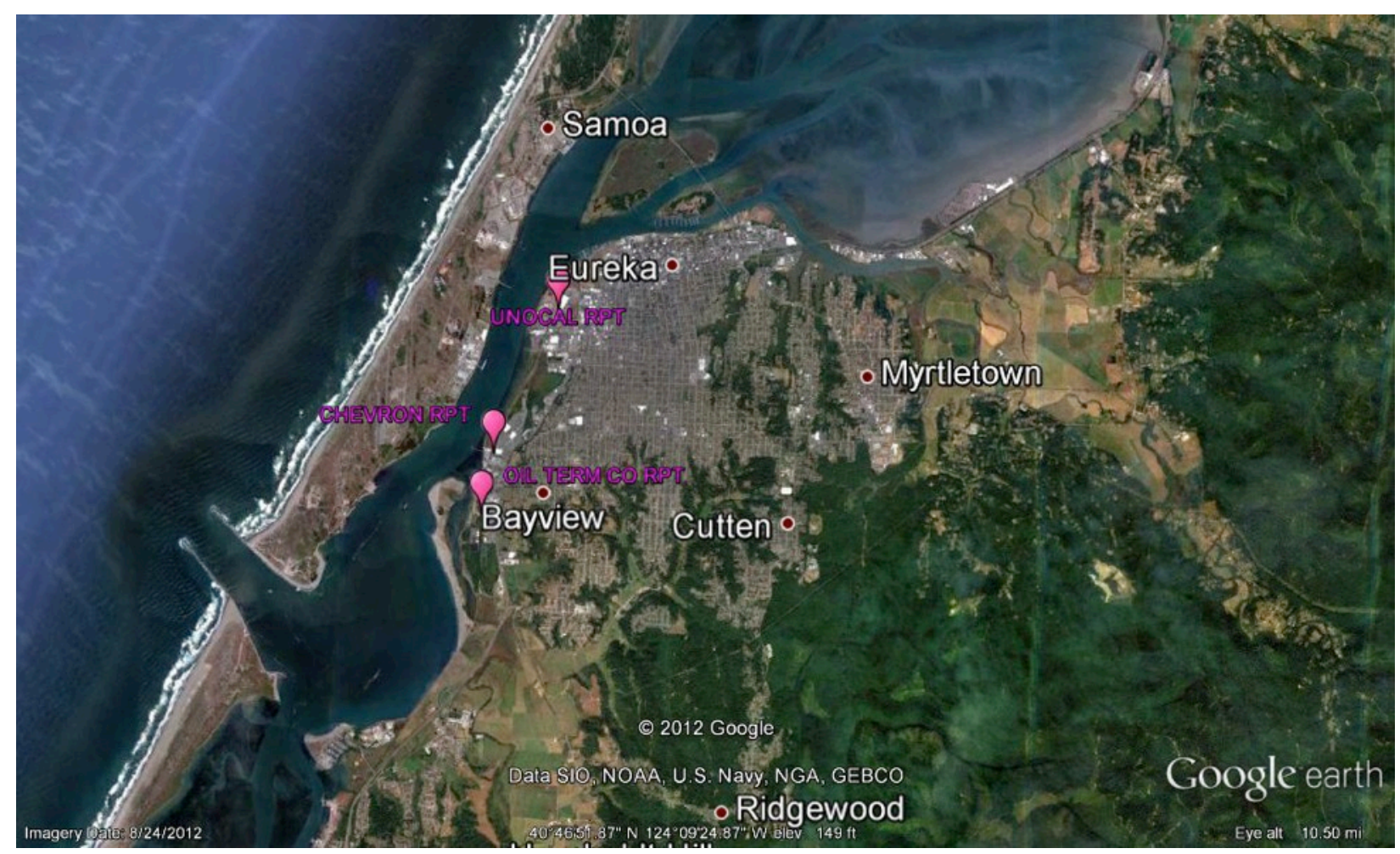

Figure 88. Satellite image of Humboldt Bay, California, showing the three oil facilities in the area (base image from Google Earth). 


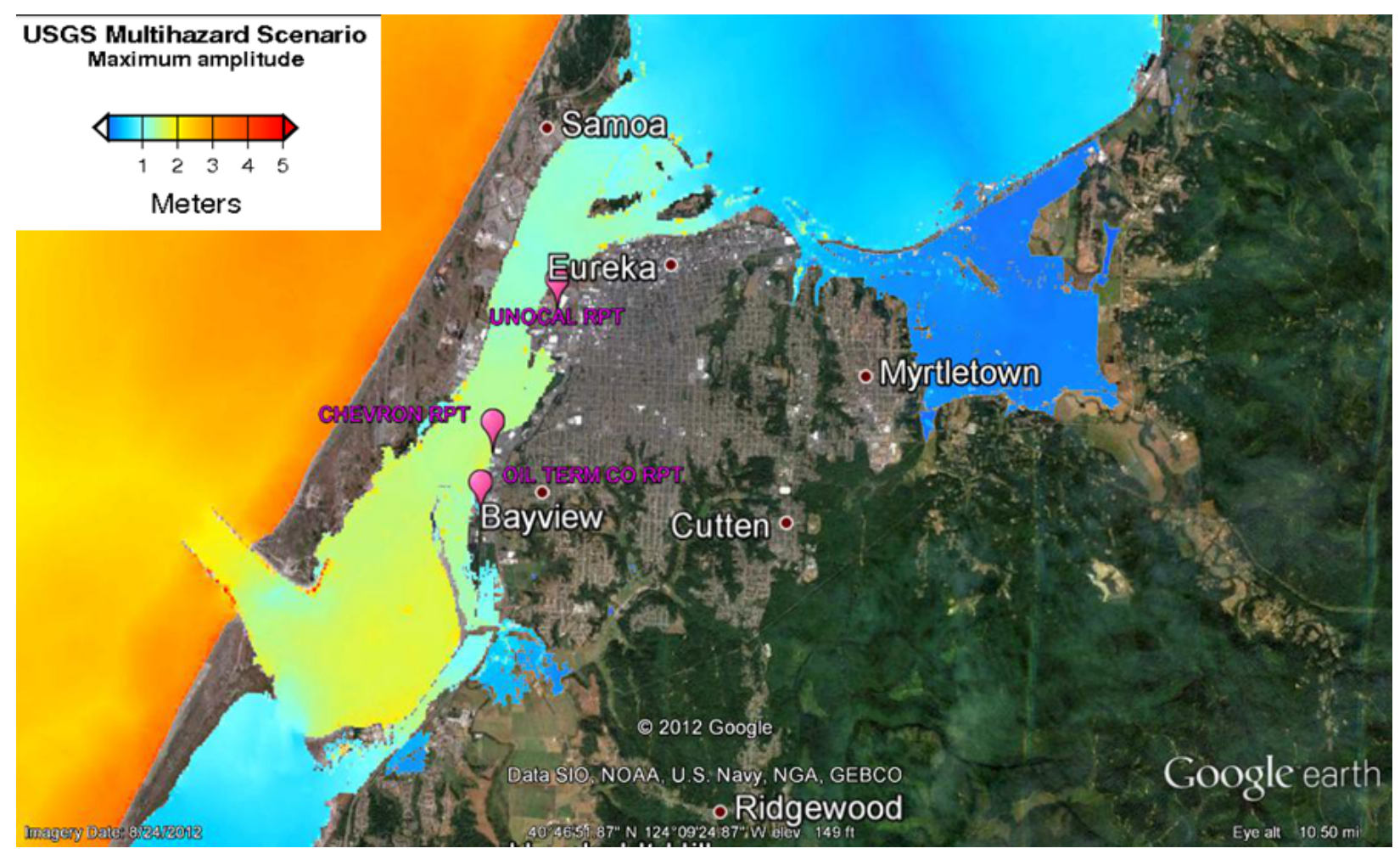

Figure 89. Satellite image of Humboldt Bay, California, showing the three oil facilities in the area and annotated with tsunami flood depths for the SAFRR tsunami scenario. The approximate depth of inundation as determined by others in this report is shown in the explanation at upper left (base image from Google Earth). 


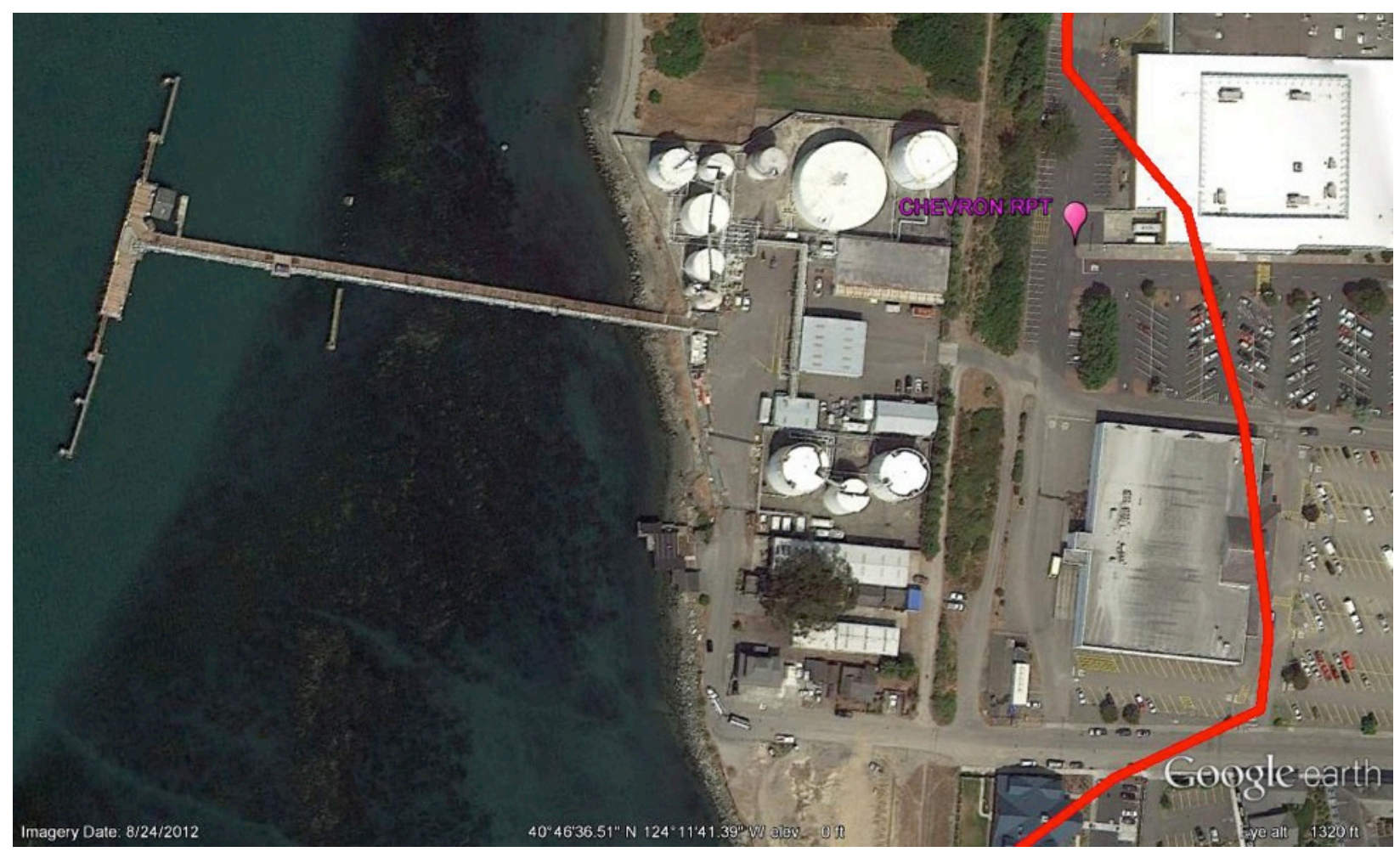

Figure 90. Satellite image of a Humboldt Bay, California, oil facility. In this image the approximate extent of inundation as determined by others in this report is shown by the red line (base image from Google Earth).

\section{San Francisco, Los Angeles, and Other Regions}

The same methodology was employed for remaining facilities, as listed in table 35 . The interested reader can find images for these remaining facilities in figures 19-62 of Scawthorn (2013), at http://www.sparisk.com/publications.html (accessed March 1, 2013). In general, Scawthorn (2013) provides two figures for most facilities - the first figure showing the facility and inland extent of flooding (denoted by the red line) and the second figure showing the same view but with shading indicating the depth of inundation. Table 35 summarizes the findings for each facility.

\section{Survey and Findings}

As shown in table 35, 17 facilities are deemed as "possible" for release of flammable liquids, and a spreading fire. Five of the 17 facilities are in Port of Richmond, and in close proximity, and 11 are within the interconnected Ports of Los Angeles and Long Beach (POLA/POLB).

To better understand the potential vulnerability of marine oil terminals to tsunami, a survey of several tank farms and oil terminals was conducted in the POLA/POLB on January 22, 2013 (see figs. 91 through 93). In summary, observations and findings of the survey were:

A typical POLA/POLB marine oil terminal cross-section is shown in figure 94. Product flow is from the ship via flexible hosing to an on-wharf manifold, then via steel piping to an on-shore manifold. The steel piping may run on or under the wharf. Onshore, the 
product piping may (not always) be partially buried, and will often have a second onshore manifold prior to the piping entering the tank secondary containment. Interior to the secondary containment, each tank will typically have a valve just prior to the tank shell. Fire lines and monitors run outside the secondary containment, often supported on the exterior wall of the secondary containment, and are therefore vulnerable to damage if tsunami run-up reaches the height of the fire line.

- Tanks are typically thin-walled steel tanks. In our observation, some tanks were bolted to their foundation but more often (especially larger tanks) were not fixed to their foundation, and thus susceptible to flotation.

- Tanks invariably will have secondary containment-typically in POLA/POLB this is a concrete wall, typically cantilevered and sometimes buttressed. Some walls were cast-inplace reinforced concrete, whereas others were built of concrete masonry units. The wall height is calculated so as to contain the contents of the largest single tank, plus rainwater, and varied in our observations from about 6 to $20 \mathrm{ft}$.

- In California, minimum engineering, inspection and maintenance criteria for marine oil terminals (MOTs) are established by Chapter 31F, Marine Oil Terminals, of the California Building Code. Chapter 31F establishes environment loading, including seismic, wind and tsunami, and specifies tsunami run-up at POLA/POLB as $8 \mathrm{ft}$ (and 7.5 7.9 ft at Port of Richmond).

- Secondary containment walls are presumably designed so as to withstand lateral fluid pressure from the tank side. Chapter $31 \mathrm{~F}$ does not specifically address secondary containment but, because tsunami run-up is specified, lateral fluid pressure appropriate to the specified tsunami run-up height should be a design condition for the secondary containment walls. Discussions with operators and POLA engineering staff could not confirm that this design condition was actually employed.

- Several of the oil terminal wharves in POLA are of flammable older wood construction, and could be structurally damaged in a significant tsunami. Other fuel-related wharves in POLA/POLB are of concrete construction, less flammable but still susceptible to significant damage when subjected to a spreading-oil-on-water fire.

- Displacements of wharf structures would likely break on-wharf product piping that in some cases run beneath the wharf decking (and therefore is more susceptible to tsunami damage). Most on-wharf and wharf-shore piping does not appear designed for tsunami currents (for example, lacked lateral support).

- Industry practice appears to be to generally valve off wharf piping from onshore storage tanks when not transferring product, so that relatively little product (for example, tens to hundreds of barrels) would be spilled given wharf piping breakage under most circumstances. The only exception to this would be during product transfer (that is, offloading a ship) but, given even a few minutes warning, valves (which are manually operated) can be readily closed. 

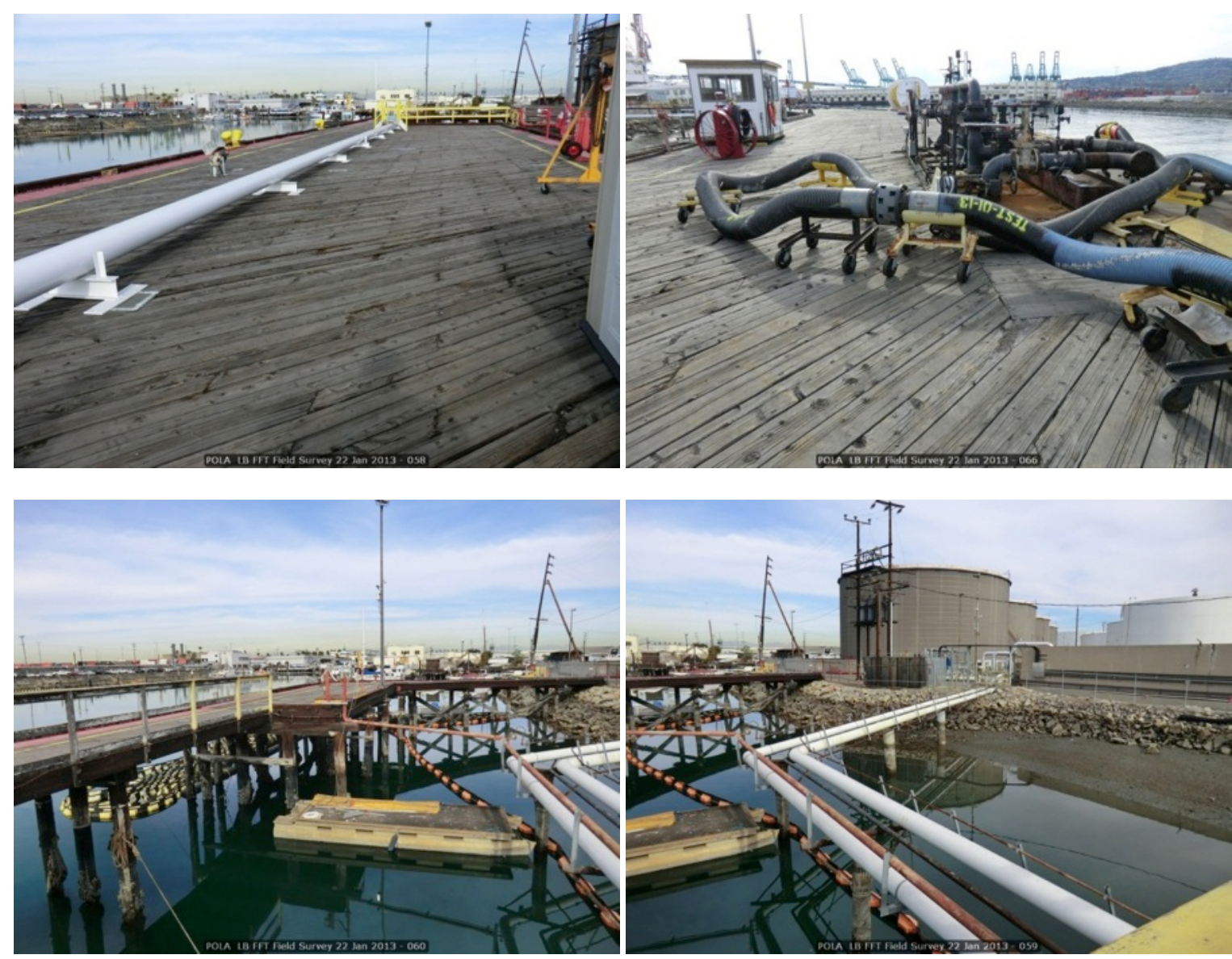

Figure 91. Photographs of Port of Los Angeles Berth 163 wood wharf and manifold and piping to storage tanks (photographs by Charles Scawthorn). 


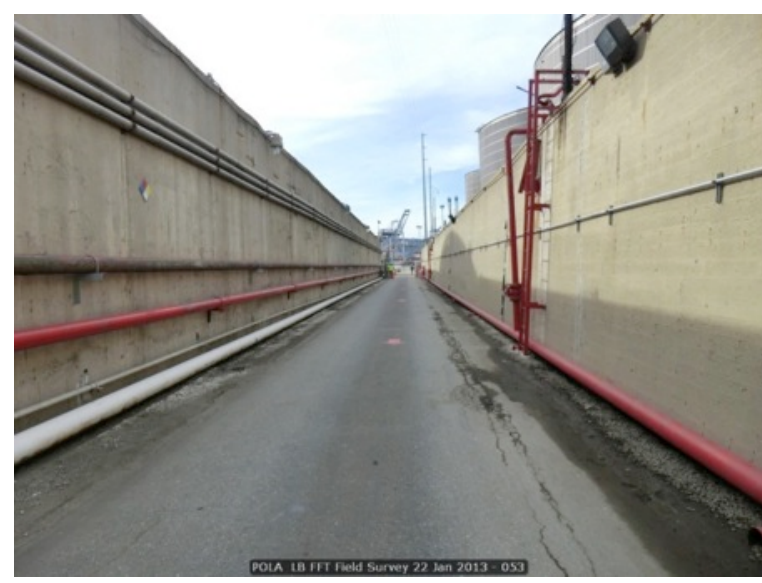

A

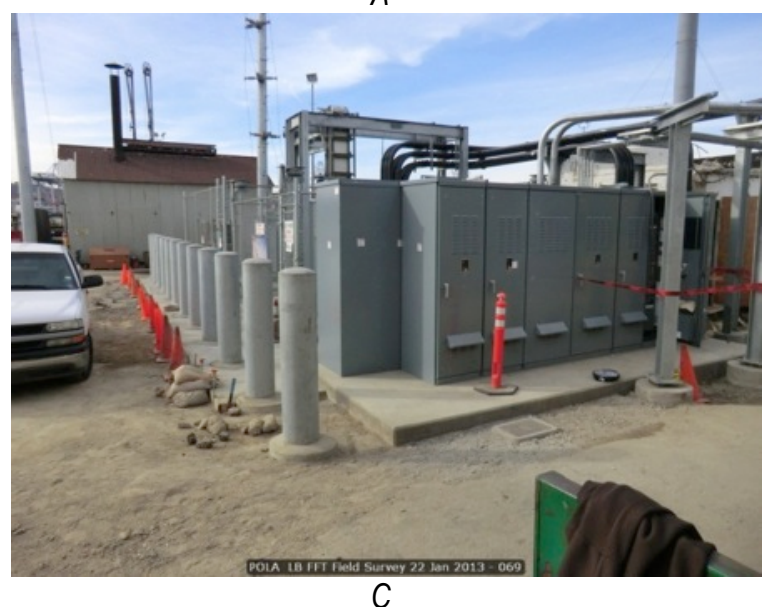

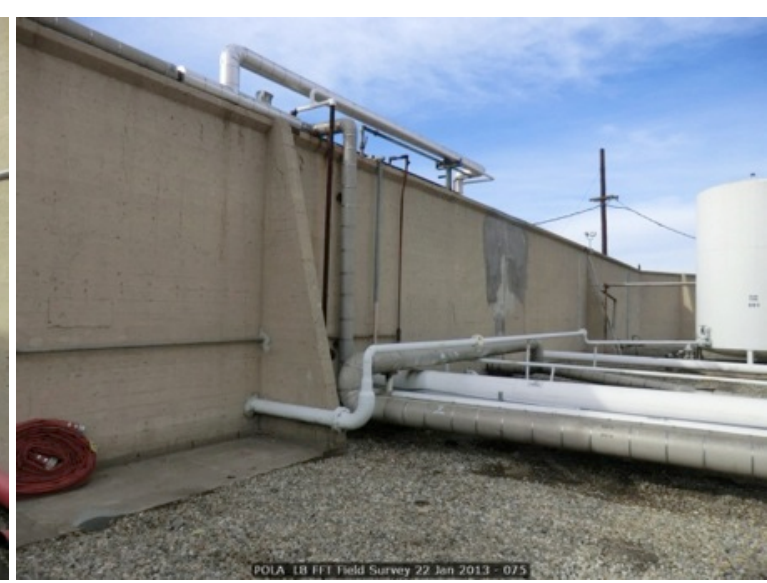

(b)

Figure 92. Photographs of Port of Los Angeles Berth 163: A, roadway leading between secondary containment leading to Berth 163, with fire lines external to containment (susceptible to tsunami damage); $B$, interior of secondary containment showing buttresses; and $C$, electrical equipment between wharf and secondary containment (photographs by Charles Scawthorn). 

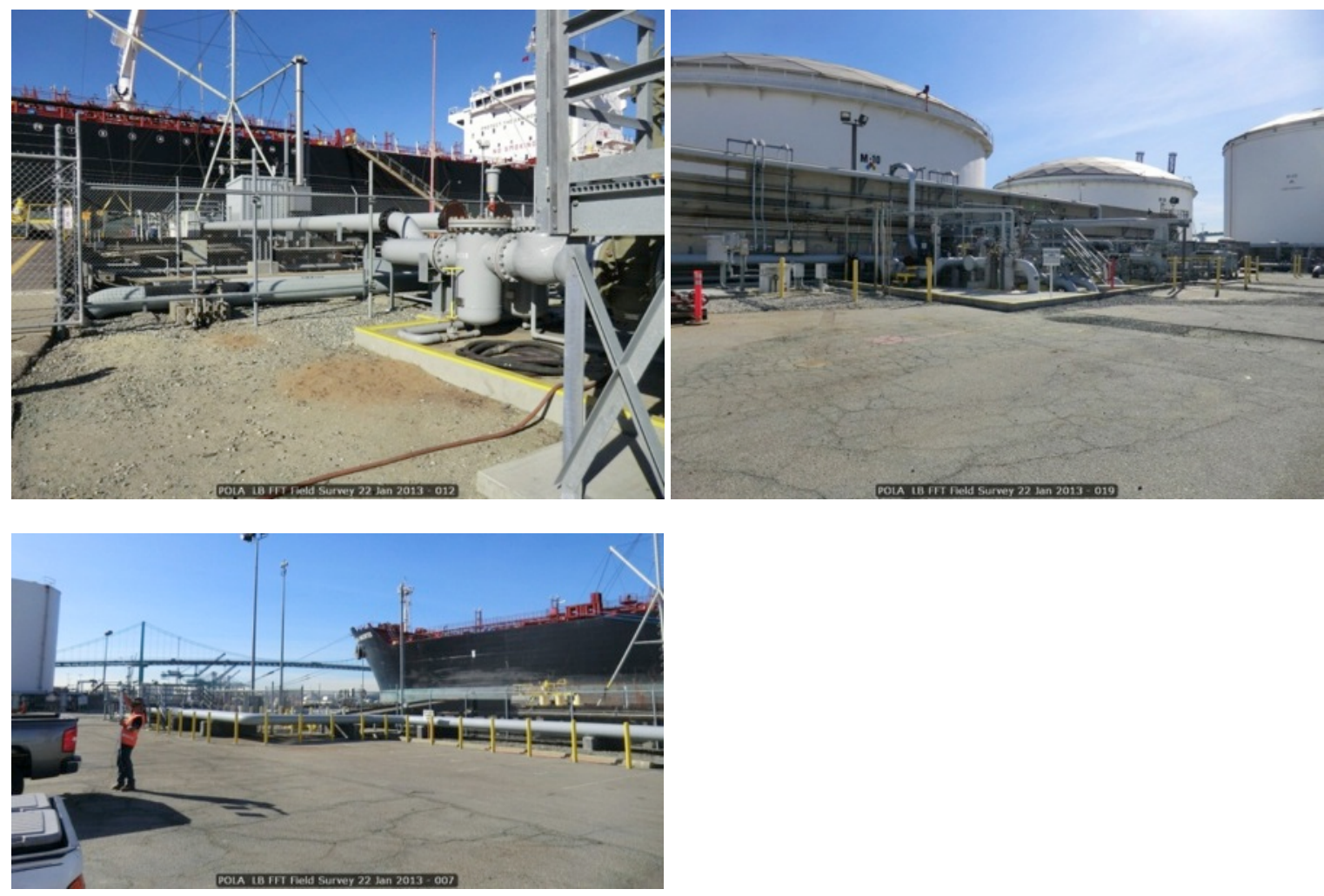

Figure 93. Photographs of Port of Los Angeles Berth 167-9 manifolding, piping, and secondary containment. Long runs of pipe not laterally restrained. (Photographs by Charles Scawthorn.)

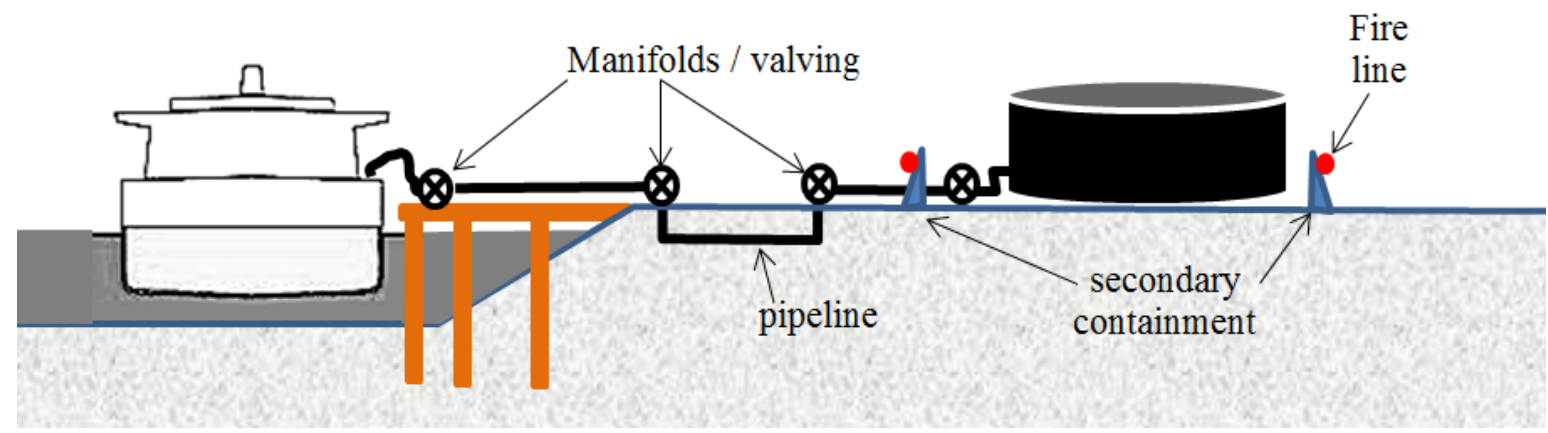

Figure 94. Cross-section diagram of a typical marine oil terminal (image from Charles Scawthorn).

Overall, given the tsunami heights predicated for the SAFRR tsunami scenario, on-wharf and onshore product piping exterior to the secondary containment would appear to be somewhat vulnerable to tsunami forces, such that the possibility of pipe breakage would appear likely in at least a few locations. A limited amount of flammable product would be released, and ignition sources are present (for example, electrical equipment). Combined with large lengths of flammable wood piers at several marine oil terminals, even a limited amount of flammable 
product release could lead to a major pier fire. However, the great majority of flammable product is held in tanks behind secondary containment. Structural integrity of the secondary containment under tsunami loading is unclear. On the basis of limited observation at POLA/POLB, we did not observe a containment or tank that appeared very likely to fail under the SAFRR tsunami scenario. However, we recommend that design for secondary containment integrity under tsunami loading should be verified, or the integrity confirmed by engineering analysis.

Given the concentration of oil tank farms in the Ports of Richmond, and especially in the POLA/POLB complex, we feel it is possible but not very likely that a spreading fire will result from tsunami damage in at least one of these facilities. If such a fire were to occur, in the context of a tsunami and its attendant other damage, it is likely it would spread over water to other facilities, resulting in a common cause fire and possibly destruction of several of these facilities.

As contrasted with Richmond, the POLA/POLB scenario is mitigated by the presence in the port of several Los Angeles City Fire Department fireboats (including one of the world's largest and most modern fireboats, fig. 95). However, strong currents from the tsunami would greatly complicate fighting a spreading fire.

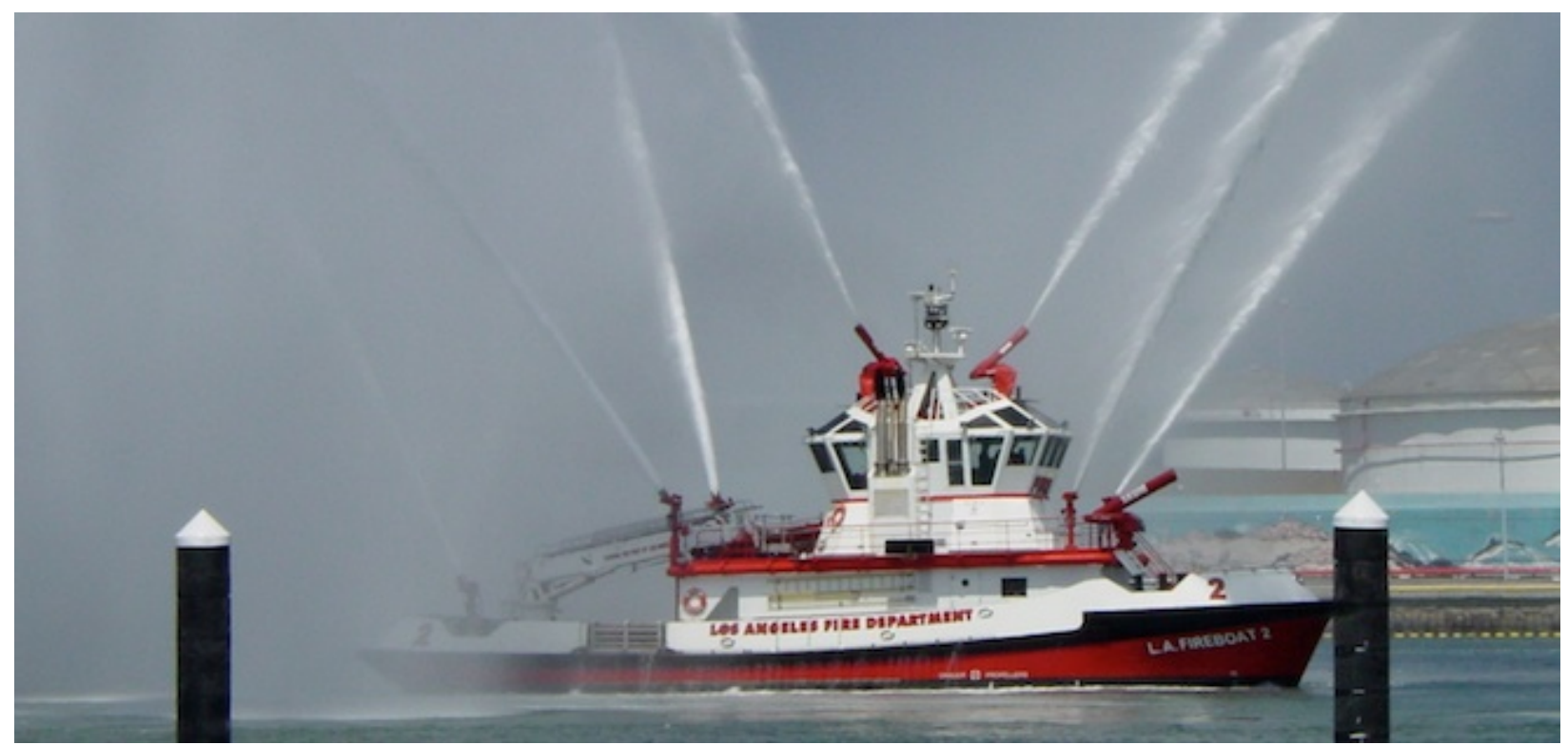

Figure 95. Photograph of Los Angeles Fire department fireboat 2, the Warner L. Lawrence. One of the largest and most technologically advanced fireboats in the world, it has the capability to pump as much as 38,000 U.S. gallons per minute (2.397 cubic meters per second) as far as 400 feet (121.9 meters). (Photograph courtesy Los Angeles Fire Department.)

Lastly, as was noted above, half a million tons of sea-going vessels were destroyed in the 2011 Tohoku tsunami (including 17,000 fishing vessels, as well as two nuclear submarines damaged). Others in this project have emphasized the strong currents that will be generated in ports as a result of the SAFRR scenario tsunami, which will make ship handling unmanageable. Figure 96 is a random "snapshot" of the traffic in POLA/POLB, showing 32 major vessels inside the breakwater (major 50,000 or more DWT - the largest vessel in the snapshot is 160,000 DWT), as well as many other vessels (and perhaps a thousand untracked pleasure craft). Given the perhaps 2 to 4 hour warning for the scenario tsunami, and possible difficulty in having sufficient pilots for all the large vessels, we feel that it is quite possible that one or more oil 
tankers may be caught in the harbor, and subjected to strong currents such as to break the ship loose (if moored) and send it careening about the channels and harbor. This situation could contribute to the size and severity of any spreading fire.
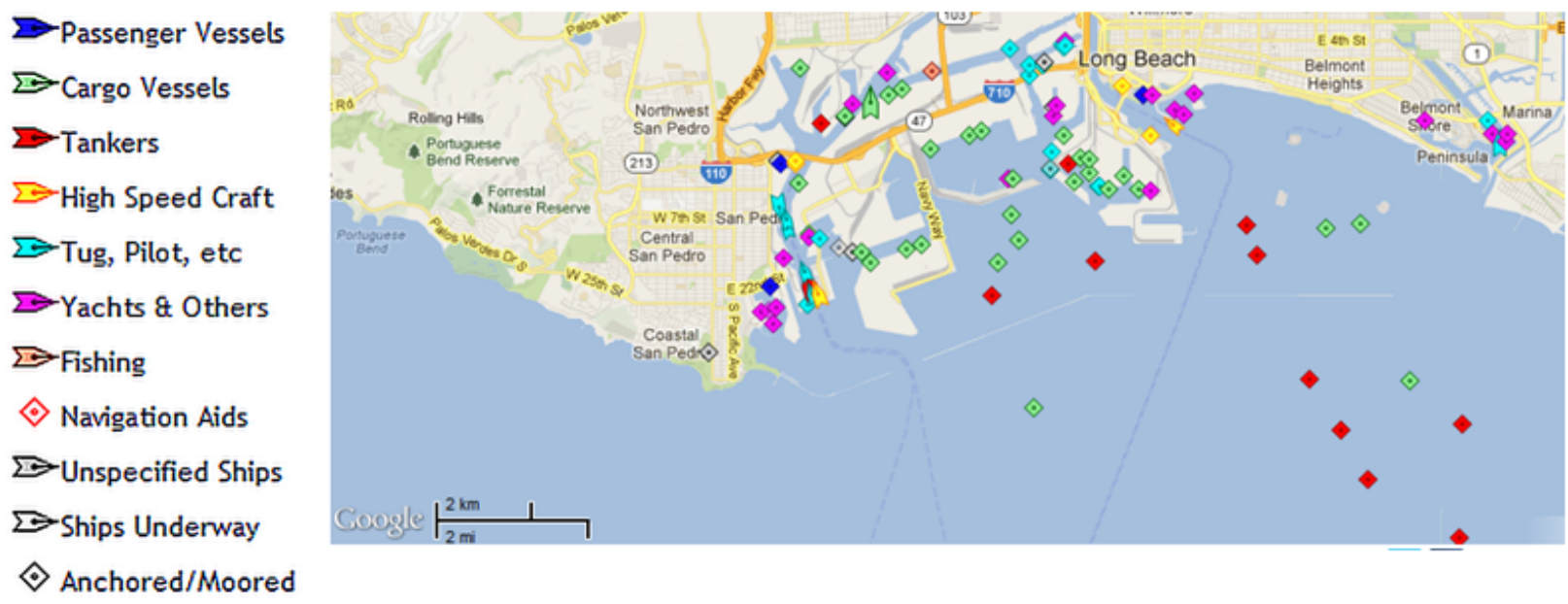

Figure 96. Map image showing a random "snapshot" of Ports of Los Angeles and Long Beach ship traffic-six tankers and 26 cargo vessels are inside the breakwater (base image from Google).

\section{Fire Study Limitations and Acknowledgments}

Regarding the methodology employed in this study, it is possible that large facilities have been overlooked, tanks misidentified, and other errors committed. It is emphasized that these findings are based only on observation and qualitative methods and that greater accuracy would be achieved with more detailed, quantitative methods. Lastly, the assistance of personnel at several POLA/POLB berths and of POLA/POLB staff is gratefully acknowledged.

\section{Acknowledgments}

The authors thank chapter reviewers: Frank Blackburn (San Francisco Fire Department, Ret.), Michael Burke (Port of Seattle), Mehmet Celebi (USGS), Laurene Eisele (Port of San Francisco), Martin Eskijian (University of Southern California), Stuart Fricke (Port of Los Angeles), Bill Graf (Imagecat, Inc.), John Headland (Moffatt and Nichol), Uday Prasad (Port of San Francisco), Steve Ng (Caltrans), Joe Roger (Port of San Francisco), Bethann Rooney (Port Authority of New York and New Jersey), Tom Shantz (Caltrans), Aaron Sherburne (Port Authority of New York and New Jersey), Bruce Smith (San Diego Association of Governments), Doug Thiessen (Port of Long Beach), Mara Tongue (USGS), Ted Trenkwalder (Ben C. Gerwick, Inc.), Zachary Whitman (University of Canterbury, Christchurch, New Zealand), and Mark Yashinsky (Caltrans). SAFRR coordinators also provided some peer review of the damages chapter: Lucy Jones (USGS), Kevin Miller (California Governor's Office of Emergency Services, Cal OES), Carl Mortensen (USGS), Geoff Plumlee (USGS), and Stephanie Ross (USGS).

Thanks also to panelists, correspondents, and other participants: Robel Afewerki (Port of Los Angeles Engineering), Rich Baratta (Port of Long Beach), Richard Berman (Port of San Francisco), Roy Bibbens (Caltrans), Chris Brown (Port of Los Angeles), Sonia Brown (Cal OES), Damon Burgett (Port of San Francisco), Ed Byrne (Port of San Francisco), Eric Caris 
(Port of Los Angeles Business Development), Tom Carter (Port of San Francisco), Mo Chang (U.S. Army Corps of Engineers), Mike Christensen (Port of Los Angeles), Bent Christiansen (Port of Los Angeles), Ken Chu (Port of San Francisco), Tim Clark (Port of Los Angeles), Brandon Cowan (Port of San Francisco), George Cummings (Los Angeles Port Police), John Davey (Port of San Francisco), Sherban Duncan (Port of San Francisco), Lauren Eisele (Port of San Francisco), Eric Endersby (Morro Bay Harbor Director), Andrienne Fedrick (Port of Los Angeles), Desiree Fox (Caltrans), Stuart Fricke (Port of Los Angeles), Keith Garcia (Los Angeles Port Police), Rene Garcia (Caltrans), Tony Gioiello (Port of Los Angeles), Aaron Golbus (Port of San Francisco), Mike Graychik (Los Angeles Port Police), Ed Green (Port of Long Beach), Anne Hardinger (City of Berkeley), Anita Hayden (Los Angeles Port Police), Jack Hedge (Port of Los Angeles Real Estate), Suzie Howser (Port of Humboldt Bay and Woodley Island Marina), Radiah Jones (U.S. Coast Guard), Jill Lemon (U.S. Coast Guard), Dan Kane (Port of Long Beach), Kevin Keady (Caltrans), Michael Keenan (Port of Los Angeles Planning), Caryn Margita (U.S. Coast Guard), Joe Maldonado (Port of Los Angeles CBM Division), Kathy Merkovsky (Port of Los Angeles), Linda McIntyre (Moss Landing Harbor District), Steve Ng (Caltrans), Leon Nixon III (Los Angeles Port Police), Diane Oshima (Port of San Francisco), Tom Ostrom (Caltrans), Karl Pan (Port of Los Angeles), Scott Phemister (Port of Long Beach), Abbas Pourheidari (Caltrans), Uday Prasad (Port of San Francisco), Steven Reel (Port of San Francisco), Jeffrey Robinson (Area G Disaster Management), Joe Roger (Port of San Francisco), Petty Santos (Los Angeles Port Police), Shaun Shahrestani (Port of Los Angeles), Daryoush Tavatli (Caltrans), Karen Taylor (Port of San Francisco), Doug Thiessen (Port of Long Beach), Curtis Thompson (Los Angeles Port Police), Martin Villa (U.S. Coast Guard), Ronnie Villanueva (City of Los Angeles), David Walsh (Port of Los Angeles), and Jennifer Williams (U.S. Coast Guard).

\section{References Cited}

Akatsuka, H., and Kobayashi, H., 2008, Fire of petroleum tank, etc. by Niigata earthquake: Japan Science and Technology Agency, Failure Knowledge Database, accessed December 18, 2012, at http://www.sozogaku.com/fkd/en/cfen/CB1012035.html.

Akiyama, M., Frangopol, D.M., Arai, M., and Koshimura, S., 2012, Probabilistic assessment of structural performance of bridges under tsunami hazard: Proceedings of the American Society of Civil Engineers Structures Congress, March 29-31, 2012, Chicago, p. 1919-1928.

American Railway Engineering and Maintenance-of-Way Association (AREMA), 2012, Chapter 9 seismic design for railway structures: Manual for Railway Engineering, vol. 2-Structures: Lanham, Md., American Railway Engineering and Maintenance-of-Way Association, p. 9-17.

American Society of Civil Engineers [ASCE], Coasts, Oceans, Ports, and Rivers Institute [COPRI], 2005, Report of damage assessment from December 26, 2004, Indian Ocean tsunami: American Society of Civil Engineers, Coasts, Oceans, Ports, and Rivers Institute American Society of Civil Engineers [ASCE], Coasts, Oceans, Ports, and Rivers Institute [COPRI], 2010, Earthquake and tsunami damage of Chile earthquake of February 27, 2010: American Society of Civil Engineers, Coasts, Oceans, Ports, and Rivers Institute American Society of Civil Engineers [ASCE], Technical Council on Lifeline Earthquake Engineering [TCLEE], 2011, Report of the 11 March $2011 \mathrm{M}_{\mathrm{w}} 9.0$ Tohoku, Japan earthquake and tsunami: American Society of Civil Engineers, Technical Council on Lifeline Earthquake Engineering 
Applied Technology Council [ATC], 2012, ATC-58 - Guidelines for seismic performance assessment of buildings, 100\% Draft: Redwood City, Calif., Applied Technology Council Asian Disaster Preparedness Center, 2005, The economic impact of the 26 December 2005 earthquake and Indian Ocean tsunami in Thailand: Bangkok, Thailand: Asian Disaster Preparedness Center, accessed May 30, 2013, at http://www.adpc.net/maininforesource/dms/thailand_assessmentreport.pdf.

Berkman, S.C., and Symons, J.M., 1964, The tsunami of May 22, 1960 as recorded at tide stations: U.S. Department of Commerce, Coast, and Geodetic Survey.

Byers, W.G., 2011, Railroad damage from two hurricanes: Natural Hazards Review, v. 12, no. 1, p. 6-8.

California Department of Finance, 2009, 2008 California statistical abstract: Sacramento, California, Department of Finance, accessed August 27, 2013, at http://www.dof.ca.gov/HTML/FS_DATA/STATABS/documents/CaliforniaStatisticalAbstract2008.pdf.

California Department of Water Resources [DWR], 2013, California land and water use: California Department of Water Resources Web site, accessed May 22, 2013, at http://www.water.ca.gov/landwateruse/lusrvymain.cfm.

California Geological Survey [CGS], 2012, California Geological Survey-Anniversary of the March 11, 2011 Tohoku-oki earthquake and tsunami: California Department of Conservation Web site, accessed May 20, 2013, at http://www.conservation.ca.gov/cgs/geologic_hazards/Tsunami/Inundation_Maps/Pages/2011 tohoku.aspx.

California State Lands Commission, 2010, Marine Oil Terminal Engineering and Maintenance Standards (MOTEMS), 2010 title 24, CCR, part 2, California Building Code, chapter 31FMarine Oil Terminals: California State Lands Commission, Marine Facilities Division, accessed August 27, 2013, at http://www.slc.ca.gov/division_pages/mfd/motems/CHAPTER\%2031F\%20MOTEMS\%20EFF ECTIVE\%2001-01-2011.pdf.

Caltrans, 2010, Memo to designers 20-13: Tsunami hazard guidelines: Sacramento, California Department of Transportation, $3 \mathrm{p}$.

Center for Deep Earth Exploration [CDEX], 2012, Deep bonds from shared adversity: Japan Agency for Marine-Earth Science and Technology, CDEX Web Magazine accessed August 27, 2013, at http://www.jamstec.go.jp/chikyu/magazine/e/future/no12/page02.html.

Chile Railways, 2010, March 3, 2010, memo from General Manager to Accounting Department of Empresa de los Ferrocarriles del Estado (Chile): Chile Railways memo.

Cruz, A.M., Franchello, G., and Krausmann, E., 2009, Assessment of tsunami risk to an oil refinery in southern Italy: European Commission, Joint Research Centre, Institute for the Protection and Security of the Citizen, Ispra, p. 68.

Davison, C., 1936, Great earthquakes: London, Thomas Murby and Company, p. 209.

Division of Agriculture and Natural Resources [DANR], Veterinary Medicine Extension, 1999, DANR guide to disaster preparedness: Davis, Calif., University of California-Davis, accessed May 31, 2013, at http://www.vetmed.ucdavis.edu/iawti/local-assets/pdfs/DANRGuide2.pdf.

Federal Highway Administration, 2011, Bridge scour and stream instability countermeasures; Experience, selection, and design guidance, 3rd ed.-Design guideline 14 rock riprap at bridge abutments: Federal Highway Administration Website, accessed August 27, 2013, at http://www.fhwa.dot.gov/engineering/hydraulics/pubs/09112/page14.cfm. 
General Accounting Office, [GAO], 2003, Comparison of States' highway construction costsLetter to Peter G. Fitzgerald-Subcommittee on financial management, the budget, and International Security Committee on Governmental Affairs, United States Senate, November 3, 2003: General Accounting Office, accessed August 27, 2013, at http://www.gao.gov/assets/100/92297.html.

Goto, C., 1985, A simulation method of oil spread due to tsunamis: Proceedings of the Japan Society of Civil Engineers, no. 357-2, p. 217-223 [in Japanese].

Goto, Y., 2008, Tsunami damage to oil storage tanks: The 14th World Conference On Earthquake Engineering, October 12-17, 2008, Beijing, accessed August 27, 2013, at http://www.iitk.ac.in/nicee/wcee/article/14_15-0005.PDF.

Headland, J., Smith, E., Dykstra, D., and Ribakovs, T., 2006, Effects of tsunamis on moored/maneuvering ships: Proceedings of the 30th International Coastal Engineering Conference, American Society of Civil Engineers, p. 1603-1624.

Hirama, S., 2013, Farmers again cultivating rice fields hit by 2011 tsunami: The Asahi Shimbun, accessed June 18, 2013, at http://ajw.asahi.com/article/0311disaster/recovery/AJ201306110061.

Hokugo, A., Nishino, T., and Inada, T., 2012, Damage and effects caused by tsunami fires-Fire Spread, Fire Fighting and Evacuation: Proceedings of the International Symposium on Engineering Lessons Learned from the 2011 Great East Japan Earthquake, March 1-4, 2012, Tokyo, Japan, p. 43-62, accessed August 27, 2013, at http://www.jaee.gr.jp/event/seminar2012/eqsympo/pdf/papers/113.pdf.

International Fund for Agricultural Development, 2005, Tsunami Response: United Nations, International Fund for Agricultural Development Web site, accessed May 17, 2013, at http://www.ifad.org/tsunami/index.htm.

International Tsunami Information Center, 2013, About tsunamis-Are tsunamis dangerous?: United Nations Educational, Scientific, and Cultural Organization Web site, accessed May 17, 2013, at http://itic.iocunesco.org/index.php?option $=$ com_content\&view $=$ category\&layout $=$ blog\&id $=1139 \&$ Itemid $=1139$ \&lang=en.

Iwabuchi, Y., Koshimura, S., and Imamura, F., 2006, Study on oil spread caused by the 1964 Niigata earthquake tsunami: Journal of Disaster Research, v. 1, p. 157-168.

Japan Fire and Disaster Management Agency, 2012, 2011 Great East Japan earthquake: Tokyo, Japan Fire Department Disaster Management Agency, status report, part 145 [13 March], 36 p. [in Japanese], accessed August 27, 2013, at http://www.fdma.go.jp/.

Japan Ministry of Agriculture, Forestry and Fisheries, 2012, FY2011 annual report on food, agriculture and rural areas in Japan: Japan Ministry of Agriculture, Forestry and Fisheries, accessed May 23, 2013, at http://www.maff.go.jp/j/wpaper/w_maff/h23/pdf/e_all.pdf.

Japan National Institute of Land and Infrastructure Management [NILIM] and Public Works Research Institute [PWRI], 2011, Quick survey report on bridge damage for the northeast Japan earthquake and tsunami: Japan National Institute of Land and Infrastructure Management and Public Works Research Institute, accessed August 27, 2013, at http://www.pwri.go.jp/caesar/event/pdf/110312kyouryou.pdf.

Johnson, R., 2011, Japan's 2011 earthquake and tsunami-Food and agriculture implications: Washington, D.C., Library of Congress, Congressional Research Service, accessed August 27, 2013, at http://www.fas.org/sgp/crs/row/R41766.pdf. 
Kajitani, Y., Chang, S.E., and Tatano, H., 2013, Economic impacts of the 2011 Tohoku-Oki earthquake and tsunami: Earthquake Spectra, v. 29, n. S1, p. S457-S478.

Kawasumi, H., 1968, General report on the Niigata earthquake of 1964: Tokyo, Tokyo Electrical Engineering College Press, 550 p.

Kelley Blue Book, 2013, Ten steps to buying a new car: Kelley Blue Book Web site, accessed June 23, 2013, at http://www.kbb.com/car-advice/car-buying/step-5-know-when-the-price-isright/.

Krausmann, E., and Cruz, A.M., 2013, Impact of the 11 March 2011, Great East Japan earthquake and tsunami on the chemical industry: Natural Hazards, v. 67, p. 811-828.

Laferrierre, R.R., Capt., 2011, Merchant vessel dispersal plan for Los Angeles-Long Beach harbors: San Pedro, U.S. Coast Guard, accessed August 27, 2013, at http://www.mxsocal.org/pdffiles/Coast\%20Guard\%20Dispersal\%20Plan.pdf.

Lander, J., Lockridge, P.A., and Kozuch, J., 1993, Tsunamis affecting the west coast of the United States 1806-1992: Boulder, Colo., National Oceanic and Atmospheric Administration, National Geophysical Data Center Key to Geophysical Research Documentation No. 29, 242 p., available at ftp://ftp.ngdc.noaa.gov/hazards/publications/Kgrd-29.pdf.

Moffatt and Nichol, 2007, Tsunami hazard assessment for the ports of Long Beach and Los Angeles: Moffatt and Nichol Engineers report prepared for the Ports of Long Beach and Los Angeles, Long Beach, Calif.

Morris, C., 1909, Morris's story of the Great Earthquake of 1908, and other historic disasters: Philadelphia?, p. 82.

National Agricultural Statistics Service [NASS], 2009, California - State and county data: United States Department of Agriculture, National Agricultural Statistics Service, 2007 Census of Agriculture, v. 1, Geographic Area Series, part 5

National Agricultural Statistics Service [NASS], 2013, United States Department of Agriculture, National Agricultural Statistics Service, accessed May 22, 2013, at http://www.nass.usda.gov/research/Cropland/sarsfaqs2.html\#Section3_9.0.

National Board of Fire Underwriters and Pacific Fire Rating Bureau, 1964, The Alaska earthquake-March 27, 1964: New York, N.Y., The National Board of Fire Underwriters

National Institute of Building Sciences and Federal Emergency Management Agency [NIBS and and FEMA], 2009, Multi-hazard loss estimation methodology hurricane model HAZUS®MH MR4 technical manual-Appendices: Washington, D.C., Federal Emergency Management Agency, $446 \mathrm{p}$.

Okal, E.A., Fritz, H.M., Raad, P.E., Synolakis, C.E., Al-Shijbi, Y., and Al-Saifi, M., 2006a, Oman field survey after the December 2004 Indian Ocean tsunami: Earthquake Spectra, v. 22, sec. 3, p. S203-S218.

Okal, E.A., Fritz, H.M., Raveloson, R., Joelson, G., Pancoskova, P., and Rambolamanana, G., 2006b, Madagascar field survey after the December 2004 Indian Ocean tsunami: Earthquake Spectra, v. 22, sec. 3, p. S263-S283.

Okal, E.A., Sladen, A., and Fritz, H.M., 2006c, Mauritius and Réunion Islands-Field survey after the December 2004 Indian Ocean tsunami: Earthquake Spectra, v. 22, sec. 3, p. S241S261.

Okamoto, S., 1984, Introduction to Earthquake Engineering: Tokyo, University of Tokyo Press, p. 78 and 80 .

Ono, K., 1968, Railroads - general report on the Niigata earthquake, in Kawasumi, H., and others, eds.: Tokyo, Tokyo Electrical Engineering College Press, p. 463-482. 
PIANC [World Association for Waterborne Transport Infrastructure] 2009, Mitigation of tsunami disasters in ports-Draft version III: PIANC Working Group 53.

Port of Oakland, 2013, Port of Oakland maritime facilities: Oakland, Calif., Port of Oakland, accessed June 29, 2013, at http://www.portofoakland.com/pdf/mari_map.pdf.

Porter, K., Wein, A., Alpers, C., Baez, A., Barnard, P., Carter, J., Corsi, A., Costner, J., Cox, D., Das, T., Dettinger, M., Done, J., Eadie, C., Eymann, M., Ferris, J., Gunturi, P., Hughes, M., Jarrett, R., Johnson, L., Le-Griffin, H.D., Mitchell, D., Morman, S., Neiman, P., Olsen, A., Perry, S., Plumlee, G., Ralph, M., Reynolds, D., Rose, A., Schaefer, K., Serakos, J., Siembieda, W., Stock, J., Strong, D., Sue Wing, I., Tang, A., Thomas, P., Topping, K., and Wills, C., 2010. Overview of the Arkstorm scenario: U.S. Geological Survey Open-File Report 2010-1312, p. 201, available at http://pubs.usgs.gov/of/2010/1312/.

Plumlee, G.S., Morman, S.A., and San Juan, C., 2013, Potential environmental and environmental-health implications of the SAFRR California tsunami scenario: U.S. Geological Survey Open-File Report 2013-1170-Fhttp://pubs.usgs.gov/of/2013/1170/F/.

Porter, K.A., Kennedy, R.P., and Bachman, R.E., 2007, Creating fragility functions for performance-based earthquake engineering: Earthquake Spectra. v. 23, sec. 2, p. 471-489, accessed January 3, 2013, at http://www.sparisk.com/pubs/Porter-2007-deriving-fragility.pdf.

Raichlen, F., 1972, Discussion of-Tsunami-responses of San Pedro Bay and Shelf, California: Journal of Waterways, Harbors and Coastal Engineering, v. 98.

Saint-Amand, P., 1961, Los terremotos de Mayo-Chile 1960: China Lake, Calif., U.S. Naval Ordnance Test Station, $39 \mathrm{p}$.

Scawthorn, C., 2013, Fire following tsunami-A contribution to the Next Wave tsunami scenario: SPA Risk LLC, accessed March 20, 2013, at http://www.sparisk.com/pubs/Scawthorn-2013-SAFRR-FFT.pdf.

Scawthorn, C., Ono, Y., Iemura, H., Ridha, M., and Purwanto, B., 2006, Performance of lifelines in Banda Aceh, Indonesia during the December 2004 great Sumatra earthquake and tsunami: Earthquake Spectra, v. 22, p. S511-S544.

Sekizawa, A., and Sasaki, K., 2012, Overview of fires following the great East-Japan earthquake: Proceedings of the International Symposium on Engineering Lessons Learned from the 2011 Great East Japan Earthquake, March 1-4, 2012, Tokyo, Japan, p. 43-62, accessed August 27, 2013, at http://www.jaee.gr.jp/event/seminar2012/eqsympo/pdf/papers/127.pdf.

Shuto, N., 1987, Spread of oil and fires due to tsunamis: International Tsunami Symposium, National Oceanic and Atmospheric Administration, Pacific Marine Environmental Laboratory, Seattle, Vancouver, B.C.

Shuto, N., 2006, Tsunamis, disasters and countermeasures: The International Workshop on Fundamentals of Coastal Effects of Tsunamis, December 26-28, 2006, Hilo, Pre-meeting materials, accessed December 2, 2012, at http://www.tsunami.oregonstate.edu/workshop/2006/doc/premeeting/Shuto.pdf.

Spaeth, M.G., and Berkman, S.C., 1967, The tsunami of March 28, 1964-As recorded at tide stations: U.S. Department of Commerce, Coast and Geodetic Survey, Technical Bulletin No. 33

Sturman, G.G., 1973, The Alaska railroad, the great Alaska earthquake of 1964-Engineering: National Academy of Sciences, p. 958-986.

Subagyono, K., Sugiharto, B., and Jaya, B., 2005, Rehabilitation strategies of the tsunami affected agricultural areas in Nangroe Aceh Darussalam, Indonesia - in Salt-affected soils from sea water intrusion: Strategies for Rehabilitation and Management Regional Workshop, 
Bangkok, Thailand, 23 p., accessed May 22, 2013, at http://www.cgiar.org/wwwarchive/www.cgiar.org/tsunami/publications/files/rehabilitationstrategies.pdf.

Suppasri, A., Mas, E., Charvet, I., Gunasekera, R., Imai, K., Fukutani, Y., Abe, Y., and Imamura, F., 2013, Building damage characteristics based on surveyed data and fragility curves of the 2011 Great East Japan tsunami: Natural Hazards, v. 66, p. 319-341.

TrueCar, Inc., 2013, TrueCar, Inc., Web site, accessed June 23, 2013, at http://www.truecar.com. U.S. Census Bureau, 2012a, Table 1060 - New motor vehicle sales and car production-19902010: U.S. Census Bureau, accessed June 23, 2013, at http://www.census.gov/compendia/statab/2012/tables/12s1060.pdf.

U.S. Census Bureau, 2012b, 2010 U.S. export and import data for Port of Los Angeles and Port of Long Beach: U.S. Census Bureau, USA Trade Online Web site, accessed October 25, 2012, at https://usatrade.census.gov/.

U.S. Census Bureau, 2013, FT920; U.S. merchandise trade-Selected highlights: U.S. Census Bureau Web site, accessed May 1, 2013, at $h t t p: / / w w w . c e n s u s . g o v / f o r e i g n-t r a d e / P r e s s-$ Release/ft920 index.html.

United Nations Food and Agriculture Organization [FAO], 2005a, FAO Field Guide—20 things to know about the impact of salt water on agricultural land in Aceh Province: United Nations Food and Agriculture Organization, accessed May 13, 2013, at http://www.fao.org/ag/tsunami/docs/saltwater-guide.pdf.

United Nations Food and Agriculture Organization [FAO], 2005b, Spotlight—After the tsunami: United Nations Food and Agriculture Organization, Agriculture and Consumer Protection Department Web site, accessed May 17, 2013, at http://www.fao.org/ag/magazine/0502sp2.htm.

Wardlow, B.D. and Egbert, S.L., 2003, A state-level comparative analysis of the GAP and NLCD land-cover data sets: Photogrammetric Engineering \& Remote Sensing. v. 69, no. 12, p. $1387-1397$

Willis, B., 1929, Earthquake Conditions in Chile: Washington, D.C., Carnegie Institution of Washington

Wilson, B.W., 1971, Tsunami-responses of San Pedro Bay and Shelf, California: Journal of Waterways Harbors and Coastal Engineering, v. 97.

Wilson, R.I., Admire, A.R., Borrero, J.C., Dengler, L.A., Legg, M.R., Lynett, P., Mccrink, T.P., Miller, K.M., Ritchie, A., Sterling, K., and Whitmore, P.M., 2012, Observations and impacts from the 2010 Chilean and 2011 Japanese tsunamis in California (USA): Pure and Applied Geophysics. v. 169, sec. 7, p. 1-21.

Yamada, T., Hiroi, U., and Sakamoto, N., 2012, Aspects of fire occurrences caused by tsunami: Proceedings of the International Symposium on Engineering Lessons Learned from the 2011 Great East Japan Earthquake, March 1-4, 2012, Tokyo, Japan, p. 43-62, accessed August 27, 2013, at $h t t p: / / w w w . j a e e . g r . j p / e v e n t / s e m i n a r 2012 /$ eqsympo/pdf/papers/71.pdf.

Yanev, P.I., Scawthorn, C., and National Center for Earthquake Engineering Research (U.S.) and EQE International, 1993, Hokkaido Nansei-Oki, Japan earthquake of July 12, 1993: Buffalo, N.Y., National Center for Earthquake Engineering Research

Yashinsky, M., 2012, Lessons for Caltrans from the 2011 great east Japan earthquake and tsunami: Proceedings of the International Symposium on Engineering Lessons Learned from the 2011 Great East Japan Earthquake, March 1-4, 2012, Tokyo, Japan, p. 43-62, accessed August 27, 2013, at http://www.jaee.gr.jp/event/seminar2012/eqsympo/pdf/papers/192.pdf. 
\#USES I

\section{Potential Environmental and Environmental-Health Implications of the SAFRR Tsunami Scenario in California}

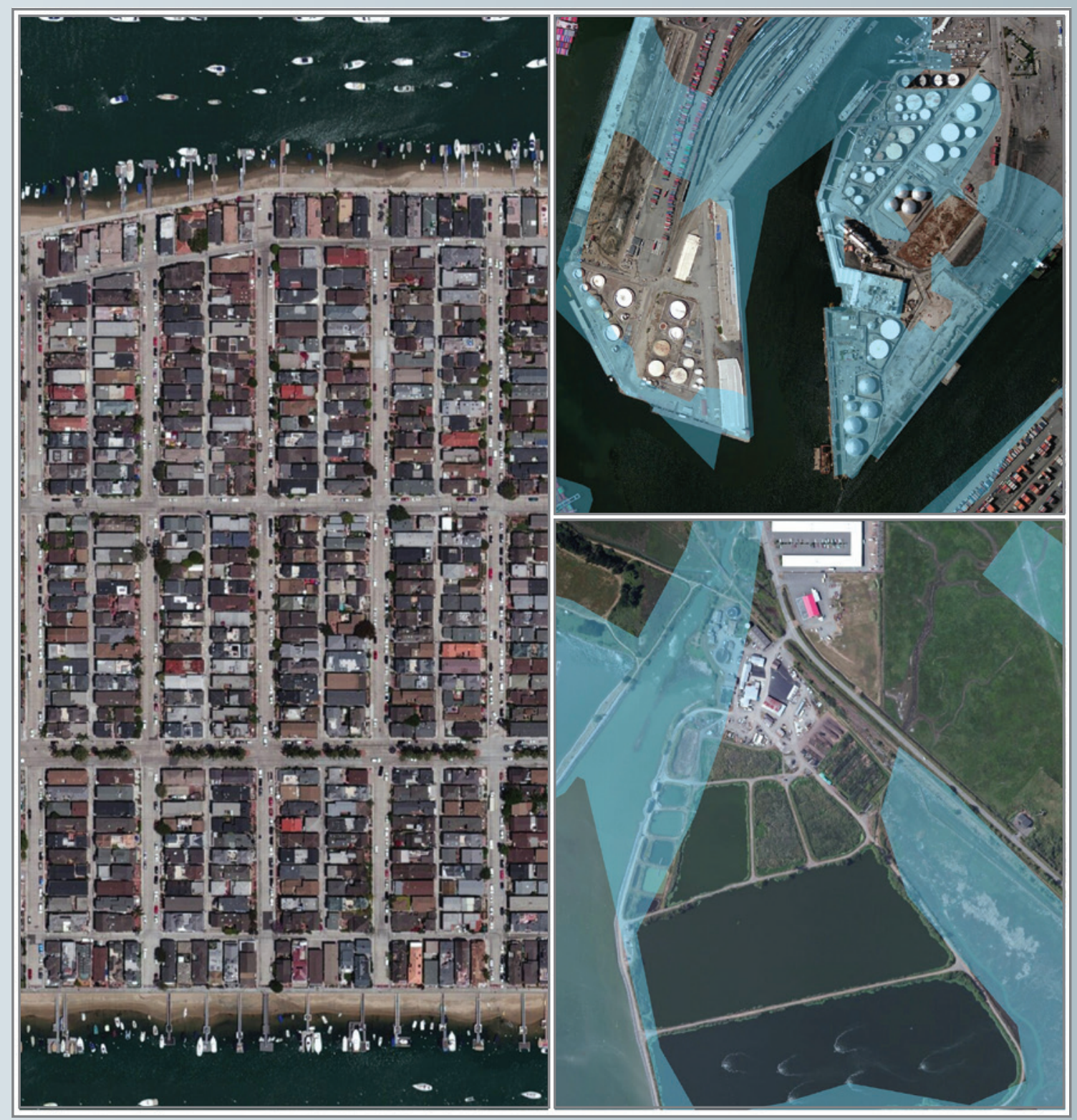

Open-File Report 2013-1170-F

California Geological Survey Special Report 229 
COVER: On the left, a satellite image shows a portion of one of the densely built residential areas indicated to lie completely within the scenario tsunami inundation zone. On the upper right, a satellite image shows one of the marine oil terminals indicated to lie partially within the scenario tsunami inundation zone (transparent blue-green). On the lower right, a satellite image shows a wastewater treatment facility indicated to lie partially within the scenario inundation zone ((transparent blue-green). 
The SAFRR (Science Application for Risk Reduction) Tsunami Scenario

Stephanie Ross and Lucile Jones, Editors

\section{Potential Environmental and Environmental-Health Implications of the SAFRR Tsunami Scenario in California}

By Geoffrey S. Plumlee, Suzette A. Morman, and Carma San Juan

Open-File Report 2013-1170-F

California Geological Survey Special Publication 229

U.S. Department of the Interior

U.S. Geological Survey 


\section{U.S. Department of the Interior \\ SALLY JEWELL, Secretary}

U.S. Geological Survey

Suzette M. Kimball, Acting Director

U.S. Geological Survey, Reston, Virginia 2013

For product and ordering information:

World Wide Web: http://www.usgs.gov/pubprod

Telephone: 1-888-ASK-USGS

For more information on the USGS-the Federal source for science about the Earth, its natural and living resources, natural hazards, and the environment:

World Wide Web: http://www.usgs.gov

Telephone: 1-888-ASK-USGS

Suggested citation:

Plumlee, G.S., Morman, S.A., and San Juan, C., 2013, Potential Environmental and EnvironmentalHealth Implications of the SAFRR Tsunami Scenario in California, chap. F, in Ross, S.L., and Jones, L.M., eds., The SAFRR (Science Application for Risk Reduction) Tsunami Scenario: U.S. Geological Survey Open-File Report 2013-1170, 34 p., http://pubs.usgs.gov/of/2013/1170/f/.

Any use of trade, product, or firm names is for descriptive purposes only and does not imply endorsement by the U.S. Government.

Although this information product, for the most part, is in the public domain, it also may contain copyrighted materials as noted in the text. Permission to reproduce copyrighted items must be secured from the copyright owner. 


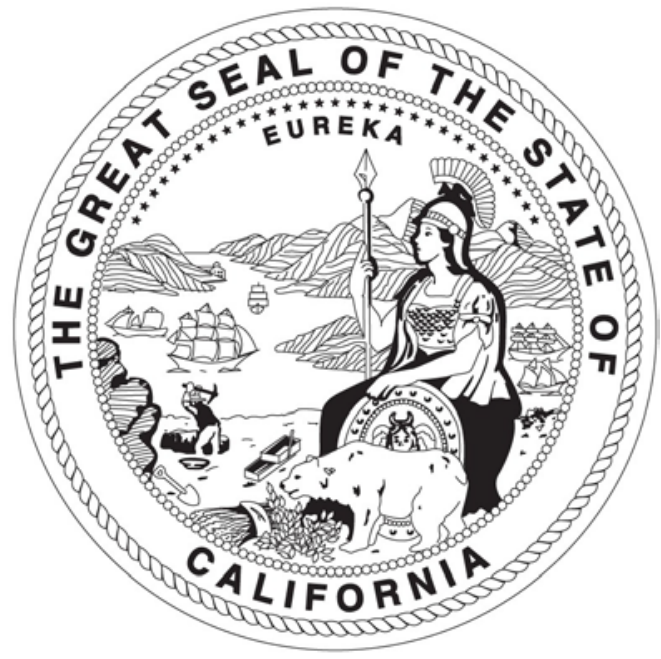

STATE OF CALIFORNIA EDMUND G. BROWN JR. GOVERNOR

THE NATURAL RESOURCES AGENCY JOHN LAIRD SECRETARY FOR RESOURCES

\author{
DEPARTMENT OF CONSERVATION \\ MARK NECHODOM \\ DIRECTOR
}

\title{
CALIFORNIA GEOLOGICAL SURVEY JOHN G. PARRISH, Ph.D. \\ STATE GEOLOGIST
}




\section{Contents}

Abstract.

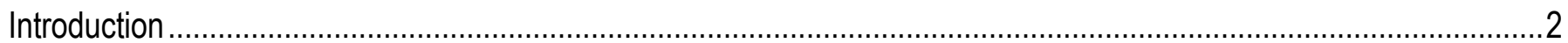

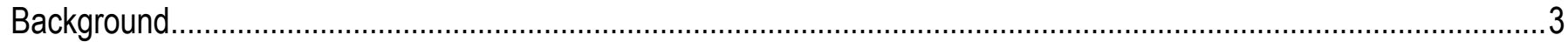

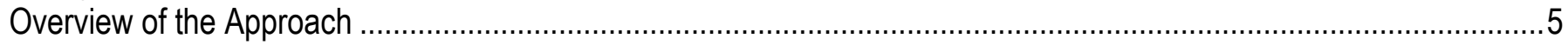

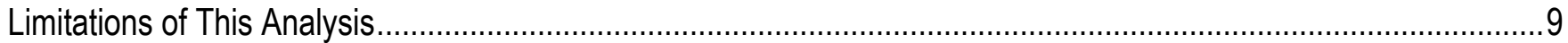

Potential Contamination from Inundation of and Damage to Ports, Naval Yards, Harbors, and Marinas .......................

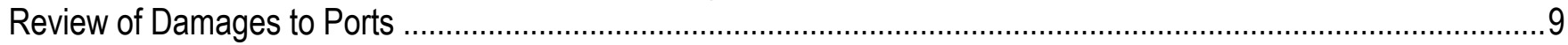

Debris

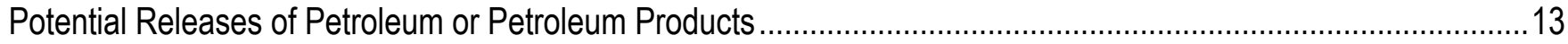

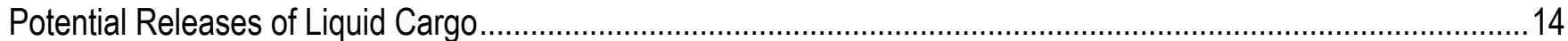

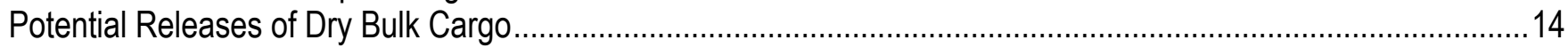

Potential Impacts from Inundated Shipbuilding and Boat Repair Yards ............................................................

Scour and Redistribution of Contaminated Harbor Sediments ...........................................................................16

Potential Contamination from Inundation of and Damage to Residential and Commercial Areas...............................17

Potential Contamination from Significant Point Sources .............................................................................. 19

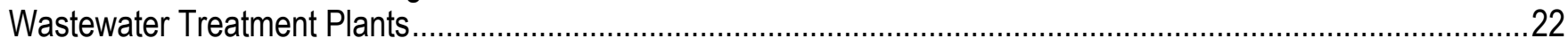

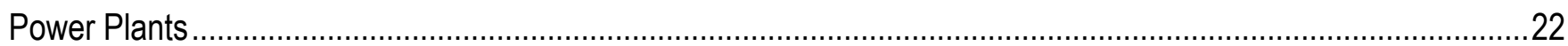

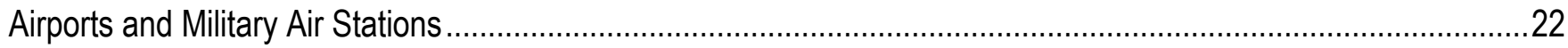

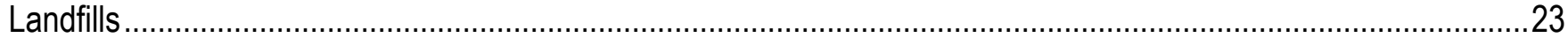

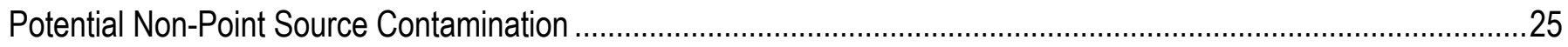

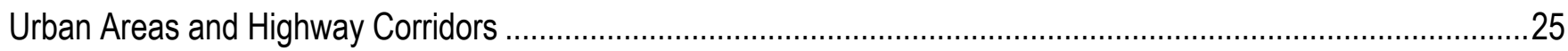

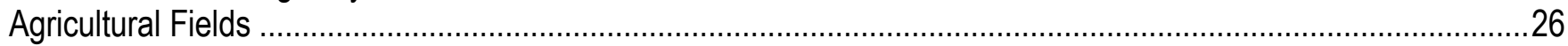

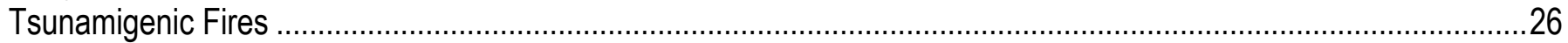

Plausible Environmental Impacts of Damages, Debris, and Contamination...............................................................2

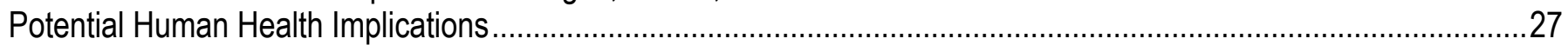

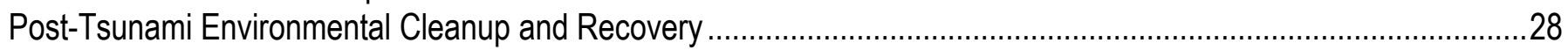

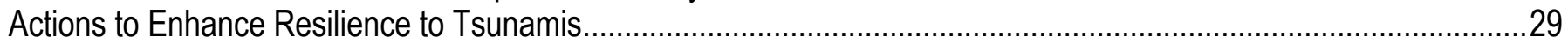

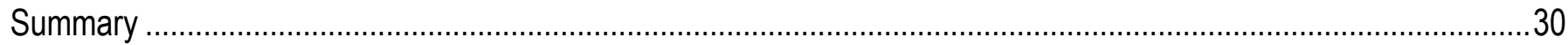

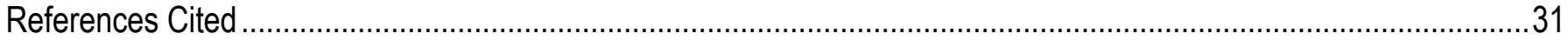




\title{
Potential Environmental and Environmental-Health Implications of the U.S. Geological Survey Science Application for Risk Reduction California Tsunami Scenario
}

By Geoffrey S. Plumlee, Suzette A. Morman, and Carma San Juan

\begin{abstract}
The California Tsunami Scenario models the impacts of a hypothetical, yet plausible, tsunami caused by an earthquake offshore from the Alaska Peninsula. In this chapter, we interpret plausible tsunami-related contamination, environmental impacts, potential for human exposures to contaminants and hazardous materials, and implications for remediation and recovery.

Inundation-related damages to major ports, boat yards, and many marinas could release complex debris, crude oil, various fuel types and other petroleum products, some liquid bulk cargo and dry bulk cargo, and diverse other pollutants into nearby coastal marine environments and onshore in the inundation zone. Tsunami-induced erosion of contaminated harbor bottom sediments could re-expose previously sequestered metal and organic pollutants (for example, organotin or DDT).

Inundation-related damage to many older buildings could produce debris containing lead paint, asbestos, pesticides, and other legacy contaminants. Intermingled household debris and externally derived debris and sediments would be left in flooded buildings. Post tsunami, mold would likely develop in inundated houses, buildings, and debris piles. Tsunamigenic fires in spilled oil, debris, cargo, vehicles, vegetation, and residential, commercial, or industrial buildings and their contents would produce potentially toxic gases and smoke, airborne ash, and residual ash/debris containing caustic alkali solids, metal toxicants, asbestos, and various organic toxicants. Inundation of and damage to wastewater treatment plants in many coastal cities could release raw sewage containing fecal solids, pathogens, and waste chemicals, as well as chemicals used to treat wastewaters.

Tsunami-related physical damages, debris, and contamination could have short- and longer-term impacts on the environment and the health of coastal marine and terrestrial ecosystems. Marine habitats in intertidal zones, marshes, sloughs, and lagoons could be damaged by erosion or sedimentation, and could receive an influx of debris, metal and organic contaminants, and sewage-related pathogens. Debris and re-exposed contaminated sediments would be a source of sea- or rain-water-leachable metal and organic contaminants that could pose chronic toxicity threats to ecosystems.

If human populations are successfully evacuated prior to the tsunami arrival, there would be no or limited numbers of drownings, other casualties, or related injuries, wounds, and infections. Immediately after the tsunami, human populations away from the inundation zone
\end{abstract}


could be transiently exposed to airborne gases, smoke, and ash from tsunamigenic fires. Cleanup and disposal, particularly of hazardous materials, would pose substantial logistical challenges and economic costs. Given the high value of the coastal residential and commercial properties in the inundation zone, it can be postulated that there would be substantial insurance claims for environmental restoration, mold mitigation, disposal of debris that contains hazardous materials, and costs of litigation related to environmental liability.

Post-tsunami cleanup, if done with appropriate mitigation (for example, dust control), personal protection, and disposal measures, would help reduce the potential for cleanup-worker and resident exposures to toxicants and pathogens in harbor waters, debris, soils, ponded waters, and buildings. A number of other steps can be taken by governments, businesses, and residents to help reduce the environmental impacts of tsunamis and to recover more quickly from these environmental impacts. For example, development of State and local policies that foster rapid assessment of potential contamination, as well as rapid decision making for disposal options should hazardous debris or sediment be identified, would help enhance recovery by speeding cleanup.

\section{Introduction}

The tsunami scenario, developed by the U.S. Geological Survey (USGS) Science Applications for Risk Reduction (SAFRR) Project, models the generation, hydrology, and impacts on the California coast of a hypothetical yet plausible tsunami triggered by an earthquake in the subduction zone offshore of the Alaska Peninsula. A primary goal of this scenario is to help educate emergency planners, businesses, universities, government agencies, and other stakeholders about plausible effects of future tsunamis, so that they can be better prepared for and their impacts can be better mitigated.

In the scenario tsunami, seismologists designed a scientifically plausible earthquake event off the Alaska Peninsula. Using information generated by the seismologists for the earthquake, other experts in marine and coastal hydrology modeled the propagation of tsunami waves from the source area to the target region along the California coast, with high resolution modeling of inundation along the California coast and in selected harbors. Based on the inundation and current modeling, other experts provided input on plausible damages that would result from the scenario tsunami (Porter and others, 2013).

In this report, we interpret plausible tsunami-related environmental impacts and contamination, plausible human exposures to contamination and hazardous materials, implications for human health impacts, and implications for post-tsunami remediation and recovery. Our study integrates (1) information on environmental and health impacts of past tsunamis, (2) a qualitative analysis of plausible environmental impacts that would result from tsunami-related damages modeled by other scenario colleagues, and (3) a qualitative GIS-based analysis of areas likely to be inundated by either the scenario tsunami or any future tsunamis that reach the full extent of historical tsunami inundation zones mapped by the California Emergency Management Agency (Cal OES).

This analysis is similar to ones conducted for the ShakeOut earthquake and ARkStorm winter storm scenarios (Plumlee and others, 2012, 2013). Our results indicate that the inundation, resulting damages, and debris from scenario tsunami on the California coasts and ports could (1) cause adverse impacts on the environment as a direct result of the tsunami, (2) pose challenges for debris cleanup and environmental restoration following the tsunami, and (3) plausibly cause some exposures of local populations to chemical and pathogen contaminants. 


\section{Background}

Tsunamis caused by submarine subduction zone earthquakes, coastal or submarine volcanic eruptions, or submarine landslides can cause massive damage to the natural and built environments in low-lying coastal areas. This can, in turn, lead to widespread environmental contamination and potential health impacts on affected ecosystems and exposed human populations. Damages and resulting environmental and health impacts are greatest when the tsunami source is close to the affected land areas, such as the damages caused in Indonesia and Thailand by the 2004 Indonesia earthquake and tsunami (Basnayake and others, 2005; Srinivas and Nakagawa, 2008), and the damages in Japan from the 2011 Tohoku earthquake and tsunami (Bird and Grossman, 2011; Shibata and others, 2012).

Due to their generally lower wave heights and energy, damages from distant sourced tsunamis (termed "teletsunamis") typically are less intense and spatially extensive than those produced by tsunamis from nearby sources, but nonetheless can cause substantial damages. Recent examples include the damages to several California ports from the 2010 Chilean earthquake and the 2011 Tohoku earthquake (Wilson and others, 2012, 2013a).

Tsunamis can cause contamination of nearshore marine and onshore coastal environments by introducing diverse debris, organic and inorganic chemicals, and pathogens. Examples include (1) remobilization of previously contaminated sediments from harbor bottoms (Wilson and others, 2012, 2013a); (2) release of contaminants or toxicant-bearing debris from damaged port facilities, berthed ships or small watercraft, and inundated coastal communities or industrial/commercial facilities (fig. 1; Ratnapradipa and others, 2012; Shibata and others, 2012; Australian Broadcasting Corporation, 2013); (3) tsunami-triggered fires (Yamada and others, 2011); and (4) sewage releases from damaged wastewater-treatment infrastructure (Bird and Grossman, 2011; Tanabe and Subramanian, 2011; Shibata and others, 2012). Shallow aquifers in the areas of tsunami inundation can be contaminated by seawater, and transient salinization of agricultural fields and die offs of terrestrial vegetation because of saltwater poisoning have been noted in tsunami inundation areas (fig. 1; United Nations Environment Program, 2007; Yoshii and others, 2012; Chagué-Goff and others, 2012). The types and amounts of environmental contamination will vary according to the source.

The recent earthquake-driven tsunamis in Indonesia and Japan underscore the types of direct impacts on public health that major tsunamis can cause (Keim, 2011). In addition to large numbers of drownings, large tsunamis can cause various other health impacts that are uncommon in other types of disasters. These include fatalities, trauma, penetrating injuries, and wounds resulting from tsunami-borne debris, and the post-disaster development of wound infections and tetanus cases. Another unusual impact is the development of tsunami lung in large numbers of people who nearly drown in tsunami floodwaters. Tsunami lung is a necrotizing lung infection caused by pathogens commonly associated with seawater aspiration, and possibly other uncommon pathogens not associated with seawater (Keim, 2011). Tsunami-triggered fires also could result in fatalities. 


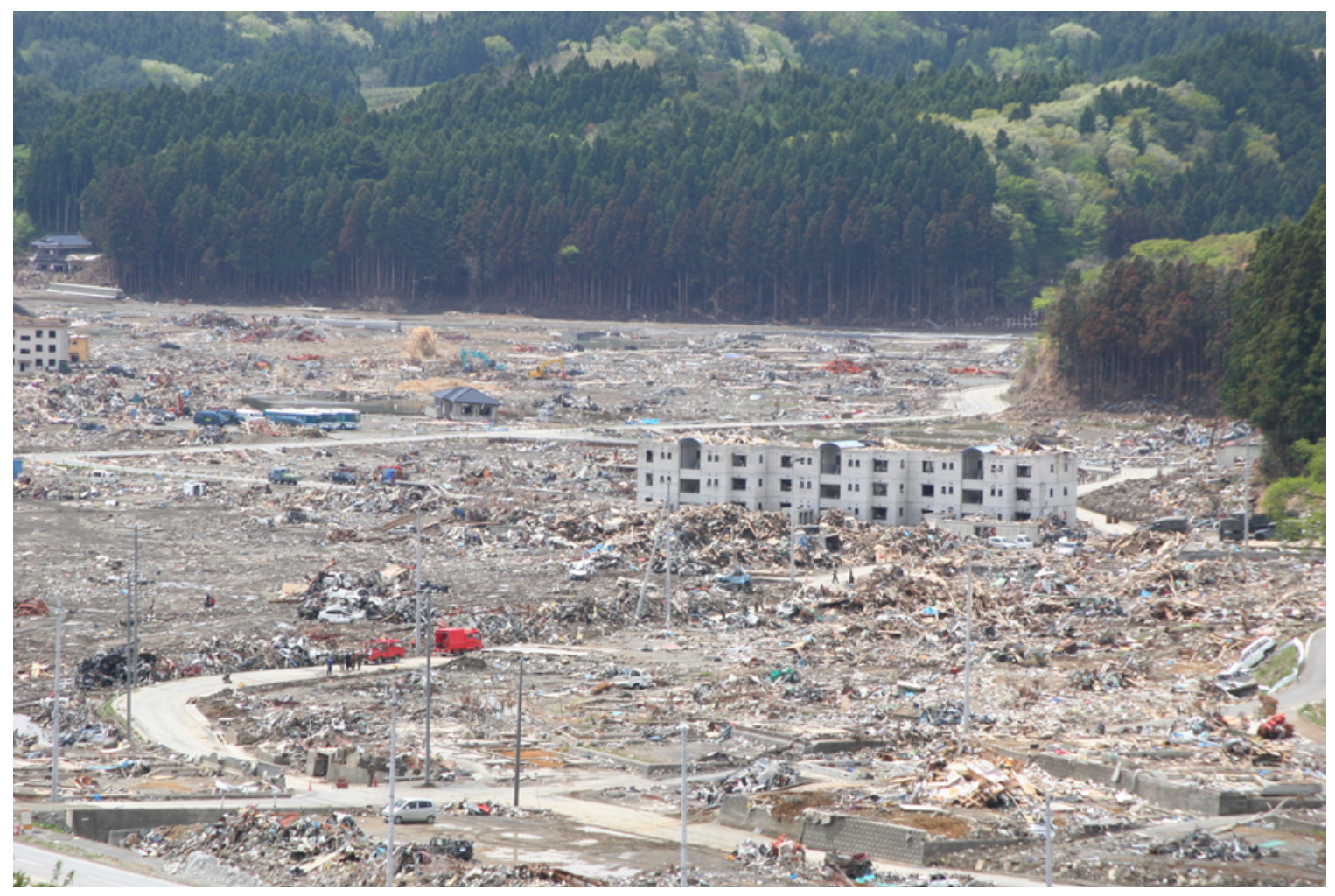

Figure 1. Photograph of the damages caused by the massive tsunami generated by the March 2011 Tohoku earthquake that devastated the northeastern coast of Japan, taken in May 2011 in the Sanriku area. Few buildings were left standing, and extensive debris deposits were left behind. Also note the dying trees at the base of the hills in the background, which were closest to the tsunami inundation area-these were presumably suffering the effects of salt water poisoning. The California scenario tsunami would not cause nearly as extensive or complete devastation as seen in Japan, but would likely cause some damage to buildings in the inundated areas, and leave behind debris. Photograph by Bruce Jaffe, U.S. Geological Survey.

In the days and months following a tsunami, additional health impacts can develop. As with other types of natural disasters, outbreaks of infectious diseases, such as cholera, most commonly occur in overcrowded refugee camps where refugees lack access to adequate medical care and cannot practice good hygiene. Lack of accessible medical care also can exacerbate preexisting medical conditions. Another substantial concern is the development of psychosocial illnesses, such as post-traumatic stress disorder. As with other flood-related disasters, posttsunami mold development may be a substantial health concern for people cleaning up and reoccupying flooded buildings (Manuel, 2013). Particularly in developed countries, loss of electrical power commonly results in the widespread use of gas-powered generators, which can, in turn, increase the potential for carbon monoxide poisoning.

The number of people who suffer direct health impacts from tsunamis is strongly influenced by many factors, including the type of the triggering event, proximity to tsunami source, offshore and onshore coastal topography, prevailing currents, tidal stage at the time of impact, population magnitudes in inundated areas, presence or absence of wave mitigation seawalls, building practices in the inundated areas, and the effectiveness of advance tsunami warnings and evacuation efforts prior to tsunami arrival. For example, the 2004 Indian Ocean 
tsunami triggered by the earthquake in Sumatra caused more than 225,000 deaths (U.S. Geological Survey, 2013) in nearby coastal areas, and tens of thousands of deaths in coastal Sri Lanka (900 mi away) and coastal India (more than 1,200 mi away). The tsunami triggered by the 2011 Japan Tohoku earthquake resulted in more than 15,000 fatalities in nearby coastal areas (National Oceanic and Atmospheric Administration, 2013). The 1946 Aleutian Island teletsunami (which occurred prior to the implementation of the Pacific Ocean tsunami warning system) killed more than 150 people in Hawaii. In contrast, teletsunamis from the 2010 Chile earthquake and the 2011 Japan Tohoku earthquake combined caused zero deaths and one death, respectively, when they hit the western coast of the United States.

Although a number of studies have summarized environmental impacts from recent tsunamis, health impacts that resulted from exposures to environmental contaminants (other than the pathogen-related infections noted previously) generally have not been identified or described in detail. This may be because (1) there have been relatively few modern tsunamis with extensive environmental impacts, (2) the heaviest exposures are transient, (3) contamination-related health impacts are small in magnitude compared to the much more visible direct health impacts, (4) it may take years after the disaster for adverse health impacts to develop, and (or) (5) adverse health impacts that are discovered may not be conclusively linked to tsunami-related environmental contamination causes.

\section{Overview of the Approach}

Based on the locations, types, and nature of the plausible damages to ports, harbors, marinas, and built areas described by Porter and others (2013) and other chapters in this full report, coupled with information on environmental impacts from past tsunamis, we inferred likely environmental consequences and potential for human exposures to scenario tsunamitriggered damages, debris, and contamination. We used Geographic Information Systems (GIS) analysis software ARC GIS to understand coastal areas where tsunami inundation could affect various potential sources of contamination. For the extent of inundation, we considered the plausible extent of inundation modeled by the tsunami scenario and the Cal OES zone of maximum inundation (Wilson and others, 2008, Barberopoulou and others, 2009), which was mapped based on the extent of flooding from all maximum considered, local and distant tsunami sources (fig. 2). The Cal OES inundation zone extends farther inland than the predicted SAFRR scenario inundation zone except for a few places; because of the higher resolution modeling, the SAFRR scenario shows inundation traveling further up some rivers and further onshore in areas of sudden topographic change. Examining both inundation zones allowed us to consider the scenario impacts and potential impacts from more extensive tsunamis similar to some that have occurred in the past. Where available, we also incorporated information on tsunami currents and wave height modeled by the scenario. This was particularly useful, for example, to evaluate where in the Ports of Los Angeles and Long Beach high currents could lead to substantial redistribution of contaminated harbor bottom sediments.

Using ARC GIS, we digitally overlaid tsunami inundation extent and depth maps on satellite/geography coverages to determine locations and sizes of both potential sources of contamination in the inundation zone and important features that could be adversely affected by inundation or tsunami-related contamination. Examples include: (1) harbors, marinas, and boat yards; (2) residential, commercial, or industrial areas; agricultural fields; (3) facilities such as oil refineries, power plants and wastewater treatment plants; and (4) lagoons, sloughs, or estuaries. The U.S. Environmental Protection Agency (EPA) Facilities Registry System database (U.S. 
Environmental Protection Agency Facilities Registry System, 2011) was used to further identify and locate environmentally significant facilities (for example, wastewater-treatment plants, oil refineries, chemical manufacturing plants, gas stations, hospitals, schools) that would occur within or near the scenario or State inundation zones (fig. 3). State GIS coverages were used to identify critical species habitats in nearshore marine areas that could be affected by the tsunami (fig. 2). The mapping feature of various commercial web sites, which list county or municipal assessors data on individual mapped properties, were used to understand general ranges in age and value of residences located within the scenario and State inundation zones. Knowing the age of a building provides key insights into the potential contaminants that could be released: for example, buildings older than the late 1970s to early 1980s have a greater likelihood of containing legacy building materials, such as asbestos and lead-based paint, and legacy pesticides (Plumlee and others, 2012).

The general types of contamination that can be released from various potential sources in the inundation zone are relatively well understood (Plumlee and others, 2013). Once the potential sources and their plausible types of environmental contaminants were identified, we applied a general knowledge of contaminant transport, fate, and impacts to develop a qualitative understanding of how tsunami-related environmental damages and contamination might vary along the California coast. We then evaluated plausible contaminant exposure pathways to human populations. 


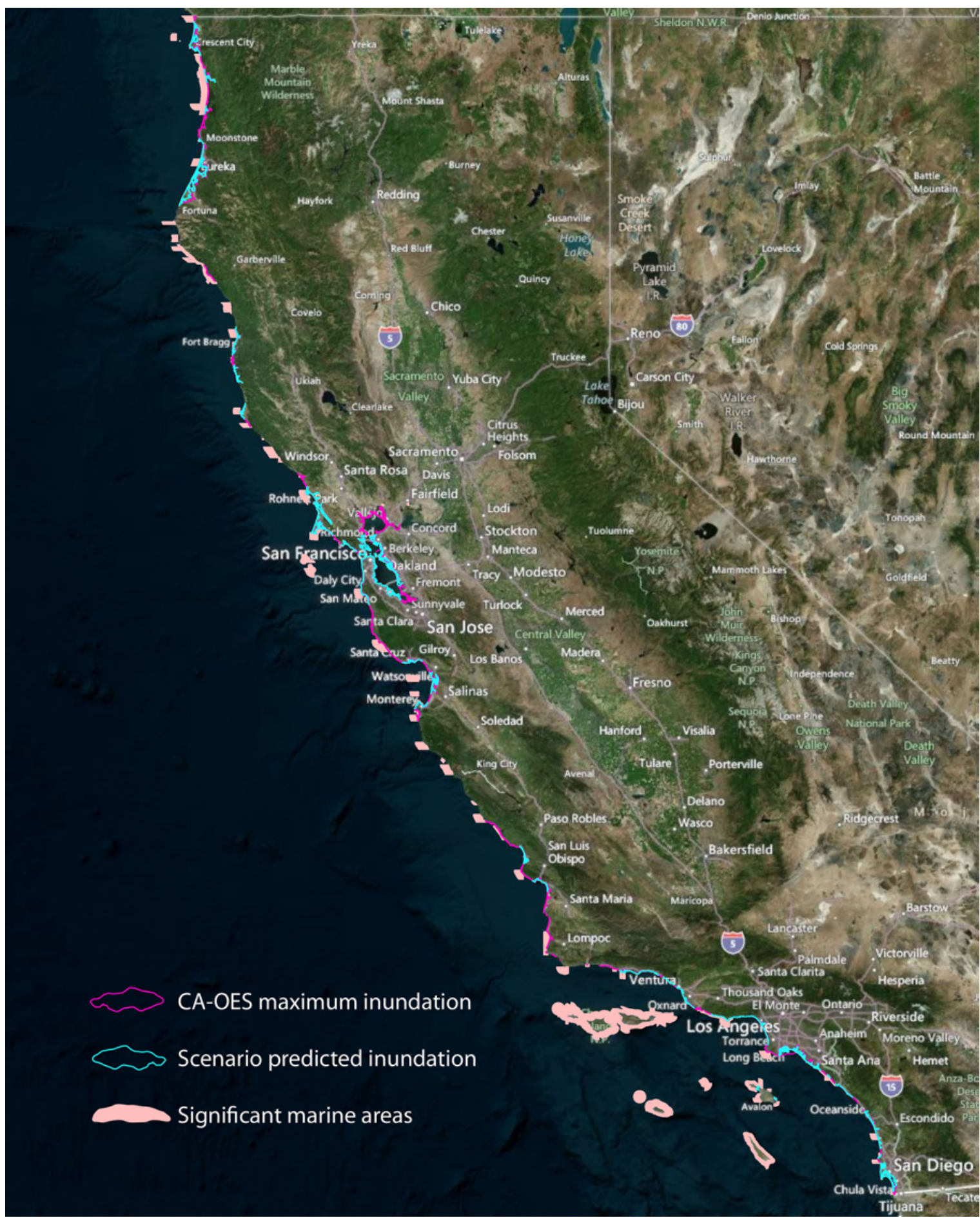

Figure 2. Map showing extent of the scenario predicted inundation zone and, where the coverage is more extensive, the California Emergency Management Agency (Cal OES) maximum tsunami inundation zone (Wilson and others, 2008; Barberopoulou and others, 2009). Significant marine areas (Areas of Special Biological Significance, State Marine Life Refuges, and State Marine Protected Areas) are also shown. 


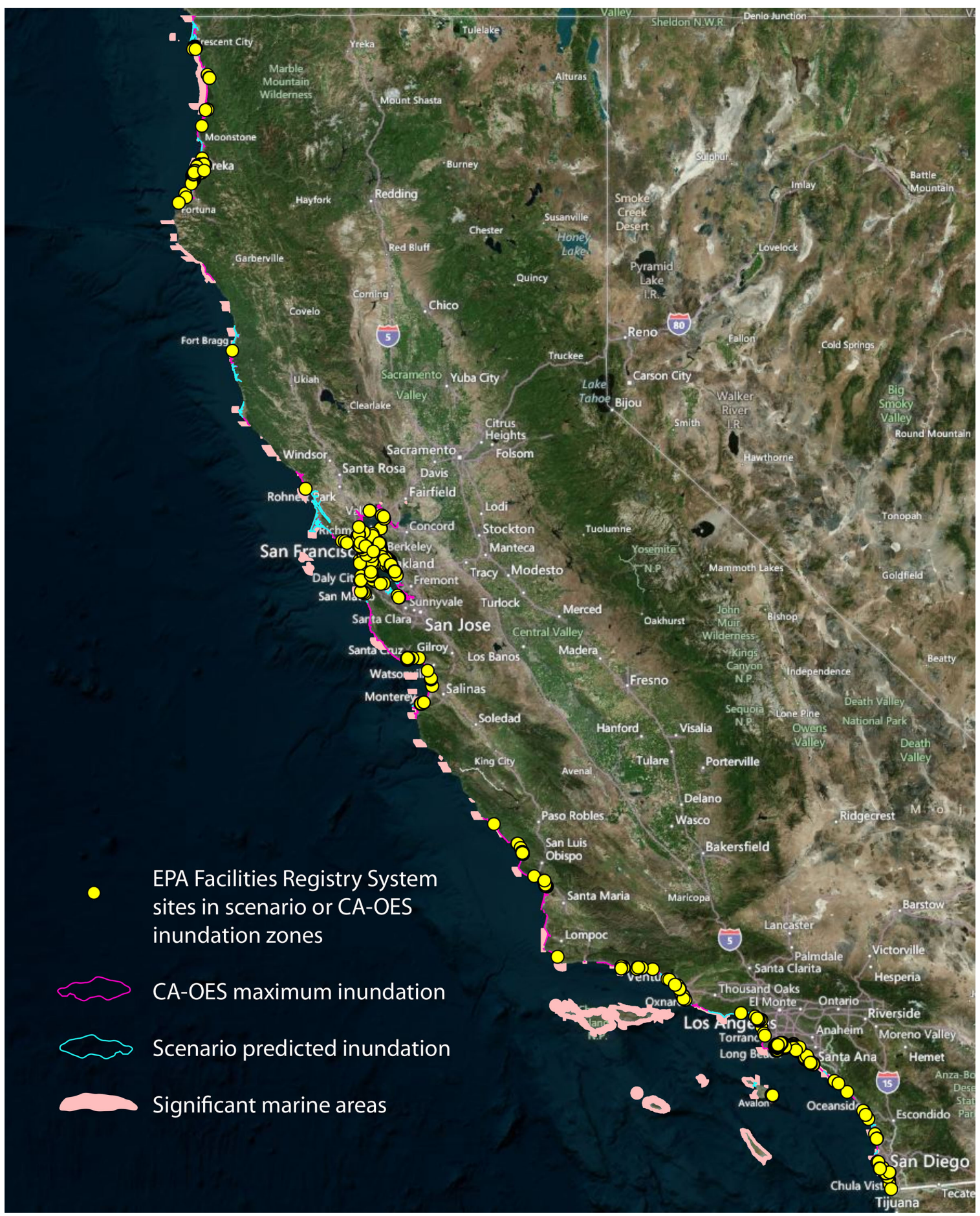

Figure 3. Map showing locations of environmentally significant facilities from the U.S. Environmental Protection Agency Facilities Registry System database (U.S. Environmental Protection Agency Facilities Registry System, 2011) indicated to fall within the predicted scenario inundation zone or the California Emergency Management Agency (Cal OES) maximum tsunami inundation zone. 


\section{Limitations of This Analysis}

As noted by other chapters in this volume, there are uncertainties in the results of the modeled scenario tsunami inundation results. There also are uncertainties in the databases and other information available for our environmental analysis. Examples of these uncertainties include (1) incorrect locations or other incorrect information on environmentally significant facilities; (2) lack of detailed knowledge of potential cargos transported through ports that could be released as a result of tsunami damages; (3) lack of detailed information on the specific contaminants that are present in buildings, commercial facilities, or industrial facilities; (4) lack of information on the vulnerability of specific facilities, warehouses, or buildings to tsunami impacts and damages; and (5) lack of information on the magnitude of possible contaminant releases that could result from specific sources if they were to be damaged. As a result, this approach should only be considered as the first of multiple steps toward a more quantitative, predictive approach to understanding the potential sources, types, environmental behavior, and environmental and health implications of contaminants that could be released into the environment by coastal tsunamis.

\section{Potential Contamination from Inundation of and Damage to Ports, Naval Yards, Harbors, and Marinas}

Both the scenario and State inundation zones extend well into major coastal ports (San Diego, Los Angeles, Long Beach, Hueneme, San Francisco, Redwood City, Oakland, Richmond, Benicia, Humboldt Bay), major active or former naval yards or ports (San Diego, San Francisco, Vallejo), and harbors (for example, Huntington Beach, Newport Bay, Crescent City). Marinas in nearly every coastal city and town are also in both inundation zones.

\section{Review of Damages to Ports}

Porter and others (2013) detail the potential damages that the scenario tsunami could cause to the Ports of Los Angeles and Long Beach (fig. 4), and provide general overviews of potential damages to other ports (San Diego, San Francisco, Oakland, Richmond, and Humboldt Bay), several harbors, and a number of coastal marinas. Plausible impacts they identified at the Port of Long Beach (POLB) included:

- Inundation of specific dock areas and structures, such as administration buildings;

- Damages to docks, piers, and pilings;

- Some damages to containerized cargo and to dry bulk cargo (gypsum, petroleum coke, prilled sulfur, salt), but no damages to liquid bulk cargo;

- Damage to 2000 import vehicles, forklifts, dryage trucks, and other vehicles parked on docks; and

- Possible unmooring of large cargo vessel or tanker, but without release of oil.

Plausible impacts identified by Porter and others (2013) at Port of Los Angeles (POLA) include

- Inundation of specific dock areas;

- Limited damages to containerized cargo;

- $\quad$ Some damages to dry bulk cargo (industrial borates);

- No damages to bulk cargo;

- Damages to about 650 import cars on the docks; 
- Sinking of and(or) extensive damages to thousands of small watercraft, as well as damages to facilities at 16 port marinas.

The scenario model predicted sufficiently high currents in some parts of both POLA and POLB to result in significant sediment scour and redeposition.

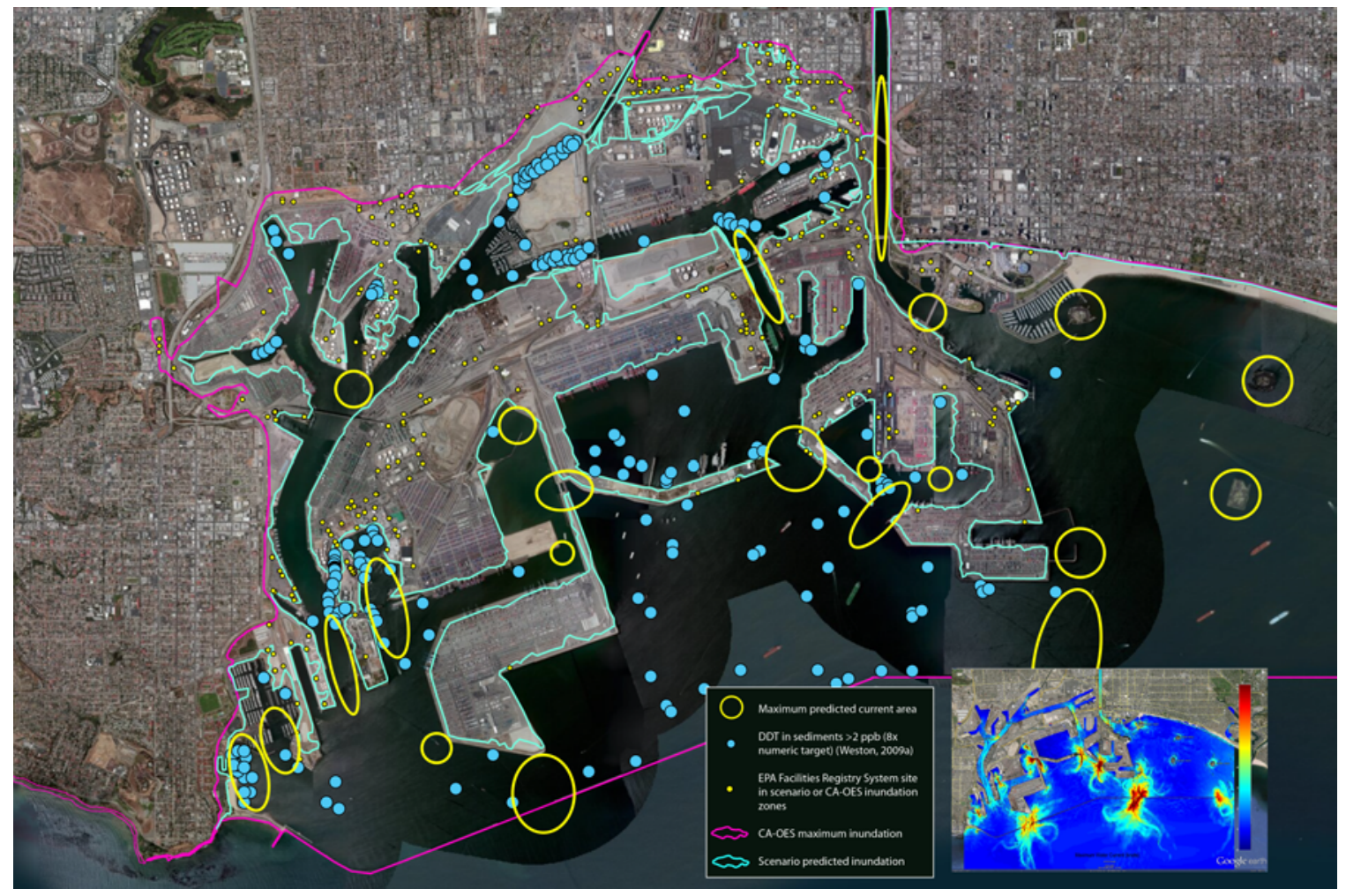

Figure 4. Satellite image of the Ports of Los Angeles and Long Beach, with map overlays showing: (a) boundaries of the scenario (cyan) and California Emergency Management Agency (Cal OES) maximum (magenta) inundation zones; (b) U.S. Environmental Protection Agency (EPA) Facilities Registry System sites (yellow dots, U.S. Environmental Protection Agency Facilities Registry System, 2011) within the inundation zones; (c) DDT concentrations (blue dots) exceeding 16 nanograms per gram (8 times the numeric target concentration) in samples of harbor sediments collected and analyzed by Weston (2009a,b); and (d) open yellow circles showing areas of highest current velocity predicted for the scenario tsunami by Lynett and Son in The SAFRR Tsunami Modeling Working Group (2013).

The Port of San Diego was predicted by the scenario to not experience inundation of its two marine terminals, but a large number of Navy piers were predicted to be inundated (Porter and others, 2013). Many different marinas within San Diego Bay and Mission Bay to the north were predicted to sustain significant damages as part of the scenario tsunami.

At Port Hueneme, some docks and warehouses were predicted to be inundated by the scenario tsunami, but the automobile import terminal was not. Significant sediment scour also was predicted to occur.

At San Francisco, a number of the piers, including Port Hueneme headquarters, substantial amounts of commercial real estate (particularly pier 39 and Fisherman's Wharf), and 
piers that receive predominantly break bulk cargo (such as steel, lumber, and other large objects) were predicted to be in the scenario inundation zone (Porter and others, 2013). Substantial damage to the commercial fishing fleet, docks, and a fish processing facility also was deemed plausible.

At the ports of Oakland, Richmond, and Redwood City, a number of docks, piers, container yards, bulk cargo areas, and some import auto offloading areas were expected to be inundated by the scenario tsunami. Multiple small craft marinas around San Francisco Bay also were likely to be inundated and damaged. A high concentration of oil storage tanks was noted in the scenario inundation zone at the port of Richmond (Porter and others, 2013; Scawthorne, 2013).

Scawthorn (2013) and Porter and others (2013) identified 17 large petroleum facilities (mostly tank farms) along the California coast (see example in fig. 5) where inundation-related damage (such as floating of large oil tanks from their foundations or breakage of piping) could potentially cause significant releases of flammable petroleum liquids that would float on the water surface. The scenario model indicates that artificial islands hosting oil-drilling platforms adjacent to the Port of Long Beach (White, Grim, Chaffee, Freeman) could plausibly be inundated (R. Wilson, Cal OES, written comm., 2013). This could lead to possible oil releases from damage to oil tanks and piping. Damage to gasoline storage tanks and transfer piping at many marinas could plausibly result in the release of smaller quantities of flammable gasoline. If ignited (most plausibly by electrical sparks), oil or gasoline releases could turn into waterborne fires that could then engulf wood piers, ships, and small watercraft, as well as buildings, vehicles, cargo, and vegetation in the inundation zone. Porter and others (2013) and Scawthorne (2013) identified a number of measures implemented at many California ports that have helped mitigate or prevent oil releases; these include installing oil storage tanks within secondary containment units, and installing rapid valve turnoffs that restrict oil flow through vulnerable piping when a potentially damaging tsunami, earthquake or other disaster is anticipated.

Our analysis indicates that the scenario tsunami and any tsunami reaching the full extent of the Cal OES inundation zone in the various ports, harbors, and marinas could release a variety of debris and potential contaminants into the marine environment and the onshore inundation zone. Depending on the materials released and the processes by which the releases occur, these materials could (1) become airborne as gases or particulate matter; contaminate onshore soils, beaches, paved surfaces, or inundated buildings; (2) contaminate harbor bottoms and nearshore marine sediments; (3) form immiscible liquid plumes that float or sink in seawater; (4) have contaminants that leach into seawater or rainfall; and (or) (5) have materials that could either coat or be ingested directly by terrestrial or marine organisms. 


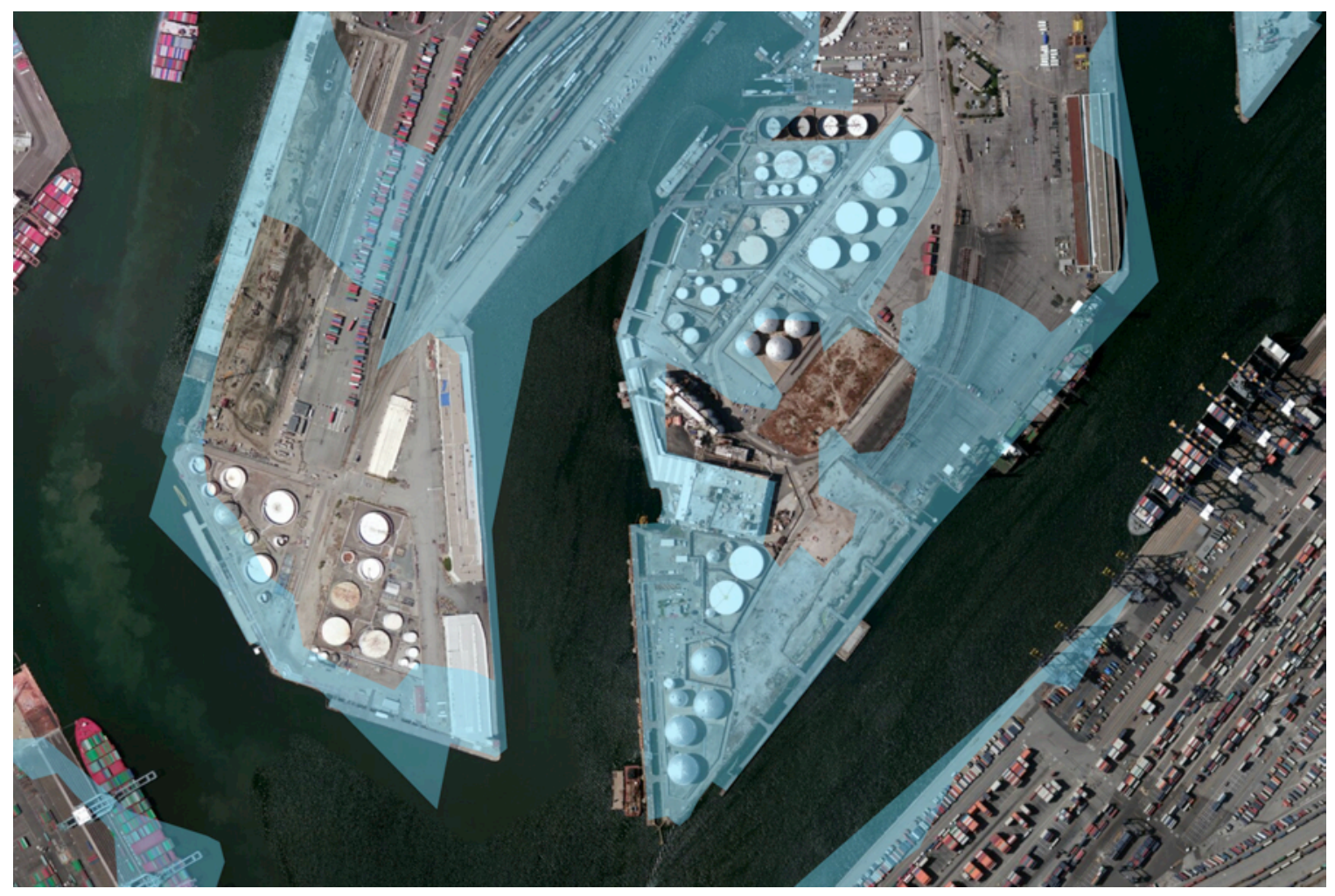

Figure 5. This satellite image shows port facilities, including a marine oil terminal, indicated to lie partially within the scenario tsunami inundation zone (transparent blue-green). The entire area of the image lies within the California Emergency Management Agency (Cal OES) maximum inundation zone.

\section{Debris}

Physical damages to piers, buildings, large and small watercraft, import automobiles parked on docks, drayage trucks, and other vehicles on docks could produce substantial quantities of debris containing a wide range of organic, metal, and other contaminants. A few examples include:

- Ammoniacal copper zinc arsenate (ACZA)-, chrome-copper-arsenate (CCA)- or creosotetreated wood from pier pilings and wood docks;

- Asbestos-containing insulation or lead paint released into the waters, air, and dock areas from damaged older facilities;

- Materials found in or used to construct ships and small watercraft of varying ages (for example, antifouling paints with copper or other metals; fiberglass; plastics; asbestos insulation; Styrofoam; rope; fishing nets; motor parts; electronics; batteries; lead ship ballast); and

- Various debris types such as automobile glass, concrete dusts and debris, mercury from fluorescent lights or older thermostats in buildings, and containers of paints and other chemicals. 
It is not clear whether damage to large cargo containers would be sufficient to cause releases of their contents, but if so, then a potentially wide range of container cargo could also be released.

The debris could either be deposited on land or remain in the ocean. Heavier debris would sink to the harbor bottoms, but many of the debris types noted above would float and could be carried by currents to coastal areas outside the ports.

Debris will pose a range of potential environmental hazards. Rainwater and seawater can leach a variety of inorganic and organic toxicants. For example, hexavalent chromium, copper, zinc, and arsenic are readily leached from AZCA-treated wood, and polycyclic aromatic hydrocarbons (PAHs) are readily leached from creosote-treated wood by both rain water and sea water (Stratus, 2006a, 2006b). This leaching could be accelerated by tsunami-induced wood breakage that exposures fresh wood surfaces for leaching. Metals, such as copper and organotin, could be leached from watercraft debris. Seawater corrosion could release a wide range of metals from steel, electronics, wiring, and other debris. As shown by the Tohoku tsunami, many types of floating debris are combustible, and so can be ignited (most likely by burning petroleum products) and burn. Accelerated oxidation of iron metal in debris piles by seawater salts also can trigger spontaneous ignition (Sekizawa and Sasaki, 2011). Freshly broken concrete can react with water to produce transient, locally significant caustic alkalinity in any waters it encounters; this alkalinity would likely diminish substantially over time. Small debris could become available for ingestion by animals or fish, and land and sea animals could become entangled in debris, such as ropes or fishing nets.

\section{Potential Releases of Petroleum or Petroleum Products}

Porter and others (2013) concluded that there would likely not be releases of petroleum liquid bulk cargo from the Ports of Los Angeles and Long Beach, nor would there be sufficient damage to the predicted one unmoored major vessel to produce an oil spill. Nonetheless, the number of potential sources for crude oil or petroleum products in the scenario and State inundation zones raises the likelihood that tsunamis could trigger multiple spills in California ports, Navy yards, harbors, and marinas having a range of sizes and compositions. These spills could come from tsunami-damaged marine oil terminals (fig. 5), refineries, small watercraft, chemical facilities, automobiles, dryage trucks, and other vehicles or equipment in the zone of inundation. Bulk petroleum cargo types that could be released in potentially large volumes include unrefined crude oil and various types of jet, bunker, and diesel fuel. Damage to fuel tanks in watercraft or vehicles would release small volumes of various vehicle-dependent fuel types.

The environmental behavior of oil and petroleum spills is well known. The more toxic fuel components (benzene, toluene, ethylbenzene, and xylenes) primarily volatilize following spills, which could create a potential inhalation exposure for cleanup workers, other people, and terrestrial organisms in the area. There also could be some dissolution of these components into seawater, with possible impacts on aquatic organisms that contact the affected seawater. Less toxic but stable heavier petroleum components would form emulsions by wave action and slowly degrade over time through photodegradation and biodegradation. Eventually, the heaviest, most tar-rich fractions could be deposited on beaches or settle to the bottom of harbors or nearshore marine environments, where they would cement bottom sediments.

Spill remediation approaches include skimming, intentional burning, and (or) application of chemical dispersants. Burning produces large amounts of smoke and leaves behind some 
residual oil ash material that can be enriched in the metals found in oils, most commonly nickel and vanadium. The application of dispersants is intended to promote dispersion of oil into smaller droplets that are more readily sorbed onto fine sediment particles that settle out.

A number of natural oil seeps from the sea floor are present along the southern California coast. These result in a natural baseline contribution of oil to the marine environment, and the baseline accumulation of tar and oil residues on local beaches (U.S. Geological Survey Seeps, 2013).

A broad range of impacts has been noted on organisms that contact spilled oil, petroleum products, or chemical dispersants applied to help disperse spilled oil. These can include (National Oceanic and Atmospheric Administration Fisheries Service, 2013):

- Oiling of bird feathers, which would inhibit flight and disrupt temperature regulation;

- Oiling of sea mammal fur, which would inhibit temperature regulation;

- Inhalation of vapors, which could lead to irritation of the respiratory tract; ingestion, which could cause injuries to the gastrointestinal tract and affect the animals' ability to digest or absorb foods;

- Dermal contact, which could cause skin irritation, chemical burns, and infections;

- Toxicity effects from absorption, such as liver, kidney, and brain damage;

- Chronic effects such as decreased reproductive success; and

- Dermal contact with and ingestion of water containing dissolved oil components.

\section{Potential Releases of Liquid Cargo}

Porter and others (2013) concluded that, based on locations of the specific piers predicted to be or not be inundated, no liquid cargo would be released as a result of the tsunami in the ports of Los Angeles, Long Beach, or San Diego, but it is unclear whether that is the case for other ports. As a result, some discussion is warranted here as to the types of liquid cargo that pass through the ports, and potential environmental concerns if there were to be tsunami-related releases of these liquid cargos.

In addition to the cargo types identified by Porter and others (2013) to pass through POLA and POLB, information on liquid cargo types passing through other California ports can be gleaned from their web sites. Cedre (2013) provided a general overview of liquid and solid bulk cargo types that have been associated with releases around the world, as well as an overview of their potential environmental impacts. In addition to crude oil and petroleum products, examples of other liquid bulk cargo types in transit through California ports (and possibly manufactured at the ports) that have been noted include liquid chemicals (for example, fertilizers and ethanol), milk, juice, and vegetable oils. The environmental behavior of a released cargo will depend on characteristics, such as how it interacts with seawater (for example, its solubility or immiscibility), and the volatility of its components. Although many of these liquid cargo materials are not toxic, large volume releases of some types can still have adverse environmental impacts. For example, vegetable oils can cause oiling of birds' feathers, asphyxiate benthic fauna, form polymers that cement beach sands and sediments, and generate noxious odors as they are biodegraded (Cedre, 2004).

\section{Potential Releases of Dry Bulk Cargo}

The scenario indicated that several types of dry bulk cargo would be affected by inundation at POLA and POLB, including industrial borates, gypsum, prilled sulfur (small pellets of elemental sulfur), and petroleum coke (Weston, 2009a, 2009b; Porter and others, 
2013). A variety of other dry bulk cargo types have been indicated to pass through various California ports, such as cement, coal, salt, metallurgical coke, solid fertilizers, sand, gravel, aggregate, rice, cottonseed, and bauxite (Tioga, 2002; Porter and others, 2013).

If dry cargo storage facilities are damaged by the tsunami, then there could be some potential for dispersal of the cargo into the environment. Tsunami waters could redistribute the cargoes within the inundation zone, or carry them into the marine environment. Damages to containment structures could expose remaining cargo to wind dispersion, rainfall, and rainfallinduced runoff.

Different dry cargo types will have substantial differences in their environmental behavior if they are released. For example, cement can react initially with rainwater or seawater to produce runoff containing caustic alkalinity; however, the alkalinity in runoff would diminish over time as the caustic solids in the cement are neutralized by carbonic acid in the rainwater. Depending on the cement type, various metals, such as hexavalent chromium and zinc, could be leached from the cement into the waters. Prilled sulfur could react over time with rainfall to produce sulfuric acid-rich runoff. Further, prilled sulfur is an easily ignitable, combustible solid that will produce sulfur dioxide and other toxic sulfur oxide gases when burned. Petroleum coke, a carbon- and ash-rich solid produced as a residual of refining processes, can, depending on the source oil composition, contain low to high levels of sulfur, nickel, vanadium, iron, and other metals or metalloids that may be leachable into water. Its dusts can become flammable and explosive. Prilled sulfur and petroleum coke dusts, if inhaled, could result in respiratory tract irritation.

Further work is needed to understand whether these dry cargos would be released, and if so, released in sufficient quantities for these impacts to be substantial in more than just the areas immediately adjacent to cargo handling and storage facilities.

\section{Potential Impacts from Inundated Shipbuilding and Boat Repair Yards}

A substantial number of active and closed shipbuilding and boat repair yards (which we will refer to as boatyards) occur within the scenario and (or) Cal OES inundation zones. Boatyards have been identified as the one of the many potential sources for metal and organic contaminants in POLA and POLB harbor sediments, such as copper, zinc, lead, organotin, polychlorinated biphenyls, and polycyclic aromatic hydrocarbons (Weston, 2009a, 2009b). A 2006 study found that Puget Sound boatyards could be a substantial source of lubrication oil, copper, zinc, lead, various organotin forms, PAHs, phenols, methylphenols, and phthalates in stormwater runoff into harbors (Johnson and others, 2006).

These contaminants were used in topside paints, antifouling hull paints, paint removal, oil-based products used as fuels or in engine or equipment lubrication (Johnson and others, 2006; Weston 2009a, 2009b). Zinc also is sourced from sacrificial metals used to protect propellers, shafts, and other metal parts. In addition to its past use in legacy paints, lead is still used in ballast keels. Phthalates are used in plasticizers and adhesives.

Both copper and organotin were designed to leach from antifouling hull paints, so that the paints would be toxic to barnacles or other marine organisms trying to grow on the hulls. As a result, antifouling paints also can be a source of seawater contamination. Organotin was used extensively in antifouling bottom paints prior to the mid-2000s, but its use has been banned in the United States since 2008 due to its adverse environmental impacts. Copper is still in use as a component of antifouling paints, although various port jurisdictions are investigating ways to diminish its usage and resulting impacts. 
As described for POLA and POLB (Water Resources Action Plan, 2009; Weston, 2009a, 2009b), a number of ports and boatyards are implementing measures to reduce runoff and other contamination into harbors. However, it is plausible that some inundated boatyards could serve as sources of contaminant-bearing debris (for example, lead from ballast manufacture, hull pieces, insulation, others) and water-borne dissolved or suspended particulate contaminants in the tsunami waters. Some of these contaminants, such as organotin or organotin-bearing woods, would be legacies from past practices at the boatyards.

\section{Scour and Redistribution of Contaminated Harbor Sediments}

The 2010 Chilean and 2011 Tohoku tsunamis triggered extensive scour and redistribution of sediments in the Crescent City and Santa Cruz Harbors (Wilson and others, 2012, 2013a). It is likely that the stronger and more spatially damaging scenario tsunami would lead to similar issues in a number of coastal harbors.

A review of the literature indicates that contaminated harbor bottom sediments are a substantial concern at many California ports (for example, see Water Resources Action Plan, 2009 and Weston 2009a, 2009b, for discussions about the Ports of Los Angeles and Long Beach) (fig. 4). The contamination includes a variety of metals (for example, lead, zinc, copper, arsenic, mercury, nickel, vanadium, organotin), metal sulfides (in anoxic sediments), many different organic chemicals (crude oil components, PAHs, PCBs, DDT and other pesticides, phthalates, and others), and diverse debris. There are many different sources to which this contamination has been attributed, and has resulted through intentional practices, accidental releases, or (in some areas) natural processes. Examples of potential sources include (for example, van Geen and Luoma, 1999; Water Resources Action Plan, 2009):

- Shipbuilding or boat repair yards;

- $\quad$ Spills from petroleum storage, transfer, or refinery facilities;

- Releases from ships or smaller watercraft;

- Releases from cargo storage or handling facilities;

- Releases from pesticide or other chemical manufacturing plants;

- Wastes from manufacturing or fabricating activities;

- Military bases;

- Wastewater-treatment plants;

- Fish-processing plants;

- Stormwater runoff inputs from docks, industrial areas, and major highways adjacent to the ports;

- Inputs of contaminated waters and sediments from rivers at some ports;

- In the Bay area, contamination from upstream historical mining operations (for example, mercury mining and mercury amalgamation gold extraction in the Coast Ranges and Sierra Nevada foothills);

- Atmospheric deposition;

- Sediments from outside the harbors carried into the harbors by marine currents; and

- Natural oil seeps.

The ports are actively pursuing policies and practices to minimize ongoing contamination. Examples include (for example, Water Resources Action Plan, 2009):

- Working with port tenants and nearby municipal entities to implement practices that reduce contamination; 
- Implementing better practices to manage storm waters and fugitive dust emissions from port facilities;

- Working with marinas to minimize discharges from small watercraft and reduce other potential sources of contamination;

- Improving port trash collection programs; and

- Enhancing sustainability programs in port facilities.

A variety of activities have been undertaken, are ongoing, or are planned to locate and remediate the most heavily contaminated sediment accumulations in key parts of many harbors. Examples of remediation methods used include: (1) dredging of contaminated sediments, with onland storage of the removed sediments in secured disposal areas, and (2) capping of contaminated underwater sediment deposits with uncontaminated sediments.

Tsunami-triggered sediment erosion and redistribution (fig. 4) could undo remediation efforts by re-depositing contaminated sediments in previously remediated parts of harbors, or by re-exposing capped sediment deposits. It also could complicate ongoing remediation efforts by commingling contaminated sediments with sunken debris, diluting contaminants by commingling contaminated sediments with uncontaminated sediments, or altering the previously mapped distribution of contaminated sediments in need of remediation.

Resuspension of sediments from the harbor bottoms into the water column would enhance their exposure to aquatic organisms, which could directly ingest the sediment particles. Sediment resuspension also would likely result in chemical transformations, such as oxidation (for example, of metal sulfides, metal(loid)s of variable oxidation state, such as arsenic), desorption of contaminants from particles, and volatilization of volatile components brought to the water-atmosphere interface. Past tsunamis also have transported marine sediments onto land in the inundation zone. Any contaminated sediment deposits left behind in the inundation zone also could undergo a variety of transformations, such as sulfide oxidation (and resulting formation of acidic, metal-rich drainage waters; Plumlee, 1999), oxidation of other organic compounds, and volatilization of methylmercury and other volatile components. Dusts from dried, disturbed sediment deposits could expose broader populations to contaminants in the sediments.

\section{Potential Contamination from Inundation of and Damage to Residential and Commercial Areas}

There are many residential and commercial areas along low-lying portions of the coast that occur within the scenario and (or) Cal OES inundation zones (figs. 6 and 7), and that could be variably destroyed, damaged, or flooded by the tsunami. In some areas, most notably San Clemente, southern Dana Point, and Malibu Beach, only the most beachward row of residences or commercial buildings is in the scenario or Cal OES inundation zones. However, a number of residential and adjacent commercial areas are indicated to be more extensively inundated. Significant examples include Balboa Island in Newport Bay (fig. 6, completely inundated, with more than 1,300 single- and multi-family residences), other parts of Newport Bay, Venice, Oxnard, and Ventura Harbor.

Particularly in southern California, residential areas that fall within the scenario and (or) Cal OES inundation zones are dominated by high-value properties (the vast majority are from $\$ 1$ 
million to $\$ 4$ million, with some $\$ 20$ million or more). Many of the residences in the inundation zones are listed in online property information databases as having been built prior to the 1970s and 1980s. If damaged by a tsunami, these older buildings could produce debris containing legacy contaminants, such as lead paint, asbestos, creosote-treated landscape timbers, mercurybearing thermostats, and chlordane and other pesticides (Plumlee and others, 2012; Australian Broadcasting Corporation, 2013). Debris from younger buildings could include fragments of CCA-treated landscape timbers and more recently used pesticides (for example, fipronil). Debris from buildings of all ages could include fragmented electronics, plastics, mercury from fluorescent lightbulbs, fabrics and other materials containing some metal colorants (for example, hexavalent chromium), fire retardants (PBDEs), and containers of household chemicals or products, such as paints, drain cleaners, pesticides, herbicides, and fertilizers (Plumlee and others, 2012; Manuel, 2013).

For buildings that are inundated but not heavily damaged, the ground floors would likely be left with deposits of intermingled household furnishings/products, debris, containers of household chemicals, and externally derived small debris and sediments transported into the buildings by the tsunami floodwaters.

Following the tsunami, mold would likely develop in inundated houses and buildings, and debris piles (Barbeau and others, 2010; Manuel, 2013). 


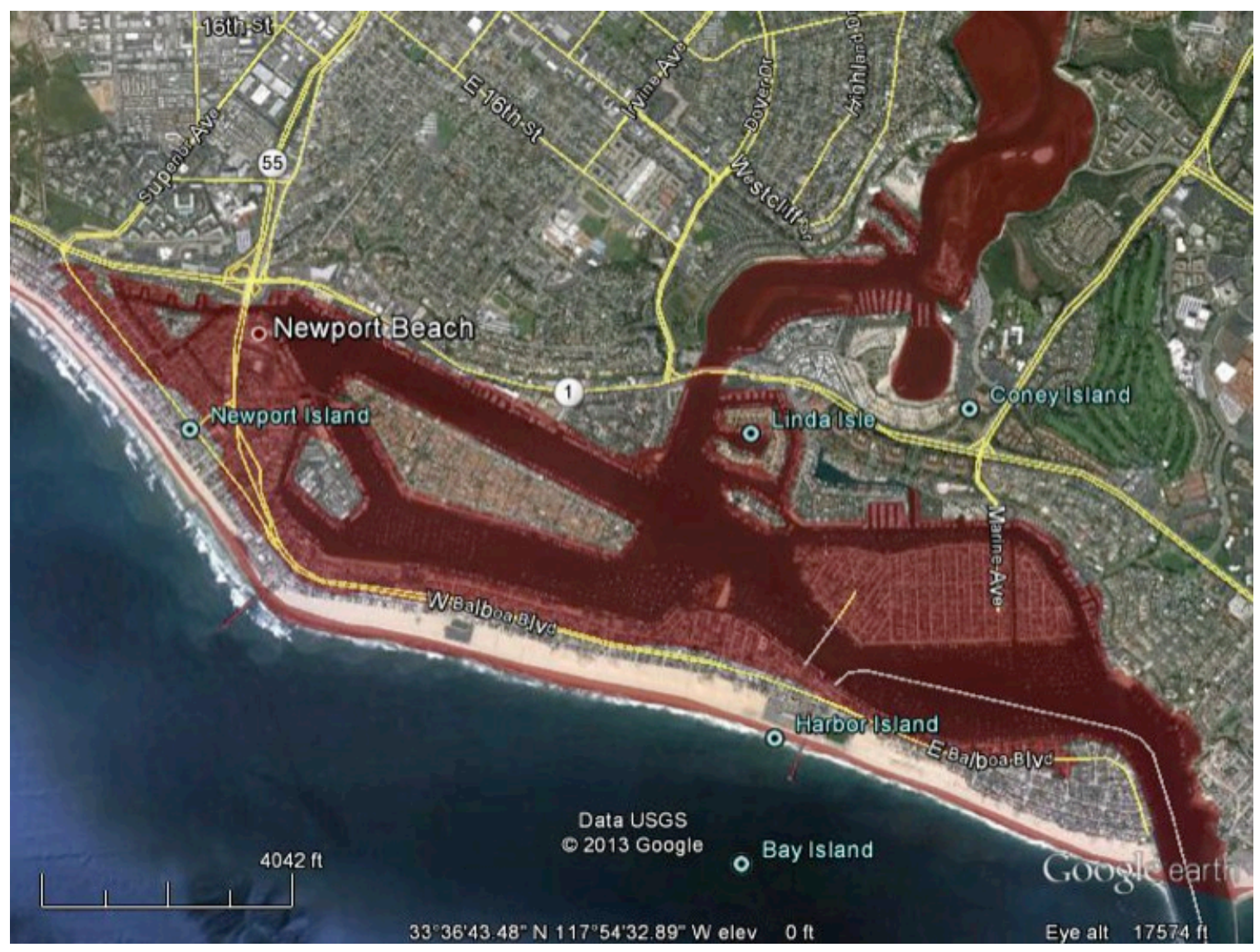

Figure 6. Satellite image (from appendix A of The SAFRR Tsunami Modeling Working Group, 2013), showing the extent of inundation of residential areas within Newport Bay.

\section{Potential Contamination from Significant Point Sources}

Analysis of the EPA facilities registry system database (U.S. Environmental Protection Agency Facilities Registry System, 2011), satellite imagery, and other GIS coverages indicates that a number of larger, environmentally significant facilities occur partially or fully within the scenario and (or) Cal OES inundation zones (fig. 3). In addition to the marine oil terminals (fig. 5), petroleum storage facilities, boat yards, and other port facilities noted in previous sections of this report, these facilities include:

Wastewater-treatment plants;

- Non-nuclear power plants;

- Naval or coast guard facilities;

- Transportation maintenance facilities;

- Chemical manufacturing plants;

- Other types of manufacturing plants (for example, that manufacture metal products, electronics, cement, or concrete products); and

- Railroad yards, paper mills, scrap yards, big box retail stores, food-processing facilities, and several airports. 
Many of these facility types may have some potential to release various types of contaminants. These include stored fuel (for example, from airports), anhydrous ammonia (for example, from refineries, chemical manufacturing plants, food-processing plants or cold food storage plants), processing chemicals (for example, acids, alkalis, solvents), manufactured chemicals (for example, borates), food products, trash, and contaminant residues from paved surfaces or soils. Some small facilities, such as dry cleaners, gasoline stations, auto dealerships, or auto body shops in the inundation zones could be localized source of contaminant releases. 


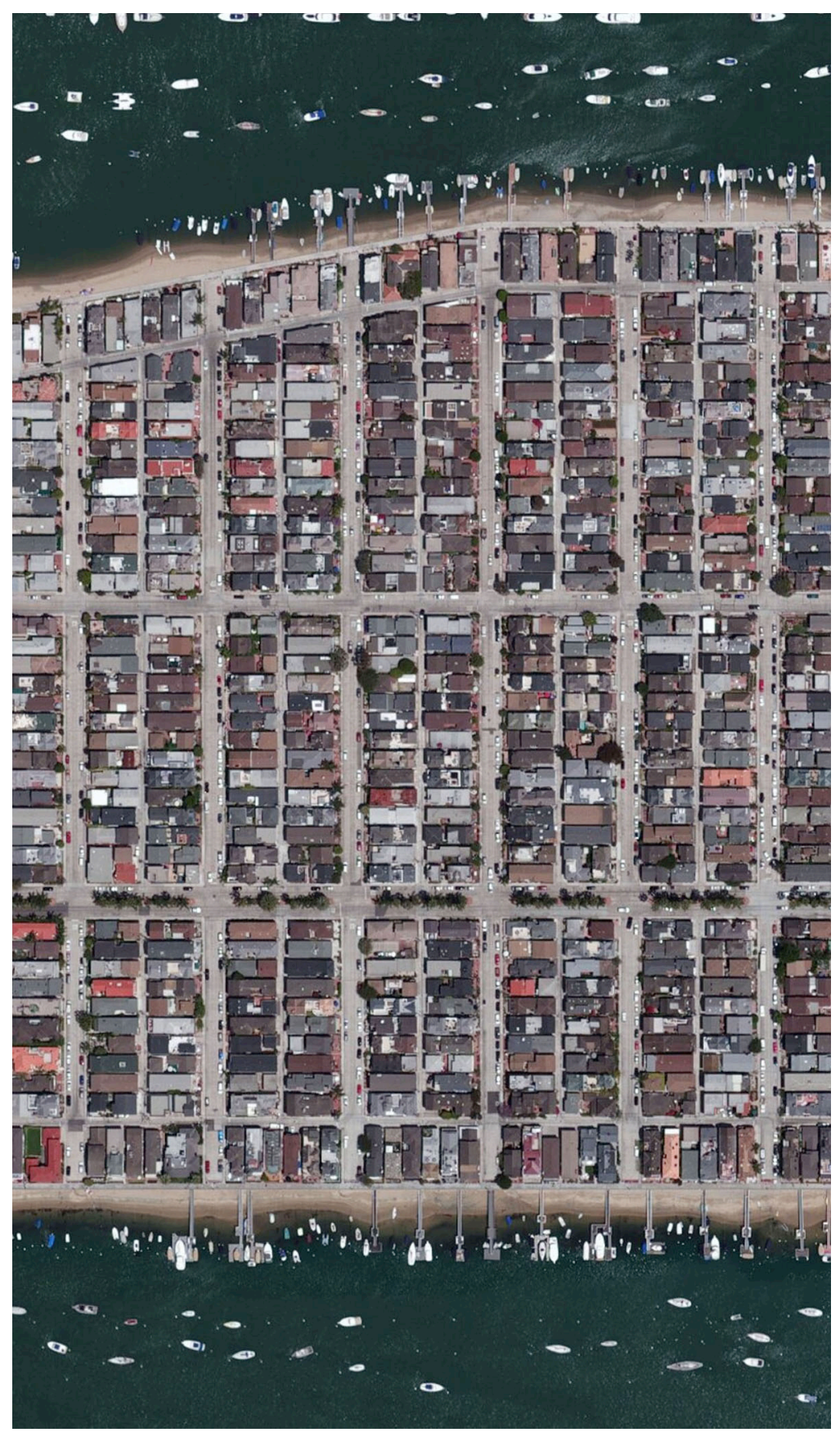

Figure 7. Satellite image showing a closeup of Balboa Island, which falls completely within the scenario and California Emergency Management Agency (Cal OES) inundation zones. Of the approximately 1,300 single- and multi-family residences are on the island, many are of older construction (for example, prior to the 1970s and 1980s), and almost all are valued in excess of $\$ 1$ million U.S. currency. 


\section{Wastewater Treatment Plants}

Wastewater-treatment plants (WWTPs) occur partially or fully within the scenario or Cal OES inundation zones in a number of coastal cities (figs. 8 and 9), and so present a substantial potential for environmental contamination from the tsunami. These include Alameda, Arcata, Avalon, Burlingame, Cardiff, Crescent City, El Granada, Eureka, Goleta, Half Moon Bay, Hercules, Huntington Beach, Manila, Mill Valley, Morro Bay, Oakland, Oceano, Pacifica, Palo Alto, Pinole, Pismo Beach, Richmond, San Buena Ventura, San Francisco, San Leandro, San Lorenzo, San Pedro, Santa Cruz, and Tiburon. These WWTPs and their feeder sewer systems, if inundated and damaged, could release: (1) raw or partially treated sewage or other contaminated wastewater; and (2) wastewater-treatment chemicals, such as disinfectants, $\mathrm{pH}$ control chemicals, and oxidants. It also is possible that sewer systems outside the inundation zone that feed into damaged or shutdown WWTPs could experience backups and release raw sewage into the environment outside the inundated areas.

Many different organic and inorganic contaminants can be present in sewage and wastewater. Examples include solid fecal matter, human hormones and metabolic wastes, components of pharmaceuticals and personal care products, detergents, fire retardants, home use pesticides and rodenticides, dissolved metals, and emulsions (Plumlee and others, 2013). Pathogens that can be present include bacteria (for example, Escherichia coli or Salmonella), protozoa, enteric viruses, and parasitic worms. There also are growing concerns that some of the bacteria present in sewage and wastewater discharges may have enhanced resistance to antibiotics.

\section{Power Plants}

Non-nuclear power plants are indicated to occur partially within the scenario or Cal OES inundation zones in the following cities - Carlsbad, Eureka, Hayward, Huntington Beach, Long Beach (several), Morro Bay, Oakland, Samoa, San Francisco, and Wilmington. Based on databases available from the California Energy Commission, nearly all these power plants use natural gas or gas from municipal solid waste as their fuel. Hence, we infer that they likely do not pose a risk for the release of large volumes of environmentally detrimental chemicals or wastes.

Neither the Diablo Canyon nor the inoperative San Onofre nuclear powerplants are indicated to occur within the scenario or Cal OES maximum inundation zones. Several peripheral buildings in the San Onofre facility (which is scheduled to be retired and decommissioned) do appear to fall within the Cal OES maximum inundation zone.

\section{Airports and Military Air Stations}

Airports in several coastal cities (Eureka, Santa Barbara, Alameda/Oakland, and Oceano) and several Navy or Coast Guard air stations are indicated to fall partially or completely within the scenario or Cal OES inundation zones. There is the potential for some compromise of fuel storage tanks (where they occur in the inundation zone), damage to aircraft and aircraft maintenance/repair facilities, and runway runoff that could release some environmental pollutants, such as petroleum or tire residues. 


\section{Landfills}

Landfills are indicated to occur partially or completely within the scenario or CA OES inundation zones in the following cities - Corte Madera (Marin), Huntington Beach, Long Beach (multiple), Los Angeles, Mill Valley, Newport Beach, Oakland, San Leandro, San Mateo, San Pedro, Sausalito, and Venice. In a number of cases, these are historical landfills that are currently not in use. Further investigation is needed to determine whether these landfills could be compromised sufficiently by the tsunami to cause the release of stored wastes or waste degradation products. A wide range of possible organic and inorganic chemicals can be present in landfill leachates, such as dissolved organic matter, ammonium, solvents, organohalogen compounds (PCBs, carbon tetrachloride, etc.), pesticides, phenols, plasticizers, metals or metalloids ( $\mathrm{Mn}, \mathrm{Hg}, \mathrm{Pb}, \mathrm{Cr}, \mathrm{Cd}, \mathrm{Cu}, \mathrm{As}$, Ni, etc., some organo-complexed or colloid-bound), and organic and inorganic acids. Leachates can vary as a function of the age of landfill. Damage to containment structures can cause release of gases, such as methane, hydrogen sulfide, and volatile organic compounds. 


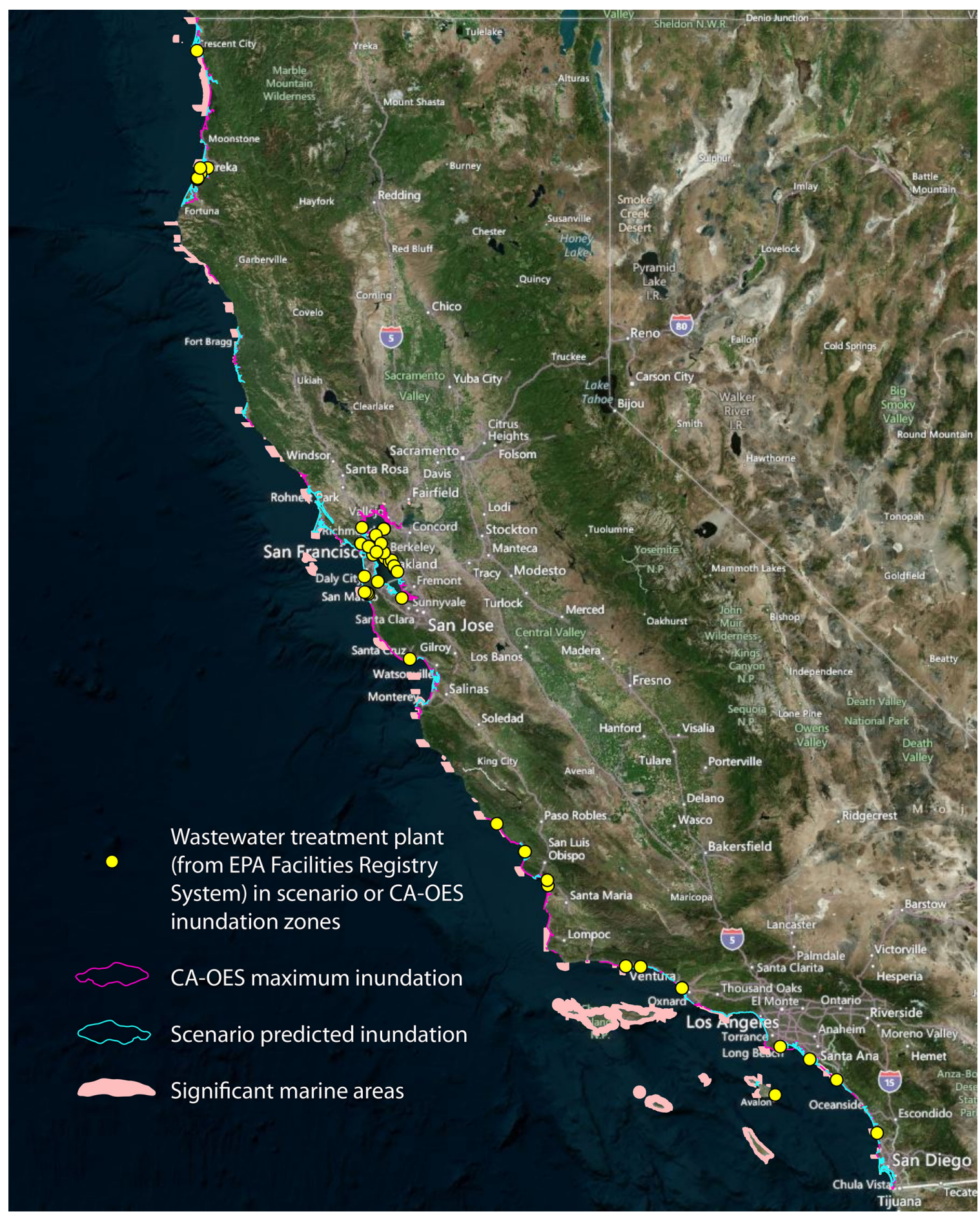

Figure 8. Map showing locations of wastewater treatment plants (data from U.S. Environmental Protection Agency Facilities Registry System, 2011) indicated to occur partially or completely in the scenario or California Emergency Management Agency (Cal OES) inundation zones. 


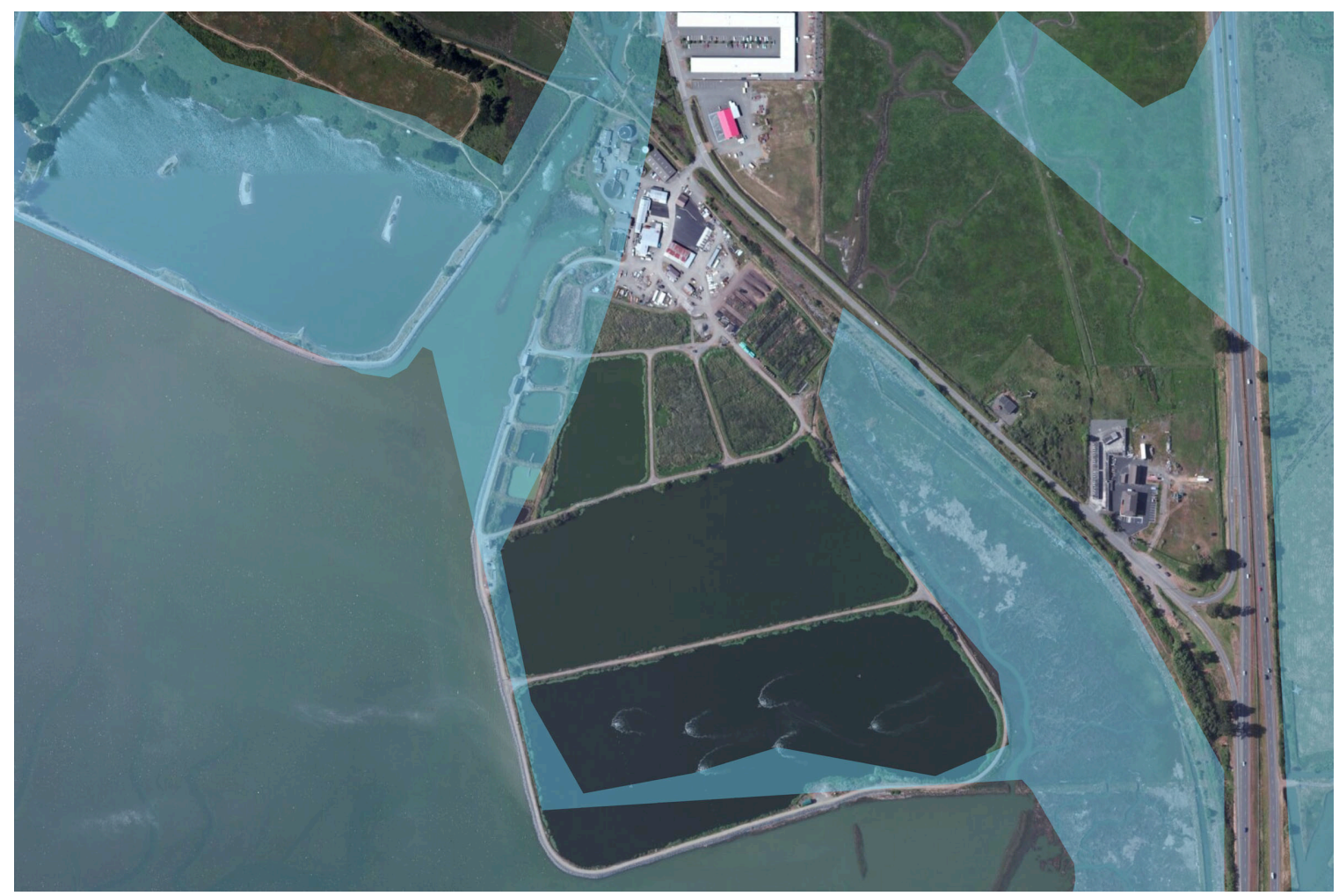

Figure 9. This satellite image shows a wastewater treatment plant indicated to lie partially within the scenario tsunami inundation zone (transparent blue-green). The entire area of the image lies within the California Emergency Management Agency (Cal OES) maximum inundation zone.

\section{Potential Non-Point Source Contamination}

There are various types of potential non-point sources from which contamination could be redistributed onland and into the nearshore marine environment by the tsunami. Examples include:

- Paved/unpaved surfaces and storm drains in urban, residential, and commercial areas;

- Inundated agricultural fields in coastal lowlands along river mouths;

- Wetlands and other areas that receive stormwater runoff from urban areas or major coastal highways (such as I-5 north of San Diego); and

- Large military bases with firing ranges, fuel storage areas or other coastal facilities that have not undergone environmental remediation.

\section{Urban Areas and Highway Corridors}

It is possible that tsunami flood waters could redistribute a variety of potentially hazardous surface chemicals (for example, petroleum or metal-rich residues from paved surfaces), contaminated soils, trash, storm drain sediments, and other materials from inundated urban and industrial areas and highway corridors. This would be somewhat analogous to stormwater runoff from urban areas and major highway corridors, which has long been recognized as a source of contamination with cumulative detrimental environmental effects. 


\section{Agricultural Fields}

Somewhat greater areas of agricultural fields are indicated to be inundated in the northern parts of the State (for example, in the Eel River lowlands) than in the southern parts of the State. Most of these are fields in which alfalfa, hay, or other pasture grasses are grown (Ratliff, 2013). A wide range of insecticides, herbicides, and fertilizers may be applied to alfalfa and pasture grasses in California, and the types applied can vary according to many factors, such as geographic location, time of year, stage of crop growth, maturity of the field, type of insect or weed present, and nutrient status of the alfalfa (Canevari and others, 2007; Meyer and others, 2007; Summers and others, 2007; University of California Integrated Pest Management Program, 2010). Many different practices can be implemented to ensure that such chemicals are applied in ways to minimize their release into the environment by overspray, runoff, and other mechanisms. However, further investigations are needed to understand what insecticides, pesticides, and fertilizers are permitted and used in agricultural areas within the tsunami inundation zones, how they are applied, and what their potential is to be transported by the tsunami either inland or into the ocean.

\section{Tsunamigenic Fires}

As noted by Porter and others (2013) and Scawthorne (2013), oil or petroleum spills can be ignited by electrical sparks, friction, or other mechanisms. As a result, they concluded that oilspread tsunamigenic fires would be possible in the Ports of Los Angeles, Long Beach, and Richmond, and that small, more localized fires could result at some marina fueling docks. Other flammable liquid bulk cargo, such as vegetable oil, if released, also might contribute to fires. Movement of spilled oil on water or on land would spread these fires to structures, berthed automobiles, cargo, and other port facilities. As noted by Tanaka (2012) for the Tohoku tsunami, and Porter and others (2013) for New York City port facilities flooded by Hurricane Sandy storm surge, a substantial number of fires also could be triggered by inundated vehicles, such as automobiles, forklifts, and drayage trucks at the ports, most likely due to electrical shorts. Similarly, electrical shorts in residences or commercial/industrial areas, and tsunami-downed power lines also could cause fires if electricity were not shut off prior to inundation. Analogous fires were caused by the Hurricane Sandy storm surge in New York and New Jersey-for example, 122 homes in the Breezy Point subdivision of Queens, New York, were burned as a result of a sea water-triggered electrical short at one residence (Gothamist, 2012), and other dwellings along the coast suffered fires from sparks caused by falling power lines.

Tsunamigenic fires in spilled oil, debris, cargo, vehicles, vegetation, and residential, commercial, or industrial buildings and their contents could produce potentially significant volumes of complex smoke, gases, airborne ash, residual ash, and debris. These materials could have a wide range of potential toxicants depending on the material being combusted. Potentially asphyxiant or irritant gases include carbon monoxide, hydrogen cyanide, hydrogen chloride, sulfur dioxide, hydrogen fluoride, hydrogen bromide, nitrogen oxides, and ammonia. Smoke, airborne ash, and residual ash/debris from the fires could contain, depending on the material being burned, various mixtures of (Plumlee and others, 2013): (1) caustic alkali solids; (2) lead, hexavalent chromium, arsenic, nickel, vanadium and other heavy metal(loid)s; (3) asbestos; and (4) various organic toxicants such as polycyclic aromatic hydrocarbons, formaldehyde, formalin, dioxins, and polychlorinated biphenyls. 


\section{Plausible Environmental Impacts of Damages, Debris, and Contamination}

Tsunami-related damages, debris, and contamination could have a variety of short-term and long-term impacts on the environment and the health of coastal marine and terrestrial ecosystems. Details of potential ecological impacts are have been studied by D. Brosnan (written commun., 2013) of University of California, Davis.

Marine habitats in near-shore and intertidal zones along the coast and ecosystems in many coastal estuaries, marshes, sloughs, and lagoons could be damaged by physical erosion or sedimentation. These areas near inundated ports, harbors, coastal cities, and coastal agricultural areas could receive an influx of debris and contaminants. Examples of ecologically important areas near cities include the San Diego and Sweetwater Marsh National Wildlife Refuges in San Diego Bay, Seal Beach National Wildlife Refuge, Salinas River National Wildlife Refuge, Pilar Point State Marine Conservation Area/James V. Fitzgerald Marine Reserve between San Francisco and El Granada, San Francisco Bay, and Humboldt Bay National Wildlife Refuge. Some ecologically sensitive areas are fisheries for seafood such as oysters (for example, Drakes and Tomales Bays) and crabs, and so could possibly suffer damage- or contaminant-related impacts on seafood supply or quality.

Shallow aquifers in the areas of tsunami inundation could plausibly be contaminated by seawater. Transient salinization of inundated agricultural fields and salt water-triggered die offs of terrestrial vegetation in or immediately adjacent to tsunami inundation areas could also occur. Agricultural fields in the inundation zone could receive debris and sediments brought in by the tsunami.

Spilled oil and petroleum products would add to the elevated baseline of crude oil from natural seeps already present along some parts of the coast. Spilled oil and petroleum products degrade through dissolution and volatilization of more toxic components, photolytic degradation, and biodegradation. However, oil and oil-seawater emulsions could coat birds and mammals that came into contact with it, with resulting impacts on birds' flight ability and the internal heat regulation of birds and mammals. Inhalation of toxic volatile oil components, as well as dermal absorption or ingestion of oil or waters with dissolved oil components, could be toxic to marine and terrestrial organisms that contact spilled oil.

Debris and re-exposed contaminated sediments would be a source of sea- or rain-waterleachable metal and organic contaminants that could potentially pose chronic toxicity threats to marine life (for example, copper, organotin) and(or) that are bioaccumulative (for example, mercury, legacy pesticides). Atmospheric weathering of metal sulfides in exposed marine sediment deposits could generate locally acidic waters with elevated levels of potentially toxic metal(loid)s such as copper, zinc, nickel, and arsenic.

Wildlife could become entangled in debris and could ingest small debris. Ingestion, dermal absorption, or inhalation of various contaminants by aquatic, terrestrial, and avian organisms has the potential to result in short-term, acute toxicity effects, or longer-term, chronic toxicity effects.

\section{Potential Human Health Implications}

If the scenario's expected evacuation of populations from the inundation zone were to be successful, there could plausibly be few or no drownings or other tsunami-related casualties, crushing injuries, puncture wounds, or infections. 
Immediately after the tsunami, human populations outside the inundation zone might be transiently exposed to airborne gases, smoke and ash from tsunamigenic fires. The intensity and duration of these exposures would be dependent on the size of the fire, weather conditions, wind direction, and other factors. Exposures to high levels of irritant gases and particulate matter in smoke could exacerbate respiratory diseases (for example, asthma, bronchitis, chronic pulmonary obstructive disease), and cause increased cardiovascular problems, such as heart attacks and strokes. The potential for longer-term health impacts from transient exposures to toxicants contained in airborne gases, smoke, and ash has not been clearly documented (or even studied) in prior fire disasters.

If widespread power outages result from the tsunami, then increased incidences of carbon monoxide poisoning from the use of portable power generators would be possible.

Infectious disease outbreaks following the tsunami would likely be prevented or mitigated by ready access of local populations to emergency relief efforts that provide clean drinking water supplies, unspoiled food, vaccinations, and other medical care.

Post-tsunami cleanup of ports, harbors, and inundated on-land areas would help reduce the potential for long-term human exposures to toxicants and pathogens in harbor waters, debris, soils, ponded waters, and buildings. Exposures to cleanup workers and people returning to inundated areas could be reduced by the use of proper personal protective equipment (such as respirators, gloves, steel-toed rubber boots, and protective clothing) and appropriate exposure mitigation practices (for example, dust control) during cleanup.

There would be some potential for increased cases of vector-borne diseases, such as mosquito-transmitted West Nile virus, but this could be mitigated by pest control measures that thwart growth of mosquito populations in ponded tsunami waters, and growth of insect and rodent populations in debris and damaged buildings. Monitoring of seafood would prevent human consumption of pathogen- or toxicant-contaminated seafood obtained from tsunamiaffected areas along the coast.

\section{Post-Tsunami Environmental Cleanup and Recovery}

Debris and contamination cleanup and disposal would pose substantial logistical challenges and economic costs following the tsunami. Deposits of small debris and contaminated sediments would be a challenge to identify, access, and clean up across all affected coastal marine and estuarine environments, and so could pose a long-term source of potential contamination in sensitive ecological areas.

Based on recent past disasters, the cleanup of debris, damaged buildings, contaminated sediments, and other potentially hazardous materials in ports, harbors, and inundation areas could be expected to vary considerably in its pace from area to area-a function of economic pressures, the insurance claim process, building and cleanup regulations, the extent of damage, and other factors. Characterization of debris for the presence of asbestos, lead paint, pesticides, and other potentially hazardous materials would be required to determine if these materials would require enhanced dust mitigation and other exposure mitigation measures during cleanup, and disposal into isolated landfills.

Similarly, characterization of tsunami sediment deposits (both onshore deposits and deposits dredged to clear harbor channels) would be needed to determine whether the sediments are contaminated and therefore require more costly disposal in isolated landfills. As with the debris, the sediments would need to be characterized for contaminants such as asbestos, heavy metals, or organic toxicants. In addition, any sediments being considered for on-land disposal, 
particularly in areas in contact with the atmosphere or oxygenated waters should be evaluated for their acid-generating potential (see net acid production tests outlined in Plumlee and others, 2007).

Although such assessments are needed environmentally, they could add significant time to the post-disaster cleanup and recovery if not accomplished quickly. The specialized removal and disposal measures for hazardous materials also would add substantially to cleanup costs.

\section{Actions to Enhance Resilience to Tsunamis}

There are actions that can be taken by companies, individuals, and governments to help prepare for and mitigate environmental impacts of a coastal tsunami.

All businesses large and small can benefit from an analysis of their facilities' location(s) within the scenario or CA OES tsunami inundation zones, and the vulnerability of their facilities to tsunami-related or surge-related damages. Once vulnerabilities are understood, then ways to mitigate these vulnerabilities can be evaluated from a cost/benefit standpoint, recognizing the potential costs stemming from environmental liability should damage and contaminant release occur. Recognition of the impacts of coastal tsunamis and storm surges also should be accounted for in business emergency operation plans. Even small businesses can take these steps to help minimize potential impacts and liability from their own facilities, and impacts on their facilities from tsunami-related contamination.

Families or individuals that live or work in the tsunami inundation zones could benefit by developing a tsunami-related emergency plan that helps them evaluate the potential hazards, and understand how and where to evacuate prior to a looming tsunami. Steps can be taken by individuals to mitigate potential environmental impacts in and adjacent to residences in the inundation zones. These could include, for example, maintaining only minimal amounts of pesticides, fertilizers, and other household chemicals in residences, and storing potentially toxic chemicals in watertight, tethered containers. Post tsunami, it is important for residents returning to inundated homes to be aware of, prepare for, and appropriately address the potential environmental hazards that could exist. Such hazards could include, for example, mold, contaminated sediments, and toxicant-bearing debris. If present, these hazards would necessitate use of appropriate respiratory and other personal protection to prevent exposure, and likely would require specialized cleanup and proper disposal practices.

Porter and others (2013) recommend that residents and businesses in the inundation zone should be aware of flood insurance through the National Flood Insurance Program or commercial sources. An additional consideration, particularly for owners of older buildings, will be whether the flood insurance adequately covers the extra costs for removal and disposal of toxicant bearing debris.

Given the high value of the coastal residential and commercial properties in the inundation zone, it can be postulated that there would be substantial insurance claims for environmental restoration, mold mitigation, disposal of debris that contains hazardous materials, and costs of litigation related to environmental liability. These costs would likely add to the economic costs estimated by Rose and others (2013) for the scenario tsunami.

The previous section outlined the need for timely characterization of tsunami debris and sediment deposits for the potential presence of contaminants. In past tsunamis, such assessments have led to delays in cleanup and recovery (R. Wilson, Cal OES, oral comm., 2013). Development of State and local policies that plan for and facilitate rapid assessment of potential contamination, and that facilitate rapid decision making for disposal options should hazardous 
debris or sediment be identified, would help enhance resilience following the tsunami. Additionally, local jurisdictions with substantial residential and commercial areas within the inundation zone can utilize information in their own property databases on the age, square footage, and construction type of buildings to better plan for the amounts and types of debris that could be generated by a tsunami. Jurisdictions can work with owners of large, environmentally significant facilities (including, for example, their own wastewater treatment plants) to help assess vulnerabilities and mitigate potential damages that could otherwise lead to the release of large volumes of contaminants during a tsunami.

\section{Summary}

This study has described a number of ways by which the SAFRR scenario tsunami could produce contamination, adversely affect the nearshore marine and coastal environments, and result in human exposures to potential tsunami-generated contaminants. There are a number of uncertainties in this type of analysis. As a result, our approach and general findings should only be considered as the first of multiple steps toward a more quantitative, predictive approach to understanding the potential sources, types, environmental behavior, and environmental and health implications of contaminants that could be released into the environment by coastal tsunamis. For example, more detailed, site-specific analyses are needed of significant industrial, commercial, and residential areas that occur in the inundation zone to assess their vulnerabilities to tsunami inundation and damage, and the specific types and volumes of resulting contaminants and debris that could be released should such damage occur.

The highest potential for inundation-related damages and resulting release of significant amounts of contaminants into the inundation zone and coastal environments would likely occur in the major ports, in inundated and damaged residential and commercial areas, and from some large facilities, such as wastewater-treatment plants. A wide range of debris types and contaminants could potentially be released, depending on the source. Potential concerns include, for example:

- Complex debris;

- Crude oil, various fuel types, and other petroleum products;

- Some liquid bulk cargo and dry bulk cargo types;

- Heavy metals such as lead, arsenic, organotin, mercury, nickel, and vanadium;

- Raw sewage and chemicals used to treat wastewater;

- Organic contaminants, such as paints, legacy pesticides, current use pesticides, herbicides, and fertilizers; and

- Smoke and ash from tsunamigenic fires.

Tsunami-related physical damages, debris, and contamination could have short- and longterm impacts on the environment and the health of coastal marine and terrestrial ecosystems. If human populations are successfully evacuated prior to the tsunami arrival, there would be no or limited numbers of drownings, other casualties, or related injuries, wounds, and infections. Immediately after the tsunami, human populations outside the inundation zone could be transiently exposed to airborne gases, smoke, and ash from tsunamigenic fires.

Post-tsunami cleanup, if done with appropriate mitigation (for example, dust control), personal protection, and disposal measures, would help reduce the potential for cleanup-worker and resident exposures to toxicants and pathogens in harbor waters, debris, soils, ponded waters, and buildings. A number of other steps can be taken by governments, businesses, and residents 
to help reduce the environmental impacts of tsunami and to recover more quickly from these environmental impacts.

\section{References Cited}

Australian Broadcasting Corporation, 2013, Tsunami leaves Japan with toxic asbestos legacy: Australian Broadcasting Corporation, Lateline transcript, accessed August 28, 2013, at http://www.abc.net.au/lateline/content/2013/s3678154.htm, Jan 28, 2013.

Barbeau, D.N., Grimsley, L.F., White, L.E., El-Dahr, J.M., and Lichtveld, M., 2010, Mold exposure and health effects following hurricanes Katrina and Rita: Annual Reviews in Public Health, v. 31, p. 165-178.

Barberopoulou, A., Borrero, J.C., Uslu, B., Kalligeris, N., Goltz, J.D., Wilson, R.I., and Synolakis, C.E., 2009, Unprecedented coverage of the Californian coast promises improved tsunami response: Eos, Transactions of the American Geophysical Union, 90(16), pp. 137138.

Basnayake, B.F.A., Chiemchaisri, C., and Mowjood, M.I.M, 2005, Solid wastes arise from the Asian tsunami disaster and their rehabilitation activities - Case study of affected coastal belts in Sri Lanka and Thailand, in Proceedings Sardinia 2005: Cagliari, Italy, Tenth International Waste Management and Landfill Symposium, 7 p., accessed August 28, 2013, at http://www.swlf.ait.ac.th/data/pdfs/715 .pdf.

Bird, W.A., and Grossman, E., 2011, Chemical aftermath-contamination and cleanup following the Tohoku earthquake and tsunami: Environmental Health Perspectives, v. 119, p. A290A301.

Canaveri, M., Vargas, R.V., and Orloff, S.B., 2007, Weed management in alfalfa, Chapter 8, in Irrigated Alfalfa Management: Berkeley, University of California Agriculture and Natural Resources Publication 8294, 19 p., accessed August 28, 2013, at http://alfalfa.ucdavis.edu/IrrigatedAlfalfa/pdfs/UCAlfalfa8294Weeds_free.pdf.

Cedre, 2004, Vegetable oil spills at sea_Operational guide: Centre of Documentation, Research and Experimentation on Accidental Water Pollution, 36 p., accessed August 28, 2013, at http://www.cedre.fr/en/publication/operational-guide/vegetable-oil/vegetable-oil.php Cedre, 2013, Spills: Centre of Documentation, Research and Experimentation on Accidental Water Pollution, accessed August 28, 2013, at http://www.cedre.fr/en/spill/alphabeticalclassification.php.

Chagué-Goff, C., Niedzielski, P., Wong, H.K.Y., Szczuciński, W., Sugawara, D., and Goff, J., 2012, Environmental impact assessment of the 2011 Tohoku-oki tsunami on the Sendai plain: Sedimentary Geology, v. 282, p. 175-187, doi:10.1016/j.sedgeo.2012.06.002.

Gothamist, 2012, Photos-Surreal devastation of Breezy Point after Hurricane Sandy: accessed August 28, 2013, at http://gothamist.com/2012/10/31/photos_the_devastation_of_breezy_po.php\#photo-1.

Johnson, A., Golding, S., and Coots, R., 2006, Chemical characterization of stormwater runoff from three Puget Sound boatyards: Washington State Department of Ecology Publication 0603-041, 57 p., accessed August 28, 2013, at https://fortress.wa.gov/ecy/publications/summarypages/0603041.html.

Keim, M.E., 2011, The public health impact of tsunami disasters: American Journal of Disaster Medicine, v. 6, p. 341-349. 
Lynett, P., and Son, S., 2013, Port and harbor hydrodynamics, in Geist, E.L., ed., Modeling for the SAFRR tsunami scenario-Generation, propagation, inundation, and currents in ports and harbors: U.S. Geological Survey Open-File Report 2013-1170-D, p. 106-119.

Manuel, J., 2013, The long road to recovery-Environmental health impacts of hurricane Sandy: Environmental Health Perspectives, v. 121, p. A152-A159.

Meyer, R.D., Marcum, D.B., Orloff, S.B., and Schmierer, J.L., 2007, Alfalfa fertilization strategies, Chapter 6, in Irrigated alfalfa management: Berkeley, University of California Agriculture and Natural Resources Publication 8294, 16 p., accessed August 28, 2013, at http://alfalfa.ucdavis.edu/IrrigatedAlfalfa/pdfs/UCAlfalfa8292Fertilization_free.pdf.

National Oceanic and Atmospheric Administration, 2013, National Geophysical Data Center

Tsunami Event web site: National Oceanic and Atmospheric Administration, August 28, 2013, at http://earthquake.usgs.gov/earthquakes/eqinthenews/2004/us2004slav/\#summary.

National Oceanic and Atmospheric Administration Fisheries Service, 2013, Impacts of oil on marine mammals and sea turtles: National Oceanic and Atmospheric Administration, accessed August 28, 2013, at http://www.nmfs.noaa.gov/pr/pdfs/health/oil_impacts.pdf.

Plumlee, G.S., 1999, The environmental geology of mineral deposits, in Plumlee, G.S., and Logsdon, M.J., (eds.), The environmental geochemistry of mineral deposits, Part A. Processes, Techniques, and Health Issues: Society of Economic Geologists, Reviews in Economic Geology, v. 6A, p. 71-116.

Plumlee, G.S., Foreman, W.T., Griffin, D.W., Lovelace, J.K., Meeker, G.P., and Demas, C.R., 2007, Characterization of flood sediments from hurricane Katrina and Rita and potential implications for human health and the environment, in Farris, G.S., Smith, G.J., Crane, M.P., Demas, C.R., Robbins, L.L., and Lavoie, D.L., eds., Science and the storms-The USGS response to the hurricanes of 2005: U.S. Geological Survey Circular 1306, p. 246-257.

Plumlee, G.S., Morman, S.A., and Cook, A., 2012, Environmental and medical geochemistry in urban disaster response and preparedness: Elements Magazine, v. 8, p. 451-457.

Plumlee, G.S., Morman, S.A., Meeker, G.P., Hoefen, T.M., Hageman, P.L., and Wolf, R.E., 2013 (in press), The environmental and medical geochemistry of potentially hazardous materials produced by disasters, in Lollar, B.S.L., ed., Treatise on Geochemistry, Second Edition, Volume 9: Amsterdam, Netherlands, Elsevier Science, 648 p.

Porter, K., Byers, W., Dykstra, D., Lim, A., Lynett, P., Ratliff, J., Scawthorn, C., Wein, A., and Wilson, R., 2013, The SAFRR Tsunami Scenario-Physical damage in California: U.S. Geological Survey Open-File Report 2013-1170-E, 183 p.

Ratliff, J., 2013, Agricultural damages from the SAFRR tsunami scenario, in Porter, Keith Byers, W., Dykstra, D., Lim, Amy, Lynett, P., Ratliff, J., Scawthorn, C., Wein, A., and Wilson, R., The SAFRR Tsunami Scenario-Physical Damage in California : U.S. Geological Survey Open-File Report 2013-1170-E, p. 127-139.

Ratnapradipa, D., Conder, J., Ruffing, A., White, V., 2012, The 2011 Japanese earthquake-An overview of environmental health impacts: Journal of Environmental Health, v. 74, p. 42-50.

Wein, A., Rose, A., Wing, I.S., Wei, D., and 2013, Economic impacts of the SAFRR tsunami scenario in California: U.S. Geological Survey Open-File Report 2013-1170-H, 46 p.

Scawthorn, C., 2013, Fire following tsunami-A contribution to the SAFRR tsunami Scenario: SPA Risk LLC, accessed August 28, 2013, at http:/www.sparisk.com/pubs/Scawthorn-2013SAFRR-FFT.pdf.

Sekizawa, A., and Sasaki, K., 2011, Overview of fires following the great East-Japan earthquake: Fire Science and Technology, v. 30, p. 91-100. 
Shibata, T., Solo-Gabriele, H., and Hata, T., 2012, Disaster waste characteristics and radiation distribution as a result of the Great East Japan Earthquake: Environmental Science \& Technology, v. 46, p. 3,618-3,624.

Srinivas, H., and Nakagawa, Y., 2008, Environmental implications for disaster preparednessLessons learnt from the Indian Ocean tsunami: Journal of Environmental Management, v. 89, p. 4-13.

Stratus, 2006a, Treated wood in aquatic environments-Technical review and use recommendations: Stratus Consulting, prepared for National Oceanic and Atmospheric Administration, National Marine Fisheries Service, accessed August 28, 2013, at http://swr.nmfs.noaa.gov/wood/copperwood_report-final.pdf.

Stratus, 2006b, Creosote-treated wood in aquatic environments-Technical review and use recommendations: Stratus Consulting, prepared for National Oceanic and Atmospheric Administration Fisheries, accessed August 28, 2013, at http://swr.nmfs.noaa.gov/wood/creosote_report-final.pdf.

Summers, C.G., Godfrey, L.D., and Natwick, E.T., 2007, Managing insects in alfalfa, Chapter 9, in Irrigated alfalfa management: University of California Agriculture and Natural Resources Publication 8295, 24 p., accessed August 28, 2013, at http://alfalfa.ucdavis.edu/IrrigatedAlfalfa/pdfs/UCAlfalfa8295Insects_free.pdf.

Tanabe, S., and Subramanian, A., 2011, Editorial_-Great eastern Japan earthquake_-Possible marine environmental contamination by toxic pollutants: Marine Pollution Bulletin, v. 62, p. 883-884.

Tanaka, T., 2012, Characteristics and problems of fires following the great east Japan earthquake in March 2011: Fire Safety Journal, v. 54, p. 197-202.

Tioga, 2002, Seaport plan waterborne cargo forecast update: Prepared for the San Francisco Bay Conservation and Development Commission by the Tioga Group, 27 p.

University of California Integrated Pest Management Program, 2010, Pest Management guidelines-Alfalfa: University of California Integrated Pest Management Program, Publication 3430, 94 p.

United Nations Environment Programme, 2007, After the tsunami, coastal ecosystem restoration-Lessons learnt: United Nations Environment Programme, accessed August 28, 2013, at http://postconflict.unep.ch/publications/dmb_tsunami_coastal.pdf.

U.S. Environmental Protection Agency Facilities Registry System, 2011, U.S. Environmental Protection Agency facilities registry system: Environmental Protection Agency Facilities State Single File CSV Download, downloaded May, 2011, from http://www.epa.gov/enviro/html/frs_demo/geospatial_data/geo_data_state_single.html.

U.S. Geological Survey, 2013, Magnitude 9.1—Off the west coast of Sumatra: U.S. Geological Survey web site, accessed May 2013 at http://earthquake.usgs.gov/earthquakes/eqinthenews/2004/us2004slav/\#summary.

U.S. Geological Survey Seeps, 2013, Natural oil and gas seeps in California: U.S. Geological Survey web site, accessed June 2013 at http://walrus.wr.usgs.gov/seeps/index.html.

Van Geen, A., and Luoma, S.N., 1999, The impact of human activities on sediments of San Francisco Bay, California-An overview: Marine Chemistry, v. 64, p. 1-6.

Water Resources Action Plan, 2009, Final 2009 water resources action plan: Ports of Los Angeles and Long Beach report, accessed August 28, 2013, at http://www.portoflosangeles.org/environment/wrap.asp. 
Weston, 2009a, Summary of sediment quality conditions in the port of Long Beach: Weston Solutions Report prepared for Port of Long Beach, accessed August 28, 2013, at http://www.portoflosangeles.org/DOC/WRAP POLB_Sediment_Quality_Summary.pdf.

Weston, 2009b, Summary of sediment quality conditions in the port of Los Angeles: Weston Solutions Report prepared for Port of Los Angeles, accessed August 28, 2013, at http://www.portoflosangeles.org/DOC/WRAP_Appendix_B1.pdf.

Wilson, R.I., Admire, A.R., Borrero, J.C., Dengler, L.A., Legg, M.R., Lynett, P., McCrink, T.P., Miller, K.M., Ritchie, A., Sterling, K., and Whitmore, P.M., 2013a, Observations and impacts from the 2012 Chilean and 2011 Japanese tsunamis in California (USA): Pure and Applied Geophysics, v. 170, p. 1,127-1,147.

Wilson, R., Davenport, C., and Jaffe, B., 2012, Sediment scour and deposition within harbors in California (USA), caused by the March 11, 2011 Tohoku-oki tsunami: Sedimentary Geology, v. 282, p. 228-240.

Wilson, R.I., Barberopoulou, A., Miller, K.M., Goltz, J.D., and Synolakis, C.E., 2008, New maximum tsunami inundation maps for use by local emergency planners in the State of California, USA: EOS Trans. American Geophysical Union 89(53), Fall Meeting Supplement, Abstract OS43D-1343.

Yamada, T., Hiroi, U., and Sakamoto, N., 2011, Aspects of fire occurrences caused by tsunami: Fire Science and Technology, v. 30, n. 4 (special issue), p. 101-105.

Yoshii, T., Imamura, M., Matsuyama, M., Koshimura, S., Matsuoka, M., Mas, E., and Jimenez, C., 2012, Salinity in soils and tsunami deposits in areas affected by the 2010 Chile and 2011 Japan tsunamis: Pure and Applied Geophysics, 20 p., doi:10.1007/s00024-012-0530-4. 


\section{\#USCS $1 \mathrm{css}$}

\section{Economic Impacts of the SAFRR Tsunami Scenario in California}
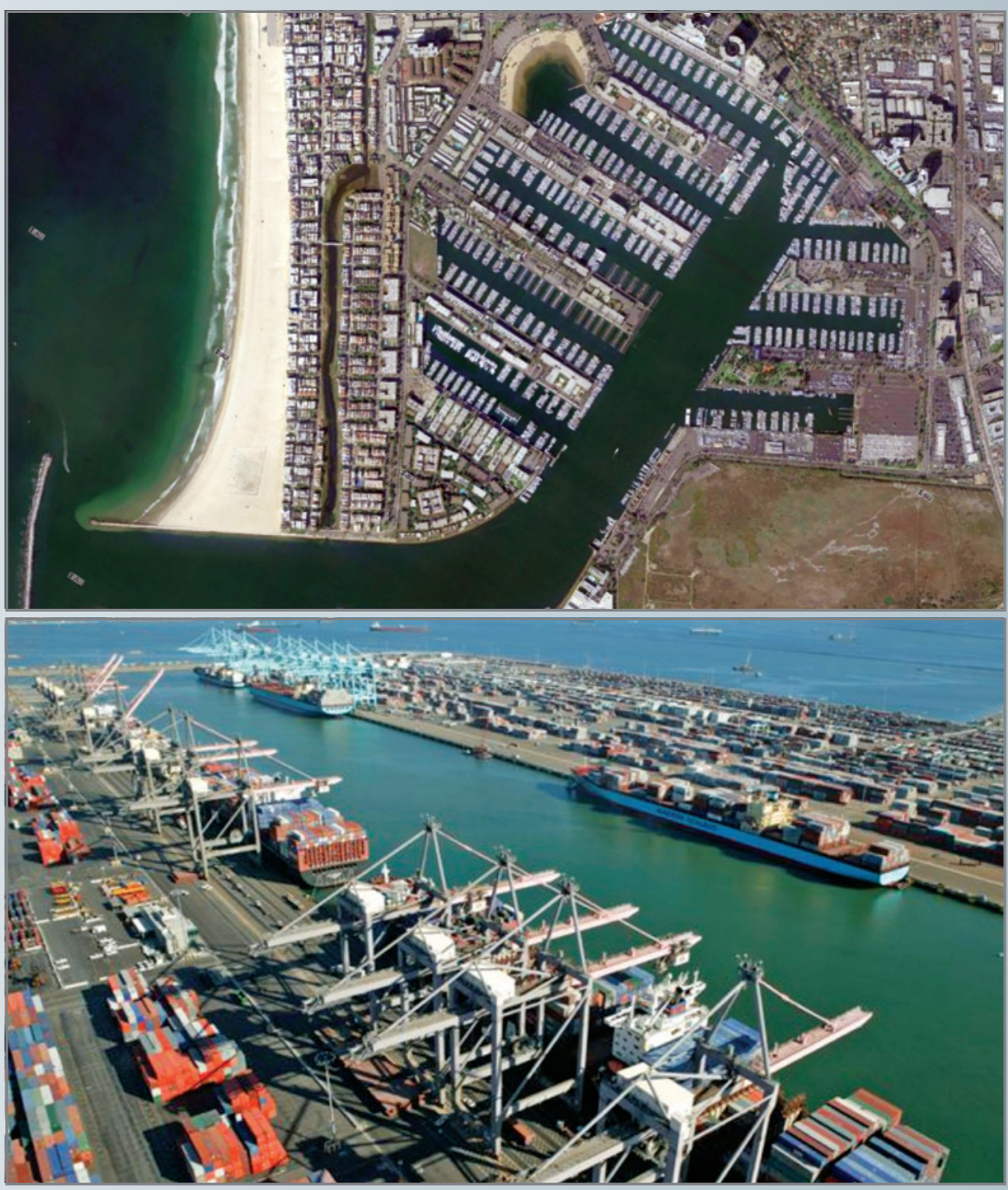

Open-File Report 2013-1170-H

California Geological Survey Special Report 229

U.S. Department of the Interior

U.S. Geological Survey 
COVER-The California coastal economy depends on activities served by ports, marinas, and, development, all of which are vulnerable to tsunamis. (top) satellite image of Marina del Rey, California, (image: USGS); (bottom) Port of Los Angeles, California (photo: Port of Los Angeles) 
The SAFRR (Science Application for Risk Reduction) Tsunami Scenario

Stephanie Ross and Lucile Jones, Editors

\section{Economic Impacts of the SAFRR Tsunami Scenario in California}

By Anne Wein, Adam Rose, lan Sue Wing, and Dan Wei

Open-File Report 2013-1170-H

California Geological Survey Special Report 229

U.S. Department of the Interior

U.S. Geological Survey 


\section{U.S. Department of the Interior \\ SALLY JEWELL, Secretary}

\section{U.S. Geological Survey \\ Suzette M. Kimball, Acting Director}

U.S. Geological Survey, Reston, Virginia 2013

For product and ordering information:

World Wide Web: http://www.usgs.gov/pubprod

Telephone: 1-888-ASK-USGS

For more information on the USGS-the Federal source for science about the Earth,

its natural and living resources, natural hazards, and the environment:

World Wide Web: http://www.usgs.gov

Telephone: 1-888-ASK-USGS

Suggested citation:

Wein, A., Rose, A., Sue Wing, I., and Wei, D., 2013, Economic impacts of the SAFRR tsunami scenario in California, chap. H, in Ross, S.L., and Jones, L.M., eds., The SAFRR (Science Application for Risk Reduction) Tsunami Scenario: U.S. Geological Survey Open-File Report 2013-1170, 50 p., http://pubs.usgs.gov/of/2013/1170/h/.

Any use of trade, product, or firm names is for descriptive purposes only and does not imply endorsement by the U.S. Government.

Although this information product, for the most part, is in the public domain, it also may contain copyrighted materials as noted in the text. Permission to reproduce copyrighted items must be secured from the copyright owner. 


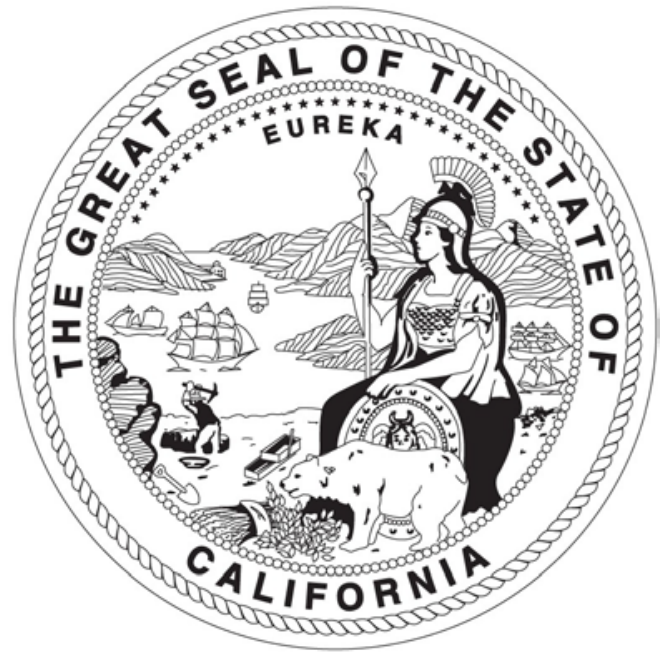

STATE OF CALIFORNIA

EDMUND G. BROWN JR. GOVERNOR

THE NATURAL RESOURCES AGENCY JOHN LAIRD

SECRETARY FOR RESOURCES

\author{
DEPARTMENT OF CONSERVATION \\ MARK NECHODOM \\ DIRECTOR
}

\title{
CALIFORNIA GEOLOGICAL SURVEY JOHN G. PARRISH, Ph.D. \\ STATE GEOLOGIST
}




\section{Contents}

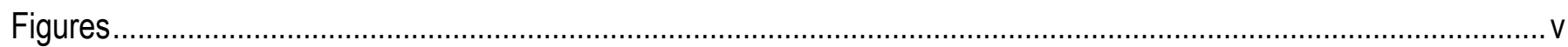

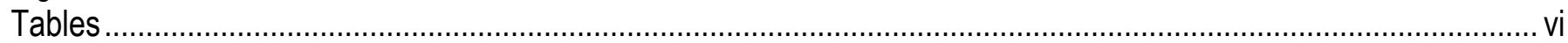

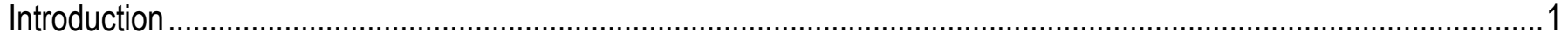

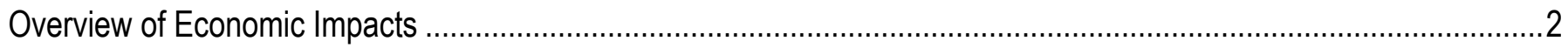

Direct Economic Impacts ..................................................................................................................

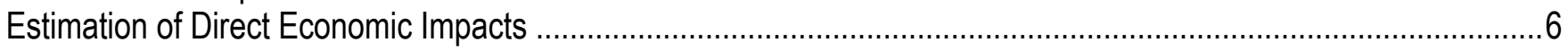

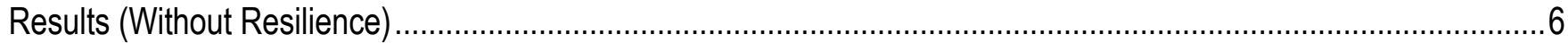

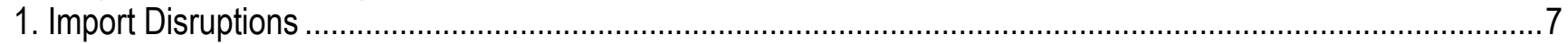

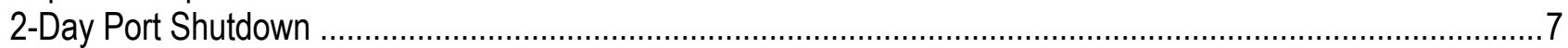

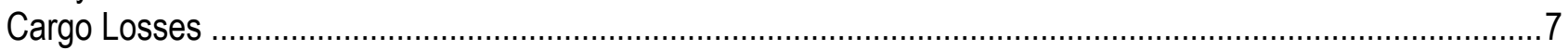

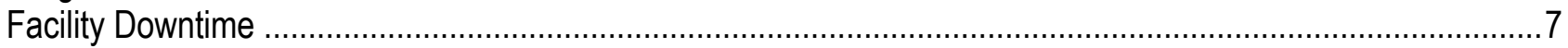

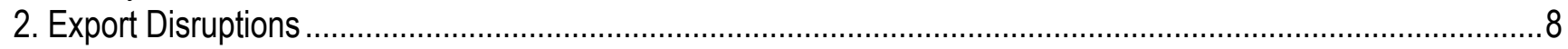

3. Direct Gross Output Losses Associated with Marina- Slip Damages at POLA .............................................

4. Gross Output Losses to POLA Commercial Fishing …….......................................................................

5. Capital Losses of Building and Content Damages .................................................................................... 9

6. Direct Gross Output Losses Associated with Marina Damages in California Coastal Counties ......................... 9

Summary of Direct Economic Impacts (Without Resilience) ..........................................................................

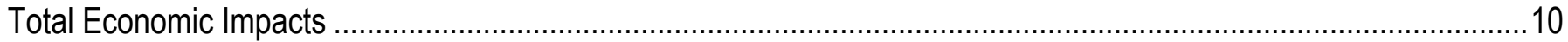

Estimation of Total Economic Impacts_Computable General Equilibrium Modeling............................................10

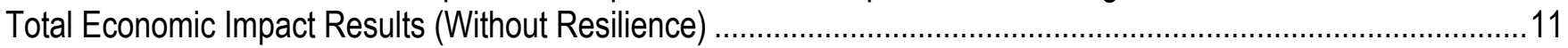

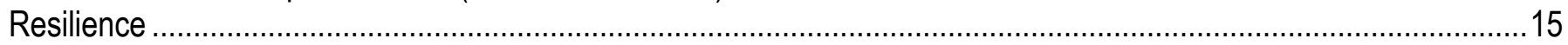

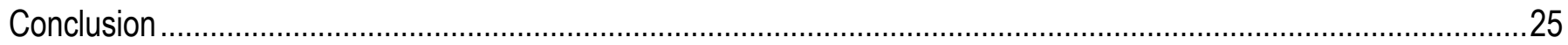

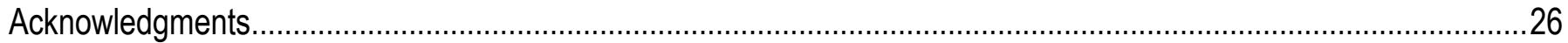

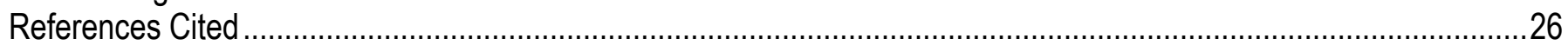

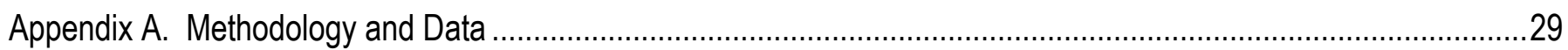

Appendix B. Tsunami Port Direct Impacts Without and With Resilience .................................................................32

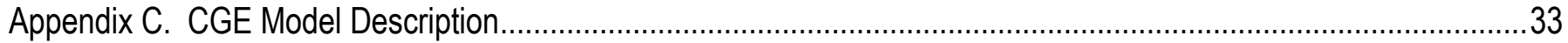

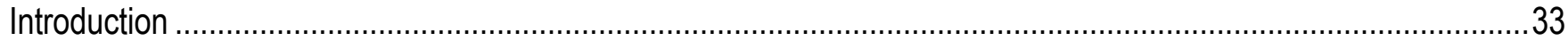

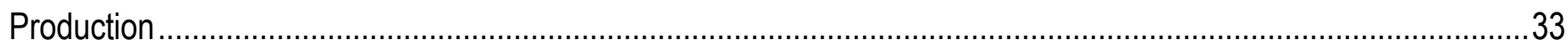

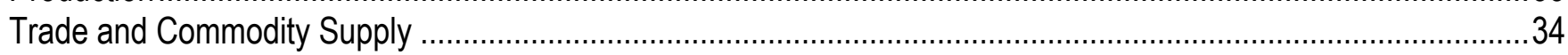

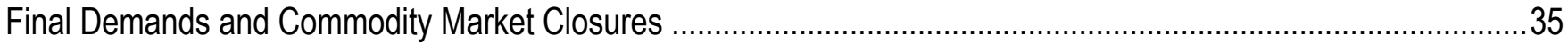

Intersectoral Factor Mobility and Static Income Closures …….....................................................................36

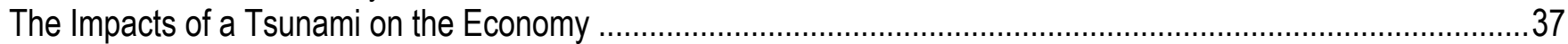

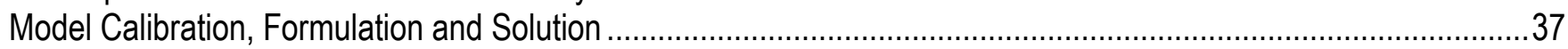

Appendix D. Calculation of Inventory Availability for Resilience ........................................................................ 41

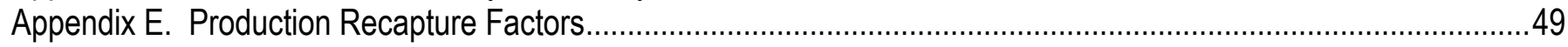

\section{Figures}

Figure 1. Estimating total economic impacts of a port disruption, cargo damages, and terminal downtime. 


\section{Tables}

Table 1. Summary of the direct impacts of the SAFRR tsunami scenario (without resilience)(in millions of 2010 dollars and percentage changes). 10

Table 2. Summary of business interruption from the SAFRR tsunami scenario, without resilience and reconstruction (in millions of 2010 dollars of Gross Domestic Product losses). 12

Table 3. Sectoral Gross Domestic Product losses from the SAFRR tsunami scenario. 14

Table 4. Methodology for direct resilience for disruptions to port related activities from the SAFRR tsunami scenario. 18

Table 5. Direct impact estimates for the SAFRR tsunami scenario before and after resilience. 22

Table 6. Property damage resilience through recapture for the SAFRR tsunami scenario. 24

Table C1. Computable general equilibrium (CGE) model sectors for the SAFRR tsunami scenario. .......38

Table C2. Elasticities of substitution, transformation, and supply or the SAFRR tsunami scenario.........40

Table D1. Real manufacturing inventories for the United States, by stage of fabrication, seasonally adjusted, end of 2011 (data from Bureau of Economic Analysis, 2013)

Table D2. Inventories by stage of fabrication for manufacturing industry in southern California region (in millions of 2010 dollars).

Table D3. Availability of raw material inputs computed from materials and supplies inventory for the southern California region (in millions of 2010 dollars)

Table D4. Finished goods held by sector for the southern California region (in millions of 2010 dollars). 46

Table D5. Available inventory in the southern California region (in millions of 2010 dollars). 


\title{
Economic Impacts of the SAFRR Tsunami Scenario in California
}

\author{
By Anne Wein, ${ }^{1}$ Adam Rose, ${ }^{2}$ lan Sue Wing, ${ }^{3}$ and Dan Wei ${ }^{2}$
}

\section{Introduction}

This study evaluates the hypothetical economic impacts of the SAFRR (Science Application for Risk Reduction) tsunami scenario to the California economy. The SAFRR scenario simulates a tsunami generated by a hypothetical magnitude 9.1 earthquake that occurs offshore of the Alaska Peninsula (Kirby and others, 2013). Economic impacts are measured by the estimated reduction in California's gross domestic product (GDP), the standard economic measure of the total value of goods and services produced. Economic impacts are derived from the physical damages from the tsunami as described by Porter and others (2013). The principal physical damages that result in disruption of the California economy are (1) about $\$ 100$ million in damages to the twin Ports of Los Angeles (POLA) and Long Beach (POLB), (2) about $\$ 700$ million in damages to marinas, and (3) about \$2.5 billion in damages to buildings and contents (properties) in the tsunami inundation zone on the California coast. The study of economic impacts does not include the impacts from damages to roads, bridges, railroads, and agricultural production or fires in fuel storage facilities because these damages will be minimal with respect to the California economy. The economic impacts of damage to other California ports are not included in this study because detailed evaluation of the physical damage to these ports was not available in time for this report.

The analysis of economic impacts is accomplished in several steps. First, estimates are made for the direct economic impacts that result in immediate business interruption losses in individual sectors of the economy due to physical damage to facilities or to disruption of the flow of production units (commodities necessary for production). Second, the total economic impacts (consisting of both direct and indirect effects) are measured by including the general equilibrium (essentially quantity and price multiplier effects) of lost production in other sectors by ripple effects upstream and downstream along the supply chain. An appropriate measure of the economic impacts on the California economy for the SAFRR tsunami scenario is the reduction in GDP.

The economic impacts are first calculated without resilience, the ability of the economy to adjust to disruptions in ways that mute potential negative impacts. There are many types of resilience, including using existing inventories of materials, using unused capacity, conserving inputs, substituting for disrupted supplies, recapturing production after the disruption is restored, and many others. A method for estimating resilience, identified in the port system and sectors affected by property damages, is applied to indicate potential reductions of direct and total economic impacts. In this SAFRR tsunami scenario analysis of economic impacts to California,

\footnotetext{
${ }^{1}$ U.S. Geological Survey; SAFRR Tsunami Scenario Economic Impact Coordinator.

${ }^{2}$ University of Southern California.

${ }^{3}$ Boston University.
} 
we implement established techniques used to model the economic impacts for two previous U.S. Geological Survey (USGS) scenarios: the southern California Shakeout earthquake (Rose and others, 2011) and the California ARkStorm severe winter storm (Sue Wing and others, written commun., 2013).

For the SAFRR tsunami scenario, we reviewed the relevant studies that assess economic impacts from previous tsunami events affecting California and elsewhere and estimate the economic impacts of potential tsunami and other threats to POLA and POLB. To our knowledge, assessment of impacts to the California economy from distant source tsunamis does not exist. Previous tsunamis, including those from the 1960 Chile earthquake, the 1964 Alaska earthquake, the 2008 Chile earthquake and the 2011 Japan earthquake, had only relatively minor or very localized severe damage (such as that in Crescent City in 1964), and no studies of the economic impacts were completed. A rare study of the economic impacts of a tsunami event has recently been produced for the Tohoku earthquake and tsunami (Kajitani and others, 2013). Quarterly declines in Japan's GDP are observed to peak at -1.63 percent in the second quarter after the event and stagnate for the rest of the year. The majority of the economic impacts are attributed to the tsunami rather than the earthquake. The hardest hit sectors are identified as agriculture, fisheries, manufacturing, retail, and tourism.

Other relevant studies have focused on the economic impacts of threats that close POLA and POLB. We find one analysis of a potential tsunami scenario affecting the California economy through disruption of port operations. Borrero and others (2005) estimated economic impacts to the southern California economy of $\$ 7$ to $\$ 40$ billion from a locally generated tsunami that closes POLA and POLB for as much as 1 year. There have also been several studies of the economic impacts of non-tsunami events affecting POLA and POLB. Analyses of an 11-day labor lockout produced a range of estimated national impacts of as much as $\$ 1.94$ billion/day (Park and others 2008, Martin Associates 2001). Examination of a potential terrorist attack that closes the San Pedro port for 1 month yielded a \$29 billion impact to the California economy (Park, 2008).

These studies have reinforced the importance of recognizing economic resilience in economic impact analyses. Hall (2004) criticized the upper-end estimate of national economic impacts from the labor lockout based on model shortcomings that neglected short-run substitution behavior and fixed the long-run economic behaviors. Following the 2011 Japanese tsunami, resilience was observed in the forms of rapid recovery of manufacturing sectors, energy conservation, and insurance (Kajitani and others, 2013).

\section{Overview of Economic Impacts}

The total economic impacts (both direct and indirect) of the tsunami will be transmitted through the damages and disruption of POLA and POLB, including damage to cargo on ships and at the ports. Other economic impacts will result from tsunami damage to buildings and contents as well as marinas along the California coast. These other economic impacts can be estimated in a rather straightforward manner as explained in the following section. The port disruptions are more complex and are explained in detail here. Figure 1 displays the major linkages in tracing a port disruption beginning with direct economic impacts through short-run and long-run impacts at five analytical time stages of a disaster scenario (see also Rose and Wei, 2013). 
The scenario begins with the Tsunami Event, which first translates into a risk of a port shutdown, cargo damage, and isolated terminal downtime for extended periods of time. At the port level, this leads to:

- Disruption of imports.

- Disruption of exports.

- Disruption of port onsite activities and operations.

Various resilience tactics would be implemented to mute impacts at the outset. Such responses would include rerouting the traffic to other ports, diversion of exports to be used as import substitutes, use of inventories by port customers, relocating activities within the ports, and rescheduling of activities once the port reopens by working overtime or extra shifts.

The next stage occurs at the macroeconomic level. Impacts stem from three aspects here as well:

- Intermediate goods shortfalls.

- Final goods shortfalls.

- Reduction in final demand associated with reduction in exports.

Both supply-side and demand-side considerations are taken into account in the total economic impact evaluation. The supply-side relates to impacts on customers of the imported goods down the supply chain, and the demand-side captures the impacts on suppliers to these customers up the supply chain. Both supply and demand considerations are needed on the import side to address disruptions of intermediate and final goods. Businesses using the imports as intermediate inputs in their production processes and their successive rounds of downstream customers are subject to supply shortfalls. In addition, the reduction in production of importusing businesses also reduces the demand for the goods produced by successive rounds of upstream suppliers within a region or nation. Because the "final" (finished) goods shortfalls to end-users (consumers, government, and purchasers of capital equipment) do not generate any forward or backward linkage effects, they are simply added to the total macroeconomic effects directly.

The shutdown of port operations preventing the shipments of exports are only estimated in terms of impacts on suppliers up the supply chain, because the downstream customers are out of the region and thus do not affect the region's GDP. Production of exports requires another perspective on the problem. Here, the disruption of port activity through the cessation of exports will reduce the demand for inputs in their production. First-round suppliers will in turn reduce their demand, thereby starting a chain reaction of production activity decreasing upstream, analogous to the case on the import side. The sum total of all of these impacts is a multiple of the original shock; hence, the term "multiplier effect" characterizes these reactions to yield the macroeconomic impacts. Disruption to port on-site operations and related activities, including marina rentals and commercial fishing, generate their own demand-side effects. There are a number of resilience tactics applicable here, and at other junctures shown in figure 1, which will be discussed in detail below.

The total-impact stage represents a summing up of all the various types of supply-side and demand-side impacts. In a linear model, all of these various boxes in figure 1 are additive, and can be calculated and presented separately to identify the relative influence of the various 
and offsetting factors. In more complex models, such as the one used in this study, there are some important interactions, such as substitution effects, between these various components, that cannot be readily decomposed.

There is also the potential of long-run effects. These could arise from permanent loss of business for the port due to advantages of newly established logistical patterns or from stigma that stems from the fear of vulnerability to a repeated disaster. In addition, economic impacts can stem from:

- Economic costs of environmental damage.

- Costs of shipping delays to the intended port.

- Costs of resilience (including of rerouting shipping to other ports, substitution of less efficient inputs into production activities down the supply chain, and other factors).

The costs of the first two options are likely to be relatively small except in the case of environmental damage such as a major oil spill, for example, which extends the duration of the port closure (see Rose and Wei, 2013). If the cost of delays of shipments to the intended ports (that is, until they or terminals are reopened) becomes extremely high, then rerouting will be pursued more aggressively. Although the costs of some resilience tactics can be significant, the benefits, in terms of avoided business interruption, are likely to more than offset the cost.

Figure 1 focuses on general port and port-related activities. It does not explicitly depict the roles of some areas of the regional economy impacted by the tsunami, such as cargo, marinas and commercial fishing. However, both of these can be readily related to the figure. Cargo enters through the disruption of imports and disruption of export boxes. The operation of marinas and commercial fishing are analogous to the disruption of port activities in terms of their placement at the microeconomic level. Of course, resilience tactics will differ between these objects of disruption, as well as differing from port-level resilience.

\section{Direct Economic Impacts}

This section summarizes the estimation and results for the direct economic impacts associated with the SAFRR tsunami scenario, including impacts associated with POLA and POLB, coastal marinas, and buildings and contents within the tsunami inundation zone in California. The direct economic impact calculations omit damage to other ports, agricultural production, transportation infrastructure, lifeline infrastructure, and nonbuilding assets such as vehicles. These omissions were deemed minor except for the case of the other ports, where the scale of damages is largely unavailable at this time. On the other hand, the direct economic impacts are inflated in the absence of resilience. Therefore, the analyzed direct economic impacts represent a lower bound on impacts without resilience to California. The analysis of the direct impacts with resilience is conducted in the resilience section to demonstrate the effectiveness of resilience and potential for further enhancement. 


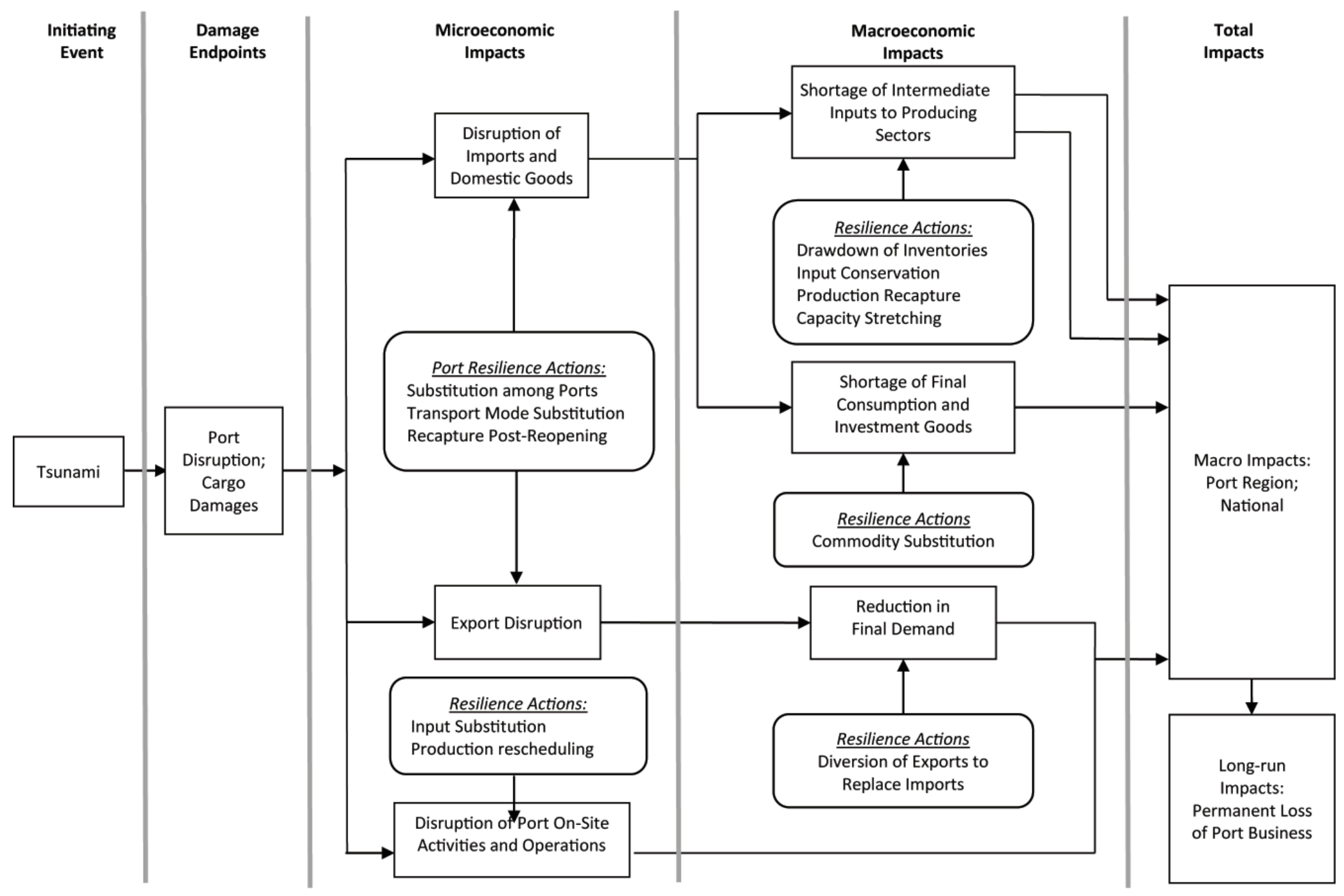

Figure 1. Estimating total economic impacts of a port disruption, cargo damages, and terminal downtime. 


\section{Estimation of Direct Economic Impacts}

The analysis of direct economic impacts uses a combination of data provided by the Tsunami Research Team members (Porter and others, 2013), outside contacts, and publically available data. Analysis of the physical damages at POLA and POLB (Dykstra and others, 2013) was used extensively except for damages to the Crescent Warehouse and Berth S101 in POLB that were determined to be recently vacated or not in use, respectively. Much of the data were refined by the authors for inclusion in the report (see appendix A for details). Part of the refinement was to make the results compatible with a 65 -sector computable general equilibrium (CGE) model that is used to determine the total economic impacts of the SAFRR tsunami scenario, as described below

Appendix B provides details of our calculations of port direct economic impacts. This appendix is in the form of an Excel spreadsheet ("Tsunami_Port_Direct Impacts without and with Resilience" and is available online at http://pubs.usgs.gov/of/2013/1170/H/). The "base case" sheet contains four tables of direct impacts of the SAFRR tsunami scenario to the twin ports without any resilience adjustments. The tables are:

- Import disruption.

- Export disruption.

- Direct revenue losses due to marina slip damages.

- Direct revenue losses to commercial fishing.

For both import disruption and export disruption, the impacts are calculated for the following three categories in both dollar values and percentage impacts:

- Impacts of a 2-day port shutdown.

- Impacts of cargo losses.

- Impacts of facility downtime

In addition, the direct import/export disruption impacts are presented for both the southern California five-county region (including Ventura, Los Angeles, Orange, San Bernardino, and Riverside) and for the rest of California. The direct impacts of slip damages at the marinas and loss to the commercial fishing industries in POLA are presented as direct revenue losses to the relevant sectors. They only pertain to the southern California region. Besides the direct impacts resulting from disruptions to the port-related activities, direct impacts also stem from capital damages to buildings and contents in California's coastal counties due to flooding (Porter, 2013). In addition to slip damages in the marinas within the port complex, damages to marinas occur along the coast of California (Porter and others, 2013).

\section{Results (Without Resilience)}

In this section we present the direct economic impacts of the tsunami scenario without resilience. Note that the results are presented in terms of the most accessible measure of loss available - values of imports and exports that would be affected by downtime and cargo damages, buildings and contents that would be damaged, and gross output (business revenue) losses for sectors related to marina activities and fishing industry. Consequently, the direct impacts cannot be summed. Please note that these measures differ from GDP, which is the more appropriate measure for total economic impacts economy-wide. 


\section{Import Disruptions}

Import disruptions are measured as the values of imports destined for southern California and the rest of California that are affected by the 2-day port shutdown, cargo losses, and terminal downtime. For southern California they are presented in the left-hand partition of table B1 under the three categories of disruption:

\section{2-Day Port Shutdown}

Dykstra and others (2013) concluded that the twin ports would be shut down for two days. The resulting direct impacts in southern California are a disruption of $\$ 417.3$ million (in 2010 dollars) of import goods from more than half of the 65 sectors. The major types of disrupted import commodities are machinery manufacturing, other transportation equipment manufacturing, and apparel-manufacturing products related to container activities. In relative terms, the major disruptions, however, are for plastics and fishing products, each representing slightly more than 0.5 percent of annual imports of these commodities.

\section{Cargo Losses}

Cargo losses are related to inundation of terminals, as well as the nature of the cargo (for example, perishable goods). Losses of cargo destined for southern California total \$60.8 million. The major imported cargo losses are automobiles, which consist of nearly 83 percent of the total value of cargo damages. These losses also represent 0.64 percent of the annual imports of this commodity in the year 2010 .

\section{Facility Downtime}

Several port facilities (cargo handling terminals) would be damaged in the tsunami scenario. For example, several marine oil terminals of POLA would only be able to operate at 50 percent capacity for 1 month due to the damage to the terminal operating systems. A few other terminals are considered unusable during debris clean up. Due to the reduced handling capacity of several terminals, the total estimated import disruption is $\$ 197$ million. Affected commodities include steel, petroleum refineries goods, and chemical products (such as caustic soda), which correspond to iron and steel manufacturing, petroleum refining, and chemical manufacturing sectors, respectively, in our 65-sectoring scheme. The latter represents only a trivial amount, whereas the former two represent approximately 65 percent and 35 percent of the total impacts to imports, respectively, in this category.

The total import disruption to the southern California region is more than $\$ 675$ million, or 0.214 percent of total annual imports to the region. Direct economic impacts from imports destined for the rest of California are presented in the right-hand partition of table B1 for the same categories of import disruptions as for southern California. All three categories of losses are lower for the rest of the state because on average a higher proportion of the affected imports are delivered to users in the southern California region than to the rest of California. The lower value is most pronounced for cargo losses, which are only $\$ 5.8$ million for the rest of California versus $\$ 60.8$ million for the southern California region alone. This result follows from the damages to automobiles that make up the majority of cargo losses. According to the data we obtained from the port expert, more than 90 percent of the imported automobiles are delivered to the southern California region. 
The total import disruption to the rest of California region is about $\$ 325$ million, or 0.061 percent of total annual imports to the region. As explained above, the difference in import disruptions (in dollar values) for different commodities/sectors between the two geographic regions are determined by the proportion of these imports that have destinations within the southern California region or in the rest of California. The percentage impact is also affected by the proportion of each type of import commodities that are imported into the region through the twin ports (versus through other modes of import).

\section{Export Disruptions}

Direct export disruptions are measured as the values of exports destined for southern California and the rest of California that are affected by the 2-day port shutdown, cargo losses, and terminal downtime. They are presented in table B2. For southern California (left-hand quadrant of table B2), the 2-day shutdown results in a total export disruption of $\$ 91.7$ million. Major types of affected exports are chemical manufacturing, machinery manufacturing, and food manufacturing products, each exceeding \$10 million. Cargo losses on the export side amount to only $\$ 2.8$ million, with the largest damage to exports of the same three sectors. Facility down time, as related to exports, is $\$ 37.2$ million, confined primarily to petroleum refining and chemical manufacturing (industrial borate) exports. The total export disruption to the southern California region is about $\$ 132$ million, or 0.034 percent of total annual exports from the region.

Total export disruptions for the rest of California are presented in the right-hand partition of table B2. The total direct impacts of the 2-day shutdown are $\$ 58.0$ million. Total facility downtime is $\$ 18.9$ million. Cargo losses are only $\$ 1.8$ million. The total impacts are about $\$ 78.2$ million, or 0.017 percent of the total annual exports from the region. Overall, the export disruptions are significantly smaller than their import counterparts presented in table B1.

\section{Direct Gross Output Losses Associated with Marina- Slip Damages at POLA}

Direct losses from damages to POLA marinas are measured as gross output (revenue) losses to the marina activity related sectors defined by Martin Associates (2007). The sectors include retail trade, scenic and sightseeing transportation, other amusement and recreation industries, and food services and drinking places related to marina operations. The results are calculated in table B3 according to the following steps:

1. Total revenues of POLA marina-related activities in 2006 were $\$ 48.2$ million (Martin Associates, 2007). The marina-slip utilization roughly remains the same between 2006 and 2010. Converting $\$ 48.2$ million to 2010 dollars, we obtain a total revenue of $\$ 51.8$ million in 2010 dollars.

2. Of the $\$ 51.8$ million, about $\$ 3.6$ million is the rental revenue to the ports. For the remaining \$48.2 million, we assume that the revenues are distributed evenly among the four marina-related sectors of retail trade, scenic and sightseeing transportation, other amusement and recreation industries, and food services and drinking places.

3. To compute the revenue losses to the affected sectors, we next divide the above revenues by 3 because 1/3 of the POLA marina slips are damaged.

4. In addition, Porter and others (2013) determined that it would take 1 month to repair the damaged slips at a linear rate. Therefore, we further divide the revenues by 12 to account for the loss in 1 month and then divide the result by 2, based on the linear repair rate to obtain the revenue losses for each sector related to marina-slip damages. 
The total estimated gross output loss to the marina-related sectors is $\$ 0.72$ million.

\section{Gross Output Losses to POLA Commercial Fishing}

Table B4 presents the results for direct revenue losses to POLA commercial fishing. Outcomes of the tsunami scenario would include perished fish on board the vessels at sea and lost fishing days - we assumed 25 percent of a day's fish haul would perish and 4 fishing days would be lost. In addition, 5 percent of the fishing fleet is assumed damaged due to vessels left in the harbor. We note that there is a lack of fragility curves for vessels tied to fixed piers, AlThese estimates should be treated as illustrative. 1 .) On the basis of conversations with fishermen, we assumed that it would take about 2 months on average to repair or replace the damaged boats. The direct revenue losses to the fishing industry of the above individual components are:

- 25 percent of one day's fish loss: $\$ 25,890$.

- 5 percent of fishing fleet damage (2-month repair time): $\$ 315,000$.

- 4 fishing days lost: \$393,534.

- Total fishing industry revenue loss: $\$ 734,425$.

\section{Capital Losses of Building and Content Damages}

The direct impacts of building and content damages (loss of capital stock) are represented by repair and replacement costs. The first row under section B in table 1 summarizes the building and content damages in coastal counties. In the southern California region, the building and content related property losses are $\$ 52$ million and $\$ 367$ million, respectively, representing about 0.004 percent and 0.047 percent of the total capital stock in this region. The building and content related property losses in the rest of California are $\$ 246.4$ million and $\$ 1.16$ billion, respectively. They represent 0.016 percent and 0.124 percent of the total capital stock in the rest of California.

\section{Direct Gross Output Losses Associated with Marina Damages in California Coastal Counties}

The damages to docks at marinas are translated into gross output (revenue) losses to three sectors related to marina activities (restaurants, retail stores, and marina-related activities) in two steps: (1) we use the estimate of $\$ 13,649$ total annual revenues per slip and the assumption that one dock has an average of 50 slips to translate the number of docks that have lost functionality into total revenue losses; (2) we distribute the revenue losses evenly among restaurants, retail trade, and marina-related activities sectors. The total direct revenue losses to the three marina activity related sectors in the southern California region are $\$ 71.4$ million. The total direct revenue losses are $\$ 50.8$ million in the rest of California.

\section{Summary of Direct Economic Impacts (Without Resilience)}

We provide a summary of the direct economic impacts of the SAFRR tsunami scenario in southern California and the rest of the State without resilience in table 1. In terms of percentage impacts, the impacts are dominated by the disruption to imports, especially from the 2-day shutdown of the twin ports and damages to building content. How the production of each sector would be affected by the import disruption is largely influenced by the dependence on these imports as production inputs, taking into account the sectors' ability to substitute disrupted import goods with other inputs. The total economic impacts stemming from the various direct impacts include the ripple effects transmitted through upstream and downstream supply-chain 
linkages, as well as the spending of wages/salaries and capital-related income and the ripple effects these induce.

Table 1. Summary of the direct impacts of the SAFRR tsunami scenario (without resilience)(in millions of 2010 dollars and percentage changes ${ }^{1}$ ).

[\%, percent; n.a., not applicable; $\$$, dollars $]$

\begin{tabular}{|c|c|c|c|c|}
\hline Impacted category & Unit of measurement & $\begin{array}{c}\text { Southern California } \\
\text { region }\end{array}$ & Rest of California & Total California \\
\hline \multicolumn{5}{|c|}{ A. Direct impacts related to ports } \\
\hline Import disruption & Import value & $\$ 675.2(0.21 \%)$ & $\$ 312.1(0.06 \%)$ & $\$ 987.3(0.12 \%)$ \\
\hline 2-day Shutdown & Import Value & $\$ 417.3(0.13 \%)$ & $\$ 208.2(0.04 \%)$ & $\$ 625.4(0.08 \%)$ \\
\hline Cargo losses & Import value & $\$ 60.8(0.02 \%)$ & $\$ 5.8(0.00 \%)$ & $\$ 66.6(0.01 \%)$ \\
\hline Facility downtime & Import value & $\$ 197.1(0.06 \%)$ & $\$ 98.2(0.02 \%)$ & $\$ 295.2(0.04 \%)$ \\
\hline Export disruption & Export value & $\$ 131.8(0.03 \%)$ & $\$ 78.2(0.02 \%)$ & $\$ 210.0(0.03 \%)$ \\
\hline 2-day Shutdown & Export Value & $\$ 91.7(0.02 \%)$ & $\$ 57.5(0.01 \%)$ & $\$ 149.2(0.02 \%)$ \\
\hline Cargo losses & Export value & $\$ 2.8(0.00 \%)$ & $\$ 1.8(0.00 \%)$ & $\$ 4.6(0.00 \%)$ \\
\hline Facility downtime & Export value & $\$ 37.2(0.01 \%)$ & $\$ 18.9(0.00 \%)$ & $\$ 56.1(0.01 \%)$ \\
\hline Marina slip damages & Gross output & $\$ 0.7(0.00 \%)$ & n.a. & $\$ 0.7(0.00 \%)$ \\
\hline Commercial fishing & Gross output & $\$ 0.7(0.00 \%)$ & n.a. & $\$ 0.7(0.00 \%)$ \\
\hline \multicolumn{5}{|c|}{ B. Direct impacts along other parts of the California coast } \\
\hline Building damages & Capital stock & $\$ 73.8 .0(0.004 \%)$ & $\$ 349.9 .4(0.016 \%)$ & $\$ 423.7(0.011 \%)$ \\
\hline Content damages & Capital stock & $\$ 521.7$. (0.047\%) & $\$ 1,646.5(0.124 \%)$ & $\$ 2,168.2(0.089 \%)$ \\
\hline Marina damages & Gross output & $\$ 71.4(0.005 \%)$ & $\$ 50.8(0.003 \%)$ & $\$ 122.2(0.004 \%)$ \\
\hline
\end{tabular}

${ }^{1}$ Percentages for output, import value, and export value are measured as proportions of annual flows; percentage of capital stock loss is measured with respect to capital stock in place.

\section{Total Economic Impacts}

This section summarizes the estimation and results for the total economic impacts (or business interruption) from the SAFRR tsunami scenario. The total economic impacts (consisting of both direct and indirect effects) are the general equilibrium (essentially quantity and price multiplier effects) of lost production in other sectors by ripple effects upstream and downstream along the supply chain. Similar to the direct impacts, total economic impacts are associated with damages and disruption at POLA and POLB, coastal marinas, and buildings and contents within the tsunami inundation zone in California. Likewise, the total economic impacts do not include resilience.

\section{Estimation of Total Economic Impacts-Computable General Equilibrium Modeling}

A computable general equilibrium (CGE) model is a stylized computational representation of the circular flow of the economy (see, for example, Sue Wing, 2009, 2011). It solves for the set of commodity and factor (intermediate inputs as well as labor and capital) prices and the set of activity levels of firms' outputs and households' incomes that equalize supply and demand across all markets in the economy. The model developed for this study divides California's economy into two regions (the five-county southern California region-Los Angeles, Orange, Riverside, San Bernardino, Ventura - and the remainder of the State), each of which consists of 65 industry sectors and households in nine different income categories.

The industry aggregation is matched with occupancy classes in HAZUS, FEMA's expert loss estimation system, which was employed by another research team member to calculate the building and content losses caused by the tsunami's physical impacts. Each sector is modeled as 
a representative firm characterized by a constant elasticity of substitution (CES) among combinations of inputs to produce a single good or service. The households in each income class are modeled as a single representative agent with CES preferences and a constant marginal propensity to save and invest out of income. Government is represented in a simplified fashion, its role in the circular flow of the economy being passive-collecting taxes from industries and passing some of the resulting revenue to the households as lump-sum transfers, in addition to purchasing commodities to create a composite government good that is consumed by the households. Two primary factors of production are represented within the model: (1) labor, whose endowment is fixed but whose allocation among sectors responds to changes in the wage rate, and (2) capital, which is treated as sector-specific and immobile among industries or regions during the short-run period relevant to the tsunami simulations. These factors are owned by the representative agents, who "rent" them out to the firms in the agents' county of residence in exchange for factor income. Each region is modeled as an open economy that engages in trade with the rest of California, the rest of the United States, and the rest of the world according to an assumption in which imports from other counties, States, and the rest of the world are imperfect substitutes for goods produced locally (known as the Armington specification).

The model is static, computing the prices and quantities of goods and factors that equalize supply and demand in all markets in the economy, subject to constraints on the external balance of payments, over a single 6-month period. The impacts of a tsunami are modeled as exogenous negative shocks to the productivity of import and export activities, damage to capital stocks in sectors sustaining direct physical damage (with concomitant reductions in endowments of sector-specific capital input), and negative shocks to the productivity of marine-related industries (fishing and marinas). The model is formulated as a mixed complementary programming problem using the Mathematical Programming System for General Equilibrium analysis (MPSGE) subsystem for the General Algebraic Modeling System (GAMS) software (Rutherford, 1999; Brooke and others, 1998) and is solved using the PATH solver (Ferris and others, 2000). A more detailed and technical description of the model is presented in appendix C. The model is calibrated using an IMPLAN (IMpact analysis for PLANning) social accounting matrix for the State of California for the year 2010 (Minnesota IMPLAN Group, Inc., 2012). The key parameters of the model are summarized in appendix $\mathrm{C}$, which also provides the sectoring scheme. The model has been successfully applied to other disaster scenarios. This includes a study of the economic impacts of a San Francisco Bay area earthquake closing off the California Aqueduct water supplies to Los Angeles County (Rose and others, 2012) and the USGS California ARkStorm severe winter storm scenario (Sue Wing and others, 2013).

\section{Total Economic Impact Results (Without Resilience)}

The two-region CGE model was applied to the tsunami's direct economic impacts presented in table 1 to estimate the total economic impacts of the event. The direct impacts are entered as a combination of import/export disruptions, capital stock damages, and direct gross output (revenue) losses, depending on the component of the economy affected (see Section III for a discussion of the methodology). The results are presented in table 2 for the five-county southern California region, the rest of California, and for California as a whole. The results are also presented for each conduit of the shock. Overall, the impacts on GDP (in 2010 dollars) are: $\$ 3.2$ billion for the five-county southern California region, $\$ 2.8$ billion for the rest of California, and $\$ 6.0$ billion for California as a whole. These impacts represent only $0.383,0.244$, and 0.303 percent of annual GDP of the three regions, respectively. 
Table 2. Summary of business interruption from the SAFRR tsunami scenario, without resilience and reconstruction (in millions of 2010 dollars of Gross Domestic Product losses).

[\%, percent; \$, dollars; POLA, Port of Los Angeles]

\begin{tabular}{lrrr}
\hline \multicolumn{1}{c}{ Impacted category } & Southern California region & Rest of California & \multicolumn{1}{c}{ Total California } \\
\hline San Pedro import total & $\$ 1,847(0.222 \%)$ & $\$ 1,327(0.116 \%)$ & $\$ 3,173(0.161 \%)$ \\
2-day port shutdown & $\$ 956(0.115 \%)$ & $\$ 780(0.068 \%)$ & $\$ 1,736(0.088 \%)$ \\
Cargo loss & $\$ 57(0.007 \%)$ & $\$ 21(0.002 \%)$ & $\$ 78(0.004 \%)$ \\
Facility downtime & $\$ 828(0.099 \%)$ & $\$ 522(0.046 \%)$ & $\$ 1,350(0.068 \%)$ \\
& $\$ 479(0.058 \%)$ & $\$ 621(0.055 \%)$ & $\$ 1,100(0.056 \%)$ \\
San Pedro export total & $\$ 357(0.043 \%)$ & $\$ 439(0.039 \%)$ & $\$ 795(0.040 \%)$ \\
2-day port shutdown & $\$ 11(0.001 \%)$ & $\$ 14(0.001 \%)$ & $\$ 25(0.001 \%)$ \\
Cargo loss & $\$ 112(0.013 \%)$ & $\$ 169(0.015 \%)$ & $\$ 281(0.014 \%)$ \\
Facility downtime & $\$ 846(0.102 \%)$ & $\$ 819(0.072 \%)$ & $\$ 1,665(0.084 \%)$ \\
California coast property damage & $\$ 54(0.006 \%)$ & $\$ 51(0.005 \%)$ & $\$ 105(0.005 \%)$ \\
total & $\$ 792(0.095 \%)$ & $\$ 767(0.067 \%)$ & $\$ 1,559(0.079 \%)$ \\
Buildings & $\$ 19(0.002 \%)$ & $\$ 14(0.001 \%)$ & $\$ 33(0.002 \%)$ \\
Contents & $\$ 17(0.002 \%)$ & $\$ 14(0.001 \%)$ & $\$ 30(0.002 \%)$ \\
Other Impacts Total & $\left.\$ 2(0 \%)^{1}\right)$ & $\$ 0^{2}(0 \%)$ & $\$ 2(0 \%)$ \\
California coast marinas & & $\$ 2,782(0.244 \%)$ & $\$ 5,971(0.303 \%)$ \\
POLA fishing & & & \\
Grand total & & & \\
\hline Less than 0.0005\%. & & & \\
Less than $\$ 500,000$. & & & \\
Totals may not add due to rounding. & & &
\end{tabular}

Import disruption impacts are the largest component of the negative economic shocks in all three regions, totaling $\$ 3.2$ billion. The total economic impacts of import disruptions represent nearly 50 percent or more of the predicted declines in total GDP in each region. The category that represents the largest share is the shutdown of the ports themselves, and the smallest by far stems from the loss of cargo. One interesting feature of import losses, in contrast to export losses to be discussed next, is that the former are higher for the southern California region than for the rest of the State. The reasons for this result are the lower direct import disruption impacts and the greater substitution stimulus from the reduced flow of imports for the rest of the State relative to the same for the southern California region.

Export disruptions are estimated to incur \$1.1 billion in GDP losses for California, with port shutdowns by far being responsible for the largest component. Again, cargo losses are by far the smallest component. Export shutdowns do not stimulate any offsetting effects, like the case of imports, because it wouldn't pay to produce more goods for export if they cannot be shipped.

Building and content damage in coastal California due to flooding is predicted to amount to $\$ 1.7$ billion in GDP losses, with the vast majority being due to content damage. Here the CGE analysis is a straightforward price and quantity multiplier effect extension of the direct impacts, and the total impacts for the two subcategories have similar proportions as the direct impacts. Other impacts of the tsunami stemming from marina damages and fishing losses are very small, totaling only $\$ 33$ million, or only 0.002 percent of State annual GDP. By far, the largest share stems from damage to marinas. 
Reductions in the value of GDP are shown in table 3 for the five most affected sectors, when losses are expressed as a percentage of annual GDP. Disruption of imports and exports incur the largest output losses in manufacturing industries (leather products, primary and fabricated metal products, machinery and ship building/repair). The pattern of losses is broadly similar for both the five-county and rest of California regions, with the former experiencing larger losses in both absolute and percentage terms. The overall magnitude of the losses affecting hardest-hit manufacturing industries is small in both absolute and percentage terms over the 6month assessment period, totaling 0.4 to 2 percent of annual output or $\$ 302$ million in the fivecounty region and $\$ 110$ million in the rest of the State. The overall change in gross output due to trade disruption is slight $(0.2$ percent for the five-county and 0.1 percent for the rest of California), accounting for losses of $\$ 2.7$ billion in the five-county region and $\$ 1.6$ billion in the rest of California.

Direct damage to capital stocks has its largest impact on a different slate of industries, and the associated output losses are at an order of magnitude smaller in percentage terms than in the imports/exports disruption case. In the five-county region the output of service sectors is most affected (healthcare, real estate, retail trade, education, and transportation), whereas in the rest of California adverse impacts are more concentrated in accommodation services, oil seed and grain farming, pipeline transportation and gas distribution, and health care services. The larger baseline GDP of these sectors in the rest of California means that the dollar value of losses is larger despite being smaller in percentage terms. The overall change in GDP due to direct destruction of buildings and contents is slight ( 0.01 to 0.2 percent), accounting for losses of $\$ 710$ million in the five-county region and almost $\$ 2$ billion in the rest of California.

Finally, looking at the combined impact of all conduits of shock, the sectors that are most affected on a percentage basis are dominated by the ones that face the largest exposure to losses from trade, with the notable exception of fishing - which is both small and hardest hit in the fivecounty region. Although fishing damages were not evaluated in the rest of California, the impact is traceable to demand reductions and price responses in the food-manufacturing and service industries. On the whole, losses for both regions are similarly small, 0.2 percent of output, totaling around $\$ 3.5$ billion.

The results are miniscule compared to the devastation of the Japanese coast in the 2011 tsunami and ensuing cascading disasters. The main reason is that the SAFFR tsunami scenario produces smaller waves and less inundation along the California coast than what occurred along the Japanese coast. The estimates in table 2, even before we make any resilience adjustments, are very much lower than those for the two previous USGS disaster simulations, where GDP losses (in 2010 dollars) were about $\$ 70$ billon for the ShakeOut (Rose and others, 2011) and a couple of hundred billion dollars for ARkStorm (Sue Wing, 2013).

Note that the results are presented in terms of business interruption relative to projected GDP. Because this assumes the economy of the southern California region and the rest of the State will continue to grow, the impacts are relatively larger than if they were compared to preevent (static or constant levels of production). However, this distinction is not likely to be great because we are only considering one 6-month forecast period. 
Table 3. Sectoral Gross Domestic Product losses from the SAFRR tsunami scenario. [mfg, manufacturing; \$, dollars; POLA, Port of Los Angeles]

\begin{tabular}{|c|c|c|c|c|c|}
\hline \multirow[t]{2}{*}{ Five-county region } & & \multicolumn{4}{|c|}{ Rest of California } \\
\hline & Mill \$ & $\%$ & & Mill \$ & $\%$ \\
\hline \multicolumn{6}{|c|}{ From San Pedro import and export disruption } \\
\hline Other primary metal $\mathrm{mfg}$ & -4.5 & -3.6 & Leather and allied product $\mathrm{mfg}$ & -2.2 & -3.4 \\
\hline Fabricated metal product $\mathrm{mfg}$ & -29.7 & -3.3 & Other primary metal $\mathrm{mfg}$ & -14.2 & -2.8 \\
\hline Leather and allied product $\mathrm{mfg}$ & -243.8 & -3.2 & $\begin{array}{l}\text { Automobile and light duty motor } \\
\text { vehicle } \mathrm{mfg}\end{array}$ & -26.9 & -2.5 \\
\hline $\begin{array}{l}\text { Automobile and light duty motor } \\
\text { vehicle } \mathrm{mfg}\end{array}$ & -93.2 & -2.9 & Fabricated metal product mfg & -74.9 & -1.9 \\
\hline $\begin{array}{l}\text { Iron and steel mills and steel } \\
\text { product mfg }\end{array}$ & -0.8 & -2.9 & Machinery mfg & -7.7 & -1.2 \\
\hline Other sectors & $-2,270.2$ & -0.3 & Other sectors & $-1,506$ & -0.2 \\
\hline Total & $-2,642.1$ & -0.3 & Total & $-1,632$ & -0.2 \\
\hline \multicolumn{6}{|c|}{ From California building and content damage } \\
\hline Health care and social assistance & -109.7 & -0.2 & Accommodation & -12.5 & -0.3 \\
\hline Educational services & -211.1 & -0.2 & Oilseed and Grain Farming & -17.2 & -0.2 \\
\hline Retail trade & -58.1 & -0.2 & Pipeline transportation & -1.5 & -0.2 \\
\hline $\begin{array}{l}\text { Transit and ground passenger } \\
\text { transport }\end{array}$ & -16.3 & -0.2 & Natural gas distribution & -0.9 & -0.2 \\
\hline Real estate and rental and leasing & -25.5 & -0.1 & $\begin{array}{l}\text { Health Care and Social } \\
\text { Assistance }\end{array}$ & -12.5 & -0.2 \\
\hline Other sectors & -132.7 & -0.02 & Other sectors & $-1,066$ & -0.1 \\
\hline Total & -553.4 & $-\mathbf{0 . 0 7}$ & Total & $-1,111$ & -0.1 \\
\hline \multicolumn{6}{|c|}{ Total including California marina and POLA fishing damages } \\
\hline Fishing & -1.4 & -4.2 & Leather and allied product $\mathrm{mfg}$ & -2.3 & -3.6 \\
\hline Other primary metal $\mathrm{mfg}$ & -4.5 & -3.6 & Other primary metal mfg & -14.1 & -2.8 \\
\hline Fabricated metal product $\mathrm{mfg}$ & -29.0 & -3.3 & $\begin{array}{l}\text { Automobile and light duty motor } \\
\text { vehicle mfg }\end{array}$ & -27.7 & -2.6 \\
\hline Leather and Allied Product Mfg & -241.9 & -3.2 & Fabricated metal product mfg & -77.7 & -2.0 \\
\hline $\begin{array}{l}\text { Automobile and light duty motor } \\
\text { vehicle mfg }\end{array}$ & -92.4 & -3.0 & Machinery mfg & -1.2 & -1.3 \\
\hline Other sectors & $-2,846.7$ & -0.3 & Other sectors & $-2,633$ & -0.3 \\
\hline Total & $-3,215.9$ & -0.4 & Total & $-2,756$ & -0.3 \\
\hline
\end{tabular}

A couple of critical economic-impact modeling closure assumptions include the savingsinvestment balance and labor supply elasticities. The static model that we have implemented cannot address the savings-investment relation, but, given the small impacts relative to the California economy, we would not expect a negligible effect on the savings-investment balance. However, a sensitivity analysis of the labor market elasticities reveals a significant effect on estimated economic impacts.

In the original fairly inelastic formulation (0.05), the economy-wide average wage fell by 0.4 percent, and the supply of labor remained essentially constant. In the second,more elastic formulation (0.5), the wage fell by 0.3 percent and the supply of labor contracted by 0.1 percent. In this analysis, the wage rate varies to clear the market (equilibrate supply and demand). In the Keynesian formulation, with the wage fixed at the baseline level and labor in perfectly elastic supply so as to be able to equilibrate the labor market, labor decreases by 0.3 percent. The consequent reduction in the economy's endowment of productive factors results in an amplification of output and GDP losses. The magnitude of losses rises as the elasticity of labor supply increases. Increasing the labor supply elasticity by an order of magnitude in the original 
formulation exacerbates losses by 22 to 26 percent, whereas in a full Keynesian closure the losses jump by 61 to 72 percent.

Note that the original formulation is more consistent with empirical evidence on labor elasticities (McClelland and Mok, 2013). However, none of the studies reviewed takes into account the effect of a disaster. Even so, we surmise that the Keynesian estimates are implausible. For a comparatively small disaster such as this, we expect that it would be more likely that individuals will keep working through the recovery period at slightly lower compensation levels rather than reduce their hours or quit their jobs.

\section{Resilience}

In this section we analyze the effect of resilience on the economic losses from the SAFRR tsunami, especially the port related disruptions or damages. Resilience refers to various tactics that can mute losses by using existing resources more efficiently (static resilience) and recovering more quickly (dynamic resilience) (Rose, 2009). We analyze only the former category in this report. Detailed notes on the data, assumptions, and methodology used in the resilience analysis are presented in table 4 . Results of the application of the resilience tactics on the direct impact estimates are presented in table 5. (See the resilience tactic worksheets in appendix B workbook "Tsunami_Port_Direct Impacts without and with Resilience," available online at $h t t p: / / p u b s . u s g s . g o v / o f / 2013 / 1170 / H /$, for details on the port direct economic impacts by sector and by region.) Production and sales recapture (for example, catching up on lost production time) is applied to total economic impacts from port damages and disruption and property damages.

- Conservation-We assume a 2-percent level of conservation for businesses to cope with the import disruptions. This resilience tactic have the effect of reducing the direct import disruption impact from $\$ 675.2$ million to $\$ 661.7$ million, or from 0.214 to 0.210 percent for the southern California region; and from $\$ 312.1$ million to $\$ 305.9$ million, or from 0.061 to 0.059 percent, for the rest of California region.

- Excess Capacity-Documented in table 5, this resilience tactic is applicable to facility downtime at the port and for the marina damages at POLA. This resilience tactic has the effect of reducing the direct import-disruption impact from $\$ 675.2$ million to $\$ 581.2$ million, or from 0.214 to 0.184 percent for the southern California region; and from $\$ 312.1$ million to \$265.6 million, or from 0.061 to 0.052 percent, for the rest of California region. For marina damages, the availability of excess capacity at the Cabrillo Marina can help reduce the direct revenue losses to the marina-activity related sectors from $\$ 719,000$ to $\$ 561,000$, or from 0.00005 to 0.00004 percent on an annual basis.

- Ship Rerouting-Based on a consultation with Capt. Dick McKenna (Marine Exchange; oral commun., 2013) we have assumed that ships will not be rerouted for a 2-day port shutdown. As for longer facility downtimes taking place in a few terminals, there is only evidence of possible ship rerouting for the industrial borate export. If rerouting occurs within southern California, ship rerouting can help reduce the total direct export disruption from $\$ 131.8$ million to $\$ 105.4$ million, or from 0.034 to 0.027 percent, for the southern California region; and from $\$ 78.2$ million to $\$ 65.0$ million, or from 0.017 to 0.014 percent, for the rest of California region. However, if exports are diverted out of other States the impact remains the same for the State of California. 
Export Diversion (Substitution for Imports)—Export diversion refers to using goods that were intended for export as substitutions for the lack of availability of imports. Therefore, the application of this resilience tactic relies on export and import disruptions for the same types of commodities in order for exports to substitute for disrupted imports. We assume that during the 2-day port shutdown, import/export shipments will wait until the resumption of the port operation, and no export will be diverted for domestic use. For extended port-facility downtime, there is only limited potential for export diversion of petroleum products, because there are disruptions to these products on both the import and export sides. All the disrupted industrial borate is exported, and all the disrupted steel is imported. Therefore, export diversion is not applicable to either of them. According to table 5, on import side, this resilience tactic has the effect of reducing the direct impact from $\$ 675.2$ million to $\$ 664.3$ million, or from 0.214 to 0.211 , percent for the southern California region; and from $\$ 312.1$ million to $\$ 306.5$ million, or from 0.061 to 0.060 percent, for the rest of California region. On the export side, export diversion can help reduce the export disruption impact from $\$ 131.8$ million to $\$ 120.9$ million, or from 0.034 to 0.031 percent, for the southern California region; and from $\$ 78.2$ million to $\$ 72.6$ million, or from 0.017 to 0.016 percent, for the rest of California region.

- Inventory Use-Use of the available inventories by the producing sector has the greatest potential to reduce the impact from import disruption. As shown in table 4, this resilience tactic has the effect of reducing the direct import disruption impact from $\$ 675.2$ million to $\$ 30$ million, or from 0.214 to 0.010 percent for the southern California region; and from $\$ 312.1$ million to only $\$ 1,833$, or from 0.061 to 0.000 percent for the rest of California region. More details of inventory utilization are presented in appendix D.

- Production or Sale Recapture from Port Disruption - This resilience strategy refers to the ability of businesses to recapture lost production by working overtime or extra shifts once their operational capability is restored and their critical inputs are available. Recapture applies to total economic impacts. On the export side, a similar concept is sale recapture. At the ports, production or sale recapture applies to the import and export disruptions from the 2-day port shutdown because no ships would be rerouted. Imports and exports would likely be delayed for 1 to 2 days on average for a week or so. We assume that the import and export disruptions would be recaptured with the exception of perishable (agricultural) products. Recapture can also be applied to import and export disruptions from the 2-week to onemonth facility downtime. This is because for a short duration of time (less than 3 months) most customers do not cancel their orders. Production recapture would not apply to lost marina slip fees, but catching up on lost days of fishing could reduce total impacts by about 75 percent. Appendix E presents the recapture factors for the other sectors served by the ports. Manufacturing sectors have the highest potential (at about 98 percent) to recapture their interrupted productions. The recapture factor for agriculture, forestry, and fishing industries is at the level of about 75 percent. The recapture factors for the service sectors range between 51 and 80 percent. The potential for recapture would be smaller for longer periods as customers begin looking elsewhere for their source of supply. Recapture can greatly reduce the total impact from import and export disruptions. For the 2-day port shutdown, recapture can reduce the total economic impact to the State from $\$ 1,736$ million to \$314 million for import disruption and from \$795 million to \$112 million for export disruption, or reductions of potential losses by 82 and 86 percent, respectively. For the facility down time, recapture can help mute the potential total economic losses to the State 
from $\$ 1,350$ million to $\$ 196$ million for import disruption and from $\$ 281$ million to $\$ 34$ million for export disruption.

- All Resilience Combined for Port Damage and Disruption-After calculating the effects of the resilience measures separately, we simulate all the above resilience adjustments together. Note, however, that the individual resilience tactics cannot be summed. We apply excess capacity and ship rerouting first, followed by export diversion. The 2-percent conservation is applied after the above three resilience adjustments. Inventories are used to deal with any remaining import disruptions. Applying all these resilience tactics can help reduce the direct import disruption impact from $\$ 675.2$ million to $\$ 28.9$ million, or from 0.214 to 0.009 percent, for the southern California region; and from $\$ 312.1$ million to $\$ 1,797$ or from 0.061 to 0.000 percent, for the rest of California region. On the export side, the combined resilience has the effect of reducing the export disruption impact from $\$ 131.8$ million to $\$ 93.89$ million, or from 0.034 to 0.024 percent, for the southern California region; and from $\$ 78.2$ million to $\$ 59.0$ million, or from 0.017 to 0.013 percent, for the rest of California region. Please note production or sale recapture can be applied after all the above resilience tactics. As indicated above, production and sale recaptures have the potential to reduce the total economic impacts by about 80 to 85 percent. Sector recapture factors can also be applied to the total economic impacts from the building and content damages. This procedure reduces those total economic impacts to the California economy by 80 percent. See table 6 . 
Table 4. Methodology for direct resilience for disruptions to port related activities from the SAFRR tsunami scenario.

[Data, green; major assumptions, red; methods, blue. Note that we assume input and import substitution resilience tactics are already incorporated into the computable general equilibrium (CGE) model as inherent resilience; no further adjustment is made to capture adaptive versions of these two tactics. \%, percent;

\begin{tabular}{|c|c|c|c|c|c|c|}
\hline $\begin{array}{c}\text { Direct impact } \\
\text { type }\end{array}$ & Conservation & Excess capacity & Ship rerouting & $\begin{array}{l}\text { Export diversion } \\
\text { for domestic use }\end{array}$ & Inventories & $\begin{array}{c}\text { Production } \\
\text { recapture }\end{array}$ \\
\hline $\begin{array}{l}\text { 2-day port } \\
\text { shutdown }\end{array}$ & $\begin{array}{l}\text { Assume } 2 \% \text {. } \\
\text { Applicable only } \\
\text { to the import } \\
\text { side. } \\
\text { Reduce percent } \\
\text { import } \\
\text { disruption by } \\
2 \% \text {. }\end{array}$ & $\begin{array}{l}\text { n.a. } \\
\text { Because the entire port is } \\
\text { shut down, excess } \\
\text { capacity will not be } \\
\text { applicable during this } \\
\text { time. }\end{array}$ & $\begin{array}{l}\text { n.a. } \\
\text { Assume ships } \\
\text { will not be } \\
\text { rerouted within } \\
2 \text { days. }\end{array}$ & $\begin{array}{l}\text { For a 2-day } \\
\text { shutdown, we } \\
\text { assume } \\
\text { import/export } \\
\text { shipments will } \\
\text { wait until the } \\
\text { port operation } \\
\text { resumes, and no } \\
\text { export will be } \\
\text { diverted for } \\
\text { import use. }\end{array}$ & $\begin{array}{l}\text { For marine oil: there is } \\
\text { a } 50 \% \text { inventory buffer } \\
\text { for a month taking into } \\
\text { account the inventories } \\
\text { both at the parts and at } \\
\text { customers. } \\
\text { For other commodities: } \\
\text { use Bureau of } \\
\text { Economic Analysis } \\
\text { manufacturing } \\
\text { inventory data. } \\
\text { Applicable only to the } \\
\text { import side. } \\
\text { See appendix D for a } \\
\text { summary of method. }\end{array}$ & $\begin{array}{l}\text { Ports recapture } \\
\text { nonperishable } \\
\text { cargo handling } \\
\text { because no ships } \\
\text { are rerouted in } 2 \\
\text { days. } \\
\text { HAZUS recapture } \\
\text { factors. } \\
\text { Applicable to both } \\
\text { import user and } \\
\text { exporter sides, and } \\
\text { port on-site } \\
\text { activities. } \\
\text { Recapture factors } \\
\text { are not applied } \\
\text { directly on the } \\
\text { input side of the } \\
\text { economic } \\
\text { modeling; rather } \\
\text { they are applied } \\
\text { directly to the } \\
\text { economic impact } \\
\text { results (no } \\
\text { resilience "base } \\
\text { case"). }\end{array}$ \\
\hline
\end{tabular}


Table 4. Methodology for direct resilience for disruptions to port related activities from the SAFRR tsunami scenario.-Continued

[Data, green; major assumptions, red; methods, blue. Note that we assume input and import substitution resilience tactics are already incorporated into the computable general equilibrium (CGE) model as inherent resilience; no further adjustment is made to capture adaptive versions of these two tactics. \%, percent; n.a., not applicable]

\begin{tabular}{|c|c|c|c|c|c|c|}
\hline $\begin{array}{c}\text { Direct impact } \\
\text { type }\end{array}$ & Conservation & Excess capacity & Ship rerouting & $\begin{array}{l}\text { Export diversion } \\
\text { for domestic use }\end{array}$ & Inventories & $\begin{array}{c}\text { Production } \\
\text { recapture }\end{array}$ \\
\hline Cargo damages & $\begin{array}{l}\text { Same as in } \\
\text { row } 1\end{array}$ & n.a. & n.a. & n.a. & Same as in row 1 & $\begin{array}{l}\text { HAZUS recapture } \\
\text { factors } \\
\text { Applicable to both } \\
\text { import user and } \\
\text { exporter sides, and } \\
\text { port on-site } \\
\text { activities. } \\
\text { Recapture factors } \\
\text { are not applied } \\
\text { directly on the input } \\
\text { side of the } \\
\text { economic modeling; } \\
\text { rather they are } \\
\text { applied directly to } \\
\text { the economic } \\
\text { impact results (no } \\
\text { resilience "base } \\
\text { case"). }\end{array}$ \\
\hline
\end{tabular}


Table 4. Methodology for direct resilience for disruptions to port related activities from the SAFRR tsunami scenario.-Continued

[Data, green; major assumptions, red; methods. Note that we assume input and import substitution resilience tactics are already incorporated into the computable general equilibrium (CGE) model as inherent resilience; no further adjustment is made to capture adaptive versions of these two tactics. blue; \%, percent; n.a., not applicable]

\begin{tabular}{|c|c|c|c|c|c|c|}
\hline $\begin{array}{c}\text { Direct impact } \\
\text { type }\end{array}$ & Conservation & Excess capacity & Ship rerouting & $\begin{array}{l}\text { Export diversion } \\
\text { for domestic use }\end{array}$ & Inventories & $\begin{array}{l}\text { Production } \\
\text { recapture }\end{array}$ \\
\hline $\begin{array}{l}\text { Facility } \\
\text { downtime }\end{array}$ & $\begin{array}{l}\text { Same as in } \\
\text { row } 1\end{array}$ & $\begin{array}{l}\text { Marine oil: Vopak and Valero } \\
\text { terminals are short of } 40 \% \\
\text { capacity to handle their } \\
\text { throughput even after using } \\
\text { excess capacity; other } \\
\text { terminals have enough } \\
\text { capacity to handle regular } \\
\text { throughput after using excess } \\
\text { capacity. } \\
\text { Steel: various available } \\
\text { alternatives at POLA/POLB } \\
\text { can help reduce impacts of } \\
\text { downtime at steel break bulk } \\
\text { terminal by } 50 \% \text {. } \\
\text { Industrial borate: no other } \\
\text { industrial borate terminal in } \\
\text { San Pedro. } \\
\text { Use the excess capacity info to } \\
\text { adjust import/export } \\
\text { disruption; for example, if } \\
\text { excess capacity of handling } \\
\text { steel import at undamaged } \\
\text { terminal is x\% of the capacity } \\
\text { of damaged steel terminal, } \\
\text { reduce steel import disruption } \\
\text { by x\%. }\end{array}$ & $\begin{array}{l}\text { Assume no ship } \\
\text { diversions for } \\
\text { imports; assume } \\
100 \% \text { export } \\
\text { rerouting for } \\
\text { Borate. } \\
\text { Reduce } \\
\text { import/export } \\
\text { disruption level } \\
\text { by percentage of } \\
\text { ships that can be } \\
\text { rerouted } \\
\text { Rerouting cost } \\
\text { needs to be } \\
\text { reported } \\
\text { separately. }\end{array}$ & $\begin{array}{l}\text { Examine the } \\
\text { disrupted export } \\
\text { and import } \\
\text { commodities at } \\
\text { the 4-digit } \\
\text { Harmonized } \\
\text { System code } \\
\text { level. Export } \\
\text { diversion is } \\
\text { applicable if } \\
\text { same type of } \\
\text { import and } \\
\text { export } \\
\text { commodities are } \\
\text { disrupted. }\end{array}$ & Same as in row 1 & Same as in row 2 \\
\hline
\end{tabular}


Table 4. Methodology for direct resilience for disruptions to port related activities from the SAFRR tsunami scenario.-Continued

[Data, green; major assumptions, red; methods, blue. Note that we assume input and import substitution resilience tactics are already incorporated into the computable general equilibrium (CGE) model as inherent resilience; no further adjustment is made to capture adaptive versions of these two tactics. \%, percent; n.a., not applicable]

\begin{tabular}{|c|c|c|c|c|c|c|}
\hline $\begin{array}{c}\text { Direct impact } \\
\text { type }\end{array}$ & Conservation & Excess capacity & Ship rerouting & $\begin{array}{l}\text { Export diversion } \\
\text { for domestic use }\end{array}$ & Inventories & $\begin{array}{c}\text { Production } \\
\text { recapture }\end{array}$ \\
\hline $\begin{array}{l}\text { Marina slips } \\
\text { damaged }\end{array}$ & n.a. & $\begin{array}{l}\text { Cabrillo Marina Phase II: } \\
\text { increase the total capacity by } \\
11 \% \text {, but all currently still } \\
\text { vacant; therefore, can be used } \\
\text { as excess capacity; when we } \\
\text { consider Cabrillo as the excess } \\
\text { capacity, we also take into } \\
\text { consideration that } 1 / 3 \text { of this } \\
\text { marina is damaged (at the } \\
\text { average damage rate of } \\
\text { marinas at the port). } \\
\text { If the excess } \\
\text { capacity/alternative locations } \\
\text { represent } \mathrm{x} \% \text { of total capacity, } \\
\text { we reduce revenue losses to } \\
\text { marina related sectors by } \mathrm{x} \% \text {. }\end{array}$ & n.a. & n.a. & n.a. & Same as in row 1 \\
\hline $\begin{array}{l}\text { Impacts to } \\
\text { commercial } \\
\text { fishing }\end{array}$ & n.a. & n.a. & n.a. & n.a. & n.a. & Same as in row 1 \\
\hline
\end{tabular}


Table 5. Direct impact estimates for the SAFRR tsunami scenario before and after resilience.

[M 2010\$, millions of; \%, percent; n.a., not applicable]

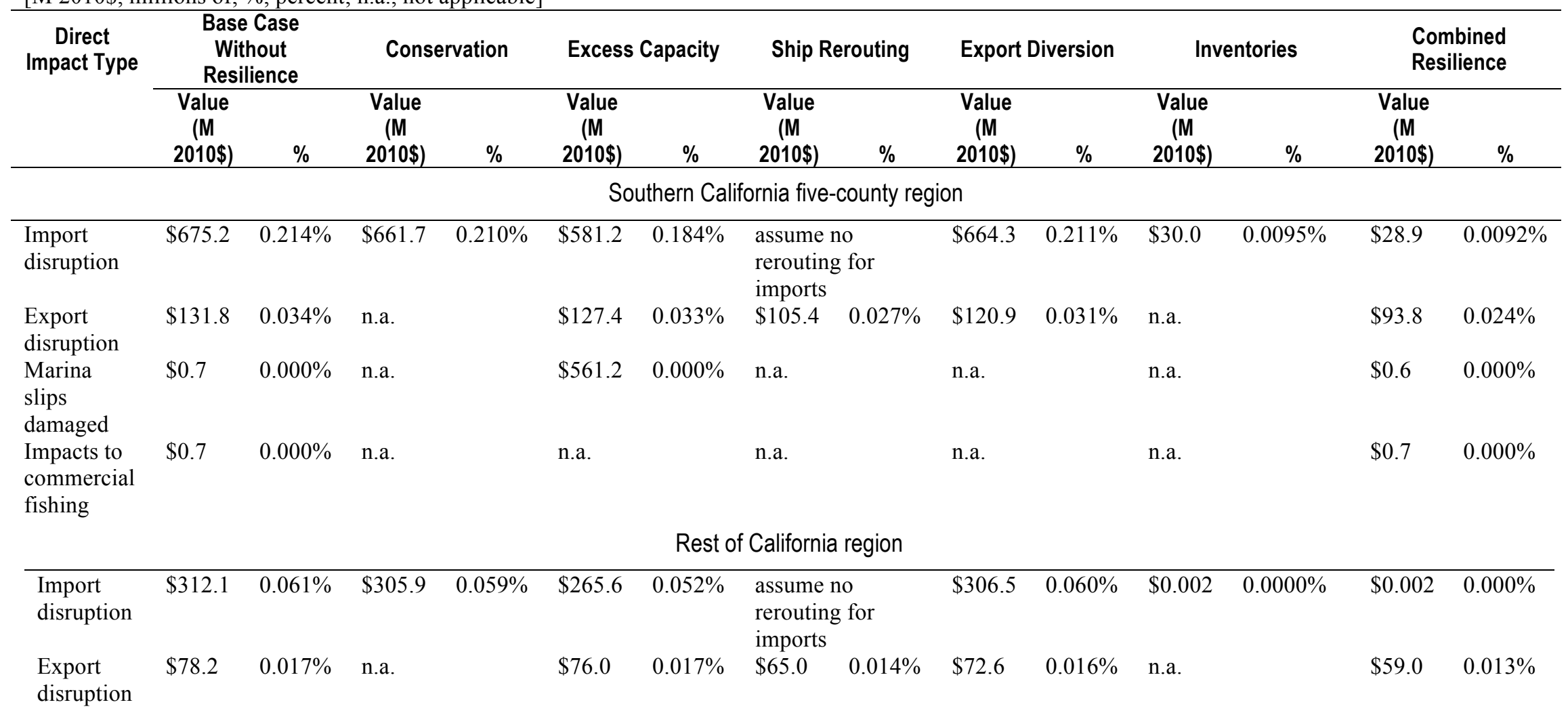


Table 5. Direct impact estimates for the SAFRR tsunami scenario before and after resilience. —Continued [M 2010\$, millions of 2010 dollars; \%, percent; n.a., not applicable]

\begin{tabular}{|c|c|c|c|c|c|c|c|c|c|c|c|c|c|c|}
\hline \multirow[t]{2}{*}{$\begin{array}{c}\text { Direct } \\
\text { Impact Type }\end{array}$} & \multicolumn{2}{|c|}{$\begin{array}{c}\text { Base Case } \\
\text { Without } \\
\text { Resilience }\end{array}$} & \multicolumn{2}{|c|}{ Conservation } & \multicolumn{2}{|c|}{ Excess Capacity } & \multicolumn{2}{|c|}{ Ship Rerouting } & \multicolumn{2}{|c|}{ Export Diversion } & \multicolumn{2}{|c|}{ Inventories } & \multicolumn{2}{|c|}{$\begin{array}{l}\text { Combined } \\
\text { Resilience }\end{array}$} \\
\hline & $\begin{array}{c}\begin{array}{c}\text { Value } \\
(\mathrm{M} \\
2010 \$)\end{array} \\
\end{array}$ & $\%$ & $\begin{array}{c}\begin{array}{c}\text { Value } \\
(\mathrm{M} \\
2010 \$)\end{array} \\
\end{array}$ & $\%$ & $\begin{array}{c}\text { Value } \\
(\mathrm{M} \\
2010 \$)\end{array}$ & $\%$ & $\begin{array}{c}\begin{array}{c}\text { Value } \\
(\mathrm{M} \\
2010 \$)\end{array} \\
\end{array}$ & $\%$ & $\begin{array}{c}\begin{array}{c}\text { Value } \\
(\mathrm{M} \\
2010 \$)\end{array} \\
\end{array}$ & $\%$ & $\begin{array}{c}\begin{array}{c}\text { Value } \\
(\mathrm{M} \\
2010 \$)\end{array} \\
\end{array}$ & $\%$ & $\begin{array}{c}\text { Value } \\
\text { (M } \\
2010 \$)\end{array}$ & $\%$ \\
\hline \multicolumn{15}{|c|}{ Total California } \\
\hline $\begin{array}{l}\text { Import } \\
\text { disruption }\end{array}$ & $\$ 987.3$ & $0.119 \%$ & $\$ 967.5$ & $0.117 \%$ & $\$ 846.8$ & $0.102 \%$ & $\begin{array}{l}\text { assume } \\
\text { reroutin } \\
\text { imports }\end{array}$ & for & $\$ 970.8$ & $0.117 \%$ & $\$ 30.0$ & $0.004 \%$ & $\$ 28.9$ & $0.003 \%$ \\
\hline $\begin{array}{l}\text { Export } \\
\text { disruption }\end{array}$ & $\$ 210.0$ & $0.025 \%$ & n.a. & & $\$ 203.4$ & $0.024 \%$ & $\$ 170.4$ & $0.020 \%$ & $\$ 193.5$ & $0.023 \%$ & n.a. & & $\$ 152.8$ & $0.018 \%$ \\
\hline $\begin{array}{l}\text { Marina slips } \\
\text { damaged }\end{array}$ & $\$ 0.7$ & $0.000 \%$ & n.a. & & $\$ 0.6$ & $0.000 \%$ & n.a. & & n.a. & & n.a. & & $\$ 0.6$ & $0.000 \%$ \\
\hline $\begin{array}{l}\text { Impacts to } \\
\text { commercial } \\
\text { fishing }\end{array}$ & $\$ 0.7$ & $0.000 \%$ & n.a. & & n.a. & & n.a. & & n.a. & & n.a. & & $\$ 0.7$ & $0.000 \%$ \\
\hline
\end{tabular}


Table 6. Property damage resilience through recapture for the SAFRR tsunami scenario. [\$M, millions of 2010 dollars; \%, percent]

\begin{tabular}{llcccccc}
\hline \multirow{2}{*}{ Impacted category } & \multicolumn{3}{c}{ Base case } & \multicolumn{3}{c}{ After recapture } \\
\cline { 3 - 8 } & & $\begin{array}{c}\text { Southern } \\
\text { California }\end{array}$ & $\begin{array}{c}\text { Rest of } \\
\text { California }\end{array}$ & $\begin{array}{c}\text { California } \\
\text { Total }\end{array}$ & $\begin{array}{c}\text { Southern } \\
\text { California }\end{array}$ & $\begin{array}{c}\text { Rest of } \\
\text { California }\end{array}$ & $\begin{array}{c}\text { California } \\
\text { Total }\end{array}$ \\
\hline \multirow{2}{*}{ Buildings } & Value (\$M) & 54 & 51 & 105 & 12 & 10 & 22 \\
& $\%$ & 0.006 & 0.005 & 0.005 & 0.001 & 0.001 & 0.001 \\
Contents & Value $(\$ M)$ & 792 & 767 & 1,559 & 164 & 139 & 303 \\
& $\%$ & 0.095 & 0.067 & 0.079 & 0.020 & 0.012 & 0.015 \\
\hline
\end{tabular}

Given the high potential for resilience in the port system and property damages identified above, and the relatively low total economic impacts from the SAFRR tsunami in the first place, we do not deem it necessary to apply the CGE model any further for the case of import disruptions, which would approach zero at the direct level. This is also the case for damages to POLA marinas.

Resilience in the California coast marinas is more challenging to determine at this time. We could assume that lost slip fees cannot be recaptured from destroyed vessels that would not occupy slips until replaced. However, we lack an assessment of excess marina capacity along the coast and an investigation of alternate and temporary mooring options. After the 2011 Japanese tsunami, Crescent City, California, boats were redirected to Eureka, but we have not attempted to identify the potential to relocate boats to remaining slips along the California coast or even along inland water bodies. Also, after the Japanese tsunami, some boat owners in Crescent City moored on buoys and rowed out to their boats as a result of fierce competition for available slips (Brett Fahning, oral commun., 2013). In such a case, the full services of a slip (with power and water) are not provided, but some of the marina-related activities could continue. Resilience of the marina sector, defined as four sectors, will also depend on other coastal recreational pursuits that could be substituted for marina activities to maintain marina-related restaurant and retail activity.

Note, of course, that the full potential resilience of the various resilience tactics will not necessarily be implemented effectively. Hence, the estimates presented above are an optimistic reduction in the SAFRR tsunami scenario direct economic impact estimates for the considered resilience strategies. Moreover, at this stage we have not included any stimulus from reconstruction that will be partially funded by disaster funds and insurance (financial forms of resilience). Therefore, it is possible that the losses in directly impacted sectors that depend on coastal locations and possess more limited resilience options (for example, marinas and small harbors) will be counterbalanced somewhat by the gains from reconstruction and related activities, similar to our simulation results on the economic impacts from the ARkStorm scenario (Sue Wing and others, 2013). Locally, this was the experience of Crescent City harbormaster, who observed other businesses profiting from the damage of the harbor after the 2011 Tohokuoki tsunami (Richard Young, oral commun., 2013). Also, delays in Federal Emergency Management Agency (FEMA) reimbursements have impeded recovery of Crescent City Harbor, and streamlining the FEMA process presents an opportunity to increase resilience in future disasters.

Given that resilience tactics are potentially very effective at reducing economic impacts for the SAFRR tsunami scenario, goods movement delay costs and impacts from environmental damages may become relatively more important. Also, the likely over evacuation of people from 
coastal areas that will affect economic activity in areas beyond the inundation area may be of interest.

\section{Conclusion}

We have estimated the direct and total economic impacts of the SAFRR tsunami scenario hitting the California coast. The results follow from the selection of the tsunami source (Kirby and others, 2013), the modeling of wave propagation and the damaging current velocities and inundation (SAFFR Tsunami Scenario Modeling Working Group, 2013), the assessment of damages (Porter and others, 2013a); and the economic impact modeling and incorporation of economic resilience. Although uncertainties at each stage propagate throughout the analysis of the scenario in forms of both under and over estimation, the potential for a tsunami to inundate land along the coast of California is firmly established (Wilson and others, written commun., 2013). An integrated analysis culminating with an estimation of economic impacts exposes vulnerabilities of sectors and the California economy. Most importantly, it emphasizes the potential effectiveness of resilience when planning for future tsunami events.

Losses stem from a combination of import and export disruptions at POLA and POLB, property damage to coastal buildings and contents, other losses related to marina damages in coastal counties, and POLA commercial fishing losses. Our estimate of total impact to GDP without resilience for California is just less than $\$ 6.0$ billion. By far the largest share of these losses, comprising more than 50 percent of the total, stems from import disruptions, due to a 2day port shutdown, loss of cargo, and port facility downtime. More than half of these losses apply to southern California. Without resilience, there would be some positive shift in economic activity to the rest of California, as production of import substitutes is needed, but still not enough to offset the negative stimulus in that region. National-scale impacts still remain to be investigated, but the results for California indicate that the impacts will be small relative to previously studied port shutdowns of weeks, months, and years.

Without resilience, $\$ 4.3$ billion of the potential total economic impacts to California stem from the 2-day port shutdown and $\$ 100$ million of physical damages to terminals and cargo at the POLA and POLB through import and export disruptions. Damages to cargo and facilities are responsible for $\$ 1.7$ billion of port impacts. Coincidentally, these port damage economic impacts are matched by $\$ 1.7$ billion of economic impacts from $\$ 2.5$ billion of coastal property damages. This result highlights a hypersensitivity of economic impacts to port damages, suggesting that it could be worthwhile investigating the effects of the SAFRR tsunami scenario on other California ports, including the Ports of Oakland, Richmond, San Diego, and Hueneme.

However, economic resilience tactics greatly reduce the total economic impact to the California economy. The ports' ability to sustain the 2-day shutdown by clearing the back log of ships in the harbor and the awaiting exports nulls most of the import and export disruption. The month-long reduced capacity at numerous marine oil terminals could be compensated for by excess capacity at a terminal and inventories at a port, off-site, and at major customers.

Resilience would have a greater effect on reducing direct impacts on the import side ( $\$ 1$ billion reduced by $\$ 30$ million) than the export side ( $\$ 200$ million reduced to $\$ 150$ million). The most effective resilience tactic on the import-disruption side is inventory use, a tactic that is not applicable to the export-disruption side. However, inventories have a limited term, such that a longer period of reduced capacity at the marine oil terminals will eventually result in fuel supply challenges for southern California. 


\section{Acknowledgments}

The authors wish to thank the many members of the SAFRR project research team for their contributions to this report. Foremost is Keith Porter, the physical damage analysis coordinator, who supplied us with the majority of the direct property damage and output loss estimates. Moffat and Nichol Engineers extended their San Pedro damage analysis to mesh with the economic impact inputs. We are also grateful to Larry Cottrill (POLB), Michael Keenan (POLA) and Captain Dick McKenna (Marina Exchange) for access to some data and their sound advice. Terminal capacity information was provided by Roger Wu (POLB), Eric Caris (POLA), Michael Galvin (POLA), and Christopher Chase (POLA). Funding for this research was provided by the U.S. Geological Survey's Land Change Science Program. We appreciated the input of port tenants and refineries that engaged in questioning to inform aspects of resilience in their operations to withstand damages and disruptions. However, the authors are solely responsible for any errors or omissions in this report.

\section{References Cited}

Borrero, J., Cho, S., Moore, J.E., Richardson, H., and Synolakis, C., 2005, "Could It Happen Here?": Civil Engineering, v. 75, no. 4, p. 54-65, 133.

Brooke, A., Kendrick, D., Meeraus, A., and Raman, R., 1998, GAMS-A user's guide: Washington, D.C., GAMS Development Corporation, 302 p.

Bureau of Economic Analysis, 2013, National economic accounts-National data on real inventories and sales data: U.S. Department of Commerce, Bureau of Economic Analysis, Web site, accessed March 14, 2013, at http://www.bea.gov/iTable/iTable.cfm?ReqID=12\&step=1\#reqid=12\&step=1\&isuri=1.

Dykstra, D., Lim, A., and Porter, K., 2013, Tsunami scenario engineering impacts of port of Long Beach and port of Los Angeles in Porter, K., Byers, W., Dykstra, D., Lim, A., Lynett, P., Ratliff, J., Scawthorn, C., Wein, A., and Wilson, R., 2013, Physical damage in the SAFRR California tsunami scenario: U.S. Geological Survey Open-File Report 2013-1170-E, 183 p., http://pubs.usgs.gov/of/2013/1170/e/.

Ferris, M.C., Munson, T.S., and Ralph, D., 2000, A homotopy method for mixed complementarity problems based on the PATH solver, in Griffiths, D.F., and Watson, G.A., eds., Numerical analysis 1999: London, Chapman and Hall, p. 143-167.

Hall, P.V., 2004, "We'd have to sink the ships'-Impact studies and the 2002 west coast port lockout": Economic Development Quarterly, v. 18, p. 354.

Kajitani, Y., Chang, S., and Tatano, H., 2013, Economic impacts of the 2011 Tohoku-Oki earthquake and tsunami: Earthquake Spectra, v. 29, no. S1, p. S457-S478.

Kirby, S., Scholl, D., Huene, R.V., and Wells, R., 2013, Alaska earthquake source for the SAFRR California tsunami scenario: U.S. Geological Survey Open-File Report 2013-1170-B, 45 p., http://pubs.usgs.gov/of/2013/1170/b/.

Martin Associates, 2001, An assessment of the impact of west coast container operations and the potential impacts of an interruption of port operations - 2000: Martin Associates report prepared for the Pacific Maritime Association, Lancaster, Pa.

Martin Associates, 2007, Economic impacts of the Port of Los Angeles: Martin Associates report prepared for Port of Los Angeles, $41 \mathrm{p}$.

McClelland, R., and Mok, S., 2012, A review of recent research on labor supply elasticities: Congressional Budget Office Working Paper 2012-12, October 2012, 41 p. 
Minnesota IMPLAN Group, Inc., 2012, Year 2010 input-output tables for California State and counties: Minnesota IMPLAN Group, Inc.

Park, J.Y., 2008, The economic impacts of dirty bomb attacks on the Los Angeles and Long Beach ports-Applying the supply-driven NIEMO (National Interstate Economic Model): Journal of Homeland Security and Emergency Management 5, v. 1, no. 21, 22 p.

Park, J.Y., Gordon, P., Moore II, J.E., Richardson, H.W., 2008, The state-by-state economic impacts of the 2002 shutdown of the Los Angeles-Long Beach ports: Growth and Change, v. 39 , no. 4, p. 548-572.

Porter, K., 2013, Building damage, in Porter, K., Byers, W., Dykstra, D., Lim, A., Lynett, P., Ratliff, J., Scawthorn, C., Wein, A., and Wilson, R., 2013, Physical damage in the SAFRR California tsunami scenario: U.S. Geological Survey Open-File Report 2013-1170-E, 183 p., http://pubs.usgs.gov/of/2013/1170/e/.

Porter, K., Byers, W., Dykstra, D., Lim, A., Lynett, P., Ratliff, J., Scawthorn, C., Wein, A., and Wilson, R., 2013a, Physical damage in the SAFRR California tsunami scenario: U.S. Geological Survey Open-File Report 2013-1170-E, 183 p., http://pubs.usgs.gov/of/2013/1170/e/.

Porter, K., Lynett, P., and Wilson, R., 2013b, Damages and restoration of marinas and small craft, in Porter, K., Byers, W., Dykstra, D., Lim, A., Lynett, P., Ratliff, J., Scawthorn, C., Wein, A., and Wilson, R., Physical damage in the SAFRR California tsunami scenario: U.S. Geological Survey Open-File Report 2013-1170-E, 183 p., http://pubs.usgs.gov/of/2013/1170/e/.

Rose, A., 2009, Economic resilience to disasters: Community and Regional Resilience Institute Research Report 8, 40 p., accessed August 13, 2013, at http://research.create.usc.edu/published_papers/75.

Rose, A., Sue Wing, I., Wei, D., and Avetisyan, M., 2012, Total regional economic losses from water supply disruptions to the Los Angeles County economy: Final Report to Los Angeles Economic Development Corporation, 66 p.

Rose, A., and Wei, D., 2013, Estimating the economic consequences of a port shutdown-The special role of resilience: Economic Systems Research, v. 25, no. 2, p. 212-232.

Rose, A., Wei, D., and Wein, A., 2011, Economic impacts of the ShakeOut scenario: Earthquake Spectra, v. 27, no. 2, p. 539-557.

Rutherford, T.F., 1999, Applied general equilibrium modeling with MPSGE as a GAMS subsystem-An overview of the modeling framework and syntax: Computational Economics, V. 14, p. $1-46$.

SAFRR Tsunami Scenario Modeling Working Group, 2013, Modeling for the SAFRR tsunami scenario-Generation, propagation, inundation, and currents in ports and harbors: U.S. Geological Survey Open-File Report 2013-1170-D, 127 p., http://pubs.usgs.gov/of/2013/1170/d/.

Sue Wing, I., 2009, Computable general equilibrium models for the analysis of energy and climate policies, in Evans, J., and Hunt, L.C., eds., International handbook on the economics of energy: Cheltenham, Edward Elgar, p. 332-366.

Sue Wing, I., 2011, Computable general equilibrium models for the analysis of economyenvironment interactions, in Batabyal, A., and Nijkamp, P., eds., Research tools in natural resource and environmental economics: Hackensack, World Scientific, p. 255-305. 
U.S. Census Bureau, 2012, 2010 U.S. export and import data for Port of Los Angeles and Port of Long Beach: U.S. Census Bureau, USA Trade Online website, accessed December, 2012, at https://usatrade.census.gov/. 


\section{Appendix A. Methodology and Data}

[Data, green; major assumptions, red; methods, blue. POLA, Port of Los Angeles; 2010\$, 2010 dollars; CGE, computable general equilibrium; M, million; K, thousand; \%, percent]

\begin{tabular}{|c|c|c|c|c|c|}
\hline $\begin{array}{l}\text { Direct } \\
\text { impact } \\
\text { type }\end{array}$ & $\begin{array}{c}\text { Data/major } \\
\text { assumptions/estimation } \\
\text { method }\end{array}$ & $\begin{array}{l}\text { Direct } \\
\text { economic } \\
\text { impact }\end{array}$ & $\begin{array}{c}\text { Further } \\
\text { conversion }\end{array}$ & $\begin{array}{c}\text { Applicable } \\
\text { resilience }\end{array}$ & Comments \\
\hline $\begin{array}{l}\text { 2-day port } \\
\text { shutdown }\end{array}$ & $\begin{array}{l}\text { U.S. Census Bureau, 2012; } \\
\text { Dykstra and others (2013). } \\
\text { Assume essentially no ship } \\
\text { diversions. } \\
\text { Import and export } \\
\text { disruption to all trade } \\
\text { commodities for } 2 \text { days. }\end{array}$ & $\begin{array}{l}\text { 1. Percent } \\
\text { import } \\
\text { disruption by } \\
\text { sector. } \\
\text { 2. Percent } \\
\text { export } \\
\text { disruption by } \\
\text { sector. }\end{array}$ & & $\begin{array}{l}\text { Inventories; } \\
\text { conservation; input } \\
\text { substitution; } \\
\text { production } \\
\text { recapture. }\end{array}$ & $\begin{array}{l}\text { Import disruption means a disruption of import input to the } \\
\text { producing sectors. For a 2-day port shutdown, it is } \\
\text { reasonable to believe that it is just a delay of shipping the } \\
\text { imports to the domestic importers. Therefore, most of the } \\
\text { economic losses should be able to make up by use of } \\
\text { inventories and production recapture. } \\
\text { Export disruption means a disruption or demand reduction } \\
\text { to exporters because of the interruption of the port } \\
\text { transportation. However, for a 2-day port shutdown, it is just } \\
\text { a delay of shipping out of the export commodities. It is } \\
\text { unlikely that the foreign buyers will cancel the order within } \\
2 \text { days. The majority of the service disruption can be made } \\
\text { up by the port by working overtime (production recapture) } \\
\text { after the port reopened. }\end{array}$ \\
\hline
\end{tabular}




\section{Appendix A. Methodology and Data—Continued}

[Data, green; major assumptions, red; methods, blue. POLA, Port of Los Angeles; 2010\$, 2010 dollars; CGE, computable general equilibrium; M, million; K, thousand; \%, percent]

\begin{tabular}{|c|c|c|c|c|c|}
\hline $\begin{array}{l}\text { Direct impact } \\
\text { type }\end{array}$ & $\begin{array}{l}\text { Data/major assumptions/estimation } \\
\text { method }\end{array}$ & Direct economic impact & $\begin{array}{l}\text { Further } \\
\text { conversion }\end{array}$ & Applicable resilience & Comments \\
\hline Cargo damages & $\begin{array}{l}\text { Damage data provided by Dykstra } \\
\text { and others (2013). } \\
\text { 1. Map cargo damage data to CGE } \\
\text { sectors. } \\
\text { 2. For imports, aggregate the data for } \\
\text { POLA and POLB and then calculate } \\
\text { percent import input disruption by } \\
\text { sector. } \\
\text { 3. For exports, aggregate data for } \\
\text { POLA and POLB and then calculate } \\
\text { export demand reduction by sector. }\end{array}$ & $\begin{array}{l}\text { 1. Percent import } \\
\text { disruption by sector. } \\
\text { 2. Percent export } \\
\text { disruption by sector. }\end{array}$ & & $\begin{array}{l}\text { Inventories; conservation; input } \\
\text { substitution; production recapture. }\end{array}$ & $\begin{array}{l}\text { Cost of cleanup } \\
\text { of the damaged } \\
\text { cargos is not } \\
\text { included in the } \\
\text { analysis. }\end{array}$ \\
\hline $\begin{array}{l}\text { Facility } \\
\text { downtime: } \\
\text { 1. POLA berths } \\
\text { 165-166 } \\
\text { (industrial } \\
\text { borates). } \\
\text { 2. POLA berths } \\
\text { 163, 164, 167- } \\
\text { 169, 187-191 } \\
\text { (marine oil and } \\
\text { fuels). } \\
\text { 3. POLA berths } \\
\text { 174-181 (steel) }\end{array}$ & $\begin{array}{l}\text { Downtime data provided by Dykstra } \\
\text { and others }(2013) \text {. } \\
\text { 1. Berths } 165-166 \text { downtime is } \\
\text { translated into export disruption for } \\
\text { borate for } 2 \text { weeks } \\
\text { 2. Berths } 163,164,167-169,187-191 \\
\text { downtime is translated into } 50 \% \\
\text { reduction in capacity for } 1 \text { month for } \\
\text { marine oil and fuels (import and/or } \\
\text { export) } \\
\text { 3. Berths } 174-181 \text { downtime is } \\
\text { translated into import disruption for } \\
\text { steel for } 2 \text { weeks }\end{array}$ & $\begin{array}{l}\text { 1. Percent direct export } \\
\text { disruption to sector } 28 \\
\text { (chemical } \\
\text { manufacturing) } \\
\text { 2. Percent import } \\
\text { disruption or Percent } \\
\text { direct export disruption } \\
\text { of sector } 26 \text { (petroleum } \\
\text { refineries). } \\
\text { 3. Percent import } \\
\text { disruption of sector } 31 \\
\text { (iron and steel mills/steel } \\
\text { product manufacturing). }\end{array}$ & & $\begin{array}{l}\text { Excess capacity; ship rerouting; } \\
\text { inventories; conservation; export } \\
\text { diversion (only in cases of import } \\
\text { and export disruption of same } \\
\text { commodity at same time); input } \\
\text { substitution; production recapture. }\end{array}$ & \\
\hline
\end{tabular}




\section{Appendix A. Methodology and Data-Continued}

[Data, green; major assumptions, red; methods, blue. POLA, Port of Los Angeles; 2010\$, 2010 dollars; CGE, computable general equilibrium; M, million; K, thousand; \%, percent]

\begin{tabular}{|c|c|c|c|}
\hline $\begin{array}{l}\text { Direct impact } \\
\text { type }\end{array}$ & Data/major assumptions/estimation method & Direct economic impact & Applicable resilience \\
\hline $\begin{array}{l}\text { Marina: } 1 / 3 \text { POLA } \\
\text { marina slips } \\
\text { damaged }\end{array}$ & $\begin{array}{l}\text { According to Martin Associates (2007), direct revenue of marina tenants } \\
\text { estimated to be } \$ 48.2 \mathrm{M} \text { in } 2006 \text {. Although there has been a capacity } \\
\text { increase of about } 11 \% \text { because new capacity is still vacant; Convert } \$ 48.2 \\
\mathrm{M} \text { to } 2010 \$ \text {, we get a total revenue of } \$ 51.8 \mathrm{M} \text { in } 2010 \$ \text {. The monthly } \\
\text { rental revenue to the port is } \$ 300 \mathrm{~K} \text {. } \\
\text { Assume marina tenants would lose } 1 / 3 \text { of their business during slip repair } \\
\text { time; it will take } 1 \text { month to repair the damaged slips at a linear rate. } \\
\text { We distribute the total revenue losses (excluding the rental revenue to the } \\
\text { port) evenly among restaurant, retail, and marina-related activities sectors. }\end{array}$ & $\begin{array}{l}\$ 300 \mathrm{~K} \text { revenue loss to POLA. As } \\
\text { for the remaining direct revenue } \\
\text { losses, we distribute them to } \\
\text { marina recreation industries, } \\
\text { restaurants, and retail trade. }\end{array}$ & $\begin{array}{l}\text { Excess capacity } \\
\text { of marina; } \\
\text { production } \\
\text { recapture. }\end{array}$ \\
\hline $\begin{array}{l}\text { Impacts to } \\
\text { commercial } \\
\text { fishing }\end{array}$ & $\begin{array}{l}\text { Economic impacts pertain to perished fish on board of the vessels at sea } \\
\text { and lost fishing days: } 25 \% \text { of a day's fish haul will perish. In addition, } 5 \% \\
\text { of fishing fleet will be damaged, and } 4 \text { fishing days lost. } \\
\text { It will take about } 2 \text { months on average to repair or replace the damaged } \\
\text { boats, so it will lead to a } 5 \% \text { of } 2 \text {-month total revenue loss to the fishing } \\
\text { industry. }\end{array}$ & $\begin{array}{l}\text { These are converted to direct } \\
\text { revenue loss to the fishing sector. }\end{array}$ & $\begin{array}{l}\text { Production } \\
\text { recapture. }\end{array}$ \\
\hline $\begin{array}{l}\text { Miscellaneous: } \\
\text { A. Cruise ship }\end{array}$ & $\begin{array}{l}\text { No POLA cruise ships affected during the } 2 \text {-day time period of the } \\
\text { scenario. }\end{array}$ & & \\
\hline
\end{tabular}




\section{Appendix B. Tsunami Port Direct Impacts Without and With Resilience}

[This appendix is provided online only as an Excel spreadsheet (Tsunami_Port_Direct Impacts without and with Resilience) at http://pubs.usgs.gov/of/2013/1170/H/] 


\section{Appendix C. CGE Model Description}

\section{Introduction}

This appendix summarizes the design, construction and application of a static computable general equilibrium (CGE) simulation model of the California economy. The application of the model simulates single semiannual period that begins with the occurrence of a tsunami.

A CGE model is a stylized computational representation of the circular flow of the economy. It solves for the set of commodity and factor prices and activity levels of firms' outputs and households' incomes that equalize supply and demand across all markets in the economy (Sue Wing, 2009, 2011). The present model divides California into two regions, the five counties surrounding Los Angeles (Los Angeles, Orange, Riverside, San Bernardino, Ventura) and an amalgam of the remaining counties in the State. Production in each region is divided into 65 industry sectors (table $\mathrm{C} 1$ ), each of which is modeled as representative firm characterized by a constant elasticity of substitution (CES) technology to produce a single good or service. Households are modeled as a representative agent with CES preferences and a constant marginal propensity to save and invest out of income. Government is also represented in a simplified fashion. Its role in the circular flow of the economy is passive-collecting taxes from industries and passing some of the resulting revenue to the households as a lump-sum transfer, in addition to purchasing commodities to create a composite government good, which is consumed by the households. Three factors of production are represented within the model - (1) labor, (2) intersectorally mobile capital, and (3) sector-specific capital, all of which are owned by the representative agent and rented out to the firms in exchange for factor income. California is modeled as an open economy that engages in trade with the rest of the United States and the rest of the world using the Armington specification (imports from other States and the rest of the world are imperfect substitutes for goods produced in California).

The static component of the model computes the prices and quantities of goods and factors that equalize supply and demand in all markets in the economy, subject to constraints on the external balance of payments. This equilibrium submodel is embedded within a dynamic process, which on a 6-month time-step specifies exogenous improvements in firms' productivity and updates the economy's capital endowments based on investment-driven accumulation of the stocks of capital. The impacts of a tsunami are modeled as exogenous shocks to the productivity of industries, reductions in household consumption and investment, and contemporaneous destruction of capital stock, with concomitant reductions in the economy's endowments of capital input.

\section{Production}

The supply side of the model employs a simple hierarchical nested CES production structure. In each region $r$ and sector $j$, the price and quantity of output are given by $P Y_{j, r}$ and $Q Y_{j, r}$. Output is produced by combining a composite of capital and labor $\left(Q K L_{j, r}\right.$, with price $\left.P K L_{j, r}\right)$ with a composite of intermediate inputs $\left(Q Z_{j, r}\right.$, with 
price $\left.P Z_{j, r}\right)$. This production relation is represented in dual form by the unit cost function:

$$
P Y_{j, r} \leq\left(1-\Phi_{Y, j, r}\right)^{-1} \cdot\left[\alpha_{K L, j, r}^{\sigma_{Y}} P K L_{j, r}^{1-\sigma_{Y}}+\alpha_{Z, j, r}^{\sigma_{Y}} P Z_{j, r}^{1-\sigma_{Y}}\right]^{1 /\left(1-\sigma_{Y}\right)} .
$$

Here, $\sigma_{Y}$ denotes the top-level the elasticity of substitution between intermediate inputs and value-added, and $\Phi_{Y, j, r}$ is a parameter that captures the impact of output losses associated with the tsunami. In turn, the capital-labor composite is produced from sectorspecific capital $\left(Q K_{j, r}\right.$, with price $\left.P K_{j, r}\right)$ and labor $\left(Q L_{j, r}\right.$, with average wage $\left.P L\right)$ according to the unit cost function:

$$
P K L_{j, r} \leq\left[\alpha_{K, j, r}^{\sigma_{K L}} P K_{j, r}^{1-\sigma_{K L}}+\alpha_{L, j, r}^{\sigma_{K L}} P L^{1-\sigma_{K L}}\right]^{1 /\left(1-\sigma_{K L}\right)},
$$

in which $\sigma_{K L}$ is the elasticity of substitution between capital and labor. Finally, the intermediate input composite is modeled as a CES aggregation of intermediate inputs of the $i$ commodities $\left(q_{i, j, r}\right.$, with "Armington" user prices $\left.P A_{i, r}\right)$ according to the unit cost function:

$$
P Z_{j, r} \leq\left[\sum_{i} \alpha_{i, j, r}^{\sigma_{Z}} P A_{i, r}^{1-\sigma_{Z}}\right]^{1 /\left(1-\sigma_{Z}\right)},
$$

where $\sigma_{Z}$ is the elasticity of substitution among intermediate inputs.

\section{Trade and Commodity Supply}

Trade is modeled according to an Armington formulation, in which the output of a sector in a particular region is allocated between consumption of locally produced goods and exports. In turn, exports are divided between goods destined for other regions within the United States and goods that satisfy foreign demand. Symmetrically, on the demand side, each consumed commodity in a particular region is a composite of domestic and imported varieties, where the latter is an amalgam of imports from other U.S. regions and from abroad.

The calibration dataset does not record bilateral trade among counties or county aggregates. Consequently, the $Q X U S_{i, r}$ units of the $i^{\text {th }}$ commodity exported by region $r$ to U.S. consumers in other locales is treated as feeding into a national pool at a commodityspecific U.S.-wide price $\left(P U S_{i}\right)$, whereas the $Q X F_{i, r}$ units exported to consumers abroad are treated as feeding an international pool at a single price (the generalized price of foreign exchange, $P F X)$. Using $P Y T_{i, r}=\left(1+\tau_{i, r}^{Y}\right) P Y_{i, r}$ to represent the gross-of-tax price of $i$ (where $\tau_{i, r}^{Y}$ denotes the production tax rate), the transformation of regional output into exports (quantity $Q X_{i, r}$ ) is specified in terms of the dual by:

$$
P Y T_{i, r} \geq\left(1-\Phi_{X, j, r}\right) \cdot\left[\beta_{X C A, i}^{\eta_{X, i}} P U S_{i}^{1-\eta_{X, i}}+\beta_{X F, i}^{\eta_{X, i}} P F X^{1-\eta_{X, i}}\right]^{1 /\left(1-\eta_{X, i}\right)} .
$$

Here, $\eta_{X}$ is the elasticity of transformation among export destinations, whereas

$\Phi_{X, j, r}$ is a parameter that is introduced to capture the adverse shock to export productivity caused by the tsunami's impact on port operations.

Symmetrically, $r$ imports $Q M U S_{i, r}$ units of $i$ from other U.S. regions and $Q M F_{i, r}$ units from abroad. Its aggregate imports of each good (quantity $Q M_{i, r}$ with price $P M_{i, r}$ ) are modeled as a CES composite of these quantities, given in terms of the dual by: 


$$
P M_{i, r} \leq\left(1-\Phi_{M, j, r}\right)^{-1} \cdot\left[\beta_{M U S, i, r}^{\sigma_{M M}} P U S_{i}^{1-\sigma_{M M, i}}+\beta_{M F, i, r}^{\sigma_{M M, i}} P F X^{1-\sigma_{M M, i}}\right]^{1 /\left(1-\sigma_{M M, i}\right)}
$$

in which $\sigma_{M M}$ is the elasticity of substitution among import origins, and the parameter $\Phi_{M, j, r}$ captures the tsunami's adverse shock to imports. In turn, each region's uses of a commodity are fulfilled by the Armington total supply $\left(Q A_{i, r}\right.$, with price $\left.P A_{i, r}\right)$, which is modeled as a CES composite of domestic and imported varieties given in dual form by

$$
P A_{i, r} \leq\left[\beta_{D, i, r}^{\sigma_{D M, i}} P Y T_{i}^{1-\sigma_{D M, i}}+\beta_{M, i, r}^{\sigma_{D M, i}} P M^{1-\sigma_{D M, i}}\right]^{1 /\left(1-\sigma_{D M, i}\right)}
$$

where $\sigma_{D M}$ is the elasticity of substitution.

We adopt a simple trade closure for the model. Each region is treated as a small open economy that cannot affect the price of foreign exchange. Following open-economy modeling convention, we designate the variable $P F X$ as the numeraire price by fixing its value at unity. The model only resolves regions within the State of California, and not elsewhere in the United States, so in the general case the trade in a particular good recorded by the benchmark input-output accounts will not balance. California's net export position vis-a-vis the rest of the United States is calculated by applying Shephard's lemma, yielding the supply-demand balance condition:

$\sum_{r} Q X U S_{i, r} \geq \sum_{r} Q M U S_{i, r}+Q B U S_{i} \Rightarrow \sum_{r} \frac{\partial P Y T_{i, r}}{\partial P U S_{i}} Q X_{i, r} \geq \sum_{r} \frac{\partial P M_{i, r}}{\partial P U S_{i}} Q M_{i, r}+Q B U S_{i}$

where $Q B U S_{i}$ is introduced as a balancing quantity of net exports of good $i$. The corresponding expression for trade with foreign countries is:

$$
\sum_{r} Q X F_{i, r} \geq \sum_{r} Q M F_{i, r}+Q B F_{i} \Rightarrow \sum_{r} \frac{\partial P T Y_{i, r}}{\partial P F X} Q X_{i, r} \geq \sum_{r} \frac{\partial P M_{i, r}}{\partial P F X} Q M_{i, r}+Q B F_{i},
$$

with balancing quantity $Q B F_{i}$.

\section{Final Demands and Commodity Market Closures}

In each region, there are $h$ household archetypes, each of which is modeled as a representative agent who with CES preferences over consumption of commodities $\left(q_{i, C, h, r}\right.$, at price $\left.P A_{i, r}\right)$. The associated dual expenditure functions are given by:

$$
P U_{h, r} \leq\left[\sum_{i} \gamma_{i, C, h, r}^{\sigma_{C}} P A_{i, r}^{1-\sigma_{C}}\right]^{1 /\left(1-\sigma_{C}\right)}
$$

where $P U_{h, r}$ is the unit expenditure index and $\sigma_{C}$ is the elasticity of substitution among inputs to consumption. There are also $g$ levels of government, each of which consumes commodity inputs $\left(q_{i, G, g, r}\right.$ at price $\left.P A_{i, r}\right)$ for the purpose of producing a government good $\left(Q G_{g, r}\right.$, at price $\left.P G_{g, r}\right)$ with CES technology. The associated cost function is:

$$
P G_{g, r} \leq\left[\sum_{i} \gamma_{i, G, g, r}^{\sigma_{G}} P A_{i, r}^{1-\sigma_{G}}\right]^{1 /\left(1-\sigma_{G}\right)}
$$

and $\sigma_{G}$ is the elasticity of substitution among inputs to government. As well, each region produces an investment good $\left(Q I_{r}\right.$, at price $\left.P I_{r}\right)$ from a CES aggregation of commodities $\left(q_{i, I, r}\right.$ at price $\left.P A_{i, r}\right)$ :

$$
P I_{r} \leq\left[\sum_{i} \gamma_{i, I, r}^{\sigma_{I}} P A_{i, r}^{1-\sigma_{I}}\right]^{1 /\left(1-\sigma_{I}\right)}
$$


and $\sigma_{I}$ is the elasticity of substitution among inputs to investment. We assume that each representative agent exhibits a fixed marginal propensity to save (MPS) and invest out of income. Supply-demand balance for households' savings $\left(Q S_{h, r}\right)$ requires:

$$
Q I_{r} \leq \sum_{h} Q S_{h, r}
$$

whereas a fixed MPS implies a constant of proportionality, $\mu_{h, r}$, which allows savings to scale with changes in activity (consumption) levels:

$$
Q S_{h, r}=\mu_{h, r} U_{h, r} .
$$

Government consumption is financed out of tax revenue and transfers. We model government $g$ as claiming a fraction $\xi_{g, r}$ of the total tax revenue raised within region $r$, as well as receiving a net transfer, $G X F E R_{g, r}$ (which for convenience we denominate in units of the numeraire). The activity level of public provision is then given by:

$$
Q G_{g, r} \leq\left(\xi_{g, r} \sum_{j} \tau_{j, r}^{Y} P Y_{j, r} Q Y_{j, r}+P F X \cdot G X F E R_{g, r}\right) / P G_{g, r} .
$$

The supply-demand balance for domestic output is given by:

$$
Q Y_{i, r} \geq Q D_{i, r}+Q X_{i, r}
$$

where the unconditional demand for domestic uses is given by Shephard's Lemma: $Q D_{i, r}=\frac{\partial P A_{i, r}}{\partial P Y T_{i, r}} Q A_{i, r}$. The supply-demand balance for imports is given by Shephard's Lemma:

$$
Q M_{i, r} \geq \frac{\partial P A_{i, r}}{\partial P M_{i, r}} Q A_{i, r}
$$

Finally, the supply-demand balance for Armington commodities is closed via the condition:

$$
Q A_{i, r} \geq \sum_{j} q_{i, j, r}+\sum_{h} q_{i, C, h, r}+q_{i, I, r}+\sum_{g} q_{i, G, g, r}
$$

in which the unconditional demands on the right-hand side are

$$
q_{i, j, r}=\frac{\partial P Y_{j, r}}{\partial P A_{i, r}} Q Y_{j, r}, q_{i, C, h, r}=\frac{\partial P U_{h, r}}{\partial P A_{i, r}} U_{h, r}, q_{i, I, r}=\frac{\partial P I_{r}}{\partial P A_{i, r}} Q I_{r} \text { and } q_{i, G, g, r}=\frac{\partial P G_{g, r}}{\partial P A_{i, r}} Q G_{g, r} .
$$

\section{Intersectoral Factor Mobility and Static Income Closures}

Given the short duration of each time step, the assumption of frictionless intersectoral reallocation of capital common in CGE models is unlikely to accurately capture the behavior of factor markets. Although we continue to treat labor as mobile across industries and regions, we model capital as a sectorally and geographically fixed factor at each time-step, with instantaneous supply-demand balance determined by the region-specific aggregate supply of capital input $\left(\mathcal{E}_{K, j, r}\right)$ :

$$
\left(1-\Phi_{K, j, r}\right) \cdot \mathcal{E}_{K, j, r} \geq \frac{\partial P K L_{j, r}}{\partial P K_{j, r}} Q K L_{j, r}
$$

The effect of capital stock destruction on the left-hand side of this expression, given by the parameter $\Phi_{K, j, r}$, is another driver of the tsunami's economic impact. Traditional CGE models close the labor market either through the "neoclassical" 
assumption of full employment (perfectly inelastic supply) or "Keynesian" variable employment (perfectly elastic supply at a fixed wage). Neither of these extremes adequately captures the impact of a large transitory shock, which typically induces simultaneous adjustments in both employment and wages. Accordingly, we model labor as a variable factor whose endowment is price responsive. This is achieved by specifying a short-run labor supply curve with elasticity $\eta_{L}$, which scales each region's labor supply from its benchmark level $\left(\mathcal{E}_{L, r}\right)$ :

$$
\sum_{r} \mathcal{E}_{L, r} \cdot P L^{\eta_{L}} \geq \sum_{j} \sum_{r} \frac{\partial P K L_{j, r}}{\partial P L} Q K L_{j, r}
$$

Regional household, investment, and government activities are bound together by an income-expenditure balance condition that constrains the value of expenditure and saving to equal the value of factor returns plus net household transfers $\left(H X F E R_{h, r}\right.$, also denominated in units of the numeraire). Thus, using $\zeta_{K, h, r}$ and $\zeta_{L, h, r}$ to denote the fixed household proportions of labor and capital remuneration within each region, income balance is given by:

$$
\begin{aligned}
\zeta_{K, h, r} \cdot & \sum_{j} P K_{j, r} \varepsilon_{K, j, r}+\zeta_{L, h, r} P L^{1-\eta_{L}} \varepsilon_{L, r}+P F X \cdot H X F E R_{h, r} \\
& \geq P U_{h, r} U_{h, r}+P I_{r} Q S_{h, r}+\sum_{i} P C A_{i} S A_{i, h, r} .
\end{aligned}
$$

Our final closure rule is the statewide balance of payments constraint, which balances the net supply of foreign exchange against the demands for transfer payments that make up the idiosyncratic components of household and government income:

$$
\sum_{i}\left(P U S_{i} \cdot Q B U S_{i}+Q B F_{i}\right)+\sum_{g} \sum_{r} G X F E R_{g, r}+\sum_{h} \sum_{r} H X F E R_{h, r}=0 .
$$

\section{The Impacts of a Tsunami on the Economy}

The static equilibrium submodel made up of equations $1-4$ is subjected to the shock of economic damage caused by the tsunami event represented by adverse shocks to the efficiency of production in key affected sectors $\left(\Phi_{Y, j, r}\right)$, shocks to the productivity of

exports and imports $\left(\Phi_{X, j, r}\right.$ and $\left.\Phi_{M, j, r}\right)$, and reductions in sectors' endowments of capital input $\left(\Phi_{K, j, r}\right)$. In the economy's baseline state these shock parameters are set to zero, whereas in the tsunami scenario they take on values between zero and one, reflecting different components of damage. Import and export losses generally affect all sectors, and primarily encompass losses associated with interrupted operation of POLA and POLB, destruction of cargo, and loss of function of damaged facilities and infrastructure. Direct damage to buildings and their contents also affects all sectors in coastal areas of both regions of California. Direct output losses affect only fishing (sector 7) and marinas (sectors 43, 61, and 63).

\section{Model Calibration, Formulation and Solution}

The vectors of technical coefficients $\boldsymbol{\alpha}, \boldsymbol{\beta}$ and $\boldsymbol{\gamma}$ in equations $1-4$ are calibrated using an IMPLAN social accounting matrix for the state of California for the year 2010 (Minnesota IMPLAN Group, Inc., 2012) in conjunction with values of the elasticities of substitution, transformation, and supply in table C2. The model is formulated as a mixed 
complementarity problem using the MPSGE subsystem for GAMS (Rutherford, 1999;

Brooke and others, 1998) and is solved using the PATH solver (Ferris and others, 2000).

Table C1. Computable general equilibrium (CGE) model sectors for the SAFRR tsunami scenario.

[NAICS, North American Industry Classification System; mfg, manufacturing]

\begin{tabular}{|c|c|c|c|}
\hline & Description & NAICS Code & 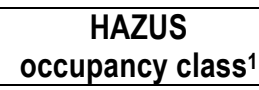 \\
\hline 1 & Oilseed and grain farming & 1111 & AGR1 \\
\hline 2 & Vegetable and melon farming & 1112 & AGR1 \\
\hline 3 & Fruit and tree nut farming & 1113 & AGR1 \\
\hline 4 & Other crop farming & 1114,1119 & AGR1 \\
\hline 5 & Animal production and aquaculture & 112 & AGR1 \\
\hline 6 & Forestry and logging & 113 & AGR1 \\
\hline 7 & Fishing & 1141 & AGR1 \\
\hline 8 & Hunting and trapping & 1142 & AGR1 \\
\hline 9 & Support activities for agriculture and forestry & 115 & AGR1 \\
\hline 10 & Oil and gas extraction & 211 & IND4 \\
\hline 11 & Other nonmetallic mineral mining and quarrying & 21239 & IND4 \\
\hline 12 & Other mining & 212 (ex. 21239) & IND4 \\
\hline 13 & $\begin{array}{l}\text { Electric power generation, transmission and } \\
\text { distribution }\end{array}$ & 2211 & COM4 \\
\hline 14 & Natural gas distribution & 2212 & COM4 \\
\hline 15 & Water and sewage & 2213 & COM4 \\
\hline 16 & Nonresidential construction & 23 & IND6 \\
\hline 17 & Residential construction & 23 & IND6 \\
\hline 18 & Food mfg & 311 & IND3 \\
\hline 19 & Beverage and tobacco product $\mathrm{mfg}$ & 312 & IND3 \\
\hline 20 & Textile and textile product mills & 313,314 & IND1 \\
\hline 21 & Apparel mfg & 315 & IND2 \\
\hline 22 & Leather and allied product $\mathrm{mfg}$ & 316 & IND2 \\
\hline 23 & Wood product mfg & 321 & IND1 \\
\hline 24 & Paper mfg & 322 & IND1 \\
\hline 25 & Printing and related support activities & 323 & IND2 \\
\hline 26 & Petroleum refineries & 32411 & IND3 \\
\hline 27 & Other petroleum and coal products $\mathrm{mfg}$ & 324 & IND3 \\
\hline 28 & Chemical mfg & 325 & IND3 \\
\hline 29 & Plastics and rubber products $\mathrm{mfg}$ & 326 & IND2 \\
\hline 30 & Nonmetallic mineral product $\mathrm{mfg}$ & 327 & IND1 \\
\hline 31 & Iron and steel mills and steel product $\mathrm{mfg}$ & 3311 and 3312 & IND4 \\
\hline 32 & Other primary metal mfg & 331 (ex. 3311), 3312 & IND4 \\
\hline 33 & Fabricated metal product $\mathrm{mfg}$ & 332 & IND4 \\
\hline 34 & Machinery mfg & 333 & IND1 \\
\hline 35 & Computer and electronic product $\mathrm{mfg}$ & 334 & IND5 \\
\hline 36 & Electrical equipment, appliance and component $\mathrm{mfg}$ & 335 & IND2 \\
\hline 37 & Automobile and light duty motor vehicle $\mathrm{mfg}$ & 33611 & IND1 \\
\hline
\end{tabular}


Table C1. Computable general equilibrium (CGE) model sectors for the SAFRR tsunami scenario.-Continued

[NAICS, North American Industry Classification System; mfg, manufacturing]

\begin{tabular}{llll}
\hline \multicolumn{1}{c}{ Description } & NAICS Code & $\begin{array}{c}\text { HAZUS } \\
\text { occupancy class } 1\end{array}$ \\
\hline 38 & Ship and boat building and repairing & 3366 & IND1 \\
39 & Other transportation equipment mfg & $336($ ex. 33611), 3366 & IND1 \\
40 & Furniture and related product mfg & 337 & IND2 \\
41 & Miscellaneous mfg & 339 & IND2 \\
42 & Wholesale & 42 & COM2 \\
43 & Retail trade & $44-45$ & COM1 \\
44 & Air transportation & 481 & COM4 \\
45 & Rail transportation & 482 & COM4 \\
46 & Water transportation & 483 & COM4 \\
47 & Truck transportation & 484 & COM4 \\
48 & Transit and ground passenger transport & 485 & COM4 \\
49 & Pipeline transportation & 486 & COM4 \\
50 & Scenic and sightseeing transport \& support activities & 487,488 & COM4 \\
51 & Couriers and messengers & 492 & COM4 \\
52 & Warehousing and storage & 493 & COM2 \\
53 & Information & 51 & COM4 \\
54 & Finance and insurance & 52 & COM4; COM5 \\
55 & Real estate and rental and leasing & 53 & COM4 \\
56 & Professional, scientific and technical services & 54 & COM4 \\
57 & Admin support and waste management and & 56 & COM4 \\
& remediation & & \\
58 & Educational services & 61 & EDU1; EDU2 \\
59 & Health care and social assistance & 62 & COM6; COM7 \\
60 & Arts, entertainment and recreation & $71($ ex. 71391-3), & COM8 \\
& & 71399 & \\
61 & Other amusement and recreation, including marinas & $71391-3,71399$ & COM8 \\
62 & Accommodation and food services & 721 & RES4 \\
63 & Food services and drinking places & 722 & COM8 \\
64 & Other services (except public administration) & 55,81 & GOM3 \\
65 & Government and non-NAICS & 92 & GOV2 \\
\hline
\end{tabular}

${ }^{1}$ Key: AGR1 Agriculture; IND1 Heavy Industry; IND2 Light Industry; IND3 Food/Drugs/Chemicals; IND4 Metals/ Minerals Processing; IND5 High Technology Industry; IND6 Construction; COM1 Retail Trade; COM2 Wholesale Trade; COM3 Personal and Repair Services; COM4 Professional/Technical Services; COM5 Banks/Financial Institutions; COM6 Hospitals; COM7 Medical Offices/Clinics; COM8 Entertainment \& Recreation; EDU1 Schools; EDU2 Colleges/Universities; RES4 Temporary Lodging for Accommodation; GOV1 General Government Services; GOV2 Emergency Response. 
Table C2. Elasticities of substitution, transformation, and supply or the SAFRR tsunami scenario.

\begin{tabular}{lcc}
\hline \multicolumn{1}{c}{ Elasticities of substitution } & & \\
\hline Between value added and a composite of intermediate inputs in production & $\sigma_{Y}$ & 0.1 \\
Between capital and labor in production & $\sigma_{K L}$ & 0.25 \\
Among intermediate inputs to production & $\sigma_{Z}$ & 0.1 \\
Among regions' imports from the rest of the United States and abroad & $\sigma_{Y Y, i}$ & 2 \\
Between domestic (California) and imported varieties of each good in regional & $\sigma_{D M, i}$ & 0.5 \\
Armington composite & $\sigma_{C}$ & 0.25 \\
Among inputs to household consumption & $\sigma_{I}$ & 0.25 \\
Among inputs to investment & $\sigma_{G}$ & 0.25 \\
Among inputs to government & \multicolumn{2}{c}{} \\
\hline \multicolumn{2}{c}{ Elasticities of transformation } & $\eta_{X}$ \\
\hline Between rest of United States and foreign exports & \multicolumn{2}{c}{2} \\
\hline Elasticities of supply & $\eta_{L}$ & 0.3 \\
\hline Labor
\end{tabular}




\section{Appendix D. Calculation of Inventory Availability for Resilience}

In disaster impact analysis, inventories of raw materials and finished goods used as inputs or intended for final customers through wholesale and retail markets can cushion the blow of a supply disruption, such as those associated with the port shutdown in this study. We summarize the methods, assumptions, and data sources we use to compute the available inventory in the southern California region that can be used to deal with supply disruptions.

Our major data source of inventories is the real inventories and sales in the national economic accounts released by the U.S. Department of Commerce, Bureau of Economic Analysis (Bureau of Economic Analysis, 2013). The data used here are only for manufacturing sectors. Table D1 presents these data for the United States for the year 2011 for three fabrication stages of inventories - materials and supplies, work-in-process, and finished goods. In the last three columns in table D1, inventory to annual sale ratios are computed.

For each of the three individual stages of fabrication, the data pertain to the total amount of inventories held by each manufacturing sector. There is no reference to the types of input in the first two categories. To disaggregate the inventories of materials and supplies into different types of raw material inputs available for each manufacturing industry, we make use of the regional input-output table. For inventories of finished goods, we create a matrix that shows the amount of own output each sector holds.

Below, we use the five-county southern California region as an example to illustrate the steps in the inventory calculation. In table D2, the first column presents the annual sectoral sales in the southern California region. Applying the national level inventory to sales ratios in the last three columns of table 1 to the annual sales of the southern California region, we estimated the inventories in the fabrication stages in the region for the manufacturing sectors (the last three columns in table D2).

For inventory of materials and supplies, we disaggregated the total value in the second column of table D2 for each sector into various raw material inputs based on the column (input) coefficients in the regional input-output table. Note that we include the following sectoral inputs as raw material inputs: agriculture, fishing, and forestry, mining, utility (except for electricity), and all manufacturing sectors. In other words, we did not count the production inputs from the electric power generation, construction, and service sectors as raw materials. Table D3 presents the calculation results, with each row representing different types of raw material inputs, and each column representing different sectors. Because we only have the inventory data for manufacturing sectors, we have omitted other sectors in the table.

For inventory of work-in-process products, because they are midway between finished commodities and raw material inputs and difficult to disaggregate on a sectoral basis, we do not include this category of inventory in our calculation to obtain the commodity inventory buffers that can help reduce the impacts of import disruptions. Table D4 shows the amount of "own" outputs that are held by each sector as finished goods inventory for the southern California region.

Finally, for each commodity in table D5, we add up the numbers over the corresponding rows in tables D3 and D4 to obtain the total amount of inventories that are available in the southern California region to be used to reduce the impact from import disruptions.

Our calculation of inventory availability is conservative from three perspectives. First, we only count for the inventories that are held by the manufacturing sectors in the region. However, the inventories held by the other sectors are likely to be small compared with those held by the 
manufacturing sectors. Major inventories of the agriculture sector may include water, gas, pesticide, and feed. The inventories for the transportation sectors may include oil, gas, and water. Most of the service sectors may only possess limited inventories. Second, we did not take into consideration the consumer goods held by the wholesalers and retailers in the region that can help cushion the supply disruption impacts to the end users. And finally, again we did not include the work-in-process inventories in our calculation. 
Table D1. Real manufacturing inventories for the United States, by stage of fabrication, seasonally adjusted, end of 2011 (data from Bureau of Economic Analysis, 2013).

[M 2005\$, millions of 2005 dollars; \%, percent]

\begin{tabular}{|c|c|c|c|c|c|c|c|}
\hline \multirow[b]{2}{*}{ Sector } & \multirow{2}{*}{$\begin{array}{c}2011 \\
\text { annual } \\
\text { sales (M } \\
2005 \$)\end{array}$} & \multicolumn{3}{|c|}{ End of 2011 inventories } & \multicolumn{3}{|c|}{ Inventory to sale ratio } \\
\hline & & $\begin{array}{l}\text { Materials } \\
\text { and } \\
\text { supplies }\end{array}$ & $\begin{array}{l}\text { Work-in- } \\
\text { process }\end{array}$ & $\begin{array}{l}\text { Finished } \\
\text { goods }\end{array}$ & $\begin{array}{l}\text { Materials } \\
\text { and } \\
\text { supplies }\end{array}$ & $\begin{array}{l}\text { Work-in- } \\
\text { process }\end{array}$ & $\begin{array}{l}\text { Finished } \\
\text { goods }\end{array}$ \\
\hline Manufacturing industries & $4,283,928$ & 182,015 & 172,059 & 194,142 & $4 \%$ & $4 \%$ & $5 \%$ \\
\hline Durable goods manufacturing industries & $2,205,444$ & 109,907 & 134,751 & 92,847 & $5 \%$ & $6 \%$ & $4 \%$ \\
\hline Wood product manufacturing & 70,596 & 4,025 & 1,456 & 3,474 & $6 \%$ & $2 \%$ & $5 \%$ \\
\hline Nonmetallic mineral product manufacturing & 79,236 & 4,263 & 1,123 & 5,260 & $5 \%$ & $1 \%$ & $7 \%$ \\
\hline Fabricated metal product manufacturing & 251,196 & 14,113 & 11,830 & 12,939 & $6 \%$ & $5 \%$ & $5 \%$ \\
\hline Machinery manufacturing & 300,228 & 18,333 & 12,806 & 15,134 & $6 \%$ & $4 \%$ & $5 \%$ \\
\hline Computer and electronic product manufacturing & 371,904 & 22,995 & 20,365 & 16,956 & $6 \%$ & $5 \%$ & $5 \%$ \\
\hline $\begin{array}{l}\text { Electrical equipment, appliance, and component } \\
\text { manufacturing }\end{array}$ & 93,468 & 5,871 & 4,938 & 2,908 & $6 \%$ & $5 \%$ & $3 \%$ \\
\hline Transportation equipment manufacturing & 632,496 & 20,699 & 69,019 & 15,138 & $3 \%$ & $11 \%$ & $2 \%$ \\
\hline Motor vehicle and parts manufacturing & 451,224 & 12,179 & 6,103 & 8,046 & $3 \%$ & $1 \%$ & $2 \%$ \\
\hline Other transportation equipment manufacturing & 183,024 & 8,534 & 62,992 & 7,103 & $5 \%$ & $34 \%$ & $4 \%$ \\
\hline Miscellaneous durable goods manufacturing & 136,980 & 7,789 & 4,451 & 11,532 & $6 \%$ & $3 \%$ & $8 \%$ \\
\hline Nondurable goods manufacturing industries & $2,079,984$ & 72,604 & 38,329 & 101,612 & $3 \%$ & $2 \%$ & $5 \%$ \\
\hline Food manufacturing & 531,648 & 10,942 & 5,653 & 22,589 & $2 \%$ & $1 \%$ & $4 \%$ \\
\hline Beverage and tobacco product manufacturing & 113,916 & 5,812 & 2,842 & 5,321 & $5 \%$ & $2 \%$ & $5 \%$ \\
\hline Textile mills & 24,156 & 1,635 & 921 & 1,979 & $7 \%$ & $4 \%$ & $8 \%$ \\
\hline Textile product mills & 19,836 & 1,272 & 573 & 1,517 & $6 \%$ & $3 \%$ & $8 \%$ \\
\hline Apparel manufacturing & 15,528 & 1,745 & 984 & 3,474 & $11 \%$ & $6 \%$ & $22 \%$ \\
\hline Leather and allied product manufacturing & 5,196 & 426 & 248 & 779 & $8 \%$ & $5 \%$ & $15 \%$ \\
\hline Paper manufacturing & 134,256 & 7,873 & 1,643 & 6,314 & $6 \%$ & $1 \%$ & $5 \%$ \\
\hline Printing and related support activities & 74,640 & 2,137 & 827 & 2,671 & $3 \%$ & $1 \%$ & $4 \%$ \\
\hline Petroleum and coal product manufacturing & 433,716 & 10,523 & 8,941 & 15,692 & $2 \%$ & $2 \%$ & $4 \%$ \\
\hline Chemical manufacturing & 552,840 & 21,286 & 13,223 & 31,137 & $4 \%$ & $2 \%$ & $6 \%$ \\
\hline Plastics and rubber product manufacturing & 163,764 & 9,056 & 2,146 & 9,725 & $6 \%$ & $1 \%$ & $6 \%$ \\
\hline
\end{tabular}


Table D2. Inventories by stage of fabrication for manufacturing industry in southern California region (in millions of 2010 dollars).

[Data in second column from Minnesota IMPLAN Group, Inc. (2012). Numbers in the remaining three columns computed by the authors]

\begin{tabular}{|c|c|c|c|c|}
\hline Sector & $\begin{array}{l}2010 \text { Annual } \\
\text { sales }\end{array}$ & $\begin{array}{c}\text { Materials } \\
\text { and supplies }\end{array}$ & $\begin{array}{l}\text { Work-in- } \\
\text { process }\end{array}$ & $\begin{array}{l}\text { Finished } \\
\text { goods }\end{array}$ \\
\hline Oilseed and grain farming & 6.81 & & & \\
\hline Vegetable and melon farming & 820.83 & & & \\
\hline Fruit and tree nut farming & $1,491.43$ & & & \\
\hline Other crop farming & $1,447.33$ & & & \\
\hline Animal production and aquaculture & 895.13 & & & \\
\hline Forestry and logging & 67.38 & & & \\
\hline Fishing & 70.43 & & & \\
\hline Hunting and trapping & 1.68 & & & \\
\hline Support activities for agriculture and forestry & 799.21 & & & \\
\hline Oil and gas extraction & $4,447.24$ & & & \\
\hline $\begin{array}{l}\text { Other nonmetallic mineral mining and } \\
\text { quarrying }\end{array}$ & 40.22 & & & \\
\hline Other mining & $1,132.62$ & & & \\
\hline $\begin{array}{l}\text { Electric power generation, transmission, and } \\
\text { distribution }\end{array}$ & $10,436.73$ & & & \\
\hline Natural gas distribution & $15,205.43$ & & & \\
\hline Water, sewage and other systems & 192.19 & & & \\
\hline Nonresidential construction & $40,214.90$ & & & \\
\hline Residential construction & $21,728.61$ & & & \\
\hline Food manufacturing & $25,194.47$ & 518.53 & 267.89 & $1,070.48$ \\
\hline Beverage and tobacco product manufacturing & $7,228.67$ & 368.81 & 180.34 & 337.65 \\
\hline Textile mills and textile product mills & $2,902.35$ & 191.79 & 98.57 & 230.65 \\
\hline Apparel manufacturing & $8,897.59$ & 999.89 & 563.83 & $1,990.61$ \\
\hline Leather and allied product manufacturing & 335.53 & 27.51 & 16.01 & 50.30 \\
\hline Wood product manufacturing & $1,380.90$ & 78.73 & 28.48 & 67.95 \\
\hline Paper manufacturing & $5,318.06$ & 311.86 & 65.08 & 250.11 \\
\hline Printing and related support activities & $4,956.64$ & 141.91 & 54.92 & 177.37 \\
\hline Petroleum refineries & $29,523.18$ & 716.30 & 608.62 & $1,068.16$ \\
\hline $\begin{array}{l}\text { Other petroleum and coal products } \\
\text { manufacturing }\end{array}$ & $1,415.89$ & 34.35 & 29.19 & 51.23 \\
\hline Chemical manufacturing & $41,590.96$ & $1,601.38$ & 994.79 & $2,342.48$ \\
\hline Plastics and rubber products manufacturing & $8,850.26$ & 489.41 & 115.98 & 525.57 \\
\hline
\end{tabular}


Table D2. Inventories by stage of fabrication for manufacturing industry in southern California region (in millions of 2010 dollars).-Continued

[Data in second column from Minnesota IMPLAN Group, Inc. (2012). Numbers in the remaining three columns computed by the authors]

\begin{tabular}{|c|c|c|c|c|}
\hline Sector & $\begin{array}{l}2010 \text { Annual } \\
\text { sales }\end{array}$ & $\begin{array}{l}\text { Materials } \\
\text { and } \\
\text { supplies }\end{array}$ & $\begin{array}{l}\text { Work-in- } \\
\text { process }\end{array}$ & $\begin{array}{l}\text { Finished } \\
\text { goods }\end{array}$ \\
\hline Nonmetallic mineral product manufacturing & $3,519.98$ & 189.38 & 49.89 & 233.67 \\
\hline $\begin{array}{l}\text { Iron and steel mills and steel product } \\
\text { manufacturing }\end{array}$ & $2,114.57$ & 87.53 & 77.65 & 76.14 \\
\hline Other primary metal manufacturing & $3,620.23$ & 149.85 & 132.94 & 130.36 \\
\hline Fabricated metal product manufacturing & $17,220.63$ & 967.51 & 811.00 & 887.03 \\
\hline Machinery manufacturing & $9,722.29$ & 593.68 & 414.70 & 490.08 \\
\hline $\begin{array}{l}\text { Computer and electronic product } \\
\text { manufacturing }\end{array}$ & $44,222.52$ & $2,734.30$ & $2,421.57$ & $2,016.21$ \\
\hline $\begin{array}{l}\text { Electrical equipment, appliance, and } \\
\text { component manufacturing }\end{array}$ & $5,715.18$ & 358.99 & 301.94 & 177.81 \\
\hline $\begin{array}{l}\text { Automobile and light duty motor vehicle } \\
\text { manufacturing }\end{array}$ & $1,280.57$ & 34.56 & 17.32 & 22.83 \\
\hline Ship and boat building and repairing & 110.11 & 5.13 & 37.90 & 4.27 \\
\hline $\begin{array}{l}\text { Other transportation equipment } \\
\text { manufacturing }\end{array}$ & $29,020.87$ & 949.73 & $3,166.80$ & 694.58 \\
\hline Furniture and related product manufacturing & $4,223.61$ & 287.88 & 103.28 & 187.84 \\
\hline Miscellaneous manufacturing & $13,535.31$ & 769.65 & 439.81 & $1,139.50$ \\
\hline Wholesale & $70,405.20$ & & & \\
\hline Retail trade & $67,965.42$ & & & \\
\hline Air transportation & $5,447.77$ & & & \\
\hline Rail transportation & $1,935.02$ & & & \\
\hline Water transportation & $1,691.02$ & & & \\
\hline Truck transportation & $10,576.43$ & & & \\
\hline Transit and ground passenger transport & $1,528.19$ & & & \\
\hline Pipeline transportation & $1,119.28$ & & & \\
\hline $\begin{array}{l}\text { Scenic and sightseeing transportation and } \\
\text { support activities for transportation }\end{array}$ & $7,164.95$ & & & \\
\hline Couriers and messengers & $3,854.49$ & & & \\
\hline Warehousing and storage & $3,959.39$ & & & \\
\hline Information & $107,126.54$ & & & \\
\hline Finance and insurance & $127,450.38$ & & & \\
\hline Real estate and rental and leasing & $184,545.94$ & & & \\
\hline $\begin{array}{l}\text { Professional, scientific, and technical } \\
\text { services }\end{array}$ & $118,419.85$ & & & \\
\hline
\end{tabular}


Table D2. Inventories by stage of fabrication for manufacturing industry in southern California region (in millions of 2010 dollars).-Continued

[Data in second column from Minnesota IMPLAN Group, Inc. (2012). Numbers in the remaining three columns computed by the authors]

\begin{tabular}{lrrrr}
\hline \multicolumn{1}{c}{ Sector } & $\begin{array}{c}\mathbf{2 0 1 0} \text { Annual } \\
\text { sales }\end{array}$ & $\begin{array}{c}\text { Materials } \\
\text { and } \\
\text { supplies }\end{array}$ & $\begin{array}{c}\text { Work-in- } \\
\text { process }\end{array}$ & $\begin{array}{c}\text { Finished } \\
\text { goods }\end{array}$ \\
\hline $\begin{array}{l}\text { Administrative and support and waste } \\
\quad \text { management and remediation services }\end{array}$ & $38,541.13$ & & & \\
Educational services & $14,022.91$ & & & \\
Health care and social assistance & $85,694.17$ & & & \\
Arts, entertainment, and recreation & $25,645.11$ & & & \\
Other amusement and recreation industries & $1,407.32$ & & & \\
$\quad$ including marinas & & & & \\
Accommodation and food services & $6,838.84$ & & & \\
Food services and drinking places & $35,200.46$ & & & \\
Other services (except public & $40,667.72$ & & & \\
$\quad$ administration) & & & & \\
Government and non-NAICS & $103,768.70$ & & & \\
Total & $271,900.35$ & $12,608.67$ & $10,998.50$ & $14,222.90$ \\
\hline
\end{tabular}

Table D3. Availability of raw material inputs computed from materials and supplies inventory for the southern California region (in millions of 2010 dollars).

[Table D3 is provided online only as an Excel spreadsheet at http://pubs.usgs.gov/of/2013/1170/h/]

Table D4. Finished goods held by sector for the southern California region (in millions of 2010 dollars).

[Table D4 is provided online only as an Excel spreadsheet at $h t t p: / / p u b s . u s g s . g o v / o f / 2013 / 1170 / h /]$ 
Table D5. Available inventory in the southern California region (in millions of 2010 dollars).

\begin{tabular}{|c|c|}
\hline Sector & Value \\
\hline Oilseed and grain farming & 0.41 \\
\hline Vegetable and melon farming & 11.46 \\
\hline Fruit and tree nut farming & 29.21 \\
\hline Other crop farming & 53.21 \\
\hline Animal production and aquaculture & 64.90 \\
\hline Forestry and logging & 13.23 \\
\hline Fishing & 1.03 \\
\hline Hunting and trapping & 0.00 \\
\hline Support activities for agriculture and forestry & 0.00 \\
\hline Oil and gas extraction & 416.10 \\
\hline Other nonmetallic mineral mining and quarrying & 3.54 \\
\hline Other mining & 71.54 \\
\hline Electric power generation, transmission, and distribution & 0.00 \\
\hline Natural gas distribution & 455.08 \\
\hline Water, sewage and other systems & 1.54 \\
\hline Nonresidential construction & 0.00 \\
\hline Residential construction & 0.00 \\
\hline Food manufacturing & $1,509.86$ \\
\hline Beverage and tobacco product manufacturing & 393.06 \\
\hline Textile mills and textile product mills & 945.02 \\
\hline Apparel manufacturing & $2,190.44$ \\
\hline Leather and allied product manufacturing & 53.80 \\
\hline Wood product manufacturing & 186.75 \\
\hline Paper manufacturing & 789.98 \\
\hline Printing and related support activities & 264.58 \\
\hline Petroleum refineries & $1,715.41$ \\
\hline Other petroleum and coal products manufacturing & 105.17 \\
\hline Chemical manufacturing & $4,616.41$ \\
\hline Plastics and rubber products manufacturing & $1,206.19$ \\
\hline Nonmetallic mineral product manufacturing & 454.95 \\
\hline Iron and steel mills and steel product manufacturing & 566.26 \\
\hline Other primary metal manufacturing & 748.73 \\
\hline Fabricated metal product manufacturing & $2,279.40$ \\
\hline Machinery manufacturing & 691.09 \\
\hline Computer and electronic product manufacturing & $3,766.17$ \\
\hline Electrical equipment, appliance, and component manufacturing & 406.03 \\
\hline Automobile and light duty motor vehicle manufacturing & 23.07 \\
\hline Ship and boat building and repairing & 4.32 \\
\hline Other transportation equipment manufacturing & $1,178.37$ \\
\hline
\end{tabular}


Table D5. Available inventory in the southern California region (in millions of 2010 dollars).Continued

\begin{tabular}{lr}
\hline \multicolumn{1}{c}{ Sector } & Value \\
\hline Furniture and related product manufacturing & 259.18 \\
Miscellaneous manufacturing & $1,356.08$ \\
Wholesale & 0.00 \\
Retail trade & 0.00 \\
Air transportation & 0.00 \\
Rail transportation & 0.00 \\
Water transportation & 0.00 \\
Truck transportation & 0.00 \\
Transit and ground passenger transport & 0.00 \\
Pipeline transportation & 0.00 \\
Scenic and sightseeing transportation and support activities for transportation & 0.00 \\
Couriers and messengers & 0.00 \\
Warehousing and storage & 0.00 \\
Information & 0.00 \\
Finance and insurance & 0.00 \\
Real estate and rental and leasing & 0.00 \\
Professional, scientific, and technical services & 0.00 \\
Administrative and support and waste management and remediation services & 0.00 \\
Educational services & 0.00 \\
Health care and social assistance & 0.00 \\
Arts, entertainment, and recreation & 0.00 \\
Other amusement and recreation industries including marinas & 0.00 \\
Accommodation and food services & 0.00 \\
Food services and drinking places & 0.00 \\
Other services (except public administration) & 0.00 \\
Government and non-NAICS & 0.00 \\
\hline
\end{tabular}




\section{Appendix E. Production Recapture Factors}

\begin{tabular}{|c|c|c|c|}
\hline Sector & Description & $1-90$ days & $91-180$ days \\
\hline 1 & Oilseed and grain farming & 0.75 & 0.56 \\
\hline 2 & Vegetable and melon farming & 0.75 & 0.56 \\
\hline 3 & Fruit and tree nut farming & 0.75 & 0.56 \\
\hline 4 & Other crop farming & 0.75 & 0.56 \\
\hline 5 & Animal production and aquaculture & 0.75 & 0.56 \\
\hline 6 & Forestry and logging & 0.75 & 0.56 \\
\hline 7 & Fishing & 0.75 & 0.56 \\
\hline 8 & Hunting and trapping & 0.75 & 0.56 \\
\hline 9 & Support activities for agriculture and forestry & 0.75 & 0.56 \\
\hline 10 & Oil and gas extraction & 0.98 & 0.74 \\
\hline 11 & $\begin{array}{l}\text { Other nonmetallic mineral mining and } \\
\text { quarrying }\end{array}$ & 0.98 & 0.74 \\
\hline 12 & Other mining & 0.98 & 0.74 \\
\hline 13 & $\begin{array}{l}\text { Electric power generation, transmission, and } \\
\text { distribution }\end{array}$ & 0.90 & 0.68 \\
\hline 14 & Natural gas distribution & 0.90 & 0.68 \\
\hline 15 & Water, sewage and other systems & 0.90 & 0.68 \\
\hline 16 & Nonresidential construction & 0.95 & 0.71 \\
\hline 17 & Residential construction & 0.95 & 0.71 \\
\hline 18 & Food manufacturing & 0.98 & 0.74 \\
\hline 19 & Beverage and tobacco product manufacturing & 0.98 & 0.74 \\
\hline 20 & Textile mills and textile product mills & 0.98 & 0.74 \\
\hline 21 & Apparel manufacturing & 0.98 & 0.74 \\
\hline 22 & Leather and allied product manufacturing & 0.98 & 0.74 \\
\hline 23 & Wood product manufacturing & 0.98 & 0.74 \\
\hline 24 & Paper manufacturing & 0.98 & 0.74 \\
\hline 25 & Printing and related support activities & 0.98 & 0.74 \\
\hline 26 & Petroleum refineries & 0.98 & 0.74 \\
\hline 27 & $\begin{array}{l}\text { Other petroleum and coal products } \\
\text { manufacturing }\end{array}$ & 0.98 & 0.74 \\
\hline 28 & Chemical manufacturing & 0.98 & 0.74 \\
\hline 29 & Plastics and rubber products manufacturing & 0.98 & 0.74 \\
\hline 30 & Nonmetallic mineral product manufacturing & 0.98 & 0.74 \\
\hline 31 & $\begin{array}{l}\text { Iron and steel mills and steel product } \\
\text { manufacturing }\end{array}$ & 0.98 & 0.74 \\
\hline 32 & Other primary metal manufacturing & 0.98 & 0.74 \\
\hline 33 & Fabricated metal product manufacturing & 0.98 & 0.74 \\
\hline
\end{tabular}




\begin{tabular}{|c|c|c|c|}
\hline Sector & Description & $1-90$ days & $91-180$ days \\
\hline 34 & Machinery manufacturing & 0.98 & 0.74 \\
\hline 35 & $\begin{array}{l}\text { Computer and electronic product } \\
\text { manufacturing }\end{array}$ & 0.98 & 0.74 \\
\hline 36 & $\begin{array}{l}\text { Electrical equipment, appliance, and } \\
\text { component manufacturing }\end{array}$ & 0.98 & 0.74 \\
\hline 37 & $\begin{array}{l}\text { Automobile and light duty motor vehicle } \\
\text { manufacturing }\end{array}$ & 0.98 & 0.74 \\
\hline 38 & Ship and boat building and repairing & 0.98 & 0.74 \\
\hline 39 & Other transportation equipment manufacturing & 0.98 & 0.74 \\
\hline 40 & Furniture and related product manufacturing & 0.98 & 0.74 \\
\hline 41 & Miscellaneous manufacturing & 0.98 & 0.74 \\
\hline 42 & Wholesale & 0.87 & 0.65 \\
\hline 43 & Retail trade & 0.87 & 0.65 \\
\hline 44 & Air transportation & 0.90 & 0.68 \\
\hline 45 & Rail transportation & 0.90 & 0.68 \\
\hline 46 & Water transportation & 0.90 & 0.68 \\
\hline 47 & Truck transportation & 0.90 & 0.68 \\
\hline 48 & Transit and ground passenger transport & 0.90 & 0.68 \\
\hline 49 & Pipeline transportation & 0.90 & 0.68 \\
\hline 50 & $\begin{array}{l}\text { Scenic and sightseeing transportation and } \\
\text { support activities for transportation }\end{array}$ & 0.90 & 0.68 \\
\hline 51 & Couriers and messengers & 0.90 & 0.68 \\
\hline 52 & Warehousing and storage & 0.87 & 0.65 \\
\hline 53 & Information & 0.90 & 0.68 \\
\hline 54 & Finance and insurance & 0.90 & 0.68 \\
\hline 55 & Real estate and rental and leasing & 0.90 & 0.68 \\
\hline 56 & Professional, scientific, and technical services & 0.90 & 0.68 \\
\hline 57 & $\begin{array}{l}\text { Administrative and support and waste } \\
\text { management and remediation services }\end{array}$ & 0.90 & 0.68 \\
\hline 58 & Educational services & 0.60 & 0.45 \\
\hline 59 & Health care and social assistance & 0.60 & 0.45 \\
\hline 60 & Arts, entertainment, and recreation & 0.60 & 0.45 \\
\hline 61 & $\begin{array}{l}\text { Other amusement and recreation industries } \\
\text { including marinas }\end{array}$ & 0.60 & 0.45 \\
\hline 62 & Accommodation & 0.60 & 0.45 \\
\hline 63 & Food services and drinking places & 0.60 & 0.45 \\
\hline 64 & Other services (except public administration) & 0.51 & 0.38 \\
\hline 65 & Government and non-NAICS & 0.80 & 0.60 \\
\hline
\end{tabular}


This page intentionally left blank 


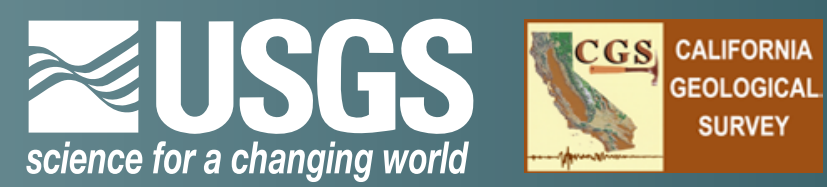

\section{Population Vulnerability and Evacuation Challenges in California for the SAFRR Tsunami Scenario}

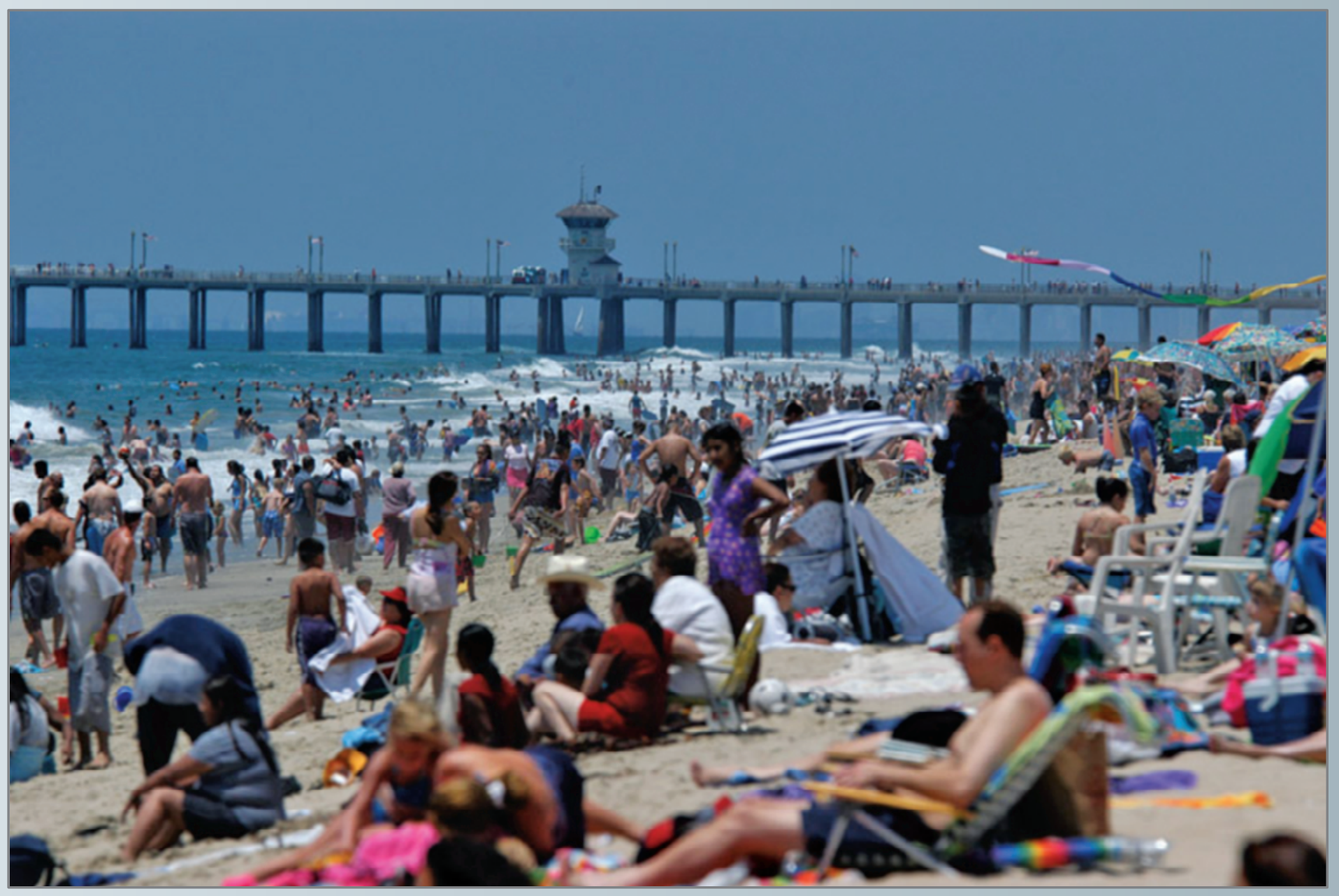

Open-File Report 2013-1170-I

California Geological Survey Special Report 229 
COVER-Photograph of Huntington Beach, California, from the City of Huntington Beach (2012), which states that all of its website content is public information. 
The SAFRR (Science Application for Risk Reduction) Tsunami Scenario

Stephanie Ross and Lucile Jones, Editors

\section{Population Vulnerability and Evacuation Challenges in California for the SAFRR Tsunami Scenario}

By Nathan Wood, Jamie Ratliff, Jeff Peters, and Kimberley Shoaf

Open-File Report 2013-1170-I

California Geological Survey Special Report 229 


\section{U.S. Department of the Interior \\ SALLY JEWELL, Secretary}

\section{U.S. Geological Survey \\ Suzette M. Kimball, Acting Director}

U.S. Geological Survey, Reston, Virginia 2013

For product and ordering information:

World Wide Web: http://www.usgs.gov/pubprod

Telephone: 1-888-ASK-USGS

For more information on the USGS-the Federal source for science about the Earth,

its natural and living resources, natural hazards, and the environment:

World Wide Web: http://www.usgs.gov

Telephone: 1-888-ASK-USGS

Suggested citation:

Wood, N., Ratliff, J., Peters, J., and Shoaf, K., 2013, Population vulnerability and evacuation challenges in California for the SAFRR tsunami scenario, chap. I in Ross, S.L., and Jones, L.M., eds., The SAFRR (Science Application for Risk Reduction) Tsunami Scenario: U.S. Geological Survey Open-File Report 2013-1170, 53 p., http://pubs.usgs.gov/of/2013/1170/i/.

Any use of trade, product, or firm names is for descriptive purposes only and does not imply endorsement by the U.S. Government.

Although this information product, for the most part, is in the public domain, it also may contain copyrighted materials as noted in the text. Permission to reproduce copyrighted items must be secured from the copyright owner. 


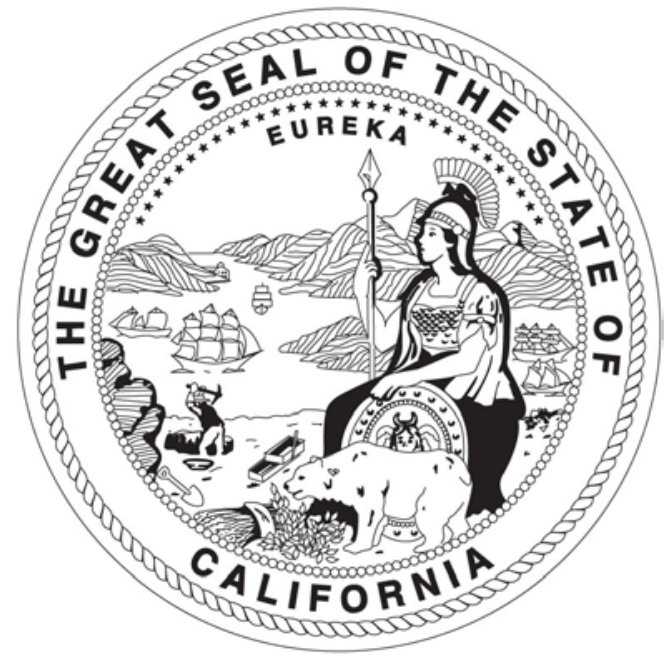

STATE OF CALIFORNIA

EDMUND G. BROWN JR. GOVERNOR

THE NATURAL RESOURCES AGENCY JOHN LAIRD

SECRETARY FOR RESOURCES

\author{
DEPARTMENT OF CONSERVATION \\ MARK NECHODOM \\ DIRECTOR
}

\title{
CALIFORNIA GEOLOGICAL SURVEY JOHN G. PARRISH, Ph.D. \\ STATE GEOLOGIST
}




\section{Contents}

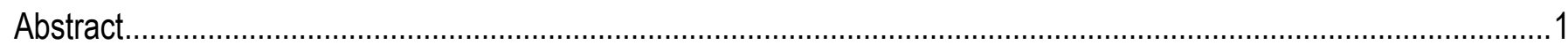

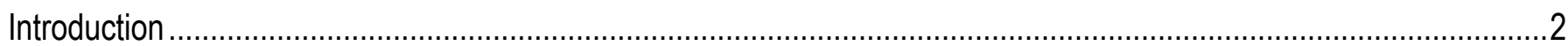

Public-Health Implications of a Distant-Source Tsunami ................................................................................

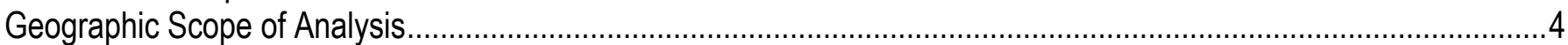

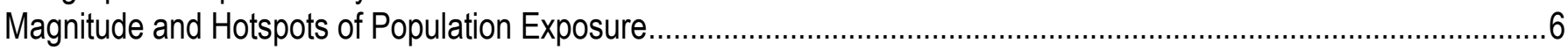

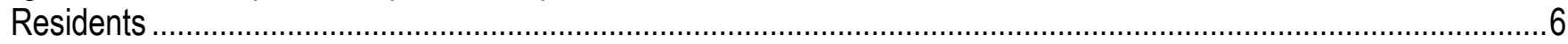

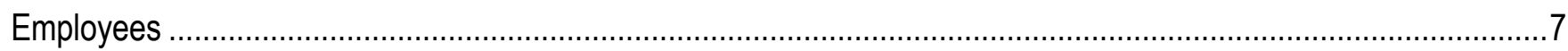

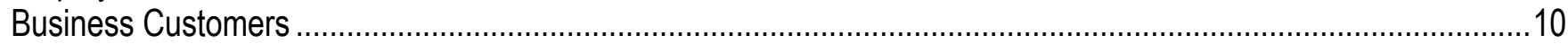

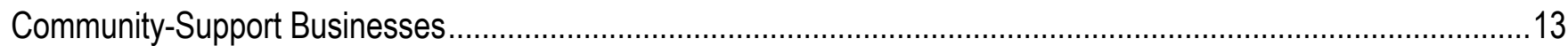

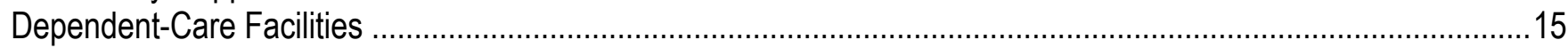

Evacuation Challenges of Healthcare Facilities ....................................................................................17

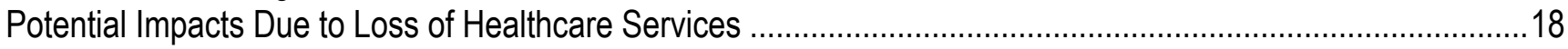

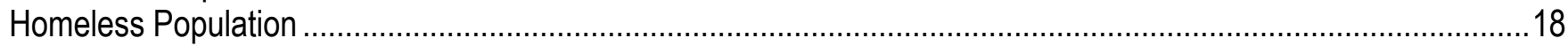

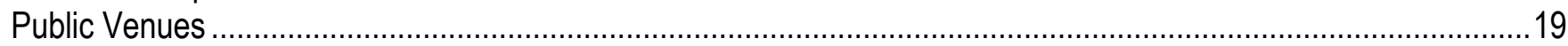

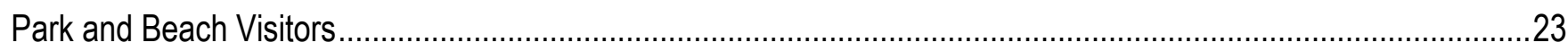

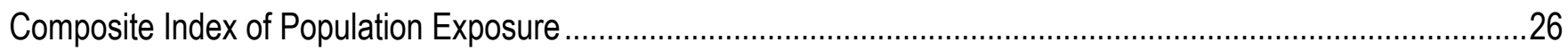

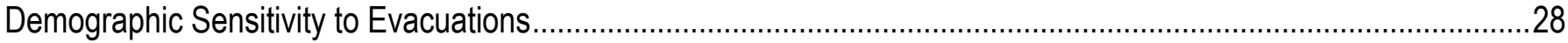

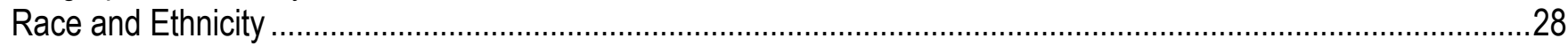

Age

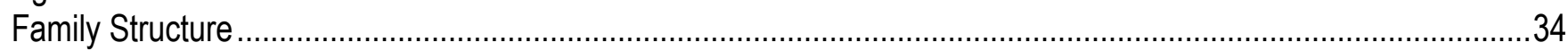

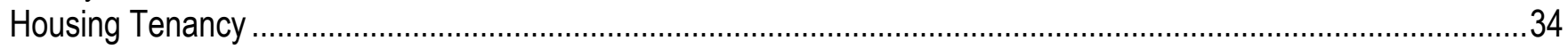

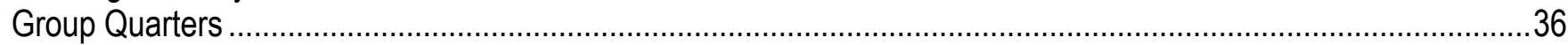

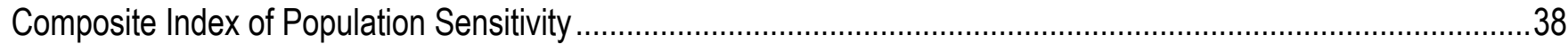

Magnitude and Challenges of Tsunami Evacuations........................................................................................ 41

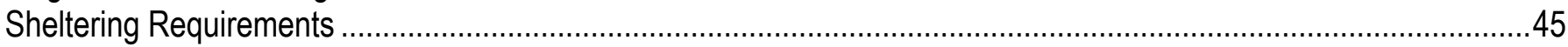

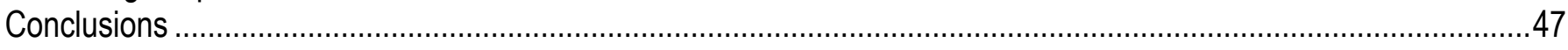

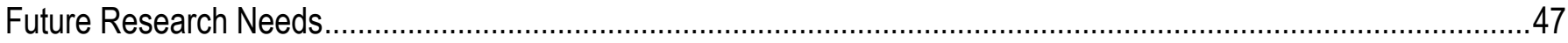

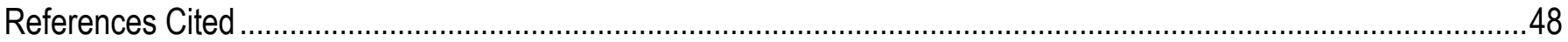

Appendix A. Estimation of Sheltering Needs .............................................................................................

\section{Figures}

1. A, Map of coastline, counties, and incorporated communities with land in the SAFRR scenario tsunamiinundation zone. ..................................................................................................................

2. Plot showing number of residents in the SAFRR tsunami-inundation zone for the California coast. ..........8

3. Plot showing number of employees in the SAFRR tsunami-inundation zone for the California coast. .......9

4. Plot showing percentage of employees, by business sector, in the SAFRR tsunami-inundation zone, California coast................................................................................................................

5. Plot showing percentage of employees at businesses in the SAFRR tsunami-inundation zone, California

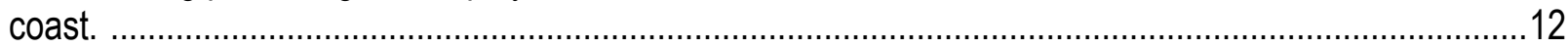

6. Plot showing number of community-support businesses and organizations in the SAFRR tsunamiinundation zone, California coast. ............................................................................................14

7. Plot showing number of dependent-care facilities in the SAFRR tsunami-inundation zone, California

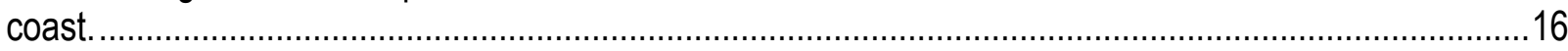

8. Map of estimated number of homeless people in Service Planning Areas (SPA) of Los Angeles county, California. 
9. Plot showing number of public venues in the SAFRR scenario tsunami-inundation zone, California coast.

10. Plot showing estimated daily number of visitors (in thousands) for the SAFRR scenario to coastal California city and county beaches, State parks, and National Park Service locations.

11.

Plot comparing normalized amount indices for incorporated California cities and towns with land in the SAFRR scenario tsunami-inundation zone.

12. Plot showing percentage of residents in the California counties located in the SAFRR tsunamiinundation zone who identify themselves as Hispanic or Latino.

13. Plot showing percentage of residents in the California counties located in the SAFRR tsunamiinundation zone who identify themselves as Asian.

14. Plot showing percentage of residents in the California counties located in the SAFRR tsunamiinundation zone who are more than 65 years old.

15. Plot showing percentage of households in the California counties located in the SAFRR scenario tsunami-inundation zone that are renter occupied.

16. Plot showing percentage of residents in the California counties located in the SAFRR tsunamiinundation zone who are in noninstitutionalized group quarters.

17. Plot comparing normalized demographic-sensitivity indices for incorporated cities and towns for California counties with land in the SAFRR tsunami-inundation zone.

18. Plot showing cumulative number of residents in the SAFRR tsunami scenario and California tsunamiinundation zones.

19. Photograph showing inundation zones for the SAFRR tsunami scenario and the statewide maximum
zone, as well as estimated residential population counts for island communities in Newport Beach,

19. Photograph showing inundation zones for the SAFRR tsunami scenario and the statewide maximum
zone, as well as estimated residential population counts for island communities in Newport Beach, California.

20. Plot showing number of residents listed by California counties and cities estimated to use public shelters in the SAFRR tsunami scenario.

\section{Tables}

1. Relative modification factors used to estimate sheltering needs 


\title{
Population Vulnerability and Evacuation Challenges in California for the SAFRR Tsunami Scenario
}

\author{
By Nathan Wood ${ }^{1}$, Jamie Ratliff', Jeff Peters ${ }^{1}$, and Kimberley Shoaf²
}

\begin{abstract}
The SAFRR tsunami scenario models the impacts of a hypothetical yet plausible tsunami associated with a magnitude 9.1 megathrust earthquake east of the Alaska Peninsula. This report summarizes community variations in population vulnerability and potential evacuation challenges to the tsunami. The most significant public-health concern for California coastal communities during a distant-source tsunami is the ability to evacuate people out of potential inundation zones. Fatalities from the SAFRR tsunami scenario could be low if emergency managers can implement an effective evacuation in the time between tsunami generation and arrival, as well as keep people from entering tsunami-prone areas until all-clear messages can be delivered. This will be challenging given the estimated 91,956 residents, 81,277 employees, as well as numerous public venues, dependent-population facilities, community-support businesses, and high-volume beaches that are in the 79 incorporated communities and 17 counties that have land in the scenario tsunamiinundation zone.

Although all coastal communities face some level of threat from this scenario, the highest concentrations of people in the scenario tsunami-inundation zone are in Long Beach, San Diego, Newport Beach, Huntington Beach, and San Francisco. Communities also vary in the prevalent categories of populations that are in scenario tsunami-inundation zones, such as residents in Long Beach, employees in San Francisco, tourists at public venues in Santa Cruz, and beach or park visitors in unincorporated Los Angeles County. Certain communities have higher percentages of groups that may need targeted outreach and preparedness training, such as renters, the very young and very old, and individuals with limited English-language skills or no English-language skills at all. Sustained education and targeted evacuation messaging is also important at several highoccupancy public venues in the scenario tsunami-inundation zone (for example, city and county beaches, State or national parks, and amusement parks). Evacuations will be challenging, particularly for certain dependent-care populations, such as patients at hospitals and children at schools and daycare centers. We estimate that approximately 8,678 of the 91,956 residents in the scenario inundation zone are likely to need publicly provided shelters in the short term. Information presented in this report could be used to support emergency managers in their efforts to identify where additional preparedness and outreach activities may be needed to manage risks associated with California tsunamis.
\end{abstract}

\footnotetext{
${ }^{1}$ U.S. Geological Survey

${ }^{2}$ Center for Public Health and Disasters, Fielding School of Public Health, University of California, Los Angeles
} 


\section{Introduction}

The California coast is a prime location for residents, recreational opportunities, tourismrelated businesses, and other commerce. In the event of a large tsunami, thousands of individuals will need to evacuate low-lying areas along the California coast and remain out of harm's way until public officials believe it is safe to return. For the SAFRR (Science Application for Risk Reduction) scenario tsunami associated with a magnitude 9.1 megathrust earthquake east of the Alaska Peninsula, California emergency managers and public-safety officials will have several hours between tsunami wave generation and arrival to initiate and coordinate evacuations. The hypothetical tsunami-producing earthquake is designed to occur at 11:57 AM PDT on Thursday 27 March 2014, which is 50 years after the $1964 \mathrm{M}_{\mathrm{w}} 9.2$ Good Friday earthquake and tsunami that occurred in the Prince William Sound region of Alaska (U.S. Geological Survey, 2012). Tsunami wave travel times to California after the initial earthquake are estimated to range from 4 hours in northern California to almost 6 hours in southern California. This timing means that the tsunami warnings and wave arrivals would occur during a workday afternoon (Ross and others, 2013).

Although 4-6 hours may seem to be sufficient time to evacuate potential tsunamiinundation zones, there have been deaths in California from previous distant tsunamis (for example, 1946, 1960, 1964, and 2011). Evacuations will be challenging given the scale of the evacuation along the entire California coast, the size and dispersed nature of the populations in inundation zones, and the unique needs of the varied populations. Evacuation messages will need to be delivered repeatedly by multiple actors over multiple channels to a highly diverse audience with varying levels of tsunami-risk knowledge, such as residents, employees at a range of business types, patrons of local stores, tourists at public venues and beaches, and individuals at dependentcare facilities. Although consistent evacuation messages may be delivered, comprehension of the message and actions taken by at-risk individuals will vary because of language or cultural barriers, differences in risk tolerances, inconsistent understanding of what actions to take, and evacuation limitations due to personal mobility and timing (National Research Council, 2010).

The immediate concern of emergency managers will be the safety of the at-risk population over the duration of the tsunami waves. The first tsunami wave of this scenario may garner the most attention, but subsequent waves may be just as threatening, or more so depending on local conditions. The one death in California that resulted from the 2011 Tohoku earthquake and tsunami occurred after the first tsunami waves had come and gone (Barnard, 2011). In addition to concerns about survival and staying safe, the quality of life of individuals may be impacted by tsunamis. Closed beaches and shorefront businesses reduce recreational opportunities and revenue. Closed roads increase commuting times. Closed dependent-care facilities, such as schools and hospitals, directly impact children or patients and affect others who would need to become caregivers, such as the parents who cannot go back to work because their child's daycare center is closed.

To better understand the range of evacuation challenges that may arise from a tsunami associated with the SAFRR scenario earthquake east of the Alaska Peninsula, we assessed the geographic variations in exposure for populations in the scenario inundation zone. We focus on three questions:

- How many people may need to evacuate, and which communities have the highest numbers of people in the tsunami-inundation zone?

- Which individuals and population groups may have greater difficulty in preparing for and responding to a tsunami?

- How many people may need to use public shelters after the tsunami? 
We focus on determining the number and types of various population groups in the SAFRR scenario tsunami-inundation zone, including residents, employees, visitors at public venues, dependent-care populations, business customers, and beach visitors. We also compare communities based on their at-risk populations and potential sheltering needs. Subsequent sections include an overview of potential public-health issues related to tsunamis, the geographic scope for our analysis, and results that address our three questions.

\section{Public-Health Implications of a Distant-Source Tsunami}

The potential loss of life from this scenario tsunami is low in California given the estimated amount of time before waves arrive, but it is possible if individuals choose not to evacuate hazardous areas, do not understand tsunami warnings, are unable to evacuate for various reasons, or are indirectly impacted owing to the loss of healthcare services. Direct impacts to individuals include injuries and illnesses that result from contact with tsunami waves, such as drowning and/or trauma from being struck by debris in the tsunami flow. Indirect impacts include secondary infections resulting from injuries or from living conditions following the disasters, such as an increase in pneumonia from water aspiration, as well as cellulitis from exposure of breaks in the skin to contaminated water (Doocy and others, 2009; Nagamatsu and others, 2011). Other indirect impacts to individuals include emotional and psychological effects, such as anxiety, depression, or other psychological pathologies (Shoaf and Rottman, 2000). In addition, any disruption to the healthcare system will impact an individual's health by introducing complications to preexisting conditions (Shoaf and Rottman, 2000; Nagamatsu and others, 2011). Healthcare-service disruptions can result from direct damage to facilities, flooding that shuts down certain floors of facilities, or loss of the surrounding lifelines, such as power and water.

Coastal communities will have approximately 4 hours in northern California and almost 6 hours in southern California after initial ground shaking begins in Alaska to evaluate the situation and evacuate tsunami-prone areas for the SAFRR tsunami scenario. Based on past distant tsunamis that have struck California, this may be sufficient time to evacuate most people in low-lying areas. The SAFRR distant-source tsunami scenario involves larger waves than those that have been recorded for historical tsunamis. Future evacuation success will be determined by the efficiency of the warning-message communication network, the effectiveness of emergency decisionmaking at the local level, and the ability of local public-safety officials to effectively engage the public to evacuate. However, even with well-executed evacuations, loss of life is possible and has happened during distant tsunamis in the following situations:

- Individuals in remote areas fail to evacuate because they do not receive warning messages, such as the drowning of a family camping on an Oregon beach during the 1964 Good Friday tsunami.

- Individuals return prematurely to hazardous areas because they do not realize there are multiple waves, such as the drowning in California near the Klamath River during the 2011 Tohoku tsunami and several deaths in Crescent City, Calif., during the 1964 Good Friday tsunami.

- Individuals are struck by falling equipment while trying to secure boats or other assets, which happened to one man in Morro Bay, Calif., during the 1960 Chilean tsunami and to another man in the Port of Los Angeles, Calif., during the 1964 Good Friday tsunami.

- Individuals have limited mobility, such as the drowning of an elderly man in Santa Cruz, Calif., who was unable to move quickly to high ground during the 1946 Aleutian tsunami. 
- Individuals with preexisting health complications become overly stressed, such as one woman who died of a heart attack in Seaside, Ore., after waves associated with the 1964 Good Friday tsunami struck her home (all examples from Lander and others, 1993).

Additional evacuation challenges will exist for those considered to be "at-risk populations," which are defined as individuals who may have additional functional needs related to communication, medical care, maintaining independence, supervision, or transportation. These functional needs may make it more difficult to evacuate the inundation zone in a timely manner. At-risk populations include children, senior citizens, and pregnant women, as well as individuals who have disabilities, live in institutional settings, are from diverse cultures, have limited English proficiency, lack transportation options, have chronic medical disorders, or have pharmacological dependencies. These populations will warrant additional evacuation time and unique response and relief procedures (U.S. Department of Health and Human Services, 2012).

\section{Geographic Scope of Analysis}

This analysis focuses on comparing population vulnerability to the scenario tsunami among the 77 incorporated cities, 2 incorporated towns, and 17 California counties that intersect the scenario tsunami-inundation zone (fig. 1) as discussed by the SAFRR Tsunami Modeling Working Group in this report. Incorporated cities and counties are delineated by 2010 census place boundaries (U.S. Census Bureau, 2010). The coastal counties also contain 52 unincorporated communities, as delineated by census-designated place boundaries, which intersect the scenario tsunami-inundation zone. Because emergency services in these areas are provided by county offices, results for these places and for other county land not in incorporated cities are aggregated and reported as "remaining land" for a given county.

The scenario tsunami-inundation mapping was limited to the significant population and economic centers along the California coast and does not represent potential inundation along the entire coastline, as was also the case with the statewide maximum tsunami-inundation zone summarized by Wilson and others (2008) and Barberopoulou and others (2009). Percentages related to remaining county lands in the scenario tsunami-inundation zone might have been larger if the whole coast was mapped; however, we believe this difference is not substantial based on a visual inspection of the scenario-inundation zone and satellite imagery of the California coast. Unmapped areas are primarily places with low populations owing to their ruggedness or remoteness. Differences in estimated amounts and percentages in each jurisdiction and the remaining unincorporated county land for the area mapped in the SAFRR tsunami scenario versus the entire California coastline are likely less than 1 percent. 


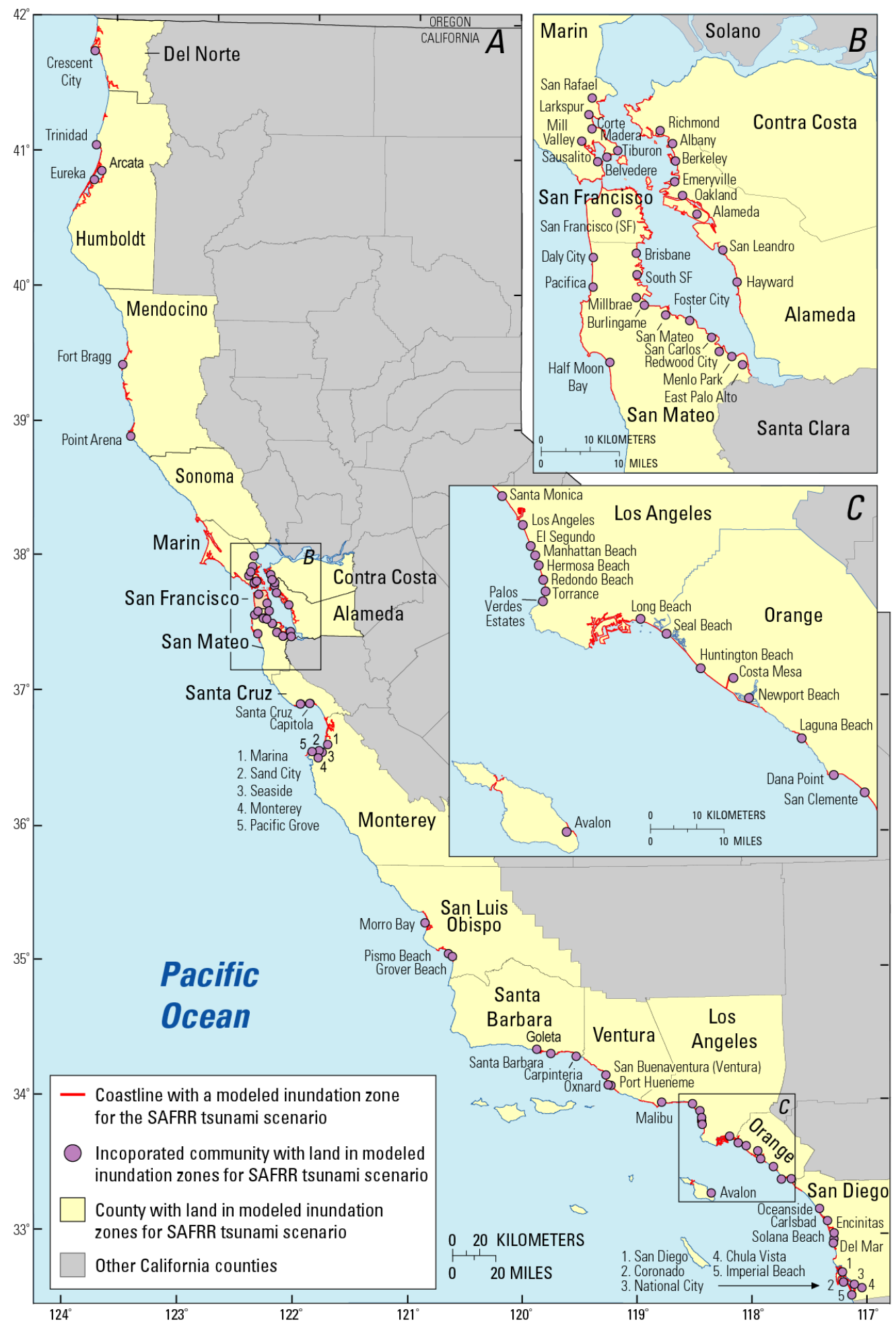

Figure 1. A, Map of coastline, counties, and incorporated communities with land in the SAFRR scenario tsunami-inundation zone. B, Enlargement of the San Francisco Bay area. C, Enlargement of Los Angeles and Orange counties. Geospatial boundaries for maps acquired from Cal-Atlas Geospatial Clearinghouse (2013). Scenario tsunami-inundation zone courtesy of the California Geological Survey. 
This analysis is based on the presence of populations and businesses in the scenario tsunami-inundation zone using various datasets and is tallied using geographic information system (GIS) tools. Results are not engineering-based loss estimates for any particular facility. Instead, the analysis focused on determining if geospatial points (for example, businesses) or polygons (for example, census blocks) are inside the inundation zone. If population polygons overlapped hazard polygons, final population values were adjusted proportionately by using the spatial ratio of each sliver within the tsunami-inundation zone. Third-quartile values are identified throughout this report to more easily identify communities that are in the top 25 percent of any one category. Inventories cannot be considered mortality estimates because aspects of individual perceptions and preparedness levels before a tsunami, and the adaptive capacity of individuals during a response, are excluded from this analysis (Turner and others, 2003). Potential mortality would only match reported inventories if all at-risk individuals were unaware of tsunami risks and what to do after being warned of an imminent threat, and if they failed to take protective measures to evacuate. This assumption is unrealistic, given the current level of tsunami-awareness efforts in California (California Emergency Management Agency, 2012) and recent distant-tsunami experiences in 2010 and 2011. Exposure counts for the various population groups also should not be combined because of the likelihood of overlap; for example, the young resident who attends daycare also may be a customer at a local store and a visitor of a local beach. This analysis is intended to help emergency managers understand where evacuations may be most challenging along the California coast and where evacuation messages and approaches may need to be tailored to address local needs.

\section{Magnitude and Hotspots of Population Exposure}

\section{Residents}

The scenario tsunami-inundation zone is home to an estimated 91,956 residents in 40,120 households, each total representing less than 1 percent of the residents and households in the 17 counties. This estimate is based on an overlay of geospatial data representing the scenario tsunamiinundation zone, community boundaries, and block-level population counts compiled for the 2010 census (U.S. Census Bureau, 2012). The number of residents in the tsunami-inundation zone varies greatly across the 17 counties (fig. 2). The cities of Long Beach and San Diego have the greatest number of residents in the tsunami-inundation zone (12,933 and 12,751 residents, respectively). There are 14 communities and unincorporated land in four counties that each have more than 1,000 residents in the scenario tsunami-inundation zone. For most communities, the scenario inundation area directly affects less than 10 percent of the residential population; however larger percentages exist in the cities of Belvedere, Del Mar, and Coronado (40, 15, and 11 percent, respectively). Eleven percent of the at-risk residents live in unincorporated areas, indicating a need for education and preparedness planning in less developed areas.

One residential group of particular concern in this scenario estimate is made up of residents living on boats in the various marinas. It is highly likely that these vessels would be damaged, representing life-safety issues during the tsunami and sheltering needs after the event. Many vessels used as residences may not be seaworthy. Live-aboard residents who can go offshore to protect themselves and their boats during a tsunami may have insufficient food, water, and fuel to use while they wait for all-clear messages to return to shore; therefore, relief efforts will be needed to care for these individuals. 


\section{Employees}

Employees present an evacuation challenge because they may be unaware of tsunami hazards or proper evacuation strategies, especially if they do not live in tsunami-inundation zones. They also may rely on business owners for information if they lack social connections to the community. The scenario tsunami-inundation zone contains an estimated 81,277 employees at 7,343 businesses in the 17 counties. This is based on an overlay of the tsunami-inundation zone and the 2011 Infogroup Employer Database (Infogroup, 2011). Our counts serve as approximations because we were unable to field-verify locations for each of the 1,001,413 businesses from the Infogroup Employer Database used in our 17-county study area. Visual interpretation of imagery, including Google Maps and 1-meter 2010 National Agriculture Imagery Program imagery (CalAtlas Geospatial Clearinghouse, 2013), was used to verify and correct business locations in the tsunami-inundation zone.

The greatest numbers of employees working within the scenario tsunami-inundation zone are in the cities of Long Beach $(11,127)$, San Francisco $(9,176)$, Newport Beach $(7,967)$, and San Diego $(6,726)$, reflecting the active ports and (or) waterfront tourism in each city (fig. 3). For most communities, the scenario inundation area directly affects less than 20 percent of the employee population. Exceptions include Belvedere (77 percent), Sausalito (56 percent), Tiburon (41 percent), and Crescent City (33 percent), where much larger percentages of the local workforce will need to evacuate.

The number of estimated employees in the scenario-inundation zone is likely to be low in the larger ports because of the dynamic nature and magnitude of employees that are associated with multiple port-related companies. For example, our economic data identifies each business location as a point (typically the primary mailbox), but employees at a port-related business could be distributed across a large area within a port complex. In addition, foreign or domestic ships may be docked in the ports during the tsunami, but onboard crew members are not accounted for in this analysis of employee exposure. 


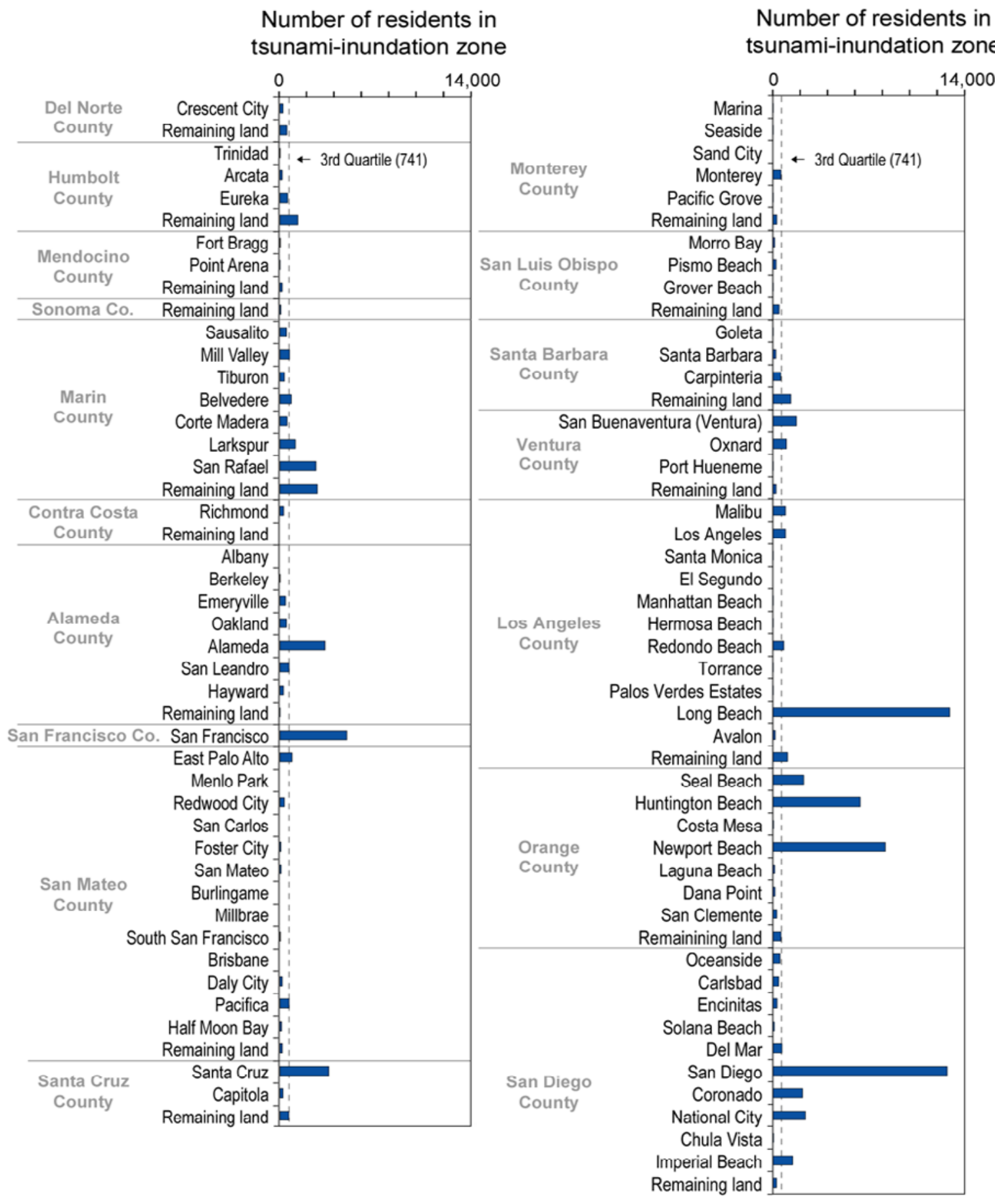

Figure 2. Plot showing number of residents in the SAFRR tsunami-inundation zone for the California coast. Co., county. 
Number of employees in tsunami-inundation zone

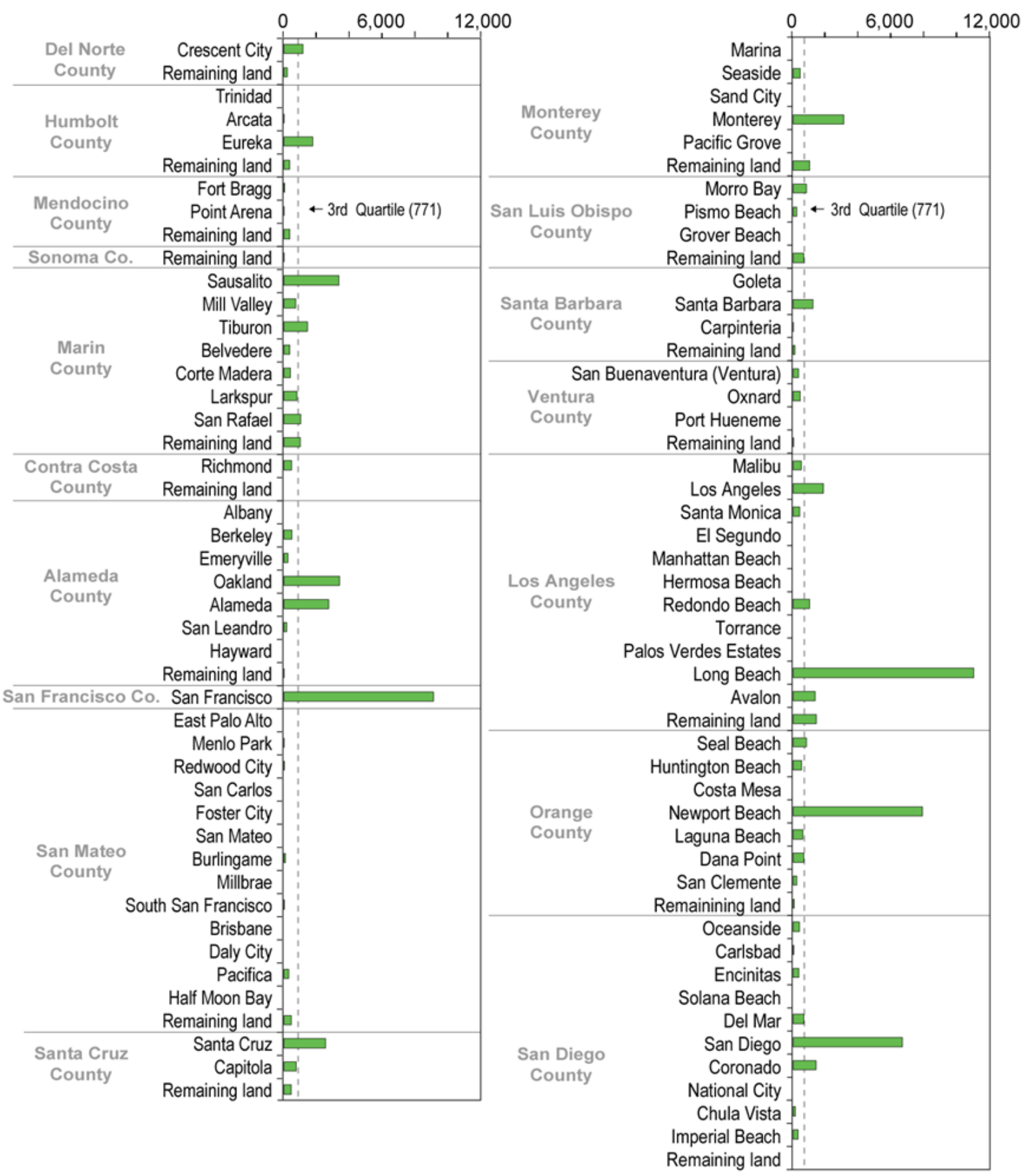

Number of employees in tsunami-inundation zone

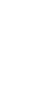




\section{Business Customers}

The primary business sectors in the scenario tsunami-inundation zone along the California coast are accommodation and food services ( 32 percent) and retail trade (12 percent), suggesting that a high number of customers also will need to evacuate (fig. 4). This analysis is based on the number of employees associated with North American Industry Classification System (NAICS) codes for businesses in the 2011 Infogroup Employer Database (see appendix A of Wood, 2007, for a listing of the codes; Infogroup, 2011). The number of employees associated with each business is considered a better indicator of business sectors and market trends than the number of businesses (Bureau of Labor Statistics, 2010).

To identify community hotspots for business customers or visitors, we subjectively grouped the multiple NAICS classes based on customer potential. We considered businesses with high onsite customer potential to include NAICS classes for accommodation and food services; arts, entertainment and recreation; educational services; healthcare and social assistance; and retail trade. We consider businesses with low onsite customer potential to include NAICS classes for administrative support and waste management; agriculture, forestry, fishing, and hunting; construction; finance and insurance; information; management of companies; manufacturing; mining; professional, scientific, and technical services; public administration; real-estate rental and leasing; transportation and warehousing utilities; wholesale trade and other, nonclassified businesses.

The majority of employees (67 percent) across the entire study area work for businesses that we think have a high customer potential (represented by the dotted line in figure 5). The stacked bar graphs in figure 5 reflect only the relative percentage of employees among the two business groups and not the absolute number of employees in the various groups. The lack of a stacked bar graph for a community (for example, Trinidad, Albany, and Torrance) indicates that there are no employees, according to our regional economic data, in the scenario tsunami-inundation zone of these communities.

Several communities, such as San Francisco and Corte Madera, have percentages similar to the statewide trend (fig. 5). In other communities, onsite customer potential at businesses in the tsunami-inundation zone is higher. For example, we estimate that all businesses in the tsunamiinundation zones of Point Arena, Burlingame, Seaside, Santa Monica, Laguna Beach, and Carlsbad have a high customer potential. In communities where at-risk businesses have a high customer potential, tsunami evacuations may be more difficult because evacuees may be unaware of the tsunami threat and unaware of what to do in the event of a tsunami. Successful tsunami-outreach efforts before an event and evacuations during an event will require emergency managers to collaborate with the private sector to reach visitor and tourist populations. This is especially important if emergency managers are to reach tourists, who traditionally are difficult to engage in long-term education, at beaches near waterfront businesses.

Although not as frequent, there are communities where the majority of the employees in the tsunami-inundation zone are at businesses have low onsite customer potential, including Fort Bragg, Menlo Park, and the unincorporated areas of Humboldt and Alameda Counties (fig. 5). In these types of communities, pre-event outreach and evacuation messaging to employees could leverage local knowledge and could be delivered through business meetings, neighborhood associations, and community fairs. If at-risk businesses are industrial, further discussions could help determine if employee evacuations would be hindered by the presence of hazardous materials, heavy machinery, seasonal equipment (for example, crab pots in a harbor), or other materials (for example, timber). 
Percentage of employees, by sector, in tsunami-inundation zone $\begin{array}{lllll}0 \% & 10 \% & 20 \% & 30 \% & 40 \%\end{array}$ Agriculture, forestry, fishing, and hunting

Mining
Utilities
Construction
Manufacturing
Wholesale trade
Retail trade

Transportation and warehousing Information Finance and insurance Real estate and rental and leasing Professional, scientific, and technical services Management of companies and enterprises Administrative and support and waste management Educational services

Health care and social assistance Arts, entertainment, and recreation Accommodation and food services Other services (except public administrationion) Public administration Unnamed

Figure 4. Plot showing percentage of employees, by business sector, in the SAFRR tsunami-inundation zone, California coast. 


\section{Percentage of employees in tsunami-inundation zone}

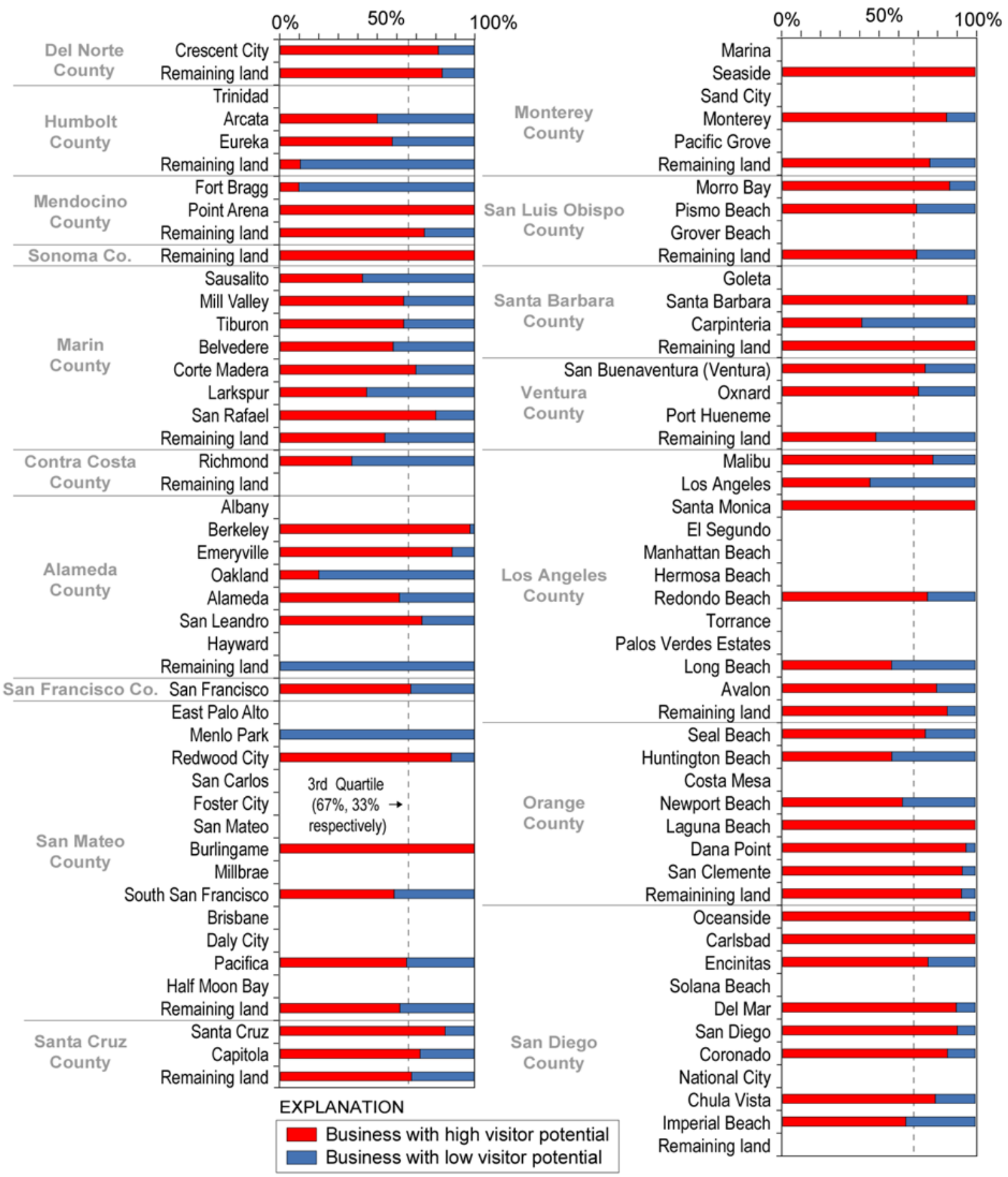

Percentage of employees in tsunami-inundation zone

$100 \%$ 


\section{Community-Support Businesses}

To provide further insight into the number of people in the scenario inundation zone, we used NAICS codes in the 2011 Infogroup Employer Database to identify certain types of businesses with customers or visitors, specifically community-support businesses, dependent-care facilities, and public venues. The high number of businesses and the dynamic nature of populations at these locations preclude our ability to determine exact visitor counts at each business; therefore, discussions of these locations are limited to the number of venues and facilities. The first category — community support—includes businesses that attract significant populations throughout a workday because they provide basic necessities, primarily to residents (although visitors may use them also). These community-support businesses include

- Banks or credit unions;

- Civil or social organizations, including social clubs, after-school programs, and lodges;

- Retail, including grocery stores, wholesale warehouse stores, and home-improvement stores;

- Government offices, including Federal, State, and local government offices, police and fire departments, courts and legal offices, and international-affairs offices;

- Libraries, including city, Federal, institutional, public, and State libraries;

- Mailing and shipping services, including U.S. Post Offices and commercial shipping facilities; and

- Religious organizations, including churches, church organizations, mosques, mediation organizations, clergy, convents and monasteries, retreat houses, spiritualists, synagogues, and places of worship (nontheistic).

There are many businesses that primarily provide community support in the tsunamiinundation zone, including 81 civil or social organizations, 34 religious organizations, 11 libraries, 139 government offices, 29 banks and credit unions, and 2,706 retail businesses (fig. 6). The greatest numbers of community-support businesses in the tsunami-inundation zone are in the cities of Newport Beach, Long Beach, San Diego, San Francisco, Sausalito, and Monterey. The majority of community-support businesses in the tsunami-inundation zone are retail businesses.

As discussed earlier in this report, tsunami warnings for this scenario will likely come during the workday, with first waves arriving approximately 4 hours later. Because many people are at community-support businesses or organizations during the workday, they will likely receive warning information while at these locations. This may complicate evacuations because customers may be aware of tsunami threats only from the perspective of their homes and, therefore, are not fully aware of evacuation procedures, or even tsunami potential, when they are out running errands or attending a religious service. Pre-event education of business owners on how to coordinate evacuations out of their stores to high ground will be important for minimizing any potential confusion during an evacuation. 
Number of community-support businesses in the tsunami-inundation zone

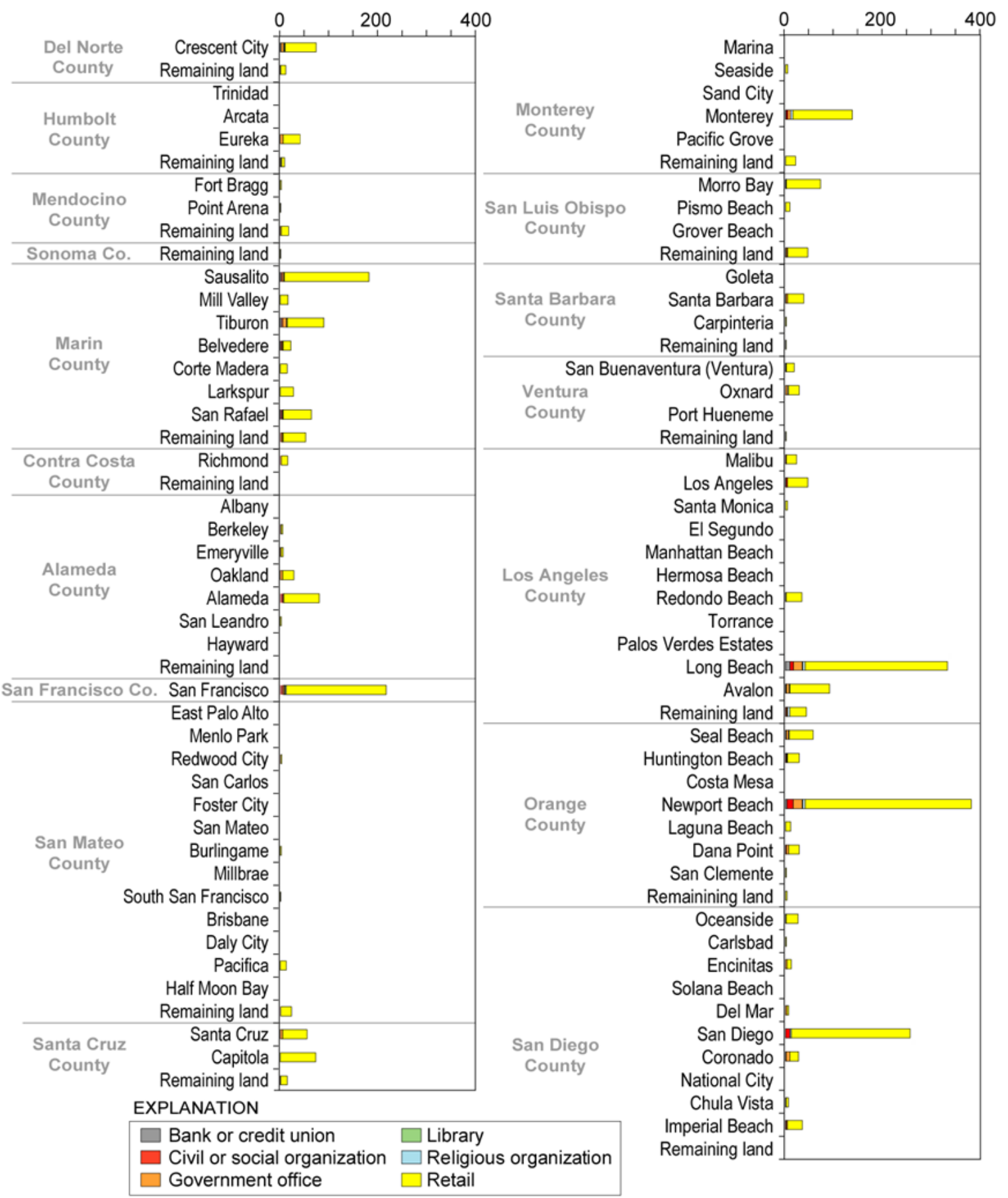

Figure 6. Plot showing number of community-support businesses and organizations in the SAFRR tsunamiinundation zone, California Coast. Co., county. 


\section{Dependent-Care Facilities}

Dependent-care facilities contain individuals who would require assistance to evacuate and include

- Medical centers, including hospitals, psychiatric and substance-abuse hospitals, mental-health services and psychiatric treatment facilities, and clinics;

- Eldercare services, including adult-care facilities, hospices, nursing homes, rest homes, retirement communities, adult homes, senior citizens' services, residential care homes, and adult daycare centers;

- Child services, including group homes, foster care, childcare centers, preschools and nursery schools (both public and private), and after-school recreational facilities;

- Schools, including religious schools, public and private schools, schools with special academics, and home-schooling centers;

- Correctional institutions, including State and Federal facilities; and

- Medical and health services, including offices for general practitioners, pediatricians, obstetricians and gynecologists, chiropractors, and acupuncturists.

A substantial number of dependent-population facilities are in the tsunami-inundation zone, including 29 schools and education-related facilities, 30 child-service facilities, 7 eldercare facilities, 415 offices of physicians or other medical personnel, and 17 medical centers (fig. 7). Most of the dependent-population facilities in the tsunami-inundation zone are in the city of Long Beach, the majority of which are medical- and health-service providers. Other communities with numerous dependent-care facilities in the tsunami-inundation zone include Mill Valley, Sausalito, and Newport Beach (with the primary type of facility providing medical and health services in each community). The majority of schools or school-related educational facilities in the tsunamiinundation zone are in Marin County (14 of the 29 education facilities in the inundation zone). The majority of medical centers in the tsunami-inundation zone are in Marin and Orange Counties (6 and 5 facilities, respectively).

Additional evacuation planning may be required in communities with large numbers of dependent-population facilities because of the limited mobility of certain groups at these facilities, such as those in schools and nursing homes. Parents may attempt to enter tsunami-prone areas to retrieve children from schools and daycare centers or adult children may attempt to enter tsunamiprone areas to retrieve their parents from eldercare facilities, and both situations present additional evacuation issues for facility managers. In addition to unique evacuation and relief issues, many dependent-population facilities represent critical social services that, if lost, could slow community recovery following an extreme event. For example, the loss of daycare centers could keep parents at home, thereby slowing business recovery. 
Number of dependant-care facilities in the tsunami-inundation zone

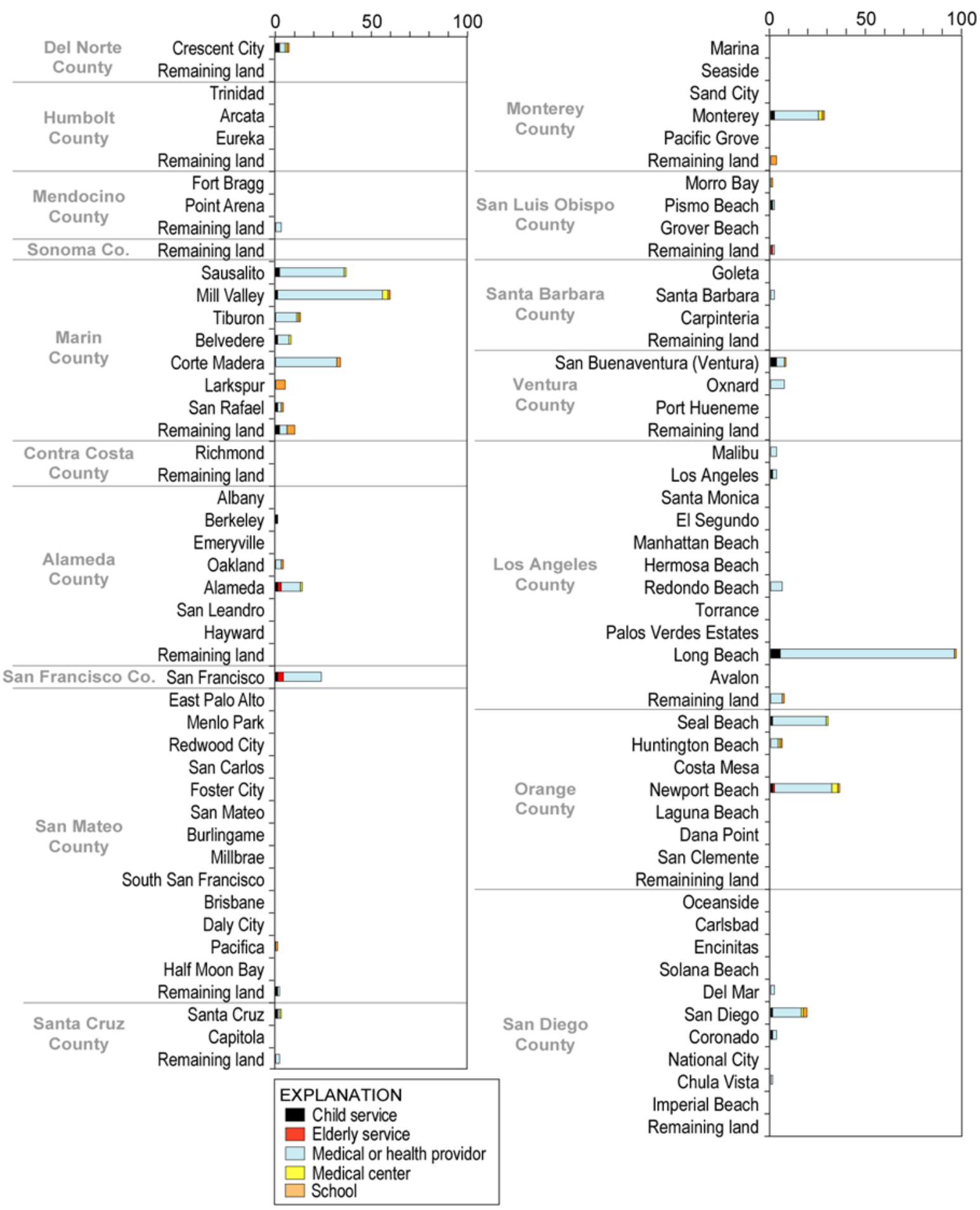
in the tsunami-inundation zone

Number of dependant-care facilities 


\section{Evacuation Challenges of Healthcare Facilities}

Hospitals in the tsunami-inundation zone may have difficulty evacuating some patients in the 4-6 hour window before wave arrival. Emergency evacuations out of unsafe buildings to nearby open areas have been completed in 30-90 minutes, but this has been in situations where imminent danger to patients is greater than that faced by moving them (for example, fires). However, a well-coordinated evacuation that removes patients from unsafe conditions to a new hospital can take $6-8$ hours or more.

Several recent evacuations illustrate the difference between simply evacuating the building and getting patients appropriate care elsewhere. Following the Northridge earthquake, one hospital felt that their patient population was in immediate danger from the building damage, and they evacuated 334 patients, including intensive-care patients, out of the building to an open area outside of the hospital in 2 hours (Schultz and others, 2003). Comprehensive evacuations that included moving patients to new facilities took between 9 and 19 hours to complete for the 6 hospitals that completely evacuated their facilities following the same earthquake (Schultz and others, 2003). Similar evacuations took place during Tropical Storm Allison in 2001, when the Texas Medical Center evacuated a great number of patients quickly out of the building, but then took more than 12 hours to transport them to definitive-care facilities (Parson, 2002). With a great deal of planning and coordination, the University of California, Los Angeles, Medical Center transferred 350 patients from an old building to a new facility across the street in 8 hours. This was accomplished by not admitting any new elective patients either the day before or the day of the transfer and by having a full staff at both facilities to maintain levels of care, ensure full functionality at both facilities, and provide additional transport staff (Groves, 2008). During Hurricane Charley in 2004, evacuating 120 patients from a Florida hospital to another facility took more than 6 hours and took more than a day at another facility to move 10 patients (Kuba and others, 2004).

The time needed to complete an evacuation is highly dependent on the level of coordination, the availability of appropriate transportation, and the availability of qualified personnel for transferring patients. Coordination during evacuations is critical to ensure that no single facility is overloaded with transfer patients, as well as for centralized tracking of patients so that family members can find them following the event. Transportation options may include buses or vans for those who are ambulatory, wheelchair-adaptable vans for some patients, and ambulances with basic or advanced life-support capacities for critical or intensive-care patients. Without the proper level of onboard medical support, a patient's health is jeopardized. For example, 4 ventilator-dependent patients died during hospital evacuations during Tropical Storm Allison, and 2 additional patients died within 24 hours (Rother, 2001). In addition, some patients may not be able to be moved immediately, such as patients undergoing dialysis (typically a 3-5 hour procedure) or undergoing surgery, either in a hospital or outpatient surgical center.

Staffing during evacuations is a significant challenge because many patients cannot simply walk out of a building to safe areas. This is an issue at hospitals where staff-to-patient ratios are not equal. It is also an issue at assisted-living facilities and senior citizen complexes where residents have fewer health needs than those in hospitals, but facilities have fewer full-time staff onsite at any one time. Nursing-facility residents are also at risk of not being able to evacuate in a timely manner because, although skilled nursing facilities are required to have an evacuation plan by regulation, many nursing facilities have not exercised those plans (Kuba and others, 2004). It is highly probable that most California nursing facilities have not contemplated a tsunami evacuation, and that the most likely scenario envisioned is a fire. 


\section{Potential Impacts Due to Loss of Healthcare Services}

The impact of the tsunami on the healthcare and community infrastructure also can have a significant effect on the health of the population. Healthcare services that are in the tsunamiinundation zone will not be available to provide health services to the population for a significant period of time following the event. Following Tropical Storm Allison, the University of Texas Medical Center had power restored in less than 3 weeks, but the facility was not fully functional for more than 6 weeks (Parson, 2002). The potential loss of hospitals, doctors' offices, clinics, and dialysis centers can have a significant impact on the accessibility of healthcare services for the entire region. Although the tsunami-inundation zone is a small percentage of the region, the California healthcare system functions at full capacity practically every day; therefore, any reduction of capacity can have an impact on the entire system.

Health services also are a personal matter, and many people may forgo care until their preferred provider is available. For at-risk populations, any delay in seeking medical care may have a detrimental effect on their health status. Following the 2011 Tohoku tsunami, it was estimated that at least 282 people died from deteriorating chronic disease conditions due to a lack of access to medical care. The Japan Ministry of Health, Labor and Welfare reported that 500 deaths could have been prevented if regular healthcare services, as delivered under normal circumstances, had been promptly provided (Nagamatsu and others, 2011).

Loss of infrastructure, such as transportation routes, electricity, and water, can impact the health of the population. Although power may not be disrupted in a significant way, loss of power in parts of the community can still impact the health of the population. Any power loss in excess of 4 hours can have an impact on the health of certain parts of the population. Four hours is the timeframe in which food that is not kept at temperature begins to present a health risk (U.S. Department of Agriculture, 2012). Individuals who rely on medical equipment (for example, ventilators, powered wheelchairs, and oxygen condensers) are also at significant risk when the power fails. Many energy-dependent pieces of equipment have an internal battery to keep them functioning for some period of time, but this time period runs from about 45 minutes to a few hours. External batteries provide additional time, but generally less than 8 hours. Without back-up power, failure of this equipment is a life-threatening event (Kailes, 2009).

\section{Homeless Population}

The homeless population is another dependent population that would be at risk from future tsunamis and would likely need assistance to evacuate. There is limited data on homeless populations for the entire California coast, therefore, a complete inventory is not possible for this tsunami scenario. To provide some insight on emergency-management issues related to homeless people, we highlight data from a 2011 homeless-count report produced by the Los Angeles Homeless Services Authority for the greater Los Angeles area. The smallest unit of analysis in this report is a service planning area (SPA), and coastal areas in Los Angeles County that are at risk to future tsunamis are part of the West Los Angeles SPA and South Bay SPA (fig. 8), which were estimated to have approximately 6,788 and 3,512 homeless people, respectively. It is not known how many of these individuals would be in tsunami-inundation zones at the time of the scenario; however, it is likely there will be some homeless individuals on the beach or in nearby coastal parks when future tsunamis occur. Preexisting mental and physical conditions of some homeless individuals in the South Bay SPA and West Los Angeles SPA may present additional evacuation challenges to public safety officials, such as substance abuse (41 and 31 percent, respectively), mental illness (15 and 48 percent), physical disabilities (15 and 31 percent), or some combination 
of all of these attributes (Los Angeles Homeless Services Authority, 2011). In addition, once they are evacuated, homeless individuals may have nowhere to go and may require public shelters.

Shelter volunteers may not be trained for meeting with the needs of the homeless population. Some homeless people may need to stay in the public shelters for longer periods of time than people who are part of other populations.

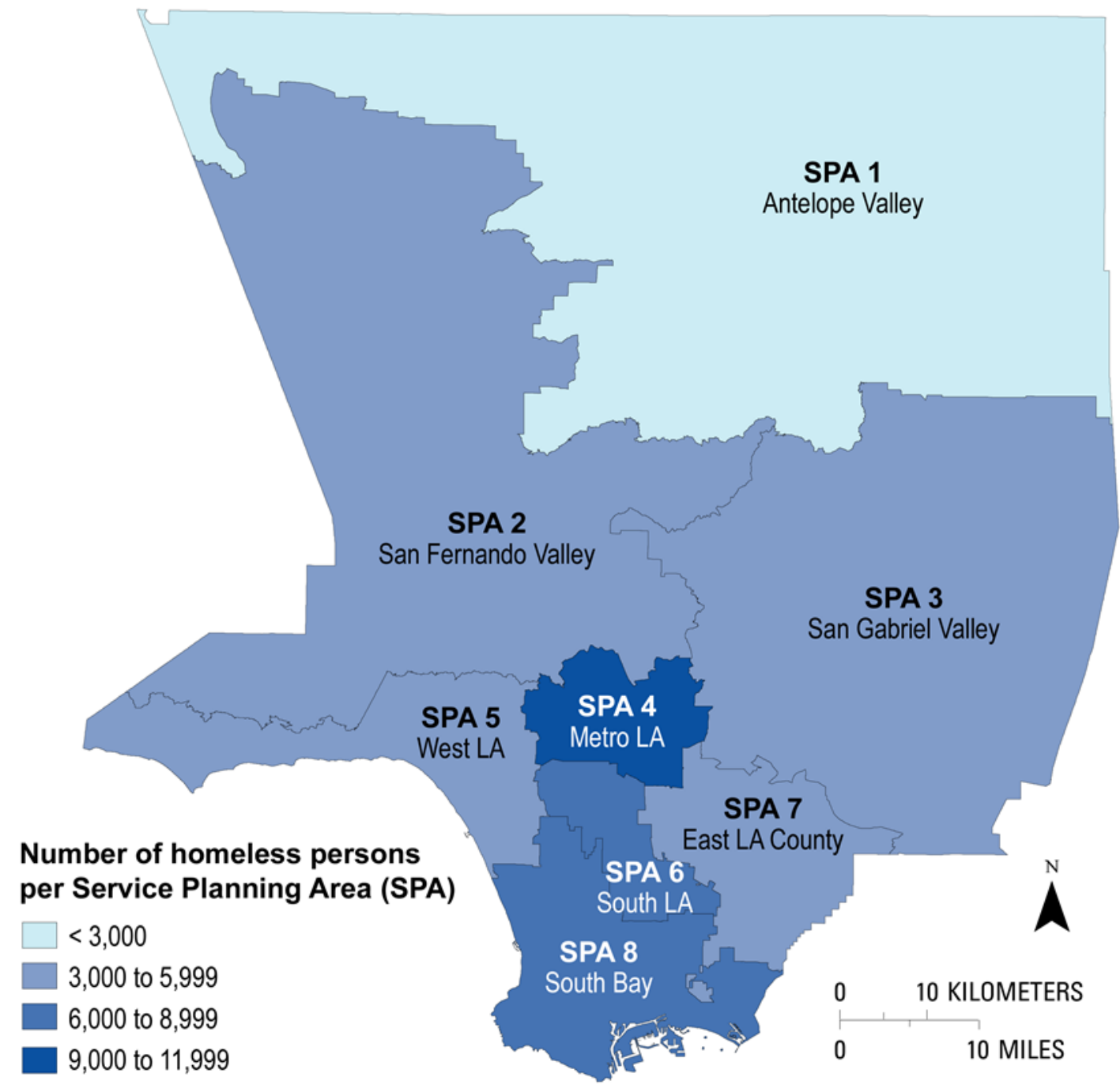

Figure 8. Map of estimated number of homeless people in Service Planning Areas (SPA) of Los Angeles county, California (based on Los Angeles Homeless Services Authority, 2011).

\section{Public Venues}

Tourists and other nonlocal populations are a significant element in coastal communities and often can outnumber residents and employees in tsunami-prone areas (Wood and Good, 2004). No consistent census count for visitors exists; therefore, the locations of public venues based on NAICS codes in the 2011 Infogroup Employer Database are used as an indicator of visitor populations. For this analysis, we consider public venues to include 
- Entertainment centers, including aquariums, botanical gardens, casinos, theaters (including live and cinematic), and amusement parks;

- Colleges, including community colleges, private universities, and public universities;

- Marina and ferries, including recreational and fishing, vessel repair and storage, and yacht clubs; and

- Overnight accommodations, including hotels, inns, resorts, hostels, cabin rentals, bed and breakfasts, and student housing.

Many public venues are in the tsunami-inundation zone, including 167 overnight accommodations, 6 colleges, 79 marinas, and 311 entertainment centers (fig. 9). The highest numbers of public venues in the tsunami-inundation zone are in the cities of San Diego, Long Beach, Newport Beach, Sausalito, and Santa Cruz. As discussed earlier, visitors may not be fully aware of evacuation procedures, or even the potential for tsunamis, especially if they are coming from areas with no history of tsunamis.

The number of public venues and facilities in tsunami-prone areas of each community provides some insight about visitor populations, but does not capture the range in magnitudes. To better understand the number of visitors that may need to be evacuated during the scenario event, we estimated onsite visitor populations for certain public venues. To do this, we took visitor numbers provided by business owners (typically provided as annual or monthly counts) and adjusted them to represent a daily estimate for a Thursday in March using methods described by Dwight and others (2007). Their study of southern California beach attendance suggests that 5.2 percent of yearly visitors come in March and that 10 percent of visits occur on Thursdays. Because we are not aware of similar work for coastal businesses, we used these percentages to estimate attendance at the following public venues on a Thursday in March:

- Monterey Bay Aquarium, 2,437 people (Barret and others, 2012);

- Santa Cruz Beach Boardwalk, 3,900 people (Season Pass/Group Sales Office, oral commun., October 1, 2012);

- $\quad$ Santa Monica Pier, 9,095 people (Westman, 2011);

- The Long Beach Convention Center, 2,454 people (Convention Center Controller, oral commun., October 2, 2012); and

- Aquarium of the Pacific in Long Beach, 2,879 guests (Aquarium Vice President of Communications, oral commun., October 1, 2012).

Examples of other high-occupancy public venues in the scenario tsunami-inundation zone are

- Public piers with high-volume tourist populations in Santa Cruz, Redondo Beach, Santa Barbara, and Pismo Beach;

- The Catalina Casino in Avalon, which includes a 1,184-seat theater and a ballroom with a capacity of 1,400 people (Catalina Island Chamber of Commerce and Visitors Bureau, 2012);

- Waterfronts that serve as ports of call for cruises, such as the city of Avalon on Catalina Island, which receives tourists from five international cruise lines, including up to 2,000 passengers on a weekly basis from a single ship (Catalina Island Chamber of Commerce and Visitors Bureau, 2012);

- Del Mar Fairgrounds, which includes a racetrack and holds events year-round; and 
- The Queen Mary ship in Long Beach, a popular tourist attraction that holds special events and has overnight accommodations.

Other high-occupancy public areas, such as SeaWorld theme park in San Diego and Cannery Row in Monterey, are near, but not in, the landward extent of the predicted scenario tsunami inundation zone. Whether or not evacuations would be called at these locations and others like them is a subject for further discussion between emergency managers and the business owners, given the uncertainty inherent in the tsunami modeling and the need to have sufficient time to evacuate before receiving full knowledge of the event.

Another category of public venues in the study area that attracts thousands of tourists are port terminals that serve cruise ships, including the World Cruise Center at the Port of Los Angeles that serves 12 different cruise lines (Pacific Cruise Ship Terminals, 2012) and the Long Beach Cruise Terminal that primarily serves Carnival cruises. Together, these cruise terminals see more than 300 cruise departures every year (Cruisetimetables, 2012). Thousands of tourists could be streaming through the port, either embarking on a cruise or returning from one. For example, a Carnival Inspiration cruise is scheduled to arrive at the Port of Long Beach on March 28, 2014 (Cruisetimetables, 2012), which is the day after our scenario earthquake and a time when port infrastructure will be damaged and waterways will still be experiencing heightened currents. There is also a scheduled departure later that day for another Carnival Inspiration cruise, which has a maximum occupancy of 2,052 passengers and 920 onboard crew (Carnival, 2012). Thus, in addition to local residents and port employees dealing with the aftermath of the tsunami, there could be 5,000 more people attempting to come into the area, based on the 920 crew members, 2,052 people leaving the arriving cruise and 2,052 people boarding the departing ship. 
Number of public venues in the tsunami-inundation zone

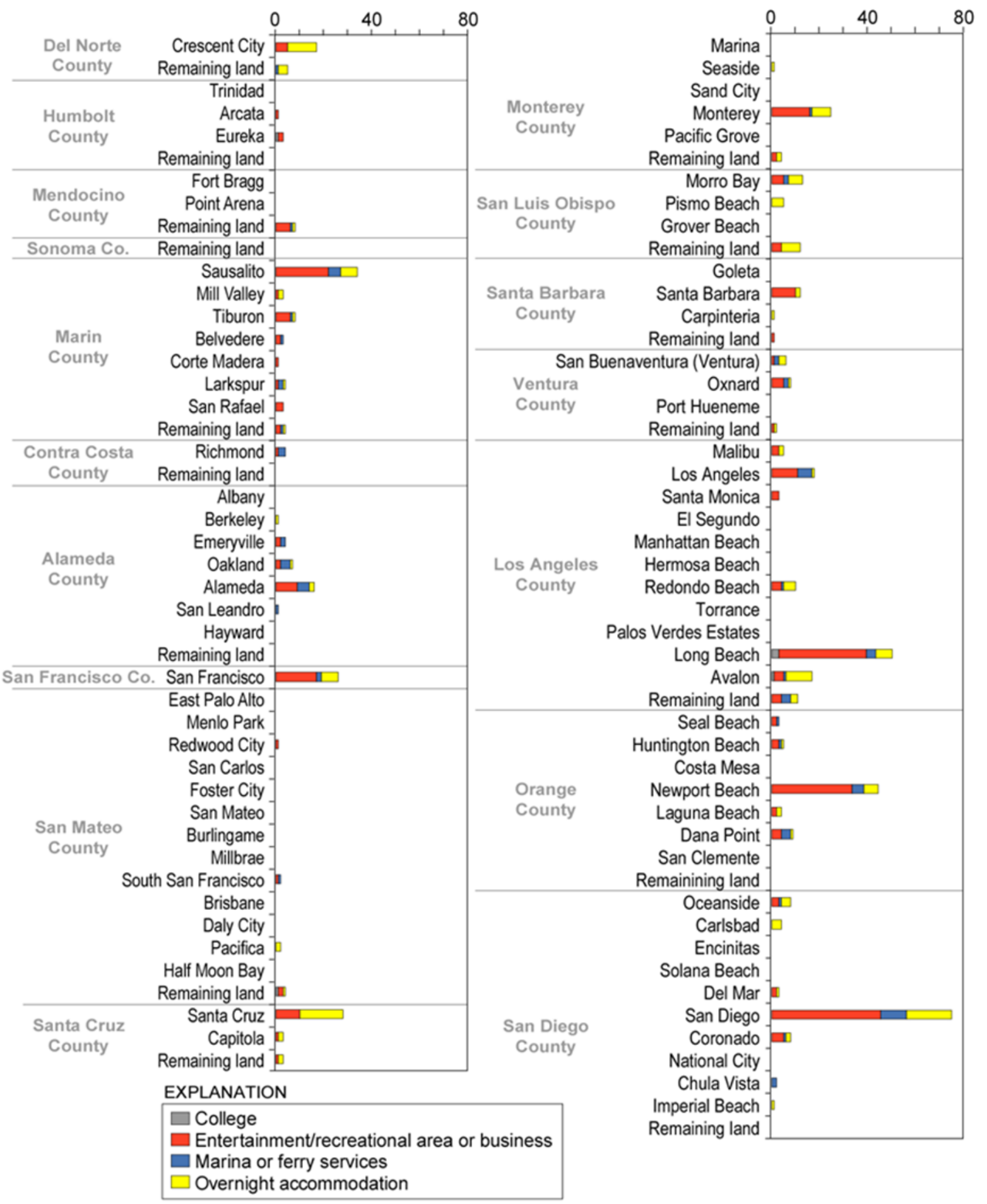

Figure 9. Plot showing number of public venues in the SAFRR scenario tsunami-inundation zone, California coast. Co., county. 


\section{Park and Beach Visitors}

In addition to public venues, residents and tourists are drawn to the tsunami-inundation zone by the multiple recreational opportunities along the 1,200-mile California coastline (Visit California, 2012), including city, county, State, and national beaches, as well as parks and waterways. Estimating the magnitude of population exposure to tsunamis for these groups is difficult given their dynamic nature. The boating community is especially difficult given the large range of their locations throughout the day and the uncertainty of their points of entry to and departure from waterways. For example, sailboats in San Francisco Bay could have originated from nearby marinas in the bay or from marinas elsewhere, such as Half Moon Bay or other points on the West Coast. Because the California maritime community is vulnerable to even minor tsunamis, the State tsunami program is developing boater-preparedness information (California Geological Survey, 2012). Gauging the extent of maritime activity in coastal California waters is beyond the scope of this assessment, and subsequent discussion is limited to visitors to beaches and parks.

Analysis of visitor data from California's State parks (California State Parks, 2010) and national parks (National Park Service, 2011) indicates that 95 parks are in the scenario tsunamiinundation zone. For the 2009-2010 fiscal year, the average number of visitors to the 95 coastal parks was $60,707,359$ people. This annual total equals 166,322 day-use visitors, on average, every day, assuming an equal distribution of visitors throughout the year. This average number of visitors is likely to be too low during the summer and on holidays, but too high for our scenario because of less favorable weather in March. National and State parks were coded by the primary county in which they are located to gauge the potential impact to communities. Although the State and national park visitors are outside of county jurisdictions, grouping the parks by county provides insight on where there may be significant tourist issues after a tsunami. When a National Oceanic and Atmospheric Administration (NOAA) tsunami alert is issued, adjacent county and city publicsafety officials will be called on to evacuate populations at coastal parks. In addition to dealing with residents and employees during an evacuation, these counties may have to contend with a substantial number of visitors at nearby parks being directed into their jurisdictions.

Attendance numbers for city and county beaches were retrieved from the United States Lifesaving Association (USLA), where they are collected annually from beach lifeguards on a volunteer basis. Beach attendance is defined by the USLA as the "people recreating in the water or on the sand, and at adjacent picnic areas, parking lots, recreation concessions and bike paths... [but] does not include people that merely transit on bikes or in cars" (United States Lifesaving Association, 2012). Because estimates are provided by lifeguards on a volunteer basis, not all beaches on the California coast have data for every year, or at all in many cases. Data on annual beach attendance were compiled for 2010 and not 2011 because (1) 2010 data contained a greater number of beaches, and (2) 2010 beach data allows for comparisons with residential data from the 2010 census population count. This analysis yielded 27 beach jurisdictions that included city and county properties and were primarily in southern California (the city of Santa Cruz being the northern-most unit). Data was not available for beaches north of Santa Cruz, suggesting that the lifeguards there do not participate in the national data-collection effort or, more likely, that the smaller numbers of visitors to beaches in northern California do not merit government-supported lifeguard agencies (Kevin Miller, California Emergency Management Agency, oral commun., May $28,2013)$.

Statistics on 2010 annual beach attendance indicate that California city and county beaches had 140,452,280 visitors, with the greatest number visiting beaches in Los Angeles County (59 million visitors) and San Diego (24 million visitors). Other beaches with high beach attendance are 
those in Long Beach (6.6 million), Huntington Beach (8.0 million), Newport Beach (7.1 million), Orange County (6.7 million), Laguna Beach (3.9 million), and Oceanside (3.8 million).

To translate annual numbers to estimates for this scenario, we relied on visitor-proportion values by Dwight and others (2007), who studied annual beach-attendance variability at 75 southern California beaches. Their work suggests that 5.2 percent of all visits occur in March, and 10 percent occur on a Thursday (with four Thursdays occurring in our scenario month). After accounting for this variability in beach attendance, and using these percentages, we estimate that 261,508 visitors would be at city, county, State, or Federal beaches and parks for our scenario tsunami on Thursday March 28, 2014 (fig. 10). 
Estimated attendance (2010), in thousands, at beach or park

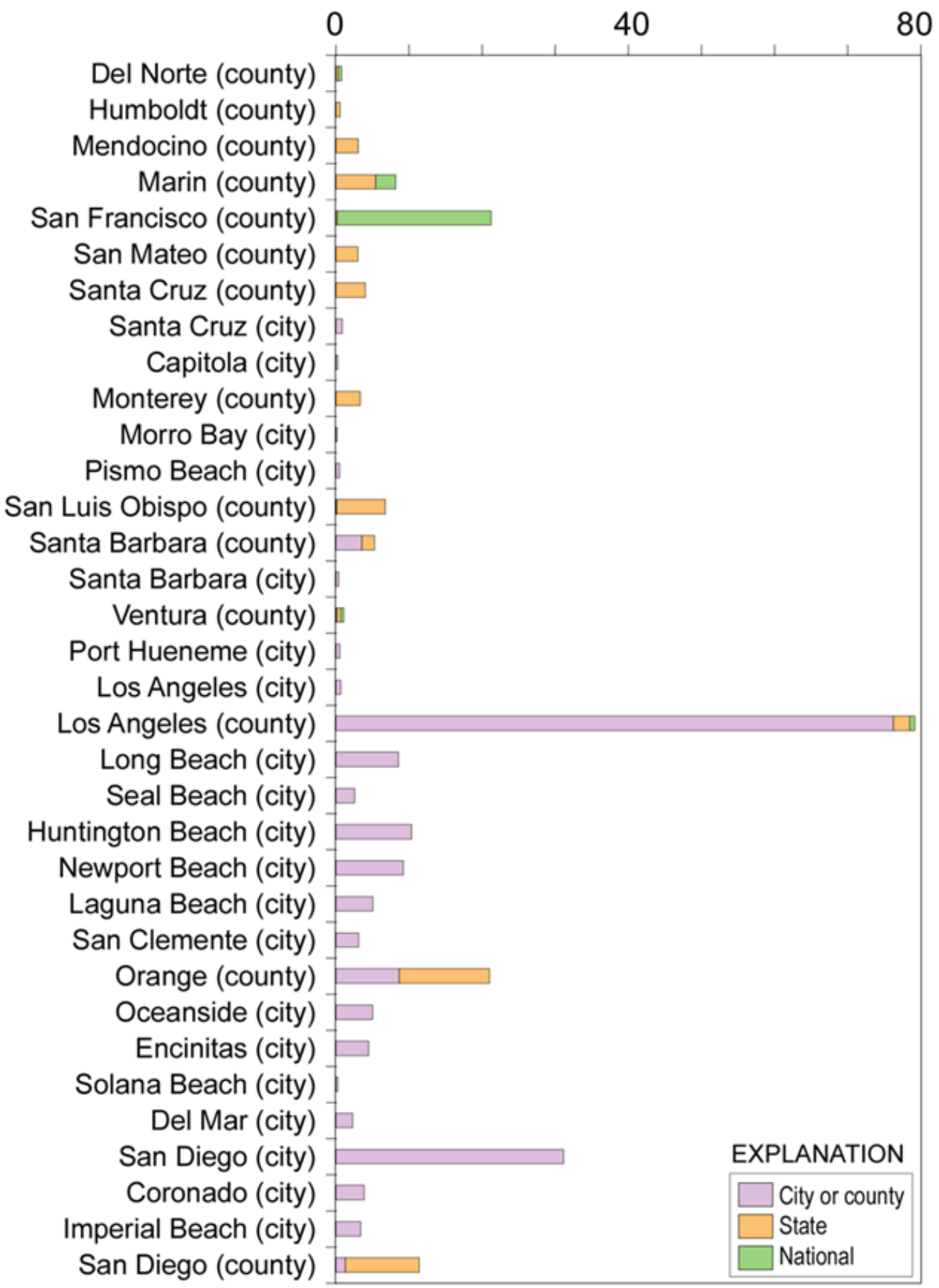

Figure 10. Plot showing estimated daily number of visitors (in thousands) for the SAFRR scenario to coastal California city and county beaches, State parks, and National Park Service locations grouped by city and county jurisdictions. 


\section{Composite Index of Population Exposure}

To provide a regional snap-shot of population exposure, we developed a composite index to compare community exposure to the SAFRR tsunami scenario for 95 geographic units - 77 incorporated cities, 2 incorporated towns, and the remaining land in 16 counties $^{3}$. The composite index was created by first normalizing values in each community for various population attributes to the maximum value in the category. Categories used for the index were the number of (1) residents, (2) employees, (3) public venues, (4) dependent-care facilities, (5) community-support businesses, and (6) beach and park visitors in the scenario tsunami-inundation zone. Normalizing data to maximum values creates a common data range of zero to one for all categories and is a simple approach for comparing disparate datasets. The normalized values in each community were added and, because there are six categories, the resulting scores ranged from zero to six (fig. 11). This unitless index allows us to compare the relative exposure levels for the 95 geographic units at regional or State levels. Because they are relative metrics, the numbers are meant for comparative purposes and do not provide much meaning for individual communities. In addition, this comparative index of population exposure simply reflects the magnitude of potential at-risk populations and does not incorporate the population density within a community, or potential limitations in egress options for evacuations.

Figure 11 illustrates the composite index for the 95 areas, where higher values indicate higher amounts. For example, the city of Long Beach has the highest composite amount value (4.6), indicating that this community consistently has one of the highest number of populations in the scenario tsunami-inundation zone. Other communities with high relative population exposure include Newport Beach, San Diego, San Francisco, and Sausalito. The dominant type of at-risk population varies somewhat in the cities and towns. For example, Long Beach has high relative exposure across all of the categories, except for beach and park attendance, whereas in Sausalito, population exposure is highest among employees, community-support businesses, and public venues.

\footnotetext{
${ }^{3}$ San Francisco is both a city and a county. Therefore, there are technically 17 counties in the scenario tsunamiinundation zone but we chose to discuss San Francisco as a city in the composite indices of population exposure and demographic sensitivity. This decision results in 16 counties for the comparative analysis.
} 


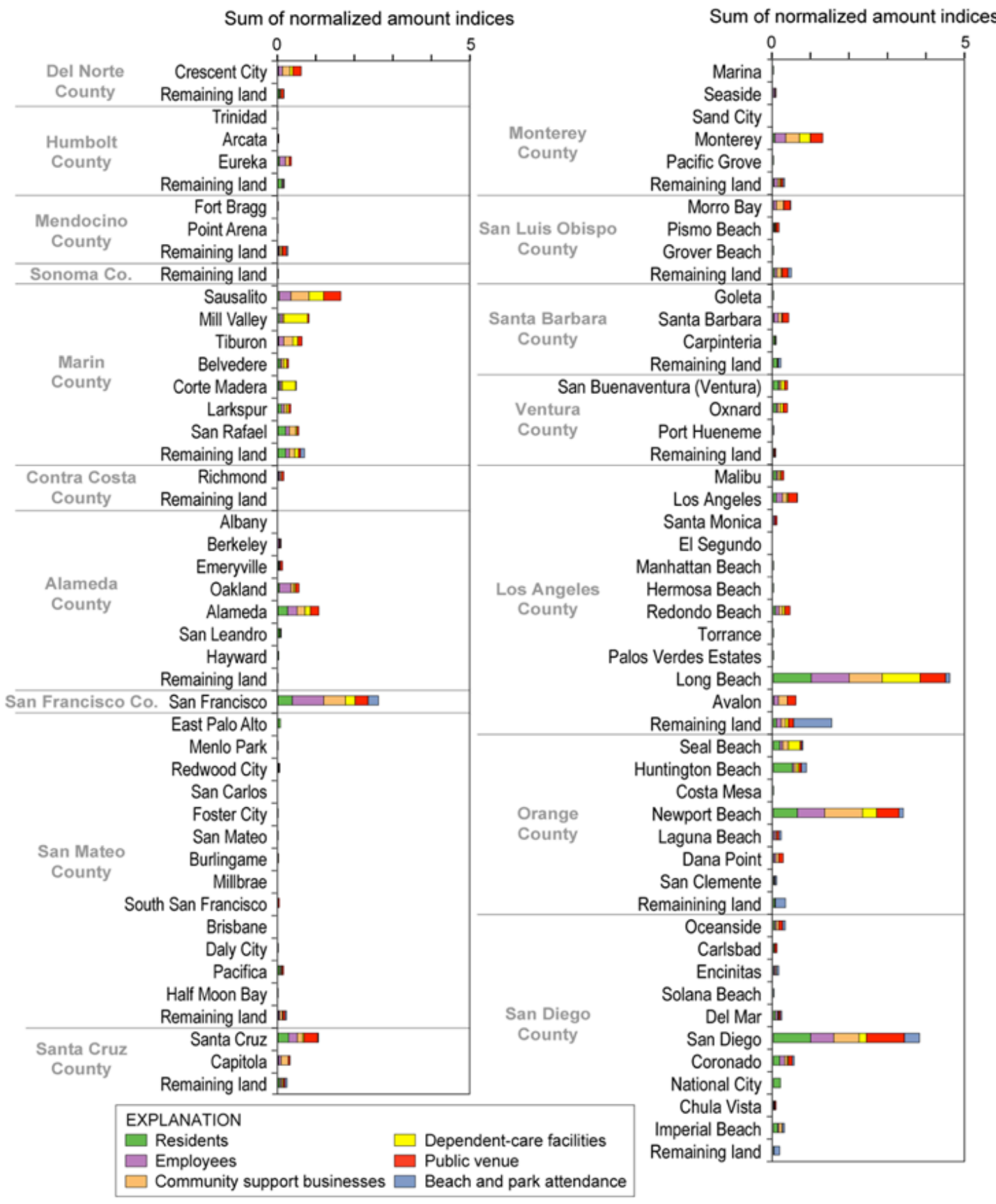

Figure 11. Plot comparing normalized amount indices for incorporated California cities and towns with land in the SAFRR scenario tsunami-inundation zone. Communities with the highest final scores have the highest numbers of residents, employees, community-support businesses, dependent-care facilities, public venues, and estimated beach and park visitors in the scenario tsunami-inundation zone. Although not observed, a final score of six would indicate that a community always had the highest number for each of the six categories. 


\section{Demographic Sensitivity to Evacuations}

Demographic factors, such as age, ethnicity, and housing tenancy, can amplify an individual's sensitivity to hazards (Morrow, 1999; Cutter and others, 2003; Laska and Morrow, 2007; Ngo, 2003). In addition to general population counts, we calculated the number of residents in tsunami-prone areas based on census block-level data of ethnicity (Hispanic or Latino), race (American Indian and Alaska Native, Asian, Black or African American, Native Hawaiian and other Pacific Islander, and White - either for each race or in combination with one or more other races), age (individuals younger than 5 and older than 65 years in age), gender with particular family structures (female-headed households with children under 18 years of age and no spouse present), and housing tenancy (renter-occupied households). Categories to discuss demographic sensitivities are not based on extensive studies of residents in the scenario tsunami-inundation zone, but instead are based on past social-science research of all types of disasters (for example, earthquakes, tornadoes, and hurricanes). It is not implied that all individuals of a certain group will exhibit identical behavior. The extent of these demographic sensitivities will be influenced by variations in local physical and social context, level of preparedness before a tsunami, and ability to respond during an event (for example, access to a car for evacuation). Similar data are not available for employees or tourists, so our discussion of demographic sensitivity is limited to residential populations in the scenario tsunami-inundation zone.

\section{Race and Ethnicity}

Tsunami-warning and evacuation messages may be difficult for some at-risk individuals to understand and act upon because of language barriers. In the Los Angeles-Long Beach-Santa Ana metropolitan statistical area (MSA), approximately 14 percent of households are considered to be linguistically isolated, which means that no one age 14 or older speaks English "very well". Of those who are linguistically isolated, the primary languages spoken in households in the Los Angeles-Long Beach-Santa Ana MSA include Asian and Pacific Island languages (31 percent), Spanish (25 percent), other Indo-European languages (23 percent), or some other language (18 percent) (U.S. Census Bureau, 2010).

The distribution of populations with limited English skills is available in the U.S. Census Bureau's American Community Survey five-year estimates. However, the data are available only for census tracts, which are geographic units used by the U.S. Census Bureau to designate homogeneous subdivisions in counties and typically include between 1,500 and 8,000 people (U.S. Census Bureau, 2000). Because of the small spatial extent of potential inundation related to the SAFRR tsunami scenario and the much larger size of the census tracts, we determined that use of tract-level demographic data to describe characteristics of the population in the scenario-inundation zone could result in inaccurate conclusions (an example of ecological fallacy). We therefore decided to use only census data available at block level. Census blocks are the smallest geographic unit used by the U.S. Census Bureau; they often correspond to a city block and can range in population from none to several hundred people.

Because census blocks lack data on limited English skills, we cannot fully comment on demographic issues related to warning-message receipt. We do, however, examine race and ethnicity data that are available at the block level to provide some insight on potential language barriers, as well as any cultural differences in warning-message receipt and evacuation efforts. Our discussion of race and ethnicity and its relation to evacuation challenges for a distant-source tsunami is, however, a subset and simplification of how this topic is typically covered in the social 
science literature on societal risk, natural hazards, and disaster management. In this larger literature, race and ethnicity are treated in a broader context for their association with variations in socioeconomic status and access to resources that may constrain hazard preparedness, mitigation, response, and recovery (Mileti, 1999). Our discussion of race and ethnicity as a proxy for language or cultural barriers during tsunami evacuations, therefore, should be interpreted as preliminary comments to initiate community-level discussions and not as exhaustive or definitive statements on the topic.

One demographic group along the entire California coast that may warrant targeted tsunami education owing to potential language barriers or cultural differences is individuals that identify themselves as Hispanic or Latino. This problem was exhibited during the March 11, 2011, tsunami when Spanish-speaking residents over-evacuated many miles inland to the tops of coastal mountain ranges in several central coastal counties in California (Wilson and others, 2012). For the scenario tsunami, 15 percent of residents in the inundation zone consider themselves to be Hispanic or Latino. At the community level, the percentage of residents in the scenario inundation zone who are Hispanic or Latino ranges from 0 to 78 percent (city of San Rafael), and this percentage is high in other communities as well, such as East Palo Alto, Avalon, Seaside, and Santa Cruz (fig. 12).

With regard to differences in race, residents in the scenario tsunami-inundation zone identify themselves as White (81 percent), Black or African American (5 percent), Asian (10 percent), American Indian and Alaska Native (2 percent), and Native Hawaiian and Other Pacific Islander (less than 1 percent). Although the regional percentage is low for at-risk individuals who considered themselves to be Asian (10 percent), there is a substantial range of at-risk individuals at the community level from 0 to 74 percent (Hayward). Other communities with high Asian populations in the scenario inundation zone are in Alameda and San Mateo Counties, and include San Leandro, Daly City, Foster City, and Redwood City (fig. 13). As is the case regarding high concentrations of Hispanic or Latino populations, targeted outreach that acknowledges high concentrations of Asian populations may be warranted in some communities, such as evacuation messaging in multiple languages. 
Percentage of residents in tsunami-inundation zone that are Hispanic or Latino

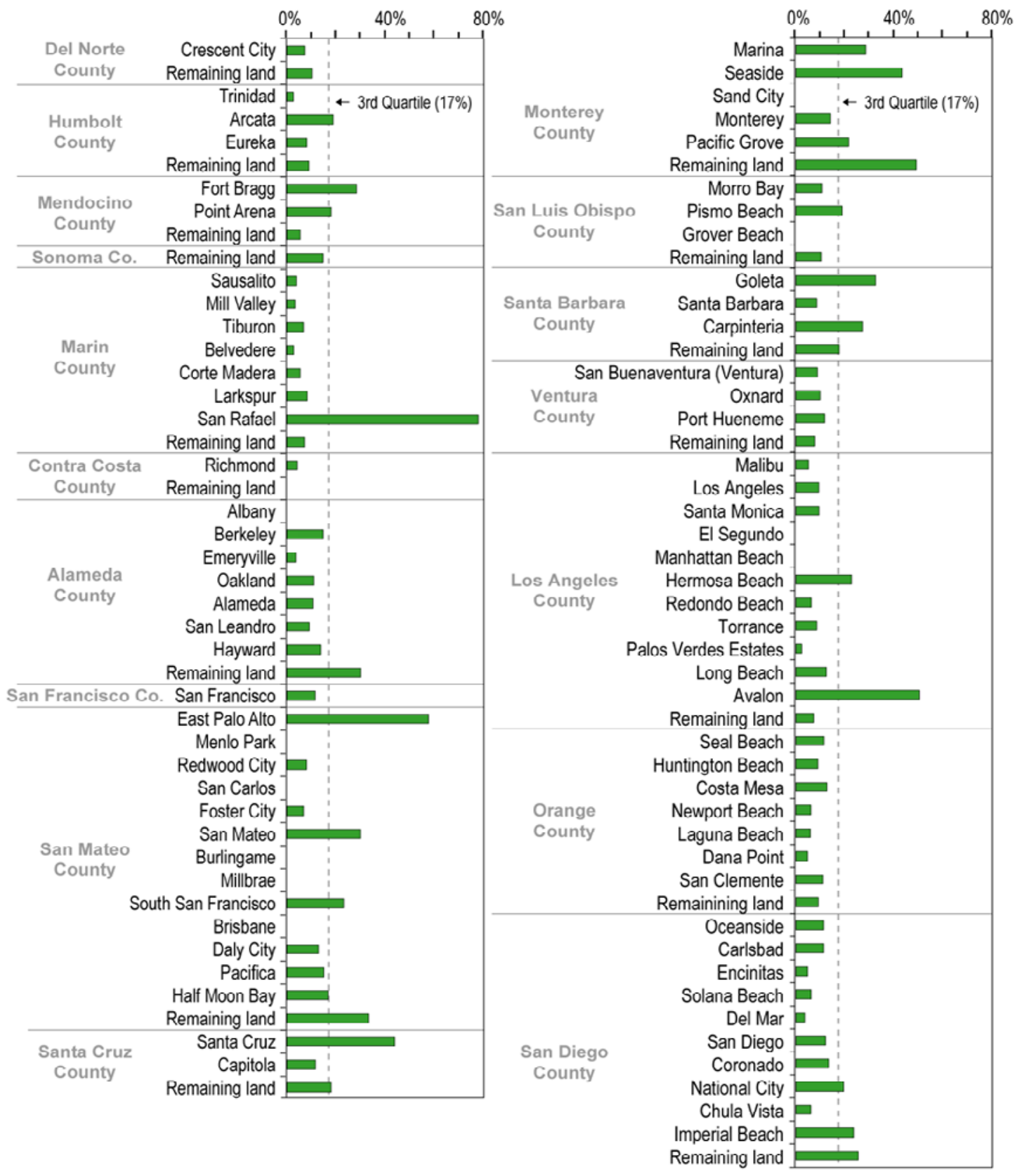

Percentage of residents in tsunami-inundation zone that are Hispanic or Latino 
Percentage of residents in tsunami-inundation zone

that are Asian

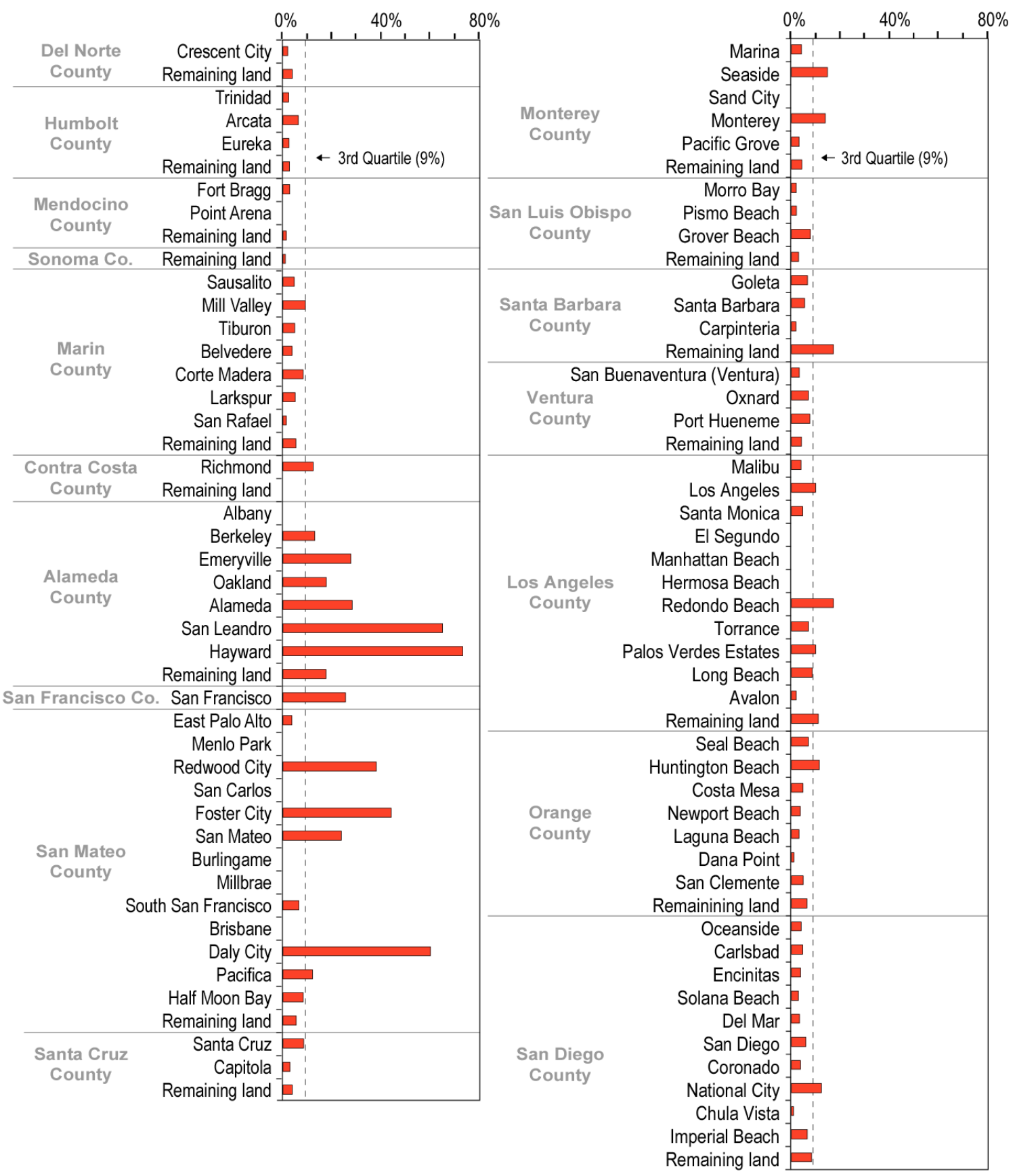

Percentage of residents in tsunami-inundation zone that are Asian 


\section{Age}

The very young and very old are considered to be more vulnerable than other age groups to sudden-onset hazards because of potential mobility and health issues (Morrow, 1999; Balaban, 2006; McGuire and others, 2007; Ngo, 2003). The very young (defined here as individuals less than 5 years in age) are considered to have heightened vulnerability because they often require direction and assistance to evacuate owing to their immaturity and size. They are also prone to developing post-traumatic stress disorders, depression, anxieties, and behavioral disorders as a result of their inability to comprehend and process the effects of a disaster (Balaban, 2006). Individuals less than 5 years in age represent a small percentage of residents in the scenario tsunami-inundation zone, specifically 4 percent across the State as a whole, and a typical range of 0 to 5 percent within individual communities ${ }^{4}$. Because of the low values and the small range in values among communities, we do not provide a bar graph to compare communities; however, data for individual communities are available for those interested.

The first tsunami wave of the SAFRR scenario is predicted to arrive on a Thursday afternoon; therefore, most children will be at school or at daycare centers. Schools often have evacuation plans, but like hospitals, rarely fully exercise them. Schools will have practiced vacating the building because of fire drills, but they may not know how to move students away from the school. Because there will be more than 4 hours between tsunami warning and arrival, school officials may dismiss students and staff before the tsunami is predicted to occur. This situation may add to the existing challenge of evacuating all residents safely because increased traffic will likely impede evacuation or school buses may not be readily available for people who need to evacuate. For example, other schools near, but outside of, the tsunami-inundation zone may be used for evacuation sites, which could further complicate evacuations (Rick Wilson, California Geological Survey, oral commun., May 28, 2013). Daycare centers for younger children also may have evacuation challenges. These centers are often private businesses and may not be included in official warning protocols of emergency personnel. They may not have a system in place to receive official warnings, are unlikely to have a television or radio on, and therefore, may not receive warnings in a timely manner. These centers are unlikely to have the capacity to transport multiple small children away from the tsunami-inundation zone and would most likely depend upon parents coming to the site to retrieve the children. As discussed earlier, parents may have difficulty getting to daycare centers if evacuation traffic clogs the roads.

The distribution of individuals older than 65 years has greater variability across the study area. This population is considered to have heightened vulnerability due to decreased mobility and health issues, reluctance to evacuate, the need for special medical equipment at shelters (McGuire and others, 2007), and the lack of social and economic resources to recover (Morrow, 1999; Ngo, 2003). Individuals older than 65 years represent 15 percent of all residents in the tsunamiinundation zone for the State as a whole, with a range from 0 to 44 percent (Mill Valley) within individual communities (fig. 14). The high percentages of at-risk individuals who are more than 65 years in age in Manhattan Beach, Pacific Grove, and Chula Vista, are due to a low number of residents in the tsunami-inundation zone (1, 2, and 6 residents, respectively). For those communities with large elderly populations in the inundation zone, unique evacuation procedures and sheltering protocols may be warranted.

\footnotetext{
${ }^{4}$ Approximately 20 percent of residents in the scenario tsunami-inundation zone of unincorporated San Diego County are less than 5 years in age. This higher percentage is because of the low number of total residents in the tsunamiinundation zone (247 residents) and does not reflect the regional trend.
} 


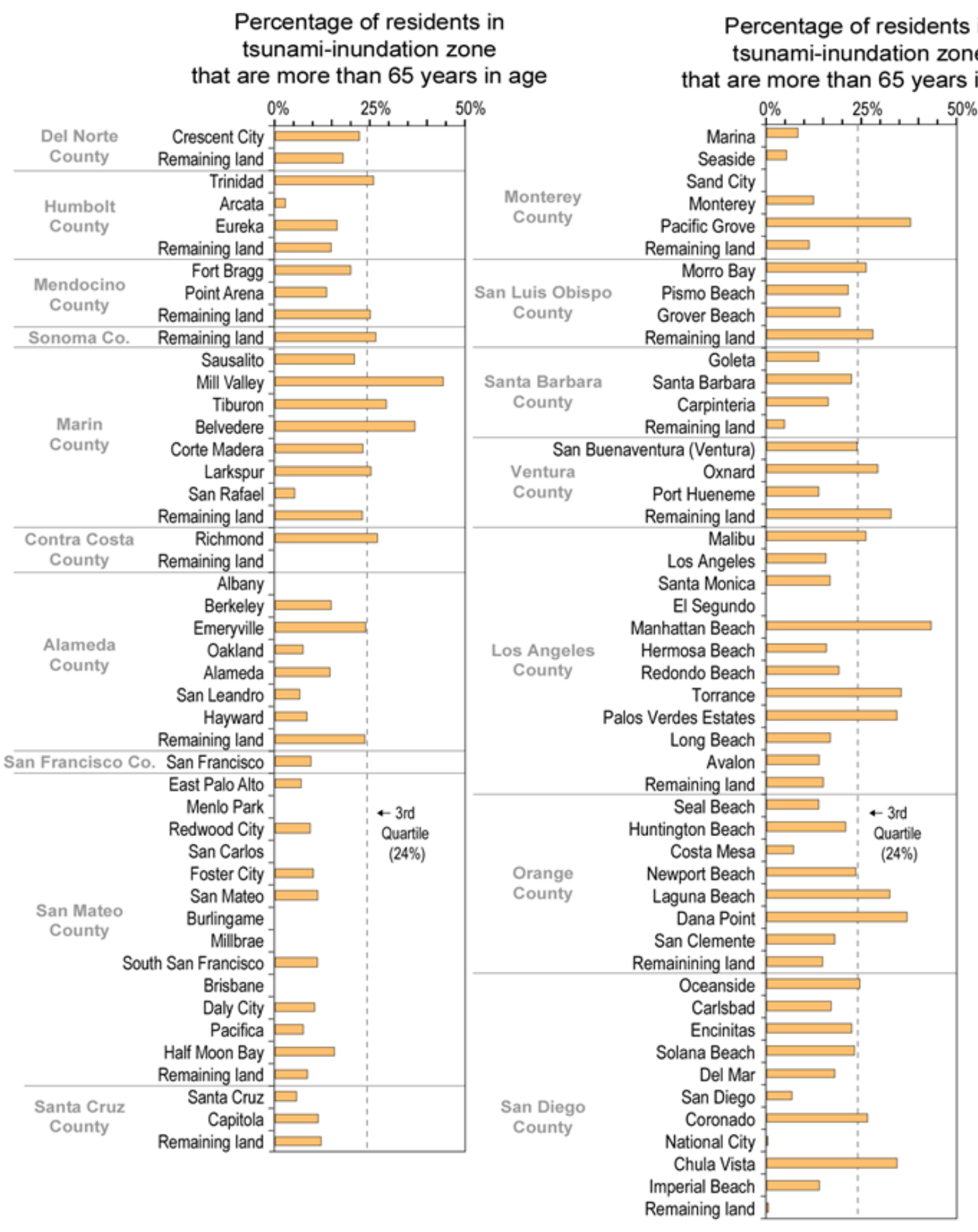

Figure 14. Plot showing percentage of residents in the California counties located in the SAFRR tsunamiinundation zone who are more than 65 years old. Co., county. 


\section{Family Structure}

Female-headed households with children under the age of 18 and no spouse present (that is, single-mother households) may be more vulnerable to future tsunamis than other households because of potential mobility issues during an evacuation and fewer financial resources to draw on when preparing for natural hazards and recovering from disasters (Enarson and Morrow, 1998; Laska and Morrow, 2007). Approximately 4 percent of households in the scenario tsunamiinundation zone are single-mother households. The highest percentages of households in the tsunami-inundation zone that are female-headed, have children under the age of 18, and have no spouse present are in Berkeley (17 percent), East Palo Alto (16 percent) and Arcata (14 percent). The high percentages of single-mother households in these communities are due to a low number of households in the tsunami-inundation zone $(8,197$, and 64 households, respectively), which is apparent in the low third-quartile value of 5 single-mother households among communities in the tsunami-inundation zone. Because of the low values and the small range in values among communities, we do not provide a bar graph to compare communities; however, data for individual communities is available for those who are interested.

\section{Housing Tenancy}

Another group considered more vulnerable to and less prepared for extreme natural hazard events is renters (Morrow, 1999; Burby and others, 2003). This lack of preparation may result from (1) higher turnover rates for renters may limit their exposure to outreach efforts, (2) preparedness campaigns may pay less attention to renters, (3) renters typically have lower incomes and fewer resources to recover, and (4) renters may not be motivated to invest in mitigation measures for rented property (Burby and others, 2003). After a disaster, renters also have little control over the speed with which rental housing is repaired or replaced (Laska and Morrow, 2007).

Approximately 53 percent of the occupied housing units in the scenario tsunami-inundation zone for the State as a whole are renter occupied. This ranges from 0 percent in some communities up to 100 percent in others (fig. 15), although high values in many communities reflect a small total number of occupied households in the tsunami-inundation zone, such as Costa Mesa, Manhattan Beach, Port Hueneme, and the unincorporated parts of San Diego County (10, 1, 6, and 76 households, respectively). For many of the remaining communities, renter-occupied households represent the majority of households in the tsunami-inundation zone. In the top 25 percent of the atrisk communities, renter-occupied households constitute at least 60 percent of the households. 


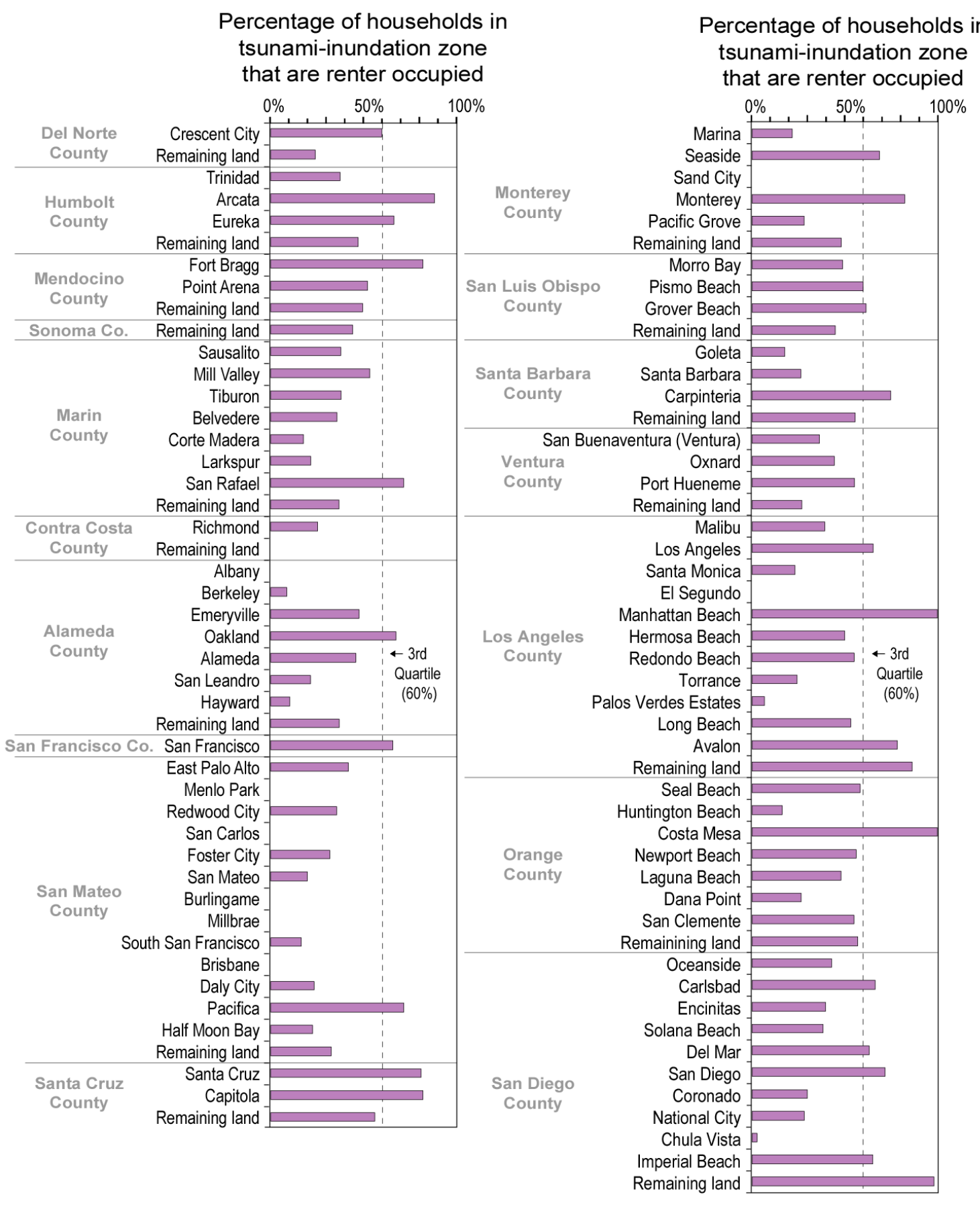

Figure 15. Plot showing percentage of households in the California counties located in the SAFRR scenario tsunami-inundation zone that are renter occupied. Co., county. 


\section{Group Quarters}

Another group of residents who will require special attention during and before a tsunami are those in group quarters, either institutionalized (for example, adult correctional, juvenile correctional, and nursing facilities) or noninstitutionalized (for example, college/university student housing and military quarters) (fig. 16). The SAFRR scenario tsunami-inundation zone contains 199 residents in institutionalized group quarters, with most of them in Alameda, San Diego, Mill Valley, and Santa Cruz (51, 43, 37, and 35 residents, respectively). Where these institutionalized populations do exist in the tsunami-inundation zone, emergency managers and public-safety officials may need to develop structured evacuations and continued supervision to ensure the safety of both the institutionalized populace and the neighboring communities. Because of the low values and the small range in values among communities, we do not provide a bar graph to compare communities; however, data for individual communities are available for those who are interested.

Some correctional institutions, such as Federal Correctional Institution on Terminal Island near the Port of Los Angeles and San Quentin State Prison in Marin County, are close to the landward extent of predicted tsunami inundation for this scenario, but not technically in the inundation zone. However, emergency managers still may decide to call for evacuations from these facilities given the uncertainty inherent in the tsunami modeling and local landscape conditions, the need to have sufficient time to evacuate before they receive full knowledge of the event, and the consequences of not evacuating these facilities.

There are 9,911 residents in the SAFRR tsunami-inundation zone that are in noninstitutionalized group quarters (fig. 16). Approximately 82 percent of this population is in San Diego (5,544 residents), Coronado (231 residents), and National City (2,342 residents), all likely reflecting military quarters associated with the naval bases near those communities. Warning these populations may be challenging to local officials because the at-risk population may not be familiar with local hazard issues, may not have experienced or have knowledge of past disasters in the area, and may not have been exposed to tsunami-awareness efforts if such efforts are geared for homeowners. There also may be military evacuation protocols that may or may not reflect local emergency-management plans. 


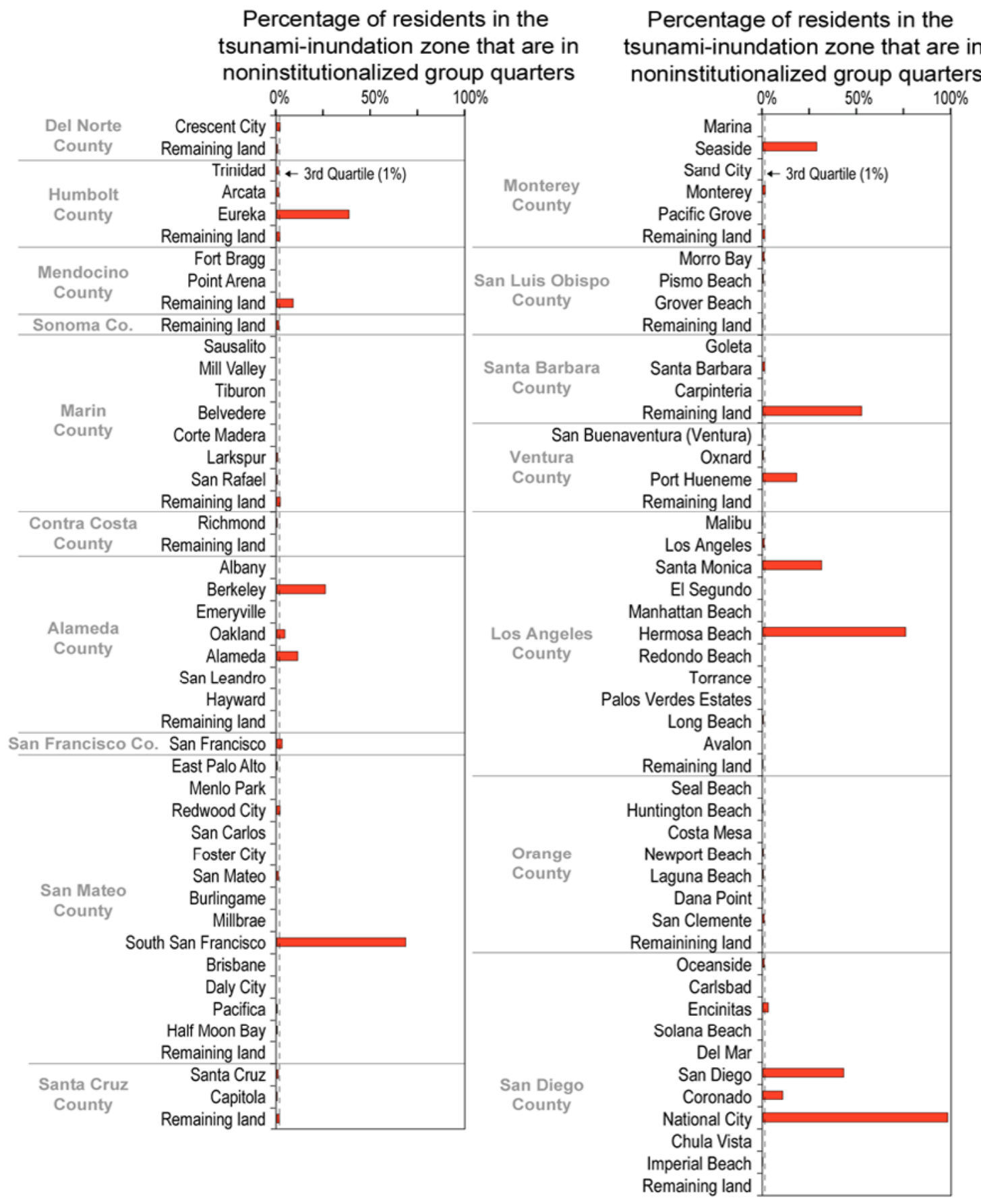

Figure 16. Plot showing percentage of residents in the California counties located in the SAFRR tsunamiinundation zone who are in noninstitutionalized group quarters. Co., county. 


\section{Composite Index of Population Sensitivity}

Throughout this section, we have highlighted various demographic attributes that may make preparing for and responding to tsunamis more challenging for at-risk residents. Parsing out individual demographic attributes provides some insight in evacuation challenges, but it is somewhat simplistic because individuals and the communities they live in are not one-dimensional. For example, renters, small children, and or non-English-speaking residents all present evacuation challenges on their own and these difficulties are compounded when all three attributes are found in the same neighborhood.

To provide some insight on the multidimensional nature of the neighborhoods in the SAFRR tsunami-inundation zone, we developed a composite index similar to the one described earlier for population exposure. We again compared the 77 incorporated cities, 2 incorporated towns and the remaining land in the 16 counties by normalizing values in each community for various demographic attributes to the maximum value in the category and then added these normalized values to yield a final aggregated number. For this composite index, we focused on the percentages of residents (or households in some cases) in the SAFRR scenario tsunami-inundation zone of each community who are in the following categories:

- Hispanic or Latino,

- Black or African American (either alone or in combination with other races),

- American Indian and Alaska Native (either alone or in combination with other races),

- Asian (either alone or in combination with other races),

- Native Hawaiian and other Pacific Islander (either alone or in combination with other races),

- Some Other Race (other than White, Black or African American, American Indian and Alaska Native, Asian, or Native Hawaiian and other Pacific Islander),

- Residents less than 5 years in age,

- Residents more than 65 years in age,

- Occupied households that are female-headed with children under the age of 18 and no spouse present,

- Occupied households that are renter occupied,

- Residents that are in institutionalized group quarters, and

- Residents that are in noninstitutionalized group quarters.

These attributes of block-level census data were chosen because of potential language barriers or cultural differences (race and ethnicity attributes), mobility issues (age and family structure attributes and institutionalized populations), or potential issues in warning dissemination (group quarters and renters) that may influence the ability of at-risk individuals to effectively receive or respond to a tsunami warning. Our previous discussion of these various demographic attributes is a subset of how these attributes are typically covered in the social-science literature on societal risk and natural hazards. This simple composite index of demographic sensitivity should be interpreted as preliminary comments to initiate community-level discussions on the types of people that are in tsunami-inundation zones and not as exhaustive or definitive statements on any one demographic attribute.

Figure 17 illustrates variations in the composite demographic-sensitivity index for the 95 areas, where higher values indicate higher sensitivity. Although not observed, a final score of 12 would indicate that one community always had the highest percentage in each of the 12 categories. The city of East Palo Alto has the highest sensitivity value (5.4), indicating that this community 
consistently has high percentages of residents in several of the demographic categories. Other communities with high relative sensitivity include San Rafael, San Mateo, Fort Bragg, and Arcata, as well as the unincorporated parts of San Diego County.

Various reasons lead to high values for different communities. Of the 95 geographic units, 19 have high relative values (we chose a normalized value of 0.66 or higher) in 1 category, 10 units have high values in 2 categories, San Rafael has high values in 3 categories, and East Palo Alto has high values in 4 categories. The high composite sensitivity value in East Palo Alto (5.4) is primarily due to the high percentages of residents who identify themselves as Hispanic or Latino, Native Hawaiian and other Pacific Islander, and some other race, and as single-mother households. In unincorporated San Diego County (4.2), higher sensitivity values are because of high percentages of residents who are less than 5 years in age; in San Rafael (4.0), the higher values result from high percentages of residents who identify themselves as Hispanic or Latino, some other race, and as renter-occupied households. In Fort Bragg and Arcata (both 3.4), higher sensitivity values are the result of high percentages of households that are occupied by renters or by single mothers.

The primary point of this exercise is to demonstrate that the type of residents in the SAFRR tsunami-inundation zone is not consistent among the at-risk communities and counties; therefore, general tsunami education and preparedness efforts that do not address local conditions or needs may not be as effective as those that do target efforts. Tsunami warning and education efforts may need to reflect a mix of certain language or cultural issues in one community, but acknowledge a mix of renters and children in another community. 
Sum of normalized sensitivity indices

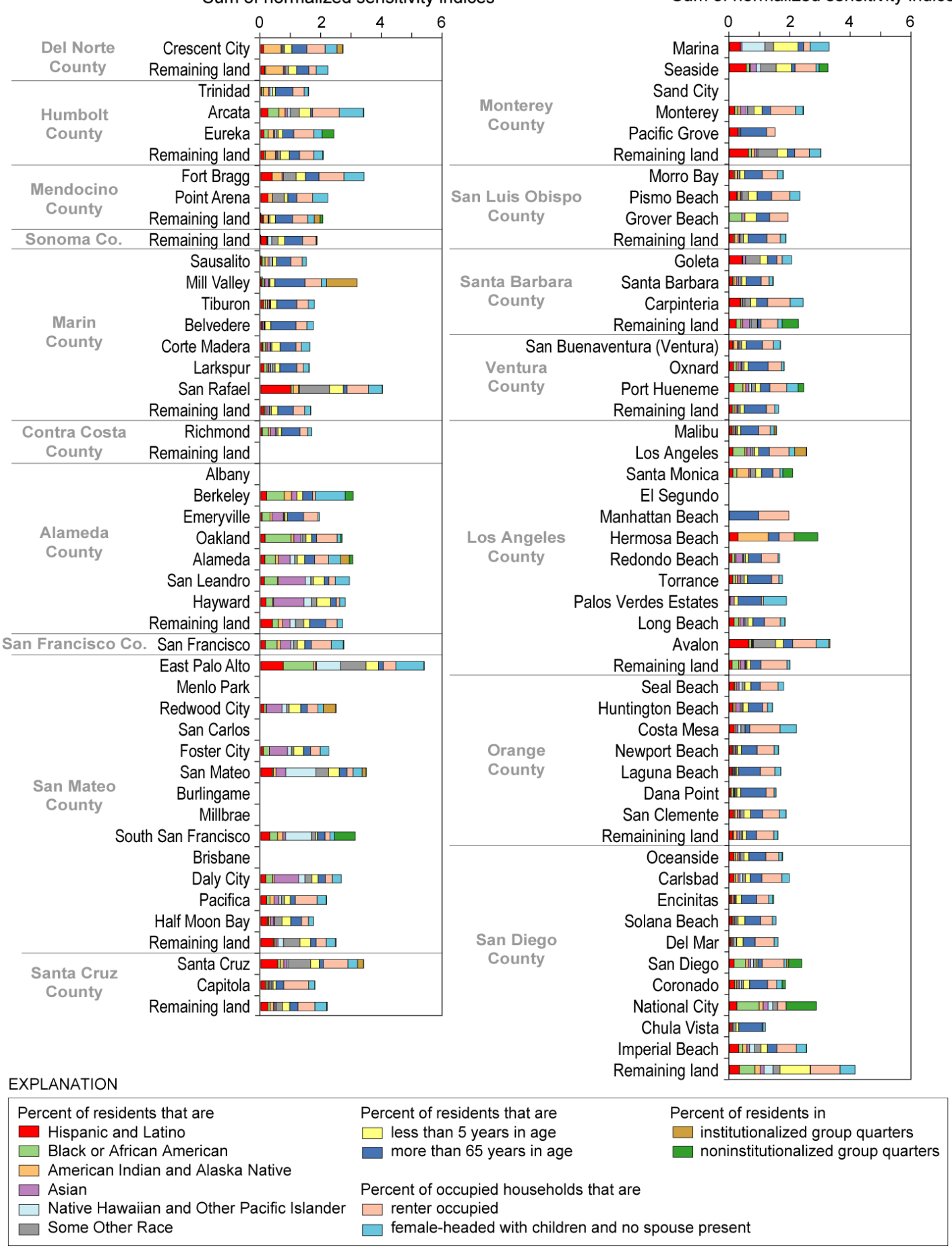

Figure 17. Plot comparing normalized demographic-sensitivity indices for incorporated cities and towns for California counties with land in the SAFRR tsunami-inundation zone. Communities with the highest final scores have the highest percentages of various demographic attributes that suggest greater sensitivity to preparing for and responding to extreme events. Co., county. 


\section{Magnitude and Challenges of Tsunami Evacuations}

When tsunamis occur, emergency managers do not have the luxury of knowing which areas will flood prior to calling for evacuations. Instead, they must make evacuation decisions based on existing knowledge of potential tsunami-inundation zones, discussions with representatives of the NOAA tsunami-warning centers and other emergency managers, and their own level of risk tolerance. To help this process and to support other tsunami risk-reduction efforts in California, a set of statewide tsunami-inundation maps have been developed and released by the California Tsunami Hazard Mitigation and Preparation Program, which is a collaboration of the California Geological Survey and the California Emergency Management Agency (California Geological Survey, 2012). These maps were created for the most significant population and economic centers on the California coast and are based on cumulative modeling efforts that incorporate a variety of large distant-source and local tsunamigenic earthquake scenarios and local landslide sources that can also generate tsunamis.

If the SAFRR scenario tsunami were to occur, emergency managers would likely use the statewide tsunami-inundation zone, or their own local evacuation zones, which are more conservative, to determine which areas to evacuate. To provide some insight on how well the statewide zone reflects potential inundation from our scenario event, we compared the number of residents in the two different zones and report results at the community level (fig. 18). Results are cumulative in figure 18; therefore, the total number of residents in the scenario inundation zone is shown in blue, and the total number of residents in the maximum tsunami-zone is the sum of the blue and orange bars. The statewide maximum tsunami-inundation zone was mapped for a slightly greater area than the SAFRR tsunami scenario. This is not an issue in the communities listed in figure 18, which are included in both mapping efforts, but may slightly affect comparisons of estimates for the unincorporated portions of each county (noted as "remaining land").

The scenario tsunami-inundation zone contains approximately 91,956 residents, who represent 34 percent of the estimated 267,381 residents in the statewide maximum tsunamiinundation zone (Wood and others, 2012). In most communities, such as Emeryville, Alameda, Oakland, Oxnard, Los Angeles, and Huntington Beach (fig. 18), residential exposure in the scenario inundation zone is substantially smaller than that for the maximum tsunami-inundation zone. In these communities, evacuations for our scenario event would require more residents than necessary to leave their homes. This should not be considered an "over-evacuation" because more precise information is not available, and real-time tsunami-inundation modeling is not currently operational at NOAA tsunami-warning centers. However, emergency managers in these communities should be prepared to communicate why the extensive evacuations were taken, namely the interest in saving lives, low-risk tolerance for responding to the event, the lack of moreprecise inundation areas, and the inherent uncertainty of tsunami generation, propagation, and inundation. These moments, which were once communicated as false alarms, provide outreach opportunities to discuss tsunami science, monitoring, and preparedness. There are several communities, such as Long Beach and San Diego, where the scenario event is a close approximation of the statewide tsunami-inundation zone. In 26 of the communities in our analysis, resident exposure to the scenario inundation zone is 75 percent or more, which is equal to the exposure to the maximum tsunami-inundation zone. In these communities, emergency managers will be able to leverage any preexisting public outreach or training that has occurred in relation to the maximum tsunami-inundation zones. Results also show that although the scenario tsunami is not the primary tsunami threat to most California coastal communities, it is a substantial threat to several communities, particularly in southern California. 
This comparison demonstrates the utility of having tsunami-scenario catalogs prior to events to help guide evacuation decisionmaking (for example, Wilson and Miller, 2012), instead of only relying on maximum tsunami-inundation zones. It also demonstrates the utility of real-time inundation modeling during actual events, such as the Short-term Inundation Forecasting for Tsunamis (SIFT) system currently under development for operational use in NOAA Tsunami Warning Centers (Titov and others, 2001).

Evacuations may be particularly difficult in areas with limited egress options, such as island and peninsula communities. If all at-risk individuals on an island attempt to evacuate by car, then traffic congestion is likely, and even a four-hour evacuation window before wave arrival (6 hours in southern California) for the USGS tsunami scenario may be inadequate. To illustrate this issue, figure 19 shows a collection of islands in Newport Beach with substantial residential populations, several of which have thousands of residents in areas where egress to the mainland is limited to one road, such as Balboa Island and Lido Isle (2,756 and 1,626 residents, respectively). In addition, more than 8,000 residents would also be asked to evacuate Balboa peninsula because it is completely within the statewide maximum tsunami-inundation zone.

In addition, more than 8,000 residents would also be asked to evacuate Balboa peninsula because it is completely within the statewide maximum tsunami-inundation zone. To date, we are not aware of any traffic studies for Balboa peninsula or the other islands in the Newport Beach area to determine the amount of time necessary for complete evacuations; therefore, it is unclear how long it would take to evacuate these areas in response to the USGS tsunami scenario (Anthony Brine, City of Newport Beach Public Works Department, oral commun., February 12, 2013). Although it was beyond the scope of this scenario assessment, an analysis of time requirements for complete evacuations may be warranted to assist with future tsunami-response planning efforts. 


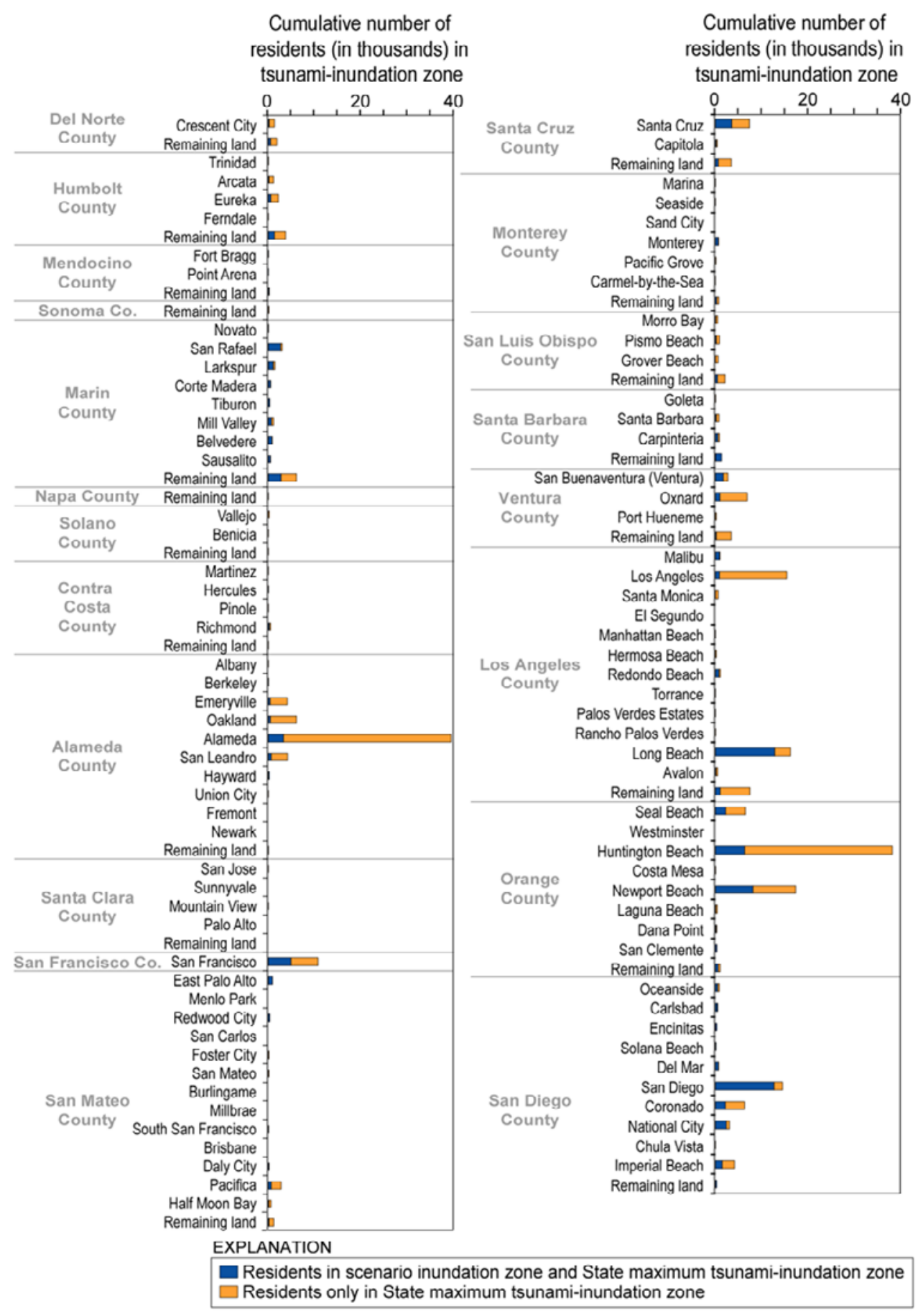

Figure 18. Plot showing cumulative number of residents in the SAFRR tsunami scenario and California tsunami-inundation zones. Co., county. 


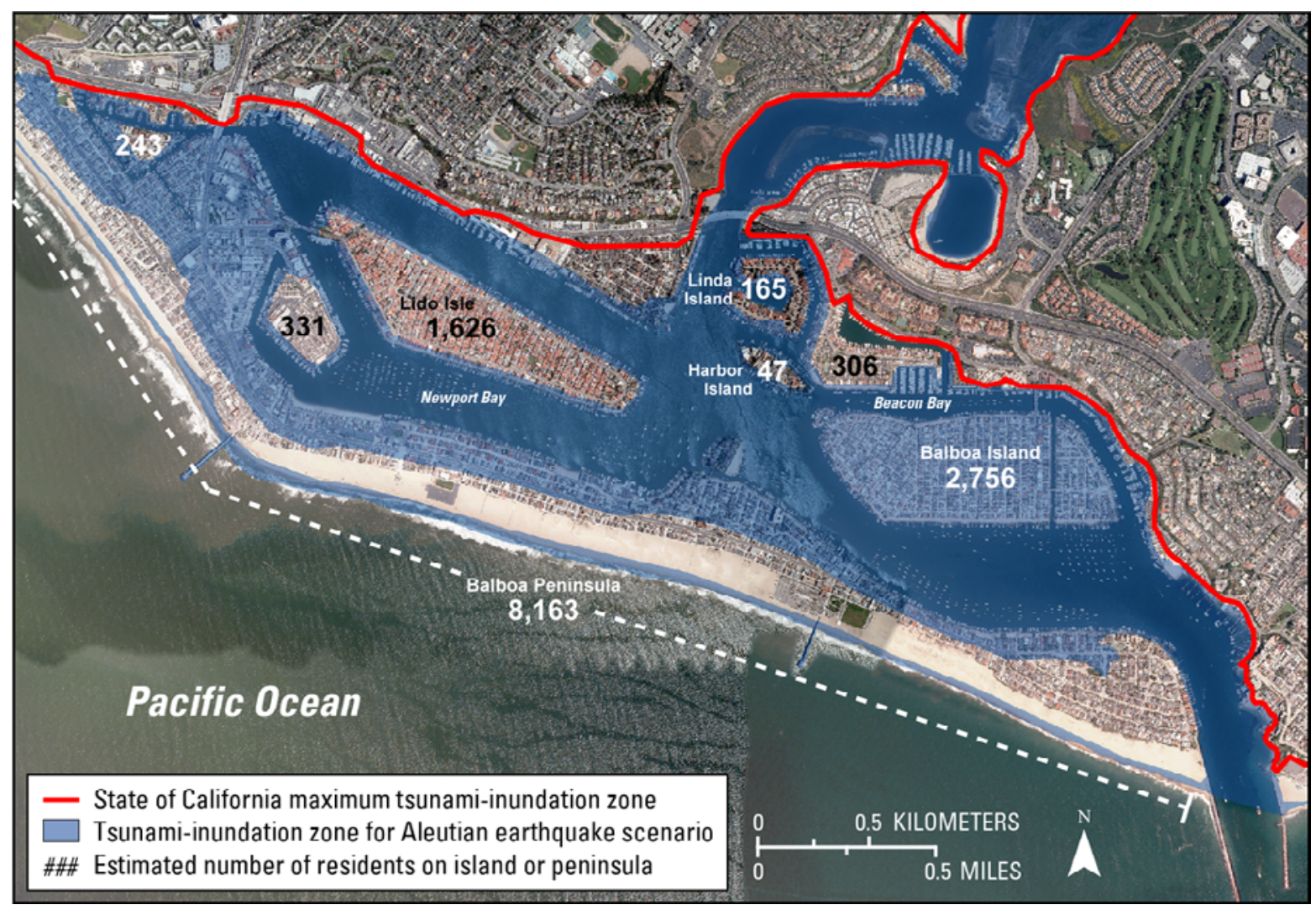

Figure 19. Photograph showing inundation zones for the SAFRR tsunami scenario and the statewide maximum zone, as well as estimated residential population counts (based on 2010 U.S. Census Bureau data) for island communities in Newport Beach, California.

The Newport Beach collection of islands also bolsters the case for scenario-specific evacuation maps instead of a maximum tsunami-inundation zone that drives evacuation decisionmaking. In this study area, scenario-specific inundation maps may reduce the likelihood of potentially unnecessary complete evacuations of Balboa Peninsula, Lido Isle, Linda Island, and Harbor Island, where the maximum inundation zones cover the locations entirely, but the scenario zone does not. In each of these areas, at-risk populations would have areas on the islands or the peninsula that are outside of likely inundation from the SAFRR tsunami scenario.

The islands and peninsula within Newport Beach are not the only places where evacuations may be challenging because of limited egress options and substantial populations on islands. We highlighted the Newport Beach area to illustrate the issue of island communities simply because of the high concentration of islands in this area. Other areas along the California coast with potential tsunami-evacuation challenges that may warrant discussions between emergency managers and traffic engineers include

- Treasure Island in San Francisco (2,880 residents);

- Bay Farm and Alameda Islands in Alameda (12,588 and 60,212 residents, respectively);

- Naples Island and Alamitos Park Peninsula in Long Beach (3,435 and 1,448 residents, respectively);

- Seabridge (1,053 residents), Sunset Beach (3,378 residents), Trinidad Island (881 residents), Humboldt Island (784 residents), and Davenport Island (511 residents) in Huntington Beach; 
- Mission Beach in San Diego (4,700 residents); and

- Silver Strand Boulevard connecting the City of Coronado peninsula to the mainland (4,799 residents).

\section{Sheltering Requirements}

The scenario tsunami could damage many homes along the California coast, forcing some residents to find shelter in the short term. Residents could also be displaced because of lack of access due to flooded roadways or because of long-term disruption damage to services (for example, water, wastewater, or electricity). Some residents may have friends and family to help them out, and others may have the financial resources to afford temporary housing or to move. Some people, however, may need to rely on publicly provided shelters, at least in the short term, while damaged homes are repaired. To gauge the potential sheltering needs in the aftermath of the scenario tsunami, we used equations contained in the Hazus-MH 2.1 flood loss-estimation methodology (Federal Emergency Management Agency, 2013).

Estimated sheltering needs are based on the magnitude of the displaced population and then modified by their income levels and age distributions. Individuals with lower incomes will be more likely to use publicly provided shelters. Age also plays a role, where younger, less established families and elderly families will be more likely to use shelters. A full description of the method of estimating sheltering needs can be found in appendix A.

Analysis was completed with population-count and age-distribution data available at the census-block level. Income distributions are available for census block groups; therefore, incomedistribution values were assigned to each block based on the larger block group value. Because of the small area likely to be inundated by the scenario tsunami, estimating sheltering needs at the census block was considered more accurate than the block group. The displaced population based on block-group-level data is 128,906 residents, which is 40 percent higher than the value using block-level data. Calculation errors in sheltering needs, therefore, could be off by 40 percent of the actual value if we used data at the block group level. We decided assigning block-group-level income distributions to census-block boundaries would result in fewer errors than using blockgroup boundaries with associated data on total residents and age distributions.

Based on the number of estimated residents in the tsunami-inundation zone and their age and income distributions, we estimate 8,678 individuals may require publicly provided shelters after the scenario tsunami (fig. 20). This number reflects 9 percent of the estimated number of residents in the scenario tsunami-inundation zone. The low percentage is likely a reflection of the typically higher incomes for households along the California coast. The communities with the highest number of people with sheltering needs include San Diego (1,095 residents), Long Beach (1,060 residents), Newport Beach (711 residents), Santa Cruz (522 residents), and National City (498 residents). Sheltering needs in National City likely will be provided by the military, rather than by city or county organizations, because 99 percent of the at-risk residents in that community are in noninstitutionalized group quarters which include military quarters. High resident demand for public shelters after the scenario tsunami may occur in San Diego (2,121 residents), Orange (1,482 residents), Los Angeles (1,418 residents), and Marin (876 residents) Counties. The length of time displaced people may need publicly provided shelters is unknown because estimating the extent of damage to individual homes is beyond the scope of this project. Some people may evacuate to shelters while tsunami waves are arriving during the predicted 12 or more hours, but then return to their homes after the event. 


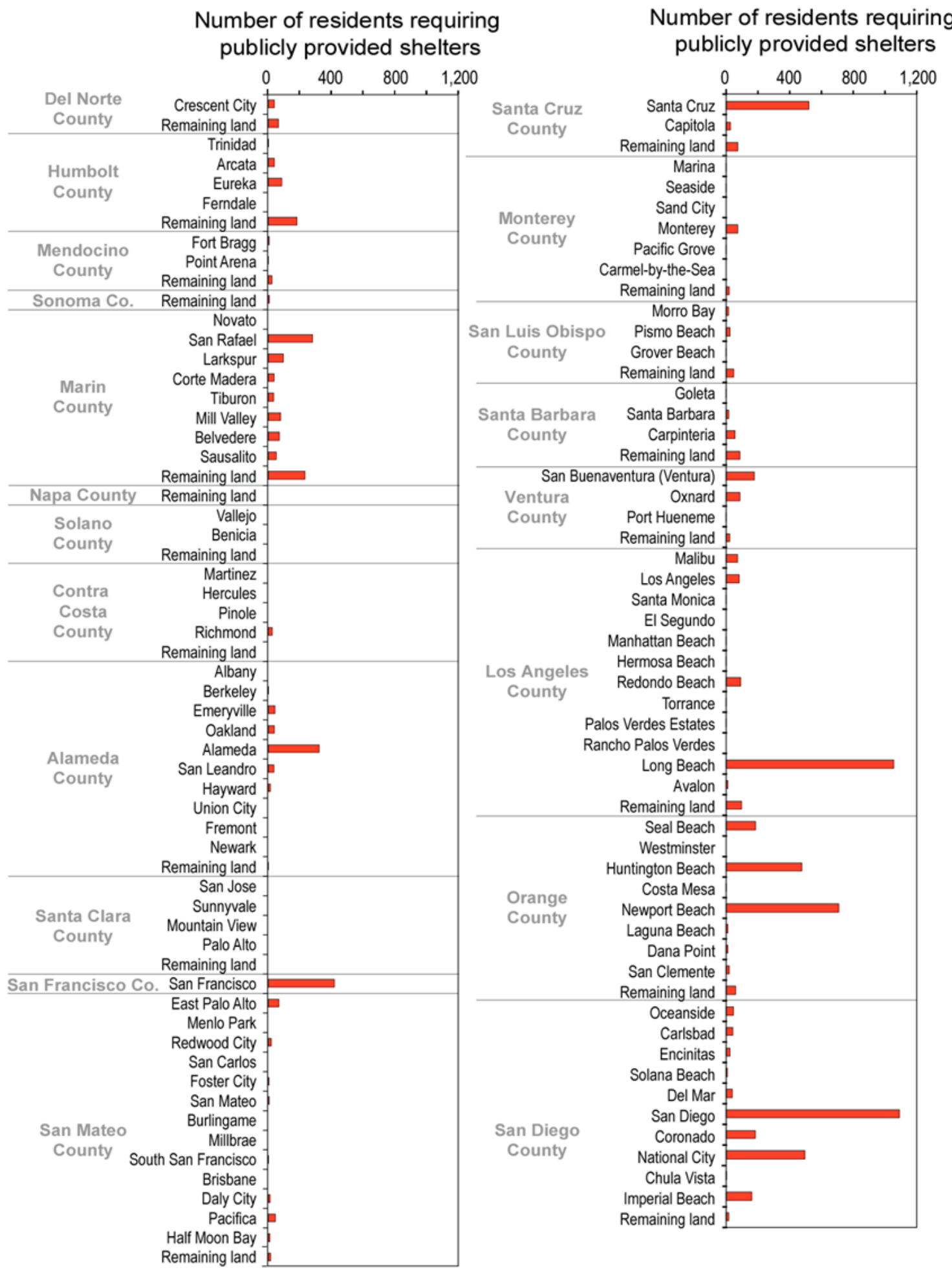

Figure 20. Plot showing number of residents listed by California counties and cities estimated to use public shelters in the SAFRR tsunami scenario. Co., county. 


\section{Conclusions}

The most significant public-health concern for California coastal communities during a distant-source tsunami is the ability to evacuate people out of the predicted inundation zone. Fatalities from the SAFRR tsunami scenario could be low (and possibly zero) if emergency managers can implement an effective evacuation in the time between tsunami generation and arrival, as well as keep people from entering tsunami-prone areas until all-clear messages can be delivered. This will be challenging given the 91,956 residents, 81,277 employees, as well as numerous public venues, dependent-population facilities, community-support businesses, and highvolume beaches that are in the 79 communities and 17 counties intersected by the scenario tsunamiinundation zone. These evacuation challenges mean that fatalities are possible from the SAFRR tsunami scenario, as well as secondary fatalities, such as vehicular accidents or heart attacks, associated with an evacuation. Although all coastal communities face some level of threat from this scenario, the highest concentrations of people in the tsunami-inundation zone are in Long Beach, San Diego, Newport Beach, Huntington Beach, and San Francisco. Communities also vary in the prevalent categories of populations that are in tsunami-prone areas, such as residents in Long Beach, employees in San Francisco, tourists at public venues in Santa Cruz, and beach or park visitors in unincorporated Los Angeles County.

Certain communities have higher percentages of groups that may need targeted outreach and preparedness training, such as renters, the very young and very old, residents in noninstitutionalized group quarters (for example, military housing and university dormitories), and individuals with limited English-language skills or no English-language skills at all. Sustained education and targeted evacuation messaging is also important at several high-occupancy public venues in the tsunami-inundation zone (for example, city and county beaches, State or national parks, and amusement parks). Education efforts and evacuation coordination for each group should address conditions and needs of the local at-risk population.

Evacuations will be challenging, particularly for certain dependent-care populations, such as patients at hospitals and children at schools and daycare centers. Moving some patients out of a hospital to another facility can take hours to complete, given their existing health conditions. Evacuating schools and childcare centers is easier than evacuating hospitals, but still requires substantial coordination among school officials, parents, and the transportation sector. People living in the tsunami-inundation zone who do not have transportation or who are home-bound need to be identified prior to a tsunami, and plans, including practice drills, should be made for facilitating their evacuation in a timely manner.

In the aftermath of the scenario tsunami, many people may find themselves with damaged homes or businesses. We estimate that approximately 8,678 of the 91,956 residents in the scenario inundation zone are likely to need publicly provided shelters in the short term. In addition, damaged healthcare facilities will impact the public health of the surrounding communities as they seek out other services in the short term. This is also true for any damaged schools or childcare centers, and parents may be unable to return to work until suitable arrangements can be made for their children.

\section{Future Research Needs}

Information presented in this report could be used to support emergency, land-use, and resource managers, as well as the coastal communities, in their efforts to identify where additional preparedness and outreach activities may be needed to manage risks associated with California 
tsunamis. Comparing the number and type of various populations in tsunami-prone areas of California coastal communities is a first step in discussing population vulnerability, but is not an exhaustive statement on the topic because variations in individual sensitivity and adaptive capacity are not fully addressed (Turner and others, 2003). The ability of individuals in a coastal community to prepare for future tsunamis, respond to an event, and recover from an event affects their overall vulnerability to extreme events. Despite similar population distributions, the same extreme natural event would mean a short-term crisis to some and a longer-term disaster to others.

Potential follow-up studies based on results presented here could focus on the adaptive capacity of individuals and communities with regard to their ability to prepare for, respond to, and recover from a damaging tsunami. The current study offers insight into the magnitude of population exposure in the scenario tsunami-inundation zone, and the next steps could focus on the ability of these individuals, as well as the managers and officials responsible for public safety, to manage and reduce their tsunami risks. For example, a gap analysis of local capabilities and capacities could provide emergency managers with a blueprint for where additional training and response planning may be warranted, such as hospitals, schools, childcare centers, and popular tourist destinations. For the healthcare industry, further work may be warranted to determine if vertical evacuation within a building at specific sites is possible, instead of requiring a complete evacuation. With regard to warning-message dissemination, further work may be warranted on determining alternative methods for serving hard-to-reach populations, such as non-English speakers, renters, institutionalized populations, and tourists. Traffic studies for large population centers and for island communities may be warranted to determine whether full evacuations are possible in four hours or less for a distant tsunami. Finally, the substantial difference in the size of at-risk populations in the statewide maximum tsunami-inundation zone and the SAFRR scenario zone suggests a need for a tsunami-scenario catalog to help guide local evacuation decision making efforts.

\section{References Cited}

Balaban, V., 2006, Psychological assessment of children in disasters and emergencies: Disasters, v. 30, no. 2, p. 178-198.

Barberopoulou, A., Borrero, J., Uslu, B., Kalligeris, N., Goltz, J., Wilson, R., and Synolakis, C., 2009, New maps of California to improve tsunami preparedness: Eos, American Geophysical Union Transactions, v. 90, no.16, p. 137-144.

Barnard, J., 2011, Dustin Weber, California man, swept to sea by tsunami and presumed dead: Huffington Post, available at http://www.huffingtonpost.com/2011/03/14/dustin-weber-tsunamidead_n_835236.html.

Barret, A., Hains, A., Jeffries, K., and Yoshida, M., 2012, Monterey Bay Aquarium connections: available at http://www.montereybayaquarium.org/PDF_files/aa/financials/aquarium_annualreview_11.pdf.

Burby, R., Steinberg, L., and Basolo, V., 2003, The tenure trap-The vulnerability of renters to joint natural and technological disasters: Urban Affairs Review, v. 39, no. 1, p. 32-58.

Bureau of Labor Statistics, 2010, United States economy at a glance: U.S. Department of Labor, Bureau of Labor Statistics, available at http://www.bls.gov/oes.

Cal-Atlas Geospatial Clearinghouse, 2013, Cal-Atlas download-Imagery: available at http://www.atlas.ca.gov/download.html\#/casil/imageryBaseMapsLandCover/imagery.

California Emergency Management Agency, 2012, Tsunami preparedness: California Emergency Management Agency, available at http://www.calema.ca.gov/PlanningandPreparedness/Pages/Tsunami-Preparedness.aspx. 
California Geological Survey, 2012, California geological survey tsunami website: California Geological Survey, available at http://www.conservation.ca.gov/cgs/geologic_hazards/Tsunami/Inundation_Maps/Pages/Index.as px.

California State Parks, 2010, Statistical report—2009/10 fiscal year: Statewide Planning Unit, Planning Division, California State Parks, available at http://www.parks.ca.gov/pages/795/files/09-10\%20statistical\%20report\%20final\%20online.pdf.

Carnival, 2012, Carnival Inspiration cruise ship: available at http://www.carnival.com/cruiseships/carnival-inspiration.aspx?shipCode=IS.

Catalina Island Chamber of Commerce and Visitors Bureau, 2012, Avalon Bay with cruise ships: Catalina Island Image Library, Catalina Island Chamber of Commerce and Visitors Bureau, website available at http://www.catalinachamber.com/mediafilming/image-library.

City of Huntington Beach, 2012, Residents: California, City of Huntington Beach, available at http://www.huntingtonbeachca.gov/residents/.

Cruisetimetables, 2012, Cruises from Los Angeles 2014: available at http://www.cruisetimetables.com/cruises-from-los-angeles-california-2014.html

Cutter, S., Boruff, B., and Shirley, W., 2003, Social vulnerability to environmental hazards: Social Science Quarterly, v. 84, no. 2, p. 242-261.

Doocy, S., Robinson, C., Moodie, C., and Burnham, G., 2009, Tsunami-related injury in Aceh Province, Indonesia: Global Public Health-An International Journal for Research, Policy and Practice, available at http://www.tandfonline.com/doi/pdf/10.1080/17441690802472612.

Dwight, R., Brinks, M., SharavanaKumar, G., Semenza, J., 2007, Beach attendance and bathing rates for southern California beaches: Ocean and Coastal Management, v. 50, no. 10, p. 847-858.

Enarson, E., and Morrow, B., 1998, The gendered terrain of disaster: Westport, Conn., Praeger, 275 p.

Federal Emergency Management Agency, 2013, Hazus-MH flood technical manual: U.S. Department of Homeland Security, 569 p., available at http://www.fema.gov/library/viewRecord.do?id=4713.

Groves, M., 2008, University of California Los Angeles health center readies move: Los Angeles Times, available at http://articles.latimes.com/2008/jun/25/local/me-ucla25.

Infogroup, 2011, Employer database: Infogroup online dataset, available at http://referenceusagov.com/Static/Home.

Kailes, J., 2009, Emergency power planning for people who use electricity and battery dependent assistive technology and medical devices: available at http://www.jik.com/Power\%20Planning\%2010.24.09.pdf.

Kuba, M., Dorian, A., Kuljian, S., and Shoaf, K., 2004, Elderly populations in disastersRecounting evacuation processes from two skilled-care facilities in central Florida: University of Colorado, Boulder, Natural Hazards Center Quick Response Research Report 172, available at http://www.colorado.edu/hazards/research/qr/qr172/qr172.pdf.

Lander, J., Lockridge, P., and Kozuch, M., 1993, Tsunamis affecting the west coast of the United States 1806-1992: National Geophysical Data Center Key to Geophysical Records Documentation No. 29 report, United States Department of Commerce, National Oceanic and Atmospheric Administration, p. 242.

Laska, S., and Morrow, B., 2007, Social vulnerabilities and Hurricane Katrina-An unnatural disaster in New Orleans: Marine Technology Society Journal, v. 40, no. 4, p. 16-26. 
Los Angeles Homeless Services Authority, 2011: Greater Los Angeles homeless count report, available at http://www.lahsa.org/docs/2011-Homeless-Count/HC11-Detailed-GeographyReport-FINAL.PDF.

McGuire, L., Ford, E., and Okoro, C., 2007, Natural disasters and older US adults with disabilities-Implications for evacuation: Disasters, v. 31, no. 1, p. 49-56.

Mileti, D., 1999, Disasters by design-A reassessment of natural hazards in the United States: Washington, D.C., Joseph Henry Press, 376 p.

Morrow, B., 1999, Identifying and mapping community vulnerability: Disasters, v. 23, no. 1, p. 118.

Nagamatsu, S., Maekawa, T., Ujike, Y., Hashimoto, S., and Fuke, N., 2011, The earthquake and tsunami-Observations by Japanese physicians since the 11 March catastrophe: Critical Care, v. 15, no. 3, 167 p.

National Park Service, 2011, National Park Service Public Use Office: available at http://www.nature.nps.gov/stats/park.cfm.

National Research Council, 2010, Tsunami warning and preparedness - An assessment of the U.S. Tsunami Program and the Nation's preparedness efforts: Committee on the Review of the Tsunami Warning and Forecast System and Overview of the Nation's Tsunami Preparedness, National Academy of Sciences, $266 \mathrm{p}$.

Ngo, E., 2003, When disasters and age collide-Reviewing vulnerability of the elderly: Natural Hazards Review, v. 2, no. 2, p. 80-89.

Pacific Cruise Ship Terminals, 2012, Cruise links: available at http:/www.pcsterminals.com/.

Parson, E., 2002, 1000-year flood paralyzes Texas medical center: Electrical Construction and Maintenance, available at http://ecmweb.com/contractor/1000-year-flood-paralyzes-.

Rother, K., 2001, Surviving the flood-Texas Medical Center's unsinkable spirit: available at http://www.theheart.org/article/178925.do.

Ross, S., Jones, L., Wilson, R., Bahng, B., Barberopoulou, A., Borrero, J., Brosnan, D., Bwarie, J., Geist, E., Johnson, L., Kirby, S., Knight, W., Long, K., Lynett, P., Miller, K., Mortensen, C., Nicolsky, D., Perry, S., Plumlee, G., Porter, K., Real, C., Ryan, K., Suleimani, E., Thio, H., Titov, V., Wein, A., Whitmore, P., Wood, N., The SAFRR (Science Application for Risk Reduction) Tsunami Scenario-Executive Summary and Introduction: U.S. Geological Survey Open-File Report 2013-1170, 29 p.

Schultz, C., Koenig, K., and Lewis, R., 2003, Implications of hospital evacuation after the Northridge, California, Earthquake: New England Journal of Medicine, v. 348, p. 1349-55. Shoaf, K., and Rottman, S., 2000, Public health impact of disasters: Australian Journal of Emergency Management, v.15, no. 3, p. 58-63.

Titov, V., Gonzales, F., Mofjeld, H., Newman, C., 2001, Project SIFT (Short-term Inundation Forecasting for Tsunamis): International Tsunami Symposium Proceedings, session 7 (7-2), p. $715-721$.

Turner, B.L., Kasperson, R.E., Matson, P.A., McCarthy, J.L., Corell, R.W., Christensen, L., Eckley, N., Kasperson, J.X., Luers, A., Martello, M.L., Polsky, C., Pulsipher, A., and Schiller, A., 2003, A framework for vulnerability analysis in sustainability science: Proceedings of the National Academy of Sciences, v. 100, no. 14, p. 8074-8079.

United States Lifesaving Association, 2012, Statistics: United States Lifesaving Association, available at http://arc.usla.org/Statistics/public.asp.

U.S. Census Bureau, 2000, Census tracts and block numbering areas: U.S. Census Bureau, available at http://www.census.gov/geo/www/cen_tract.html. 
U.S. Census Bureau, 2010, 2010 TIGER/Line ${ }^{\circledR}$ Shapefiles: U.S. Census Bureau, available at http://www.census.gov/cgi-bin/geo/shapefiles2010/main/.

U.S. Census Bureau, 2012, American FactFinder: U.S. Census Bureau, available at http://factfinder2.census.gov/faces/nav/jsf/pages/index.xhtml.

U.S. Department of Agriculture, 2012, Keeping food safe during an emergency: Food Safety and Inspection Service, available at http://www.fsis.usda.gov/Fact_Sheets/keeping_food_Safe_during_an_emergency/index.asp.

U.S. Geological Survey, 2012, Earthquake “Top 10” Lists \& Maps, available at http://earthquake.usgs.gov/earthquakes/eqarchives/.

U.S. Department of Health and Human Services, 2012, At-risk, behavioral health and community resilience (ABC): Office of the Assistant Secretary for Preparedness and Response, available at http://www.phe.gov/Preparedness/planning/abc/Pages/default.aspx.

Visit California, 2012, Media center-The facts: Visit California, available at http://media.visitcalifornia.com/Facts-Learning/The-Facts/.

Westman, A., 2011, Santa Monica Pier visitor counts-Spring and summer 2011: Urban Place Consulting Group, Inc., 10 p.

Wilson, R.I., Admire, A.R., Borrero, J.C., Dengler, L.A., Legg, M.R., Lynett, P., Miller, K.M., Ritchie, A., Sterling, K., McCrink, T.P., and Whitmore, P.M., 2012, Observations and impacts from the 2010 Chilean and 2011 Japanese tsunami in California (USA): Pure and Applied Geophysics, available at http://dx.doi.org/10.1007/s00024-012-0527-z.

Wilson, R.I., Barberopoulou, A., Miller, K.M., Goltz, J.D., and Synolakis, C.E., 2008, New maximum tsunami inundation maps for use by local emergency planners in the State of California, USA [abs.]: Eos, American Geophysical Union Transactions, v. 89, no. 53, Fall Meeting Supplement. Abstract OS43D-1343.

Wilson, R.I., and Miller, K.M., 2012, Improving tsunami hazard mitigation and preparedness using real-time and post-tsunami field data [abs.]: American Geophysical Union Fall Meeting, December 3-7, Abstract NH31C-1614.

Wisner, B., Blaikie, P., Cannon, T., and Davis, I., 2004, At risk-Natural hazards, people's vulnerability and disasters (2nd edition): New York, Routledge, $471 \mathrm{p}$.

Wood, N., 2007, Variations in city exposure and sensitivity to tsunami hazards in Oregon: U.S. Geological Survey Scientific Investigations Report 2007-5283, 37 p., available at http://pubs.usgs.gov/sir/2007/5283/.

Wood, N., and Good, J., 2004, Vulnerability of a port and harbor community to earthquake and tsunami hazards - The use of GIS in community hazard planning: Coastal Management, v. 32, no. 3, p. 243-269.

Wood, N., Ratliff, J., and Peters, J., 2013, Community exposure to tsunami hazards in California: U.S. Geological Survey Scientific Investigations Report 2012-5222, 49 p. 


\section{Appendix A. Estimation of Sheltering Needs}

The number of people using publicly provided shelters is estimated in the Hazus-MH MR5 flood loss-estimation methodology (Federal Emergency Management Agency, 2013) by

$$
\# S T P=\sum_{k=1}^{5} \sum_{m=1}^{3}\left(\alpha_{k m} * D P * H I_{k} * H A_{m}\right), \quad \text { Equation } 1
$$

where

\#STP is the number of people using established shelters, $\alpha_{k m}$ is a constant (see below),

$D P$ is displaced population,

$H I_{k}$ is percentage of population in the $k$ th income class, and $H A_{m}$ is percentage of population in $m$ th age class.

Modifying factors based on income and age is represented by the $\alpha \mathrm{km}$ constant and is defined as:

$$
\alpha_{k m}=\left(I W x I M_{k}\right)+\left(A W x A M_{m}\right), \quad \text { Equation } 2
$$

where

$I W$ is Shelter Category Weight for Income (default value is 0.80 ), $A W$ is Shelter Category Weight for Age (default value is 0.20 ), $I M_{k}$ is Relative Modification Factor for Income (values in table A1), and $A M_{m}$ is Relative Modification Factor for Age (values in table A1). 
Table 1. Relative modification factors used to estimate sheltering needs

\begin{tabular}{lllc} 
Category & Class & Description & $\begin{array}{l}\text { Default for Communities with } \\
\mathbf{6 0 \%} \text { or More of Households } \\
\text { with Income } \$ \mathbf{3 5 , 0 0 0}\end{array}$ \\
\hline Income & $\mathrm{IM}_{1}$ & Household income $<\$ 10,000$ & 0.46 \\
Income & $\mathrm{IM}_{2}$ & $\$ 10,000<$ Household income $<\$ 15,000$ & 0.36 \\
Income & $\mathrm{IM}_{3}$ & $\$ 15,000<$ Household income $<\$ 25,000$ & 0.12 \\
Income & $\mathrm{IM}_{4}$ & $\$ 25,000<$ Household income $<\$ 35,000$ & 0.05 \\
Income & $\mathrm{IM}_{5}$ & $\$ 35,000<$ Household income & 0.01 \\
Age & $\mathrm{AM}_{1}$ & Population less than 16 years old & 0.05 \\
Age & $\mathrm{AM}_{2}$ & Population between 16 and 65 years old & 0.2 \\
Age & $\mathrm{AM}_{3}$ & Population more than 65 years old & 0.5 \\
\hline
\end{tabular}




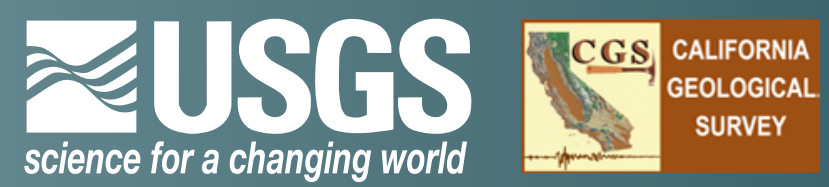

\section{Emergency Management Response to a Warning-Level Alaska-Source Tsunami Impacting California}
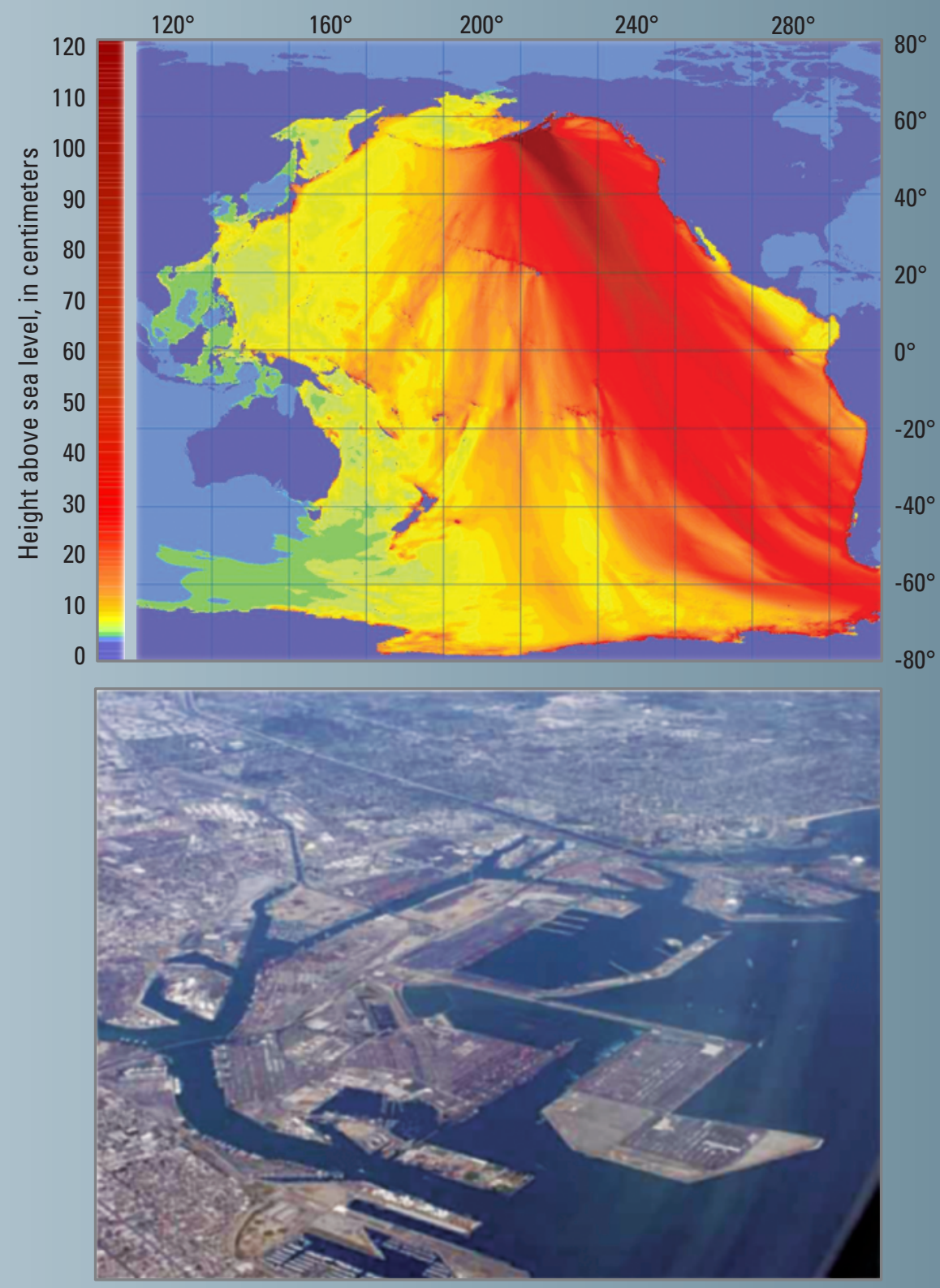

Open-File Report 2013-1170-J

California Geological Survey Special Report 229 
COVER: NOAA's modeled tsunami energy maps can highlight coastal areas of heightened concern to decision-makers. Protecting the Ports of Los Angeles and Long Beach requires extensive planning and coordination. 
The SAFRR (Science Application for Risk Reduction) Tsunami Scenario

Stephanie Ross and Lucile Jones, Editors

\section{Emergency Management Response to a Warning- Level Alaska-Source Tsunami Impacting California}

Kevin M. Miller and Kate Long

Open-File Report 2013-1170-J

California Geological Survey Special Report 229

U.S. Department of the Interior

U.S. Geological Survey 


\section{U.S. Department of the Interior SALLY JEWELL, Secretary}

\section{U.S. Geological Survey Suzette M. Kimball, Acting Director}

\section{U.S. Geological Survey, Reston, Virginia 2013}

For product and ordering information:

World Wide Web: http://www.usgs.gov/pubprod

Telephone: 1-888-ASK-USGS

For more information on the USGS-the Federal source for science about the Earth, its natural and living resources, natural hazards, and the environment:

World Wide Web: http://www.usgs.gov

Telephone: 1-888-ASK-USGS

Suggested citation:

Miller, K., and Long, K., 2013, Emergency management response to a warning-level Alaska-source tsunami impacting California, chap. J., in Ross, S.L., and Jones, L.M., eds., The SAFRR (Science Application for Risk Reduction) Tsunami Scenario: U.S. Geological Survey Open-File Report 2013-1170, 245 p., http://pubs.usgs.gov/of/2013/1170/j/.

Any use of trade, product, or firm names is for descriptive purposes only and does not imply endorsement by the U.S. Government.

Although this information product, for the most part, is in the public domain, it also may contain copyrighted materials as noted in the text. Permission to reproduce copyrighted items must be secured from the copyright owner. 


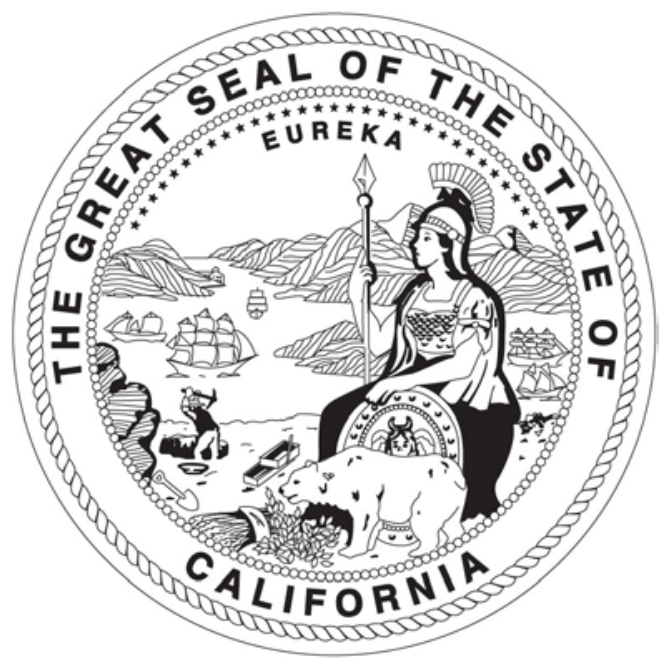

STATE OF CALIFORNIA EDMUND G. BROWN JR. GOVERNOR

THE NATURAL RESOURCES AGENCY JOHN LAIRD SECRETARY FOR RESOURCES

\author{
DEPARTMENT OF CONSERVATION \\ MARK NECHODOM \\ DIRECTOR
}

CALIFORNIA GEOLOGICAL SURVEY JOHN G. PARRISH, Ph.D. STATE GEOLOGIST 


\section{Contents}

The SAFRR (Science Application for Risk Reduction) Tsunami Scenario ................................................................ ii

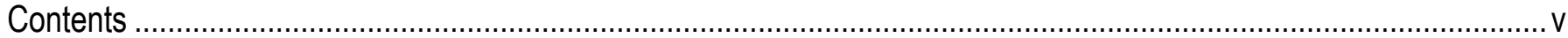

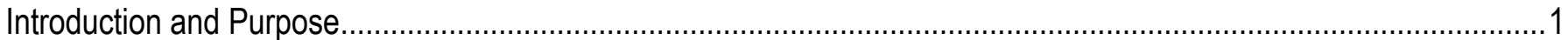

Top Down: Information Flow during Tsunami Alert and Warning .......................................................................

Federal Role in Threat Identification and Alert Dissemination ......................................................................

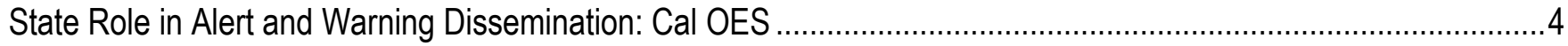

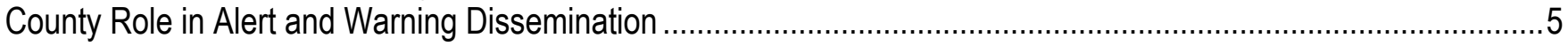

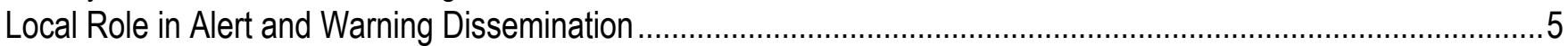

Bottom Up: Emergency Management Protocol in Response to Tsunami................................................................

All Disasters Are Local .....................................................................................................................

Across Time: The Emergency Management "Life" of a Tsunami in Seven Periods, a Timeline of Tsunami

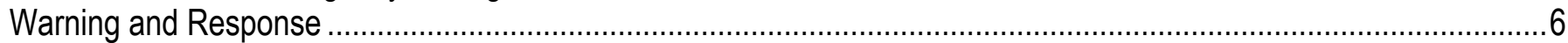

Period 1: Initial Earthquake Event and Notification ....................................................................................

General Description of Period 1 (Bulletins 1-3: Thursday March 27th 11:54 a.m. until 2:05 p.m. PDT;

0-2 hours after earthquake) .......................................................................................................

Scenario-Informed Situation, Emergency Management Activities, Key Considerations and Challenges

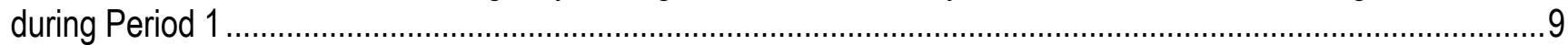

Key Considerations during Period 1 ......................................................................................................... 11

Highlighted Emergency Management Challenges during Period 1 ................................................................11

Period 2: First NOAA-Verified Alert Message at Warning Level .................................................................... 13

General Description of Period 2 (Bulletins 4-7: Thursday March 27th 2:05 p.m. through 6:01 p.m.; 2-

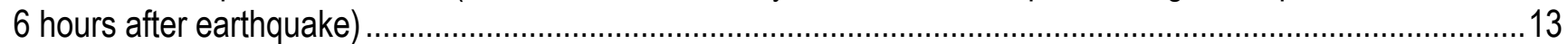

Scenario-Informed Situation, Emergency Management Activities, Key Considerations and Challenges ...............14

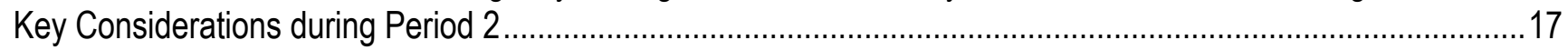

Highlighted Emergency Management Challenges during Period 2 ….............................................................17

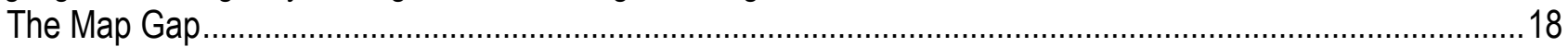

Decision Making as Information Unfolds ..........................................................................................2

Seaward Evacuation Guidance Specifics ...........................................................................................2

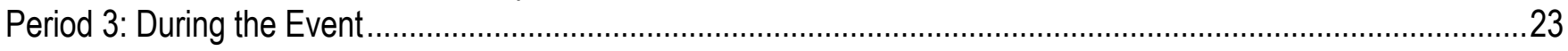

General Description of Period 3 (Bulletins 8-25: Thursday March 27th 6:01 p.m. through Friday March

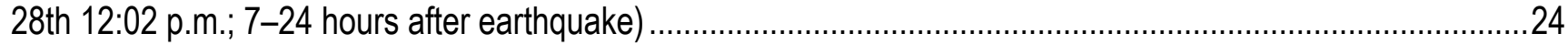

Scenario-Informed Situation, Emergency Management Activities, Key Considerations and Challenges ..............24

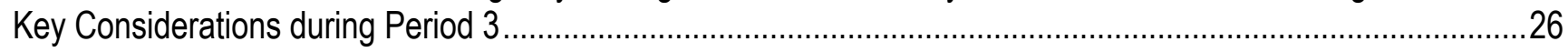

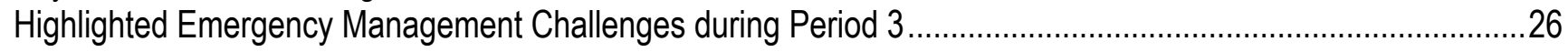

Incomplete Land Evacuations .....................................................................................................26

Keeping People From Returning to Evacuated Areas Prematurely.........................................................26

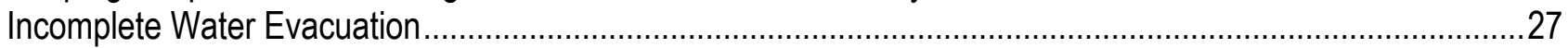

Period 4: Warning Cancelled for Specific Areas ..........................................................................................2 28

General Description of Period 4 (Bulletins 26-33: Friday March 28th 12:02 p.m. through Friday March

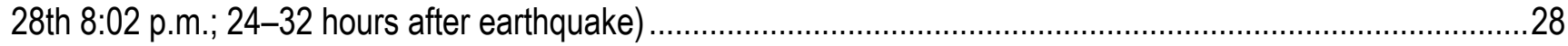

Scenario-Informed Situation, Emergency Management Activities, Key Considerations and Challenges ...............28 


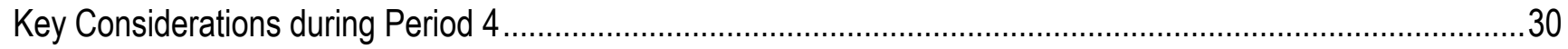

Highlighted Emergency Management Challenges during Period 4 …..........................................................30

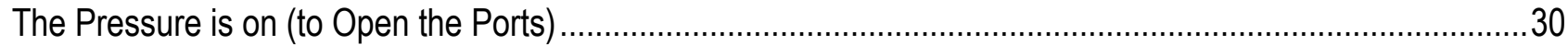

Wild Card: Fire Following Tsunami..................................................................................................

Media Control-Information Flow ...................................................................................................

Period 5: Evacuation ALL CLEAR as Determined by Each Coastal Jurisdiction ..................................................31

General Description of Period 5 (Bulletins 34-49: Friday March 28th 8:02 p.m. through Saturday March

29th 12:00 p.m.; 32-48 hours after earthquake) ..................................................................................... 31

Scenario-Informed Situation, Emergency Management Activities, Key Considerations and Challenges ..............32

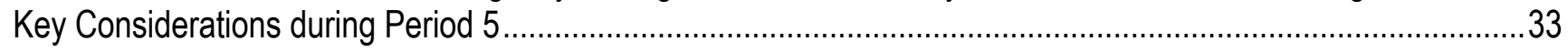

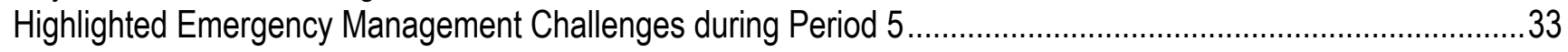

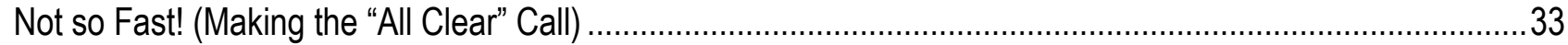

Phased Reentry ......................................................................................................................

Wild Card: Blockage in a Major Port Channel..............................................................................33

Period 6: Advisory CANCELLATION for Coastal Waterways ………………………………........................... 34

General Description of Period 6 (Bulletin 50: Saturday March 29th 12:00 p.m.; 48 hours after

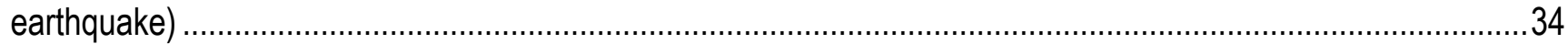

Scenario-Informed Situation, Emergency Management Activities, Key Considerations and Challenges ...............34

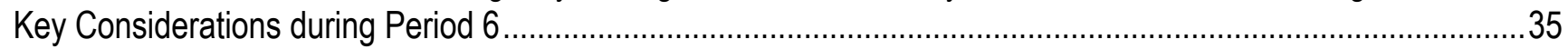

Highlighted Emergency Management Challenges during Period 6 ................................................................

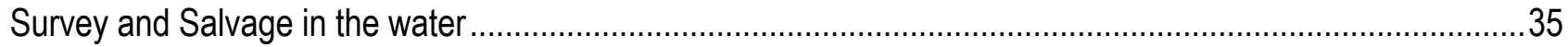

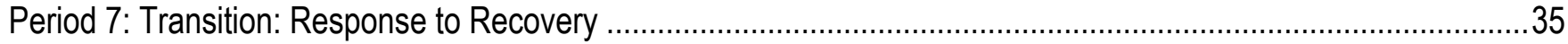

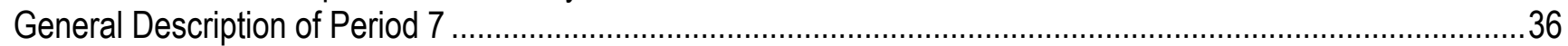

Scenario-Informed Situation, Emergency Management Activities, Key Considerations and Challenges ................36

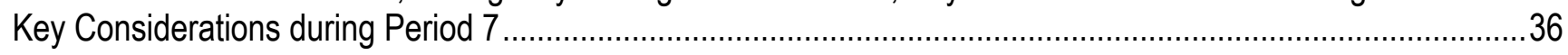

Highlighted Emergency Management Challenges during Period 7 ..................................................................37

Quick and Accurate Damage Assessments are Important ........................................................................37

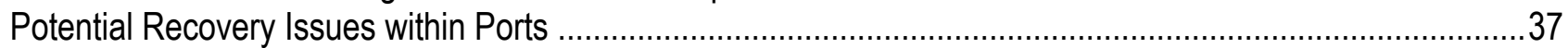

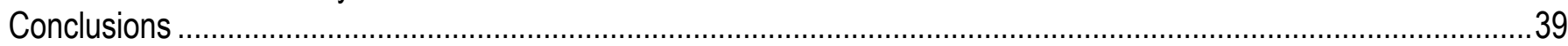

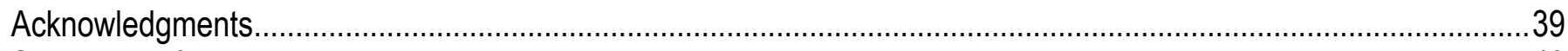

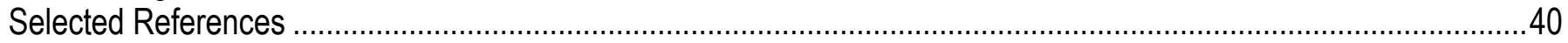

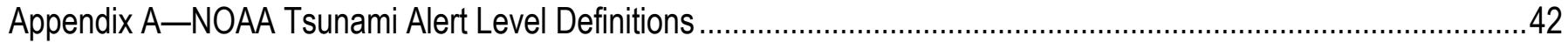

Appendix B-NOAA WCATWC Tsunami Scenario Alert Bulletins ........................................................................... 44 


\title{
Emergency Management Response to a Warning- Level Alaska-Source Tsunami Impacting California
}

\author{
By Kevin M. Miller ${ }^{1}$ and Kate Long ${ }^{1}$
}

\section{Introduction and Purpose}

This chapter is directed towards two audiences: Firstly, it targets nonemergency management readers, providing them with insight on the process and challenges facing emergency managers in responding to tsunami Warning, particularly given this "short fuse" scenario. It is called "short fuse" because there is only a 5.5-hour window following the earthquake before arrival of the tsunami within which to evaluate the threat, disseminate alert and warning messages, and respond. This action initiates a period when crisis communication is of paramount importance. An additional dynamic that is important to note is that within 15 minutes of the earthquake, the National Oceanic and Atmospheric Administration (NOAA) and the National Weather Service (NWS) will issue alert bulletins for the entire Pacific Coast. This is one-half the time actually presented by recent tsunamis from Japan, Chile, and Samoa. Second, the chapter provides emergency managers at all levels with insights into key considerations they may need to address in order to augment their existing plans and effectively respond to tsunami events.

We look at emergency management response to the tsunami threat from three perspectives:

- "Top Down" (Threat analysis and Alert/Warning information from the Federal agency charged with Alert and Warning)

- "Bottom Up" (Emergency management's Incident Command approach to responding to emergencies and disasters based on the needs of impacted local jurisdictions)

- "Across Time" (From the initiating earthquake event through emergency response) We focus on these questions:

- What are the government roles, relationships, and products that support Tsunami Alert and Warning dissemination? (Emergency Planning and Preparedness.)

- What roles, relationships, and products support emergency management response to Tsunami Warning and impact? (Engendering prudent public safety response.)

- What are the key emergency management activities, considerations, and challenges brought out by the SAFRR tsunami scenario? (Real emergencies)

- How do these activities, considerations, and challenges play out as the tsunami event unfolds across the "life" of the event? (Lessons)

\footnotetext{
${ }^{1}$ California Governor's Office of Emergency Services (Cal OES)
} 


\section{Top Down: Information Flow during Tsunami Alert and Warning}

Certain potentially life-threatening or damaging emergency/disaster events, such as earthquakes and terrorist attacks, are referred to as "no notice" or sudden-onset events by emergency managers. These events do not provide advance warnings. Other threats, such as hurricanes - and a "distant source" tsunami like the one discussed in this scenario-provide emergency managers with the opportunity to warn the public and provide life-safety instructions. For "advance notice" events such as distant source tsunamis, Alert and Warning dissemination is the initial key emergency-management-related function, central to minimizing loss of life, injury and, to some extent, property damage. Timely Warning notification to all potentially affected areas is undertaken using a central information source and delivered through multiple, redundant, backup communication channels as illustrated by figure 1 .

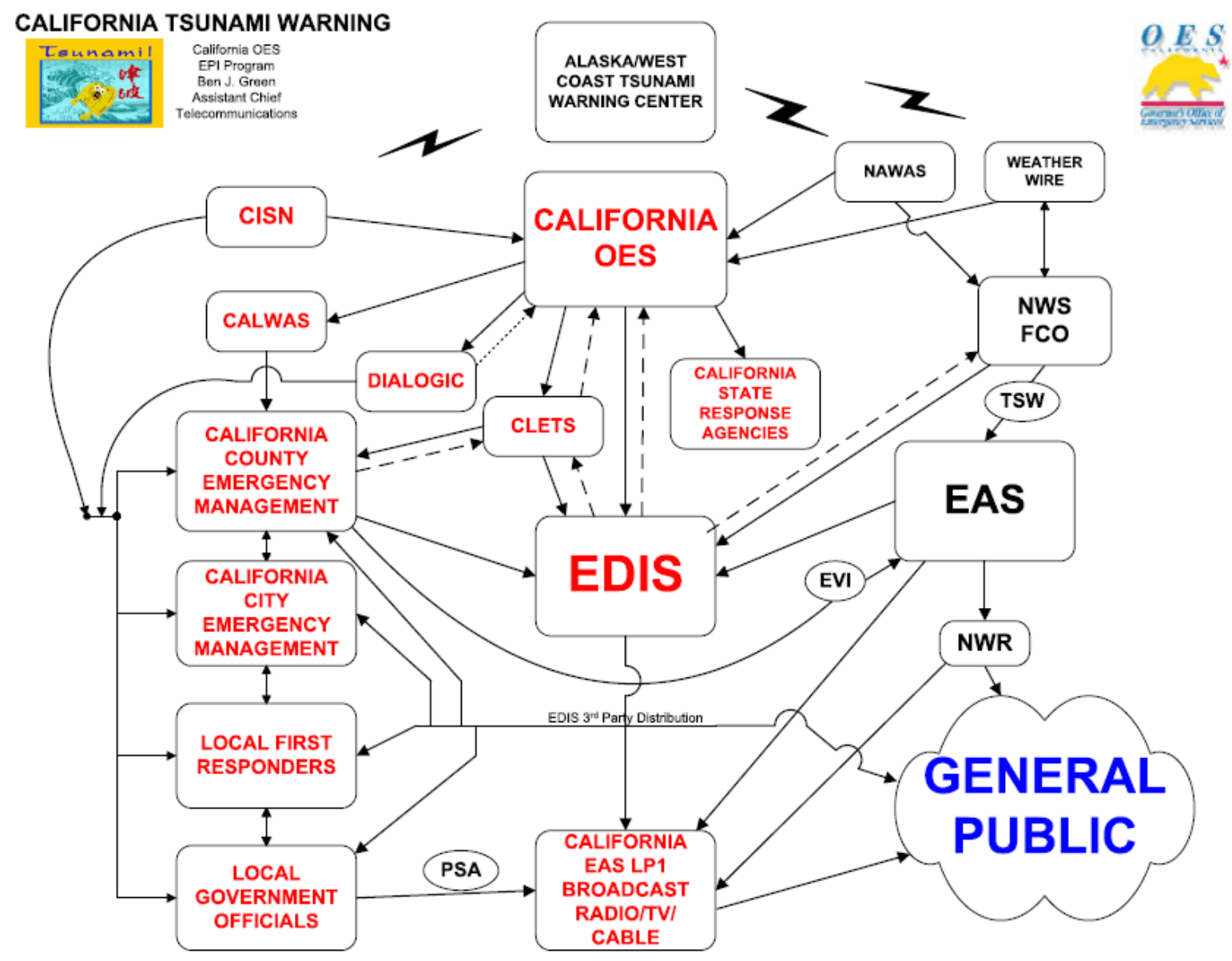

Figure 1. Flow diagram showing how Alert and Warning dissemination is "top down," from Federal to State to local. Courtesy of Ben Green, California Governor's Office of Emergency Services. 


\section{Federal Role in Threat Identification and Alert Dissemination}

The National Oceanographic and Atmospheric Administration (NOAA) is the federally designated agency responsible for official alert and warning for a tsunami, generated anywhere in the world, that may impact U.S. states and territories. The Tsunami Warning and Education Act of 2006 (TWEA) was passed by Congress following the devastating Indian Ocean tsunami. The purpose of this law was to authorize and strengthen the tsunami detection, forecast, warning, and mitigation program of NOAA, to be carried out by its component agency, the National Weather Service (NWS). This is done by the agency's two Warning Centers through their alert and notification responsibilities. For the U.S. West Coast, including California, these alerts are issued by NOAA's West Coast and Alaska Tsunami Warning Center (WCATWC) in Palmer, Alaska. The WCATWC has most of North America under its Area Of Responsibility (AOR), while NOAA's Pacific Tsunami Warning Center (PTWC) in Hawaii provides alerts to the remainder of the Pacific Basin (see fig. 2). TWEA also vested NOAA and the Warning Centers with responsibilities for international coordination for detection, warnings, and outreach for tsunamis. The full responsibilities of the Warning Centers include (A) continuously monitoring data from seismological, deep ocean, and tidal monitoring stations; (B) evaluating earthquakes that have the potential to generate tsunamis; (C) evaluating deep ocean buoy data and tidal monitoring stations for indications of tsunamis resulting from earthquakes and other sources; and (D) disseminating forecasts and tsunami Warning Bulletins to Federal, State, and local government officials and the public.

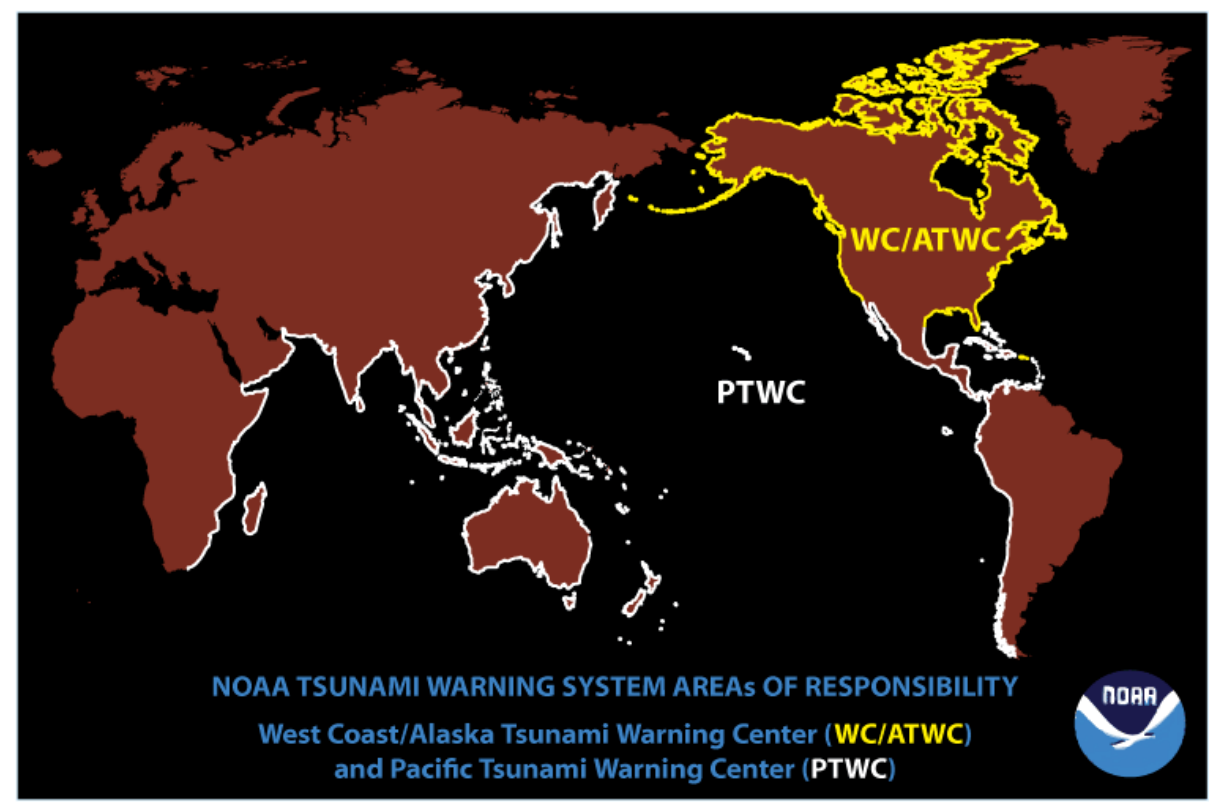

Figure 2. World map showing Areas of Responsibility (AOR) of the two Tsunami Warning Centers of the National Oceanic and Atmospheric Administration (NOAA). Courtesy NOAA.

NOAA uses four levels of tsunami alert in the United States; they are, in order of decreasing urgency: Warning, Advisory, Watch, and Information Statement. Each has a distinct 
meaning relating to local emergency response (fig. 3). For a more detailed explanation of alert levels, see appendix A

\begin{tabular}{|l|l|l|}
\hline Alert Level & Threat & Action \\
\hline WarningWarning & Inundating wave possible & Full evacuation suggested \\
\hline AdvisoryAdvisory & Strong currents likely & Stay away from the shore \\
\hline Watch & & \\
\hline Information & Danger level not known yet & Stay alert for more information \\
\hline I & & \\
\hline
\end{tabular}

Figure 3. Table of the NOAA tsunami alert levels, each with distinct meaning relating to local emergency response.

\section{State Role in Alert and Warning Dissemination: Cal OES}

The California State Warning Center (CSWC), operated by the California Governor's Office of Emergency Services (Cal OES), is the designated "Warning Point" agency for dissemination of alerts issued by the WCATWC. CSWC is notified of the potential tsunami by WCATWC, simultaneously through various, redundant notification systems initiated at the Federal level, and this notice is then forwarded by the State to local level Warning Points (figure $1)$.

For alert and warning for potential tsunami, Cal OES's primary roles as designated State Warning Point are to (1) receive Tsunami Information Bulletins from WCATWC; (2) relay the messages to potentially impacted Operational Areas (counties); and (3) provide ongoing liaison between the WCATWC and potentially impacted California counties. CSWC is only authorized to communicate the original WCATWC tsunami alert; it does not undertake any threat analysis and will not advise local governments regarding response issues, such as Emergency Operations Center (EOC) activations or evacuations.

Upon receipt of WCATWC's initial Alert Bulletin, CSWC forwards the information to the Cal OES Earthquake and Tsunami and regional duty officers and to county emergency management offices. The CSWC also notifies the Cal OES Regional Duty Officer for all active Watch and Warning alerts issued in their area of responsibility. The Cal OES Regional Duty Officer will verify that counties, unincorporated areas, and special districts within their area of responsibility have received the CSWC Watch/Advisory/Warning alerts. All information from the WCATWC is passed directly to the county via redundant methods. 


\section{County Role in Alert and Warning Dissemination}

Counties receive information from Cal OES through their designated Warning Point, and they provide threat notification to jurisdictions within. The Warning Point agency designated by each county may vary. County governments are responsible for notifying their constituent cities and special districts through multiple, redundant means. In addition, they notify county departments (sheriff, fire, medical, harbor, and so forth) as appropriate. Examples of county departments with Warning-response and event-response roles include Emergency Operations/Management Departments; local police dispatch centers (coastal cities' police agencies and coastal sheriff substations); County Fire Emergency Command and Control Centers; Department of Public Works Dispatch Centers; Department of Health Services; Departments of Beaches and Harbors; Airport Police; and Ports.

In the case of a Warning-level tsunami alert, evacuation within each city is the responsibility of that local jurisdiction; however the county may assist cities and special districts in evacuation and provide wider traffic control. In addition, for unincorporated county areas, the county is the "local authority" ordering evacuations. The county will use the Emergency Alert System (EAS) through local radio and television stations to deliver tsunami Warning and evacuation messages. Additional methods used to evacuate the public may include emergency service units using public alert systems, door-to-door notification, media announcements; announcements on Travelers Information Service; and sounding of sirens (for example, a steady blast indicates peacetime emergency), if available.

\section{Local Role in Alert and Warning Dissemination}

This chapter highlights issues presented by the SAFRR (Science Application for Risk Reduction) tsunami scenario to the Port of Los Angeles (POLA) and Port of Long Beach (POLB), both in Los Angeles County. We use the Ports of Los Angeles and Long Beach as an example of local entities and how they might respond to this scenario. This is by no means intended to represent all possibilities in California, because there are many types of communities, small marinas, coastal cities, beaches, parks, and so on along the State's 1,100-mile coastline. We describe this particular community's response as a way to demonstrate the flow of information and manner of operational response by the emergency management system from Federal to State to county to local level, addressing needs at all levels during an ongoing tsunami emergency, from beginning to end. The local level is where the public will be most influenced by emergency actions designed to protect lives and property.

All orders for evacuation within a given local jurisdiction are under the authority and responsibility of that jurisdiction. The local role is not only disseminating warnings, but executing all evacuation orders and related public safety actions. In Los Angeles County, immediate alert notification is made by the County Warning Point to the Los Angeles County Department of Beaches and Harbors, the U.S. Coast Guard Los Angeles Command Center/Los Angeles Station; the Port of Los Angeles Police, and the Port of Long Beach Police. The Port of Los Angeles is within the City of Los Angeles, which has civil authority over evacuation. The Port of Long Beach is within the City of Long Beach, which has civil authority over its 
evacuation. The roles of the Cities of Los Angeles and Long Beach and Port Authority in Alert and Warning dissemination cross over into response actions resulting from the Warning, and they will be discussed further in the next section.

\section{Bottom Up: Emergency Management Protocol in Response to Tsunami}

\section{All Disasters Are Local}

Although Alert and Warning (identification of a tsunami threat and dissemination of that threat) described in the previous section cascade "top down" from the WCATWC, the actual emergency management response activities undertaken to save lives and protect property-both during the WARNING period and event response operations - are "bottom up" from the local jurisdiction. Both legal authorities and the actual way agencies are organized to coordinate delivery of emergency management services acknowledge a basic concept: "All disasters are local."

From car accidents to crime scenes to freeway closures, most emergencies are "manageable" enough to be resolved by the local authority. Emergency services organizations, including police, fire, ambulance, and emergency management, successfully address such daily emergencies as their normal routine. However, some emergency events become so large or complex that local resources are exhausted and external resources must be brought to bear. In emergency management parlance, when available response resources are insufficient, local authorities are unable to effectively stabilize life-safety and property protection threats, and an emergency transitions to a "disaster." However, it is important to note that even when an emergency becomes a disaster that requires multiagency management, the emergency services community still adheres to the "All disasters are local" concept, meaning local governments remain in charge. That is, official response to all emergencies is determined by local need, at local direction. When a local jurisdiction requests help from other entities, be they county, State or Federal, the assisting jurisdictions and resources are provided in support of the affected jurisdiction; the affected jurisdiction retains its authorities, responsibilities, and command of the incident.

The complexity of emergency management coordination comes as disaster events impact multiple jurisdictions and more than one individual "incident" occurs. The example provided by the SAFRR tsunami scenario has broad impacts on coastal counties across California. Such an event exponentially increases the number of agencies needed to respond and the need for prioritization of scarce resources across jurisdictions in need.

\section{Across Time: The Emergency Management "Life" of a Tsunami in Seven Periods, a Timeline of Tsunami Warning and Response}

The following sections discuss key emergency management considerations and issues raised in this SAFRR tsunami scenario, with emphasis on how they relate to the Ports of Los Angeles and Long Beach as an example of a local response, affecting those on the immediate coast. During recent tsunamis affecting California, the course of action in activating and 
operating the emergency management system has followed a timeline that, for the purposes of this chapter, is described via seven general time periods.

Period 1: $\quad$ Initial Earthquake Event Notification

Prior to NOAA verification of tsunamigenic hazard, via Alert Bulletin at a level considered actionable by emergency managers (Advisory or Warning). State and local government notification of earthquake from U.S. Geological Survey (USGS) via pager or California Integrated Seismic Network (CISN) Display

Period 2: $\quad$ First NOAA-verified Alert Message at Warning Level

From first verified NOAA Alert-level Bulletin through the arrival of first waves in California. Includes local government actions in issuing Evacuation Orders and other pronouncements.

Period 3: $\quad$ During the Event

From first wave arrival in California through Warning cancellation

Period 4: $\quad$ Warning cancelled for specific areas

Advisory still in place in those areas

Period 5: $\quad$ Evacuation ALL CLEAR as determined by each coastal jurisdiction Advisory still in place for those jurisdictions

Period 6: $\quad$ Advisory CANCELLATION

Emergency Response Actions continue

Period 7: $\quad$ Transition: Response to Recovery

\section{Period 1: Initial Earthquake Event and Notification}

When a large, undersea earthquake occurs, it is the responsibility of the Federal government through NOAA's Tsunami Warning Centers to notify states within their area of responsibility of potentially imminent danger and assess, evaluate, and confirm any threat.

General Description of Period 1 (Bulletins 1-3: Thursday March 27th 11:54 a.m. until 2:05 p.m. PDT; 0-2 hours after earthquake)

Immediately following the identification of an earthquake around the Pacific Ocean with tsunamigenic potential on the west coast, NOAA's West Coast and Alaska Tsunami Warning Center (WCATWC) begins preliminary evaluation to determine whether a tsunami has actually been generated and what areas are forecasted for impact. Databases of preexisting numerical tsunami model results are matched against the location and magnitude of the earthquake, and historical data are analyzed. Pending this assessment, initial alert bulletins from WCATWC can often be limited to an Information Statement. If the earthquake event warrants, the initial bulletin(s) may immediately place potentially impacted areas of the State at the Watch or Warning level. Particularly for areas very close to the origin of the earthquake, a Warning level of alert will be immediate, weighing the need to have urgent timely advice over the need for increased confidence through additional data and analysis. Both Advisory and Warning level 
alert bulletins will trigger response actions by emergency managers. The WCATWC begins initial conference calls with State-level Warning Points and National Weather Service-Warning Forecast Offices (WFOs). As California's Warning Point, Cal OES makes initial contact with the impacted coastal counties to prepare for subsequent briefings as situation emerges. 
Scenario-Informed Situation, Emergency Management Activities, Key Considerations and Challenges during Period 1

On Thursday, March 27, 2014, a large earthquake occurs offshore at 11:50 a.m. PDT (local California time) offshore the Alaska Peninsula region of Alaska. The earthquake is located in the vicinity of a known subduction zone, under the Aleutian trench, which is capable of producing dangerous tsunamis with potential to seriously impact the coastline of California. Initially, the only information known is a magnitude and location of the earthquake. Preliminary earthquake information relayed by automated alerting systems (Advanced National Seismic System, USGS, CISN, and the WCATWC) indicates an unverified magnitude of 8.2.

- Immediately following identification of an earthquake around the Pacific Ocean of the size and location that might generate a tsunami on the west coast, NOAA's West Coast and Alaska Tsunami Warning Center (WCATWC) begins preliminary evaluation to determine whether a tsunami has actually been generated and which areas are forecasted for impact. At the WCATWC, databases of preexisting numerical tsunami model results are matched against the location and magnitude of the earthquake. In the case of this SAFRR scenario earthquake, the initially identified size and location of the event make it of immediate concern.

- Based on seismic information alone, NOAA/NWS Bulletin \#1 is issued by WCATWC within 3 minutes after the earthquake. Bulletin \#1 projects first wave arrival in Los Angeles at 5:35 pm, 5 hours 45 minutes from issuance of this message.

- Bulletin \#1 initiates a Watch-level alert for the entire coastline of California, Oregon, and Washington States. A Watch activates the Emergency Alert System, which automatically and simultaneously relays notifications about the possible tsunami to emergency management systems and personnel, television, and radio stations. TV Stations begin scrolling a crawler message across their video programming "TSUNAMI WATCH FOR CALIFORNIA."

- The information in the initial WCATWC Bulletin is based solely on seismic readings and provides early information about estimated initial tsunami surge arrival times for points on the coast of California. In the SAFRR tsunami scenario Bulletin \#1, arrival time estimates are provided (as with all bulletins) within an expected accuracy of plus or minus 15 minutes. 
ESTIMATED ARRIVAL TIMES FOR CALIFORNIA

CRESCENT CITY

SAN FRANCISCO

SANTA BARBARA

SAN PEDRO

LA JOLLA
4:12 p.m PDT MAR 27

5:06 p.m. PDT MAR 27

5:21 p.m. PDT MAR 27

5:37 p.m. PDT MAR 27

5:48 p.m. PDT MAR 27

Figure 4. NOAA/NWS/WCATWC Bulletin \#1: estimated initial tsunami surge arrival times

- At the local level, the Cities of Los Angeles and Long Beach, each responsible for determining the local need for evacuation orders, must stand by for WCATWC's next alert bulletins for determination that a tsunami has actually been generated. Evacuation may be considered costly monetarily, in terms of public safety, and in terms of public confidence. However, Bulletin \#1 indicates that if a tsunami has been generated, it will arrive in less than 6 hours. In the case of a subsequent Warning-level alert, extensive evacuations could be triggered that could take as long as 6 hours. The time window to take appropriate action is already abutting Bulletin \#1; the jurisdictions must poise senior decision makers to be able to order evacuations quickly once WCATWC confirms the threat, and they wait anxiously for additional information.

- The State Warning Center and all Warning Points in California coastal counties, the U.S. Coast Guard, the U.S. Navy, and the public, including the media, are automatically notified of the WATCH simultaneously through the variety of existing systems and backup notification systems described earlier in this chapter. During this period, the WCATWC begins evaluation based on forecast models to determine whether the WATCH status will be upgraded, cancelled, or remain the same upon issuance of the next Alert Bulletin \#2.

- Bulletin \#2 is issued and California remains in WATCH status pending continued evaluation of forecast models. Bulletin \#2 arrives at 12:31 p.m. PDT and indicates an updated magnitude - the earthquake has now been adjusted to magnitude 8.6. Any earthquake above magnitude 7.5 on a submarine thrust fault has a strong potential to generate a tsunami.

- WCATWC initiates its first West Coast conference call conducted to provide state Warning Points and weather forecast officers with the latest available forecast analysis, as well as observed information, as available. Geographic areas of heightened concern are called out and discussed, each state is polled for attendance and concerns, and a question/answer exchange provided. Participants include the Cal OES Earthquake and Tsunami Duty Officer, California State Warning Center, and coastal NWS Weather Forecast Meteorologists. Counterparts are on the line from Alaska, Washington, Oregon, and British Columbia. Technical information received from WCATWC calls includes specific areas/locations of heightened concern based on initial wave arrival times, forecast wave heights, and normal tide conditions.

- The Cal OES Executive Duty Officer, Earthquake and Tsunami Duty Officer, and California State Warning Center confer and agree on the need to initiate the first statewide conference 
call to 20 coastal county emergency managers. These counties are (from north to south): Del Norte, Humboldt, Mendocino, Sonoma, Marin, Napa, Solano, Contra Costa, San Francisco, Alameda, San Mateo, Santa Clara, Santa Cruz, Monterey, San Luis Obispo, Santa Barbara, Ventura, Los Angeles, Orange, and San Diego.

- Bulletin \#3 is issued, and California remains in WATCH status pending continued evaluation of forecast models. Bulletin \#3 is issued at 1:03 p.m. and indicates another updated magnitude of the earthquake to M9.0. Depending on depth and earthquake mechanism, a large tsunami can easily be expected from an earthquake of this magnitude. The possibility of its adversely affecting California's entire coast is now a strong possibility.

- The most important actions during this period are (1) notifications and (2) information flow and exchange from WCATWC to the State, to the counties, and to coastal cities.

\section{Key Considerations during Period 1}

Key emergency management considerations during this period include:

1.1 Confirm receipt and notification of initial information from WCATWC across entities responsible for public safety at Federal (for example, Coast Guard), state, county, and local jurisdictions.

1.2 Focus on prioritized areas of highest concern, based on wave amplitude and arrival time.

1.3 Analyze tide conditions at arrival times. Prepare for proper response and protective measure actions.

1.4 For Port Captains, assess which vessels will be at high risk during tsunami or carry cargo that could create a hazardous condition in the event of vessel damage (especially liquid bulk, including petroleum). Evaluate timing necessary and prioritize potential vessel evacuation.

1.5 Ensure private entities with responsibility in ports and marinas are included in the information loop; establish contacts for coordination between port and local jurisdiction emergency managers with jurisdictional responsibility for land evacuations.

1.6 Within potentially impacted jurisdictions, use WATCH period to review emergency plans, identify areas in danger with highest priority, and be poised to initiate immediate action should an Advisory or Warning be issued.

1.7 Assess local offshore (storm) conditions. Consider compounding factors: Darkness and high tide—sunset is at 1815; high tide builds and peaks at 2000, 2 hours and 30 minutes after initial wave arrival in Los Angeles/Long Beach. (High tide will be occurring atop continued, worsening tsunami surges in the initial arrival of this event). Build in conservative interpretation for potential errors in forecasted amplitudes and arrival times.

1.8 Begin coordination with media; disseminate correct information about Watch and how public should respond if Alert Level moves to Advisory or Warning. Ensure media are briefed on how to disseminate evacuation information based on local jurisdiction authority.

1.9 Contend with public perception and possible traffic issues where those in coastal areas begin to selfevacuate based on WATCH information and media coverage.

\section{Highlighted Emergency Management Challenges during Period 1}

This scenario tsunami would be the most serious tsunami event in the United States since Alaska 1964. In fact, a similar actual tsunami hitting the same areas today could become the worst in U.S. history, given increased development in low-lying areas along the coasts of California, Oregon, Washington, Alaska, and Hawaii. Emergency managers across California have extensive and well exercised emergency plans, but the potential need to fully address landbased and ocean-based evacuations as well as infrastructure protection within a short number of hours will present challenges that may only become apparent as the disaster unfolds. This 
scenario provides an opportunity to raise and examine consequential issues that have not been understood nor addressed through previous experience.

The Warning level tsunami from Alaska will provide specific challenges to ensuring that port authorities, harbormasters, ship and boat owners and operators, and terminal operators are all properly notified. Evacuation considerations must address appropriate groups with potentially differing recommendations based on ship size, which ships are appropriate to send to sea, and how much time is available and needed by each vessel to do so. Large military, container, and cruise ships have different requirements and capabilities when it comes to going to the open ocean from mid-size fishing vessels and from small recreational, private yachts and boats. Who you send to sea will depend on weather conditions. Small operators must consider having enough fuel for extended periods (2-4 days for this event) and whether they have the seagoing ability to get to distant ports if the home port is destroyed. This may sound far-fetched, but it is exactly what happened to Crescent City Harbor in the 2011 Tohoku, Japan, tsunami. For large ships, the time needed to get crew aboard to allow the vessel to depart may be more critical than seagoing capability. How much time is required to board and move to an offshore depth safe from dangerous tsunami currents and whether this time fits within the 3-4 hour window of safety becomes critical.

The public's primary source of information during a disaster is not directly from emergency management personnel, but rather from the media. The automated NOAA alerts available to emergency managers are simultaneously available to the media, and they constitute "breaking news"- meaning the media will voraciously seek information. It is important for emergency managers to coordinate messaging and be able to provide the media with accurate public safety information, in order to give the public correct instructions about what they need to do to protect themselves. California media outlets largely understand that the correct safety information for the west coast is coming out of the West Coast Alaska Tsunami Warning Center (WCATWC), but this understanding may not be universal, especially at the level of the national media. In addition to providing information, emergency management organizations must monitor the media to correct misinformation, hearsay, and self-appointed experts.

Initial focus in the media in recent events has been on expected first-wave arrival times and projected wave height, provided in the Warnings. A vital point not typically addressed by media is the dangerous tsunami activity that occurs after the first wave. Since the public will get their information from the media, rather than from emergency managers directly. It is important for the media to understand that the first wave is almost never the largest, that waves may last for many hours (47 in this event). People's returning after the first wave, thinking it is safe and that danger has passed, accounts for many unnecessary deaths in tsunamis. Additionally, tsunamis are not surfable. There is generally no breaking wave face, they are driven by a push of water hundreds of miles long, they create strong, unpredictable currents, and they carry sediment and dangerous, deadly debris. An additional key element of information is the time of expected high tide. This can make a huge difference in whether a section of coast is inundated or not by simply the timing of tsunami surges with respect to low or high tide.

Additional topics for emergency management education and coordination with media include explanations of how to respond to NOAA-issued Tsunami Alerts (WATCH, Warning, and Advisory; contextual historical tsunami information relative to the current tsunami and geographic areas affected; explanations of warning signs that a tsunami is coming (official vs. natural warning); definitions of tsunami terminology; provision of Web resources; and information about tsunami detection and forecasting. The media must also be provided timely 
information on what emergency-response safety measures are being undertaken and where, including information about evacuation areas, routes, shelters, and real-time updates of important developments as they occur.

\section{Period 2: First NOAA-Verified Alert Message at Warning Level}

During Period 2 the state is responsible for disseminating and clarifying actionable information coming from NOAA/WCATWC, and for offering assistance to local governments. Local governments must notify their affected populations and secure their safety, through evacuation and other measures, during this period.

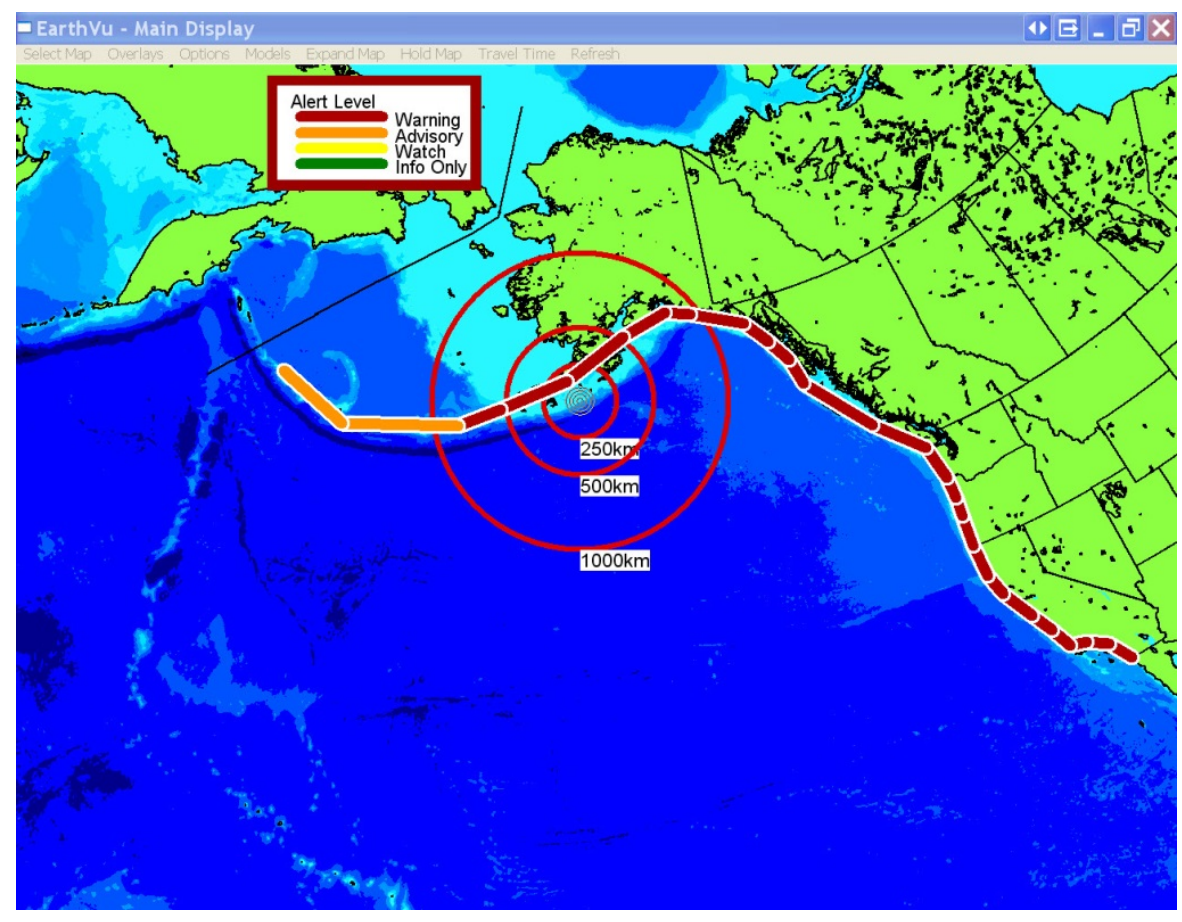

Figure 5. Annotated map of northeast Pacific Ocean and adjacent lands constituting Bulletin \#4 Alert Status of West Coast: Warning. Courtesy WCATWC.

General Description of Period 2 (Bulletins 4-7: Thursday March 27th 2:05 p.m. through 6:01 p.m.; 2-6 hours after earthquake)

Bulletin 4 has been received and, based on observed readings from deep ocean buoys and coastal tide gauges, the WCATWC confirmed that a tsunami had been generated and issued an alert bulletin placing the entire California coastline in a Warning.

The Warning message in the Bulletin 4 now reads:

"Tsunami warning in effect for the coastal areas of California from the California-Mexico border to the Oregon-California border impacts for tsunami warning areas. 
Impacts for tsunami warning areas:

- Widespread dangerous coastal flooding accompanied by powerful currents is possible and may continue for many hours after tsunami arrival.

- The first wave may not be the largest.

Recommended actions:

- If you are in a warning area - move inland to higher ground.

- Be alert to instructions from your local emergency officials.

- Do not go to the coast to observe the tsunami.

- Do not return to the coast until local emergency officials indicate it is safe to do so."

During the time between Warning for California and first wave arrival, the WCATWC continues to acquire additional information as the tsunami passes successive deep ocean buoys or coastal tide gauges, adjusts the initial modeling forecasts, and continues to use sequentially numbered bulletins to update not only the alert level, but forecasts for first-wave arrival times and projected wave amplitudes. Schedules for periodic briefing calls are initiated between the WCATWC and State Warning Points. Cal OES initiates a similar schedule for communication with State agencies and all 20 potentially impacted counties on the coast. Counties in turn ensure communication is continued with their city jurisdictions, special districts, and especially to impacted sectors such as ports and marinas. The California Geological Survey deploys tsunami observation teams to predetermined locations to provide updates to Cal OES and the impacted counties after the tsunami arrives.

Emergency Operations Centers begin to activate at the port, local jurisdiction, county, and state level. The U.S. Coast Guard activates its protocol for Planned Response to a tsunami. This includes provision of mutual aid to the Ports and affected jurisdictions statewide to support eventual search and rescue operations, launch of coast guard air asset support according to policy, notification of commercial vessels and applicable facilities of the tsunami Warning, closing of ports to all inbound vessel traffic and encouraging vessels to move to a safe location, and conducting of patrols of waterways within the affected zone to ensure maritime security. The Federal Emergency Management Agency (FEMA) activates its Regional Operations Center. Local emergency managers initiate plans, including evacuation if warranted, and recommended protective measures as necessary. City and/or county emergency managers are responsible for determining if land evacuations are necessary in the ports. Harbormasters determine efficacy and timing for allowed departure of vessels from harbors and marinas, or recommend that boats do not leave if their owners are not prepared to stay offshore for an extended period of time. All evacuations and protective emergency measures must commence quickly and be completed or established prior to first wave arrival. Based on need, local jurisdictions may request Mutual Aid, or state assistance using established assistance request processes.

Scenario-Informed Situation, Emergency Management Activities, Key Considerations and Challenges 
Approximately 2 hours and 15 minutes after the earthquake, at 2:05 p.m., (2 hours and 9 minutes after the initial WCATWC WATCH Bulletin), Bulletin \#4 puts California into a Warning with approximately 3 hours and 30 minutes remaining to the start of tsunami, at 5:35 p.m., along the Los Angeles coast. The challenge now becomes enacting all decisions to quickly engender desired response actions to adequately inform and protect the public within this remaining window of time.

At all levels of emergency management, Emergency Operations Centers are fully activated. Trained emergency personnel are called in to staff functions of the incident command structure. Cooperating State, Federal, and local agencies assume liaison roles upon request.

- To convey situational information, Cal OES convenes its first statewide conference call with the 20 coastal county emergency managers and establishes a schedule for subsequent hourly update calls. The purpose of these calls is to relay technical information received on the WCATWC call with Cal OES as the State's Warning Point, as well as address concerns, answer questions, focus on any specific areas of heightened concern based on information provided in the bulletins or otherwise, and receive information from county emergency managers on the coast. Each county will in turn conduct information exchange among its cities and districts.

On the statewide call, participating counties include all 20 of California's coastal counties. Also in attendance are: regional agencies (for example, Metropolitan Transportation Commission), State agencies (for example, California Geological Survey, California State Parks, Department of Fish and Wildlife, Caltrans, Department of Health Services, Department of Water Resources, CalFire), Federal agencies (for example, USGS, NOAA, USCG, U.S. Navy) and NOAA Weather Forecast Meteorologists from the Eureka, Monterey, Oxnard, San Diego, and Sacramento offices.

- Hourly WCATWC calls with West Coast Warning Points and Cal OES statewide conference calls continue. Statewide coordination calls progressively focus on specific areas or locations of heightened concern based on initial wave arrival times, forecast wave heights, and normal tide conditions.

- Additional discussions on statewide calls include exchange of information regarding protective measures and emergency response actions being taken by counties (cities, ports, terminals), consistency of public information messaging and media coordination, whether State assistance is needed or being received (for example, reconnaissance flights, changeable message road signs, responders), evacuations being conducted (City of Long Beach, Ports, Los Angeles), and shelters being opened. This information will also be provided via situational reports from each operational area (county) for each 12-hour staffing period.

- Emergency Operations Centers (EOCs) at all jurisdictional levels develop their strategic plans (objectives, course of action) and a staffing pattern for the following 12-hour period. The California Geological Survey sends observers to safe locations along the coast to provide real-time, trusted, subject matter expert observations back to the State. Public Information is coordinated through the Office of Public Information at Cal OES Headquarters. Staff from various State and Federal agencies continue to arrive at the State Operations Center in Sacramento and Regional Emergency Operation Centers in the Bay Area and Southern California and may then be deployed to the field to begin assisting with response activities and damage assessment in the most affected coastal counties. 
- According to Bulletin \#4, first-wave arrival time at San Pedro in the Port of Los Angeles is projected to be as little as $3 \frac{1}{2}$ hours away. The decision to begin evacuations must be executed so that evacuations can begin immediately. For cities on the coast with local geographic public safety responsibility, the change from Watch to Warning has triggered the need for the important evacuation decision within the entity's area of jurisdiction. This includes all areas within the city limits, unincorporated county, and county and state beaches. For the Port of Los Angeles, the jurisdiction responsible for ordering evacuation is the City of Los Angeles. For the Port of Long Beach, the jurisdiction responsible for ordering evacuation is the City of Long Beach. Decision makers have to act quickly to approve evacuation and publicize these orders. Public safety officials (police and fire) responsible for the actual evacuation must immediately begin its implementation. The 3 hour and 30 minute window will continue to shrink as the evacuation order goes out and people begin to move away from the coast.

- As a result of the short timeframe prior to first-wave arrival, local jurisdictions may not have time to completely evacuate areas within the designated inundation zone and will need to prioritize. Automated telephone notification systems are activated to notify residents within evacuation areas (for example, Reverse-911). The Cities will notify their respective ports, which will in turn notify tenants and initiate their emergency plans. Public venues near the coast and beaches will present particular challenges, as will dependent care facilities (such as schools, hospitals, and convalescent care facilities), where evacuation may be slower and require vehicles for nonambulatory patient transport.

- County and local agencies also have responsibility for area security and area reentry. First responders are deployed to traffic checkpoints at the edge of the evacuation zone to direct traffic out and restrict traffic from coming back in to dangerous areas. Traffic control points are set up at strategic locations to reduce traffic flow toward the coast and to restrict sightseer traffic to the coast, as required.

- As each area is evacuated, public safety agencies will set up Traffic Control Points consisting of roadblocks, barricades, and (or) a system of patrols to secure evacuated areas. Traffic Control Points require multiagency coordination and many personnel for extended periods of time. Public safety agencies will be using their auxiliaries and volunteers to staff traffic control points and requesting mutual aid assistance from inland communities.

- The Ports of Los Angeles and Long Beach must consider evacuation and safety and protection of populations and assets on the water as well as on land. On land, employees working throughout individually managed port terminals and other facilities must be notified and evacuated. A Federal Border Patrol detention facility within the Port of Los Angeles houses some 1,200 detainees and will implement its secure, independent plan to take appropriate protective measures.

- The U.S. Coast Guard (USCG) has ultimate authority over vessel traffic. Authority to close the port lies with the Captain of the Port, under jurisdiction of USCG Sector Commander of USCG District 11, Sector Los Angeles. (This is one of three sectors in California, the others being San Francisco and San Diego). The 11th Coast Guard District encompasses the States of California, Arizona, Nevada, and Utah, the coastal and offshore waters out more than a thousand miles, and the offshore waters of Mexico and Central America down to South America. The USCG Captain of the Ports will take charge of determining and prioritizing evacuation of large ships in the ports and determining which and how many will have time to leave port for deeper, safe water depths, beyond the high-velocity tsunami surge. The port 
must also notify incoming vessels to remain at sea. Port Authorities and vessel owners must assess whether liquid bulk vessels can (have enough time to be) successfully depart from the port during the Warning period, prior to the start of tsunami, and when the cutoff time for departure will be. For vessels that cannot make it out in time, moorings may be manned from onboard or other measures taken to secure ships as best as possible.

\section{Key Considerations during Period 2}

2.1 "Short fuse" event for evacuations: The 3.5-hour window to order, initiate, and complete evacuations is very short; in some cases it could be shorter than the anticipated time required to clear dangerous areas and address special needs of various populations (see following section, "Decision Making on a Short Fuse").

2.2 Activate automated telephone notification systems and other local protocols to ensure rapid notification of residents/workers/visitors within the zone regarding evacuation.

2.3 Coordinate with port and marina authorities regarding disparate maritime communities (vessels $=$ large, medium, small). Evacuate different-sized boats and ships to open ocean or not? Consider offshore conditions, timing of event, and ability of members of maritime community to stay offshore for extended time before recommending maritime evacuation. Determine if it is appropriate to leave personnel on ships during the event or evacuate to safety on land. Threats to life-safety should overrule consideration of damage to ships/boats/docks.

2.4 Need to direct people away from the zone safely via designated routes and methods. (Implement evacuation plan. Pre-identify/designate/sign optimum evacuation routes.) . If evacuation time is short, evacuation on foot instead of by vehicle may be recommended, especially in areas of limited egress, such as the ports.

2.5 Identify refuge/staging areas with the capacity to shelter the evacuated population.

2.6 Need to secure road entry/exit points. (Need to alert key first responders at the local level, if warranted by situation. Need to assist with first responders deployed to evacuation sites.) Need to keep those who want to "watch" away from shore.

2.7 Given the widespread impact of the tsunami along the coast, collaboration and coordination will be required to secure a vast evacuation perimeter up and down Los Angeles County and the State.

2.8 Is there an adequate number of first responder staff, informed of proper protocol for this type of scenario, and available for rapid deployment? Just-in-time training for out of region mutual aid may be required.

2.9 Need to stage/move emergency equipment outside of inundation area. Need to establish ingress/egress routes for emergency vehicles and evacuation buses and establish evacuation routes.

2.10All first responders must be out of danger zones at least 30 minutes prior to first wave arrival. (at 5:05 p.m.) They must remain out until all-clear for first responders is issued.

2.11Determine and request need for mutual aid/outside resources to initiate evacuation, secure evacuation area, and prepare for response.

$2.12 \mathrm{Need}$ to coordinate with media (to ensure they have accurate local information on which locations and people require evacuation and information to both zone-inhabitants and public regarding need to stay away for prolonged period). In addition, areas to be evacuated will be based on pre-identified evacuation plans, maps, and (or) maximum mapped inundation zone. However, the tsunami may not inundate all mapped areas. This will be an ongoing education and public information issue as the event progresses.

\section{Highlighted Emergency Management Challenges during Period 2}

Once the Warning is provided by WCATWC, local jurisdictions must approve evacuation orders. Evacuations are not ordered lightly, and in the City of Los Angeles, for example, the order must be agreed upon by the Police Chief, Fire Chief, Director of Emergency Services, and Mayor. This can further truncate the window between evacuation initiation and first wave arrival. The evacuation time window may be desperately short, depending on the size and character of areas within the inundation zone to be evacuated within the short 3.5-hour window 
remaining. Emergency managers must consider the estimated time needed to thoroughly evacuate an area, including limited egress areas (islands/peninsulas); populations more difficult to reach (for example, people with language barriers or people in group housing, at public venues, and beach and coastal visitors); those that may require extended evacuation time (in areas at a far distance to high ground); those requiring additional time to evacuate (such as schools, care facilities, hospitals); and those with special evacuation limitations (such as jails/prisons). They must consider accommodation of special populations (elderly, those with access and /functional needs). There may be a recommendation to identify structures that can be used for vertical evacuation structures for areas that cannot be adequately evacuated within the remaining timeframe allotted (for example, concrete and steel frame structures, three stories or higher). Note that vertical evacuation is a last resort and moving to higher ground if readily available is always a safer option.

The Map Gap

There is a significant issue illustrated by the SAFRR tsunami scenario. There will be areas evacuated on the basis of the scenario that will not ultimately be inundated by the tsunami. However, during an actual event, this information would not be available to emergency managers as the tsunami event unfolds (knowing this in advance is a scenario "artificiality"). In other words, you won't know what areas will actually be inundated by water until the tsunami happens. Therefore, you must evacuate based on previous projections. In this case, given the short time allowed, and availability of worst-case inundation line maps from the State of California, recommendations will be made for full evacuation of this entire zone. Inundation zone mapping information currently available to emergency managers uses a "maximum inundation zone" that will not be reached during every Warning level tsunami event, yet is the best (and only) available information in advance of a tsunami (see figs. 6 and 7). 

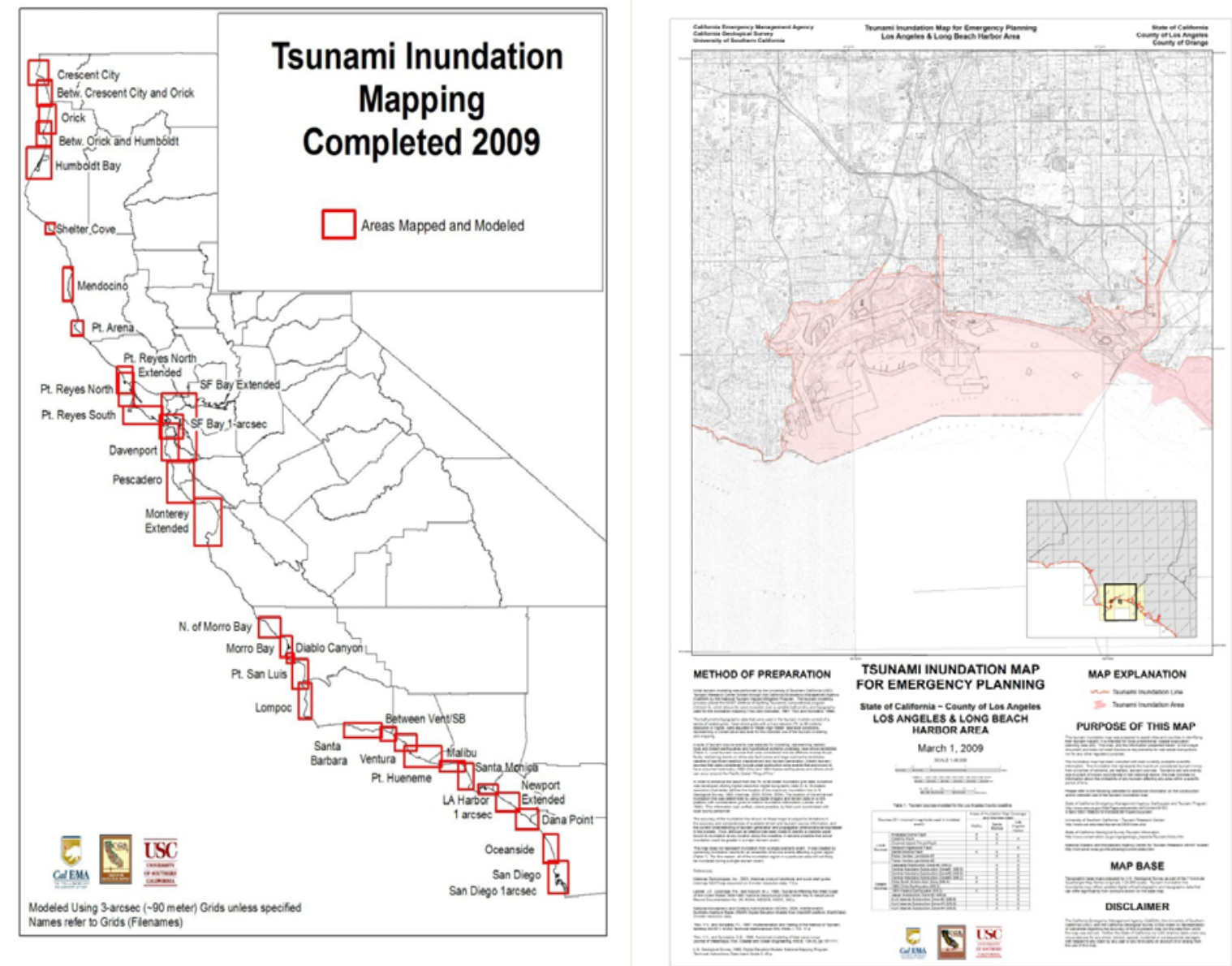

Figure 6. Tsunami inundation maps for emergency planning: Los Angeles and Long Beach Harbor area. 


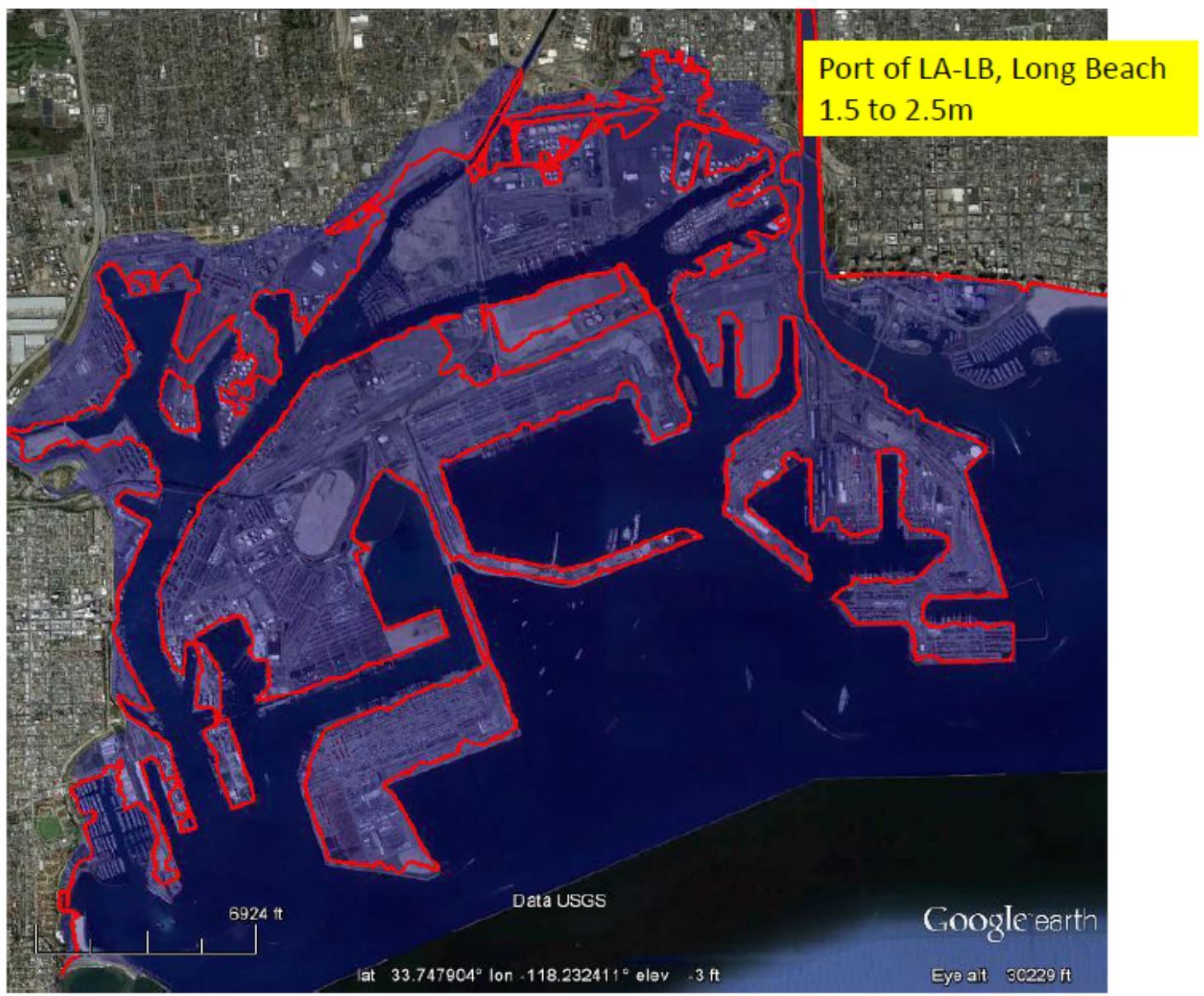

Figure 7. Map of Los Angeles and Long Beach Harbor area showing expected SAFRR Scenario Inundation Line compared to State Maximum Inundation Line. Note: This information WOULD NOT be available during any ongoing real tsunami. Red line is the inundation line for this Alaska tsunami scenario. Blue area is the maximum inundation from State maps used for pre-planning emergency response.

Decision Making as Information Unfolds

NOAA's WCATWC provides three key pieces of information that are central to providing emergency managers with the data they need in order to make crucial and immediate Warning response decisions. The first of these is initial wave arrival times at various locations along the coast. The second element of information is NOAA's forecast wave heights (amplitudes) at various locations. Arrival times and amplitudes are provided for as many as 30 locations with existing tide gauges along the coastline of California. These are updated as the tsunami progresses, and as the scope of the threat is revealed, State and local emergency managers can begin to ask more detailed questions to gain a clear picture of what may be expected regarding specific coastal areas of heightened concern. This is important information that ongoing conference calls with the WCATWC, the State, coastal counties, and coastal cities 
and communities provide a critical opportunity to discuss and clarify as an event unfolds. The third type of information is the normal tide conditions across the expected wave-arrival period. This piece of the picture is key because the difference in wave height if the highest wave surges are coming in at high tide or low tide can mean the difference between dry-land inundation and no inundation.

\section{Seaward Evacuation Guidance Specifics}

There are several issues regarding tsunami response of specific concern to the maritime community, defined as ports, harbors, marinas, and the vessels and people who make use of them. There is little time following a Tsunami Warning to make informed decisions regarding seaward evacuation of vessels, nor to determine who is appropriate (vessels, people) to send to the open ocean (considering prevailing weather, oceangoing capabilities, length of time to remain evacuated, fuel, food, speed of the vessel, and distance to alternative ports). The California Tsunami Program, comprising Cal OES and the California Geological Survey, in coordination with county emergency managers and port/harbor authorities, has highlighted these concerns, observed recent events, undertaken a work plan to make recommendations for mitigating tsunami risk to ports, harbors, and marinas, and actively solicited input, feedback and participation of those affected communities. The State of California Tsunami Program has research underway to inform and provide consistent statewide policy, including the following overarching recommendations:

- a single depth contour for offshore evacuations,

- hazard thresholds defined and addressed for harbor facilities,

- hazard thresholds defined and addressed for vessels and best practices for ship (re)positioning, and

- protocol recommendations of minimum times required for evacuate vs. do not evacuate (depending on type of vessel).

\section{SPECIAL NOTE: The Alamitos Breakpoint}

The SAFRR tsunami scenario, using modeled data and simulated bulletins, was able to bring to light a previously unrealized potential issue with regard to existing NOAA Breakpoints and a possible need for a change of protocol of how Alert delivery classifies specific coastal areas of Southern California during tsunamis. This issue was important for state officials to be aware of and discuss with county officials and was discussed with NOAA officials at the WCATWC. The results were (1) the scenario bulletins were changed to more accurately reflect what would be issued by existing protocol/practice during an actual event and (2) the option of moving the Alamitos Breakpoint further south was discussed.

Note: Warning, Watch and Advisory extents are set based on distance from epicenter, tsunami travel time, or pre-computed threat estimates, and are listed in the messages as extending from $\mathrm{X}$ to $\mathrm{Y}$ (along a coastline).

Issue \#1 (Affects how bulletins were developed for this scenario):

As the SAFRR scenario originally stood, areas from Alamitos Bay to the Mexico border started in an Advisory (non-evacuation situation) and were upgraded to a Warning level (evacuation situation) an hour-and-a-half after the first wave arrived. This encompassed the coastlines of Orange and San Diego Counties. Initially the bulletins developed for this scenario 
placed areas south of Alamitos Bay in an Advisory while those to the north were placed in a Warning (as of 2pm, Bulletin \#4, fig. 8). At 7pm (as of Bulletin \#9), areas to the south of Alamitos Bay transitioned from an Advisory to Warning. This was subsequent to the "start of tsunami" for this entire southern California section of coastline.

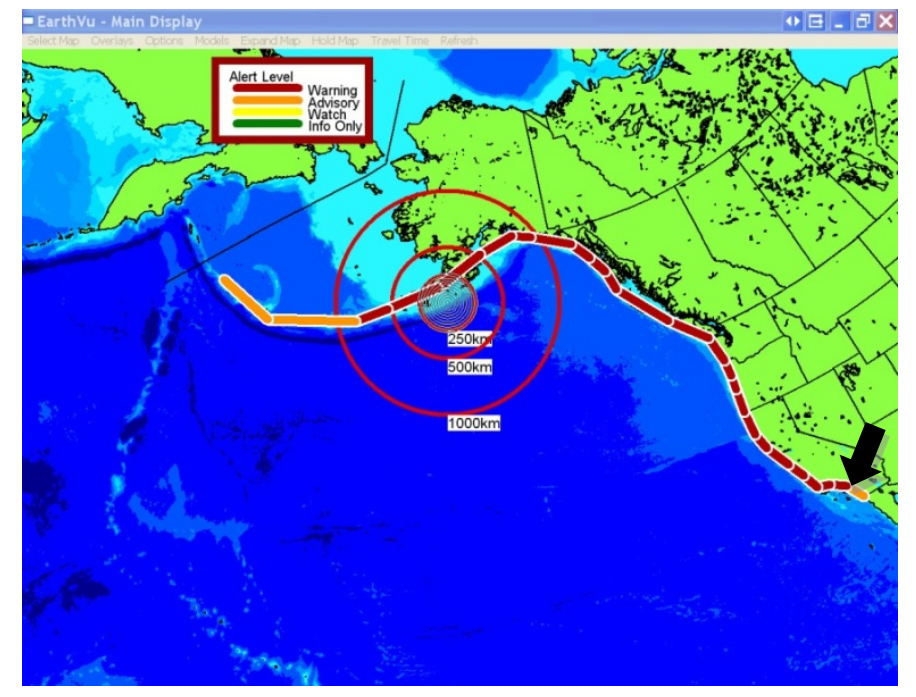

Figure 8. Annotated map of northeast Pacific Ocean and adjacent lands constituting previous SAFRR Scenario Bulletin \#4 Alert Status of West Coast: Warning/Avisory. Courtesy WCATWC.

Under this scenario, areas where inundation would likely occur (Huntington Beach, Newport Beach, Dana Point, and Coronado) would not have been officially evacuated before the tsunami arrived because they were in an Advisory. If this had been the case, government decision makers in the areas in and around Orange and San Diego counties would have been in a dangerous and difficult situation because they would not have called evacuations during an Advisory but by the time they were upgraded to a Warning... inundation would likely have been occurring and no one would have been officially evacuated. With upgrade to a Warning, this would have turned from an evacuation issue into a life-safety issue for the newly alerted areas.

This issue was identified by the State of California (California Geological Survey and California Emergency Management Agency) and discussed with the WCATWC. It was noted that bulletins developed for the scenario were based on a variety of modeled data with different variations of the same source and released somewhat differently than would be done during an actual event. The Bulletins developed by the WCATWC for SAFRR relied strictly on this modeled data and followed protocol within the WCATWC guidelines, without applying three important inputs that would occur during an actual event before bulletins are released widely to the public:

1. Consultation among the scientific team in the WCATWC,

2. Real data coming from DART Buoys, and

3. West Coast conference calls with state/province emergency managers and Warning Coordination Meteorologists with the National Weather Service, regional Weather Forecast Offices.

The above inputs and discussion would help confirm and guide decisions before bulletins were released during an actual tsunami event. 
As a result, Bulletin \#4 through Bulletin \#9 were adjusted, as they would be during a real event, to place the coastline south of Alamitos Bay to the Mexican Border into a Warning - thus reflecting the same threat level for the similar coastal settings to the north and south of this breakpoint (fig. 9).

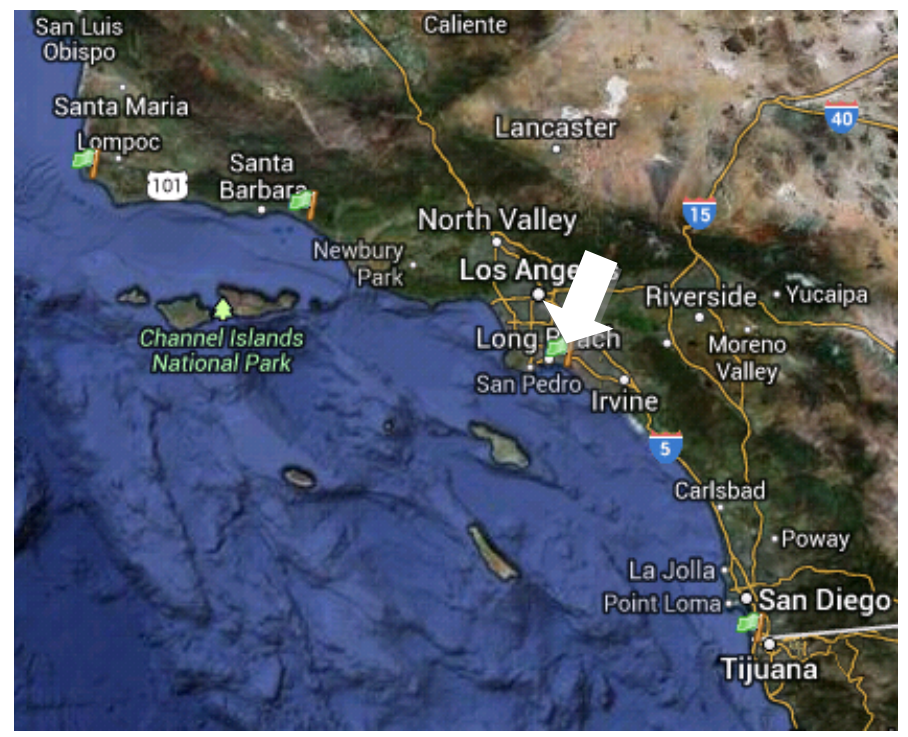

Figure 9. Google image map of Southern California coastline showing Alamitos Breakpoint location.

Issue \#2 (Should the Breakpoint be moved from the Alamitos Bay to the Orange County-San Diego County line?)

The SAFRR scenario has raised a potentially important long-term issue: Should a break point exist with potentially differing levels of alert (for example, Warning/Advisory) between very similar flat, low-lying, densely populated geographies of southern Los Angeles and northern Orange counties? This includes low-lying, highly populated areas like Long Beach (Belmont Shore, Naples Island), Seal Beach, Huntington Beach, and Newport Beach (Islands in Newport Bay and the Balboa Peninsula).

This issue was also discussed, and protocol may be changed based on this discussion and continued follow up with the Weather Forecast Offices in San Diego and Oxnard. This could result in a permanent adjustment, but retain the existence of a breakpoint between the Ports of Los Angeles/Long Beach and San Diego, possibly at the Orange and San Diego county border.

\section{Period 3: During the Event}

During Period 3 the first tsunami waves begin to progressively hit the coast of California from north to south. Areas within mapped tsunami inundation zones will be dangerous during this time. Impacts are observed via remote means by the media and emergency managers; post-event reconnaissance is planned/staged. 
General Description of Period 3 (Bulletins 8-25: Thursday March 27th 6:01 p.m. through Friday March 28th 12:02 p.m.; 7-24 hours after earthquake)

Regularly scheduled conference calls exchanging updated information flow among all affected jurisdictions, continuing at multiple levels: WCATWC-to-States/WFOs, State-toCounties, and County-to-Cities/Cities-Port/Marina Authorities and maritime communities. Assessment and reporting of local jurisdiction actions may include evacuations conducted, shelters opened, and remote intelligence gathering of evacuation shortfalls and damage or casualties sustained. Tactics for impact assessment, rescue, and response are refined as observed impacts are reported remotely. Mutual aid needs are projected by impacted jurisdictions. County and State level support activities continue and may include coordination of the mutual aid requests, coordination of public information messaging, assessment and provision of State assistance needed, and coordination of resources through mission tasking.

\section{Scenario-Informed Situation, Emergency Management Activities, Key Considerations and Challenges}

At 5 hours and 45 minutes after the earthquake the first tsunami surges begin to arrive at the Ports of Los Angeles and Long Beach. The time is 5:35 p.m., and it is 40 minutes before sundown. High tide will continue to build for another 2.5 hours following estimated first surge arrivals, peaking at around 8:00 p.m. As demonstrated by recent tsunamis around the world, this is a time when the highest waves and most extreme currents can occur; the first surge is almost never the worst. Thus, worsening tsunami surges are hitting the outer coast and funneling into the ports atop increasing tidal conditions.

In the harbor, successive tsunami surges may be increasing in height. Although the greatest inundation danger may be at high tide, extreme fluctuations, both positive waves that inundate normally dry land and negative waves that expose the sea floor and threaten large vessels in port, will extend for many hours.

As the event progresses through the Warning period, areas experience flooding inundation approaching the maximum state-mapped inundation zone. These include the City of Long Beach downtown area, below the bluff. Some areas in the Port of Long Beach will also be inundated. However, much of POLB and POLA will experience substantially smaller amounts of inundation than the maximum mapped inundation zone (see "The Map Gap" section above and fig. 7).

- Hourly calls with the WCATWC continue to collect and provide the latest available technical support information. In addition to estimated wave height information, observations from deep ocean assessment buoys and tide gauge readings from around the Pacific Ocean already experiencing the tsunami are being reported. Information about current and projected status of subsequent alert bulletins is provided: whether or when Warning level is expected to be downgraded, expected length of time before downgrade (if available), which areas of coastline remain in which alert level, and answers to any pertinent questions from locally affected communities.

- Statewide calls continue every other hour alternating with WCATWC multistate conference calls to relay technical updates and maintain updated situation status of affected communities as the event unfolds up and down the coast. Evaluations of evacuation status, assessment of 
local resource needs from the State, reporting of local damage sustained, and State personnel deployment are also provided to the Regional Emergency Operations Center (REOC) and State Operations Center (SOC) by counties . Primary information flow is from affected coastal areas to the REOCs to the SOC and eventually to the Governor's office.

- The scenario tsunami will impact all 20 coastal counties in California. At this time the State's Emergency Operations Centers (SOC and REOCs) are fully staffed and working to support impacted counties by working with unaffected counties and state resources to coordinate and support local needs/requests for assistance. The SOC and REOCs house a variety of organizational representatives, which may include expert staff from FEMA, the U.S. Coast Guard, California Geological Survey, California State Parks, CalTrans, Regional Transportation Authorities (MTC, LA Metro, BART), Department of Water Resources, National Weather Service, American Red Cross, Utilities (PG\&E, SCE, SDG\&E), American Red Cross, and private sector business continuity groups.

- At the local EOCs, critical, ongoing actions include assessing the success of evacuation and planning for post-Warning reentry into the evacuation zone and rescue, as well as perimeter security for the evacuation areas. Implementation of these actions may be assisted by personnel from adjacent, unaffected jurisdictions or facilitated through use of State resources.

- During the period while the tsunami is in progress with damaging waves, currents, and inundation, a challenge for authorities will be to ensure public safety by maintaining security of an extensive perimeter. Access will only be provided once an "all clear" has been declared by local civil authorities. The evacuation in Los Angeles County will span not only the Ports, but residential, business, beach, and commercial areas. Beyond the damage to Los Angeles County, the tsunami will impact the entire California coast, requiring a secure perimeter on the coastline of most of California's 20 coastal counties. Police/responder personnel requests to staff perimeters and assist with other response activities could stress even Mutual Aid resources from inland counties. POLA and POLB have their own police and fire resources, but may also request personnel resources from their cities, and the County of Los Angeles may need to request State augmentation of first responder personnel (for example, California Highway Patrol, California National Guard). This function will need to be turned over to private security providers in each county as soon as feasible, because law mutual aid (police; sheriff) and the California National Guard are not sustainable long-term solutions.

- Reception centers, feeding operations, and sheltering for evacuated residents will be operational, including care for people and animals and those with access and functional needs. This will be a function of the American Red Cross, California National Guard, NGOs and faith-based organizations

- The harbor district may experience power outages due to localized tsunami flooding, as well as intentional shutdown to preserve facility operational integrity.

- In the Los Angeles County coordination of public information will take place at the county level, with the Sheriff's Department responsible for media coordination, including preparation of daily County Emergency Operation Center press briefings, assisting in the preparation of press announcements for key elected officials, and responding to inquiries from the media in conjunction with appropriate departmental subject-matter experts. The Sheriff will make every attempt to coordinate emergency public information releases with impacted jurisdictions and agencies in order to ensure consistency. All press briefings and media releases will follow the policies and procedures outlined in the Los Angeles County Emergency Public Information Plan. 


\section{Key Considerations during Period 3}

3.1 Continue communication with State and Federal tsunami forecast experts and field observation teams.

3.2 Assess effectiveness of evacuation efforts to prepare for initial search and rescue operations upon all-clear. Consider alternatives for safe evacuation of stranded populations (such as aerial).

3.3 Receive evacuees at refuge/staging areas with the capacity to shelter the evacuated population.

3.4 Continued need for securing evacuation zone and keeping people away from shore who want to go down and watch.

3.5 Continued need to stage emergency equipment outside of inundation area. Need to establish ingress/egress routes for emergency vehicles and evacuation buses and establish evacuation routes.

3.6 Continued need to coordinate with media (rumor control, continued correct information regarding evacuation zone and need to stay away for prolonged period). For consistency in messaging, information will be coordinated across emergency public affairs offices at the county level regarding evacuation areas and at the NOAA/State level for questions about additional forecast information.

3.7 Consider and plan for the length of the event through multiple 12-hour staffing periods, which may fatigue emergency decision-making and response personnel. Dangerous tsunami activity, especially in maritime communities, may last for days. Make sure there are adequate personnel available for sustained operations of local, county, regional and State emergency operations functions.

\section{Highlighted Emergency Management Challenges during Period 3}

Incomplete Land Evacuations

The Cities of Los Angeles and Long Beach will use standing evacuation plans based on the maximum mapped inundation line to determine areas to be evacuated. In spite of redundant communication methods, there are likely to be those who do not hear the order, those who decide not to leave, and those who may not have time to evacuate during the 3.5-hour evacuation window prior to first wave arrival. Examples within the latter group could include vulnerable groups such as those in dependent care or with mobility or functional and access needs. For their own safety, it is important that first responders themselves avoid re-entering dangerous areas until cleared to do so.

\section{Keeping People From Returning to Evacuated Areas Prematurely}

Tsunami waves are expected to continue to arrive on land, and evacuation orders will stay in force, for some 47 hours. Local authorities will have used the best available information - maximum mapped inundation zones - to establish and maintain evacuation perimeters. As the tsunami event period continues, there will be areas where observed inundation does not reach all areas evacuated. This is likely to create pressure from residents to lift evacuation orders - perhaps prematurely. 
Maintaining security around the Ports of Los Angeles and Long Beach could be one of the most challenging undertaken in the region because of the scope and geographic complexity of the area.

The expense and regional economic impact of interrupted commercial activities within the ports creates strong port-tenant need to lift evacuation orders as soon as possible. There will be pressure to reopen the on-land portions of the port - or even to keep it open throughout to allow movement of goods and commerce already in the port and arriving from inland.

In addition to these pressures, continued maintenance of safety perimeters across the 47hour life of the tsunami Warning will include the problem of those who want to "go see" or "surf" the tsunami. All of these issues with the public wanting and in some cases demanding to return to potentially unsafe areas will need to be met with education, both in advance of a tsunami and during the event. Elected officials and emergency responders must understand the nature of the ongoing threat. The media will be another powerful partner, and to ensure coverage of the appropriate safety message, emergency managers should be prepared to provide continued availability of educated spokespersons.

Incomplete Water Evacuation

Using preestablished priorities and judgment about timing and relative dangers within the ports waterways, the U.S. Coast Guard Captain of the Port will have evacuated commercial vessels prior to first wave arrival. Within the Port, remaining vessels will be secured, in many cases with their crews aboard.

In previous Advisory-level tsunamis in California there have been examples of smaller vessels that have become caught in strong tsunami currents as they make a late attempt to leave harbor. No two tsunamis are alike, and currents and surges during this scenario event would be on the order of three times as bad as recent actual events. However people may base decisions on their own experience in POLA and POLB with recent tsunamis from Chile and Japan. Mariners who refuse to heed the Warning and attempt to leave or enter the harbor during the extreme currents of tsunami surges will likely require rescue. Should these situations arise, decisions will need to be made about whether to attempt rescue and risk lives of response personnel. During the recent Japanese tsunami in 2011, harbor personnel in Santa Barbara were injured assisting mariners attempting to dock during ongoing tsunami surges. Numerous vessels had difficulty entering and leaving harbor entrances in the midst of tsunami surges.

The "short fuse" nature of this event may exacerbate the above situations because of the short time window to make decisions, prepare, and leave should a mariner decide to do so. Problems have occurred with late entering/exiting vessels at the seaward entrances to harbors during recent tsunamis. Given less time to try to make it out within the reduced Warning period, less informed citizens may make the wrong decision and ultimately not make it out in time. In the 2011 event, a vessel in Crescent City, the Amanda B nearly foundered trying to make it out while tsunami surges were beginning to occur. There appears to be significant potential for dangerous behavior by boat owners in POLA and POLB. Boat owners expecting to trailer their boats should expect congested boat ramps and must remember that they have to get their boat to the trailer, out of the water, and out of the tsunami zone before the tsunami arrives. 


\section{Period 4: Warning Cancelled for Specific Areas}

General Description of Period 4 (Bulletins 26-33: Friday March 28th 12:02 p.m. through Friday March 28th 8:02 p.m.; 24-32 hours after earthquake)

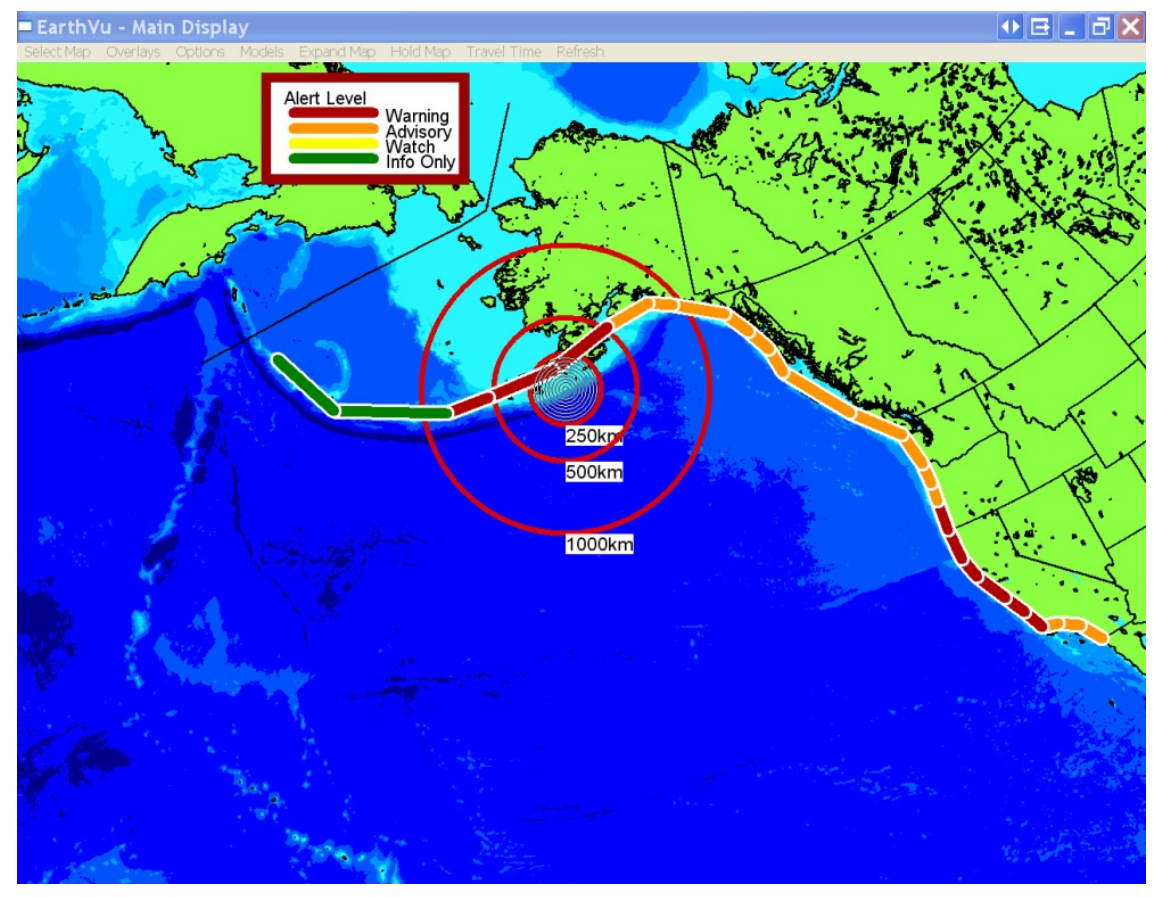

Figure 10. Annotated map of northeast Pacific Ocean and adjacent lands constituting Bulletin \#31 Alert Status of West Coast (Warning/Advisory). Courtesy WCATWC.

Where a Warning was in effect and then cancelled (compare fig. 9 to fig. 10), local authorities may begin safety assessment of impacted land-based areas to determine a schedule for lifting of evacuation orders, allowing re-entry into inundated and nonimpacted evacuation areas. Initial "Windshield Surveys" assess life-safety and damage in preparation for search and rescue operations and other response efforts. Closure of or limited access to harbors, marinas, and beaches remain in place. Access to evacuation areas remain limited to response personnel until deemed safe for the public to return; shelters remain open.

\section{Scenario-Informed Situation, Emergency Management Activities, Key Considerations and Challenges}

At 32 hours after the earthquake, the Warning ends for California. This indicates that the danger of continuing dry-land inundation from incoming surges has passed. The alert is downgraded by the WCATWC to Advisory status, which is conveyed via alert Bulletin 34 . Advisory status indicates continued strong, dangerous currents in the ports. It is still not safe to 
go in or near the water, nor to allow vessels to enter and leave the port. The U.S. Coast Guard will maintain closure of all dangerous waters until at least the Advisory level threat is lifted.

- At this time, the WCATWC is unable to determine when danger has passed in many areas. Local conditions, particularly strong currents in channels and harbors, can cause wide variations in tsunami wave action. Consequently, local emergency management officials, and not the WCATWC, will make all-clear determinations.

- The WCATWC will issue a cancellation in either of the following situations: (1) an evaluation of sea level data has confirmed that a destructive tsunami will not impact the affected area; or (2) following a destructive tsunami when data indicate that the threat has largely subsided to nondestructive levels. Following a destructive tsunami, the WCATWC provides guidance to local officials regarding when they can consider the threat to have passed based on local conditions.

- In general, after receipt of a Tsunami Warning, agencies can assume all-clear status when their area is free from damaging waves for two hours, unless the WCATWC has announced expected times of arrival (ETAs) for additional waves or local conditions warrant continuation of the Tsunami Warning status. This requires that the local government, or scientific staff from the California Geological Survey, are able to observe the waves from a safe distance and height.

- Hence, if no wave or only insignificant waves occur, local agencies may assume "all clear" status two hours after the latest ETA announced by WCATWC, unless the presence of strong currents in channels and harbors has been noted, which may warrant continuation of the Tsunami Warning. The public should not return to low-lying areas until the tsunami threat has passed and local authorities announce "all clear."

- At 12 hours (approximately 23:00) "B-Shift" staff comes on duty for Tsunami Duty Officer, State Operations Center, and Regional Emergency Operations Center. A briefing is held to transfer information about critical issues and activities occurring during the previous 12 hours and convey objectives, priorities, and a strategic course of action established by the management team for the incoming staff.

- Hourly West Coast calls between WCATWC and State Warning Points and Cal OES statewide conference calls with coastal counties and State agencies continue as long as the Advisory is in place. Statewide calls continue to focus on updated status of continuing dangerous conditions (strong, damaging, dangerous currents within the port and ocean waters), information about current and projected status of subsequent alert bulletins, whether observations indicate when Advisory level is expected to be downgraded, expected length of time before downgrade (if available), which areas of coastline remain in which alert level, and answers to any pertinent questions from locally affected communities.

- It is important for the emergency management community to understand that tsunamis, including this one, are long-duration events, in which unpredictable, dangerous conditions exist for many hours. This requires development and planning for multiple staffing periods at the outset of the event. If local and county jurisdictions do not have enough staff to maintain this capacity, there may be a need to call on assistance from other, unaffected jurisdictions.

- As the Advisory continues, staffing at City, County, and State EOCs will rotate back to AShift" at 11:00 on March 28, then back to "B-Shift" at 23:00 for another 12-hour work period. 


\section{Key Considerations during Period 4}

4.1 Maintain appropriate and consistent tsunami evacuation and response planning. Due to the length of the event, there may be pressure to allow people and businesses to "return to normal." Consider all life safety issues and protocols before allowing return to normalcy.

4.2 Maintain emergency response and evacuation protocol in and along the waterfront areas. Strong tsunami currents will likely continue during this time period.

4.3 Localized initial safety assessment for search and rescue, emergency medical attention, and to determine continuing hazards (debris fields, fires, fuel leaks, hazardous material spills, damaged, unsafe structures).

4.4 Localized determination and implementation of strategy for reopening of evacuated and inundated areas, including phased or facilitated reentry where damage or continuing hazards exists.

4.5 Localized assessment of ongoing need to provide services to those displaced by home damage/destruction.

4.6 Begin response operations, including rescue, stabilization of ongoing hazard conditions, debris removal for emergency egress.

4.7 Assess need for equipment and response personnel staging areas near, but outside, damaged and affected areas.

4.8 Begin county and statewide assessment of overall unmet needs and requirements for outside resources through mutual aid, State resources and request for Federal assistance.

4.9 Continued need to coordinate with media (rumor control, continued correct information regarding Advisory and continued maritime danger, status of evacuation order).

\section{Highlighted Emergency Management Challenges during Period 4}

The Pressure is on (to Open the Ports)

During Periods 4 and 5 the port remains closed based on scientific advice and tide gauge readings by the NOAA WCATWC, conveyed by Cal OES to county emergency managers. The California Geological Survey will also have observers stationed near the coast to provide scientific observations and advice relevant to emergency management and locally important decisions. Hard data and observed information, supported by qualified, trusted expertise will become increasingly important the longer the event lasts and the longer the port remains closed, as pressure to reopen will be coming from a variety of different sources. There may be pressure from the ports themselves, because lengthy disruption will be costly to port tenants and customers. The stature of the San Pedro Port Complex is well recognized due to the large volume of commerce that flows through it and its importance to the local, regional, State and national economies. There will also be political pressure at all levels, as well as media scrutiny of emergency operations. The decisions being made and actions taken to protect lives and property could be questioned. The jurisdictions and agencies responding may be well advised to proclaim local, county, and State emergencies through their political leaders (Boards of Supervisors, Governor) to support decisions and allow needed emergency operations to continue undeterred by outside influences. A coordinated plan for reopening and provision of public information about how this will be implemented may be a good strategy for alleviating public concern. 
Overall, infrastructure impact on the ports is not catastrophic, based on the Moffat and Nichols section of Porter and others (2013). However, Charles Scawthorn's contribution (in Porter and others, 2013) includes concern about potential "fire following" if flooding damaged petrochemical tank farms within the ports. Considering the history of similar ports in the past 50 years and the quantity of petrochemicals stored at these ports, one or more fires would likely result. For example, if a tank were to rupture and a fire were to ignite on Mormon Island in the Port of Los Angeles, a 5-square-kilometer fire could cause the loss of product, tanks, control systems, and other assets at 7 berths housing 28 million barrels of stored petroleum products in 48 tanks, plus 350,000 tons of industrial chemicals. This would present significant problems in terms of fire agency resources, air deployment, access to potentially flooded areas, and management of a tsunami-threat-compounded conflagration. Porter and others (2013) also highlights the possibility that many minor to small individual incidents will arise as a result of this event. The combined effect of managing response and communication and coordinating response to all of these possible fires at the same time will tax the resources and capabilities of any singly affected jurisdiction or responding agency. The importance of staff support for full and rapid implementation of the emergency management system at all levels will become increasingly paramount.

Media Control-Information Flow

A lesson learned during the 2011 Tohoku tsunami for California is that once the broad scope of the tsunami event becomes clear, the State will open a Joint Information Center (JIC) along with coordinating agencies, to facilitate information exchange with the media. As the JIC very often becomes the "face" of an incident, it would allow press releases to be made available as well as be a coordinated location for broadcast media outlets to interview incident publicinformation-office staff and receive important information. Given the unprecedented scope of this event - that is, in placing the entire coast in a Warning - coordinating common and consistent messaging information across agencies through the JIC is warranted and advantageous. The importance of accurate public safety messaging underscores the need for high-level media coordination and timely briefing of emergency operations and strategic planning to restore normalcy to the ports and harbor community.

\section{Period 5: Evacuation ALL CLEAR as Determined by Each Coastal Jurisdiction}

\section{General Description of Period 5 (Bulletins 34-49: Friday March 28th 8:02 p.m. through Saturday March 29th 12:00 p.m.; 32-48 hours after earthquake)}

Once local authorities in affected areas have assessed safety issues to the extent they are able to begin search and rescue operations and other response efforts, they may reopen areas to the public. Authority is seated at each coastal jurisdiction. Reopening areas may include phased or facilitated reentry where damage or continuing hazards exists (debris fields, fires, fuel leaks, 
hazardous material spills, damaged or unsafe structures). Shelters remain open. However, shelter populations begin to drop as those evacuated from areas that were not inundated return home. While the threat of dry-land inundation has ended, waterways, ports, piers, and beaches remain closed due to dangerous currents affecting areas in and near the water, with people recommended to stay away from the shoreline.

\section{Scenario-Informed Situation, Emergency Management Activities, Key Considerations and Challenges}

- Evacuated areas must remain closed to the public until after the threat of a tsunami no longer exists and local authorities announce an "all clear." Local authorities can reopen risk areas 2 hours after the last observed wave, or 2 hours after the estimated time of arrival has passed without a wave coming ashore. The risk-area incident commander, in consultation with the County EOC, will make the decision to allow reentry following short-term evacuations. For long-term evacuations, local authorities, in conjunction with health and safety agencies, make the decisions for reentry. Reentry criteria, for both short-term and long-term evacuations, will account for public needs, and for public and response personnel safety. Residents should enter through control points to ensure that safety and sanitary precautions are provided.

- Local authorities will control reentry via media releases, evacuation/staging area coordination, and modification of closure levels at Traffic Control Points. Coordination between the County EOC, local EOCs, and all primary and support agencies involved is critical in controlling reentry.

- Emergency response actions continue at the local level depending on circumstances, whether damage has occurred and life safety or rescue situations exist. Upon all-clear, emergency personnel can now get back into the hazard area and begin rescue and evacuation of any injured.

- Damage is expected to be modest in the Ports of Los Angeles and Long Beach, especially if liquid bulk vessels have been successfully evacuated from the port during the Warning period. Overall, it is expected that the ports' land commerce will return to service within a day or two following the tsunami, with the exception of a few terminals where flooding is expected to damage operations buildings and some warehouses. Maritime transportation could take longer, since no assessment of underwater damage will begin until the Advisory is lifted.

- At the State level, monitoring and reporting activities continue, including providing or closing out missions and continuing to assist local officials with collection of damage information needed for a Preliminary Damage Assessment document necessary to request State and Federal assistance. Public information and media relations at the State level continue to be coordinated via Cal OES Headquarters Public Information Office, with possible establishment of a Joint Information Center(s) near affected areas.

- Calls with WCATWC continue, with focus on expected duration of the Advisory and whether continued localized areas of heightened concern exist or will remain in place following cancellation of the Advisory. Statewide Cal OES calls with coastal counties continue, focusing on status of evacuations, status of EOC activations, preliminary damage assessments, and beginning to address recovery issues, including whether local proclamations will be sought. 


\title{
Key Considerations during Period 5
}

5.1 Maintain emergency response and evacuation protocol in and along waterfront areas. Strong tsunami currents will likely continue during this time period.

5.2 Rescue/evacuation of those in damaged areas/facilities that were not evacuated before the event.

5.3 Managing response and egress in areas of damage or where continuing hazards exist (debris fields, fires, fuel leaks, hazardous material spills, damaged, unsafe structures, egress issues).

5.4 Facilitating orderly reentry while continuing response operations.

5.5 Addressing needs of those with long-term displacement due to damage. Assess need for field offices and phone numbers for affected populations.

5.6 Continued need to coordinate with media (rumor control, continued correct information regarding Advisory and continued maritime danger, varied status/limitations of local "all clear" orders).

\section{Highlighted Emergency Management Challenges during Period 5}

\author{
Not so Fast! (Making the "All Clear" Call)
}

Affected areas must be thoroughly inspected for safety issues before providing the "all clear" allowing residents and employees back in. The "all clear," like evacuation, is under the authority of the most local, incorporated jurisdiction. Assessments of the impacted area, following significant flooding, must be conducted before permitting public reentry. These assessments include the extent of damage to public infrastructure on land and over water, as well as safety of roads, bridges, buildings, machinery, and other facilities. The presence of public health risks in water, broken sewer lines, downed utility lines, animal or human remains, must be determined and addressed, and the presence of hazardous materials or other risks must be ascertained.

\section{Phased Reentry}

Specific procedures for limited reentry, following a damaging tsunami, can be established based on the situation. If the tsunami causes significant flooding and damage, the area may be hazardous and the potential for looting of damaged homes and businesses exists. Public reentry will need to be limited to residents and business owners and may be limited in duration. A valid driver's license or other form of government-issued identification (copy of a business license for a business owner), indicating residency inside the restricted area, will be required for entry. Reestablishment of electricity may be a consideration but will not necessarily preclude reentry.

\section{Wild Card: Blockage in a Major Port Channel}

Although deep, wide main channels in POLA and POLB are not projected to require long port-wide closure by Moffat and Nichol (in Porter and others, 2013), it is notable that a single large ship attempting to move in the ports during the tsunami could complicate recovery if it were to lose control. While the port is officially closed, priority would be to stop any unauthorized ship that could cause problems from moving. Barring this, an out-ofcontrol vessel would pose a serious challenge for the Coast Guard and other water authorities to the safety of their own personnel. They would need to make an informed decision about whether they could safely stop a large vessel loose in the harbor from causing damage to itself (sinking, causing hazardous spillage) and damaging other port structures and infrastructure. This would involve coordination and assessment of the situation with tug and pilot personnel. 


\title{
Period 6: Advisory CANCELLATION for Coastal Waterways
}

\author{
General Description of Period 6 (Bulletin 50: Saturday March 29th 12:00 p.m.; 48 hours after \\ earthquake)
}

Dry-land response operations continue. Additionally, WCATWC cancellation of the Advisory allows port authorities and private marinas to begin assessment of damage to vessels and infrastructure in and near the water. Where vessels have sunk or become beached, fuel spills may have occurred, or other significant hazards to navigation may exist; portions of the ports may remain closed to vessel traffic until appropriate measures can be taken to clear hazards. Debris clearance, contamination clean up, and dredging typically include permitting issues and require assistance from a variety of State and Federal agencies with cooperation by private entities. These activities could take days or even weeks to complete.

\section{Scenario-Informed Situation, Emergency Management Activities, Key Considerations and Challenges}

At 48 hours after the earthquake, the Advisory is cancelled. This indicates the end of dangerous wave surges and currents. It is March 29 at about 11:02 a.m., two days after initial notification.

- Under this SAFRR tsunami scenario, in the Ports of Los Angeles and Long Beach, the level of inundation, hardened infrastructure and relatively deep, wide main channels are expected to result in damage that should not require long port-wide closure. The Moffat and Nichol analysis (in Porter and others, 2013) indicates that the ports should not remain completely shut down for more than two days. In many areas of the POLA and POLB, land operations can resume alongside cleanup and repair. Many terminals and docks should be able to quickly resume operations and goods movement.

- Inspection of harbor channels for hazards to navigation in the form of sunken vessels or other debris is finally able to begin, now that the Advisory is lifted. The amount and location of debris will impact reopening of the ports' waterways, and closure may be further extended beyond the two days projected for port operations to resume if significant navigational hazards or hazardous materials spills exist. Sunken and damaged boats may be carried and be deposited as debris from small boat marinas into larger channels by strong tsunami currents. There may also be sediment movement; however, POLA's and POLB's deep, wide shipping lanes mean that debris and sediment may be isolated - although they could limit some traffic, they should not interrupt the bulk of maritime transportation.

- At the local level, response operations continue, including sheltering of displaced populations, land-based debris removal, and restoration of utilities. If a Federal disaster was declared by the President during the event, Cal OES and FEMA recovery personnel will be prepositioned to begin quantifying damage to determine State and Federal recovery program availability; however, these Federal/State/local joint Preliminary Damage Assessments (PDAs) will not begin until local governments address life-safety and property protection issues. 


\section{Key Considerations during Period 6}

6.1 Continued response issues and coordination of scarce response resources; status of local emergencies, State emergency proclamations, and Federal emergency declarations.

6.2 Full maritime safety assessment to determine in-water infrastructure and debris/dredging issues that will impact port and marina reopening.

6.3 Priority of commercial port reopening and coordination among jurisdictional entities with authorities within ports.

6.4 Continued need to coordinate with media (rumor control, continued status/limitations of "all clear" orders based on severe damage).

6.5 Local, county, State, and Federal coordination of resources for response activities and continued emergency management operations.

6.6 Expediting completion of Preliminary Damage Assessments by State and Federal partners while they continue to address response.

Highlighted Emergency Management Challenges during Period 6

Survey and Salvage in the water

It is important to note that following the ports' expected 2-day closure by the Coast Guard Captain of the Port, based on 48 hours of dangerous waves during the Tsunami Warning and subsequent Advisory, there will be an additional period in which port waters could be closed due to hazards to navigation. This could be an additional period of days or longer (perhaps weeks) to allow for surveying for sunken and floating debris, as well as an unknown time (weeks, months) to coordinate salvage (removal, movement) of wreckage, sunken small boats, or other fragments and remains in portions of the ports. Surveying under water is neither straightforward nor easy, and safe conditions, in terms of both currents and weather, would need to exist before either divers or survey vessels could be allowed in the water.

There could be hazardous material spills, which would require cordoning off areas of the ports. Modeling indicates that debris from the small-boat marinas in the Port of Los Angeles would likely travel into the main channel. In addition, surveys must confirm that no hazards to navigation from sediment transport and other material from the seafloor had been deposited in shipping channels to such a degree that they posed hazards to navigation.

The permitting and removal process has significant, potentially lengthy, regulatory and environmental hurdles to overcome and involves permits, Federal and State agency approvals, followed by logistics and coordination of activities. In Crescent City, following the 2011 Tohoku tsunami, it took 6 months before all permits could be cleared to begin sediment removal in the middle of the harbor, and it was a year before the harbor was cleared, largely because of the complexity of regulations surrounding removal of debris. Major issues surrounded whether the debris contained contaminants and whether the grain size would allow disposal of the sediment further out to sea or would require it to be transported to landfills on land. Financial difficulties were also a factor.

\section{Period 7: Transition: Response to Recovery}




\section{General Description of Period 7}

During the post-event response period, threats to life-safety and loss of property are assessed, confirmed, or addressed to resolution, including egress and hazardous materials issues. With this resolution begins recovery, including reopening of facilities and repair of damage. Cal OES Recovery Branch personnel and often FEMA representatives are deployed to affected coastal jurisdictions, assisting with preliminary damage assessment. If proclamations of local emergency have not already been initiated, these assessments will accompany local requests for State and Federal assistance. In cases where a State proclamation or Federal declaration is approved, various loan and reimbursement grant programs may be made available. Transition activities may take weeks; recovery activities extend for many months and in some cases, years.

\section{Scenario-Informed Situation, Emergency Management Activities, Key Considerations and Challenges}

- Staff from various State and Federal agencies are in the field assisting with cleanup and damage assessment, assisting with local proclamations, and assisting local governments and port authorities with coordination among regulatory agencies. All affected county departments, agencies, and coastal cities are responsible for submitting status and damage assessment reports to the county emergency management agency following an actual tsunami occurrence according to the county's Disaster Information Reporting Procedures. Damage assessment includes damage resulting from both tsunamis and earthquakes, if applicable. The Los Angeles County Office of Emergency Management will use damage assessment information to initiate standard disaster response and recovery procedures outlined in the County Emergency Operations Center Standard Operating Procedures. The county is responsible for submitting preliminary damage assessments to the State.

- Full assessment begins of hazards to navigation, sunken vessels, damage to on-land structures or piers and water-related infrastructure; whether material deposited on the seafloor will require dredging begins to be coordinated. Depending on what has occurred as a result of the tsunami, this could be a lengthy and arduous process.

- Emergency Proclamations will be made by local jurisdictions based on the scale of impact and the internal assessment that the event has exceeded the jurisdiction's capacity to respond. As this "disaster" event unfolds regionally, subsequent proclamations will most assuredly expand to the county and then the state level. Because of the severity and widespread impacts of this tsunami there will be a designation of a number of counties as disaster areas. This is done via Gubernatorial Disaster Proclamation and, beyond that, via a Federal Disaster Declaration by the President. Depending on the severity and clear impacts of the event, such designations may be made while the event is still underway, or they may be done postevent as the extent of damage is quantified. State and Federal disaster designations can trigger funding programs addressing both response and recovery costs.

Key Considerations during Period 7 
7.1 Expediting debris clearance and dredging permit issues to expedite port commercial restoration. (Clear coordination among Federal/State regulatory agencies needed to fast-track a streamlined recovery process and lessen local burdens.)

7.2 Recovery planning to assess consequences and coordinate handling of complex incident-specific, complicated issues. Examples:

7.2.1 State assistance with local preliminary damage assessments.

7.2.2 State assistance with proper completion of applications for securing local proclamations.

7.2.3 Federal/State staffing, including divers to assess underwater damage and hazards to navigation.

7.2.4 Federal/State agency assistance with regulatory and permitting issues related to dredging and debris removal assessment and process.

7.2.5 Upon need, establish localized incident management offices (for example, Incident Operations Center, Disaster Field Office, Joint Information Center).

7.3 Address long-duration emergency management staffing patterns (EOC/Activation and all operations for multiple days/weeks).

7.4 Continued need to coordinate with media (rumor control, response/recovery progress).

7.5 Expediting and facilitating of recovery/rebuilding effort, including emergency regulations permit waivers.

7.6 Pressure on emergency management will be based on public and commercial demand to reopen ports and address cost of port damage/closure.

7.7 Pursuance of Gubernatorial Proclamation.

7.8 Pursuance of Major Presidential Disaster Declaration.

\section{Highlighted Emergency Management Challenges during Period 7}

Quick and Accurate Damage Assessments are Important

If a Federal declaration of major disaster is sought, as it most likely would be with a natural disaster of this severity, speed, accuracy, and completion of information about locally incurred damage and associated costs are important. For this reason, State officials (Cal OES, Governor's Office) are asking questions about response activities, damage incurred, shelters opened, populations affected, and other details every step of the way. State-level field coordinators and recovery experts will be dispatched to affected coastal communities to ensure that preliminary damage assessment forms to be submitted are as complete and accurate as possible. Each county, as well as the State as a whole, must meet specific monetary loss thresholds in order to facilitate assistance that will be important and possibly necessary for a full recovery and return to normal operations for all affected areas. It is the mission of all emergency management agencies to ensure that, if needed, this aid is sought. This assistance also requires the signature and approval of elected officials; therefore it is generally important to request assistance as quickly as possible. Expediting applications for assistance is important not only to meet statutory deadlines, but also while the political pressure is on to provide assistance to those who need it.

Potential Recovery Issues within Ports 
The following insights are taken from recent experience with FEMA Pubic Assistance Program-funded recovery from damages to smaller harbors (Crescent City and Santa Cruz) during the recent Chile and Japan tsunamis:

As with all disaster events, saving lives and protecting property is always the top priority. Once the response phase of the disaster winds down, State and local government agencies affected by a tsunami should begin assessing damage and compiling a list of projects that require immediate or permanent (long-term) repairs. When the assessment is complete, public agencies should begin the process of determining whether any permits, approvals, consultations, or authorizations (collectively called permits for this article) are needed to perform the repairs. Although exemptions exist for disaster repair projects under the National Environmental Policy Act and the California Environmental Quality Act, other Federal or State laws or executive orders may not contain such exemptions and require approval by one or more regulatory agencies. In some instances emergency permits are available with expedited processing procedures, or regulatory agencies may allow the repair work to proceed while the permit(s) are being processed.

Damages suffered by public agencies in Major Disaster Declaration "California Tsunami Waves" declared by President Obama, through FEMA, on April 18, 2011, fell into several broad categories including:

- Debris removal including sunken vessels and damaged docks,

- Replacing damaged piles,

- Replacing or repairing damaged docks,

- Repairing breakwaters,

- Rock slope protection within the harbor, and

- Dredging.

All of these types of projects are regulated by one or more of the following agencies:

- The Army Corp of Engineers (404 permit),

- U.S. Environmental Protection Agency (Approval of dredging plan and disposal of sediment),

- U.S. Fish and Wildlife Service (Consultation if threatened or endangered species may be affected),

- National Marine Fisheries Service (Consultation if native fish may be affected);

- Regional Water Quality Control Board (401 Water Quality Certification),

- California Coastal Commission (Coastal Development Permit),

- State Lands Commission (Dredging in state-owned tidelands or submerged waters), or

- National Oceanic and Atmospheric Administration Marine Sanctuary (Review of dredging plan).

Permitting a dredging operation within a harbor can be a complicated process requiring the preparation and approval of a dredging plan, collecting sediment samples, laboratory analysis, and finally dredging and disposal. Each step takes time to perform, and other repair projects may hinge on the dredging to occur first. For this reason, agencies should provide updates to decision makers and the public on their progress in repairing tsunami related damage so they are not left with the impression that nothing is being done.

Recommendations for future tsunami events:

4. Affected jurisdictions should know in advance which agencies may have permitting jurisdiction and know how to contact them. 
5. When applying for permits from State or Federal agencies, subgrantees should determine if permits can be issued on an emergency basis or if the permitting agency will allow the subgrantee to proceed with the condition that a permit will be secured in the immediate future.

6. Permitting agencies should be made aware of the time frames in which repairs must be made to meet any critical deadlines or events such as the start of a fish or crab season.

7. At the applicant briefing(s), it should be made very clear that subgrantees cannot start permanent repair work until all required permits have been obtained.

8. Decision makers and the public should be provided updates on the progress of repairing tsunami damage so they are aware of the progress being made.

Smaller harbor districts have limited resources and may need the assistance of consultants to help complete the permitting process. Cal OES and FEMA should be ready to help pay the cost of these services if required.

\section{Conclusions}

This tsunami would be worse than any experienced in historical time by the State of California, and by the United States as a nation. It would be worse than the 1964 tsunami from Alaska, which resulted in the destruction of much of Crescent City's downtown and 12 deaths statewide. It would be 4 to 5 times worse in California than the Tohoku tsunami from Japan in 2011, which resulted in $\$ 100$ million in damage to 27 harbors and marinas down the length of the State's coast.

Such an event would stretch the State's emergency response system up to and beyond its limits. However, the system is built to expand beyond its limits, with cities calling upon the State and the State asking the Federal government when its resources and personnel capabilities have been reached. And California has had plenty of experience putting its emergency management practices into play over recent decades - during earthquakes, wildfires, and flooding events.

The trick will be to understand the nature of the tsunami to come, its impacts, and what the public needs to know ahead of time to understand what to do to save their lives and protect their property when the warning comes. While we may have a warning window on the day (or night) of the tsunami, it can be years between damaging, life threatening events. Sustaining public preparedness and government capabilities to respond to this specific threat is key. When the next tsunami comes from Alaska, we will have only five and one-half hours to prove we know what to do.

The analysis and expertise brought to bear by this scenario report can provide the basis for ever-increasingly informed emergency response and evacuation planning.

\section{Acknowledgments}

The authors thank Jim Goltz, Rich Eisner and Johanna Fenton (Cal OES, retired), Jeff Terry (Los Angeles County Office of Emergency Management), and Anne Wein (USGS) for thoughtful reviews that improved the report. 


\section{Selected References}

California Emergency Management Agency, 2012, [March 2011 California tsunami after action/corrective action report] Japan tsunami marine debris (JTMD) concept of operations: California Emergency Management Agency, 32 p. (Available online at www.calepa.ca.gov/Disaster/Documents/2012/JapanTsunami.pdf.)

California Integrated Seismic Network, 2013, California integrated seismic network. (Available online at http://www.cisn.org/.)

City of Los Angeles, 2008, Tsunami response plan annex, in Emergency operations master plans and procedures: City of Los Angeles, 51 p. (Available online at http://emergency.lacity.org/stellent/groups/departments/@emd_contributor/documents/contrib utor_web_content/lacityp_013228.pdf.)

Dengler, L.A., Fenton, J., Goltz, J.D., Miller, K.M., and Wilson, R.I., 2011, Building tsunamiresilient communities in the United States - an example from California: Seventh International Workshop on Coastal Disaster Prevention, Tokyo, Japan, January 26-27, 2011, Proceeding, 14 p.

Miller, K.M., and Wilson, R.I., 2012, A culture of tsunami preparedness and applying knowledge from recent tsunamis affecting California: American Geophysical Union, Fall Meeting 2012. (Available online at http://fallmeeting.agu.org/2012/eposters/eposter/nh33a-1641/.)

Long Beach Fire Department, 2013, Long Beach Fire Department Disaster Management Bureau: City of Long Beach Emergency Management (Available online at http://www.longbeach.gov/fire/emergency_prep.)

Lynett, P., Wilson, R.I., and Miller, K.M., 2012, Maritime Hazard Analysis And Map Production In California: American Geophysical Union Fall Meeting 2012. (Available online at http://nthmp.tsunami.gov/2012tsuhazworkshop/abstracts/LynettCAmaritime_abs.pdf.)

Miller, K.M., Wilson, R.I., Goltz, J.D., Fenton, J., Long, K., Dengler, L., and Rosinski, A., 2011, State emergency response and field observation activities in California (USA) during the March 11, 2011, Tohoku Tsunami: American Geophysical Union Fall Meeting 2011. (Available online at http://adsabs.harvard.edu/abs/2011AGUFMNH11A1346M.)

Moffatt \& Nichol, 2007, Tsunami hazard assessment for the Ports of Long Beach and Los Angeles: Moffatt \& Nichol, Engineers, Final Report prepared for Port of Long Beach and Port of Los Angeles, M\&N File 4839-169. (Available online at http://www.portoflosangeles.org/DOC/REPORT_Tsunami_April_2007.pdf.)

National Atmospheric and Oceanic Administration, 2013a, National Tsunami Hazard Mitigation Program: (Available online at http://nthmp.tsunami.gov/index.html.)

National Atmospheric and Oceanic Administration, 2013b, Tsunami.gov. (Available online at www.tsunami.gov.)

Porter, K., Byers, W., Dykstra, C., Lim, A., Lynett, P., Ratliff, J., Scawthorn, C., Wein, A., and Wilson, R., 2013, Physical damage in the SAFRR California tsunami scenario: U.S. Geological Survey open-File Report 2013-1170-E, 183 p., http://pubs.usgs.gov/of/2013/1170/E/.

United States Coast Guard, 2013, Port directory: United States Coast Guard, Homeport (Available online at http://homeport.uscg.mil/lalb.)

United States Congress, 2006, Tsunami warning and education act (H.R. 1674): 109th Congress, accessed June 1, 2013, at http://www.govtrack.us/congress/bills/109/hr1674. 
Wilson, R.I., and Miller, K.M., 2011, Tsunami hazard mapping activities in Northern California: United States Geological Survey Northern California Hazards Workshop.

Wilson, R.I., Dengler, L.A., Legg, M.R., Long, K., and Miller, K.M., 2010a, The 2010 Chilean tsunami on the California coastline: American Geophysical Union Fall Meeting. (Available online at http://pubs.usgs.gov/of/2010/1152/presentations/of2010-1152_poster_e_wilsonchile.pdf.)

Wilson, R.I, Barberopoulou, A., Borrero, J.C., Bryant, W.A, Dengler, L.A., Goltz, J.D., Legg, M.R., McGuire, T., Miller, K.M., Real, C.R., Synolakis, C.E., and Uslu, B., 2010b, Development of new databases for tsunami hazard analysis in California: U.S. Geological Survey Open-File Report 2010-1152, p. 31. (Available online at http://pubs.usgs.gov/of/2010/1152/.)

Wilson, R.I., Barberopoulou, A., Miller, K.M., Goltz, J.D., and Synolakis, C.E., 2010c, New maximum tsunami inundation maps for use by local emergency planners in the State of California, USA: U.S. Geological Survey Open-File Report 2010-1152, p. 32. (Available online at http://pubs.usgs.gov/of/2010/1152/.)

Wilson, R.I., Miller, K.M., and Rosinski, A.M., 2011a, California's pre- and post- tsunami field observation team and clearinghouse: Earthquake Engineering Research Institute Annual Meeting, 2011.

Wilson, R.I., Dengler, L.A., Goltz, J.D., Legg, M.R., and Miller, K.M., 2011b, Emergency response and field observation activities of geoscientists in California (USA) during the September 29, 2009, Samoa tsunami: Earth Science Reviews, v. 107, p. 193-200. (Available online at http://www.sciencedirect.com/science/article/pii/S0012825211000195.) 


\section{Appendix A-NOAA Tsunami Alert Level Definitions}

- A Tsunami Warning is issued when a tsunami with the potential to generate widespread inundation is imminent, expected, or occurring. Warnings alert the public that dangerous coastal flooding accompanied by powerful currents is possible and may continue for several hours after initial arrival. Warnings alert emergency management officials to take action for the entire tsunami hazard zone. Appropriate actions to be taken by local officials may include the evacuation of low-lying coastal areas and the repositioning of ships to deep waters when there is time to safely do so. Warnings may be updated, adjusted geographically, downgraded, or canceled. To provide the earliest possible alert, initial Warnings are normally based only on seismic information. Warnings are issued when the earthquake information or tsunami forecasts indicate that a wave height over 1 meter (or over 3 feet) in amplitude is expected, possible, or ongoing.

- A Tsunami Advisory is issued when a tsunami with the potential to generate strong currents or waves dangerous to those in or very near the water is imminent, expected, or occurring. The threat may continue for several hours after initial arrival, but significant inundation is not expected for areas under an Advisory. Appropriate actions to be taken by local officials may include closing beaches, evacuating harbors and marinas, and the repositioning of ships to deep waters when there is time to safely do so. Advisories are normally updated to continue the Advisory, expand/contract affected areas, upgrade to a Warning, or cancel the Advisory. Advisories are issued when the tsunami wave height forecast is in the range of $1 / 3$ to 1 meter (or $1-3$ feet).

- A Tsunami Watch is issued to alert emergency management officials and the public of an event which may later impact the WATCH area. The WATCH area may be upgraded to a Warning or Advisory - or canceled - based on updated information and analysis.

Therefore, emergency management officials and the public should prepare to take action. Watches are normally issued based on seismic information without confirmation that a destructive tsunami is underway.

- A Tsunami Information Statement is issued to inform emergency management officials and the public that an earthquake has occurred, or that a tsunami Warning, Watch, or Advisory has been issued for another section of the ocean. In most cases, Information Statements are issued to indicate that there is no threat of a destructive tsunami and to prevent unnecessary evacuations as the earthquake may have been felt in coastal areas. An Information Statement may, in appropriate situations, caution about the possibility of destructive local tsunamis. Information Statements may be reissued with additional information, though normally these messages are not updated. However, a Watch, 
Advisory, or Warning may be issued for the area, if necessary, after analysis and (or) updated information becomes available. 


\section{Appendix B-NOAA WCATWC Tsunami Scenario Alert Bulletins}

\begin{tabular}{|c|c|c|c|c|}
\hline Bulletin \# & $\begin{array}{l}\text { NOAA Alert } \\
\text { Level(s) }\end{array}$ & Bulletin Time/Date & $\begin{array}{l}\text { Geographic } \\
\text { Breakpoint }\end{array}$ & $\begin{array}{l}\text { Period (in this } \\
\text { Chapter) }\end{array}$ \\
\hline Bulletin 1 & Watch & 1154 AM PDT THU MAR 272014 & All & 1 \\
\hline Bulletin 2 & Watch & 1231 PM PDT THU MAR 272014 & All & 1 \\
\hline Bulletin 3 & Watch & 103 PM PDT THU MAR 272014 & All & 1 \\
\hline Bulletin 4 & Warning & 205 PM PDT THU MAR 272014 & All & 2 \\
\hline Bulletin 5 & Warning & 301 PM PDT THU MAR 272014 & All & 2 \\
\hline Bulletin 6 & Warning & 401 PM PDT THU MAR 272014 & All & 2 \\
\hline Bulletin 7 & Warning & 502 PM PDT THU MAR 272014 & All & 2 \\
\hline Bulletin 8 & Warning & 601 PM PDT THU MAR 272014 & All & 3 \\
\hline Bulletin 9 & Warning & 701 PM PDT THU MAR 272014 & All & 3 \\
\hline $\begin{array}{l}\text { Bulletin } \\
10\end{array}$ & Warning & 801 PM PDT THU MAR 272014 & All & 3 \\
\hline $\begin{array}{l}\text { Bulletin } \\
11\end{array}$ & Warning & 901 PM PDT THU MAR 272014 & All & 3 \\
\hline $\begin{array}{l}\text { Bulletin } \\
12\end{array}$ & Warning & 1001 PM PDT THU MAR 272014 & All & 3 \\
\hline $\begin{array}{l}\text { Bulletin } \\
13\end{array}$ & Warning & 1100 PM PDT THU MAR 272014 & All & 3 \\
\hline $\begin{array}{l}\text { Bulletin } \\
14\end{array}$ & Warning & 1201 AM PDT FRI MAR 282014 & All & 3 \\
\hline $\begin{array}{l}\text { Bulletin } \\
15\end{array}$ & Warning & 100 AM PDT FRI MAR 282014 & All & 3 \\
\hline $\begin{array}{l}\text { Bulletin } \\
16\end{array}$ & Warning & 201 AM PDT FRI MAR 282014 & All & 3 \\
\hline $\begin{array}{l}\text { Bulletin } \\
17\end{array}$ & Warning & 300 AM PDT FRI MAR 282014 & All & 3 \\
\hline $\begin{array}{l}\text { Bulletin } \\
18\end{array}$ & Warning & 400 AM PDT FRI MAR 282014 & All & 3 \\
\hline $\begin{array}{l}\text { Bulletin } \\
19\end{array}$ & Warning & 500 AM PDT FRI MAR 282014 & All & 3 \\
\hline $\begin{array}{l}\text { Bulletin } \\
20\end{array}$ & Warning & 600 AM PDT FRI MAR 282014 & All & 3 \\
\hline $\begin{array}{l}\text { Bulletin } \\
21\end{array}$ & Warning & 701 AM PDT FRI MAR 282014 & All & 3 \\
\hline $\begin{array}{l}\text { Bulletin } \\
22\end{array}$ & Warning & 800 AM PDT FRI MAR 282014 & All & 3 \\
\hline $\begin{array}{l}\text { Bulletin } \\
23\end{array}$ & Warning & 901 AM PDT FRI MAR 282014 & All & 3 \\
\hline $\begin{array}{l}\text { Bulletin } \\
24\end{array}$ & Warning & 1001 AM PDT FRI MAR 282014 & All & 3 \\
\hline $\begin{array}{l}\text { Bulletin } \\
25\end{array}$ & Warning & 1101 AM PDT FRI MAR 282014 & All & 3 \\
\hline $\begin{array}{l}\text { Bulletin } \\
26\end{array}$ & Warning/Advisory & 1202 PM PDT FRI MAR 282014 & @ Alamitos & 4 \\
\hline Bulletin & Warning/Advisory & 100 PM PDT FRI MAR 282014 & (a) Alamitos & 4 \\
\hline
\end{tabular}




\begin{tabular}{|c|c|c|c|c|}
\hline 27 & & & & \\
\hline $\begin{array}{l}\text { Bulletin } \\
28\end{array}$ & Warning/Advisory & 201 PM PDT FRI MAR 282014 & (a) Alamitos & 4 \\
\hline $\begin{array}{l}\text { Bulletin } \\
29\end{array}$ & Warning/Advisory & 300 PM PDT FRI MAR 282014 & (a) Alamitos & 4 \\
\hline $\begin{array}{l}\text { Bulletin } \\
30\end{array}$ & Warning/Advisory & 400 PM PDT FRI MAR 282014 & (a) Alamitos & 4 \\
\hline $\begin{array}{l}\text { Bulletin } \\
31\end{array}$ & Warning/Advisory & 504 PM PDT FRI MAR 282014 & $\begin{array}{c}\text { Concepcion } \\
\text { Con }\end{array}$ & 4 \\
\hline $\begin{array}{l}\text { Bulletin } \\
32\end{array}$ & Warning/Advisory & 601 PM PDT FRI MAR 282014 & $\begin{array}{l}@ \\
\text { Concepcion }\end{array}$ & 4 \\
\hline $\begin{array}{l}\text { Bulletin } \\
33\end{array}$ & Warning/Advisory & 701 PM PDT FRI MAR 282014 & $\begin{array}{l}@ \\
\text { Concepcion }\end{array}$ & 4 \\
\hline $\begin{array}{l}\text { Bulletin } \\
34\end{array}$ & Advisory & 802 PM PDT FRI MAR 282014 & All & 5 \\
\hline $\begin{array}{l}\text { Bulletin } \\
35\end{array}$ & Advisory & 902 PM PDT FRI MAR 282014 & All & 5 \\
\hline $\begin{array}{l}\text { Bulletin } \\
36\end{array}$ & Advisory & 1000 PM PDT FRI MAR 282014 & All & 5 \\
\hline $\begin{array}{l}\text { Bulletin } \\
37\end{array}$ & Advisory & 1100 PM PDT FRI MAR 282014 & All & 5 \\
\hline $\begin{array}{l}\text { Bulletin } \\
38\end{array}$ & Advisory & 1200 AM PDT SAT MAR 292014 & All & 5 \\
\hline $\begin{array}{l}\text { Bulletin } \\
39\end{array}$ & Advisory & 100 AM PDT SAT MAR 292014 & All & 5 \\
\hline $\begin{array}{l}\text { Bulletin } \\
40\end{array}$ & Advisory & 201 AM PDT SAT MAR 292014 & All & 5 \\
\hline $\begin{array}{l}\text { Bulletin } \\
41\end{array}$ & Advisory & 300 AM PDT SAT MAR 292014 & All & 5 \\
\hline $\begin{array}{l}\text { Bulletin } \\
42\end{array}$ & Advisory & 401 AM PDT SAT MAR 292014 & All & 5 \\
\hline $\begin{array}{l}\text { Bulletin } \\
43\end{array}$ & Advisory & 500 AM PDT SAT MAR 292014 & All & 5 \\
\hline $\begin{array}{l}\text { Bulletin } \\
44\end{array}$ & Advisory & 600 AM PDT SAT MAR 292014 & All & 5 \\
\hline $\begin{array}{l}\text { Bulletin } \\
45\end{array}$ & Advisory & 701 AM PDT SAT MAR 292014 & All & 5 \\
\hline $\begin{array}{l}\text { Bulletin } \\
46\end{array}$ & Advisory & 801 AM PDT SAT MAR 292014 & All & 5 \\
\hline $\begin{array}{l}\text { Bulletin } \\
47\end{array}$ & Advisory/Cancel & 901 AM PDT SAT MAR 292014 & (a) Rincon & 5 \\
\hline $\begin{array}{l}\text { Bulletin } \\
48\end{array}$ & Advisory/Cancel & 1002 AM PDT SAT MAR 292014 & (a) Rincon & 5 \\
\hline $\begin{array}{l}\text { Bulletin } \\
49\end{array}$ & Advisory/Cancel & 1101 AM PDT SAT MAR 292014 & (a) Rincon & 5 \\
\hline $\begin{array}{l}\text { Bulletin } \\
50\end{array}$ & Cancel & 1200 PM PDT SAT MAR 292014 & All & 6 \\
\hline
\end{tabular}


WEAK51 PAAQ 271854

TSUAK1

BULLETIN

PUBLIC TSUNAMI MESSAGE NUMBER 1

NWS WEST COAST/ALASKA TSUNAMI WARNING CENTER PALMER AK 1054 AM AKDT THU MAR 272014

...A TSUNAMI WARNING IS NOW IN EFFECT...

...A TSUNAMI WATCH IS NOW IN EFFECT...

WARNINGS/ADVISORIES/WATCHES - UPDATED

TSUNAMI WARNING IN EFFECT FOR...

* THE COASTAL AREAS OF BRITISH COLUMBIA AND ALASKA FROM THE NORTH TIP OF VANCOUVER ISLAND BRITISH COLUMBIA TO ATTU ALASKA

TSUNAMI WATCH IN EFFECT FOR...

* THE COASTAL AREAS OF CALIFORNIA - OREGON - WASHINGTON AND 
BRITISH COLUMBIA FROM THE CALIFORNIA-MEXICO BORDER TO THE NORTH TIP OF VANCOUVER ISLAND BRITISH COLUMBIA

PRELIMINARY EARTHQUAKE PARAMETERS

* MAGNITUDE 8.2

* ORIGIN TIME 1050 AKDT MAR 272014

1150 PDT MAR 272014

1850 UTC MAR 272014

* COORDINATES 55.2 NORTH 156.7 WEST

* DEPTH 11 MILES

* LOCATION 100 MILES SE OF CHIGNIK ALASKA 485 MILES SW OF ANCHORAGE ALASKA

IMPACTS FOR TSUNAMI WARNING AREAS

* WIDESPREAD DANGEROUS COASTAL FLOODING ACCOMPANIED BY POWERFUL CURRENTS IS POSSIBLE AND MAY CONTINUE FOR MANY HOURS AFTER TSUNAMI ARRIVAL.

* THE FIRST WAVE MAY NOT BE THE LARGEST.

IMPACTS FOR TSUNAMI WATCH AREAS

* EXPECTED IMPACT IS UNKNOWN AT THIS TIME.

* THE WATCH WILL BE UPGRADED OR CANCELED AT LEAST TWO HOURS BEFORE EXPECTED IMPACT.

RECOMMENDED ACTIONS - UPDATED

* IF YOU ARE IN A WARNING AREA - MOVE INLAND TO HIGHER GROUND.

* IF YOU ARE IN A WATCH AREA - STAY ALERT FOR FURTHER INSTRUCTIONS.

* BE ALERT TO INSTRUCTIONS FROM YOUR LOCAL EMERGENCY OFFICIALS.

* DO NOT GO TO THE COAST TO OBSERVE THE TSUNAMI.

* DO NOT RETURN TO THE COAST UNTIL LOCAL EMERGENCY OFFICIALS INDICATE IT IS SAFE TO DO SO. 
FORECASTS AND/OR OBSERVATIONS OF TSUNAMI ACTIVITY

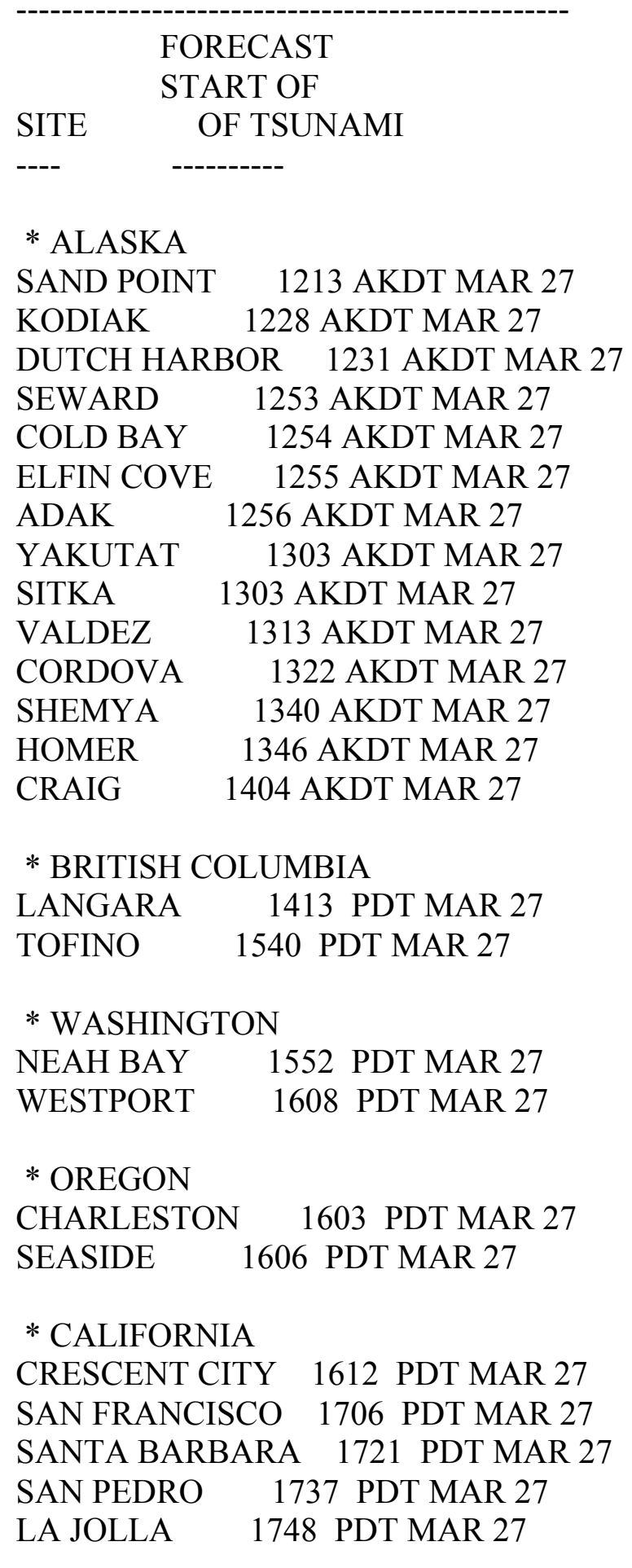

NEXT UPDATE AND ADDITIONAL INFORMATION 
* THIS MESSAGE WILL BE UPDATED IN 30 MINUTES.

* REFER TO THE INTERNET SITE WCATWC.ARH.NOAA.GOV FOR MORE INFORMATION.

* PACIFIC COASTAL RESIDENTS OUTSIDE CALIFORNIA... OREGON... WASHINGTON... BRITISH COLUMBIA AND ALASKA SHOULD REFER TO THE PACIFIC TSUNAMI WARNING CENTER MESSAGES FOR INFORMATION ON THIS EVENT AT PTWC.WEATHER.GOV.

$\$ \$$

WEAK51 PAAQ 271931

TSUAK1

BULLETIN

PUBLIC TSUNAMI MESSAGE NUMBER 2

NWS WEST COAST/ALASKA TSUNAMI WARNING CENTER PALMER AK 1131 AM AKDT THU MAR 272014

THIS MESSAGE INCREASES MAGNITUDE TO 8.6.

...THE TSUNAMI WARNING REMAINS IN EFFECT...

...A TSUNAMI WATCH IS NOW IN EFFECT...

WARNINGS/ADVISORIES/WATCHES

TSUNAMI WARNING IN EFFECT FOR...

* THE COASTAL AREAS OF BRITISH COLUMBIA AND ALASKA FROM THE NORTH TIP OF VANCOUVER ISLAND BRITISH COLUMBIA TO ATTU ALASKA

TSUNAMI WATCH IN EFFECT FOR... 
* THE COASTAL AREAS OF CALIFORNIA - OREGON - WASHINGTON AND BRITISH COLUMBIA FROM THE CALIFORNIA-MEXICO BORDER TO THE NORTH TIP OF VANCOUVER ISLAND BRITISH COLUMBIA

IMPACTS FOR TSUNAMI WARNING AREAS

* WIDESPREAD DANGEROUS COASTAL FLOODING ACCOMPANIED BY POWERFUL CURRENTS IS POSSIBLE AND MAY CONTINUE FOR MANY HOURS AFTER TSUNAMI ARRIVAL.

* THE FIRST WAVE MAY NOT BE THE LARGEST.

IMPACTS FOR TSUNAMI WATCH AREAS

* EXPECTED IMPACT IS UNKNOWN AT THIS TIME.

* THE WATCH WILL BE UPGRADED OR CANCELED AT LEAST TWO HOURS BEFORE EXPECTED IMPACT.

RECOMMENDED ACTIONS

* IF YOU ARE IN A WARNING AREA - MOVE INLAND TO HIGHER GROUND.

* IF YOU ARE IN A WATCH AREA - STAY ALERT FOR FURTHER INSTRUCTIONS.

* BE ALERT TO INSTRUCTIONS FROM YOUR LOCAL EMERGENCY OFFICIALS.

* DO NOT GO TO THE COAST TO OBSERVE THE TSUNAMI.

* DO NOT RETURN TO THE COAST UNTIL LOCAL EMERGENCY OFFICIALS INDICATE IT IS SAFE TO DO SO.

FORECASTS AND/OR OBSERVATIONS OF TSUNAMI ACTIVITY

$\begin{array}{ll} & \text { FORECAST } \\ & \text { START OF } \\ \text { SITE } & \text { OF TSUNAMI } \\ --- & ---- \\ \text { * ALASKA } & \\ \text { SAND POINT } 1207 \text { AKDT MAR } 27\end{array}$




\begin{tabular}{|c|c|}
\hline \multirow{2}{*}{\multicolumn{2}{|c|}{$\begin{array}{l}\text { KODIAK } \\
\text { DUTCH HARBOR }\end{array}$}} \\
\hline & DUTCH HARBOR \\
\hline SEWARD & 1246 AKDT MAR 27 \\
\hline COLD BAY & 1247 AKDT MAR 27 \\
\hline ELFIN COVE & 1248 AKDT MAR 27 \\
\hline ADAK & 1251 AKDT MAR 27 \\
\hline YAKUTAT & 1256 AKDT MAR 27 \\
\hline SITKA & 1256 AKDT MAR 27 \\
\hline VALDEZ & 1305 AKDT MAR 27 \\
\hline CORDOVA & 1315 AKDT MAR 27 \\
\hline SHEMYA & 1334 AKDT MAR 27 \\
\hline HOMER & 1339 AKDT MAR 27 \\
\hline CRAIG & 1357 AKDT MAR 27 \\
\hline \multicolumn{2}{|c|}{ * BRITISH COLUMBIA } \\
\hline LANGARA & 1406 PDT MAR 27 \\
\hline TOFINO & 1533 PDT MAR 27 \\
\hline \multicolumn{2}{|c|}{ * WASHINGTON } \\
\hline NEAH BAY & 1545 PDT MAR 27 \\
\hline WESTPORT & 1601 PDT MAR 27 \\
\hline \multicolumn{2}{|l|}{ * OREGON } \\
\hline \multicolumn{2}{|l|}{ CHARLESTON } \\
\hline SEASIDE & 1600 PDT MAR 27 \\
\hline \multicolumn{2}{|c|}{ * CALIFORNIA } \\
\hline \multicolumn{2}{|c|}{ CRESCENT CITY } \\
\hline \multicolumn{2}{|c|}{ SAN FRANCISCO } \\
\hline \multicolumn{2}{|c|}{ SANTA BARBARA 1718 PDT MAR } \\
\hline SAN PEDRO & 1734 PDT MAR 27 \\
\hline LA JOLLA & 1745 PDT MAR 27 \\
\hline
\end{tabular}

FORECAST MODELS PROJECT THAT 22 FOOT/6.7 METER WAVES COULD DEVELOP ALONG THE COAST OF ALASKA. WAVES OF THIS SIZE ARE KNOWN TO CAUSE INUNDATION AND DAMAGE TO COASTAL STRUCTURES. IN ALASKA THE TSUNAMI IS EXPECTED TO REACH PEAK SIZE 30 MINUTES TO TWO HOURS AFTER THE EXPECTED ARRIVAL TIME.

ADDITIONAL OBSERVATIONS OF TSUNAMI ACTIVITY - UPDATED

DEEP OCEAN PRESSURE SENSOR DATA INDICATES A TSUNAMI WAS GENERATED. PRELIMINARY EARTHQUAKE PARAMETERS - UPDATED 
* MAGNITUDE 8.6

* ORIGIN TIME 1050 AKDT MAR 272014

1150 PDT MAR 272014

1850 UTC MAR 272014

* COORDINATES 55.2 NORTH 156.7 WEST

* DEPTH 11 MILES

* LOCATION 100 MILES SE OF CHIGNIK ALASKA 485 MILES SW OF ANCHORAGE ALASKA

NEXT UPDATE AND ADDITIONAL INFORMATION

* THIS MESSAGE WILL BE UPDATED IN 30 MINUTES.

* REFER TO THE INTERNET SITE WCATWC.ARH.NOAA.GOV FOR MORE INFORMATION.

* PACIFIC COASTAL RESIDENTS OUTSIDE CALIFORNIA... OREGON... WASHINGTON... BRITISH COLUMBIA AND ALASKA SHOULD REFER TO THE PACIFIC TSUNAMI WARNING CENTER MESSAGES FOR INFORMATION ON THIS EVENT AT PTWC.WEATHER.GOV.

$\$ \$$ 
WEAK51 PAAQ 272003

TSUAK1

BULLETIN

PUBLIC TSUNAMI MESSAGE NUMBER 3

NWS WEST COAST/ALASKA TSUNAMI WARNING CENTER PALMER AK

1203 PM AKDT THU MAR 272014

THIS MESSAGE INCREASES MAGNITUDE TO 9.0 AND EXPANDS THE WARNING AREA.

...THE TSUNAMI WARNING REMAINS IN EFFECT...

...A TSUNAMI WATCH IS NOW IN EFFECT...

WARNINGS/ADVISORIES/WATCHES - UPDATED

TSUNAMI WARNING IN EFFECT FOR...

* THE COASTAL AREAS OF OREGON - WASHINGTON AND BRITISH COLUMBIA FROM THE OREGON-CALIFORNIA BORDER TO THE NORTH TIP OF VANCOUVER ISLAND BRITISH COLUMBIA

* THE COASTAL AREAS OF BRITISH COLUMBIA AND ALASKA FROM THE 
NORTH TIP OF VANCOUVER ISLAND BRITISH COLUMBIA TO ATTU ALASKA

TSUNAMI WATCH IN EFFECT FOR...

* THE COASTAL AREAS OF CALIFORNIA FROM THE CALIFORNIA-MEXICO BORDER TO THE OREGON-CALIFORNIA BORDER

IMPACTS FOR TSUNAMI WARNING AREAS

* WIDESPREAD DANGEROUS COASTAL FLOODING ACCOMPANIED BY POWERFUL CURRENTS IS POSSIBLE AND MAY CONTINUE FOR MANY HOURS AFTER TSUNAMI ARRIVAL.

* THE FIRST WAVE MAY NOT BE THE LARGEST.

IMPACTS FOR TSUNAMI WATCH AREAS

* EXPECTED IMPACT IS UNKNOWN AT THIS TIME.

* THE WATCH WILL BE UPGRADED OR CANCELED AT LEAST TWO HOURS BEFORE EXPECTED IMPACT.

\section{RECOMMENDED ACTIONS}

* IF YOU ARE IN A WARNING AREA - MOVE INLAND TO HIGHER GROUND.

* IF YOU ARE IN A WATCH AREA - STAY ALERT FOR FURTHER INSTRUCTIONS.

* BE ALERT TO INSTRUCTIONS FROM YOUR LOCAL EMERGENCY OFFICIALS.

* DO NOT GO TO THE COAST TO OBSERVE THE TSUNAMI.

* DO NOT RETURN TO THE COAST UNTIL LOCAL EMERGENCY OFFICIALS INDICATE IT IS SAFE TO DO SO.

FORECASTS AND/OR OBSERVATIONS OF TSUNAMI ACTIVITY

$\begin{array}{llll} & \text { FORECAST } & \text { FORECAST FORECAST } & \text { OBSERVED } \\ \text { SITE } & \text { START OF } & \text { TSUNAMI MAX TSUNAMI } & \text { TSUNAMI } \\ \text { OF TSUNAMI } & \text { DURATION HEIGHT } & \text { HEIGHT }\end{array}$




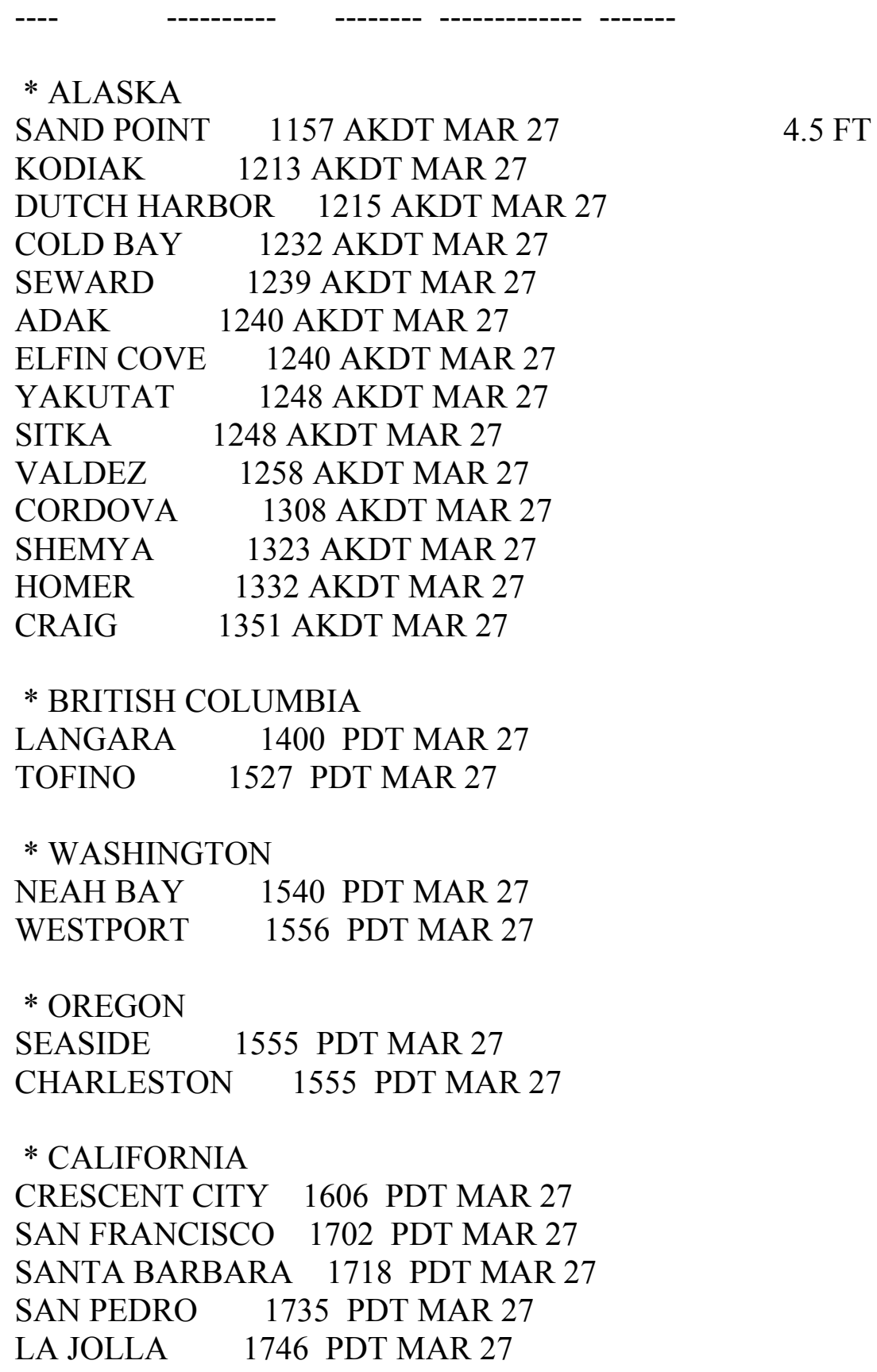

FORECAST MAX TSUNAMI HEIGHT IS THE HIGHEST EXPECTED WATER LEVEL 
ABOVE THE TIDE.

FORECAST TSUNAMI DURATION IS THE APPROXIMATE LENGTH OF TIME WHICH THE TSUNAMI MAY PRODUCE DANGEROUS CURRENTS AND WAVE ACTIVITY.

OBSERVED TSUNAMI HEIGHT IS THE HIGHEST WATER LEVEL ABOVE THE TIDE LEVEL AT THE TIME OF MEASUREMENT.

ADDITIONAL OBSERVATIONS OF TSUNAMI ACTIVITY - UPDATED

DEEP OCEAN PRESSURE SENSOR DATA INDICATES A TSUNAMI WAS GENERATED.

PRELIMINARY EARTHQUAKE PARAMETERS - UPDATED

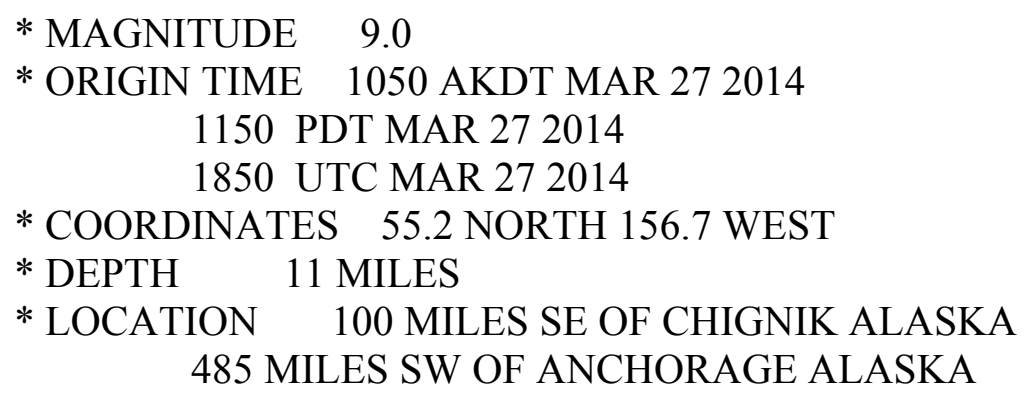

NEXT UPDATE AND ADDITIONAL INFORMATION

* THIS MESSAGE WILL BE UPDATED IN 60 MINUTES.

* REFER TO THE INTERNET SITE WCATWC.ARH.NOAA.GOV FOR MORE INFORMATION.

* PACIFIC COASTAL RESIDENTS OUTSIDE CALIFORNIA... OREGON... WASHINGTON... BRITISH COLUMBIA AND ALASKA SHOULD REFER TO THE PACIFIC TSUNAMI WARNING CENTER MESSAGES FOR INFORMATION ON THIS EVENT AT PTWC.WEATHER.GOV. 
WEAK51 PAAQ 272105

TSUAK1

BULLETIN

PUBLIC TSUNAMI MESSAGE NUMBER 4

NWS WEST COAST/ALASKA TSUNAMI WARNING CENTER PALMER AK

105 PM AKDT THU MAR 272014

THIS MESSAGE EXPANDS THE WARNING/ADVISORY AREA AND REMOVES THE WATCH. FORECAST TSUNAMI HEIGHTS ARE ADDED BELOW.

...THE TSUNAMI WARNING REMAINS IN EFFECT...

...A TSUNAMI ADVISORY IS NOW IN EFFECT...

WARNINGS/ADVISORIES/WATCHES - UPDATED

TSUNAMI WARNING IN EFFECT FOR...

* THE COASTAL AREAS OF CALIFORNIA FROM THE CALIFORNIA-MEXICO BORDER TO THE OREGON-CALIFORNIA BORDER

* THE COASTAL AREAS OF OREGON - WASHINGTON - BRITISH COLUMBIA AND ALASKA FROM THE OREGON-CALIFORNIA BORDER TO NIKOLSKI ALASKA 
TSUNAMI ADVISORY IN EFFECT FOR...

* THE COASTAL AREAS OF ALASKA FROM NIKOLSKI ALASKA TO ATTU ALASKA

IMPACTS FOR TSUNAMI WARNING AREAS

* WIDESPREAD DANGEROUS COASTAL FLOODING ACCOMPANIED BY POWERFUL CURRENTS IS POSSIBLE AND MAY CONTINUE FOR MANY HOURS AFTER TSUNAMI ARRIVAL.

* THE FIRST WAVE MAY NOT BE THE LARGEST.

IMPACTS FOR TSUNAMI ADVISORY AREAS

* A TSUNAMI CAPABLE OF PRODUCING STRONG CURRENTS OR WAVES DANGEROUS

TO PERSONS IN OR VERY NEAR THE WATER IS EXPECTED.

* CURRENTS MAY BE HAZARDOUS TO SWIMMERS... BOATS... AND COASTAL STRUCTURES AND MAY CONTINUE FOR MANY HOURS AFTER THE TSUNAMI ARRIVAL.

* THE FIRST WAVE MAY NOT BE THE LARGEST.

RECOMMENDED ACTIONS - UPDATED

* IF YOU ARE IN A WARNING AREA - MOVE INLAND TO HIGHER GROUND.

* IF YOU ARE IN AN ADVISORY AREA - MOVE OFF THE BEACH AND OUT OF HARBORS AND MARINAS. WIDESPREAD INUNDATION OF LAND IS NOT EXPECTED FOR ADVISORY AREAS.

* BE ALERT TO INSTRUCTIONS FROM YOUR LOCAL EMERGENCY OFFICIALS.

* DO NOT GO TO THE COAST TO OBSERVE THE TSUNAMI.

* DO NOT RETURN TO THE COAST UNTIL LOCAL EMERGENCY OFFICIALS INDICATE IT IS SAFE TO DO SO. 
FORECASTS AND/OR OBSERVATIONS OF TSUNAMI ACTIVITY

$\begin{array}{llll} & \text { FORECAST } & \text { FORECAST FORECAST } & \text { OBSERVED } \\ \text { SITE } & \text { START OF } & \text { TSUNAMI MAX TSUNAMI } & \text { TSUNAMI } \\ & \text { OF TSUNAMI } & \text { DURATION HEIGHT } & \text { HEIGHT }\end{array}$

* ALASKA

SAND POINT 1157 AKDT MAR 2748 HRS $12.0 \mathrm{FT}+/-3.6$ 4.5FT

KODIAK 1213 AKDT MAR $27 \quad 12 \mathrm{HRS} \quad 2.9 \mathrm{FT}+/-0.9 \quad 4.5 \mathrm{FT}$

DUTCH HARBOR 1215 AKDT MAR $27 \quad 9 \mathrm{HRS} \quad 2.1 \mathrm{FT}+/-0.6 \quad 0.8 \mathrm{FT}$

COLD BAY 1232 AKDT MAR $27 \quad 9$ HRS $\quad 2.1 \mathrm{FT}+/-0.6$

SEWARD $\quad 1239$ AKDT MAR $27 \quad 9 \mathrm{HRS} \quad 1.8 \mathrm{FT}+/-0.6 \quad 3.2 \mathrm{FT}$

ADAK 1240 AKDT MAR $27 \quad 6$ HRS $1.4 \mathrm{FT}+/-0.4 \quad 0.6 \mathrm{FT}$

ELFIN COVE 1240 AKDT MAR $27 \quad 6$ HRS $\quad 1.3 \mathrm{FT}+/-0.4 \quad 1.3 \mathrm{FT}$

YAKUTAT 1248 AKDT MAR 27 9 HRS $2.0 \mathrm{FT}+/-0.6$

SITKA $\quad 1248$ AKDT MAR $27 \quad 15$ HRS $3.3 \mathrm{FT}+/-1.0 \quad 2.6 \mathrm{FT}$

VALDEZ 1258 AKDT MAR $27 \quad 6$ HRS $1.1 \mathrm{FT}+/-0.3$

CORDOVA 1308 AKDT MAR $27 \quad$ Less than $1 \mathrm{FT}$

SHEMYA 1323 AKDT MAR $27 \quad$ Less than $1 \mathrm{FT}$

HOMER $\quad 1332$ AKDT MAR $27 \quad 9$ HRS $2.3 \mathrm{FT}+/-0.7$

CRAIG 1351 AKDT MAR 27

* BRITISH COLUMBIA

LANGARA $\quad 1400$ PDT MAR $276 \mathrm{HRS} \quad 1.1 \mathrm{FT}+/-0.3$

TOFINO 1527 PDT MAR 2712 HRS $\quad 2.3 \mathrm{FT}+/-0.7$

* WASHINGTON

NEAH BAY 1540 PDT MAR $27 \quad 6$ HRS $\quad 1.4 \mathrm{FT}+/-0.4$

WESTPORT 1556 PDT MAR 279 HRS $1.7 \mathrm{FT}+/-0.5$

* OREGON

SEASIDE 1555 PDT MAR $27 \quad 18$ HRS $\quad 4.1 \mathrm{FT}+/-1.2$

CHARLESTON 1555 PDT MAR 27 9 HRS $2.0 \mathrm{FT}+/-0.6$

* CALIFORNIA

CRESCENT CITY 1606 PDT MAR $2721 \mathrm{HRS}$ 4.9FT +/- 1.5

SAN FRANCISCO 1702 PDT MAR 27 9 HRS 2.1FT +/- 0.6

SANTA BARBARA 1718 PDT MAR 27 9 HRS $1.9 \mathrm{FT}+/-0.6$

SAN PEDRO 1735 PDT MAR $276 \mathrm{HRS} \quad 1.6 \mathrm{FT}+/-0.5$

LA JOLLA 1746 PDT MAR $2712 \mathrm{HRS} \quad 2.5 \mathrm{FT}+/-0.7$

A 4.5-FOOT TSUNAMI HAS BEEN REPORTED AT KODIAK AK. KING COVE AK HAS REPORTED A 4.3-FOOT TSUNAMI, AND CHIGNIK AK HAS REPORTED A 21.8-FOOT TSUNAMI. 
FORECAST MAX TSUNAMI HEIGHT IS THE HIGHEST EXPECTED WATER LEVEL ABOVE THE TIDE.

FORECAST TSUNAMI DURATION IS THE APPROXIMATE LENGTH OF TIME WHICH THE TSUNAMI MAY PRODUCE DANGEROUS CURRENTS AND WAVE ACTIVITY.

OBSERVED TSUNAMI HEIGHT IS THE HIGHEST WATER LEVEL ABOVE THE TIDE LEVEL AT THE TIME OF MEASUREMENT.

ADDITIONAL OBSERVATIONS OF TSUNAMI ACTIVITY - UPDATED

\begin{tabular}{|c|c|c|}
\hline & \multicolumn{2}{|c|}{ OBSERVED MAX } \\
\hline SITE & OF MEASUREMENT & TSUNAMI H \\
\hline KING COVE AK & 2023 UTC 3-27 & $4.33 \mathrm{FT}$ \\
\hline CHIGNIK AK & 2026 UTC 3-27 & $21.82 \mathrm{FT}$ \\
\hline NIKOLSKI AK & 2054 UTC 3-27 & $1.61 \mathrm{FT}$ \\
\hline UNALASKA AK & 2056 UTC 3-27 & $1.44 \mathrm{FT}$ \\
\hline
\end{tabular}

HEIGHT - OBSERVED MAX TSUNAMI HEIGHT IS THE WATER LEVEL ABOVE THE TIDE LEVEL AT THE TIME OF MEASUREMENT.

PRELIMINARY EARTHQUAKE PARAMETERS

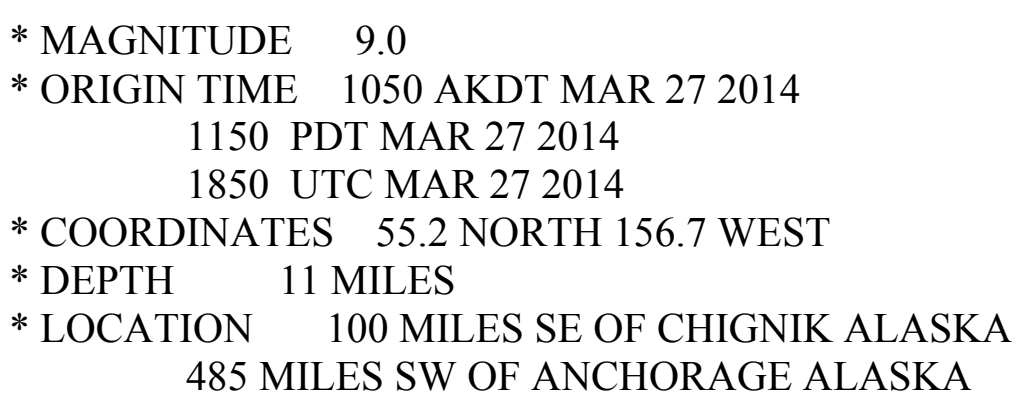

NEXT UPDATE AND ADDITIONAL INFORMATION

* THIS MESSAGE WILL BE UPDATED IN 60 MINUTES.

* REFER TO THE INTERNET SITE WCATWC.ARH.NOAA.GOV FOR MORE INFORMATION.

* PACIFIC COASTAL RESIDENTS OUTSIDE CALIFORNIA... OREGON... WASHINGTON... BRITISH COLUMBIA AND ALASKA SHOULD REFER TO THE 
PACIFIC TSUNAMI WARNING CENTER MESSAGES FOR INFORMATION ON THIS EVENT AT PTWC.WEATHER.GOV.

$\$ \$$

WEAK51 PAAQ 272201

TSUAK1

BULLETIN

PUBLIC TSUNAMI MESSAGE NUMBER 5

NWS WEST COAST/ALASKA TSUNAMI WARNING CENTER PALMER AK

201 PM AKDT THU MAR 272014

THIS MESSAGE IS UPDATED WITH NEW OBSERVATIONS.

...THE TSUNAMI WARNING REMAINS IN EFFECT...

...THE TSUNAMI ADVISORY REMAINS IN EFFECT...

WARNINGS/ADVISORIES/WATCHES

TSUNAMI WARNING IN EFFECT FOR...

* THE COASTAL AREAS OF CALIFORNIA - OREGON - WASHINGTON BRITISH COLUMBIA AND ALASKA FROM THE CALIFORNIA-MEXICO BORDER TO NIKOLSKI ALASKA

TSUNAMI ADVISORY IN EFFECT FOR... 
* THE COASTAL AREAS OF ALASKA FROM NIKOLSKI ALASKA TO ATTU ALASKA

IMPACTS FOR TSUNAMI WARNING AREAS

* WIDESPREAD DANGEROUS COASTAL FLOODING ACCOMPANIED BY POWERFUL CURRENTS IS POSSIBLE AND MAY CONTINUE FOR MANY HOURS AFTER TSUNAMI ARRIVAL.

* THE FIRST WAVE MAY NOT BE THE LARGEST.

IMPACTS FOR TSUNAMI ADVISORY AREAS

* A TSUNAMI CAPABLE OF PRODUCING STRONG CURRENTS OR WAVES DANGEROUS

TO PERSONS IN OR VERY NEAR THE WATER IS EXPECTED.

* CURRENTS MAY BE HAZARDOUS TO SWIMMERS... BOATS... AND COASTAL STRUCTURES AND MAY CONTINUE FOR MANY HOURS AFTER THE TSUNAMI ARRIVAL.

* THE FIRST WAVE MAY NOT BE THE LARGEST.

\section{RECOMMENDED ACTIONS}

* IF YOU ARE IN A WARNING AREA - MOVE INLAND TO HIGHER GROUND.

* IF YOU ARE IN AN ADVISORY AREA - MOVE OFF THE BEACH AND OUT OF HARBORS AND MARINAS. WIDESPREAD INUNDATION OF LAND IS NOT EXPECTED FOR ADVISORY AREAS.

* BE ALERT TO INSTRUCTIONS FROM YOUR LOCAL EMERGENCY OFFICIALS.

* DO NOT GO TO THE COAST TO OBSERVE THE TSUNAMI.

* DO NOT RETURN TO THE COAST UNTIL LOCAL EMERGENCY OFFICIALS INDICATE IT IS SAFE TO DO SO.

FORECASTS AND/OR OBSERVATIONS OF TSUNAMI ACTIVITY

FORECAST FORECAST FORECAST OBSERVED

START OF TSUNAMI MAX TSUNAMI TSUNAMI 


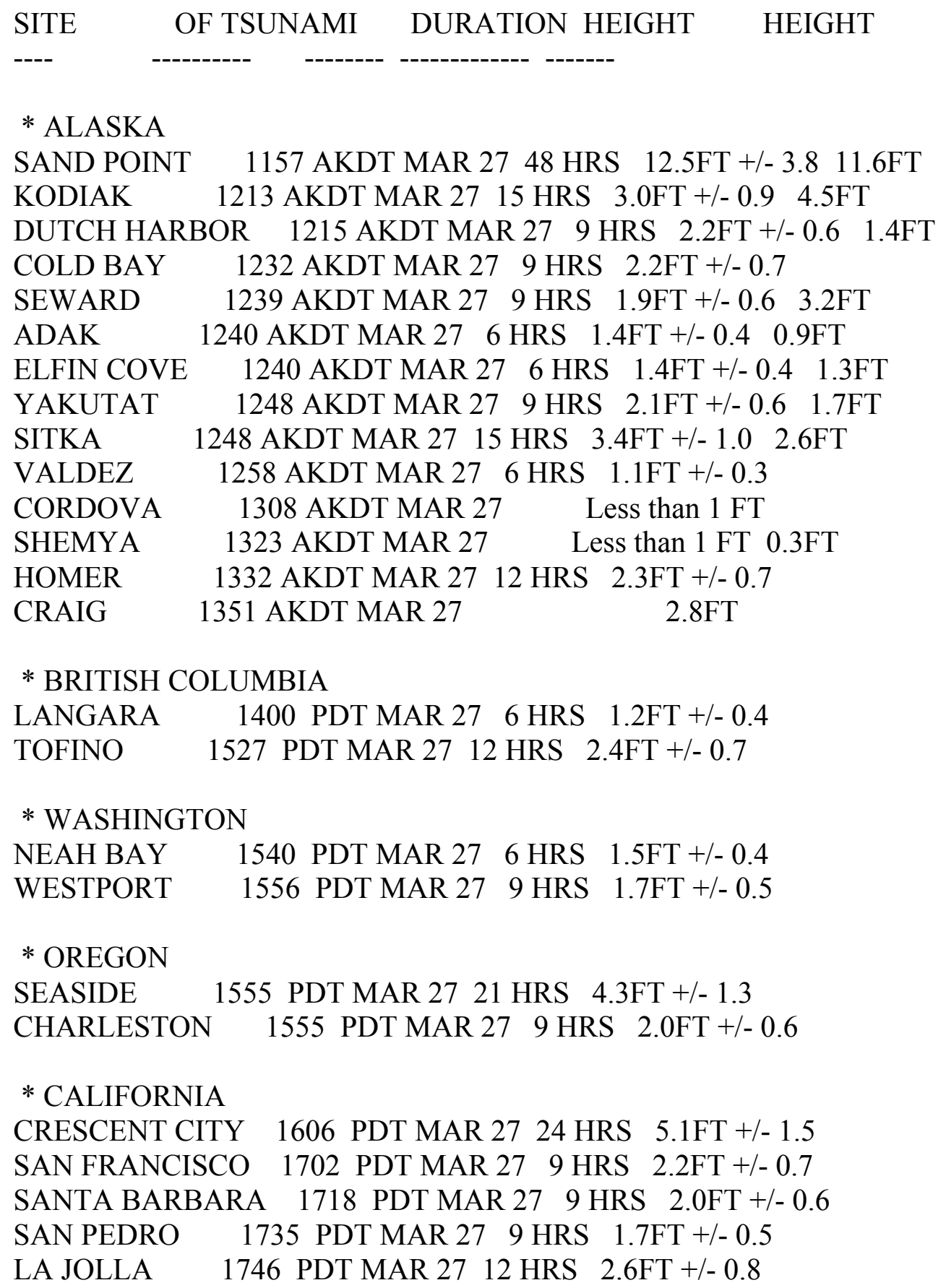

FORECAST MAX TSUNAMI HEIGHT IS THE HIGHEST EXPECTED WATER LEVEL ABOVE THE TIDE.

FORECAST TSUNAMI DURATION IS THE APPROXIMATE LENGTH OF TIME WHICH THE TSUNAMI MAY PRODUCE DANGEROUS CURRENTS AND WAVE ACTIVITY.

OBSERVED TSUNAMI HEIGHT IS THE HIGHEST WATER LEVEL ABOVE THE TIDE LEVEL AT THE TIME OF MEASUREMENT. 
ADDITIONAL OBSERVATIONS OF TSUNAMI ACTIVITY - UPDATED

\begin{tabular}{|c|c|c|}
\hline & OBSERVED & MAX \\
\hline SITE & OF MEASUREMENT & TSUNAMI H \\
\hline KING COVE AK & 2023 UTC 3-27 & $4.33 \mathrm{FT}$ \\
\hline CHIGNIK AK & 2026 UTC 3-27 & $21.82 \mathrm{FT}$ \\
\hline NIKOLSKI AK & 2054 UTC 3-27 & $1.61 \mathrm{FT}$ \\
\hline UNALASKA AK & 2056 UTC 3-27 & $1.44 \mathrm{FT}$ \\
\hline $\begin{array}{l}\text { HEIGHT - OBSEI } \\
\text { TIDE LEVE }\end{array}$ & $\begin{array}{l}\text { VED MAX TSUNAMI HE } \\
\text { AT THE TIME OF MEAS }\end{array}$ & $\begin{array}{l}\text { GHT IS THE } \\
\text { UREMENT. }\end{array}$ \\
\hline PRELIMINARY E & ARTHQUAKE PARAMETI & iRS \\
\hline * MAGNITUDE & 9.0 & \\
\hline * ORIGIN TIME & 1050 AKDT MAR 272014 & \\
\hline $1150 \mathrm{P}$ & T MAR 272014 & \\
\hline $1850 \mathrm{U}$ & TC MAR 272014 & \\
\hline * COORDINATE & 55.2 NORTH 156.7 WES & \\
\hline * DEPTH & MILES & \\
\hline * LOCATION & 100 MILES SE OF CHIGNI & K ALASKA \\
\hline
\end{tabular}

NEXT UPDATE AND ADDITIONAL INFORMATION

* THIS MESSAGE WILL BE UPDATED IN 60 MINUTES.

* REFER TO THE INTERNET SITE WCATWC.ARH.NOAA.GOV FOR MORE INFORMATION.

* PACIFIC COASTAL RESIDENTS OUTSIDE CALIFORNIA... OREGON... WASHINGTON... BRITISH COLUMBIA AND ALASKA SHOULD REFER TO THE PACIFIC TSUNAMI WARNING CENTER MESSAGES FOR INFORMATION ON THIS EVENT AT PTWC.WEATHER.GOV.

$\$ \$$ 
WEAK51 PAAQ 272301

TSUAK1

BULLETIN

PUBLIC TSUNAMI MESSAGE NUMBER 6

NWS WEST COAST/ALASKA TSUNAMI WARNING CENTER PALMER AK

301 PM AKDT THU MAR 272014

THIS MESSAGE IS UPDATED WITH NEW OBSERVATIONS AND FORECAST DURATIONS.

...THE TSUNAMI WARNING REMAINS IN EFFECT...

...THE TSUNAMI ADVISORY REMAINS IN EFFECT...

WARNINGS/ADVISORIES/WATCHES

TSUNAMI WARNING IN EFFECT FOR...

* THE COASTAL AREAS OF CALIFORNIA - OREGON - WASHINGTON BRITISH COLUMBIA AND ALASKA FROM THE CALIFORNIA-MEXICO BORDER TO NIKOLSKI ALASKA 
TSUNAMI ADVISORY IN EFFECT FOR...

* THE COASTAL AREAS OF ALASKA FROM NIKOLSKI ALASKA TO ATTU ALASKA

IMPACTS FOR TSUNAMI WARNING AREAS

* WIDESPREAD DANGEROUS COASTAL FLOODING ACCOMPANIED BY POWERFUL CURRENTS IS POSSIBLE AND MAY CONTINUE FOR MANY HOURS AFTER TSUNAMI ARRIVAL.

* THE FIRST WAVE MAY NOT BE THE LARGEST.

IMPACTS FOR TSUNAMI ADVISORY AREAS

* A TSUNAMI CAPABLE OF PRODUCING STRONG CURRENTS OR WAVES

DANGEROUS

TO PERSONS IN OR VERY NEAR THE WATER IS EXPECTED.

* CURRENTS MAY BE HAZARDOUS TO SWIMMERS... BOATS... AND COASTAL STRUCTURES AND MAY CONTINUE FOR MANY HOURS AFTER THE TSUNAMI ARRIVAL.

* THE FIRST WAVE MAY NOT BE THE LARGEST.

\section{RECOMMENDED ACTIONS}

* IF YOU ARE IN A WARNING AREA - MOVE INLAND TO HIGHER GROUND.

* IF YOU ARE IN AN ADVISORY AREA - MOVE OFF THE BEACH AND OUT OF HARBORS AND MARINAS. WIDESPREAD INUNDATION OF LAND IS NOT EXPECTED FOR ADVISORY AREAS.

* BE ALERT TO INSTRUCTIONS FROM YOUR LOCAL EMERGENCY OFFICIALS.

* DO NOT GO TO THE COAST TO OBSERVE THE TSUNAMI.

* DO NOT RETURN TO THE COAST UNTIL LOCAL EMERGENCY OFFICIALS INDICATE IT IS SAFE TO DO SO.

FORECASTS AND/OR OBSERVATIONS OF TSUNAMI ACTIVITY 


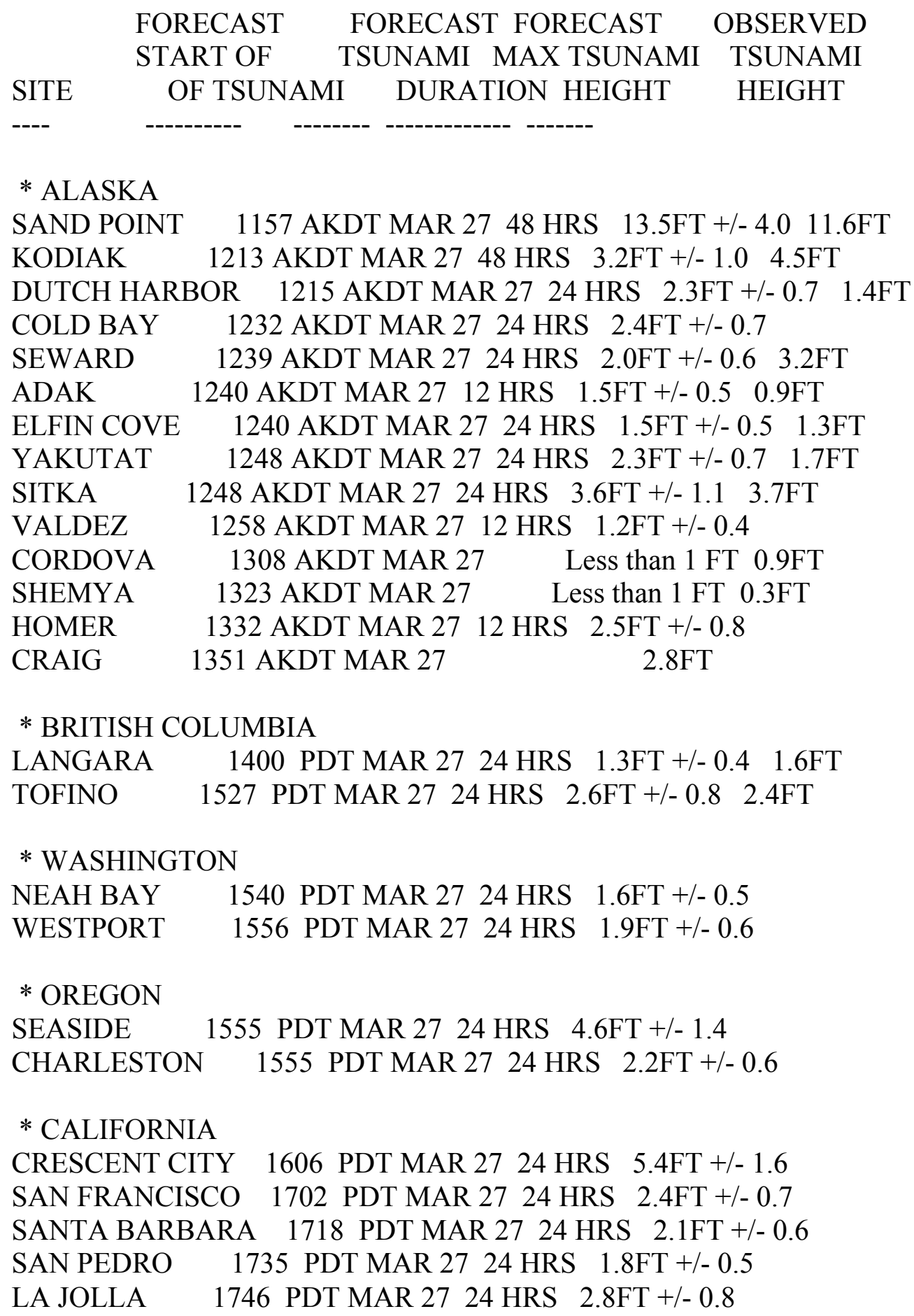

FORECAST MODELS PROJECT TSUNAMIS UP TO 15.0-FOOT HEIGHT COULD DEVELOP

ALONG THE COASTS OF CANADA - WASHINGTON - OREGON AND CALIFORNIA. WAVES OF THIS SIZE ARE KNOWN TO CAUSE INUNDATION AND DAMAGE TO COASTAL STRUCTURES. TSUNAMIS ARE EXPECTED TO REACH PEAK 
SIZE ONE TO THREE HOURS AFTER THE EXPECTED ARRIVAL TIME.

FORECAST MAX TSUNAMI HEIGHT IS THE HIGHEST EXPECTED WATER LEVEL ABOVE THE TIDE.

FORECAST TSUNAMI DURATION IS THE APPROXIMATE LENGTH OF TIME WHICH THE TSUNAMI MAY PRODUCE DANGEROUS CURRENTS AND WAVE ACTIVITY.

OBSERVED TSUNAMI HEIGHT IS THE HIGHEST WATER LEVEL ABOVE THE TIDE LEVEL AT THE TIME OF MEASUREMENT.

ADDITIONAL OBSERVATIONS OF TSUNAMI ACTIVITY - UPDATED

\begin{tabular}{|c|c|c|}
\hline \multirow{2}{*}{ SITE } & \multicolumn{2}{|c|}{ OBSERVED MAX } \\
\hline & OF MEASUREMENT & TSUNAMI \\
\hline $\mathrm{KING} \mathrm{CC}$ & 2023 UTC 3-27 & $4.33 \mathrm{I}$ \\
\hline CHIGNIK AK & 2026 UTC 3-27 & $21.82 \mathrm{FT}$ \\
\hline NIKOLSKI AK & 2054 UTC 3-27 & $1.61 \mathrm{FT}$ \\
\hline UNALASKA AK & 2056 UTC 3-27 & $1.44 \mathrm{FT}$ \\
\hline PORT ALEXANDH & 2114 UTC 3 & $3-27$ \\
\hline ADAK AK & 2142 UTC $3-27$ & $0.86 \mathrm{FT}$ \\
\hline CRAIG AK & 2152 UTC 3-27 & $2.79 \mathrm{FT}$ \\
\hline LAPUSH WA & 2241 UTC 3-27 & $3.15 \mathrm{FT}$ \\
\hline FORD O & 2252 UTC 3-27 & 4.92 \\
\hline GARIBALDI OR & 2259 UTC $3-27$ & $1.05 \mathrm{FT}$ \\
\hline \multicolumn{3}{|c|}{$\begin{array}{l}\text { HEIGHT - OBSERVED MAX TSUNAMI HEIGHT IS TH } \\
\text { TIDE LEVEL AT THE TIME OF MEASUREMENT. }\end{array}$} \\
\hline \multicolumn{3}{|c|}{ PRELIMINARY EARTHQUAKE PARAMETERS } \\
\hline \multicolumn{3}{|l|}{ * MAGNITUDE } \\
\hline \multirow{2}{*}{\multicolumn{3}{|c|}{1150 PDT }} \\
\hline & & \\
\hline \multicolumn{3}{|c|}{1850 UTC MAR 272014} \\
\hline \multicolumn{3}{|c|}{ * COORDINATES 55.2 NORTH 156.7 WEST } \\
\hline * DEPTH & MILES & \\
\hline * LOCATION & $00 \mathrm{MIL}$ & $\mathrm{AI}$ \\
\hline
\end{tabular}

NEXT UPDATE AND ADDITIONAL INFORMATION

* THIS MESSAGE WILL BE UPDATED IN 60 MINUTES. 
* REFER TO THE INTERNET SITE WCATWC.ARH.NOAA.GOV FOR MORE INFORMATION.

* PACIFIC COASTAL RESIDENTS OUTSIDE CALIFORNIA... OREGON... WASHINGTON... BRITISH COLUMBIA AND ALASKA SHOULD REFER TO THE PACIFIC TSUNAMI WARNING CENTER MESSAGES FOR INFORMATION ON THIS EVENT AT PTWC.WEATHER.GOV.

WEAK51 PAAQ 280002

TSUAK1

BULLETIN

PUBLIC TSUNAMI MESSAGE NUMBER 7

NWS WEST COAST/ALASKA TSUNAMI WARNING CENTER PALMER AK 402 PM AKDT THU MAR 272014

THIS MESSAGE IS UPDATED WITH NEW OBSERVATIONS.

...THE TSUNAMI WARNING REMAINS IN EFFECT...

...THE TSUNAMI ADVISORY REMAINS IN EFFECT...

WARNINGS/ADVISORIES/WATCHES

TSUNAMI WARNING IN EFFECT FOR...

* THE COASTAL AREAS OF CALIFORNIA - OREGON - WASHINGTON BRITISH COLUMBIA AND ALASKA FROM THE CALIFORNIA-MEXICO BORDER TO NIKOLSKI ALASKA

TSUNAMI ADVISORY IN EFFECT FOR...

* THE COASTAL AREAS OF ALASKA FROM NIKOLSKI ALASKA TO ATTU ALASKA 
IMPACTS FOR TSUNAMI WARNING AREAS

* WIDESPREAD DANGEROUS COASTAL FLOODING ACCOMPANIED BY POWERFUL CURRENTS IS POSSIBLE AND MAY CONTINUE FOR MANY HOURS AFTER TSUNAMI ARRIVAL.

* THE FIRST WAVE MAY NOT BE THE LARGEST.

IMPACTS FOR TSUNAMI ADVISORY AREAS

* A TSUNAMI CAPABLE OF PRODUCING STRONG CURRENTS OR WAVES DANGEROUS

TO PERSONS IN OR VERY NEAR THE WATER IS EXPECTED.

* CURRENTS MAY BE HAZARDOUS TO SWIMMERS... BOATS... AND COASTAL STRUCTURES AND MAY CONTINUE FOR MANY HOURS AFTER THE TSUNAMI ARRIVAL.

* THE FIRST WAVE MAY NOT BE THE LARGEST.

\section{RECOMMENDED ACTIONS}

* IF YOU ARE IN A WARNING AREA - MOVE INLAND TO HIGHER GROUND.

* IF YOU ARE IN AN ADVISORY AREA - MOVE OFF THE BEACH AND OUT OF HARBORS AND MARINAS. WIDESPREAD INUNDATION OF LAND IS NOT EXPECTED FOR ADVISORY AREAS.

* BE ALERT TO INSTRUCTIONS FROM YOUR LOCAL EMERGENCY OFFICIALS.

* DO NOT GO TO THE COAST TO OBSERVE THE TSUNAMI.

* DO NOT RETURN TO THE COAST UNTIL LOCAL EMERGENCY OFFICIALS INDICATE IT IS SAFE TO DO SO.

FORECASTS AND/OR OBSERVATIONS OF TSUNAMI ACTIVITY

$\begin{array}{llll} & \text { FORECAST } & \text { FORECAST FORECAST } & \text { OBSERVED } \\ \text { SITE } & \text { START OF } & \text { TSUNAMI MAX TSUNAMI } & \text { TSUNAMI } \\ - & \text { OF TSUNAMI } & \text { DURATION HEIGHT } & \text { HEIGHT }\end{array}$


* ALASKA

SAND POINT 1157 AKDT MAR $2748 \mathrm{HRS}$ 15.2FT +/- 4.5 11.6FT

KODIAK 1213 AKDT MAR $2748 \mathrm{HRS} \quad 3.6 \mathrm{FT}+/-1.1 \quad 4.5 \mathrm{FT}$

DUTCH HARBOR 1215 AKDT MAR 2724 HRS $2.6 \mathrm{FT}+/-0.8$ 1.4FT

COLD BAY 1232 AKDT MAR $2724 \mathrm{HRS} \quad 2.7 \mathrm{FT}+/-0.8$

SEWARD $\quad 1239$ AKDT MAR $2724 \mathrm{HRS} \quad 2.3 \mathrm{FT}+/-0.7 \quad$ 4.1FT

ADAK 1240 AKDT MAR $2712 \mathrm{HRS} \quad 1.7 \mathrm{FT}+/-0.5 \quad 0.9 \mathrm{FT}$

ELFIN COVE 1240 AKDT MAR $2724 \mathrm{HRS} \quad 1.7 \mathrm{FT}+/-0.5 \quad 1.3 \mathrm{FT}$

YAKUTAT 1248 AKDT MAR 2724 HRS $\quad 2.6 \mathrm{FT}+/-0.8 \quad$ 1.7FT

SITKA 1248 AKDT MAR $2724 \mathrm{HRS} \quad 4.1 \mathrm{FT}+/-1.2 \quad 3.7 \mathrm{FT}$

VALDEZ 1258 AKDT MAR $27 \quad 12 \mathrm{HRS} \quad 1.3 \mathrm{FT}+/-0.4$

CORDOVA 1308 AKDT MAR 27 Less than $1 \mathrm{FT}$ 0.9FT

SHEMYA 1323 AKDT MAR 27 Less than 1 FT $0.3 \mathrm{FT}$

HOMER $\quad 1332$ AKDT MAR 2712 HRS $2.8 \mathrm{FT}+/-0.8$

CRAIG 1351 AKDT MAR 27 3.9FT

* BRITISH COLUMBIA

LANGARA 1400 PDT MAR $2724 \mathrm{HRS} \quad 1.4 \mathrm{FT}+/-0.4 \quad 1.6 \mathrm{FT}$

TOFINO 1527 PDT MAR $2724 \mathrm{HRS} \quad 2.9 \mathrm{FT}+/-0.9$ 2.4FT

* WASHINGTON

NEAH BAY 1540 PDT MAR $2724 \mathrm{HRS} \quad 1.8 \mathrm{FT}+/-0.5 \quad 2.0 \mathrm{FT}$

WESTPORT 1556 PDT MAR $2724 \mathrm{HRS} \quad 2.1 \mathrm{FT}+/-0.6 \quad 2.1 \mathrm{FT}$

* OREGON

SEASIDE 1555 PDT MAR 2724 HRS 5.2FT +/- 1.6

CHARLESTON 1555 PDT MAR 2724 HRS $2.5 \mathrm{FT}+/-0.7 \quad$ 1.6FT

* CALIFORNIA

CRESCENT CITY 1606 PDT MAR 2736 HRS $6.1 \mathrm{FT}+/-1.8$ 5.9FT

SAN FRANCISCO 1702 PDT MAR 2724 HRS $\quad 2.7 \mathrm{FT}+/-0.8$ 2.4FT

SANTA BARBARA 1718 PDT MAR $2724 \mathrm{HRS} \quad 2.4 \mathrm{FT}+/-0.7$

SAN PEDRO 1735 PDT MAR $2724 \mathrm{HRS}$ 2.0FT +/- 0.6

LA JOLLA 1746 PDT MAR 2724 HRS 3.1FT +/- 0.9

FORECAST MODELS PROJECT TSUNAMIS UP TO 15.0-FOOT HEIGHT COULD DEVELOP

ALONG THE COASTS OF CANADA - WASHINGTON - OREGON AND

CALIFORNIA. WAVES OF THIS SIZE ARE KNOWN TO CAUSE INUNDATION AND DAMAGE TO COASTAL STRUCTURES. TSUNAMIS ARE EXPECTED TO REACH PEAK

SIZE ONE TO THREE HOURS AFTER THE EXPECTED ARRIVAL TIME.

FORECAST MAX TSUNAMI HEIGHT IS THE HIGHEST EXPECTED WATER LEVEL ABOVE THE TIDE. 
FORECAST TSUNAMI DURATION IS THE APPROXIMATE LENGTH OF TIME WHICH THE TSUNAMI MAY PRODUCE DANGEROUS CURRENTS AND WAVE ACTIVITY.

OBSERVED TSUNAMI HEIGHT IS THE HIGHEST WATER LEVEL ABOVE THE TIDE LEVEL AT THE TIME OF MEASUREMENT.

ADDITIONAL OBSERVATIONS OF TSUNAMI ACTIVITY - UPDATED

\begin{tabular}{|c|c|c|}
\hline \multirow[b]{2}{*}{ SITE } & \multicolumn{2}{|c|}{ TIME $\quad$ OBSERVED MAX } \\
\hline & OF MEASUREMENT & TSUNAMI HEIGHT \\
\hline KING COVE AK & 2023 UTC 3-27 & $4.33 \mathrm{FT}$ \\
\hline CHIGNIK AK & 2026 UTC $3-27$ & $21.82 \mathrm{FT}$ \\
\hline NIKOLSKI AK & 2054 UTC 3-27 & $1.61 \mathrm{FT}$ \\
\hline UNALASKA AK & 2056 UTC 3-27 & $1.44 \mathrm{FT}$ \\
\hline PORT ALEXANDER & 2114 UTC 3- & $1.41 \mathrm{FT}$ \\
\hline LAPUSH WA & 2241 UTC $3-27$ & $3.15 \mathrm{FT}$ \\
\hline PORT ANGELES WA & 2354 UTC $3-27$ & $1.38 \mathrm{FT}$ \\
\hline GARIBALDI OR & 2259 UTC $3-27$ & $1.05 \mathrm{FT}$ \\
\hline PORT ORFORD OR & 2355 UTC $3-27$ & $6.76 \mathrm{FT}$ \\
\hline NEWPORT OR & 2309 UTC 3-27 & $2.46 \mathrm{FT}$ \\
\hline ARENA COVE CA & 2313 UTC 3-27 & $5.58 \mathrm{FT}$ \\
\hline EUREKA CA & 2314 UTC 3-27 & $2.76 \mathrm{FT}$ \\
\hline POINT REYES CA & 2344 UTC $3-27$ & $3.15 \mathrm{FT}$ \\
\hline MONTEREY CA & 2338 UTC $3-27$ & 3.97 FT \\
\hline MIDWAY IS & 2304 UTC 3-27 & $1.44 \mathrm{FT}$ \\
\hline NAWILIWILI HI & 2323 UTC $3-27$ & $2.20 \mathrm{FT}$ \\
\hline HALEIWA HI & 2338 UTC $3-27$ & $4.99 \mathrm{FT}$ \\
\hline HONOLULU HI & 2338 UTC $3-27$ & $2.23 \mathrm{FT}$ \\
\hline KAHULUI HI & 2341 UTC 3-27 & $7.15 \mathrm{FT}$ \\
\hline KAWAIHAE HI & 2347 UTC $3-27$ & $1.74 \mathrm{FT}$ \\
\hline
\end{tabular}

HEIGHT - OBSERVED MAX TSUNAMI HEIGHT IS THE WATER LEVEL ABOVE THE TIDE LEVEL AT THE TIME OF MEASUREMENT.

PRELIMINARY EARTHQUAKE PARAMETERS

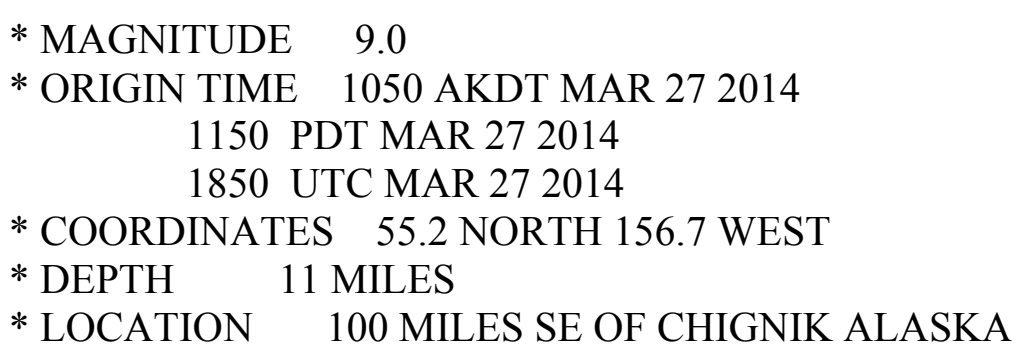


NEXT UPDATE AND ADDITIONAL INFORMATION

* THIS MESSAGE WILL BE UPDATED IN 60 MINUTES.

* REFER TO THE INTERNET SITE WCATWC.ARH.NOAA.GOV FOR MORE INFORMATION.

* PACIFIC COASTAL RESIDENTS OUTSIDE CALIFORNIA... OREGON... WASHINGTON... BRITISH COLUMBIA AND ALASKA SHOULD REFER TO THE PACIFIC TSUNAMI WARNING CENTER MESSAGES FOR INFORMATION ON THIS EVENT AT PTWC.WEATHER.GOV.

$\$ \$$

WEAK51 PAAQ 280101

TSUAK1

BULLETIN

PUBLIC TSUNAMI MESSAGE NUMBER 8

NWS WEST COAST/ALASKA TSUNAMI WARNING CENTER PALMER AK

501 PM AKDT THU MAR 272014

THIS MESSAGE IS UPDATED WITH NEW OBSERVATIONS.

...THE TSUNAMI WARNING REMAINS IN EFFECT...

...THE TSUNAMI ADVISORY REMAINS IN EFFECT...

WARNINGS/ADVISORIES/WATCHES

TSUNAMI WARNING IN EFFECT FOR...

* THE COASTAL AREAS OF CALIFORNIA - OREGON - WASHINGTON BRITISH COLUMBIA AND ALASKA FROM THE CALIFORNIA-MEXICO BORDER TO NIKOLSKI ALASKA

TSUNAMI ADVISORY IN EFFECT FOR...

* THE COASTAL AREAS OF ALASKA FROM NIKOLSKI ALASKA TO ATTU ALASKA 
IMPACTS FOR TSUNAMI WARNING AREAS

* WIDESPREAD DANGEROUS COASTAL FLOODING ACCOMPANIED BY POWERFUL CURRENTS IS POSSIBLE AND MAY CONTINUE FOR MANY HOURS AFTER TSUNAMI ARRIVAL.

* THE FIRST WAVE MAY NOT BE THE LARGEST.

IMPACTS FOR TSUNAMI ADVISORY AREAS

* A TSUNAMI CAPABLE OF PRODUCING STRONG CURRENTS OR WAVES DANGEROUS

TO PERSONS IN OR VERY NEAR THE WATER IS EXPECTED.

* CURRENTS MAY BE HAZARDOUS TO SWIMMERS... BOATS... AND COASTAL STRUCTURES AND MAY CONTINUE FOR MANY HOURS AFTER THE TSUNAMI ARRIVAL.

* THE FIRST WAVE MAY NOT BE THE LARGEST.

\section{RECOMMENDED ACTIONS}

* IF YOU ARE IN A WARNING AREA - MOVE INLAND TO HIGHER GROUND.

* IF YOU ARE IN AN ADVISORY AREA - MOVE OFF THE BEACH AND OUT OF HARBORS AND MARINAS. WIDESPREAD INUNDATION OF LAND IS NOT EXPECTED FOR ADVISORY AREAS.

* BE ALERT TO INSTRUCTIONS FROM YOUR LOCAL EMERGENCY OFFICIALS.

* DO NOT GO TO THE COAST TO OBSERVE THE TSUNAMI.

* DO NOT RETURN TO THE COAST UNTIL LOCAL EMERGENCY OFFICIALS INDICATE IT IS SAFE TO DO SO.

FORECASTS AND/OR OBSERVATIONS OF TSUNAMI ACTIVITY

$\begin{array}{llll} & \text { FORECAST } & \text { FORECAST FORECAST } & \text { OBSERVED } \\ \text { SITE } & \text { START OF } & \text { TSUNAMI MAX TSUNAMI } & \text { TSUNAMI } \\ - & \text { OF TSUNAMI } & \text { DURATION HEIGHT } & \text { HEIGHT }\end{array}$


* ALASKA

SAND POINT 1157 AKDT MAR 2748 HRS $\quad$ 16.1FT +/- 4.8 11.6FT

KODIAK 1213 AKDT MAR $2748 \mathrm{HRS} \quad 3.8 \mathrm{FT}+/-1.2 \quad 4.5 \mathrm{FT}$

DUTCH HARBOR 1215 AKDT MAR 2724 HRS $\quad 2.8 \mathrm{FT}+/-0.8$ 1.4FT

COLD BAY 1232 AKDT MAR $2724 \mathrm{HRS} \quad 2.9 \mathrm{FT}+/-0.9$

SEWARD $\quad 1239$ AKDT MAR $2724 \mathrm{HRS} \quad 2.5 \mathrm{FT}+/-0.7 \quad 4.1 \mathrm{FT}$

ADAK 1240 AKDT MAR $2712 \mathrm{HRS} \quad 1.8 \mathrm{FT}+/-0.6 \quad 1.0 \mathrm{FT}$

ELFIN COVE 1240 AKDT MAR $2724 \mathrm{HRS} \quad 1.8 \mathrm{FT}+/-0.5 \quad 1.3 \mathrm{FT}$

YAKUTAT 1248 AKDT MAR 2724 HRS $\quad 2.7 \mathrm{FT}+/-0.8 \quad 2.4 \mathrm{FT}$

$\begin{array}{llll}\text { SITKA } & 1248 \text { AKDT MAR } 2724 \mathrm{HRS} & 4.4 \mathrm{FT}+/-1.3 & 3.7 \mathrm{FT}\end{array}$

VALDEZ 1258 AKDT MAR $27 \quad 12 \mathrm{HRS} \quad 1.4 \mathrm{FT}+/-0.4$

CORDOVA 1308 AKDT MAR $27 \quad$ Less than $1 \mathrm{FT}$ 0.9FT

SHEMYA 1323 AKDT MAR $27 \quad$ Less than 1 FT $0.3 \mathrm{FT}$

HOMER $\quad 1332$ AKDT MAR 2712 HRS 3.0FT +/- 0.9

CRAIG 1351 AKDT MAR 27 3.9FT

* BRITISH COLUMBIA

LANGARA 1400 PDT MAR $2724 \mathrm{HRS} \quad 1.5 \mathrm{FT}+/-0.5 \quad 1.6 \mathrm{FT}$

TOFINO 1527 PDT MAR $2724 \mathrm{HRS} \quad 3.1 \mathrm{FT}+/-0.9$ 2.4FT

* WASHINGTON

NEAH BAY 1540 PDT MAR $2724 \mathrm{HRS} \quad 1.9 \mathrm{FT}+/-0.62 .0 \mathrm{FT}$

WESTPORT 1556 PDT MAR $27 \quad 24 \mathrm{HRS} \quad 2.2 \mathrm{FT}+/-0.7 \quad 2.1 \mathrm{FT}$

* OREGON

SEASIDE 1555 PDT MAR 2724 HRS $5.5 \mathrm{FT}+/-1.7$

CHARLESTON 1555 PDT MAR 2724 HRS $2.6 \mathrm{FT}+/-0.8 \quad 2.7 \mathrm{FT}$

* CALIFORNIA

CRESCENT CITY 1606 PDT MAR 2736 HRS 6.5FT +/- 2.0 6.7FT

SAN FRANCISCO 1702 PDT MAR 2724 HRS 2.9FT +/- 0.9 3.4FT

SANTA BARBARA 1718 PDT MAR $2724 \mathrm{HRS} \quad 2.6 \mathrm{FT}+/-0.8 \quad 1.9 \mathrm{FT}$

SAN PEDRO 1735 PDT MAR $2724 \mathrm{HRS} \quad 2.2 \mathrm{FT}+/-0.6 \quad 1.2 \mathrm{FT}$

LA JOLLA 1746 PDT MAR 2724 HRS 3.3FT +/- 1.0

FORECAST MAX TSUNAMI HEIGHT IS THE HIGHEST EXPECTED WATER LEVEL ABOVE THE TIDE.

FORECAST TSUNAMI DURATION IS THE APPROXIMATE LENGTH OF TIME WHICH THE TSUNAMI MAY PRODUCE DANGEROUS CURRENTS AND WAVE ACTIVITY.

OBSERVED TSUNAMI HEIGHT IS THE HIGHEST WATER LEVEL ABOVE THE TIDE LEVEL AT THE TIME OF MEASUREMENT. 
ADDITIONAL OBSERVATIONS OF TSUNAMI ACTIVITY - UPDATED

\begin{tabular}{|c|c|c|}
\hline \multirow[b]{2}{*}{ SITE } & \multicolumn{2}{|c|}{ OBSERVED MAX } \\
\hline & F MEASUREMENT & TSUNAMI HEIC \\
\hline KING COVE AK & 2023 UTC 3-27 & $4.33 \mathrm{FT}$ \\
\hline CHIGNIK AK & 2026 UTC 3-27 & $21.82 \mathrm{FT}$ \\
\hline NIKOLSKI AK & 2054 UTC 3-27 & $1.61 \mathrm{FT}$ \\
\hline UNALASKA AK & 2056 UTC 3-27 & $1.44 \mathrm{FT}$ \\
\hline PORT ALEXANDER AF & 2114 UTC 3-2 & $1.41 \mathrm{FT}$ \\
\hline LAPUSH WA & 2241 UTC 3-27 & $3.15 \mathrm{FT}$ \\
\hline PORT ANGELES WA & 2354 UTC 3-27 & $1.38 \mathrm{FT}$ \\
\hline GARIBALDI OR & 2259 UTC 3-27 & $1.05 \mathrm{FT}$ \\
\hline PORT ORFORD OR & 2355 UTC $3-27$ & $6.76 \mathrm{FT}$ \\
\hline NEWPORT OR & 2309 UTC 3-27 & $2.46 \mathrm{FT}$ \\
\hline ARENA COVE CA & 2313 UTC 3-27 & $5.58 \mathrm{FT}$ \\
\hline EUREKA CA & 0006 UTC 3-28 & 4.23 FT \\
\hline POINT REYES CA & 2344 UTC 3-27 & $3.15 \mathrm{FT}$ \\
\hline ALAMEDA CA & 0029 UTC 3-28 & $1.12 \mathrm{FT}$ \\
\hline MONTEREY CA & 2338 UTC $3-27$ & 3.97 FT \\
\hline PORT SAN LUIS CA & 0022 UTC $3-28$ & $5.58 \mathrm{FT}$ \\
\hline SANTA MONICA CA & 0044 UTC 3-28 & $2.43 \mathrm{FT}$ \\
\hline MIDWAY IS & 2304 UTC $3-27$ & $1.44 \mathrm{FT}$ \\
\hline NAWILIWILI HI & 2323 UTC $3-27$ & $2.20 \mathrm{FT}$ \\
\hline HALEIWA HI & 2338 UTC $3-27$ & $4.99 \mathrm{FT}$ \\
\hline HONOLULU HI & 2338 UTC 3-27 & $2.23 \mathrm{FT}$ \\
\hline KAHULUI HI & 2341 UTC $3-27$ & $7.15 \mathrm{FT}$ \\
\hline KAWAIHAE HI & 0014 UTC 3-28 & $2.89 \mathrm{FT}$ \\
\hline WAKE ISLAND & 0052 UTC 3-28 & $0.33 \mathrm{FT}$ \\
\hline
\end{tabular}

HEIGHT - OBSERVED MAX TSUNAMI HEIGHT IS THE WATER LEVEL ABOVE THE TIDE LEVEL AT THE TIME OF MEASUREMENT.

PRELIMINARY EARTHQUAKE PARAMETERS

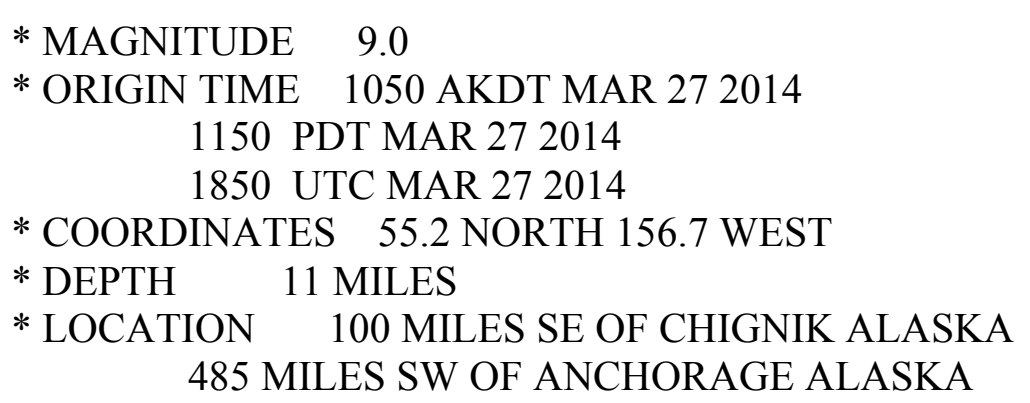

NEXT UPDATE AND ADDITIONAL INFORMATION 
* THIS MESSAGE WILL BE UPDATED IN 60 MINUTES.

* REFER TO THE INTERNET SITE WCATWC.ARH.NOAA.GOV FOR MORE INFORMATION.

* PACIFIC COASTAL RESIDENTS OUTSIDE CALIFORNIA... OREGON... WASHINGTON... BRITISH COLUMBIA AND ALASKA SHOULD REFER TO THE PACIFIC TSUNAMI WARNING CENTER MESSAGES FOR INFORMATION ON THIS EVENT AT PTWC.WEATHER.GOV.

$\$ \$$

WEAK51 PAAQ 280201

TSUAK1

BULLETIN

PUBLIC TSUNAMI MESSAGE NUMBER 9

NWS WEST COAST/ALASKA TSUNAMI WARNING CENTER PALMER AK 601 PM AKDT THU MAR 272014

...THE TSUNAMI WARNING REMAINS IN EFFECT...

...THE TSUNAMI ADVISORY REMAINS IN EFFECT...

WARNINGS/ADVISORIES/WATCHES - UPDATED

TSUNAMI WARNING IN EFFECT FOR...

* THE COASTAL AREAS OF CALIFORNIA - OREGON - WASHINGTON BRITISH COLUMBIA AND ALASKA FROM THE CALIFORNIA-MEXICO BORDER TO NIKOLSKI ALASKA

TSUNAMI ADVISORY IN EFFECT FOR...

* THE COASTAL AREAS OF ALASKA FROM NIKOLSKI ALASKA TO ATTU ALASKA 
IMPACTS FOR TSUNAMI WARNING AREAS

* WIDESPREAD DANGEROUS COASTAL FLOODING ACCOMPANIED BY POWERFUL CURRENTS IS POSSIBLE AND MAY CONTINUE FOR MANY HOURS AFTER TSUNAMI ARRIVAL.

* THE FIRST WAVE MAY NOT BE THE LARGEST.

IMPACTS FOR TSUNAMI ADVISORY AREAS

* A TSUNAMI CAPABLE OF PRODUCING STRONG CURRENTS OR WAVES DANGEROUS

TO PERSONS IN OR VERY NEAR THE WATER IS EXPECTED.

* CURRENTS MAY BE HAZARDOUS TO SWIMMERS... BOATS... AND COASTAL STRUCTURES AND MAY CONTINUE FOR MANY HOURS AFTER THE TSUNAMI ARRIVAL.

* THE FIRST WAVE MAY NOT BE THE LARGEST.

RECOMMENDED ACTIONS

* IF YOU ARE IN A WARNING AREA - MOVE INLAND TO HIGHER GROUND.

* IF YOU ARE IN AN ADVISORY AREA - MOVE OFF THE BEACH AND OUT OF HARBORS AND MARINAS. WIDESPREAD INUNDATION OF LAND IS NOT EXPECTED FOR ADVISORY AREAS.

* BE ALERT TO INSTRUCTIONS FROM YOUR LOCAL EMERGENCY OFFICIALS.

* DO NOT GO TO THE COAST TO OBSERVE THE TSUNAMI.

* DO NOT RETURN TO THE COAST UNTIL LOCAL EMERGENCY OFFICIALS INDICATE IT IS SAFE TO DO SO.

FORECASTS AND/OR OBSERVATIONS OF TSUNAMI ACTIVITY

$\begin{array}{llll} & \text { FORECAST } & \text { FORECAST FORECAST } & \text { OBSERVED } \\ \text { SITE } & \text { START OF } & \text { TSUNAMI MAX TSUNAMI } & \text { TSUNAMI } \\ --- & \text { OF TSUNAMI } & \text { DURATION HEIGHT } & \text { HEIGHT } \\ * \text { * } & & & \end{array}$




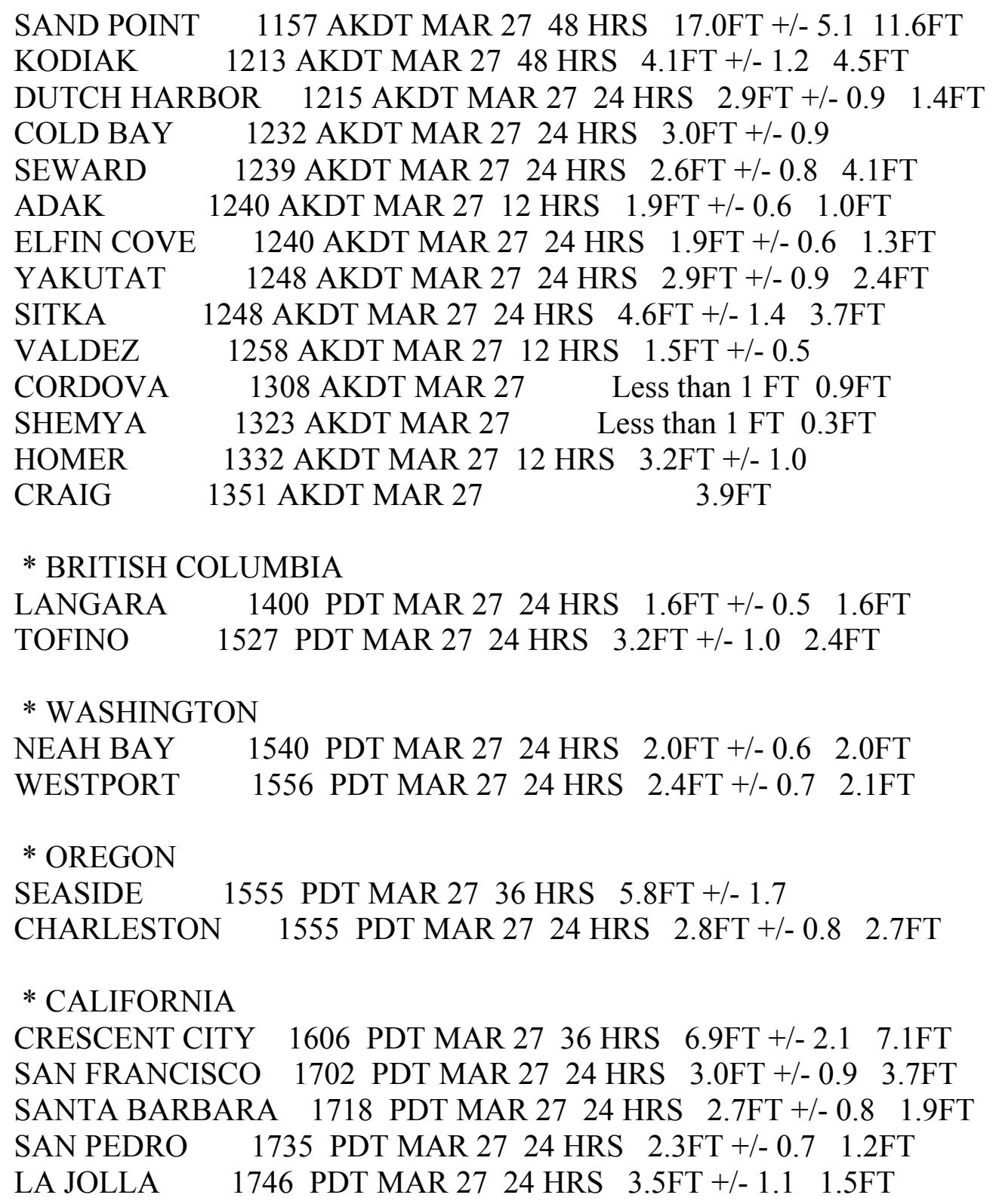

FORECAST MAX TSUNAMI HEIGHT IS THE HIGHEST EXPECTED WATER LEVEL ABOVE THE TIDE.

FORECAST TSUNAMI DURATION IS THE APPROXIMATE LENGTH OF TIME WHICH THE TSUNAMI MAY PRODUCE DANGEROUS CURRENTS AND WAVE ACTIVITY.

OBSERVED TSUNAMI HEIGHT IS THE HIGHEST WATER LEVEL ABOVE THE TIDE LEVEL AT THE TIME OF MEASUREMENT. 


\begin{tabular}{|c|c|c|}
\hline \multirow[b]{2}{*}{ SITE } & \multicolumn{2}{|c|}{ OBSERVED MAX } \\
\hline & MEASUREMENT & TSUNAMI HEIGHT \\
\hline KING COVE AK & 2023 UTC 3-27 & $433 \mathrm{FT}$ \\
\hline CHIGNIK AK & 2026 UTC $3-27$ & $21.82 \mathrm{FT}$ \\
\hline NIKOLSKI AK & 2054 UTC 3-27 & $1.61 \mathrm{FT}$ \\
\hline UNALASKA AK & 2056 UTC 3-27 & $1.44 \mathrm{FT}$ \\
\hline PORT ALEXANDER A & 2114 UTC 3-2 & $1.41 \mathrm{FT}$ \\
\hline LAPUSH WA & 2241 UTC 3-27 & $3.15 \mathrm{FT}$ \\
\hline PORT ANGELES WA & 2354 UTC 3-27 & $1.38 \mathrm{FT}$ \\
\hline GARIBALDI OR & 2259 UTC 3-27 & $1.05 \mathrm{FT}$ \\
\hline PORT ORFORD OR & 2355 UTC 3-27 & $6.76 \mathrm{FT}$ \\
\hline NEWPORT OR & 2309 UTC 3-27 & $2.46 \mathrm{FT}$ \\
\hline ARENA COVE CA & 2313 UTC 3-27 & $5.58 \mathrm{FT}$ \\
\hline EUREKA CA & 0006 UTC 3-28 & $4.23 \mathrm{FT}$ \\
\hline POINT REYES CA & 0142 UTC 3-28 & $3.38 \mathrm{FT}$ \\
\hline ALAMEDA CA & 0141 UTC 3-28 & $1.84 \mathrm{FT}$ \\
\hline MONTEREY CA & 2338 UTC 3-27 & $3.97 \mathrm{FT}$ \\
\hline PORT SAN LUIS CA & 0108 UTC 3-28 & $14.30 \mathrm{FT}$ \\
\hline SANTA MONICA CA & 0157 UTC 3-28 & $3.38 \mathrm{FT}$ \\
\hline SAN DIEGO CA & 0120 UTC 3-28 & $1.44 \mathrm{FT}$ \\
\hline MIDWAY IS & 2304 UTC 3-27 & $1.44 \mathrm{FT}$ \\
\hline NAWILIWILI HI & 2323 UTC 3-27 & $2.20 \mathrm{FT}$ \\
\hline HALEIWA HI & 2338 UTC $3-27$ & $4.99 \mathrm{FT}$ \\
\hline HONOLULU HI & 2338 UTC 3-27 & $2.23 \mathrm{FT}$ \\
\hline KAHULUI HI & 2341 UTC 3-27 & $7.15 \mathrm{FT}$ \\
\hline KAWAIHAE HI & 0014 UTC 3-28 & $2.89 \mathrm{FT}$ \\
\hline WAKE ISLAND & 0052 UTC 3-28 & $0.33 \mathrm{FT}$ \\
\hline
\end{tabular}

HEIGHT - OBSERVED MAX TSUNAMI HEIGHT IS THE WATER LEVEL ABOVE THE TIDE LEVEL AT THE TIME OF MEASUREMENT.

PRELIMINARY EARTHQUAKE PARAMETERS

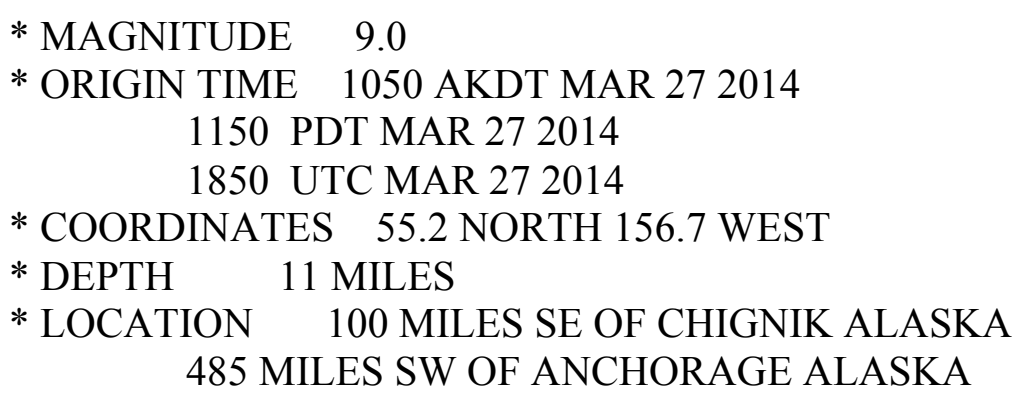

NEXT UPDATE AND ADDITIONAL INFORMATION 
* THIS MESSAGE WILL BE UPDATED IN 60 MINUTES.

* REFER TO THE INTERNET SITE WCATWC.ARH.NOAA.GOV FOR MORE INFORMATION.

* PACIFIC COASTAL RESIDENTS OUTSIDE CALIFORNIA... OREGON... WASHINGTON... BRITISH COLUMBIA AND ALASKA SHOULD REFER TO THE PACIFIC TSUNAMI WARNING CENTER MESSAGES FOR INFORMATION ON THIS EVENT AT PTWC.WEATHER.GOV.

$\$ \$$

WEAK51 PAAQ 280301

TSUAK1

BULLETIN

PUBLIC TSUNAMI MESSAGE NUMBER 10

NWS WEST COAST/ALASKA TSUNAMI WARNING CENTER PALMER AK

701 PM AKDT THU MAR 272014

THIS MESSAGE IS UPDATED WITH NEW OBSERVATIONS.

...THE TSUNAMI WARNING REMAINS IN EFFECT...

...THE TSUNAMI ADVISORY REMAINS IN EFFECT...

WARNINGS/ADVISORIES/WATCHES

TSUNAMI WARNING IN EFFECT FOR...

* THE COASTAL AREAS OF CALIFORNIA - OREGON - WASHINGTON BRITISH COLUMBIA AND ALASKA FROM THE CALIFORNIA-MEXICO BORDER TO NIKOLSKI ALASKA

TSUNAMI ADVISORY IN EFFECT FOR...

* THE COASTAL AREAS OF ALASKA FROM NIKOLSKI ALASKA TO ATTU ALASKA 
IMPACTS FOR TSUNAMI WARNING AREAS

* WIDESPREAD DANGEROUS COASTAL FLOODING ACCOMPANIED BY POWERFUL CURRENTS IS POSSIBLE AND MAY CONTINUE FOR MANY HOURS AFTER TSUNAMI ARRIVAL.

* THE FIRST WAVE MAY NOT BE THE LARGEST.

IMPACTS FOR TSUNAMI ADVISORY AREAS

* A TSUNAMI CAPABLE OF PRODUCING STRONG CURRENTS OR WAVES DANGEROUS

TO PERSONS IN OR VERY NEAR THE WATER IS EXPECTED.

* CURRENTS MAY BE HAZARDOUS TO SWIMMERS... BOATS... AND COASTAL STRUCTURES AND MAY CONTINUE FOR MANY HOURS AFTER THE TSUNAMI ARRIVAL.

* THE FIRST WAVE MAY NOT BE THE LARGEST.

\section{RECOMMENDED ACTIONS}

* IF YOU ARE IN A WARNING AREA - MOVE INLAND TO HIGHER GROUND.

* IF YOU ARE IN AN ADVISORY AREA - MOVE OFF THE BEACH AND OUT OF HARBORS AND MARINAS. WIDESPREAD INUNDATION OF LAND IS NOT EXPECTED FOR ADVISORY AREAS.

* BE ALERT TO INSTRUCTIONS FROM YOUR LOCAL EMERGENCY OFFICIALS.

* DO NOT GO TO THE COAST TO OBSERVE THE TSUNAMI.

* DO NOT RETURN TO THE COAST UNTIL LOCAL EMERGENCY OFFICIALS INDICATE IT IS SAFE TO DO SO.

FORECASTS AND/OR OBSERVATIONS OF TSUNAMI ACTIVITY

$\begin{array}{llll} & \text { FORECAST } & \text { FORECAST FORECAST } & \text { OBSERVED } \\ \text { SITE } & \text { START OF } & \text { TSUNAMI MAX TSUNAMI } & \text { TSUNAMI } \\ - & \text { OF TSUNAMI } & \text { DURATION HEIGHT } & \text { HEIGHT }\end{array}$


* BRITISH COLUMBIA

LANGARA $\quad 1400$ PDT MAR $2724 \mathrm{HRS} \quad 1.7 \mathrm{FT}+/-0.5 \quad 1.6 \mathrm{FT}$

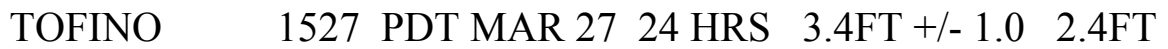

* WASHINGTON

NEAH BAY 1540 PDT MAR $2724 \mathrm{HRS} \quad 2.1 \mathrm{FT}+/-0.62 .0 \mathrm{FT}$

WESTPORT 1556 PDT MAR $2724 \mathrm{HRS} \quad 2.5 \mathrm{FT}+/-0.7 \quad 2.1 \mathrm{FT}$

* OREGON

SEASIDE $\quad 1555$ PDT MAR 2736 HRS $\quad 6.1 \mathrm{FT}+/-1.8$

CHARLESTON 1555 PDT MAR 2724 HRS 2.9FT +/- 0.9 2.7FT

* CALIFORNIA

CRESCENT CITY 1606 PDT MAR 2748 HRS 7.3FT +/- 2.2 7.1FT

SAN FRANCISCO 1702 PDT MAR $2724 \mathrm{HRS} \quad 3.2 \mathrm{FT}+/-1.0 \quad 3.7 \mathrm{FT}$

SANTA BARBARA 1718 PDT MAR $2724 \mathrm{HRS} \quad 2.9 \mathrm{FT}+/-0.9 \quad 2.6 \mathrm{FT}$

SAN PEDRO 1735 PDT MAR $2724 \mathrm{HRS} \quad 2.4 \mathrm{FT}+/-0.7 \quad 2.8 \mathrm{FT}$

LA JOLLA $\quad 1746$ PDT MAR 2724 HRS $3.7 \mathrm{FT}+/-1.1 \quad 2.3 \mathrm{FT}$

SIGNIFICANT TSUNAMI ACTIVITY IS EXPECTED TO CONTINUE FOR UP TO 48 HOURS

ALONG SOUTHERN ALASKA COASTS EAST OF NIKOLSKI.

MUCH DAMAGE HAS BEEN REPORTED ALONG THE OREGON COAST FROM LINCOLN CITY

TO NESKOWIN. WAVES HAVE ERODED THE BEACHES AROUND CASCADE HEAD DAMAGING

LOCAL RESERVES. LOS ANGELES CA REPORTED A 1.2-FOOT/0.4-METER

TSUNAMI AND THERE ARE CONCERNS THAT THE SUDDEN RISE IN WATER LEVEL MAY

PART MOORING LINES IN THE HARBOR.

FORECAST MAX TSUNAMI HEIGHT IS THE HIGHEST EXPECTED WATER LEVEL ABOVE THE TIDE.

FORECAST TSUNAMI DURATION IS THE APPROXIMATE LENGTH OF TIME WHICH THE TSUNAMI MAY PRODUCE DANGEROUS CURRENTS AND WAVE ACTIVITY.

OBSERVED TSUNAMI HEIGHT IS THE HIGHEST WATER LEVEL ABOVE THE TIDE LEVEL AT THE TIME OF MEASUREMENT.

ADDITIONAL OBSERVATIONS OF TSUNAMI ACTIVITY - UPDATED

TIME OBSERVED MAX 


\begin{tabular}{|c|c|c|}
\hline SAND POINT AK & 1945 UTC 3-27 & $11.60 \mathrm{FT}$ \\
\hline KING COVE AK & 2023 UTC 3-27 & $4.33 \mathrm{FT}$ \\
\hline CHIGNIK AK & 2026 UTC 3-27 & $21.82 \mathrm{FT}$ \\
\hline NIKOLSKI AK & 2054 UTC 3-27 & $1.61 \mathrm{FT}$ \\
\hline UNALASKA AK & 2056 UTC 3-27 & $1.44 \mathrm{FT}$ \\
\hline KODIAK AK & 2100 UTC $3-27$ & $4.50 \mathrm{FT}$ \\
\hline SEWARD AK & 2110 UTC $3-27$ & 4.11 FT \\
\hline ADAK AK & 2145 UTC $3-27$ & $1.03 \mathrm{FT}$ \\
\hline ELFIN COVE AK & 2133 UTC $3-27$ & $1.32 \mathrm{FT}$ \\
\hline YAKUTAT AK & 2132 UTC $3-27$ & 2.44 FT \\
\hline PORT ALEXANDER AI & 2114 UTC 3-2 & $1.41 \mathrm{FT}$ \\
\hline CORDOVA AK & 2235 UTC $3-27$ & $1.82 \mathrm{FT}$ \\
\hline SHEMYA AK & 2245 UTC 3-27 & $0.34 \mathrm{FT}$ \\
\hline SITKA AK & 2222 UTC 3-27 & $3.74 \mathrm{FT}$ \\
\hline CRAIG AK & 2255 UTC $3-27$ & $3.88 \mathrm{FT}$ \\
\hline LAPUSH WA & 2241 UTC $3-27$ & $3.15 \mathrm{FT}$ \\
\hline PORT ANGELES WA & 2354 UTC $3-27$ & $1.38 \mathrm{FT}$ \\
\hline GARIBALDI OR & 2259 UTC $3-27$ & $1.05 \mathrm{FT}$ \\
\hline NEWPORT OR & 2309 UTC 3-27 & $2.46 \mathrm{FT}$ \\
\hline PORT ORFORD OR & 2355 UTC $3-27$ & $6.76 \mathrm{FT}$ \\
\hline ARENA COVE CA & 2313 UTC 3-27 & $5.58 \mathrm{FT}$ \\
\hline EUREKA CA & 0006 UTC $3-28$ & $4.23 \mathrm{FT}$ \\
\hline POINT REYES CA & 0142 UTC 3-28 & $3.38 \mathrm{FT}$ \\
\hline ALAMEDA CA & 0141 UTC 3-28 & $1.84 \mathrm{FT}$ \\
\hline MONTEREY CA & 2338 UTC $3-27$ & $3.97 \mathrm{FT}$ \\
\hline PORT SAN LUIS CA & 0108 UTC 3-28 & $14.30 \mathrm{FT}$ \\
\hline SANTA MONICA CA & 0157 UTC $3-28$ & $3.38 \mathrm{FT}$ \\
\hline SAN DIEGO CA & 0214 UTC 3-28 & $1.74 \mathrm{FT}$ \\
\hline MIDWAY IS & 2304 UTC 3-27 & $1.44 \mathrm{FT}$ \\
\hline NAWILIWILI HI & 2323 UTC $3-27$ & $2.20 \mathrm{FT}$ \\
\hline HALEIWA HI & 2338 UTC $3-27$ & 4.99 FT \\
\hline HONOLULU HI & 2338 UTC $3-27$ & $2.23 \mathrm{FT}$ \\
\hline KAHULUI HI & 2341 UTC 3-27 & $7.15 \mathrm{FT}$ \\
\hline KAWAIHAE HI & 0014 UTC 3-28 & $2.89 \mathrm{FT}$ \\
\hline WAKE ISLAND & 0052 UTC 3-28 & $0.33 \mathrm{FT}$ \\
\hline
\end{tabular}

HEIGHT - OBSERVED MAX TSUNAMI HEIGHT IS THE WATER LEVEL ABOVE THE TIDE LEVEL AT THE TIME OF MEASUREMENT.

PRELIMINARY EARTHQUAKE PARAMETERS

* MAGNITUDE 9.0

* ORIGIN TIME 1050 AKDT MAR 272014 
1150 PDT MAR 272014

1850 UTC MAR 272014

* COORDINATES 55.2 NORTH 156.7 WEST

* DEPTH 11 MILES

* LOCATION 100 MILES SE OF CHIGNIK ALASKA 485 MILES SW OF ANCHORAGE ALASKA

NEXT UPDATE AND ADDITIONAL INFORMATION

* THIS MESSAGE WILL BE UPDATED IN 60 MINUTES.

* REFER TO THE INTERNET SITE WCATWC.ARH.NOAA.GOV FOR MORE INFORMATION.

* PACIFIC COASTAL RESIDENTS OUTSIDE CALIFORNIA... OREGON... WASHINGTON... BRITISH COLUMBIA AND ALASKA SHOULD REFER TO THE PACIFIC TSUNAMI WARNING CENTER MESSAGES FOR INFORMATION ON THIS EVENT AT PTWC.WEATHER.GOV.

$\$ \$$ 
WEAK51 PAAQ 280401

TSUAK1

BULLETIN

PUBLIC TSUNAMI MESSAGE NUMBER 11

NWS WEST COAST/ALASKA TSUNAMI WARNING CENTER PALMER AK 801 PM AKDT THU MAR 272014

THIS MESSAGE IS UPDATED WITH NEW OBSERVATIONS.

...THE TSUNAMI WARNING REMAINS IN EFFECT...

...THE TSUNAMI ADVISORY REMAINS IN EFFECT...

WARNINGS/ADVISORIES/WATCHES

TSUNAMI WARNING IN EFFECT FOR...

* THE COASTAL AREAS OF CALIFORNIA - OREGON - WASHINGTON BRITISH COLUMBIA AND ALASKA FROM THE CALIFORNIA-MEXICO BORDER TO NIKOLSKI ALASKA

TSUNAMI ADVISORY IN EFFECT FOR...

* THE COASTAL AREAS OF ALASKA FROM NIKOLSKI ALASKA TO ATTU ALASKA 
IMPACTS FOR TSUNAMI WARNING AREAS

* A TSUNAMI WITH SIGNIFICANT WIDESPREAD INUNDATION OF LAND IS EXPECTED.

* WIDESPREAD DANGEROUS COASTAL FLOODING ACCOMPANIED BY POWERFUL CURRENTS IS POSSIBLE AND MAY CONTINUE FOR MANY HOURS AFTER TSUNAMI ARRIVAL.

* THE FIRST WAVE MAY NOT BE THE LARGEST.

IMPACTS FOR TSUNAMI ADVISORY AREAS

* A TSUNAMI CAPABLE OF PRODUCING STRONG CURRENTS OR WAVES DANGEROUS

TO PERSONS IN OR VERY NEAR THE WATER IS EXPECTED.

* CURRENTS MAY BE HAZARDOUS TO SWIMMERS... BOATS... AND COASTAL STRUCTURES AND MAY CONTINUE FOR MANY HOURS AFTER THE TSUNAMI ARRIVAL.

* THE FIRST WAVE MAY NOT BE THE LARGEST.

RECOMMENDED ACTIONS

* IF YOU ARE IN A WARNING AREA - MOVE INLAND TO HIGHER GROUND.

* IF YOU ARE IN AN ADVISORY AREA - MOVE OFF THE BEACH AND OUT OF HARBORS AND MARINAS. WIDESPREAD INUNDATION OF LAND IS NOT EXPECTED FOR ADVISORY AREAS.

* BE ALERT TO INSTRUCTIONS FROM YOUR LOCAL EMERGENCY OFFICIALS.

* DO NOT GO TO THE COAST TO OBSERVE THE TSUNAMI.

* DO NOT RETURN TO THE COAST UNTIL LOCAL EMERGENCY OFFICIALS INDICATE IT IS SAFE TO DO SO.

FORECASTS AND/OR OBSERVATIONS OF TSUNAMI ACTIVITY

FORECAST FORECAST FORECAST OBSERVED 


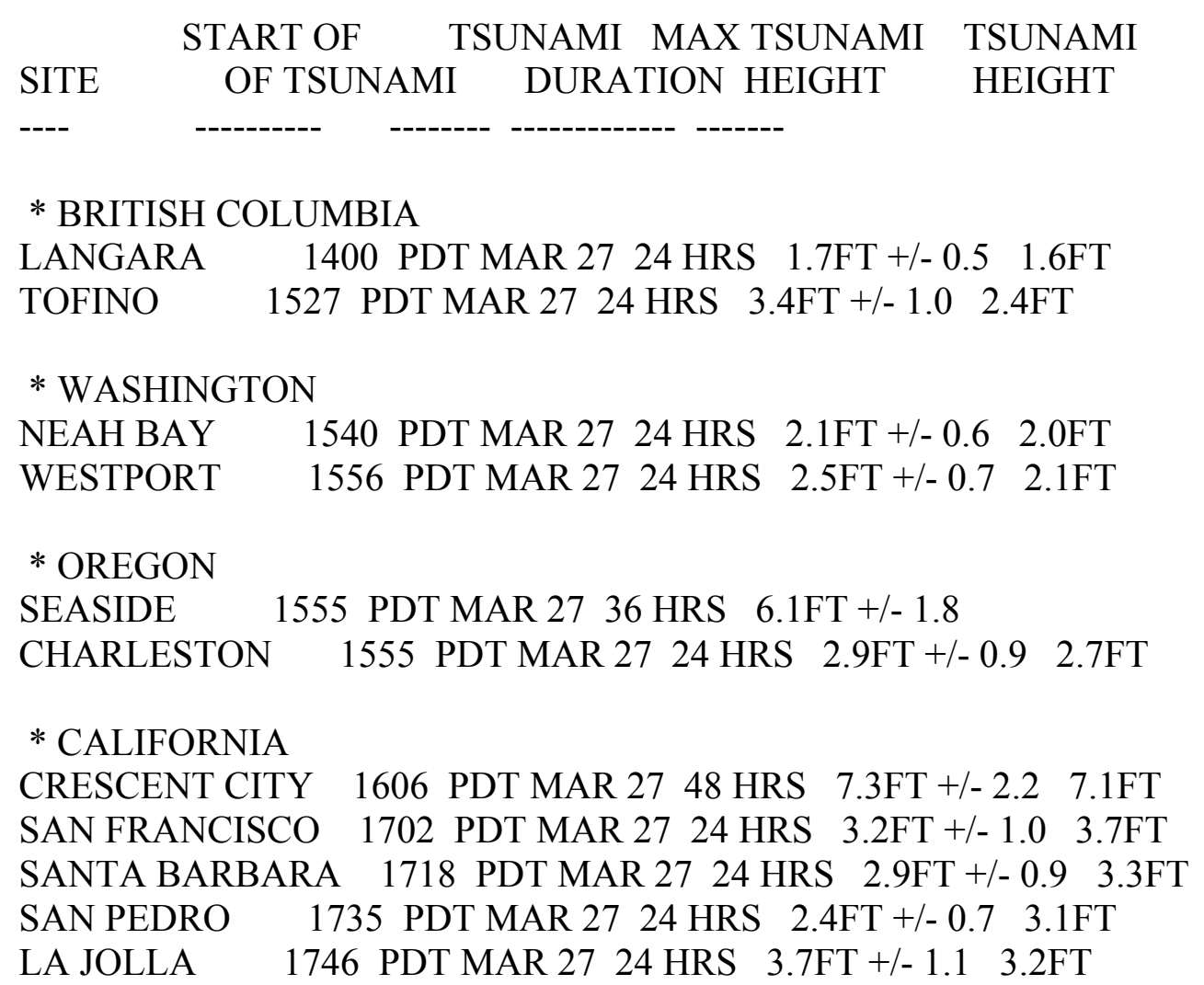

SIGNIFICANT TSUNAMI ACTIVITY IS EXPECTED TO CONTINUE FOR UP TO 48 HOURS

ALONG SOUTHERN ALASKA COASTS EAST OF NIKOLSKI.

PT REYES REPORTS HEAVY SURF AND STRONG CURRENTS.

APPROXIMATELY 50 FEET OF SHORELINE HAS BEEN ERODED FROM POINT REYES BEACH SOUTH AND 35 FEET FROM POINT REYES BEACH NORTH.

FORECAST MAX TSUNAMI HEIGHT IS THE HIGHEST EXPECTED WATER LEVEL ABOVE THE TIDE.

FORECAST TSUNAMI DURATION IS THE APPROXIMATE LENGTH OF TIME WHICH THE TSUNAMI MAY PRODUCE DANGEROUS CURRENTS AND WAVE ACTIVITY.

OBSERVED TSUNAMI HEIGHT IS THE HIGHEST WATER LEVEL ABOVE THE TIDE LEVEL AT THE TIME OF MEASUREMENT.

ADDITIONAL OBSERVATIONS OF TSUNAMI ACTIVITY - UPDATED

$\begin{array}{ll} & \text { TIME } \\ \text { SITE } & \text { OF MEASUREMENT TSUNAMI HEIGHT }\end{array}$




\begin{tabular}{|c|c|c|}
\hline SAND POINT AK & 1945 UTC 3-27 & $11.60 \mathrm{FT}$ \\
\hline KING COVE AK & 2023 UTC 3-27 & $4.33 \mathrm{FT}$ \\
\hline CHIGNIK AK & 2026 UTC 3-27 & $21.82 \mathrm{FT}$ \\
\hline NIKOLSKI AK & 2054 UTC 3-27 & $1.61 \mathrm{FT}$ \\
\hline UNALASKA AK & 2056 UTC 3-27 & $1.44 \mathrm{FT}$ \\
\hline KODIAK AK & 2100 UTC $3-27$ & $4.50 \mathrm{FT}$ \\
\hline SEWARD AK & 2110 UTC $3-27$ & 4.11 FT \\
\hline ADAK AK & 2145 UTC $3-27$ & $1.03 \mathrm{FT}$ \\
\hline ELFIN COVE AK & 2133 UTC 3-27 & $1.32 \mathrm{FT}$ \\
\hline YAKUTAT AK & 2132 UTC 3-27 & $2.44 \mathrm{FT}$ \\
\hline PORT ALEXANDER A & 2114 UTC 3-2 & $1.41 \mathrm{FT}$ \\
\hline CORDOVA AK & 2235 UTC $3-27$ & $1.82 \mathrm{FT}$ \\
\hline SHEMYA AK & 2245 UTC 3-27 & $0.34 \mathrm{FT}$ \\
\hline SITKA AK & 2222 UTC $3-27$ & $3.74 \mathrm{FT}$ \\
\hline CRAIG AK & 2255 UTC $3-27$ & $3.88 \mathrm{FT}$ \\
\hline LAPUSH WA & 2241 UTC $3-27$ & $3.15 \mathrm{FT}$ \\
\hline PORT ANGELES WA & 2354 UTC $3-27$ & $1.38 \mathrm{FT}$ \\
\hline GARIBALDI OR & 2259 UTC 3-27 & $1.05 \mathrm{FT}$ \\
\hline NEWPORT OR & 2309 UTC 3-27 & $2.46 \mathrm{FT}$ \\
\hline PORT ORFORD OR & 2355 UTC $3-27$ & $6.76 \mathrm{FT}$ \\
\hline ARENA COVE CA & 2313 UTC 3-27 & $5.58 \mathrm{FT}$ \\
\hline EUREKA CA & 0006 UTC 3-28 & $4.23 \mathrm{FT}$ \\
\hline POINT REYES CA & 0142 UTC 3-28 & $3.38 \mathrm{FT}$ \\
\hline ALAMEDA CA & 0141 UTC 3-28 & $1.84 \mathrm{FT}$ \\
\hline MONTEREY CA & 2338 UTC $3-27$ & $3.97 \mathrm{FT}$ \\
\hline PORT SAN LUIS CA & 0108 UTC $3-28$ & $14.30 \mathrm{FT}$ \\
\hline SANTA MONICA CA & 0157 UTC 3-28 & $3.38 \mathrm{FT}$ \\
\hline SAN DIEGO CA & 0214 UTC 3-28 & $1.74 \mathrm{FT}$ \\
\hline MIDWAY IS & 2304 UTC 3-27 & $1.44 \mathrm{FT}$ \\
\hline NAWILIWILI HI & 2323 UTC $3-27$ & $2.20 \mathrm{FT}$ \\
\hline HALEIWA HI & 2338 UTC $3-27$ & $4.99 \mathrm{FT}$ \\
\hline HONOLULU HI & 2338 UTC $3-27$ & $2.23 \mathrm{FT}$ \\
\hline KAHULUI HI & 2341 UTC 3-27 & $7.15 \mathrm{FT}$ \\
\hline KAWAIHAE HI & 0014 UTC 3-28 & $2.89 \mathrm{FT}$ \\
\hline WAKE ISLAND & 0052 UTC 3-28 & $0.33 \mathrm{FT}$ \\
\hline GUAM & 0321 UTC 3-28 & $30 \mathrm{FT}$ \\
\hline
\end{tabular}

HEIGHT - OBSERVED MAX TSUNAMI HEIGHT IS THE WATER LEVEL ABOVE THE TIDE LEVEL AT THE TIME OF MEASUREMENT.

PRELIMINARY EARTHQUAKE PARAMETERS

* MAGNITUDE 9.0

* ORIGIN TIME 1050 AKDT MAR 272014

1150 PDT MAR 272014 
1850 UTC MAR 272014

* COORDINATES 55.2 NORTH 156.7 WEST

* DEPTH 11 MILES

* LOCATION 100 MILES SE OF CHIGNIK ALASKA 485 MILES SW OF ANCHORAGE ALASKA

NEXT UPDATE AND ADDITIONAL INFORMATION

* THIS MESSAGE WILL BE UPDATED IN 60 MINUTES.

* REFER TO THE INTERNET SITE WCATWC.ARH.NOAA.GOV FOR MORE INFORMATION.

* PACIFIC COASTAL RESIDENTS OUTSIDE CALIFORNIA... OREGON... WASHINGTON... BRITISH COLUMBIA AND ALASKA SHOULD REFER TO THE PACIFIC TSUNAMI WARNING CENTER MESSAGES FOR INFORMATION ON THIS EVENT AT PTWC.WEATHER.GOV. 
WEAK51 PAAQ 280501

TSUAK1

BULLETIN

PUBLIC TSUNAMI MESSAGE NUMBER 12

NWS WEST COAST/ALASKA TSUNAMI WARNING CENTER PALMER AK

901 PM AKDT THU MAR 272014

THIS MESSAGE IS UPDATED WITH NEW OBSERVATIONS.

...THE TSUNAMI WARNING REMAINS IN EFFECT...

...THE TSUNAMI ADVISORY REMAINS IN EFFECT...

WARNINGS/ADVISORIES/WATCHES

TSUNAMI WARNING IN EFFECT FOR...

* THE COASTAL AREAS OF CALIFORNIA - OREGON - WASHINGTON BRITISH COLUMBIA AND ALASKA FROM THE CALIFORNIA-MEXICO BORDER TO NIKOLSKI ALASKA

TSUNAMI ADVISORY IN EFFECT FOR...

* THE COASTAL AREAS OF ALASKA FROM NIKOLSKI ALASKA TO ATTU ALASKA 
IMPACTS FOR TSUNAMI WARNING AREAS

* WIDESPREAD DANGEROUS COASTAL FLOODING ACCOMPANIED BY POWERFUL CURRENTS IS POSSIBLE AND MAY CONTINUE FOR MANY HOURS AFTER TSUNAMI ARRIVAL.

* THE FIRST WAVE MAY NOT BE THE LARGEST.

IMPACTS FOR TSUNAMI ADVISORY AREAS

* A TSUNAMI CAPABLE OF PRODUCING STRONG CURRENTS OR WAVES DANGEROUS

TO PERSONS IN OR VERY NEAR THE WATER IS EXPECTED.

* CURRENTS MAY BE HAZARDOUS TO SWIMMERS... BOATS... AND COASTAL STRUCTURES AND MAY CONTINUE FOR MANY HOURS AFTER THE TSUNAMI ARRIVAL.

* THE FIRST WAVE MAY NOT BE THE LARGEST.

\section{RECOMMENDED ACTIONS}

* IF YOU ARE IN A WARNING AREA - MOVE INLAND TO HIGHER GROUND.

* IF YOU ARE IN AN ADVISORY AREA - MOVE OFF THE BEACH AND OUT OF HARBORS AND MARINAS. WIDESPREAD INUNDATION OF LAND IS NOT EXPECTED FOR ADVISORY AREAS.

* BE ALERT TO INSTRUCTIONS FROM YOUR LOCAL EMERGENCY OFFICIALS.

* DO NOT GO TO THE COAST TO OBSERVE THE TSUNAMI.

* DO NOT RETURN TO THE COAST UNTIL LOCAL EMERGENCY OFFICIALS INDICATE IT IS SAFE TO DO SO.

FORECASTS AND/OR OBSERVATIONS OF TSUNAMI ACTIVITY

$\begin{array}{llll} & \text { FORECAST } & \text { FORECAST FORECAST } & \text { OBSERVED } \\ \text { STITE } & \text { START OF } & \text { TSUNAMI MAX TSUNAMI } & \text { TSUNAMI } \\ & \text { OF TSUNAMI } & \text { DURATION HEIGHT } & \text { HEIGHT }\end{array}$


* WASHINGTON

NEAH BAY $\quad 1540$ PDT MAR $2736 \mathrm{HRS}$ 2.1FT +/- 0.6 2.0FT

$\begin{array}{lllll}\text { WESTPORT } \quad 1556 \text { PDT MAR } 27 & 36 \mathrm{HRS} & 2.5 \mathrm{FT}+/-0.7 & 2.1 \mathrm{FT}\end{array}$

* OREGON

SEASIDE $\quad 1555$ PDT MAR 2736 HRS $6.1 \mathrm{FT}+/-1.8$

CHARLESTON $\quad 1555$ PDT MAR 2736 HRS 2.9FT +/- 0.9 2.7FT

* CALIFORNIA

CRESCENT CITY 1606 PDT MAR $2748 \mathrm{HRS}$ 7.3FT +/- 2.2 7.1FT

SAN FRANCISCO 1702 PDT MAR $2736 \mathrm{HRS} \quad 3.2 \mathrm{FT}+/-1.0 \quad 3.7 \mathrm{FT}$

SANTA BARBARA 1718 PDT MAR $27 \quad 36 \mathrm{HRS} \quad 2.9 \mathrm{FT}+/-0.9 \quad 3.3 \mathrm{FT}$

SAN PEDRO $\quad 1735$ PDT MAR $27 \quad 36 \mathrm{HRS} \quad 2.4 \mathrm{FT}+/-0.7 \quad 3.1 \mathrm{FT}$

LA JOLLA $\quad 1746$ PDT MAR $2736 \mathrm{HRS} \quad 3.7 \mathrm{FT}+/-1.1 \quad 3.5 \mathrm{FT}$

SIGNIFICANT TSUNAMI ACTIVITY IS EXPECTED TO CONTINUE FOR UP TO 48 HOURS

ALONG SOUTHERN ALASKA COASTS EAST OF NIKOLSKI AND IN BRITISH COLUMBIA.

FORECAST MAX TSUNAMI HEIGHT IS THE HIGHEST EXPECTED WATER LEVEL ABOVE THE TIDE.

FORECAST TSUNAMI DURATION IS THE APPROXIMATE LENGTH OF TIME WHICH THE TSUNAMI MAY PRODUCE DANGEROUS CURRENTS AND WAVE ACTIVITY.

OBSERVED TSUNAMI HEIGHT IS THE HIGHEST WATER LEVEL ABOVE THE TIDE LEVEL AT THE TIME OF MEASUREMENT.

ADDITIONAL OBSERVATIONS OF TSUNAMI ACTIVITY - UPDATED

\begin{tabular}{|c|c|c|}
\hline \multirow[b]{2}{*}{ SITE } & \multicolumn{2}{|c|}{ OBSERVED MAX } \\
\hline & OF MEASUREMENT & TSUNAMI HEIGHT \\
\hline SANI & $1045 \mathrm{I}$ & 1160 ET \\
\hline KING COVE AK & 2023 UTC 3-27 & $4.33 \mathrm{FT}$ \\
\hline CHIGNIK AK & 2026 UTC 3-27 & $21.82 \mathrm{FT}$ \\
\hline NIKOLSKI AK & 2054 UTC 3-27 & $1.61 \mathrm{FT}$ \\
\hline UNALASKA AK & 2056 UTC 3-27 & $1.44 \mathrm{FT}$ \\
\hline KODIAK AK & 2100 UTC 3-27 & $4.50 \mathrm{FT}$ \\
\hline SEWARD AK & 2110 UTC 3-27 & $4.11 \mathrm{FT}$ \\
\hline ADAK AK & 2145 UTC 3-27 & $1.03 \mathrm{FT}$ \\
\hline ELFIN COVE AK & 2133 UTC 3-27 & $1.32 \mathrm{FT}$ \\
\hline YAKUTAT AK & 2132 UTC 3-27 & $2.44 \mathrm{FT}$ \\
\hline PORT ALEXANDE & 2114 UTC & $1.41 \mathrm{FT}$ \\
\hline
\end{tabular}




\begin{tabular}{|c|c|c|}
\hline CORDOVA AK & 2235 UTC 3-27 & $1.82 \mathrm{FT}$ \\
\hline SHEMYA AK & 2245 UTC 3-27 & $0.34 \mathrm{FT}$ \\
\hline SITKA AK & 2222 UTC 3-27 & $3.74 \mathrm{FT}$ \\
\hline CRAIG AK & 2255 UTC 3-27 & $3.88 \mathrm{FT}$ \\
\hline LANGARA BC & 2300 UTC 3-27 & $1.60 \mathrm{FT}$ \\
\hline TOFINO BC & 2334 UTC 3-27 & $2.41 \mathrm{FT}$ \\
\hline LAPUSH WA & 2241 UTC 3-27 & $3.15 \mathrm{FT}$ \\
\hline PORT ANGELES WA & 2354 UTC 3-27 & $1.38 \mathrm{FT}$ \\
\hline GARIBALDI OR & 2259 UTC 3-27 & $1.05 \mathrm{FT}$ \\
\hline NEWPORT OR & 2309 UTC 3-27 & $2.46 \mathrm{FT}$ \\
\hline PORT ORFORD OR & 2355 UTC 3-27 & $6.76 \mathrm{FT}$ \\
\hline ARENA COVE CA & 2313 UTC 3-27 & $5.58 \mathrm{FT}$ \\
\hline EUREKA CA & 0006 UTC 3-28 & $4.23 \mathrm{FT}$ \\
\hline POINT REYES CA & 0142 UTC 3-28 & $3.38 \mathrm{FT}$ \\
\hline ALAMEDA CA & 0141 UTC 3-28 & $1.84 \mathrm{FT}$ \\
\hline MONTEREY CA & 2338 UTC 3-27 & $3.97 \mathrm{FT}$ \\
\hline PORT SAN LUIS CA & 0108 UTC 3-28 & $14.30 \mathrm{FT}$ \\
\hline SANTA MONICA CA & 0157 UTC 3-28 & $3.38 \mathrm{FT}$ \\
\hline SAN DIEGO CA & 0214 UTC 3-28 & $1.74 \mathrm{FT}$ \\
\hline MIDWAY IS & 2304 UTC 3-27 & $1.44 \mathrm{FT}$ \\
\hline NAWILIWILI HI & 2323 UTC 3-27 & $2.20 \mathrm{FT}$ \\
\hline HALEIWA HI & 2338 UTC 3-27 & $4.99 \mathrm{FT}$ \\
\hline HONOLULU HI & 2338 UTC 3-27 & $2.23 \mathrm{FT}$ \\
\hline KAHULUI HI & 2341 UTC 3-27 & $7.15 \mathrm{FT}$ \\
\hline KAWAIHAE HI & 0014 UTC 3-28 & $2.89 \mathrm{FT}$ \\
\hline WAKE ISLAND & 0052 UTC 3-28 & $0.33 \mathrm{FT}$ \\
\hline GUAM & 0321 UTC 3-28 & $30 \mathrm{FT}$ \\
\hline PAGO PAGO AM S & 0433 UTC 3 & $3-28$ \\
\hline
\end{tabular}

HEIGHT - OBSERVED MAX TSUNAMI HEIGHT IS THE WATER LEVEL ABOVE THE TIDE LEVEL AT THE TIME OF MEASUREMENT.

PRELIMINARY EARTHQUAKE PARAMETERS

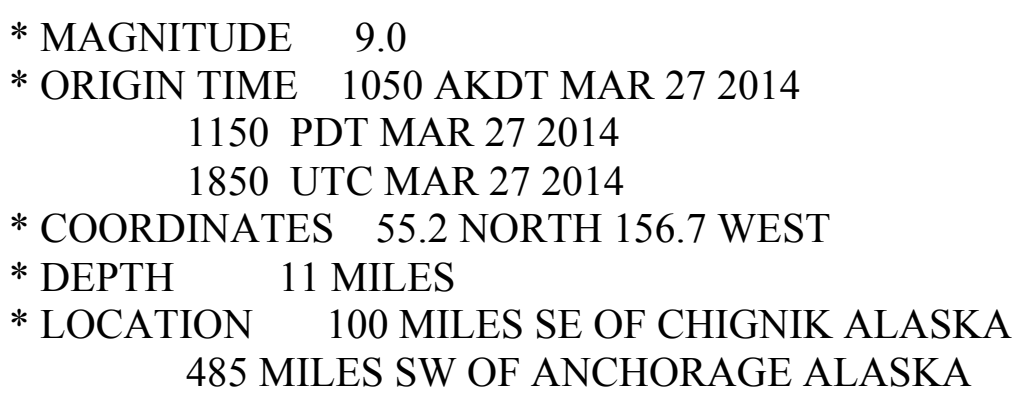

NEXT UPDATE AND ADDITIONAL INFORMATION 
* THIS MESSAGE WILL BE UPDATED IN 60 MINUTES.

* REFER TO THE INTERNET SITE WCATWC.ARH.NOAA.GOV FOR MORE INFORMATION.

* PACIFIC COASTAL RESIDENTS OUTSIDE CALIFORNIA... OREGON... WASHINGTON... BRITISH COLUMBIA AND ALASKA SHOULD REFER TO THE PACIFIC TSUNAMI WARNING CENTER MESSAGES FOR INFORMATION ON THIS EVENT AT PTWC.WEATHER.GOV.

$\$ \$$

WEAK51 PAAQ 280600

TSUAK1

BULLETIN

PUBLIC TSUNAMI MESSAGE NUMBER 13

NWS WEST COAST/ALASKA TSUNAMI WARNING CENTER PALMER AK 1000 PM AKDT THU MAR 272014

IN THIS MESSAGE THE FORECAST CHART HAS BEEN REMOVED AND ALL OBSERVATIONS ARE CONTAINED IN THE OBSERVATION TABLE. SIGNIFICANT TSUNAMI ACTIVITY IS EXPECTED FOR MANY LOCATIONS ON THE WEST COAST FOR UP TO 48 HOURS.

...THE TSUNAMI WARNING REMAINS IN EFFECT...

...THE TSUNAMI ADVISORY REMAINS IN EFFECT...

WARNINGS/ADVISORIES/WATCHES

TSUNAMI WARNING IN EFFECT FOR...

* THE COASTAL AREAS OF CALIFORNIA - OREGON - WASHINGTON BRITISH COLUMBIA AND ALASKA FROM THE CALIFORNIA-MEXICO BORDER TO NIKOLSKI ALASKA

TSUNAMI ADVISORY IN EFFECT FOR...

* THE COASTAL AREAS OF ALASKA FROM NIKOLSKI ALASKA TO ATTU 


\section{ALASKA}

IMPACTS FOR TSUNAMI WARNING AREAS

* WIDESPREAD DANGEROUS COASTAL FLOODING ACCOMPANIED BY POWERFUL CURRENTS IS POSSIBLE AND MAY CONTINUE FOR MANY HOURS AFTER TSUNAMI ARRIVAL.

* THE FIRST WAVE MAY NOT BE THE LARGEST.

IMPACTS FOR TSUNAMI ADVISORY AREAS

* A TSUNAMI CAPABLE OF PRODUCING STRONG CURRENTS OR WAVES DANGEROUS

TO PERSONS IN OR VERY NEAR THE WATER IS EXPECTED.

* CURRENTS MAY BE HAZARDOUS TO SWIMMERS... BOATS... AND COASTAL STRUCTURES AND MAY CONTINUE FOR MANY HOURS AFTER THE TSUNAMI ARRIVAL.

* THE FIRST WAVE MAY NOT BE THE LARGEST.

RECOMMENDED ACTIONS

* IF YOU ARE IN A WARNING AREA - MOVE INLAND TO HIGHER GROUND.

* IF YOU ARE IN AN ADVISORY AREA - MOVE OFF THE BEACH AND OUT OF HARBORS AND MARINAS. WIDESPREAD INUNDATION OF LAND IS NOT EXPECTED FOR ADVISORY AREAS.

* BE ALERT TO INSTRUCTIONS FROM YOUR LOCAL EMERGENCY OFFICIALS.

* DO NOT GO TO THE COAST TO OBSERVE THE TSUNAMI.

* DO NOT RETURN TO THE COAST UNTIL LOCAL EMERGENCY OFFICIALS INDICATE IT IS SAFE TO DO SO.

SIGNIFICANT TSUNAMI ACTIVITY IS EXPECTED TO CONTINUE FOR UP TO 48 HOURS AFTER THE WAVES INITIAL ARRIVAL ALONG SOUTHERN ALASKA COASTS

EAST OF NIKOLSKI AND ALONG THE US AND CANADIAN WEST COAST. 


\begin{tabular}{|c|c|c|}
\hline \multirow[b]{2}{*}{ SITE } & \multicolumn{2}{|c|}{ OBSERVED MAX } \\
\hline & OF MEASUREMENT & TSUNA \\
\hline SAND POINT AK & 1945 UTC 3-27 & $11.60 \mathrm{FT}$ \\
\hline KING COVE AK & 2023 UTC 3-27 & $4.33 \mathrm{FT}$ \\
\hline CHIGNIK AK & 2026 UTC 3-27 & $21.82 \mathrm{FT}$ \\
\hline NIKOLSKI AK & 2054 UTC $3-27$ & $1.61 \mathrm{FT}$ \\
\hline UNALASKA AK & 2056 UTC $3-27$ & $1.44 \mathrm{FT}$ \\
\hline KODIAK AK & 2100 UTC $3-27$ & $4.50 \mathrm{FT}$ \\
\hline SEWARD AK & 2110 UTC $3-27$ & $4.11 \mathrm{FT}$ \\
\hline ADAK AK & 2145 UTC $3-27$ & $1.03 \mathrm{FT}$ \\
\hline ELFIN COVE AK & 2133 UTC $3-27$ & $1.32 \mathrm{FT}$ \\
\hline YAKUTAT AK & 2132 UTC $3-27$ & 2.44 FT \\
\hline PORT ALEXANDER A & 2114 UTC $3-27$ & $1.41 \mathrm{FT}$ \\
\hline CORDOVA AK & 2235 UTC $3-27$ & $1.82 \mathrm{FT}$ \\
\hline SHEMYA AK & 2245 UTC $3-27$ & $0.34 \mathrm{FT}$ \\
\hline SITKA AK & 2222 UTC $3-27$ & $.74 \mathrm{FT}$ \\
\hline CRAIG AK & 2255 UTC $3-27$ & $3.88 \mathrm{FT}$ \\
\hline LANGARA BC & 2300 UTC $3-27$ & $1.60 \mathrm{FT}$ \\
\hline TOFINO BC & 2334 UTC $3-27$ & $2.41 \mathrm{FT}$ \\
\hline NEAH BAY WA & 2234 UTC $3-27$ & $2.02 \mathrm{FT}$ \\
\hline LAPUSH WA & 2241 UTC 3-27 & $3.15 \mathrm{FT}$ \\
\hline WESTPORT WA & 2302 UTC $3-27$ & $2.11 \mathrm{FT}$ \\
\hline PORT ANGELES WA & 2354 UTC $3-27$ & $1.38 \mathrm{FT}$ \\
\hline GARIBALDI OR & 2259 UTC 3-27 & $1.05 \mathrm{FT}$ \\
\hline NEWPORT OR & 2309 UTC 3-27 & $2.46 \mathrm{FT}$ \\
\hline CHARLESTON OR & 2333 UTC $3-27$ & $2.74 \mathrm{FT}$ \\
\hline PORT ORFORD OR & 2355 UTC 3-27 & $6.76 \mathrm{FT}$ \\
\hline CRESCENT CITY CA & 0100 UTC $3-28$ & $7.11 \mathrm{FT}$ \\
\hline ARENA COVE CA & 2313 UTC 3-27 & $5.58 \mathrm{FT}$ \\
\hline EUREKA CA & 0006 UTC $3-28$ & $4.23 \mathrm{FT}$ \\
\hline POINT REYES CA & 0142 UTC 3-28 & $3.38 \mathrm{FT}$ \\
\hline SAN FRANCISCO & 0155 UTC $3-28$ & $3.71 \mathrm{FT}$ \\
\hline ALAMEDA CA & 0141 UTC 3-28 & $1.84 \mathrm{FT}$ \\
\hline MONTEREY CA & 2338 UTC $3-27$ & $3.97 \mathrm{FT}$ \\
\hline PORT SAN LUIS CA & 0108 UTC $3-28$ & $14.30 \mathrm{FT}$ \\
\hline SANTA BARBARA CA & 0145 UTC 3-28 & $2.64 \mathrm{FT}$ \\
\hline SANTA MONICA CA & 0157 UTC $3-28$ & $3.38 \mathrm{FT}$ \\
\hline SAN PEDRO CA & 0230 UTC $3-28$ & $3.11 \mathrm{FT}$ \\
\hline LA JOLLA CA & 0222 UTC 3-28 & $3.5 \mathrm{FT}$ \\
\hline SAN DIEGO CA & 0214 UTC 3-28 & $1.74 \mathrm{FT}$ \\
\hline MIDWAY IS & 2304 UTC $3-27$ & $1.44 \mathrm{FT}$ \\
\hline NAWILIWILI HI & 2323 UTC $3-27$ & $2.20 \mathrm{FT}$ \\
\hline HALEIWA HI & 2338 UTC $3-27$ & $4.99 \mathrm{FT}$ \\
\hline
\end{tabular}




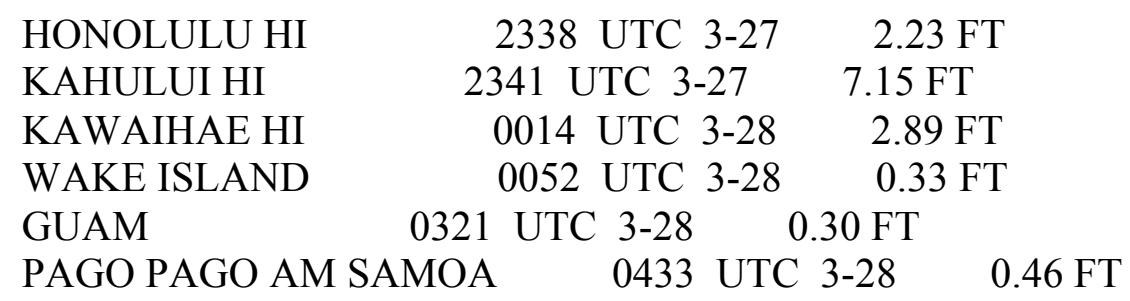

HEIGHT - OBSERVED MAX TSUNAMI HEIGHT IS THE WATER LEVEL ABOVE THE TIDE LEVEL AT THE TIME OF MEASUREMENT.

PRELIMINARY EARTHQUAKE PARAMETERS

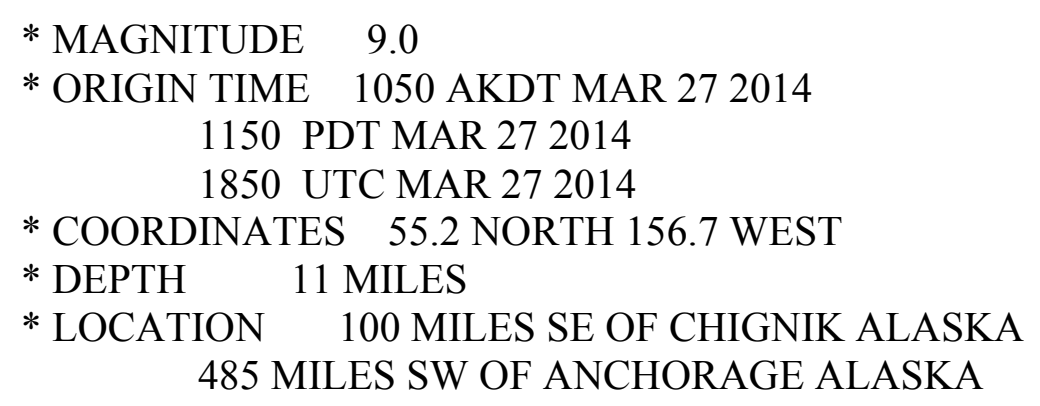

NEXT UPDATE AND ADDITIONAL INFORMATION

* THIS MESSAGE WILL BE UPDATED IN 60 MINUTES.

* REFER TO THE INTERNET SITE WCATWC.ARH.NOAA.GOV FOR MORE INFORMATION.

* PACIFIC COASTAL RESIDENTS OUTSIDE CALIFORNIA... OREGON... WASHINGTON... BRITISH COLUMBIA AND ALASKA SHOULD REFER TO THE PACIFIC TSUNAMI WARNING CENTER MESSAGES FOR INFORMATION ON THIS EVENT AT PTWC.WEATHER.GOV. 
WEAK51 PAAQ 280701

TSUAK1

BULLETIN

PUBLIC TSUNAMI MESSAGE NUMBER 14

NWS WEST COAST/ALASKA TSUNAMI WARNING CENTER PALMER AK

1101 PM AKDT THU MAR 272014

NO NEW INFORMATION IS CONTAINED IN THIS MESSAGE.

...THE TSUNAMI WARNING REMAINS IN EFFECT...

...THE TSUNAMI ADVISORY REMAINS IN EFFECT...

WARNINGS/ADVISORIES/WATCHES

TSUNAMI WARNING IN EFFECT FOR...

* THE COASTAL AREAS OF CALIFORNIA - OREGON - WASHINGTON BRITISH COLUMBIA AND ALASKA FROM THE CALIFORNIA-MEXICO BORDER TO NIKOLSKI ALASKA

TSUNAMI ADVISORY IN EFFECT FOR...

* THE COASTAL AREAS OF ALASKA FROM NIKOLSKI ALASKA TO ATTU ALASKA

IMPACTS FOR TSUNAMI WARNING AREAS 
* WIDESPREAD DANGEROUS COASTAL FLOODING ACCOMPANIED BY POWERFUL CURRENTS IS POSSIBLE AND MAY CONTINUE FOR MANY HOURS AFTER TSUNAMI ARRIVAL.

* THE FIRST WAVE MAY NOT BE THE LARGEST.

IMPACTS FOR TSUNAMI ADVISORY AREAS

* A TSUNAMI CAPABLE OF PRODUCING STRONG CURRENTS OR WAVES DANGEROUS

TO PERSONS IN OR VERY NEAR THE WATER IS EXPECTED.

* CURRENTS MAY BE HAZARDOUS TO SWIMMERS... BOATS... AND COASTAL STRUCTURES AND MAY CONTINUE FOR MANY HOURS AFTER THE TSUNAMI ARRIVAL.

* THE FIRST WAVE MAY NOT BE THE LARGEST.

RECOMMENDED ACTIONS

* IF YOU ARE IN A WARNING AREA - MOVE INLAND TO HIGHER GROUND.

* IF YOU ARE IN AN ADVISORY AREA - MOVE OFF THE BEACH AND OUT OF HARBORS AND MARINAS. WIDESPREAD INUNDATION OF LAND IS NOT EXPECTED FOR ADVISORY AREAS.

* BE ALERT TO INSTRUCTIONS FROM YOUR LOCAL EMERGENCY OFFICIALS.

* DO NOT GO TO THE COAST TO OBSERVE THE TSUNAMI.

* DO NOT RETURN TO THE COAST UNTIL LOCAL EMERGENCY OFFICIALS INDICATE IT IS SAFE TO DO SO.

SIGNIFICANT TSUNAMI ACTIVITY IS EXPECTED TO CONTINUE FOR UP TO 48 HOURS AFTER THE WAVES INITIAL ARRIVAL ALONG SOUTHERN ALASKA COASTS

EAST OF NIKOLSKI AND ALONG THE US AND CANADIAN WEST COAST.

ADDITIONAL OBSERVATIONS OF TSUNAMI ACTIVITY - UPDATED

$\begin{array}{ll} & \text { TIME } \\ \text { SITE } & \text { OF MEASUREMENT TSUNAMI HEIGHT }\end{array}$




\begin{tabular}{|c|c|c|}
\hline AND POINT AK & 1945 UTC 3-27 & $11.60 \mathrm{FT}$ \\
\hline KING COVE AK & 2023 UTC 3-27 & $4.33 \mathrm{FT}$ \\
\hline CHIGNIK AK & 2026 UTC 3-27 & $21.82 \mathrm{FT}$ \\
\hline NIKOLSKI AK & 2054 UTC $3-27$ & $1.61 \mathrm{FT}$ \\
\hline UNALASKA AK & 2056 UTC 3-27 & $1.44 \mathrm{FT}$ \\
\hline KODIAK AK & 2100 UTC $3-27$ & 4.50 FT \\
\hline SEWARD AK & 2110 UTC $3-27$ & $4.11 \mathrm{FT}$ \\
\hline ADAK AK & 2145 UTC $3-27$ & $.03 \mathrm{FT}$ \\
\hline ELFIN COVE AK & 2133 UTC $3-27$ & $1.32 \mathrm{FT}$ \\
\hline YAKUTAT AK & 2132 UTC 3-27 & $2.44 \mathrm{FT}$ \\
\hline PORT ALEXANDER AK & 2114 UTC $3-27$ & $1.41 \mathrm{FT}$ \\
\hline CORDOVA AK & 2235 UTC $3-27$ & $1.82 \mathrm{FT}$ \\
\hline SHEMYA AK & 2245 UTC $3-27$ & $0.34 \mathrm{FT}$ \\
\hline SITKA AK & 2222 UTC $3-27$ & $74 \mathrm{FT}$ \\
\hline CRAIG AK & 2255 UTC $3-27$ & $.88 \mathrm{FT}$ \\
\hline LANGARA BC & 2300 UTC $3-27$ & $1.60 \mathrm{FT}$ \\
\hline TOFINO BC & 2334 UTC $3-27$ & $2.41 \mathrm{FT}$ \\
\hline NEAH BAY WA & 2234 UTC $3-27$ & $2.02 \mathrm{FT}$ \\
\hline LAPUSH WA & 2241 UTC 3-27 & $3.15 \mathrm{FT}$ \\
\hline WESTPORT WA & 2302 UTC $3-27$ & $2.11 \mathrm{FT}$ \\
\hline PORT ANGELES WA & 2354 UTC $3-27$ & $1.38 \mathrm{FT}$ \\
\hline GARIBALDI OR & 2259 UTC 3-27 & $1.05 \mathrm{FT}$ \\
\hline NEWPORT OR & 2309 UTC 3-27 & $2.46 \mathrm{FT}$ \\
\hline CHARLESTON OR & 2333 UTC $3-27$ & $2.74 \mathrm{FT}$ \\
\hline PORT ORFORD OR & 2355 UTC $3-27$ & $6.76 \mathrm{FT}$ \\
\hline CRESCENT CITY CA & 0100 UTC $3-28$ & $7.11 \mathrm{FT}$ \\
\hline ARENA COVE CA & 2313 UTC $3-27$ & $5.58 \mathrm{FT}$ \\
\hline EUREKA CA & 0006 UTC 3-28 & $4.23 \mathrm{FT}$ \\
\hline POINT REYES CA & 0142 UTC 3-28 & $3.38 \mathrm{FT}$ \\
\hline SAN FRANCISCO & 0155 UTC $3-28$ & $3.71 \mathrm{FT}$ \\
\hline ALAMEDA CA & 0141 UTC 3-28 & $1.84 \mathrm{FT}$ \\
\hline MONTEREY CA & 2338 UTC $3-27$ & $3.97 \mathrm{FT}$ \\
\hline PORT SAN LUIS CA & 0108 UTC $3-28$ & 14.30 FT \\
\hline SANTA BARBARA CA & 0145 UTC $3-28$ & $2.64 \mathrm{FT}$ \\
\hline SANTA MONICA CA & 0157 UTC 3-28 & $3.38 \mathrm{FT}$ \\
\hline SAN PEDRO CA & 0230 UTC $3-28$ & $3.11 \mathrm{FT}$ \\
\hline LA JOLLA CA & 0222 UTC 3-28 & $3.5 \mathrm{FT}$ \\
\hline SAN DIEGO CA & 0214 UTC 3-28 & $1.74 \mathrm{FT}$ \\
\hline MIDWAY IS & 2304 UTC $3-27$ & $1.44 \mathrm{FT}$ \\
\hline NAWILIWILI HI & 2323 UTC $3-27$ & $2.20 \mathrm{FT}$ \\
\hline HALEIWA HI & 2338 UTC $3-27$ & $4.99 \mathrm{FT}$ \\
\hline HONOLULU HI & 2338 UTC $3-27$ & $2.23 \mathrm{FT}$ \\
\hline KAHULUI HI & 2341 UTC $3-27$ & $7.15 \mathrm{FT}$ \\
\hline KAWAIHAE HI & 0014 UTC 3-28 & $2.89 \mathrm{FT}$ \\
\hline WAKE ISLAND & 0052 UTC $3-28$ & $0.33 \mathrm{FT}$ \\
\hline GUAM & 321 UTC $3-28$ & $0 \mathrm{FT}$ \\
\hline
\end{tabular}


PAGO PAGO AM SAMOA 0433 UTC 3-28 $0.46 \mathrm{FT}$

HEIGHT - OBSERVED MAX TSUNAMI HEIGHT IS THE WATER LEVEL ABOVE THE TIDE LEVEL AT THE TIME OF MEASUREMENT.

PRELIMINARY EARTHQUAKE PARAMETERS

* MAGNITUDE 9.0

* ORIGIN TIME 1050 AKDT MAR 272014

1150 PDT MAR 272014

1850 UTC MAR 272014

* COORDINATES 55.2 NORTH 156.7 WEST

* DEPTH 11 MILES

* LOCATION 100 MILES SE OF CHIGNIK ALASKA 485 MILES SW OF ANCHORAGE ALASKA

NEXT UPDATE AND ADDITIONAL INFORMATION

* THIS MESSAGE WILL BE UPDATED IN 60 MINUTES.

* REFER TO THE INTERNET SITE WCATWC.ARH.NOAA.GOV FOR MORE INFORMATION.

* PACIFIC COASTAL RESIDENTS OUTSIDE CALIFORNIA... OREGON... WASHINGTON... BRITISH COLUMBIA AND ALASKA SHOULD REFER TO THE PACIFIC TSUNAMI WARNING CENTER MESSAGES FOR INFORMATION ON THIS EVENT AT PTWC.WEATHER.GOV.

$\$ \$$ 
WEAK51 PAAQ 280800

TSUAK1

BULLETIN

PUBLIC TSUNAMI MESSAGE NUMBER 15

NWS WEST COAST/ALASKA TSUNAMI WARNING CENTER PALMER AK 1200 AM AKDT FRI MAR 282014

NO NEW INFORMATION IS CONTAINED IN THIS MESSAGE.

...THE TSUNAMI WARNING REMAINS IN EFFECT...

...THE TSUNAMI ADVISORY REMAINS IN EFFECT...

WARNINGS/ADVISORIES/WATCHES

TSUNAMI WARNING IN EFFECT FOR...

* THE COASTAL AREAS OF CALIFORNIA - OREGON - WASHINGTON BRITISH COLUMBIA AND ALASKA FROM THE CALIFORNIA-MEXICO BORDER TO NIKOLSKI ALASKA

TSUNAMI ADVISORY IN EFFECT FOR...

* THE COASTAL AREAS OF ALASKA FROM NIKOLSKI ALASKA TO ATTU ALASKA

IMPACTS FOR TSUNAMI WARNING AREAS 
* WIDESPREAD DANGEROUS COASTAL FLOODING ACCOMPANIED BY POWERFUL CURRENTS IS POSSIBLE AND MAY CONTINUE FOR MANY HOURS AFTER TSUNAMI ARRIVAL.

* THE FIRST WAVE MAY NOT BE THE LARGEST.

IMPACTS FOR TSUNAMI ADVISORY AREAS

* A TSUNAMI CAPABLE OF PRODUCING STRONG CURRENTS OR WAVES DANGEROUS

TO PERSONS IN OR VERY NEAR THE WATER IS EXPECTED.

* CURRENTS MAY BE HAZARDOUS TO SWIMMERS... BOATS... AND COASTAL STRUCTURES AND MAY CONTINUE FOR MANY HOURS AFTER THE TSUNAMI ARRIVAL.

* THE FIRST WAVE MAY NOT BE THE LARGEST.

RECOMMENDED ACTIONS

* IF YOU ARE IN A WARNING AREA - MOVE INLAND TO HIGHER GROUND.

* IF YOU ARE IN AN ADVISORY AREA - MOVE OFF THE BEACH AND OUT OF HARBORS AND MARINAS. WIDESPREAD INUNDATION OF LAND IS NOT EXPECTED FOR ADVISORY AREAS.

* BE ALERT TO INSTRUCTIONS FROM YOUR LOCAL EMERGENCY OFFICIALS.

* DO NOT GO TO THE COAST TO OBSERVE THE TSUNAMI.

* DO NOT RETURN TO THE COAST UNTIL LOCAL EMERGENCY OFFICIALS INDICATE IT IS SAFE TO DO SO.

SIGNIFICANT TSUNAMI ACTIVITY IS EXPECTED TO CONTINUE FOR UP TO 48 HOURS AFTER THE WAVES INITIAL ARRIVAL ALONG SOUTHERN ALASKA COASTS

EAST OF NIKOLSKI AND ALONG THE US AND CANADIAN WEST COAST.

ADDITIONAL OBSERVATIONS OF TSUNAMI ACTIVITY - UPDATED

$\begin{array}{ll} & \text { TIME } \\ \text { SITE } & \text { OF MEASUREMENT TSUNAMI HEIGHT }\end{array}$




\begin{tabular}{|c|c|c|}
\hline SAND POINT AK & 1945 UTC 3-27 & $11.60 \mathrm{FT}$ \\
\hline KING COVE AK & 2023 UTC 3-27 & $4.33 \mathrm{FT}$ \\
\hline CHIGNIK AK & 2026 UTC 3-27 & $21.82 \mathrm{FT}$ \\
\hline NIKOLSKI AK & 2054 UTC 3-27 & $1.61 \mathrm{FT}$ \\
\hline UNALASKA AK & 2056 UTC 3-27 & $1.44 \mathrm{FT}$ \\
\hline KODIAK AK & 2100 UTC $3-27$ & $4.50 \mathrm{FT}$ \\
\hline SEWARD AK & 2110 UTC 3-27 & $4.11 \mathrm{FT}$ \\
\hline ADAK AK & 2145 UTC $3-27$ & $.03 \mathrm{FT}$ \\
\hline ELFIN COVE AK & 2133 UTC 3-27 & $1.32 \mathrm{FT}$ \\
\hline YAKUTAT AK & 2132 UTC 3-27 & $2.44 \mathrm{FT}$ \\
\hline PORT ALEXANDER AK & 2114 UTC $3-27$ & $1.41 \mathrm{FT}$ \\
\hline CORDOVA AK & 2235 UTC $3-27$ & $1.82 \mathrm{FT}$ \\
\hline SHEMYA AK & 2245 UTC $3-27$ & $0.34 \mathrm{FT}$ \\
\hline SITKA AK & 2222 UTC $3-27$ & $74 \mathrm{FT}$ \\
\hline CRAIG AK & 2255 UTC $3-27$ & $88 \mathrm{FT}$ \\
\hline LANGARA BC & 2300 UTC $3-27$ & $1.60 \mathrm{FT}$ \\
\hline TOFINO BC & 2334 UTC $3-27$ & $2.41 \mathrm{FT}$ \\
\hline NEAH BAY WA & 2234 UTC 3-27 & 2.02 FT \\
\hline LAPUSH WA & 2241 UTC 3-27 & $3.15 \mathrm{FT}$ \\
\hline WESTPORT WA & 2302 UTC 3-27 & $2.11 \mathrm{FT}$ \\
\hline PORT ANGELES WA & 2354 UTC 3-27 & $1.38 \mathrm{FT}$ \\
\hline GARIBALDI OR & 2259 UTC 3-27 & $1.05 \mathrm{FT}$ \\
\hline NEWPORT OR & 2309 UTC 3-27 & $2.46 \mathrm{FT}$ \\
\hline CHARLESTON OR & 2333 UTC $3-27$ & $2.74 \mathrm{FT}$ \\
\hline PORT ORFORD OR & 2355 UTC 3-27 & $6.76 \mathrm{FT}$ \\
\hline CRESCENT CITY CA & 0100 UTC $3-28$ & $7.11 \mathrm{FT}$ \\
\hline ARENA COVE CA & 2313 UTC $3-27$ & $5.58 \mathrm{FT}$ \\
\hline EUREKA CA & 0006 UTC 3-28 & $4.23 \mathrm{FT}$ \\
\hline POINT REYES CA & 0142 UTC 3-28 & $3.38 \mathrm{FT}$ \\
\hline SAN FRANCISCO & 0155 UTC $3-28$ & $3.71 \mathrm{FT}$ \\
\hline ALAMEDA CA & 0141 UTC 3-28 & $1.84 \mathrm{FT}$ \\
\hline MONTEREY CA & 2338 UTC $3-27$ & $3.97 \mathrm{FT}$ \\
\hline PORT SAN LUIS CA & 0108 UTC $3-28$ & 14.30 FT \\
\hline SANTA BARBARA CA & 0145 UTC $3-28$ & $2.64 \mathrm{FT}$ \\
\hline SANTA MONICA CA & 0157 UTC 3-28 & $3.38 \mathrm{FT}$ \\
\hline SAN PEDRO CA & 0230 UTC $3-28$ & $3.11 \mathrm{FT}$ \\
\hline LA JOLLA CA & 0222 UTC $3-28$ & $3.5 \mathrm{FT}$ \\
\hline SAN DIEGO CA & 0214 UTC 3-28 & $1.74 \mathrm{FT}$ \\
\hline MIDWAY IS & 2304 UTC $3-27$ & $1.44 \mathrm{FT}$ \\
\hline NAWILIWILI HI & 2323 UTC $3-27$ & $2.20 \mathrm{FT}$ \\
\hline HALEIWA HI & 2338 UTC $3-27$ & $4.99 \mathrm{FT}$ \\
\hline HONOLULU HI & 2338 UTC $3-27$ & $2.23 \mathrm{FT}$ \\
\hline KAHULUI HI & 2341 UTC $3-27$ & $7.15 \mathrm{FT}$ \\
\hline KAWAIHAE HI & 0014 UTC 3-28 & $2.89 \mathrm{FT}$ \\
\hline WAKE ISLAND & 0052 UTC $3-28$ & $0.33 \mathrm{FT}$ \\
\hline GUAM & 321 UTC $3-28$ & 0 FT \\
\hline
\end{tabular}


PAGO PAGO AM SAMOA $\quad 0433$ UTC $3-28 \quad 0.46$ FT

HEIGHT - OBSERVED MAX TSUNAMI HEIGHT IS THE WATER LEVEL ABOVE THE TIDE LEVEL AT THE TIME OF MEASUREMENT.

PRELIMINARY EARTHQUAKE PARAMETERS

* MAGNITUDE 9.0

* ORIGIN TIME 1050 AKDT MAR 272014

1150 PDT MAR 272014

1850 UTC MAR 272014

* COORDINATES 55.2 NORTH 156.7 WEST

* DEPTH 11 MILES

* LOCATION 100 MILES SE OF CHIGNIK ALASKA 485 MILES SW OF ANCHORAGE ALASKA

NEXT UPDATE AND ADDITIONAL INFORMATION

* THIS MESSAGE WILL BE UPDATED IN 60 MINUTES.

* REFER TO THE INTERNET SITE WCATWC.ARH.NOAA.GOV FOR MORE INFORMATION.

* PACIFIC COASTAL RESIDENTS OUTSIDE CALIFORNIA... OREGON... WASHINGTON... BRITISH COLUMBIA AND ALASKA SHOULD REFER TO THE PACIFIC TSUNAMI WARNING CENTER MESSAGES FOR INFORMATION ON THIS EVENT AT PTWC.WEATHER.GOV.

$\$ \$$ 
WEAK51 PAAQ 280901

TSUAK1

BULLETIN

PUBLIC TSUNAMI MESSAGE NUMBER 16

NWS WEST COAST/ALASKA TSUNAMI WARNING CENTER PALMER AK

101 AM AKDT FRI MAR 282014

THIS MESSAGE CONTINUES THE WARNING AND ADVISORY AS IN THE PREVIOUS MESSAGE.

...THE TSUNAMI WARNING REMAINS IN EFFECT...

...THE TSUNAMI ADVISORY REMAINS IN EFFECT...

WARNINGS/ADVISORIES/WATCHES

TSUNAMI WARNING IN EFFECT FOR...

* THE COASTAL AREAS OF CALIFORNIA - OREGON - WASHINGTON BRITISH COLUMBIA AND ALASKA FROM THE CALIFORNIA-MEXICO BORDER TO NIKOLSKI ALASKA

TSUNAMI ADVISORY IN EFFECT FOR...

* THE COASTAL AREAS OF ALASKA FROM NIKOLSKI ALASKA TO ATTU ALASKA

IMPACTS FOR TSUNAMI WARNING AREAS 
* WIDESPREAD DANGEROUS COASTAL FLOODING ACCOMPANIED BY POWERFUL CURRENTS IS POSSIBLE AND MAY CONTINUE FOR MANY HOURS AFTER TSUNAMI ARRIVAL.

* THE FIRST WAVE MAY NOT BE THE LARGEST.

IMPACTS FOR TSUNAMI ADVISORY AREAS

* A TSUNAMI CAPABLE OF PRODUCING STRONG CURRENTS OR WAVES DANGEROUS

TO PERSONS IN OR VERY NEAR THE WATER IS EXPECTED.

* CURRENTS MAY BE HAZARDOUS TO SWIMMERS... BOATS... AND COASTAL STRUCTURES AND MAY CONTINUE FOR MANY HOURS AFTER THE TSUNAMI ARRIVAL.

* THE FIRST WAVE MAY NOT BE THE LARGEST.

RECOMMENDED ACTIONS

* IF YOU ARE IN A WARNING AREA - MOVE INLAND TO HIGHER GROUND.

* IF YOU ARE IN AN ADVISORY AREA - MOVE OFF THE BEACH AND OUT OF HARBORS AND MARINAS. WIDESPREAD INUNDATION OF LAND IS NOT EXPECTED FOR ADVISORY AREAS.

* BE ALERT TO INSTRUCTIONS FROM YOUR LOCAL EMERGENCY OFFICIALS.

* DO NOT GO TO THE COAST TO OBSERVE THE TSUNAMI.

* DO NOT RETURN TO THE COAST UNTIL LOCAL EMERGENCY OFFICIALS INDICATE IT IS SAFE TO DO SO.

SIGNIFICANT TSUNAMI ACTIVITY IS EXPECTED TO CONTINUE FOR UP TO 48 HOURS AFTER THE WAVES INITIAL ARRIVAL ALONG SOUTHERN ALASKA COASTS

EAST OF NIKOLSKI AND ALONG THE US AND CANADIAN WEST COAST.

ADDITIONAL OBSERVATIONS OF TSUNAMI ACTIVITY - UPDATED

$\begin{array}{ll} & \text { TIME OBSERVED MAX } \\ \text { SITE } & \text { OF MEASUREMENT TSUNAMI HEIGHT }\end{array}$




\begin{tabular}{|c|c|c|}
\hline \\
\hline SAND POINT AK & 1945 UTC 3-27 & $11.60 \mathrm{FT}$ \\
\hline KING COVE AK & 2023 UTC 3-27 & $4.33 \mathrm{FT}$ \\
\hline CHIGNIK AK & 2026 UTC 3-27 & $21.82 \mathrm{FT}$ \\
\hline NIKOLSKI AK & 2054 UTC 3-27 & $1.61 \mathrm{FT}$ \\
\hline UNALASKA AK & 2056 UTC 3-27 & $1.44 \mathrm{FT}$ \\
\hline KODIAK AK & 2100 UTC 3-27 & $4.50 \mathrm{FT}$ \\
\hline SEWARD AK & 2110 UTC 3-27 & 4.11 FT \\
\hline ADAK AK & 2145 UTC 3-27 & $.03 \mathrm{FT}$ \\
\hline ELFIN COVE AK & 2133 UTC 3-27 & $1.32 \mathrm{FT}$ \\
\hline YAKUTAT AK & 2132 UTC 3-27 & $2.44 \mathrm{FT}$ \\
\hline PORT ALEXANDER AK & 2114 UTC 3-2 & $1.41 \mathrm{~F}$ \\
\hline CORDOVA AK & 2235 UTC 3-27 & $1.82 \mathrm{FT}$ \\
\hline SHEMYA AK & 2245 UTC 3-27 & $0.34 \mathrm{FT}$ \\
\hline SITKA AK & 2222 UTC 3-27 & $74 \mathrm{FT}$ \\
\hline CRAIG AK & 2255 UTC 3-27 & $.88 \mathrm{FT}$ \\
\hline LANGARA BC & 2300 UTC 3-27 & $1.60 \mathrm{FT}$ \\
\hline TOFINO BC & 2334 UTC 3-27 & $.41 \mathrm{FT}$ \\
\hline NEAH BAY WA & 2234 UTC 3-27 & $2.02 \mathrm{FT}$ \\
\hline LAPUSH WA & 2241 UTC 3-27 & $3.15 \mathrm{FT}$ \\
\hline WESTPORT WA & 2302 UTC 3-27 & $2.11 \mathrm{FT}$ \\
\hline PORT ANGELES WA & 2354 UTC 3-27 & $1.38 \mathrm{FT}$ \\
\hline GARIBALDI OR & 2259 UTC 3-27 & $1.05 \mathrm{FT}$ \\
\hline NEWPORT OR & 2309 UTC 3-27 & $2.46 \mathrm{FT}$ \\
\hline CHARLESTON OR & 2333 UTC 3-27 & $2.74 \mathrm{FT}$ \\
\hline ORFORD OR & 2355 UTC 3-27 & $6.76 \mathrm{FT}$ \\
\hline CRESCENT CITY CA & 0100 UTC 3-28 & $7.11 \mathrm{FT}$ \\
\hline ARENA COVE CA & 2313 UTC 3-27 & $5.58 \mathrm{FT}$ \\
\hline EUREKA CA & 0006 UTC 3-28 & $4.23 \mathrm{FT}$ \\
\hline POINT REYES CA & 0142 UTC 3-28 & $3.38 \mathrm{FT}$ \\
\hline RANCISCO & 0155 UTC 3-28 & $3.71 \mathrm{FT}$ \\
\hline ALAMEDA CA & 0141 UTC 3-28 & $1.84 \mathrm{FT}$ \\
\hline MONTEREY CA & 2338 UTC 3-27 & $3.97 \mathrm{FT}$ \\
\hline PORT SAN LUIS CA & 0108 UTC 3-28 & $14.30 \mathrm{FT}$ \\
\hline SANTA BARBARA CA & 0145 UTC 3-28 & $2.64 \mathrm{FT}$ \\
\hline SANTA MONICA CA & 0157 UTC 3-28 & $3.38 \mathrm{FT}$ \\
\hline SAN PEDRO CA & 0230 UTC 3-28 & $3.11 \mathrm{FT}$ \\
\hline LA JOLLA CA & 0222 UTC 3-28 & $3.5 \mathrm{FT}$ \\
\hline SAN DIEGO CA & 0214 UTC 3-28 & $1.74 \mathrm{FT}$ \\
\hline MIDWAY IS & 2304 UTC 3-27 & $1.44 \mathrm{FT}$ \\
\hline NAWILIWILI HI & 2323 UTC 3-27 & $2.20 \mathrm{FT}$ \\
\hline HALEIWA HI & 2338 UTC 3-27 & $4.99 \mathrm{FT}$ \\
\hline HONOLULU HI & 2338 UTC 3-27 & $2.23 \mathrm{FT}$ \\
\hline KAHULUI HI & 2341 UTC 3-27 & $7.15 \mathrm{FT}$ \\
\hline KAWAIHAE HI & 0014 UTC 3-28 & $2.89 \mathrm{FT}$ \\
\hline WAKE ISLAND & 0052 UTC 3-28 & $0.33 \mathrm{FT}$ \\
\hline
\end{tabular}



GUAM
0321 UTC 3-28
PAGO PAGO AM SAMOA
0433 UTC 3-28
0.46 FT

HEIGHT - OBSERVED MAX TSUNAMI HEIGHT IS THE WATER LEVEL ABOVE THE TIDE LEVEL AT THE TIME OF MEASUREMENT.

PRELIMINARY EARTHQUAKE PARAMETERS
* MAGNITUDE 9.0
* ORIGIN TIME 1050 AKDT MAR 272014
1150 PDT MAR 272014
1850 UTC MAR 272014
* COORDINATES 55.2 NORTH 156.7 WEST
* DEPTH 11 MILES
* LOCATION 100 MILES SE OF CHIGNIK ALASKA 485 MILES SW OF ANCHORAGE ALASKA

NEXT UPDATE AND ADDITIONAL INFORMATION

* THIS MESSAGE WILL BE UPDATED IN 60 MINUTES.

* REFER TO THE INTERNET SITE WCATWC.ARH.NOAA.GOV FOR MORE INFORMATION.

* PACIFIC COASTAL RESIDENTS OUTSIDE CALIFORNIA... OREGON... WASHINGTON... BRITISH COLUMBIA AND ALASKA SHOULD REFER TO THE PACIFIC TSUNAMI WARNING CENTER MESSAGES FOR INFORMATION ON THIS EVENT AT PTWC.WEATHER.GOV. 
WEAK51 PAAQ 281000

TSUAK1

BULLETIN

PUBLIC TSUNAMI MESSAGE NUMBER 17

NWS WEST COAST/ALASKA TSUNAMI WARNING CENTER PALMER AK 200 AM AKDT FRI MAR 282014

THIS MESSAGE CONTINUES THE WARNING AND ADVISORY AS IN THE PREVIOUS MESSAGE.

...THE TSUNAMI WARNING REMAINS IN EFFECT...

...THE TSUNAMI ADVISORY REMAINS IN EFFECT...

WARNINGS/ADVISORIES/WATCHES

TSUNAMI WARNING IN EFFECT FOR...

* THE COASTAL AREAS OF CALIFORNIA - OREGON - WASHINGTON BRITISH COLUMBIA AND ALASKA FROM THE CALIFORNIA-MEXICO BORDER TO NIKOLSKI ALASKA

TSUNAMI ADVISORY IN EFFECT FOR...

* THE COASTAL AREAS OF ALASKA FROM NIKOLSKI ALASKA TO ATTU ALASKA

IMPACTS FOR TSUNAMI WARNING AREAS 
* WIDESPREAD DANGEROUS COASTAL FLOODING ACCOMPANIED BY POWERFUL CURRENTS IS POSSIBLE AND MAY CONTINUE FOR MANY HOURS AFTER TSUNAMI ARRIVAL.

* THE FIRST WAVE MAY NOT BE THE LARGEST.

IMPACTS FOR TSUNAMI ADVISORY AREAS

* A TSUNAMI CAPABLE OF PRODUCING STRONG CURRENTS OR WAVES DANGEROUS

TO PERSONS IN OR VERY NEAR THE WATER IS EXPECTED.

* CURRENTS MAY BE HAZARDOUS TO SWIMMERS... BOATS... AND COASTAL STRUCTURES AND MAY CONTINUE FOR MANY HOURS AFTER THE TSUNAMI ARRIVAL.

* THE FIRST WAVE MAY NOT BE THE LARGEST.

RECOMMENDED ACTIONS

* IF YOU ARE IN A WARNING AREA - MOVE INLAND TO HIGHER GROUND.

* IF YOU ARE IN AN ADVISORY AREA - MOVE OFF THE BEACH AND OUT OF HARBORS AND MARINAS. WIDESPREAD INUNDATION OF LAND IS NOT EXPECTED FOR ADVISORY AREAS.

* BE ALERT TO INSTRUCTIONS FROM YOUR LOCAL EMERGENCY OFFICIALS.

* DO NOT GO TO THE COAST TO OBSERVE THE TSUNAMI.

* DO NOT RETURN TO THE COAST UNTIL LOCAL EMERGENCY OFFICIALS INDICATE IT IS SAFE TO DO SO.

SIGNIFICANT TSUNAMI ACTIVITY IS EXPECTED TO CONTINUE FOR UP TO 48 HOURS AFTER THE WAVES INITIAL ARRIVAL ALONG SOUTHERN ALASKA COASTS

EAST OF NIKOLSKI AND ALONG THE US AND CANADIAN WEST COAST.

ADDITIONAL OBSERVATIONS OF TSUNAMI ACTIVITY - UPDATED

$\begin{array}{ll} & \text { TIME OBSERVED MAX } \\ \text { SITE } & \text { OF MEASUREMENT TSUNAMI HEIGHT }\end{array}$




\begin{tabular}{|c|c|c|}
\hline \\
\hline SAND POINT AK & 1945 UTC 3-27 & $11.60 \mathrm{FT}$ \\
\hline KING COVE AK & 2023 UTC 3-27 & $4.33 \mathrm{FT}$ \\
\hline CHIGNIK AK & 2026 UTC 3-27 & $21.82 \mathrm{FT}$ \\
\hline NIKOLSKI AK & 2054 UTC 3-27 & $1.61 \mathrm{FT}$ \\
\hline UNALASKA AK & 2056 UTC 3-27 & $1.44 \mathrm{FT}$ \\
\hline KODIAK AK & 2100 UTC 3-27 & $4.50 \mathrm{FT}$ \\
\hline SEWARD AK & 2110 UTC 3-27 & 4.11 FT \\
\hline ADAK AK & 2145 UTC 3-27 & $.03 \mathrm{FT}$ \\
\hline ELFIN COVE AK & 2133 UTC 3-27 & $1.32 \mathrm{FT}$ \\
\hline YAKUTAT AK & 2132 UTC 3-27 & $2.44 \mathrm{FT}$ \\
\hline PORT ALEXANDER AK & 2114 UTC 3-2 & $1.41 \mathrm{~F}$ \\
\hline CORDOVA AK & 2235 UTC 3-27 & $1.82 \mathrm{FT}$ \\
\hline SHEMYA AK & 2245 UTC 3-27 & $0.34 \mathrm{FT}$ \\
\hline SITKA AK & 2222 UTC 3-27 & $74 \mathrm{FT}$ \\
\hline CRAIG AK & 2255 UTC 3-27 & $.88 \mathrm{FT}$ \\
\hline LANGARA BC & 2300 UTC 3-27 & $1.60 \mathrm{FT}$ \\
\hline TOFINO BC & 2334 UTC 3-27 & $.41 \mathrm{FT}$ \\
\hline NEAH BAY WA & 2234 UTC 3-27 & $2.02 \mathrm{FT}$ \\
\hline LAPUSH WA & 2241 UTC 3-27 & $3.15 \mathrm{FT}$ \\
\hline WESTPORT WA & 2302 UTC 3-27 & $2.11 \mathrm{FT}$ \\
\hline PORT ANGELES WA & 2354 UTC 3-27 & $1.38 \mathrm{FT}$ \\
\hline GARIBALDI OR & 2259 UTC 3-27 & $1.05 \mathrm{FT}$ \\
\hline NEWPORT OR & 2309 UTC 3-27 & $2.46 \mathrm{FT}$ \\
\hline CHARLESTON OR & 2333 UTC 3-27 & $2.74 \mathrm{FT}$ \\
\hline ORFORD OR & 2355 UTC 3-27 & $6.76 \mathrm{FT}$ \\
\hline CRESCENT CITY CA & 0100 UTC 3-28 & $7.11 \mathrm{FT}$ \\
\hline ARENA COVE CA & 2313 UTC 3-27 & $5.58 \mathrm{FT}$ \\
\hline EUREKA CA & 0006 UTC 3-28 & $4.23 \mathrm{FT}$ \\
\hline POINT REYES CA & 0142 UTC 3-28 & $3.38 \mathrm{FT}$ \\
\hline RANCISCO & 0155 UTC 3-28 & $3.71 \mathrm{FT}$ \\
\hline ALAMEDA CA & 0141 UTC 3-28 & $1.84 \mathrm{FT}$ \\
\hline MONTEREY CA & 2338 UTC 3-27 & $3.97 \mathrm{FT}$ \\
\hline PORT SAN LUIS CA & 0108 UTC 3-28 & $14.30 \mathrm{FT}$ \\
\hline SANTA BARBARA CA & 0145 UTC 3-28 & $2.64 \mathrm{FT}$ \\
\hline SANTA MONICA CA & 0157 UTC 3-28 & $3.38 \mathrm{FT}$ \\
\hline SAN PEDRO CA & 0230 UTC 3-28 & $3.11 \mathrm{FT}$ \\
\hline LA JOLLA CA & 0222 UTC 3-28 & $3.5 \mathrm{FT}$ \\
\hline SAN DIEGO CA & 0214 UTC 3-28 & $1.74 \mathrm{FT}$ \\
\hline MIDWAY IS & 2304 UTC 3-27 & $1.44 \mathrm{FT}$ \\
\hline NAWILIWILI HI & 2323 UTC 3-27 & $2.20 \mathrm{FT}$ \\
\hline HALEIWA HI & 2338 UTC 3-27 & $4.99 \mathrm{FT}$ \\
\hline HONOLULU HI & 2338 UTC 3-27 & $2.23 \mathrm{FT}$ \\
\hline KAHULUI HI & 2341 UTC 3-27 & $7.15 \mathrm{FT}$ \\
\hline KAWAIHAE HI & 0014 UTC 3-28 & $2.89 \mathrm{FT}$ \\
\hline WAKE ISLAND & 0052 UTC 3-28 & $0.33 \mathrm{FT}$ \\
\hline
\end{tabular}



GUAM
0321 UTC 3-28
PAGO PAGO AM SAMOA
0433 UTC 3-28
0.46 FT

HEIGHT - OBSERVED MAX TSUNAMI HEIGHT IS THE WATER LEVEL ABOVE THE TIDE LEVEL AT THE TIME OF MEASUREMENT.

PRELIMINARY EARTHQUAKE PARAMETERS
* MAGNITUDE 9.0
* ORIGIN TIME 1050 AKDT MAR 272014
1150 PDT MAR 272014
1850 UTC MAR 272014
* COORDINATES 55.2 NORTH 156.7 WEST
* DEPTH 11 MILES
* LOCATION 100 MILES SE OF CHIGNIK ALASKA 485 MILES SW OF ANCHORAGE ALASKA

NEXT UPDATE AND ADDITIONAL INFORMATION

* THIS MESSAGE WILL BE UPDATED IN 60 MINUTES.

* REFER TO THE INTERNET SITE WCATWC.ARH.NOAA.GOV FOR MORE INFORMATION.

* PACIFIC COASTAL RESIDENTS OUTSIDE CALIFORNIA... OREGON... WASHINGTON... BRITISH COLUMBIA AND ALASKA SHOULD REFER TO THE PACIFIC TSUNAMI WARNING CENTER MESSAGES FOR INFORMATION ON THIS EVENT AT PTWC.WEATHER.GOV. 
WEAK51 PAAQ 281100

TSUAK1

BULLETIN

PUBLIC TSUNAMI MESSAGE NUMBER 18

NWS WEST COAST/ALASKA TSUNAMI WARNING CENTER PALMER AK 300 AM AKDT FRI MAR 282014

THIS MESSAGE CONTINUES THE WARNING AND ADVISORY AS IN THE PREVIOUS MESSAGE.

...THE TSUNAMI WARNING REMAINS IN EFFECT...

...THE TSUNAMI ADVISORY REMAINS IN EFFECT...

WARNINGS/ADVISORIES/WATCHES

TSUNAMI WARNING IN EFFECT FOR...

* THE COASTAL AREAS OF CALIFORNIA - OREGON - WASHINGTON BRITISH COLUMBIA AND ALASKA FROM THE CALIFORNIA-MEXICO BORDER TO NIKOLSKI ALASKA

TSUNAMI ADVISORY IN EFFECT FOR...

* THE COASTAL AREAS OF ALASKA FROM NIKOLSKI ALASKA TO ATTU ALASKA

IMPACTS FOR TSUNAMI WARNING AREAS 
* WIDESPREAD DANGEROUS COASTAL FLOODING ACCOMPANIED BY POWERFUL CURRENTS IS POSSIBLE AND MAY CONTINUE FOR MANY HOURS AFTER TSUNAMI ARRIVAL.

* THE FIRST WAVE MAY NOT BE THE LARGEST.

IMPACTS FOR TSUNAMI ADVISORY AREAS

* A TSUNAMI CAPABLE OF PRODUCING STRONG CURRENTS OR WAVES DANGEROUS

TO PERSONS IN OR VERY NEAR THE WATER IS EXPECTED.

* CURRENTS MAY BE HAZARDOUS TO SWIMMERS... BOATS... AND COASTAL STRUCTURES AND MAY CONTINUE FOR MANY HOURS AFTER THE TSUNAMI ARRIVAL.

* THE FIRST WAVE MAY NOT BE THE LARGEST.

RECOMMENDED ACTIONS

* IF YOU ARE IN A WARNING AREA - MOVE INLAND TO HIGHER GROUND.

* IF YOU ARE IN AN ADVISORY AREA - MOVE OFF THE BEACH AND OUT OF HARBORS AND MARINAS. WIDESPREAD INUNDATION OF LAND IS NOT EXPECTED FOR ADVISORY AREAS.

* BE ALERT TO INSTRUCTIONS FROM YOUR LOCAL EMERGENCY OFFICIALS.

* DO NOT GO TO THE COAST TO OBSERVE THE TSUNAMI.

* DO NOT RETURN TO THE COAST UNTIL LOCAL EMERGENCY OFFICIALS INDICATE IT IS SAFE TO DO SO.

SIGNIFICANT TSUNAMI ACTIVITY IS EXPECTED TO CONTINUE FOR UP TO 48 HOURS AFTER THE WAVES INITIAL ARRIVAL ALONG SOUTHERN ALASKA COASTS

EAST OF NIKOLSKI AND ALONG THE US AND CANADIAN WEST COAST.

ADDITIONAL OBSERVATIONS OF TSUNAMI ACTIVITY - UPDATED

$\begin{array}{ll} & \text { TIME OBSERVED MAX } \\ \text { SITE } & \text { OF MEASUREMENT TSUNAMI HEIGHT }\end{array}$




\begin{tabular}{|c|c|c|}
\hline \\
\hline SAND POINT AK & 1945 UTC 3-27 & $11.60 \mathrm{FT}$ \\
\hline KING COVE AK & 2023 UTC 3-27 & $4.33 \mathrm{FT}$ \\
\hline CHIGNIK AK & 2026 UTC 3-27 & $21.82 \mathrm{FT}$ \\
\hline NIKOLSKI AK & 2054 UTC 3-27 & $1.61 \mathrm{FT}$ \\
\hline UNALASKA AK & 2056 UTC 3-27 & $1.44 \mathrm{FT}$ \\
\hline KODIAK AK & 2100 UTC 3-27 & $4.50 \mathrm{FT}$ \\
\hline SEWARD AK & 2110 UTC 3-27 & 4.11 FT \\
\hline ADAK AK & 2145 UTC 3-27 & $.03 \mathrm{FT}$ \\
\hline ELFIN COVE AK & 2133 UTC 3-27 & $1.32 \mathrm{FT}$ \\
\hline YAKUTAT AK & 2132 UTC 3-27 & $2.44 \mathrm{FT}$ \\
\hline PORT ALEXANDER AK & 2114 UTC 3-2 & $1.41 \mathrm{~F}$ \\
\hline CORDOVA AK & 2235 UTC 3-27 & $1.82 \mathrm{FT}$ \\
\hline SHEMYA AK & 2245 UTC 3-27 & $0.34 \mathrm{FT}$ \\
\hline SITKA AK & 2222 UTC 3-27 & $74 \mathrm{FT}$ \\
\hline CRAIG AK & 2255 UTC 3-27 & $.88 \mathrm{FT}$ \\
\hline LANGARA BC & 2300 UTC 3-27 & $1.60 \mathrm{FT}$ \\
\hline TOFINO BC & 2334 UTC 3-27 & $.41 \mathrm{FT}$ \\
\hline NEAH BAY WA & 2234 UTC 3-27 & $2.02 \mathrm{FT}$ \\
\hline LAPUSH WA & 2241 UTC 3-27 & $3.15 \mathrm{FT}$ \\
\hline WESTPORT WA & 2302 UTC 3-27 & $2.11 \mathrm{FT}$ \\
\hline PORT ANGELES WA & 2354 UTC 3-27 & $1.38 \mathrm{FT}$ \\
\hline GARIBALDI OR & 2259 UTC 3-27 & $1.05 \mathrm{FT}$ \\
\hline NEWPORT OR & 2309 UTC 3-27 & $2.46 \mathrm{FT}$ \\
\hline CHARLESTON OR & 2333 UTC 3-27 & $2.74 \mathrm{FT}$ \\
\hline ORFORD OR & 2355 UTC 3-27 & $6.76 \mathrm{FT}$ \\
\hline CRESCENT CITY CA & 0100 UTC 3-28 & $7.11 \mathrm{FT}$ \\
\hline ARENA COVE CA & 2313 UTC 3-27 & $5.58 \mathrm{FT}$ \\
\hline EUREKA CA & 0006 UTC 3-28 & $4.23 \mathrm{FT}$ \\
\hline POINT REYES CA & 0142 UTC 3-28 & $3.38 \mathrm{FT}$ \\
\hline RANCISCO & 0155 UTC 3-28 & $3.71 \mathrm{FT}$ \\
\hline ALAMEDA CA & 0141 UTC 3-28 & $1.84 \mathrm{FT}$ \\
\hline MONTEREY CA & 2338 UTC 3-27 & $3.97 \mathrm{FT}$ \\
\hline PORT SAN LUIS CA & 0108 UTC 3-28 & $14.30 \mathrm{FT}$ \\
\hline SANTA BARBARA CA & 0145 UTC 3-28 & $2.64 \mathrm{FT}$ \\
\hline SANTA MONICA CA & 0157 UTC 3-28 & $3.38 \mathrm{FT}$ \\
\hline SAN PEDRO CA & 0230 UTC 3-28 & $3.11 \mathrm{FT}$ \\
\hline LA JOLLA CA & 0222 UTC 3-28 & $3.5 \mathrm{FT}$ \\
\hline SAN DIEGO CA & 0214 UTC 3-28 & $1.74 \mathrm{FT}$ \\
\hline MIDWAY IS & 2304 UTC 3-27 & $1.44 \mathrm{FT}$ \\
\hline NAWILIWILI HI & 2323 UTC 3-27 & $2.20 \mathrm{FT}$ \\
\hline HALEIWA HI & 2338 UTC 3-27 & $4.99 \mathrm{FT}$ \\
\hline HONOLULU HI & 2338 UTC 3-27 & $2.23 \mathrm{FT}$ \\
\hline KAHULUI HI & 2341 UTC 3-27 & $7.15 \mathrm{FT}$ \\
\hline KAWAIHAE HI & 0014 UTC 3-28 & $2.89 \mathrm{FT}$ \\
\hline WAKE ISLAND & 0052 UTC 3-28 & $0.33 \mathrm{FT}$ \\
\hline
\end{tabular}



GUAM
0321 UTC 3-28
PAGO PAGO AM SAMOA
0433 UTC 3-28
0.46 FT

HEIGHT - OBSERVED MAX TSUNAMI HEIGHT IS THE WATER LEVEL ABOVE THE TIDE LEVEL AT THE TIME OF MEASUREMENT.

PRELIMINARY EARTHQUAKE PARAMETERS
* MAGNITUDE 9.0
* ORIGIN TIME 1050 AKDT MAR 272014
1150 PDT MAR 272014
1850 UTC MAR 272014
* COORDINATES 55.2 NORTH 156.7 WEST
* DEPTH 11 MILES
* LOCATION 100 MILES SE OF CHIGNIK ALASKA 485 MILES SW OF ANCHORAGE ALASKA

NEXT UPDATE AND ADDITIONAL INFORMATION

* THIS MESSAGE WILL BE UPDATED IN 60 MINUTES.

* REFER TO THE INTERNET SITE WCATWC.ARH.NOAA.GOV FOR MORE INFORMATION.

* PACIFIC COASTAL RESIDENTS OUTSIDE CALIFORNIA... OREGON... WASHINGTON... BRITISH COLUMBIA AND ALASKA SHOULD REFER TO THE PACIFIC TSUNAMI WARNING CENTER MESSAGES FOR INFORMATION ON THIS EVENT AT PTWC.WEATHER.GOV. 
WEAK51 PAAQ 281200

TSUAK1

BULLETIN

PUBLIC TSUNAMI MESSAGE NUMBER 19

NWS WEST COAST/ALASKA TSUNAMI WARNING CENTER PALMER AK 400 AM AKDT FRI MAR 282014

THIS MESSAGE CONTINUES THE WARNING AND ADVISORY AS IN THE PREVIOUS MESSAGE.

...THE TSUNAMI WARNING REMAINS IN EFFECT...

...THE TSUNAMI ADVISORY REMAINS IN EFFECT...

WARNINGS/ADVISORIES/WATCHES

TSUNAMI WARNING IN EFFECT FOR...

* THE COASTAL AREAS OF CALIFORNIA - OREGON - WASHINGTON BRITISH COLUMBIA AND ALASKA FROM THE CALIFORNIA-MEXICO BORDER TO NIKOLSKI ALASKA

TSUNAMI ADVISORY IN EFFECT FOR...

* THE COASTAL AREAS OF ALASKA FROM NIKOLSKI ALASKA TO ATTU ALASKA

IMPACTS FOR TSUNAMI WARNING AREAS 
* WIDESPREAD DANGEROUS COASTAL FLOODING ACCOMPANIED BY POWERFUL CURRENTS IS POSSIBLE AND MAY CONTINUE FOR MANY HOURS AFTER TSUNAMI ARRIVAL.

* THE FIRST WAVE MAY NOT BE THE LARGEST.

IMPACTS FOR TSUNAMI ADVISORY AREAS

* A TSUNAMI CAPABLE OF PRODUCING STRONG CURRENTS OR WAVES DANGEROUS

TO PERSONS IN OR VERY NEAR THE WATER IS EXPECTED.

* CURRENTS MAY BE HAZARDOUS TO SWIMMERS... BOATS... AND COASTAL STRUCTURES AND MAY CONTINUE FOR MANY HOURS AFTER THE TSUNAMI ARRIVAL.

* THE FIRST WAVE MAY NOT BE THE LARGEST.

RECOMMENDED ACTIONS

* IF YOU ARE IN A WARNING AREA - MOVE INLAND TO HIGHER GROUND.

* IF YOU ARE IN AN ADVISORY AREA - MOVE OFF THE BEACH AND OUT OF HARBORS AND MARINAS. WIDESPREAD INUNDATION OF LAND IS NOT EXPECTED FOR ADVISORY AREAS.

* BE ALERT TO INSTRUCTIONS FROM YOUR LOCAL EMERGENCY OFFICIALS.

* DO NOT GO TO THE COAST TO OBSERVE THE TSUNAMI.

* DO NOT RETURN TO THE COAST UNTIL LOCAL EMERGENCY OFFICIALS INDICATE IT IS SAFE TO DO SO.

SIGNIFICANT TSUNAMI ACTIVITY IS EXPECTED TO CONTINUE FOR UP TO 48 HOURS AFTER THE WAVES INITIAL ARRIVAL ALONG SOUTHERN ALASKA COASTS

EAST OF NIKOLSKI AND ALONG THE US AND CANADIAN WEST COAST.

ADDITIONAL OBSERVATIONS OF TSUNAMI ACTIVITY - UPDATED

$\begin{array}{ll} & \text { TIME } \\ \text { SITE } & \text { OF MEASUREMENT TSUNAMI HEIGHT }\end{array}$




\begin{tabular}{|c|c|c|}
\hline \\
\hline SAND POINT AK & 1945 UTC 3-27 & $11.60 \mathrm{FT}$ \\
\hline KING COVE AK & 2023 UTC 3-27 & $4.33 \mathrm{FT}$ \\
\hline CHIGNIK AK & 2026 UTC 3-27 & $21.82 \mathrm{FT}$ \\
\hline NIKOLSKI AK & 2054 UTC 3-27 & $1.61 \mathrm{FT}$ \\
\hline UNALASKA AK & 2056 UTC 3-27 & $1.44 \mathrm{FT}$ \\
\hline KODIAK AK & 2100 UTC 3-27 & $4.50 \mathrm{FT}$ \\
\hline SEWARD AK & 2110 UTC 3-27 & 4.11 FT \\
\hline ADAK AK & 2145 UTC 3-27 & $.03 \mathrm{FT}$ \\
\hline ELFIN COVE AK & 2133 UTC 3-27 & $1.32 \mathrm{FT}$ \\
\hline YAKUTAT AK & 2132 UTC 3-27 & $2.44 \mathrm{FT}$ \\
\hline PORT ALEXANDER AK & 2114 UTC 3-2 & $1.41 \mathrm{~F}$ \\
\hline CORDOVA AK & 2235 UTC 3-27 & $1.82 \mathrm{FT}$ \\
\hline SHEMYA AK & 2245 UTC 3-27 & $0.34 \mathrm{FT}$ \\
\hline SITKA AK & 2222 UTC 3-27 & $74 \mathrm{FT}$ \\
\hline CRAIG AK & 2255 UTC 3-27 & $.88 \mathrm{FT}$ \\
\hline LANGARA BC & 2300 UTC 3-27 & $1.60 \mathrm{FT}$ \\
\hline TOFINO BC & 2334 UTC 3-27 & $.41 \mathrm{FT}$ \\
\hline NEAH BAY WA & 2234 UTC 3-27 & $2.02 \mathrm{FT}$ \\
\hline LAPUSH WA & 2241 UTC 3-27 & $3.15 \mathrm{FT}$ \\
\hline WESTPORT WA & 2302 UTC 3-27 & $2.11 \mathrm{FT}$ \\
\hline PORT ANGELES WA & 2354 UTC 3-27 & $1.38 \mathrm{FT}$ \\
\hline GARIBALDI OR & 2259 UTC 3-27 & $1.05 \mathrm{FT}$ \\
\hline NEWPORT OR & 2309 UTC 3-27 & $2.46 \mathrm{FT}$ \\
\hline CHARLESTON OR & 2333 UTC 3-27 & $2.74 \mathrm{FT}$ \\
\hline ORFORD OR & 2355 UTC 3-27 & $6.76 \mathrm{FT}$ \\
\hline CRESCENT CITY CA & 0100 UTC 3-28 & $7.11 \mathrm{FT}$ \\
\hline ARENA COVE CA & 2313 UTC 3-27 & $5.58 \mathrm{FT}$ \\
\hline EUREKA CA & 0006 UTC 3-28 & $4.23 \mathrm{FT}$ \\
\hline POINT REYES CA & 0142 UTC 3-28 & $3.38 \mathrm{FT}$ \\
\hline RANCISCO & 0155 UTC 3-28 & $3.71 \mathrm{FT}$ \\
\hline ALAMEDA CA & 0141 UTC 3-28 & $1.84 \mathrm{FT}$ \\
\hline MONTEREY CA & 2338 UTC 3-27 & $3.97 \mathrm{FT}$ \\
\hline PORT SAN LUIS CA & 0108 UTC 3-28 & $14.30 \mathrm{FT}$ \\
\hline SANTA BARBARA CA & 0145 UTC 3-28 & $2.64 \mathrm{FT}$ \\
\hline SANTA MONICA CA & 0157 UTC 3-28 & $3.38 \mathrm{FT}$ \\
\hline SAN PEDRO CA & 0230 UTC 3-28 & $3.11 \mathrm{FT}$ \\
\hline LA JOLLA CA & 0222 UTC 3-28 & $3.5 \mathrm{FT}$ \\
\hline SAN DIEGO CA & 0214 UTC 3-28 & $1.74 \mathrm{FT}$ \\
\hline MIDWAY IS & 2304 UTC 3-27 & $1.44 \mathrm{FT}$ \\
\hline NAWILIWILI HI & 2323 UTC 3-27 & $2.20 \mathrm{FT}$ \\
\hline HALEIWA HI & 2338 UTC 3-27 & $4.99 \mathrm{FT}$ \\
\hline HONOLULU HI & 2338 UTC 3-27 & $2.23 \mathrm{FT}$ \\
\hline KAHULUI HI & 2341 UTC 3-27 & $7.15 \mathrm{FT}$ \\
\hline KAWAIHAE HI & 0014 UTC 3-28 & $2.89 \mathrm{FT}$ \\
\hline WAKE ISLAND & 0052 UTC 3-28 & $0.33 \mathrm{FT}$ \\
\hline
\end{tabular}



GUAM
0321 UTC 3-28
PAGO PAGO AM SAMOA
0433 UTC 3-28
0.46 FT

HEIGHT - OBSERVED MAX TSUNAMI HEIGHT IS THE WATER LEVEL ABOVE THE TIDE LEVEL AT THE TIME OF MEASUREMENT.

PRELIMINARY EARTHQUAKE PARAMETERS
* MAGNITUDE 9.0
* ORIGIN TIME 1050 AKDT MAR 272014
1150 PDT MAR 272014
1850 UTC MAR 272014
* COORDINATES 55.2 NORTH 156.7 WEST
* DEPTH 11 MILES
* LOCATION 100 MILES SE OF CHIGNIK ALASKA 485 MILES SW OF ANCHORAGE ALASKA

NEXT UPDATE AND ADDITIONAL INFORMATION

* THIS MESSAGE WILL BE UPDATED IN 60 MINUTES.

* REFER TO THE INTERNET SITE WCATWC.ARH.NOAA.GOV FOR MORE INFORMATION.

* PACIFIC COASTAL RESIDENTS OUTSIDE CALIFORNIA... OREGON... WASHINGTON... BRITISH COLUMBIA AND ALASKA SHOULD REFER TO THE PACIFIC TSUNAMI WARNING CENTER MESSAGES FOR INFORMATION ON THIS EVENT AT PTWC.WEATHER.GOV. 
WEAK51 PAAQ 281300

TSUAK1

BULLETIN

PUBLIC TSUNAMI MESSAGE NUMBER 20

NWS WEST COAST/ALASKA TSUNAMI WARNING CENTER PALMER AK 500 AM AKDT FRI MAR 282014

THIS MESSAGE CONTINUES THE WARNING AND ADVISORY AS IN THE PREVIOUS MESSAGE.

...THE TSUNAMI WARNING REMAINS IN EFFECT...

...THE TSUNAMI ADVISORY REMAINS IN EFFECT...

WARNINGS/ADVISORIES/WATCHES

TSUNAMI WARNING IN EFFECT FOR...

* THE COASTAL AREAS OF CALIFORNIA - OREGON - WASHINGTON BRITISH COLUMBIA AND ALASKA FROM THE CALIFORNIA-MEXICO BORDER TO NIKOLSKI ALASKA

TSUNAMI ADVISORY IN EFFECT FOR...

* THE COASTAL AREAS OF ALASKA FROM NIKOLSKI ALASKA TO ATTU ALASKA

IMPACTS FOR TSUNAMI WARNING AREAS 
* WIDESPREAD DANGEROUS COASTAL FLOODING ACCOMPANIED BY POWERFUL CURRENTS IS POSSIBLE AND MAY CONTINUE FOR MANY HOURS AFTER TSUNAMI ARRIVAL.

* THE FIRST WAVE MAY NOT BE THE LARGEST.

IMPACTS FOR TSUNAMI ADVISORY AREAS

* A TSUNAMI CAPABLE OF PRODUCING STRONG CURRENTS OR WAVES DANGEROUS

TO PERSONS IN OR VERY NEAR THE WATER IS EXPECTED.

* CURRENTS MAY BE HAZARDOUS TO SWIMMERS... BOATS... AND COASTAL STRUCTURES AND MAY CONTINUE FOR MANY HOURS AFTER THE TSUNAMI ARRIVAL.

* THE FIRST WAVE MAY NOT BE THE LARGEST.

RECOMMENDED ACTIONS

* IF YOU ARE IN A WARNING AREA - MOVE INLAND TO HIGHER GROUND.

* IF YOU ARE IN AN ADVISORY AREA - MOVE OFF THE BEACH AND OUT OF HARBORS AND MARINAS. WIDESPREAD INUNDATION OF LAND IS NOT EXPECTED FOR ADVISORY AREAS.

* BE ALERT TO INSTRUCTIONS FROM YOUR LOCAL EMERGENCY OFFICIALS.

* DO NOT GO TO THE COAST TO OBSERVE THE TSUNAMI.

* DO NOT RETURN TO THE COAST UNTIL LOCAL EMERGENCY OFFICIALS INDICATE IT IS SAFE TO DO SO.

SIGNIFICANT TSUNAMI ACTIVITY IS EXPECTED TO CONTINUE FOR UP TO 48 HOURS AFTER THE WAVES INITIAL ARRIVAL ALONG SOUTHERN ALASKA COASTS

EAST OF NIKOLSKI AND ALONG THE US AND CANADIAN WEST COAST.

ADDITIONAL OBSERVATIONS OF TSUNAMI ACTIVITY - UPDATED

$\begin{array}{ll} & \text { TIME } \\ \text { SITE } & \text { OF MEASUREMENT TSUNAMI HEIGHT }\end{array}$




\begin{tabular}{|c|c|c|}
\hline \\
\hline SAND POINT AK & 1945 UTC 3-27 & $11.60 \mathrm{FT}$ \\
\hline KING COVE AK & 2023 UTC 3-27 & $4.33 \mathrm{FT}$ \\
\hline CHIGNIK AK & 2026 UTC 3-27 & $21.82 \mathrm{FT}$ \\
\hline NIKOLSKI AK & 2054 UTC 3-27 & $1.61 \mathrm{FT}$ \\
\hline UNALASKA AK & 2056 UTC 3-27 & $1.44 \mathrm{FT}$ \\
\hline KODIAK AK & 2100 UTC 3-27 & $4.50 \mathrm{FT}$ \\
\hline SEWARD AK & 2110 UTC 3-27 & 4.11 FT \\
\hline ADAK AK & 2145 UTC 3-27 & $.03 \mathrm{FT}$ \\
\hline ELFIN COVE AK & 2133 UTC 3-27 & $1.32 \mathrm{FT}$ \\
\hline YAKUTAT AK & 2132 UTC 3-27 & $2.44 \mathrm{FT}$ \\
\hline PORT ALEXANDER AK & 2114 UTC 3-2 & $1.41 \mathrm{~F}$ \\
\hline CORDOVA AK & 2235 UTC 3-27 & $1.82 \mathrm{FT}$ \\
\hline SHEMYA AK & 2245 UTC 3-27 & $0.34 \mathrm{FT}$ \\
\hline SITKA AK & 2222 UTC 3-27 & $74 \mathrm{FT}$ \\
\hline CRAIG AK & 2255 UTC 3-27 & $.88 \mathrm{FT}$ \\
\hline LANGARA BC & 2300 UTC 3-27 & $1.60 \mathrm{FT}$ \\
\hline TOFINO BC & 2334 UTC 3-27 & $.41 \mathrm{FT}$ \\
\hline NEAH BAY WA & 2234 UTC 3-27 & $2.02 \mathrm{FT}$ \\
\hline LAPUSH WA & 2241 UTC 3-27 & $3.15 \mathrm{FT}$ \\
\hline WESTPORT WA & 2302 UTC 3-27 & $2.11 \mathrm{FT}$ \\
\hline PORT ANGELES WA & 2354 UTC 3-27 & $1.38 \mathrm{FT}$ \\
\hline GARIBALDI OR & 2259 UTC 3-27 & $1.05 \mathrm{FT}$ \\
\hline NEWPORT OR & 2309 UTC 3-27 & $2.46 \mathrm{FT}$ \\
\hline CHARLESTON OR & 2333 UTC 3-27 & $2.74 \mathrm{FT}$ \\
\hline ORFORD OR & 2355 UTC 3-27 & $6.76 \mathrm{FT}$ \\
\hline CRESCENT CITY CA & 0100 UTC 3-28 & $7.11 \mathrm{FT}$ \\
\hline ARENA COVE CA & 2313 UTC 3-27 & $5.58 \mathrm{FT}$ \\
\hline EUREKA CA & 0006 UTC 3-28 & $4.23 \mathrm{FT}$ \\
\hline POINT REYES CA & 0142 UTC 3-28 & $3.38 \mathrm{FT}$ \\
\hline RANCISCO & 0155 UTC 3-28 & $3.71 \mathrm{FT}$ \\
\hline ALAMEDA CA & 0141 UTC 3-28 & $1.84 \mathrm{FT}$ \\
\hline MONTEREY CA & 2338 UTC 3-27 & $3.97 \mathrm{FT}$ \\
\hline PORT SAN LUIS CA & 0108 UTC 3-28 & $14.30 \mathrm{FT}$ \\
\hline SANTA BARBARA CA & 0145 UTC 3-28 & $2.64 \mathrm{FT}$ \\
\hline SANTA MONICA CA & 0157 UTC 3-28 & $3.38 \mathrm{FT}$ \\
\hline SAN PEDRO CA & 0230 UTC 3-28 & $3.11 \mathrm{FT}$ \\
\hline LA JOLLA CA & 0222 UTC 3-28 & $3.5 \mathrm{FT}$ \\
\hline SAN DIEGO CA & 0214 UTC 3-28 & $1.74 \mathrm{FT}$ \\
\hline MIDWAY IS & 2304 UTC 3-27 & $1.44 \mathrm{FT}$ \\
\hline NAWILIWILI HI & 2323 UTC 3-27 & $2.20 \mathrm{FT}$ \\
\hline HALEIWA HI & 2338 UTC 3-27 & $4.99 \mathrm{FT}$ \\
\hline HONOLULU HI & 2338 UTC 3-27 & $2.23 \mathrm{FT}$ \\
\hline KAHULUI HI & 2341 UTC 3-27 & $7.15 \mathrm{FT}$ \\
\hline KAWAIHAE HI & 0014 UTC 3-28 & $2.89 \mathrm{FT}$ \\
\hline WAKE ISLAND & 0052 UTC 3-28 & $0.33 \mathrm{FT}$ \\
\hline
\end{tabular}



GUAM
0321 UTC 3-28
PAGO PAGO AM SAMOA
0433 UTC 3-28
0.46 FT

HEIGHT - OBSERVED MAX TSUNAMI HEIGHT IS THE WATER LEVEL ABOVE THE TIDE LEVEL AT THE TIME OF MEASUREMENT.

PRELIMINARY EARTHQUAKE PARAMETERS

* MAGNITUDE 9.0

* ORIGIN TIME 1050 AKDT MAR 272014

1150 PDT MAR 272014

1850 UTC MAR 272014

* COORDINATES 55.2 NORTH 156.7 WEST

* DEPTH 11 MILES

* LOCATION 100 MILES SE OF CHIGNIK ALASKA 485 MILES SW OF ANCHORAGE ALASKA

NEXT UPDATE AND ADDITIONAL INFORMATION

* THIS MESSAGE WILL BE UPDATED IN 60 MINUTES.

* REFER TO THE INTERNET SITE WCATWC.ARH.NOAA.GOV FOR MORE INFORMATION.

* PACIFIC COASTAL RESIDENTS OUTSIDE CALIFORNIA... OREGON... WASHINGTON... BRITISH COLUMBIA AND ALASKA SHOULD REFER TO THE PACIFIC TSUNAMI WARNING CENTER MESSAGES FOR INFORMATION ON THIS EVENT AT PTWC.WEATHER.GOV. 
WEAK51 PAAQ 281401

TSUAK1

\section{BULLETIN}

PUBLIC TSUNAMI MESSAGE NUMBER 21

NWS WEST COAST/ALASKA TSUNAMI WARNING CENTER PALMER AK 601 AM AKDT FRI MAR 282014

THIS MESSAGE CONTINUES THE WARNING AND ADVISORY AS IN THE PREVIOUS MESSAGE.

...THE TSUNAMI WARNING REMAINS IN EFFECT...

...THE TSUNAMI ADVISORY REMAINS IN EFFECT...

WARNINGS/ADVISORIES/WATCHES

TSUNAMI WARNING IN EFFECT FOR...

* THE COASTAL AREAS OF CALIFORNIA - OREGON - WASHINGTON BRITISH COLUMBIA AND ALASKA FROM THE CALIFORNIA-MEXICO BORDER TO NIKOLSKI ALASKA

TSUNAMI ADVISORY IN EFFECT FOR...

* THE COASTAL AREAS OF ALASKA FROM NIKOLSKI ALASKA TO ATTU ALASKA

IMPACTS FOR TSUNAMI WARNING AREAS 
* WIDESPREAD DANGEROUS COASTAL FLOODING ACCOMPANIED BY POWERFUL CURRENTS IS POSSIBLE AND MAY CONTINUE FOR MANY HOURS AFTER TSUNAMI ARRIVAL.

* THE FIRST WAVE MAY NOT BE THE LARGEST.

IMPACTS FOR TSUNAMI ADVISORY AREAS

* A TSUNAMI CAPABLE OF PRODUCING STRONG CURRENTS OR WAVES DANGEROUS

TO PERSONS IN OR VERY NEAR THE WATER IS EXPECTED.

* CURRENTS MAY BE HAZARDOUS TO SWIMMERS... BOATS... AND COASTAL STRUCTURES AND MAY CONTINUE FOR MANY HOURS AFTER THE TSUNAMI ARRIVAL.

* THE FIRST WAVE MAY NOT BE THE LARGEST.

RECOMMENDED ACTIONS

* IF YOU ARE IN A WARNING AREA - MOVE INLAND TO HIGHER GROUND.

* IF YOU ARE IN AN ADVISORY AREA - MOVE OFF THE BEACH AND OUT OF HARBORS AND MARINAS. WIDESPREAD INUNDATION OF LAND IS NOT EXPECTED FOR ADVISORY AREAS.

* BE ALERT TO INSTRUCTIONS FROM YOUR LOCAL EMERGENCY OFFICIALS.

* DO NOT GO TO THE COAST TO OBSERVE THE TSUNAMI.

* DO NOT RETURN TO THE COAST UNTIL LOCAL EMERGENCY OFFICIALS INDICATE IT IS SAFE TO DO SO.

SIGNIFICANT TSUNAMI ACTIVITY IS EXPECTED TO CONTINUE FOR UP TO 48 HOURS AFTER THE WAVES INITIAL ARRIVAL ALONG SOUTHERN ALASKA COASTS

EAST OF NIKOLSKI AND ALONG THE US AND CANADIAN WEST COAST.

ADDITIONAL OBSERVATIONS OF TSUNAMI ACTIVITY - UPDATED

$\begin{array}{ll} & \text { TIME } \\ \text { SITE } & \text { OF MEASUREMENT TSUNAMI HEIGHT }\end{array}$




\begin{tabular}{|c|c|c|}
\hline SAND POINT AK & 1945 UTC 3-27 & $11.60 \mathrm{FT}$ \\
\hline KING COVE AK & 2023 UTC 3-27 & $4.33 \mathrm{FT}$ \\
\hline CHIGNIK AK & 2026 UTC 3-27 & $21.82 \mathrm{FT}$ \\
\hline NIKOLSKI AK & 2054 UTC 3-27 & $1.61 \mathrm{FT}$ \\
\hline UNALASKA AK & 2056 UTC 3-27 & $1.44 \mathrm{FT}$ \\
\hline KODIAK AK & 2100 UTC $3-27$ & $4.50 \mathrm{FT}$ \\
\hline SEWARD AK & 2110 UTC 3-27 & $4.11 \mathrm{FT}$ \\
\hline ADAK AK & 2145 UTC $3-27$ & $.03 \mathrm{FT}$ \\
\hline ELFIN COVE AK & 2133 UTC 3-27 & $1.32 \mathrm{FT}$ \\
\hline YAKUTAT AK & 2132 UTC 3-27 & $2.44 \mathrm{FT}$ \\
\hline PORT ALEXANDER AK & 2114 UTC $3-27$ & $1.41 \mathrm{FT}$ \\
\hline CORDOVA AK & 2235 UTC $3-27$ & $1.82 \mathrm{FT}$ \\
\hline SHEMYA AK & 2245 UTC $3-27$ & $0.34 \mathrm{FT}$ \\
\hline SITKA AK & 2222 UTC $3-27$ & $74 \mathrm{FT}$ \\
\hline CRAIG AK & 2255 UTC $3-27$ & $88 \mathrm{FT}$ \\
\hline LANGARA BC & 2300 UTC $3-27$ & $1.60 \mathrm{FT}$ \\
\hline TOFINO BC & 2334 UTC $3-27$ & $2.41 \mathrm{FT}$ \\
\hline NEAH BAY WA & 2234 UTC 3-27 & 2.02 FT \\
\hline LAPUSH WA & 2241 UTC 3-27 & $3.15 \mathrm{FT}$ \\
\hline WESTPORT WA & 2302 UTC 3-27 & $2.11 \mathrm{FT}$ \\
\hline PORT ANGELES WA & 2354 UTC 3-27 & $1.38 \mathrm{FT}$ \\
\hline GARIBALDI OR & 2259 UTC 3-27 & $1.05 \mathrm{FT}$ \\
\hline NEWPORT OR & 2309 UTC 3-27 & $2.46 \mathrm{FT}$ \\
\hline CHARLESTON OR & 2333 UTC $3-27$ & $2.74 \mathrm{FT}$ \\
\hline PORT ORFORD OR & 2355 UTC 3-27 & $6.76 \mathrm{FT}$ \\
\hline CRESCENT CITY CA & 0100 UTC $3-28$ & $7.11 \mathrm{FT}$ \\
\hline ARENA COVE CA & 2313 UTC $3-27$ & $5.58 \mathrm{FT}$ \\
\hline EUREKA CA & 0006 UTC 3-28 & $4.23 \mathrm{FT}$ \\
\hline POINT REYES CA & 0142 UTC 3-28 & $3.38 \mathrm{FT}$ \\
\hline SAN FRANCISCO & 0155 UTC $3-28$ & $3.71 \mathrm{FT}$ \\
\hline ALAMEDA CA & 0141 UTC 3-28 & $1.84 \mathrm{FT}$ \\
\hline MONTEREY CA & 2338 UTC $3-27$ & $3.97 \mathrm{FT}$ \\
\hline PORT SAN LUIS CA & 0108 UTC $3-28$ & 14.30 FT \\
\hline SANTA BARBARA CA & 0145 UTC $3-28$ & $2.64 \mathrm{FT}$ \\
\hline SANTA MONICA CA & 0157 UTC 3-28 & $3.38 \mathrm{FT}$ \\
\hline SAN PEDRO CA & 0230 UTC $3-28$ & $3.11 \mathrm{FT}$ \\
\hline LA JOLLA CA & 0222 UTC $3-28$ & $3.5 \mathrm{FT}$ \\
\hline SAN DIEGO CA & 0214 UTC 3-28 & $1.74 \mathrm{FT}$ \\
\hline MIDWAY IS & 2304 UTC $3-27$ & $1.44 \mathrm{FT}$ \\
\hline NAWILIWILI HI & 2323 UTC $3-27$ & $2.20 \mathrm{FT}$ \\
\hline HALEIWA HI & 2338 UTC $3-27$ & $4.99 \mathrm{FT}$ \\
\hline HONOLULU HI & 2338 UTC $3-27$ & $2.23 \mathrm{FT}$ \\
\hline KAHULUI HI & 2341 UTC $3-27$ & $7.15 \mathrm{FT}$ \\
\hline KAWAIHAE HI & 0014 UTC 3-28 & $2.89 \mathrm{FT}$ \\
\hline WAKE ISLAND & 0052 UTC $3-28$ & $0.33 \mathrm{FT}$ \\
\hline GUAM & 321 UTC $3-28$ & 0 FT \\
\hline
\end{tabular}


PAGO PAGO AM SAMOA 0433 UTC 3-28 $0.46 \mathrm{FT}$

HEIGHT - OBSERVED MAX TSUNAMI HEIGHT IS THE WATER LEVEL ABOVE THE TIDE LEVEL AT THE TIME OF MEASUREMENT.

PRELIMINARY EARTHQUAKE PARAMETERS

* MAGNITUDE 9.0

* ORIGIN TIME 1050 AKDT MAR 272014

1150 PDT MAR 272014

1850 UTC MAR 272014

* COORDINATES 55.2 NORTH 156.7 WEST

* DEPTH 11 MILES

* LOCATION 100 MILES SE OF CHIGNIK ALASKA 485 MILES SW OF ANCHORAGE ALASKA

NEXT UPDATE AND ADDITIONAL INFORMATION

* THIS MESSAGE WILL BE UPDATED IN 60 MINUTES.

* REFER TO THE INTERNET SITE WCATWC.ARH.NOAA.GOV FOR MORE INFORMATION.

* PACIFIC COASTAL RESIDENTS OUTSIDE CALIFORNIA... OREGON... WASHINGTON... BRITISH COLUMBIA AND ALASKA SHOULD REFER TO THE PACIFIC TSUNAMI WARNING CENTER MESSAGES FOR INFORMATION ON THIS EVENT AT PTWC.WEATHER.GOV.

$\$ \$$ 
WEAK51 PAAQ 281500

TSUAK1

\section{BULLETIN}

PUBLIC TSUNAMI MESSAGE NUMBER 22

NWS WEST COAST/ALASKA TSUNAMI WARNING CENTER PALMER AK 700 AM AKDT FRI MAR 282014

THIS MESSAGE CONTINUES THE WARNING AND ADVISORY AS IN THE PREVIOUS MESSAGE.

...THE TSUNAMI WARNING REMAINS IN EFFECT...

...THE TSUNAMI ADVISORY REMAINS IN EFFECT...

WARNINGS/ADVISORIES/WATCHES

TSUNAMI WARNING IN EFFECT FOR...

* THE COASTAL AREAS OF CALIFORNIA - OREGON - WASHINGTON BRITISH COLUMBIA AND ALASKA FROM THE CALIFORNIA-MEXICO BORDER TO NIKOLSKI ALASKA

TSUNAMI ADVISORY IN EFFECT FOR...

* THE COASTAL AREAS OF ALASKA FROM NIKOLSKI ALASKA TO ATTU ALASKA

IMPACTS FOR TSUNAMI WARNING AREAS 
* WIDESPREAD DANGEROUS COASTAL FLOODING ACCOMPANIED BY POWERFUL CURRENTS IS POSSIBLE AND MAY CONTINUE FOR MANY HOURS AFTER TSUNAMI ARRIVAL.

* THE FIRST WAVE MAY NOT BE THE LARGEST.

IMPACTS FOR TSUNAMI ADVISORY AREAS

* A TSUNAMI CAPABLE OF PRODUCING STRONG CURRENTS OR WAVES DANGEROUS

TO PERSONS IN OR VERY NEAR THE WATER IS EXPECTED.

* CURRENTS MAY BE HAZARDOUS TO SWIMMERS... BOATS... AND COASTAL STRUCTURES AND MAY CONTINUE FOR MANY HOURS AFTER THE TSUNAMI ARRIVAL.

* THE FIRST WAVE MAY NOT BE THE LARGEST.

RECOMMENDED ACTIONS

* IF YOU ARE IN A WARNING AREA - MOVE INLAND TO HIGHER GROUND.

* IF YOU ARE IN AN ADVISORY AREA - MOVE OFF THE BEACH AND OUT OF HARBORS AND MARINAS. WIDESPREAD INUNDATION OF LAND IS NOT EXPECTED FOR ADVISORY AREAS.

* BE ALERT TO INSTRUCTIONS FROM YOUR LOCAL EMERGENCY OFFICIALS.

* DO NOT GO TO THE COAST TO OBSERVE THE TSUNAMI.

* DO NOT RETURN TO THE COAST UNTIL LOCAL EMERGENCY OFFICIALS INDICATE IT IS SAFE TO DO SO.

SIGNIFICANT TSUNAMI ACTIVITY IS EXPECTED TO CONTINUE FOR UP TO 48 HOURS AFTER THE WAVES INITIAL ARRIVAL ALONG SOUTHERN ALASKA COASTS

EAST OF NIKOLSKI AND ALONG THE US AND CANADIAN WEST COAST.

ADDITIONAL OBSERVATIONS OF TSUNAMI ACTIVITY - UPDATED

$\begin{array}{ll} & \text { TIME } \\ \text { SITE } & \text { OF MEASUREMENT TSUNAMI HEIGHT }\end{array}$




\begin{tabular}{|c|c|c|}
\hline AND POINT AK & 1945 UTC 3-27 & $11.60 \mathrm{FT}$ \\
\hline KING COVE AK & 2023 UTC 3-27 & $4.33 \mathrm{FT}$ \\
\hline CHIGNIK AK & 2026 UTC 3-27 & $21.82 \mathrm{FT}$ \\
\hline NIKOLSKI AK & 2054 UTC $3-27$ & $1.61 \mathrm{FT}$ \\
\hline UNALASKA AK & 2056 UTC 3-27 & $1.44 \mathrm{FT}$ \\
\hline KODIAK AK & 2100 UTC $3-27$ & 4.50 FT \\
\hline SEWARD AK & 2110 UTC $3-27$ & $4.11 \mathrm{FT}$ \\
\hline ADAK AK & 2145 UTC $3-27$ & $.03 \mathrm{FT}$ \\
\hline ELFIN COVE AK & 2133 UTC $3-27$ & $1.32 \mathrm{FT}$ \\
\hline YAKUTAT AK & 2132 UTC 3-27 & $2.44 \mathrm{FT}$ \\
\hline PORT ALEXANDER AK & 2114 UTC $3-27$ & $1.41 \mathrm{FT}$ \\
\hline CORDOVA AK & 2235 UTC $3-27$ & $1.82 \mathrm{FT}$ \\
\hline SHEMYA AK & 2245 UTC $3-27$ & $0.34 \mathrm{FT}$ \\
\hline SITKA AK & 2222 UTC $3-27$ & $74 \mathrm{FT}$ \\
\hline CRAIG AK & 2255 UTC $3-27$ & $.88 \mathrm{FT}$ \\
\hline LANGARA BC & 2300 UTC $3-27$ & $1.60 \mathrm{FT}$ \\
\hline TOFINO BC & 2334 UTC $3-27$ & $2.41 \mathrm{FT}$ \\
\hline NEAH BAY WA & 2234 UTC $3-27$ & $2.02 \mathrm{FT}$ \\
\hline LAPUSH WA & 2241 UTC 3-27 & $3.15 \mathrm{FT}$ \\
\hline WESTPORT WA & 2302 UTC $3-27$ & $2.11 \mathrm{FT}$ \\
\hline PORT ANGELES WA & 2354 UTC $3-27$ & $1.38 \mathrm{FT}$ \\
\hline GARIBALDI OR & 2259 UTC 3-27 & $1.05 \mathrm{FT}$ \\
\hline NEWPORT OR & 2309 UTC 3-27 & $2.46 \mathrm{FT}$ \\
\hline CHARLESTON OR & 2333 UTC $3-27$ & $2.74 \mathrm{FT}$ \\
\hline PORT ORFORD OR & 2355 UTC $3-27$ & $6.76 \mathrm{FT}$ \\
\hline CRESCENT CITY CA & 0100 UTC $3-28$ & $7.11 \mathrm{FT}$ \\
\hline ARENA COVE CA & 2313 UTC $3-27$ & $5.58 \mathrm{FT}$ \\
\hline EUREKA CA & 0006 UTC 3-28 & $4.23 \mathrm{FT}$ \\
\hline POINT REYES CA & 0142 UTC 3-28 & $3.38 \mathrm{FT}$ \\
\hline SAN FRANCISCO & 0155 UTC $3-28$ & $3.71 \mathrm{FT}$ \\
\hline ALAMEDA CA & 0141 UTC 3-28 & $1.84 \mathrm{FT}$ \\
\hline MONTEREY CA & 2338 UTC $3-27$ & $3.97 \mathrm{FT}$ \\
\hline PORT SAN LUIS CA & 0108 UTC $3-28$ & 14.30 FT \\
\hline SANTA BARBARA CA & 0145 UTC $3-28$ & $2.64 \mathrm{FT}$ \\
\hline SANTA MONICA CA & 0157 UTC 3-28 & $3.38 \mathrm{FT}$ \\
\hline SAN PEDRO CA & 0230 UTC $3-28$ & $3.11 \mathrm{FT}$ \\
\hline LA JOLLA CA & 0222 UTC 3-28 & $3.5 \mathrm{FT}$ \\
\hline SAN DIEGO CA & 0214 UTC 3-28 & $1.74 \mathrm{FT}$ \\
\hline MIDWAY IS & 2304 UTC $3-27$ & $1.44 \mathrm{FT}$ \\
\hline NAWILIWILI HI & 2323 UTC $3-27$ & $2.20 \mathrm{FT}$ \\
\hline HALEIWA HI & 2338 UTC $3-27$ & $4.99 \mathrm{FT}$ \\
\hline HONOLULU HI & 2338 UTC $3-27$ & $2.23 \mathrm{FT}$ \\
\hline KAHULUI HI & 2341 UTC $3-27$ & $7.15 \mathrm{FT}$ \\
\hline KAWAIHAE HI & 0014 UTC 3-28 & $2.89 \mathrm{FT}$ \\
\hline WAKE ISLAND & 0052 UTC $3-28$ & $0.33 \mathrm{FT}$ \\
\hline GUAM & 321 UTC $3-28$ & $0 \mathrm{FT}$ \\
\hline
\end{tabular}


PAGO PAGO AM SAMOA 0433 UTC 3-28 $0.46 \mathrm{FT}$

HEIGHT - OBSERVED MAX TSUNAMI HEIGHT IS THE WATER LEVEL ABOVE THE TIDE LEVEL AT THE TIME OF MEASUREMENT.

PRELIMINARY EARTHQUAKE PARAMETERS

* MAGNITUDE 9.0

* ORIGIN TIME 1050 AKDT MAR 272014

1150 PDT MAR 272014

1850 UTC MAR 272014

* COORDINATES 55.2 NORTH 156.7 WEST

* DEPTH 11 MILES

* LOCATION 100 MILES SE OF CHIGNIK ALASKA 485 MILES SW OF ANCHORAGE ALASKA

NEXT UPDATE AND ADDITIONAL INFORMATION

* THIS MESSAGE WILL BE UPDATED IN 60 MINUTES.

* REFER TO THE INTERNET SITE WCATWC.ARH.NOAA.GOV FOR MORE INFORMATION.

* PACIFIC COASTAL RESIDENTS OUTSIDE CALIFORNIA... OREGON... WASHINGTON... BRITISH COLUMBIA AND ALASKA SHOULD REFER TO THE PACIFIC TSUNAMI WARNING CENTER MESSAGES FOR INFORMATION ON THIS EVENT AT PTWC.WEATHER.GOV.

$\$ \$$ 
WEAK51 PAAQ 281601

TSUAK1

\section{BULLETIN}

PUBLIC TSUNAMI MESSAGE NUMBER 23

NWS WEST COAST/ALASKA TSUNAMI WARNING CENTER PALMER AK 801 AM AKDT FRI MAR 282014

THIS MESSAGE CONTINUES THE WARNING AND ADVISORY AS IN THE PREVIOUS MESSAGE.

...THE TSUNAMI WARNING REMAINS IN EFFECT...

...THE TSUNAMI ADVISORY REMAINS IN EFFECT...

WARNINGS/ADVISORIES/WATCHES

TSUNAMI WARNING IN EFFECT FOR...

* THE COASTAL AREAS OF CALIFORNIA - OREGON - WASHINGTON BRITISH COLUMBIA AND ALASKA FROM THE CALIFORNIA-MEXICO BORDER TO NIKOLSKI ALASKA

TSUNAMI ADVISORY IN EFFECT FOR...

* THE COASTAL AREAS OF ALASKA FROM NIKOLSKI ALASKA TO ATTU ALASKA

IMPACTS FOR TSUNAMI WARNING AREAS 
* WIDESPREAD DANGEROUS COASTAL FLOODING ACCOMPANIED BY POWERFUL CURRENTS IS POSSIBLE AND MAY CONTINUE FOR MANY HOURS AFTER TSUNAMI ARRIVAL.

* THE FIRST WAVE MAY NOT BE THE LARGEST.

IMPACTS FOR TSUNAMI ADVISORY AREAS

* A TSUNAMI CAPABLE OF PRODUCING STRONG CURRENTS OR WAVES DANGEROUS

TO PERSONS IN OR VERY NEAR THE WATER IS EXPECTED.

* CURRENTS MAY BE HAZARDOUS TO SWIMMERS... BOATS... AND COASTAL STRUCTURES AND MAY CONTINUE FOR MANY HOURS AFTER THE TSUNAMI ARRIVAL.

* THE FIRST WAVE MAY NOT BE THE LARGEST.

RECOMMENDED ACTIONS

* IF YOU ARE IN A WARNING AREA - MOVE INLAND TO HIGHER GROUND.

* IF YOU ARE IN AN ADVISORY AREA - MOVE OFF THE BEACH AND OUT OF HARBORS AND MARINAS. WIDESPREAD INUNDATION OF LAND IS NOT EXPECTED FOR ADVISORY AREAS.

* BE ALERT TO INSTRUCTIONS FROM YOUR LOCAL EMERGENCY OFFICIALS.

* DO NOT GO TO THE COAST TO OBSERVE THE TSUNAMI.

* DO NOT RETURN TO THE COAST UNTIL LOCAL EMERGENCY OFFICIALS INDICATE IT IS SAFE TO DO SO.

SIGNIFICANT TSUNAMI ACTIVITY IS EXPECTED TO CONTINUE FOR UP TO 48 HOURS AFTER THE WAVES INITIAL ARRIVAL ALONG SOUTHERN ALASKA COASTS

EAST OF NIKOLSKI AND ALONG THE US AND CANADIAN WEST COAST.

ADDITIONAL OBSERVATIONS OF TSUNAMI ACTIVITY - UPDATED

$\begin{array}{ll} & \text { TIME } \\ \text { SITE } & \text { OF MEASUREMENT TSUNAMI HEIGHT }\end{array}$




\begin{tabular}{|c|c|c|}
\hline AND POINT AK & 1945 UTC 3-27 & $11.60 \mathrm{FT}$ \\
\hline KING COVE AK & 2023 UTC 3-27 & $4.33 \mathrm{FT}$ \\
\hline CHIGNIK AK & 2026 UTC 3-27 & $21.82 \mathrm{FT}$ \\
\hline NIKOLSKI AK & 2054 UTC $3-27$ & $1.61 \mathrm{FT}$ \\
\hline UNALASKA AK & 2056 UTC 3-27 & $1.44 \mathrm{FT}$ \\
\hline KODIAK AK & 2100 UTC $3-27$ & 4.50 FT \\
\hline SEWARD AK & 2110 UTC $3-27$ & $4.11 \mathrm{FT}$ \\
\hline ADAK AK & 2145 UTC $3-27$ & $.03 \mathrm{FT}$ \\
\hline ELFIN COVE AK & 2133 UTC $3-27$ & $1.32 \mathrm{FT}$ \\
\hline YAKUTAT AK & 2132 UTC 3-27 & $2.44 \mathrm{FT}$ \\
\hline PORT ALEXANDER AK & 2114 UTC $3-27$ & $1.41 \mathrm{FT}$ \\
\hline CORDOVA AK & 2235 UTC $3-27$ & $1.82 \mathrm{FT}$ \\
\hline SHEMYA AK & 2245 UTC $3-27$ & $0.34 \mathrm{FT}$ \\
\hline SITKA AK & 2222 UTC $3-27$ & $74 \mathrm{FT}$ \\
\hline CRAIG AK & 2255 UTC $3-27$ & $.88 \mathrm{FT}$ \\
\hline LANGARA BC & 2300 UTC $3-27$ & $1.60 \mathrm{FT}$ \\
\hline TOFINO BC & 2334 UTC $3-27$ & $2.41 \mathrm{FT}$ \\
\hline NEAH BAY WA & 2234 UTC $3-27$ & $2.02 \mathrm{FT}$ \\
\hline LAPUSH WA & 2241 UTC 3-27 & $3.15 \mathrm{FT}$ \\
\hline WESTPORT WA & 2302 UTC $3-27$ & $2.11 \mathrm{FT}$ \\
\hline PORT ANGELES WA & 2354 UTC $3-27$ & $1.38 \mathrm{FT}$ \\
\hline GARIBALDI OR & 2259 UTC 3-27 & $1.05 \mathrm{FT}$ \\
\hline NEWPORT OR & 2309 UTC 3-27 & $2.46 \mathrm{FT}$ \\
\hline CHARLESTON OR & 2333 UTC $3-27$ & $2.74 \mathrm{FT}$ \\
\hline PORT ORFORD OR & 2355 UTC $3-27$ & $6.76 \mathrm{FT}$ \\
\hline CRESCENT CITY CA & 0100 UTC $3-28$ & $7.11 \mathrm{FT}$ \\
\hline ARENA COVE CA & 2313 UTC $3-27$ & $5.58 \mathrm{FT}$ \\
\hline EUREKA CA & 0006 UTC 3-28 & $4.23 \mathrm{FT}$ \\
\hline POINT REYES CA & 0142 UTC 3-28 & $3.38 \mathrm{FT}$ \\
\hline SAN FRANCISCO & 0155 UTC $3-28$ & $3.71 \mathrm{FT}$ \\
\hline ALAMEDA CA & 0141 UTC 3-28 & $1.84 \mathrm{FT}$ \\
\hline MONTEREY CA & 2338 UTC $3-27$ & $3.97 \mathrm{FT}$ \\
\hline PORT SAN LUIS CA & 0108 UTC $3-28$ & 14.30 FT \\
\hline SANTA BARBARA CA & 0145 UTC $3-28$ & $2.64 \mathrm{FT}$ \\
\hline SANTA MONICA CA & 0157 UTC 3-28 & $3.38 \mathrm{FT}$ \\
\hline SAN PEDRO CA & 0230 UTC $3-28$ & $3.11 \mathrm{FT}$ \\
\hline LA JOLLA CA & 0222 UTC 3-28 & $3.5 \mathrm{FT}$ \\
\hline SAN DIEGO CA & 0214 UTC 3-28 & $1.74 \mathrm{FT}$ \\
\hline MIDWAY IS & 2304 UTC $3-27$ & $1.44 \mathrm{FT}$ \\
\hline NAWILIWILI HI & 2323 UTC $3-27$ & $2.20 \mathrm{FT}$ \\
\hline HALEIWA HI & 2338 UTC $3-27$ & $4.99 \mathrm{FT}$ \\
\hline HONOLULU HI & 2338 UTC $3-27$ & $2.23 \mathrm{FT}$ \\
\hline KAHULUI HI & 2341 UTC $3-27$ & $7.15 \mathrm{FT}$ \\
\hline KAWAIHAE HI & 0014 UTC 3-28 & $2.89 \mathrm{FT}$ \\
\hline WAKE ISLAND & 0052 UTC $3-28$ & $0.33 \mathrm{FT}$ \\
\hline GUAM & 321 UTC $3-28$ & $0 \mathrm{FT}$ \\
\hline
\end{tabular}


PAGO PAGO AM SAMOA 0433 UTC 3-28 $0.46 \mathrm{FT}$

HEIGHT - OBSERVED MAX TSUNAMI HEIGHT IS THE WATER LEVEL ABOVE THE TIDE LEVEL AT THE TIME OF MEASUREMENT.

PRELIMINARY EARTHQUAKE PARAMETERS

* MAGNITUDE 9.0

* ORIGIN TIME 1050 AKDT MAR 272014

1150 PDT MAR 272014

1850 UTC MAR 272014

* COORDINATES 55.2 NORTH 156.7 WEST

* DEPTH 11 MILES

* LOCATION 100 MILES SE OF CHIGNIK ALASKA 485 MILES SW OF ANCHORAGE ALASKA

NEXT UPDATE AND ADDITIONAL INFORMATION

* THIS MESSAGE WILL BE UPDATED IN 60 MINUTES.

* REFER TO THE INTERNET SITE WCATWC.ARH.NOAA.GOV FOR MORE INFORMATION.

* PACIFIC COASTAL RESIDENTS OUTSIDE CALIFORNIA... OREGON... WASHINGTON... BRITISH COLUMBIA AND ALASKA SHOULD REFER TO THE PACIFIC TSUNAMI WARNING CENTER MESSAGES FOR INFORMATION ON THIS EVENT AT PTWC.WEATHER.GOV.

$\$ \$$ 
WEAK51 PAAQ 281701

TSUAK1

\section{BULLETIN}

PUBLIC TSUNAMI MESSAGE NUMBER 24

NWS WEST COAST/ALASKA TSUNAMI WARNING CENTER PALMER AK 901 AM AKDT FRI MAR 282014

THIS MESSAGE CONTINUES THE WARNING AND ADVISORY AS IN THE PREVIOUS MESSAGE.

...THE TSUNAMI WARNING REMAINS IN EFFECT...

...THE TSUNAMI ADVISORY REMAINS IN EFFECT...

WARNINGS/ADVISORIES/WATCHES

TSUNAMI WARNING IN EFFECT FOR...

* THE COASTAL AREAS OF CALIFORNIA - OREGON - WASHINGTON BRITISH COLUMBIA AND ALASKA FROM THE CALIFORNIA-MEXICO BORDER TO NIKOLSKI ALASKA

TSUNAMI ADVISORY IN EFFECT FOR...

* THE COASTAL AREAS OF ALASKA FROM NIKOLSKI ALASKA TO ATTU ALASKA

IMPACTS FOR TSUNAMI WARNING AREAS 
* WIDESPREAD DANGEROUS COASTAL FLOODING ACCOMPANIED BY POWERFUL CURRENTS IS POSSIBLE AND MAY CONTINUE FOR MANY HOURS AFTER TSUNAMI ARRIVAL.

* THE FIRST WAVE MAY NOT BE THE LARGEST.

IMPACTS FOR TSUNAMI ADVISORY AREAS

* A TSUNAMI CAPABLE OF PRODUCING STRONG CURRENTS OR WAVES DANGEROUS

TO PERSONS IN OR VERY NEAR THE WATER IS EXPECTED.

* CURRENTS MAY BE HAZARDOUS TO SWIMMERS... BOATS... AND COASTAL STRUCTURES AND MAY CONTINUE FOR MANY HOURS AFTER THE TSUNAMI ARRIVAL.

* THE FIRST WAVE MAY NOT BE THE LARGEST.

RECOMMENDED ACTIONS

* IF YOU ARE IN A WARNING AREA - MOVE INLAND TO HIGHER GROUND.

* IF YOU ARE IN AN ADVISORY AREA - MOVE OFF THE BEACH AND OUT OF HARBORS AND MARINAS. WIDESPREAD INUNDATION OF LAND IS NOT EXPECTED FOR ADVISORY AREAS.

* BE ALERT TO INSTRUCTIONS FROM YOUR LOCAL EMERGENCY OFFICIALS.

* DO NOT GO TO THE COAST TO OBSERVE THE TSUNAMI.

* DO NOT RETURN TO THE COAST UNTIL LOCAL EMERGENCY OFFICIALS INDICATE IT IS SAFE TO DO SO.

SIGNIFICANT TSUNAMI ACTIVITY IS EXPECTED TO CONTINUE FOR UP TO 48 HOURS AFTER THE WAVES INITIAL ARRIVAL ALONG SOUTHERN ALASKA COASTS

EAST OF NIKOLSKI AND ALONG THE US AND CANADIAN WEST COAST.

ADDITIONAL OBSERVATIONS OF TSUNAMI ACTIVITY - UPDATED

$\begin{array}{ll} & \text { TIME } \\ \text { SITE } & \text { OF MEASUREMENT TSUNAMI HEIGHT }\end{array}$




\begin{tabular}{|c|c|c|}
\hline AND POINT AK & 1945 UTC 3-27 & $11.60 \mathrm{FT}$ \\
\hline KING COVE AK & 2023 UTC 3-27 & $4.33 \mathrm{FT}$ \\
\hline CHIGNIK AK & 2026 UTC 3-27 & $21.82 \mathrm{FT}$ \\
\hline NIKOLSKI AK & 2054 UTC $3-27$ & $1.61 \mathrm{FT}$ \\
\hline UNALASKA AK & 2056 UTC 3-27 & $1.44 \mathrm{FT}$ \\
\hline KODIAK AK & 2100 UTC $3-27$ & 4.50 FT \\
\hline SEWARD AK & 2110 UTC $3-27$ & $4.11 \mathrm{FT}$ \\
\hline ADAK AK & 2145 UTC $3-27$ & $.03 \mathrm{FT}$ \\
\hline ELFIN COVE AK & 2133 UTC $3-27$ & $1.32 \mathrm{FT}$ \\
\hline YAKUTAT AK & 2132 UTC 3-27 & $2.44 \mathrm{FT}$ \\
\hline PORT ALEXANDER AK & 2114 UTC $3-27$ & $1.41 \mathrm{FT}$ \\
\hline CORDOVA AK & 2235 UTC $3-27$ & $1.82 \mathrm{FT}$ \\
\hline SHEMYA AK & 2245 UTC $3-27$ & $0.34 \mathrm{FT}$ \\
\hline SITKA AK & 2222 UTC $3-27$ & $74 \mathrm{FT}$ \\
\hline CRAIG AK & 2255 UTC $3-27$ & $.88 \mathrm{FT}$ \\
\hline LANGARA BC & 2300 UTC $3-27$ & $1.60 \mathrm{FT}$ \\
\hline TOFINO BC & 2334 UTC $3-27$ & $2.41 \mathrm{FT}$ \\
\hline NEAH BAY WA & 2234 UTC $3-27$ & $2.02 \mathrm{FT}$ \\
\hline LAPUSH WA & 2241 UTC 3-27 & $3.15 \mathrm{FT}$ \\
\hline WESTPORT WA & 2302 UTC $3-27$ & $2.11 \mathrm{FT}$ \\
\hline PORT ANGELES WA & 2354 UTC $3-27$ & $1.38 \mathrm{FT}$ \\
\hline GARIBALDI OR & 2259 UTC 3-27 & $1.05 \mathrm{FT}$ \\
\hline NEWPORT OR & 2309 UTC 3-27 & $2.46 \mathrm{FT}$ \\
\hline CHARLESTON OR & 2333 UTC $3-27$ & $2.74 \mathrm{FT}$ \\
\hline PORT ORFORD OR & 2355 UTC $3-27$ & $6.76 \mathrm{FT}$ \\
\hline CRESCENT CITY CA & 0100 UTC $3-28$ & $7.11 \mathrm{FT}$ \\
\hline ARENA COVE CA & 2313 UTC $3-27$ & $5.58 \mathrm{FT}$ \\
\hline EUREKA CA & 0006 UTC 3-28 & $4.23 \mathrm{FT}$ \\
\hline POINT REYES CA & 0142 UTC 3-28 & $3.38 \mathrm{FT}$ \\
\hline SAN FRANCISCO & 0155 UTC $3-28$ & $3.71 \mathrm{FT}$ \\
\hline ALAMEDA CA & 0141 UTC 3-28 & $1.84 \mathrm{FT}$ \\
\hline MONTEREY CA & 2338 UTC $3-27$ & $3.97 \mathrm{FT}$ \\
\hline PORT SAN LUIS CA & 0108 UTC $3-28$ & 14.30 FT \\
\hline SANTA BARBARA CA & 0145 UTC $3-28$ & $2.64 \mathrm{FT}$ \\
\hline SANTA MONICA CA & 0157 UTC 3-28 & $3.38 \mathrm{FT}$ \\
\hline SAN PEDRO CA & 0230 UTC $3-28$ & $3.11 \mathrm{FT}$ \\
\hline LA JOLLA CA & 0222 UTC 3-28 & $3.5 \mathrm{FT}$ \\
\hline SAN DIEGO CA & 0214 UTC 3-28 & $1.74 \mathrm{FT}$ \\
\hline MIDWAY IS & 2304 UTC $3-27$ & $1.44 \mathrm{FT}$ \\
\hline NAWILIWILI HI & 2323 UTC $3-27$ & $2.20 \mathrm{FT}$ \\
\hline HALEIWA HI & 2338 UTC $3-27$ & $4.99 \mathrm{FT}$ \\
\hline HONOLULU HI & 2338 UTC $3-27$ & $2.23 \mathrm{FT}$ \\
\hline KAHULUI HI & 2341 UTC $3-27$ & $7.15 \mathrm{FT}$ \\
\hline KAWAIHAE HI & 0014 UTC 3-28 & $2.89 \mathrm{FT}$ \\
\hline WAKE ISLAND & 0052 UTC $3-28$ & $0.33 \mathrm{FT}$ \\
\hline GUAM & 321 UTC $3-28$ & $0 \mathrm{FT}$ \\
\hline
\end{tabular}


PAGO PAGO AM SAMOA 0433 UTC 3-28 $0.46 \mathrm{FT}$

HEIGHT - OBSERVED MAX TSUNAMI HEIGHT IS THE WATER LEVEL ABOVE THE TIDE LEVEL AT THE TIME OF MEASUREMENT.

PRELIMINARY EARTHQUAKE PARAMETERS

* MAGNITUDE 9.0

* ORIGIN TIME 1050 AKDT MAR 272014

1150 PDT MAR 272014

1850 UTC MAR 272014

* COORDINATES 55.2 NORTH 156.7 WEST

* DEPTH 11 MILES

* LOCATION 100 MILES SE OF CHIGNIK ALASKA 485 MILES SW OF ANCHORAGE ALASKA

NEXT UPDATE AND ADDITIONAL INFORMATION

* THIS MESSAGE WILL BE UPDATED IN 60 MINUTES.

* REFER TO THE INTERNET SITE WCATWC.ARH.NOAA.GOV FOR MORE INFORMATION.

* PACIFIC COASTAL RESIDENTS OUTSIDE CALIFORNIA... OREGON... WASHINGTON... BRITISH COLUMBIA AND ALASKA SHOULD REFER TO THE PACIFIC TSUNAMI WARNING CENTER MESSAGES FOR INFORMATION ON THIS EVENT AT PTWC.WEATHER.GOV.

$\$ \$$ 
WEAK51 PAAQ 281801

TSUAK1

\section{BULLETIN}

PUBLIC TSUNAMI MESSAGE NUMBER 25

NWS WEST COAST/ALASKA TSUNAMI WARNING CENTER PALMER AK 1001 AM AKDT FRI MAR 282014

THIS MESSAGE REDUCES THE WARNING FOR SOME AREAS IN SOUTHERN CALIFORNIA TO AN ADVISORY.

...THE TSUNAMI WARNING REMAINS IN EFFECT...

...THE TSUNAMI ADVISORY REMAINS IN EFFECT...

WARNINGS/ADVISORIES/WATCHES - UPDATED

TSUNAMI WARNING IN EFFECT FOR...

* THE COASTAL AREAS OF CALIFORNIA - OREGON - WASHINGTON BRITISH COLUMBIA AND ALASKA FROM ALAMITOS BAY

CALIFORNIA/LOCATED 20 MILES SE OF L.A./ TO NIKOLSKI ALASKA

TSUNAMI ADVISORY IN EFFECT FOR...

* THE COASTAL AREAS OF CALIFORNIA FROM THE CALIFORNIA-MEXICO BORDER TO ALAMITOS BAY CALIFORNIA/LOCATED 20 MILES SE OF L.A./

* THE COASTAL AREAS OF ALASKA FROM NIKOLSKI ALASKA TO ATTU ALASKA 
IMPACTS FOR TSUNAMI WARNING AREAS

* WIDESPREAD DANGEROUS COASTAL FLOODING ACCOMPANIED BY POWERFUL CURRENTS IS POSSIBLE AND MAY CONTINUE FOR MANY HOURS AFTER TSUNAMI ARRIVAL.

* THE FIRST WAVE MAY NOT BE THE LARGEST.

IMPACTS FOR TSUNAMI ADVISORY AREAS

* A TSUNAMI CAPABLE OF PRODUCING STRONG CURRENTS OR WAVES DANGEROUS

TO PERSONS IN OR VERY NEAR THE WATER IS EXPECTED.

* CURRENTS MAY BE HAZARDOUS TO SWIMMERS... BOATS... AND COASTAL STRUCTURES AND MAY CONTINUE FOR MANY HOURS AFTER THE TSUNAMI ARRIVAL.

* THE FIRST WAVE MAY NOT BE THE LARGEST.

\section{RECOMMENDED ACTIONS}

* IF YOU ARE IN A WARNING AREA - MOVE INLAND TO HIGHER GROUND.

* IF YOU ARE IN AN ADVISORY AREA - MOVE OFF THE BEACH AND OUT OF HARBORS AND MARINAS. WIDESPREAD INUNDATION OF LAND IS NOT EXPECTED FOR ADVISORY AREAS.

* BE ALERT TO INSTRUCTIONS FROM YOUR LOCAL EMERGENCY OFFICIALS.

* DO NOT GO TO THE COAST TO OBSERVE THE TSUNAMI.

* DO NOT RETURN TO THE COAST UNTIL LOCAL EMERGENCY OFFICIALS INDICATE IT IS SAFE TO DO SO.

SIGNIFICANT TSUNAMI ACTIVITY IS EXPECTED TO CONTINUE FOR UP TO 48 HOURS AFTER THE WAVES INITIAL ARRIVAL ALONG SOUTHERN ALASKA COASTS

EAST OF NIKOLSKI AND ALONG THE US AND CANADIAN WEST COAST.

ADDITIONAL OBSERVATIONS OF TSUNAMI ACTIVITY - UPDATED 


\begin{tabular}{|c|c|c|}
\hline \multirow[b]{2}{*}{ SITE } & \multicolumn{2}{|c|}{ OBSERVED MAX } \\
\hline & MEASUREMENT & TSUNAMI HEIGHT \\
\hline SAND POINT AK & 1945 UTC 3-27 & $1160 \mathrm{FT}$ \\
\hline KING COVE AK & 2023 UTC 3-27 & $4.33 \mathrm{FT}$ \\
\hline CHIGNIK AK & 2026 UTC 3-27 & $21.82 \mathrm{FT}$ \\
\hline NIKOLSKI AK & 2054 UTC 3-27 & $1.61 \mathrm{FT}$ \\
\hline UNALASKA AK & 2056 UTC 3-27 & $1.44 \mathrm{FT}$ \\
\hline KODIAK AK & 2100 UTC 3-27 & $4.50 \mathrm{FT}$ \\
\hline SEWARD AK & 2110 UTC 3-27 & $4.11 \mathrm{FT}$ \\
\hline ADAK AK & 2145 UTC 3-27 & $.03 \mathrm{FT}$ \\
\hline ELFIN COVE AK & 2133 UTC 3-27 & $1.32 \mathrm{FT}$ \\
\hline YAKUTAT AK & 2132 UTC 3-27 & $2.44 \mathrm{FT}$ \\
\hline PORT ALEXANDER AI & 2114 UTC 3-27 & $1.41 \mathrm{FT}$ \\
\hline CORDOVA AK & 2235 UTC 3-27 & $1.82 \mathrm{FT}$ \\
\hline SHEMYA AK & 2245 UTC 3-27 & $0.34 \mathrm{FT}$ \\
\hline SITKA AK & 2222 UTC 3-27 & $.74 \mathrm{FT}$ \\
\hline CRAIG AK & 2255 UTC 3-27 & $.88 \mathrm{FT}$ \\
\hline LANGARA BC & 2300 UTC 3-27 & $1.60 \mathrm{FT}$ \\
\hline TOFINO BC & 2334 UTC 3-27 & $2.41 \mathrm{FT}$ \\
\hline NEAH BAY WA & 2234 UTC 3-27 & $2.02 \mathrm{FT}$ \\
\hline LAPUSH WA & 2241 UTC 3-27 & $3.15 \mathrm{FT}$ \\
\hline WESTPORT WA & 2302 UTC 3-27 & $2.11 \mathrm{FT}$ \\
\hline PORT ANGELES WA & 2354 UTC 3-27 & $1.38 \mathrm{FT}$ \\
\hline GARIBALDI OR & 2259 UTC 3-27 & $1.05 \mathrm{FT}$ \\
\hline NEWPORT OR & 2309 UTC 3-27 & $2.46 \mathrm{FT}$ \\
\hline CHARLESTON OR & 2333 UTC 3-27 & $2.74 \mathrm{FT}$ \\
\hline PORT ORFORD OR & 2355 UTC 3-27 & $6.76 \mathrm{FT}$ \\
\hline CRESCENT CITY CA & 0100 UTC 3-28 & $7.11 \mathrm{FT}$ \\
\hline ARENA COVE CA & 2313 UTC 3-27 & $5.58 \mathrm{FT}$ \\
\hline EUREKA CA & 0006 UTC 3-28 & $4.23 \mathrm{FT}$ \\
\hline POINT REYES CA & 0142 UTC 3-28 & $3.38 \mathrm{FT}$ \\
\hline SAN FRANCISCO & 0155 UTC 3-28 & $3.71 \mathrm{FT}$ \\
\hline ALAMEDA CA & 0141 UTC 3-28 & $1.84 \mathrm{FT}$ \\
\hline MONTEREY CA & 2338 UTC 3-27 & $3.97 \mathrm{FT}$ \\
\hline PORT SAN LUIS CA & 0108 UTC 3-28 & $14.30 \mathrm{FT}$ \\
\hline SANTA BARBARA CA & 0145 UTC 3-28 & $2.64 \mathrm{FT}$ \\
\hline SANTA MONICA CA & 0157 UTC 3-28 & $3.38 \mathrm{FT}$ \\
\hline SAN PEDRO CA & 0230 UTC 3-28 & $3.11 \mathrm{FT}$ \\
\hline LA JOLLA CA & 0222 UTC 3-28 & $3.5 \mathrm{FT}$ \\
\hline SAN DIEGO CA & 0214 UTC 3-28 & $1.74 \mathrm{FT}$ \\
\hline MIDWAY IS & 2304 UTC 3-27 & $1.44 \mathrm{FT}$ \\
\hline NAWILIWILI HI & 2323 UTC 3-27 & $2.20 \mathrm{FT}$ \\
\hline HALEIWA HI & 2338 UTC 3-27 & $4.99 \mathrm{FT}$ \\
\hline HONOLULU HI & 2338 UTC 3-27 & $2.23 \mathrm{FT}$ \\
\hline
\end{tabular}




$\begin{array}{lrc}\text { KAHULUI HI } & \text { 2341 UTC 3-27 } & 7.15 \mathrm{FT} \\ \text { KAWAIHAE HI } & \text { 0014 UTC 3-28 } & 2.89 \mathrm{FT} \\ \text { WAKE ISLAND } & \text { 0052 UTC 3-28 } & 0.33 \mathrm{FT} \\ \text { GUAM } & 0321 \text { UTC 3-28 } & 0.30 \mathrm{FT}\end{array}$

$\begin{array}{llll}\text { PAGO PAGO AM SAMOA } & 0433 \text { UTC } 3-28 \quad 0.46 \mathrm{FT}\end{array}$

HEIGHT - OBSERVED MAX TSUNAMI HEIGHT IS THE WATER LEVEL ABOVE THE TIDE LEVEL AT THE TIME OF MEASUREMENT.

PRELIMINARY EARTHQUAKE PARAMETERS

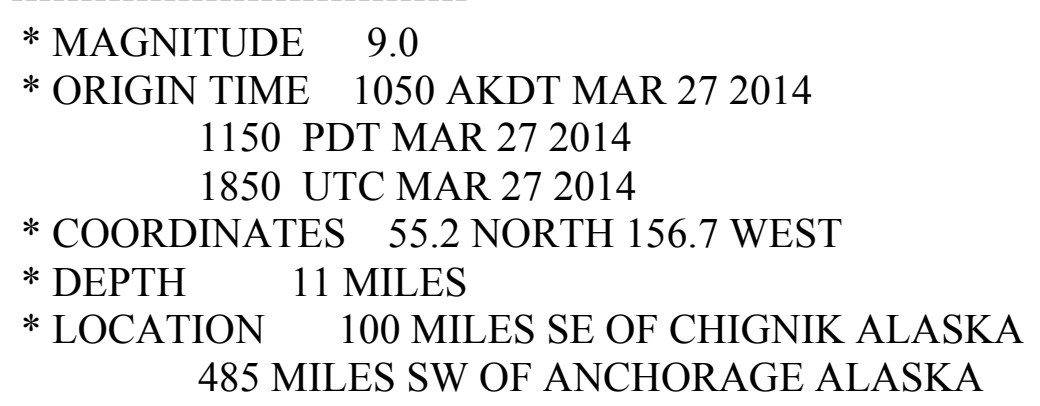

NEXT UPDATE AND ADDITIONAL INFORMATION

* THIS MESSAGE WILL BE UPDATED IN 60 MINUTES.

* REFER TO THE INTERNET SITE WCATWC.ARH.NOAA.GOV FOR MORE INFORMATION.

* PACIFIC COASTAL RESIDENTS OUTSIDE CALIFORNIA... OREGON... WASHINGTON... BRITISH COLUMBIA AND ALASKA SHOULD REFER TO THE PACIFIC TSUNAMI WARNING CENTER MESSAGES FOR INFORMATION ON THIS EVENT AT PTWC.WEATHER.GOV. 
WEAK51 PAAQ 281902

TSUAK1

BULLETIN

PUBLIC TSUNAMI MESSAGE NUMBER 26

NWS WEST COAST/ALASKA TSUNAMI WARNING CENTER PALMER AK

1102 AM AKDT FRI MAR 282014

THIS MESSAGE REDUCES THE TSUNAMI WARNING TO A TSUNAMI ADVISORY FOR AREAS OF SOUTHERN ALASKA/ BRITISH COLUMBIA AND WASHIGTON.

THE TSUNAMI ADVISORY FOR THE WESTERN ALEUTIANS IS CANCELLED.

...THE TSUNAMI WARNING REMAINS IN EFFECT...

...THE TSUNAMI ADVISORY REMAINS IN EFFECT...

WARNINGS/ADVISORIES/WATCHES - UPDATED

TSUNAMI WARNING IN EFFECT FOR...

* THE COASTAL AREAS OF CALIFORNIA AND OREGON FROM ALAMITOS BAY CALIFORNIA/LOCATED 20 MILES SE OF L.A./ TO THE

OREGON-WASHINGTON BORDER

* THE COASTAL AREAS OF ALASKA FROM KENNEDY ENTRANCE ALASKA/LOCATED 40 MILES SW OF HOMER/ TO NIKOLSKI ALASKA

TSUNAMI ADVISORY IN EFFECT FOR...

* THE COASTAL AREAS OF CALIFORNIA FROM THE CALIFORNIA-MEXICO BORDER TO ALAMITOS BAY CALIFORNIA/LOCATED 20 MILES SE OF L.A./ 
* THE COASTAL AREAS OF WASHINGTON - BRITISH COLUMBIA AND ALASKA FROM THE OREGON-WASHINGTON BORDER TO KENNEDY ENTRANCE ALASKA/LOCATED 40 MILES SW OF HOMER/

CANCELLATIONS

* THE TSUNAMI ADVISORY IS CANCELED FOR THE COASTAL AREAS OF ALASKA FROM NIKOLSKI ALASKA TO ATTU ALASKA

* FOR OTHER US AND CANDIAN PACIFIC COASTS IN NORTH AMERICA THIS IS FOR INFORMATION ONLY.

IMPACTS FOR TSUNAMI WARNING AREAS

* WIDESPREAD DANGEROUS COASTAL FLOODING ACCOMPANIED BY POWERFUL CURRENTS IS POSSIBLE AND MAY CONTINUE FOR MANY HOURS AFTER TSUNAMI ARRIVAL.

* THE FIRST WAVE MAY NOT BE THE LARGEST.

IMPACTS FOR TSUNAMI ADVISORY AREAS

* A TSUNAMI CAPABLE OF PRODUCING STRONG CURRENTS OR WAVES DANGEROUS

TO PERSONS IN OR VERY NEAR THE WATER IS EXPECTED.

* CURRENTS MAY BE HAZARDOUS TO SWIMMERS... BOATS... AND COASTAL STRUCTURES AND MAY CONTINUE FOR MANY HOURS AFTER THE TSUNAMI ARRIVAL.

* THE FIRST WAVE MAY NOT BE THE LARGEST.

\section{RECOMMENDED ACTIONS}

* IF YOU ARE IN A WARNING AREA - MOVE INLAND TO HIGHER GROUND.

* IF YOU ARE IN AN ADVISORY AREA - MOVE OFF THE BEACH AND OUT OF HARBORS AND MARINAS. WIDESPREAD INUNDATION OF LAND IS NOT EXPECTED FOR ADVISORY AREAS.

* BE ALERT TO INSTRUCTIONS FROM YOUR LOCAL EMERGENCY OFFICIALS. 
* DO NOT GO TO THE COAST TO OBSERVE THE TSUNAMI.

* DO NOT RETURN TO THE COAST UNTIL LOCAL EMERGENCY OFFICIALS INDICATE IT IS SAFE TO DO SO.

SIGNIFICANT TSUNAMI ACTIVITY IS EXPECTED TO CONTINUE FOR UP TO 24 MORE HOURS FOR AREAS STILL IN A LEVEL OF ALERT.

ADDITIONAL OBSERVATIONS OF TSUNAMI ACTIVITY - UPDATED

\begin{tabular}{|c|c|c|}
\hline \multirow[b]{2}{*}{ SITE } & \multicolumn{2}{|c|}{ OBSERVED MAX } \\
\hline & OF MEASUREMENT & TSUNA \\
\hline SAND POINT AK & 1945 UTC 3-27 & $11.60 \mathrm{FT}$ \\
\hline KING COVE AK & 2023 UTC $3-27$ & $4.33 \mathrm{FT}$ \\
\hline CHIGNIK AK & 2026 UTC 3-27 & $21.82 \mathrm{FT}$ \\
\hline NIKOLSKI AK & 2054 UTC $3-27$ & $1.61 \mathrm{FT}$ \\
\hline UNALASKA AK & 2056 UTC 3-27 & $1.44 \mathrm{FT}$ \\
\hline KODIAK AK & 2100 UTC $3-27$ & $4.50 \mathrm{FT}$ \\
\hline SEWARD AK & 2110 UTC 3-27 & 4.11 FT \\
\hline ADAK AK & 2145 UTC 3-27 & $1.03 \mathrm{FT}$ \\
\hline ELFIN COVE AK & 2133 UTC 3-27 & $1.32 \mathrm{FT}$ \\
\hline YAKUTAT AK & 2132 UTC 3-27 & $2.44 \mathrm{FT}$ \\
\hline PORT ALEXANDER A & 2114 UTC 3-2 & $1.41 \mathrm{FT}$ \\
\hline CORDOVA AK & 2235 UTC 3-27 & $1.82 \mathrm{FT}$ \\
\hline SHEMYA AK & 2245 UTC 3-27 & $0.34 \mathrm{FT}$ \\
\hline SITKA AK & 2222 UTC 3-27 & $3.74 \mathrm{FT}$ \\
\hline CRAIG AK & 2255 UTC $3-27$ & $3.88 \mathrm{FT}$ \\
\hline LANGARA BC & 2300 UTC $3-27$ & $1.60 \mathrm{FT}$ \\
\hline TOFINO BC & 2334 UTC $3-27$ & $2.41 \mathrm{FT}$ \\
\hline NEAH BAY WA & 2234 UTC 3-27 & 2.02 FT \\
\hline LAPUSH WA & 2241 UTC 3-27 & $3.15 \mathrm{FT}$ \\
\hline WESTPORT WA & 2302 UTC $3-27$ & $2.11 \mathrm{FT}$ \\
\hline PORT ANGELES WA & 2354 UTC $3-27$ & $1.38 \mathrm{FT}$ \\
\hline GARIBALDI OR & 2259 UTC 3-27 & $1.05 \mathrm{FT}$ \\
\hline NEWPORT OR & 2309 UTC 3-27 & $2.46 \mathrm{FT}$ \\
\hline CHARLESTON OR & 2333 UTC $3-27$ & $2.74 \mathrm{FT}$ \\
\hline PORT ORFORD OR & 2355 UTC $3-27$ & $6.76 \mathrm{FT}$ \\
\hline CRESCENT CITY CA & 0100 UTC 3-28 & $7.11 \mathrm{FT}$ \\
\hline ARENA COVE CA & 2313 UTC $3-27$ & $5.58 \mathrm{FT}$ \\
\hline EUREKA CA & 0006 UTC 3-28 & $4.23 \mathrm{FT}$ \\
\hline POINT REYES CA & 0142 UTC 3-28 & $3.38 \mathrm{FT}$ \\
\hline SAN FRANCISCO & 0155 UTC $3-28$ & $3.71 \mathrm{FT}$ \\
\hline ALAMEDA CA & 0141 UTC 3-28 & $1.84 \mathrm{FT}$ \\
\hline
\end{tabular}




\begin{tabular}{|c|c|c|}
\hline MONTEREY CA & 2338 UTC 3-27 & $3.97 \mathrm{FT}$ \\
\hline PORT SAN LUIS CA & 0108 UTC 3-28 & 14.30 FT \\
\hline SANTA BARBARA CA & 0145 UTC 3-28 & $2.64 \mathrm{FT}$ \\
\hline SANTA MONICA CA & 0157 UTC 3-28 & $3.38 \mathrm{FT}$ \\
\hline SAN PEDRO CA & 0230 UTC 3-28 & $3.11 \mathrm{FT}$ \\
\hline LA JOLLA CA & 0222 UTC 3-28 & $3.5 \mathrm{FT}$ \\
\hline SAN DIEGO CA & 0214 UTC 3-28 & $1.74 \mathrm{FT}$ \\
\hline MIDWAY IS & 2304 UTC 3-27 & $1.44 \mathrm{FT}$ \\
\hline NAWILIWILI HI & 2323 UTC 3-27 & $2.20 \mathrm{FT}$ \\
\hline HALEIWA HI & 2338 UTC 3-27 & $4.99 \mathrm{FT}$ \\
\hline HONOLULU HI & 2338 UTC 3-27 & $2.23 \mathrm{FT}$ \\
\hline KAHULUI HI & 2341 UTC $3-27$ & $7.15 \mathrm{FT}$ \\
\hline KAWAIHAE HI & \multirow{2}{*}{$\begin{array}{ccc}0014 & \text { UTC } & 3-28 \\
0052 & \text { UTC } & 3-28\end{array}$} & $2.89 \mathrm{FT}$ \\
\hline WAKE ISLAND & & $0.33 \mathrm{FT}$ \\
\hline GUAM & 0321 UTC 3-28 & $30 \mathrm{FT}$ \\
\hline PAGO F & $0433 \mathrm{U}^{\prime}$ & $3-28$ \\
\hline
\end{tabular}

HEIGHT - OBSERVED MAX TSUNAMI HEIGHT IS THE WATER LEVEL ABOVE THE TIDE LEVEL AT THE TIME OF MEASUREMENT.

PRELIMINARY EARTHQUAKE PARAMETERS

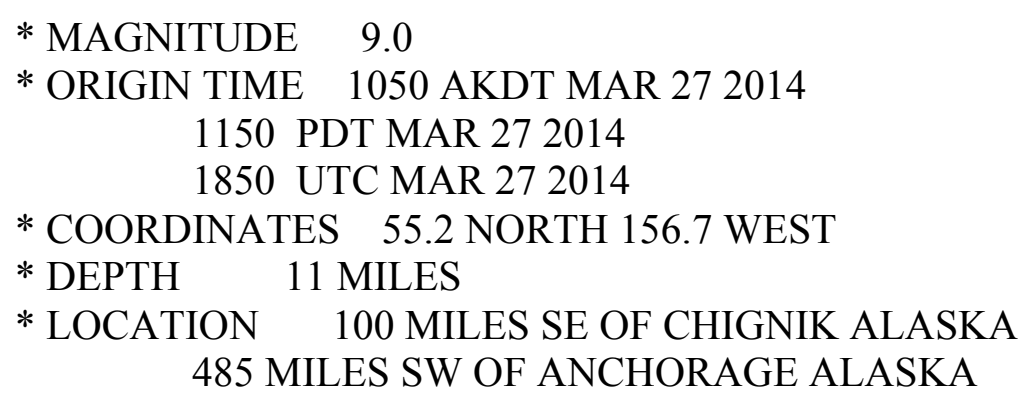

NEXT UPDATE AND ADDITIONAL INFORMATION

* THIS MESSAGE WILL BE UPDATED IN 60 MINUTES.

* REFER TO THE INTERNET SITE WCATWC.ARH.NOAA.GOV FOR MORE INFORMATION.

* PACIFIC COASTAL RESIDENTS OUTSIDE CALIFORNIA... OREGON... WASHINGTON... BRITISH COLUMBIA AND ALASKA SHOULD REFER TO THE PACIFIC TSUNAMI WARNING CENTER MESSAGES FOR INFORMATION ON THIS EVENT AT PTWC.WEATHER.GOV. 
WEAK51 PAAQ 282000

TSUAK1

BULLETIN

PUBLIC TSUNAMI MESSAGE NUMBER 27

NWS WEST COAST/ALASKA TSUNAMI WARNING CENTER PALMER AK 1200 PM AKDT FRI MAR 282014

THIS MESSAGE CONTINUES THE WARNING AND ADVISORY AS IN THE PREVIOUS MESSAGE.

...THE TSUNAMI WARNING REMAINS IN EFFECT...

...THE TSUNAMI ADVISORY REMAINS IN EFFECT...

WARNINGS/ADVISORIES/WATCHES

TSUNAMI WARNING IN EFFECT FOR...

* THE COASTAL AREAS OF CALIFORNIA AND OREGON FROM ALAMITOS BAY CALIFORNIA/LOCATED 20 MILES SE OF L.A./ TO THE OREGON-WASHINGTON BORDER

* THE COASTAL AREAS OF ALASKA FROM KENNEDY ENTRANCE ALASKA/LOCATED 40 MILES SW OF HOMER/ TO NIKOLSKI ALASKA

TSUNAMI ADVISORY IN EFFECT FOR...

* THE COASTAL AREAS OF CALIFORNIA FROM THE CALIFORNIA-MEXICO BORDER TO ALAMITOS BAY CALIFORNIA/LOCATED 20 MILES SE OF L.A./ 
* THE COASTAL AREAS OF WASHINGTON - BRITISH COLUMBIA AND ALASKA FROM THE OREGON-WASHINGTON BORDER TO KENNEDY ENTRANCE ALASKA/LOCATED 40 MILES SW OF HOMER/

* FOR OTHER US AND CANDIAN PACIFIC COASTS IN NORTH AMERICA THIS IS FOR INFORMATION ONLY.

IMPACTS FOR TSUNAMI WARNING AREAS

* WIDESPREAD DANGEROUS COASTAL FLOODING ACCOMPANIED BY POWERFUL CURRENTS IS POSSIBLE AND MAY CONTINUE FOR MANY HOURS AFTER TSUNAMI ARRIVAL.

* THE FIRST WAVE MAY NOT BE THE LARGEST.

IMPACTS FOR TSUNAMI ADVISORY AREAS

* A TSUNAMI CAPABLE OF PRODUCING STRONG CURRENTS OR WAVES DANGEROUS

TO PERSONS IN OR VERY NEAR THE WATER IS EXPECTED.

* CURRENTS MAY BE HAZARDOUS TO SWIMMERS... BOATS... AND COASTAL STRUCTURES AND MAY CONTINUE FOR MANY HOURS AFTER THE TSUNAMI ARRIVAL.

* THE FIRST WAVE MAY NOT BE THE LARGEST.

RECOMMENDED ACTIONS

* IF YOU ARE IN A WARNING AREA - MOVE INLAND TO HIGHER GROUND.

* IF YOU ARE IN AN ADVISORY AREA - MOVE OFF THE BEACH AND OUT OF HARBORS AND MARINAS. WIDESPREAD INUNDATION OF LAND IS NOT EXPECTED FOR ADVISORY AREAS.

* BE ALERT TO INSTRUCTIONS FROM YOUR LOCAL EMERGENCY OFFICIALS.

* DO NOT GO TO THE COAST TO OBSERVE THE TSUNAMI.

* DO NOT RETURN TO THE COAST UNTIL LOCAL EMERGENCY OFFICIALS INDICATE IT IS SAFE TO DO SO. 
SIGNIFICANT TSUNAMI ACTIVITY IS EXPECTED TO CONTINUE FOR UP TO 24 MORE HOURS FOR AREAS STILL IN A LEVEL OF ALERT.

ADDITIONAL OBSERVATIONS OF TSUNAMI ACTIVITY - UPDATED

\begin{tabular}{|c|c|c|}
\hline \multirow[b]{2}{*}{ SITE } & \multicolumn{2}{|c|}{ TIME $\quad$ OBSERVED MAX } \\
\hline & MEASUREMENT & SUNAMI HEIGHT \\
\hline SAND POINT AK & 1945 UTC 3-27 & $11.60 \mathrm{FT}$ \\
\hline KING COVE AK & 2023 UTC $3-27$ & $4.33 \mathrm{FT}$ \\
\hline CHIGNIK AK & 2026 UTC 3-27 & $21.82 \mathrm{FT}$ \\
\hline NIKOLSKI AK & 2054 UTC 3-27 & $1.61 \mathrm{FT}$ \\
\hline UNALASKA AK & 2056 UTC 3-27 & $1.44 \mathrm{FT}$ \\
\hline KODIAK AK & 2100 UTC $3-27$ & $4.50 \mathrm{FT}$ \\
\hline SEWARD AK & 2110 UTC $3-27$ & $4.11 \mathrm{FT}$ \\
\hline ADAK AK & 2145 UTC $3-27$ & $.03 \mathrm{FT}$ \\
\hline ELFIN COVE AK & 2133 UTC $3-27$ & $1.32 \mathrm{FT}$ \\
\hline YAKUTAT AK & 2132 UTC $3-27$ & 2.44 FT \\
\hline PORT ALEXANDER A & 2114 UTC $3-27$ & $1.41 \mathrm{FT}$ \\
\hline CORDOVA AK & 2235 UTC $3-27$ & $1.82 \mathrm{FT}$ \\
\hline SHEMYA AK & 2245 UTC $3-27$ & $0.34 \mathrm{FT}$ \\
\hline SITKA AK & 2222 UTC $3-27$ & $74 \mathrm{FT}$ \\
\hline CRAIG AK & 2255 UTC $3-27$ & $88 \mathrm{FT}$ \\
\hline LANGARA BC & 2300 UTC 3-27 & $1.60 \mathrm{FT}$ \\
\hline TOFINO BC & 2334 UTC $3-27$ & $2.41 \mathrm{FT}$ \\
\hline NEAH BAY WA & 2234 UTC $3-27$ & $2.02 \mathrm{FT}$ \\
\hline LAPUSH WA & 2241 UTC 3-27 & $3.15 \mathrm{FT}$ \\
\hline WESTPORT WA & 2302 UTC $3-27$ & $2.11 \mathrm{FT}$ \\
\hline PORT ANGELES WA & 2354 UTC 3-27 & $1.38 \mathrm{FT}$ \\
\hline GARIBALDI OR & 2259 UTC $3-27$ & $1.05 \mathrm{FT}$ \\
\hline NEWPORT OR & 2309 UTC 3-27 & $2.46 \mathrm{FT}$ \\
\hline CHARLESTON OR & 2333 UTC $3-27$ & $2.74 \mathrm{FT}$ \\
\hline PORT ORFORD OR & 2355 UTC 3-27 & $6.76 \mathrm{FT}$ \\
\hline CRESCENT CITY CA & 0100 UTC 3-28 & $7.11 \mathrm{FT}$ \\
\hline ARENA COVE CA & 2313 UTC 3-27 & $5.58 \mathrm{FT}$ \\
\hline EUREKA CA & 0006 UTC 3-28 & $4.23 \mathrm{FT}$ \\
\hline POINT REYES CA & 0142 UTC 3-28 & $3.38 \mathrm{FT}$ \\
\hline SAN FRANCISCO & 0155 UTC 3-28 & $3.71 \mathrm{FT}$ \\
\hline ALAMEDA CA & 0141 UTC 3-28 & $1.84 \mathrm{FT}$ \\
\hline MONTEREY CA & 2338 UTC $3-27$ & 3.97 FT \\
\hline PORT SAN LUIS CA & 0108 UTC 3-28 & $14.30 \mathrm{FT}$ \\
\hline SANTA BARBARA CA & 0145 UTC 3-28 & $2.64 \mathrm{FT}$ \\
\hline SANTA MONICA CA & 0157 UTC 3-28 & $3.38 \mathrm{FT}$ \\
\hline SAN PEDRO CA & 0230 UTC 3-28 & $3.11 \mathrm{FT}$ \\
\hline LA JOLLA CA & 0222 UTC 3-28 & $3.5 \mathrm{FT}$ \\
\hline SAN DIEGO CA & 0214 UTC 3-28 & $1.74 \mathrm{FT}$ \\
\hline
\end{tabular}




$\begin{array}{lcc}\text { MIDWAY IS } & 2304 \text { UTC 3-27 } & 1.44 \mathrm{FT} \\ \text { NAWILIWILI HI } & 2323 \text { UTC 3-27 } & 2.20 \mathrm{FT} \\ \text { HALEIWA HI } & 2338 \text { UTC 3-27 } & 4.99 \mathrm{FT} \\ \text { HONOLULU HI } & 2338 \text { UTC 3-27 } & 2.23 \mathrm{FT} \\ \text { KAHULUI HI } & 2341 \text { UTC 3-27 } & 7.15 \mathrm{FT} \\ \text { KAWAIHAE HI } & 0014 \text { UTC 3-28 } & 2.89 \mathrm{FT} \\ \text { WAKE ISLAND } & 0052 \text { UTC 3-28 } & 0.33 \mathrm{FT} \\ \text { GUAM } & 0321 \text { UTC 3-28 } 0.30 \mathrm{FT}\end{array}$

$\begin{array}{llll}\text { PAGO PAGO AM SAMOA } 0433 \text { UTC } & 3-28 \quad 0.46 \text { FT }\end{array}$

HEIGHT - OBSERVED MAX TSUNAMI HEIGHT IS THE WATER LEVEL ABOVE THE TIDE LEVEL AT THE TIME OF MEASUREMENT.

PRELIMINARY EARTHQUAKE PARAMETERS

* MAGNITUDE 9.0

* ORIGIN TIME 1050 AKDT MAR 272014

1150 PDT MAR 272014

1850 UTC MAR 272014

* COORDINATES 55.2 NORTH 156.7 WEST

* DEPTH 11 MILES

* LOCATION 100 MILES SE OF CHIGNIK ALASKA 485 MILES SW OF ANCHORAGE ALASKA

NEXT UPDATE AND ADDITIONAL INFORMATION

* THIS MESSAGE WILL BE UPDATED IN 60 MINUTES.

* REFER TO THE INTERNET SITE WCATWC.ARH.NOAA.GOV FOR MORE INFORMATION.

* PACIFIC COASTAL RESIDENTS OUTSIDE CALIFORNIA... OREGON... WASHINGTON... BRITISH COLUMBIA AND ALASKA SHOULD REFER TO THE PACIFIC TSUNAMI WARNING CENTER MESSAGES FOR INFORMATION ON THIS EVENT AT PTWC.WEATHER.GOV. 
WEAK51 PAAQ 282101

TSUAK1

BULLETIN

PUBLIC TSUNAMI MESSAGE NUMBER 28

NWS WEST COAST/ALASKA TSUNAMI WARNING CENTER PALMER AK

101 PM AKDT FRI MAR 282014

THIS MESSAGE CONTINUES THE WARNING AND ADVISORY AS IN THE PREVIOUS MESSAGE.

...THE TSUNAMI WARNING REMAINS IN EFFECT...

...THE TSUNAMI ADVISORY REMAINS IN EFFECT...

WARNINGS/ADVISORIES/WATCHES

TSUNAMI WARNING IN EFFECT FOR...

* THE COASTAL AREAS OF CALIFORNIA AND OREGON FROM ALAMITOS BAY CALIFORNIA/LOCATED 20 MILES SE OF L.A./ TO THE

OREGON-WASHINGTON BORDER

* THE COASTAL AREAS OF ALASKA FROM KENNEDY ENTRANCE

ALASKA/LOCATED 40 MILES SW OF HOMER/ TO NIKOLSKI ALASKA

TSUNAMI ADVISORY IN EFFECT FOR...

* THE COASTAL AREAS OF CALIFORNIA FROM THE CALIFORNIA-MEXICO BORDER TO ALAMITOS BAY CALIFORNIA/LOCATED 20 MILES SE OF L.A./ 
* THE COASTAL AREAS OF WASHINGTON - BRITISH COLUMBIA AND ALASKA FROM THE OREGON-WASHINGTON BORDER TO KENNEDY ENTRANCE ALASKA/LOCATED 40 MILES SW OF HOMER/

* FOR OTHER US AND CANDIAN PACIFIC COASTS IN NORTH AMERICA THIS IS FOR INFORMATION ONLY.

IMPACTS FOR TSUNAMI WARNING AREAS

* WIDESPREAD DANGEROUS COASTAL FLOODING ACCOMPANIED BY POWERFUL CURRENTS IS POSSIBLE AND MAY CONTINUE FOR MANY HOURS AFTER TSUNAMI ARRIVAL.

* THE FIRST WAVE MAY NOT BE THE LARGEST.

IMPACTS FOR TSUNAMI ADVISORY AREAS

* A TSUNAMI CAPABLE OF PRODUCING STRONG CURRENTS OR WAVES DANGEROUS

TO PERSONS IN OR VERY NEAR THE WATER IS EXPECTED.

* CURRENTS MAY BE HAZARDOUS TO SWIMMERS... BOATS... AND COASTAL STRUCTURES AND MAY CONTINUE FOR MANY HOURS AFTER THE TSUNAMI ARRIVAL.

* THE FIRST WAVE MAY NOT BE THE LARGEST.

\section{RECOMMENDED ACTIONS}

* IF YOU ARE IN A WARNING AREA - MOVE INLAND TO HIGHER GROUND.

* IF YOU ARE IN AN ADVISORY AREA - MOVE OFF THE BEACH AND OUT OF HARBORS AND MARINAS. WIDESPREAD INUNDATION OF LAND IS NOT EXPECTED FOR ADVISORY AREAS.

* BE ALERT TO INSTRUCTIONS FROM YOUR LOCAL EMERGENCY OFFICIALS.

* DO NOT GO TO THE COAST TO OBSERVE THE TSUNAMI.

* DO NOT RETURN TO THE COAST UNTIL LOCAL EMERGENCY OFFICIALS INDICATE IT IS SAFE TO DO SO. 
SIGNIFICANT TSUNAMI ACTIVITY IS EXPECTED TO CONTINUE FOR UP TO 24 MORE HOURS FOR AREAS STILL IN A LEVEL OF ALERT.

ADDITIONAL OBSERVATIONS OF TSUNAMI ACTIVITY - UPDATED

\begin{tabular}{|c|c|c|}
\hline \multirow[b]{2}{*}{ SITE } & \multicolumn{2}{|c|}{ TIME $\quad$ OBSERVED MAX } \\
\hline & MEASUREMENT & SUNAMI HEIGHT \\
\hline SAND POINT AK & 1945 UTC 3-27 & $11.60 \mathrm{FT}$ \\
\hline KING COVE AK & 2023 UTC $3-27$ & $4.33 \mathrm{FT}$ \\
\hline CHIGNIK AK & 2026 UTC 3-27 & $21.82 \mathrm{FT}$ \\
\hline NIKOLSKI AK & 2054 UTC 3-27 & $1.61 \mathrm{FT}$ \\
\hline UNALASKA AK & 2056 UTC 3-27 & $1.44 \mathrm{FT}$ \\
\hline KODIAK AK & 2100 UTC $3-27$ & $4.50 \mathrm{FT}$ \\
\hline SEWARD AK & 2110 UTC $3-27$ & $4.11 \mathrm{FT}$ \\
\hline ADAK AK & 2145 UTC $3-27$ & $.03 \mathrm{FT}$ \\
\hline ELFIN COVE AK & 2133 UTC $3-27$ & $1.32 \mathrm{FT}$ \\
\hline YAKUTAT AK & 2132 UTC $3-27$ & 2.44 FT \\
\hline PORT ALEXANDER A & 2114 UTC $3-27$ & $1.41 \mathrm{FT}$ \\
\hline CORDOVA AK & 2235 UTC $3-27$ & $1.82 \mathrm{FT}$ \\
\hline SHEMYA AK & 2245 UTC $3-27$ & $0.34 \mathrm{FT}$ \\
\hline SITKA AK & 2222 UTC $3-27$ & $74 \mathrm{FT}$ \\
\hline CRAIG AK & 2255 UTC $3-27$ & $88 \mathrm{FT}$ \\
\hline LANGARA BC & 2300 UTC 3-27 & $1.60 \mathrm{FT}$ \\
\hline TOFINO BC & 2334 UTC $3-27$ & $2.41 \mathrm{FT}$ \\
\hline NEAH BAY WA & 2234 UTC $3-27$ & $2.02 \mathrm{FT}$ \\
\hline LAPUSH WA & 2241 UTC 3-27 & $3.15 \mathrm{FT}$ \\
\hline WESTPORT WA & 2302 UTC $3-27$ & $2.11 \mathrm{FT}$ \\
\hline PORT ANGELES WA & 2354 UTC 3-27 & $1.38 \mathrm{FT}$ \\
\hline GARIBALDI OR & 2259 UTC $3-27$ & $1.05 \mathrm{FT}$ \\
\hline NEWPORT OR & 2309 UTC 3-27 & $2.46 \mathrm{FT}$ \\
\hline CHARLESTON OR & 2333 UTC $3-27$ & $2.74 \mathrm{FT}$ \\
\hline PORT ORFORD OR & 2355 UTC 3-27 & $6.76 \mathrm{FT}$ \\
\hline CRESCENT CITY CA & 0100 UTC 3-28 & $7.11 \mathrm{FT}$ \\
\hline ARENA COVE CA & 2313 UTC 3-27 & $5.58 \mathrm{FT}$ \\
\hline EUREKA CA & 0006 UTC 3-28 & $4.23 \mathrm{FT}$ \\
\hline POINT REYES CA & 0142 UTC 3-28 & $3.38 \mathrm{FT}$ \\
\hline SAN FRANCISCO & 0155 UTC 3-28 & $3.71 \mathrm{FT}$ \\
\hline ALAMEDA CA & 0141 UTC 3-28 & $1.84 \mathrm{FT}$ \\
\hline MONTEREY CA & 2338 UTC $3-27$ & 3.97 FT \\
\hline PORT SAN LUIS CA & 0108 UTC 3-28 & $14.30 \mathrm{FT}$ \\
\hline SANTA BARBARA CA & 0145 UTC 3-28 & $2.64 \mathrm{FT}$ \\
\hline SANTA MONICA CA & 0157 UTC 3-28 & $3.38 \mathrm{FT}$ \\
\hline SAN PEDRO CA & 0230 UTC 3-28 & $3.11 \mathrm{FT}$ \\
\hline LA JOLLA CA & 0222 UTC 3-28 & $3.5 \mathrm{FT}$ \\
\hline SAN DIEGO CA & 0214 UTC 3-28 & $1.74 \mathrm{FT}$ \\
\hline
\end{tabular}




$\begin{array}{lcc}\text { MIDWAY IS } & 2304 \text { UTC 3-27 } & 1.44 \mathrm{FT} \\ \text { NAWILIWILI HI } & 2323 \text { UTC 3-27 } & 2.20 \mathrm{FT} \\ \text { HALEIWA HI } & 2338 \text { UTC 3-27 } & 4.99 \mathrm{FT} \\ \text { HONOLULU HI } & 2338 \text { UTC 3-27 } & 2.23 \mathrm{FT} \\ \text { KAHULUI HI } & 2341 \text { UTC 3-27 } & 7.15 \mathrm{FT} \\ \text { KAWAIHAE HI } & 0014 \text { UTC 3-28 } & 2.89 \mathrm{FT} \\ \text { WAKE ISLAND } & 0052 \text { UTC 3-28 } & 0.33 \mathrm{FT} \\ \text { GUAM } & 0321 \text { UTC 3-28 } 0.30 \mathrm{FT}\end{array}$

$\begin{array}{llll}\text { PAGO PAGO AM SAMOA } 0433 \text { UTC } & 3-28 \quad 0.46 \text { FT }\end{array}$

HEIGHT - OBSERVED MAX TSUNAMI HEIGHT IS THE WATER LEVEL ABOVE THE TIDE LEVEL AT THE TIME OF MEASUREMENT.

PRELIMINARY EARTHQUAKE PARAMETERS

* MAGNITUDE 9.0

* ORIGIN TIME 1050 AKDT MAR 272014

1150 PDT MAR 272014

1850 UTC MAR 272014

* COORDINATES 55.2 NORTH 156.7 WEST

* DEPTH 11 MILES

* LOCATION 100 MILES SE OF CHIGNIK ALASKA 485 MILES SW OF ANCHORAGE ALASKA

NEXT UPDATE AND ADDITIONAL INFORMATION

* THIS MESSAGE WILL BE UPDATED IN 60 MINUTES.

* REFER TO THE INTERNET SITE WCATWC.ARH.NOAA.GOV FOR MORE INFORMATION.

* PACIFIC COASTAL RESIDENTS OUTSIDE CALIFORNIA... OREGON... WASHINGTON... BRITISH COLUMBIA AND ALASKA SHOULD REFER TO THE PACIFIC TSUNAMI WARNING CENTER MESSAGES FOR INFORMATION ON THIS EVENT AT PTWC.WEATHER.GOV. 
WEAK51 PAAQ 282200

TSUAK1

BULLETIN

PUBLIC TSUNAMI MESSAGE NUMBER 29

NWS WEST COAST/ALASKA TSUNAMI WARNING CENTER PALMER AK 200 PM AKDT FRI MAR 282014

THIS MESSAGE CONTINUES THE WARNING AND ADVISORY AS IN THE PREVIOUS MESSAGE.

...THE TSUNAMI WARNING REMAINS IN EFFECT...

...THE TSUNAMI ADVISORY REMAINS IN EFFECT...

WARNINGS/ADVISORIES/WATCHES

TSUNAMI WARNING IN EFFECT FOR...

* THE COASTAL AREAS OF CALIFORNIA AND OREGON FROM ALAMITOS BAY CALIFORNIA/LOCATED 20 MILES SE OF L.A./ TO THE OREGON-WASHINGTON BORDER

* THE COASTAL AREAS OF ALASKA FROM KENNEDY ENTRANCE ALASKA/LOCATED 40 MILES SW OF HOMER/ TO NIKOLSKI ALASKA

TSUNAMI ADVISORY IN EFFECT FOR...

* THE COASTAL AREAS OF CALIFORNIA FROM THE CALIFORNIA-MEXICO BORDER TO ALAMITOS BAY CALIFORNIA/LOCATED 20 MILES SE OF L.A./ 
* THE COASTAL AREAS OF WASHINGTON - BRITISH COLUMBIA AND ALASKA FROM THE OREGON-WASHINGTON BORDER TO KENNEDY ENTRANCE ALASKA/LOCATED 40 MILES SW OF HOMER/

* FOR OTHER US AND CANDIAN PACIFIC COASTS IN NORTH AMERICA THIS IS FOR INFORMATION ONLY.

IMPACTS FOR TSUNAMI WARNING AREAS

* WIDESPREAD DANGEROUS COASTAL FLOODING ACCOMPANIED BY POWERFUL CURRENTS IS POSSIBLE AND MAY CONTINUE FOR MANY HOURS AFTER TSUNAMI ARRIVAL.

* THE FIRST WAVE MAY NOT BE THE LARGEST.

IMPACTS FOR TSUNAMI ADVISORY AREAS

* A TSUNAMI CAPABLE OF PRODUCING STRONG CURRENTS OR WAVES DANGEROUS

TO PERSONS IN OR VERY NEAR THE WATER IS EXPECTED.

* CURRENTS MAY BE HAZARDOUS TO SWIMMERS... BOATS... AND COASTAL STRUCTURES AND MAY CONTINUE FOR MANY HOURS AFTER THE TSUNAMI ARRIVAL.

* THE FIRST WAVE MAY NOT BE THE LARGEST.

RECOMMENDED ACTIONS

* IF YOU ARE IN A WARNING AREA - MOVE INLAND TO HIGHER GROUND.

* IF YOU ARE IN AN ADVISORY AREA - MOVE OFF THE BEACH AND OUT OF HARBORS AND MARINAS. WIDESPREAD INUNDATION OF LAND IS NOT EXPECTED FOR ADVISORY AREAS.

* BE ALERT TO INSTRUCTIONS FROM YOUR LOCAL EMERGENCY OFFICIALS.

* DO NOT GO TO THE COAST TO OBSERVE THE TSUNAMI.

* DO NOT RETURN TO THE COAST UNTIL LOCAL EMERGENCY OFFICIALS INDICATE IT IS SAFE TO DO SO. 
SIGNIFICANT TSUNAMI ACTIVITY IS EXPECTED TO CONTINUE FOR UP TO 24 MORE HOURS FOR AREAS STILL IN A LEVEL OF ALERT.

ADDITIONAL OBSERVATIONS OF TSUNAMI ACTIVITY - UPDATED

\begin{tabular}{|c|c|c|}
\hline \multirow[b]{2}{*}{ SITE } & \multicolumn{2}{|c|}{ TIME $\quad$ OBSERVED MAX } \\
\hline & MEASUREMENT & SUNAMI HEIGHT \\
\hline SAND POINT AK & 1945 UTC 3-27 & $11.60 \mathrm{FT}$ \\
\hline KING COVE AK & 2023 UTC $3-27$ & $4.33 \mathrm{FT}$ \\
\hline CHIGNIK AK & 2026 UTC 3-27 & $21.82 \mathrm{FT}$ \\
\hline NIKOLSKI AK & 2054 UTC 3-27 & $1.61 \mathrm{FT}$ \\
\hline UNALASKA AK & 2056 UTC 3-27 & $1.44 \mathrm{FT}$ \\
\hline KODIAK AK & 2100 UTC $3-27$ & $4.50 \mathrm{FT}$ \\
\hline SEWARD AK & 2110 UTC $3-27$ & $4.11 \mathrm{FT}$ \\
\hline ADAK AK & 2145 UTC $3-27$ & $.03 \mathrm{FT}$ \\
\hline ELFIN COVE AK & 2133 UTC $3-27$ & $1.32 \mathrm{FT}$ \\
\hline YAKUTAT AK & 2132 UTC $3-27$ & 2.44 FT \\
\hline PORT ALEXANDER A & 2114 UTC $3-27$ & $1.41 \mathrm{FT}$ \\
\hline CORDOVA AK & 2235 UTC $3-27$ & $1.82 \mathrm{FT}$ \\
\hline SHEMYA AK & 2245 UTC $3-27$ & $0.34 \mathrm{FT}$ \\
\hline SITKA AK & 2222 UTC $3-27$ & $74 \mathrm{FT}$ \\
\hline CRAIG AK & 2255 UTC $3-27$ & $88 \mathrm{FT}$ \\
\hline LANGARA BC & 2300 UTC 3-27 & $1.60 \mathrm{FT}$ \\
\hline TOFINO BC & 2334 UTC $3-27$ & $2.41 \mathrm{FT}$ \\
\hline NEAH BAY WA & 2234 UTC $3-27$ & $2.02 \mathrm{FT}$ \\
\hline LAPUSH WA & 2241 UTC 3-27 & $3.15 \mathrm{FT}$ \\
\hline WESTPORT WA & 2302 UTC $3-27$ & $2.11 \mathrm{FT}$ \\
\hline PORT ANGELES WA & 2354 UTC 3-27 & $1.38 \mathrm{FT}$ \\
\hline GARIBALDI OR & 2259 UTC $3-27$ & $1.05 \mathrm{FT}$ \\
\hline NEWPORT OR & 2309 UTC 3-27 & $2.46 \mathrm{FT}$ \\
\hline CHARLESTON OR & 2333 UTC $3-27$ & $2.74 \mathrm{FT}$ \\
\hline PORT ORFORD OR & 2355 UTC 3-27 & $6.76 \mathrm{FT}$ \\
\hline CRESCENT CITY CA & 0100 UTC 3-28 & $7.11 \mathrm{FT}$ \\
\hline ARENA COVE CA & 2313 UTC 3-27 & $5.58 \mathrm{FT}$ \\
\hline EUREKA CA & 0006 UTC 3-28 & $4.23 \mathrm{FT}$ \\
\hline POINT REYES CA & 0142 UTC 3-28 & $3.38 \mathrm{FT}$ \\
\hline SAN FRANCISCO & 0155 UTC 3-28 & $3.71 \mathrm{FT}$ \\
\hline ALAMEDA CA & 0141 UTC 3-28 & $1.84 \mathrm{FT}$ \\
\hline MONTEREY CA & 2338 UTC $3-27$ & 3.97 FT \\
\hline PORT SAN LUIS CA & 0108 UTC 3-28 & $14.30 \mathrm{FT}$ \\
\hline SANTA BARBARA CA & 0145 UTC 3-28 & $2.64 \mathrm{FT}$ \\
\hline SANTA MONICA CA & 0157 UTC 3-28 & $3.38 \mathrm{FT}$ \\
\hline SAN PEDRO CA & 0230 UTC 3-28 & $3.11 \mathrm{FT}$ \\
\hline LA JOLLA CA & 0222 UTC 3-28 & $3.5 \mathrm{FT}$ \\
\hline SAN DIEGO CA & 0214 UTC 3-28 & $1.74 \mathrm{FT}$ \\
\hline
\end{tabular}




$\begin{array}{lcc}\text { MIDWAY IS } & 2304 \text { UTC 3-27 } & 1.44 \mathrm{FT} \\ \text { NAWILIWILI HI } & 2323 \text { UTC 3-27 } & 2.20 \mathrm{FT} \\ \text { HALEIWA HI } & 2338 \text { UTC 3-27 } & 4.99 \mathrm{FT} \\ \text { HONOLULU HI } & 2338 \text { UTC 3-27 } & 2.23 \mathrm{FT} \\ \text { KAHULUI HI } & 2341 \text { UTC 3-27 } & 7.15 \mathrm{FT} \\ \text { KAWAIHAE HI } & 0014 \text { UTC 3-28 } & 2.89 \mathrm{FT} \\ \text { WAKE ISLAND } & 0052 \text { UTC 3-28 } & 0.33 \mathrm{FT} \\ \text { GUAM } & 0321 \text { UTC 3-28 } 0.30 \mathrm{FT}\end{array}$

$\begin{array}{llll}\text { PAGO PAGO AM SAMOA } 0433 \text { UTC } & 3-28 \quad 0.46 \text { FT }\end{array}$

HEIGHT - OBSERVED MAX TSUNAMI HEIGHT IS THE WATER LEVEL ABOVE THE TIDE LEVEL AT THE TIME OF MEASUREMENT.

PRELIMINARY EARTHQUAKE PARAMETERS

* MAGNITUDE 9.0

* ORIGIN TIME 1050 AKDT MAR 272014

1150 PDT MAR 272014

1850 UTC MAR 272014

* COORDINATES 55.2 NORTH 156.7 WEST

* DEPTH 11 MILES

* LOCATION 100 MILES SE OF CHIGNIK ALASKA 485 MILES SW OF ANCHORAGE ALASKA

NEXT UPDATE AND ADDITIONAL INFORMATION

* THIS MESSAGE WILL BE UPDATED IN 60 MINUTES.

* REFER TO THE INTERNET SITE WCATWC.ARH.NOAA.GOV FOR MORE INFORMATION.

* PACIFIC COASTAL RESIDENTS OUTSIDE CALIFORNIA... OREGON... WASHINGTON... BRITISH COLUMBIA AND ALASKA SHOULD REFER TO THE PACIFIC TSUNAMI WARNING CENTER MESSAGES FOR INFORMATION ON THIS EVENT AT PTWC.WEATHER.GOV. 
WEAK51 PAAQ 282300

TSUAK1

BULLETIN

PUBLIC TSUNAMI MESSAGE NUMBER 30

NWS WEST COAST/ALASKA TSUNAMI WARNING CENTER PALMER AK 300 PM AKDT FRI MAR 282014

THIS MESSAGE CONTINUES THE WARNING AND ADVISORY AS IN THE PREVIOUS MESSAGE.

...THE TSUNAMI WARNING REMAINS IN EFFECT...

...THE TSUNAMI ADVISORY REMAINS IN EFFECT...

WARNINGS/ADVISORIES/WATCHES

TSUNAMI WARNING IN EFFECT FOR...

* THE COASTAL AREAS OF CALIFORNIA AND OREGON FROM ALAMITOS BAY CALIFORNIA/LOCATED 20 MILES SE OF L.A./ TO THE OREGON-WASHINGTON BORDER

* THE COASTAL AREAS OF ALASKA FROM KENNEDY ENTRANCE ALASKA/LOCATED 40 MILES SW OF HOMER/ TO NIKOLSKI ALASKA

TSUNAMI ADVISORY IN EFFECT FOR...

* THE COASTAL AREAS OF CALIFORNIA FROM THE CALIFORNIA-MEXICO BORDER TO ALAMITOS BAY CALIFORNIA/LOCATED 20 MILES SE OF L.A./ 
* THE COASTAL AREAS OF WASHINGTON - BRITISH COLUMBIA AND ALASKA FROM THE OREGON-WASHINGTON BORDER TO KENNEDY ENTRANCE ALASKA/LOCATED 40 MILES SW OF HOMER/

* FOR OTHER US AND CANDIAN PACIFIC COASTS IN NORTH AMERICA THIS IS FOR INFORMATION ONLY.

IMPACTS FOR TSUNAMI WARNING AREAS

* WIDESPREAD DANGEROUS COASTAL FLOODING ACCOMPANIED BY POWERFUL CURRENTS IS POSSIBLE AND MAY CONTINUE FOR MANY HOURS AFTER TSUNAMI ARRIVAL.

* THE FIRST WAVE MAY NOT BE THE LARGEST.

IMPACTS FOR TSUNAMI ADVISORY AREAS

* A TSUNAMI CAPABLE OF PRODUCING STRONG CURRENTS OR WAVES DANGEROUS

TO PERSONS IN OR VERY NEAR THE WATER IS EXPECTED.

* CURRENTS MAY BE HAZARDOUS TO SWIMMERS... BOATS... AND COASTAL STRUCTURES AND MAY CONTINUE FOR MANY HOURS AFTER THE TSUNAMI ARRIVAL.

* THE FIRST WAVE MAY NOT BE THE LARGEST.

RECOMMENDED ACTIONS

* IF YOU ARE IN A WARNING AREA - MOVE INLAND TO HIGHER GROUND.

* IF YOU ARE IN AN ADVISORY AREA - MOVE OFF THE BEACH AND OUT OF HARBORS AND MARINAS. WIDESPREAD INUNDATION OF LAND IS NOT EXPECTED FOR ADVISORY AREAS.

* BE ALERT TO INSTRUCTIONS FROM YOUR LOCAL EMERGENCY OFFICIALS.

* DO NOT GO TO THE COAST TO OBSERVE THE TSUNAMI.

* DO NOT RETURN TO THE COAST UNTIL LOCAL EMERGENCY OFFICIALS INDICATE IT IS SAFE TO DO SO. 
SIGNIFICANT TSUNAMI ACTIVITY IS EXPECTED TO CONTINUE FOR UP TO 18 MORE HOURS FOR AREAS STILL IN A LEVEL OF ALERT.

ADDITIONAL OBSERVATIONS OF TSUNAMI ACTIVITY - UPDATED

\begin{tabular}{|c|c|c|}
\hline \multirow[b]{2}{*}{ SITE } & \multicolumn{2}{|c|}{ OBSERVED MAX } \\
\hline & MEASUREMENT & SUNAMI HEIGHT \\
\hline SAND POINT AK & 1945 UTC $3-27$ & $11.60 \mathrm{FT}$ \\
\hline KING COVE AK & 2023 UTC 3-27 & $4.33 \mathrm{FT}$ \\
\hline CHIGNIK AK & 2026 UTC 3-27 & $21.82 \mathrm{FT}$ \\
\hline NIKOLSKI AK & 2054 UTC 3-27 & $1.61 \mathrm{FT}$ \\
\hline UNALASKA AK & 2056 UTC 3-27 & $1.44 \mathrm{FT}$ \\
\hline KODIAK AK & 2100 UTC $3-27$ & $4.50 \mathrm{FT}$ \\
\hline SEWARD AK & 2110 UTC $3-27$ & 4.11 FT \\
\hline ADAK AK & 2145 UTC $3-27$ & $.03 \mathrm{FT}$ \\
\hline ELFIN COVE AK & 2133 UTC $3-27$ & $1.32 \mathrm{FT}$ \\
\hline YAKUTAT AK & 2132 UTC 3-27 & $2.44 \mathrm{FT}$ \\
\hline PORT ALEXANDER AK & 2114 UTC $3-27$ & $1.41 \mathrm{FT}$ \\
\hline CORDOVA AK & 2235 UTC $3-27$ & $1.82 \mathrm{FT}$ \\
\hline SHEMYA AK & 2245 UTC 3-27 & $0.34 \mathrm{FT}$ \\
\hline SITKA AK & 2222 UTC 3-27 & $74 \mathrm{FT}$ \\
\hline CRAIG AK & 2255 UTC $3-27$ & $88 \mathrm{FT}$ \\
\hline LANGARA BC & 2300 UTC $3-27$ & $1.60 \mathrm{FT}$ \\
\hline TOFINO BC & 2334 UTC $3-27$ & $.41 \mathrm{FT}$ \\
\hline NEAH BAY WA & 2234 UTC $3-27$ & $2.02 \mathrm{FT}$ \\
\hline LAPUSH WA & 2241 UTC 3-27 & $3.15 \mathrm{FT}$ \\
\hline WESTPORT WA & 2302 UTC $3-27$ & $2.11 \mathrm{FT}$ \\
\hline PORT ANGELES WA & 2354 UTC 3-27 & $1.38 \mathrm{FT}$ \\
\hline GARIBALDI OR & 2259 UTC $3-27$ & $1.05 \mathrm{FT}$ \\
\hline NEWPORT OR & 2309 UTC 3-27 & $2.46 \mathrm{FT}$ \\
\hline CHARLESTON OR & 2333 UTC $3-27$ & $2.74 \mathrm{FT}$ \\
\hline PORT ORFORD OR & 2355 UTC 3-27 & $6.76 \mathrm{FT}$ \\
\hline CRESCENT CITY CA & 0100 UTC $3-28$ & $7.11 \mathrm{FT}$ \\
\hline ARENA COVE CA & 2313 UTC 3-27 & $5.58 \mathrm{FT}$ \\
\hline EUREKA CA & 0006 UTC 3-28 & $4.23 \mathrm{FT}$ \\
\hline POINT REYES CA & 0142 UTC 3-28 & $3.38 \mathrm{FT}$ \\
\hline SAN FRANCISCO & 0155 UTC 3-28 & $3.71 \mathrm{FT}$ \\
\hline ALAMEDA CA & 0141 UTC 3-28 & $1.84 \mathrm{FT}$ \\
\hline MONTEREY CA & 2338 UTC $3-27$ & $3.97 \mathrm{FT}$ \\
\hline PORT SAN LUIS CA & 0108 UTC 3-28 & $14.30 \mathrm{FT}$ \\
\hline SANTA BARBARA CA & 0145 UTC 3-28 & 2.64 FT \\
\hline SANTA MONICA CA & 0157 UTC 3-28 & $3.38 \mathrm{FT}$ \\
\hline SAN PEDRO CA & 0230 UTC 3-28 & $3.11 \mathrm{FT}$ \\
\hline LA JOLLA CA & 0222 UTC 3-28 & $3.5 \mathrm{FT}$ \\
\hline SAN DIEGO CA & 0214 UTC $3-28$ & $1.74 \mathrm{FT}$ \\
\hline
\end{tabular}




$\begin{array}{lcc}\text { MIDWAY IS } & 2304 \text { UTC 3-27 } & 1.44 \mathrm{FT} \\ \text { NAWILIWILI HI } & 2323 \text { UTC 3-27 } & 2.20 \mathrm{FT} \\ \text { HALEIWA HI } & 2338 \text { UTC 3-27 } & 4.99 \mathrm{FT} \\ \text { HONOLULU HI } & 2338 \text { UTC 3-27 } & 2.23 \mathrm{FT} \\ \text { KAHULUI HI } & 2341 \text { UTC 3-27 } & 7.15 \mathrm{FT} \\ \text { KAWAIHAE HI } & 0014 \text { UTC 3-28 } & 2.89 \mathrm{FT} \\ \text { WAKE ISLAND } & 0052 \text { UTC 3-28 } & 0.33 \mathrm{FT} \\ \text { GUAM } & 0321 \text { UTC 3-28 } 0.30 \mathrm{FT}\end{array}$

$\begin{array}{llll}\text { PAGO PAGO AM SAMOA } 0433 \text { UTC } & 3-28 \quad 0.46 \text { FT }\end{array}$

HEIGHT - OBSERVED MAX TSUNAMI HEIGHT IS THE WATER LEVEL ABOVE THE TIDE LEVEL AT THE TIME OF MEASUREMENT.

PRELIMINARY EARTHQUAKE PARAMETERS

* MAGNITUDE 9.0

* ORIGIN TIME 1050 AKDT MAR 272014

1150 PDT MAR 272014

1850 UTC MAR 272014

* COORDINATES 55.2 NORTH 156.7 WEST

* DEPTH 11 MILES

* LOCATION 100 MILES SE OF CHIGNIK ALASKA 485 MILES SW OF ANCHORAGE ALASKA

NEXT UPDATE AND ADDITIONAL INFORMATION

* THIS MESSAGE WILL BE UPDATED IN 60 MINUTES.

* REFER TO THE INTERNET SITE WCATWC.ARH.NOAA.GOV FOR MORE INFORMATION.

* PACIFIC COASTAL RESIDENTS OUTSIDE CALIFORNIA... OREGON... WASHINGTON... BRITISH COLUMBIA AND ALASKA SHOULD REFER TO THE PACIFIC TSUNAMI WARNING CENTER MESSAGES FOR INFORMATION ON THIS EVENT AT PTWC.WEATHER.GOV. 
WEAK51 PAAQ 290004

TSUAK1

BULLETIN

PUBLIC TSUNAMI MESSAGE NUMBER 31

NWS WEST COAST/ALASKA TSUNAMI WARNING CENTER PALMER AK

404 PM AKDT FRI MAR 282014

THIS MESSAGE DOWNGRADES THE TSUNAMI WARNING TO AN ADVISORY FOR SOME AREAS OF CALIFORNIA AND OREGON.

...THE TSUNAMI WARNING REMAINS IN EFFECT...

...THE TSUNAMI ADVISORY REMAINS IN EFFECT...

WARNINGS/ADVISORIES/WATCHES - UPDATED

TSUNAMI WARNING IN EFFECT FOR...

* THE COASTAL AREAS OF CALIFORNIA AND OREGON FROM POINT CONCEPTION CALIFORNIA TO DOUGLAS-LANE COUNTY LINE OREGON/10 MILES SW OF FLORENCE/

* THE COASTAL AREAS OF ALASKA FROM KENNEDY ENTRANCE

ALASKA/LOCATED 40 MILES SW OF HOMER/ TO NIKOLSKI ALASKA

TSUNAMI ADVISORY IN EFFECT FOR...

* THE COASTAL AREAS OF CALIFORNIA FROM THE CALIFORNIA-MEXICO BORDER TO ALAMITOS BAY CALIFORNIA/LOCATED 20 MILES SE OF L.A./ 
* THE COASTAL AREAS OF CALIFORNIA FROM ALAMITOS BAY CALIFORNIA/LOCATED 20 MILES SE OF L.A./ TO POINT CONCEPTION CALIFORNIA

* THE COASTAL AREAS OF OREGON FROM DOUGLAS-LANE COUNTY LINE OREGON/10 MILES SW OF FLORENCE/ TO THE OREGON-WASHINGTON BORDER

* THE COASTAL AREAS OF WASHINGTON - BRITISH COLUMBIA AND ALASKA FROM THE OREGON-WASHINGTON BORDER TO KENNEDY ENTRANCE ALASKA/LOCATED 40 MILES SW OF HOMER/

* FOR OTHER US AND CANDIAN PACIFIC COASTS IN NORTH AMERICA THIS IS FOR INFORMATION ONLY.

IMPACTS FOR TSUNAMI WARNING AREAS

* WIDESPREAD DANGEROUS COASTAL FLOODING ACCOMPANIED BY POWERFUL CURRENTS IS POSSIBLE AND MAY CONTINUE FOR MANY HOURS AFTER TSUNAMI ARRIVAL.

* THE FIRST WAVE MAY NOT BE THE LARGEST.

IMPACTS FOR TSUNAMI ADVISORY AREAS

* A TSUNAMI CAPABLE OF PRODUCING STRONG CURRENTS OR WAVES DANGEROUS

TO PERSONS IN OR VERY NEAR THE WATER IS EXPECTED.

* CURRENTS MAY BE HAZARDOUS TO SWIMMERS... BOATS... AND COASTAL STRUCTURES AND MAY CONTINUE FOR MANY HOURS AFTER THE TSUNAMI ARRIVAL.

* THE FIRST WAVE MAY NOT BE THE LARGEST.

\section{RECOMMENDED ACTIONS}

* IF YOU ARE IN A WARNING AREA - MOVE INLAND TO HIGHER GROUND.

* IF YOU ARE IN AN ADVISORY AREA - MOVE OFF THE BEACH AND OUT OF HARBORS AND MARINAS. WIDESPREAD INUNDATION OF LAND IS NOT EXPECTED FOR ADVISORY AREAS. 
* BE ALERT TO INSTRUCTIONS FROM YOUR LOCAL EMERGENCY OFFICIALS.

* DO NOT GO TO THE COAST TO OBSERVE THE TSUNAMI.

* DO NOT RETURN TO THE COAST UNTIL LOCAL EMERGENCY OFFICIALS INDICATE IT IS SAFE TO DO SO.

SIGNIFICANT TSUNAMI ACTIVITY IS EXPECTED TO CONTINUE FOR UP TO 18 MORE HOURS FOR AREAS STILL IN A LEVEL OF ALERT.

ADDITIONAL OBSERVATIONS OF TSUNAMI ACTIVITY - UPDATED

\begin{tabular}{|c|c|c|}
\hline \multirow[b]{2}{*}{ SITE } & \multicolumn{2}{|c|}{ TIME OBSERVED MAX } \\
\hline & DF MEASUREMENT & TSUNAMI HEIGHT \\
\hline SAND POINT AK & 1945 UTC 3-27 & $11.60 \mathrm{FT}$ \\
\hline KING COVE AK & 2023 UTC 3-27 & $4.33 \mathrm{FT}$ \\
\hline CHIGNIK AK & 2026 UTC 3-27 & $21.82 \mathrm{FT}$ \\
\hline NIKOLSKI AK & 2054 UTC $3-27$ & $1.61 \mathrm{FT}$ \\
\hline UNALASKA AK & 2056 UTC 3-27 & $1.44 \mathrm{FT}$ \\
\hline KODIAK AK & 2100 UTC $3-27$ & $4.50 \mathrm{FT}$ \\
\hline SEWARD AK & 2110 UTC $3-27$ & $4.11 \mathrm{FT}$ \\
\hline ADAK AK & 2145 UTC $3-27$ & $1.03 \mathrm{FT}$ \\
\hline ELFIN COVE AK & 2133 UTC 3-27 & $1.32 \mathrm{FT}$ \\
\hline YAKUTAT AK & 2132 UTC $3-27$ & 2.44 FT \\
\hline PORT ALEXANDER A & 2114 UTC 3-2 & $1.41 \mathrm{FT}$ \\
\hline CORDOVA AK & 2235 UTC $3-27$ & $1.82 \mathrm{FT}$ \\
\hline SHEMYA AK & 2245 UTC 3-27 & $0.34 \mathrm{FT}$ \\
\hline SITKA AK & 2222 UTC 3-27 & $3.74 \mathrm{FT}$ \\
\hline CRAIG AK & 2255 UTC $3-27$ & $3.88 \mathrm{FT}$ \\
\hline LANGARA BC & 2300 UTC $3-27$ & $1.60 \mathrm{FT}$ \\
\hline TOFINO BC & 2334 UTC $3-27$ & $2.41 \mathrm{FT}$ \\
\hline NEAH BAY WA & 2234 UTC $3-27$ & $2.02 \mathrm{FT}$ \\
\hline LAPUSH WA & 2241 UTC 3-27 & $3.15 \mathrm{FT}$ \\
\hline WESTPORT WA & 2302 UTC $3-27$ & $2.11 \mathrm{FT}$ \\
\hline PORT ANGELES WA & 2354 UTC 3-27 & $1.38 \mathrm{FT}$ \\
\hline GARIBALDI OR & 2259 UTC $3-27$ & $1.05 \mathrm{FT}$ \\
\hline NEWPORT OR & 2309 UTC 3-27 & $2.46 \mathrm{FT}$ \\
\hline CHARLESTON OR & 2333 UTC $3-27$ & $2.74 \mathrm{FT}$ \\
\hline PORT ORFORD OR & 2355 UTC 3-27 & $6.76 \mathrm{FT}$ \\
\hline CRESCENT CITY CA & 0100 UTC $3-28$ & $7.11 \mathrm{FT}$ \\
\hline ARENA COVE CA & 2313 UTC 3-27 & $5.58 \mathrm{FT}$ \\
\hline EUREKA CA & 0006 UTC 3-28 & $4.23 \mathrm{FT}$ \\
\hline POINT REYES CA & 0142 UTC 3-28 & $3.38 \mathrm{FT}$ \\
\hline SAN FRANCISCO & 0155 UTC $3-28$ & $3.71 \mathrm{FT}$ \\
\hline
\end{tabular}




\begin{tabular}{|c|c|c|}
\hline ALAMEDA CA & 0141 UTC 3-28 & $1.84 \mathrm{FT}$ \\
\hline MONTEREY CA & 2338 UTC 3-27 & $3.97 \mathrm{FT}$ \\
\hline PORT SAN LUIS CA & 0108 UTC $3-28$ & $14.30 \mathrm{FT}$ \\
\hline SANTA BARBARA C & 0145 UTC 3 & $2.64 \mathrm{FT}$ \\
\hline SANTA MONICA CA & 0157 UTC 3- & $3.38 \mathrm{FT}$ \\
\hline SAN PEDRO CA & 0230 UTC 3-28 & $3.11 \mathrm{FT}$ \\
\hline LA JOLLA CA & 0222 UTC 3-28 & $3.5 \mathrm{FT}$ \\
\hline SAN DIEGO CA & 0214 UTC 3-28 & $1.74 \mathrm{FT}$ \\
\hline MIDWAY IS & 2304 UTC 3-27 & $1.44 \mathrm{FT}$ \\
\hline NAWILIWILI HI & 2323 UTC 3-27 & $2.20 \mathrm{FT}$ \\
\hline HALEIWA HI & 2338 UTC 3-27 & 4.99 FT \\
\hline HONOLULU HI & 2338 UTC 3-27 & $2.23 \mathrm{FT}$ \\
\hline KAHULUI HI & 2341 UTC 3-27 & $7.15 \mathrm{FT}$ \\
\hline KAWAIHAE HI & 0014 UTC 3-28 & $2.89 \mathrm{FT}$ \\
\hline WAKE ISLAND & 0052 UTC 3-28 & $0.33 \mathrm{FT}$ \\
\hline GUAM & 0321 UTC 3-28 & $30 \mathrm{FT}$ \\
\hline PAGO PAGO AM SAM & $0433 \mathrm{UT}$ & $3-28$ \\
\hline
\end{tabular}

HEIGHT - OBSERVED MAX TSUNAMI HEIGHT IS THE WATER LEVEL ABOVE THE TIDE LEVEL AT THE TIME OF MEASUREMENT.

PRELIMINARY EARTHQUAKE PARAMETERS

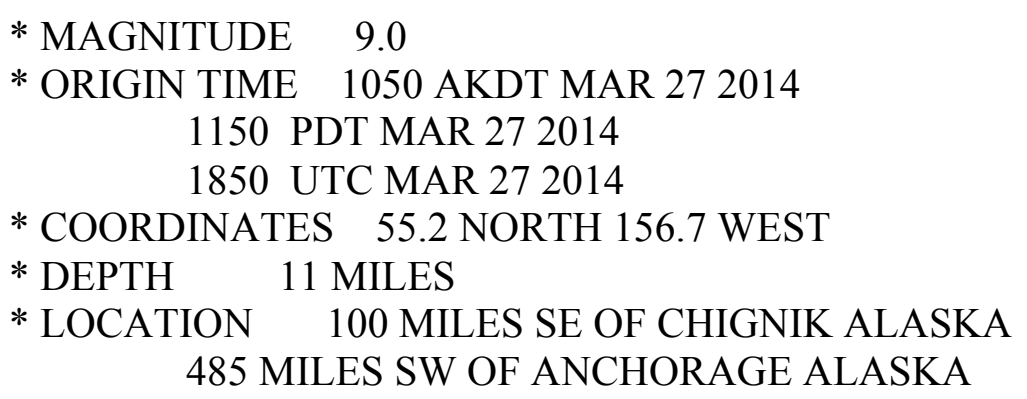

NEXT UPDATE AND ADDITIONAL INFORMATION

* THIS MESSAGE WILL BE UPDATED IN 60 MINUTES.

* REFER TO THE INTERNET SITE WCATWC.ARH.NOAA.GOV FOR MORE INFORMATION.

* PACIFIC COASTAL RESIDENTS OUTSIDE CALIFORNIA... OREGON... WASHINGTON... BRITISH COLUMBIA AND ALASKA SHOULD REFER TO THE PACIFIC TSUNAMI WARNING CENTER MESSAGES FOR INFORMATION ON THIS EVENT AT PTWC.WEATHER.GOV. 
WEAK51 PAAQ 290101

TSUAK1

BULLETIN

PUBLIC TSUNAMI MESSAGE NUMBER 32

NWS WEST COAST/ALASKA TSUNAMI WARNING CENTER PALMER AK 501 PM AKDT FRI MAR 282014

THIS MESSAGE CONTINUES THE WARNING AND ADVISORY AS IN THE PREVIOUS MESSAGE.

...THE TSUNAMI WARNING REMAINS IN EFFECT...

...THE TSUNAMI ADVISORY REMAINS IN EFFECT...

WARNINGS/ADVISORIES/WATCHES

TSUNAMI WARNING IN EFFECT FOR...

* THE COASTAL AREAS OF CALIFORNIA AND OREGON FROM POINT CONCEPTION CALIFORNIA TO DOUGLAS-LANE COUNTY LINE OREGON/10 MILES SW OF FLORENCE/

* THE COASTAL AREAS OF ALASKA FROM KENNEDY ENTRANCE ALASKA/LOCATED 40 MILES SW OF HOMER/ TO NIKOLSKI ALASKA

TSUNAMI ADVISORY IN EFFECT FOR...

* THE COASTAL AREAS OF CALIFORNIA FROM THE CALIFORNIA-MEXICO BORDER TO POINT CONCEPTION CALIFORNIA

* THE COASTAL AREAS OF OREGON - WASHINGTON - BRITISH COLUMBIA 
AND ALASKA FROM DOUGLAS-LANE COUNTY LINE OREGON/10 MILES SW OF FLORENCE/ TO KENNEDY ENTRANCE ALASKA/LOCATED 40 MILES SW OF HOMER/

* FOR OTHER US AND CANDIAN PACIFIC COASTS IN NORTH AMERICA THIS IS FOR INFORMATION ONLY.

IMPACTS FOR TSUNAMI WARNING AREAS

* WIDESPREAD DANGEROUS COASTAL FLOODING ACCOMPANIED BY POWERFUL CURRENTS IS POSSIBLE AND MAY CONTINUE FOR MANY HOURS AFTER TSUNAMI ARRIVAL.

* THE FIRST WAVE MAY NOT BE THE LARGEST.

IMPACTS FOR TSUNAMI ADVISORY AREAS

* A TSUNAMI CAPABLE OF PRODUCING STRONG CURRENTS OR WAVES DANGEROUS

TO PERSONS IN OR VERY NEAR THE WATER IS EXPECTED.

* CURRENTS MAY BE HAZARDOUS TO SWIMMERS... BOATS... AND COASTAL STRUCTURES AND MAY CONTINUE FOR MANY HOURS AFTER THE TSUNAMI ARRIVAL.

* THE FIRST WAVE MAY NOT BE THE LARGEST.

\section{RECOMMENDED ACTIONS}

* IF YOU ARE IN A WARNING AREA - MOVE INLAND TO HIGHER GROUND.

* IF YOU ARE IN AN ADVISORY AREA - MOVE OFF THE BEACH AND OUT OF HARBORS AND MARINAS. WIDESPREAD INUNDATION OF LAND IS NOT EXPECTED FOR ADVISORY AREAS.

* BE ALERT TO INSTRUCTIONS FROM YOUR LOCAL EMERGENCY OFFICIALS.

* DO NOT GO TO THE COAST TO OBSERVE THE TSUNAMI.

* DO NOT RETURN TO THE COAST UNTIL LOCAL EMERGENCY OFFICIALS INDICATE IT IS SAFE TO DO SO. 
SIGNIFICANT TSUNAMI ACTIVITY IS EXPECTED TO CONTINUE FOR UP TO 18 MORE HOURS FOR AREAS STILL IN A LEVEL OF ALERT.

ADDITIONAL OBSERVATIONS OF TSUNAMI ACTIVITY - UPDATED

\begin{tabular}{|c|c|c|}
\hline \multirow[b]{2}{*}{ SITE } & \multicolumn{2}{|c|}{ OBSERVED MAX } \\
\hline & MEASUREMENT & SUNAMI HEIGHT \\
\hline SAND POINT AK & 1945 UTC $3-27$ & $11.60 \mathrm{FT}$ \\
\hline KING COVE AK & 2023 UTC 3-27 & $4.33 \mathrm{FT}$ \\
\hline CHIGNIK AK & 2026 UTC 3-27 & $21.82 \mathrm{FT}$ \\
\hline NIKOLSKI AK & 2054 UTC 3-27 & $1.61 \mathrm{FT}$ \\
\hline UNALASKA AK & 2056 UTC 3-27 & $1.44 \mathrm{FT}$ \\
\hline KODIAK AK & 2100 UTC $3-27$ & $4.50 \mathrm{FT}$ \\
\hline SEWARD AK & 2110 UTC $3-27$ & 4.11 FT \\
\hline ADAK AK & 2145 UTC $3-27$ & $.03 \mathrm{FT}$ \\
\hline ELFIN COVE AK & 2133 UTC $3-27$ & $1.32 \mathrm{FT}$ \\
\hline YAKUTAT AK & 2132 UTC 3-27 & $2.44 \mathrm{FT}$ \\
\hline PORT ALEXANDER AK & 2114 UTC $3-27$ & $1.41 \mathrm{FT}$ \\
\hline CORDOVA AK & 2235 UTC $3-27$ & $1.82 \mathrm{FT}$ \\
\hline SHEMYA AK & 2245 UTC 3-27 & $0.34 \mathrm{FT}$ \\
\hline SITKA AK & 2222 UTC 3-27 & $74 \mathrm{FT}$ \\
\hline CRAIG AK & 2255 UTC $3-27$ & $88 \mathrm{FT}$ \\
\hline LANGARA BC & 2300 UTC $3-27$ & $1.60 \mathrm{FT}$ \\
\hline TOFINO BC & 2334 UTC $3-27$ & $.41 \mathrm{FT}$ \\
\hline NEAH BAY WA & 2234 UTC $3-27$ & $2.02 \mathrm{FT}$ \\
\hline LAPUSH WA & 2241 UTC 3-27 & $3.15 \mathrm{FT}$ \\
\hline WESTPORT WA & 2302 UTC $3-27$ & $2.11 \mathrm{FT}$ \\
\hline PORT ANGELES WA & 2354 UTC 3-27 & $1.38 \mathrm{FT}$ \\
\hline GARIBALDI OR & 2259 UTC $3-27$ & $1.05 \mathrm{FT}$ \\
\hline NEWPORT OR & 2309 UTC 3-27 & $2.46 \mathrm{FT}$ \\
\hline CHARLESTON OR & 2333 UTC $3-27$ & $2.74 \mathrm{FT}$ \\
\hline PORT ORFORD OR & 2355 UTC 3-27 & $6.76 \mathrm{FT}$ \\
\hline CRESCENT CITY CA & 0100 UTC $3-28$ & $7.11 \mathrm{FT}$ \\
\hline ARENA COVE CA & 2313 UTC 3-27 & $5.58 \mathrm{FT}$ \\
\hline EUREKA CA & 0006 UTC 3-28 & $4.23 \mathrm{FT}$ \\
\hline POINT REYES CA & 0142 UTC 3-28 & $3.38 \mathrm{FT}$ \\
\hline SAN FRANCISCO & 0155 UTC 3-28 & $3.71 \mathrm{FT}$ \\
\hline ALAMEDA CA & 0141 UTC 3-28 & $1.84 \mathrm{FT}$ \\
\hline MONTEREY CA & 2338 UTC $3-27$ & $3.97 \mathrm{FT}$ \\
\hline PORT SAN LUIS CA & 0108 UTC 3-28 & $14.30 \mathrm{FT}$ \\
\hline SANTA BARBARA CA & 0145 UTC 3-28 & 2.64 FT \\
\hline SANTA MONICA CA & 0157 UTC 3-28 & $3.38 \mathrm{FT}$ \\
\hline SAN PEDRO CA & 0230 UTC 3-28 & $3.11 \mathrm{FT}$ \\
\hline LA JOLLA CA & 0222 UTC 3-28 & $3.5 \mathrm{FT}$ \\
\hline SAN DIEGO CA & 0214 UTC $3-28$ & $1.74 \mathrm{FT}$ \\
\hline
\end{tabular}




$\begin{array}{lcc}\text { MIDWAY IS } & 2304 \text { UTC 3-27 } & 1.44 \mathrm{FT} \\ \text { NAWILIWILI HI } & 2323 \text { UTC 3-27 } & 2.20 \mathrm{FT} \\ \text { HALEIWA HI } & 2338 \text { UTC 3-27 } & 4.99 \mathrm{FT} \\ \text { HONOLULU HI } & 2338 \text { UTC 3-27 } & 2.23 \mathrm{FT} \\ \text { KAHULUI HI } & 2341 \text { UTC 3-27 } & 7.15 \mathrm{FT} \\ \text { KAWAIHAE HI } & 0014 \text { UTC 3-28 } & 2.89 \mathrm{FT} \\ \text { WAKE ISLAND } & 0052 \text { UTC 3-28 } & 0.33 \mathrm{FT} \\ \text { GUAM } & 0321 \text { UTC 3-28 } 0.30 \mathrm{FT}\end{array}$

$\begin{array}{llll}\text { PAGO PAGO AM SAMOA } 0433 \text { UTC } & 3-28 \quad 0.46 \text { FT }\end{array}$

HEIGHT - OBSERVED MAX TSUNAMI HEIGHT IS THE WATER LEVEL ABOVE THE TIDE LEVEL AT THE TIME OF MEASUREMENT.

PRELIMINARY EARTHQUAKE PARAMETERS

* MAGNITUDE 9.0

* ORIGIN TIME 1050 AKDT MAR 272014

1150 PDT MAR 272014

1850 UTC MAR 272014

* COORDINATES 55.2 NORTH 156.7 WEST

* DEPTH 11 MILES

* LOCATION 100 MILES SE OF CHIGNIK ALASKA 485 MILES SW OF ANCHORAGE ALASKA

NEXT UPDATE AND ADDITIONAL INFORMATION

* THIS MESSAGE WILL BE UPDATED IN 60 MINUTES.

* REFER TO THE INTERNET SITE WCATWC.ARH.NOAA.GOV FOR MORE INFORMATION.

* PACIFIC COASTAL RESIDENTS OUTSIDE CALIFORNIA... OREGON... WASHINGTON... BRITISH COLUMBIA AND ALASKA SHOULD REFER TO THE PACIFIC TSUNAMI WARNING CENTER MESSAGES FOR INFORMATION ON THIS EVENT AT PTWC.WEATHER.GOV. 
WEAK51 PAAQ 290201

TSUAK1

BULLETIN

PUBLIC TSUNAMI MESSAGE NUMBER 33

NWS WEST COAST/ALASKA TSUNAMI WARNING CENTER PALMER AK

601 PM AKDT FRI MAR 282014

THIS MESSAGE CONTINUES THE WARNING AND ADVISORY AS IN THE PREVIOUS MESSAGE.

...THE TSUNAMI WARNING REMAINS IN EFFECT...

...THE TSUNAMI ADVISORY REMAINS IN EFFECT...

WARNINGS/ADVISORIES/WATCHES

TSUNAMI WARNING IN EFFECT FOR...

* THE COASTAL AREAS OF CALIFORNIA AND OREGON FROM POINT CONCEPTION CALIFORNIA TO DOUGLAS-LANE COUNTY LINE OREGON/10 MILES SW OF FLORENCE/

* THE COASTAL AREAS OF ALASKA FROM KENNEDY ENTRANCE

ALASKA/LOCATED 40 MILES SW OF HOMER/ TO NIKOLSKI ALASKA

TSUNAMI ADVISORY IN EFFECT FOR...

* THE COASTAL AREAS OF CALIFORNIA FROM THE CALIFORNIA-MEXICO BORDER TO POINT CONCEPTION CALIFORNIA

* THE COASTAL AREAS OF OREGON - WASHINGTON - BRITISH COLUMBIA 
AND ALASKA FROM DOUGLAS-LANE COUNTY LINE OREGON/10 MILES SW OF FLORENCE/ TO KENNEDY ENTRANCE ALASKA/LOCATED 40 MILES SW OF HOMER/

* FOR OTHER US AND CANDIAN PACIFIC COASTS IN NORTH AMERICA THIS IS FOR INFORMATION ONLY.

IMPACTS FOR TSUNAMI WARNING AREAS

* WIDESPREAD DANGEROUS COASTAL FLOODING ACCOMPANIED BY POWERFUL CURRENTS IS POSSIBLE AND MAY CONTINUE FOR MANY HOURS AFTER TSUNAMI ARRIVAL.

* THE FIRST WAVE MAY NOT BE THE LARGEST.

IMPACTS FOR TSUNAMI ADVISORY AREAS

* A TSUNAMI CAPABLE OF PRODUCING STRONG CURRENTS OR WAVES DANGEROUS

TO PERSONS IN OR VERY NEAR THE WATER IS EXPECTED.

* CURRENTS MAY BE HAZARDOUS TO SWIMMERS... BOATS... AND COASTAL STRUCTURES AND MAY CONTINUE FOR MANY HOURS AFTER THE TSUNAMI ARRIVAL.

* THE FIRST WAVE MAY NOT BE THE LARGEST.

\section{RECOMMENDED ACTIONS}

* IF YOU ARE IN A WARNING AREA - MOVE INLAND TO HIGHER GROUND.

* IF YOU ARE IN AN ADVISORY AREA - MOVE OFF THE BEACH AND OUT OF HARBORS AND MARINAS. WIDESPREAD INUNDATION OF LAND IS NOT EXPECTED FOR ADVISORY AREAS.

* BE ALERT TO INSTRUCTIONS FROM YOUR LOCAL EMERGENCY OFFICIALS.

* DO NOT GO TO THE COAST TO OBSERVE THE TSUNAMI.

* DO NOT RETURN TO THE COAST UNTIL LOCAL EMERGENCY OFFICIALS INDICATE IT IS SAFE TO DO SO. 
SIGNIFICANT TSUNAMI ACTIVITY IS EXPECTED TO CONTINUE FOR UP TO 18 MORE HOURS FOR AREAS STILL IN A LEVEL OF ALERT.

ADDITIONAL OBSERVATIONS OF TSUNAMI ACTIVITY - UPDATED

\begin{tabular}{|c|c|c|}
\hline \multirow[b]{2}{*}{ SITE } & \multicolumn{2}{|c|}{ OBSERVED MAX } \\
\hline & MEASUREMENT & SUNAMI HEIGHT \\
\hline SAND POINT AK & 1945 UTC $3-27$ & $11.60 \mathrm{FT}$ \\
\hline KING COVE AK & 2023 UTC 3-27 & $4.33 \mathrm{FT}$ \\
\hline CHIGNIK AK & 2026 UTC 3-27 & $21.82 \mathrm{FT}$ \\
\hline NIKOLSKI AK & 2054 UTC 3-27 & $1.61 \mathrm{FT}$ \\
\hline UNALASKA AK & 2056 UTC 3-27 & $1.44 \mathrm{FT}$ \\
\hline KODIAK AK & 2100 UTC $3-27$ & $4.50 \mathrm{FT}$ \\
\hline SEWARD AK & 2110 UTC $3-27$ & 4.11 FT \\
\hline ADAK AK & 2145 UTC $3-27$ & $.03 \mathrm{FT}$ \\
\hline ELFIN COVE AK & 2133 UTC $3-27$ & $1.32 \mathrm{FT}$ \\
\hline YAKUTAT AK & 2132 UTC 3-27 & $2.44 \mathrm{FT}$ \\
\hline PORT ALEXANDER AK & 2114 UTC $3-27$ & $1.41 \mathrm{FT}$ \\
\hline CORDOVA AK & 2235 UTC $3-27$ & $1.82 \mathrm{FT}$ \\
\hline SHEMYA AK & 2245 UTC 3-27 & $0.34 \mathrm{FT}$ \\
\hline SITKA AK & 2222 UTC 3-27 & $74 \mathrm{FT}$ \\
\hline CRAIG AK & 2255 UTC $3-27$ & $88 \mathrm{FT}$ \\
\hline LANGARA BC & 2300 UTC $3-27$ & $1.60 \mathrm{FT}$ \\
\hline TOFINO BC & 2334 UTC $3-27$ & $.41 \mathrm{FT}$ \\
\hline NEAH BAY WA & 2234 UTC $3-27$ & $2.02 \mathrm{FT}$ \\
\hline LAPUSH WA & 2241 UTC 3-27 & $3.15 \mathrm{FT}$ \\
\hline WESTPORT WA & 2302 UTC $3-27$ & $2.11 \mathrm{FT}$ \\
\hline PORT ANGELES WA & 2354 UTC 3-27 & $1.38 \mathrm{FT}$ \\
\hline GARIBALDI OR & 2259 UTC $3-27$ & $1.05 \mathrm{FT}$ \\
\hline NEWPORT OR & 2309 UTC 3-27 & $2.46 \mathrm{FT}$ \\
\hline CHARLESTON OR & 2333 UTC $3-27$ & $2.74 \mathrm{FT}$ \\
\hline PORT ORFORD OR & 2355 UTC 3-27 & $6.76 \mathrm{FT}$ \\
\hline CRESCENT CITY CA & 0100 UTC $3-28$ & $7.11 \mathrm{FT}$ \\
\hline ARENA COVE CA & 2313 UTC 3-27 & $5.58 \mathrm{FT}$ \\
\hline EUREKA CA & 0006 UTC 3-28 & $4.23 \mathrm{FT}$ \\
\hline POINT REYES CA & 0142 UTC 3-28 & $3.38 \mathrm{FT}$ \\
\hline SAN FRANCISCO & 0155 UTC 3-28 & $3.71 \mathrm{FT}$ \\
\hline ALAMEDA CA & 0141 UTC 3-28 & $1.84 \mathrm{FT}$ \\
\hline MONTEREY CA & 2338 UTC $3-27$ & $3.97 \mathrm{FT}$ \\
\hline PORT SAN LUIS CA & 0108 UTC 3-28 & $14.30 \mathrm{FT}$ \\
\hline SANTA BARBARA CA & 0145 UTC 3-28 & 2.64 FT \\
\hline SANTA MONICA CA & 0157 UTC 3-28 & $3.38 \mathrm{FT}$ \\
\hline SAN PEDRO CA & 0230 UTC 3-28 & $3.11 \mathrm{FT}$ \\
\hline LA JOLLA CA & 0222 UTC 3-28 & $3.5 \mathrm{FT}$ \\
\hline SAN DIEGO CA & 0214 UTC $3-28$ & $1.74 \mathrm{FT}$ \\
\hline
\end{tabular}




$\begin{array}{lcc}\text { MIDWAY IS } & 2304 \text { UTC 3-27 } & 1.44 \mathrm{FT} \\ \text { NAWILIWILI HI } & 2323 \text { UTC 3-27 } & 2.20 \mathrm{FT} \\ \text { HALEIWA HI } & 2338 \text { UTC 3-27 } & 4.99 \mathrm{FT} \\ \text { HONOLULU HI } & 2338 \text { UTC 3-27 } & 2.23 \mathrm{FT} \\ \text { KAHULUI HI } & 2341 \text { UTC 3-27 } & 7.15 \mathrm{FT} \\ \text { KAWAIHAE HI } & 0014 \text { UTC 3-28 } & 2.89 \mathrm{FT} \\ \text { WAKE ISLAND } & 0052 \text { UTC 3-28 } & 0.33 \mathrm{FT} \\ \text { GUAM } & 0321 \text { UTC 3-28 } 0.30 \mathrm{FT}\end{array}$

$\begin{array}{llll}\text { PAGO PAGO AM SAMOA } 0433 \text { UTC } & 3-28 \quad 0.46 \text { FT }\end{array}$

HEIGHT - OBSERVED MAX TSUNAMI HEIGHT IS THE WATER LEVEL ABOVE THE TIDE LEVEL AT THE TIME OF MEASUREMENT.

PRELIMINARY EARTHQUAKE PARAMETERS

* MAGNITUDE 9.0

* ORIGIN TIME 1050 AKDT MAR 272014

1150 PDT MAR 272014

1850 UTC MAR 272014

* COORDINATES 55.2 NORTH 156.7 WEST

* DEPTH 11 MILES

* LOCATION 100 MILES SE OF CHIGNIK ALASKA 485 MILES SW OF ANCHORAGE ALASKA

NEXT UPDATE AND ADDITIONAL INFORMATION

* THIS MESSAGE WILL BE UPDATED IN 60 MINUTES.

* REFER TO THE INTERNET SITE WCATWC.ARH.NOAA.GOV FOR MORE INFORMATION.

* PACIFIC COASTAL RESIDENTS OUTSIDE CALIFORNIA... OREGON... WASHINGTON... BRITISH COLUMBIA AND ALASKA SHOULD REFER TO THE PACIFIC TSUNAMI WARNING CENTER MESSAGES FOR INFORMATION ON THIS EVENT AT PTWC.WEATHER.GOV. 
WEAK51 PAAQ 290302

TSUAK1

BULLETIN

PUBLIC TSUNAMI MESSAGE NUMBER 34

NWS WEST COAST/ALASKA TSUNAMI WARNING CENTER PALMER AK

702 PM AKDT FRI MAR 282014

THIS MESSAGE DOWNGRADES THE TSUNAMI WARNING TO AN ADVISORY FOR ALL AREAS IN CALIFORNIA AND OREGON WHICH WERE IN A WARNING.

...THE TSUNAMI WARNING REMAINS IN EFFECT...

...THE TSUNAMI ADVISORY REMAINS IN EFFECT...

WARNINGS/ADVISORIES/WATCHES - UPDATED

TSUNAMI WARNING IN EFFECT FOR...

* THE COASTAL AREAS OF ALASKA FROM KENNEDY ENTRANCE ALASKA/LOCATED 40 MILES SW OF HOMER/ TO NIKOLSKI ALASKA

TSUNAMI ADVISORY IN EFFECT FOR...

* THE COASTAL AREAS OF CALIFORNIA FROM THE CALIFORNIA-MEXICO BORDER TO POINT CONCEPTION CALIFORNIA

* THE COASTAL AREAS OF CALIFORNIA AND OREGON FROM POINT CONCEPTION CALIFORNIA TO DOUGLAS-LANE COUNTY LINE OREGON/10 MILES SW OF FLORENCE/

* THE COASTAL AREAS OF OREGON - WASHINGTON - BRITISH COLUMBIA 
AND ALASKA FROM DOUGLAS-LANE COUNTY LINE OREGON/10 MILES SW OF FLORENCE/ TO KENNEDY ENTRANCE ALASKA/LOCATED 40 MILES SW OF HOMER/

* FOR OTHER US AND CANDIAN PACIFIC COASTS IN NORTH AMERICA THIS IS FOR INFORMATION ONLY.

IMPACTS FOR TSUNAMI WARNING AREAS

* WIDESPREAD DANGEROUS COASTAL FLOODING ACCOMPANIED BY POWERFUL CURRENTS IS POSSIBLE AND MAY CONTINUE FOR MANY HOURS AFTER TSUNAMI ARRIVAL.

* THE FIRST WAVE MAY NOT BE THE LARGEST.

IMPACTS FOR TSUNAMI ADVISORY AREAS

* A TSUNAMI CAPABLE OF PRODUCING STRONG CURRENTS OR WAVES DANGEROUS

TO PERSONS IN OR VERY NEAR THE WATER IS EXPECTED.

* CURRENTS MAY BE HAZARDOUS TO SWIMMERS... BOATS... AND COASTAL STRUCTURES AND MAY CONTINUE FOR MANY HOURS AFTER THE TSUNAMI ARRIVAL.

* THE FIRST WAVE MAY NOT BE THE LARGEST.

\section{RECOMMENDED ACTIONS}

* IF YOU ARE IN A WARNING AREA - MOVE INLAND TO HIGHER GROUND.

* IF YOU ARE IN AN ADVISORY AREA - MOVE OFF THE BEACH AND OUT OF HARBORS AND MARINAS. WIDESPREAD INUNDATION OF LAND IS NOT EXPECTED FOR ADVISORY AREAS.

* BE ALERT TO INSTRUCTIONS FROM YOUR LOCAL EMERGENCY OFFICIALS.

* DO NOT GO TO THE COAST TO OBSERVE THE TSUNAMI.

* DO NOT RETURN TO THE COAST UNTIL LOCAL EMERGENCY OFFICIALS INDICATE IT IS SAFE TO DO SO. 
SIGNIFICANT TSUNAMI ACTIVITY IS EXPECTED TO CONTINUE FOR UP TO 15 MORE HOURS FOR AREAS STILL IN A LEVEL OF ALERT.

ADDITIONAL OBSERVATIONS OF TSUNAMI ACTIVITY - UPDATED

\begin{tabular}{|c|c|c|}
\hline \multirow[b]{2}{*}{ SITE } & \multicolumn{2}{|c|}{ OBSERVED MAX } \\
\hline & MEASUREMENT & SUNAMI HEIGHT \\
\hline SAND POINT AK & 1945 UTC $3-27$ & $11.60 \mathrm{FT}$ \\
\hline KING COVE AK & 2023 UTC 3-27 & $4.33 \mathrm{FT}$ \\
\hline CHIGNIK AK & 2026 UTC 3-27 & $21.82 \mathrm{FT}$ \\
\hline NIKOLSKI AK & 2054 UTC 3-27 & $1.61 \mathrm{FT}$ \\
\hline UNALASKA AK & 2056 UTC 3-27 & $1.44 \mathrm{FT}$ \\
\hline KODIAK AK & 2100 UTC $3-27$ & $4.50 \mathrm{FT}$ \\
\hline SEWARD AK & 2110 UTC $3-27$ & 4.11 FT \\
\hline ADAK AK & 2145 UTC $3-27$ & $.03 \mathrm{FT}$ \\
\hline ELFIN COVE AK & 2133 UTC $3-27$ & $1.32 \mathrm{FT}$ \\
\hline YAKUTAT AK & 2132 UTC 3-27 & $2.44 \mathrm{FT}$ \\
\hline PORT ALEXANDER AK & 2114 UTC $3-27$ & $1.41 \mathrm{FT}$ \\
\hline CORDOVA AK & 2235 UTC $3-27$ & $1.82 \mathrm{FT}$ \\
\hline SHEMYA AK & 2245 UTC 3-27 & $0.34 \mathrm{FT}$ \\
\hline SITKA AK & 2222 UTC 3-27 & $74 \mathrm{FT}$ \\
\hline CRAIG AK & 2255 UTC $3-27$ & $88 \mathrm{FT}$ \\
\hline LANGARA BC & 2300 UTC $3-27$ & $1.60 \mathrm{FT}$ \\
\hline TOFINO BC & 2334 UTC $3-27$ & $.41 \mathrm{FT}$ \\
\hline NEAH BAY WA & 2234 UTC $3-27$ & $2.02 \mathrm{FT}$ \\
\hline LAPUSH WA & 2241 UTC 3-27 & $3.15 \mathrm{FT}$ \\
\hline WESTPORT WA & 2302 UTC $3-27$ & $2.11 \mathrm{FT}$ \\
\hline PORT ANGELES WA & 2354 UTC 3-27 & $1.38 \mathrm{FT}$ \\
\hline GARIBALDI OR & 2259 UTC $3-27$ & $1.05 \mathrm{FT}$ \\
\hline NEWPORT OR & 2309 UTC 3-27 & $2.46 \mathrm{FT}$ \\
\hline CHARLESTON OR & 2333 UTC $3-27$ & $2.74 \mathrm{FT}$ \\
\hline PORT ORFORD OR & 2355 UTC 3-27 & $6.76 \mathrm{FT}$ \\
\hline CRESCENT CITY CA & 0100 UTC $3-28$ & $7.11 \mathrm{FT}$ \\
\hline ARENA COVE CA & 2313 UTC 3-27 & $5.58 \mathrm{FT}$ \\
\hline EUREKA CA & 0006 UTC 3-28 & $4.23 \mathrm{FT}$ \\
\hline POINT REYES CA & 0142 UTC 3-28 & $3.38 \mathrm{FT}$ \\
\hline SAN FRANCISCO & 0155 UTC 3-28 & $3.71 \mathrm{FT}$ \\
\hline ALAMEDA CA & 0141 UTC 3-28 & $1.84 \mathrm{FT}$ \\
\hline MONTEREY CA & 2338 UTC $3-27$ & $3.97 \mathrm{FT}$ \\
\hline PORT SAN LUIS CA & 0108 UTC 3-28 & $14.30 \mathrm{FT}$ \\
\hline SANTA BARBARA CA & 0145 UTC 3-28 & 2.64 FT \\
\hline SANTA MONICA CA & 0157 UTC 3-28 & $3.38 \mathrm{FT}$ \\
\hline SAN PEDRO CA & 0230 UTC 3-28 & $3.11 \mathrm{FT}$ \\
\hline LA JOLLA CA & 0222 UTC 3-28 & $3.5 \mathrm{FT}$ \\
\hline SAN DIEGO CA & 0214 UTC $3-28$ & $1.74 \mathrm{FT}$ \\
\hline
\end{tabular}




$\begin{array}{lcc}\text { MIDWAY IS } & 2304 \text { UTC 3-27 } & 1.44 \mathrm{FT} \\ \text { NAWILIWILI HI } & 2323 \text { UTC 3-27 } & 2.20 \mathrm{FT} \\ \text { HALEIWA HI } & 2338 \text { UTC 3-27 } & 4.99 \mathrm{FT} \\ \text { HONOLULU HI } & 2338 \text { UTC 3-27 } & 2.23 \mathrm{FT} \\ \text { KAHULUI HI } & 2341 \text { UTC 3-27 } & 7.15 \mathrm{FT} \\ \text { KAWAIHAE HI } & 0014 \text { UTC 3-28 } & 2.89 \mathrm{FT} \\ \text { WAKE ISLAND } & 0052 \text { UTC 3-28 } & 0.33 \mathrm{FT} \\ \text { GUAM } & 0321 \text { UTC 3-28 } 0.30 \mathrm{FT}\end{array}$

$\begin{array}{llll}\text { PAGO PAGO AM SAMOA } 0433 \text { UTC } & 3-28 \quad 0.46 \text { FT }\end{array}$

HEIGHT - OBSERVED MAX TSUNAMI HEIGHT IS THE WATER LEVEL ABOVE THE TIDE LEVEL AT THE TIME OF MEASUREMENT.

PRELIMINARY EARTHQUAKE PARAMETERS

* MAGNITUDE 9.0

* ORIGIN TIME 1050 AKDT MAR 272014

1150 PDT MAR 272014

1850 UTC MAR 272014

* COORDINATES 55.2 NORTH 156.7 WEST

* DEPTH 11 MILES

* LOCATION 100 MILES SE OF CHIGNIK ALASKA 485 MILES SW OF ANCHORAGE ALASKA

NEXT UPDATE AND ADDITIONAL INFORMATION

* THIS MESSAGE WILL BE UPDATED IN 60 MINUTES.

* REFER TO THE INTERNET SITE WCATWC.ARH.NOAA.GOV FOR MORE INFORMATION.

* PACIFIC COASTAL RESIDENTS OUTSIDE CALIFORNIA... OREGON... WASHINGTON... BRITISH COLUMBIA AND ALASKA SHOULD REFER TO THE PACIFIC TSUNAMI WARNING CENTER MESSAGES FOR INFORMATION ON THIS EVENT AT PTWC.WEATHER.GOV. 
WEAK51 PAAQ 290402

TSUAK1

BULLETIN

PUBLIC TSUNAMI MESSAGE NUMBER 35

NWS WEST COAST/ALASKA TSUNAMI WARNING CENTER PALMER AK 802 PM AKDT FRI MAR 282014

THIS MESSAGE DOWNGRADES THE TSUNAMI WARNING TO AN ADVISORY FOR SOME REGIONS IN THE EASTERN ALEUTIAN ISLANDS.

...THE TSUNAMI WARNING REMAINS IN EFFECT...

...THE TSUNAMI ADVISORY REMAINS IN EFFECT...

WARNINGS/ADVISORIES/WATCHES - UPDATED

TSUNAMI WARNING IN EFFECT FOR...

* THE COASTAL AREAS OF ALASKA FROM KENNEDY ENTRANCE ALASKA/LOCATED 40 MILES SW OF HOMER/ TO UNIMAK PASS

ALASKA/LOCATED 80 MILES NE OF DUTCH HARBOR/

TSUNAMI ADVISORY IN EFFECT FOR...

* THE COASTAL AREAS OF CALIFORNIA - OREGON - WASHINGTON BRITISH COLUMBIA AND ALASKA FROM THE CALIFORNIA-MEXICO BORDER TO KENNEDY ENTRANCE ALASKA/LOCATED 40 MILES SW OF HOMER/

* THE COASTAL AREAS OF ALASKA FROM UNIMAK PASS ALASKA/LOCATED 80 MILES NE OF DUTCH HARBOR/ TO NIKOLSKI ALASKA 
* FOR OTHER US AND CANDIAN PACIFIC COASTS IN NORTH AMERICA THIS IS FOR INFORMATION ONLY.

IMPACTS FOR TSUNAMI WARNING AREAS

* WIDESPREAD DANGEROUS COASTAL FLOODING ACCOMPANIED BY POWERFUL CURRENTS IS POSSIBLE AND MAY CONTINUE FOR MANY HOURS AFTER TSUNAMI ARRIVAL.

* THE FIRST WAVE MAY NOT BE THE LARGEST.

IMPACTS FOR TSUNAMI ADVISORY AREAS

* A TSUNAMI CAPABLE OF PRODUCING STRONG CURRENTS OR WAVES DANGEROUS

TO PERSONS IN OR VERY NEAR THE WATER IS EXPECTED.

* CURRENTS MAY BE HAZARDOUS TO SWIMMERS... BOATS... AND COASTAL STRUCTURES AND MAY CONTINUE FOR MANY HOURS AFTER THE TSUNAMI ARRIVAL.

* THE FIRST WAVE MAY NOT BE THE LARGEST.

RECOMMENDED ACTIONS

* IF YOU ARE IN A WARNING AREA - MOVE INLAND TO HIGHER GROUND.

* IF YOU ARE IN AN ADVISORY AREA - MOVE OFF THE BEACH AND OUT OF HARBORS AND MARINAS. WIDESPREAD INUNDATION OF LAND IS NOT EXPECTED FOR ADVISORY AREAS.

* BE ALERT TO INSTRUCTIONS FROM YOUR LOCAL EMERGENCY OFFICIALS.

* DO NOT GO TO THE COAST TO OBSERVE THE TSUNAMI.

* DO NOT RETURN TO THE COAST UNTIL LOCAL EMERGENCY OFFICIALS INDICATE IT IS SAFE TO DO SO.

SIGNIFICANT TSUNAMI ACTIVITY IS EXPECTED TO CONTINUE FOR UP TO 15 MORE HOURS FOR AREAS STILL IN A LEVEL OF ALERT. 


\begin{tabular}{|c|c|c|}
\hline \multirow[b]{2}{*}{ SITE } & \multicolumn{2}{|c|}{ OBSERVED MAX } \\
\hline & OF MEASUREMENT & TSUNA \\
\hline SAND POINT AK & 1945 UTC 3-27 & $11.60 \mathrm{FT}$ \\
\hline KING COVE AK & 2023 UTC 3-27 & $4.33 \mathrm{FT}$ \\
\hline CHIGNIK AK & 2026 UTC 3-27 & $21.82 \mathrm{FT}$ \\
\hline NIKOLSKI AK & 2054 UTC $3-27$ & $1.61 \mathrm{FT}$ \\
\hline UNALASKA AK & 2056 UTC $3-27$ & $1.44 \mathrm{FT}$ \\
\hline KODIAK AK & 2100 UTC $3-27$ & $4.50 \mathrm{FT}$ \\
\hline SEWARD AK & 2110 UTC $3-27$ & $4.11 \mathrm{FT}$ \\
\hline ADAK AK & 2145 UTC $3-27$ & $1.03 \mathrm{FT}$ \\
\hline ELFIN COVE AK & 2133 UTC $3-27$ & $1.32 \mathrm{FT}$ \\
\hline YAKUTAT AK & 2132 UTC $3-27$ & 2.44 FT \\
\hline PORT ALEXANDER A & 2114 UTC $3-27$ & $1.41 \mathrm{FT}$ \\
\hline CORDOVA AK & 2235 UTC $3-27$ & $1.82 \mathrm{FT}$ \\
\hline SHEMYA AK & 2245 UTC $3-27$ & $0.34 \mathrm{FT}$ \\
\hline SITKA AK & 2222 UTC $3-27$ & $.74 \mathrm{FT}$ \\
\hline CRAIG AK & 2255 UTC $3-27$ & $3.88 \mathrm{FT}$ \\
\hline LANGARA BC & 2300 UTC $3-27$ & $1.60 \mathrm{FT}$ \\
\hline TOFINO BC & 2334 UTC $3-27$ & $2.41 \mathrm{FT}$ \\
\hline NEAH BAY WA & 2234 UTC $3-27$ & $2.02 \mathrm{FT}$ \\
\hline LAPUSH WA & 2241 UTC 3-27 & $3.15 \mathrm{FT}$ \\
\hline WESTPORT WA & 2302 UTC $3-27$ & $2.11 \mathrm{FT}$ \\
\hline PORT ANGELES WA & 2354 UTC $3-27$ & $1.38 \mathrm{FT}$ \\
\hline GARIBALDI OR & 2259 UTC 3-27 & $1.05 \mathrm{FT}$ \\
\hline NEWPORT OR & 2309 UTC 3-27 & $2.46 \mathrm{FT}$ \\
\hline CHARLESTON OR & 2333 UTC $3-27$ & $2.74 \mathrm{FT}$ \\
\hline PORT ORFORD OR & 2355 UTC 3-27 & $6.76 \mathrm{FT}$ \\
\hline CRESCENT CITY CA & 0100 UTC $3-28$ & $7.11 \mathrm{FT}$ \\
\hline ARENA COVE CA & 2313 UTC 3-27 & $5.58 \mathrm{FT}$ \\
\hline EUREKA CA & 0006 UTC $3-28$ & $4.23 \mathrm{FT}$ \\
\hline POINT REYES CA & 0142 UTC 3-28 & $3.38 \mathrm{FT}$ \\
\hline SAN FRANCISCO & 0155 UTC $3-28$ & $3.71 \mathrm{FT}$ \\
\hline ALAMEDA CA & 0141 UTC 3-28 & $1.84 \mathrm{FT}$ \\
\hline MONTEREY CA & 2338 UTC $3-27$ & $3.97 \mathrm{FT}$ \\
\hline PORT SAN LUIS CA & 0108 UTC $3-28$ & $14.30 \mathrm{FT}$ \\
\hline SANTA BARBARA CA & 0145 UTC 3-28 & $2.64 \mathrm{FT}$ \\
\hline SANTA MONICA CA & 0157 UTC $3-28$ & $3.38 \mathrm{FT}$ \\
\hline SAN PEDRO CA & 0230 UTC $3-28$ & $3.11 \mathrm{FT}$ \\
\hline LA JOLLA CA & 0222 UTC 3-28 & $3.5 \mathrm{FT}$ \\
\hline SAN DIEGO CA & 0214 UTC 3-28 & $1.74 \mathrm{FT}$ \\
\hline MIDWAY IS & 2304 UTC $3-27$ & $1.44 \mathrm{FT}$ \\
\hline NAWILIWILI HI & 2323 UTC $3-27$ & $2.20 \mathrm{FT}$ \\
\hline HALEIWA HI & 2338 UTC $3-27$ & $4.99 \mathrm{FT}$ \\
\hline
\end{tabular}




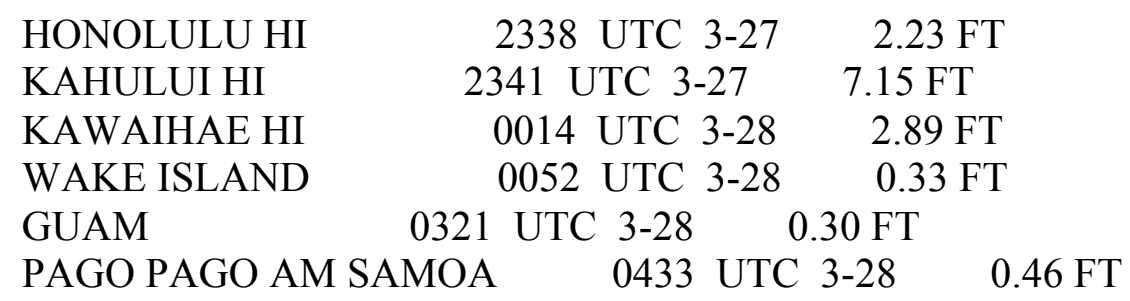

HEIGHT - OBSERVED MAX TSUNAMI HEIGHT IS THE WATER LEVEL ABOVE THE TIDE LEVEL AT THE TIME OF MEASUREMENT.

PRELIMINARY EARTHQUAKE PARAMETERS

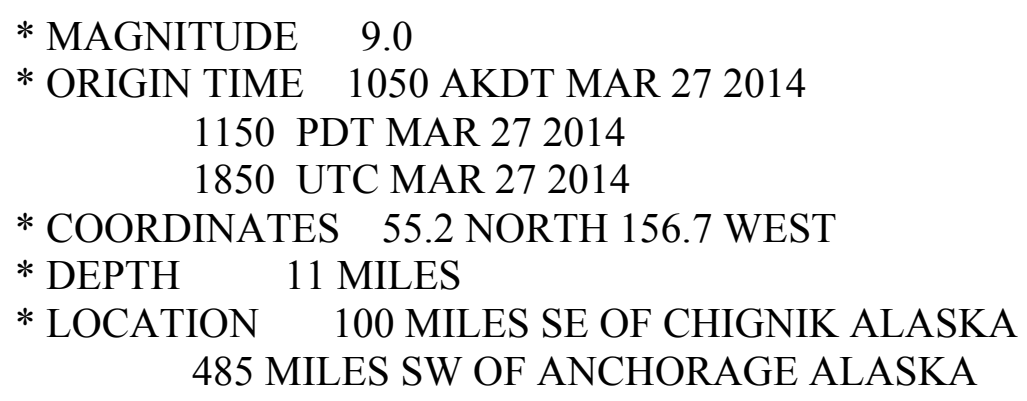

NEXT UPDATE AND ADDITIONAL INFORMATION

* THIS MESSAGE WILL BE UPDATED IN 60 MINUTES.

* REFER TO THE INTERNET SITE WCATWC.ARH.NOAA.GOV FOR MORE INFORMATION.

* PACIFIC COASTAL RESIDENTS OUTSIDE CALIFORNIA... OREGON... WASHINGTON... BRITISH COLUMBIA AND ALASKA SHOULD REFER TO THE PACIFIC TSUNAMI WARNING CENTER MESSAGES FOR INFORMATION ON THIS EVENT AT PTWC.WEATHER.GOV.

$\$ \$$ 
WEAK51 PAAQ 290500

TSUAK1

BULLETIN

PUBLIC TSUNAMI MESSAGE NUMBER 36

NWS WEST COAST/ALASKA TSUNAMI WARNING CENTER PALMER AK 900 PM AKDT FRI MAR 282014

THIS MESSAGE CONTINUES THE WARNING AND ADVISORY AS IN THE PREVIOUS MESSAGE.

...THE TSUNAMI WARNING REMAINS IN EFFECT...

...THE TSUNAMI ADVISORY REMAINS IN EFFECT...

WARNINGS/ADVISORIES/WATCHES

TSUNAMI WARNING IN EFFECT FOR...

* THE COASTAL AREAS OF ALASKA FROM KENNEDY ENTRANCE ALASKA/LOCATED 40 MILES SW OF HOMER/ TO UNIMAK PASS ALASKA/LOCATED 80 MILES NE OF DUTCH HARBOR/

TSUNAMI ADVISORY IN EFFECT FOR...

* THE COASTAL AREAS OF CALIFORNIA - OREGON - WASHINGTON BRITISH COLUMBIA AND ALASKA FROM THE CALIFORNIA-MEXICO BORDER TO KENNEDY ENTRANCE ALASKA/LOCATED 40 MILES SW OF HOMER/

* THE COASTAL AREAS OF ALASKA FROM UNIMAK PASS ALASKA/LOCATED 80 MILES NE OF DUTCH HARBOR/ TO NIKOLSKI ALASKA 
* FOR OTHER US AND CANDIAN PACIFIC COASTS IN NORTH AMERICA THIS IS FOR INFORMATION ONLY.

IMPACTS FOR TSUNAMI WARNING AREAS

* WIDESPREAD DANGEROUS COASTAL FLOODING ACCOMPANIED BY POWERFUL CURRENTS IS POSSIBLE AND MAY CONTINUE FOR MANY HOURS AFTER TSUNAMI ARRIVAL.

* THE FIRST WAVE MAY NOT BE THE LARGEST.

IMPACTS FOR TSUNAMI ADVISORY AREAS

* A TSUNAMI CAPABLE OF PRODUCING STRONG CURRENTS OR WAVES DANGEROUS

TO PERSONS IN OR VERY NEAR THE WATER IS EXPECTED.

* CURRENTS MAY BE HAZARDOUS TO SWIMMERS... BOATS... AND COASTAL STRUCTURES AND MAY CONTINUE FOR MANY HOURS AFTER THE TSUNAMI ARRIVAL.

* THE FIRST WAVE MAY NOT BE THE LARGEST.

\section{RECOMMENDED ACTIONS}

* IF YOU ARE IN A WARNING AREA - MOVE INLAND TO HIGHER GROUND.

* IF YOU ARE IN AN ADVISORY AREA - MOVE OFF THE BEACH AND OUT OF HARBORS AND MARINAS. WIDESPREAD INUNDATION OF LAND IS NOT EXPECTED FOR ADVISORY AREAS.

* BE ALERT TO INSTRUCTIONS FROM YOUR LOCAL EMERGENCY OFFICIALS.

* DO NOT GO TO THE COAST TO OBSERVE THE TSUNAMI.

* DO NOT RETURN TO THE COAST UNTIL LOCAL EMERGENCY OFFICIALS INDICATE IT IS SAFE TO DO SO.

SIGNIFICANT TSUNAMI ACTIVITY IS EXPECTED TO CONTINUE FOR UP TO 12 MORE HOURS FOR AREAS STILL IN A LEVEL OF ALERT.

ADDITIONAL OBSERVATIONS OF TSUNAMI ACTIVITY - UPDATED 


\begin{tabular}{|c|c|c|}
\hline \multirow[b]{2}{*}{ SITE } & \multicolumn{2}{|c|}{ OBSERVED MAX } \\
\hline & MEASUREMENT & TSUNAMI HEIGHT \\
\hline SAND POINT AK & 1945 UTC 3-27 & $1160 \mathrm{FT}$ \\
\hline KING COVE AK & 2023 UTC 3-27 & $4.33 \mathrm{FT}$ \\
\hline CHIGNIK AK & 2026 UTC 3-27 & $21.82 \mathrm{FT}$ \\
\hline NIKOLSKI AK & 2054 UTC 3-27 & $1.61 \mathrm{FT}$ \\
\hline UNALASKA AK & 2056 UTC 3-27 & $1.44 \mathrm{FT}$ \\
\hline KODIAK AK & 2100 UTC 3-27 & $4.50 \mathrm{FT}$ \\
\hline SEWARD AK & 2110 UTC 3-27 & $4.11 \mathrm{FT}$ \\
\hline ADAK AK & 2145 UTC 3-27 & $.03 \mathrm{FT}$ \\
\hline ELFIN COVE AK & 2133 UTC 3-27 & $1.32 \mathrm{FT}$ \\
\hline YAKUTAT AK & 2132 UTC 3-27 & $2.44 \mathrm{FT}$ \\
\hline PORT ALEXANDER AI & 2114 UTC 3-27 & $1.41 \mathrm{FT}$ \\
\hline CORDOVA AK & 2235 UTC 3-27 & $1.82 \mathrm{FT}$ \\
\hline SHEMYA AK & 2245 UTC 3-27 & $0.34 \mathrm{FT}$ \\
\hline SITKA AK & 2222 UTC 3-27 & $.74 \mathrm{FT}$ \\
\hline CRAIG AK & 2255 UTC 3-27 & $.88 \mathrm{FT}$ \\
\hline LANGARA BC & 2300 UTC 3-27 & $1.60 \mathrm{FT}$ \\
\hline TOFINO BC & 2334 UTC 3-27 & $2.41 \mathrm{FT}$ \\
\hline NEAH BAY WA & 2234 UTC 3-27 & $2.02 \mathrm{FT}$ \\
\hline LAPUSH WA & 2241 UTC 3-27 & $3.15 \mathrm{FT}$ \\
\hline WESTPORT WA & 2302 UTC 3-27 & $2.11 \mathrm{FT}$ \\
\hline PORT ANGELES WA & 2354 UTC 3-27 & $1.38 \mathrm{FT}$ \\
\hline GARIBALDI OR & 2259 UTC 3-27 & $1.05 \mathrm{FT}$ \\
\hline NEWPORT OR & 2309 UTC 3-27 & $2.46 \mathrm{FT}$ \\
\hline CHARLESTON OR & 2333 UTC 3-27 & $2.74 \mathrm{FT}$ \\
\hline PORT ORFORD OR & 2355 UTC 3-27 & $6.76 \mathrm{FT}$ \\
\hline CRESCENT CITY CA & 0100 UTC 3-28 & $7.11 \mathrm{FT}$ \\
\hline ARENA COVE CA & 2313 UTC 3-27 & $5.58 \mathrm{FT}$ \\
\hline EUREKA CA & 0006 UTC 3-28 & $4.23 \mathrm{FT}$ \\
\hline POINT REYES CA & 0142 UTC 3-28 & $3.38 \mathrm{FT}$ \\
\hline SAN FRANCISCO & 0155 UTC 3-28 & $3.71 \mathrm{FT}$ \\
\hline ALAMEDA CA & 0141 UTC 3-28 & $1.84 \mathrm{FT}$ \\
\hline MONTEREY CA & 2338 UTC 3-27 & $3.97 \mathrm{FT}$ \\
\hline PORT SAN LUIS CA & 0108 UTC 3-28 & $14.30 \mathrm{FT}$ \\
\hline SANTA BARBARA CA & 0145 UTC 3-28 & $2.64 \mathrm{FT}$ \\
\hline SANTA MONICA CA & 0157 UTC 3-28 & $3.38 \mathrm{FT}$ \\
\hline SAN PEDRO CA & 0230 UTC 3-28 & $3.11 \mathrm{FT}$ \\
\hline LA JOLLA CA & 0222 UTC 3-28 & $3.5 \mathrm{FT}$ \\
\hline SAN DIEGO CA & 0214 UTC 3-28 & $1.74 \mathrm{FT}$ \\
\hline MIDWAY IS & 2304 UTC 3-27 & $1.44 \mathrm{FT}$ \\
\hline NAWILIWILI HI & 2323 UTC 3-27 & $2.20 \mathrm{FT}$ \\
\hline HALEIWA HI & 2338 UTC 3-27 & $4.99 \mathrm{FT}$ \\
\hline HONOLULU HI & 2338 UTC 3-27 & $2.23 \mathrm{FT}$ \\
\hline
\end{tabular}




$\begin{array}{lrc}\text { KAHULUI HI } & \text { 2341 UTC 3-27 } & 7.15 \mathrm{FT} \\ \text { KAWAIHAE HI } & \text { 0014 UTC 3-28 } & 2.89 \mathrm{FT} \\ \text { WAKE ISLAND } & \text { 0052 UTC 3-28 } & 0.33 \mathrm{FT} \\ \text { GUAM } & 0321 \text { UTC 3-28 } & 0.30 \mathrm{FT}\end{array}$

$\begin{array}{llll}\text { PAGO PAGO AM SAMOA } & 0433 \text { UTC } 3-28 \quad 0.46 \mathrm{FT}\end{array}$

HEIGHT - OBSERVED MAX TSUNAMI HEIGHT IS THE WATER LEVEL ABOVE THE TIDE LEVEL AT THE TIME OF MEASUREMENT.

PRELIMINARY EARTHQUAKE PARAMETERS

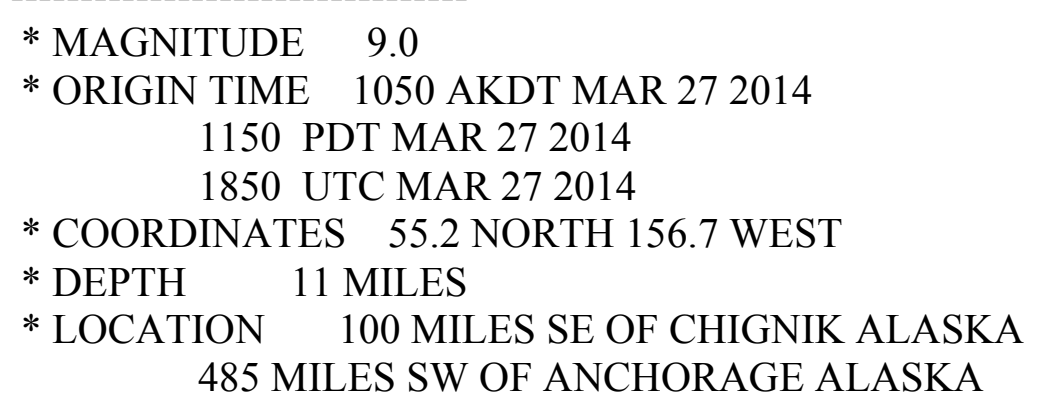

NEXT UPDATE AND ADDITIONAL INFORMATION

* THIS MESSAGE WILL BE UPDATED IN 60 MINUTES.

* REFER TO THE INTERNET SITE WCATWC.ARH.NOAA.GOV FOR MORE INFORMATION.

* PACIFIC COASTAL RESIDENTS OUTSIDE CALIFORNIA... OREGON... WASHINGTON... BRITISH COLUMBIA AND ALASKA SHOULD REFER TO THE PACIFIC TSUNAMI WARNING CENTER MESSAGES FOR INFORMATION ON THIS EVENT AT PTWC.WEATHER.GOV.

$\$ \$$ 
WEAK51 PAAQ 290600

TSUAK1

BULLETIN

PUBLIC TSUNAMI MESSAGE NUMBER 37

NWS WEST COAST/ALASKA TSUNAMI WARNING CENTER PALMER AK 1000 PM AKDT FRI MAR 282014

THIS MESSAGE CONTINUES THE WARNING AND ADVISORY AS IN THE PREVIOUS MESSAGE.

...THE TSUNAMI WARNING REMAINS IN EFFECT...

...THE TSUNAMI ADVISORY REMAINS IN EFFECT...

WARNINGS/ADVISORIES/WATCHES

TSUNAMI WARNING IN EFFECT FOR...

* THE COASTAL AREAS OF ALASKA FROM KENNEDY ENTRANCE ALASKA/LOCATED 40 MILES SW OF HOMER/ TO UNIMAK PASS

ALASKA/LOCATED 80 MILES NE OF DUTCH HARBOR/

TSUNAMI ADVISORY IN EFFECT FOR...

* THE COASTAL AREAS OF CALIFORNIA - OREGON - WASHINGTON BRITISH COLUMBIA AND ALASKA FROM THE CALIFORNIA-MEXICO BORDER TO KENNEDY ENTRANCE ALASKA/LOCATED 40 MILES SW OF HOMER/

* THE COASTAL AREAS OF ALASKA FROM UNIMAK PASS ALASKA/LOCATED 80 MILES NE OF DUTCH HARBOR/ TO NIKOLSKI ALASKA

* FOR OTHER US AND CANDIAN PACIFIC COASTS IN NORTH AMERICA - 
THIS IS FOR INFORMATION ONLY.

IMPACTS FOR TSUNAMI WARNING AREAS

* WIDESPREAD DANGEROUS COASTAL FLOODING ACCOMPANIED BY POWERFUL CURRENTS IS POSSIBLE AND MAY CONTINUE FOR MANY HOURS AFTER TSUNAMI ARRIVAL.

* THE FIRST WAVE MAY NOT BE THE LARGEST.

IMPACTS FOR TSUNAMI ADVISORY AREAS

* A TSUNAMI CAPABLE OF PRODUCING STRONG CURRENTS OR WAVES DANGEROUS

TO PERSONS IN OR VERY NEAR THE WATER IS EXPECTED.

* CURRENTS MAY BE HAZARDOUS TO SWIMMERS... BOATS... AND COASTAL STRUCTURES AND MAY CONTINUE FOR MANY HOURS AFTER THE TSUNAMI ARRIVAL.

* THE FIRST WAVE MAY NOT BE THE LARGEST.

RECOMMENDED ACTIONS

* IF YOU ARE IN A WARNING AREA - MOVE INLAND TO HIGHER GROUND.

* IF YOU ARE IN AN ADVISORY AREA - MOVE OFF THE BEACH AND OUT OF HARBORS AND MARINAS. WIDESPREAD INUNDATION OF LAND IS NOT EXPECTED FOR ADVISORY AREAS.

* BE ALERT TO INSTRUCTIONS FROM YOUR LOCAL EMERGENCY OFFICIALS.

* DO NOT GO TO THE COAST TO OBSERVE THE TSUNAMI.

* DO NOT RETURN TO THE COAST UNTIL LOCAL EMERGENCY OFFICIALS INDICATE IT IS SAFE TO DO SO.

SIGNIFICANT TSUNAMI ACTIVITY IS EXPECTED TO CONTINUE FOR UP TO 12 MORE HOURS FOR AREAS STILL IN A LEVEL OF ALERT.

ADDITIONAL OBSERVATIONS OF TSUNAMI ACTIVITY - UPDATED 
TIME OBSERVED MAX

SITE OF MEASUREMENT TSUNAMI HEIGHT

\begin{tabular}{|c|c|c|}
\hline & & \\
\hline SAND POINT AK & 1945 UTC 3-27 & $11.60 \mathrm{FT}$ \\
\hline KING COVE AK & 2023 UTC 3-27 & $4.33 \mathrm{FT}$ \\
\hline CHIGNIK AK & 2026 UTC 3-27 & $21.82 \mathrm{FT}$ \\
\hline NIKOLSKI AK & 2054 UTC 3-27 & $1.61 \mathrm{FT}$ \\
\hline UNALASKA AK & 2056 UTC 3-27 & $1.44 \mathrm{FT}$ \\
\hline KODIAK AK & 2100 UTC 3-27 & 4.50 FT \\
\hline SEWARD AK & 2110 UTC 3-27 & 4.11 FT \\
\hline ADAK AK & 2145 UTC $3-27$ & $.03 \mathrm{FT}$ \\
\hline ELFIN COVE AK & 2133 UTC 3-27 & $1.32 \mathrm{FT}$ \\
\hline YAKUTAT AK & 2132 UTC 3-27 & $2.44 \mathrm{FT}$ \\
\hline PORT ALEXANDER Al & 2114 UTC 3-2 & $27 \quad 1.41 \mathrm{FT}$ \\
\hline CORDOVA AK & 2235 UTC 3-27 & $1.82 \mathrm{FT}$ \\
\hline SHEMYA AK & 2245 UTC 3-27 & $0.34 \mathrm{FT}$ \\
\hline SITKA AK & 2222 UTC 3-27 & $.74 \mathrm{FT}$ \\
\hline CRAIG AK & 2255 UTC 3-27 & $.88 \mathrm{FT}$ \\
\hline LANGARA BC & 2300 UTC 3-27 & $1.60 \mathrm{FT}$ \\
\hline TOFINO BC & 2334 UTC 3-27 & $2.41 \mathrm{FT}$ \\
\hline NEAH BAY WA & 2234 UTC 3-27 & $2.02 \mathrm{FT}$ \\
\hline LAPUSH WA & 2241 UTC 3-27 & $3.15 \mathrm{FT}$ \\
\hline WESTPORT WA & 2302 UTC 3-27 & $2.11 \mathrm{FT}$ \\
\hline PORT ANGELES WA & 2354 UTC 3-27 & $1.38 \mathrm{FT}$ \\
\hline GARIBALDI OR & 2259 UTC 3-27 & $1.05 \mathrm{FT}$ \\
\hline NEWPORT OR & 2309 UTC 3-27 & $2.46 \mathrm{FT}$ \\
\hline CHARLESTON OR & 2333 UTC 3-27 & $2.74 \mathrm{FT}$ \\
\hline PORT ORFORD OR & 2355 UTC 3-27 & $6.76 \mathrm{FT}$ \\
\hline CRESCENT CITY CA & 0100 UTC 3-28 & $7.11 \mathrm{FT}$ \\
\hline ARENA COVE CA & 2313 UTC 3-27 & $5.58 \mathrm{FT}$ \\
\hline EUREKA CA & 0006 UTC 3-28 & $4.23 \mathrm{FT}$ \\
\hline POINT REYES CA & 0142 UTC 3-28 & $3.38 \mathrm{FT}$ \\
\hline SAN FRANCISCO & 0155 UTC 3-28 & $3.71 \mathrm{FT}$ \\
\hline ALAMEDA CA & 0141 UTC 3-28 & $1.84 \mathrm{FT}$ \\
\hline MONTEREY CA & 2338 UTC 3-27 & $3.97 \mathrm{FT}$ \\
\hline PORT SAN LUIS CA & 0108 UTC 3-28 & $14.30 \mathrm{FT}$ \\
\hline SANTA BARBARA CA & 0145 UTC 3-28 & $2.64 \mathrm{FT}$ \\
\hline SANTA MONICA CA & 0157 UTC 3-28 & $3.38 \mathrm{FT}$ \\
\hline SAN PEDRO CA & 0230 UTC 3-28 & $3.11 \mathrm{FT}$ \\
\hline LA JOLLA CA & 0222 UTC 3-28 & $3.5 \mathrm{FT}$ \\
\hline SAN DIEGO CA & 0214 UTC 3-28 & $1.74 \mathrm{FT}$ \\
\hline MIDWAY IS & 2304 UTC 3-27 & $1.44 \mathrm{FT}$ \\
\hline NAWILIWILI HI & 2323 UTC 3-27 & $2.20 \mathrm{FT}$ \\
\hline HALEIWA HI & 2338 UTC 3-27 & $4.99 \mathrm{FT}$ \\
\hline HONOLULU HI & 2338 UTC 3-27 & $2.23 \mathrm{FT}$ \\
\hline KAHULUI HI & 2341 UTC 3-27 & $7.15 \mathrm{FT}$ \\
\hline
\end{tabular}




$\begin{array}{lrccc}\text { KAWAIHAE HI } & 0014 & \text { UTC } & 3-28 & 2.89 \mathrm{FT} \\ \text { WAKE ISLAND } & \text { 0052 } & \text { UTC } & 3-28 & 0.33 \mathrm{FT} \\ \text { GUAM } & 0321 & \text { UTC } & 3-28 & 0.30 \mathrm{FT}\end{array}$
HEIGHT - OBSERVED MAX TSUNAMI HEIGHT IS THE WATER LEVEL ABOVE THE TIDE LEVEL AT THE TIME OF MEASUREMENT.

PRELIMINARY EARTHQUAKE PARAMETERS

* MAGNITUDE 9.0

* ORIGIN TIME 1050 AKDT MAR 272014

1150 PDT MAR 272014

1850 UTC MAR 272014

* COORDINATES 55.2 NORTH 156.7 WEST

* DEPTH 11 MILES

* LOCATION 100 MILES SE OF CHIGNIK ALASKA 485 MILES SW OF ANCHORAGE ALASKA

\section{NEXT UPDATE AND ADDITIONAL INFORMATION}

* THIS MESSAGE WILL BE UPDATED IN 60 MINUTES.

* REFER TO THE INTERNET SITE WCATWC.ARH.NOAA.GOV FOR MORE INFORMATION.

* PACIFIC COASTAL RESIDENTS OUTSIDE CALIFORNIA... OREGON... WASHINGTON... BRITISH COLUMBIA AND ALASKA SHOULD REFER TO THE PACIFIC TSUNAMI WARNING CENTER MESSAGES FOR INFORMATION ON THIS EVENT AT PTWC.WEATHER.GOV. 
WEAK51 PAAQ 290700

TSUAK1

BULLETIN

PUBLIC TSUNAMI MESSAGE NUMBER 38

NWS WEST COAST/ALASKA TSUNAMI WARNING CENTER PALMER AK 1100 PM AKDT FRI MAR 282014

THIS MESSAGE CONTINUES THE WARNING AND ADVISORY AS IN THE PREVIOUS MESSAGE.

...THE TSUNAMI WARNING REMAINS IN EFFECT...

...THE TSUNAMI ADVISORY REMAINS IN EFFECT...

WARNINGS/ADVISORIES/WATCHES

TSUNAMI WARNING IN EFFECT FOR...

* THE COASTAL AREAS OF ALASKA FROM KENNEDY ENTRANCE ALASKA/LOCATED 40 MILES SW OF HOMER/ TO UNIMAK PASS

ALASKA/LOCATED 80 MILES NE OF DUTCH HARBOR/

TSUNAMI ADVISORY IN EFFECT FOR...

* THE COASTAL AREAS OF CALIFORNIA - OREGON - WASHINGTON BRITISH COLUMBIA AND ALASKA FROM THE CALIFORNIA-MEXICO BORDER TO KENNEDY ENTRANCE ALASKA/LOCATED 40 MILES SW OF HOMER/

* THE COASTAL AREAS OF ALASKA FROM UNIMAK PASS ALASKA/LOCATED 80 MILES NE OF DUTCH HARBOR/ TO NIKOLSKI ALASKA

* FOR OTHER US AND CANDIAN PACIFIC COASTS IN NORTH AMERICA THIS IS FOR INFORMATION ONLY. 
IMPACTS FOR TSUNAMI WARNING AREAS

* WIDESPREAD DANGEROUS COASTAL FLOODING ACCOMPANIED BY POWERFUL CURRENTS IS POSSIBLE AND MAY CONTINUE FOR MANY HOURS AFTER TSUNAMI ARRIVAL.

* THE FIRST WAVE MAY NOT BE THE LARGEST.

IMPACTS FOR TSUNAMI ADVISORY AREAS

* A TSUNAMI CAPABLE OF PRODUCING STRONG CURRENTS OR WAVES DANGEROUS

TO PERSONS IN OR VERY NEAR THE WATER IS EXPECTED.

* CURRENTS MAY BE HAZARDOUS TO SWIMMERS... BOATS... AND COASTAL STRUCTURES AND MAY CONTINUE FOR MANY HOURS AFTER THE TSUNAMI ARRIVAL.

* THE FIRST WAVE MAY NOT BE THE LARGEST.

\section{RECOMMENDED ACTIONS}

* IF YOU ARE IN A WARNING AREA - MOVE INLAND TO HIGHER GROUND.

* IF YOU ARE IN AN ADVISORY AREA - MOVE OFF THE BEACH AND OUT OF HARBORS AND MARINAS. WIDESPREAD INUNDATION OF LAND IS NOT EXPECTED FOR ADVISORY AREAS.

* BE ALERT TO INSTRUCTIONS FROM YOUR LOCAL EMERGENCY OFFICIALS.

* DO NOT GO TO THE COAST TO OBSERVE THE TSUNAMI.

* DO NOT RETURN TO THE COAST UNTIL LOCAL EMERGENCY OFFICIALS INDICATE IT IS SAFE TO DO SO.

SIGNIFICANT TSUNAMI ACTIVITY IS EXPECTED TO CONTINUE FOR UP TO 12 MORE HOURS FOR AREAS STILL IN A LEVEL OF ALERT.

ADDITIONAL OBSERVATIONS OF TSUNAMI ACTIVITY - UPDATED

TIME OBSERVED MAX 


\begin{tabular}{|c|c|c|}
\hline SAND POINT AK & 1945 UTC $3-27$ & $11.60 \mathrm{FT}$ \\
\hline KING COVE AK & 2023 UTC 3-27 & $4.33 \mathrm{FT}$ \\
\hline CHIGNIK AK & 2026 UTC $3-27$ & $21.82 \mathrm{FT}$ \\
\hline NIKOLSKI AK & 2054 UTC 3-27 & $1.61 \mathrm{FT}$ \\
\hline UNALASKA AK & 2056 UTC $3-27$ & $1.44 \mathrm{FT}$ \\
\hline KODIAK AK & 2100 UTC $3-27$ & $4.50 \mathrm{FT}$ \\
\hline SEWARD AK & 2110 UTC $3-27$ & $4.11 \mathrm{FT}$ \\
\hline ADAK AK & 2145 UTC $3-27$ & $1.03 \mathrm{FT}$ \\
\hline ELFIN COVE AK & 2133 UTC $3-27$ & $1.32 \mathrm{FT}$ \\
\hline YAKUTAT AK & 2132 UTC 3-27 & $2.44 \mathrm{FT}$ \\
\hline PORT ALEXANDER AK & 2114 UTC $3-2$ & $1.41 \mathrm{FT}$ \\
\hline CORDOVA AK & 2235 UTC $3-27$ & $1.82 \mathrm{FT}$ \\
\hline SHEMYA AK & 2245 UTC 3-27 & $0.34 \mathrm{FT}$ \\
\hline SITKA AK & 2222 UTC 3-27 & $3.74 \mathrm{FT}$ \\
\hline CRAIG AK & 2255 UTC $3-27$ & $3.88 \mathrm{FT}$ \\
\hline LANGARA BC & 2300 UTC $3-27$ & $1.60 \mathrm{FT}$ \\
\hline TOFINO BC & 2334 UTC $3-27$ & $2.41 \mathrm{FT}$ \\
\hline NEAH BAY WA & 2234 UTC $3-27$ & $2.02 \mathrm{FT}$ \\
\hline LAPUSH WA & 2241 UTC 3-27 & $3.15 \mathrm{FT}$ \\
\hline WESTPORT WA & 2302 UTC $3-27$ & $2.11 \mathrm{FT}$ \\
\hline PORT ANGELES WA & 2354 UTC $3-27$ & $1.38 \mathrm{FT}$ \\
\hline GARIBALDI OR & 2259 UTC $3-27$ & $1.05 \mathrm{FT}$ \\
\hline NEWPORT OR & 2309 UTC 3-27 & $2.46 \mathrm{FT}$ \\
\hline CHARLESTON OR & 2333 UTC $3-27$ & $2.74 \mathrm{FT}$ \\
\hline PORT ORFORD OR & 2355 UTC $3-27$ & $6.76 \mathrm{FT}$ \\
\hline CRESCENT CITY CA & 0100 UTC $3-28$ & $7.11 \mathrm{FT}$ \\
\hline ARENA COVE CA & 2313 UTC 3-27 & $5.58 \mathrm{FT}$ \\
\hline EUREKA CA & 0006 UTC 3-28 & $4.23 \mathrm{FT}$ \\
\hline POINT REYES CA & 0142 UTC $3-28$ & $3.38 \mathrm{FT}$ \\
\hline SAN FRANCISCO & 0155 UTC $3-28$ & $3.71 \mathrm{FT}$ \\
\hline ALAMEDA CA & 0141 UTC 3-28 & $1.84 \mathrm{FT}$ \\
\hline MONTEREY CA & 2338 UTC $3-27$ & 3.97 FT \\
\hline PORT SAN LUIS CA & 0108 UTC $3-28$ & $14.30 \mathrm{FT}$ \\
\hline SANTA BARBARA CA & 0145 UTC $3-2$ & $2.64 \mathrm{FT}$ \\
\hline SANTA MONICA CA & 0157 UTC $3-28$ & $3.38 \mathrm{FT}$ \\
\hline SAN PEDRO CA & 0230 UTC $3-28$ & $3.11 \mathrm{FT}$ \\
\hline LA JOLLA CA & 0222 UTC $3-28$ & $3.5 \mathrm{FT}$ \\
\hline SAN DIEGO CA & 0214 UTC $3-28$ & $1.74 \mathrm{FT}$ \\
\hline MIDWAY IS & 2304 UTC $3-27$ & $1.44 \mathrm{FT}$ \\
\hline NAWILIWILI HI & 2323 UTC $3-27$ & $2.20 \mathrm{FT}$ \\
\hline HALEIWA HI & 2338 UTC $3-27$ & $4.99 \mathrm{FT}$ \\
\hline HONOLULU HI & 2338 UTC $3-27$ & $2.23 \mathrm{FT}$ \\
\hline KAHULUI HI & 2341 UTC $3-27$ & $7.15 \mathrm{FT}$ \\
\hline KAWAIHAE HI & 0014 UTC 3-28 & $2.89 \mathrm{FT}$ \\
\hline
\end{tabular}




$$
\begin{aligned}
& \text { WAKE ISLAND } \quad 0052 \text { UTC 3-28 } 0.33 \text { FT } \\
& \text { GUAM 0321 UTC 3-28 0.30 FT } \\
& \text { PAGO PAGO AM SAMOA } 0433 \text { UTC 3-28 } 0.46 \text { FT }
\end{aligned}
$$

HEIGHT - OBSERVED MAX TSUNAMI HEIGHT IS THE WATER LEVEL ABOVE THE TIDE LEVEL AT THE TIME OF MEASUREMENT.

\section{PRELIMINARY EARTHQUAKE PARAMETERS}

* MAGNITUDE 9.0

* ORIGIN TIME 1050 AKDT MAR 272014

1150 PDT MAR 272014

1850 UTC MAR 272014

* COORDINATES 55.2 NORTH 156.7 WEST

* DEPTH 11 MILES

* LOCATION 100 MILES SE OF CHIGNIK ALASKA 485 MILES SW OF ANCHORAGE ALASKA

NEXT UPDATE AND ADDITIONAL INFORMATION

* THIS MESSAGE WILL BE UPDATED IN 60 MINUTES.

* REFER TO THE INTERNET SITE WCATWC.ARH.NOAA.GOV FOR MORE INFORMATION.

* PACIFIC COASTAL RESIDENTS OUTSIDE CALIFORNIA... OREGON... WASHINGTON... BRITISH COLUMBIA AND ALASKA SHOULD REFER TO THE PACIFIC TSUNAMI WARNING CENTER MESSAGES FOR INFORMATION ON THIS EVENT AT PTWC.WEATHER.GOV. 
WEAK51 PAAQ 290800

TSUAK1

BULLETIN

PUBLIC TSUNAMI MESSAGE NUMBER 39

NWS WEST COAST/ALASKA TSUNAMI WARNING CENTER PALMER AK 1200 AM AKDT SAT MAR 292014

THIS MESSAGE CONTINUES THE WARNING AND ADVISORY AS IN THE PREVIOUS MESSAGE.

...THE TSUNAMI WARNING REMAINS IN EFFECT...

...THE TSUNAMI ADVISORY REMAINS IN EFFECT...

WARNINGS/ADVISORIES/WATCHES

TSUNAMI WARNING IN EFFECT FOR...

* THE COASTAL AREAS OF ALASKA FROM KENNEDY ENTRANCE ALASKA/LOCATED 40 MILES SW OF HOMER/ TO UNIMAK PASS

ALASKA/LOCATED 80 MILES NE OF DUTCH HARBOR/

TSUNAMI ADVISORY IN EFFECT FOR...

* THE COASTAL AREAS OF CALIFORNIA - OREGON - WASHINGTON BRITISH COLUMBIA AND ALASKA FROM THE CALIFORNIA-MEXICO BORDER TO KENNEDY ENTRANCE ALASKA/LOCATED 40 MILES SW OF HOMER/

* THE COASTAL AREAS OF ALASKA FROM UNIMAK PASS ALASKA/LOCATED 80 MILES NE OF DUTCH HARBOR/ TO NIKOLSKI ALASKA

* FOR OTHER US AND CANDIAN PACIFIC COASTS IN NORTH AMERICA THIS IS FOR INFORMATION ONLY. 
IMPACTS FOR TSUNAMI WARNING AREAS

* WIDESPREAD DANGEROUS COASTAL FLOODING ACCOMPANIED BY POWERFUL CURRENTS IS POSSIBLE AND MAY CONTINUE FOR MANY HOURS AFTER TSUNAMI ARRIVAL.

* THE FIRST WAVE MAY NOT BE THE LARGEST.

IMPACTS FOR TSUNAMI ADVISORY AREAS

* A TSUNAMI CAPABLE OF PRODUCING STRONG CURRENTS OR WAVES DANGEROUS

TO PERSONS IN OR VERY NEAR THE WATER IS EXPECTED.

* CURRENTS MAY BE HAZARDOUS TO SWIMMERS... BOATS... AND COASTAL STRUCTURES AND MAY CONTINUE FOR MANY HOURS AFTER THE TSUNAMI ARRIVAL.

* THE FIRST WAVE MAY NOT BE THE LARGEST.

RECOMMENDED ACTIONS

* IF YOU ARE IN A WARNING AREA - MOVE INLAND TO HIGHER GROUND.

* IF YOU ARE IN AN ADVISORY AREA - MOVE OFF THE BEACH AND OUT OF HARBORS AND MARINAS. WIDESPREAD INUNDATION OF LAND IS NOT EXPECTED FOR ADVISORY AREAS.

* BE ALERT TO INSTRUCTIONS FROM YOUR LOCAL EMERGENCY OFFICIALS.

* DO NOT GO TO THE COAST TO OBSERVE THE TSUNAMI.

* DO NOT RETURN TO THE COAST UNTIL LOCAL EMERGENCY OFFICIALS INDICATE IT IS SAFE TO DO SO.

SIGNIFICANT TSUNAMI ACTIVITY IS EXPECTED TO CONTINUE FOR UP TO 12 MORE HOURS FOR AREAS STILL IN A LEVEL OF ALERT.

ADDITIONAL OBSERVATIONS OF TSUNAMI ACTIVITY - UPDATED

$\begin{array}{ll} & \text { TIME } \\ \text { SITE } & \text { OF MEASUREMENT TSUNAMI HEIGHT }\end{array}$




\begin{tabular}{|c|c|c|}
\hline AND POINT AK & 1945 UTC 3-27 & $11.60 \mathrm{FT}$ \\
\hline KING COVE AK & 2023 UTC 3-27 & $4.33 \mathrm{FT}$ \\
\hline CHIGNIK AK & 2026 UTC 3-27 & $21.82 \mathrm{FT}$ \\
\hline NIKOLSKI AK & 2054 UTC $3-27$ & $1.61 \mathrm{FT}$ \\
\hline UNALASKA AK & 2056 UTC 3-27 & $1.44 \mathrm{FT}$ \\
\hline KODIAK AK & 2100 UTC $3-27$ & 4.50 FT \\
\hline SEWARD AK & 2110 UTC $3-27$ & $4.11 \mathrm{FT}$ \\
\hline ADAK AK & 2145 UTC $3-27$ & $.03 \mathrm{FT}$ \\
\hline ELFIN COVE AK & 2133 UTC $3-27$ & $1.32 \mathrm{FT}$ \\
\hline YAKUTAT AK & 2132 UTC 3-27 & $2.44 \mathrm{FT}$ \\
\hline PORT ALEXANDER AK & 2114 UTC $3-27$ & $1.41 \mathrm{FT}$ \\
\hline CORDOVA AK & 2235 UTC $3-27$ & $1.82 \mathrm{FT}$ \\
\hline SHEMYA AK & 2245 UTC $3-27$ & $0.34 \mathrm{FT}$ \\
\hline SITKA AK & 2222 UTC $3-27$ & $74 \mathrm{FT}$ \\
\hline CRAIG AK & 2255 UTC $3-27$ & $.88 \mathrm{FT}$ \\
\hline LANGARA BC & 2300 UTC $3-27$ & $1.60 \mathrm{FT}$ \\
\hline TOFINO BC & 2334 UTC $3-27$ & $2.41 \mathrm{FT}$ \\
\hline NEAH BAY WA & 2234 UTC $3-27$ & $2.02 \mathrm{FT}$ \\
\hline LAPUSH WA & 2241 UTC 3-27 & $3.15 \mathrm{FT}$ \\
\hline WESTPORT WA & 2302 UTC $3-27$ & $2.11 \mathrm{FT}$ \\
\hline PORT ANGELES WA & 2354 UTC $3-27$ & $1.38 \mathrm{FT}$ \\
\hline GARIBALDI OR & 2259 UTC 3-27 & $1.05 \mathrm{FT}$ \\
\hline NEWPORT OR & 2309 UTC 3-27 & $2.46 \mathrm{FT}$ \\
\hline CHARLESTON OR & 2333 UTC $3-27$ & $2.74 \mathrm{FT}$ \\
\hline PORT ORFORD OR & 2355 UTC $3-27$ & $6.76 \mathrm{FT}$ \\
\hline CRESCENT CITY CA & 0100 UTC $3-28$ & $7.11 \mathrm{FT}$ \\
\hline ARENA COVE CA & 2313 UTC $3-27$ & $5.58 \mathrm{FT}$ \\
\hline EUREKA CA & 0006 UTC 3-28 & $4.23 \mathrm{FT}$ \\
\hline POINT REYES CA & 0142 UTC 3-28 & $3.38 \mathrm{FT}$ \\
\hline SAN FRANCISCO & 0155 UTC $3-28$ & $3.71 \mathrm{FT}$ \\
\hline ALAMEDA CA & 0141 UTC 3-28 & $1.84 \mathrm{FT}$ \\
\hline MONTEREY CA & 2338 UTC $3-27$ & $3.97 \mathrm{FT}$ \\
\hline PORT SAN LUIS CA & 0108 UTC $3-28$ & 14.30 FT \\
\hline SANTA BARBARA CA & 0145 UTC $3-28$ & $2.64 \mathrm{FT}$ \\
\hline SANTA MONICA CA & 0157 UTC 3-28 & $3.38 \mathrm{FT}$ \\
\hline SAN PEDRO CA & 0230 UTC $3-28$ & $3.11 \mathrm{FT}$ \\
\hline LA JOLLA CA & 0222 UTC 3-28 & $3.5 \mathrm{FT}$ \\
\hline SAN DIEGO CA & 0214 UTC 3-28 & $1.74 \mathrm{FT}$ \\
\hline MIDWAY IS & 2304 UTC $3-27$ & $1.44 \mathrm{FT}$ \\
\hline NAWILIWILI HI & 2323 UTC $3-27$ & $2.20 \mathrm{FT}$ \\
\hline HALEIWA HI & 2338 UTC $3-27$ & $4.99 \mathrm{FT}$ \\
\hline HONOLULU HI & 2338 UTC $3-27$ & $2.23 \mathrm{FT}$ \\
\hline KAHULUI HI & 2341 UTC $3-27$ & $7.15 \mathrm{FT}$ \\
\hline KAWAIHAE HI & 0014 UTC 3-28 & $2.89 \mathrm{FT}$ \\
\hline WAKE ISLAND & 0052 UTC $3-28$ & $0.33 \mathrm{FT}$ \\
\hline GUAM & 321 UTC $3-28$ & $0 \mathrm{FT}$ \\
\hline
\end{tabular}


PAGO PAGO AM SAMOA 0433 UTC 3-28 $0.46 \mathrm{FT}$

HEIGHT - OBSERVED MAX TSUNAMI HEIGHT IS THE WATER LEVEL ABOVE THE TIDE LEVEL AT THE TIME OF MEASUREMENT.

PRELIMINARY EARTHQUAKE PARAMETERS

* MAGNITUDE 9.0

* ORIGIN TIME 1050 AKDT MAR 272014

1150 PDT MAR 272014

1850 UTC MAR 272014

* COORDINATES 55.2 NORTH 156.7 WEST

* DEPTH 11 MILES

* LOCATION 100 MILES SE OF CHIGNIK ALASKA 485 MILES SW OF ANCHORAGE ALASKA

NEXT UPDATE AND ADDITIONAL INFORMATION

* THIS MESSAGE WILL BE UPDATED IN 60 MINUTES.

* REFER TO THE INTERNET SITE WCATWC.ARH.NOAA.GOV FOR MORE INFORMATION.

* PACIFIC COASTAL RESIDENTS OUTSIDE CALIFORNIA... OREGON... WASHINGTON... BRITISH COLUMBIA AND ALASKA SHOULD REFER TO THE PACIFIC TSUNAMI WARNING CENTER MESSAGES FOR INFORMATION ON THIS EVENT AT PTWC.WEATHER.GOV.

$\$ \$$ 
WEAK51 PAAQ 290901

TSUAK1

\section{BULLETIN}

PUBLIC TSUNAMI MESSAGE NUMBER 40

NWS WEST COAST/ALASKA TSUNAMI WARNING CENTER PALMER AK 101 AM AKDT SAT MAR 292014

THIS MESSAGE CONTINUES THE WARNING AND ADVISORY AS IN THE PREVIOUS MESSAGE.

...THE TSUNAMI WARNING REMAINS IN EFFECT...

...THE TSUNAMI ADVISORY REMAINS IN EFFECT...

WARNINGS/ADVISORIES/WATCHES

TSUNAMI WARNING IN EFFECT FOR...

* THE COASTAL AREAS OF ALASKA FROM KENNEDY ENTRANCE ALASKA/LOCATED 40 MILES SW OF HOMER/ TO UNIMAK PASS

ALASKA/LOCATED 80 MILES NE OF DUTCH HARBOR/

TSUNAMI ADVISORY IN EFFECT FOR...

* THE COASTAL AREAS OF CALIFORNIA - OREGON - WASHINGTON BRITISH COLUMBIA AND ALASKA FROM THE CALIFORNIA-MEXICO BORDER TO KENNEDY ENTRANCE ALASKA/LOCATED 40 MILES SW OF HOMER/

* THE COASTAL AREAS OF ALASKA FROM UNIMAK PASS ALASKA/LOCATED 80 MILES NE OF DUTCH HARBOR/ TO NIKOLSKI ALASKA

* FOR OTHER US AND CANDIAN PACIFIC COASTS IN NORTH AMERICA THIS IS FOR INFORMATION ONLY.

IMPACTS FOR TSUNAMI WARNING AREAS 
* WIDESPREAD DANGEROUS COASTAL FLOODING ACCOMPANIED BY POWERFUL CURRENTS IS POSSIBLE AND MAY CONTINUE FOR MANY HOURS AFTER TSUNAMI ARRIVAL.

* THE FIRST WAVE MAY NOT BE THE LARGEST.

IMPACTS FOR TSUNAMI ADVISORY AREAS

* A TSUNAMI CAPABLE OF PRODUCING STRONG CURRENTS OR WAVES DANGEROUS

TO PERSONS IN OR VERY NEAR THE WATER IS EXPECTED.

* CURRENTS MAY BE HAZARDOUS TO SWIMMERS... BOATS... AND COASTAL STRUCTURES AND MAY CONTINUE FOR MANY HOURS AFTER THE TSUNAMI ARRIVAL.

* THE FIRST WAVE MAY NOT BE THE LARGEST.

\section{RECOMMENDED ACTIONS}

* IF YOU ARE IN A WARNING AREA - MOVE INLAND TO HIGHER GROUND.

* IF YOU ARE IN AN ADVISORY AREA - MOVE OFF THE BEACH AND OUT OF HARBORS AND MARINAS. WIDESPREAD INUNDATION OF LAND IS NOT EXPECTED FOR ADVISORY AREAS.

* BE ALERT TO INSTRUCTIONS FROM YOUR LOCAL EMERGENCY OFFICIALS.

* DO NOT GO TO THE COAST TO OBSERVE THE TSUNAMI.

* DO NOT RETURN TO THE COAST UNTIL LOCAL EMERGENCY OFFICIALS INDICATE IT IS SAFE TO DO SO.

SIGNIFICANT TSUNAMI ACTIVITY IS EXPECTED TO CONTINUE FOR UP TO 9 MORE HOURS FOR AREAS STILL IN A LEVEL OF ALERT.

ADDITIONAL OBSERVATIONS OF TSUNAMI ACTIVITY - UPDATED

\begin{tabular}{|c|c|c|}
\hline & OBSERVEI & MAX \\
\hline SITE & OF MEASUREMENT & TSUNAMI HEIGHT \\
\hline SAND POINT AK & 1945 UTC 3-27 & $11.60 \mathrm{FT}$ \\
\hline
\end{tabular}




\begin{tabular}{|c|c|c|}
\hline KING COVE AK & 2023 UTC 3-27 & $4.33 \mathrm{FT}$ \\
\hline CHIGNIK AK & 2026 UTC 3-27 & $21.82 \mathrm{FT}$ \\
\hline NIKOLSKI AK & 2054 UTC $3-27$ & $1.61 \mathrm{FT}$ \\
\hline UNALASKA AK & 2056 UTC 3-27 & $1.44 \mathrm{FT}$ \\
\hline KODIAK AK & 2100 UTC $3-27$ & $4.50 \mathrm{FT}$ \\
\hline SEWARD AK & 2110 UTC $3-27$ & $4.11 \mathrm{FT}$ \\
\hline ADAK AK & 2145 UTC 3-27 & $1.03 \mathrm{FT}$ \\
\hline ELFIN COVE AK & 2133 UTC $3-27$ & $1.32 \mathrm{FT}$ \\
\hline YAKUTAT AK & 2132 UTC $3-27$ & $2.44 \mathrm{FT}$ \\
\hline PORT ALEXANDER AK & 2114 UTC $3-2$ & $1.41 \mathrm{FT}$ \\
\hline CORDOVA AK & 2235 UTC $3-27$ & $1.82 \mathrm{FT}$ \\
\hline SHEMYA AK & 2245 UTC 3-27 & $0.34 \mathrm{FT}$ \\
\hline SITKA AK & 2222 UTC $3-27$ & $3.74 \mathrm{FT}$ \\
\hline CRAIG AK & 2255 UTC $3-27$ & $3.88 \mathrm{FT}$ \\
\hline LANGARA BC & 2300 UTC $3-27$ & $1.60 \mathrm{FT}$ \\
\hline TOFINO BC & 2334 UTC $3-27$ & $2.41 \mathrm{FT}$ \\
\hline NEAH BAY WA & 2234 UTC $3-27$ & $2.02 \mathrm{FT}$ \\
\hline LAPUSH WA & 2241 UTC 3-27 & $3.15 \mathrm{FT}$ \\
\hline WESTPORT WA & 2302 UTC $3-27$ & $2.11 \mathrm{FT}$ \\
\hline PORT ANGELES WA & 2354 UTC $3-27$ & $1.38 \mathrm{FT}$ \\
\hline GARIBALDI OR & 2259 UTC $3-27$ & $1.05 \mathrm{FT}$ \\
\hline NEWPORT OR & 2309 UTC 3-27 & $2.46 \mathrm{FT}$ \\
\hline CHARLESTON OR & 2333 UTC $3-27$ & $2.74 \mathrm{FT}$ \\
\hline PORT ORFORD OR & 2355 UTC $3-27$ & $6.76 \mathrm{FT}$ \\
\hline CRESCENT CITY CA & 0100 UTC $3-28$ & $7.11 \mathrm{FT}$ \\
\hline ARENA COVE CA & 2313 UTC 3-27 & $5.58 \mathrm{FT}$ \\
\hline EUREKA CA & 0006 UTC $3-28$ & $4.23 \mathrm{FT}$ \\
\hline POINT REYES CA & 0142 UTC $3-28$ & $3.38 \mathrm{FT}$ \\
\hline SAN FRANCISCO & 0155 UTC 3-28 & $3.71 \mathrm{FT}$ \\
\hline ALAMEDA CA & 0141 UTC 3-28 & $1.84 \mathrm{FT}$ \\
\hline MONTEREY CA & 2338 UTC $3-27$ & 3.97 FT \\
\hline PORT SAN LUIS CA & 0108 UTC $3-28$ & $14.30 \mathrm{FT}$ \\
\hline SANTA BARBARA CA & 0145 UTC $3-28$ & $2.64 \mathrm{FT}$ \\
\hline SANTA MONICA CA & 0157 UTC 3-28 & $3.38 \mathrm{FT}$ \\
\hline SAN PEDRO CA & 0230 UTC $3-28$ & $3.11 \mathrm{FT}$ \\
\hline LA JOLLA CA & 0222 UTC 3-28 & $3.5 \mathrm{FT}$ \\
\hline SAN DIEGO CA & 0214 UTC $3-28$ & $1.74 \mathrm{FT}$ \\
\hline MIDWAY IS & 2304 UTC $3-27$ & $1.44 \mathrm{FT}$ \\
\hline NAWILIWILI HI & 2323 UTC $3-27$ & $2.20 \mathrm{FT}$ \\
\hline HALEIWA HI & 2338 UTC $3-27$ & $4.99 \mathrm{FT}$ \\
\hline HONOLULU HI & 2338 UTC $3-27$ & $2.23 \mathrm{FT}$ \\
\hline KAHULUI HI & 2341 UTC $3-27$ & $7.15 \mathrm{FT}$ \\
\hline KAWAIHAE HI & 0014 UTC $3-28$ & $2.89 \mathrm{FT}$ \\
\hline WAKE ISLAND & 0052 UTC $3-28$ & $0.33 \mathrm{FT}$ \\
\hline GUAM & 321 UTC 3-28 & $30 \mathrm{FT}$ \\
\hline
\end{tabular}


HEIGHT - OBSERVED MAX TSUNAMI HEIGHT IS THE WATER LEVEL ABOVE THE TIDE LEVEL AT THE TIME OF MEASUREMENT.

PRELIMINARY EARTHQUAKE PARAMETERS

* MAGNITUDE 9.0

* ORIGIN TIME 1050 AKDT MAR 272014

1150 PDT MAR 272014

1850 UTC MAR 272014

* COORDINATES 55.2 NORTH 156.7 WEST

* DEPTH 11 MILES

* LOCATION 100 MILES SE OF CHIGNIK ALASKA 485 MILES SW OF ANCHORAGE ALASKA

NEXT UPDATE AND ADDITIONAL INFORMATION

* THIS MESSAGE WILL BE UPDATED IN 60 MINUTES.

* REFER TO THE INTERNET SITE WCATWC.ARH.NOAA.GOV FOR MORE INFORMATION.

* PACIFIC COASTAL RESIDENTS OUTSIDE CALIFORNIA... OREGON... WASHINGTON... BRITISH COLUMBIA AND ALASKA SHOULD REFER TO THE PACIFIC TSUNAMI WARNING CENTER MESSAGES FOR INFORMATION ON THIS EVENT AT PTWC.WEATHER.GOV.

$\$ \$$ 
WEAK51 PAAQ 291000

TSUAK1

BULLETIN

PUBLIC TSUNAMI MESSAGE NUMBER 41

NWS WEST COAST/ALASKA TSUNAMI WARNING CENTER PALMER AK 200 AM AKDT SAT MAR 292014

THIS MESSAGE CONTINUES THE WARNING AND ADVISORY AS IN THE PREVIOUS MESSAGE.

...THE TSUNAMI WARNING REMAINS IN EFFECT...

...THE TSUNAMI ADVISORY REMAINS IN EFFECT...

WARNINGS/ADVISORIES/WATCHES

TSUNAMI WARNING IN EFFECT FOR...

* THE COASTAL AREAS OF ALASKA FROM KENNEDY ENTRANCE ALASKA/LOCATED 40 MILES SW OF HOMER/ TO UNIMAK PASS ALASKA/LOCATED 80 MILES NE OF DUTCH HARBOR/

TSUNAMI ADVISORY IN EFFECT FOR...

* THE COASTAL AREAS OF CALIFORNIA - OREGON - WASHINGTON BRITISH COLUMBIA AND ALASKA FROM THE CALIFORNIA-MEXICO BORDER TO KENNEDY ENTRANCE ALASKA/LOCATED 40 MILES SW OF HOMER/

* THE COASTAL AREAS OF ALASKA FROM UNIMAK PASS ALASKA/LOCATED 80 MILES NE OF DUTCH HARBOR/ TO NIKOLSKI ALASKA

* FOR OTHER US AND CANDIAN PACIFIC COASTS IN NORTH AMERICA THIS IS FOR INFORMATION ONLY.

IMPACTS FOR TSUNAMI WARNING AREAS 
* WIDESPREAD DANGEROUS COASTAL FLOODING ACCOMPANIED BY POWERFUL CURRENTS IS POSSIBLE AND MAY CONTINUE FOR MANY HOURS AFTER TSUNAMI ARRIVAL.

* THE FIRST WAVE MAY NOT BE THE LARGEST.

IMPACTS FOR TSUNAMI ADVISORY AREAS

* A TSUNAMI CAPABLE OF PRODUCING STRONG CURRENTS OR WAVES DANGEROUS

TO PERSONS IN OR VERY NEAR THE WATER IS EXPECTED.

* CURRENTS MAY BE HAZARDOUS TO SWIMMERS... BOATS... AND COASTAL STRUCTURES AND MAY CONTINUE FOR MANY HOURS AFTER THE TSUNAMI ARRIVAL.

* THE FIRST WAVE MAY NOT BE THE LARGEST.

RECOMMENDED ACTIONS

* IF YOU ARE IN A WARNING AREA - MOVE INLAND TO HIGHER GROUND.

* IF YOU ARE IN AN ADVISORY AREA - MOVE OFF THE BEACH AND OUT OF HARBORS AND MARINAS. WIDESPREAD INUNDATION OF LAND IS NOT EXPECTED FOR ADVISORY AREAS.

* BE ALERT TO INSTRUCTIONS FROM YOUR LOCAL EMERGENCY OFFICIALS.

* DO NOT GO TO THE COAST TO OBSERVE THE TSUNAMI.

* DO NOT RETURN TO THE COAST UNTIL LOCAL EMERGENCY OFFICIALS INDICATE IT IS SAFE TO DO SO.

SIGNIFICANT TSUNAMI ACTIVITY IS EXPECTED TO CONTINUE FOR UP TO 9 MORE HOURS FOR AREAS STILL IN A LEVEL OF ALERT.

ADDITIONAL OBSERVATIONS OF TSUNAMI ACTIVITY - UPDATED

\begin{tabular}{|c|c|c|}
\hline & OBSERVE & D MAX \\
\hline SITE & OF MEASUREMENT & TSUNAMI HEIGHT \\
\hline SAND F & 5 UTC $3-27$ & $11.60 \mathrm{FT}$ \\
\hline
\end{tabular}




\begin{tabular}{|c|c|c|}
\hline CHIGNIK AK & 2026 UTC 3-27 & $21.82 \mathrm{FT}$ \\
\hline NIKOLSKI AK & 2054 UTC 3-27 & $1.61 \mathrm{FT}$ \\
\hline UNALASKA AK & 2056 UTC 3-27 & $1.44 \mathrm{FT}$ \\
\hline KODIAK AK & 2100 UTC 3-27 & $4.50 \mathrm{FT}$ \\
\hline SEWARD AK & 2110 UTC 3-27 & $4.11 \mathrm{FT}$ \\
\hline ADAK AK & 2145 UTC 3-27 & $1.03 \mathrm{FT}$ \\
\hline ELFIN COVE AK & 2133 UTC 3-27 & $1.32 \mathrm{FT}$ \\
\hline YAKUTAT AK & 2132 UTC 3-27 & $2.44 \mathrm{FT}$ \\
\hline PORT ALEXANDER A & 2114 UTC 3 & $1.41 \mathrm{FT}$ \\
\hline CORDOVA AK & 2235 UTC 3-27 & $1.82 \mathrm{FT}$ \\
\hline SHEMYA AK & 2245 UTC 3-27 & $0.34 \mathrm{FT}$ \\
\hline SITKA AK & 2222 UTC 3-27 & $3.74 \mathrm{FT}$ \\
\hline CRAIG AK & 2255 UTC 3-27 & $3.88 \mathrm{FT}$ \\
\hline LANGARA BC & 2300 UTC 3-27 & $1.60 \mathrm{FT}$ \\
\hline TOFINO BC & 2334 UTC 3-27 & $2.41 \mathrm{FT}$ \\
\hline NEAH BAY WA & 2234 UTC 3-27 & $2.02 \mathrm{FT}$ \\
\hline LAPUSH WA & 2241 UTC 3-27 & $3.15 \mathrm{FT}$ \\
\hline WESTPORT WA & 2302 UTC 3-27 & $2.11 \mathrm{FT}$ \\
\hline PORT ANGELES WA & 2354 UTC 3-2 & $1.38 \mathrm{FT}$ \\
\hline GARIBALDI OR & 2259 UTC 3-27 & $1.05 \mathrm{FT}$ \\
\hline NEWPORT OR & 2309 UTC 3-27 & $2.46 \mathrm{FT}$ \\
\hline CHARLESTON OR & 2333 UTC 3-27 & $2.74 \mathrm{FT}$ \\
\hline PORT ORFORD OR & 2355 UTC 3-27 & $6.76 \mathrm{FT}$ \\
\hline CRESCENT CITY CA & 0100 UTC 3-2 & $7.11 \mathrm{FT}$ \\
\hline ARENA COVE CA & 2313 UTC 3-27 & $5.58 \mathrm{FT}$ \\
\hline EUREKA CA & 0006 UTC 3-28 & $4.23 \mathrm{FT}$ \\
\hline POINT REYES CA & 0142 UTC 3-28 & $3.38 \mathrm{FT}$ \\
\hline SAN FRANCISCO & 0155 UTC 3-28 & $3.71 \mathrm{FT}$ \\
\hline ALAMEDA CA & 0141 UTC 3-28 & $1.84 \mathrm{FT}$ \\
\hline MONTEREY CA & 2338 UTC 3-27 & $3.97 \mathrm{FT}$ \\
\hline PORT SAN LUIS CA & 0108 UTC 3-28 & $14.30 \mathrm{FT}$ \\
\hline SANTA BARBARA CA & 0145 UTC 3 & $2.64 \mathrm{FT}$ \\
\hline SANTA MONICA CA & 0157 UTC 3-2 & $3.38 \mathrm{FT}$ \\
\hline SAN PEDRO CA & 0230 UTC 3-28 & $3.11 \mathrm{FT}$ \\
\hline LA JOLLA CA & 0222 UTC 3-28 & $3.5 \mathrm{FT}$ \\
\hline SAN DIEGO CA & 0214 UTC 3-28 & $1.74 \mathrm{FT}$ \\
\hline MIDWAY IS & 2304 UTC 3-27 & $1.44 \mathrm{FT}$ \\
\hline NAWILIWILI HI & 2323 UTC 3-27 & $2.20 \mathrm{FT}$ \\
\hline HALEIWA HI & 2338 UTC 3-27 & 4.99 FT \\
\hline HONOLULU HI & 2338 UTC 3-27 & $2.23 \mathrm{FT}$ \\
\hline KAHULUI HI & 2341 UTC 3-27 & $7.15 \mathrm{FT}$ \\
\hline KAWAIHAE HI & 0014 UTC 3-28 & $2.89 \mathrm{FT}$ \\
\hline WAKE ISLAND & 0052 UTC 3-28 & $0.33 \mathrm{FT}$ \\
\hline GUAM & 0321 UTC 3-28 & $.30 \mathrm{FT}$ \\
\hline PAGO PAGO & 0433 & $3-28$ \\
\hline
\end{tabular}


HEIGHT - OBSERVED MAX TSUNAMI HEIGHT IS THE WATER LEVEL ABOVE THE TIDE LEVEL AT THE TIME OF MEASUREMENT.

PRELIMINARY EARTHQUAKE PARAMETERS

* MAGNITUDE 9.0

* ORIGIN TIME 1050 AKDT MAR 272014

1150 PDT MAR 272014

1850 UTC MAR 272014

* COORDINATES 55.2 NORTH 156.7 WEST

* DEPTH 11 MILES

* LOCATION 100 MILES SE OF CHIGNIK ALASKA 485 MILES SW OF ANCHORAGE ALASKA

NEXT UPDATE AND ADDITIONAL INFORMATION

* THIS MESSAGE WILL BE UPDATED IN 60 MINUTES.

* REFER TO THE INTERNET SITE WCATWC.ARH.NOAA.GOV FOR MORE INFORMATION.

* PACIFIC COASTAL RESIDENTS OUTSIDE CALIFORNIA... OREGON... WASHINGTON... BRITISH COLUMBIA AND ALASKA SHOULD REFER TO THE PACIFIC TSUNAMI WARNING CENTER MESSAGES FOR INFORMATION ON THIS EVENT AT PTWC.WEATHER.GOV. 
WEAK51 PAAQ 291101

TSUAK1

BULLETIN

PUBLIC TSUNAMI MESSAGE NUMBER 42

NWS WEST COAST/ALASKA TSUNAMI WARNING CENTER PALMER AK 301 AM AKDT SAT MAR 292014

THIS MESSAGE CONTINUES THE WARNING AND ADVISORY AS IN THE PREVIOUS MESSAGE.

...THE TSUNAMI WARNING REMAINS IN EFFECT...

...THE TSUNAMI ADVISORY REMAINS IN EFFECT...

WARNINGS/ADVISORIES/WATCHES

TSUNAMI WARNING IN EFFECT FOR...

* THE COASTAL AREAS OF ALASKA FROM KENNEDY ENTRANCE ALASKA/LOCATED 40 MILES SW OF HOMER/ TO UNIMAK PASS

ALASKA/LOCATED 80 MILES NE OF DUTCH HARBOR/

TSUNAMI ADVISORY IN EFFECT FOR...

* THE COASTAL AREAS OF CALIFORNIA - OREGON - WASHINGTON BRITISH COLUMBIA AND ALASKA FROM THE CALIFORNIA-MEXICO BORDER TO KENNEDY ENTRANCE ALASKA/LOCATED 40 MILES SW OF HOMER/

* THE COASTAL AREAS OF ALASKA FROM UNIMAK PASS ALASKA/LOCATED 80 MILES NE OF DUTCH HARBOR/ TO NIKOLSKI ALASKA

* FOR OTHER US AND CANDIAN PACIFIC COASTS IN NORTH AMERICA THIS IS FOR INFORMATION ONLY.

IMPACTS FOR TSUNAMI WARNING AREAS

* WIDESPREAD DANGEROUS COASTAL FLOODING ACCOMPANIED BY POWERFUL 
CURRENTS IS POSSIBLE AND MAY CONTINUE FOR MANY HOURS AFTER TSUNAMI ARRIVAL.

* THE FIRST WAVE MAY NOT BE THE LARGEST.

IMPACTS FOR TSUNAMI ADVISORY AREAS

* A TSUNAMI CAPABLE OF PRODUCING STRONG CURRENTS OR WAVES

DANGEROUS

TO PERSONS IN OR VERY NEAR THE WATER IS EXPECTED.

* CURRENTS MAY BE HAZARDOUS TO SWIMMERS... BOATS... AND COASTAL STRUCTURES AND MAY CONTINUE FOR MANY HOURS AFTER THE TSUNAMI ARRIVAL.

* THE FIRST WAVE MAY NOT BE THE LARGEST.

\section{RECOMMENDED ACTIONS}

* IF YOU ARE IN A WARNING AREA - MOVE INLAND TO HIGHER GROUND.

* IF YOU ARE IN AN ADVISORY AREA - MOVE OFF THE BEACH AND OUT OF HARBORS AND MARINAS. WIDESPREAD INUNDATION OF LAND IS NOT EXPECTED FOR ADVISORY AREAS.

* BE ALERT TO INSTRUCTIONS FROM YOUR LOCAL EMERGENCY OFFICIALS.

* DO NOT GO TO THE COAST TO OBSERVE THE TSUNAMI.

* DO NOT RETURN TO THE COAST UNTIL LOCAL EMERGENCY OFFICIALS INDICATE IT IS SAFE TO DO SO.

SIGNIFICANT TSUNAMI ACTIVITY IS EXPECTED TO CONTINUE FOR UP TO 9 MORE HOURS FOR AREAS STILL IN A LEVEL OF ALERT.

ADDITIONAL OBSERVATIONS OF TSUNAMI ACTIVITY - UPDATED

\begin{tabular}{|c|c|c|}
\hline \multirow[b]{2}{*}{ SITE } & \multicolumn{2}{|c|}{ OBSERVED MAX } \\
\hline & OF MEASUREMENT & TSUNAMI $\mathrm{H}$ \\
\hline SA & 5 UTC $3-27$ & $11.60 \mathrm{FT}$ \\
\hline & 2023 UTC 3-27 & 4.3 \\
\hline CHIGNIK AK & 2026 UTC 3-27 & $21.82 \mathrm{FT}$ \\
\hline
\end{tabular}




\begin{tabular}{|c|c|c|}
\hline NIKOLSKI AK & 2054 UTC 3-27 & $1.61 \mathrm{FT}$ \\
\hline UNALASKA AK & 2056 UTC 3-27 & $1.44 \mathrm{FT}$ \\
\hline KODIAK AK & 2100 UTC 3-27 & $4.50 \mathrm{FT}$ \\
\hline SEWARD AK & 2110 UTC 3-27 & $4.11 \mathrm{FT}$ \\
\hline ADAK AK & 2145 UTC 3-27 & $.03 \mathrm{FT}$ \\
\hline ELFIN COVE AK & 2133 UTC 3-27 & $1.32 \mathrm{FT}$ \\
\hline YAKUTAT AK & 2132 UTC 3-27 & $2.44 \mathrm{FT}$ \\
\hline PORT ALEXANDER A & 2114 UTC 3-2 & $1.41 \mathrm{FT}$ \\
\hline CORDOVA AK & 2235 UTC $3-27$ & $1.82 \mathrm{FT}$ \\
\hline SHEMYA AK & 2245 UTC 3-27 & $0.34 \mathrm{FT}$ \\
\hline SITKA AK & 2222 UTC 3-27 & $.74 \mathrm{FT}$ \\
\hline CRAIG AK & 2255 UTC 3-27 & $.88 \mathrm{FT}$ \\
\hline LANGARA BC & 2300 UTC 3-27 & $1.60 \mathrm{FT}$ \\
\hline TOFINO BC & 2334 UTC 3-27 & $2.41 \mathrm{FT}$ \\
\hline NEAH BAY WA & 2234 UTC 3-27 & $2.02 \mathrm{FT}$ \\
\hline LAPUSH WA & 2241 UTC 3-27 & $3.15 \mathrm{FT}$ \\
\hline WESTPORT WA & 2302 UTC 3-27 & $2.11 \mathrm{FT}$ \\
\hline PORT ANGELES WA & 2354 UTC 3-27 & $1.38 \mathrm{FT}$ \\
\hline GARIBALDI OR & 2259 UTC 3-27 & $1.05 \mathrm{FT}$ \\
\hline NEWPORT OR & 2309 UTC 3-27 & $2.46 \mathrm{FT}$ \\
\hline CHARLESTON OR & 2333 UTC 3-27 & $2.74 \mathrm{FT}$ \\
\hline PORT ORFORD OR & 2355 UTC 3-27 & $6.76 \mathrm{FT}$ \\
\hline CRESCENT CITY CA & 0100 UTC 3-28 & $7.11 \mathrm{FT}$ \\
\hline ARENA COVE CA & 2313 UTC 3-27 & $5.58 \mathrm{FT}$ \\
\hline EUREKA CA & 0006 UTC 3-28 & $4.23 \mathrm{FT}$ \\
\hline POINT REYES CA & 0142 UTC 3-28 & $3.38 \mathrm{FT}$ \\
\hline SAN FRANCISCO & 0155 UTC 3-28 & $3.71 \mathrm{FT}$ \\
\hline ALAMEDA CA & 0141 UTC 3-28 & $1.84 \mathrm{FT}$ \\
\hline MONTEREY CA & 2338 UTC 3-27 & $3.97 \mathrm{FT}$ \\
\hline PORT SAN LUIS CA & 0108 UTC 3-28 & $14.30 \mathrm{FT}$ \\
\hline SANTA BARBARA CA & 0145 UTC $3-28$ & $2.64 \mathrm{FT}$ \\
\hline SANTA MONICA CA & 0157 UTC 3-28 & $3.38 \mathrm{FT}$ \\
\hline SAN PEDRO CA & 0230 UTC 3-28 & $3.11 \mathrm{FT}$ \\
\hline LA JOLLA CA & 0222 UTC 3-28 & $3.5 \mathrm{FT}$ \\
\hline SAN DIEGO CA & 0214 UTC 3-28 & $1.74 \mathrm{FT}$ \\
\hline MIDWAY IS & 2304 UTC 3-27 & $1.44 \mathrm{FT}$ \\
\hline NAWILIWILI HI & 2323 UTC 3-27 & $2.20 \mathrm{FT}$ \\
\hline HALEIWA HI & 2338 UTC 3-27 & $4.99 \mathrm{FT}$ \\
\hline HONOLULU HI & 2338 UTC 3-27 & $2.23 \mathrm{FT}$ \\
\hline KAHULUI HI & 2341 UTC 3-27 & $7.15 \mathrm{FT}$ \\
\hline KAWAIHAE HI & 0014 UTC 3-28 & $2.89 \mathrm{FT}$ \\
\hline WAKE ISLAND & 0052 UTC 3-28 & $0.33 \mathrm{FT}$ \\
\hline GUAM & 0321 UTC 3-28 & $30 \mathrm{FT}$ \\
\hline PAGO PAGO AM SAM & 0433 UTC 3- & $0.46 \mathrm{~F}$ \\
\hline
\end{tabular}

HEIGHT - OBSERVED MAX TSUNAMI HEIGHT IS THE WATER LEVEL ABOVE THE 
TIDE LEVEL AT THE TIME OF MEASUREMENT.

PRELIMINARY EARTHQUAKE PARAMETERS

* MAGNITUDE 9.0

* ORIGIN TIME 1050 AKDT MAR 272014

1150 PDT MAR 272014

1850 UTC MAR 272014

* COORDINATES 55.2 NORTH 156.7 WEST

* DEPTH 11 MILES

* LOCATION 100 MILES SE OF CHIGNIK ALASKA 485 MILES SW OF ANCHORAGE ALASKA

NEXT UPDATE AND ADDITIONAL INFORMATION

* THIS MESSAGE WILL BE UPDATED IN 60 MINUTES.

* REFER TO THE INTERNET SITE WCATWC.ARH.NOAA.GOV FOR MORE INFORMATION.

* PACIFIC COASTAL RESIDENTS OUTSIDE CALIFORNIA... OREGON... WASHINGTON... BRITISH COLUMBIA AND ALASKA SHOULD REFER TO THE PACIFIC TSUNAMI WARNING CENTER MESSAGES FOR INFORMATION ON THIS EVENT AT PTWC.WEATHER.GOV.

$\$ \$$ 
WEAK51 PAAQ 291200

TSUAK1

BULLETIN

PUBLIC TSUNAMI MESSAGE NUMBER 43

NWS WEST COAST/ALASKA TSUNAMI WARNING CENTER PALMER AK 400 AM AKDT SAT MAR 292014

THIS MESSAGE CONTINUES THE WARNING AND ADVISORY AS IN THE PREVIOUS MESSAGE.

...THE TSUNAMI WARNING REMAINS IN EFFECT...

...THE TSUNAMI ADVISORY REMAINS IN EFFECT...

WARNINGS/ADVISORIES/WATCHES

TSUNAMI WARNING IN EFFECT FOR...

* THE COASTAL AREAS OF ALASKA FROM KENNEDY ENTRANCE ALASKA/LOCATED 40 MILES SW OF HOMER/ TO UNIMAK PASS ALASKA/LOCATED 80 MILES NE OF DUTCH HARBOR/

TSUNAMI ADVISORY IN EFFECT FOR...

* THE COASTAL AREAS OF CALIFORNIA - OREGON - WASHINGTON BRITISH COLUMBIA AND ALASKA FROM THE CALIFORNIA-MEXICO BORDER TO KENNEDY ENTRANCE ALASKA/LOCATED 40 MILES SW OF HOMER/

* THE COASTAL AREAS OF ALASKA FROM UNIMAK PASS ALASKA/LOCATED 80 MILES NE OF DUTCH HARBOR/ TO NIKOLSKI ALASKA

* FOR OTHER US AND CANDIAN PACIFIC COASTS IN NORTH AMERICA THIS IS FOR INFORMATION ONLY.

IMPACTS FOR TSUNAMI WARNING AREAS

* WIDESPREAD DANGEROUS COASTAL FLOODING ACCOMPANIED BY POWERFUL CURRENTS IS POSSIBLE AND MAY CONTINUE FOR MANY HOURS AFTER 
TSUNAMI ARRIVAL.

* THE FIRST WAVE MAY NOT BE THE LARGEST.

IMPACTS FOR TSUNAMI ADVISORY AREAS

* A TSUNAMI CAPABLE OF PRODUCING STRONG CURRENTS OR WAVES DANGEROUS

TO PERSONS IN OR VERY NEAR THE WATER IS EXPECTED.

* CURRENTS MAY BE HAZARDOUS TO SWIMMERS... BOATS... AND COASTAL STRUCTURES AND MAY CONTINUE FOR MANY HOURS AFTER THE TSUNAMI ARRIVAL.

* THE FIRST WAVE MAY NOT BE THE LARGEST.

\section{RECOMMENDED ACTIONS}

* IF YOU ARE IN A WARNING AREA - MOVE INLAND TO HIGHER GROUND.

* IF YOU ARE IN AN ADVISORY AREA - MOVE OFF THE BEACH AND OUT OF HARBORS AND MARINAS. WIDESPREAD INUNDATION OF LAND IS NOT EXPECTED FOR ADVISORY AREAS.

* BE ALERT TO INSTRUCTIONS FROM YOUR LOCAL EMERGENCY OFFICIALS.

* DO NOT GO TO THE COAST TO OBSERVE THE TSUNAMI.

* DO NOT RETURN TO THE COAST UNTIL LOCAL EMERGENCY OFFICIALS INDICATE IT IS SAFE TO DO SO.

SIGNIFICANT TSUNAMI ACTIVITY IS EXPECTED TO CONTINUE FOR UP TO 6 MORE HOURS FOR AREAS STILL IN A LEVEL OF ALERT.

ADDITIONAL OBSERVATIONS OF TSUNAMI ACTIVITY - UPDATED

\begin{tabular}{|c|c|c|}
\hline \multirow[b]{2}{*}{ SITE } & \multicolumn{2}{|c|}{ TIME OBSERVED MAX } \\
\hline & OF MEASUREMENT & TSUNAMI HEIGHT \\
\hline SAND POINT AK & 1945 UTC 3-27 & $11.60 \mathrm{FT}$ \\
\hline KING COVE AK & 2023 UTC 3-27 & $4.33 \mathrm{FT}$ \\
\hline CHIGNIK AK & 2026 UTC 3-27 & $21.82 \mathrm{FT}$ \\
\hline NIKOLSKI AK & 2054 UTC 3-27 & $1.61 \mathrm{FT}$ \\
\hline
\end{tabular}




\begin{tabular}{|c|c|c|}
\hline UNALASKA AK & 2056 UTC 3-27 & $1.44 \mathrm{FT}$ \\
\hline KODIAK AK & 2100 UTC 3-27 & $4.50 \mathrm{FT}$ \\
\hline SEWARD AK & 2110 UTC 3-27 & $4.11 \mathrm{FT}$ \\
\hline ADAK AK & 2145 UTC 3-27 & $.03 \mathrm{FT}$ \\
\hline ELFIN COVE AK & 2133 UTC 3-27 & $1.32 \mathrm{FT}$ \\
\hline YAKUTAT AK & 2132 UTC 3-27 & $2.44 \mathrm{FT}$ \\
\hline PORT ALEXANDER A & 2114 UTC 3-2 & $1.41 \mathrm{~F}$ \\
\hline CORDOVA AK & 2235 UTC 3-27 & $1.82 \mathrm{FT}$ \\
\hline SHEMYA AK & 2245 UTC 3-27 & $0.34 \mathrm{FT}$ \\
\hline SITKA AK & 2222 UTC 3-27 & $.74 \mathrm{FT}$ \\
\hline CRAIG AK & 2255 UTC 3-27 & $.88 \mathrm{FT}$ \\
\hline LANGARA BC & 2300 UTC 3-27 & $1.60 \mathrm{FT}$ \\
\hline TOFINO BC & 2334 UTC 3-27 & $2.41 \mathrm{FT}$ \\
\hline NEAH BAY WA & 2234 UTC 3-27 & $2.02 \mathrm{FT}$ \\
\hline LAPUSH WA & 2241 UTC 3-27 & $3.15 \mathrm{FT}$ \\
\hline WESTPORT WA & 2302 UTC 3-27 & $2.11 \mathrm{FT}$ \\
\hline PORT ANGELES WA & 2354 UTC 3-27 & $1.38 \mathrm{FT}$ \\
\hline GARIBALDI OR & 2259 UTC 3-27 & $1.05 \mathrm{FT}$ \\
\hline NEWPORT OR & 2309 UTC 3-27 & $2.46 \mathrm{FT}$ \\
\hline CHARLESTON OR & 2333 UTC 3-27 & $2.74 \mathrm{FT}$ \\
\hline PORT ORFORD OR & 2355 UTC 3-27 & $6.76 \mathrm{FT}$ \\
\hline CRESCENT CITY CA & 0100 UTC 3-28 & $7.11 \mathrm{FT}$ \\
\hline ARENA COVE CA & 2313 UTC 3-27 & $5.58 \mathrm{FT}$ \\
\hline EUREKA CA & 0006 UTC 3-28 & $4.23 \mathrm{FT}$ \\
\hline POINT REYES CA & 0142 UTC 3-28 & $3.38 \mathrm{FT}$ \\
\hline SAN FRANCISCO & 0155 UTC 3-28 & $3.71 \mathrm{FT}$ \\
\hline ALAMEDA CA & 0141 UTC 3-28 & $1.84 \mathrm{FT}$ \\
\hline MONTEREY CA & 2338 UTC 3-27 & $3.97 \mathrm{FT}$ \\
\hline PORT SAN LUIS CA & 0108 UTC 3-28 & $14.30 \mathrm{FT}$ \\
\hline SANTA BARBARA CA & 0145 UTC $3-28$ & $2.64 \mathrm{FT}$ \\
\hline SANTA MONICA CA & 0157 UTC 3-28 & $3.38 \mathrm{FT}$ \\
\hline SAN PEDRO CA & 0230 UTC 3-28 & $3.11 \mathrm{FT}$ \\
\hline LA JOLLA CA & 0222 UTC 3-28 & $3.5 \mathrm{FT}$ \\
\hline SAN DIEGO CA & 0214 UTC 3-28 & $1.74 \mathrm{FT}$ \\
\hline MIDWAY IS & 2304 UTC 3-27 & $1.44 \mathrm{FT}$ \\
\hline NAWILIWILI HI & 2323 UTC 3-27 & $2.20 \mathrm{FT}$ \\
\hline HALEIWA HI & 2338 UTC 3-27 & $4.99 \mathrm{FT}$ \\
\hline HONOLULU HI & 2338 UTC 3-27 & $2.23 \mathrm{FT}$ \\
\hline KAHULUI HI & 2341 UTC 3-27 & $7.15 \mathrm{FT}$ \\
\hline KAWAIHAE HI & 0014 UTC 3-28 & $2.89 \mathrm{FT}$ \\
\hline WAKE ISLAND & 0052 UTC 3-28 & $0.33 \mathrm{FT}$ \\
\hline GUAM & 0321 UTC 3-28 & $0 \mathrm{FT}$ \\
\hline
\end{tabular}

PAGO PAGO AM SAMOA 0433 UTC 3-28 0.46 FT

HEIGHT - OBSERVED MAX TSUNAMI HEIGHT IS THE WATER LEVEL ABOVE THE TIDE LEVEL AT THE TIME OF MEASUREMENT. 
PRELIMINARY EARTHQUAKE PARAMETERS

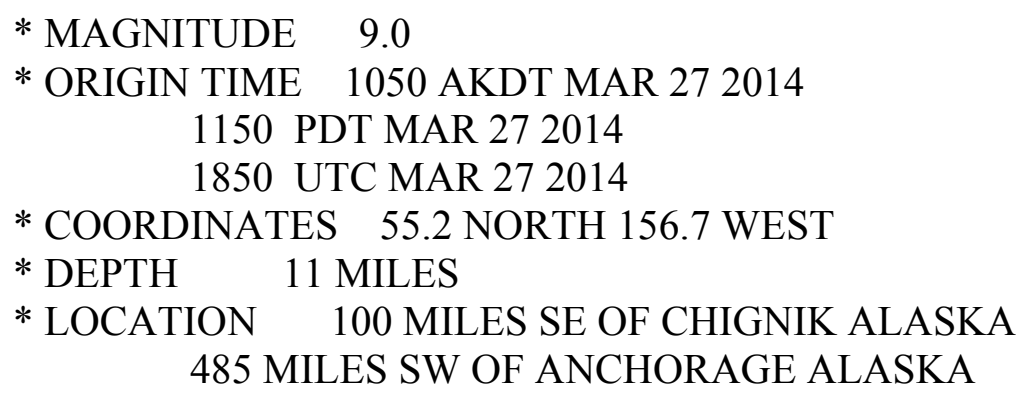

* THIS MESSAGE WILL BE UPDATED IN 60 MINUTES.

* REFER TO THE INTERNET SITE WCATWC.ARH.NOAA.GOV FOR MORE INFORMATION.

* PACIFIC COASTAL RESIDENTS OUTSIDE CALIFORNIA... OREGON... WASHINGTON... BRITISH COLUMBIA AND ALASKA SHOULD REFER TO THE PACIFIC TSUNAMI WARNING CENTER MESSAGES FOR INFORMATION ON THIS EVENT AT PTWC.WEATHER.GOV.

$\$ \$$ 
WEAK51 PAAQ 291300

TSUAK1

BULLETIN

PUBLIC TSUNAMI MESSAGE NUMBER 44

NWS WEST COAST/ALASKA TSUNAMI WARNING CENTER PALMER AK 500 AM AKDT SAT MAR 292014

THIS MESSAGE CONTINUES THE WARNING AND ADVISORY AS IN THE PREVIOUS MESSAGE.

...THE TSUNAMI WARNING REMAINS IN EFFECT...

...THE TSUNAMI ADVISORY REMAINS IN EFFECT...

WARNINGS/ADVISORIES/WATCHES

TSUNAMI WARNING IN EFFECT FOR...

* THE COASTAL AREAS OF ALASKA FROM KENNEDY ENTRANCE ALASKA/LOCATED 40 MILES SW OF HOMER/ TO UNIMAK PASS ALASKA/LOCATED 80 MILES NE OF DUTCH HARBOR/

TSUNAMI ADVISORY IN EFFECT FOR...

* THE COASTAL AREAS OF CALIFORNIA - OREGON - WASHINGTON BRITISH COLUMBIA AND ALASKA FROM THE CALIFORNIA-MEXICO BORDER TO KENNEDY ENTRANCE ALASKA/LOCATED 40 MILES SW OF HOMER/

* THE COASTAL AREAS OF ALASKA FROM UNIMAK PASS ALASKA/LOCATED 80 MILES NE OF DUTCH HARBOR/ TO NIKOLSKI ALASKA

* FOR OTHER US AND CANDIAN PACIFIC COASTS IN NORTH AMERICA THIS IS FOR INFORMATION ONLY.

IMPACTS FOR TSUNAMI WARNING AREAS

* WIDESPREAD DANGEROUS COASTAL FLOODING ACCOMPANIED BY POWERFUL CURRENTS IS POSSIBLE AND MAY CONTINUE FOR MANY HOURS AFTER TSUNAMI ARRIVAL. 
* THE FIRST WAVE MAY NOT BE THE LARGEST.

IMPACTS FOR TSUNAMI ADVISORY AREAS

* A TSUNAMI CAPABLE OF PRODUCING STRONG CURRENTS OR WAVES DANGEROUS

TO PERSONS IN OR VERY NEAR THE WATER IS EXPECTED.

* CURRENTS MAY BE HAZARDOUS TO SWIMMERS... BOATS... AND COASTAL STRUCTURES AND MAY CONTINUE FOR MANY HOURS AFTER THE TSUNAMI ARRIVAL.

* THE FIRST WAVE MAY NOT BE THE LARGEST.

\section{RECOMMENDED ACTIONS}

* IF YOU ARE IN A WARNING AREA - MOVE INLAND TO HIGHER GROUND.

* IF YOU ARE IN AN ADVISORY AREA - MOVE OFF THE BEACH AND OUT OF HARBORS AND MARINAS. WIDESPREAD INUNDATION OF LAND IS NOT EXPECTED FOR ADVISORY AREAS.

* BE ALERT TO INSTRUCTIONS FROM YOUR LOCAL EMERGENCY OFFICIALS.

* DO NOT GO TO THE COAST TO OBSERVE THE TSUNAMI.

* DO NOT RETURN TO THE COAST UNTIL LOCAL EMERGENCY OFFICIALS INDICATE IT IS SAFE TO DO SO.

SIGNIFICANT TSUNAMI ACTIVITY IS EXPECTED TO CONTINUE FOR UP TO 6 MORE HOURS FOR AREAS STILL IN A LEVEL OF ALERT.

ADDITIONAL OBSERVATIONS OF TSUNAMI ACTIVITY - UPDATED

\begin{tabular}{|c|c|c|}
\hline \multirow[b]{2}{*}{ SITE } & \multicolumn{2}{|c|}{ OBSERVED MAX } \\
\hline & OF MEASUREMENT & TSUNAMI H \\
\hline SAND POINT AK & 1945 UTC 3-27 & $11.60 \mathrm{~F}$ \\
\hline KING COVE AK & 2023 UTC 3-27 & $4.33 \mathrm{FT}$ \\
\hline CHIGNIK AK & 2026 UTC 3-27 & $21.82 \mathrm{FT}$ \\
\hline NIKOLSKI AK & 2054 UTC 3-27 & $1.61 \mathrm{FT}$ \\
\hline UNALASKA AK & 2056 UTC 3-27 & $1.44 \mathrm{FT}$ \\
\hline
\end{tabular}




\begin{tabular}{|c|c|c|}
\hline KODIAK AK & 2100 UTC 3-27 & $4.50 \mathrm{FT}$ \\
\hline SEWARD AK & 2110 UTC 3-27 & $4.11 \mathrm{FT}$ \\
\hline ADAK AK & 2145 UTC 3-27 & $1.03 \mathrm{FT}$ \\
\hline ELFIN COVE AK & 2133 UTC 3-27 & $1.32 \mathrm{FT}$ \\
\hline YAKUTAT AK & 2132 UTC 3-27 & $2.44 \mathrm{FT}$ \\
\hline PORT ALEXANDER A & 2114 UTC 3 & $1.41 \mathrm{FT}$ \\
\hline CORDOVA AK & 2235 UTC $3-27$ & $1.82 \mathrm{FT}$ \\
\hline SHEMYA AK & 2245 UTC $3-27$ & $0.34 \mathrm{FT}$ \\
\hline SITKA AK & 2222 UTC 3-27 & $3.74 \mathrm{FT}$ \\
\hline CRAIG AK & 2255 UTC 3-27 & $3.88 \mathrm{FT}$ \\
\hline LANGARA BC & 2300 UTC 3-27 & $1.60 \mathrm{FT}$ \\
\hline TOFINO BC & 2334 UTC 3-27 & $2.41 \mathrm{FT}$ \\
\hline NEAH BAY WA & 2234 UTC 3-27 & $2.02 \mathrm{FT}$ \\
\hline LAPUSH WA & 2241 UTC 3-27 & $3.15 \mathrm{FT}$ \\
\hline WESTPORT WA & 2302 UTC 3-27 & $2.11 \mathrm{FT}$ \\
\hline PORT ANGELES WA & 2354 UTC 3-2 & $1.38 \mathrm{FT}$ \\
\hline GARIBALDI OR & 2259 UTC 3-27 & $1.05 \mathrm{FT}$ \\
\hline NEWPORT OR & 2309 UTC 3-27 & $2.46 \mathrm{FT}$ \\
\hline CHARLESTON OR & 2333 UTC 3-27 & $2.74 \mathrm{FT}$ \\
\hline PORT ORFORD OR & 2355 UTC 3-27 & $6.76 \mathrm{FT}$ \\
\hline CRESCENT CITY CA & 0100 UTC 3-2 & $7.11 \mathrm{FT}$ \\
\hline ARENA COVE CA & 2313 UTC 3-27 & $5.58 \mathrm{FT}$ \\
\hline EUREKA CA & 0006 UTC 3-28 & $4.23 \mathrm{FT}$ \\
\hline POINT REYES CA & 0142 UTC 3-28 & $3.38 \mathrm{FT}$ \\
\hline SAN FRANCISCO & 0155 UTC 3-28 & $3.71 \mathrm{FT}$ \\
\hline ALAMEDA CA & 0141 UTC 3-28 & $1.84 \mathrm{FT}$ \\
\hline MONTEREY CA & 2338 UTC 3-27 & $3.97 \mathrm{FT}$ \\
\hline PORT SAN LUIS CA & 0108 UTC 3-28 & $14.30 \mathrm{FT}$ \\
\hline SANTA BARBARA CA & 0145 UTC 3 & $2.64 \mathrm{FT}$ \\
\hline SANTA MONICA CA & 0157 UTC 3-2 & $3.38 \mathrm{FT}$ \\
\hline SAN PEDRO CA & 0230 UTC 3-28 & $3.11 \mathrm{FT}$ \\
\hline LA JOLLA CA & 0222 UTC 3-28 & $3.5 \mathrm{FT}$ \\
\hline SAN DIEGO CA & 0214 UTC 3-28 & $1.74 \mathrm{FT}$ \\
\hline MIDWAY IS & 2304 UTC 3-27 & $1.44 \mathrm{FT}$ \\
\hline NAWILIWILI HI & 2323 UTC 3-27 & $2.20 \mathrm{FT}$ \\
\hline HALEIWA HI & 2338 UTC 3-27 & 4.99 FT \\
\hline HONOLULU HI & 2338 UTC 3-27 & $2.23 \mathrm{FT}$ \\
\hline KAHULUI HI & 2341 UTC 3-27 & $7.15 \mathrm{FT}$ \\
\hline KAWAIHAE HI & 0014 UTC 3-28 & $2.89 \mathrm{FT}$ \\
\hline WAKE ISLAND & 0052 UTC 3-28 & $0.33 \mathrm{FT}$ \\
\hline GUAM & 0321 UTC 3-28 & $.30 \mathrm{FT}$ \\
\hline PAGO PAGO AM SAM & 0433 UTC & $3-28$ \\
\hline
\end{tabular}

HEIGHT - OBSERVED MAX TSUNAMI HEIGHT IS THE WATER LEVEL ABOVE THE TIDE LEVEL AT THE TIME OF MEASUREMENT. 
PRELIMINARY EARTHQUAKE PARAMETERS

* MAGNITUDE 9.0

* ORIGIN TIME 1050 AKDT MAR 272014

1150 PDT MAR 272014

1850 UTC MAR 272014

* COORDINATES 55.2 NORTH 156.7 WEST

* DEPTH 11 MILES

* LOCATION 100 MILES SE OF CHIGNIK ALASKA 485 MILES SW OF ANCHORAGE ALASKA

NEXT UPDATE AND ADDITIONAL INFORMATION

* THIS MESSAGE WILL BE UPDATED IN 60 MINUTES.

* REFER TO THE INTERNET SITE WCATWC.ARH.NOAA.GOV FOR MORE INFORMATION.

* PACIFIC COASTAL RESIDENTS OUTSIDE CALIFORNIA... OREGON... WASHINGTON... BRITISH COLUMBIA AND ALASKA SHOULD REFER TO THE PACIFIC TSUNAMI WARNING CENTER MESSAGES FOR INFORMATION ON THIS EVENT AT PTWC.WEATHER.GOV.

$\$ \$$ 
WEAK51 PAAQ 291401

TSUAK1

BULLETIN

PUBLIC TSUNAMI MESSAGE NUMBER 45

NWS WEST COAST/ALASKA TSUNAMI WARNING CENTER PALMER AK 601 AM AKDT SAT MAR 292014

THIS MESSAGE CONTINUES THE WARNING AND ADVISORY AS IN THE PREVIOUS MESSAGE.

...THE TSUNAMI WARNING REMAINS IN EFFECT...

...THE TSUNAMI ADVISORY REMAINS IN EFFECT...

WARNINGS/ADVISORIES/WATCHES

TSUNAMI WARNING IN EFFECT FOR...

* THE COASTAL AREAS OF ALASKA FROM KENNEDY ENTRANCE ALASKA/LOCATED 40 MILES SW OF HOMER/ TO UNIMAK PASS ALASKA/LOCATED 80 MILES NE OF DUTCH HARBOR/

TSUNAMI ADVISORY IN EFFECT FOR...

* THE COASTAL AREAS OF CALIFORNIA - OREGON - WASHINGTON BRITISH COLUMBIA AND ALASKA FROM THE CALIFORNIA-MEXICO BORDER TO KENNEDY ENTRANCE ALASKA/LOCATED 40 MILES SW OF HOMER/

* THE COASTAL AREAS OF ALASKA FROM UNIMAK PASS ALASKA/LOCATED 80 MILES NE OF DUTCH HARBOR/ TO NIKOLSKI ALASKA

* FOR OTHER US AND CANDIAN PACIFIC COASTS IN NORTH AMERICA THIS IS FOR INFORMATION ONLY.

IMPACTS FOR TSUNAMI WARNING AREAS

* WIDESPREAD DANGEROUS COASTAL FLOODING ACCOMPANIED BY POWERFUL CURRENTS IS POSSIBLE AND MAY CONTINUE FOR MANY HOURS AFTER TSUNAMI ARRIVAL. 
* THE FIRST WAVE MAY NOT BE THE LARGEST.

IMPACTS FOR TSUNAMI ADVISORY AREAS

* A TSUNAMI CAPABLE OF PRODUCING STRONG CURRENTS OR WAVES DANGEROUS

TO PERSONS IN OR VERY NEAR THE WATER IS EXPECTED.

* CURRENTS MAY BE HAZARDOUS TO SWIMMERS... BOATS... AND COASTAL STRUCTURES AND MAY CONTINUE FOR MANY HOURS AFTER THE TSUNAMI ARRIVAL.

* THE FIRST WAVE MAY NOT BE THE LARGEST.

\section{RECOMMENDED ACTIONS}

* IF YOU ARE IN A WARNING AREA - MOVE INLAND TO HIGHER GROUND.

* IF YOU ARE IN AN ADVISORY AREA - MOVE OFF THE BEACH AND OUT OF HARBORS AND MARINAS. WIDESPREAD INUNDATION OF LAND IS NOT EXPECTED FOR ADVISORY AREAS.

* BE ALERT TO INSTRUCTIONS FROM YOUR LOCAL EMERGENCY OFFICIALS.

* DO NOT GO TO THE COAST TO OBSERVE THE TSUNAMI.

* DO NOT RETURN TO THE COAST UNTIL LOCAL EMERGENCY OFFICIALS INDICATE IT IS SAFE TO DO SO.

SIGNIFICANT TSUNAMI ACTIVITY IS EXPECTED TO CONTINUE FOR UP TO 6 MORE HOURS FOR AREAS STILL IN A LEVEL OF ALERT.

ADDITIONAL OBSERVATIONS OF TSUNAMI ACTIVITY - UPDATED

\begin{tabular}{|c|c|c|}
\hline \multirow[b]{2}{*}{ SITE } & \multicolumn{2}{|c|}{ OBSERVED MAX } \\
\hline & OF MEASUREMENT & TSUNAMI HEIGHT \\
\hline SAND POINT A & 1945 UTC 3-27 & $11.60 \mathrm{FT}$ \\
\hline KING COVE AK & 2023 UTC 3-27 & $4.33 \mathrm{FT}$ \\
\hline CHIGNIK AK & 2026 UTC 3-27 & $21.82 \mathrm{FT}$ \\
\hline NIKOLSKI AK & 2054 UTC 3-27 & $1.61 \mathrm{FT}$ \\
\hline UNALASKA AK & 2056 UTC 3-27 & $1.44 \mathrm{FT}$ \\
\hline KODIAK AK & 2100 UTC $3-27$ & $4.50 \mathrm{FT}$ \\
\hline
\end{tabular}




\begin{tabular}{|c|c|c|}
\hline SEWARD AK & 2110 UTC $3-27$ & $4.11 \mathrm{FT}$ \\
\hline ADAK AK & 2145 UTC $3-27$ & $1.03 \mathrm{FT}$ \\
\hline ELFIN COVE AK & 2133 UTC 3-27 & $1.32 \mathrm{FT}$ \\
\hline YAKUTAT AK & 2132 UTC 3-27 & $2.44 \mathrm{FT}$ \\
\hline PORT ALEXANDER A & 2114 UTC 3-2 & $1.41 \mathrm{FT}$ \\
\hline CORDOVA AK & 2235 UTC $3-27$ & $1.82 \mathrm{FT}$ \\
\hline SHEMYA AK & 2245 UTC 3-27 & $0.34 \mathrm{FT}$ \\
\hline SITKA AK & 2222 UTC 3-27 & $3.74 \mathrm{FT}$ \\
\hline CRAIG AK & 2255 UTC $3-27$ & $3.88 \mathrm{FT}$ \\
\hline LANGARA BC & 2300 UTC 3-27 & $1.60 \mathrm{FT}$ \\
\hline TOFINO BC & 2334 UTC $3-27$ & $2.41 \mathrm{FT}$ \\
\hline NEAH BAY WA & 2234 UTC 3-27 & $2.02 \mathrm{FT}$ \\
\hline LAPUSH WA & 2241 UTC 3-27 & $3.15 \mathrm{FT}$ \\
\hline WESTPORT WA & 2302 UTC $3-27$ & $2.11 \mathrm{FT}$ \\
\hline PORT ANGELES WA & 2354 UTC $3-27$ & $1.38 \mathrm{FT}$ \\
\hline GARIBALDI OR & 2259 UTC $3-27$ & $1.05 \mathrm{FT}$ \\
\hline NEWPORT OR & 2309 UTC 3-27 & $2.46 \mathrm{FT}$ \\
\hline CHARLESTON OR & 2333 UTC 3-27 & $2.74 \mathrm{FT}$ \\
\hline PORT ORFORD OR & 2355 UTC 3-27 & $6.76 \mathrm{FT}$ \\
\hline CRESCENT CITY CA & 0100 UTC $3-28$ & $7.11 \mathrm{FT}$ \\
\hline ARENA COVE CA & 2313 UTC 3-27 & $5.58 \mathrm{FT}$ \\
\hline EUREKA CA & 0006 UTC 3-28 & 4.23 FT \\
\hline POINT REYES CA & 0142 UTC 3-28 & $3.38 \mathrm{FT}$ \\
\hline SAN FRANCISCO & 0155 UTC $3-28$ & $3.71 \mathrm{FT}$ \\
\hline ALAMEDA CA & 0141 UTC 3-28 & $1.84 \mathrm{FT}$ \\
\hline MONTEREY CA & 2338 UTC $3-27$ & $3.97 \mathrm{FT}$ \\
\hline PORT SAN LUIS CA & 0108 UTC $3-28$ & $14.30 \mathrm{FT}$ \\
\hline SANTA BARBARA CA & 0145 UTC $3-2$ & $2.64 \mathrm{FT}$ \\
\hline SANTA MONICA CA & 0157 UTC 3-28 & $3.38 \mathrm{FT}$ \\
\hline SAN PEDRO CA & 0230 UTC $3-28$ & $3.11 \mathrm{FT}$ \\
\hline LA JOLLA CA & 0222 UTC 3-28 & $3.5 \mathrm{FT}$ \\
\hline SAN DIEGO CA & 0214 UTC $3-28$ & $1.74 \mathrm{FT}$ \\
\hline MIDWAY IS & 2304 UTC $3-27$ & $1.44 \mathrm{FT}$ \\
\hline NAWILIWILI HI & 2323 UTC 3-27 & $2.20 \mathrm{FT}$ \\
\hline HALEIWA HI & 2338 UTC $3-27$ & $4.99 \mathrm{FT}$ \\
\hline HONOLULU HI & 2338 UTC $3-27$ & $2.23 \mathrm{FT}$ \\
\hline KAHULUI HI & 2341 UTC 3-27 & $7.15 \mathrm{FT}$ \\
\hline KAWAIHAE HI & 0014 UTC 3-28 & $2.89 \mathrm{FT}$ \\
\hline WAKE ISLAND & 0052 UTC 3-28 & $0.33 \mathrm{FT}$ \\
\hline GUAM & 0321 UTC 3-28 & $30 \mathrm{FT}$ \\
\hline PAGO PAGO AM SAM & 0433 UTC 3 & $3-28$ \\
\hline
\end{tabular}

HEIGHT - OBSERVED MAX TSUNAMI HEIGHT IS THE WATER LEVEL ABOVE THE TIDE LEVEL AT THE TIME OF MEASUREMENT.

PRELIMINARY EARTHQUAKE PARAMETERS 


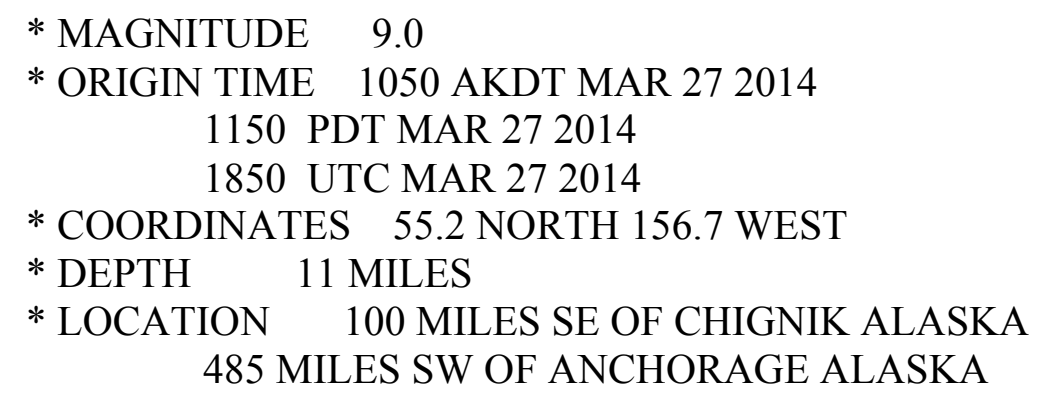

* THIS MESSAGE WILL BE UPDATED IN 60 MINUTES.

* REFER TO THE INTERNET SITE WCATWC.ARH.NOAA.GOV FOR MORE INFORMATION.

* PACIFIC COASTAL RESIDENTS OUTSIDE CALIFORNIA... OREGON... WASHINGTON... BRITISH COLUMBIA AND ALASKA SHOULD REFER TO THE PACIFIC TSUNAMI WARNING CENTER MESSAGES FOR INFORMATION ON THIS EVENT AT PTWC.WEATHER.GOV. 
WEAK51 PAAQ 291501

TSUAK1

BULLETIN

PUBLIC TSUNAMI MESSAGE NUMBER 46

NWS WEST COAST/ALASKA TSUNAMI WARNING CENTER PALMER AK 701 AM AKDT SAT MAR 292014

THIS MESSAGE CONTINUES THE WARNING AND ADVISORY AS IN THE PREVIOUS MESSAGE.

...THE TSUNAMI WARNING REMAINS IN EFFECT...

...THE TSUNAMI ADVISORY REMAINS IN EFFECT...

WARNINGS/ADVISORIES/WATCHES

TSUNAMI WARNING IN EFFECT FOR...

* THE COASTAL AREAS OF ALASKA FROM KENNEDY ENTRANCE ALASKA/LOCATED 40 MILES SW OF HOMER/ TO UNIMAK PASS

ALASKA/LOCATED 80 MILES NE OF DUTCH HARBOR/

TSUNAMI ADVISORY IN EFFECT FOR...

* THE COASTAL AREAS OF CALIFORNIA - OREGON - WASHINGTON BRITISH COLUMBIA AND ALASKA FROM THE CALIFORNIA-MEXICO BORDER TO KENNEDY ENTRANCE ALASKA/LOCATED 40 MILES SW OF HOMER/

* THE COASTAL AREAS OF ALASKA FROM UNIMAK PASS ALASKA/LOCATED 80 MILES NE OF DUTCH HARBOR/ TO NIKOLSKI ALASKA

* FOR OTHER US AND CANDIAN PACIFIC COASTS IN NORTH AMERICA THIS IS FOR INFORMATION ONLY.

IMPACTS FOR TSUNAMI WARNING AREAS

* WIDESPREAD DANGEROUS COASTAL FLOODING ACCOMPANIED BY POWERFUL CURRENTS IS POSSIBLE AND MAY CONTINUE FOR MANY HOURS AFTER TSUNAMI ARRIVAL. 
* THE FIRST WAVE MAY NOT BE THE LARGEST.

IMPACTS FOR TSUNAMI ADVISORY AREAS

* A TSUNAMI CAPABLE OF PRODUCING STRONG CURRENTS OR WAVES DANGEROUS

TO PERSONS IN OR VERY NEAR THE WATER IS EXPECTED.

* CURRENTS MAY BE HAZARDOUS TO SWIMMERS... BOATS... AND COASTAL STRUCTURES AND MAY CONTINUE FOR MANY HOURS AFTER THE TSUNAMI ARRIVAL.

* THE FIRST WAVE MAY NOT BE THE LARGEST.

\section{RECOMMENDED ACTIONS}

* IF YOU ARE IN A WARNING AREA - MOVE INLAND TO HIGHER GROUND.

* IF YOU ARE IN AN ADVISORY AREA - MOVE OFF THE BEACH AND OUT OF HARBORS AND MARINAS. WIDESPREAD INUNDATION OF LAND IS NOT EXPECTED FOR ADVISORY AREAS.

* BE ALERT TO INSTRUCTIONS FROM YOUR LOCAL EMERGENCY OFFICIALS.

* DO NOT GO TO THE COAST TO OBSERVE THE TSUNAMI.

* DO NOT RETURN TO THE COAST UNTIL LOCAL EMERGENCY OFFICIALS INDICATE IT IS SAFE TO DO SO.

SIGNIFICANT TSUNAMI ACTIVITY IS EXPECTED TO CONTINUE FOR UP TO 3 MORE HOURS FOR AREAS STILL IN A LEVEL OF ALERT.

ADDITIONAL OBSERVATIONS OF TSUNAMI ACTIVITY - UPDATED

\begin{tabular}{|c|c|c|}
\hline \multirow[b]{2}{*}{ SITE } & \multicolumn{2}{|c|}{ OBSERVED MAX } \\
\hline & OF MEASUREMENT & TSUNAMI HEIGHT \\
\hline SAND POINT A & 1945 UTC 3-27 & $11.60 \mathrm{FT}$ \\
\hline KING COVE AK & 2023 UTC 3-27 & $4.33 \mathrm{FT}$ \\
\hline CHIGNIK AK & 2026 UTC 3-27 & $21.82 \mathrm{FT}$ \\
\hline NIKOLSKI AK & 2054 UTC 3-27 & $1.61 \mathrm{FT}$ \\
\hline UNALASKA AK & 2056 UTC 3-27 & $1.44 \mathrm{FT}$ \\
\hline KODIAK AK & 2100 UTC $3-27$ & $4.50 \mathrm{FT}$ \\
\hline
\end{tabular}




\begin{tabular}{|c|c|c|}
\hline SEWARD AK & 2110 UTC $3-27$ & $4.11 \mathrm{FT}$ \\
\hline ADAK AK & 2145 UTC $3-27$ & $1.03 \mathrm{FT}$ \\
\hline ELFIN COVE AK & 2133 UTC 3-27 & $1.32 \mathrm{FT}$ \\
\hline YAKUTAT AK & 2132 UTC 3-27 & $2.44 \mathrm{FT}$ \\
\hline PORT ALEXANDER A & 2114 UTC 3-2 & $1.41 \mathrm{FT}$ \\
\hline CORDOVA AK & 2235 UTC $3-27$ & $1.82 \mathrm{FT}$ \\
\hline SHEMYA AK & 2245 UTC 3-27 & $0.34 \mathrm{FT}$ \\
\hline SITKA AK & 2222 UTC 3-27 & $3.74 \mathrm{FT}$ \\
\hline CRAIG AK & 2255 UTC $3-27$ & $3.88 \mathrm{FT}$ \\
\hline LANGARA BC & 2300 UTC 3-27 & $1.60 \mathrm{FT}$ \\
\hline TOFINO BC & 2334 UTC $3-27$ & $2.41 \mathrm{FT}$ \\
\hline NEAH BAY WA & 2234 UTC 3-27 & $2.02 \mathrm{FT}$ \\
\hline LAPUSH WA & 2241 UTC 3-27 & $3.15 \mathrm{FT}$ \\
\hline WESTPORT WA & 2302 UTC $3-27$ & $2.11 \mathrm{FT}$ \\
\hline PORT ANGELES WA & 2354 UTC $3-27$ & $1.38 \mathrm{FT}$ \\
\hline GARIBALDI OR & 2259 UTC $3-27$ & $1.05 \mathrm{FT}$ \\
\hline NEWPORT OR & 2309 UTC 3-27 & $2.46 \mathrm{FT}$ \\
\hline CHARLESTON OR & 2333 UTC 3-27 & $2.74 \mathrm{FT}$ \\
\hline PORT ORFORD OR & 2355 UTC 3-27 & $6.76 \mathrm{FT}$ \\
\hline CRESCENT CITY CA & 0100 UTC $3-28$ & $7.11 \mathrm{FT}$ \\
\hline ARENA COVE CA & 2313 UTC 3-27 & $5.58 \mathrm{FT}$ \\
\hline EUREKA CA & 0006 UTC 3-28 & 4.23 FT \\
\hline POINT REYES CA & 0142 UTC 3-28 & $3.38 \mathrm{FT}$ \\
\hline SAN FRANCISCO & 0155 UTC $3-28$ & $3.71 \mathrm{FT}$ \\
\hline ALAMEDA CA & 0141 UTC 3-28 & $1.84 \mathrm{FT}$ \\
\hline MONTEREY CA & 2338 UTC $3-27$ & $3.97 \mathrm{FT}$ \\
\hline PORT SAN LUIS CA & 0108 UTC $3-28$ & $14.30 \mathrm{FT}$ \\
\hline SANTA BARBARA CA & 0145 UTC $3-2$ & $2.64 \mathrm{FT}$ \\
\hline SANTA MONICA CA & 0157 UTC 3-28 & $3.38 \mathrm{FT}$ \\
\hline SAN PEDRO CA & 0230 UTC $3-28$ & $3.11 \mathrm{FT}$ \\
\hline LA JOLLA CA & 0222 UTC 3-28 & $3.5 \mathrm{FT}$ \\
\hline SAN DIEGO CA & 0214 UTC $3-28$ & $1.74 \mathrm{FT}$ \\
\hline MIDWAY IS & 2304 UTC $3-27$ & $1.44 \mathrm{FT}$ \\
\hline NAWILIWILI HI & 2323 UTC 3-27 & $2.20 \mathrm{FT}$ \\
\hline HALEIWA HI & 2338 UTC $3-27$ & $4.99 \mathrm{FT}$ \\
\hline HONOLULU HI & 2338 UTC $3-27$ & $2.23 \mathrm{FT}$ \\
\hline KAHULUI HI & 2341 UTC 3-27 & $7.15 \mathrm{FT}$ \\
\hline KAWAIHAE HI & 0014 UTC 3-28 & $2.89 \mathrm{FT}$ \\
\hline WAKE ISLAND & 0052 UTC 3-28 & $0.33 \mathrm{FT}$ \\
\hline GUAM & 0321 UTC 3-28 & $30 \mathrm{FT}$ \\
\hline PAGO PAGO AM SAM & 0433 UTC 3 & $3-28$ \\
\hline
\end{tabular}

HEIGHT - OBSERVED MAX TSUNAMI HEIGHT IS THE WATER LEVEL ABOVE THE TIDE LEVEL AT THE TIME OF MEASUREMENT.

PRELIMINARY EARTHQUAKE PARAMETERS 


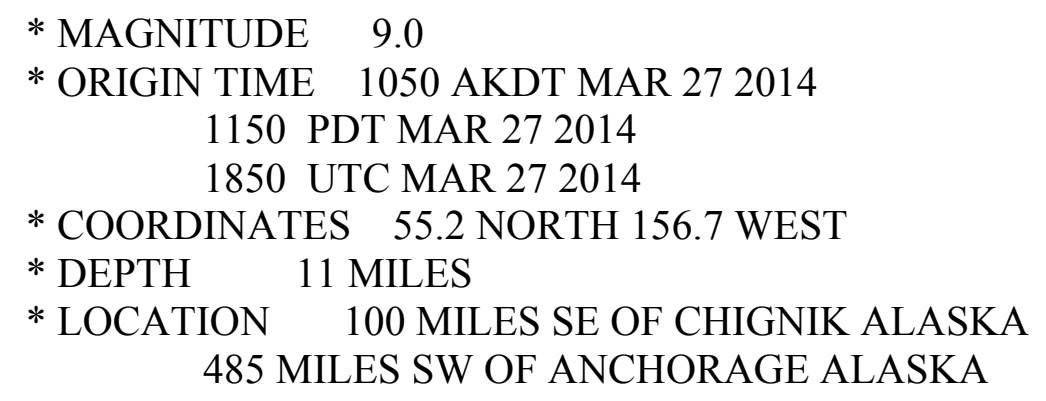

* THIS MESSAGE WILL BE UPDATED IN 60 MINUTES.

* REFER TO THE INTERNET SITE WCATWC.ARH.NOAA.GOV FOR MORE INFORMATION.

* PACIFIC COASTAL RESIDENTS OUTSIDE CALIFORNIA... OREGON... WASHINGTON... BRITISH COLUMBIA AND ALASKA SHOULD REFER TO THE PACIFIC TSUNAMI WARNING CENTER MESSAGES FOR INFORMATION ON THIS EVENT AT PTWC.WEATHER.GOV. 
WEAK51 PAAQ 291601

TSUAK1

BULLETIN

PUBLIC TSUNAMI MESSAGE NUMBER 47

NWS WEST COAST/ALASKA TSUNAMI WARNING CENTER PALMER AK

801 AM AKDT SAT MAR 292014

THIS MESSAGE CANCELS THE ADVISORY FOR AREAS IN SOUTHERN CALIFORNIA.

...THE TSUNAMI WARNING REMAINS IN EFFECT...

...THE TSUNAMI ADVISORY REMAINS IN EFFECT...

WARNINGS/ADVISORIES/WATCHES - UPDATED

TSUNAMI WARNING IN EFFECT FOR...

* THE COASTAL AREAS OF ALASKA FROM KENNEDY ENTRANCE ALASKA/LOCATED 40 MILES SW OF HOMER/ TO UNIMAK PASS

ALASKA/LOCATED 80 MILES NE OF DUTCH HARBOR/

TSUNAMI ADVISORY IN EFFECT FOR...

* THE COASTAL AREAS OF CALIFORNIA - OREGON - WASHINGTON BRITISH COLUMBIA AND ALASKA FROM RINCON POINT

CALIFORNIA/LOCATED 15 MILES SE OF SANTA BARBARA/ TO KENNEDY

ENTRANCE ALASKA/LOCATED 40 MILES SW OF HOMER/

* THE COASTAL AREAS OF ALASKA FROM UNIMAK PASS ALASKA/LOCATED 80 MILES NE OF DUTCH HARBOR/ TO NIKOLSKI ALASKA

\section{CANCELLATIONS}

* THE TSUNAMI ADVISORY IS CANCELED FOR THE COASTAL AREAS OF CALIFORNIA FROM THE CALIFORNIA-MEXICO BORDER TO RINCON POINT CALIFORNIA/LOCATED 15 MILES SE OF SANTA BARBARA/

* FOR OTHER US AND CANDIAN PACIFIC COASTS IN NORTH AMERICA THIS IS FOR INFORMATION ONLY. 
IMPACTS FOR TSUNAMI WARNING AREAS

* WIDESPREAD DANGEROUS COASTAL FLOODING ACCOMPANIED BY POWERFUL CURRENTS IS POSSIBLE AND MAY CONTINUE FOR MANY HOURS AFTER TSUNAMI ARRIVAL.

* THE FIRST WAVE MAY NOT BE THE LARGEST.

IMPACTS FOR TSUNAMI ADVISORY AREAS

* A TSUNAMI CAPABLE OF PRODUCING STRONG CURRENTS OR WAVES DANGEROUS

TO PERSONS IN OR VERY NEAR THE WATER IS EXPECTED.

* CURRENTS MAY BE HAZARDOUS TO SWIMMERS... BOATS... AND COASTAL STRUCTURES AND MAY CONTINUE FOR MANY HOURS AFTER THE TSUNAMI ARRIVAL.

* THE FIRST WAVE MAY NOT BE THE LARGEST.

RECOMMENDED ACTIONS

* IF YOU ARE IN A WARNING AREA - MOVE INLAND TO HIGHER GROUND.

* IF YOU ARE IN AN ADVISORY AREA - MOVE OFF THE BEACH AND OUT OF HARBORS AND MARINAS. WIDESPREAD INUNDATION OF LAND IS NOT EXPECTED FOR ADVISORY AREAS.

* BE ALERT TO INSTRUCTIONS FROM YOUR LOCAL EMERGENCY OFFICIALS.

* DO NOT GO TO THE COAST TO OBSERVE THE TSUNAMI.

* DO NOT RETURN TO THE COAST UNTIL LOCAL EMERGENCY OFFICIALS INDICATE IT IS SAFE TO DO SO.

SIGNIFICANT TSUNAMI ACTIVITY IS EXPECTED TO CONTINUE FOR UP TO 3 MORE HOURS FOR AREAS STILL IN A LEVEL OF ALERT.

ADDITIONAL OBSERVATIONS OF TSUNAMI ACTIVITY - UPDATED

$\begin{array}{lll} & \text { TIME } & \text { OBSERVED MAX } \\ \text { SITE } & \text { OF MEASUREMENT TSUNAMI HEIGHT }\end{array}$




\begin{tabular}{|c|c|c|}
\hline AND POINT AK & 1945 UTC 3-27 & $11.60 \mathrm{FT}$ \\
\hline KING COVE AK & 2023 UTC 3-27 & $4.33 \mathrm{FT}$ \\
\hline CHIGNIK AK & 2026 UTC 3-27 & $21.82 \mathrm{FT}$ \\
\hline NIKOLSKI AK & 2054 UTC $3-27$ & $1.61 \mathrm{FT}$ \\
\hline UNALASKA AK & 2056 UTC 3-27 & $1.44 \mathrm{FT}$ \\
\hline KODIAK AK & 2100 UTC $3-27$ & 4.50 FT \\
\hline SEWARD AK & 2110 UTC $3-27$ & $4.11 \mathrm{FT}$ \\
\hline ADAK AK & 2145 UTC $3-27$ & $.03 \mathrm{FT}$ \\
\hline ELFIN COVE AK & 2133 UTC $3-27$ & $1.32 \mathrm{FT}$ \\
\hline YAKUTAT AK & 2132 UTC 3-27 & $2.44 \mathrm{FT}$ \\
\hline PORT ALEXANDER AK & 2114 UTC $3-27$ & $1.41 \mathrm{FT}$ \\
\hline CORDOVA AK & 2235 UTC $3-27$ & $1.82 \mathrm{FT}$ \\
\hline SHEMYA AK & 2245 UTC $3-27$ & $0.34 \mathrm{FT}$ \\
\hline SITKA AK & 2222 UTC $3-27$ & $74 \mathrm{FT}$ \\
\hline CRAIG AK & 2255 UTC $3-27$ & $.88 \mathrm{FT}$ \\
\hline LANGARA BC & 2300 UTC $3-27$ & $1.60 \mathrm{FT}$ \\
\hline TOFINO BC & 2334 UTC $3-27$ & $2.41 \mathrm{FT}$ \\
\hline NEAH BAY WA & 2234 UTC $3-27$ & $2.02 \mathrm{FT}$ \\
\hline LAPUSH WA & 2241 UTC 3-27 & $3.15 \mathrm{FT}$ \\
\hline WESTPORT WA & 2302 UTC $3-27$ & $2.11 \mathrm{FT}$ \\
\hline PORT ANGELES WA & 2354 UTC $3-27$ & $1.38 \mathrm{FT}$ \\
\hline GARIBALDI OR & 2259 UTC 3-27 & $1.05 \mathrm{FT}$ \\
\hline NEWPORT OR & 2309 UTC 3-27 & $2.46 \mathrm{FT}$ \\
\hline CHARLESTON OR & 2333 UTC $3-27$ & $2.74 \mathrm{FT}$ \\
\hline PORT ORFORD OR & 2355 UTC $3-27$ & $6.76 \mathrm{FT}$ \\
\hline CRESCENT CITY CA & 0100 UTC $3-28$ & $7.11 \mathrm{FT}$ \\
\hline ARENA COVE CA & 2313 UTC $3-27$ & $5.58 \mathrm{FT}$ \\
\hline EUREKA CA & 0006 UTC 3-28 & $4.23 \mathrm{FT}$ \\
\hline POINT REYES CA & 0142 UTC 3-28 & $3.38 \mathrm{FT}$ \\
\hline SAN FRANCISCO & 0155 UTC $3-28$ & $3.71 \mathrm{FT}$ \\
\hline ALAMEDA CA & 0141 UTC 3-28 & $1.84 \mathrm{FT}$ \\
\hline MONTEREY CA & 2338 UTC $3-27$ & $3.97 \mathrm{FT}$ \\
\hline PORT SAN LUIS CA & 0108 UTC $3-28$ & 14.30 FT \\
\hline SANTA BARBARA CA & 0145 UTC $3-28$ & $2.64 \mathrm{FT}$ \\
\hline SANTA MONICA CA & 0157 UTC 3-28 & $3.38 \mathrm{FT}$ \\
\hline SAN PEDRO CA & 0230 UTC $3-28$ & $3.11 \mathrm{FT}$ \\
\hline LA JOLLA CA & 0222 UTC 3-28 & $3.5 \mathrm{FT}$ \\
\hline SAN DIEGO CA & 0214 UTC 3-28 & $1.74 \mathrm{FT}$ \\
\hline MIDWAY IS & 2304 UTC $3-27$ & $1.44 \mathrm{FT}$ \\
\hline NAWILIWILI HI & 2323 UTC $3-27$ & $2.20 \mathrm{FT}$ \\
\hline HALEIWA HI & 2338 UTC $3-27$ & $4.99 \mathrm{FT}$ \\
\hline HONOLULU HI & 2338 UTC $3-27$ & $2.23 \mathrm{FT}$ \\
\hline KAHULUI HI & 2341 UTC $3-27$ & $7.15 \mathrm{FT}$ \\
\hline KAWAIHAE HI & 0014 UTC 3-28 & $2.89 \mathrm{FT}$ \\
\hline WAKE ISLAND & 0052 UTC $3-28$ & $0.33 \mathrm{FT}$ \\
\hline GUAM & 321 UTC $3-28$ & $0 \mathrm{FT}$ \\
\hline
\end{tabular}


PAGO PAGO AM SAMOA 0433 UTC 3-28 $0.46 \mathrm{FT}$

HEIGHT - OBSERVED MAX TSUNAMI HEIGHT IS THE WATER LEVEL ABOVE THE TIDE LEVEL AT THE TIME OF MEASUREMENT.

PRELIMINARY EARTHQUAKE PARAMETERS

* MAGNITUDE 9.0

* ORIGIN TIME 1050 AKDT MAR 272014

1150 PDT MAR 272014

1850 UTC MAR 272014

* COORDINATES 55.2 NORTH 156.7 WEST

* DEPTH 11 MILES

* LOCATION 100 MILES SE OF CHIGNIK ALASKA 485 MILES SW OF ANCHORAGE ALASKA

NEXT UPDATE AND ADDITIONAL INFORMATION

* THIS MESSAGE WILL BE UPDATED IN 60 MINUTES.

* REFER TO THE INTERNET SITE WCATWC.ARH.NOAA.GOV FOR MORE INFORMATION.

* PACIFIC COASTAL RESIDENTS OUTSIDE CALIFORNIA... OREGON... WASHINGTON... BRITISH COLUMBIA AND ALASKA SHOULD REFER TO THE PACIFIC TSUNAMI WARNING CENTER MESSAGES FOR INFORMATION ON THIS EVENT AT PTWC.WEATHER.GOV.

$\$ \$$ 
WEAK51 PAAQ 291702

TSUAK1

BULLETIN

PUBLIC TSUNAMI MESSAGE NUMBER 48

NWS WEST COAST/ALASKA TSUNAMI WARNING CENTER PALMER AK 902 AM AKDT SAT MAR 292014

THIS MESSAGE DOWNGRADES THE PREVIOUSLY WARNED REGION IN ALASKA TO

ADVISORY AND CANCELS THE ADVISORY FOR PORTIONS OF ALASKA/ BRITISH COLUMBIA AND WASHINGTON.

...THE TSUNAMI ADVISORY REMAINS IN EFFECT...

WARNINGS/ADVISORIES/WATCHES - UPDATED

TSUNAMI ADVISORY IN EFFECT FOR...

* THE COASTAL AREAS OF CALIFORNIA AND OREGON FROM RINCON POINT CALIFORNIA/LOCATED 15 MILES SE OF SANTA BARBARA/ TO THE OREGON-WASHINGTON BORDER

* THE COASTAL AREAS OF ALASKA FROM KENNEDY ENTRANCE ALASKA/LOCATED 40 MILES SW OF HOMER/ TO UNIMAK PASS ALASKA/LOCATED 80 MILES NE OF DUTCH HARBOR/

CANCELLATIONS

* THE TSUNAMI ADVISORY IS CANCELED FOR THE COASTAL AREAS OF WASHINGTON - BRITISH COLUMBIA AND ALASKA FROM THE OREGON-WASHINGTON BORDER TO KENNEDY ENTRANCE ALASKA/LOCATED 40 MILES SW OF HOMER/

* THE TSUNAMI ADVISORY IS CANCELED FOR THE COASTAL AREAS OF ALASKA FROM UNIMAK PASS ALASKA/LOCATED 80 MILES NE OF DUTCH HARBOR/ TO NIKOLSKI ALASKA

* FOR OTHER US AND CANDIAN PACIFIC COASTS IN NORTH AMERICA THIS IS FOR INFORMATION ONLY.

IMPACTS FOR TSUNAMI ADVISORY AREAS 
* A TSUNAMI CAPABLE OF PRODUCING STRONG CURRENTS OR WAVES DANGEROUS

TO PERSONS IN OR VERY NEAR THE WATER IS EXPECTED.

* CURRENTS MAY BE HAZARDOUS TO SWIMMERS... BOATS... AND COASTAL STRUCTURES AND MAY CONTINUE FOR MANY HOURS AFTER THE TSUNAMI ARRIVAL.

* THE FIRST WAVE MAY NOT BE THE LARGEST.

RECOMMENDED ACTIONS - UPDATED

* IF YOU ARE IN AN ADVISORY AREA - MOVE OFF THE BEACH AND OUT OF HARBORS AND MARINAS. WIDESPREAD INUNDATION OF LAND IS NOT EXPECTED FOR ADVISORY AREAS.

* BE ALERT TO INSTRUCTIONS FROM YOUR LOCAL EMERGENCY OFFICIALS.

* DO NOT GO TO THE COAST TO OBSERVE THE TSUNAMI.

* DO NOT RETURN TO THE COAST UNTIL LOCAL EMERGENCY OFFICIALS INDICATE IT IS SAFE TO DO SO.

SIGNIFICANT TSUNAMI ACTIVITY IS EXPECTED TO CONTINUE FOR UP TO 3 MORE HOURS FOR AREAS STILL IN A LEVEL OF ALERT.

ADDITIONAL OBSERVATIONS OF TSUNAMI ACTIVITY - UPDATED

\begin{tabular}{|c|c|c|}
\hline \multirow[b]{2}{*}{ SITE } & \multicolumn{2}{|c|}{ OBSERVED MAX } \\
\hline & OF MEASUREMENT & TSUNAMI HEIGHT \\
\hline SAND POINT AK & 1945 UTC 3-27 & $11.60 \mathrm{FT}$ \\
\hline KING COVE AK & 2023 UTC 3-27 & $4.33 \mathrm{FT}$ \\
\hline CHIGNIK AK & 2026 UTC 3-27 & $21.82 \mathrm{FT}$ \\
\hline NIKOLSKI AK & 2054 UTC 3-27 & $1.61 \mathrm{FT}$ \\
\hline UNALASKA AK & 2056 UTC 3-27 & $1.44 \mathrm{FT}$ \\
\hline KODIAK AK & 2100 UTC $3-27$ & $4.50 \mathrm{FT}$ \\
\hline SEWARD AK & 2110 UTC 3-27 & $4.11 \mathrm{FT}$ \\
\hline ADAK AK & 2145 UTC $3-27$ & $1.03 \mathrm{FT}$ \\
\hline ELFIN COVE AK & 2133 UTC $3-27$ & $1.32 \mathrm{FT}$ \\
\hline YAKUTAT AK & 2132 UTC $3-27$ & $2.44 \mathrm{FT}$ \\
\hline PORT ALEXANDE & 2114 UTC & $1.41 \mathrm{FT}$ \\
\hline CORDOVA AK & 2235 UTC 3-27 & $1.82 \mathrm{FT}$ \\
\hline
\end{tabular}




\begin{tabular}{|c|c|c|}
\hline SHEMYA AK & 2245 UTC 3-27 & $0.34 \mathrm{FT}$ \\
\hline SITKA AK & 2222 UTC 3-27 & $3.74 \mathrm{FT}$ \\
\hline CRAIG AK & 2255 UTC $3-27$ & $3.88 \mathrm{FT}$ \\
\hline LANGARA BC & 2300 UTC 3-27 & $1.60 \mathrm{FT}$ \\
\hline TOFINO BC & 2334 UTC 3-27 & $2.41 \mathrm{FT}$ \\
\hline NEAH BAY WA & 2234 UTC 3-27 & $2.02 \mathrm{FT}$ \\
\hline LAPUSH WA & 2241 UTC 3-27 & $3.15 \mathrm{FT}$ \\
\hline WESTPORT WA & 2302 UTC 3-27 & $2.11 \mathrm{FT}$ \\
\hline PORT ANGELES WA & 2354 UTC 3-2 & $1.38 \mathrm{FT}$ \\
\hline GARIBALDI OR & 2259 UTC 3-27 & $1.05 \mathrm{FT}$ \\
\hline NEWPORT OR & 2309 UTC 3-27 & $2.46 \mathrm{FT}$ \\
\hline CHARLESTON OR & 2333 UTC 3-27 & $2.74 \mathrm{FT}$ \\
\hline PORT ORFORD OR & 2355 UTC 3-27 & $6.76 \mathrm{FT}$ \\
\hline CRESCENT CITY CA & 0100 UTC 3-28 & $7.11 \mathrm{FT}$ \\
\hline ARENA COVE CA & 2313 UTC 3-27 & $5.58 \mathrm{FT}$ \\
\hline EUREKA CA & 0006 UTC 3-28 & $4.23 \mathrm{FT}$ \\
\hline POINT REYES CA & 0142 UTC 3-28 & $3.38 \mathrm{FT}$ \\
\hline SAN FRANCISCO & 0155 UTC 3-28 & $3.71 \mathrm{FT}$ \\
\hline ALAMEDA CA & 0141 UTC 3-28 & $1.84 \mathrm{FT}$ \\
\hline MONTEREY CA & 2338 UTC $3-27$ & $3.97 \mathrm{FT}$ \\
\hline PORT SAN LUIS CA & 0108 UTC 3-28 & $14.30 \mathrm{FT}$ \\
\hline SANTA BARBARA CA & 0145 UTC 3- & $2.64 \mathrm{FT}$ \\
\hline SANTA MONICA CA & 0157 UTC 3-2 & $3.38 \mathrm{FT}$ \\
\hline SAN PEDRO CA & 0230 UTC 3-28 & $3.11 \mathrm{FT}$ \\
\hline LA JOLLA CA & 0222 UTC 3-28 & $3.5 \mathrm{FT}$ \\
\hline SAN DIEGO CA & 0214 UTC 3-28 & $1.74 \mathrm{FT}$ \\
\hline MIDWAY IS & 2304 UTC 3-27 & $1.44 \mathrm{FT}$ \\
\hline NAWILIWILI HI & 2323 UTC 3-27 & $2.20 \mathrm{FT}$ \\
\hline HALEIWA HI & 2338 UTC 3-27 & $4.99 \mathrm{FT}$ \\
\hline HONOLULU HI & 2338 UTC 3-27 & $2.23 \mathrm{FT}$ \\
\hline KAHULUI HI & 2341 UTC 3-27 & $7.15 \mathrm{FT}$ \\
\hline KAWAIHAE HI & 0014 UTC 3-28 & $2.89 \mathrm{FT}$ \\
\hline WAKE ISLAND & 0052 UTC 3-28 & $0.33 \mathrm{FT}$ \\
\hline GUAM & 0321 UTC 3-28 & $30 \mathrm{FT}$ \\
\hline PAGO PAGO AM SAM & 0433 UTC & $3-28$ \\
\hline
\end{tabular}

HEIGHT - OBSERVED MAX TSUNAMI HEIGHT IS THE WATER LEVEL ABOVE THE TIDE LEVEL AT THE TIME OF MEASUREMENT.

PRELIMINARY EARTHQUAKE PARAMETERS

\footnotetext{
* MAGNITUDE 9.0

* ORIGIN TIME 1050 AKDT MAR 272014

1150 PDT MAR 272014

1850 UTC MAR 272014

* COORDINATES 55.2 NORTH 156.7 WEST
} 
* DEPTH 11 MILES

* LOCATION 100 MILES SE OF CHIGNIK ALASKA 485 MILES SW OF ANCHORAGE ALASKA

NEXT UPDATE AND ADDITIONAL INFORMATION

* THIS MESSAGE WILL BE UPDATED IN 60 MINUTES.

* REFER TO THE INTERNET SITE WCATWC.ARH.NOAA.GOV FOR MORE INFORMATION.

* PACIFIC COASTAL RESIDENTS OUTSIDE CALIFORNIA... OREGON... WASHINGTON... BRITISH COLUMBIA AND ALASKA SHOULD REFER TO THE PACIFIC TSUNAMI WARNING CENTER MESSAGES FOR INFORMATION ON THIS EVENT AT PTWC.WEATHER.GOV.

$\$ \$$ 
WEAK51 PAAQ 291801

TSUAK1

BULLETIN

PUBLIC TSUNAMI MESSAGE NUMBER 49

NWS WEST COAST/ALASKA TSUNAMI WARNING CENTER PALMER AK 1001 AM AKDT SAT MAR 292014

THIS MESSAGE CANCELS THE TSUNAMI ADVISORY FOR TE CAST OF OREGON. ...THE TSUNAMI ADVISORY REMAINS IN EFFECT...

WARNINGS/ADVISORIES/WATCHES - UPDATED

TSUNAMI ADVISORY IN EFFECT FOR...

* THE COASTAL AREAS OF CALIFORNIA FROM RINCON POINT CALIFORNIA/LOCATED 15 MILES SE OF SANTA BARBARA/ TO THE OREGON-CALIFORNIA BORDER

* THE COASTAL AREAS OF ALASKA FROM KENNEDY ENTRANCE ALASKA/LOCATED 40 MILES SW OF HOMER/ TO UNIMAK PASS ALASKA/LOCATED 80 MILES NE OF DUTCH HARBOR/

\section{CANCELLATIONS}

* THE TSUNAMI ADVISORY IS CANCELED FOR THE COASTAL AREAS OF OREGON FROM THE OREGON-CALIFORNIA BORDER TO THE OREGON-WASHINGTON BORDER

* FOR OTHER US AND CANDIAN PACIFIC COASTS IN NORTH AMERICA THIS IS FOR INFORMATION ONLY.

IMPACTS FOR TSUNAMI ADVISORY AREAS

* A TSUNAMI CAPABLE OF PRODUCING STRONG CURRENTS OR WAVES DANGEROUS

TO PERSONS IN OR VERY NEAR THE WATER IS EXPECTED.

* CURRENTS MAY BE HAZARDOUS TO SWIMMERS... BOATS... AND COASTAL STRUCTURES AND MAY CONTINUE FOR MANY HOURS AFTER THE TSUNAMI ARRIVAL. 
* THE FIRST WAVE MAY NOT BE THE LARGEST.

\section{RECOMMENDED ACTIONS}

* IF YOU ARE IN AN ADVISORY AREA - MOVE OFF THE BEACH AND OUT OF HARBORS AND MARINAS. WIDESPREAD INUNDATION OF LAND IS NOT EXPECTED FOR ADVISORY AREAS.

* BE ALERT TO INSTRUCTIONS FROM YOUR LOCAL EMERGENCY OFFICIALS.

* DO NOT GO TO THE COAST TO OBSERVE THE TSUNAMI.

* DO NOT RETURN TO THE COAST UNTIL LOCAL EMERGENCY OFFICIALS INDICATE IT IS SAFE TO DO SO.

SIGNIFICANT TSUNAMI ACTIVITY IS EXPECTED TO CONTINUE FOR UP TO 3 MORE HOURS FOR AREAS STILL IN A LEVEL OF ALERT.

ADDITIONAL OBSERVATIONS OF TSUNAMI ACTIVITY - UPDATED

\begin{tabular}{|c|c|c|}
\hline \multirow[b]{2}{*}{ SITE } & \multicolumn{2}{|c|}{ TIME OBSERVED MAX } \\
\hline & F MEASUREMENT & TSUNAMI HEIGHT \\
\hline SAND POINT AK & 1945 UTC 3-27 & $11.60 \mathrm{FT}$ \\
\hline KING COVE AK & 2023 UTC 3-27 & $4.33 \mathrm{FT}$ \\
\hline CHIGNIK AK & 2026 UTC 3-27 & $21.82 \mathrm{FT}$ \\
\hline NIKOLSKI AK & 2054 UTC 3-27 & $1.61 \mathrm{FT}$ \\
\hline UNALASKA AK & 2056 UTC $3-27$ & $1.44 \mathrm{FT}$ \\
\hline KODIAK AK & 2100 UTC $3-27$ & $4.50 \mathrm{FT}$ \\
\hline SEWARD AK & 2110 UTC 3-27 & $4.11 \mathrm{FT}$ \\
\hline ADAK AK & 2145 UTC 3-27 & $1.03 \mathrm{FT}$ \\
\hline ELFIN COVE AK & 2133 UTC 3-27 & $1.32 \mathrm{FT}$ \\
\hline YAKUTAT AK & 2132 UTC $3-27$ & $2.44 \mathrm{FT}$ \\
\hline PORT ALEXANDER A & 2114 UTC 3 & $1.41 \mathrm{FT}$ \\
\hline CORDOVA AK & 2235 UTC 3-27 & $1.82 \mathrm{FT}$ \\
\hline SHEMYA AK & 2245 UTC $3-27$ & $0.34 \mathrm{FT}$ \\
\hline SITKA AK & 2222 UTC 3-27 & $3.74 \mathrm{FT}$ \\
\hline CRAIG AK & 2255 UTC $3-27$ & $3.88 \mathrm{FT}$ \\
\hline LANGARA BC & 2300 UTC 3-27 & $1.60 \mathrm{FT}$ \\
\hline TOFINO BC & 2334 UTC 3-27 & $2.41 \mathrm{FT}$ \\
\hline NEAH BAY WA & 2234 UTC $3-27$ & $2.02 \mathrm{FT}$ \\
\hline LAPUSH WA & 2241 UTC 3-27 & $3.15 \mathrm{FT}$ \\
\hline WESTPORT WA & 2302 UTC $3-27$ & $2.11 \mathrm{FT}$ \\
\hline
\end{tabular}




\begin{tabular}{|c|c|c|}
\hline PORT ANGELES WA & 2354 UTC 3-27 & $1.38 \mathrm{FT}$ \\
\hline GARIBALDI OR & 2259 UTC 3-27 & $1.05 \mathrm{FT}$ \\
\hline NEWPORT OR & 2309 UTC 3-27 & $2.46 \mathrm{FT}$ \\
\hline CHARLESTON OR & 2333 UTC 3-27 & $2.74 \mathrm{FT}$ \\
\hline PORT ORFORD OR & 2355 UTC 3-27 & $6.76 \mathrm{FT}$ \\
\hline CRESCENT CITY CA & 0100 UTC 3-28 & $7.11 \mathrm{FT}$ \\
\hline ARENA COVE CA & 2313 UTC 3-27 & $5.58 \mathrm{FT}$ \\
\hline EUREKA CA & 0006 UTC 3-28 & $4.23 \mathrm{FT}$ \\
\hline POINT REYES CA & 0142 UTC 3-28 & $3.38 \mathrm{FT}$ \\
\hline SAN FRANCISCO & 0155 UTC 3-28 & $3.71 \mathrm{FT}$ \\
\hline ALAMEDA CA & 0141 UTC 3-28 & $1.84 \mathrm{FT}$ \\
\hline MONTEREY CA & 2338 UTC 3-27 & $3.97 \mathrm{FT}$ \\
\hline PORT SAN LUIS CA & 0108 UTC 3-28 & $14.30 \mathrm{FT}$ \\
\hline SANTA BARBARA CA & 0145 UTC 3-2 & $2.64 \mathrm{FT}$ \\
\hline SANTA MONICA CA & 0157 UTC 3-28 & $3.38 \mathrm{FT}$ \\
\hline SAN PEDRO CA & 0230 UTC 3-28 & $3.11 \mathrm{FT}$ \\
\hline LA JOLLA CA & 0222 UTC 3-28 & $3.5 \mathrm{FT}$ \\
\hline SAN DIEGO CA & 0214 UTC 3-28 & $1.74 \mathrm{FT}$ \\
\hline MIDWAY IS & 2304 UTC 3-27 & $1.44 \mathrm{FT}$ \\
\hline NAWILIWILI HI & 2323 UTC 3-27 & $2.20 \mathrm{FT}$ \\
\hline HALEIWA HI & 2338 UTC 3-27 & $4.99 \mathrm{FT}$ \\
\hline HONOLULU HI & 2338 UTC 3-27 & $2.23 \mathrm{FT}$ \\
\hline KAHULUI HI & 2341 UTC 3-27 & $7.15 \mathrm{FT}$ \\
\hline KAWAIHAE HI & 0014 UTC 3-28 & $2.89 \mathrm{FT}$ \\
\hline WAKE ISLAND & 0052 UTC 3-28 & $0.33 \mathrm{FT}$ \\
\hline GUAM & 321 UTC 3-28 & $0 \mathrm{FT}$ \\
\hline PAGO PAGO AM & IOA $\quad 0433 \mathrm{~L}$ & -28 \\
\hline
\end{tabular}

HEIGHT - OBSERVED MAX TSUNAMI HEIGHT IS THE WATER LEVEL ABOVE THE TIDE LEVEL AT THE TIME OF MEASUREMENT.

PRELIMINARY EARTHQUAKE PARAMETERS

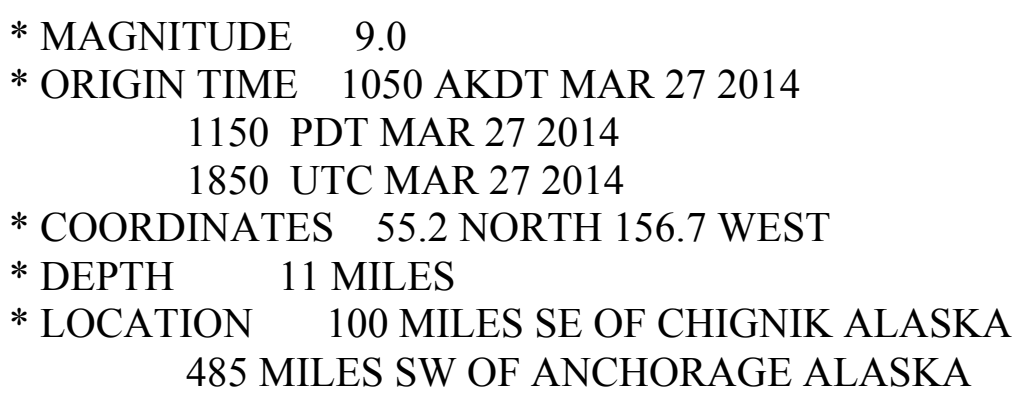

NEXT UPDATE AND ADDITIONAL INFORMATION

* THIS MESSAGE WILL BE UPDATED IN 60 MINUTES. 
* REFER TO THE INTERNET SITE WCATWC.ARH.NOAA.GOV FOR MORE INFORMATION.

* PACIFIC COASTAL RESIDENTS OUTSIDE CALIFORNIA... OREGON... WASHINGTON... BRITISH COLUMBIA AND ALASKA SHOULD REFER TO THE PACIFIC TSUNAMI WARNING CENTER MESSAGES FOR INFORMATION ON THIS EVENT AT PTWC.WEATHER.GOV.

$\$ \$$ 
WEAK51 PAAQ 291900

TSUAK1

BULLETIN

PUBLIC TSUNAMI MESSAGE NUMBER 50

NWS WEST COAST/ALASKA TSUNAMI WARNING CENTER PALMER AK 1100 AM AKDT SAT MAR 292014

...THE TSUNAMI ADVISORY IS CANCELLED...

CANCELLATIONS

* THE TSUNAMI ADVISORY IS CANCELED FOR THE COASTAL AREAS OF CALIFORNIA FROM RINCON POINT CALIFORNIA/LOCATED 15 MILES SE OF SANTA BARBARA/ TO THE OREGON-CALIFORNIA BORDER

* THE TSUNAMI ADVISORY IS CANCELED FOR THE COASTAL AREAS OF ALASKA FROM KENNEDY ENTRANCE ALASKA/LOCATED 40 MILES SW OF HOMER/ TO UNIMAK PASS ALASKA/LOCATED 80 MILES NE OF DUTCH HARBOR/

IMPACTS - UPDATED

* TSUNAMI ACTIVITY HAS SUBSIDED ALONG THE COASTS OF THE U.S. WEST COAST STATES... BRITISH COLUMBIA AND ALASKA.

* ONGOING ACTIVITY MAY PERSIST IN SOME AREAS CAUSING STRONG CURRENTS DANGEROUS TO SWIMMERS AND BOATS.

* THE DETERMINATION TO RE-OCCUPY HAZARD ZONES MUST BE MADE BY LOCAL OFFICIALS.

RECOMMENDED ACTIONS - UPDATED

* DO NOT RE-OCCUPY HAZARD ZONES UNTIL LOCAL EMERGENCY OFFICIALS INDICATE IT IS SAFE TO DO SO.

OBSERVATIONS OF TSUNAMI ACTIVITY - UPDATED

$\begin{array}{lll} & \text { TIME } & \\ \text { SITE } & \text { OF MEASUREMENTED MAX }\end{array}$




\begin{tabular}{|c|c|c|}
\hline AND POINT AK & 1945 UTC 3-27 & $11.60 \mathrm{FT}$ \\
\hline KING COVE AK & 2023 UTC 3-27 & $4.33 \mathrm{FT}$ \\
\hline CHIGNIK AK & 2026 UTC 3-27 & $21.82 \mathrm{FT}$ \\
\hline NIKOLSKI AK & 2054 UTC $3-27$ & $1.61 \mathrm{FT}$ \\
\hline UNALASKA AK & 2056 UTC 3-27 & $1.44 \mathrm{FT}$ \\
\hline KODIAK AK & 2100 UTC $3-27$ & 4.50 FT \\
\hline SEWARD AK & 2110 UTC $3-27$ & $4.11 \mathrm{FT}$ \\
\hline ADAK AK & 2145 UTC $3-27$ & $.03 \mathrm{FT}$ \\
\hline ELFIN COVE AK & 2133 UTC $3-27$ & $1.32 \mathrm{FT}$ \\
\hline YAKUTAT AK & 2132 UTC 3-27 & $2.44 \mathrm{FT}$ \\
\hline PORT ALEXANDER AK & 2114 UTC $3-27$ & $1.41 \mathrm{FT}$ \\
\hline CORDOVA AK & 2235 UTC $3-27$ & $1.82 \mathrm{FT}$ \\
\hline SHEMYA AK & 2245 UTC $3-27$ & $0.34 \mathrm{FT}$ \\
\hline SITKA AK & 2222 UTC $3-27$ & $74 \mathrm{FT}$ \\
\hline CRAIG AK & 2255 UTC $3-27$ & $.88 \mathrm{FT}$ \\
\hline LANGARA BC & 2300 UTC $3-27$ & $1.60 \mathrm{FT}$ \\
\hline TOFINO BC & 2334 UTC $3-27$ & $2.41 \mathrm{FT}$ \\
\hline NEAH BAY WA & 2234 UTC $3-27$ & $2.02 \mathrm{FT}$ \\
\hline LAPUSH WA & 2241 UTC 3-27 & $3.15 \mathrm{FT}$ \\
\hline WESTPORT WA & 2302 UTC $3-27$ & $2.11 \mathrm{FT}$ \\
\hline PORT ANGELES WA & 2354 UTC $3-27$ & $1.38 \mathrm{FT}$ \\
\hline GARIBALDI OR & 2259 UTC 3-27 & $1.05 \mathrm{FT}$ \\
\hline NEWPORT OR & 2309 UTC 3-27 & $2.46 \mathrm{FT}$ \\
\hline CHARLESTON OR & 2333 UTC $3-27$ & $2.74 \mathrm{FT}$ \\
\hline PORT ORFORD OR & 2355 UTC $3-27$ & $6.76 \mathrm{FT}$ \\
\hline CRESCENT CITY CA & 0100 UTC $3-28$ & $7.11 \mathrm{FT}$ \\
\hline ARENA COVE CA & 2313 UTC $3-27$ & $5.58 \mathrm{FT}$ \\
\hline EUREKA CA & 0006 UTC 3-28 & $4.23 \mathrm{FT}$ \\
\hline POINT REYES CA & 0142 UTC 3-28 & $3.38 \mathrm{FT}$ \\
\hline SAN FRANCISCO & 0155 UTC $3-28$ & $3.71 \mathrm{FT}$ \\
\hline ALAMEDA CA & 0141 UTC 3-28 & $1.84 \mathrm{FT}$ \\
\hline MONTEREY CA & 2338 UTC $3-27$ & $3.97 \mathrm{FT}$ \\
\hline PORT SAN LUIS CA & 0108 UTC $3-28$ & 14.30 FT \\
\hline SANTA BARBARA CA & 0145 UTC $3-28$ & $2.64 \mathrm{FT}$ \\
\hline SANTA MONICA CA & 0157 UTC 3-28 & $3.38 \mathrm{FT}$ \\
\hline SAN PEDRO CA & 0230 UTC $3-28$ & $3.11 \mathrm{FT}$ \\
\hline LA JOLLA CA & 0222 UTC 3-28 & $3.5 \mathrm{FT}$ \\
\hline SAN DIEGO CA & 0214 UTC 3-28 & $1.74 \mathrm{FT}$ \\
\hline MIDWAY IS & 2304 UTC $3-27$ & $1.44 \mathrm{FT}$ \\
\hline NAWILIWILI HI & 2323 UTC $3-27$ & $2.20 \mathrm{FT}$ \\
\hline HALEIWA HI & 2338 UTC $3-27$ & $4.99 \mathrm{FT}$ \\
\hline HONOLULU HI & 2338 UTC $3-27$ & $2.23 \mathrm{FT}$ \\
\hline KAHULUI HI & 2341 UTC $3-27$ & $7.15 \mathrm{FT}$ \\
\hline KAWAIHAE HI & 0014 UTC 3-28 & $2.89 \mathrm{FT}$ \\
\hline WAKE ISLAND & 0052 UTC $3-28$ & $0.33 \mathrm{FT}$ \\
\hline GUAM & 321 UTC $3-28$ & $0 \mathrm{FT}$ \\
\hline
\end{tabular}


PAGO PAGO AM SAMOA $\quad 0433$ UTC $3-28 \quad 0.46$ FT

HEIGHT - OBSERVED MAX TSUNAMI HEIGHT IS THE WATER LEVEL ABOVE THE TIDE LEVEL AT THE TIME OF MEASUREMENT.

NEXT UPDATE AND ADDITIONAL INFORMATION

* THIS WILL BE THE LAST WEST COAST/ALASKA TSUNAMI WARNING CENTER BULLETIN ISSUED FOR THIS EVENT.

* REFER TO THE INTERNET SITE WCATWC.ARH.NOAA.GOV FOR MORE INFORMATION.

* PACIFIC COASTAL REGIONS OUTSIDE CALIFORNIA... OREGON... WASHINGTON... BRITISH COLUMBIA AND ALASKA SHOULD REFER TO THE PACIFIC TSUNAMI WARNING CENTER MESSAGES FOR INFORMATION AT PTWC.WEATHER.GOV.

$\$ \$$ 


\section{Communication Products for the Science Application for Risk Reduction (SAFRR) Tsunami Scenario}

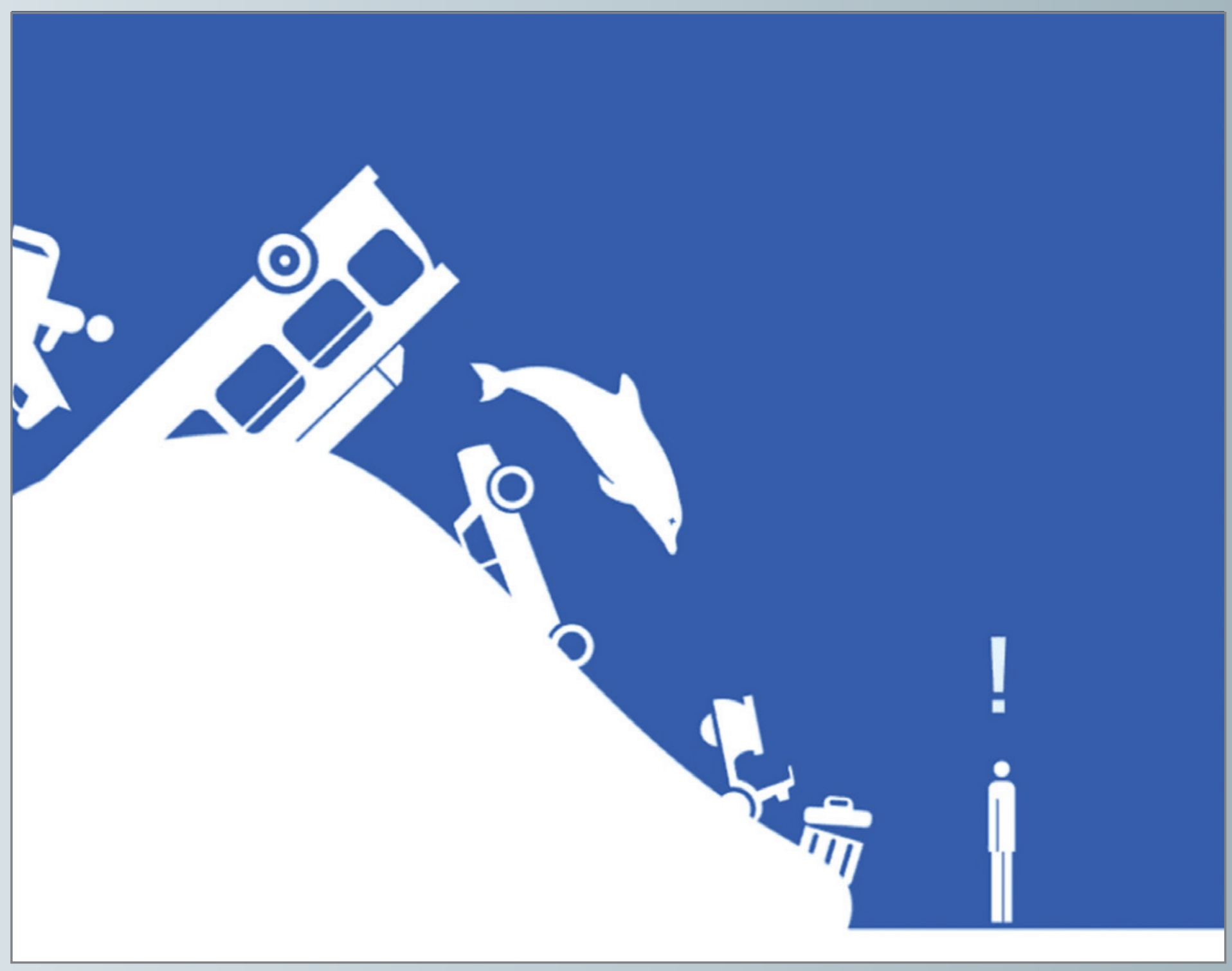

Open-File Report 2013-1170-K

California Geological Survey Special Report 229 
COVER: Image from the prototype mobile device game app, "Splash," developed by students at Art Center College of Design game. A player can only survive and win "Splash" by running uphill and away from the tsunami. 
The SAFRR (Science Application for Risk Reduction) Tsunami Scenario

Stephanie Ross and Lucile Jones, Editors

\section{Communication Products for the Science Application for Risk Reduction (SAFRR) Tsunami Scenario}

By Suzanne Perry

Open-File Report 2013-1170-K

California Geological Survey Special Report 229

U.S. Department of the Interior

U.S. Geological Survey 


\section{U.S. Department of the Interior \\ SALLY JEWELL, Secretary}

\section{U.S. Geological Survey \\ Suzette M. Kimball, Acting Director}

U.S. Geological Survey, Reston, Virginia 2013

For product and ordering information:

World Wide Web: http://www.usgs.gov/pubprod

Telephone: 1-888-ASK-USGS

For more information on the USGS-the Federal source for science about the Earth, its natural and living resources, natural hazards, and the environment:

World Wide Web: http://www.usgs.gov

Telephone: 1-888-ASK-USGS

Suggested citation:

Perry, S., 2013, Communication products for the Science Application for Risk Reduction (SAFRR) tsunami scenario, chap. K, in Ross, S.L., and Jones, L.M., eds., The SAFRR (Science Application for Risk Reduction) Tsunami Scenario: U.S. Geological Survey Open-File Report 2013-1170, 12 p., http://pubs.usgs.gov/of/2013/1170/k/.

Any use of trade, product, or firm names is for descriptive purposes only and does not imply endorsement by the U.S. Government.

Although this information product, for the most part, is in the public domain, it also may contain copyrighted materials as noted in the text. Permission to reproduce copyrighted items must be secured from the copyright owner. 


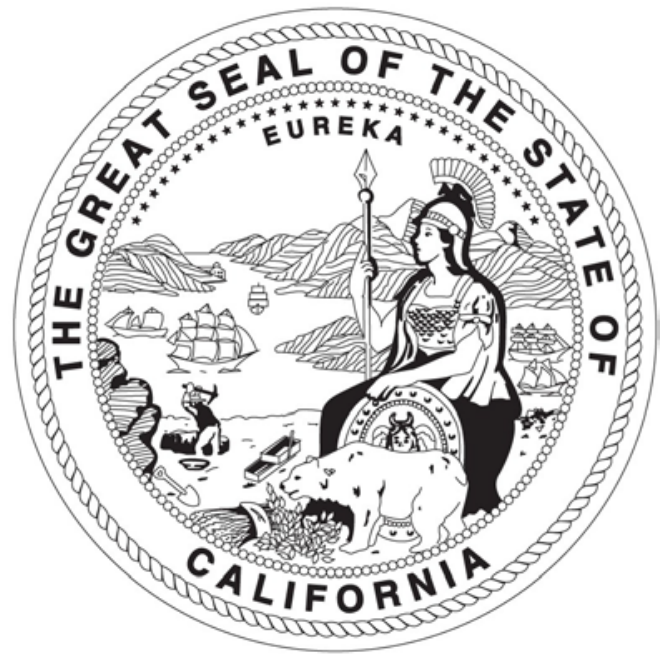

STATE OF CALIFORNIA

EDMUND G. BROWN JR. GOVERNOR

THE NATURAL RESOURCES AGENCY JOHN LAIRD

SECRETARY FOR RESOURCES

\author{
DEPARTMENT OF CONSERVATION \\ MARK NECHODOM \\ DIRECTOR
}

\title{
CALIFORNIA GEOLOGICAL SURVEY JOHN G. PARRISH, Ph.D. \\ STATE GEOLOGIST
}




\title{
Communication Products for the Science Application for Risk Reduction (SAFRR) Tsunami Scenario
}

\author{
By Suzanne Perry
}

\section{Product Development Overview}

Science Application for Risk Reduction (SAFRR), like its predecessor the Multi-Hazards Demonstration Project, has a mission to increase the use of science by decision-makers of all kinds. Thus, an important part of any SAFRR scenario is development of products that enhance usability of the science. In this tsunami scenario, the focus has been on development of three kinds of products:

- products that augment typical outputs of scientific studies, such as reports, to make the results of the scenario more relevant and usable to nonscientists;

- products that distill local impacts and allow users in specific locales to identify which aspects of the broad regional study apply to their local area; and

- products that effectively deliver disaster preparedness messaging to one group of people who are not usually interested in disaster preparedness - those ages 18 to 34 .

\section{Products that Augment Typical Outputs}

A motion graphics animation movie, 4 to 5 minutes in length, will be created by a professional artist or designer to summarize the principal scenario results. This movie is scheduled for production in late 2013, when all project research has been completed. Similar movies were created previously for the ShakeOut and ARkStorm scenarios. Figure 1 shows a frame from the movie "Preparedness Now" (2008, http://www.youtube.com/watch?v=opXZY1zZ8xk). In 4 minutes, that movie summarizes the key results of the ShakeOut scenario and basic earthquake mitigation practices. The movie has had multiple uploads to YouTube, with nearly 200,000 hits overall, and has been adapted several times for use in ShakeOut drills around the United States. It has been shown a very large but uncounted number of times to raptly attentive audiences in high school and college classrooms, as well as in meetings with local governments and communities. In addition, as part of the final report for the current scenario, we intend to develop an infographic-style timeline to communicate what happens from the time the tsunami is generated until the last of the damage is restored, to indicate the events, decisions, and uncertainties that arise as the disaster unfolds. 


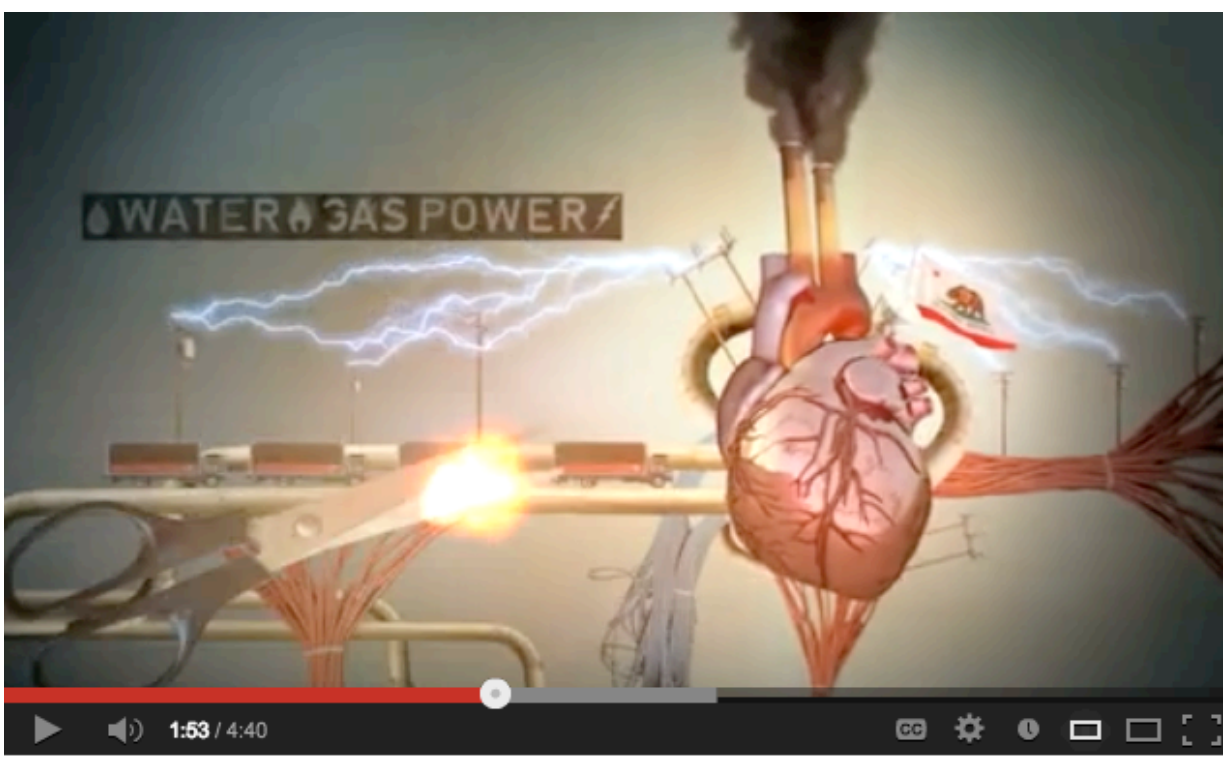

Figure 1. A still frame from the motion graphics movie "Preparedness Now," metaphorically visualizing lifeline disruption caused by the ShakeOut scenario earthquake.

\section{Products that Distill Local Impacts from the Regional Study}

In previous SAFRR scenarios, this author has worked closely with local governments to develop additional documents that extract the parts of the larger regional study applicable to their locales and, where necessary, make reasonable extrapolations from the study. For this scenario, we intend to develop an interactive, map-based Web product that allows users to select a location and see which scenario datasets and results pertain to that location. Over time, we intend to extend this product to include results from previous scenarios.

\section{Products that Deliver Effective Tsunami Messaging}

The existence of the scenario helps to shine a spotlight on tsunami issues more generally. It also provides an opportunity to experiment with novel methods of communicating tsunami safety in ways that may be outside the scope of ongoing preparedness programs with fixed budget and purview. During the 2 years of scenario development, we polled and compiled experience from a large number of emergency managers, first responders, tsunami educators, and coordinators of this scenario, as well as reviewing existing products - especially the brochure "How to Survive a Tsunami" (California Emergency Management Agency, 2009)—and tsunami eyewitness accounts and newspaper reports. This effort was made to identify aspects of tsunamis and tsunami safety that are misunderstood in ways that compromise public safety. Table 1 contains the compiled list of important aspects of tsunamis where dangerous misunderstanding is common. It represents the results of the gathered experience and in particular was shaped by the repeated input of Tsunami Program leads Kevin Miller and Kate Long of the California Emergency Management Agency (now the California Governor's Office of Emergency Services, or Cal OES), Earthquake/Tsunami/Volcano Program Manager John Schelling of the State of Washington, and psychology Ph.D. candidate Katherine Thompson of the Center for Research on Environmental Decisions, Columbia University. 
The compilation in table 1 served as the foundation of a project to create prototype tsunami education materials that are engaging, entertaining, and compelling as well as informative. Another important guide in development of materials was the summary of pertinent findings from social and behavioral sciences (table 2). The materials produced are targeted to reach 18-34-year-olds, an audience that has been difficult to engage through traditional preparedness messaging (for example, Federal Emergency Management Agency, 2009; Hawai'i Disaster Preparedness, 2012; Partnership for a Healthy Durham, 2012). One of the materials, a short animated movie, is being developed with the additional intent that the movie will serve as a "calling card" to the hospitality industry. The intent is that the movie, by demonstrating that tsunami information products can be positive, enjoyable, and nonthreatening as well as informative, will increase the hospitality industry's willingness to discuss broader distribution of tsunami information for hotel guests and staff.

After this movie is completed, Liesel Ritchie at the University of Colorado, Boulder, will conduct an evaluation. The purpose of the evaluation study is to ascertain what information the movie successfully conveyed and whether the intended tsunami information is conveyed to and retained by people 18 to 34 years old.

For this scenario's messaging products, we collaborated with the Designmatters program at Art Center College of Design in Pasadena, California, one of the premier schools in the Nation for marketers, advertisers, graphic designers, and product designers. Designmatters is unique in the Nation and perhaps the world because its students conduct research and class practicum projects in which they apply their creativity, skills, and expertise to social causes. The Designmatters approach is to educate while entertaining and to attract attention to serious issues using methods that may be lighthearted and fun. For each of its scenarios, SAFRR has had a Designmatters class focus on scenario issues. The movie "Preparedness Now" (fig. 1) was the result of one such class.

For the tsunami scenario, a Designmatters class developed prototypes for a tsunami education and awareness campaign after close interaction with SAFRR scenario coordinators and partners. They instructed the class in the basics of tsunami science, described the National Oceanic and Atmospheric Administration (NOAA) system of official warnings, and provided insights from sociology, psychology, and anthropology (table 2) about how to motivate action and how to communicate about rare events with large uncertainties of occurrence (see, for example, Wood and others, 2011; Shome and Marx, 2009).

Table 1 summarizes those tsunami concepts that are poorly understood, with reduced public safety as a consequence. These concepts form the basis of an awareness campaign that includes a suite of short animated movies in planning and development by Art Center College of Design. 
Table 1. Tsunami concepts that are not well understood by the public, with consequently reduced public safety.

1. A tsunami is a kind of wave but not the typical ocean wave we know. A tsunami:

- often looks like a wall of water;

- sometimes looks like a fast-rising flood;

- has multiple surges of waves.

- Each wave keeps flowing in for many minutes.

- Waves can keep coming for 24 hours or longer.

- Waves will vary in height.

- Big waves can arrive after smaller ones and a large, dangerous wave could come at any time-at the beginning, middle, or end of the tsunami.

- Even when the water looks calm or shallow, it can be deadly dangerous with powerful, unpredictable currents and whirlpools.

2. Sometimes you will know a tsunami is coming because you hear a warning from an official source like an announcement on television or a lifeguard with a bullhorn. (Official sources include loudspeaker, siren, lifeguard, television, Internet, radio, automated phone call, and door to door visit by hotel staff or police.)

3. Often you will have to rely on yourself to recognize signs that a tsunami is coming:

- if you feel earthquake shaking while you are on a beach

- if you see the water pull away from shore like a very sudden, very low tide

- if you see a wall of water coming toward shore

- if you hear a sound like a freight train coming from the water

... a tsunami could be coming. Get to higher ground immediately.

4. Many people, if they see, hear, or feel a tsunami warning sign, won't take action immediately

- Instead they will look around, see what other people are doing, wait and see what happens next.

- But with a tsunami, every minute can be critical. So take action immediately with the first sign, even if you aren't certain it means "tsunami."

- Don't wait for a second sign. You can't outrun a tsunami.

5. To protect yourself and your loved ones in a tsunami:

- get to higher ground and get away from the water

-tsunamis move with incredible force but they can't go far uphill and they eventually lose power as they move over land

- if you can't get to higher ground, as a last resort go high up in a tall, sturdy building but ONLY do this as a last resort.

6. Get away from the water, not just the beach.

- Tsunamis come into rivers, bays, marinas, and harbors too

7. Stay away from the water until officials say it is okay to return (because of all the properties of tsunamis in point 1).

8. NEVER move closer to the water to watch the tsunami (because of all the properties of tsunamis in point $1)$.

9. Never try to surf a tsunami (because of all the properties in point 1).

10. Possible Topics for Additional Modules:

- Tsunami facts and earth science 
- Social science about human behavioral response to tsunami signs and warnings

- What to do if there is no higher ground (vertical evacuation)

- How to know where the safe zones are (note: will address overevacuation issues)

- Why you can't surf a tsunami and it can be deadly to try

- Tsunami currents - tsunamis in harbors

- Where to get more information

- Real life examples of survival and death by following or not following these guidelines

To guide development of the messaging movie, Thompson of CRED and Perry of USGS provided the Art Center class with a summary of precepts from the social and behavioral sciences that are relevant to tsunami messaging. Table 2 presents this summary.

Table 2. Results from social and behavioral sciences pertinent to tsunami messaging.

- In many ways, motivating people to pay attention to tsunami safety is the same as motivating them to watch a commercial. However, there are important differences because of the way people deal with rare dangers.

- In our culture, people are reluctant to take action (like fleeing a beach) if nobody else is taking action. There are two effective ways to confront this. Point out that this will be their likely reaction; and apply "monkey see, monkey do"-show others taking the desired action.

- It is very hard for people to imagine themselves in rare situations, so just saying "remember these warning signs" won't work. People won't internalize or remember the information because they do not believe it will ever apply to them. People ignore messages that they think don't pertain to them. Best strategy is to acknowledge their feeling that this is not going to happen. You want to give the sense that a tsunami is rare but is going to happen to someone, and if you listen to this message, then you will be ready if you are the one.

- Connect what you want people to do with why they should do it. Don't just give orders or instructions. The why needs to tap the emotions and values that are most important to people. In this context, the keys are control (there is an action I can take), survival (if I do this I will be safe), confidence (I can protect people who matter to me), and peace of mind (by watching this movie, I am taking the right step).

- Don't show misconceptions, because that reinforces the misconception. People will remember that they saw something but not remember that what they saw was wrong. Only show what is true, not a myth or misunderstanding. If you need to show the wrong kind of wave ("most people think a tsunami is like a common ocean wave"), best to show a wave that is clearly not real, such as the famous old Japanese painting of a tsunami.

- Repetition of the message helps. The repetition can be with visuals or words or both. For example, it will help cement the message "get to higher ground" if multiple people are seen doing this, and in different situations - such as moving uphill from a beach, and from a river, and from a harbor. 
- The visuals and the narration don't have to be identical. Messages, emotions, and values can be conveyed using graphics or words. For example, the graphics can show the characteristics of a tsunami wave-you don't need to list them all.

- Don't try to catch attention by being too vivid, hyperbolic, or scary. This will only cause backlash, and people will tune out the message. Everyone has a different threshold for what is too vivid. For most people it should be okay to hear "because he went down to watch the tsunami, he died" but not to watch the victim struggling and drowning.

- Most people are motivated to act if it will improve their situation and they respond to messages framed in a positive way. Do this to be safe... Do this to protect your loved ones... Here is what to do to be protected. In such a short movie, there may only be time for a single approach, and if that is the case, use this kind of positive wording.

- However, not everyone is reached by this positive approach. A large minority of people are instead motivated to act to avoid things getting worse. Those people instead need to hear If you don't do this you could get hurt... or If you return to the beach you will get hurt.

- A single example is more persuasive than saying "this affects many people." That is why journalists focus on one individual within a big story. Charities get more donations if they show a single starving orphan in Africa - with personal details about that orphanthan if they show an entire group of kids in Africa who all need help. If possible, it would be good to add some examples of what happened to particular individuals in particular tsunamis.

Prototype products of the Art Center campaign include:

- Twitter feeds from identities created for two NOAA dart buoys, one a crabby old buoy that complains a lot, the other an enthusiastic young buoy. The buoys will occasionally dispense tsunami science and safety information and issue warnings and advisories, but will gain followers because of the jokes, wisecracks, and entertaining tweets they make the rest of the time.

- "Splash," a simple, chase style game app for mobile devices, in which a tsunami chases a cartoon icon representing the player (fig. 2). The player can only win the game by avoiding the tsunami, that is, by running to higher ground and away from the water. Those playing the game learn correct response to a tsunami, probably without realizing that they have just been educated about getting to higher ground. 


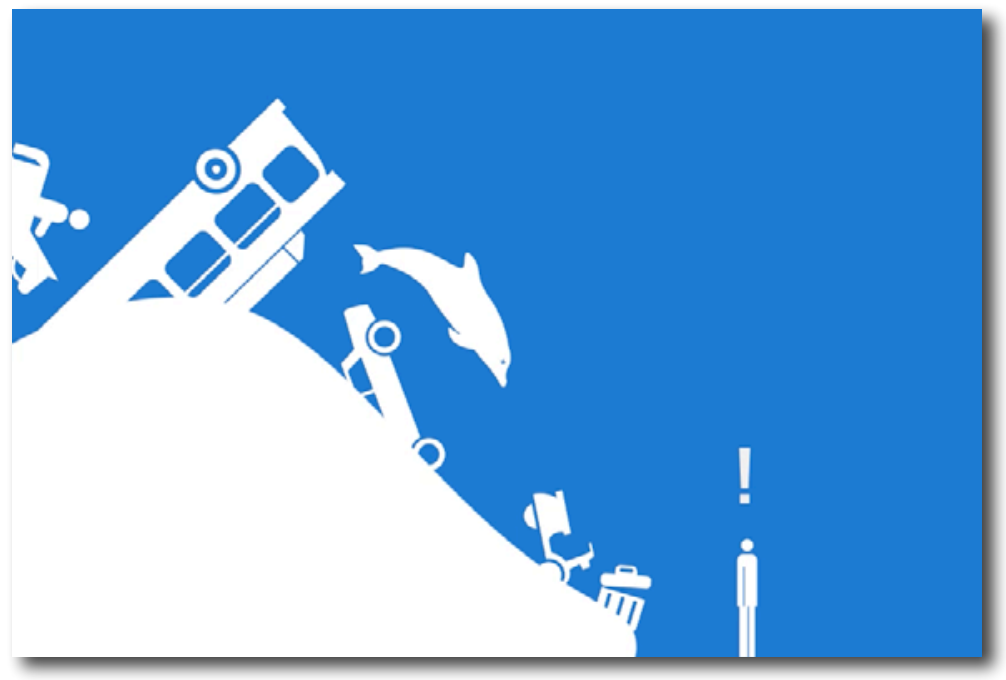

Figure 2. A still frame from the proposed tsunami game app "Splash." The player can only survive and win the game by running uphill and away from the water.

Public billboards, posters, advertisements on buses, t-shirts, tote bags, temporarily erected statues, Web pages, and more are the pieces of an awareness campaign called "The Next Wave: Know the Tsunami (Empower Yourself)." The campaign focuses on educating people about safe and unsafe areas in their community in the event of a tsunami. It culminates in a day of public events, which include a triathalon and an Internet-connected treasure hunt called a geocache (fig. 3), a hunt that leads participants from a beach to areas that are safe from tsunami inundation and that delivers players to a music festival finale. Along their way, participants pass walls painted in temporary chalk to indicate areas that would be underwater in a tsunami.

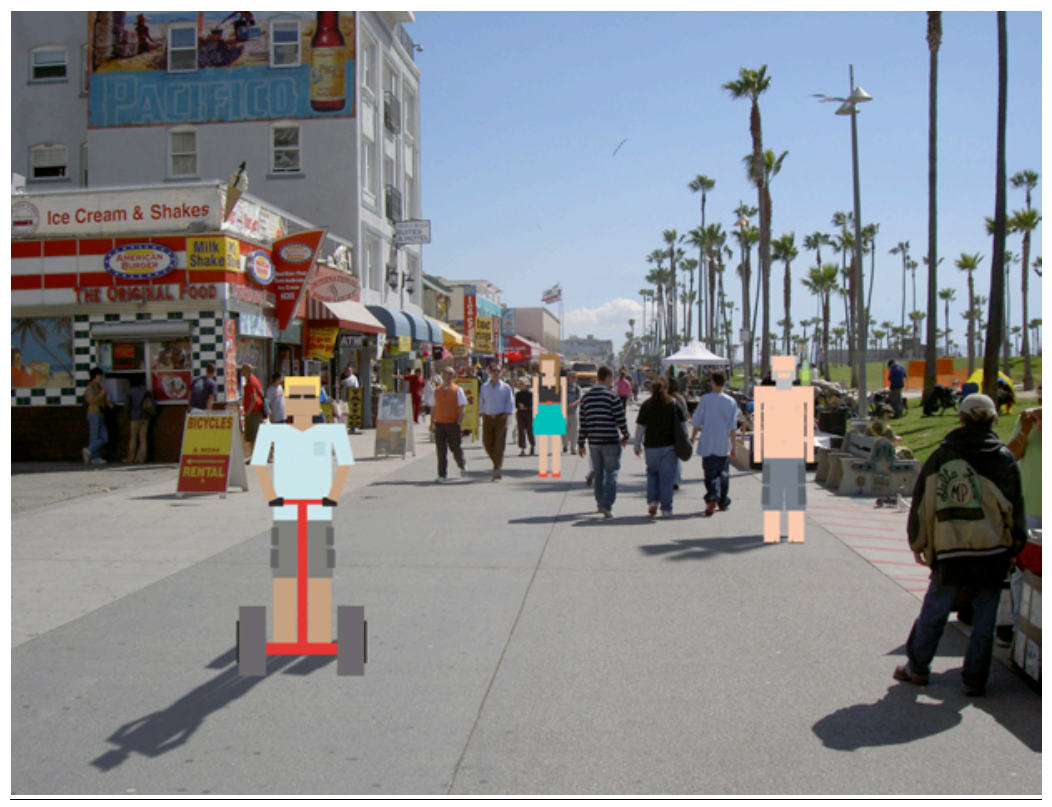

Figure 3. Photograph showing street setup for part of the geocache event, during the proposed public awareness campaign called "The Next Wave." 
The logo for this campaign (fig. 4) uses symbols common in tsunami inundation and evacuation signs around the world (fig. 5). The background is red, rather than the blue of the tsunami signage, to make clear that this campaign is related to but separate from those signs and to emphasize the urgency in increased awareness and danger in tsunamis. The "V" in the word Wave has a second arm that is higher than the first, a subtle reminder to move to higher ground during a tsunami.

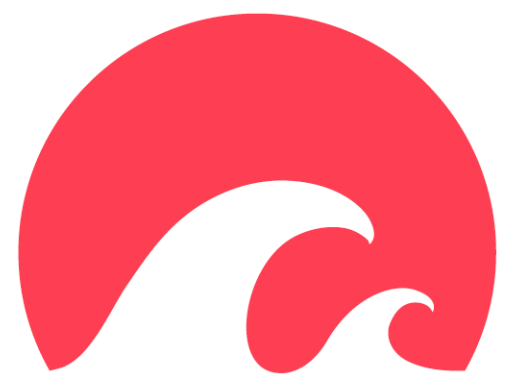

\section{THE NEXT WAVE}

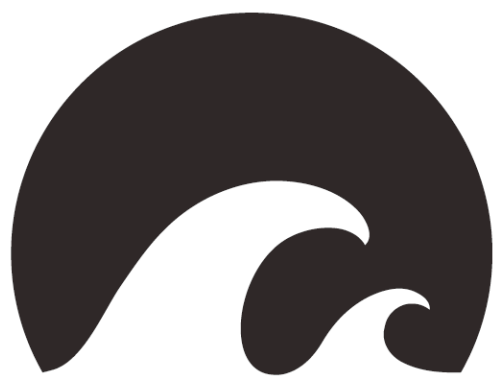

\section{THE NEXT WAVE}

Figure 4. Logo for the tsunami public awareness campaign, in two color schemes

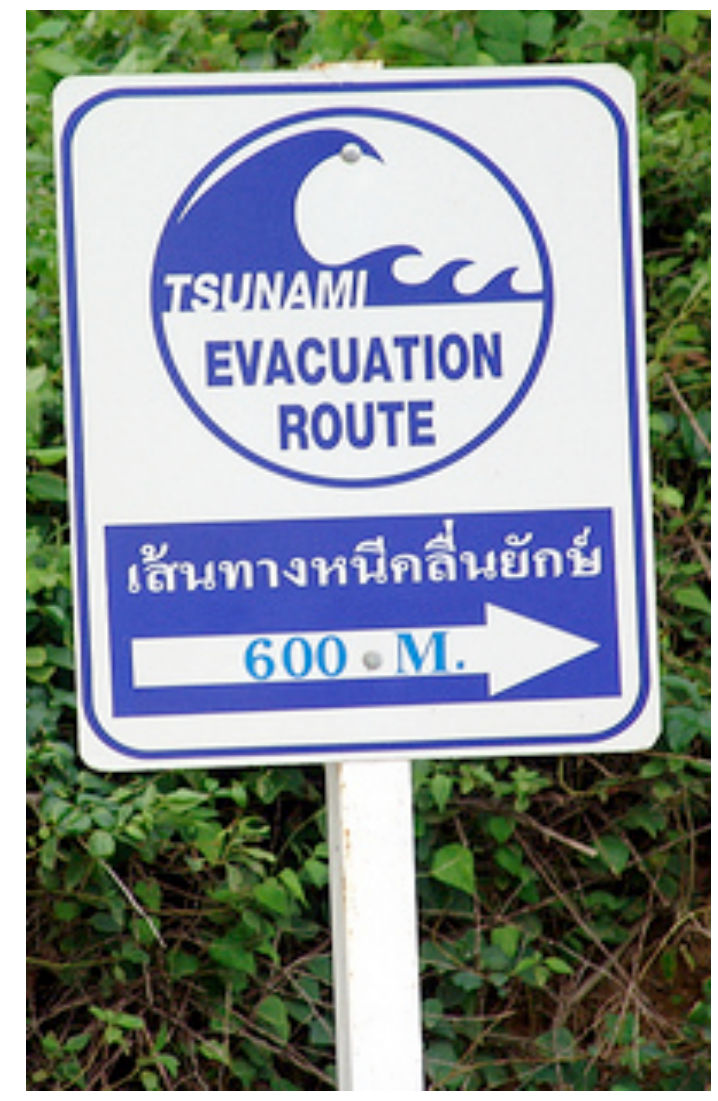

Figure 5. For comparison, this photograph shows a sample tsunami evacuation route sign in Thailand. 
The campaign uses two visual languages. One is a beautiful, serene ocean image (fig. 6) to impart a sense of familiarity and safety. The other is a collection of cartoon pictograms (fig. 7), to instill a sense of community and fun.

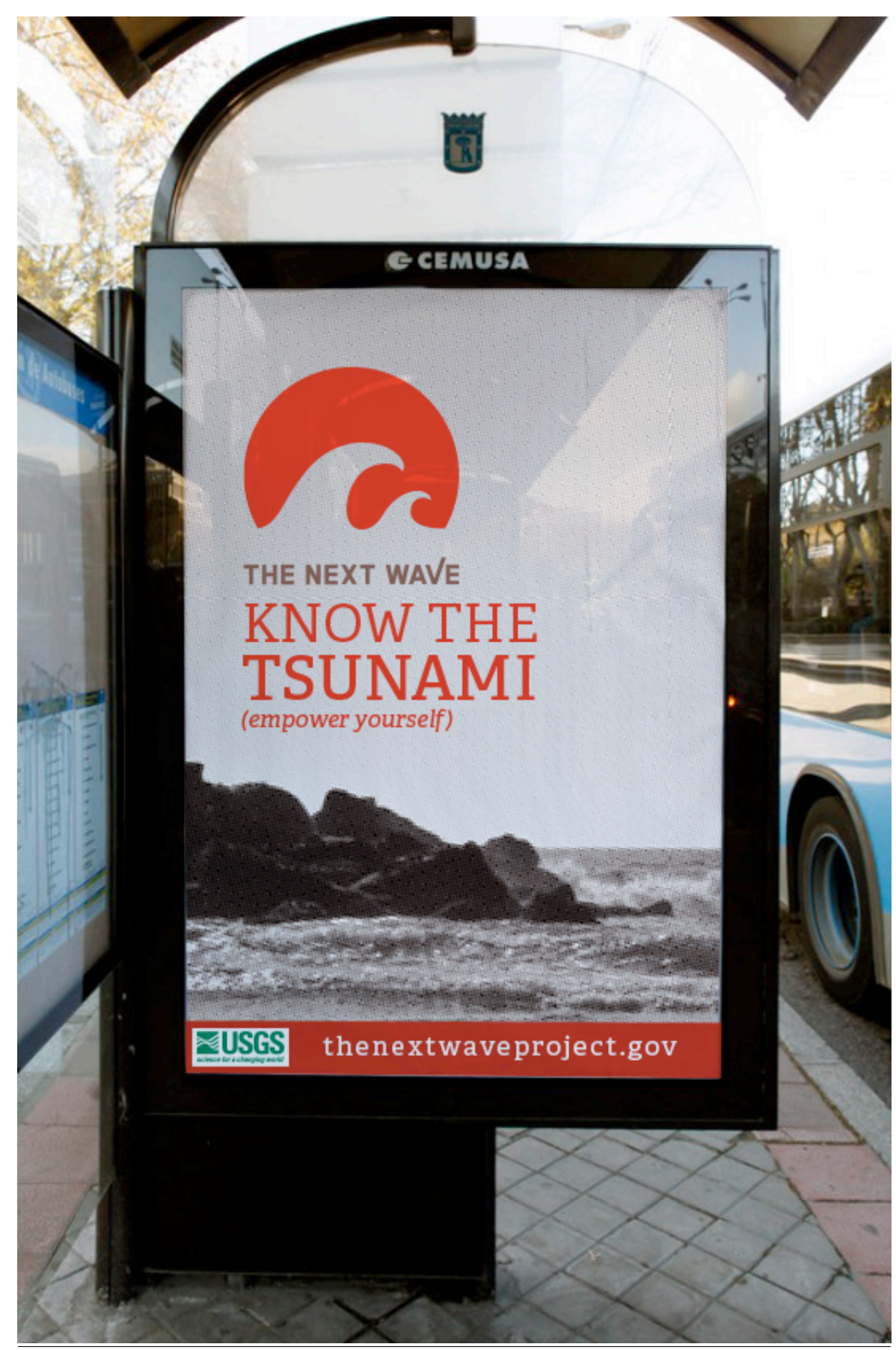

Figure 1 Figure 6. Photograph showing a bus-stop billboard in one visual language (using a serene ocean image) for the public awareness campaign "The Next Wave." 


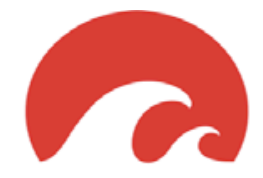

THE NEXT WAVE

KNOW THE TSUNAMI (empower yourself)
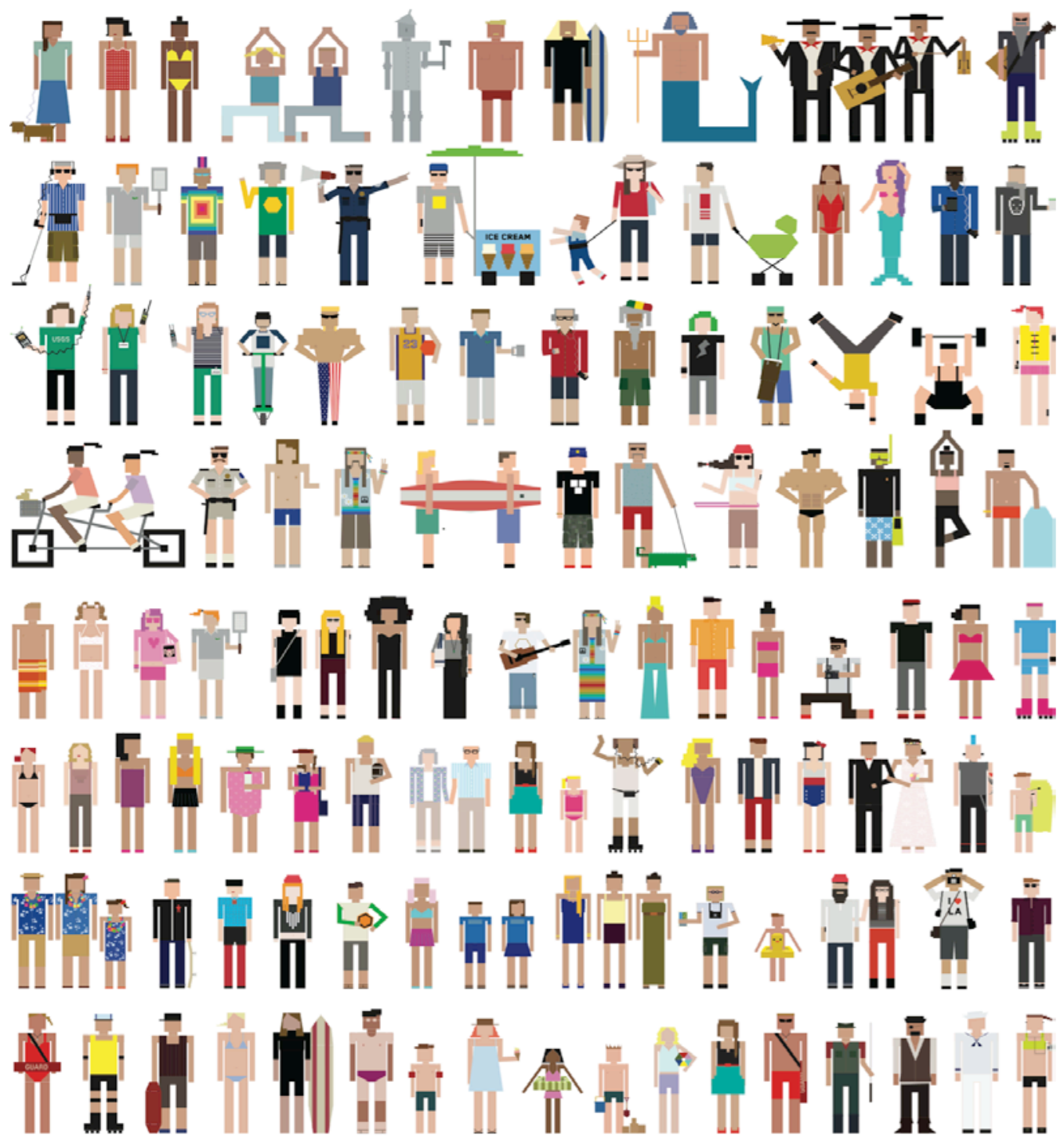

thenextwaveproject.gov

₹USGS

Figure 2 Figure 7. Poster in the other visual language (cartoon pictograms) for the public awareness campaign "The Next Wave." 


\section{Response to the Proposed Campaign}

The prototype campaign has been presented to scenario coordinators, partnering agencies, and emergency managers, with mostly positive response-but also a large minority of negative reactions. The positive responses have expressed excitement about the creativity of the ideas and enthusiasm that this stands a good chance of reaching some who are difficult to reach with traditional messaging. The negative reactions dislike the logo and the name and reveal concern and frustration within the tsunami mitigation community about how to reduce widespread and persistent misunderstanding that affects tsunami safety.

The campaign logo shows "hooked" waves, and the perceived problems with this are that representing tsunamis with cresting waves perpetuates misconceptions about what tsunamis are like and will encourage surfers to try to surf tsunamis. It is reasonable to propose that a new and separate effort needs to be made to convince surfers that tsunamis provide a poor and potentially deadly surfing experience. However, given the widespread - international — use of similar hooked waves in tsunami signage and information materials, it is reasonable to use a logo that makes visual reference to those materials. Nonetheless, it also makes sense to experiment with logos that still make visual connection to existing tsunami images, but help to evolve the images to communicate additional and more correct tsunami properties.

The campaign name raised objections because it uses the word "wave," and some in the tsunami community wish to eradicate the word "wave" from tsunami discussion and use only the words "surge" or "tsunami." This approach would be difficult for tsunami scientists to accept because a tsunami is, in fact, a type of wave. Far more importantly, those who are not tsunami scientists already think of tsunamis as waves, and changing the terminology could result in messaging that is less likely to reach its target audiences.

The Art Center students initially conducted an informal research survey in which they asked participants "what is a tsunami?" Every answer included reference to a tsunami as a wave. Art Center's conclusion was that it would be confusing and would reduce transmission of important messages to avoid use of "wave" when discussing tsunamis. The campaign instead focuses on raising awareness that the tsunami is a different kind of wave than people expect or know. A number of tsunami messaging professionals have indicated to us that they prefer this tactic.

As this report is being published, scenario coordinators continue to work closely with the tsunami mitigation community and Art Center to adapt the prototype campaign so that it will be of use to the preparedness and mitigation community while also effectively communicating with the target audience. Meanwhile, the conflicting reactions to the Art Center campaign indicate a need for consensus among tsunami messaging professionals. Thus, SAFRR has offered completion funding and impetus to reestablish and conclude an effort originally begun by NOAA to develop consensus tsunami messaging. That effort will resume in late 2013. 


\section{References}

California Emergency Management Agency, 2009, How to survive a tsunami: California Emergency Management Agency Earthquake and Tsunami Program, 2 p.

Federal Emergency Management Agency [FEMA], 2009, Personal preparedness in Americafindings from the 2009 Citizen Corps national survey: Federal Emergency Management Agency, $91 \mathrm{p}$.

Hawai'i Disaster Preparedness, 2012, Hawai'i Disaster Preparedness Statewide Survey Results: Accessed June 12, 2013, at http://www.getreadyhawaii.org/index.php/media/hawaii-disasterpreparedness-statewide-survey-results.

Partnership for a Healthy Durham, 2012, 2011 Durham County community health assessment: Durham County, North Carolina Department of Public Health, 512 p.

Shome, D., and Marx, S., 2009, The psychology of climate change communication: Columbia University, Center for Research on Environmental Decision Making, $54 \mathrm{p}$.

Wood, M.M., Mileti, D.S., Kano, M., Kelley, M.M., Regan, R., and Bourque, L.B., 2011, Communicating actionable risk for terrorism and other hazards: Risk Analysis, v. 32, p. 601615. 
This page intentionally left blank 


\section{Tsunami Mitigation and Preparedness Activities in California}

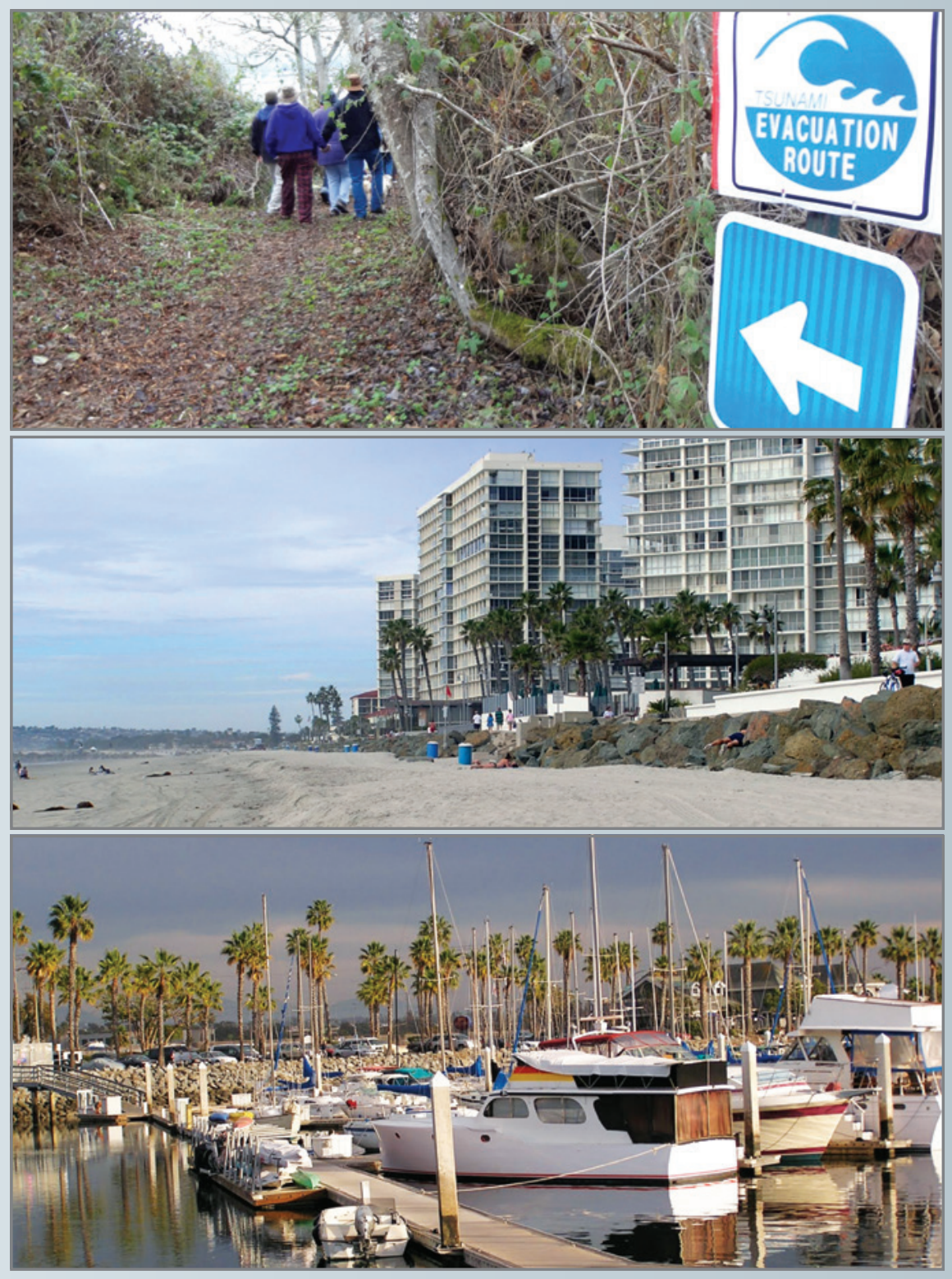

Open-File Report 2013-1170-L

California Geological Survey Special Report 229 
COVER-Top: Warning signs guide people to safe, high ground as a tsunami approaches King Salmon, Humboldt County, California. Middle: Buildings and infrastructure adjacent to beaches are common on the coast, and an important target of tsunami education and mitigation.

Coronado, San Diego County, California. Bottom: Fixed piers, infrastructure, and boating vessels of all varieties provide ample opportunity and challenge for mitigating the effects of tsunamis, here at Ventura Harbor, California. Photos by Rick Wilson. 
The SAFRR (Science Application for Risk Reduction) Tsunami Scenario

Stephanie Ross and Lucile Jones, Editors

\section{Tsunami Mitigation and Preparedness Activities in California}

By Rick Wilson and Kevin Miller

Open-File Report 2013-1170-L

California Geological Survey Special Report 229

U.S. Department of the Interior

U.S. Geological Survey 


\section{U.S. Department of the Interior \\ SALLY JEWELL, Secretary}

\section{U.S. Geological Survey \\ Suzette M. Kimball, Acting Director}

U.S. Geological Survey, Reston, Virginia 2013

For product and ordering information:

World Wide Web: http://www.usgs.gov/pubprod

Telephone: 1-888-ASK-USGS

For more information on the USGS-the Federal source for science about the Earth,

its natural and living resources, natural hazards, and the environment:

World Wide Web: http://www.usgs.gov

Telephone: 1-888-ASK-USGS

Suggested citation:

Wilson, R., and Miller, K., 2013, Tsunami mitigation and preparedness activities in California, chap. L in Ross, S.L., and Jones, L.M., eds., The SAFRR (Science Application for Risk Reduction) Tsunami Scenario: U.S. Geological Survey Open-File Report 2013-1170, 10 p., http://pubs.usgs.gov/of/2013/1170///.

Any use of trade, product, or firm names is for descriptive purposes only and does not imply endorsement by the U.S. Government.

Although this information product, for the most part, is in the public domain, it also may contain copyrighted materials as noted in the text. Permission to reproduce copyrighted items must be secured from the copyright owner. 


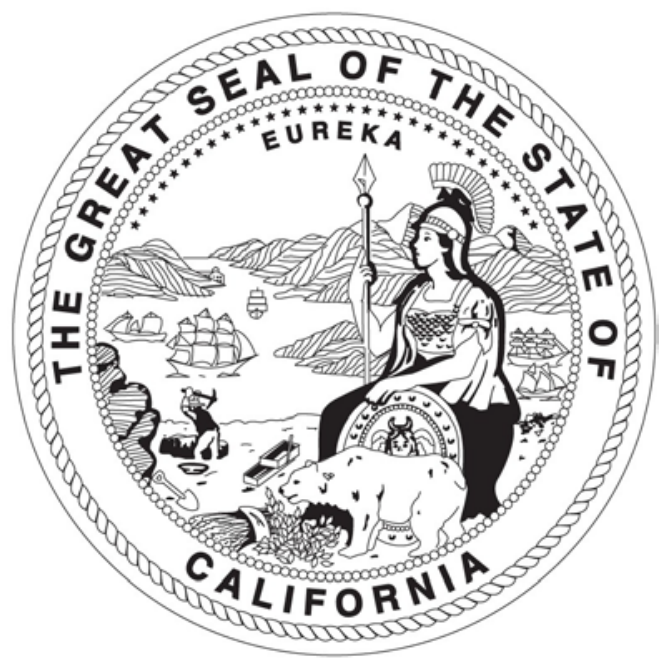

STATE OF CALIFORNIA EDMUND G. BROWN JR. GOVERNOR

THE NATURAL RESOURCES AGENCY JOHN LAIRD SECRETARY FOR RESOURCES

\author{
DEPARTMENT OF CONSERVATION \\ MARK NECHODOM \\ DIRECTOR
}

CALIFORNIA GEOLOGICAL SURVEY JOHN G. PARRISH, Ph.D. STATE GEOLOGIST 


\section{Contents}

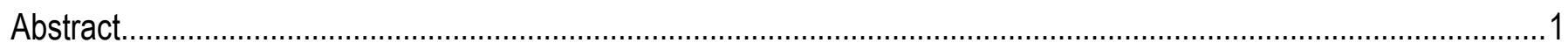

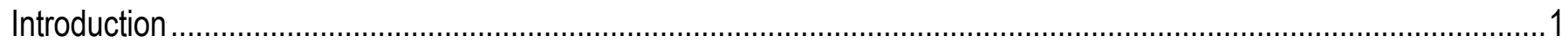

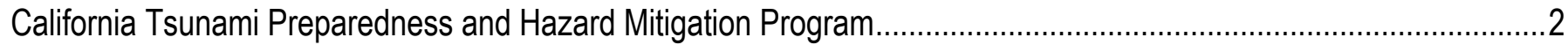

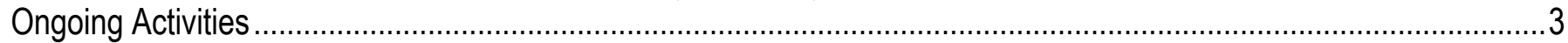

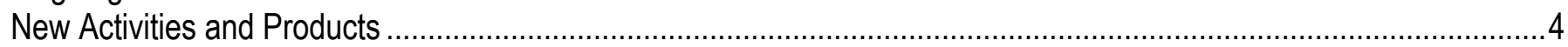

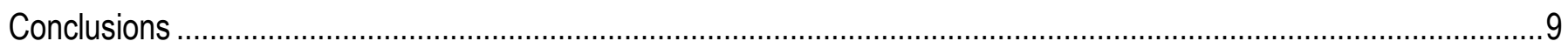

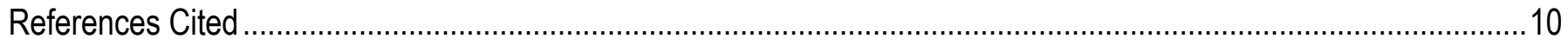

\section{Figures}

1. January 2012 tsunami evacuation drill in King Salmon, Humboldt County.............................................

2. Tsunami flow-regime map for Crescent City harbor.........................................................................5

3. Map showing draft tsunami current velocity hazard zones using 2011 Tohoku event modeling in

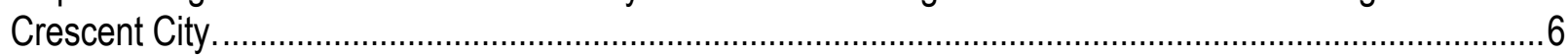

4. Draft map showing offshore bathymetric depths off the coast of San Diego Bay. ...................................

5. Draft playbook tsunami evacuation for the Imperial Beach area......................................................... 


\title{
Tsunami Mitigation and Preparedness Activities in California
}

\author{
By Rick Wilson ${ }^{1}$ and Kevin Miller ${ }^{2}$
}

\begin{abstract}
Scenario planning and final results associated with the U.S. Geological Survey Science Application for Risk Reduction (SAFRR) tsunami project are providing great benefits to the ongoing tsunami risk-reduction efforts of the California Tsunami Preparedness and Hazard Mitigation Program. This program, led by the California Governor's Office of Emergency Services and the California Geological Survey, works with coastal communities to improve tsunami preparedness and mitigation at the local level through various efforts, such as improving tsunami hazard analysis, establishing consistent evacuation communications and planning, and leveraging national risk-reduction efforts associated with the National Tsunami Hazard Mitigation Program.

The recent 2010 Chilean and 2011 Tohoku tsunamis did not cause notable inundation of dry land in California, but dozens of harbors sustained damages totaling nearly $\$ 100$ million (Wilson and others, 2012a). Estimates associated with the SAFRR distant tsunami scenario suggest socioeconomic and environmental losses could be even larger. Information gathered from these events and the SAFRR scenario is guiding the development and implementation of new strategies for emergency response, maritime planning, and land-use planning, including

- a reassessment of the tsunami threat along the California coast;

- $\quad$ scenario-specific, tsunami evacuation "playbook" maps and guidance;

- in-harbor hazard maps and offshore safety zones for potential boat evacuation during future distant source events;

- "probability-based" products for land-use planning under the California Seismic Hazard Mapping Act; and

- an expansion of real-time and post-tsunami field reconnaissance teams and information sharing through a state-wide clearinghouse.

The state tsunami program has benefitted greatly from participation in the SAFRR tsunami scenario process, and hopes to continue this relationship with the U.S. Geological Survey to help improve tsunami preparedness in California.
\end{abstract}

\section{Introduction}

The 2013 U.S. Geological Survey (USGS) Science Application for Risk Reduction (SAFRR) tsunami scenario project provides a broad analysis of the impacts from a large distantsource tsunami event along the entire California coast. Like with previous SAFRR scenarios (for

\footnotetext{
${ }^{1}$ California Geological Survey

${ }^{2}$ California Governor's Office of Emergency Services
} 
example, the 2008 ShakeOut earthquake and 2011 ARkStorm flood scenarios), the State of California has acquired useful information that will help it prepare for future large-scale disasters. The State and Federal partnership through the SAFRR project has improved the understanding of physical events (for example, tsunami source mechanisms and sediment deposition), potential socioeconomic and environmental losses, and challenges to an effective response and recovery for a significant state-wide tsunami event. The purpose of this chapter is to summarize current tsunami risk-reduction efforts of the California Tsunami Preparedness and Hazard Mitigation Program (referred to as the "state tsunami program" herein) and to discuss how results from the SAFRR tsunami scenario will support these ongoing efforts.

\section{California Tsunami Preparedness and Hazard Mitigation Program}

The state tsunami program is a hazard-reduction program managed by the California Governor's Office of Emergency Services (Cal OES), with assistance from the California Geological Survey (CGS), and in cooperation with the National Oceanic and Atmospheric Administration's (NOAA's) National Weather Service and other Federal, State, and local agencies. The program promotes tsunami planning, preparedness, and hazard mitigation among California's coastal communities (fig. 1), and participates in the National Tsunami Hazard Mitigation Program (NTHMP), which is responsible for setting U.S. policy and guidance for tsunami warning and long-term planning. Within the state, the program works through the California Tsunami Steering Committee with its 20 coastal and San Francisco Bay Area county emergency management partners and other State and Federal agencies with tsunami hazard responsibilities.

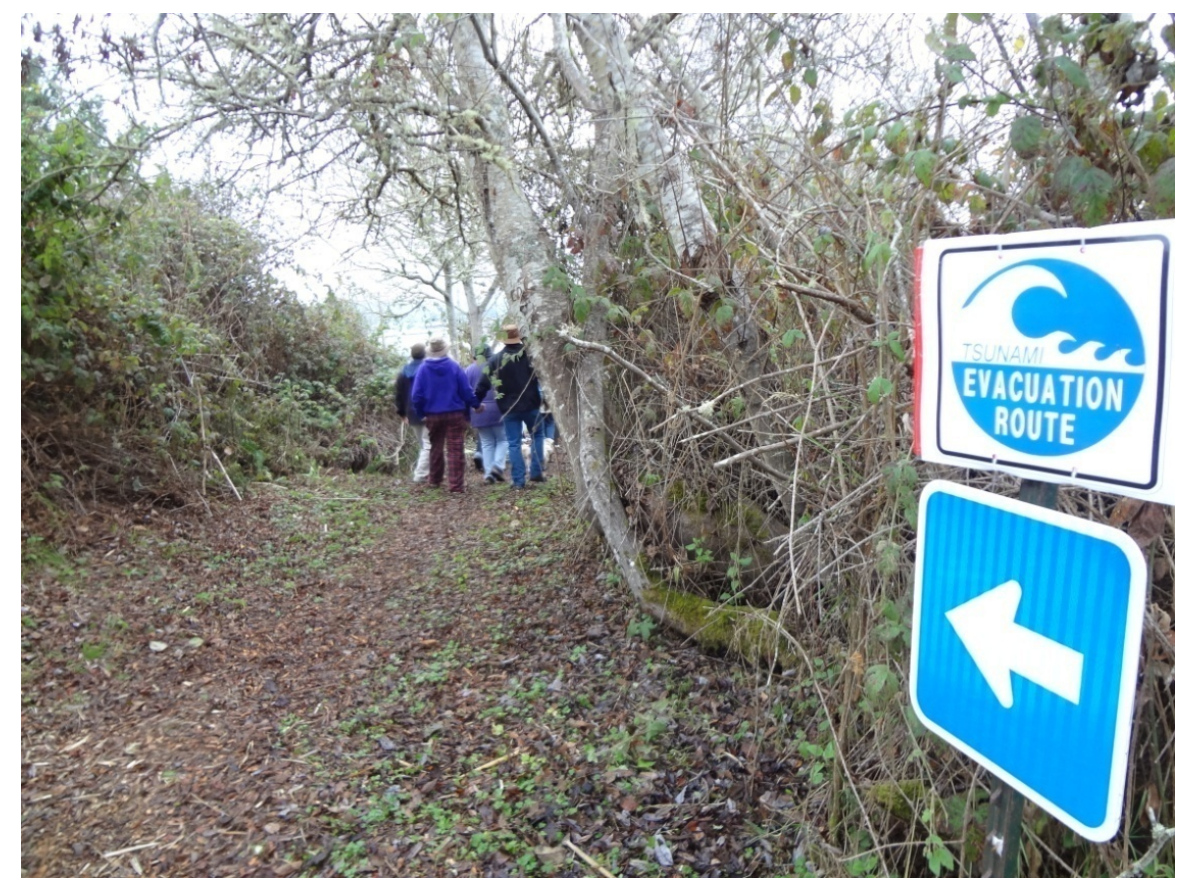

Figure 1. January 2012 tsunami evacuation drill in King Salmon, Humboldt County (photograph by Rick Wilson, California Geological Survey). Tsunami evacuation drills, exercises, and workshops are vital to sustaining community-level tsunami preparedness. 


\section{Ongoing Activities}

The State tsunami program has first sought to identify and characterize the tsunami hazard in California, and then integrate this knowledge into the state's emergency management system and hazard mitigation efforts. The program promotes tsunami planning, preparedness, and mitigation in California's coastal communities, and applies the latest scientifically vetted information to improve emergency management through the following activities:

1. Tsunami scenario modeling;

2. Inundation zone maps/Evacuation zone mapping;

3. State/Local emergency response and evacuation planning;

4. Exercises and training;

5. Warning system testing; and,

6. NTHMP coordination and support.

The progress and completion of these activities have been implemented through several specific tasks. The following paragraphs summarize each of these tasks.

Development and completion of tsunami inundation maps for the entire California coast for the purposes of local tsunami evacuation planning.--Definition of the hazard zone is vital to guiding emergency response through the unknowns of any incoming tsunami. The state completed tsunami inundation modeling and 130 maps for all low-lying, populated sections of the California coast (Wilson and others, 2008; Barberopoulou and others, 2009). Maps noting zones of maximum tsunami inundation from a variety of local and distant tsunami sources were developed to assist coastal jurisdictions to: (1) identify areas likely to be inundated in a tsunami; (2) facilitate the development of plans for evacuating vulnerable populations; and (3) place tsunami-evacuation signs.

Collaboration and coordination to assure that all coastal operational areas have tsunami response plans and the capability to implement plans. - The state tsunami program works with communities on their response planning to Tsunami Alert messages (Warnings, Advisories, Watches, and Information Statements) issued by the West Coast/Alaska Tsunami Warning Center (WC/ATWC). This assistance is in accordance with plans and procedures developed in cooperation with the California State Warning Center and Cal OES Executive staff. During events, especially prior to the arrival of a tsunami, the state program transfers information about expected arrival times and wave heights from the WC/ATWC to the communities, and provides feedback to the communities regarding evacuation. On an annual basis, the Cal OES works with the NOAA Weather Forecast Office in Eureka and with the Redwood Coast Tsunami Work Group to conduct a multi-county test of the Emergency Alert System. This test is important to the region as it faces a significant local threat from the Cascadia subduction zone just offshore. Considerable planning goes into this "live-code" warning communications test, including gaining approval from the Federal Communications Commission and coordinating California Civil Air Patrol-supported activities. The program also provides assistance on the use of new rapid notification and situational awareness technologies for earthquake and tsunami emergencies.

Communication with local emergency managers and the public to maintain ongoing tsunami preparedness in coastal communities. - Cal OES convenes and chairs the California Tsunami Steering Committee, which includes representatives of all coastal counties, 
the National Weather Service, and several State agencies. The state program also supports planning and technical assistance guidance to local government in the form of workshops, exercise facilitation, review of local tsunami response plans, and guidance in the use of tsunami inundation maps. As an example, the state tsunami program held more than 90 meetings, workshops, and community forums with local planning partners and the public from August 2011 to August 2012. Sharing new ideas and obtaining feedback during these meetings are the keys to sustaining state-to-federal and state-to-local communication, and to improving preparedness and outreach. Sustained activities that work toward the overall goal of preparing government officials, first responders, emergency planners, and the public include development and dissemination of outreach materials (for example, brochures, pamphlets, DVDs), educational workshops, support of exercises and evacuation drills, participation in National Tsunami Preparedness Week, and support of regional work groups.

Collaboration between NOAA National Weather Service and the state tsunami program to assist jurisdictions in the planning, preparedness, and mitigation activities that qualify them for TsunamiReady ${ }^{\mathrm{TM}}$.- -TsunamiReady $^{\mathrm{TM}}$ is a NOAA designation recognizing tsunami preparedness activities at a community level. To help these communities achieve TsunamiReady ${ }^{\mathrm{TM}}$ status, the state tsunami program assists communities in the development of tsunami evacuation plans, the purchase of tsunami hazard signs, and the development of tsunami sign placement plans. California has 34 communities (counties, cities, and other entities) that have qualified for TsunamiReady ${ }^{\mathrm{TM}}$ (National Weather Service, 2013), more than any other state in the nation.

Updates of the tsunami source and deposit databases produced by CGS.-The tsunami source database catalogs the input parameters applied to the tsunami model simulations for tsunami hazard map production. The tsunami deposit database has been completed for the northern region of the state, adjacent to the Cascadia subduction zone, and will be used to validate the probabilistic analysis needed to create land-use planning maps for tsunamis. These databases are being updated with the tsunami source and deposit information collected during the SAFRR project.

Representation of California in the NTHMP regional and national meetings that address budgeting, policy, and procedural issues.-Emergency management and science representatives from Cal OES and CGS, respectively, represent the state on the NTHMP Coordinating Committee and the three subcommittees that address national issues related to mapping and modeling, mitigation and education, and warning coordination. The participation of the state tsunami program in the NTHMP is important for coordinating effective and consistent tsunami preparedness activities with partners in Federal agencies and other States. The NTHMP also provides Federal funding support for state tsunami programs to maintain and improve tsunami planning at a local level.

\section{New Activities and Products}

Although significant accomplishments have been achieved by the state tsunami program, the SAFRR scenario and the 2010 Chile and 2011 Tohoku tsunamis have helped identify areas where improvements in tsunami hazard analysis and emergency response planning are needed (Lynett and others, 2012; Miller and others, 2012; Wilson and others, 2012a, 2012b). Post-event survey teams and questionnaires were used to gather information on both the physical effects and emergency response lessons (Wilson and others, 2012a). The 2010 tsunami caused approximately \$3million in damage to 12 harbors in California, while the 2011 tsunami caused 
more than \$100million in damage to 27 harbors (fig. 2). During both events, people on docks and near the ocean were at risk to injury; one fatality occurred during the 2011 tsunami at the mouth of the Klamath River. In addition, the significant sediment deposition and damage within Crescent City and Santa Cruz Harbors during the 2011 event caused long delays in recovery of those harbors because of regulatory and reconstruction issues (Wilson and others, 2012b).

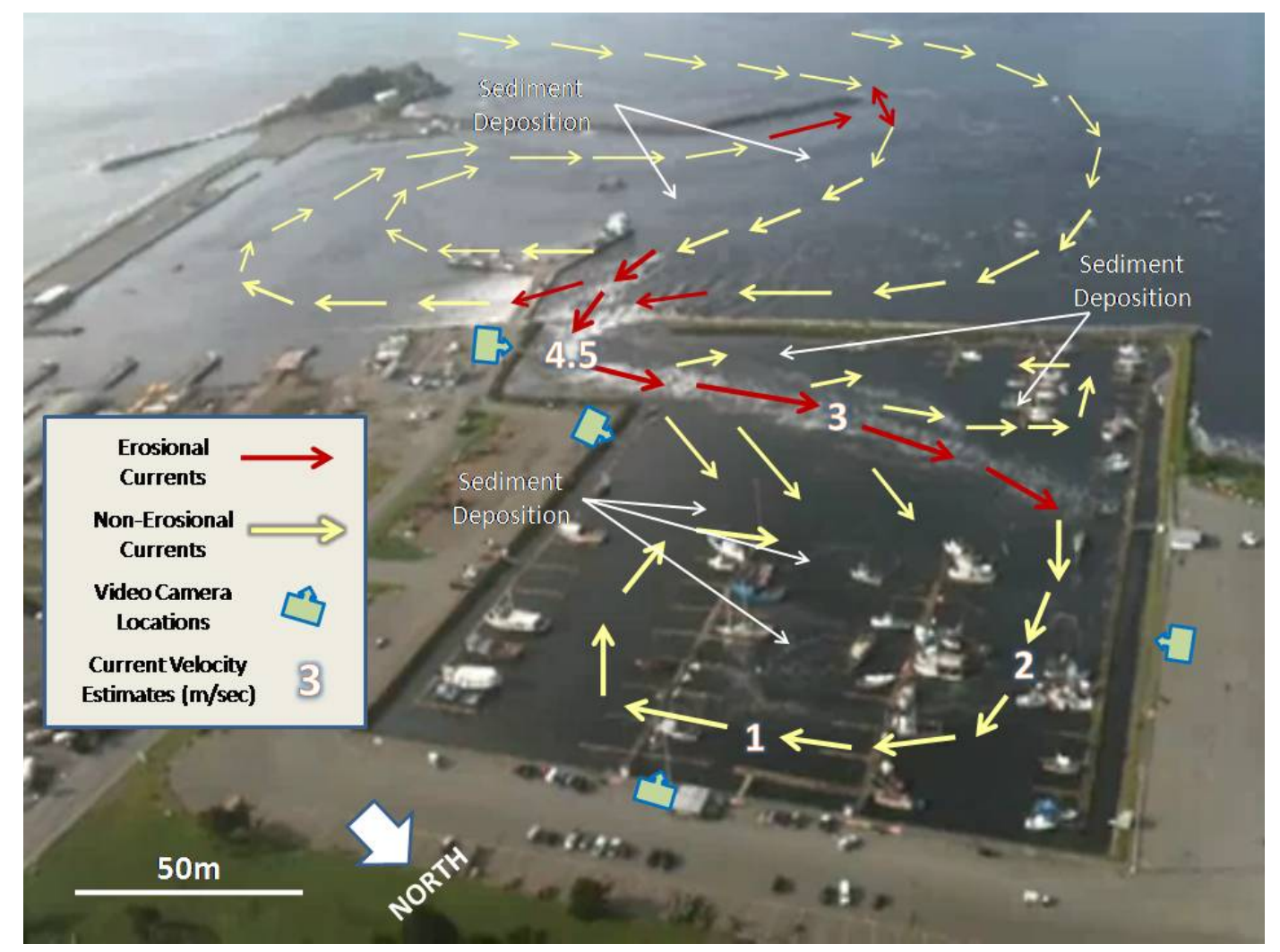

Figure 2. Tsunami flow-regime map for Crescent City harbor (from Wilson and others, 2012a). Current directions and velocities and areas of sediment erosion and deposition are based on observations of the various (30) ground-level and aerial video, pre- and post-tsunami bathymetry, and sediment analyses.

The SAFRR project also provides a framework for evaluating the statewide impacts from a much larger, distant-source tsunami. The potential loss of life and projected billions of dollars in damage and recovery costs in the SAFRR scenario demonstrates the importance of sustained and improved tsunami preparedness and mitigation for the State of California (Porter and others, 2013; Wein, 2013).

Based on the analysis of these recent events in Chile, Japan, and California, and the information provided by the SAFRR scenario, the state tsunami program is enhancing existing products and developing new products that will improve tsunami preparedness and mitigation statewide. These products will help: (1) the maritime community better understand tsunami hazards within their ports and harbors, as well as if and where boats should go offshore to be safe; (2) emergency managers to develop evacuation plans for smaller "Warning" level events where extensive evacuation is not required; and (3) coastal land-use planners, engineers, and policymakers better understand the tsunami hazard from a probabilistic (risk-based) approach. 
The ultimate goal of these improvements is to save lives and reduce immediate and long-term impact to coastal communities.

Maritime communities in California were impacted the most during the 2010 and 2011 tsunamis, and could be impacted again, as demonstrated by the SAFRR tsunami scenario. Although millions of dollars were lost during the 2010 and 2011 events, the eyewitness accounts and video information collected after each event provided a resource for improving tsunami hazard analysis in harbors and bays. Through a Co-operative Technical Partnership developed between the State and Federal Emergency Management Agency (FEMA), observed strong tsunami currents and damage are being used to validate/calibrate numerical tsunami model currents. Using validated modeling, the state tsunami program has initiated a plan to develop three sets of products for these maritime communities: (1) detailed maps identifying in-harbor tsunami hazards, such as strong currents and eddies, peak amplitude surges, and large tidal fluctuations (fig. 3); (2) offshore safety zones where ships can evacuate to and safely gather during a tsunami (fig. 4); and (3) preparedness, mitigation, and recovery/continuity plans to help maritime communities be more resilient to tsunami hazards. Harbor-specific guidance will be created to help maritime communities better prepare for, respond to, and recover from future tsunamis. Most of this mapping and guidance work with the maritime communities will be completed by the year 2015 .

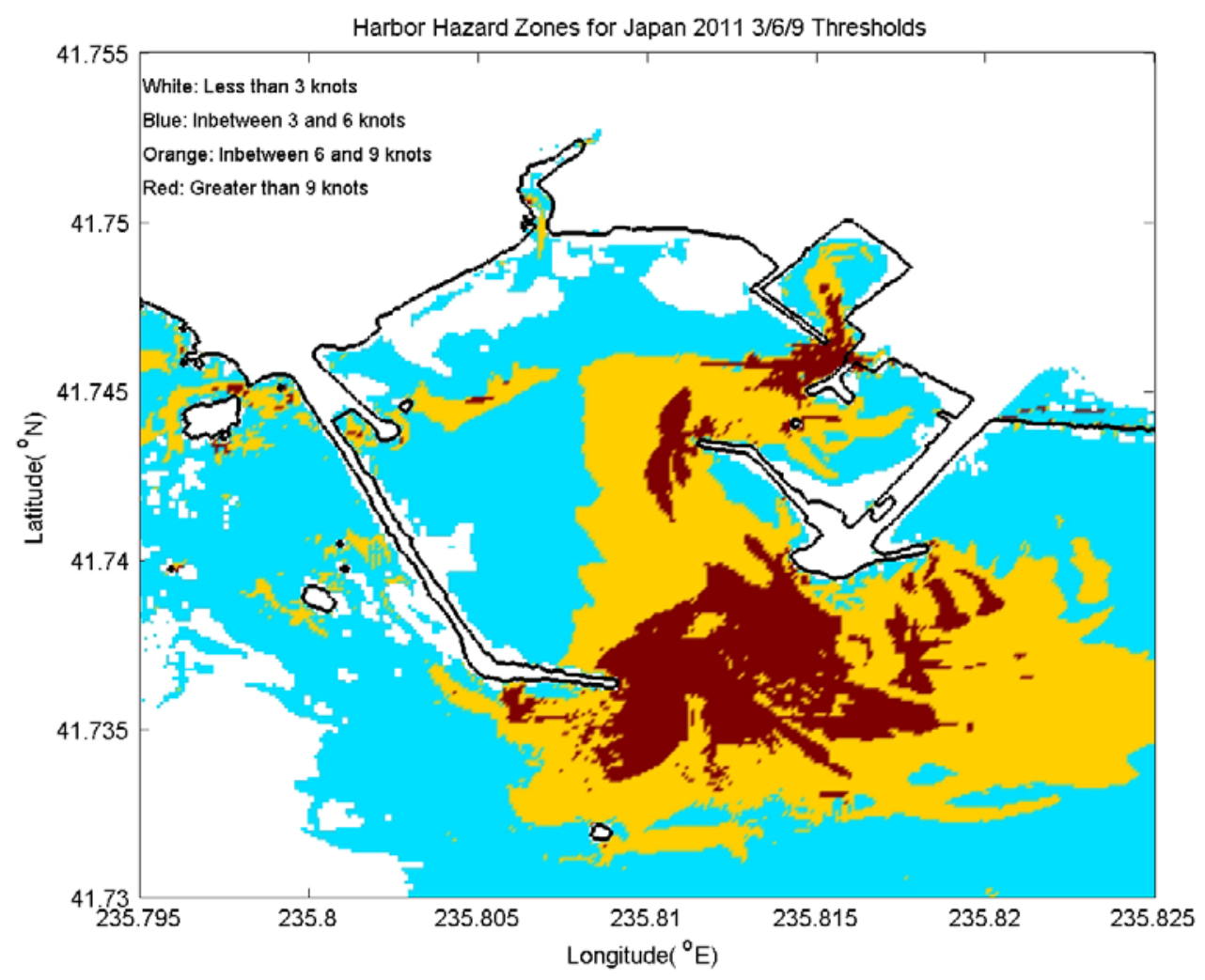

Figure 3. Map showing draft tsunami current velocity hazard zones using 2011 Tohoku event modeling in Crescent City (from Lynett and others, in press). The colors are water velocity groupings related to anticipated damage levels to harbor facilities and boats: 3-6 knots (blue) for minor damage; 6-9 knots (yellow) for moderate damage; and greater than 9 knots (red) for severe damage. 


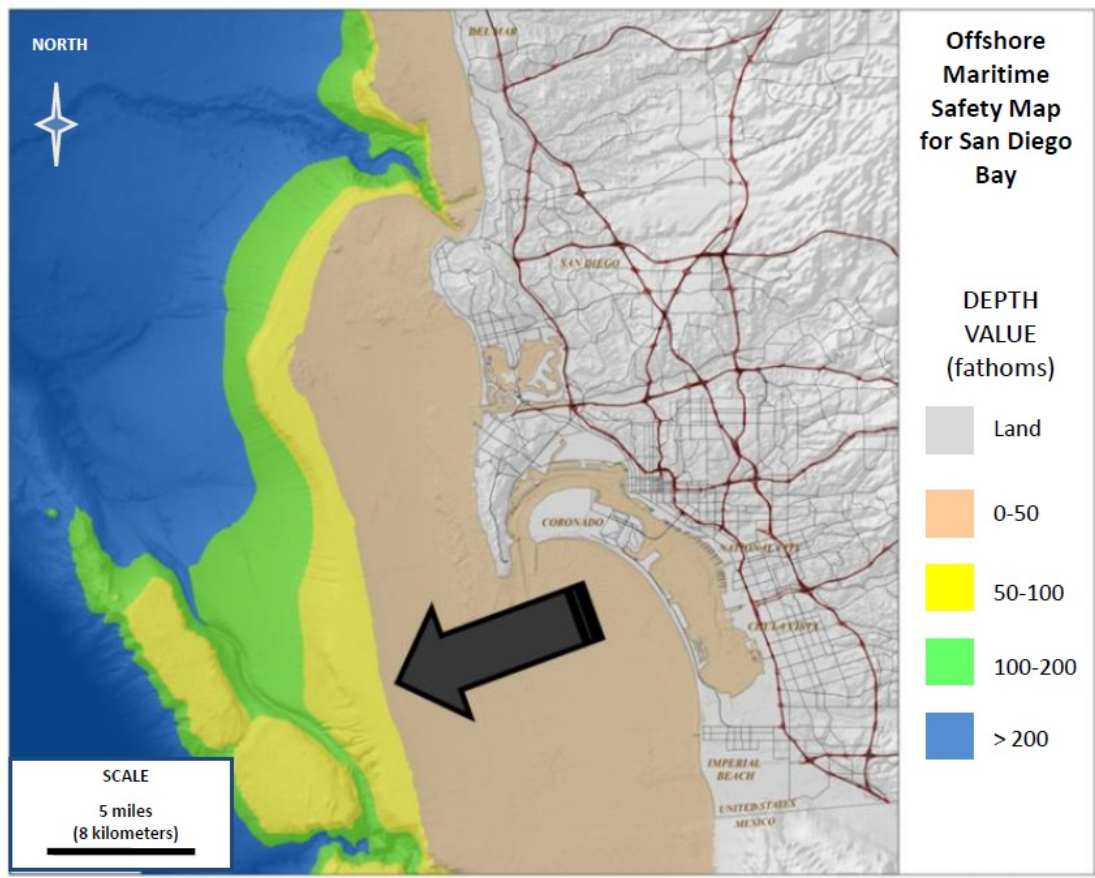

Figure 4. Draft map showing offshore bathymetric depths off the coast of San Diego Bay. Maps similar to this are used to help maritime communities plan for offshore evacuation of ships prior to a tsunami's arrival. Additional modeling is being used to determine if ships can evacuate closer to shore than the NOAA-recommended 100-fathom (600-foot) depth.

The state program also has been involved in improving statewide and local emergency response planning activities. New information available from the 2011 Japan event, a recently created tsunami deposit database, and new paleotsunami and paleoseismic work being done in Oregon, is being evaluated to determine if the existing tsunami hazard analysis for the Cascadia subduction zone is adequate. California also has been in discussions with the State of Nevada to develop tsunami inundation maps for the Lake Tahoe region so that evacuation planning and tsunami sign placement can be done in an accurate and consistent manner. Real-time and posttsunami field teams also have been expanded to capture additional detailed information that can be shared in a timely manner during and after an event through a state-wide clearinghouse. These new products and related efforts will result in more accurate and efficient emergency response by coastal communities, potentially reducing the loss of lives and property during future tsunamis.

Recent moderate to minor tsunami events have challenged existing evacuation protocols. During the 2011 tsunami in California, the arrival of significant tsunami activity, which was only forecasted to be between 1 and $2.5 \mathrm{~m}$ for areas within a "Warning" along the coast, coincided with low tide conditions and, therefore, was not expected to inundate dry land. Considerable inconsistencies between communities conducting evacuation and response were noted. Only a few communities in the state called full evacuations and, in most cases, no evacuations were initiated. Many emergency managers indicated that secondary evacuation lines for smaller Warning-level events would have been useful, reducing the potential for under- or overevacuation, and alleviating the need for an "all or nothing" decision. As a result, scenariospecific, tsunami evacuation "playbook" maps and guidance recommendations are being produced detailing inundation from tsunamis of various sizes and source locations (fig. 5). 


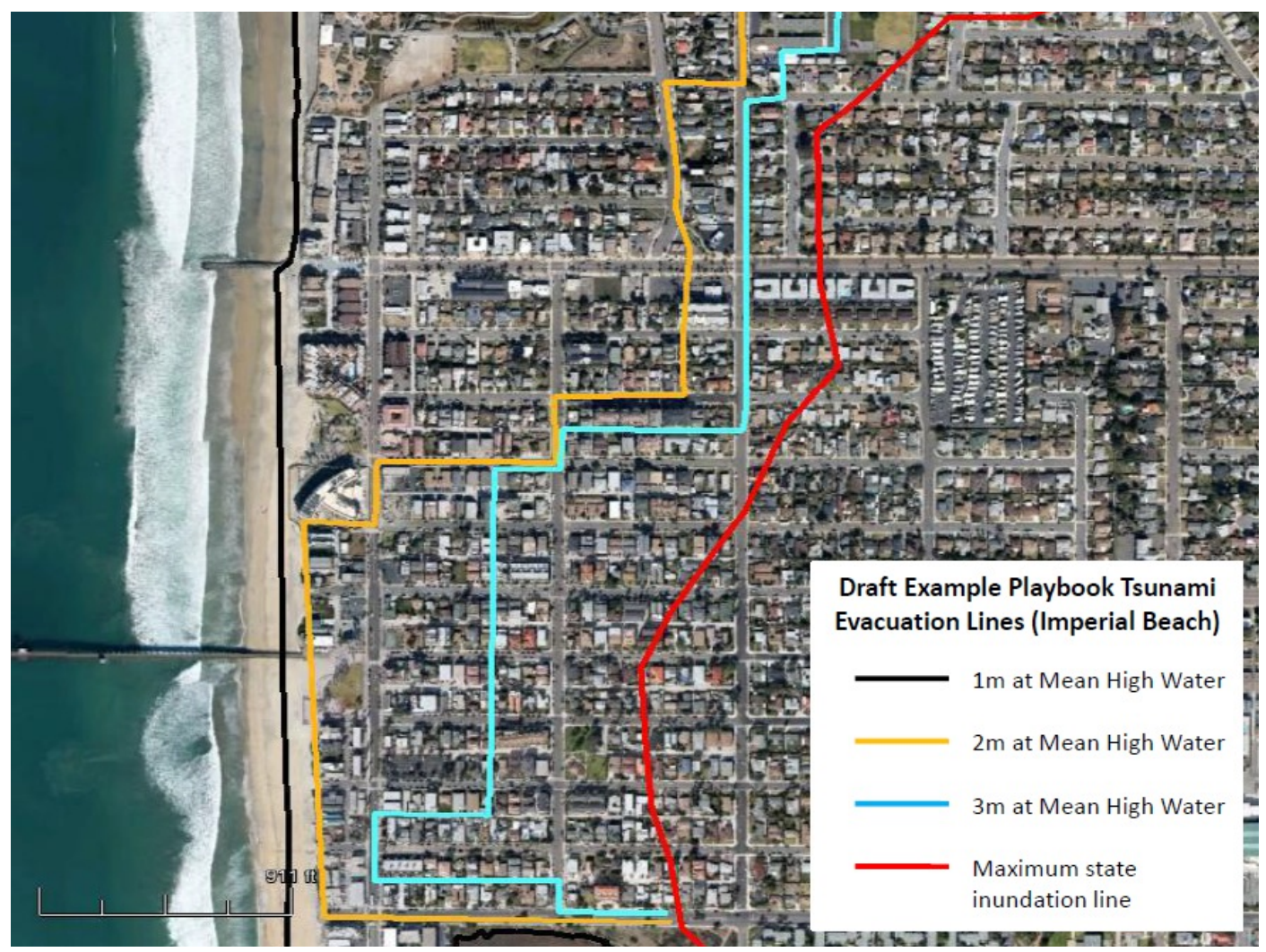

Figure 5. Draft playbook tsunami evacuation for the Imperial Beach area. The lines represent secondary evacuation zones based on various land elevations that can be used by communities for less-thanmaximum tsunami events.

In addition, a formula that incorporates forecasted tsunami amplitudes (wave heights), tidal conditions, storm activity, and site-specific tsunami run-up potential into a "maximum predicted tsunami run-up height" is being developed to determine which evacuation scenario is most appropriate and conservative to use. These products, expected to be available by the end of 2013, will help coastal emergency managers prepare local response plans when minor distantsource tsunamis, or larger tsunamis from local and regional sources are generated.

Along with improvements to evacuation planning and maritime planning, the state tsunami program has made progress towards the development of products for the coastal landuse planning, engineering, and policymaking communities. Because the existing state-wide tsunami inundation maps are based on maximum inundating maps, and not a time- or risk-based approach, they should not be used for making land-use planning decisions. As with other flood and seismic hazards, a probabilistic tsunami hazard analysis (PTHA) should be completed and utilized. Maps and associated products based on PTHA methods will be similar to other probabilistic flood- and seismic-hazard maps by representing standard risk levels (average return periods) for tsunami hazards that can be used in not only land-use planning, but possibly also in implementing building design criteria, producing more consistent inundation maps for evacuation planning, and setting flood insurance rates. The initial phase of PTHA and land-use planning product development, which has been funded by the NTHMP, includes: (1) development of a technical work group to evaluate existing PTHA methods; (2) determination of the adequacy of the PTHA methods for land-use planning and other uses; (3) acceptance and 
improvements made to the PTHA methods; (4) determination of the appropriate risk levels for PTHA-based map production; and (5) initiation of development of PTHA-based maps for the California coast. The process and products of this PTHA in California also will form the basis for the NTHMP to implement nationwide. With this initial work being completed by autumn 2013, the state tsunami program is collaborating with other entities interested in developing PTHA maps for the entire State.

In addition to working on the SAFRR project, the state tsunami program also has partnered with the USGS to improve tsunami planning and preparedness in California in other ways. The USGS completed a vulnerability analysis based on the existing state tsunami inundation maps. The study, titled "Community Exposure to Tsunami Hazards in California," (Wood and others, 2013), provides first responders, emergency planners, and other stakeholders, with valuable new information about the people who live in, work in, and visit each of the 20 counties and the more than 150 incorporated and unincorporated communities located along the state's coast. The state program will work with the report authors to provide individual information sheets to each community for incorporation into their local hazard mitigation plans.

In order to help guide, develop, and improve future tsunami preparedness and mitigation activities, the state tsunami program formed the California Tsunami Policy Work Group (CTPWG) in 2011 (Johnson and Real, 2013). Comprised of members from Federal, State, and local agencies, as well as private organizations, the CTPWG works closely with the state tsunami program to understand the state of tsunami preparedness in California. The CTPWG was formed to help identify gaps and issues in current tsunami hazard mitigation, to make recommendations that will work to eliminate these impediments, and to advise on the development and implementation of effective tsunami hazard products to improve community resiliency. This report should be available by autumn 2013 .

\section{Conclusions}

The California Tsunami Preparedness and Hazard Mitigation Program will continue to provide support to communities at risk of tsunami hazards. Evaluations of recent tsunamis have resulted in the development of new products to help evacuation planning, maritime planning, and land-use planning. "Playbooks" for less-than-maximum tsunami events will allow communities to more accurately identify and plan for the areas to evacuate in minor to moderate tsunamis. Tsunami-current hazard maps within harbors and offshore safety zones will provide maritime communities a foundation for developing and improving emergency response plans. New tsunami maps developed using probabilistic-based methods will assist in community land-use planning and site evaluations.

The state program also has benefitted from detailed knowledge developed through the range of multi-disciplinary expertise brought to bear by the U.S. Geological Survey to analyze the Science Application for Risk Reduction (SAFRR) tsunami scenario. The SAFRR project provides the framework for evaluating the statewide impacts from a single, large, distant-source tsunami. The potential loss of life, and projected billions of dollars in damage and recovery costs that this scenario estimates, underscores the importance of sustained investment in tsunami preparedness and mitigation for the State of California. Recommendations within this SAFRR report will be carried forward through sustained activities mentioned above to continue to prepare state emergency managers, scientists, the maritime and coastal land-use policy communities, and the public for the next tsunami. 


\section{References Cited}

Barberopoulou, A., Borrero, J.C., Uslu, B., Kalligeris, N., Goltz, J.D., Wilson, R.I., and Synolakis, C.E., 2009, Unprecedented coverage of the Californian coast promises improved tsunami response: Eos, American Geophysical Union Transactions, v. 90, no. 16, p. 137-138.

Johnson, L.A., and Real, C.D., 2013, Public-policy issues associated with the SAFRR tsunami scenario: U.S. Geological Survey Open-File Report 2013-1170-M, 44 p.

Lynett, P., Borrero, J., Weiss, R., Son, S., Greer, D., and Renteria, W., 2012, Observations and modeling of tsunami-induced currents in ports and harbors: Earth and Planetary Science Letters, v. 327-328, p. 68-74.

Lynett, P.J., Borrero, J.C., and Song, S., in press, Numerical simulations of tsunami-induced maritime hazards in Crescent City, California: University of Southern California Viterbi, School of Engineering, report for State of California, $52 \mathrm{p}$.

Miller, K.M., and Wilson, R.I., 2012, A culture of tsunami preparedness and applying emergency response lessons from recent tsunamis affecting California: San Francisco, American Geophysical Union Fall meeting poster.

National Weather Service, 2013, TsunamiReady ${ }^{\mathrm{TM}}$ website: National Weather Service, http://www.tsunamiready.noaa.gov/ts-communities.htm.

Porter, K., Byers, W., Dykstra, D., Lim, A., Lynett, P., Ratliff, J., Scawthorn, C., Wein, A., and Wilson, R., 2013, Physical damage in the SAFRR California tsunami scenario: U.S. Geological Survey Open-File Report 2013-1170-E, 183 p., http://pubs.usgs.gov/of/2013/1170/e/.

Wein, A., Rose, A., Sue Wing, I., Wei, D., 2013, Economic impacts of the SAFRR tsunami scenario in California: U.S. Geological Survey Open-File Report 2013-1170-H, 56 p., http://pubs.usgs.gov/of/2013/1170/h/.

Wilson, R.I., Barberopoulou, A., Miller, K.M., Goltz, J.D., and Synolakis, C.E., 2008, New maximum tsunami inundation maps for use by local emergency planners in the state of California, USA [abs]: Eos, American Geophysical Union Transactions, v. 89, no. 53, Fall meeting supplement, abs. OS43D-1343.

Wilson, R.I., Admire, A.R., Borrero, J.C., Dengler, L.A., Legg, M.R., Lynett, P., Miller, K.M., Ritchie, A., Sterling, K., McCrink, T.P., and Whitmore, P.M., 2012a, Observations and impacts from the 2010 Chilean and 2011 Japanese tsunami in California (USA): Pure and Applied Geophysics, accessed August 23, 2013, at http://dx.doi.org/10.1007/s00024-0120527-z.

Wilson, R., Davenport, C., and Jaffe, B., 2012b, Sediment scour and deposition within harbors in California (USA), caused by the March 11, 2011 Tohoku-oki Tsunami: Sedimentary Geology, v. 282, p. 228-240, doi:10.1016/j.sedgeo.2012.06.001.

Wood, N., Ratliff, J., and Peters, J., 2013, Community exposure to tsunami hazards in California: U.S. Geological Survey Scientific Investigations Report 2012-5222, 49 p. 


\section{Public Policy Issues Associated with the SAFRR Tsunami Scenario}

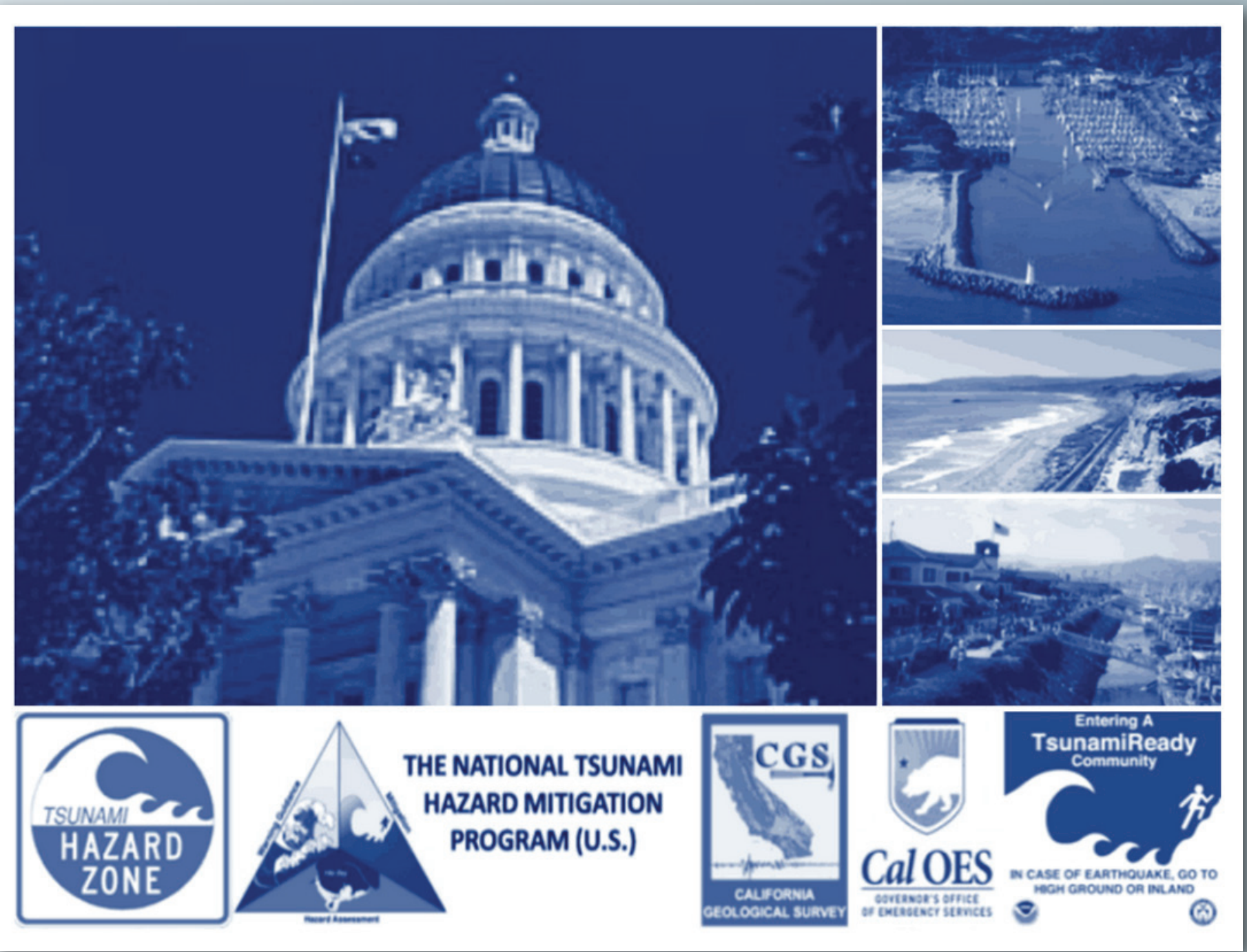

Open-File Report 2013-1170-M

California Geological Survey Special Report 229 
COVER-Public policy for the tsunami risk management is an amalgamation of national, State, and local government laws, programs, and plans. Photos clockwise from top: California State Capital Building (photo: California Geological Survey); Santa Cruz, California, harbor (photo: santacruzharbor.org); shoreline, San Clemente, California (photo: California State Parks); festival at Ventura Harbor (photo: venturaharborvillage.com); tsunami information sign, Tsunami Ready Program, National Oceanic and Atmospheric Administration (NOAA); logo, California Governor's Office of Emergency Services; logo, California Geological Survey; logo, National Tsunami Hazard Mitigation Program; sign, tsunami hazard zone, NOAA. 
The SAFRR (Science Application for Risk Reduction) Tsunami Scenario

Stephanie Ross and Lucile Jones, Editors

\section{Public-Policy Issues Associated with the SAFRR Tsunami Scenario}

By Laurie A. Johnson and Charles R. Real

Open-File Report 2013-1170-M

California Geological Survey Special Report 229

U.S. Department of the Interior

U.S. Geological Survey 


\section{U.S. Department of the Interior \\ SALLY JEWELL, Secretary}

\section{U.S. Geological Survey \\ Suzette M. Kimball, Acting Director}

U.S. Geological Survey, Reston, Virginia 2013

For product and ordering information:

World Wide Web: http://www.usgs.gov/pubprod

Telephone: 1-888-ASK-USGS

For more information on the USGS-the Federal source for science about the Earth,

its natural and living resources, natural hazards, and the environment:

World Wide Web: http://www.usgs.gov

Telephone: 1-888-ASK-USGS

Suggested citation:

Johnson, L.A., and Real, C.R., 2013, Public-policy issues associated with the SAFRR tsunami scenario, chap. M, in Ross, S.L., and Jones, L.M., eds., The SAFRR (Science Application for Risk Reduction) Tsunami Scenario: U.S. Geological Survey Open-File Report 2013-1170, 39 p., http://pubs.usgs.gov/of/2013/1170/m/.

Any use of trade, product, or firm names is for descriptive purposes only and does not imply endorsement by the U.S. Government.

Although this information product, for the most part, is in the public domain, it also may contain copyrighted materials as noted in the text. Permission to reproduce copyrighted items must be secured from the copyright owner. 


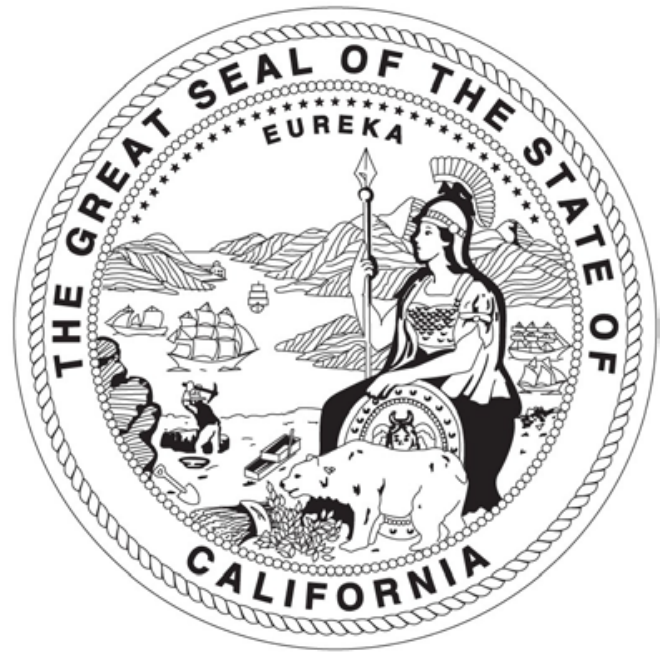

STATE OF CALIFORNIA

EDMUND G. BROWN JR. GOVERNOR

THE NATURAL RESOURCES AGENCY JOHN LAIRD

SECRETARY FOR RESOURCES

\author{
DEPARTMENT OF CONSERVATION \\ MARK NECHODOM \\ DIRECTOR
}

\title{
CALIFORNIA GEOLOGICAL SURVEY JOHN G. PARRISH, Ph.D. \\ STATE GEOLOGIST
}




\section{Contents}

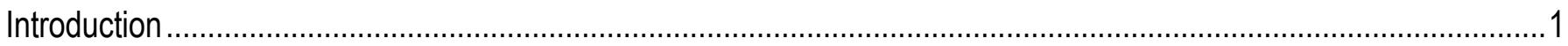

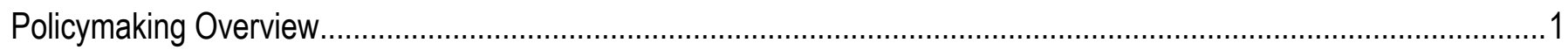

U.S. and California Tsunami and Disaster Management Policy Framework ...........................................................

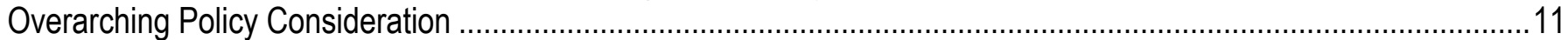

Priority Policy Issues: Mitigation and Preparedness ......................................................................................

Need for a Robust Policy Framework for Tsunami Hazard Assessment and Mitigation Planning............................12

The Tsunami Scenario Would Have Severe Impacts ...................................................................................

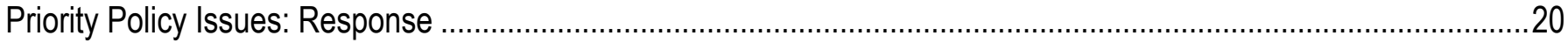

Onshore/Offshore Evacuations and Emergency Response Will Be Challenged by Existing

Warning/Evacuation Protocols and Disruptions To Communications ..................................................................21

Lack of Experience in Dealing With the Complexity of a Major Tsunami Evacuation, Sheltering, and

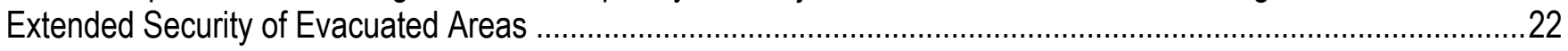

Response Effectiveness Will Depend on Cooperation and Coordination at All Levels of Government....................25

Priority Policy Issues: Recovery .............................................................................................................2

Unprecedented Recovery Challenges for Hardest Hit Coastal Communities, Ports and Harbors, and

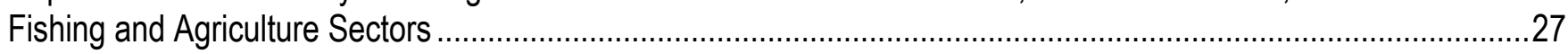

Challenges in Rebuilding More Resiliently For a Historically Infrequent Hazard, Like Tsunami...............................31

Priority Policy Issues: Risk Awareness .....................................................................................................

Building the Awareness of At-Risk Communities to Tsunami and Their Potential Damaging and Fatal

Effects

Building Constituencies that can Carry a Common Message Forward Over Time is a Key Policy

Challenge

Strengthening Tsunami Risk Awareness Among Key Professionals is Also a Key Policy Issue .............................33

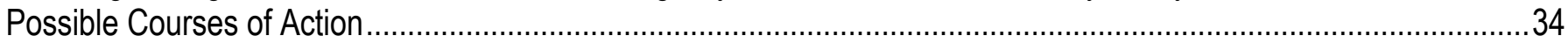

Ensure Continued Funding and Support for the National Tsunami Hazard Mitigation Program,

TsunamiReady and Affiliated State and Local Programs ............................................................................ 34

Recruit and Assist All California Coastal Communities and Ports and Harbors to Become TsunamiReady ..............34

Develop a Coordinated and Sufficiently Robust Policy Framework for Tsunami Hazard Assessment and

Mitigation Planning for California Coastal Communities and Ports and Harbors ...................................................34

Explore Opportunities to Advance Multi-Hazard Mitigation Planning Along California's Coast and Bays ..................35

Encourage Responders and Government Managers to Conduct Self-Assessments, Devise Exercises,

and More Carefully Consider the Geographic Scale of This and Other Tsunami Scenarios .....................................35

Work to Address Recovery Challenges .........................................................................................................

Develop and Consistently Communicate Common Messages About Tsunami Risk ...............................................36

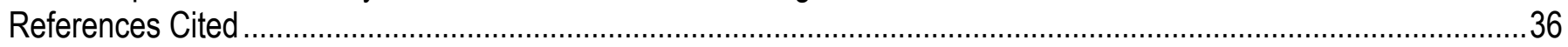

\section{Tables}

1. Generalized framework for U.S. tsunami disaster policy. .................................................................. 8

2. Status of tsunami hazard assessment and mitigation planning in California coastal counties and ...............

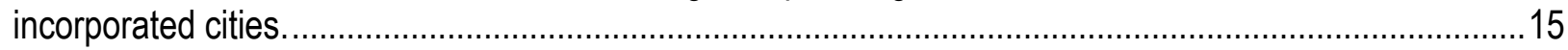

3. Status of tsunami hazard assessment and mitigation planning for California's major ports and .................... harbors. 


\section{Public-Policy Issues Associated with the SAFRR Tsunami Scenario}

By Laurie A. Johnson ${ }^{1}$ and Charles R. Real ${ }^{2}$

\section{Introduction}

The SAFRR (Science Application for Risk Reduction) tsunami scenario simulates a tsunami generated by a hypothetical magnitude 9.1 earthquake that occurs offshore of the Alaska Peninsula (Kirby and others, 2013). In addition to the work performed by the authors on public-policy issues associated with the SAFRR tsunami scenario, this section of the scenario also reflects the policy discussions of the State of California's Tsunami Policy Work Group, a voluntary advisory body formed in October 2011, which operates under the California Natural Resources Agency (CNRA), Department of Conservation, and is charged with identifying, evaluating, and making recommendations to resolve issues that are preventing full and effective implementation of tsunami hazard mitigation and risk reduction throughout California's coastal communities. It also presents the analyses of plans and hazard policies of California's coastal counties, incorporated cities, and major ports performed by the staff of the California Geological Survey (CGS) and Lauren Prehoda, Office of Environmental and Government Affairs, California Department of Conservation. It also draws on the policy framework and assessment prepared for the ARkStorm Pacific Coast winter storm and catastrophic flooding (Topping and others, 2010). This chapter was peer-reviewed by Robert Olson, Robert Olson and Associates, and Martin Eskijian, consulting engineer.

\section{Policymaking Overview}

In the United States, public policymaking is the responsibility of elected bodies, such as city councils, State legislatures, and the U.S. Congress. Managers of cities, counties, and special districts, as well as regional, State and Federal agencies also participate in policymaking, helping conceptualize and create policies. The policymaking process tends to evolve in response to societal or community problems perceived by citizens, interest groups, and political leaders. A rational description of the policymaking process can be described as a cycle (Newell, 2004, p. 153) of:

- Agenda setting, when issues are brought to the attention of policymakers.

- Policy formulation, when options are considered and a course of action is adopted.

- Implementation, when adopted policies are put into action.

- Evaluation, when a policy assessment is performed and ways to modify or improve policies are provided.

\footnotetext{
${ }^{1}$ Laurie Johnson Consulting Research.

${ }^{2}$ California Geological Survey.
} 
Within this cycle, this tsunami policy assessment largely corresponds with the agenda and policy formulation stages. However, as Birkland (1997) and others have aptly documented, policy agenda setting and policy transformations rarely occur in such a rational, staged way. For U.S. disaster policy, much of the formulation and implementation have occurred mostly during relatively brief periods of time- - usually following disastrous events (Birkland, 1997; Birkland, 2006; Rubin, 2012). As Birkland advises, "a disaster can often do in an instant what years of interest group activity, policy entrepreneurship, advocacy, lobbying, and research may not be able to do" (Birkland, 2006, p. 5). This is what occurred in aftermath of the catastrophic 2004 Indian Ocean tsunami, when Congress passed the Tsunami Warning and Education Act of 2006 - a key piece of Federal legislation aimed at strengthening the tsunami detection, warning, education, and preparedness efforts in the U.S. (U.S. Congress, 2005; U.S. Congress, 2006).

This policy assessment considers the priority issues raised by the SAFRR tsunami scenario, with particular emphasis on the modeled physical, social, and economic impacts on California's coastal communities, ports, and harbors. Issues of tsunami science, modeling techniques, and national tsunami forecasting are not major components of this assessment. The priority policy issues are organized around the basic functions of disaster management - mitigation and preparedness, response, and recovery - as well as risk awareness, which is a major behavioral factor in disaster management. In addition, this assessment also identifies overarching policy considerations and possible courses of action.

\section{U.S. and California Tsunami and Disaster Management Policy Framework}

In the United States, most governance and policymaking works as a shared system in which, according to May and Williams (1986, p. 21), "common or overlapping responsibilities are apportioned among layers of government." "Federal shared governance creates an intergovernmental partnership for which noteworthy decision-making power about program or regulatory design and/or operations is exercised by both those in the Federal Government and those in subnational governments" (May and Williams 1986, p. 21). In the modern U.S. disaster management system, local governments, special districts, and tribal governments have primary responsibility for supplying disaster-related resources; regional, State, and Federal agencies are to provide support as requested (Federal Emergency Management Agency [FEMA], 2005). This shared system is triggered from the "bottom-up." Local governments are aided as needed by States, and both are aided, in turn, by the Federal Government. By design, the system requires extensive coordination and cooperation among all levels of government, as well as the many private organizations involved in disaster management. It is also a system of incentives, in that States and localities are encouraged, but not required, to participate.

Table 1 generalizes the current disaster policy framework in the United States for the basic disaster management functions, combining preparedness and mitigation, and adding risk awareness, with an emphasis on tsunami-related policy. The fundamental roles and responsibilities of each level of public policymaking - Federal, State, regional, county, and localities, as well as the private sector, are briefly described.

The Federal Government is primarily responsible for the Nation's tsunami alert and warning system, providing response and recovery assistance following major disasters, promoting risk awareness and preparedness, and encouraging State, local, and private mitigation and preparedness efforts, in some cases through the use of incentives. Major Federal legislation and programs include the following:

- Tsunami Warning and Education Act of 2006 designates the National Oceanographic and Atmospheric Agency (NOAA) through the National Weather Service (NWS) to provide continued 
tsunami alert and notification responsibilities for a tsunami, generated anywhere in the world, that may impact U.S. States and territories. For the West Coast, including California, these alerts are issued by NOAA's West Coast and Alaska Tsunami Warning Center (WCATWC). The WCATWC has most of North America under its area of responsibility, whereas NOAA's Pacific Tsunami Warning Center (PTWC) provides alerts to the remainder of the Pacific Basin.

National Tsunami Hazard Mitigation Program (NTHMP). The NTHMP was first formed by Congressional action in 1995 and strengthened by the Tsunami Warning and Education Act of 2006. The NTHMP is a partnership between NOAA, the United States Geological Survey (USGS), the Federal Emergency Management Agency (FEMA), the National Science Foundation (NSF), and the 28 U.S. coastal States, territories, and commonwealths. It is focused on reducing the impact of tsunamis through hazard assessment, warning guidance, and mitigation (NOAA, 2013a). It also sets the standards for tsunami source identification, numerical modeling, and inundation and hazard mapping.

- TsunamiReady Program is led by the NWS at NOAA, and is part of the NTHMP. It is designed to help cities, towns, counties, universities, and other large sites in coastal areas reduce the potential for disastrous tsunami-related consequences (NOAA, 2013b). To be designated "TsunamiReady," a community must meet certain criteria for (1) communications and coordination, (2) receipt of tsunami warnings, (3) local warning dissemination, (4) preparedness, and (5) administration of a formal tsunami hazard operations plan. As of May 22, 2013, there were 144 TsunamiReady ${ }^{\mathrm{TM}}$ sites in 11 States, Puerto Rico, Guam and the Northern Mariana Islands, American Samoa, and one international site (NOAA, 2013b). Thirty-five of those sites are located in California, 21 of which are localities, seven are counties, three are government sites, two are Indian tribes, one is the University of California at Santa Barbara, and one is San Francisco airport. None of California's ports have been designated TsunamiReady, but some, such as the Port of Los Angeles, are located in cities or counties that have achieved this status.

- National Response Framework (NRF) is a guide to how the Nation responds to all types of disasters and emergencies (FEMA, 2013). It is built on scalable, flexible, and adaptable concepts identified in the National Incident Management System (NIMS) to align key roles and responsibilities across the country. The NRF describes specific authorities and best practices for managing response that include actions to save lives, protect property and the environment, stabilize communities, and meet basic human needs following an incident, as well as the execution of emergency plans and actions to support short-term recovery. Under the NRF, the Secretary of Homeland Security is the principal Federal official for domestic incident management and FEMA leads Federal response to incidents in which Federal assistance is provided under the Stafford Act.

- Robert T. Stafford Disaster Relief and Emergency Assistance Act (Stafford Act) provides for individual and household post-disaster assistance, Public Assistance grants to restore damaged public facilities and infrastructure, and mitigation grants that fund both local hazard mitigation planning and projects to help strengthen communities against future disaster losses (FEMA, 2007). Interacting with Stafford Act programs are the National Incident Management System (NIMS), which provides a standardized nationwide protocol for managing response at each level of government, and the NRF (FEMA, 2008) and the National Disaster Recovery Framework (FEMA 2011), which coordinate disaster response and recovery activities among Federal agencies.

- National Disaster Recovery Framework (NDRF) is a guide that enables effective recovery support to disaster-impacted States, tribes, and territorial and local jurisdictions (FEMA, 2011). It also defines a coordinating structure that can be activated and scaled as appropriate depending on the size and nature of the disaster and defines some key positions-Federal, State, and Tribal Disaster 
Recovery Coordinators (FDRC, SDRC, and TDRC) and Local Disaster Recovery Managers (LDRMs) - as well as six recovery support functions (RSF) — community planning and capacity building, economic, health and social services, housing, infrastructure systems, and cultural and natural resources. FEMA is designated as the lead Federal agency to facilitate and coordinate RSF activities and recovery planning at the national level, and a series of RSF annexes further define the scope of each RSF and designate a Federal agency as the RSF coordinator along with a number of primary agencies and supporting organizations. The NDRF timeframe can extend for months, even years, following a major disaster.

- U.S. Coast Guard has incident response responsibility for the coastal zone, which includes all U.S. waters subject to tides, as well as specified ports and harbors. In tsunami response, the U.S. Coast Guard would provide mutual aid to the ports and affected jurisdictions statewide to support search and rescue operations, launch air support according to policy, notify commercial vessels and applicable facilities of a tsunami warning, close ports to all inbound vessel traffic and encourage vessels to move to a safe location, and conduct patrols of waterways within the affected zone to ensure maritime security.

- Disaster Mitigation Act of 2000 (DMA 2000) requires State and local adoption of FEMA-approved Hazard Mitigation Plans (HMP) as a precondition for receipt of Federal mitigation project grant funding. It also provides a competitive Pre-Disaster Mitigation (PDM) grant program to fund local hazard mitigation planning efforts and mitigation projects. Local HMPs typically contain maps showing areas of potential natural hazards, as well as a discussion of historic occurrences, an assessment of exposure and risk to infrastructure, proposed policies to mitigate the impact of future occurrences, and an Action Plan that must indicate priorities for mitigation activities that become formally adopted by the local governing body. Mitigation actions are commonly evaluated and prioritized using a tool from FEMA that evaluates strengths, weaknesses, opportunities, and constraints of proposed actions through a series of questions considering the following aspects: (1) social (community acceptance and effect of differing segments of population), (2) technical (feasibility, long-term solution, secondary impacts), (3) administrative (staffing requirements, funding needs, necessary maintenance and operations), (4) political (necessary support, local champion, public support), (5) legal (State authority, existing local authority, potential for legal challenge), and (6) economic (expected benefit, cost of implementation, contribution to economic goals, outside funding needs).

- National Flood Insurance Program (NFIP) provides flood insurance through the private sector, with backing by the Federal Government. Insurance is also reinforced by 100 -year and 500 -year floodplain mapping, together with rate reductions in relation to local government mitigation actions. Various types of flood mitigation and project grants are also administered. Tsunami losses are covered under the NFIP. However, the Flood Insurance Rate Maps (FIRMs) do not, as of yet, model tsunami risk as part of coastal flood mapping. The program requires communities to adhere to strict flood-resistant building codes in designated flood zones to qualify for the program. For coastal communities, such standards recognize hazards of coastal storm surge and hurricane-driven flood waters and provide specifications for building materials, design, and construction, which also help to provide resistance against low amplitude tsunami inundation. The NFIP represents the national position on "shared-risk." The Federal Government will help, but it aims to encourage local governments and individuals to share flood risk.

- Coastal Zone Management Act of 1972 is administered by NOAA's Office of Ocean and Coastal Resource Management (OCRM) which works with States and territories to operate a system of National Estuarine Research Reserves, implement the National Coastal Zone Management (NCZM) 
Program, and develop a system of marine protected areas. The NCZM program is a voluntary StateFederal partnership which encourages States to adopt their own management programs to meet the Federal goals of protection, restoration, and appropriate development of coastal zone resources. The OCRM has a modest annual budget that it primarily uses to match State funds for implementing resource improvements, enhancements, and pollution control in the designated coastal zone and national estuarine research reserves. The State of California is a participant in the NCZM Program and the California Coastal Commission and Bay Conservation and Development Commission are two designated State agencies responsible for developing and implementing the State's Coastal Zone Management Plan (CZMP).

The State of California participates in the national tsunami preparedness and risk awareness programs and also provides response and recovery assistance following major disasters, and encourages local and private mitigation and preparedness efforts, in some cases through the use of incentives. Major State legislation and programs include the following:

- California Tsunami Preparedness and Hazard Mitigation Program (TPHMP). The program is funded by NOAA under the NTHMP and managed by the California Governor's Office of Emergency Services (Cal OES) with assistance from the California Geological Survey (CGS). It provides leadership and guidance, as well as financial support, for many tsunami preparedness, planning and hazard mitigation activities in the State. These include tsunami scenario modeling, preparation of tsunami inundation zone maps and evacuation zone maps, development and implementation of State and local emergency response and evacuation plans, tsunami-related exercises and training, and testing of the tsunami warning system. In 2009, the State TPHMP released a series of "Tsunami Inundation Maps for Emergency Planning," which have provided the basis for preparedness, planning, and education activities in California. These activities have including the preparation of evacuation and emergency response plans, production of multilanguage brochures, development and support of tsunami scenario-driven exercises and drills, development of workshops to educate both emergency managers and public, and establishment of a comprehensive information Web site (see http://www.tsunami.ca.gov), a preparedness Web site (see http://myhazards.calema.ca.gov/), and a Web service to assist in preparation of local hazard mitigation plans (see http://myplan.calema.ca.gov/). Activities are coordinated through the California Tsunami Steering Committee, comprised of representatives from the four regional NWS offices, all relevant State agencies, and each of the 20 coastal and San Francisco Bay area counties.

- California Coastal Act of 1976, established the California Coastal Commission (CCC) as an independent, quasi-judicial State agency to protect, conserve, restore, and enhance environmental and human-based resources of the California coast and ocean for use by current and future generations. The CCC, in partnership with the State's 60 coastal cities and 15 coastal counties, regulates the use of land and water in the coastal zone - an area specifically mapped by the California Legislature that varies in width from several hundred feet in highly urbanized areas to as much as 5 miles in certain rural areas and extends offshore in a 3-mile-wide band. The act requires all local governments within the coastal zone to develop local coastal plans (LCPs) that are then reviewed and certified by the CCC. Although the LCPs are primarily focused on environmental protection and public coastal access issues, these plans must also consider public safety issues. It is at this time that the $\mathrm{CCC}$ transfers permitting authority for most new development to the local government. The CCC retains appellate authority over development within 300 feet of the high tide line or the first public road, whichever is landward. About 90 percent of the State's coastal zone falls into an LCP. Development activities are broadly defined by the California Coastal Act to include 
(among others): construction of buildings, divisions of land, and activities that change the intensity of use of land or public access to coastal waters. These activities generally require a coastal permit from either the CCC or the local government. The Coastal Commission is one of California's two designated coastal-management agencies for the purpose of administering the Federal Coastal Zone Management Act. Following the 2011 Tohoku Oki tsunami in Japan, the California Coastal Commission added a requirement for the assessment of tsunami hazards for proposed development located in designated Coastal Zone and for recertification of LCPs. Most coastal counties and cities have not yet completed their LCP plan updates and the CCC's recertification process.

- California State Lands Commission, established in 1938, has jurisdiction over State lands, waterways, and resources. Public and private entities may apply to the commission for leases or permits to use, or conduct activities on, State lands for many purposes including marinas, industrial wharves, tanker anchorages, dredging, mining, and oil and gas (California State Lands Commission, 2013). For example, owners and developers of marinas along the State's bays are required to acquire a lease for use of the State's land at the marina site. The State Lands Commission also issues dredging permits to both public and private parties for work in harbors and waterways. After the 1994 Northridge earthquake, the State Lands Commission was funded through FEMA's Hazard Mitigation Grant Program (HMGP) to develop standards for marine oil terminals. In 2005, the Marine Oil Terminal Engineering and Maintenance Standards (MOTEMS) became an enforceable chapter in the California Building Code (chapter 31F), and more than 30 marine oil terminals along California's coast were mandated to comply with a comprehensive inspection program, along with updated requirements for mooring, berthing, seismic vulnerability and other mechanical systems. Mooring and berthing requirements have since been updated to consider the largest vessels calling at a terminal. Also, each marine oil terminal is now required to have a "tsunami plan," for shutting down operations, vacating the terminal, and doing whatever else is deemed necessary. Sea-level rise is also required to be considered under the standards.

- Bay Conservation and Development Commission (BCDC), established by the McAteer-Petris Act of 1965, is the Federally designated State coastal-management agency for the San Francisco Bay segment of the California coastal zone. This designation empowers the commission to use the authority of the Federal Coastal Zone Management Act to ensure that Federal projects and activities are consistent with the policies of the San Francisco Bay Plan and State law. It is the only regional agency with any direct authority to regulate land use. BCDC issues permits for filling, dredging, and changes in use in San Francisco Bay, including salt ponds, managed wetlands, and the shoreline. BCDC makes these permitting decisions in concert with the policies in its long-term guidance document, the San Francisco Bay Plan, which, among other things, specifies which areas along the shoreline should be used for ports, recreation, wildlife refuges, and other purposes. BCDC's shoreline jurisdiction to regulate development only extends to 100 feet upland from the Bay. Local governments in the San Francisco Bay area have the most comprehensive authority over land use. State Seismic Hazard Mapping Act of 1990 provides for a statewide seismic hazard mapping and technical advisory program to assist cities and counties in fulfilling their responsibilities to protect public health and safety by reducing and mitigating the effects of strong ground shaking, liquefaction, landslides, or other ground failure and other seismic hazards caused by earthquakes. The State Geologist, and thus the California Geological Survey, is charged with preparing the statewide maps and managing the technical advisory program. The act also directs cities and counties to take the seismic hazard map information into account in the preparation of the safety element of their general plans and in formulating land-use management policies and regulations. The act also requires the disclosure of State-specified natural hazards to prospective buyers of residential 
property at the time of sale. The act also explicitly states that the State Geologist may also map the potential effects of tsunami and seiche when information becomes available from other sources and the State Geologist determines the information is appropriate for use by local government.

- Safety element in local General Plans. All counties and incorporated cities in California are required to prepare safety elements to be included in local General Plans (California Government Code Section 65302, subdivision (g)) and are subject to the requirement for consistency with the general plan of zoning, subdivision, and capital improvements decisions. The safety element must include mapping of known seismic and other geologic hazards, as well as flood hazard zones. It also must address evacuation routes, military installations, peak-load water supply requirements, and minimum road widths and clearances around structures, as those items relate to identified fire and geologic hazards. Cities and counties may adopt their local hazard mitigation plan (LHMP) as a part of the safety element of their general plans.

- California Oil Spill Prevention and Response Act of 1990, led to the establishment of the Office of Oil Spill Prevention and Response (OSPR) in the California Department of Fish and Wildlife (CDFW) with primary authority to direct prevention, removal, abatement, response, containment, clean up, and mitigation of oil spills in the marine waters of California. The act created harbor safety committees for the harbors and adjacent regions of San Diego Bay; Los Angeles/Long Beach Harbor; Port Hueneme; San Francisco, San Pablo, and Suisun Bays; and Humboldt Bay. Committee membership is prescribed in the act and draws from the range of stakeholders - both public and private - involved with ports and harbors. Each harbor safety committee is required to plan "for the safe navigation and operation of vessels within its geographic region of responsibility ... (by preparing a) ... harbor safety plan which encompasses all vessel traffic within its region and addresses the region's unique safety needs" (State of California, 2005). Plans are required to address regional harbor conditions and include "existing and expected conditions of weather, tidal ranges, tidal currents (directions and velocities), and other factors which might impair or restrict visibility or impact vessel navigation" (State of California, 2005). The act also gave the State Lands Commission authorities over marine terminals.

- California Building Standards Code is published in its entirety every 3 years by order of the California legislature, with supplements published in intervening years. The current code adopted in 2010 (California Code of Regulations, title 24, volume 1 of part 2) is derived in large part from the 2009 International Building Code (California Building Standards Commission, 2010). The California legislature also delegates authority to various State agencies, boards, commissions and departments to create building regulations to implement the State's statutes. These building regulations or standards have the force of law and take effect 180 days after their publication unless otherwise stipulated. A city, county, or city and county may establish more restrictive building standards reasonably necessary because of local climatic, geological, or topographical conditions. Findings of the local condition(s) and the adopted local building standard(s) must be filed with the California Building Standards Commission to become effective and may not be effective sooner than the effective date of the latest edition of California Building Standards Code.

In addition to these key policies programs, State and local emergency planning is guided by the Incident Command System (ICS)/Standardized Emergency Management System (SEMS) to coordinate response and recovery activities statewide. Counties serve as operational areas under the State's emergency response framework. 
Table 1. Generalized framework for U.S. tsunami disaster policy.

[Adapted from Topping and others, 2010]

Mitigation and Preparedness

Federal Implement National Tsunami Hazard Mitigation Program (NTHMP) working with Statelocal agencies to improve tsunami detection, warning, preparedness and response, and including management of the TsunamiReady program.

Manage Tsunami Warning Centers and Deep-Ocean Assessment and Report of Tsunamis (DART) sensor network

Require State-local adoption of Federal Emergency Managemen Agency (FEMA)-approved hazard mitigation plans for mitigation grant eligibility. Provide State-local pre- and post-disaster mitigation project grants.

Provide Federally backed private flood insurance, 100- and 500year floodplain maps, rate reductions linked to adoption of flood provisions in building codes other mitigation actions, and mitigation grants.

Make building-site mitigation improvements reducing risks to Federal infrastructure.
Response

alert and warning system and dissemination protocols.

Implement National Response

Framework (NRF) and National

Incident Management Systems

(NIMS).

Determine if a Presidential

disaster declaration is warranted

U.S. Coast Guard implements tsunami protocol of Planned

Response overseeing port and harbor evacuation and maritime movements.

Provide mutual aid and State and

local assistance as requested

Provide training and technical

support for preparedness and

response, including local

response planning through the

Tsunami Ready program.

Establish and support

communication and information mechanisms.
Risk Awareness

Provide State and local assistance

o State and local governments,

Indian tribes or authorized tribal

organizations, and certain

specified private nonprofit

organizations for eligible

emergency work and the repair, restoration, and replacement of

damaged public facilities and

infrastructure.

Provide grant and loan assistance

to individuals, families, and

businesses for damages and

conomic losses.

Provide limited resources for

long-term recovery planning.

Fund post-disaster mitigation to

reduce future losses.

Provide residential and

commercial resources for

recovery via the National Flood

Insurance Program (NFIP)
Create and administer public

education programs to promote

risk awareness that work at a

national level, and also fund

State, regional, and locally

specific efforts. Example:

National Tsunami Preparedness

Week.

Provide limited funding for research and outreach on risk communication. 
Table 1. Generalized framework for U.S. tsunami disaster policy.-Continued

[Adapted from Topping and others, 2010]

Mitigation and Preparedness

\section{State Implement State Tsunami}

Hazard Mitigation Program

(NTHMP) working with

Federal-State-local agencies to

improve tsunami detection,

warning, preparedness and

response.

Prepare State Hazard Mitigation

Plan.

Require cities and counties to

adopt general plans, including

safety elements, Local Coastal

Plans, and official hazard zones

issued as part of the Seismic

Hazard Mapping Act.

Require cities and counties to

approve developments consistent

with general plans.

Adopt the State building code

and mandate local adoption and

enforcement.

Make building-site and

infrastructure mitigation

improvements reducing risks to

State-owned facilities and

infrastructure.

\begin{tabular}{ll}
\multicolumn{1}{c}{ Response } & \multicolumn{1}{c}{ Recovery } \\
Initiate California State Warning & Provide State financial assistance \\
Center (CSWC) as the & to affected local governments and \\
designated Warning Point & other eligible entities for the
\end{tabular}

Pation of

tsunami alerts and warnings.

Implement State Emergency

Plan framework and

Standardized Emergency

Management System (SEMS).

Issue emergency proclamations

and make Federal disaster

declaration request.

Coordinate requests for Federal

assistance; utilize mutual aid

regions and operational areas to

support and coordinate local and

Federal response.

Provide training and technical

assistance to local agency

response organizations.

Coordinate nongovernmental

organization support for State

and local response.

Provide and coordinate the flow

of information internally and

externally to the public. facilities and infrastructure.

Administer Federal recovery

programs to repair public

facilities and infrastructure and

provide necessary additional

funds.

Coordinate Federal assistance

available for individuals,

households, and businesses.

Help administer Federal programs

for post-disaster mitigation.

Administer State-mandated

planning, zoning, subdivision,

environmental review, and

building related requirements.
Risk Awareness

Participate in national tsunami

risk awareness programs.

Create and administer public

education programs to promote

risk awareness, and also fund

locally specific efforts. 
Table 1. Generalized framework for U.S. tsunami disaster policy.-Continued [Adapted from Topping and others, 2010]

\begin{tabular}{|c|c|c|c|c|}
\hline & Mitigation and Preparedness & Response & Recovery & Risk Awareness \\
\hline Local & $\begin{array}{l}\text { Make building-site mitigation } \\
\text { improvements to reduce risks to } \\
\text { local infrastructure. } \\
\text { Prepare and adopt State- } \\
\text { mandated city and county } \\
\text { general plans, including safety } \\
\text { elements, Local Coastal Plans, } \\
\text { hazard zones, and building } \\
\text { codes. } \\
\text { Prepare and adopt FEMA- } \\
\text { approved Local Hazard } \\
\text { Mitigation Plans. }\end{array}$ & $\begin{array}{l}\text { Have primary responsibility for } \\
\text { evacuation and disaster } \\
\text { response. } \\
\text { Establish priorities for allocation } \\
\text { of personnel and resources. } \\
\text { Provide information and locally } \\
\text { based assessments. } \\
\text { Request assistance and mutual } \\
\text { aid using tiered relationships. } \\
\text { Obtain and disseminate } \\
\text { information to the local public. } \\
\text { Coordinate laterally with local } \\
\text { nongovernmental organizations } \\
\text { (NGOs), community-based } \\
\text { organizations (CBOs), faith- } \\
\text { based organizations (FBOs), } \\
\text { medical providers, other local } \\
\text { agencies, and private sector. } \\
\text { Coordinate vertically with State } \\
\text { and Federal agencies/ responders }\end{array}$ & $\begin{array}{l}\text { Primary responsibility for } \\
\text { recovery; request State and } \\
\text { Federal assistance as necessary. } \\
\text { Review and approve permits for } \\
\text { repairs and reconstruction in } \\
\text { accordance with local plans, } \\
\text { zoning and subdivision } \\
\text { regulations, the California } \\
\text { Environmental Quality Act, the } \\
\text { California Coastal Act, and } \\
\text { building codes. }\end{array}$ & $\begin{array}{l}\text { Participate in national and State } \\
\text { risk awareness programs. } \\
\text { Create and administer local } \\
\text { tsunami risk awareness } \\
\text { programs. } \\
\text { Disclose coastal flooding risk } \\
\text { (and tsunami information as } \\
\text { available) as part of land } \\
\text { development and other locally } \\
\text { controlled development review. }\end{array}$ \\
\hline Private & $\begin{array}{l}\text { Buy NFIP and other hazards } \\
\text { insurance and business } \\
\text { interruption insurance } \\
\text { Make building-site mitigation } \\
\text { improvements reducing risks to } \\
\text { privately owned infrastructure } \\
\text { Make building-site mitigation } \\
\text { improvements reducing risks to } \\
\text { private property. }\end{array}$ & $\begin{array}{l}\text { Coordinate with local agency } \\
\text { responders. } \\
\text { Provide resources for support of } \\
\text { local and regional response } \\
\text { efforts. } \\
\text { Provide information to } \\
\text { emergency responders. } \\
\text { Coordinate communication with } \\
\text { local businesses and } \\
\text { organizations. } \\
\text { Coordinate vertically with } \\
\text { corporate parent and partner } \\
\text { entities and organizations. }\end{array}$ & $\begin{array}{l}\text { Repair and rebuild according to } \\
\text { codes and regulations. } \\
\text { Businesses and individuals } \\
\text { provide resources for recovery via } \\
\text { insurance, grants, and reserves. } \\
\text { Nongovernmental and } \\
\text { philanthropic organizations } \\
\text { provide resources for recovery } \\
\text { through donations, services and } \\
\text { grants. }\end{array}$ & $\begin{array}{l}\text { Mortgage lenders disclose } \\
\text { tsunami risk when it is consistent } \\
\text { with NFIP mapped coastal } \\
\text { flooding areas. } \\
\text { Private insurance promotes risk } \\
\text { awareness as part of the } \\
\text { underwriting process. } \\
\text { Create nonprofit organizations to } \\
\text { promote two-way risk } \\
\text { communication for their } \\
\text { particular hazard. }\end{array}$ \\
\hline
\end{tabular}




\section{Overarching Policy Consideration}

The disaster management policy framework for tsunami hazards and impacts is not as well developed as it is for other hazards and disaster management policy areas in both the State of California and the United States. The lack of experience, risk awareness, and institutionalized planning and implementation practices for tsunami mitigation, preparedness, response, and recovery could amplify impacts and losses from this scenario, even beyond what has been estimated as for coastal government, maritime, business, and tourism sectors and the general public.

This scenario hypothesizes a disaster that can be adequately managed within existing national and State disaster policies. However, there will be gaps - areas where mitigation and preparedness activities were not heeded or fully achieved; areas where the warnings, evacuations, and response activities will not be well executed and coordinated; and areas where the recovery challenges may be significant and take years to resolve. There are also significant gaps in tsunami risk awareness that potentially undermine the effectiveness of the existing disaster policy framework and can negatively influence the response activities and recovery challenges posed by this scenario.

In practice, the U.S. disaster management policies and programs tend to work reasonably well in moderate and localized disasters. However, they are not well equipped to address large-scale or catastrophic events that stretch societal resources. Also, with few modern tsunami experiences in the United States and California, the vast majority of the U.S. disaster policy framework reflects learning from other peril-related events (that is, floods, hurricanes, earthquakes), which, in comparison with this scenario, were more moderate in terms of their spatial extent and likely impacts.

The SAFRR tsunami scenario would affect the entire Pacific coastline of the United States and require a significant multi-State mobilization of response-related resources. The tsunami would begin striking the California coast about 4 to 5 hours after the magnitude 9.1 earthquake occurs offshore of the Alaska Peninsula, and it would inundate California coastal areas unlike any tsunami in recent history. Although State and local agencies would have time to activate emergency operations centers and begin evacuating low-lying coastal areas, harbors and marinas, and reposition boats and ships safely offshore, this would still be a relatively short timeframe to fully evacuate and secure highly populated and congested areas, including public beaches and ports, harbors, and marina facilities. The scenario damage assessment assumes that all the port, business, and governmental entities made timely and correct decisions and actions on saving assets ahead of the scenario tsunami's arrival. Delayed or incorrect decisions/actions, especially with regard to heavily populated areas, marine oil facilities, and tankers and other large ships could significantly increase the potential for escalated losses or cascading impacts.

There is an overarching risk awareness challenge to reach the general public, as well as the special interest sectors, such as the maritime community, and to adequately train and prepare the multiple levels and types of governments needed to mitigate tsunami hazards and prepare to manage the impacts and consequences of this scenario and other potential tsunamis that threaten the State. After all, the SAFRR tsunami scenario is not the "worst case" for a vast part of California's coastline. A major near-field tsunami on the Cascadia Subduction Zone would have a far shorter warning time and could cause far greater devastation, especially in northern California.

The National Tsunami Hazard Mitigation Program (NTHMP), first formed by Congressional action in 1995 and strengthened by the Tsunami Warning and Education Act of 2006, is the major source of Federal support for the Nation's tsunami warning system, the TsunamiReady program that promotes community preparedness for tsunamis, and hazard assessment, mitigation and readiness activities in 28 U.S. coastal States, territories, and commonwealths. Federal funding for the NTHMP is scheduled to end in 2013. Unless the Tsunami Warning and Education Act of 2006 is reauthorized, the 
foundation of the Nation's and California's tsunami policy framework will be significantly diminished and the future of the TsunamiReady program and State leadership for local tsunami hazard assessment, mitigation and preparedness will be at significant risk.

\section{Priority Policy Issues: Mitigation and Preparedness}

Hazard mitigation is a disaster management function ideally preceding and lessening the impacts $\mathrm{o}$, disasters (pre-event mitigation) or helping to reduce repetitive future losses after disasters (post-event mitigation). FEMA defines hazard mitigation as "sustained action taken to reduce or eliminate longterm risk to people and their property from hazards" (FEMA, 2012a). Preparedness is a disaster management function that works to ensure efficient and effective emergency management and response activities during times of crisis. It is "achieved and maintained through a continuous cycle of planning, organizing, training, equipping, exercising, evaluating, and taking corrective action" (FEMA, 2012b). In a sense, mitigation and preparedness are two sides of the same coin. Mitigation works to prevent future losses, whereas preparedness helps to maintain a state of readiness to deal with the expected residual response demands.

Primary Federal legislation fostering tsunami-related mitigation and preparedness includes the National Tsunami Hazard Mitigation Program (NTHMP), the Stafford Act, the Disaster Mitigation Act of 2000 (DMA 2000), and the National Flood Insurance Program (NFIP). National mitigation laws and authorities generally authorize financial support to State and local governments and, in the case of flood insurance, to the private market supporting mitigation actions. In turn, these tend to be mirrored in State laws and programs, such as the California Tsunami Preparedness and Hazard Mitigation Program (TPHMP), and in some cases, local mitigation laws and policies. Additional State legislation and mandates fostering mitigation and preparedness include the safety element requirement of local General Plans, the California Coastal Act (1976), Oil Spill Prevention and Response Act (1990), and permitting requirements of the Bay Conservation and Development Commission (BCDC) for San Francisco Bay. Some key mitigation and preparedness policy issues are (1) lack of a coordinated and sufficiently robust policy framework for tsunami hazard assessment and mitigation planning and (2) disproportionate levels of mitigation and preparedness among California's coastal communities, ports, and harbors.

\section{Need for a Robust Policy Framework for Tsunami Hazard Assessment and Mitigation Planning}

California coastal communities and ports and harbors lack a coordinated and sufficiently robust policy framework for tsunami hazard assessment and mitigation planning. California has 20 counties, 100 incorporated and 52 unincorporated cities, 7 major port regions, and more than 100 additional smaller ports, harbors, and marinas that border the Pacific Ocean and San Francisco Bay and are therefore exposed to threats posed by the SAFRR tsunami scenario.

\section{Coastal Communities}

Table 2 summarizes the status of tsunami hazard mitigation and planning among Californian's 20 coastal counties and 101 incorporated cities based on a review of their (1) participation in TsunamiReady, (2) participation in NFIP, and (3) demonstrated comment to toward lessening the impact of tsunamis as indicated in Local Hazard Mitigation Plans (LHMP).

The review found that all the coastal counties and incorporated coastal cities participate in the NFIP, whereas, only 35 percent of counties and 16 percent of incorporated cities along California's coastline are designated "TsunamiReady." The number of TsunamiReady communities has been 
steadily increasing since the 2011 Japanese tsunami. Participation in these two programs provides a rough indication of how risk averse a community is to tsunamis and floods in general.

The LHMPs of coastal counties and incorporated cities were also reviewed to determine if the LHMPs considered tsunami hazards and also whether their Action Plans include mitigation actions specific to tsunami hazard. The results are summarized in three categories: N-the LHMP did not address tsunami hazard; P - the LHMP Action Plan passively addresses the tsunami hazard (broad, general actions that address a multitude of natural hazards including tsunami); and A- the LHMP Action Plan actively and specifically addresses tsunami hazard.

In general, the concern for tsunami hazard appears to increase from the southern to the northern part of the State, which is consistent with the known degree of hazard and experience from historical occurrences. Counties also appear to be more aggressive in addressing tsunami hazard than cities. Onequarter of the county and 44 percent of the incorporated city LHMPs that were reviewed were prepared before 2010 and prior to the Maule, Chile, and Tohoku, Japan, tsunamis. The profiling of tsunami hazard, connectivity with the local safety element and emergency operations plans, and inclusion of tsunami mitigation in action plans has also generally improved in the updated plans.

There is considerable variability in the tsunami hazard mitigation actions planned or undertaken by the majority of coastal counties and incorporated cities. Most are focused on improvements in emergency management with a common action calling for the designation of the community as TsunamiReady. Only a few communities identified significant structural mitigation, such as building a new bridge to facilitate evacuation or improving walk ramps from the beach to higher ground, as priority mitigation actions. This may be partly due to the higher cost of structural mitigations but is most likely due to a priority for life safety, considering the high exposure of existing development, as well as beach populations during summer months.

The review did not evaluate safety elements or local coastal plans (LCPs), which also contain such information. A cursory review of the safety elements for coastal communities found that they contain descriptions of tsunami hazard and history; however, other than general statements regarding the need for new development to avoid areas subject to natural hazards, they do not detail hazard mitigation specifically for tsunami, nor indicate the level of commitment to take action. For most communities, this is likely due to their lack of tsunami experience and also that most safety elements predate recent tsunamis that have caused significant damage in California and elsewhere in the world. Following the 2011 Tohoku Oki tsunami in Japan, the California Coastal Commission added a requirement for the assessment of tsunami hazards for proposed development located in the designated coastal zone and for recertification of LCPs. However, only a few communities have begun the recertification process and only a few plans were available for this review.

\section{Coastal Ports and Harbors}

As noted by Wilson and Miller (2013), dozens of California's harbors sustained damage totaling nearly \$100 million from the 2010 Chile and 2011 Japan tsunamis even though there wasn't significant inundation of any of California's coastal land from either of these events. Table 3 summarizes the results of a review of the status of tsunami hazard assessment and mitigation planning for the seven major harbor regions identified in the California Oil Spill Prevention and Response Act of 1990-(from south to north) San Diego Port and Harbor; Port of Los Angeles (considers both City of Los Angeles and Los Angeles County); Port of Long Beach; Port Hueneme; San Francisco Bay (includes Port of San Francisco, Port of Oakland, County of San Francisco and Alameda County); San Pablo Bay (includes Port of Richmond and Marin, Sonoma, Napa, Solano, and Contra Costa Counties and the Association of Bay Area Government's multijurisdictional multi-hazard plan); Suisun Bay (includes Solano and Contra 
Costa Counties); Humboldt Bay; and Crescent City Harbor (a small harbor with heightened concern for tsunami hazards and shown for comparison).

This review considered whether a port commissioned a special tsunami-hazard analysis or risk assessment that would indicate a heightened awareness and concern about tsunami hazard and risk to operations. To what extent the results of such studies triggered mitigation was not assessed. Outside studies, such as those conducted by a university were noted but did not typically evaluate risk to facilities. The review considered the following factors as proxies to assess the status of tsunami risk awareness, mitigation, and planning for ports and harbors (posed as questions in order of importance):

- Did the LHMP for the county or city where the port is located specifically include tsunami hazard mitigation? Do the mitigation goals/objectives specifically include tsunami hazard? Is there a harbor annex that considers tsunami hazard?

- Is the city or county where the port is located certified as TsunamiReady? Currently none of the major port and harbors are in California are certified as TsunamiReady but some of the cities or counties in which they are located are certified.

- Does the port's harbor safety plan explicitly recognize tsunami threat?

- Does the city or county emergency operations plan explicitly recognize tsunami threat to the port/harbor?

This analysis found that the tsunami hazard has been assessed for all principal ports/harbors except for Port Hueneme, for which the U.S. Navy may have commissioned an evaluation. Overall, perception of the hazard as moderate or serious appears to highest in the northern part of the State and less in the southern part of the State, which is consistent with the known degree of hazard. Exceptions are the Ports of Los Angeles and Long Beach, which have commissioned tsunami hazard and risk studies. Harbor safety plans rarely mention specific natural hazards, including tsunamis, or reference the LHMP and county/city emergency operation plans. Humboldt Bay is an exception. The Humboldt Bay Harbor Safety Plan has a tsunami annex that is also part of the county emergency operations plan. Only Crescent City's LHMP has a port/harbor annex. 
Table 2. Status of tsunami hazard assessment and mitigation planning in California coastal counties and incorporated cities.

[LHMP, Local Hazard Mitigation Plan. N, tsunami hazard not addressed in the LHMP Action Plan; P, tsunami hazard passively addressed in the LHMP Action Plan; A, tsunami hazard actively addressed in the LHMP Action Plan. \%, percent]

\begin{tabular}{|c|c|c|c|c|c|c|}
\hline \multirow[t]{2}{*}{ Coastal Jurisdiction } & \multirow{2}{*}{$\begin{array}{c}\text { Local Hazard Mitigation } \\
\text { Plan (LHMP) }\end{array}$} & \multicolumn{3}{|c|}{ Tsunami in LHMP Action Plan } & \multirow{2}{*}{$\begin{array}{l}\text { Designated } \\
\text { "TsunamiReady" }\end{array}$} & \multirow{2}{*}{$\begin{array}{c}\text { Participates in } \\
\text { NFIP }\end{array}$} \\
\hline & & $\mathbf{N}$ & $\mathbf{P}$ & A & & \\
\hline Counties & $100 \%$ & $25 \%$ & $30 \%$ & $45 \%$ & $35 \%$ & $100 \%$ \\
\hline Incorporated cities & $93 \%$ & $48 \%$ & $21 \%$ & $31 \%$ & $16 \%$ & $100 \%$ \\
\hline
\end{tabular}


Table 3. Status of tsunami hazard assessment and mitigation planning for California's major ports and harbors.

[Y, yes; N, no; n.a., not applicable; LHMP, Local Hazard Mitigation Plan]

\begin{tabular}{|c|c|c|c|c|c|c|c|c|c|}
\hline Port/Harbor & $\begin{array}{l}\text { San } \\
\text { Diego }\end{array}$ & $\begin{array}{l}\text { Los } \\
\text { Angeles }\end{array}$ & $\begin{array}{l}\text { Long } \\
\text { Beach }\end{array}$ & $\begin{array}{l}\text { Port } \\
\text { Heuneme }\end{array}$ & $\begin{array}{l}\text { San Francisco } \\
\text { Bay }\end{array}$ & $\begin{array}{l}\text { San Pablo } \\
\text { Bay }\end{array}$ & $\begin{array}{l}\text { Suisun } \\
\text { Bay }\end{array}$ & $\begin{array}{l}\text { Humboldt } \\
\text { Bay }\end{array}$ & $\begin{array}{l}\text { Crescent City } \\
\text { Harbor }\end{array}$ \\
\hline $\begin{array}{l}\text { 1. Tsunami risk or hazard } \\
\text { assessment? }\end{array}$ & $\mathrm{Y}^{1}$ & $\mathrm{Y}^{2}$ & $\mathrm{Y}^{2}$ & $\mathrm{~N}$ & $\mathrm{Y}^{3}$ & $\mathrm{Y}^{3}$ & $\mathrm{Y}^{3}$ & $\mathrm{Y}^{4}$ & $\mathrm{Y}$ \\
\hline 2a. LHMP-harbor annex? & $\mathrm{N}$ & $\mathrm{N}$ & $\mathrm{N}$ & $\mathrm{N}$ & $\mathrm{N}$ & $\mathrm{N}$ & $\mathrm{N}$ & $\mathrm{Y}$ & $\mathrm{Y}$ \\
\hline $\begin{array}{l}\text { 2b. LHMP-tsunami } \\
\text { goals/objectives? }\end{array}$ & $\mathrm{Y}$ & $\mathrm{Y}$ & $\mathrm{Y}$ & $\mathrm{N}$ & $\mathrm{Y}$ & $\mathrm{Y}^{5}$ & $\mathrm{~N}$ & $\mathrm{Y}$ & $\mathrm{Y}$ \\
\hline 2c. LHMP-Tsunami in action plan? & $\mathrm{N}$ & $\mathrm{Y}$ & $\mathrm{Y}$ & $\mathrm{N}$ & $\mathrm{Y}$ & $\mathrm{Y}^{5}$ & $\mathrm{~N}$ & $\mathrm{Y}$ & $\mathrm{Y}$ \\
\hline 3. Is city/county TsunamiReady ${ }^{\mathrm{TM}}$ ? & $\mathrm{Y}$ & $\mathrm{Y}$ & $\mathrm{N}$ & Y & $\mathrm{Y}$ & $\mathrm{N}$ & $\mathrm{N}$ & $\mathrm{N}$ & $\mathrm{Y}$ \\
\hline $\begin{array}{l}\text { 4. Harbor Safety Plan mentions } \\
\text { tsunami? }\end{array}$ & $\mathrm{N}$ & $\mathrm{N}^{6}$ & $\mathrm{~N}^{6}$ & $\mathrm{~N}$ & $\mathrm{~N}$ & $\mathrm{~N}$ & $\mathrm{~N}$ & $\mathrm{Y}^{7}$ & n.a. \\
\hline $\begin{array}{l}\text { 5. Emergency plan mentions } \\
\text { tsunami? }\end{array}$ & $\mathrm{Y}$ & $\mathrm{Y}$ & $\mathrm{Y}^{8}$ & $\mathrm{~N}$ & $\mathrm{Y}$ & $\mathrm{Y}$ & $\mathrm{Y}$ & $\mathrm{Y}$ & $\mathrm{Y}$ \\
\hline
\end{tabular}

${ }^{1}$ University of Southern California Tsunami Research Center completed new assessment in 2011.

${ }^{2}$ Tsunami hazard/risk assessment done (Uslu and others, 2010; Moffatt and Nichol, 2012).

${ }^{3}$ Special tsunami study done for San Francisco Bay (Borrero and others, 2006).

${ }^{4}$ Tsunami hazard assessment has been done for Humboldt Bay (Uslu and others, 2008).

${ }^{5}$ Marin, Sonoma, and Contra Costa County Local Hazard Mitigation Plans; Association of Bay Area Governments assessment.

${ }^{6}$ Los Angeles County Tsunami Response Plan includes port area.

${ }^{7}$ Humboldt Bay harbor safety plan has extensive annex for tsunami and cross-references to emergency plan.

${ }^{8}$ Harbor safety training includes earthquake safety but not tsunami. 
In general, the documents reviewed indicate that the majority of California's coastal communities and ports and harbors more often consider tsunami hazards to be an emergency management issue rather than a land use or development policy issue. There is also a lack of connectivity on tsunami policy issues between various plans in a given community. A more robust and integrated planning framework would help to reinforce knowledge of hazards and the potential impacts, mitigation actions that could be taken to reduce community vulnerability, and improved and more coordinated response efforts across all responsible government agencies during a disaster. The overall policy question raised is what tools, information, and potential legislative actions could help strengthen California's tsunami hazard assessment and mitigation planning policy framework?

\section{How Can Tsunami Hazard Assessment Models and Mapping Be Improved?}

CGS, in partnership with the University of Southern California's Tsunami Research Center, has developed a series of tsunami inundation maps for parts of the California coastline to assist emergency managers in developing community evacuation plans (State of California, 2009). The potential tsunami hazard inundation areas shown on these maps are based on the maximum area extent of potential inundation derived from an ensemble of maximum credible events that could occur on near and distant tsunami sources.

The National Research Council's 2011 assessment of the U.S. tsunami program called for more consistent and comprehensive risk mapping and vulnerability nationwide - a national tsunami risk assessment (National Research Council, 2011). Pilot projects funded by NTHMP and FEMA are underway in California to develop more probabilistic approaches to tsunami hazard assessment that account for the likelihood of occurrence and estimates of potential inundation area, flow depth, velocity, and other physical parameters which all could more appropriately support the land-use planning, zoning, and construction related mitigation planning and actions of coastal communities and maritime facilities. Modeling advances made as part of these pilot projects and the SAFRR tsunami scenario can help to better characterize the probabilities of tsunami hazard (for example, at 100-, 500-, 1,000-, and 2,500year return periods) along California's coast. However, the complexity of such modeling and uncertainties in the model results can present some challenges for public policymaking. To serve as a basis for public policy, advanced tsunami hazard assessment models need to be open and transparent and peer-reviewed or otherwise professionally recognized as "standard-of-practice." Guidelines may also be needed for their testing, evaluation, and use.

\section{How Can Tsunami Hazard Zones Be Defined and Implemented For Community Land-Use Planning, Zoning, and Construction Related Mitigation Planning and Actions?}

The California Seismic Hazard Mapping Act explicitly provides for the State Geologist to also map the potential effects of tsunami and seiche when information becomes available from other sources and is deemed appropriate for use by local government. Under the act, an official tsunami hazard zone would trigger tsunami design requirements for proposed construction and existing statutes would also require a site-specific investigation of associated geotechnical hazards and a plan to mitigate identified hazards before a building permit is issued.

An expert advisory committee could provide guidance on the development of the tsunami hazard mapping criteria and other products necessary to support its implementation. The zonation work may also benefit from close consultation with those entities responsible for developing the tsunami resilient codes that are currently under development. Guidelines may also be needed for local agencies responsible for integrating the hazard zones into local land use, zoning, subdivision and development permitting processes as well as LHMPs, LCPs, and the safety elements of local general plans. 
Legislative changes may also be needed to ensure better integration of the tsunami hazard zones in State and local planning and development requirements and consistency with any tsunami-resilient building design code provisions that are adopted. Areas subject to policy inconsistencies could include areas where the tsunami hazard zones extend inland beyond the coastal zones and regulatory authorities offered by the California Coastal Act. Communities may want to avoid confusion about tsunami hazard reduction efforts and strive for consistent standards within a jurisdiction's general plan throughout the areal extent of officially designated tsunami hazard zones.

\section{How Can Tsunami Hazard Zones Be Defined and Implemented For Ports and Harbors Related Mitigation Planning and Actions?}

CGS is currently developing hazard products tailored for the maritime community that are based on detailed hydrodynamic modeling of harbors to assist in identifying vulnerable port and harbor infrastructure and designating offshore safety zones for evacuation planning and response. More detailed tsunami hazard maps of harbors and channel areas are needed statewide to help identify highhazard areas (such as areas of high current velocity, turbulence, and eddies) and safer locations for facilities and passageways to reduce the risk of damage to harbor infrastructure and abandoned vessels. Consistent statewide guidelines for maritime tsunami response and recovery are needed and it would be useful to have their development guided by a statewide advisory committee comprised of key State agencies (for example, Cal OES, CGS, CCC, Department of Fish and Wildlife), military (including the U.S. Coast Guard), NOAA, local port harbor authorities, maritime organizations, and key stakeholders. The guidelines could include standards for a more appropriate depth contour for offshore evacuations; hazard thresholds for harbor facilities and vessels; best practices for ship (re)positioning in a tsunami; and recommended protocols for evacuations - when not to evacuate and when to issue an "all clear" following a harbor evacuation. Such information could be distributed to harbor authorities along with guidance or training on their use. Coastal charts and maps could also be revised to be consistent with the new information, and broad communication and dissemination efforts could work to reach various interest groups and stakeholders (for example, military/transport/cruise ships, commercial fishing boats, and recreational boaters, as well as port, wharf/dock, and marina managers).

\section{How Can Tsunami Resilient Building Design Provisions Be Adopted and Implemented?}

California's Building Code and the International Building Code (IBC) contain provisions for weather-related flood-resilient design, and all coastal communities participate in the National Flood Insurance Program that requires adherence to specified flood design standards. However, these design standards do not consider the unique characteristics of tsunami-induced flooding. Tsunami resilient design standards are currently under development by the American Society of Civil Engineers (ASCE) Subcommittee on Tsunami Loads and Effects and anticipated for release in 2016. Given this schedule, they would be incorporated into the 2018 edition of the IBC at the earliest. These standards will only address new construction that is initiated once the new building code is in place.

Opportunities may exist to adopt interim provisions once the ASCE standards are released in 2016 or to expedite adoption of the IBC provisions once available. Incentives to encourage local adoption and implementation may also be needed. For example, the Building Code Effectiveness Grading Schedule (BCEGS), which assesses and rates both local building code adoption and enforcement practices, could collaborate in monitoring local implementation and increase community ratings once tsunami resilient building provisions are adopted and enforced.

As coastal engineering codes and standards become more formalized, the State could consider requiring that engineers performing site-specific tsunami inundation and engineering analyses as part of 
coastal development projects to be a "diplomate" with Coastal Engineering certification from the ASCE Academy of Coastal, Ocean, Port, and Navigation Engineers (COPNE) (American Society of Civil Engineers, 2013). The State might also consider developing its own certification for civil engineers specializing in coastal engineering.

\section{The Tsunami Scenario Would Have Severe Impacts}

The tsunami scenario would severely impact communities and ports and harbors that have made sustained tsunami mitigation and preparedness efforts, as well as those that have not. This could result in varying levels of impacts, potentially including significant life losses and demands for response and recovery resources. Most of California's coastal neighborhoods, businesses and industries, and infrastructure have not been built to withstand tsunami forces. Under such conditions, life safety is of paramount importance, which puts mitigation and preparedness planning at the forefront of risk reduction strategies. But, as the planning analyses have shown, tsunami hazard awareness, mitigation and preparedness planning, and actions vary considerably across California's communities and ports and harbors.

Funding for predisaster mitigation, under the Stafford Act and Disaster Mitigation Act is infinitesimally small relative to the nationwide need and it has historically tended to reward good mitigation performance through additional funding (Topping and others, 2010). And, the TsunamiReady program, as a voluntary program, is more apt to attract better mitigation performers seeking this designation. And, thus in the SAFRR tsunami scenario or another major tsunami affecting the West Coast, there will likely be areas with significant damage and potential life loss, whereas other areas will emerge relatively unscathed.

There are both funding and engagement challenges in getting the most vulnerable and unprepared coastal communities and ports and harbors to voluntarily undertake mitigation and preparedness actions ahead of a tsunami disaster. More coastal communities need to be encouraged to participate in the TsunamiReady program. There also needs to be enhanced coordination and information sharing among coastal communities on tsunami mitigation and preparedness plans and actions, which might be a State-led program activity. This includes promoting better sharing of best practices and developing multi-jurisdictional evacuation and response plans.

The community planning analysis also found that coastal county and city participants in the TsunamiReady program did not meet the program guidelines equally effectively. A review of standards for program designation and development of a process for ongoing maintenance of the TsunamiReady designation may also be useful in ensuring that TsunamiReady designated communities are indeed ready for the impacts of a future tsunami.

Coastal communities and regional government associations might also need to be more strongly encouraged to work more collaboratively on tsunami hazard mitigation and preparedness planning. Neighboring communities could also be encouraged to integrate their local hazard mitigation plans into a multi-jurisdictional plan that would help qualify as an enhanced plan and be eligible for the associated disaster recovery assistance benefits under the Stafford Act and the Disaster Mitigation Act. The State Hazard Mitigation Plan could also be strengthened to provide more direction to coastal communities by addressing broad regional issues and helping to shape tsunami hazard mitigation strategies for local communities to follow. Alternative sources of funding for advance planning and mitigation are also needed, especially if Federal or State support for the NTHMP ends.

Additional emphasis needs to be placed on ensuring that the State's many ports, harbors, and maritime facilities also undertake mitigation and preparedness planning and actions. Currently, there is limited data available on marina damage and tsunami loss modeling for marinas is just in its infancy. As 
described in Wilson and Miller (2013), the State, through the NTHMP, has been working to enhance the information and resources available for the maritime community on tsunami preparedness and response planning and preparedness planning is underway at some of the State's largest ports. Harbor authorities could be further encouraged to prepare tsunami preparedness, response, and recovery plans for their facilities. State guidelines for maritime tsunami response and recovery, along with a robust dissemination and training program, also could be developed.

\section{Priority Policy Issues: Response}

For tsunamis, emergency response begins when a potential tsunami threat is identified and the threat analysis and notification protocols are initiated. These functions are Federally led by NOAA's national tsunami warning centers which issue Alert Bulletins designating a tsunami WATCH, ADVISORY or WARNING. There are standardized templates for the series of alert bulletins that also contain information regarding first wave arrival times and projected wave amplitudes for specified locations. The alert bulletins are disseminated using many redundant communication paths, including the NOAA Weather Wire Service, NOAA Weather Radio (NWR), Emergency Managers Weather Information Network (EMWIN), email/cell phone text messaging, Emergency Alert System (EAS), U.S. Coast Guard and U.S. Navy, and the Integrated Public Alert and Warning System (IPAWS).

The California State Warning Center (CSWC) is the designated Warning Point agency authorized to transmit the national tsunami alert bulletins statewide. The CSWC forwards information it receives to Cal OES and county emergency management offices. It does not, however, independently designate alert levels; only the national tsunami warning center can designate the alert level. All information from the West Coast and Alaska Tsunami Warning Center (WCATWC) is passed directly to the counties by redundant methods as well. The public and media get this information almost simultaneously through the variety of communications systems.

Once a credible tsunami threat is confirmed, Cal OES regional and State operation centers initiate a series of conference call briefings for California's coastal counties and State agencies. Under California's Standard Emergency Management System (SEMS), each county in California is an operational area (OA) and responsible for notifying and coordinating with their local jurisdictions (cities and special districts) and unincorporated areas through multiple, redundant means.

Local jurisdictions are responsible for ordering evacuations within their geographic limits; counties are the "local authority" for unincorporated county areas. Local jurisdictions and port authorities, where they exist, generally share civil authority over evacuations of low-lying coastal areas. Port authorities, harbor masters, and the U.S. Coast Guard are responsible for offshore evacuation and directing the movement of boats and ships out of harbors to deep waters. Depending on the alert level, and local vulnerability, past experience, and plans, initial decisions may range from waiting for further information, initiating a phased evacuation, or ordering a total evacuation. Most counties and local jurisdictions in California have developed local methods for disseminating emergency messages, including the Emergency Alert System (EAS), residential telephone emergency notification system (TENS; similar to Reverse 911), sirens, local radio communications, media announcements, and others. As noted by Brosnan and others (written commun., 2013), some of California's fishing communities have also developed emergency communication systems and protocols.

Some key response policy issues are (1) challenges with existing warning dissemination and evacuation information and protocols and localized disruptions of communications systems; (2) lack of experience and gaps in policy and guidelines for handling a major tsunami evacuation, sheltering, and extended security of evacuated areas; and (3) significant demands on different levels of government and the need for cooperation at each tier and within every organization involved in the response. 


\section{Onshore/Offshore Evacuations and Emergency Response Will Be Challenged by Existing Warning/Evacuation Protocols and Disruptions To Communications}

The coordination and effectiveness of both onshore and offshore evacuations and emergency response activities will be challenged by existing tsunami warning dissemination and evacuation information and protocols and localized disruptions to communications systems. In the SAFRR tsunami, a large earthquake occurs offshore of the Alaska Peninsula, at 10:50 Pacific Daylight Time (PDT) on Thursday, March 27, 2014. NOAA issues the first tsunami alert bulletin within 3 minutes of the earthquake's occurrence. The bulletin activates a WARNING for the coastal areas of British Columbia and Alaska and a WATCH for the coastal areas of Washington, Oregon, and California. Initial arrival times are estimated to range from 16:02 PDT at Crescent City, California (a little more than 5 hours) to 17:38 PDT at La Jolla, California (about 61/2 hours). The Emergency Alert System is also activated at this time and begins relaying the notifications to emergency management systems and personnel, television, and radio stations.

Local emergency managers are immediately faced with a dilemma — wait for the next alert bulletin which will confirm the tsunami and better estimate the arrival time or begin evacuations and response activities immediately to ensure that evacuations and infrastructure protection are completed in a timely and safe manner? The managers at the seven major ports and more than 100 smaller marinas and harbors also face similar evacuation decisions as soon as they hear the news. This will likely be the first tsunami experience for much of the maritime community, which also may not have emergency plans or may have limited experience with offshore evacuations. Few California residents, especially in the San Francisco Bay area and Southern California, have much experience with tsunamis or mass evacuations.

In the SAFRR tsunami scenario, the first official notification that puts California into the WARNING stage and offers the first information about estimated wave heights and duration comes at 12:05 PDT. It forecasts the tsunami reaching Crescent City at 15:58 PDT (less than 4 hours), San Francisco at 16:55 PDT (less than 5 hours), San Pedro at 17:27 PDT, and La Jolla at 17:38 PDT (less than $5 \frac{1}{2}$ hours). The maximum tsunami heights are forecast to reach 10.1 feet $(+/-3.0$ feet) in Crescent City, 5.0 feet (+/- 1.5 feet) in San Francisco, 3.7 feet (+/- 1.1 feet) in San Pedro, and 8.4 feet $(+/-2.5$ feet) in La Jolla. The durations are forecast to range from 18 to 48 hours.

Reliable and redundant communications systems will be crucial to evacuation decision makers and emergency responders, as well as the evacuees (both onshore and offshore). Responders will need to communicate with each other to manage both onshore and offshore evacuations and response activities, and individuals and vessel operators will need to receive updates of the tsunami warnings/alerts and notifications of when it is safe to return.

The public's primary sources of information during a disaster are the media and landline phones and cellular networks. The phone and cellular communication networks may be overwhelmed during the initial evacuation period and more remote and significantly impacted coastal areas, particularly in Northern California, are likely to experience system disruptions once the tsunami begins. What will happen when elements of the communication network are broken or diminished in capacity? What will be the "workarounds" necessary for the coordination to take place? What if the disruptions continue for long periods of time, such as weeks or months? 
What Alert Dissemination Protocols and Communication System Improvements are Needed to Ensure Safe and Timely Evacuations?

In this scenario and for other near-source tsunamis, waiting for WARNING alert leaves very little time to complete safe and timely evacuations. Since the 2011 Japan tsunami, the national tsunami warning centers have been improving and standardizing how warnings are disseminated to State and local agencies in order to address some of the warning confusion, problems with Web access, and other issues reported at the time. The SAFRR tsunami scenario provides a useful source of information to test revised protocols and see what improvements could be made to alert dissemination protocols.

In recent tsunamis, alert notifications have also triggered inappropriate reactions by parts of the public, especially those who are unfamiliar with the tsunami hazard and what the alert levels mean. Additional explanations of how to respond to NOAA-issued Tsunami Alerts (WATCH, WARNING, and ADVISORY) could also be part of emergency management education and coordination with the media.

Once the tsunami has subsided, local response agencies are responsible for issuing "all clear" messages and allowing reentry into evacuated areas. Similarly, port authorities, harbor masters, and the U.S. Coast Guard will be determining when to allow vessel operators to return to shore. These decisions are often made with little to no scientific information. The tsunami warning centers could be encouraged to develop guidelines and protocols for providing hazard updates/information to help local response agencies decide when to issue the "all clear."

On an annual basis, Cal OES collaborates with the NOAA Weather Forecast Office in Eureka and the Redwood Coast Tsunami Work Group to conduct a multicounty test of the EAS. Considerable planning goes into this "live-code" warning communications test, and such tests need to be continued and expanded to other parts of the California coast. Development and full implementation of the FEMA-Federal Communications Commission wireless-carrier partnership for the Commercial Mobile Alert System (CMAS), Next Gen 911, Reverse 911 and regional broadband public safety networks in California needs to be continued. These systems need to develop the capability to focus messages to specific regions to prevent unnecessary disruption in unaffected areas.

Experience in Japan demonstrated the potential effectiveness of broadcasting evacuation warnings through cellular networks to the general public using mobile phone applications. Implementation in the United States and California would require formal agreements between government agencies that issue warnings and cellular network providers, and the development of mobile phone applications for the general public to use to receive tsunami evacuation warnings.

\section{Lack of Experience in Dealing With the Complexity of a Major Tsunami Evacuation, Sheltering, and Extended Security of Evacuated Areas}

There is a lack of experience among California's State and local emergency responders, port and government managers as well as gaps in policy and guidelines for dealing with the complexity of a major tsunami evacuation, sheltering, and extended security of evacuated areas. Local jurisdictions are responsible for developing tsunami evacuation and response plans but, as the community planning analysis showed, there are varying levels of tsunami hazard awareness and preparedness included in local plans and policy. The short fuse nature of this evacuation scenario is going to present some crucial challenges for evacuation management, especially for public venues, critical facilities, schools, hospitals, and dependent-care facilities near the coast and beaches.

Many local emergency managers are likely to rely on the maximum tsunami hazard zones published on California's tsunami inundation maps, because the likely extent of the tsunami will not be 
known until it arrives. What also will not be known until later is that the inundation area for the SAFRR scenario tsunami directly impacts far fewer residents $(91,956)$ and business employees $(81,277)$ than those located in the State's tsunami inundation maps (267,347 residents and 168,565 employees). Being too quick or overly conservative in determining which areas to evacuate can be costly for coastal businesses, public safety, and public confidence, but being too late or limiting the evacuation area can be catastrophic.

There are also some "hot spots" where the concentrations of residents and employees at risk of inundation are quite high. These include Huntington Beach, Newport Beach, Los Angeles, and Long Beach in southern California; Oakland, Alameda, Emeryville, and Belvedere in the San Francisco Bay area; and Crescent City in northern California. Also, as noted by Wood and others (2013), some of these areas are further challenged by access limitations, with few roads, bridges, or pedestrian pathways off island or out of low-lying areas.

The ports planning analysis showed that there are also varying levels of tsunami hazard awareness and preparedness at California's major ports; smaller ports and harbors may have done little planning because none is currently required. Port authorities, harbormasters, the U.S. Coast Guard and others involved in evacuation decision making must consider safety and protection of populations and assets on the water as well as on land. On land, employees working at port terminals and other facilities must be notified and evacuated. In the water, decisions must be made about vessels currently in the port and harbor areas as well as those attempting to enter.

Vessel-related decisions will likely involve differing recommendations based on vessel size and weather and ocean/tide conditions — which vessels to evacuate offshore and how much time is available and needed by each vessel to do so? Small craft marinas are especially vulnerable to the high currents associated with tsunamis, and offshore evacuations of recreational vessels are rarely feasible and not encouraged by State emergency managers. Also, unlike onshore evacuees, offshore evacuation decision makers and the vessel operators must carefully consider prolonged safety issues - having enough food, water, and fuel for extended periods (an estimated 2 to 4 days for this tsunami scenario) and whether their vessels can get to more distant harbors if their home port is destroyed. Many operators may not get the message in time, or have time to get a crew aboard to allow the vessel to safely depart before the tsunami's arrival. As described in Brosnan and others (written commun., 2013), decisions will also need to be made about whether it is appropriate to leave personnel onboard vessels during the tsunami event or evacuate them back to shore.

After coastal areas and ports have been evacuated, local responders will also have to manage security and re-entry. Traffic checkpoints will need to be established the edge of the evacuation zones to direct and restrict traffic from coming back into dangerous areas. Additional traffic control points may also need to be established at strategic locations further inland to reduce traffic flow toward the coast. Emergency equipment will need to be staged outside the inundation area. Maritime security will similarly need to be provided and likely to involve waterway patrols. Loose or unauthorized large vessels moving in a closed port could cause significant damage. Some people will inevitably be unable to make it out in time before local responders begin to leave the danger zones before the tsunami's arrival. Air rescues are likely to be carried out by the U.S. Coast Guard and other qualified agencies and personnel. Given the widespread and complex of impacts along the coast and ports, there will be significant staffing requirements to secure the vast evacuation perimeter up and down the State. This will all require multiagency coordination. Often, cooperating agencies develop a Multiagency Coordination System (MACS) to better define how they will work together and to work together more efficiently; however, multiagency coordination can take place without established protocols. 
Any people who do not evacuate will need to be instructed to seek opportunities for "vertical" evacuation and resist the urge to evacuate during the tsunami inundation. Typically, the first tsunami wave is not the highest, and tidal variations could increase the risk of the later waves. Local responders will also be instructed to remain outside the danger zones until an "all clear" for responders is issued, but they too will be pressured to help before the tsunami recedes.

The extended duration of this tsunami scenario will mean that many evacuees will need overnight shelter and, for the most heavily impacted communities, evacuations may turn into protracted displacements. It is estimated that 8,489 people will require shelter for the SAFRR tsunami scenario. However, relying on the State's tsunami inundation maps, emergency managers would be collectively responding to provide shelter for a much larger number of displaced people than may be necessary. In addition to shelters, reception, refuge, feeding and staging areas will be needed. As Wood and others (2013) reveal, there will also be special needs issues with impacted populations including tourists, nonEnglish speakers, very old or very young people, and people from group quarters and dependent care facilities, including schools, colleges and jails.

In this scenario, the WARNING is cancelled at 12 to 14 hours after the earthquake's occurrence; however, in and along waterfront areas, strong tsunami currents will likely continue. Once they are given the "all clear," local responders begin "windshield surveys" and initial safety assessments to determine search and rescue and other response needs and plan for an orderly reentry. Areas that were not inundated will likely be given the "all clear" quickly, whereas a phased or facilitated reentry may be needed where damage or continuing hazards exist.

According to Porter and others (2013), there will be at least two days in which operations at major ports will be halted in the SAFRR scenario. The first day will consist of safely shutting down and securing operations, deploying tug boats, removing vessels where possible, and generally preparing for the tsunami arrival and evacuation of personnel. The second day would be focused on inspections of facilities prior to restoring operations. All loading and unloading equipment will be disengaged to prevent damage from tsunami waves and currents, as well as any sudden power losses.

As Plumlee and others (2013) and Brosnan and others (written commun., 2013) describe, debris fields, fires, fuel leaks, hazardous material spills, and damaged and unsafe structures all may exist in flooded coastal and port areas. Sunk or beached vessels may affect port and harbor navigation. Debris clearance, contamination clean up, and utility restoration could take days to weeks to complete, especially if the damages are significant. Helping displaced residents and vessel operators to return will also require coordination. There may be public health issues to consider as contaminated water could impact soils and structures inundated by flooding. For some areas, sheltering of displaced populations may also continue for some time.

\section{What Additional Plans, Policies, and Guidelines Are Needed to Deal With the Complexity of Both Onshore and Offshore Tsunami Evacuation, Sheltering, and the Extended Security of Evacuated Areas?}

For most coastal communities, the SAFRR scenario inundations will not extend as far inland as the maximum inundation line shown on the State's tsunami inundation maps. The State TPHMP is currently developing tsunami evacuation "playbooks" that will provide more detailed models of potential inundation areas for a number of different tsunami scenarios. Playbook maps will show expected areas of flooding for tsunamis of various wave heights, such as one, two, three and four meters above the Mean High Water (high tide) line. Other scenarios in the playbooks will provide modeled inundation lines for a magnitude 9.2 eastern Aleutians tsunami; worst-case tsunami scenarios for specific local sources, such as submarine faults and landslides, that might arrive on shore within 10 minutes; and a magnitude 9+ Cascadia scenario that will arrive on shore within about 10 minutes along 
the northern California coast and within 2 hours along the rest of the California coast. According to Wilson and Miller (2013), a formula that incorporates forecasted tsunami amplitudes (wave heights), tidal conditions, storm activity, and site-specific tsunami run-up potential into a "maximum predicted tsunami run-up height" is being developed to determine which evacuation scenario is most appropriate and conservative to use. These products are expected to be available by the end of 2013. They are intended to assist coastal emergency managers in preparing local evacuation response plans that are more tsunami source specific.

Only a few of California's ports, harbors, and marinas, have conducted detailed studies of potential tsunami in-harbor hazards and risks to facilities. To help address the information gap, the State TPHMP is also developing a set a products for maritime communities: (1) detailed maps identifying inharbor tsunami hazards, such as potential harbor areas with strong currents and eddies, peak amplitude surges, large tidal fluctuations; (2) offshore safety zones where ships can evacuate to and safely gather during a tsunami; and (3) planning guidelines for evacuations, response and recovery. The maritime mapping and guidelines are expected to be completed by 2015.

The SAFRR tsunami scenario will ultimately serve as a useful tool for emergency management training and exercises and for testing and improving existing policies and plans. It provides important justification of the need for both the community playbooks and maritime planning products and the need for robust dissemination and training efforts associated with their release. More coordination in tsunami preparedness and response planning could be encouraged among adjacent coastal communities. Communities could also be encouraged to share evacuation plans and maps and collaborate on key public education and training messages. The State TPHMP and regional associations of governments along the coast could play a critical in helping promote and facilitate multi-community collaboration.

The scenario also raises some additional policy issues that might be considered in existing or future national and State tsunami program efforts. How to provide more time-based guidance on evacuations in a variety of potential inundation areas and harbor areas? How to manage multimodal evacuations (for example, on foot, by boat, by private car or truck, and using public transportation), as well as the suitability of vertical evacuations? Many of the California's coastal areas, particularly ports, islands and peninsulas, such as in Newport Beach, have limited egress options. Adding pedestrian bridges or vertical evacuation sites could provide significant life safety benefits. Another issue is how to effectively maintain security during a protracted evacuation of both communities and port areas?

Given the broad geographic nature of the SAFRR tsunami scenario, it will be important to provide clear and consistent information to the media and public throughout the response period and to also tailor messaging as needed to different communities, regions, and response issues. The SAFRR scenario provides a good opportunity to test State, local, and Federal communications plans and coordinate with the media on appropriate public-safety messaging during various stages of the tsunami response - notification, evacuation areas and routes, sheltering, reentry and other real-time updates on developments as they occur.

\section{Response Effectiveness Will Depend on Cooperation and Coordination at All Levels of Government}

The widespread nature of this large-scale West Coast tsunami scenario would place significant demands on different levels of government. Response effectiveness will depend on cooperation and coordination of operations at each tier and within every organization in the system. For the tsunami scenario, local, State, and Federal level emergency and disaster proclamations are likely to be made quickly. The U.S. response framework will be initiated as defined at the Federal level by the National Incident Management System (NIMS) and National Response Framework (NRF) and carried forward 
by State, county, and local agencies. FEMA will likely activate its National Operations Coordination Center and its Regional Operations Centers. State emergency management agencies, including Cal OES, will activate their State operations centers as well as any regional operations commands. Local emergency managers will activate their emergency operations centers and depending on the need may request mutual aid or State assistance using established processes.

The U.S. framework is predicated on the principles of (FEMA, 2013):

- Engaged partnership" both vertically and horizontally among various agencies, both public and private.

- "Tiered response" to recognize local primacy for response and to overlap and establish lines of authority and communication along the vertical continuum from the local up to the Federal level.

- "Scalable, flexible, and adaptable response" so that roles and relationships are clearly outlined and remain the same in any scale of disaster, even though the amount of resources may vary according to the needs of the event.

- "Unity of effort/unity of command" to avoid duplication in effort, confusion, and overlapping/overstepping actions.

- "Readiness to act," train, and prepare so that the emergency responders understand the system at their own level and are prepared to coordinate through the chain of coordination envisioned in the "Engaged Partnership."

A fundamental assumption embedded in the response framework is that, in fact, the system structure can be effectively scaled up to a disaster of any size, and coordination, information flow, and communication are the fundamental building blocks of this multi-governmental and multiorganizational style of response. Although well proven in more limited emergency events, there have been few tests of the system in dealing with a widespread event, like the SAFRR tsunami scenario. The system will only be as strong as its weakest link. FEMA and Cal OES and other West Coast State emergency management agencies, as well as the multitude of local and maritime emergency responders, have limited experience with tsunamis, and most tsunami in the recent past have come from distant sources allowing some lead time for evacuations and preparations. FEMA and California counties are working on an Earthquake and Tsunami Response Plan for the West Coast, focusing on the consequences of a Cascadia Subduction Zone earthquake and tsunami (see Redwood Coast Tsunami Work Group Facebook page, accessed August 23, 2013 at https://www.facebook.com/RCTWG?filter=3).

A second key element is the high level of responsibility delegated to the local agencies to manage the disaster, in effect the "bottom up" approach that the system is built on. This means that response effectiveness depends first and foremost on the capacity and capability of the local actors on the scene. Will local governments and port and harbor facilities have functional capacity to effectively activate and operate the local emergency response, communication, and coordination protocols? Will there be sufficient numbers of knowledgeable personnel to handle emergency operations functions through the tsunami's duration? How will State and Federal actors determine when and how to respond in a situation where there is wide unevenness in the capacity and capabilities of various local actors? When and how will county and State agencies initiate their assessments of unmet needs and identify outside resources through mutual aid, State resources and requests for Federal assistance? How will resources (equipment, supplies, personnel - all potentially scarce or not matched to need geographically) be allocated among multiple and competing needs? Will State and Federal response structures be stretched by the breadth and duration of the event that their effectiveness is compromised? 
How will the need to reach far outside the impacted areas to mobilize and obtain needed resources affect the timing and delivery of support?

Experience has shown that in some disasters, the responders defined in an emergency response plan are not always the ones who take on key roles and responsibilities. In these instances, ad hoc organizational structures were created by local leadership because for any number of reasons that proves to be the most effective way to proceed. How will the United States' and California's premise of unity of command be affected when people less trained are substituted into the response roles and systems? How will ad hoc structures be tethered to the command structure and tiered response system? What are effective ways of utilizing ad hoc community or private structures to take advantage of the capacities they provide?

\section{Priority Policy Issues: Recovery}

Once the tsunami subsides, and threats to life-safety and property are stabilized, the recovery process along California's coast will begin. Because this scenario will likely trigger a Presidential disaster declaration, Federal assistance for individuals and families, government agencies, tribal organizations, and private nonprofit organizations will be available under the Stafford Act. The National Disaster Recovery Framework (FEMA, 2011) would also begin to guide Federal agency coordination and assistance, and Cal OES's Recovery Branch would deploy, along with FEMA and other Federal personnel, to affected coastal areas. Early recovery activities would include damage assessment, restoration of utilities and community services, and addressing short-term housing and business needs. Long-term repairs, rebuilding and other recovery activities would then likely continue for many months and even years, especially in the most heavily impacted coastal areas.

This section presents two key policy issues: (1) post-disaster recovery challenges for the hardest hit coastal communities, ports and harbors, and parts of the State's fishing and agriculture sectors and (2) challenges of rebuilding more resiliently for a historically infrequent hazard, like tsunami.

\section{Unprecedented Recovery Challenges for Hardest Hit Coastal Communities, Ports and Harbors, and Fishing and Agriculture Sectors}

The tsunami scenario would generate unprecedented recovery challenges for the hardest hit coastal communities, ports and harbors, and parts of the State's fishing and agriculture sectors. The tsunami scenario would affect approximately 1,840 Census blocks statewide and produce an estimated $\$ 1.8$ billion in building and content damage (roughly 2.2 percent of building value and 18 percent of content value in these census blocks). Areas where tsunami building damage would be concentrated could require long-term access limitations, which, unless well secured, could lead to looting and extensive blight. There would also be significant needs for both short-term and long-term housing and business facilities. Any long-term population and business relocations could negatively affect community recovery. In addition to buildings, coastal roads, bridges, and railroads will also sustain damage. Building and infrastructure damage clusters would likely exist in pockets along the entire California coast and around San Francisco Bay.

According to Porter and others (2013), damage is expected to be modest in most of California's major ports, especially if large vessels were successfully evacuated. Two of Southern California's major ports - the Ports of Los Angeles and Long Beach - are expected to sustain direct damages amounting to $\$ 113$ million, mainly to imported vehicles, containers, and some waterfront facilities. Land-based commerce for most major ports would likely return to service within one or two days following the tsunami scenario with a few facility exceptions where tsunami-related flooding damages buildings and 
other maritime facilities. Maritime transportation could take longer to restore due to debris and sedimentation issues in the navigation channels or a lengthy cleanup caused by an oil spill into port waters. Rose and others (2013) estimate that direct economic impacts to southern California and the rest of California caused by a 2-day shutdown at major ports as well as facility downtime and cargo losses, could amount to $\$ 1.2$ billion.

Other harbors and marinas across the State would likely sustain damage estimated at about $\$ 600$ million. According to Porter and others (2013), more than 5,600 smaller watercraft would sink (about 1 in 7), 7,900 smaller watercraft would be damaged but repairable (about 1 in 5), 140 docks would be destroyed ( 1 in 6), and 5,350 docks would be damaged but repairable (about half). Small craft that are damaged and become free floating will be a debris issue during and after the tsunami. Some of these may sink in the center of the navigation channels and may pose a navigation issue for other vessels until they are removed.

For those ports, harbors, and marinas that have significant sediment deposition and damage, the permitting process for sediment removal, as well as the complexities of the removal and reconstruction processes, could prolong their recovery for a year or more. Major issues include whether the debris contains contaminants and whether the sediment can be disposed in the ocean or has to be transported to landfills. An underwater inspection may be required before port channels can be reopened. There could be potentially lengthy Federal and State agency approvals, followed by logistical and coordination issues.

As Brosnan and others (written commun., 2013) describe, the fishing industry statewide is also vulnerable to damage to boats and infrastructure (for example, docks, processing plants) from tsunami waves, currents, and debris and other factors. Damage to harbors and onshore fishing facilities and protracted boat repairs could also result in losses and extended impacts to the fishing industry.

According to Ratliff and Wein (2013), approximately 9,600 acres of agricultural land lies in the scenario inundation zone; this is a very small part of the approximately 25 million acres of agricultural land in the State. Non-crop uses such as pastureland make up the majority of inundated agriculture, at 57 percent of the total. Alfalfa farming occupies 42 percent of inundated agricultural land, and trucktransported crops and field crops represent 0.5 percent and 0.4 percent, respectively, of inundated agricultural land. Humboldt County has the highest percentage of inundated agricultural land; San Luis Obispo, Mendocino, and Sonoma Counties also have relatively high percentages. Salinization, debris deposition, soil scour, and contamination all present long-term issues that would need to be carefully and quickly dealt with in order to minimize downtime for affected farms. Most of the exposed agricultural acres lie in the poorer northern counties of the State, and recovery costs could be extensive, slowing recovery and further impacting farming businesses and employees in these counties.

\section{What Recovery Financing Resources and Gaps Are Likely for the Tsunami Scenario?}

In California, more than 10,000 people would likely register for FEMA Individual Assistance which would provide funds for emergency housing, housing repairs, and contents replacement. There would likely be significant recovery financing challenges for all impacted residential properties and tenants that do not have National Flood Insurance Program (NFIP) or other insurance coverage. Higher valued residential properties (for example, condominiums, apartment complexes, properties owned by real estate investment trusts) tend to have excess-NFIP insurance coverage. Ensuring that people living in the mapped tsunami inundation zones also have flood insurance could help close the residential recovery funding gaps.

Similarly, impacted small commercial and industrial business owners and property owners, including fisherman, private marina owners, and fishing and harbor facility owners, without NFIP or 
other insurance coverage would also face recovery financing challenges and could be encouraged to carry NFIP or other commercial flood insurance. Small Business Administration (SBA) post-disaster loans would be a critical recovery resource for impacted small businesses and apartment owners, but these sectors would be challenged to accept additional debt burdens. Private insurance is more likely to be carried by medium and large commercial and industrial businesses and would provide resources for structural and contents related losses related to flooding (that is, excess NFIP). Many businesses in the hardest hit areas would be challenged to sustain themselves over a prolonged recovery period of time with limited resources (both funds and supplies) and displaced markets. As described by Wein and others (2013), long-term business and economic interruptions are not expected to be significant, but these losses would largely be unfunded.

FEMA Public Assistance (PA) is designed to cover emergency response costs and repair costs for public facilities and infrastructure, including publicly owned port, marina, and harbor facilities. Thousands of claims would be likely in California alone from qualifying State and local governments, nonprofits, and utility providers. However, given that the tsunami scenario would affect the entire West Coast of the United States, it is important to consider that the PA program would simultaneously be addressing losses in Alaska and other West Coast States, which could delay the distribution of these funds by a year or two into the recovery.

Also, the Public Assistance program is essentially a reimbursement-based program, and State and local government agencies and other qualifying entities would need to front-end the costs until reimbursements are made. They also would need to provide the required 25 percent match of the Stafford Act programs. Although reimbursement is the preferred method for funding Public Assistance costs, regulations give FEMA the authority to provide advances for immediate needs. Similarly, FEMA has the regulatory ability to waive the local share and provide 100 percent funding for a limited period of time, usually for a designated emergency period.

The tsunami scenario could also result in a fiscal crisis for local governments and special districts struggling to meet the response and recovery needs of such a scenario, while simultaneously facing significant sales and property tax revenue reductions due. This would be especially true in coastal communities that depend heavily on tourism, agricultural, and maritime activities or face significant housing losses or declining home values in the aftermath of the tsunami scenario. The impacts could have cascading effects, as localities and special districts turn to county and State levels for financial assistance. Local governments and utility providers do typically carry some levels of private insurance, although the coverage may not be sufficient.

Private insurance would also provide some resources to the medium and large ports that carry it. However, recovery financing would likely be an issue for those that are uninsured as well as smaller ports, harbors, marinas, and other maritime and fishing businesses that are unlikely to be insured. Agricultural business recovery would also face long-term term financial challenges in restoring losses caused by floodwaters, addressing soil pollution and hazard materials issues, and any longer-term delays in crop restoration and maturity. Post-disaster agricultural assistance programs would be critical to this sector's recovery, but these often come in the form of loans requiring repayment and having rather stringent rules.

There would likely be significant pressure placed on Congress to pass supplemental disaster funding legislation to collectively address the multi-State and Federal recovery needs posed by both the Alaska Peninsula earthquake and tsunami. Supplemental disaster funding approved by Congress after recent disasters, such as Hurricanes Sandy and Katrina, funded a multitude of needs, including housing repair programs, additional funding for community facilities and infrastructure restoration, private property buyouts in hazardous areas, and economic restoration and development projects. However, 
given current Federal fiscal challenges, such political action may be difficult in future disasters, and California could also be competing with Oregon, Washington, and Alaska for allocations. States would need to cooperate in advocating for and allocating any resulting funds.

\section{What Additional Plans, Policies, and Guidelines Assist the Recovery of California's Coastal Communities and Ports and Harbors Following a Major Tsunami?}

California's State and local emergency management agencies and other agencies normally involved in environmental review, land use, development, and construction have limited experience dealing with a large-scale, statewide recovery and rebuilding effort like the one posed by the SAFRR tsunami scenario. The National Disaster Recovery Framework (NDRF) provides guidance on how Federal agencies will coordinate to support key recovery support functions of: community planning and capacity building, economics, health and social services, housing, infrastructure systems, and natural and cultural resources (FEMA, 2011). It also calls for the appointment of Federal and State disaster recovery coordinators as well as local disaster recovery managers (LDRM) with post-disaster responsibilities to (1) lead in the creation of recovery organizations and initiatives and to coordinate their activities and (2) to work with State and Federal recovery partners in damage and impact assessments, prioritizing recovery issues and needs, identifying recovery funding sources, measuring recovery progress, and ensuring effective and consistent communication with stakeholders and the public (FEMA, 2011).

A statewide or regional coordinating, or advising, body may be needed to help craft policy and coordinate financing and long-term recovery technical assistance to impacted coastal communities, businesses, and individuals. The State currently has some legal mechanisms in place (for example, State redevelopment legislation, geologic hazard abatement districts, and the Disaster Recovery and Reconstruction Act) that could aid in these kinds of efforts. Regional associations of governments could also provide leadership to coastal counties, cities, special districts, and unincorporated areas to collaborate and coordinate in advance recovery planning, especially on issues of resource sharing and regional concern. Such planning might use the SAFRR scenario or consider the likely impacts, particularly on regionally shared transportation, water, power and other essential facilities and lifelines, for larger and/or more localized tsunamis that are expected to impact the region. In turn, coastal cities, counties, and special districts (including school, water, and port and harbor districts) could be encouraged to prepare operational recovery plans utilizing findings from the tsunami scenarios. State and local governments may need to take special efforts to involve the maritime and coastal agricultural communities in understanding their potential losses and planning for post-tsunami recovery.

Plans, policies and guidelines that are used in normal times to guide land use, development, and construction will inevitably need modifications to deal with the time-compressed, decision environment of post-disaster recovery (Olshansky and others, 2012). As reported by Plumlee and others (2013), port dredging and disposal and debris removal, both onshore and offshore, are crucial post-disaster problems with potentially complex regulatory and permitting processes. Streamlining these post-disaster processes while also ensuring environmental protection could substantially benefit local community recovery. Policies and programs may also need to be developed to address the removal of contaminated top soil, desalinization of soils, and the detoxification of concrete and other affected building materials. Although regulatory exemptions exist for disaster repair projects under the National Environmental Policy Act and the California Environmental Quality Act, other Federal or State laws or executive orders may not contain such exemptions and require approval by one or more regulatory agencies. In some instances, emergency permits are available with expedited processing procedures, or regulatory agencies may allow the repair work to proceed while the permit(s) are being processed. Post-disaster 
recovery planning and procedures - addressing issues like preparation of a dredging plan, collecting sediment samples, laboratory analysis, and dredging and disposal—could be included in any future State guidance for maritime tsunami response and recovery.

\section{Challenges in Rebuilding More Resiliently For a Historically Infrequent Hazard, Like Tsunami}

Recent tsunamis in Chile and Japan have repeatedly shown that most structures receiving two or more meters of tsunami-induced flooding will likely be destroyed or need to be demolished. In this scenario, there will be pockets of catastrophic damage in communities all along the California coast.

Under NFIP, properties that are more than 50 percent damaged are supposed to have flood risk mitigation as part of rebuilding. Policies would need to be developed by State and local agencies to address standards for rebuilding areas of heavy damage as well as moderately damaged buildings and enforce the NFIP requirements for 50 percent or greater damaged structures. This may be politically challenging if tsunami resilient design standards have not yet been adopted as part of the CBC.

Local governments (for example, city and county) may be pressured to make less than 50 percent damage determinations so that people can rebuild to pre-disaster conditions. There may also be pressure to modify State and Federal policies and make exceptions for the tsunami disaster because tsunami has historically been a relatively infrequent hazard. The State TPHMP's plans to develop probabilistic tsunami hazard maps would provide an important resource to assist State and local agencies in managing post-disaster land-use planning, zoning, and rebuilding actions. Furthermore, creation of an official tsunami hazard zone under California's Seismic Hazard Mapping Act would also trigger tsunami design requirements for local post-disaster land use planning, zoning and rebuilding, including requirements for more site-specific investigation of associated geotechnical hazards and a plan to mitigate identified hazards before a building permit is issued. Local coastal counties and cities, as well as key reviewing and permitting agencies, such as the CCC, might need additional planning and technical assistance and guidelines to assist in implementing such an integrated mitigation policy framework post-disaster.

There could also be opportunities to advance multi-hazard mitigation planning post-disaster and address issues of future tsunami risk, sea level rise and future coastal flooding and erosion, and earthquake-induced liquefaction. Multi-hazard mitigation options could include relocation and redevelopment of buyout areas, structural elevations, or retrofitting of slab-on-grade foundations. Mitigation incentives could be provided through a variety of planning and recovery financing mechanisms. For example, California Assembly Bill 2140, passed in 2006, provides an option for the State to increase its part of the local match for FEMA Public Assistance grants that it provides to disaster-impacted counties and cities, if they have a FEMA-approved LHMP that has also been adopted (by reference or incorporation) into the safety element of their general plan. This requirement could be strengthened post-disaster and also linked with Local Coastal Plan requirements. The SAFRR tsunami scenario provides an opportunity for State agencies, including Cal OES, CGS, the CCC, and BCDC to explore where mitigation policies and programs for dealing with different hazards might be combined and strengthened.

\section{Priority Policy Issues: Risk Awareness}

An important function of risk awareness is to enhance the capacity of a person, household, or governmental unit to make informed resource allocation choices (Topping and others, 2010). As each becomes more aware of the tsunami risk that California faces, the greater the likelihood that they may decide to invest in resiliency actions. 
This section presents three key policy issues: (1) building awareness of tsunami risk; (2) building constituencies that can carry a common message forward over time; and (3) educating and training key professionals working in engineering, planning, maritime industries, and emergency management along California's coast.

\section{Building the Awareness of At-Risk Communities to Tsunami and Their Potential Damaging and Fatal Effects}

Since the mid-1990s, California's emergency management community has been engaged in tsunami planning as part of multi-hazard planning. The catastrophic sequence of recent global tsunamis, starting with the December 26, 2004, Indian Ocean tsunami, have heightened tsunami risk awareness in the United States and California, and brought expanded funding to support the National Tsunami Hazard Mitigation Program as well as State and local tsunami emergency preparedness and public education programs.

The California Tsunami Steering Committee oversees the State's TPHMP, and its representatives come from all the coastal California counties, the NWS, and several State agencies. State program activities that are particularly focused on tsunami risk awareness include development and dissemination of outreach materials (brochures, pamphlets, DVDs), conducting educational workshops, supporting exercises and evacuation drills, participating in National Tsunami Preparedness Week, supporting regional work groups, purchasing tsunami hazard signs and developing tsunami sign placement plans, and coordinating with the NWS to support coastal communities in achieving TsunamiReady recognition. California currently leads the Nation in the number of communities (counties and cities) that have been recognized as TsunamiReady.

As the analyses for the SAFRR tsunami scenario have shown, however, there are significant gaps in tsunami risk awareness among the general public, at-risk populations, key responders, and State and local policymakers. Some key opportunities for building awareness, particularly of California's most at-risk populations include:

- Amending California's natural hazards disclosure law (California Civil Code sec. 1103 et seq.) to require that real-estate purchasers be notified by the seller or seller's agent when the property for sale is located in a tsunami hazard zone.

- Expanding "Tsunami Preparedness Week" to "Tsunami Preparedness Month." More time would allow for a more comprehensive public education and outreach program including school activities, fairs, town-hall meetings, evacuation exercises, live code tests of warning systems, and other special events.

- Expanding California's annual earthquake exercise and outreach effort known as the "Great California ShakeOut" to include tsunami education and preparedness in the program's goals and objectives, Web site, distributed material, and activities. Since its advent in 2008, California's ShakeOut program has dramatically increased community awareness and preparedness for earthquake hazards in California. In 2012, more than 9.4 million Californians registered for the Great California ShakeOut (Southern California Earthquake Center, 2013).

- Adding TsunamiReady awareness into the Great California ShakeOut activities.

- Promoting tsunami education and preparedness materials to hotel emergency coordinators who can share it with hotel guests.

- Ensuring that the "Risk Awareness" part of FEMA's Risk MAP (Mapping, Assessment, Planning) Program includes map-based information on tsunami risk. The Risk MAP theme to "clearly and effectively inform the public of their flood risk and impacts" exists but awaits implementation and 
offers an opportunity to better link tsunami hazards into coastal flooding risks (see http://www.fema.gov/library/viewRecord.do?id=3587, accessed August 23, 2013).

\section{Building Constituencies that can Carry a Common Message Forward Over Time is a Key Policy Challenge}

Few of California's coastal communities, businesses, and residents have experienced a significant tsunami and understand, first hand, the risks. To raise risk awareness, there need to be constituencies that support clear and consistent messaging over the long-term.

Effective messaging needs to be consistent, unrelenting, and come from trusted sources (Topping and others, 2010). Most people respond better to graphic images than numerical data regarding risk and most also have difficulty dealing with probabilistic information; low probability events become "zero probability events" in people's minds (Daniels and others, 2006). The basic tsunami risk awareness message needs to resonate with the core survival values of at-risk local governments, special districts, businesses, residents along California's coast and stimulate them to advocate for action and take preparedness and mitigation actions themselves (for example, through training, obtaining insurance, knowing how to evacuate, having survival supplies at hand, and being able to communicate with local authorities following a disaster).

Such efforts especially need to focus on areas where the greatest chance of isolation might occur and making sure that neighbors are capable first responders to the event. This requires a variety of partnerships of awareness. Community-based disaster response training programs like Community Emergency Response Training (CERT) may be a good vehicle for risk awareness promotion and communication at the neighborhood level. Similar efforts within the maritime community also could be developed and promoted. The Redwood Coast Tsunami Work Group is a form of coalition building for a common tsunami hazard (see Redwood Coast Tsunami Work Group Facebook page, accessed August 23, 2013 at https://www.facebook.com/RCTWG?filter=3) and a model that might be promoted in other regions of the State, such as the San Francisco Bay area, the central coast, and southern California.

The NTHMP provides a valuable multilevel coordination framework. Federal agencies working in partnership with the States and their communities to collect, interpret, and disseminate information on tsunami; promote public hazard awareness; and provide national, State, and local leadership and incentives to engage communities in tsunami preparedness and mitigation (for example TsunamiReady). For California's tsunami risk message to be delivered with one unified political voice (at a Federal, State, or regional level) sustained funding for the NTHMP and its State counterpart is needed, and some new programmatic efforts will be required. Champions may need to be developed among locally elected officials, possibly through the California League of Cities, the California State Association of Counties, the State Legislature, and California's Congressional delegation. West Coast States could also work as a coalition to advocate for sustained funding.

Educating the media (including media meteorologists) can also build pre-event alliances as part of the message delivery system. The Pacific Tsunami Warning Center has had some success in working with the media on tsunami risk awareness that may yield lessons for California (see http://www.weather.gov/ptwcl, accessed August 23, 2013).

\section{Strengthening Tsunami Risk Awareness Among Key Professionals is Also a Key Policy Issue}

Tsunami hazard assessment, and mitigation and response planning are still relatively "young" fields for engineering, emergency management, and scientists. Educational elements of the NTHMP and State TPHMP may need to be strengthened to reach key professionals working in engineering, as well as land-use, hazard mitigation, and response planning along California's coast. 
In engineering, for example, college curriculums, licensing, and continuing education in coastal engineering, structural engineering, and civil engineering could include the broad topic of tsunami hazard, including source generation and propagation, hydrodynamic inundation modeling and its limitations, and sources and treatment of uncertainty. Similar curricula and continuing education might also be developed and promoted in college urban planning and emergency management programs across the State.

The maritime community also may need more focused training and education efforts. These might include incorporating a tsunami hazard component into harbor master guidebooks and ship-pilot licensing and boater-safety training programs. This might include information on basic tsunami characteristics, flow dynamics, the tsunami warning process, vessel evacuation procedures, designated harbor and offshore safety areas, and response planning for fuel, food, communications, and other supplies.

\section{Possible Courses of Action}

The SAFRR tsunami scenario aims to use science to inform decisions that enhance community resiliency, in this case resiliency against a tsunami that affects the entire West Coast of the United States. To actually enhance resiliency, however, significant disaster policy changes, programmatic adjustments, and organizational and individual behavioral adaptations will be required to face the immense challenges that such an extreme event poses. Some possible courses of actions that this assessment offers follow:

\section{Ensure Continued Funding and Support for the National Tsunami Hazard Mitigation Program, TsunamiReady and Affiliated State and Local Programs}

Federal funding for the NTHMP is scheduled to end in 2013. Unless the Tsunami Warning and Education Act of 2006 is reauthorized, the foundation of the Nation's and California's tsunami policy framework will be significantly diminished and the future of the TsunamiReady program, and State leadership for local tsunami hazard assessment, mitigation, and preparedness will be at significant risk.

\section{Recruit and Assist All California Coastal Communities and Ports and Harbors to Become TsunamiReady}

The TsunamiReady program, as a voluntary program, is more apt to attract better mitigation performers seeking this designation. Mechanisms are needed to encourage the most vulnerable and unprepared coastal communities and ports and harbors to voluntarily undertake mitigation and preparedness actions ahead of a tsunami disaster. The TsunamiReady program could help enhance communication, coordination, and information sharing among coastal communities on tsunami mitigation and preparedness plans and best practices. The standards for TsunamiReady designation might also be reviewed and a process for maintaining TsunamiReady designations over time might also be developed to help ensure that TsunamiReady designated communities and ports and harbors are indeed ready for the impacts of a future tsunami.

\section{Develop a Coordinated and Sufficiently Robust Policy Framework for Tsunami Hazard Assessment and Mitigation Planning for California Coastal Communities and Ports and Harbors}

A more robust and integrated planning framework would help to reinforce knowledge of hazards and their potential impacts, improve mitigation actions that could be taken to reduce vulnerability, and 
result in improved and more coordinated response efforts across all responsible government agencies during a disaster. Adoption of official State tsunami hazard zones under the State Seismic Hazard Mapping Act could provide a strong foundation for such an integrated framework. Guidelines could link the hazard zones into State and local land use, zoning, subdivision and development permitting processes as well as LHMPs, LCPs, and the safety elements of local general plans. Legislative changes may be needed to ensure better integration of the tsunami hazard zones in State and local planning and development requirements and consistency with any tsunami-resilient building design code provisions that are adopted. Similarly, consistent statewide guidelines for maritime tsunami response and recovery could be developed for use in harbor safety planning; evacuation, response and recovery planning by port, harbor and marina management; and pilot licensing and boater training programs.

\section{Explore Opportunities to Advance Multi-Hazard Mitigation Planning Along California's Coast and Bays}

The SAFRR tsunami scenario provides an opportunity to advance multi-hazard mitigation planning along California's coast and bays to more holistically address issues of future tsunami risk, sea-level rise and future coastal flooding and erosion, and earthquake-induced liquefaction. State agencies, including Cal OES, CGS, the CCC, and BCDC, could explore where mitigation policies and programs for dealing with different hazards might be combined and strengthened. Multi-hazard mitigation options could include relocation and redevelopment of buyout areas, structural elevations, or retrofitting of slab-on-grade foundations.

\section{Encourage Responders and Government Managers to Conduct Self-Assessments, Devise Exercises, and More Carefully Consider the Geographic Scale of This and Other Tsunami Scenarios}

Emergency responders and government managers at all levels could be encouraged to conduct self-assessments, devise exercises, and more carefully consider how the short-fuse intensity and wide geographic scale of the SAFRR and other tsunami scenarios could challenge current assumptions in warning and evacuation protocols, emergency response and planning documents, organizational structures and systems, and their abilities to scale up and meet the needs of such events and overcome the relative lack of experience that most managers and the general public will have with tsunamispecific issues. Such assessments and exercises could help to create more locally and regionally specific scenarios of impacts and also identify gaps in public and private sector resources available to respond to and recover from a large-scale tsunami. Political leaders, policymakers, and administrators could be involved in such assessments and exercises, and the level of emergency complexity and testing could be increased over time. An ongoing cycle of activities to account for normal staff turnover, provide refresher training, and update plans and operating procedures is needed to maintain an effective state of readiness. Tsunami evacuation "playbooks" under development by the State TPHMP will provide more detailed models of potential inundation areas for a number of different tsunami scenarios. Coastal emergency managers can then use them in preparing local evacuation response plans that are more tsunami source specific. Similarly, the State TPHMP maritime mapping and guidelines will help California's ports, harbors, and marinas to better plan for evacuations, response, and recovery. The SAFRR tsunami scenario provides important justification of the need for both the community playbooks and maritime planning products and the need for robust dissemination and training efforts associated with their release. The SAFRR tsunami scenario also provides a useful source of information to test 
national tsunami warning protocols and see what improvements could be made to alert dissemination protocols.

\section{Work to Address Recovery Challenges}

Work should be considered to address recovery challenges likely for the most vulnerable coastal communities and ports and harbors, as well parts of the State's fishing and agriculture sectors. The SAFFR tsunami scenario could also result in a fiscal crisis for coastal local governments and special districts struggling to meet the response and recovery needs of such a tsunami disaster, while simultaneously facing significant sales and property tax revenue reductions. This would be especially true in coastal communities that depend heavily on tourism, agricultural, and maritime activities impacted by the tsunami. The impacts could have cascading effects. All California coastal counties and cities could be encouraged to become participate communities in the National Flood Insurance Program. Similarly, NFIP coverage could be promoted to coastal residents and businesses to offer some additional protection from tsunami-induced flooding. Efforts could also be encouraged to streamline regulatory and permitting processes that would be required for port dredging and disposal and debris removal, both on- and offshore, after a tsunami disaster. Policies and programs may also be needed to address the removal of contaminated topsoil, desalinization of soils, and the detoxification of concrete and other affected building materials.

\section{Develop and Consistently Communicate Common Messages About Tsunami Risk}

It is essential to develop and consistently communicate common messages to educate the general public, at-risk populations, and businesses, State and local policymakers, and key professionals about tsunami risk. Federal, State, and local models exist for crafting and executing a robust tsunami risk awareness and education program for a major tsunami striking California and the rest of the West Coast. Multilevel, multifactor involvement needs to be a core component of such an effort. Opportunities for building awareness, particularly of California's most at-risk populations, include amending California's natural hazards disclosure law (California Civil Code sec. 1103 et seq.) to require that real estate purchasers be notified by the seller or seller's agent when the property for sale is located in a tsunami hazard zone and expanding California's annual earthquake exercise and outreach effort known as "ShakeOut" to include tsunami education and preparedness. Because tsunami hazard assessment, and mitigation and response planning are still relatively "young" fields tsunami education and training needs to be strengthened to reach key professionals working in engineering, as well as land-use, hazard mitigation, and response planning along California's coast.

\section{References Cited}

American Society of Civil Engineers, 2013, Academy of coastal, ocean, port and navigation engineers: American Society of Civil Engineers Web site, accessed August 26, 2013, at http://www.asce.org/Certification/Academy-of-Coastal,-Ocean,-Port---Navigation-Engineers/.

Birkland, T., 1997, After disaster-Agenda setting, public policy, and focusing events: Washington

D.C., Georgetown University Press, 192 p.

Birkland, T., 2006, Lessons of disaster-Policy change after catastrophic events, Washington, D.C.: Georgetown University Press.

Borrero, J., Dengler, L., Burak, U., and Synolakis, C., 2006, Numerical modeling of tsunami effects at marine oil terminals in San Francisco Bay: California State Lands Commission, Marine Facilities Division, accessed August 26, 2013, at 
http://www.google.com/url?sa=t\&rct=j\&q=\&esrc=s\&source=web\&cd=1\&ved=0CC8QFjAA\&url=htt $\mathrm{p} \% 3 \mathrm{~A} \% 2 \mathrm{~F} \% 2 \mathrm{Fwww}$. slc.ca.gov$\% 2 \mathrm{Fdivision}$ pages $\% 2 \mathrm{Fmfd} \% 2 \mathrm{Fmotems} \% 2 \mathrm{Fsftsunamireport} \% 2 \mathrm{Fsf}$ mot_final_report.doc\&ei=nOTHUb_1DqiQigKylYDoBg\&usg=AFQjCNGFCI2LjjoUqD10Myi70iN VfnGEiQ'ssig2=mEATGbNHGyxN1-8ADi6qNg\&bvm=bv.48293060,d.cGE.

California State Lands Commission, 2013, About us_-Land leasing: California State Lands

Commission Web site, accessed August 26, 2013, at

http://www.slc.ca.gov/About_The_CSLC/Land_Leasing.html.

California Building Standards Commission, 2010, 2010 California building code, title 24, v. 1 of part 2:

California Building Standards Commission, accessed August 26, 2013, at

http://publicecodes.cyberregs.com/st/ca/st/b200v10/st_ca_st_b200v10_intro.htm.

Daniels, R., Kettl, D., and Kunreuther, H., ed., 2006, On risk and disaster-Lessons from hurricane

Katrina: Philadelphia, University of Pennsylvania Press, 293 p.

Federal Emergency Management Agency [FEMA], 2005, Disaster assistance-A guide to recovery programs, FEMA 229(4): Washington, D.C., Federal Emergency Management Agency, accessed August 26, 2013, at http://www.fema.gov/txt/rebuild/ltrc/recoveryprograms229.txt.

Federal Emergency Management Agency [FEMA], 2007, Robert T. Stafford Disaster Relief And

Emergency Assistance Act, as amended, and related authorities, FEMA 592: Washington, D.C.,

Federal Emergency Management Agency, 113 p.

Federal Emergency Management Agency [FEMA], 2008, National response framework: Washington,

D.C., Federal Emergency Management Agency Web site, accessed August 26, 2013, at

http://www.fema.gov/national-response-framework.

Federal Emergency Management Agency [FEMA], 2011, National disaster recovery framework-

Strengthening disaster recovery for the Nation: Washington, D.C., Federal Emergency Management

Agency, accessed August 26, 2013, at http://www.fema.gov/pdf/recoveryframework/ndrf.pdf.

Federal Emergency Management Agency [FEMA], 2012a, Multi-hazard mitigation planning:

FEMA.gov, http://www.fema.gov/multi-hazard-mitigation-planning.

Federal Emergency Management Agency [FEMA], 2012b, Preparedness: Washington, D.C., Federal

Emergency Management Agency Web site, accessed August 26, 2013, at

http://www.fema.gov/preparedness-0\#item1.

Federal Emergency Management Agency [FEMA], 2013, National response framework: Washington

D.C., Federal Emergency Management Agency, Web site, accessed August 26, 2013, at

http://www.fema.gov/library/viewRecord.do?id=7371.

Kirby, S., Scholl, D., Huene, R.V., and Wells, R., 2013, Alaska earthquake source for the SAFRR

California tsunami scenario: U.S. Geological Survey Open-File Report 2013-1170-B, 45 p., http://pubs.usgs.gov/of/2013/1170/b/.

May, P.J., and Williams, W., 1986. Disaster policy implementation-Managing programs under shared governance: New York, N.Y., Plenum Press, 210 p.

Moffatt and Nichol, 2012, Tsunami scenario engineering impacts of Port of Long Beach and Port of Los Angeles: Moffatt and Nichol report prepared for the U.S. Geological Survey, $51 \mathrm{p}$.

National Oceanic and Atmospheric Administration [NOAA], 2013a, About the national tsunami hazard mitigation program: National Oceanic and Atmospheric Administration, National Tsunami Hazard Mitigation Program Web site, accessed August 26, 2013, at http://nthmp.tsunami.gov/about_program.html.

National Oceanic and Atmospheric Admistration, [NOAA], 2013b, California-36 TsunamiReady sites: National Oceanic and Atmospheric Administration, TsunamiReady Web site, accessed August 26, 2013, at http://www.tsunamiready.noaa.gov/ts-com/ca-ts.htm. 
National Research Council, 2011, Tsunami warning and preparedness-An assessment of the U.S. tsunami program and the Nation's preparedness efforts: Washington D.C., The National Academies Press, $284 \mathrm{p}$.

Newell, C., ed. 2004, The Effective Local Government Manager, 3rd ed: Washington, D.C., International City/County Management Association, Municipal Management Series, 267 p.

Olshansky, R.B., Hopkins, L.D., and Johnson, L.A., 2012, Disaster and recovery-Processes compressed in time: Natural Hazards Review, v. 13, no. 3, p. 173-178, doi:10.1061/(ASCE)NH.15276996.0000077.

Plumlee, G.S., Morman, S.A., and San Juan, C., 2013, Potential environmental and environmentalhealth implications of the SAFRR California tsunami scenario: U.S. Geological Survey Open-File Report 2013-1170-F, 39 p., http://pubs.usgs.gov/of/2013/1170/f/.

Porter, K., Byers, W., Dykstra, D., Lim, A., Lynett, P., Ratliff, J., Scawthorn, C., Wein, A., and Wilson, R., 2013, Physical damage in the SAFRR California tsunami scenario: U.S. Geological Survey OpenFile Report 2013-1170-E, 183 p., http://pubs.usgs.gov/of/2013/1170/E/.

Rubin, C., 2012, Emergency management-The American experience 1900-2010, 2nd ed.: Boca Raton, Fla., CRC Press, Taylor and Francis Group, 303 p.

Southern California Earthquake Center, 2013, The great California shakeout-Check the Stats:

Southern California Earthquake Center, Web site, accessed August 26, 2013, at http://www.shakeout.org/california/.

State of California, 2005, California code of regulations, title 14, division 1, subdivision 4, chapter 3: State of California Web site, accessed August 26, 2013, at https://nrm.dfg.ca.gov/FileHandler.ashx?DocumentID=21888\&inline=true.

State of California, 2009, Tsunami inundation maps for emergency planning: State of California, Department of Conservation, Web site, accessed August 26, 2013, at http://www.conservation.ca.gov/cgs/geologic_hazards/Tsunami/Inundation_Maps/Pages/Statewide_M aps.aspx.

Topping, K.C., Johnson, L.A., Eadie, C.C., and Siembieda, W., 2010, Public policy issues, in Overview of the ARkStorm scenario: U.S. Geological Survey Open-File Report 2010-1312, http://pubs.usgs.gov/of/2010/1312/.

U.S. Congress, House and Senate Appropriations Committees, 2005, Emergency supplemental appropriations act for defense-The Global War on Terror, and tsunami relief: U.S. Government Printing Office, U.S. Congress, 109th, Public Law 13, accessed August 26, 2013, at http://www.gpo.gov/fdsys/pkg/PLAW-109publ13/html/PLAW-109publ13.htm.

U.S. Congress, House Science, Space, and Technology Committee, 2006, Tsunami Warning and Education Act: U.S. Congress, 109th, H.R. 109-698, accessed August 26, 2013, at http://beta.congress.gov/congressional-report/109th-congress/house-report/698/1.

Uslu, B., Borrero, J., Dengler, L., Synolakis, C., and Barberopoulou, A., 2008, Tsunami inundation from great earthquakes on the Cascadia subduction zone along the northern California coast, in Wallendorf, L., Ewing L., Jones, C., and Jaffe, B., eds., Solutions to coastal disasters 2008: American Society of Civil Engineers, p. 204-214.

Uslu, B., Eble, M., Titov, V.V., and Bernard, E.N., 2010, Distant tsunami threats to the ports of Los Angeles and Long Beach, California: National Oceanic and Atmospheric Administration, Office of Oceanic and Atmospheric Research Special Report, Tsunami Hazard Assessment Special Series, v. 2, 111 p., accessed August 26, 2013, at http://nctr.pmel.noaa.gov/hazard_assessment_reports/02_LA_LB_CA_3532_web.pdf. 
Wein, A., Rose, A., Sue Wing, I., Wei, D., 2013, Economic impacts of the SAFRR tsunami scenario in California: U.S. Geological Survey Open-File Report 2013-1170-H, 56 p., http://pubs.usgs.gov/of/2013/1170/h/.

Wilson, R., and Miller, K., 2013, Tsunami mitigation and preparedness activities in California: U.S. Geological Survey Open-File Report 2013-1170-L, 10 p., http://pubs.usgs.gov/of/2013/1170/1/. Wood, N., Ratliff, J., Peters, J., and Shoaf, K., 2013, Population vulnerability and evacuation challenges in California for the SAFRR tsunami scenario: U.S. Geological Survey Open-File Report 2013-1170I, 53 p., http://pubs.usgs.gov/of/2013/1170/i/. 